Universidad deValladolid

PROGRAMA DE DOCTORADO EN CIENCIA E INGENIERÍA AGROALIMENTARIA Y DE BIOSISTEMAS

\title{
Estudio etnobotánico de la Montaña Palentina
}

\author{
Presentada por Juan Cruz Pascual Gil \\ para optar al grado de \\ Doctor por la Universidad de Valladolid
}

Dirigida por:

Baudilio Herrero Villacorta

JUNIO 2019 

A mis padres, hermana y sobrinos 



\section{AGRADECIMIENTOS}

Con este trabajo se cumple uno de los empeños que lleva ocupándome diez años, desde aquel día en que un encuentro casual con Baudilio Herrero sirviera para retomar mi actividad académica y de este modo recorrer un largo camino que se consuma con la realización de esta Tesis Doctoral. Sin duda, el mayor agradecimiento es para mi tutor Baudilio, con el que comparto amistad, por transmitirme la pasión por la etnobotánica, por su impulso y animo incesante, por su disponibilidad inmediata, por sus correcciones precisas y meticulosas, así como por su orientación constante. Satisfecho y orgulloso de continuar juntos el proyecto en la Asociación Etnobotánica Palentina.

Quiero agradecer la colaboración desinteresada de todas las personas que me han ofrecido su tiempo y sobre todo su conocimiento, la sabiduría de gente generosa, humilde y orgullosa de sus tradiciones, que forman parte de esta bella comarca. Sirva este trabajo como homenaje a todos ellos. Imposible mencionar la totalidad, aunque si destacar aquellos con los que he compartido extensas conversaciones y paseos por el campo como: Victorino Pascual, Edelmira Cenera, Máxima Pascual, Victorino Macho, Gildo Ramos o Serafina Salvador, de los que he recibido lecciones continuas de etnobotánica y de vida.

A las personas que me ayudaron en la búsqueda de informantes, Jorge Ibáñez, Fernando Cuevas, Eduardo Vielba, Juan Bores y Wifredo Román. A Elsa Herrero por iniciar la recopilación de saberes en la montaña, a Nuria Rodríguez por su apoyo con el inglés, y a David Frechilla por el paginado, a los tres por su amistad.

La colaboración de la Diputación Provincial de Palencia ha sido importante para la financiación y desarrollo del proyecto, señalar la sensibilidad mostrada para la recuperación de estos conocimientos, en especial a Adolfo Palacios, Santiago Vázquez y Beatriz Román.

Por otro lado, significar la aportación al trabajo de los archivos de la Fundación Piedad Isla, persona a la que admiro por el retrato que realizó de la memoria del alma de los pueblos y personas de la Montaña Palentina.

Mencionar a todos los grandes profesionales de la etnobotánica que han sentado las bases teóricas del trabajo, como Manuel Pardo de Santayana, Ramón Morales, Javier Tardío, Laura Aceituno o Emilio Blanco.

En especial, gracias a mis padres por darme lo más importante en la vida, a mi hermana Noemí por su comprensión y por sus dos regalos: Gael y Noé. A mis abuelos en el recuerdo, a los que me hubiera gustado entrevistar y constatar en primera persona su sabiduría. A toda mi familia y a mis amigos, a los que me acompañan siempre y a los que lo hacen en la distancia con amor incondicional y palabras mágicas, continuemos esta lucha de gigantes. Por último, mi gratitud al pueblo de Verdeña cuna familiar y raíz del estudio, deseando que este trabajo sirva para la recuperación del esplendor de tiempos pasados. 



\section{RESUMEN}

Los profundos cambios sociales acontecidos en las últimas décadas en la sociedad rural, como la modernización y la globalización, han provocado el despoblamiento rural y con ello el abandono de usos tradicionales y la pérdida de conocimientos derivados de las relaciones de las personas con el medio ambiente. La población de la Montaña Palentina ha descendido un $43 \%$, desde los años 60 del siglo pasado hasta la actualidad, formando parte de esa zona rural conocida como la España vaciada.

La presente tesis muestra los resultados del estudio etnobotánico realizado en la comarca de la Montaña Palentina (Palencia), enclavada en la vertiente meridional de la Cordillera Cantábrica y con una superficie de $1576 \mathrm{~km}^{2}$, que engloba 16 municipios y 116 localidades. La economía tradicional se basaba principalmente en la ganadería extensiva, en pequeñas explotaciones agropecuarias familiares con cultivos de secano. También la minería tuvo gran importancia hasta los años 90 del siglo pasado en cuanto a mano de obra ocupada y creación de riqueza.

Este trabajo tiene como objetivo principal recoger los usos tradicionales de las plantas, así como conservar los valores culturales y etnográficos, determinar las plantas más útiles en la zona, distribuir el conocimiento tradicional en categorías de uso y contrastar la información con otras zonas.

Para el registro de información sobre usos de las plantas en la cultura tradicional se utilizaron distintos tipos de entrevista: individuales, colectivas, de campo o con muestras de plantas. Resultando la más común, el tipo de entrevista individual semiabierta o semiestructurada.

Los datos se han recogido en dos fases, la primera de abril de 2010 a diciembre de 2011, y la segunda de marzo de 2015 hasta agosto de 2018, realizando 139 entrevistas en las que han participado 187 personas, de ellas el $88 \%$ eran mayores de 70 años, y el $47 \%$ fueron mujeres.

Se ha realizado un catálogo etnobotánico que recopila los usos, conocimientos y manejo de 447 taxones, 327 son de obtención silvestre, representando el 73,15\% del total. Se han recogido un total de 654 nombres vulgares, algunos de ellos inéditos como cepico (Thymus zygis) o hierba de la cólica (Thymus pulegioides), y 10438 informes de uso (RU) distribuidos en 11 categorías de uso diferentes. También se recogen usos populares inéditos como la utilización de hojas de tiraña (Pinguicula grandiflora) para ayudar a las vacas a expulsar la placenta tras el parto, o el rizoma de genciana (Gentiana lutea) para inducir el abandono del chupete de los niños.

En el estudio se ha cuantificado la utilidad de las plantas en la zona mediante el uso de los índices: Frecuencia Relativa de Citación (FRC), Importancia Cultural (IC), Vigencia (IV) y etnobotanicidad (IE), con el propósito de valorar la importancia de las especies citadas en la zona y poder compararla con otros estudios etnobotánicos.

Las especies arbóreas destacan en cuanto a importancia cultural, el roble (Quercus spp.), el chopo (Populus spp.) y el haya (Fagus sylvatica), todas ellas son manejadas frecuentemente en la cultura tradicional como forraje para el ganado, combustible, en la construcción de edificaciones, y para la elaboración de diversas herramientas y utensilios, dada la versatilidad de la madera como materia prima. 
La vigencia o abandono de los usos está relacionado con las categorías de uso, se mantienen algunos usos en alimentación humana, los derivados de aprovechamientos esporádicos de frutos y setas, también algunos usos combustibles y ornamentales, así como los medicinales que tratan problemas leves de salud, sin embargo, los usos veterinarios, ganaderos, medioambientales, tecnológicos y artesanales, y los relacionados con la construcción se encuentran prácticamente abandonados. Los mayores valores en el índice de Vigencia (IV) lo alcanzan tres especies herbáceas: 0,64 el orégano (Origanum vulgare), 0,59 para el té (Sideritis hyssopifolia), y un valor de 0,57 la manzanilla (Chamaemelum nobile).

Este estudio etnobotánico recopila el conocimiento tradicional relativo a las plantas en la comarca de la Montaña Palentina, pudiendo contribuir al fomento de la identidad cultural y al desarrollo de la comarca. 


\section{ABSTRACT}

The profound social changes that have occurred in recent decades in rural society, such as modernization and globalization, have led to rural depopulation and with it, the abandonment of traditional uses and the loss of knowledge that derives from people's relationships with their environment. The population of the Palencia Mountain region has fallen by $43 \%$ from the 1960 s to the present, forming part of that rural area known as the 'Emptied Spain'.

This thesis shows the results of an ethnobotanical study carried out in the Palencia Mountain region (Palencia). This area is located on the southern slope of the Cantabrian Mountains and extends $1576 \mathrm{~km}^{2}$, comprising 16 municipalities and 116 localities. The traditional economy was mainly based on extensive cattle farming on small family farms with cereal crops. Coal mining was also very important until the 1990s in terms of employment and wealth creation.

The main objective of this work is the collection of traditional uses of the local plants. This study also aims to preserve the cultural and ethnographic values, determine the most useful plants in the area, organise the traditional knowledge in categories of use, and compare the information with other regions.

The information about the plants' uses in traditional culture was obtained through individual, collective, field or with samples of plants interviews. The most commonly used was the semiopen or semi-structured individual interview.

The data was collected in two phases, the first one from April 2010 to December 2011, and the second one from March 2015 to August 2018. In total, 139 interviews were carried out in which 187 people participated, $88 \%$ were older than 70 years of age and $47 \%$ were women.

An ethnobotanical catalogue has been compiled collecting the uses, knowledge and management of 447 or taxa, 327 were collected in the field, representing $73.15 \%$ of the total. A total of 654 vernacular names have been brought together, some of them previously unpublished as cepico (Thymus zygis) or hierba de la cólica (Thymus pulegioides), and a total of 10438 reports of use (RU) have been distributed in 11 different categories of use. Novel popular uses such as the use of tiraña leaves (Pinguicula grandiflora) to help the cows to expel the placenta after parturition, or the gentian rhizome (Gentiana lutea) to wean children off the pacifier, are also included.

The usefulness of the plants in the area has been quantified via the use of the indexes: Relative Frequency of Citation (RFC), Cultural Importance (CI), Validity (IV) and Ethnobotanical Significance (IE), with the purpose of assessing the importance of the species named in the area and be able to compare it with other ethnobotanical studies.

Tree species stand out in terms of cultural importance, Oak (Quercus spp.), Poplar (Populus spp.) and Beech (Fagus sylvatica). These are frequently managed in traditional culture as fodder for cattle, fuel, in building construction, and for the production of various tools and utensils, given the versatility of wood as a raw material.

The maintenance or abandonment of traditional knowledge is related to the category of use. Some uses are still current in the human food category like the ones derived from sporadic use of fruits and mushrooms, also some fuel and ornamental uses. In addition, there are current medicinal uses to treat minor health problems. However, veterinary, livestock, environmental, 
technological and artisanal uses, and those related to construction are practically abandoned. The highest values in the Validity Index (IV) are reached by three herbaceous species: 0,64 oregano (Origanum vulgare), 0,59 for tea (Sideritis hyssopifolia), and a value of 0,57 for chamomile (Chamaemelum nobile).

This ethnobotanical study collects the traditional knowledge related to plants in the Palencia Mountain region, and can contribute to the promotion of cultural identity and the development of the region. 


\section{ÍNDICE}

1. INTRODUCCIÓN

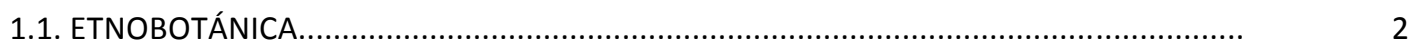

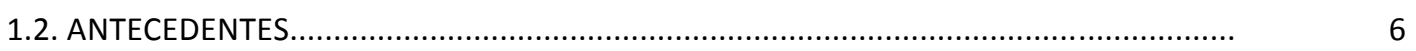

1.3. JUSTIFICACIÓN...............................................................................................

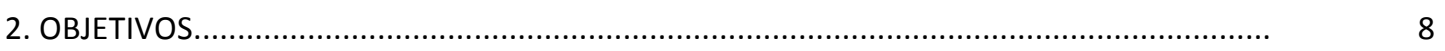

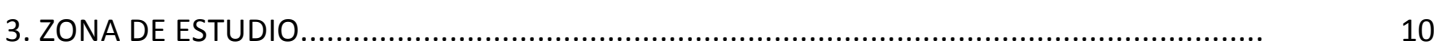

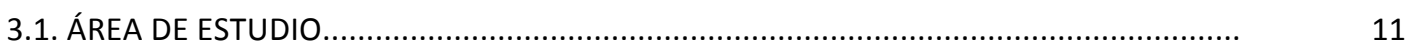

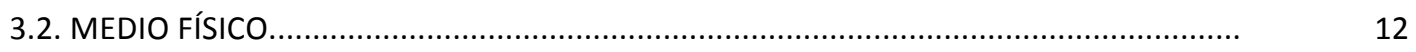

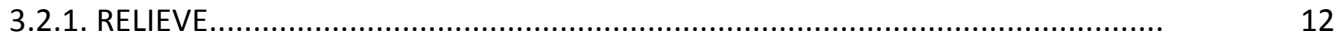

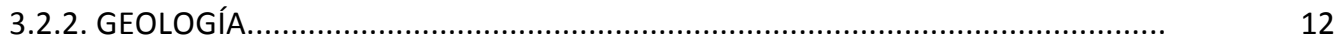

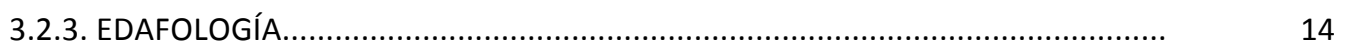

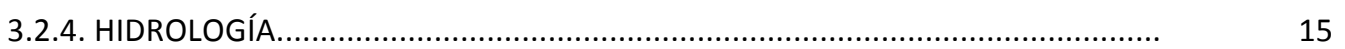

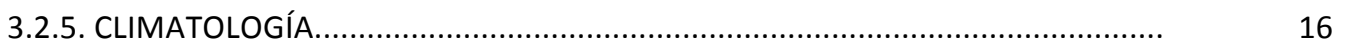

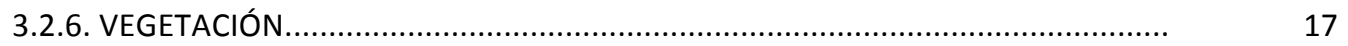

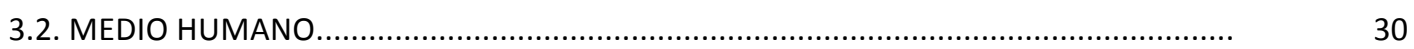

3.2.1. POBLACIÓN...................................................................................... 30

3.2.2. ACTIVIDAD ECONÓMICA.....................................................................

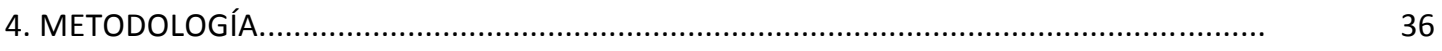

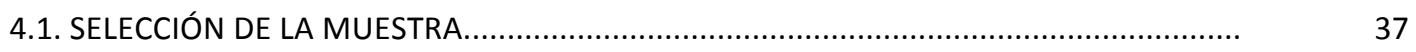

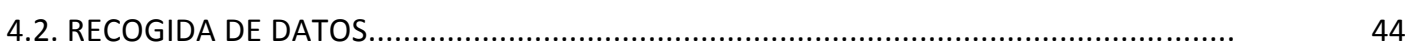

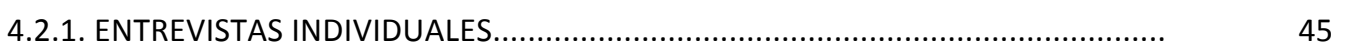

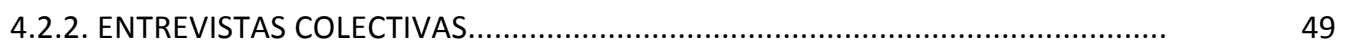

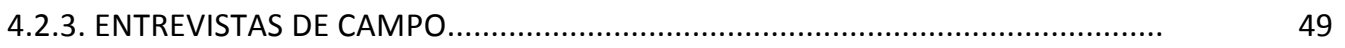

4.2.4. ENTREVISTAS CON MUESTRAS DE PLANTAS............................................... 50

4.2.5. RECOLECCIÓN E IDENTIFICACIÓN DE MUESTRAS............................................

4.3. ORGANIZACIÓN DE LOS DATOS.....................................................................

4.4. TRATAMIENTO DE LOS DATOS...............................................................................

4.4.1. CRITERIOS DE ACEPTACIÓN Y RECHAZO DE REGISTROS.................................

4.4.2. ÍNDICES Y CUANTIFICACIÓN DE LOS DATOS..................................................

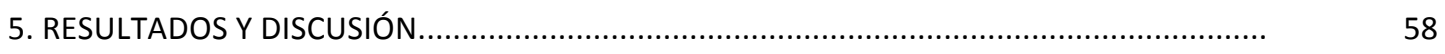

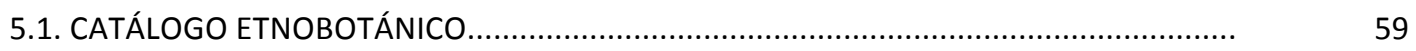

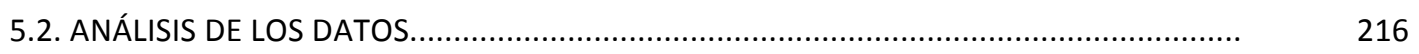

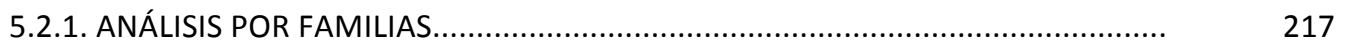

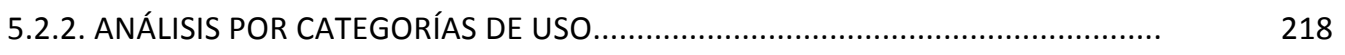

WILD FOOD PLANTS GATHERED IN THE UPPER PISUERGA RIVER BASIN,

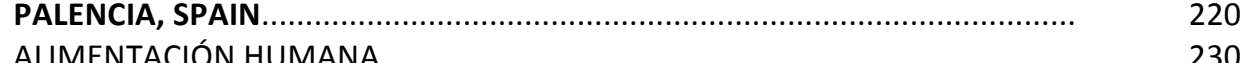

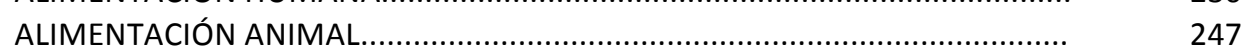

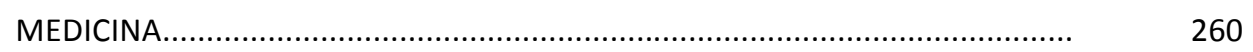

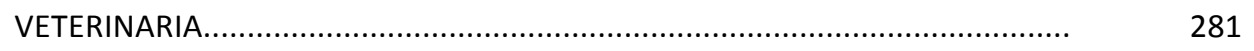

USO TÓXICO Y NOCIVO.............................................................................. 294

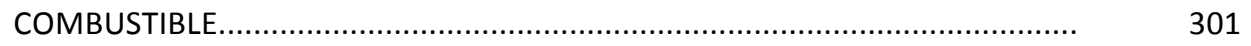

CONSTRUCCIÓN.................................................................................... $\quad 309$

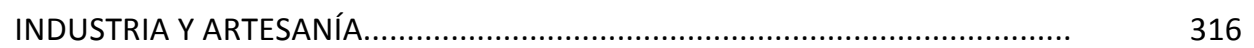

USO MEDIOAMBIENTAL....................................................................

USO ORNAMENTAL............................................................................. 339

USO SOCIAL, SIMBÓLICO Y RITUAL........................................................

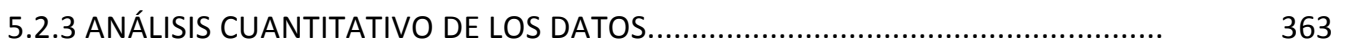

FRECUENCIA DE CITACIÓN..................................................................... 


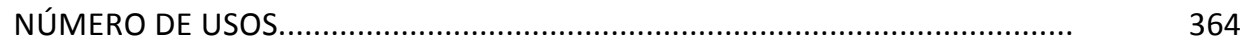

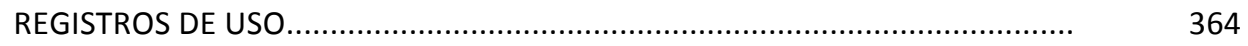

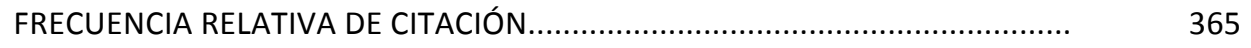

ÍNDICE DE IMPORTANCIA CULTURAL........................................................ 366

IMPORTANCIA CULTURAL DE LAS CATEGORÍAS...................................... 367

IMPORTANCIA CULTURAL DE LAS FAMILIAS......................................... 369

COMPARATIVA DE ÍNDICES............................................................... 371

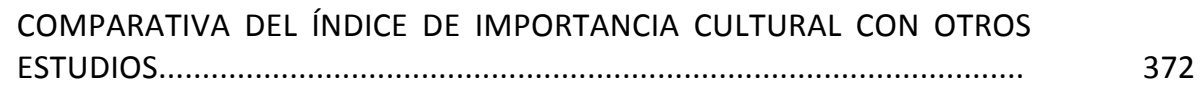

ÍNDICE DE VIGENCIA..........................................................................

RELACIÓN ENTRE VIGENCIA E IMPORTANCIA CULTURAL....................... 377

ÍNDICE DE ETNOBOTANICIDAD............................................................ 378

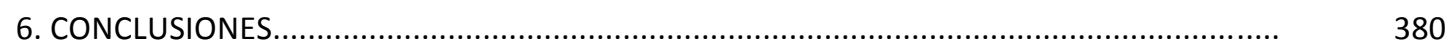

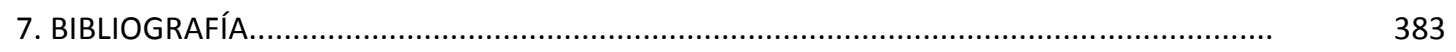

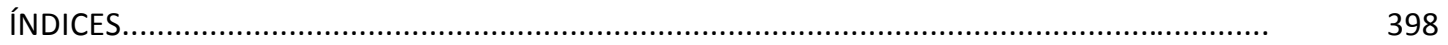

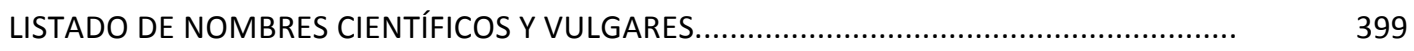

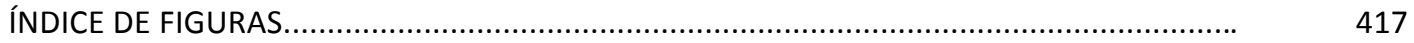

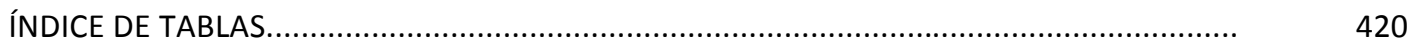




\section{INTRODUCCIÓN}




\section{INTRODUCCIÓN}

Los profundos cambios sociales acontecidos en las últimas décadas en la sociedad rural han provocado importantes transformaciones en los modos de vida y en las relaciones con el medio ambiente. El creciente despoblamiento rural y el abandono de usos tradicionales tanto en ganadería, agricultura, artesanía u otros campos, han puesto en peligro gran cantidad de conocimientos tradicionales. Asimismo, la modernización y globalización de la sociedad ha uniformado muchas costumbres y tradiciones, lo que supone pérdida de riqueza y diversidad cultural.

El campo resultaba hasta hace poco tiempo, espacio fundamental de trabajo y medio de vida principal, transformándose con el tiempo en lugar de esparcimiento y paseo. Las plantas solucionaban necesidades primordiales como alimentación humana y del ganado, servían como remedio medicinal, veterinario, incluso útil en diversas aplicaciones tecnológicas, simbólicas o rituales. Estos conocimientos empíricos adquiridos por los habitantes de la comarca se transmitieron durante generaciones como un engranaje por tradición oral, cadena de comunicación que comenzó su ruptura por las importantes transformaciones acaecidas a mediados del siglo XX, la globalización y la acción homogeneizadora de la sociedad industrial, exponiéndonos a la pérdida del rico patrimonio de la comarca de la Montaña Palentina, bienes como: conocimientos, técnicas, actividades y expresiones cotidianas, que pueden desaparecen sin dejar rastro.

Por tanto, urge recopilar estas sabidurías y tradiciones, reflejo de una vida pasada, que son una parte importantísima de la identidad y personalidad cultural de cada pueblo (Pardo de Santayana, 2008).

El presente trabajo etnobotánico pretende describir y analizar los usos que la población de la comarca de la Montaña Palentina ha atribuido a las plantas de su entorno, así como determinar cuáles de ellas tienen una mayor importancia o relevancia en la cultura local.

\subsection{ETNOBOTÁNICA}

La etnobotánica es la ciencia que estudia todas las posibles interrelaciones entre personas y plantas a lo largo de la historia de la humanidad. Este término ya fue acuñado por el arqueólogo Harshberger en 1895 en trabajos que consistían en listas o catálogos de plantas con especificación de sus respectivos usos. Al comenzar a interesarse por la disciplina investigadores provenientes de la etnografía, el objeto de estudio se fue ampliando a la totalidad de las relaciones ser humano-planta, incluyéndose los aspectos etnográficos y simbólicos. Desde esta concepción inicial del significado de etnobotánica surgieron posteriormente un sinfín de definiciones.

Para Robinns et al. (1916), la etnobotánica no trata sólo de un catalogo de plantas útiles, sino de la percepción local del medio natural a través de las costumbres y rituales, para Portères (1961) la etnobotánica es el estudio de la trama vegetal de la humanidad, disciplina interpretativa y asociativa que busca, utiliza e interpreta las interrelaciones entre las sociedades humanas y las plantas.

Ford (1978) incluye una concepción más amplia de esta disciplina, estudiando el lugar de las plantas en la cultura y la interacción directa de las personas con las plantas, sin limitarse a ningún tipo de sociedad, incluyendo usos, nombres, creencias y manejos. 
Posteriormente, dentro de la disciplina, Berlín en 1992 distinguía dos corrientes principales: la cognitiva y la utilitaria. La primera se preocupa de cómo perciben los humanos la naturaleza, y la segunda, de cómo la usan o manejan. La faceta utilitarista tiene un valor primordial, pero no deben olvidarse otras interacciones como el manejo, las creencias, los conocimientos, las impresiones o las valoraciones sobre las plantas.

La etnobotánica, además de ser una herramienta útil para la recopilación, descripción y estudio de la cultura botánica popular, es ciencia útil para ayudar a conservar el patrimonio etnográfico, los saberes tradicionales sobre las plantas y sus implicaciones culturales, prospectando el contexto sociológico y cultural concreto de un área geográfica definida. Para muchos, el desarrollo de los lugares estudiados debe ser uno de los objetivos prioritarios. No debe olvidarse nunca que los primeros beneficiarios de estos estudios deben ser sus depositarios (Toledo, 1982). Se emplea como herramienta para el desarrollo de regiones deprimidas, estudiándose tanto los recursos vegetales locales como su gestión sostenible.

El concepto utilitarista de la sociedad actual provoca la infravaloración de lo antiguo, resultando complicado reconstruir el saber que ya solo se preserva en la memoria de unas pocas personas que la protagonizaron. Por ello, uno de los principales objetivos de este trabajo es rescatar del olvido todo los conocimientos que vinculan a las plantas con el patrimonio y la cultura tradicional de las personas de la singular comarca de la Montaña Palentina.

La noción más generalizada de patrimonio es fundamentalmente jurídica y económica. Este concepto ha ido evolucionando hasta incluir todos aquellos elementos de la cultura que por diversos motivos se valoran socialmente. La idea de patrimonio nació con una dimensión artística e histórica. Este tipo de bienes de alta valoración estética e historicidad demostrada siguen siendo los de mayor reconocimiento social. Esta idea del patrimonio se basaba en el protagonismo exclusivista ejercido por las élites ilustradas que consideraban sublimes sus productos culturales (arte, ciencia, etc.), frente a los populares, "incultos" que se tenían por vulgares (Gómez Pellón, 1999).

A partir del romanticismo en el siglo XIX, comienza a aceptarse que la historia de la cultura es la historia de toda la cultura. El único valor que se le ha dado muchas veces al folclore o saber popular es considerarlo una manifestación fósil de la civilización anterior en la que todos los conocimientos eran considerados válidos. Curiosamente, había pasado mucho tiempo desde que en el siglo I d. C. el griego Dioscórides escribiera su clásica obra en la que recopilaba todo el saber de las distintas civilizaciones sobre plantas curativas, sin hacer distinciones entre el conocimiento de las élites y del pueblo. Muchos de estos conocimientos y prácticas de carácter popular se han revalorizado gracias a su implicación positiva en el desarrollo sostenible del planeta y por representar una alternativa a la sociedad globalizadora actual (Hunn, 1999). En la Convención de La Haya, reunida a instancias de la UNESCO en 1954, se habla, por primera vez, de bienes culturales, a partir de entonces se comenzó a valorar la herencia cultural global.

El concepto de patrimonio cultural se refiere a todas las creaciones humanas que conforman la cultura, es decir, los conocimientos, ideas, hábitos y actitudes adquiridos por el hombre en cuanto que es miembro de una sociedad (Tylor, 1987). La parte más desconocida del patrimonio es quizá el etnográfico, ya que su contenido es en buena medida intangible, y no ha recibido atención por los medios académicos ni una gran valoración social. Incluye toda la herencia cultural tanto material como ideacional transmitida por la costumbre. Se trata de rasgos muy significativos de la vida de la comunidad, fruto de su experiencia histórica y de sus 
peculiares relaciones con el medio, que contribuyen claramente a la conformación de la identidad del grupo.

El patrimonio etnográfico es el reflejo de la vida cotidiana de la comunidad y representa la especificidad de un pueblo, es por lo tanto identitario y referencia, expresión significativa de la cultura de un grupo social, cuyos rasgos más expresivos se transmiten consuetudinariamente. No se trata de bienes de gran valor económico o especialmente llamativos por su excepcionalidad. Su fuerza viene de su capacidad de conferir cohesión al grupo, al transmitir emociones mediante signos comprendidos por los pertenecientes a dicho grupo. Estos bienes son de gran aprecio social, ya que representan a toda la sociedad sin restringirse a un sector en concreto (Pardo de Santayana \& Gómez Pellón, 2003).

En el seno del patrimonio etnográfico se distinguen dos tipos de bienes culturales: los materiales y los inmateriales. Asimismo, los materiales son divididos en inmuebles y muebles.

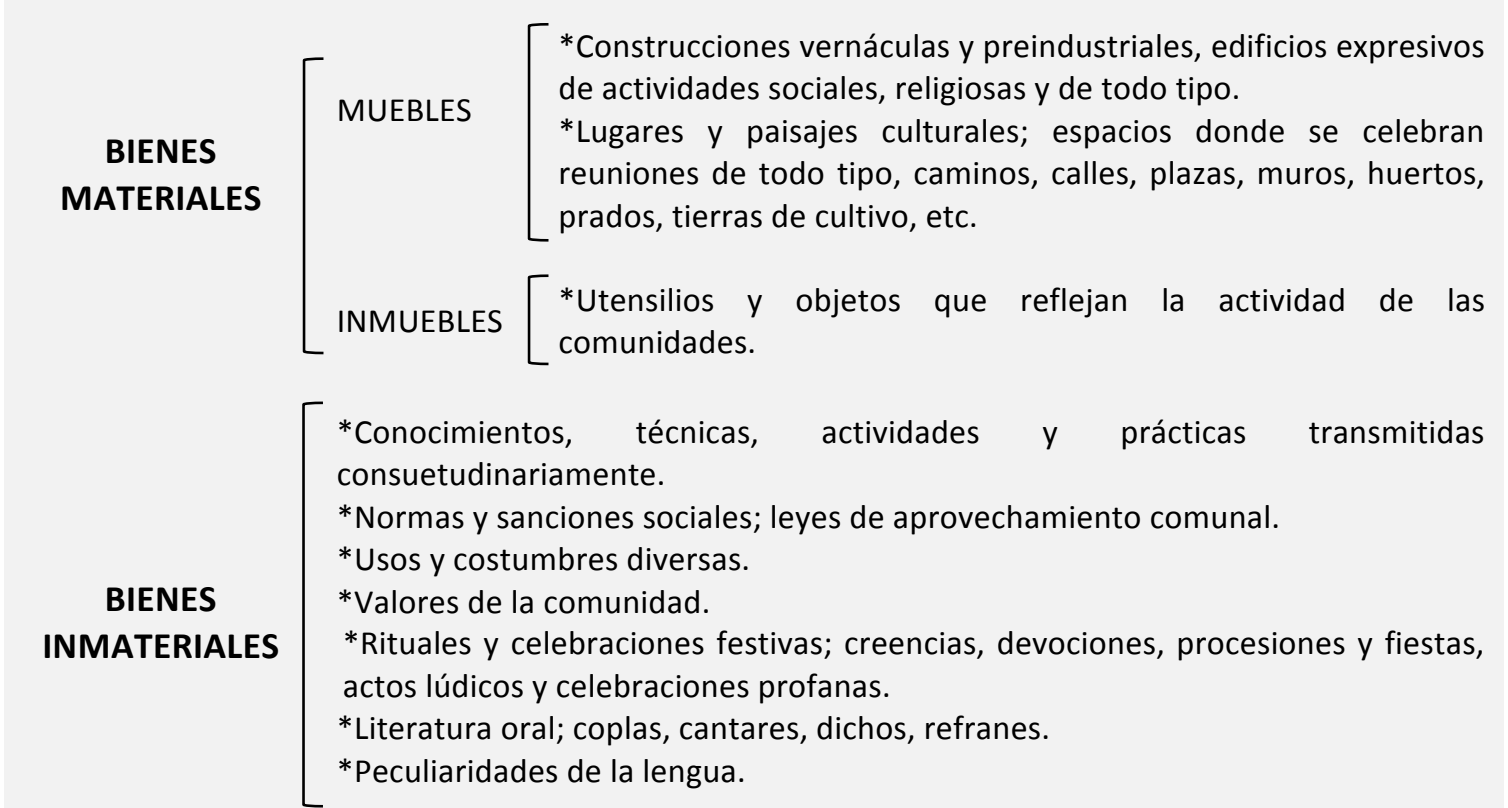

FIGURA 1: Tipos de bienes que componen el patrimonio etnográfico, tal y como es entendido en la legislación emanada del Estado y de las Comunidades Autónomas.

Si recorremos los distintos tipos de bienes que componen el patrimonio etnográfico (Fig. 1), en cada uno de ellos aparecen aspectos culturales relacionados con los vegetales. El éxito de las poblaciones humanas ha dependido del conocimiento y de la manipulación de su entorno, en el que las plantas tienen un papel básico. El ser humano se ha valido de los vegetales para solucionar la mayoría de sus necesidades vitales. En las llamadas sociedades tradicionales los vegetales no son solo el soporte material con el que satisfacer estas necesidades, sino que también cumplen una función simbólica importante. Son el elemento material de rituales que escenifican la identidad y las aspiraciones de los grupos humanos.

Este patrimonio es cambiante como la cultura. Cada generación hereda bienes que la anterior había seleccionado por su funcionalidad, relegando unos y adquiriendo otros nuevos por la creatividad de sus miembros o debido a préstamos culturales. No es un proceso meramente acumulativo. Además de cambiante, es especialmente frágil debido a la acción homogeneizadora y universalizadora de la sociedad industrial. La globalización afectó primero 
a las zonas urbanas y seguidamente a las rurales, en las que los bajos rendimientos económicos provocaron el éxodo rural, con el consiguiente envejecimiento y ruptura del engranaje entre generaciones. Es así como se pierden numerosos bienes: conocimientos, técnicas, actividades y expresiones cotidianas, que a menudo desaparecen sin dejar rastro.

A todos estos factores señalados anteriormente se pueden añadir la escasa financiación de los proyectos de investigación, la insuficiente protección institucional y la escasa valoración social. Sin embargo, cada vez hay una mayor sensibilidad hacia el patrimonio etnográfico, lo cual redundará en un futuro de manera satisfactoria en beneficio del mismo.

Esta fragilidad nos plantea la problemática del patrimonio cultural, la legislación existente al respecto y la conservación integral. La idea de patrimonio no aparece en la legislación española hasta 1985, cuando se redacta la Ley de Patrimonio Histórico Español, aunque la Constitución de 1978 ya habla de la obligación por parte de los poderes públicos de conservar el patrimonio histórico, cultural y artístico.

La ley de 1985 define el patrimonio como la "riqueza colectiva que contiene las expresiones más dignas de aprecio en la aportación histórica de los españoles a la cultura universal", y se refiere al contenido del patrimonio etnográfico como aquellos "bienes muebles e inmuebles y los conocimientos y actividades que son o han sido expresión relevante de la cultura tradicional del pueblo español en sus aspectos materiales, sociales o espirituales". La Ley da la misma importancia a todos los patrimonios, y obliga a promocionar y tutelar el libre uso y disfrute de éstos. En esta ley se equiparan los bienes etnográficos al resto de los bienes muebles e inmuebles.

En 1999, señala Jorrín, que para poder conservar el patrimonio etnográfico de una manera eficaz, es necesario seguir los siguientes pasos: documentar los bienes mediante catálogos e inventarios; seleccionar los más significativos; jerarquizar los planes de actuación; programar etnografías de urgencia; recolectar objetos y artefactos; recopilar y almacenar en soportes adecuados datos y cuestionarios sobre el patrimonio inmaterial.

La Ley 33/2015, de 21 de septiembre respecto al patrimonio inmaterial dice que "cuando se trate de conocimientos o actividades que se hallen en previsible peligro de desaparecer, la Administración competente adoptará las medidas oportunas conducentes al estudio y documentación científicos de estos bienes". Deberán promover la realización de Inventarios de los Conocimientos Tradicionales, relevantes para la conservación y el uso sostenible de la biodiversidad y geodiversidad, con especial atención a los etnobotánicos.

Para determinar la importancia y la relevancia de las plantas en un territorio se ha desarrollado en los últimos años el término de etnobotánica cuantitativa, aportado por Prance et al. (1987), existiendo un creciente interés en mejorar la recopilación tradicional de datos en estudios etnobotánicos, incorporando métodos de investigación cuantitativa en el procesamiento de datos e interpretación de resultados, elaborándose índices para significar el valor cultural de las plantas en una determinada región. Los índices más populares están basados en el consenso de informadores y en el grado de acuerdo entre los entrevistados (Albuquerque et al. 2006). Son varios los índices que valoran la relevancia cultural de las especies en una región: Frecuencia de Citación (FC), Frecuencia Relativa de Citación e Índice de Importancia Cultural (IC). Por otro lado la pervivencia de los conocimientos se evalúa con el Índice de Vigencia (IV). 


\subsection{ANTECEDENTES}

Los estudios etnobotánicos en España han tomado un auge sobresaliente, por lo que podemos decir que es uno de los países mejor estudiados de Europa (Pardo de Santayana et al., 2010). Prueba de ello son las más de 30 tesis doctorales leídas sobre la temática en las últimas dos décadas, además de tesinas, trabajos fin de carrera y numerosos estudios realizados fuera de las instituciones académicas o de investigación.

Antes del desarrollo de esta disciplina se debe destacar la figura de Pío Font Quer, considerado como el padre de la Etnobotánica en España con su obra "Plantas medicinales. El Dioscórides renovado" (1962), en la cual se recoge información botánica y medicinal de diversas especies en España.

Dentro de estos estudios y publicaciones, se deben citar los notables trabajos realizados en determinados territorios como: La Cerdanya en Girona (Muntané, 1991), el Vallés Oriental en Barcelona (Bonet, 1993), La Manchuela en Albacete (Sánchez López, 1994), Sierra Mágina en Jaén (Mesa, 1996), la sierra de El Caurel en Lugo (Blanco, 1996), las sierras de Alcaraz y Segura en Albacete (Verde et al., 1998), La Calabria en Badajoz (Blanco \& Cuadrado, 2000), el Montseny en Barcelona (Bonet, 2001), los Montes de Toledo (Blanco, 2002), la comarca de Campoo en Cantabria (Pardo de Santayana, 2003), los Villares y Valdepeñas en Jaén (Ortuño, 2003), el concejo de Piloña en Asturias (San Miguel, 2004), el municipio de Palacios del Sil en León (García Jiménez, 2007), el Poniente Granadino (Benítez, 2009), la Sierra Norte de Madrid (Aceituno Mata, 2010), La Pernía, Polentinos y el Valle de Castillería en Palencia (Pascual, 2013) o el Cerrato Palentino (Pascual et al., 2016).

Otros trabajos etnobotánicos destacados se han llevado a cabo en provincias, como los realizados en Granada (González-Tejero, 1989), Castellón (Mulet, 1991), Jaén (Guzmán, 1997), Segovia (Blanco, 1998), Albacete (Fajardo et al., 2000), Cuenca (Fajardo et al., 2007), Toledo (Criado et al., 2008), Salamanca (Velasco et al., 2010), o Ávila (Blanco, 2017).

Además de estos estudios de carácter general, se han realizado trabajos concretos sobre plantas alimentarias, distinguimos los llevados a cabo en Montseny (Bonet \& Vallès, 2002), en Madrid (Tardío et al, 2002), en Albacete (Rivera et al., 2006), en Gorbeialdea (Menendez Baceta, 2009), en Doñana (Rodríguez Franco, 2013), específicos sobre plantas medicinales, algunos ejemplos como los realizados en el Pirineo aragonés (Villar et al, 1987), en Murcia (Obón \& Rivera, 1991), en Pallars (Agelet, 1999), en La Coruña (Latorre, 2008), en Navarra (Akerreta, 2009) o en Terra Chá (Anllo, 2011), o sobre huertos y cultivos, en Lanzarote (Gil González et al., 2005), en Cádiz (Mulero et al., 2008) o en Asturias (Dapena et al., 2008).

La información de muchos de estos trabajos y publicaciones ha sido reagrupada en el Inventario de los Conocimientos Tradicionales relativos a la Biodiversidad, llevada a cabo en dos fases: fase I (Pardo de Santayana et al., 2014) y fase II con tres volúmenes (Pardo de Santayana et al., 2018a; Pardo de Santayana et al., 2018b; Pardo de Santayana et al., 2018c), y en el Inventario de los Conocimientos Tradicionales relativos a la Biodiversidad Agrícola (Tardío et al., 2018).

En la provincia de Palencia cabe reseñar la obra de Macho Tomé (1893) que recopila conocimientos relativos a la flora medicinal en el Partido Judicial de Saldaña, la publicación de Oria de Rueda et al. (1996) sobre plantas silvestres, con algunas referencias generales sobre utilidades de las mismas, y la de Muriel Martín (2008) centrada en aplicaciones medicinales de las plantas. 
Por último, en la Escuela Técnica Superior de Ingenierías Agrarias de Palencia (ETSIIAA) existen antecedentes de trabajos fin de carrera realizados bajo esta temática (Herrero Laborda, 1998; Álvarez Baz, 2004; Escobar García, 2006; Blanco Esteban, 2007; Martín Franco, 2007; Antón Herrera, 2009; Sedano Pérez, 2011; y Pascual, 2013), centrados en una comarca, en usos particulares de las plantas o con una clara tendencia hacia el conocimiento de las aplicaciones medicinales. Su posible puesta en práctica hace que muchos trabajos etnobotánicos tengan un claro sesgo de carácter etnofarmacológico, despreocupándose en parte de aspectos no utilitarios, en apariencia inútiles, pero de un gran significado simbólico en el entramado social y cultural, que al fin y al cabo expresan el sentido de los intereses de los grupos humanos y que suponen un patrimonio etnográfico.

Encontramos antecedentes de estudios etnobotánicos en la zona en los trabajos de Herrero Laborda (1998) y del propio investigador, que prospectó información en los municipios de La Pernía, Polentinos y en el valle de Castillería (Pascual, 2013), abarcando una pequeña parte del total correspondiente a la comarca de la Montaña Palentina. Otras obras interesantes en la comarca son las publicaciones de Alcalde Crespo (1981; 1982; 1991; 1992) sobre distintas áreas de la Montaña Palentina, aunque todas ellas de carácter etnográfico.

\subsection{JUSTIFICACIÓN}

El despoblamiento y los cambios socioculturales de las últimas décadas han supuesto una nueva relación con el medio ambiente. Las plantas del entorno resultaban hasta estos cambios, imprescindibles para solucionar las necesidades vitales de los habitantes de la comarca de la Montaña Palentina. Los conocimientos no se han transmitido entre generaciones debido a las transformaciones anteriormente mencionadas, por lo que se hace necesario recopilarlo y analizarlo antes de que se pierda este legado cultural (Pardo de Santayana \& Gómez Pellón, 2003).

La zona de estudio posee una elevada riqueza paisajística y cultural, este es uno de los hechos que ha motivado la elección de la zona como lugar de investigación para elaborar este estudio etnobotánico. Otro motivo viene condicionado por la historia familiar ligada a la misma.

El presente trabajo pretende aunar el tradicional estudio etnobotánico en la recopilación de conocimientos populares sobre las plantas, con la etnobotánica cuantitativa en la interpretación y comparación de la información.

Por todo ello considero el actual estudio novedoso, pues no existe ningún trabajo que analice de forma rigorosa y detallada el conocimiento botánico en la comarca de la Montaña Palentina, compagina la conservación, interpretación y cuantificación del patrimonio cultural con el interés por la naturaleza y trata de rescatar todas aquellas técnicas tradicionales que han sido sostenibles a lo largo de la historia.

Asimismo, este trabajo etnobotánico es una herramienta práctica para fomentar el desarrollo de esta zona deprimida. Mediante el estudio, será posible el abordaje de catálogos acerca de los recursos naturales locales, al tiempo que se podrá valorar la sostenibilidad de su explotación, se señalan bienes promisorios y se revalorizan los ya existentes, pudiendo presentarse como reclamo del turismo llamado ecológico. Además de estos posibles efectos económicos, quizá pueda fomentar actividades saludables, y ser difundido en las escuelas para ayudar a la educación ambiental, integrando en ella la tradición y la identidad local. 


\section{OBJETIVOS}




\section{OBJETIVOS}

El objetivo general pretendido en la elaboración de la presente tesis es el estudio del conocimiento relativo a los usos tradicionales de las plantas, tanto silvestres como cultivadas, en la comarca de la Montaña Palentina. Los objetivos específicos planteados fueron los siguientes:

1. Identificación taxonómica de las especies con usos tradicionales.

2. Catalogación de los diferentes nombres vernáculos empleados por la población local, relacionándolos con la nomenclatura científica de las especies.

3. Elaboración de un catalogo etnobotánico, describiendo los usos tradicionales de los taxones identificados y especificando para cada uno de ellos la frecuencia de citación, usos, partes empleadas, aplicaciones y manejo.

4. Recogida de costumbres, creencias y relaciones sociales en las que aparece la implicación de las plantas.

5. Contraste bibliográfico de los usos de las plantas en la zona de estudio frente a otros estudios etnobotánicos.

6. Conservación de los valores culturales y etnográficos de la zona de estudio relacionados con el conocimiento y uso de las plantas.

7. Determinación comparativa mediante índices, de la importancia cultural de las plantas más útiles en la zona.

8. Cuantificación de la vigencia de las especies empleadas, estimando en que medida los usos o tradiciones se han abandonado.

9. Desarrollo y perfeccionamiento de la metodología para la recopilación de información, basándonos en trabajos etnobotánicos anteriores publicados en la Península Ibérica.

A nivel particular, se pretende ampliar formación en materia de metodología de trabajo científico, manejo de bibliografía, ofimática y botánica, así como adquirir conocimientos etnográficos y contacto con la cultura local. 


\section{ZONA DE ESTUDIO}




\section{ZONA DE ESTUDIO}

\section{1. ÁREA DE ESTUDIO}

La Montaña Palentina está enclavada en la vertiente meridional de la Cordillera Cantábrica, que se prolonga por su extremo occidental en la provincia de León y por el oriental en la provincia de Burgos. Su límite septentrional lo constituye la demarcación provincial. El límite meridional está marcado por el tránsito de los materiales paleozoicos y mesozoicos a los cenozoicos, que se corresponden con el paso del relieve de montaña al relieve suave y ondulado del páramo detrítico terciario. Este límite coincide en la parte occidental con la línea de ferrocarril, León-Bilbao, conocido como tren de La Robla. Se sitúa entre las coordenadas $42^{\circ}$ $11^{\prime} 25^{\prime \prime}$ y $43^{\circ} 04^{\prime} 05^{\prime \prime}$ de latitud $\mathrm{N}$ y entre los $3^{\circ} 59^{\prime} 26^{\prime \prime}$ y $4^{\circ} 54^{\prime} 12^{\prime \prime}$ de longitud W.

La Montaña Palentina es una superficie de $1576 \mathrm{~km}^{2}$, engloba 16 municipios y 116 localidades, y está conformado por 4 unidades morfoestructurales: Fuentes Carrionas-La Peña, La Pernía, La Braña y La Lora, aunque esta última se decidió excluirla del estudio al considerarla una unidad morfoestructural singular, digna de abordar en un estudio diferenciado.

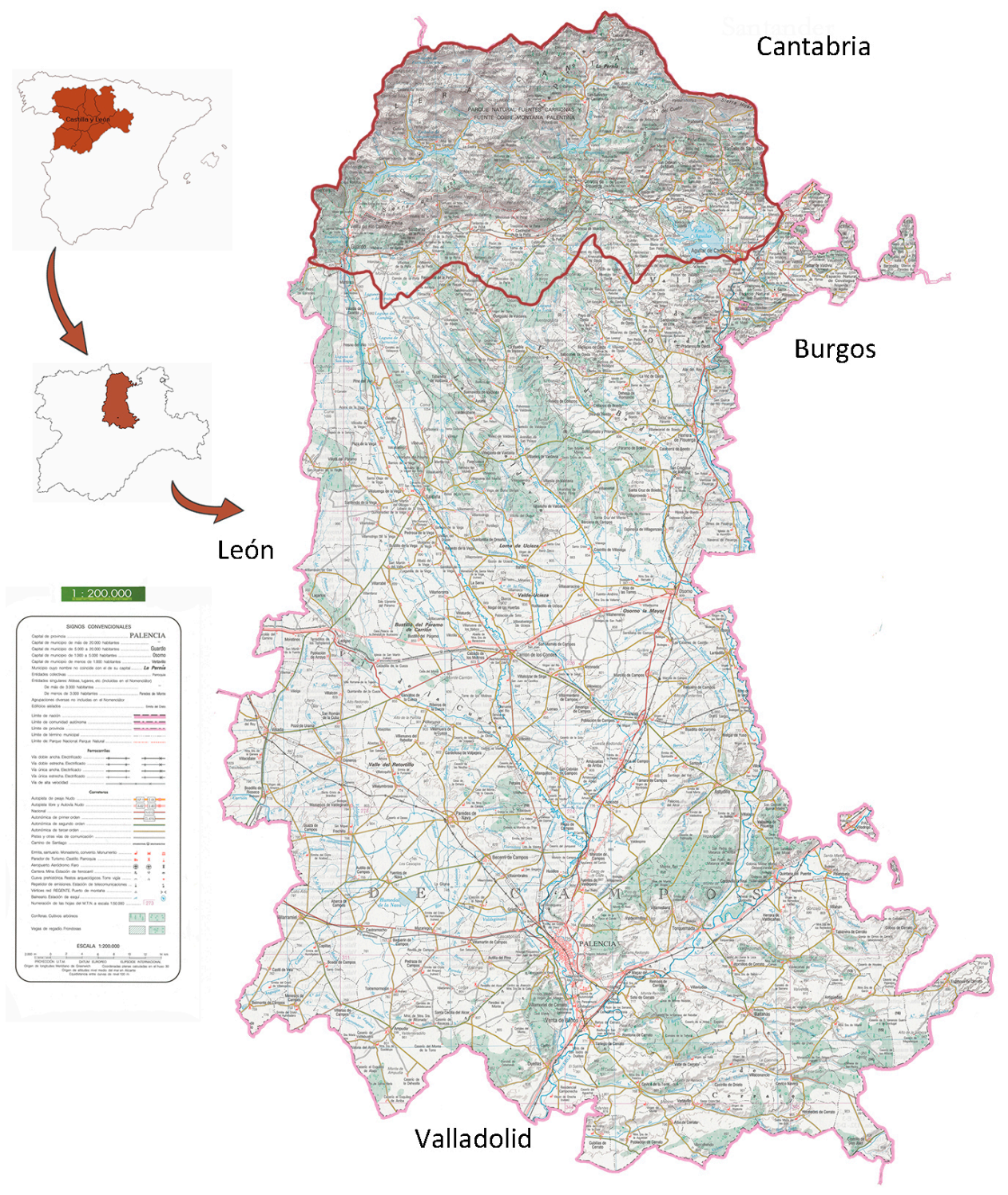

FIGURA 2: Mapa provincial de Palencia. Instituto Geográfico Nacional (2014). 


\subsection{MEDIO FÍSICO}

\subsubsection{RELIEVE}

La característica principal de la comarca de la Montaña Palentina es su carácter montañoso. El relieve se caracteriza por un fuerte contraste entre las planicies de los valles y las altitudes de las montañas formadas por la orogenia alpina, y que han sido erosionadas en el transcurso del tiempo por dos cuencas fundamentales, produciendo pendientes muy acusadas al oeste y más suaves al este. Esto es debido a la petrografía de las dos zonas, las del oeste formadas por rocas duras que quedan al descubierto en ocasiones, erosionadas por los arrastres fluviales, mientras que al este, en más abundante en calizas blandas y areniscas, más erosionables.

La acción de desgaste provocada por la disección fluvial ha contribuido al resalte de peñas y crestas entre valles encajados al oeste y amplios al este, y es el motivo de una primera diferenciación en el paisaje: la mitad occidental (Fuentes Carrionas, La Peña) y nororiental (Sierra de Peñalabra, La Pernía, valles de Santullán y Mudá) de la Montaña Palentina. Se caracteriza por las elevadas altitudes de sus cumbres, con picos como: del Infierno (2537 m), Curavacas (2528 m), Espigüete $(2450 \mathrm{~m}$ ) o Pico Murcia $(2341 \mathrm{~m})$ en la mitad occidental, y Peña Labra (2029 m), Pico Tres Mares (2175 m) y Valdecebollas (2143) en la oriental, entre otros varios, de más de $2000 \mathrm{~m}$, y por los fuertes desniveles que se hacen notar especialmente al acceder desde la superficie suavemente ondulada de los páramos. Entre los valles cabe destacar los de Pineda y Cardaño en Fuentes Carrionas, los de La Castillería, Los Redondos, Santullán y Mudá al noreste y los de Cervera y Aguilar de Campoo en el centro y sureste de la comarca, respectivamente.

Las sierras limítrofes (Peña Prieta, Peña Labra, Híjar) se sitúan en la vertiente meridional de las estribaciones de la Cordillera Cantábrica, enlazando por el oeste con las montañas de León y por el este con las de Burgos. Las de la parte sur (Sierra de la Peña), sirven de contacto y transición con la llanura castellano-leonesa.

Los acusados desniveles contribuyen a configurar ese carácter de relieve montañoso. De los $1000 \mathrm{~m}$ de altitud que constituyen las zonas más bajas y deprimidas del corredor por el que discurren los ríos Carrión y Pisuerga, se pasa en apenas $10 \mathrm{~km}$ a cimas que superan los $2000 \mathrm{~m}$, encontrándose el fondo de estos valles a menudo recortados por fuertes pendientes. La extensión de las llanuras aluviales suele ser pequeña.

\subsubsection{GEOLOGÍA}

Las características geológicas de la zona de estudio presentan una gran complejidad. En la figura 3 se muestra el mapa geológico de la Montaña Palentina, quedando definidas las características estratigráficas, paleontológicas y tectónicas, como terrenos pertenecientes a la era Primaria, principalmente entre los periodos Devónico y Carbonífero, con fauna fósil de este segundo periodo. 

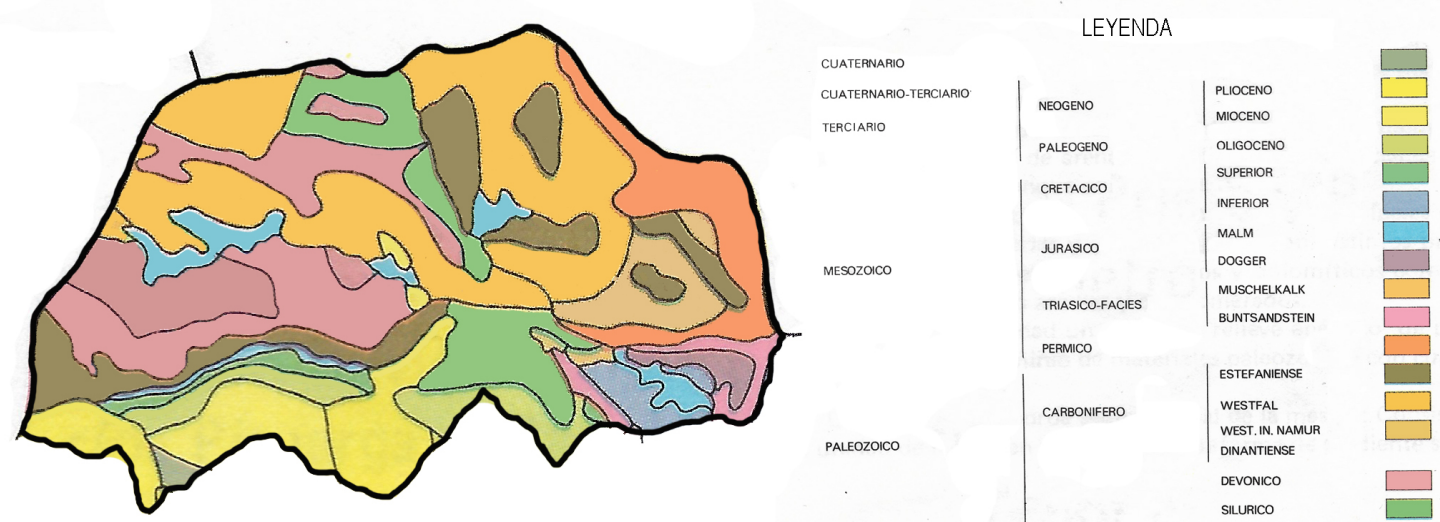

Figura 3: Mapa geológico de la Montaña Palentina. Fuente: Mapa de cultivos y aprovechamientos de la provincia de Palencia (1985).

Se puede dividir en dos unidades geomorfológicas:

- Estribaciones meridionales de las sierras de Peña Prieta y Peña Labra, se trata de un área de intensa disección fluvial, a cargo de las cuencas de cabeceras de los ríos Pisuerga y Carrión. Los materiales paleozoicos, siempre del Devónico y Carbonífero, se pueden dividir atendiendo a las propiedades litológicas, en dos subzonas, este y oeste, separadas por la divisoria de aguas del Carrión y Pisuerga.

El Devónico de la subzona oeste está constituido por cuarcitas superficiales, areniscas ferruginosas con cuarcitas intercaladas, estratos homogéneos de calizas fosilíferas y pizarras arcillosas algo carbonosas, las cuales en avanzado grado de meteorización dan lugar a arcillas en un estado posterior, mientras que las areniscas están en estado de desintegración muy silicatadas y poco o nada ferruginosas, mostrando tonalidades más claras.

El perfil carbonífero de esta subzona está formado por calizas azules de montaña en superficie Por debajo aparecen los conglomerados, pizarras y nuevos conglomerados y ya en los valles de montaña areniscas con intercalaciones de cuarcita. La zubzona oriental, también formada por materiales carboníferos y devónicos, presenta solamente diferencias en los primeros, con una serie formada por calizas de montaña, conglomerados de cuarzo y arcilla y pizarras muy compactas y carbonosas, las cuales son muy poco meteorizables comparadas con las del oeste.

Los materiales mesozoicos pertenecen al Keuper de facies germánica con margas y arcillas irisadas y yesíferas, junto con distintos pisos jurásicos y cretácicos, fundamentalmente calizos y dolomíticos con niveles de areniscas silíceas, margas o arcillas y conglomerados.

Supone esta unidad un sector de relieve enérgico, de pendientes elevadas y con un predominio de materiales paleozoicos, con cuarcitas, pizarras y areniscas.

- Los páramos del borde septentrional de la meseta; consiste esta segunda unidad de relieve en una amplia plataforma de gradiente suave hacia el sur-sureste apoyada en los relieves de la Cordillera Cantábrica y con alturas entre 800-1200 m.

Los materiales superficiales corresponden a las rañas pliocenas formadas por cantos de cuarcita redondeados con arcillas sabulosas rojizas y arenosas. Su potencia es muy variable 
llegando a espesores de hasta $30 \mathrm{~m}$. Se apoyan indistintamente sobre las facies y tramos miocenos y en realidad no forman una única superficie, sino varios aterrazamientos.

\subsubsection{EDAFOLOGÍA}

La edafogénesis presenta en la zona una gran variedad de situaciones dada la gran diversidad de substratos, de formas de relieve y de microclimas. El mosaico resultante es por ello enormemente contrastado no siendo raro encontrar cambios bruscos. El principal factor limitante de la edafogénesis son las pendientes: pasados los $30 \circ 35^{\circ}$ de inclinación el desarrollo de suelos es prácticamente inviable. En áreas de pendientes medias $\left(20^{\circ}\right)$ los suelos necesitan para conservarse una cubierta vegetal continua y con un denso sistema radicular.

La cubierta edáfica en la Montaña Palentina se caracteriza principalmente por escasez de suelos profundos, discontinuidad de la cubierta con extensos afloramientos de la roca madre y secuencias de suelos, y de cadenas de suelos, consecuencia de los abundantes aportes horizontales y desde las zonas culminantes de las vertientes.

Los suelos de la zona de estudio, siguiendo las normas de clasificación americana, pertenecen básicamente a cuatro órdenes: Entisoles, Inceptisoles, Mollisoles y Alfisoles, como se puede observar en la figura 4.

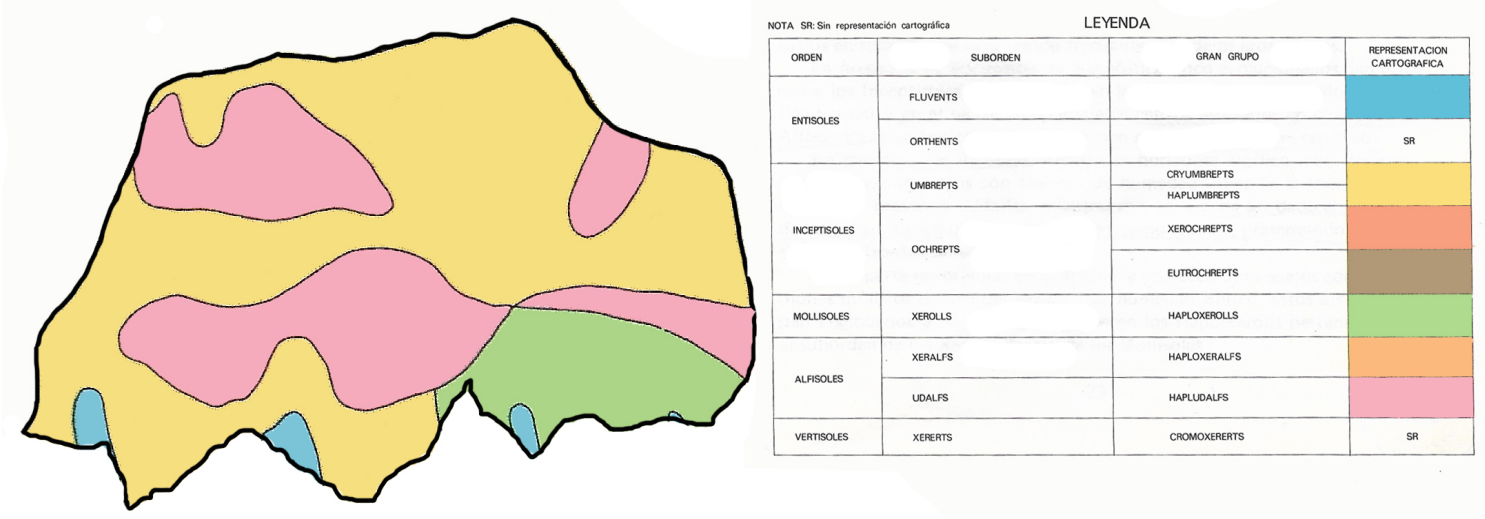

Fıgura 4: Mapa edafológico de la Montaña Palentina. Fuente: Mapa de cultivos y aprovechamientos de la provincia de Palencia (1985).

Entisoles: Son suelos muy recientes y sin evolucionar, diferenciados en dos subórdenes:

Fluvents: son los suelos aluviales formados por los aportes recientes de los ríos, situándose por tanto en sus márgenes. Tienen poca extensión y se trata de suelos profundos, fértiles y con buena aireación. El suelo típico de las vegas.

Orthents: son suelos muy poco profundos formados sobre roca madre. Son los suelos de las zonas más abruptas como montes, cerros, sierras y laderas de gran inclinación. Suelos muy pobres y no utilizables para el cultivo con vocación ganadera o forestal.

Inceptisoles: Son los más frecuentes en la zona, y son suelos medianamente profundos, con mucha materia orgánica en superficie. Su uso más común es como pastizales y praderas alternando con alguna labor y aprovechamiento forestal. 
Mollisoles: Aparecen en la parte suroriental de la comarca en zonas de semejantes características a los inceptisoles, pero con reacción más básica. Se trata de suelos agrícolas con un horizonte de espesor y alta carga orgánica.

Alfisoles: Suelos formados por acumulación de arcilla iluviada, pobres en materia orgánica y que suelen sostener parcialmente la zona cultivada.

\subsubsection{HIDROLOGIA}

La Montaña Palentina es el origen hidrográfico provincial y en ella se encuentran los pantanos y la divisorias de las vertientes Cantábricas del Duero y Ebro. El pico denominado Tres Mares origina las corrientes fluviales, que dirigen sus caudales hacia los mares Mediterráneo, Cantábrico y océano Atlántico. Los ríos que nacen en este pico son el Híjar, el Nansa y el Pisuerga.

Los dos ríos que caracterizan a la provincia de Palencia por su importancia, son el Carrión al Oeste y que no sale de la provincia y el Pisuerga al Este, hasta que cruza la provincia por el Sur. El nacimiento del Carrión se inicia en la confluencia de las provincias de León, Cantabria y Palencia, recogiendo las aguas de los parajes montañosos. Nace en las estribaciones meridionales de la Sierra de Peña Prieta y hasta el pantano de Camporredondo recoge las aguas de arroyos y torrenteras, entre los que podemos citar: Arauz, Valdenievas y Valdetriollo.

El pantano de Camporredondo se abastece por el Arroyo Las Lomas, y a su vez abastece al embalse de Compuerto, el cual recoge las aguas de los arroyos Abiano, de la Cárcava y de la Cueva. Desde este embalse y hasta su salida de la montaña recorre los términos de Velilla del Río Carrión y Guardo. Aguas abajo se encuentra el embalse de Velilla de pequeña capacidad.

El río Pisuerga nace en la vertiente norte del pico Valdecebollas y forma un valle abierto en su cabecera formando una cuenca que conforma la comarca de La Pernía, alcanza la localidad de Cervera de Pisuerga y se dirige hacia el este de la provincia, hasta llegar a Aguilar de Campoo, desde donde prosigue en un recorrido vertical, por el margen oriental de la provincia de Palencia, sus aguas son embalsadas en dos pantanos: el de Requejada recrecido por los ríos Lores, Lebanza, Resoba y Castillería, y el de Aguilar de Campoo. Tiene un recorrido de $60 \mathrm{~km}$ a lo largo de la comarca de la Montaña Palentina. El embalse de Ruesga almacena las aguas procedentes del río Rivera y las vierte en la margen derecha del río Pisuerga.

La densidad de la red hidrográfica, la importancia de las precipitaciones y las características de sus cuencas han permitido la construcción de los embalses ya mencionados de Requejada, Ruesga, Aguilar, Camporrendondo y Compuerto. Las reservas de sus aguas se sueltan en el período de aguas bajas para reducir estiajes y cubrir las necesidades agrícolas y humanas. Son abastecedores temporales y además se utilizan como área de esparcimiento y recreo de enorme pujanza durante el verano.

La cuenca del río Rubagón conforma la unidad de La Braña, este río desemboca en el río Camesa que tributa sus aguas al río Pisuerga por su margen izquierdo. El río Boedo nace en Peña Redonda y atraviesa Villanueva de la Peña, Traspeña de la Peña, Castrejón de la Peña y Loma de Castrejón. 


\subsubsection{CLIMATOLOGÍA}

Climatológicamente constituye una zona de transición entre el clima con influencia oceánica y el clima mediterráneo continental, compartiendo rasgos de ambos dominios y con un gradiente noroeste-sureste, en cuanto a temperaturas y precipitaciones, correspondiendo al noroeste las temperaturas más bajas y lluvias más abundantes. Esta transición climática no es gradual sino que presenta múltiples facies condicionadas por la topografía. Las zonas de mayor altitud conocen numerosas nevadas y días de niebla, así como temperaturas más frías que las zonas situadas en posiciones de abrigo con condiciones algo más benignas, y que suelen coincidir con los emplazamientos de varios asentamientos urbanos en los fondos de los valles.

Las lluvias y la presencia de nieve en las laderas y cimas condicionan el régimen pluvionival de los ríos más importantes de Palencia, como el Carrión y Pisuerga, que tienen su cuenca de alimentación, circunscrita a los límites de la Montaña Palentina.

Las temperaturas más frías del extremo occidental se deben a sus mayores altitudes, y la mayor pluviosidad se deriva de su cercanía a las sierras que actúan como barreras naturales de las borrascas que penetran por el Noroeste de la Península. La temperatura media de la Montaña Palentina está en torno a $9{ }^{\circ} \mathrm{C}$, con temperaturas medias de las máximas y mínimas que oscilan entre $23{ }^{\circ} \mathrm{C}$ y $-3,8{ }^{\circ} \mathrm{C}$. Las precipitaciones medias están en torno a los $806 \mathrm{~mm}$, oscilando entre los $1300 \mathrm{~mm}$ y los $670 \mathrm{~mm}$.

TABLA 1: Indicadores climáticos en la Montaña Palentina. (Fuente: Estación meteorológica de Cervera de Pisuerga, 1932-2018, AEMET).

\begin{tabular}{lc}
\hline Indicadores & Montaña Palentina \\
\hline Temperatura media anual $\left({ }^{\circ} \mathbf{C}\right)$ & 9,0 \\
\hline Temperatura media de las máximas $\left({ }^{\circ} \mathbf{C}\right)$ & 23 \\
\hline Temperatura media de las mínimas $\left({ }^{\circ} \mathbf{C}\right)$ & $-3,8$ \\
Precipitación media anual $(\mathbf{m m})$ & 806 \\
Media de días de lluvia al año & 92 \\
Media de días de nieve al año & 24 \\
Meses con mayor precipitación & Nov-Dic \\
Meses de menor precipitación & Jul-Ago \\
\hline
\end{tabular}

TABLA 2: Temperaturas de la estación de Cervera de Pisuerga para los años 1932-2018. (Fuente: AEMET). Siendo: T = Temperatura media mensual $\left({ }^{\circ} \mathrm{C}\right)$; $\operatorname{Tmax}=$ Temperatura máxima absoluta $\left({ }^{\circ} \mathrm{C}\right)$; $\operatorname{Tmin}=\operatorname{Temperatura}$ mínima absoluta $\left({ }^{\circ} \mathrm{C}\right)$; TMmax = Temperatura media de las máximas $\left({ }^{\circ} \mathrm{C}\right)$; $\mathrm{TMmin}=$ Temperatura media de las mínimas $\left({ }^{\circ} \mathrm{C}\right)$.

\begin{tabular}{lrrrrrrrrrrrrr}
\hline & Enero & Febrero & Marzo & Abril & Mayo & Junio & Julio & Agosto & Setiem. & Octubre & Noviem. & $\begin{array}{r}\text { Diciem. } \\
\text { Media } \\
\text { anual }\end{array}$ \\
\hline T & 1,6 & 2,6 & 5,2 & 7,3 & 10,6 & 14,7 & 17,3 & 16,9 & 14,3 & 9,7 & 5,1 & 2,4 & 9,0 \\
Tmax & 12,8 & 14,7 & 18,8 & 22,0 & 25,8 & 30,8 & 33,4 & 33,1 & 29,9 & 23,3 & 17,5 & 13,4 & 23,0 \\
Tmin & $-10,8$ & $-9,7$ & $-7,4$ & $-4,7$ & $-2,3$ & 1,0 & 2,9 & 3,0 & 0,3 & $-2,8$ & $-6,5$ & $-9,2$ & $-3,8$ \\
TMmax & 6,4 & 7,8 & 11,2 & 13,5 & 17,1 & 22,1 & 25,8 & 25,6 & 22,0 & 16,0 & 10,1 & 6,9 & 15,4 \\
TMmin & $-3,2$ & $-2,6$ & $-0,8$ & 1,1, & 4,0 & 7,1 & 8,9 & 8,8 & 6,5 & 3,5 & 0,1 & $-2,0$ & 2,6 \\
\hline
\end{tabular}

El análisis de la temperaturas medias anuales pone de relieve la intensidad y duración del período frío que se alarga desde el mes de octubre hasta mayo y un período cálido relativamente corto, con una estación primaveral que se reduce a algunas semanas de mayo y junio, y un verano que ocupa los meses de julio y agosto sin llegar a ser excesivamente cálido. Otro período de transición como es el otoño, tampoco adquiere una duración significativa. 


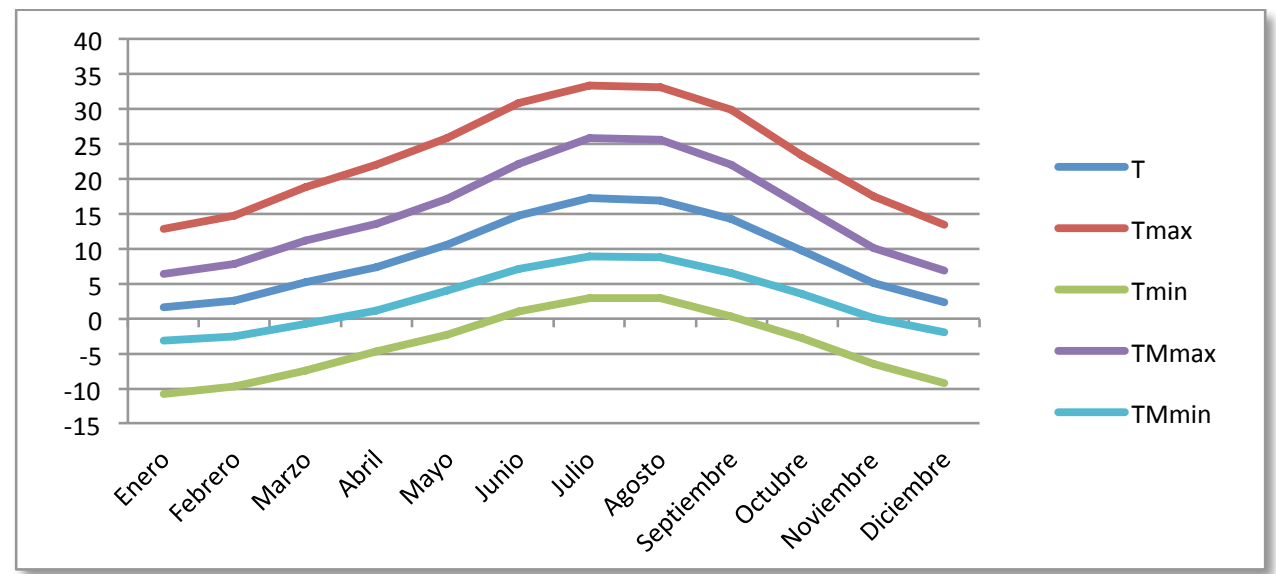

Figura 5: Resumen de temperaturas en la estación de Cervera de Pisuerga (1932-2018). (Fuente: AEMET). Siendo: $\mathrm{T}=$ Temperatura media mensual $\left({ }^{\circ} \mathrm{C}\right) ; \operatorname{Tmax}=$ Temperatura máxima absoluta $\left({ }^{\circ} \mathrm{C}\right) ; \operatorname{Tmin}=$ Temperatura mínima absoluta $\left({ }^{\circ} \mathrm{C}\right) ; \mathrm{TMmax}=$ Temperatura media de las máximas $\left({ }^{\circ} \mathrm{C}\right) ; \mathrm{TMmin}=$ Temperatura media de las mínimas $\left({ }^{\circ} \mathrm{C}\right)$.

Las precipitaciones no presentan una distribución homogénea, incrementándose según nos vayamos adentrando desde la cuenca sedimentaria al ámbito montano en una serie de aureolas que se acercan bastante a las curvas hipsométricas. Las montañas de la Sierra del Brezo y de la Peña, situadas al oeste de la comarca, retienen en forma de nieblas y lluvias gran parte de las masas de aire húmedo procedentes del Atlántico. Esto origina abundante nubosidad y frecuentes precipitaciones repartidas a lo largo del año. El período húmedo en la comarca está entre 9-10 meses como media, siendo los meses de mayores precipitaciones diciembre y enero, y los meses más secos julio y agosto. La pluviometría media mensual, oscila entre los $628,1 \mathrm{l} / \mathrm{m}^{2}$ de Aguilar de Campoo y los $1164,5 \mathrm{l} / \mathrm{m}^{2}$ de Triollo.

\subsubsection{VEGETACIÓN}

El territorio en estudio desde el punto de vista fitogeográfico puede enmarcarse mayoritariamente en la región Eurosiberiana, provincia Atlántico-Europea y la parte más suroriental pertenece a la región Mediterránea, provincia Mediterránea-Central-Ibérica.

El piso al que corresponde la mayor parte de la zona es el montano, ubicado entre los $600 \mathrm{y}$ $1600 \mathrm{~m}$, salvo algunos terrenos de alta montaña que pertenecen al piso subalpino.

La vegetación arbórea autóctona queda restringida a bosques de haya y roble albar, poco extensos debido a una explotación abusiva de su madera, localizados entre los 1000 y $1700 \mathrm{~m}$ de altitud, destacan los robledales y hayedos; junto a otros de menor extensión pero de singular valor, como son: abedulares, alamedas y tejedas, así como acebedas, avellanedas, mostellares, y saucedas.

En los bordes de los bosques, aparecen orlas arbustivas con: majuelos, rosales, endrinos, espinos pudios, agracejos, etc.

Las comunidades de sustitución más extendidas son los brezales y escobales y sobre suelos ricos son frecuentes los tojal-brezales o los aulagares.

Entre las áreas de pastos pueden citarse las praderas de siega o diente y los pastizales de altura. Los modelos de sucesión no suelen ser lineales: prado-matorral-bosque, pudiendo 
ocurrir que se salten etapas de este modelo ideal o producirse modelos regresivos intermedios.

En los roquedos, peñas y pedregales crecen plantas rupículas de una gran riqueza y variedad.

En parajes encharcados o muy húmedos se desarrollan agrupaciones vegetales como turberas, saucedas, cervunales y comunidades de plantas acuáticas.

A continuación se describen las formaciones vegetales que podemos encontrar en esta comarca.

\section{Formaciones arbóreas:}

En estas comunidades las especies de porte arbóreo son predominantes, formando espacios casi completamente cubiertos por estas especies, que a su vez, singularizan las principales unidades de vegetación que cubren el terreno. En la Montaña palentina, la superficie cubierta por arbolado es de $353 \mathrm{~km}^{2}$, que representa un $27 \%$ de su superficie

\section{Robledales caducifolios}

Este tipo de bosque es representativo de la zona de estudio, el de roble albar o cajiga (Quercus petraea (Matt.) Liebl.), el cual se desarrolla en laderas y faldas de montaña de piso montano, preferentemente en solanas. El roble albar de gran longevidad, alcanza gran envergadura en las localidades de San Salvador de Cantamuda o Carracedo. Aparece acompañado por árboles como: haya (Fagus sylvatica L.), abedul (Betula pubescens Ehrh.), álamo temblón (Populus tremula L.), o arce (Acer campestre L.). En el estrato arbustivo, aparecen avellano (Corylus avellana L.), serbal (Sorbus aucuparia L.), maíllo (Malus sylvestris (L.) Mill.), mostajo (Sorbus aria (L.) Crantz), acebo (Ilex aquifolium L.) y espino albar (Crataegus monogyna Jacq.), como acompañantes más frecuentes.

Cuando se incorporan especies más exigentes en humedad, como el haya, pueden formar bosques mixtos. En áreas más xéricas, entra en contacto con el rebollo (Quercus pyrenaica Willd.) que llega a desplazar al roble albar. Los robledales ocupan laderas umbrosas de fuerte pendiente, no manifiesta preferencias edáficas acusadas, aunque es más abundante en suelos ácidos. Ocupa el área más septentrional de la comarca y las laderas norte de la Sierra del Brezo y Peña Redonda.

Al permitir el robledal la llegada de luz al suelo, el sotobosque está formado por arbustos y matas como: cornejos (Cornus sanguinea L.), zarzamoras (Rubus ulmifolius Schott y Rubus caesius L.), frambuesos (Rubus idaeus L.), boneteros (Euonymus europaeus L.), madreselvas (Lonicera xylosteum L. y L. periclymenum L.), zarzas (Rosa arvensis Huds., $R$. canina L., $R$. pendulina L., $R$. spinosissima L., etc.), barbadilos (Viburnum lantana L.) y hiedras (Hedera helix L.). En terreno silíceo los matorrales están constituidos por brezales (Erica australis L, E. arborea L., E. cinerea L., etc.), arándanos (Vaccinium myrtillus L.) y escobales (Genista florida L. y Cytisus scoparius (L.) Link.), y en terreno calizo, aulagas o argomas (Genista hispanica L.) y Erica vagans $\mathrm{L}$.

El estrato herbáceo es variado, tanto en composición como en cobertura según disponibilidad de nutrientes minerales, aparecen: Anemone nemorosa L., Astrantia major L., Campanula rapunculus L., Helleborus viridis L., Lilium martagon L., Linaria triornithophora (L.) Cav., 
Lysimachia nemorum L., Melampyrum pratense L., Primula veris L. o Prunella grandiflora L. También los helechos comunes (Pteridium aquilinum (L.) Kuhn), los lastones de bosque (Brachypodium sylvaticum (Huds.) P.Beauv., B. pinnatum (L.) P.Beauv., Carex sylvatica Huds., Luzula sylvatica (Huds.) Gaudin y Briza media L.).

Los robledales en cuya composición forman parte árboles de roble albar, rebollo y los híbridos entre dichas especies, dan lugar a formaciones de robledales mixtos. En sus estratos inferiores están constituidos por elementos del robledal albar y del rebollar, con proporciones variables según predominen las condiciones ambientales más propicias para uno u otro tipo de bosque.

\section{Robledales marcescentes}

Bosques que en su etapa madura presentan un estrato arbóreo constituido fundamentalmente por el rebollar o melojar (Quercus pyrenaica), de gran extensión en la zona, y que tienden a habitar solanas y zonas secas, aunque se desarrollan en cualquier orientación. Los rebollares son el bosque más extendido en la Montaña Palentina, siendo más significativo en la zona meridional de la comarca. La mayor extensión se concentra en el entorno de Cervera de Pisuerga, y se extiende a Mudá y Barruelo de Santullán

En el estrato arbustivo aparecen especies como abedules (Betula pubenscens), acebos (Ilex aquifolium), escobas (Cytisus scoparius), endrinos (Prunus spinosa L.), majuelos (Crataegus monogyna), arces (Acer campestre), maílos (Malus sylvestris), barbadillos (Viburnum lantana) y zarzas (Rubus ulmifolius y Rosa spp.).

El sotobosque es rico en brezos (Erica sp.), hiedras (Hedera helix L.), uvas de perro (Bryonia cretica L.). En el estrato herbáceo es bastante disperso, siendo común las mencionadas en el robledal caducifolio, así como: amiérganos (Fragaria vesca L.), melisa (Melittis melissophyllum L.), pulmonaria (Pulmonaria longifolia L.), Holcus mollis L., Linaria triornithophora, Prunella vulgaris L., Stellaria holostea L. o Teucrium scorodonia L.

Los rebollares aparecen sobre sustratos variados, aunque son más habituales en suelos de origen silíceo, sobre: areniscas, cuarcitas y pizarras. En las etapas de sustitución pueden aparecer argomas (Genista hispanica), brezos (Erica vagans) y especies espinosas (Rosa spp. Rubus ulmifolius).

\section{Hayedos}

Bosques cuyo estrato arbóreo está dominado por el haya (Fagus sylvatica), que constituye formaciones densas con alturas que pueden sobrepasar los $15 \mathrm{~m}$. Son comunidades que dejan pocas oportunidades a otros árboles, ya que forman masas densas y umbrosas, aunque pueden encontrarse salpicados algunos tejos (Taxus baccata L.), robles (Quercus petraea, Q. pyrenaica), abedules (Betula pubescens), amargosos (Sorbus aucuparia), mostajos (Sorbus aria), y fresnos (Fraxinus excelsior L.).

Los hayedos suelen ocupar las laderas orientadas al norte, en general, aquellas áreas donde se dan las condiciones de humedad necesarias para su adecuado desarrollo, como vaguadas o cabeceras de valle donde se produce acumulación de nieblas. Las principales masas se encuentran en el puerto de Piedrasluengas, valle de Los Redondos, entorno de Lores, y vertiente norte de Peña Redonda. 
El sotobosque generalmente es poco denso y viven avellanos (Corylus avellana), escobas (Genista florida), pequeños arbustos como arándanos (Vaccinium myrtillus), ruscos (Ruscus aculeatus L.), groselleros (Ribes alpinum L.), o Daphne laureola L.

El estrato herbáceo puede alcanzar un mayor grado de cobertura por la presencia de especies como: Luzula sylvatica y Deschampsia flexuosa (L.) Trin. en hayedos acidófilos o Brachypodium pinnatum, Carex sylvatica y Epipactis helleborine (L.) Crantz en los eútrofos; además son comunes: Anemone nemorosa, Euphorbia dulcis L., Helleborus viridis, Oxalis acetosella L. y Stellaria holostea. Son frecuentes asimismo los helechos: Dryopteris affinis Fraser-Jenk., $D$. dilatata (Hoffm.) A. Gray, D. filix-mas (L.) Schott y Blechnum spicant (L.) Sm.

Las comunidades de sustitución de los hayedos acidófilos están representados por distintos tipos de brezales y escobales, esto en general sobre suelos más profundos. Los prados de siega y diente, así como los pastizales de litosuelos silíceos completan la serie de estos bosques. En zonas calcáreas las etapas seriales son más variadas, pues se incluyen comunidades de arbustos espinosos, con dominancia del espino albar (Crataegus monogyna), y las formaciones de avellano o pudio (Rhamnus alpina $\mathrm{L}$.).

Los matorrales de Genista hispanica constituye la etapa subarbustiva de degradación, si bien en la orla superior de los hayedos meridionales se introducen elementos de los sabinares rastreros.

\section{Abedulares}

Bosque de porte no muy elevado, menor de $15 \mathrm{~m}$, cuyo estrato arbóreo está dominado por el abedul (Betula pubescens), con frecuencia acompañado por serbales (Sorbus aucuparia). En los abedulares que se desarrollan a mayor altitud, también aparece haya (Fagus sylvatica) y roble albar (Quercus petraea). El abedul aparece en terrenos silíceos y frescos, es un árbol rustico que aguanta las inclemencias de los inviernos fríos y no tiene problemas de orientación. El abedular se desarrolla sobre sustratos silicícolas, la mayoría los encontramos en vaguadas, por lo que se ven enriquecidos por avellanos (Corylus avellana) y diversas especies de sauces (Salix spp.).

En el sotobosque se junta con acebos (Ilex aquifolium), brezos (Erica arborea), brecina (Calluna vulgaris (L.) Hull), escobas (Cytisus cantabricus (Willk.) Rchb.f., Genista florida) y arándanos (Vaccinium myrtillus).

Entre las herbáceas viven: Anemone nemorosa, Deschampsia flexuosa, Veratrum album L., y helechos como Blechnum spicant y Dryopteris dilatata. Las comunidades herbáceas asociadas a los abedulares son pastizales de litosuelos silíceos

\section{Alamedas}

Se trata de pequeñas formaciones arbóreas de densidad variable y porte intermedio de 10-12 $\mathrm{m}$ como máximo, con el álamo temblón (Populus tremula) como especie dominante. Algún abedul (Betula pubescens), serbal (Sorbus aucuparia) o roble albar (Quercus petraea) aparecen ocasionalmente como acompañantes. Ocupan terrenos silíceos, generalmente con suelos esqueléticos y con frecuencia sobre canchales. 
El estrato arbustivo está representado por brezo blanco (Erica arborea), brecina (Calluna vulgaris) y arándano (Vaccinium myrtillus). Cuando estas alamedas se encuentran cerca de robledales, su sotobosque se enriquece de escoba (Cytisus scoparius) y espino albar (Crataegus monogyna).

En el estrato herbáceo aparece: Teucrium scorodonia, Dactylis glomerata L. y Deschampsia flexuosa.

\section{Tejedas}

Los bosques de tejos (Taxus baccata), son escasos y prosperan en condiciones de humedad abundante. El tejo es frecuente encontrarlo salpicando bosques de hayas y robles, tolera la sombra intensa, pudiendo vivir bajo el dosel de estas formaciones boscosas. Prefiere sustratos calizos con orientación septentrional, acompañando a los tejos aparecen hayas, robles albares, mostajos (Sorbus aria) y avellanos (Corylus avellana). La Tejeda de Tosande constituye una de las masas más destacadas de la península Ibérica.

En el estrato arbustivo encontramos, pudio (Rhamnus alpina), grosellero (Ribes alpinum) y adelfilla (Daphne laureola), y entre las herbáceas acompañantes: Anemone nemorosa, Arenaria montana L., Corydalis cava (L.) Schweigg. \& Körte, Euphorbia hyberna L., Erythronium dens-canis L., Helleborus viridis, Melica uniflora Retz., Mercurialis perennis L., Polygonatum verticillatum (L.) All., Sanicula europaea L., Stellaria holostea, Teucrium scorodonia.

\section{Acebales}

El acebo (Ilex aquifolium) se encuentra diseminado en los bosques caducifolios de hayas y robles. En ocasiones forma pequeñas masas, distribuidas de forma dispersa, entre los que podemos señalar, los acebales de San Salvador de Cantamuda, Perapertú, Brañosera y Salcedillo. Estas masas monespecíficas son fruto del manejo del hombre. Conforman un bosque muy sombrío, que dificulta el desarrollo de otros estratos inferiores, su hojarasca se descompone con dificultad y entre ella, se observa un estrato herbáceo conformado por especies como: Sanicula europaea, Melica uniflora y Blechnum spicant.

En ocasiones crecen matas de acebo dentro de pastizales en los que aparecen: Briza media, Cynosurus cristatus L., Festuca rubra L., Lolium perenne L., o Plantago major L.

\section{Encinares}

Los encinares son formaciones boscosas con la encina (Quercus rotundifolia Lam.) como elemento dominante. No suelen alcanzar un porte elevado, dado el continuo manejo y las condiciones edáficas. En estos encinares es frecuente que aparezcan ejemplares de quejigos (Quercus faginea), sabina albar (Juniperus thurifera L.) y rebollo (Quercus pyrenaica).

El estrato arbustivo y subarbustivo es diverso, y generalmente cerrado y enmarañado, como elementos de estos estratos se encuentra el barbadillo (Viburnum lantana), enebro (Juniperus communis L.), espino albar (Crataegus monogyna), endrino (Prunus spinosa), amíllomo (Amelanchier ovalis Medik.), espirea (Spiraea hypericifolia L.), aulaga (Genista scorpius (L.) DC.) y diversas especies del género Rosa. 
En el estrato herbáceo son frecuentes Teucrium chamaedrys L., Carex halleriana y Brachipodium pinnatum, entre otras. Los pastizales calcícolas de litosuelos y los lastonares (Brachypodium pinnatum) configuran la etapa herbácea.

Ocupan laderas de solana de las sierras calcáreas, concretamente en la Sierra de La Peña y el extremo oriental de Las Loras. Estos encinares resisten mejor el ambiente duro de la roca casi desnuda, con capas de suelo poco profundas.

\section{Sabinares}

Bosques de densidad variable, generalmente abiertos y de porte medio, en los que la especie dominante es la sabina albar (Juniperus thurifera), aparecen como acompañantes, encina (Quercus rotundifolia), quejigo (Quercus faginea) y con frecuencia, tejo (Taxus baccata). Ocupan áreas expuestas al sol, en las sierras más meridionales de la comarca, como Peña Lampa, Peña Mayor y el Brezo.

El estrato arbustivo está representado por sabina rastrera (Juniperus sabina Sm.), enebro rastrero (Juniperus communis subsp. alpina), gayuba (Arctostaphylos uva-ursi (L.) Spreng.), cerezo de Santa Lucía (Prunus mahaleb L.) y argoma (Genista hispanica). La etapa arbustiva de degradación está formada por enebrales y sabinares rastreros, a los que suele acompañar el agracejo (Berberis vulgaris L.) y el espino albar (Crataegus monogyna).

El nivel herbáceo está poco desarrollado, donde encontraremos entre otras especies, Koeleria vallesiana (Honck.) Bertol. ex Schult., Festuca hystrix Boiss., Ononis pusilla L. y Teucrium chamaedrys.

\section{Pinares}

Existe una masa forestal natural, en Peña Mayor, cuyo estrato arbóreo está formado por el pino albar (Pinus sylvestris L.), es una agrupación concentrada con árboles cuya altura puede alcanzar los $15 \mathrm{~m}$.

Acompañan al pino especies caducifolias como el haya (Fagus sylvatica) y el mostajo (Sorbus aria). El estrato subarbustivo está formado por gayuba (Arctostaphyllos uva-ursi), y matas rastreras de enebro (Juniperus communis subsp. alpina) y sabina (Juniperus sabina).

El estrato herbáceo es muy reducido, destacando entre sus componentes Brachypodium pinnatum.

Los pinares de repoblación realizados principalmente con pino albar (Pinus sylvestris) y pino negral (Pinus nigra J.F.Arnold), cubren un área de 4630 ha, que representan el 3,5\% de la superficie comarcal.

\section{Formaciones arbustivas-arborescentes}

Estas formaciones dominadas por arbustos, que se ramifican en varios troncos delgados a poca altura del suelo, suelen situarse en los márgenes y claros del bosque, su papel ecológico es fundamental en la regeneración natural de los bosques. En la Montaña Palentina representan el $2 \%$ de su superficie, extendiéndose por unos $26 \mathrm{~km}^{2}$. 


\section{Avellanedas}

Formaciones arbustivas de porte alto dominadas por avellanos (Corylus avellana), entran a formar parte de estas comunidades otras especies como espino albar (Crataegus monogyna), acebo (Ilex aquifolium) y fresno (Fraxinus excelsior).

En el sotobosque son frecuentes las zarzas (Rubus ulmifolius), y en áreas calcáreas aparecen elementos del matorral calcícola como: argoma, brezo común y lastón.

El estrato herbáceo se corresponde con el que se desarrolla en los hayedos y robledales, dado que las avellanedas constituyen comunidades de sustitución de estos bosques caducifolios.

\section{Formaciones de pudio}

Se trata de comunidades arbustivas, de porte medio alto, generalmente muy abiertas que tienen como elemento dominante el pudio o amargoso (Rhamnus alpina). Junto al pudio, aparecen acebos (Ilex aquifolium), fresnos (Fraxinus excelsior), mostajos (Sorbus aria), tejos (Taxus baccata), agracejos (Berberis vulgaris) y groselleros (Ribes alpinum).

El estrato inferior está ocupado por un matorral denso, participando especies como enebros y sabinas rastreras (Juniperus communis subsp. alpina y Juniperus sabina), así como gayuba (Arctostaphyllos uva-ursi) y argoma (Genista hispanica). Estas comunidades pueden ser resultado de una etapa de sustitución de hayedo calcícola, o bien, una comunidad permanente de canchales y afloramientos rocosos.

\section{Saucedas}

Formaciones riparias densas, donde están presentes sauces arbustivos como: Salix atrocinerea Brot., S. bicolor Ehrh. ex Willd., S. eleagnos Scop., S. purpurea L. y S. triandra L. Sobresaliendo entre estos arbustos, podemos encontrar elementos de porte arbóreo como: Salix alba L., S. $x$ fragilis L., fresnos y abedules.

En el estrato arbustivo boneteros (Euonymus europaeus), cornejos (Cornus sanguinea), zarzamoras (Rubus ulmifolius), hiedras (Hedera helix), uvas de perro (Bryonia cretica) y Clematis vitalba $\mathrm{L}$.

En el estrato herbáceo aparecen ortigas (Urtica dioica L.), juncos (Juncus inflexus L., J. effusus L.), Helleborus foetidus L., Primula elatior (L.) Hill o Arum italicum Mill.

Se desarrollan en márgenes de ríos y arroyos, ocupando el lecho de inundación de los cauces, o delimitando el curso de agua que desciende por la vaguada. En la cola de los 5 embalses ubicados en esta comarca, podemos encontrar masas significativas de esta formación arbustiva. 


\section{Mostajares}

Son comunidades arbusto-arborescentes cuyo elemento dominante es el mostajo (Sorbus aria), otras especies que acompañan al mostajo son el espino albar (Crataegus monogyna), el maíllo (Malus sylvestris) y diversas especies del género Rosa.

El estrato inferior está formado por escobas (Cytisus cantabricus, C. scoparius), este estrato está habitualmente manejado para uso como pasto. El mostajo es una especie ampliamente difundida en la comarca, no obstante, no forma masas densas, cabe destacar un pequeño rodal en la proximidad de La Lastra. El mostajo es una especie que forma parte del bosquejo florístico de hayedos y robledales.

Entre las herbáceas figuran: Anemone hepatica L., A. nemorosa, Helleborus viridis, Oxalis acetosella, o Primula veris $\mathrm{L}$.

\section{Matorrales}

Agrupa formaciones vegetales dominadas por plantas leñosas de porte, en general inferior a 2 m de altura. Ocupan unos $140 \mathrm{~km}^{2}$, cubriendo el 10,5\% de la superficie comarcal, representan un alto porcentaje como consecuencia de la intensa actividad humana ejercida sobre formaciones boscosas más estabilizadas, así como por el abandono de prados y tierras de labor. Se llega a esta fase intermedia de sucesión de la vegetación, por degradación en el primer caso, y por recuperación en el segundo supuesto.

\section{Escobales}

Formaciones de matas altas o subarbustos que pueden dar lugar a masas muy cerradas, con alturas que oscilan entre 1 y $2 \mathrm{~m}$. Las especies que caracterizan estas comunidades son leguminosas como: Cytisus cantabricus, C. oromediterraneus (G. López \& C.E. Jarvis) Rivas Mart. \& al, C. scoparius, Genista florida y G. obtusiramea Spach. Es muy frecuente que los escobales presenten mezcla de dos o más especies. Además, incorporan especies arbustivas espinosas, como espino albar (Crataegus monogyna), endrino (Prunus spinosa) y rosas (Rosa spp.).

Dependiendo del grado de cobertura que presenten pueden desarrollarse estratos inferiores de subarbustos y hierbas, asociándose: arándanos (Vaccinium myrtillus), brezos (Erica arborea, E. australis), Agrostis capillaris L., Calluna vulgaris, Daboecia cantabrica (Huds.) K.Koch, Helictotrichon marginatum (Lowe) Röser.

Forman comunidades extensas sobre suelos de naturaleza silícea, ocupando básicamente dos franjas, una a menor altitud, dominada por Genista florida y Cytisus scoparius, y una segunda banda a mayor altitud dominada por Cytisus oromediterraneus con presencia esporádica de Genista obtusiramea y Cytisus scoparius. La presencia de escobales sobre sustratos calizos es esporádica, no forman masas extensas. 


\section{Brezales}

Matorrales cerrados, dominados por ericáceas y leguminosas de porte arbustivo bajo. Las matas más representativas son los brezos (Erica spp.), los tojos (Ulex gallii Planch.) y las brecinas (Calluna vulgaris), acompañados por herbáceas en composición y densidad variable.

El brezal de brezo rojo (Erica australis) forma masas densas, en las que aparecen como acompañantes otras especies leñosas como: Erica arborea, E. umbellata L., Daboecia cantabrica, Genista tridentata L., Halimium alyssoides (Lam.) K.Koch y Vaccinium myrtillus. Se extienden con más frecuencia en la parte septentrional del territorio, mezclándose con todo tipo de escobales.

El matorral de brecina (Calluna vulgaris), tiene como acompañantes: Erica vagans y E. tetralix L. Es frecuente en zonas altimontanas de suelos húmedos, así como en zonas bajas sobre terrenos con cierta humedad edáfica.

El brezal-tojal, cuenta con especies dominantes como Erica cinerea, E. vagans, Ulex europaeus L. y Genista anglica. Este tipo de brezal de influencia oceánica, se desarrolla en zonas de collado donde capturan los vientos oceánicos húmedos.

\section{Matorrales de argoma}

Se trata de formaciones con aspecto almohadillado, no muy densas, compuestas por matas de pequeño porte, inferior a $1 \mathrm{~m}$, la especie característica y dominante es la argoma (Genista hispanica subsp. occidentalis), que suele ir acompañada del brezo común (Erica vagans).

El estrato herbáceo está dominado por gramíneas bastas o lastonares, formado principalmente por Brachypodium pinnatum, Bromus erectus Huds., Seseli cantabricum Lange, Anthyllis vulneraria L. y Thymus praecox Opiz. Estos matorrales de argoma aparecen en afloramientos calcáreos dispersos por toda la comarca.

\section{Matorrales de aulaga}

La aulaga (Genista scorpius) da lugar a formaciones espinosas de porte bajo y densidad variable que suelen incluir otras matas calcícolas como sabina y enebro rastrero, endrino y diversas especies de rosas. Se desarrollan en laderas calcáreas de solana, en la parte meridional de la comarca, en ocasiones aparecen de forma dispersa ocupando roca desnuda, y otras veces, forman rodales densos sobre suelos originados por depósitos finos de ladera.

El estrato herbáceo es ralo, encontrando especies como: Helichrysum stoechas (L.) Moench, Ononis pusilla y Aphyllanthes monspeliensis L.

\section{Sabinares rastreros}

Matorral de porte muy bajo, formando rodales de tamaño variable, que llegan a tapizar laderas de amplitud considerable. Las especies dominantes son sabina rastrera (Juniperus sabina), enebro rastrero (Juniperus communis subsp. alpina) y la gayuba (Arctostaphylos uvaursi). Ocasionalmente les acompañan otros arbustos como genistas espinosas, espino albar o encinas de porte arbustivo. 
Crecen sobre suelos poco profundos de naturaleza calcárea, desde altitudes más bajas hasta el piso subalpino. En las laderas de las sierras del Brezo y de La Peña, se presentan grandes extensiones de este matorral.

\section{Formaciones herbáceas}

En estas formaciones vegetales, las especies herbáceas dominan y alcanzan coberturas significativas, su porte no suele superar los $50 \mathrm{~cm}$, en ocasiones algunas plantas leñosas de porte bajo pueden formar parte de estas comunidades vegetales. Cubren unos $497 \mathrm{~km}^{2} \mathrm{y}$ representan el $37,5 \%$ de la superficie territorial.

\section{Pastizales y cervunales}

Engloba comunidades herbáceas condicionadas por el manejo ganadero, y las que resultan del proceso de degradación de matorrales, generalmente por medio del fuego. Dentro de estos pastos, se pueden distinguir: pastizales de diente, cervunales, pastos de roca (petranos) y pastos de sustitución de comunidades arbustivas. Cubren el $28,5 \%$ de la superficie de la Montaña Palentina.

Los pastizales de aprovechamiento ganadero, son los que soportan más intensamente la acción del ganado, cuentan con especies como: Achillea millefolium L., Arrhenatherum elatius (L.) P.Beauv. ex J.Presl \& C.Presl., Festuca rubra, Poa pratensis L., Trifolium pratense L., Trifolium repens L., etc.

Los cervunales, son menos diversos, presentando como especie dominante el cervuno, (Nardus stricta L.). Los cervunales encuentran su hábitat optimo en áreas de alta montaña, el resto de pastos pueden aparecer en diferentes niveles altitudinales.

Los pastos petranos y los que resultan por sustitución de matorrales, suelen tener un aspecto ralo, y su composición botánica depende de la naturaleza del sustrato, según sean suelos silíceos o calizos.

\section{Prados de siega}

Comunidades herbáceas densas donde dominan gramíneas y otras especies herbáceas que se ven favorecidas por acción combinada de siega y pastoreo. Cubre el $9 \%$ del territorio. Las especies más habituales son: Dactylis glomerata, Holcus lanatus L., Cynosurus cristatus, Trifolium repens, Taraxacum campylodes G.E.Haglund, Plantago lanceolata L., Rhinanthus minor L., etc.

Los mejores prados se establecen en suelos profundos fértiles en los fondos de valles, mayoritariamente localizados en los entornos de los pueblos. 


\section{Formaciones de zonas rocosas}

La vegetación asociada a roquedos es muy singular. En este tipo de comunidades se refugian el mayor número de endemismos o especies amenazadas de la montaña, Esta comunidades se extienden en un área de unos $132 \mathrm{~km}^{2}$ que representa el $10 \%$ de territorio.

\section{Comunidades de roquedos}

Las comunidades rupícolas se desarrollan sobre afloramientos rocosos, que parecen desprovistos de vegetación, donde se desarrollan diversas especies herbáceas y algunas matas que ocupan las fracturas de la roca.

En roquedos calcáreos las plantas más características son especies del género Saxifraga ( $S$. canaliculata Boiss. \& Reut. ex Engl., S. conifera Coss. \& Durieu, S. tridactylites L.), además le acompañan elementos de los pastizales sobre rocas muy expuestas al sol.

En roquedos silíceos, tiene especial importancia especies del género Sedum (S. album L., $S$. anglicum Huds., S. brevifolium DC., S. hirsutum All.), acompañadas por Agrostis delicatula Pourr. ex Lapeyr. Se establecen en paredes verticales y afloramientos rocosos degradados donde prácticamente ha desaparecido la capa de suelo.

\section{Comunidades de gleras}

Generalmente están cubiertos por comunidades de líquenes crustáceos, en los márgenes se ven colonizados por comunidades del entorno. En pedregales silíceos se introducen especies como Calluna vulgaris, Erica arborea y Vaccinium myrtilus. En canchales calcáreos, la presencia de Rhamnus alpina resulta común.

Estas formaciones se sitúan al pie de las cumbres y crestas montañosas, en áreas de mayor altitud, aunque también son frecuentes en zonas más bajas.

\section{Vegetación de alta montaña}

Comunidades que se desarrollan en condiciones climáticas difíciles, por encima de $1800 \mathrm{~m}$. En alta montaña calcárea, los matorrales apenas están representados, las formaciones herbáceas se encuentran representadas por tres tipos de comunidades: pastizales, vegetación de roquedos y vegetación de gleras.

Los pastizales presentan como especies más características: Oreochloa seslerioides (All.) K.Richt., Festuca burnatii St.-Yves y Saxifraga conifera. En las fisuras viven plantas como: Saxifraga canaliculata, Euphorbia pyrenaica Jord. y Anemone pavoniana Boiss. Las gleras calizas presentan especies como: Crepis pygmaea L., Arabis alpina L. y Carduus carlinoides Gouan.

En la alta montaña silícea, se desarrollan comunidades de matorral, de pastizal, de roquedos y de gleras. Los matorrales están formados por enebro rastrero, brecina y arándanos (Vaccinum myrtillus y $V$. uliginosum L.). Los pastizales están dominados por Luzula caespitosa (J.Gay ex E.Mey.) Steud. y Festuca eskia Ramond ex DC., a las que acompañan especies como: Deschampsia flexuosa, Silene ciliata y Juncus trifidus. 
Las comunidades de roquedo cuentan con especies como: Primula pedemontana Thomas ex Gaudin, Oreochloa blanka Deyl o Saxifraga pentadactylis. Las comunidades de glera, dependiendo del grosor de los cantos puede estar dominado por helechos o por especies como: Linaria alpina (L.) Mill., Spergula viscosa Lag. y Ranunculus parnassifolius L. cuando los cantos son finos.

\section{Formaciones de humedales}

Las comunidades hidrófilas conforman ambientes de estructura diversa y heterogénea que engloban formaciones vegetales que se pueden incluir en los apartados anteriores, si nos atenemos al porte que presentan sus especies dominantes. No obstante, hay un elemento, la alta disponibilidad y proximidad del agua, que define y determina estas formaciones vegetales. Representan el 0,5\% de la superficie del territorio estudiado.

\section{Turberas}

Comunidades que se desarrollan sobre una capa continua de turba formada por esfagnos (musgos del género Sphagnum), estos musgos forma abombamientos, a modo de almohadas, que están empapados de agua y que se conectan entre si por canalillos de agua. Las plantas comunes de estas comunidades son especies de los géneros Carex y Juncus, así como Narthecium ossifragum (L.) Huds., Erica tetralix y Parnassia palustris L. Están bien representadas en la cuenca alta del Carrión, en altitudes elevadas, sobre sustratos impermeables planos.

\section{Vegetación de riberas y lagunas}

Las riberas y zonas húmedas, dado que disponen de suficiente agua, en ellas se desarrollan bosques de riparios donde crecen: chopos (Populus nigra), álamos blancos (Populus alba), fresnos (Fraxinus excelsior), sauces (Salix alba, S. $x$ fragilis) y olmos (Ulmus minor Mill.), los alisos (Alnus glutinosa (L.) Gaertn.), están escasamente representados.

En los bordes de los cursos de agua, charcas y lagunas permanentes, se desarrolla vegetación helófita, formada por plantas que mantienen sumergido parte de su cuerpo vegetativo, las especies más representativas son: Potamogeton natans L., P. polygonifolius Pourr., en las áreas marginales de las charcas se establecen diversas especies de los géneros Carex y Juncus. En las zonas más bajas la presencia de Sparganium erectum L. y Typha latifolia L. se hace frecuente.

\section{Cultivos, vegetación arvense y ruderal}

El paisaje rural está dominado por los pastizales y prados destinados al aprovechamiento ganadero, con pequeñas superficies dedicadas al cultivo de secano (cebada, avena y centeno), que ocupan el $12 \%$ de la superficie, los cultivos de regadío (maíz, alfalfa, hortalizas) representan el $2 \%$ de la superficie del territorio, están localizados en la vega media del río Pisuerga, como aprovechamiento de regadío merece ser destacado la superficie destinada al cultivo de chopos (Populus $x$ canadensis Moench). 
La vegetación arvense está formada por especies asociadas a los cultivos agrícolas, cuyas estrategias reproductoras son más eficaces que en las plantas cultivadas, constituyendo en ocasiones plagas difíciles de controlar, entre estas plantas podemos señalar la amapola (Papaver rhoeas L.), avena loca (Avena fatua L., A. sterilis L.), neguilla (Agrostemma githago L.), gébenas (Brassica nigra (L.) K.Koch, Sinapis arvensis L.), azulinas (Cyanus segetum Hill) y ceñilgos (Chenopodium album L.).

Las comunidades ruderales, que se encuentran cerca de las poblaciones y en los márgenes de caminos, suelen presentar plantas con querencias nitrófilas y que soportan el pisoteo, entre las plantas más frecuentes están las achicorias (Cichorium intybus L.), viboreras (Echium vulgare L.), malvas (Malva sylvestris L.), gébenas (Raphanus raphanistrum L., Sisymbrium austriacum Jacq.), relojillos (Erodium ciconium (L.) L'Hér.), escoba aujera (Chondrilla juncea L.), hinojo (Foeniculum vulgare Mill.), centidonia (Polygonum aviculare L.), Ilantenes (Plantago coronopus L., P. lanceolata) y cebadilla de ratón (Hordeum murinum L.). En zonas de mayor tránsito de ganado, los pastos se degradan y son sustituidos por cardales, donde es frecuente encontrar el cardillo (Scolymus hispanicus L.), el cardo mariano (Silybum marianum (L.) Gaertn.) o grandes cardos borriqueros (Onopordum acanthium L., O. nervosum Boiss.). 


\subsection{MEDIO HUMANO}

\subsubsection{POBLACIÓN}

Este área se integra por 16 términos municipales, donde se encuentran repartidos 116 núcleos de población, con una superficie de $1576 \mathrm{~km}^{2}$, el 19,34\% del territorio provincial y el 1,59\% de la superficie castellano y leonesa.

Los aspectos fundamentales en el comportamiento demográfico de la zona de estudio son, el descenso poblacional, la disminución de la densidad de población, el envejecimiento y la disminución del índice de crecimiento vegetativo, y la concentración de la población en cinco núcleos: Aguilar de Campoo, Barruelo de Santullán, Cervera de Pisuerga, Guardo y Velilla del Río Carrión. Entre Aguilar de Campoo, Cervera de Pisuerga y Guardo concentran más del $70 \%$ de la población de la zona.

TABLA 3: Población y densidad 2018 en la Montaña Palentina. (Fuente: www.ine.es)

\begin{tabular}{lccc}
\hline \multicolumn{1}{c}{ Población } & $\mathbf{k m}^{\mathbf{2}}$ & Población $\mathbf{2 0 1 8}$ & $\begin{array}{r}\text { Densidad } \\
\text { (hab// } \mathbf{k m}^{\mathbf{2}} \text { ) }\end{array}$ \\
\hline Aguilar de Campoo & 236 & 6842 & $\mathbf{2 8 , 9 9}$ \\
\hline Barruelo de Santullán & 53 & 1183 & 22,32 \\
\hline Brañosera & 62 & 246 & 3,96 \\
\hline Castrejón de la Peña & 106 & 360 & 3,39 \\
\hline Cervera de Pisuerga & 323 & 2316 & 7,17 \\
\hline Dehesa de Montejo & 44 & 136 & 3,09 \\
\hline Guardo & 64 & 6153 & 96,14 \\
\hline Mudá & 7 & 82 & 11,71 \\
\hline Pernía (La) & 167 & 320 & 1,92 \\
\hline Polentinos & 15 & 42 & 2,80 \\
\hline Respenda de la Peña & 66 & 154 & 2,33 \\
\hline Salinas de Pisuerga & 19 & 317 & 16,68 \\
\hline San Cebrián de Mudá & 44 & 162 & 3,68 \\
\hline Santibáñez de la Peña & 110 & 1044 & 9,49 \\
\hline Triollo & 63 & 64 & 1,02 \\
\hline Velilla del Río Carrión & 198 & 1299 & 6,56 \\
\hline TOTAL & $\mathbf{1 5 7 6}$ & $\mathbf{2 0 7 2 0}$ & $\mathbf{1 3 , 1 5}$ \\
\hline
\end{tabular}

La población total asentada en el territorio es de 20720 habitantes según el padrón del año 2018 , población que representa el $12,78 \%$ del total provincial.

La densidad de población de la zona es de $13,15 \mathrm{hab} / \mathrm{km}^{2}$, frente a los $20,12 \mathrm{hab} / \mathrm{km}^{2}$ del total de la provincia de Palencia, apareciendo municipios como Triollo, La Pernía, Polentinos o Respenda de la Peña que no superan los $3 \mathrm{hab} / \mathrm{km}^{2}$.

La regresión demográfica acaecida en la comarca a lo largo de la segunda mitad del siglo pasado y que se prolonga en las dos primeras décadas del siglo XXI, se debe a la salida de la población en busca de nuevas oportunidades laborales, a las capitales provinciales o cabeceras comarcales con mayor desarrollo industrial. Este proceso migratorio conocido como éxodo rural coincidente con la década de los sesenta de la anterior centuria ha hecho mella con especial relevancia en las áreas de montaña (Delgado et al., 2007).

En torno a los años 50, la Montaña Palentina alcanzó su máximo esplendor en cuanto a nivel de población con más de 40000 habitantes. A partir de ese momento comenzó una dinámica 
de descenso poblacional debido principalmente a la crisis de la minería, el declive industrial y la dinámica demográfica general.

La evolución de la población en la Montaña ha sido negativa, con tasas de crecimiento inferiores a las del conjunto de la provincia y muy inferiores a las de la región. Esta tendencia poblacional negativa se suavizó en los últimos años, reduciéndose la pérdida de población debido a la pujanza del entorno de Aguilar y en menor medida de Cervera de Pisuerga, si bien el último año vuelve a tasas de pérdida de población.

TABLA 4: Evolución de la población en la Montaña Palentina. (Fuente: www.ine.es)

\begin{tabular}{|c|c|c|c|c|c|c|}
\hline Localidad & 1996 & 2006 & 2012 & 2018 & $\begin{array}{c}\text { variación } \\
96 / 18\end{array}$ & $\begin{array}{c}\text { variación } \\
12 / 18\end{array}$ \\
\hline Aguilar de Campoo & 7741 & 7303 & 7203 & 6842 & $-11,61 \%$ & $-5,01$ \\
\hline Barruelo de Santullán & 2052 & 1510 & 1403 & 1183 & $-42,35 \%$ & $-15,70$ \\
\hline Brañosera & 317 & 267 & 233 & 246 & $-22,40 \%$ & 5,58 \\
\hline Castrejón de la Peña & 659 & 526 & 444 & 360 & $-45,37 \%$ & $-18,90$ \\
\hline Cervera de Pisuerga & 2796 & 2623 & 2572 & 2316 & $-17,17 \%$ & $-9,95$ \\
\hline Dehesa de Montejo & 264 & 173 & 150 & 136 & $-48,48$ & $-9,93$ \\
\hline Guardo & 8779 & 7835 & 7027 & 6153 & $-29,91$ & $-12,40$ \\
\hline Mudá & 142 & 98 & 100 & 82 & $-42,25$ & $-18,00$ \\
\hline Pernía (La) & 493 & 418 & 373 & 320 & $-35,09$ & $-14,20$ \\
\hline Polentinos & 98 & 69 & 63 & 42 & $-57,14$ & $-33,30$ \\
\hline Respenda de la Peña & 305 & 225 & 193 & 154 & $-49,41$ & $-20,20$ \\
\hline Salinas de Pisuerga & 296 & 325 & 375 & 317 & 7,09 & $-15,50$ \\
\hline San Cebrián de Mudá & 218 & 165 & 170 & 162 & $-25,69$ & $-4,71$ \\
\hline Santibáñez de la Peña & 1636 & 1335 & 1196 & 1044 & $-36,19$ & $-12,70$ \\
\hline Triollo & 102 & 71 & 70 & 64 & $-37,25$ & $-8,57$ \\
\hline Velilla del Río Carrión & 1976 & 1573 & 1493 & 1299 & $-34,26$ & $-13,00$ \\
\hline TOTAL & 27874 & 24516 & 23054 & 20720 & $-25,67$ & $-10,10$ \\
\hline
\end{tabular}

La evolución de la población en el conjunto de la comarca sigue dos tendencias claramente diferenciadas. Hasta 1960 la población crece a un ritmo intenso y continuado, con el paréntesis de la década de 1930, marcada por la Guerra Civil. Desde entonces la disminución ha seguido un ritmo igualmente intenso, pasando de 36089 habitantes en 1960 a 20720 en la actualidad, aunque todavía conserva 1600 habitantes más de los que tenía en 1900 (Diputación de Palencia, 2011e).

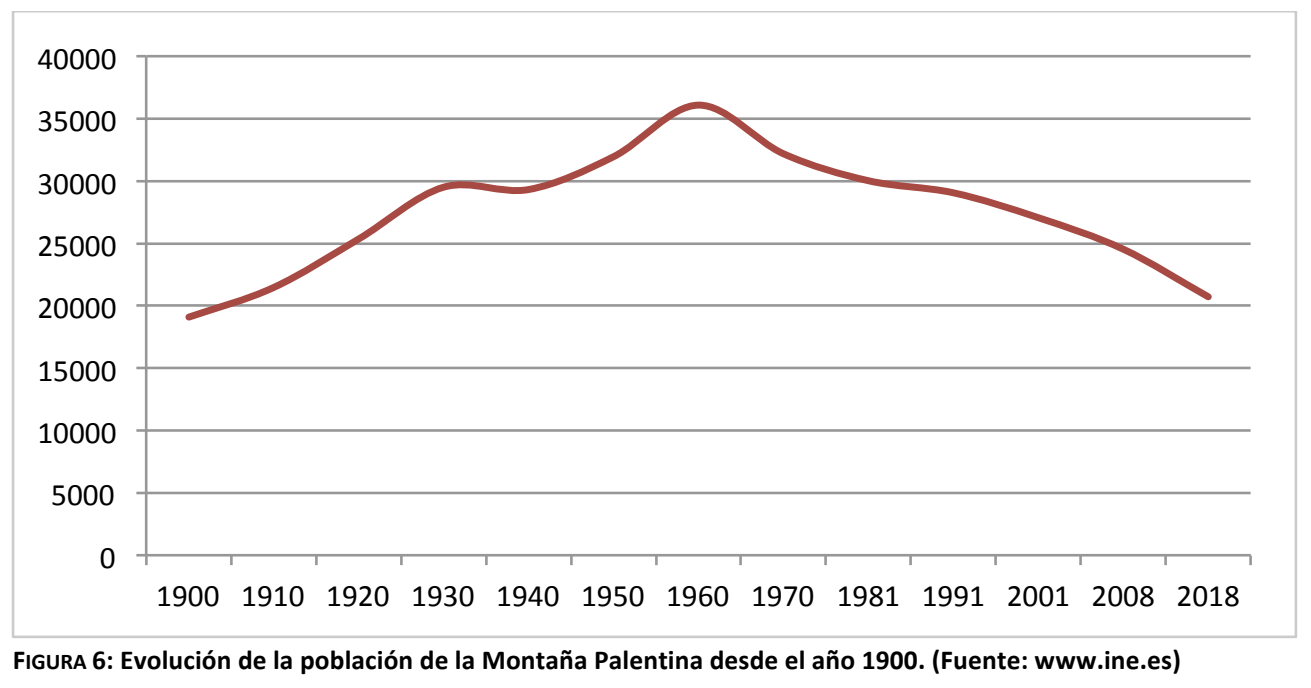


El fuerte descenso a partir de 1960 es debido a las medidas económicas tomadas en el país con el Plan de Estabilización, lo que provoca la crisis en el sector minero y forestal. A éste hay que añadir la fuerte emigración, favorecida por la situación de auge económico que se vive en Europa. El destino principal de la emigración fue País Vasco, Palencia y Madrid, que supuso más de un 55\% del total (Junta de Castilla y León, 1989).

Los grandes municipios de la comarca con más de 2000 habitantes son Aguilar de Campoo, Cervera de Pisuerga y Guardo, hay que tener en cuenta la variación del mapa municipal, pero en general, la evolución de la población es continua en la primera mitad del siglo XX, muy acusada en el periodo 1950-1980, para ir decreciendo lentamente desde entonces hasta la actualidad, tal como señala la figura 7.

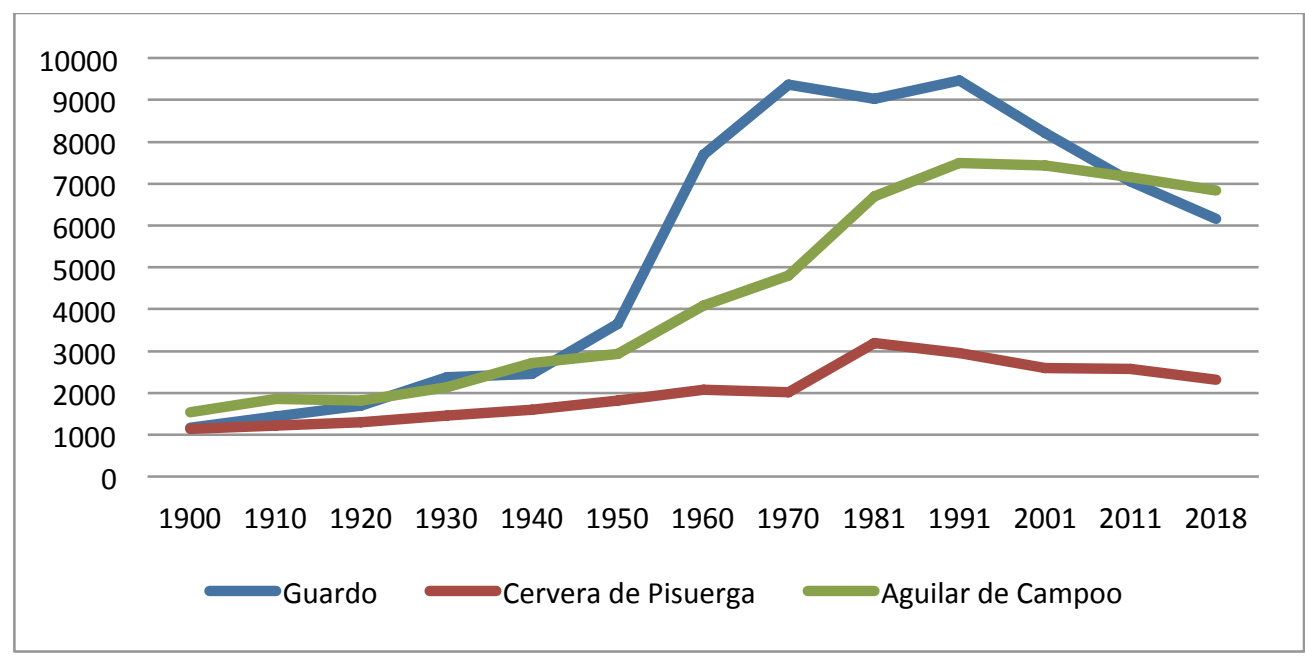

Figura 7: Evolución de la población en los municipios de más de 2000 habitantes de la Montaña Palentina desde el año 1900. (Fuente: www.ine.es)

Según la pirámide de población de la figura 8 , la estructura de la población presenta caracteres propios de una dinámica regresiva, con más de un $25 \%$ de la población mayor de 64 años, $10 \%$ menor de 15 años y menor aún en los tramos de edades inferiores. Existe un gran peso de la población adulta masculina en las edades entre 40 y 54 años, que obedece a los problemas de género de la emigración del medio rural al urbano. También existe una gran proporción de mujeres en edades superiores. Este tipo de estructura se corresponde con la evolución demográfica decreciente, que producirá un crecimiento vegetativo muy negativo.

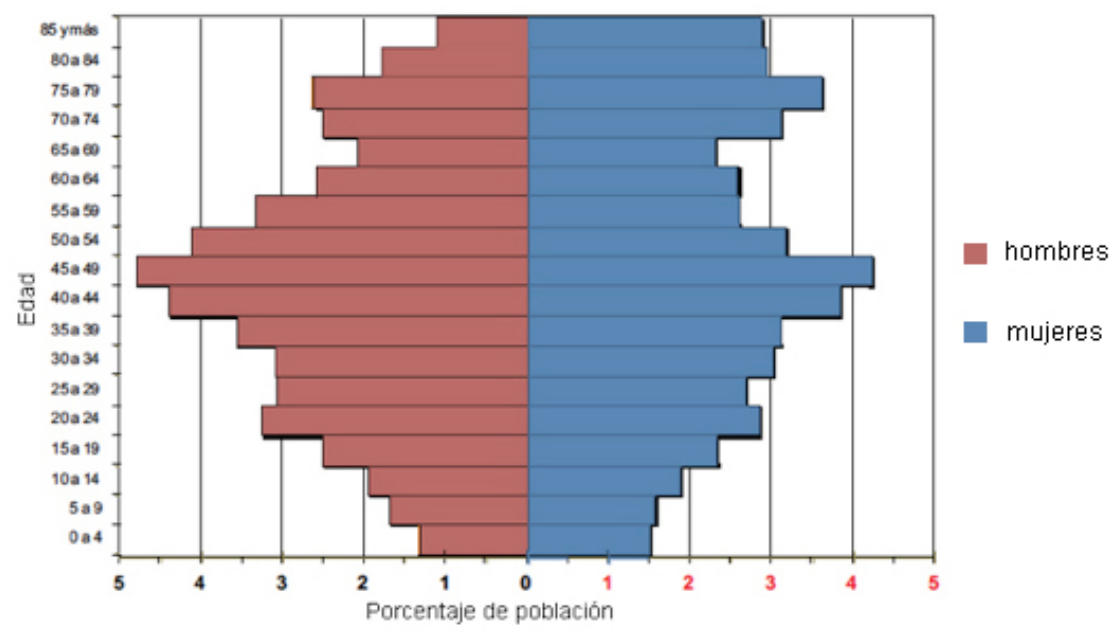

FIgURA 8: Pirámide de población de la Montaña Palentina año 2018. (Fuente: www.ine.es) 
La situación demográfica actual del área es consecuencia del proceso emigratorio soportado en las últimas décadas, así como del descenso de la natalidad y la fecundidad, encontrándonos con una población muy envejecida.

\subsubsection{ACTIVIDAD ECONÓMICA}

Hasta hace poco tiempo la actividad agraria ha sido el elemento fundamental aunque no exclusivo de la base económica de la comarca. En aquellos municipios que concentran un mayor número de habitantes y que han alcanzado un mayor desarrollo urbano, la actividad industrial tiene un peso considerable en la economía de la zona.

En el global, el principal sector de la comarca es el de los servicios, que aglutina el $51 \%$ de los cotizantes, seguido de la industria (35\%), aunque varía en función del tamaño de los municipios.

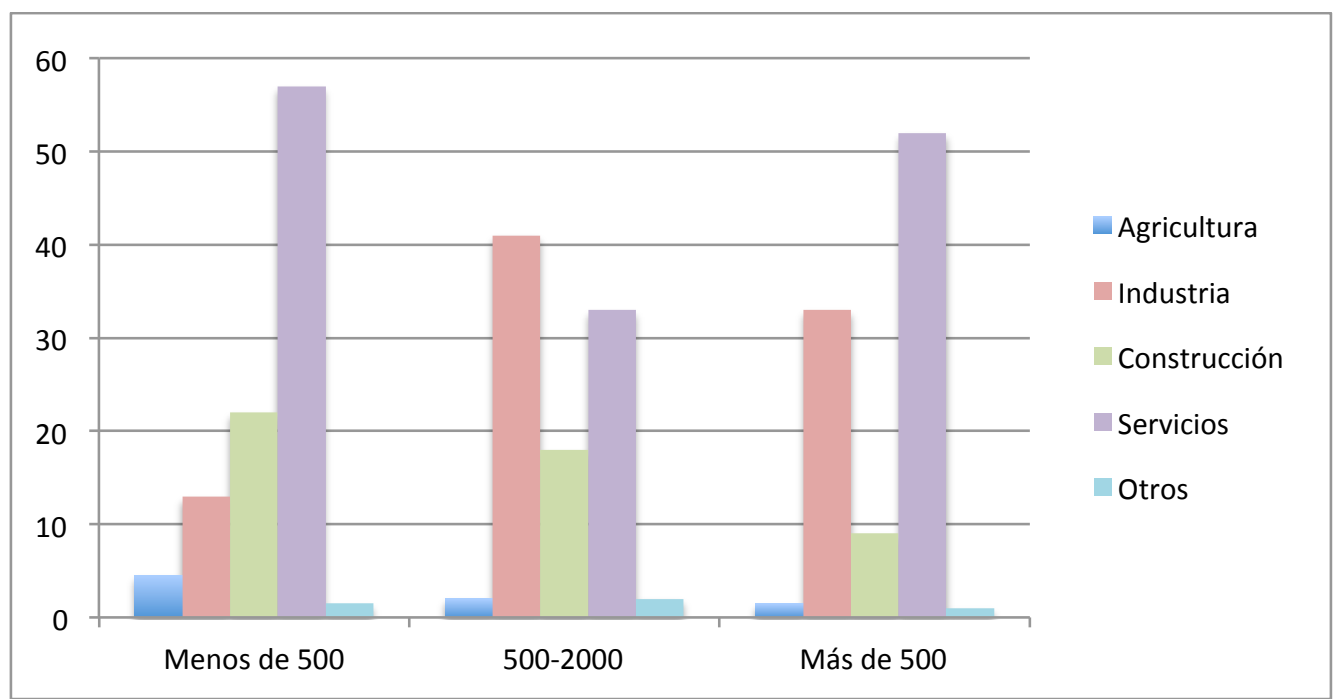

FIGURA 9: Trabajadores por sector en la Montaña Palentina año 2018, teniendo en cuenta el número de habitantes del núcleo urbano (Fuente: Servicio de Información Estadística de la Junta de Castilla y León sobre las cuentas de cotización a la Seguridad Social correspondientes a 2018).

Los grandes municipios, de más de 2000 habitantes, suponen el $86 \%$ de los trabajadores y son los que marcan la pauta general de la comarca. En los de 500 a 2000 habitantes predomina el sector industrial (42\%), tiene un mayor peso la construcción, en detrimento del sector servicios, y en los más pequeños, que sólo suponen el $5 \%$ de los trabajadores, la característica más destacable, además del predominio del sector servicios, es la importancia de la construcción, que alcanza el $23 \%$ de los cotizantes.

La ganadería extensiva constituye el aprovechamiento agrario más relevante de la zona, en tanto que permite rentabilizar los recursos pastables de las zonas de alta montaña. Las características ecológicas como relieve, clima o vegetación acotan los aprovechamientos tanto agrícolas como ganaderos.

La economía tradicional hasta hace unos pocos años consistía en explotaciones agropecuarias familiares basadas en cultivos de secano y la explotación comunal de las tierras para la ganadería extensiva. Para el consumo tanto de la casa como del ganado, se cultivaban sobre todo cereales, leguminosas y patatas, cuyo cultivo se generalizó a partir del siglo XIX. En menor medida se cultivaban verduras y hortalizas en los huertos familiares y algunos frutales. 


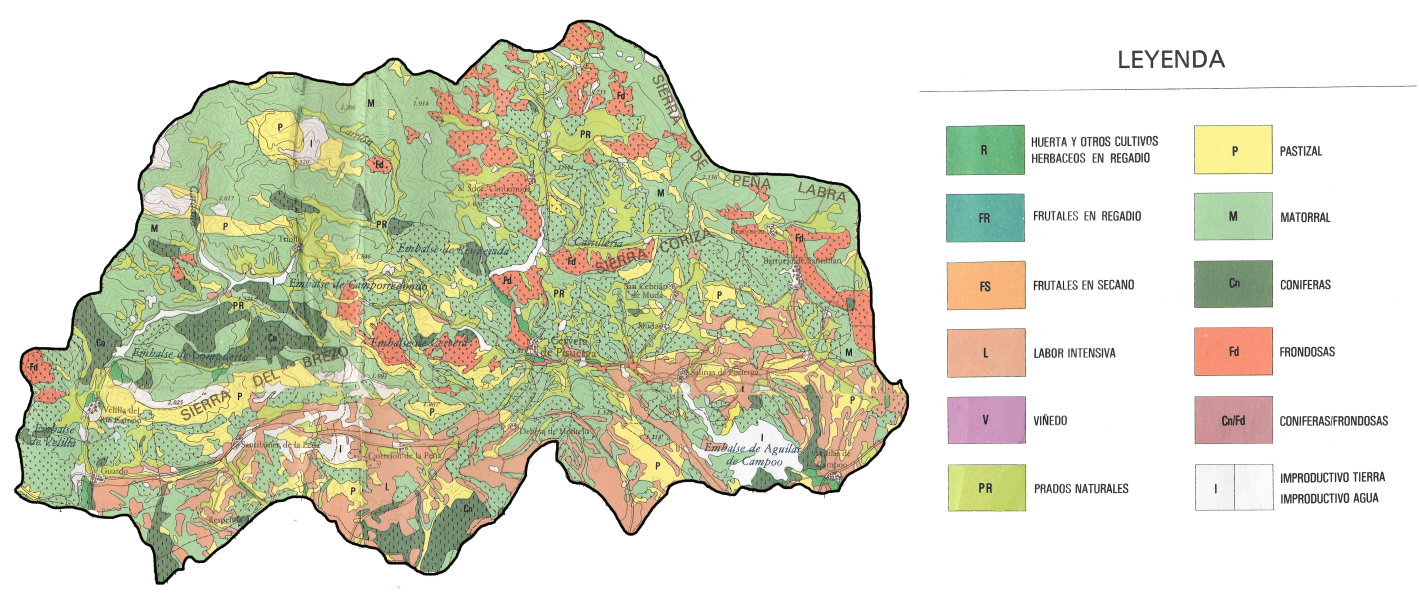

FIGURA 10: Mapa de cultivos y aprovechamientos de la Montaña Palentina. Fuente: Mapa de cultivos y aprovechamientos de la provincia de Palencia (1985).

En su conjunto el sector agrario ha sufrido un proceso de transformación, aún no finalizado, que ha implicado, en los últimos años, una reducción de la población activa agraria, así como del número de explotaciones. El régimen de tenencia tradicional de la tierra es el de propiedad o tenencia directa, siendo más escasos los casos de arrendamiento. Sin embargo, en la última década se ha producido un aumento de la superficie de las tierras explotadas en arrendamiento debido a la disminución del número de explotaciones.

El problema más grave al que se enfrenta la agricultura de la comarca es el de la elevada edad, puesto que el titular de la explotación se caracteriza por encontrarse entre las edades de 35 a 64 años, dejando entrever que la falta de reemplazo generacional será evidente en los próximos años.

Las limitaciones que el medio impone al desarrollo de la agricultura junto con la crisis de los últimos años, han supuesto que progresivamente, haya ido perdiendo importancia la actividad productiva, acentuándose el aprovechamiento ganadero de la comarca. Existe una creciente especialización ganadera manifestada por el aumento de la superficie de tierras dedicadas a pastos permanentes.

TABLA 5: Distribución municipal de aprovechamientos en la Montaña Palentina, 1996. (Fuente: Cámara Agraria Provincial. Alario et al., 1999).

\begin{tabular}{|c|c|c|c|c|c|c|c|c|c|}
\hline \multirow[t]{2}{*}{ Municipio } & \multirow{2}{*}{$\begin{array}{c}\text { Total } \\
\text { ha }\end{array}$} & \multicolumn{2}{|c|}{ Tierras de labor } & \multicolumn{2}{|c|}{$\begin{array}{l}\text { Prados y } \\
\text { pastizales }\end{array}$} & \multicolumn{2}{|c|}{ Terreno forestal } & \multicolumn{2}{|c|}{ Otras superficies } \\
\hline & & ha & $\%$ & ha & $\%$ & ha & $\%$ & ha & $\%$ \\
\hline Aguilar de Campoo & 23615 & 6004 & 25,42 & 9432 & 39,94 & 4516 & 19,12 & 3663 & 15,51 \\
\hline Barruelo de Santullán & 5246 & 710 & 13,53 & 2430 & 46,32 & 1577 & 30,06 & 529 & 10,08 \\
\hline Berzosilla & 1955 & 320 & 16,37 & 173 & 8,85 & 1373 & 70,23 & 89 & 4,55 \\
\hline Brañosera & 6192 & 14 & 0,23 & 4092 & 66,09 & 1798 & 29,04 & 288 & 4,65 \\
\hline Castrejón de la Peña & 10637 & 4827 & 45,38 & 2540 & 23,88 & 2204 & 20,72 & 1066 & 10,02 \\
\hline Cervera de Pisuerga & 31957 & 2483 & 7,77 & 7368 & 23,06 & 11243 & 35,18 & 10863 & 33,99 \\
\hline Dehesa de Montejo & 4333 & 1237 & 28,55 & 1174 & 27,09 & 1153 & 26,61 & 769 & 17,75 \\
\hline Guardo & 6357 & 1198 & 18,85 & 560 & 8,81 & 3004 & 47,25 & 1595 & 25,09 \\
\hline Mudá & 683 & 10 & 1,46 & 568 & 83,16 & 76 & 11,13 & 29 & 4,25 \\
\hline Pernía (La) & 16528 & 0 & 0,00 & 2448 & 14,81 & 5981 & 36,19 & 8099 & 49,00 \\
\hline Salinas de Pisuerga & 1939 & 319 & 16,45 & 1362 & 70,24 & 181 & 9,33 & 77 & 3,97 \\
\hline Santibáñez de la Peña & 11022 & 2995 & 27,17 & 1474 & 13,37 & 3509 & 31,84 & 3044 & 27,62 \\
\hline Triollo & 6289 & 0 & 0,00 & 484 & 7,70 & 976 & 15,52 & 4829 & 76,78 \\
\hline Velilla del Río Carrión & 19811 & 19 & 0,10 & 1616 & 8,16 & 6419 & 32,40 & 11757 & 59,35 \\
\hline
\end{tabular}


Para el trabajo de la tierra y el transporte era fundamental la pareja de vacas o bueyes. El resto de la cabaña ganadera se solía explotar extensivamente, de modo colectivo, en praderías y zonas comunales mediante el cuidado en vecería de todos los vecinos o contratando pastores. La raza de ganado vacuno más abundante en la zona es la Pardo-Alpina, aunque aparece también Frisona, Mestiza y Tudanca. Durante los meses de invierno, de diciembre a marzo, el ganado está estabulado, con una alimentación basada en forrajes, paja y heno, y el resto del año el ganado permanece en los montes. Además, existe la Marca de Garantía "Carne de Cervera", primera carne de la región que consiguió esta figura de calidad en 1998.

En cuanto al aprovechamiento forestal, apenas es explotado debido a que la especie más extendida es el roble de alto valor ecológico, con escasas posibilidades de utilización industrial, pero si es importante su aprovechamiento como leña. La corta de madera para leña, junto con los pastos son los principales aprovechamientos de los montes públicos para los vecinos.

La minería tuvo en la zona cierta importancia en cuanto a mano de obra ocupada y creación de riqueza. El origen de la actividad extractiva data de finales del siglo XIX, y dio origen al establecimiento de la línea férrea de vía estrecha La Robla-Bilbao, que atraviesa la comarca longitudinalmente. A lo largo de los años sesenta se produjo el declive de la minería tradicional con especial importancia en la cuenca de Barruelo, debido a la sustitución del carbón por combustibles derivados del petróleo, y más adelante en la cuenca de Guardo que entró en un profundo proceso de reconversión. Hoy en día la actividad minera se encuentra prácticamente extinguida.

En la industria, el auge de Guardo comienza en 1943 con la construcción de una planta de obtención de carburos a partir de calizas, propiedad de Explosivos Río Tinto. En 1986 la planta pasó a formar parte de Erkimia, comenzando un proceso de reestructuración. El otro impulso de la zona es la construcción a finales de la década de 1950 de la Central Térmica "Terminor" en Velilla del Río Carrión, que entró en funcionamiento en 1963. En 1980 se iniciaron las obras de la 2a fase de la central, convirtiéndose en dinamizadora de la economía del entorno de Guardo, hasta que en la actualidad afronta su cierre definitivo.

En la Montaña Palentina oriental la principal industria es la galletera, que se inició a finales del siglo XIX por iniciativa de empresarios locales, aprovechando que gracias al Canal de Castilla se disponía de harina y de buenas comunicaciones. Se localiza exclusivamente en la localidad de Aguilar de Campoo.

En lo que respecta al sector servicios, se da una elevada concentración de establecimientos en las cabeceras comarcales (Guardo, Aguilar y Cervera).

Se han introducido, sin embargo, nuevas actividades, valores y usos en el espacio rural, asociados a los intereses, demandas y patrones culturales ligados a las poblaciones urbanas, que muchas veces contemplan el espacio rural como un gran parque, marco ideal para el ocio de naturaleza. El turismo rural ha aumentado el número de turistas y visitantes, y sectores como la hostelería han crecido propiciados por las ayudas europeas. 


\section{METODOLOGÍA}




\section{METODOLOGÍA}

\subsection{SELECCIÓN DE LA MUESTRA}

Para llevar a cabo la recogida de datos necesitamos contactar con las personas con mayores conocimientos y que mejor puedan representar la cultura local. La selección de los informantes no fue aleatoria y en todo momento se procuró realizar un muestreo premeditado que nos condujera a las personas más sabias, las que atesoran en su memoria las costumbres y modos de vida tradicionales en la zona. Bernard (1994) denomina "expertos" a las personas que conservan en su memoria o costumbres la riqueza cultural relacionada con las plantas, tratándose de personas mayores de 60 años que han vivido la época en la que esta sabiduría les resultaba necesaria para vivir.

En todos los pueblos visitados se preguntaba por las personas de mayores conocimientos en el tema, incluso nos aconsejaban de un pueblo a otro quién podía colaborar mejor en el estudio. Este modo de actuar es consecuencia de la observación de que normalmente en cada pueblo existía una persona o familia que tradicionalmente había ejercido a modo de curandera, asesorando a los vecinos en los casos de algún malestar o dolencia, o aconsejando remedios veterinarios para el ganado. Estas personas conocían ciertas plantas que no se debían consumir, y por supuesto estaban en contacto directo con la cultura local, lo que conlleva un amplio conocimiento del uso de las plantas en las diferentes categorías planteadas.

Si bien se obtuvo mucha información de estos eruditos locales, no es desdeñable la información del resto de informantes, que también son buenos conocedores de las costumbres, prácticas y tradiciones de la zona. En el caso de encontrarnos con una persona receptiva y dispuesta a aportar de datos, se la planteó realizar una entrevista minuciosa con el objetivo de extraer la mayor información posible.

La vinculación familiar en la zona de estudio facilitó la obtención de informantes en las localidades más cercanas a Verdeña, núcleo del origen familiar. En otros casos, la consecución de informantes se estableció entre parientes ubicados en un mismo pueblo o en diferentes, esta relación sirve de contacto previo y plantea un marco previo de confianza muy interesante para la obtención de mejores datos.

Hemos contado también con la ayuda desinteresada de mediadores que han facilitado el contacto de personas concretas atractivas para la investigación, se trata de alcaldes pedáneos, agentes medioambientales o de desarrollo local, trabajadores en residencias de la tercera edad, personas conocidas por el investigador $u$ otras que forman parte de la sociedad y el entorno de la comarca. Con todas estas aportaciones se generó una extensa red de contactos que concluyó con la obtención de datos de 187 personas, que fueron visitadas en un total de 76 localidades, tal y como se indica en la figura 11, procurando que toda la zona de estudio tuviera representatividad.

No se estableció un tamaño muestral previo, sino que se determinó el fin de la captación de informantes al percibir un descenso de información novedosa y de repetición de datos en las entrevistas. Según Martin (1995), a medida que aumenta el número de informantes entrevistados se obtiene menos información en cada entrevista realizada, siguiendo la ley de los rendimientos decrecientes. 


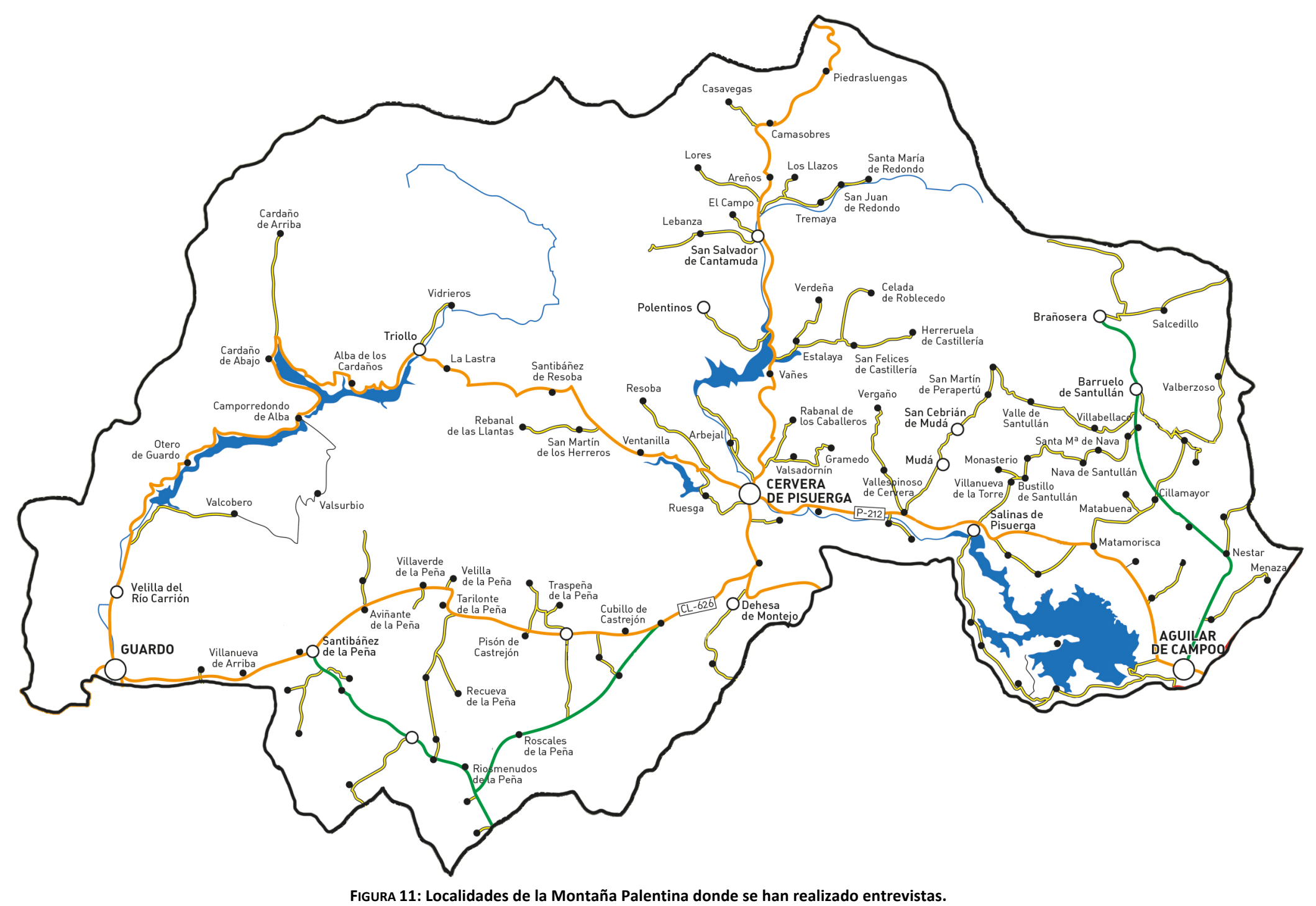


Consideramos un informante como el número de personas que participan en una entrevista, esa es la razón por la que el número de informantes y de personas entrevistadas sea diferente en el estudio. De manera que, el número de entrevistas será igual al número de informantes. Esta consideración se justifica para no multiplicar el número de registros de uso cuando en una entrevista participa más de una persona, y para asignar un registro de uso completado entre varias personas a un solo informante. De este modo, la entrevista es el núcleo de información en el que se agregan todos los datos aportados por las personas participantes.

Los datos de campo fueron recogidos en dos fases diferentes, la primera fase de abril de 2010 a diciembre de 2011 en la que se realizaron 50 entrevistas a 67 personas, en 18 localidades de las zonas de La Pernía, Polentinos y el Valle de Castillería. La segunda fase se extendió desde marzo de 2015 hasta agosto de 2018, en la que se llevaron a cabo 89 entrevistas a 120 personas, en 62 localidades de la comarca de la Montaña Palentina, repitiendo alguna de las localidades ya visitadas en la primera fase. El total de entrevistas entre las dos fases de estudio es de 139, igual al número de informantes 139, resultando el número total de personas entrevistadas igual a 187. A los informantes más destacados se les ha visitado en varias ocasiones, incluyendo los nuevos datos aportados en el núcleo principal de la entrevista realizada en la primera visita.

Todos las personas entrevistadas se describen en la tabla 6, señalando la localidad de nacimiento, número de entrevista, nombre y apellidos, edad en el momento de la entrevista, sexo y número de visitas realizadas a cada persona en la fase I (n1) y en la fase II (n2).

TABLA 6: Listado de personas entrevistadas, señalando localidad de nacimiento, número de entrevista, nombre y apellidos, edad en el momento de la entrevista, sexo, número de visitas fase I (n1) y número de visitas fase II (n2).

\begin{tabular}{|c|c|c|c|c|c|c|}
\hline Localidad & $\begin{array}{c}\text { № } \\
\text { entrevista }\end{array}$ & Nombre y apellidos & Edad & Sexo & n1 & n2 \\
\hline \multirow[t]{2}{*}{ Aguilar de Campoo } & 55 & Jacoba Santamaría Cuesta & 86 & $\mathrm{H}$ & & 1 \\
\hline & 69 & Consuelo Alonso Toribio & 69 & $\mathrm{H}$ & & 1 \\
\hline \multirow[t]{3}{*}{ Alba de los Cardaños } & 93 & Isidoro Redondo Pérez & 76 & V & & 1 \\
\hline & 115 & Pablo Martino Martín & 69 & V & & 2 \\
\hline & 73 & Valentín Presa Alonso & 56 & V & & 2 \\
\hline Arbejal & 92 & Benjamín Ramos Díez & 81 & V & & 3 \\
\hline \multirow[t]{2}{*}{ Areños } & 45 & Anónimo & - & $\mathrm{H}$ & 1 & \\
\hline & 41 & Susana Díez Duque & 70 & $\mathrm{H}$ & 1 & \\
\hline Aviñante de la Peña & 127 & Alfonso Heras Martín & 91 & V & & 1 \\
\hline \multirow[t]{5}{*}{ Barruelo de Santullán } & 120 & Consuelo Estébanez Muñoz & 91 & $\mathrm{H}$ & & 1 \\
\hline & 122 & Isabel Chocán López & 74 & $\mathrm{H}$ & & 1 \\
\hline & 59 & Jesús Díez de Celis & 83 & V & & 1 \\
\hline & 59 & Laudina de Mier de Río & 80 & $\mathrm{H}$ & & 1 \\
\hline & 60 & María Fontaneda Ontillera & 74 & $\mathrm{H}$ & & 1 \\
\hline Brañosera & 58 & José Luis Santiago Pérez & 67 & V & & 4 \\
\hline \multirow[t]{3}{*}{ Camasobres } & 36 & Adelina de Mier Llorente & 74 & $\mathrm{H}$ & 2 & \\
\hline & 36 & Pilar de Mier Llorente & 75 & $\mathrm{H}$ & 2 & \\
\hline & 46 & Anónimo & - & V & 1 & \\
\hline \multirow[t]{3}{*}{ Camporredondo de Alba } & 138 & Agustina Martínez de la Gala & 79 & $\mathrm{H}$ & & 1 \\
\hline & 112 & Alejandro Santos Salvador & 86 & V & & 2 \\
\hline & 112 & Eutimio Santos Santos & 72 & V & & 1 \\
\hline \multirow[t]{4}{*}{ Casavegas } & 38 & Anónimo & - & $\mathrm{H}$ & 1 & \\
\hline & 38 & Anónimo & - & $\mathrm{H}$ & 1 & \\
\hline & 38 & Anónimo & - & $\mathrm{H}$ & 1 & \\
\hline & 38 & Anónimo & - & V & 1 & \\
\hline \multirow[t]{5}{*}{ Celada de Roblecedo } & 22 & Edelmira Cenera Mediavilla & 84 & $\mathrm{H}$ & 2 & 2 \\
\hline & 23 & Florentino García Cabeza & 60 & V & 1 & \\
\hline & 21 & Laura Cenera Mediavilla & 83 & $\mathrm{H}$ & 1 & \\
\hline & 4 & Serafina Salvador Fuente & 80 & $\mathrm{H}$ & 5 & \\
\hline & 21 & Ursicinio García Olea & 82 & V & 1 & \\
\hline Cervera de Pisuerga & 54 & Felisa Cuena Fernández & 86 & $\mathrm{H}$ & & 1 \\
\hline
\end{tabular}




\begin{tabular}{|c|c|c|c|c|c|c|}
\hline Localidad & $\begin{array}{c}\text { № } \\
\text { entrevista }\end{array}$ & Nombre y apellidos & Edad & Sexo & n1 & $\mathrm{n} 2$ \\
\hline \multirow[t]{2}{*}{ Cillamayor } & 89 & Ángel Fernández Serna & 85 & $\mathrm{H}$ & & 1 \\
\hline & 89 & Bonifacio González Ortega & 86 & V & & 1 \\
\hline Cubillo de la Peña & 139 & Jesús Llano García & 66 & V & & 1 \\
\hline Dehesa de Montejo & 137 & Mercedes Mencía Roscales & 78 & $\mathrm{H}$ & & 1 \\
\hline \multirow[t]{3}{*}{ El Campo } & 42 & Anónimo & - & $\mathrm{H}$ & 1 & \\
\hline & 42 & Anónimo & - & $\mathrm{H}$ & 1 & \\
\hline & 42 & Anónimo & - & $\mathrm{H}$ & 1 & \\
\hline \multirow[t]{4}{*}{ Estalaya } & 12 & Ana Alonso Díez & 72 & $\mathrm{H}$ & 1 & \\
\hline & 47 & Anónimo & - & $\mathrm{H}$ & 1 & \\
\hline & 10 & Clementino Abad Cabeza & 83 & V & 1 & \\
\hline & 10 & Eugenio Moreno Abad & 77 & V & 1 & \\
\hline Gramedo & 87 & Severino de la Hera García & 85 & V & & 1 \\
\hline Guardo & 128 & Antonia Fernández Hompanera & 74 & $\mathrm{H}$ & & 1 \\
\hline \multirow[t]{2}{*}{ Herreruela de Castillería } & 24 & Inocencia Díez Calvo & 79 & $\mathrm{H}$ & 2 & 1 \\
\hline & 90 & Moisés Cenera Llorente & 86 & V & & 1 \\
\hline \multirow[t]{3}{*}{ La Lastra } & 114 & Crescencio Sierra Ruesga & 90 & V & & 3 \\
\hline & 113 & Laureano Sierra Martín & 64 & V & & 1 \\
\hline & 114 & Oliva Martín Díez & 86 & $\mathrm{H}$ & & 2 \\
\hline \multirow[t]{3}{*}{ Lebanza } & 80 & Adolfo Gutiérrez Díez & 83 & V & & 1 \\
\hline & 48 & Anónimo & - & V & 1 & \\
\hline & 19 & Julia Díez Gutiérrez & 72 & $\mathrm{H}$ & 1 & \\
\hline \multirow[t]{6}{*}{ Lores } & 119 & Casilda Morante Moreno & 85 & $\mathrm{H}$ & & 1 \\
\hline & 119 & Cesar Alonso Romero & 51 & V & & 1 \\
\hline & 39 & Eladio de la Hera Díez & 84 & V & 1 & \\
\hline & 119 & Herminia Morante Moreno & 90 & $\mathrm{H}$ & & 1 \\
\hline & 119 & Luis Ángel Morante Calvo & 50 & V & & 1 \\
\hline & 40 & Santiago Alonso Merino & 75 & V & 1 & \\
\hline Los Llazos & 49 & Anónimo & - & $\mathrm{H}$ & 1 & \\
\hline \multirow[t]{4}{*}{ Matabuena } & 97 & Gregorio Costana Díez & 85 & V & & 2 \\
\hline & 105 & Julio Vielba Porras & 80 & V & & 2 \\
\hline & 88 & Miguel Vielba Porras & 81 & V & & 2 \\
\hline & 105 & Saturnina Costana Díez & 78 & $\mathrm{H}$ & & 1 \\
\hline Matamorisca & 86 & Segunda Villa Iglesias & 94 & $\mathrm{H}$ & & 1 \\
\hline Menaza & 125 & Eutiquiano García Merino & 102 & V & & 1 \\
\hline Monasterio & 95 & Andrés Llanillo Vielba & 71 & V & & 1 \\
\hline Mudá & 103 & Carlos García Torices & 85 & V & & 1 \\
\hline \multirow[t]{3}{*}{ Nava de Santullán } & 75 & Aquilino Ruíz Pérez & 79 & V & & 3 \\
\hline & 74 & Pablo García Vélez & 88 & V & & 2 \\
\hline & 82 & Pablo Rojo Díez & 69 & V & & 2 \\
\hline \multirow[t]{2}{*}{ Nestar } & 68 & Petra Fernández Terán & 88 & $\mathrm{H}$ & & 2 \\
\hline & 68 & Valeriano Terán González & 89 & V & & 1 \\
\hline \multirow[t]{3}{*}{ Otero de Guardo } & 73 & Antonio Reguero Mancebo & 86 & V & & 1 \\
\hline & 73 & José Vejo Alonso & 73 & V & & 2 \\
\hline & 73 & Silverio Mancebo Mancebo & 85 & V & & 3 \\
\hline \multirow[t]{2}{*}{ Piedrasluengas } & 79 & Manuel Gómez Alonso & 99 & V & & 1 \\
\hline & 37 & Prudencio Díez Díez & 79 & V & 1 & \\
\hline Pisón de Castrejón & 134 & Andrés Peral Rodríguez & 90 & V & & 1 \\
\hline \multirow[t]{7}{*}{ Polentinos } & 17 & Candelas Martín Merino & 84 & $\mathrm{H}$ & 1 & \\
\hline & 27 & Eusebio Sordo Martín & 87 & V & 3 & \\
\hline & 26 & Francisco Merino Ruesga & 71 & V & 1 & \\
\hline & 117 & Josefa Sordo Sordo & 95 & $\mathrm{H}$ & & 1 \\
\hline & 44 & Mariano Sordo Fuente & 92 & V & 1 & \\
\hline & 26 & Soledad Ruesga Ruesga & 80 & $\mathrm{H}$ & 1 & \\
\hline & 109 & Vicente Merino Merino & 82 & V & & 1 \\
\hline \multirow[t]{2}{*}{ Rabanal de los Caballeros } & 25 & Ángel Gómez Díaz & 71 & V & 1 & 1 \\
\hline & 87 & Baudilia Merino Delgado & 77 & $\mathrm{H}$ & & 1 \\
\hline \multirow[t]{3}{*}{ Rebanal de las Llantas } & 100 & Agustina Barreda Valle & 81 & $\mathrm{H}$ & & 2 \\
\hline & 100 & Felicitas Barreda Valle & 87 & $\mathrm{H}$ & & 1 \\
\hline & 99 & Jerónimo Calvo Díez & 87 & V & & 1 \\
\hline
\end{tabular}




\begin{tabular}{|c|c|c|c|c|c|c|}
\hline Localidad & $\begin{array}{c}\text { № } \\
\text { entrevista }\end{array}$ & Nombre y apellidos & Edad & Sexo & n1 & n2 \\
\hline Rebanal de las Llantas & 84 & Paulino Pérez Díez & 86 & $\mathrm{~V}$ & & 3 \\
\hline \multirow[t]{4}{*}{ Recueva de la Peña } & 130 & Alejandro Mata Fernández & 79 & V & & 1 \\
\hline & 66 & Alpiniana del Valle Arto & 85 & $\mathrm{H}$ & & 1 \\
\hline & 63 & Rosario Mota Fernández & 84 & $\mathrm{H}$ & & 2 \\
\hline & 63 & Samuel Hospital del Amo & 85 & $\mathrm{~V}$ & & 2 \\
\hline \multirow[t]{4}{*}{ Resoba } & 98 & Honores Ibáñez Ramos & 92 & $\mathrm{H}$ & & 2 \\
\hline & 51 & María Ramos Ramos & 80 & $\mathrm{H}$ & & 2 \\
\hline & 51 & Pilar Ramos Ramos & 54 & $\mathrm{H}$ & & 3 \\
\hline & 98 & Santiago Ramos Merino & 90 & V & & 1 \\
\hline \multirow[t]{3}{*}{ Riosmenudos de la Peña } & 130 & Paz Noriega Revuelta & 73 & $\mathrm{H}$ & & 1 \\
\hline & 130 & Pedro Pelaz García & 83 & V & & 1 \\
\hline & 130 & Teresa Mata Hospital & 83 & $\mathrm{H}$ & & 1 \\
\hline \multirow[t]{2}{*}{ Roscales de la Peña } & 70 & María Olvido de la Hera Sotos & 72 & $\mathrm{H}$ & & 1 \\
\hline & 70 & Quirina Calle Quijano & 86 & $\mathrm{H}$ & & 2 \\
\hline Ruesga & 111 & Leandro Lores Lores & 81 & V & & 2 \\
\hline \multirow[t]{2}{*}{ Salcedillo } & 124 & Andrés González Llorente & 89 & V & & 1 \\
\hline & 123 & Urbano González Llorente & 96 & V & & 1 \\
\hline \multirow[t]{2}{*}{ Salinas de Pisuerga } & 83 & Hermenegildo Ramos Sobrado & 87 & V & & 4 \\
\hline & 104 & Santos Montero Vélez & 74 & V & & 1 \\
\hline \multirow[t]{3}{*}{ San Cebrián de Mudá } & 56 & Argentina Arto Herrero & 80 & $\mathrm{H}$ & & 1 \\
\hline & 102 & Benjamín Roche Arto & 89 & V & & 1 \\
\hline & 56 & Gervino Gutiérrez Aparicio & 79 & V & & 1 \\
\hline \multirow[t]{5}{*}{ San Felices de Castillería } & 13 & Ascensión Torres Ramasco & 75 & $\mathrm{H}$ & 2 & \\
\hline & 15 & Francisco Torres Ramasco & 77 & V & 2 & \\
\hline & 53 & Josefina Gutiérrez Llorente & 94 & $\mathrm{H}$ & & 1 \\
\hline & 13 & Julia Torres Ramasco & 73 & $\mathrm{H}$ & 2 & \\
\hline & 14 & Ubaldino Díez García & 78 & $\mathrm{~V}$ & 1 & \\
\hline \multirow[t]{4}{*}{ San Juan de Redondo } & 110 & Celestina de Mier Simón & 76 & $\mathrm{H}$ & & 1 \\
\hline & 32 & Clemente Simón Simón & 79 & V & 1 & 1 \\
\hline & 31 & Javier Vilda Vilda & 49 & V & 1 & \\
\hline & 118 & Mariano de Mier Simón & 78 & V & & 1 \\
\hline San Martín de los Herreros & 81 & Prudencia Redondo Villa & 89 & $\mathrm{H}$ & & 2 \\
\hline \multirow[t]{2}{*}{ San Martín de Perapertú } & 78 & Benito Gómez Revilla & 89 & V & & 1 \\
\hline & 57 & Delfín Estalayo Vélez & 85 & $\mathrm{~V}$ & & 2 \\
\hline \multirow[t]{4}{*}{ San Salvador de Cantamuda } & 43 & Asunción Ibáñez Ruesga & 83 & $\mathrm{H}$ & 1 & \\
\hline & 20 & Emiliano Vega Cuevas & 65 & V & 1 & \\
\hline & 18 & Isaac Ibáñez Llorente & 75 & V & 2 & 1 \\
\hline & 18 & Victorina Ibáñez Llorente & 75 & $\mathrm{H}$ & 2 & 1 \\
\hline Santa María de Nava & 121 & Felipe García Arto & 79 & V & & 1 \\
\hline \multirow[t]{4}{*}{ Santa María de Redondo } & 35 & Ángel Torres Celis & 97 & V & 1 & \\
\hline & 28 & Francisco Torres Ramasco & 74 & V & 1 & \\
\hline & 34 & Francisco García González & 72 & V & 1 & \\
\hline & 33 & Ascensión Torres de la Fuente & 72 & $\mathrm{H}$ & 1 & \\
\hline \multirow[t]{7}{*}{ Santibáñez de la Peña } & 64 & Blanca Merino Rodríguez & 69 & $\mathrm{H}$ & & 1 \\
\hline & 67 & Anónimo & - & $\mathrm{H}$ & & 1 \\
\hline & 67 & Anónimo & - & $\mathrm{H}$ & & 1 \\
\hline & 67 & Anónimo & - & $\mathrm{H}$ & & 1 \\
\hline & 67 & Anónimo & - & $\mathrm{H}$ & & 1 \\
\hline & 67 & Anónimo & - & V & & 1 \\
\hline & 64 & Luis Mediavilla de la Gala & 75 & V & & 1 \\
\hline \multirow[t]{2}{*}{ Santibáñez de Resoba } & 101 & Ignacio García Redondo & 66 & V & & 1 \\
\hline & 101 & Máximo Redondo García & 80 & V & & 1 \\
\hline \multirow[t]{2}{*}{ Tarilonte de la Peña } & 132 & Esperanza Allende Fernández & 89 & $\mathrm{H}$ & & 1 \\
\hline & 132 & Onofre Villacorta Calvo & 94 & V & & 1 \\
\hline Traspeña de la Peña & 65 & Felisa Rodríguez Rodríguez & 92 & $\mathrm{H}$ & & 1 \\
\hline \multirow[t]{2}{*}{ Tremaya } & 29 & Mercedes Rueda Ramasco & 71 & $\mathrm{H}$ & 1 & \\
\hline & 30 & Simón Estalayo Cenera & 78 & V & 1 & \\
\hline Triollo & 52 & Ángel Merino Rodríguez & 79 & V & & 1 \\
\hline & 62 & Marina Martín Montes & 86 & $\mathrm{H}$ & & 1 \\
\hline
\end{tabular}




\begin{tabular}{|c|c|c|c|c|c|c|}
\hline Localidad & $\begin{array}{c}\text { № } \\
\text { entrevista }\end{array}$ & Nombre y apellidos & Edad & Sexo & n1 & $\mathrm{n} 2$ \\
\hline Valberzoso & 126 & Francisco Martín Montes & 79 & V & & 1 \\
\hline \multirow[t]{2}{*}{ Valcobero } & 136 & Amalia Vargas Santos & 105 & $\mathrm{H}$ & & 1 \\
\hline & 85 & Victorino Macho Largo & 71 & V & & 5 \\
\hline \multirow[t]{2}{*}{ Valle de Santullán } & 14 & Argentina Iglesias Vielba & 70 & $\mathrm{H}$ & 1 & 1 \\
\hline & 96 & Fernando Polanco San Millán & 78 & $\mathrm{H}$ & & 1 \\
\hline Vallespinoso de Cervera & 77 & Ovidio Llanillo Andérez & 81 & V & & 1 \\
\hline Valsadornín & 76 & Francisco Montero Roldán & 75 & V & & 1 \\
\hline Valsurbio & 129 & Juan Pedro Vargas Pérez & 68 & V & & 1 \\
\hline Vañes & 91 & Fidel Ramos de la Hera & 89 & V & & 1 \\
\hline Velilla de la Peña & 131 & Emilia Martín Macho & 80 & $\mathrm{H}$ & & 1 \\
\hline Velilla del Río Carrión & 94 & Salomón Fraile de la Hoz & 95 & V & & 2 \\
\hline \multirow[t]{2}{*}{ Ventanilla } & 106 & Félix de la Vega Gil & 68 & V & & 2 \\
\hline & 107 & María Simal Ruíz & 86 & $\mathrm{H}$ & & 1 \\
\hline \multirow[t]{14}{*}{ Verdeña } & 9 & Adela de las Heras Pascual & 82 & $\mathrm{H}$ & 1 & 1 \\
\hline & 16 & Clementino Arto de la Hera & 66 & V & 1 & \\
\hline & 7 & Elsa Pascual Montero & 80 & $\mathrm{H}$ & 1 & \\
\hline & 3 & Eludivina Pascual Montero & 83 & $\mathrm{H}$ & 3 & \\
\hline & 11 & Emiliano Iglesias Morante & 86 & V & 1 & \\
\hline & 2 & Ester Pascual Montero & 87 & $\mathrm{H}$ & 2 & \\
\hline & 11 & Etelvina Abad Pérez & 84 & $\mathrm{H}$ & 1 & \\
\hline & 8 & Máxima Pascual Pascual & 75 & $\mathrm{H}$ & 4 & 3 \\
\hline & 8 & Obdulia Pascual Pascual & 77 & $\mathrm{H}$ & 1 & 1 \\
\hline & 5 & Raquel Fuente Díez & 65 & $\mathrm{H}$ & 1 & \\
\hline & 6 & Sabina Fuente Merino & 69 & $\mathrm{H}$ & 1 & 1 \\
\hline & 1 & Sandalio Pascual Montero & 81 & V & 4 & 1 \\
\hline & 7 & Santiago García Bascones & 79 & V & 1 & \\
\hline & 8 & Victorino Pascual Pascual & 78 & V & 6 & 4 \\
\hline Vergaño & 116 & Amador García Cuena & 82 & V & & 1 \\
\hline Vidrieros & 61 & Sagrario Moreno Vejo & 90 & $\mathrm{H}$ & & 3 \\
\hline Villabellaco & 126 & Julia García Costana & 73 & $\mathrm{H}$ & & 2 \\
\hline \multirow[t]{4}{*}{ Villanueva de Arriba } & 72 & Dativo Martín Díez & 77 & V & & 1 \\
\hline & 71 & Francisco Martín Herrero & 89 & V & & 1 \\
\hline & 128 & Laura García Val & 40 & $\mathrm{H}$ & & 1 \\
\hline & 72 & Victoria del Amo de la Hera & 75 & $\mathrm{H}$ & & 2 \\
\hline Villanueva de la Torre & 108 & Carlina García Torices & 85 & $\mathrm{H}$ & & 3 \\
\hline \multirow[t]{2}{*}{ Villanueva de la Peña } & 133 & Julio Alcalde Alcalde & 86 & V & & 1 \\
\hline & 135 & Restituto Calderón del Amo & 94 & V & & 1 \\
\hline
\end{tabular}

Un aspecto a tener en cuenta en la valoración de los resultados es la edad de los informantes. En el rango de edad comprendido entre los 70 y los 90 años se obtiene gran cantidad de información, al tratarse de personas que no perdieron la cadena de transmisión oral de conocimientos y que además conocieron en profundidad el modo de vida y las costumbres de la zona, siendo los depositarios de esta sabiduría. Si estas personas se encuentran en buenas condiciones son las que mayor cantidad de conocimientos aportaron. La media de edad de los informantes es de 79,8 años, oscilando entre los 105 años del informante de mayor edad y los 40 años del más joven. El $88 \%$ de los entrevistados tenía más de 70 años, siendo el rango de 80-89 años el más representado con un $42 \%$.

Solamente un 3\% de las personas tenía menos de 60 años, por lo general, poco interesados en temas del pasado, con escaso conocimiento de las tradiciones locales o intoxicados por una cultura más global. Este porcentaje es bajo por dos consideraciones, la primera por encontrarnos ante una población muy envejecida que representa solo una pequeñísima parte de los habitantes de la zona, y la segunda por la obtención de menor número de datos en este rango de edad. 


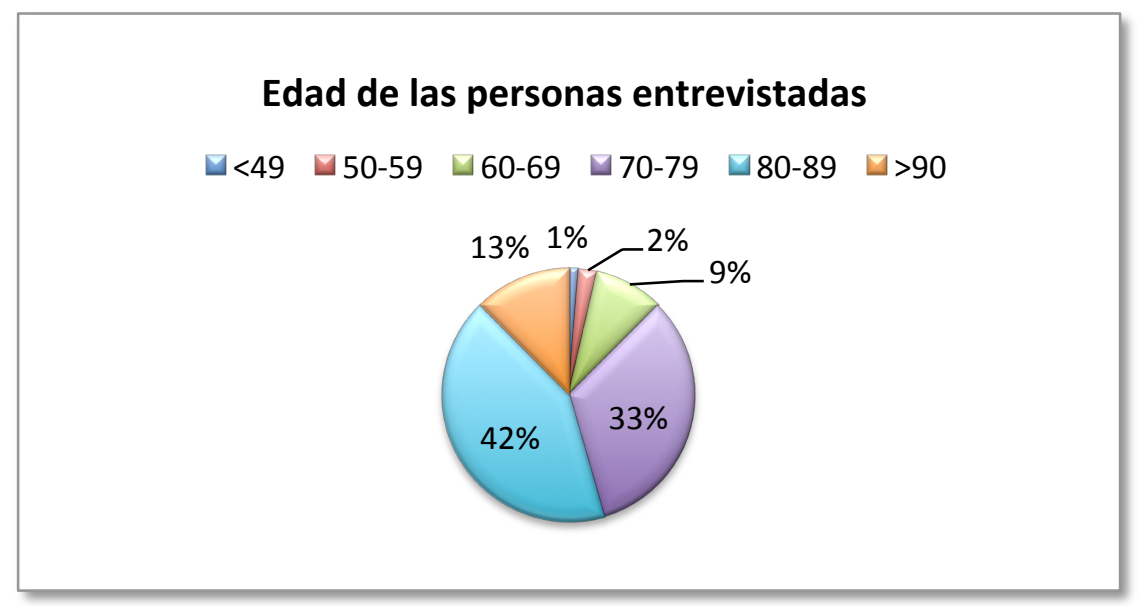

FIGURA 12: Porcentajes de rangos de edad de las personas entrevistadas.

Otro aspecto que tuvimos en cuenta fue el sexo de los informantes, debido a que tradicionalmente las mujeres aportan muchos más datos sobre plantas medicinales $u$ ornamentales, y los hombres lo hacen más sobre plantas veterinarias o plantas utilizadas en tecnologías. En consecuencia, el $53 \%$ de las entrevistas fue a varones y el $47 \%$ fue a mujeres, tratando de equilibrar la posible importancia cultural de unas especies u otras.

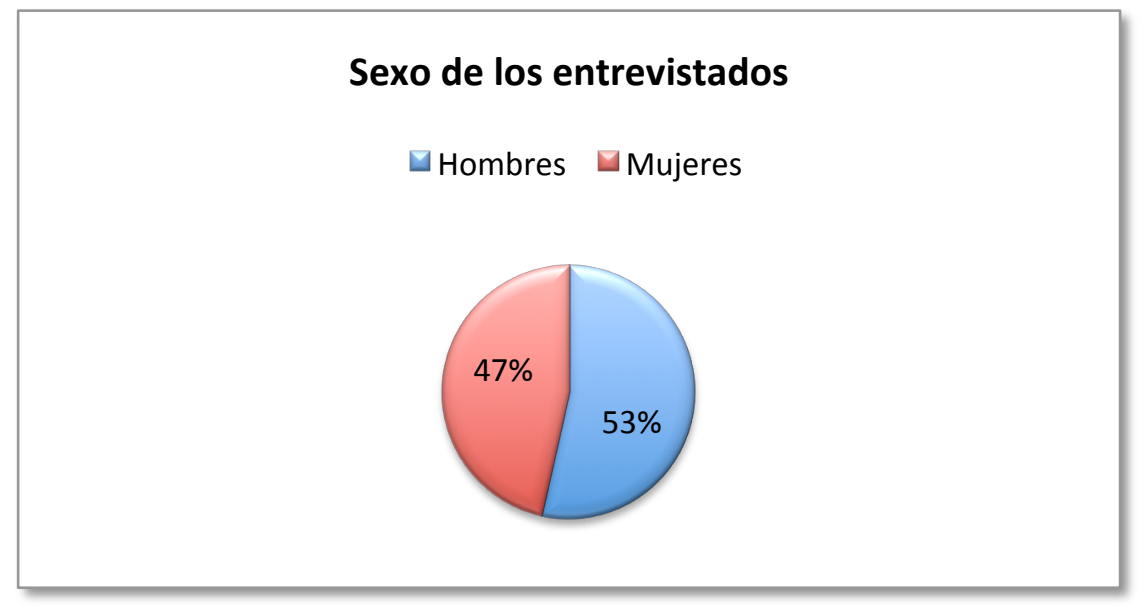

FIGURA 13: Porcentaje de personas entrevistadas según el sexo.

El perfil profesional mayoritario del informante masculino fue la agricultura y la ganadería que se ejercían de forma conjunta (68\%), también se entrevistó a numerosos mineros (9\%) con dedicación exclusiva e incluso los hay que combinaron esta profesión con pequeñas propiedades agrícolas o ganaderas (8\%). Otras profesiones (14\%) ejercidas por los entrevistados fueron la albañilería, cantería, agente forestal o transportista. Entre las mujeres la mayoría son amas de casa que compaginan estas labores con las necesarias para atender el ganado y las tierras de labor de su propiedad (88\%). Otras profesiones (12\%) mencionadas fueron peluquera, monja, modista o vendedora. 


\subsection{RECOGIDA DE DATOS}

Al ser la etnobotánica una disciplina que une etnología y botánica, los métodos utilizados proceden de ambas, tanto en la obtención de información a través de entrevistas (método etnológico), como en la recolección y determinación de las plantas mencionadas (método botánico). El presente estudio podríamos diferenciarlo en dos fases:

1. Trabajo de campo con diversas visitas a la zona, donde se hizo reconocimiento previo del medio, así como recolección de plantas y herborización de aquellas que consideramos pudieran tener interés, posteriormente se realizaron entrevistas en casas y lugares públicos, entrevistas en campo y recolección de testigos.

2. TRABAjo de gabinete en el que se identifican los testigos y se ordena y analiza la información recogida en las entrevistas.

ESQUEMA METODOLÓGICO:

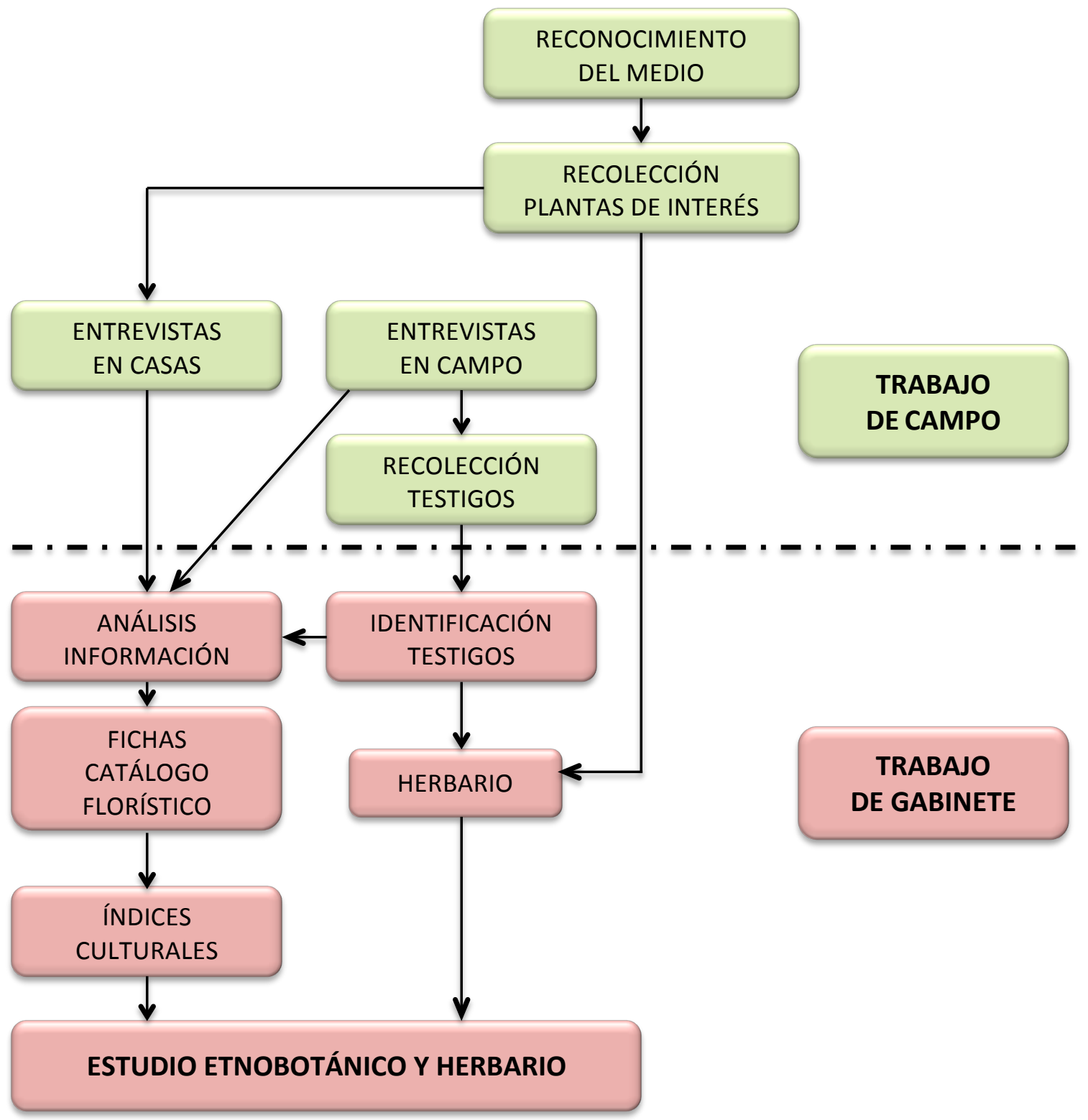

FIGURA 14: Esquema metodológico del estudio etnobotánico realizado en la comarca de la Montaña Palentina. 
El presente estudio se basa exclusivamente en los datos obtenidos en nuestro trabajo de campo, a través de las 139 entrevistas realizadas a 187 personas de la comarca de la Montaña Palentina, y posterior selección, ordenación y contraste de los datos obtenidos.

El trabajo de campo comenzó en el mes de marzo de 2010 con el reconocimiento del medio y la recolección de plantas con posible interés etnobotánico en la zona, con el objetivo de recabar información del medio, contactar con la cultura local y crear un herbario que nos ayudase en las futuras entrevistas. Las entrevistas de la primera fase comenzaron el mes de abril de 2010 y finalizaron en diciembre de 2011, y las de la segunda fase se iniciaron en marzo de 2015 y finalizaron en agosto de 2018, en ambas fases se cubrieron todas las épocas del año, aprovechando la floración de muchas especies en primavera y de buena parte del verano, durante el cual también se recogió información sobre recolección de ciertas especies. Ya el otoño sirvió para tomar datos sobre recolección de numerosos frutos y de especies de floración tardía.

Los materiales empleados en el trabajo de campo fueron: cuaderno, bolígrafo, ordenador portátil para grabación de audio de entrevistas en lugares públicos o privados, teléfono móvil para grabación de audio de entrevistas de campo y captura de fotografías, cámara modelo "go pro" para realización de videos a los informantes, bolsas para toma de muestras, azada y tijeras de podar.

Para el registro de información sobre usos de las plantas en la cultura tradicional se suelen utilizar distintos tipos de entrevista: individuales, colectivas, de campo o con muestras de plantas. La más común en estudios etnobotánicos es la individual de tipo semiabierta o semiestructurada, al ofrecer al entrevistador libertad suficiente para ir dirigiendo la charla hacia los puntos de mayor interés y dominio (Alexiades, 1996), además de permitir al informante abordar temas que en principio no se tuvieron en cuenta. En las entrevistas abiertas se deja al informante libertad para que desarrolle sus conocimientos sin un guión de preguntas prefijado y en las entrevistas cerradas, el informante se ciñe a un cuestionario redactado previamente. Por ello, la solución adoptada fue la mixta para guiar al informante y no acosarle con cuestionarios rígidos, buscando el equilibrio entre dejar libre la memoria de entrevistado y guiar la conversación para abarcar todos los temas que rastreamos en la investigación.

Durante las entrevistas se trata de obtener la información lo más completa posible, recogiendo datos sobre modos de preparación o elaboración, partes empleadas, época de recolección o vigencia de uso. Para considerar una entrevista como tal, todo informante ha tenido que ser preguntado en todas las categorías de uso definidas.

La información introducida en la base de datos final se ha hecho en función de la entrevista realizada, independientemente del número de participantes, contando como un registro el mencionado en una entrevista.

\subsubsection{ENTREVISTAS INDIVIDUALES}

Este tipo de entrevistas se realizó en lugares privados (casas, tenadas, patios...) o públicos (casas de concejo, ayuntamiento, bares, teleclubs...), la mayoría se desarrollaron en casas particulares resultando éstas las más fructíferas en cuanto a información obtenida, ya que se conseguía un ambiente distendido que propiciaba la empatía y confianza del informante para profundizar en los temas que se proponían. 
Se preparó un listado de temas descrito en la tabla 7, que sirvió de guía para las entrevistas, así como para clasificar la información en categorías de uso. Para la confección de este listado nos apoyamos en la primera fase de entrevistas en varios estudios etnobotánicos (Herrero Laborda, 1998; Escobar García, 2006; Pardo de Santayana, 2008).

\section{CLASIFICACIÓN DE CATEGORÍAS}

CATEgoría 1. Medicinales : Usadas para mejorar, curar o prevenir la salud de las personas.

\begin{tabular}{|c|c|c|c|}
\hline Aparato circulatorio & Aparato excretor & Aparato respiratorio & Metabolismo \\
\hline Circulación & Diurético & Asma & Diabetes \\
\hline Colesterol & Piedras riñón & Bronquios & Fiebre \\
\hline Hipertensión & Próstata & Catarros & Hepatitis \\
\hline Purificar & Aparato locomotor & Gripe & Tiroides \\
\hline Aparato digestivo & Dolores óseos & & Sistema nervioso \\
\hline Aperitivo & Dolores musculares & Dermatología & Anestésico \\
\hline Cólico & Golpes & Alopecia & Dolor de cabeza \\
\hline Diarrea & Gota & Callos & Excitantes \\
\hline Digestivo & Reúma & Cáncer de piel & Memoria \\
\hline Dolor estomago & Roturas & Picaduras & Relajante \\
\hline Estreñimiento & Aparato reproductor & Piojos & $\underline{\text { Varios }}$ \\
\hline $\begin{array}{l}\text { Gases } \\
\text { Lombrices }\end{array}$ & Abortivos & $\begin{array}{l}\text { Sarna } \\
\text { Verrugas }\end{array}$ & Dolor oídos \\
\hline Vomitivo & Fertilizantes & Heridas & Ojos \\
\hline & $\begin{array}{c}\text { Menstruación } \\
\text { Partos }\end{array}$ & Quemaduras & $\begin{array}{l}\text { Infecciones } \\
\text { Tónicos }\end{array}$ \\
\hline \multicolumn{4}{|c|}{ Usadas para mejorar la salud del ganado, curar y prevenir: } \\
\hline Aparato circulatorio & Aparato excretor & Aparato respiratorio & \\
\hline \multirow{2}{*}{$\begin{array}{c}\text { Circulación } \\
\text { Purificar }\end{array}$} & Diurético & \multirow{2}{*}{$\begin{array}{c}\text { Tos } \\
\text { Pulmonía }\end{array}$} & \multirow{2}{*}{$\begin{array}{c}\text { Fiebre } \\
\text { Sistema nervioso } \\
\end{array}$} \\
\hline & Aparato locomotor & & \\
\hline Aparato digestivo & Cojera & Dermatología & Calmante \\
\hline \multirow{3}{*}{$\begin{array}{l}\text { Aperitivo } \\
\text { Cólico } \\
\text { Diarrea }\end{array}$} & Golpes & Gripe & Excitante \\
\hline & Roturas & Heridas & \multirow{5}{*}{$\begin{array}{l}\underline{\text { Varios }} \\
\text { Infecciones } \\
\text { Ojos }\end{array}$} \\
\hline & Aparato reproductor & Picaduras & \\
\hline Digestivo & Fertilizantes & Piojos & \\
\hline $\begin{array}{c}\text { Empacho } \\
\text { Estreñimiento }\end{array}$ & Partos & Sarna & \\
\hline Lombrices & & & \\
\hline
\end{tabular}

Categoría 2. Alimentación humana : Utilizadas para alimentación de personas.

Recolección silvestres

Raíces

Brotes tiernos

Hojas

Flores

Frutos
Bebidas

Infusiones

Licores
Aditivos alimenticios

Condimentos
Alimentos elaborados

Mermeladas 
TABLA 7 : (Continuación) Listado de clasificación de categorías de uso en la primera fase de entrevistas.

Categoría 3. Alimentación Animal : Utilizadas como alimentación para el ganado.

\section{Plantas recolectadas \\ Hojas y ramas \\ Tallos y flores \\ Frutos}

\section{Plantas pastadas \\ Pasto \\ Ramoneo}

CAtegoría 4. TeCnología y ARTESANÍA : Utilizadas en fabricación, elaboraciones y procesos.

\begin{tabular}{c} 
Construcción \\
\hline Vigas \\
Ripia \\
Solado
\end{tabular}

Cestería
Hogar

Mobiliario

Útiles

Aislantes

Techumbres

Mullidas

\section{Aperos}

De transporte

De laboreo
Instrumentos y juegos

\section{Herramientas}

Mangos

Herramientas

Varios

Categoría 5. Combustibles : Usadas como combustible calorífico.

\section{Encendido}

Leña

Carbón vegetal

CATEgoría 6. Simbólicos Y TRAdicionales : Utilizadas en la cultura local.

\section{Ceremonias \\ Religiosas \\ Oficiales}

\section{Tradiciones \\ Juegos \\ Mayos}

Magia o superstición

Religiosas

Categoría 7. Ornamental: Plantas para adorno u ornamento.
Adorno floral
Flor cortada
Flor seca
Jardinería
Exterior
Interior

CATEgoría 8. Tóxicas : Plantas venenosas, tóxicas o prohibidas.

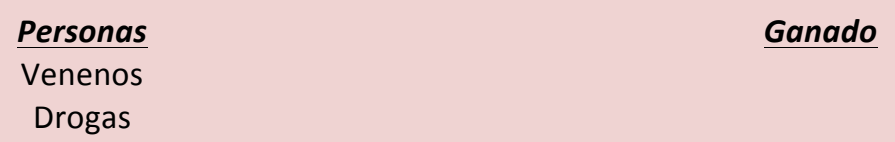

\section{Ganado}


En la segunda fase de entrevistas el listado se basó en la clasificación de la información en categorías de uso siguiendo los criterios establecidos en el Inventario Español de los Conocimientos Tradicionales relativos a la Biodiversidad (Pardo de Santayana et al., 2014), descrita en la tabla 8. Aunque se retocaron aspectos de ella con el tiempo, eliminando subcategorías no mencionadas y con nula relevancia en la zona de estudio como "Algas" o "Embarcaciones", sirvió en todo momento para orientarnos y organizar la información recibida, tratando en todas las entrevistas de abordar todos los temas. Posteriormente, los datos de las entrevistas de la primera fase se readaptaron al modelo de la segunda fase para homogeneizar el estudio.

TABLA 8: Relación de categorías de uso consideradas.

\begin{tabular}{l}
\hline Categorías: \\
\hline Alimentación humana \\
Alimentación animal \\
Medicina \\
Veterinaria \\
Uso tóxico y nocivo \\
Uso combustible \\
Construcción \\
Industria y artesanía \\
Uso medioambiental \\
Uso ornamental \\
Uso social, simbólico y ritual \\
\hline
\end{tabular}

Previa a la charla, se explicaba el trabajo que se estaba llevando a cabo y posteriormente se comenzaba la entrevista con alguna pregunta general sencilla sobre algún cultivo típico local o alguna planta medicinal que se usara en la zona, esto servía para que el informante se sintiera con capacidad suficiente de abordar las preguntas y al mismo tiempo poder ir conduciendo la entrevista por todos los temas de la guía de categorías señalada. El tipo de preguntas abiertas para comenzar la charla podía ser: ¿qué cultivos se daban en la zona?, ¿qué plantas se usaban para curar o para calentar la lumbre?..., en general, preguntas que abren un tema referente a una categoría de uso. A medida que avanzaba la entrevista profundizábamos en aquellos aspectos en los que considerábamos que el informante había mostrado un mayor interés o conocimiento. Bajo la apariencia de una conversación distendida y cómoda se dirige al informante hilando unos temas con otros, plasmando nuestra experiencia y dominio en la recopilación de información con el paso del tiempo. Cuando de un tema no se obtenía más datos se daba paso al siguiente, apoyándonos en el listado de la clasificación de categorías de uso para no dejar en el olvido ningún aspecto.

Una vez finalizado el recorrido por todas las categorías de uso y con la confianza del informante, se realizaban preguntas más concretas que nos servían para despejar dudas surgidas en la propia entrevista o en entrevistas de otros informantes, por ejemplo: ¿conoce el nombre de esta planta mencionada en otra localidad?, ¿se usa esta planta del mismo modo que en el pueblo vecino?..., estos datos son válidos para aunar criterios y contrastarlos entre diferentes localidades.

Aunque la mayoría de las entrevistas se plantearon de forma individual, en ocasiones, el interés de la conversación hizo participe a alguna otra persona del entorno (algún familiar o vecino), que pudo aportar datos y recuerdos que también se incorporaron a la información de esa entrevista. 
La duración de las entrevistas varía desde los 45 minutos la más corta, hasta casi 10 horas la más larga, realizada en varias sesiones, aunque la media general ronda las 2 horas de duración. Comprobamos que transcurridas esas 2 horas, el cansancio del informante provoca que sus respuestas y explicaciones sean más breves y escuetas, por lo que se opta por finalizar la jornada y emplazar al informante a una nueva cita, reanudando en el mismo punto hasta completar todos los temas del listado de categorías de uso.

Todas las entrevistas fueron grabadas en un equipo informático portátil, sirviendo posteriormente para transcribir fielmente los datos aportados, además se tomaron anotaciones en cuadernos de notas en los que se recogen breves apuntes sobre las conversaciones. La grabación de las conversaciones permite conservar su discurso con toda su originalidad, complejidad y riqueza, pudiendo repasar los datos conforme avanza el análisis de la información, y reflexionar sobre algunos aspectos que pudieron pasar inadvertidos en un primer momento (Gispert \& González, 1993). Se informaba sobre la grabación de la entrevista, en un principio condicionaba la confianza del informante, pero al poco tiempo conseguíamos hacer olvidar este hecho para que la entrevista continuara según los términos previstos.

\subsubsection{ENTREVISTAS COLECTIVAS}

Cuatro entrevistas se hicieron de forma colectiva, con más de dos personas aportando datos, realizadas en las localidades de: Casavegas, El Campo, Santibáñez de la Peña y Lores. En dos casos el lugar de la entrevista fue la casa de concejo y en otros dos casos la calle. El método y materiales empleados fueron los mismos que para las entrevistas individuales, utilizando encuestas semiestructuradas, siguiendo la clasificación de las categorías de uso señalado en ambas fases de la recogida de datos y grabando la información en un equipo portátil.

Por lo general, las entrevistas resultaron más engorrosas al querer todas las personas participar con sus conocimientos sin orden alguno, pero por el contrario facilitaron el recuerdo de datos, pudiendo completar información entre los datos aportados por todos los informantes o consensuar las respuestas definitivas.

Observamos que en este tipo de entrevistas los informantes prefieren mantenerse en el anonimato, y salvo la entrevista realizada en Lores, en el resto de entrevistas los informantes ocultaron sus datos personales.

\subsubsection{ENTREVISTAS DE CAMPO}

Siempre que fue posible se ofreció al informante una salida al campo, bien a continuación de la primera entrevista, o bien concertando otro día. Tuvimos en cuenta el estado físico de los informantes para sugerir los paseos, pues varios de ellos presentaban dificultades de movilidad. El $25 \%$ de las entrevistas se complementaron con una salida de campo, este porcentaje pudiera ser mayor, pero en ocasiones por disponibilidad de tiempo del informante, y otras por la elevada edad de los mismos, impidieron este paseo. Cabe apuntar al respecto que algunas de las especies señaladas lo fueron en localizaciones de difícil acceso por su lejanía o por su altitud.

En otros casos revisitamos al informante en numerosas ocasiones, proponiendo paseos en todas las épocas del año y en diferentes comunidades naturales (arbóreas, arbustivas, rocosas, 
herbáceas, humedales, etc.), esta metodología tiene la ventaja de poder identificar plantas en diferentes estados fenológicos y localizadas en diferentes hábitats.

Las entrevistas de campo presentan más ventajas, como poder recolectar plantas para su identificación in situ evitando posibles confusiones, también son de gran ayuda para aclarar nombres vulgares, para refrescar la memoria sobre el uso de las plantas, e incluso para descubrir plantas antes no mencionadas o temas que quedaron encubiertos en una primera entrevista.

Las plantas señaladas por el informante se etiquetaban y se guardaban en bolsas para proceder posteriormente a una correcta identificación. Las conversaciones de campo se grabaron con el teléfono móvil para proceder a la correcta transcripción de la charla. En la segunda fase de entrevistas desarrollada entre marzo de 2015 y agosto de 2018 contamos con el apoyo material de una cámara modelo "go pro", realizando videos explicativos a los informantes sobre los usos de una determinada planta. Se han elaborado 684 videos con la información filmada.

Como inconveniente de este tipo de entrevistas podemos señalar la dificultad de tomar notas, fotografías, grabar videos y recoger testigos, al mismo tiempo, mientras se mantiene una conversación continua. La organización previa del material y la experiencia adquirida fueron fundamentales para minimizar los contratiempos surgidos en los paseos por el campo.

\subsubsection{ENTREVISTAS CON MUESTRAS DE PLANTAS}

En el caso de tener que solventar dudas sobre ciertas plantas citadas en las entrevistas individuales, se recurrió a realizar entrevistas mostrando plantas a los informantes. Se utilizaron tanto plantas frescas recogidas por el investigador previamente, como pliegos de herbario. Observamos que la exposición de pliegos de herbario, en muchos casos, solo servía para confundir al informante y que, en general, no son capaces de identificar una planta prensada y herborizada, por lo que desechamos los pliegos de herbario como método de obtención de información. De las plantas frescas recién recolectadas si obtuvimos datos adicionales, aunque algunos informantes están acostumbrados a reconocer las plantas vivas en su hábitat y del mismo modo, pueden generarse confusiones.

Este tipo de entrevista se revela útil en el caso de no poder acudir al campo con el informante, y así aclarar la información generada en una primera toma de contacto.

\subsubsection{RECOLECCIÓN E IDENTIFICACIÓN DE MUESTRAS}

En la realización de trabajos etnobotánicos es primordial la recolección de muestras para elaborar un herbario testigo que pueda respaldar las identificaciones descritas (Martin, 1995; Alexiades, 1996). Los testigos fueron recolectados durante las entrevistas de campo y en reconocimientos de campo hechos por el investigador, tratando de incluir al menos un pliego de las especies silvestres, descartando las especies cultivadas de menor dificultad para la identificación.

Una vez prensados y etiquetados los testigos, se depositaron 55 ejemplares en el herbario del área de Botánica, PALAB, del Campus de Palencia de la Universidad de Valladolid, y otros 548 ejemplares pasaron a formar parte del herbario personal del investigador. 
En la identificación botánica se emplearon las obras de Flora Ibérica (Castroviejo et al., 19862019) y las Claves ilustradas de la Flora del País Vasco y territorios limítrofes (Aizpuru et al., 1999). Seguimos el criterio nomenclatural de Flora Ibérica para los volúmenes que en la actualidad están publicados y para el resto las claves del País Vasco.

Posteriormente se han actualizado los nombres de las plantas y se han encuadrado en su correspondiente familia de acuerdo a la cuarta aproximación sobre ordenación de los Grupos Filogenéticos de Angiospermas (APG IV, 2016), criterios que se recogen en la base de datos The Plant List (2013).

\subsection{ORGANIZACIÓN DE LOS DATOS}

Una vez finalizada una entrevista y las identificaciones de material botánico vinculadas a la misma, pasamos a transcribir fielmente los datos aportados, sin que transcurra demasiado tiempo para no olvidar detalles importantes. Todos los datos recogidos en el trabajo de campo se registran en una base de datos de Office diseñada por el investigador, de tal manera, que permita mediante consultas poder acceder de un modo rápido a la información y además posibiliten el tratamiento numérico y la cuantificación de los resultados. De este modo la base sirve para el registro textual de información y para el análisis de la misma.

La estructura de la base de datos que se muestra en la tabla 9, se planteó interrelacionando su contenido, a partir de una tabla principal "Recogida de datos" de formato Excel relacionada a su vez con las tablas "Categorías de uso" y "Especies", esta última a su vez vinculada con las tablas "Informantes" y "Comentarios". A medida que se escuchaban las grabaciones se transportaban los datos a los diferentes modelos de tablas

TABLA 9: Estructura de la base de datos.

\begin{tabular}{|c|c|c|}
\hline Tabla & Tipo de tabla & Contenido \\
\hline Recogida datos & Principal & $\begin{array}{l}\text { Nombre científico, familia, nombre vulgar, registros de } \\
\text { uso/categoría, informantes, pliegos herbario, fotos, } \\
\text { videos, índices etnobotánicos }\end{array}$ \\
\hline Categorías de uso & Vinculada principal & $\begin{array}{l}\text { Nombre científico, familia, nombre vulgar, registros de } \\
\text { uso/subcategoría }\end{array}$ \\
\hline Especies & Vinculada principal & $\begin{array}{l}\text { Nombre científico, familia, nombre vulgar, categoría de } \\
\text { uso, subcategoría de uso, vigencia, informantes }\end{array}$ \\
\hline Informantes & Vinculada especies & $\begin{array}{l}\text { Orden entrevista, nombre, apellidos, edad, sexo, } \\
\text { profesión, fecha, número de entrevistas y especies } \\
\text { mencionadas }\end{array}$ \\
\hline Comentarios & Vinculada especies & $\begin{array}{l}\text { Nombre científico, nombre vulgar, informante, categoría } \\
\text { de uso, subcategoría de uso y comentario }\end{array}$ \\
\hline
\end{tabular}

La tabla principal recoge todas las especies citadas en el estudio etnobotánico, su nombre científico, la familia a la que pertenece, los nombres vulgares por los que se reconoce a cada especie, los registros de uso de cada categoría y que informantes han mencionado determinada especie, tal y como muestra la figura 15, también recoge información de los pliegos de herbario, las fotos y videos realizados de cada especie, así como índices: Frecuencia relativa de citación (FRC), Importancia cultural (IC) y Vigencia (IV). 


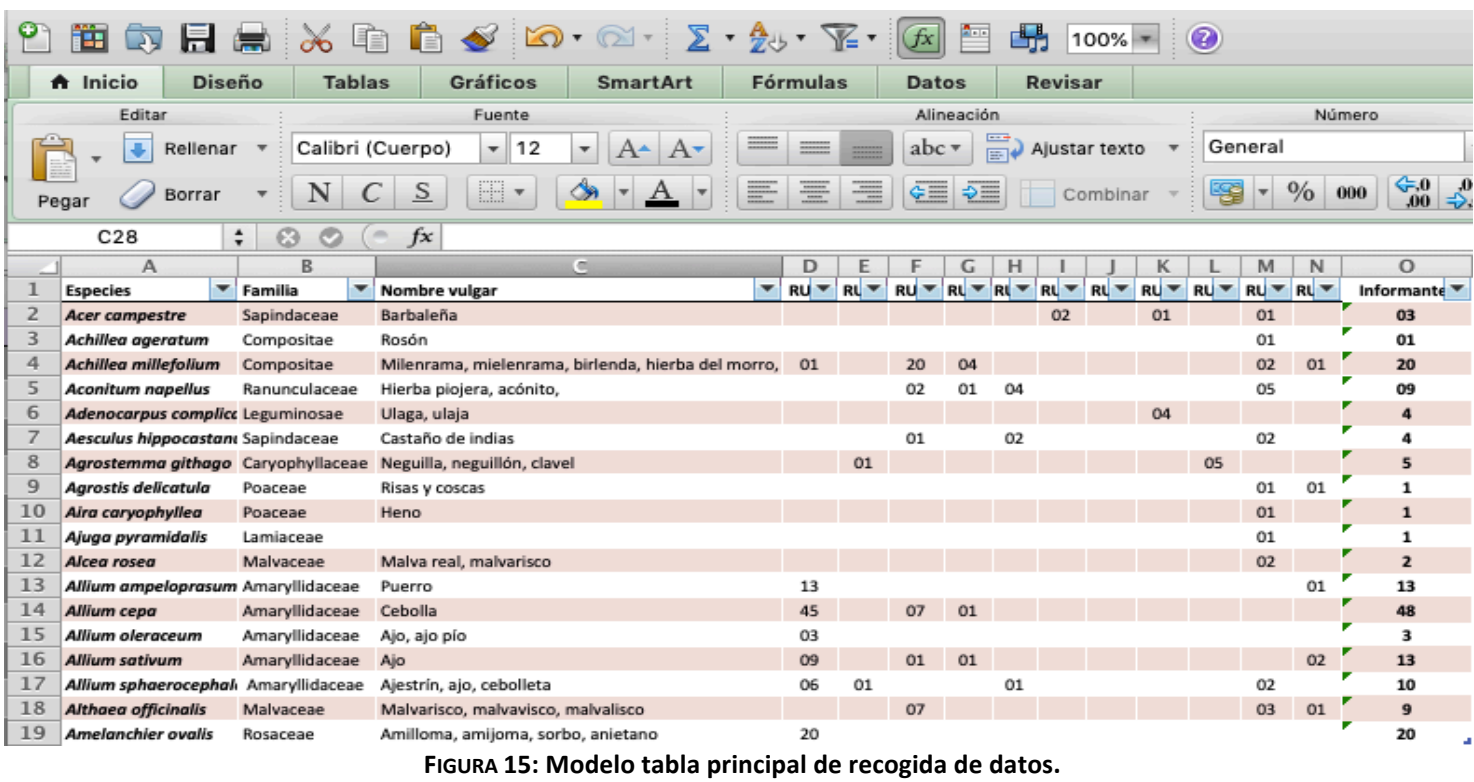

La tabla principal se vincula con cada tabla de las 11 categorías de uso (figura 16), cuyo contenido refleja nombre científico, familia, nombre vulgar, registros de uso de cada especie en cada subcategoría.

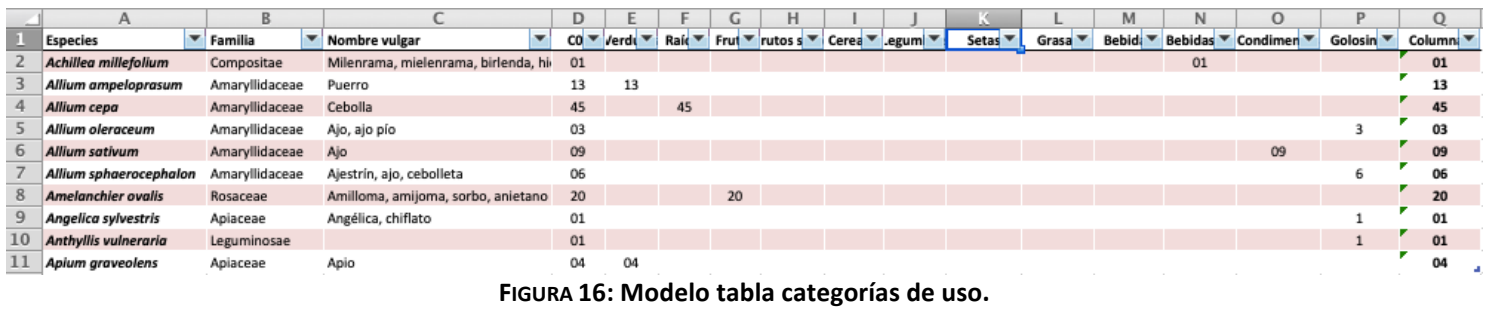

También desde la tabla principal se accede a las tablas de especies (figura 17), cuyo contenido refleja el nombre científico, categorías de uso, vigencia e informantes.

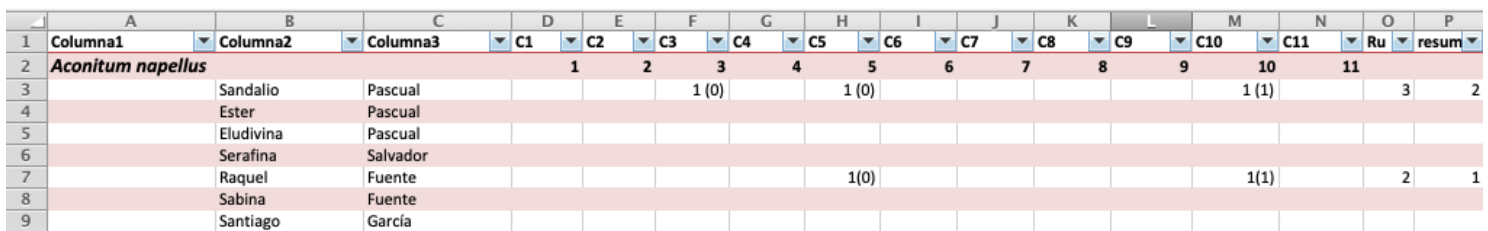

FIGURA 17: Modelo tabla de especies.

Desde la tabla de especies se accede la tabla de informantes (figura 18) que contiene orden de entrevista, nombre, apellidos, edad, sexo, profesión, fecha, número de entrevistas y especies mencionadas,

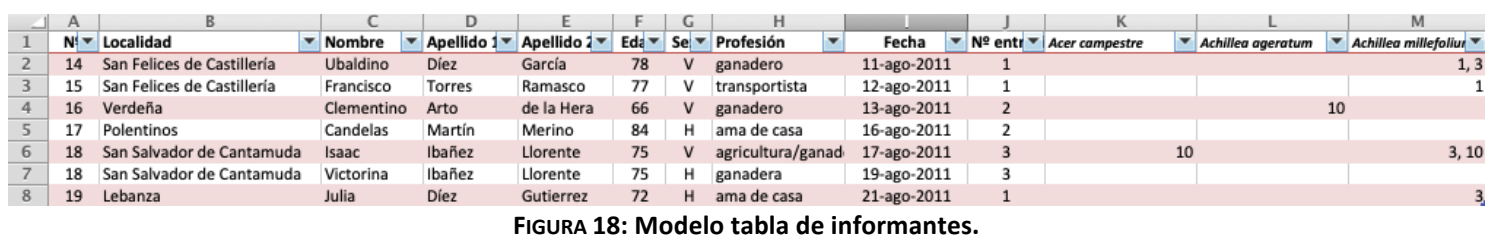


y por último, también desde la tabla de especies se accede a los comentarios o ficha de la especie (figura 19) que contiene la nombre científico, nombre vulgar, informante, categoría de uso, subcategoría de uso y los comentarios tal y como los mencionó el informante.

Aconitum napellus
\[ \begin{array}{l}\text { Acónito }=84 \\ \text { hierba piojera }=01,19,28,129\end{array} \]
Categoría 3. Medicina:
Tóxicas para personas y animales:
01 = la hierba piojera es venenosa, todo el arroyo de Valsurbio estaba lleno, cogíamos la hoja
la hervía, había una familia con piojos y los pegaba en la escuela, nos lavaba la cabeza y
santo remedio, se cría donde hay humedad, se cogía la planta entera a veces sin flor, para
los piojos todo igual sin flor, cortábamos la planta entera y no esperábamos a que secara, la
cocíamos en un puchero después de 10 minutos y lavábamos la cabeza en una palancana y
aparecían los piojos en la palangana.
Categoría 5. Uso Toxico y nocivo:
Tóxicas para personas y animales:
01 = Acónito me parece que era una hierba tóxica. el árnica es toxica, la dedalera y el acónito
$03=$ en la sierra las vacas pacen todo de alrededor pero esta no la comen.
$29=$ por bajo del puente llevaban a pacer los corderos y a veces alguno se moría porque
decían que comían acónito venenoso
$84=$ el acónito es venenoso, aquí lo conocíamos

El manejo de este tipo de tablas plantea la ventaja de poder contrastar gran cantidad de datos cuantitativos y el inconveniente de encontrarnos con muchas tablas y de gran tamaño, frente al empleo de una base de datos de tipo Ms Access que interrelaciona las tablas y facilita la introducción de datos coincidentes en varios campos, pero que maneja de forma menos eficiente los datos numéricos referentes a índices y registros de uso. La elección y elaboración de esta estructura de tablas se justifica además, porque el sistema informático Mac Os con el que opera el investigador no permite la instalación de la base Ms Access, solo válida para el sistema operativo Windows de Microsoft.

\subsection{TRATAMIENTO DE LOS DATOS}

\subsubsection{CRITERIOS DE ACEPTACIÓN Y RECHAZO DE REGISTROS}

Toda la información recogida proviene de los informantes entrevistados y ha servido para elaborar el catalogo etnobotánico, no se ha incluido información de carácter bibliográfica. Antes de la transcripción de una entrevista se han contrastado todos los datos, comprobando el consenso entre las distintas entrevistas realizadas. Los datos dudosos se rechazaron después de confrontarlos con información bibliográfica y comprobar que no existía ninguna coincidencia, los datos incompletos también se rechazaron en el caso de no tener la certeza de que agrupando varios se podían aceptar.

Se aceptaron los registros referentes a especies de obtención silvestre solo en el caso de tener testigos para corroborarlo, muestras con las que posteriormente se elaboró el herbario. Para las especies cultivadas no se siguió este criterio puesto que su identificación es menos problemática. 
Del mismo modo también se aceptaron registros aún cuando el informante no hubiera hecho uso de una especie, pero sí hubiera observado en primera persona su uso o hubiera recibido el conocimiento de una persona muy cercana y de confianza. Un ejemplo, puede ser el caso de informantes que mencionaron como su madre manipulaba especies para tratar alguna enfermedad, y que sin embargo ellos ya nunca más volvieron a utilizar.

Se incluye la información proporcionada por los informantes incluso con una sola referencia, siempre y cuando consideremos que el registro es detallado y el informante de confianza. Este criterio no sigue el adoptado por Johns (1990) que recomienda rechazar los datos proporcionados por menos de tres informantes. El rechazo de este tipo de datos únicos puede derivar en pérdida de información, sobre todo en culturas en claro proceso de abandono de sus costumbres, como es el caso de la Montaña Palentina, considerando que un único registro significa un uso abandonado hace más tiempo. La referencia más insignificante constituye, en ocasiones, la información más valiosa (Mesa, 1996).

\subsection{2. ÍNDICES Y CUANTIFICACIÓN DE LOS DATOS}

La cuantificación de datos en etnobotánica se basa en la utilización de varios índices (Cotton, 2002). Para realizar un análisis detallado se consideran los valores correspondientes a la Frecuencia de Citación (FC), el Número de Usos (NU), el número de Registros de Uso (RU), y los índices de Frecuencia Relativa de Citación (FRC), de Importancia Cultural (IC), de Vigencia (IV) y de Etnobotanicidad (IE). El estudio analiza los dos primeros índices de acuerdo a los criterios de Tardío y Pardo de Santayana (2008), con el propósito de determinar los valores más significativos y la importancia de las especies mencionadas en la zona. También analiza el índice de Vigencia según los criterios de Aceituno Mata (2010) y el índice de etnobotanicidad siguiendo los criterios de Portères (1970).

Los índices correspondientes a Frecuencia Relativa de Citación (FRC), de Importancia Cultural (IC), de Vigencia (IV) se calculan exclusivamente para las especies de obtención silvestre citadas en el estudio. Se justifica la exclusión de las especies cultivadas al comprobar que los datos obtenidos para estas plantas son de dominios culturales diferentes, la recogida de datos para especies de alimentación humana o animal conlleva una metodología diferente, separando en las entrevistas las especies que se obtienen de modo silvestre de las que son cultivadas en huertos o terrenos de laboreo. De este modo se evita el sesgo derivado de la distinta metodología en la recogida de datos.

\section{FRECUENCIA CITACIÓN (FC):}

La Frecuencia de Citación representa el número de informantes que han citado una especie, considerando una cita cualquier información aportada sobre nombres vulgares, usos, manejo o saberes relacionados con esa especie, y contabilizando como un informante al total de personas interrogadas en una entrevista. El número total de informantes en el estudio fue de 139, pudiendo variar el valor desde 0 cuando una especie no es mencionada por ningún informante, hasta 139 en el caso de que fuera mencionada por todos los informantes. 


\section{NÚMERO DE USOS (NU):}

El número de usos representa la cantidad de categorías de uso en la que un taxón ha sido citado. El número total de categorías planteada en el estudio es igual a 11, pudiendo variar el valor desde 0 cuando una especie no es mencionada en ninguna categoría, hasta 11 en el caso de que fuera mencionada en todas ellas.

\section{REGISTROS DE USO (RU):}

En el análisis de los datos se contabilizan los registros de uso (RU), considerando que un registro de uso representa cada referencia hecha por un informante sobre una especie en una categoría de uso concreta.

\section{FRECUENCIA RELATIVA DE CITACIÓN (FRC):}

La Frecuencia Relativa de Citación (FRC) (Tardío \& Pardo de Santayana, 2008) tiene en cuenta número de informantes que citan una especie, en relación al número total de informantes del estudio. Se obtiene dividiendo el número de informantes que han citado una especie (s), conocido también como frecuencia de citación ( $\mathrm{FC}$ ), entre el número total de informantes que participaron en el estudio (N), en nuestro caso 139 informantes. Este índice varía desde 0 cuando nadie considera útil una especie en concreto, hasta 1 en el caso de que todos los informantes mencionaran su uso.

$$
F R C_{s}=\frac{F_{s}}{N}=\frac{\sum_{i=i_{1}}^{i_{N}} R U_{i}}{N}
$$

En la misma terminología, el numerador puede ser visto como el sumatorio de todos los informes de uso (RU) de todos los informantes entrevistados sin la consideración de la categoría de uso.

Este índice no tiene en cuenta la cantidad de usos, ni las categorías en las que se menciona una especie, solamente el número de informantes que citan una especie, en relación al número total de informantes del estudio. Por tanto, este índice varía desde 0 cuando nadie considera útil una especie en concreto, hasta 1 en el caso de que todos los informantes mencionaran su uso.

\section{ÍNDICE DE IMPORTANCIA CULTURAL (IC):}

El índice de Importancia Cultural (IC) (Tardío \& Pardo de Santayana, 2008), se obtiene dividiendo los registros de uso (RU) de una especie (s) dentro de una determinada categoría de uso (u) entre el número total de informantes $(N)$, para a continuación hacer el sumatorio de los cocientes para cada categoría de uso. Se utilizan los registros de uso de las once categorías incluidas en el estudio: alimentación humana, alimentación animal, medicina, veterinaria, 
tóxico y nocivo, combustible, construcción, industria y artesanía, medioambiental, ornamental, y social, simbólico y ritual.

$$
I C_{s}=\frac{\sum_{\mathrm{u}=\mathrm{u}_{1}}^{\mathrm{u}_{\mathrm{NC}}} \sum_{\mathrm{i}=\mathrm{i}_{1}}^{\mathrm{i}_{\mathrm{N}}} \mathrm{RU}_{\mathrm{ui}}}{\mathbf{N}}
$$

No solamente el índice tiene en cuenta el número de informantes que citan el uso de una especie, también denominado expansión del uso, sino también la diversidad de usos y versatilidad de una especie. Los valores entre los que oscila varían desde 0 hasta NC (Número total de categorías), de 0 a 11, alcanzando su valor máximo cuando todos los informantes mencionan a una especie en todas las categorías consideradas.

Si la especie es mencionada en una sola categoría de uso, su valor es igual a la frecuencia relativa de citación (FRC).

\section{ÍNDICE DE VIGENCIA (IV):}

La vigencia de uso de una especie indica si su uso pervive en la actualidad o si bien está abandonado. La determinación de la vigencia no resulta fácil pues hay que considerar la continuidad del uso de cada registro obtenido, unas veces por indicación expresa del informante, otras por el empleo de la forma verbal del pasado en el relato del uso y otras por observación directa. Los datos recogidos se refieren a usos y manejos de plantas silvestres, no a los saberes, esa es la razón de que no aparezca este índice en determinadas especies, este es el caso, por ejemplo, de una especie citada como tóxica. La vigencia de uso se expresa como una parte del valor del índice de Importancia Cultural (IC), ya que es el resultado de la suma de la importancia de los usos vigentes (IV) y de la importancia de los usos no vigentes.

$$
I_{s}=\frac{\sum_{\mathrm{u}=\mathrm{u}_{1}}^{\mathrm{u}_{\mathrm{NC}}} \sum_{\mathrm{i}=\mathrm{i}_{1}}^{\mathrm{i}_{\mathrm{N}}} \mathrm{RU}_{\mathrm{vig}} \mathrm{ui}}{\mathbf{N}}
$$

El índice de Vigencia (IV) fue propuesto por Aceituno Mata (2010), y referido al índice de Importancia Cultural se obtiene dividiendo los registros de uso vigentes $\left(R U_{\text {vig }}\right)$ de una especie (s) dentro de una categoría determinada de uso $(\mathrm{u})$ entre el número total de informantes $(\mathrm{N})$, para a continuación hacer el sumatorio de los cocientes para cada categoría de uso, en nuestro estudio once categorías.

Este índice alcanza su valor máximo cuando todos los informantes mencionan a una especie en todas las categorías consideradas y además consideran que todos sus usos perviven. Los valores entre los que oscila este índice varían desde 0 hasta NC (Número total de categorías), de 0 a 11, considerando que un bajo valor de este índice significa la desaparición del uso de una determinada especie. 


\section{ÍNDICE DE ETNOBOTANICIDAD (IE):}

El índice de etnobotanicidad fue definido por Portères (1970) y se obtiene dividiendo el número de especies silvestres empleadas en un determinado territorio (NS) entre el número total de especies que constituyen la flora del mismo (NTS), expresado en porcentaje.

$$
I E=\frac{\mathrm{NS}}{\mathrm{NTS}} x 100
$$

Este índice permite comparar la riqueza etnobotánica de las distintas regiones y determinar el grado de conocimiento que una sociedad tiene sobre su flora, expresando la riqueza etnobotánica en términos cuantitativos. 


\section{RESULTADOS Y DISCUSIÓN}




\section{RESULTADOS Y DISCUSIÓN}

\subsection{CATALOGO ETNOBOTÁNICO}

Un catálogo etnobotánico se utiliza para inventariar los conocimientos sobre usos y manejos de las plantas en una determinada cultura. Nuestro catálogo consta de un compendio de fichas de los taxones sobre los que se ha recopilado información, y se ha ordenado en grupos vegetales y por familias, dentro de cada familia se han ordenado alfabéticamente los géneros y especies.

El esquema de las fichas del catálogo se muestra a continuación, detallando con posterioridad cada uno de los apartados que lo componen.

FAMILIA

Nombre científico autor

Nombres vulgares (número de citas)

Testimonios: Pliegos de herbario, fotografías, videos

Frecuencia de citación (FC):

Número de usos (NU):

Número informes de uso (RU):

Frecuencia Relativa de Citación (FRC):

Índice de Importancia Cultural (IC):

Índice de Vigencia (IV):

Obtención: silvestre/cultivada/comprada

Vigencia: vigente (\%)/abandonado

Conocimientos:

ECOLOGÍA

LÉXICO

Usos:

CATEGORÍAS DE USO

Subcategorías de uso (número de citas): Descripción

Observaciones:

\section{Nombre científico}

Las fichas fueron ordenadas en grupos vegetales (Pteridófitos, Gimnospermas, Angiospermas monocotiledóneas y Angiospermas dicotiledóneas) y dentro de cada grupos se presentan los registros ordenados alfabéticamente por familia, género y especie. Al final del catálogo se incluye la información sobre el uso tradicional de los hongos.

En general, se detalla hasta el nivel de especie, solo se detalla el nivel subespecie en el caso de Prunus domestica subsp. insitia, y hasta el nivel variedad en los casos de las siguientes especies cultivadas: Beta vulgaris var. altissima, Beta vulgaris var. cicla, Brassica oleracea var. acephala, Brassica oleracea var. botrytis, Brassica oleracea var. capitata, y Brassica oleracea var. gemmifera. 
A destacar que en ocasiones se compila la información sobre varias especies de un mismo género, dado que la taxonomía popular no las diferencia por especies, como es el caso del género Salix, brezos (Erica spp.), pinos (Pinus spp.), robles (Quercus spp.), violetas (Viola spp.) y rosas (Rosa spp.), género para el cual se elaboró una ficha exclusiva de las especies cultivadas. En algunos casos no se puede precisar si las citas se refieren a alguna o a todas las especies del género identificadas.

\section{Nombre vulgar}

Los nombres locales tradicionales se recogen considerando las diferencias de género en los nombres, como ejemplo "acebo" y "aceba", no así las diferencias en número, "garbanzo" o "garbanzos", siempre con nombres en singular. También se han tenido en cuenta las diferencias fonéticas como: acera, ancera, acedera, acidera, acerón. No se ha seguido un criterio de ordenación riguroso, pero si se ha procurado agrupar los nombres vulgares en función de las variantes fonéticas y del número de citas. Entre paréntesis se indica el número de informantes que han citado un determinado nombre.

\section{Testimonios}

Se indica el número de pliego de herbario (PALAB0000) o (000P), dependiendo del lugar de depósito, "PALAB0000" en el área de Botánica, del Campus de Palencia de la Universidad de Valladolid, y "000P" en el herbario personal del investigador, incluyendo al menos un pliego de cada una de las especies silvestres que aparecen en el catálogo. También se indica el número de fotografía "000F" o el de video "000V" realizados para documentar una especie y sus usos.

\section{Tabla de datos cuantitativos}

La tabla presenta de forma clara los datos referentes a:

- Frecuencia de citación (FC): número de informantes que han citado un taxón.

- Número de usos (NU): número de categorías de uso en la que un taxón ha sido citado.

- Registro de uso (RU): cada una de las referencias hechas por un informante sobre un taxón en una categoría de uso.

- Frecuencia Relativa de citación (FRC): es el índice obtenido dividiendo la frecuencia de citación entre el número total de informantes que participaron en el estudio.

- Importancia Cultural (IC): es el número registros de uso de un taxón, en una determinada categoría de uso, entre el número total de informantes entrevistados.

- Índice de Vigencia (IV): es el número registros de uso vigentes de un taxón, en una categoría de uso, entre el número total de informantes entrevistados.

La Frecuencia relativa de citación, el índice de Importancia cultural y el índice de Vigencia solo se han calculado para las especies silvestres, y solo se ha evaluado para usos y no para conocimientos (como por ejemplo el conocimiento de la toxicidad de ciertas especies).

\section{Modo de obtención}

Se señalan los tres posibles métodos de obtención: silvestre, cultivada o comprada.

\section{Vigencia}

Recoge la información referente a la vigencia de uso de un registro, expresada en porcentaje, en el caso de que el porcentaje sea cero se señala como uso abandonado. 


\section{Ecología}

Se indican datos sobre hábitat o ecología aportados por los informantes, como por ejemplo el lugar donde se desarrolla una determinada especie.

\section{Léxico}

Explicaciones y observaciones en torno a los nombres vulgares recogidos.

\section{Usos}

La información recogida es exclusivamente aportada por los informantes entrevistados en el trabajo de campo sobre usos y conocimientos, modos de aplicación, partes utilizadas, época de recolección, etc. La información se clasificó según las categorías y subcategorías de uso establecidas en el Inventario Español de los Conocimientos Tradicionales relativos a la Biodiversidad (Pardo de Santayana et al., 2014). Con letra cursiva y entrecomillado se señalan transcripciones literales de los informantes. Entre paréntesis se indica el número de registros de uso que obtiene cada subcategoría o información de segundo nivel.

\section{Observaciones}

Las fichas se completan, en ocasiones, con comentarios, notas de interés y datos obtenidos por el entrevistador, que amplían la información general de la ficha. 


\section{PTERIDOFITOS}

ASPLENIACEAE

\section{Asplenium trichomanes $\mathrm{L}$.}

Golondrillo (1), golondrino (1)

236P, 486P; 371V

\begin{tabular}{lc|}
\hline Frecuencia de citación (FC): & 2 \\
\hline Número de usos (NU): & 1 \\
\hline Número registros de uso (RU): & 2 \\
\hline Frecuencia Relativa de Citación (FRC): & $\mathbf{0 , 0 1}$ \\
\hline Índice de Importancia Cultural (IC): & $\mathbf{0 , 0 1}$ \\
\hline Índice de Vigencia (IV): & $\mathbf{0 , 0 0}$ \\
\hline
\end{tabular}

Obtención: silvestre

Vigencia: abandonado

Conocimientos:

ECOLOGÍA

Se encuentra en lugares sombríos y rocosos, según los testimonios recogidos "Se cría en cuevas, en paredes que estén oscuras y entre las peñas. Es muy parecido al halecho pero más menudo, no da flores, solo hojucas pequeñas".

Usos:

\section{VETERINARIA}

- Concepción, embarazo y parto (1): El liquido resultante de la cocción de las frondes, se utilizaba en San Martín de Perapertú para adminístraselo a las vacas recién paridas, ya que resultaba un buen remedio para ayudar a eliminar la placenta tras el parto.

- Sistema respiratorio (1): En Villanueva de la Torre emplean las frondes de esta planta para el tratamiento de las congestiones del ganado vacuno, mediante una cocción en agua que posteriormente se daba a beber con una botella, en ocasiones se añadían a la mezcla agayugas (fruto de Arctostaphylos uva-ursi) para potenciar el efecto curativo.

Observaciones: Es posible que también se recolectara para el mismo uso la especie Asplenium viride con un aspecto similar y presente en la zona de estudio. En la zona de Campoo se emplea el escolondrillo, Asplenium ruta-muraria para vaciar la placenta de las vacas tras el parto (Pardo de Santayana, 2008).

\section{CYSTOPTERIDACEAE}

Cystopteris fragilis (L.) Bernh.

Helecho (1)

335P; 183F; 399V

\begin{tabular}{lc}
\hline Frecuencia de citación (FC): & 1 \\
\hline Número de usos (UN): & 1 \\
\hline Número registros de uso (RU): & 1 \\
\hline Frecuencia Relativa de Citación (FRC): & 0.01 \\
\hline Índice de Importancia Cultural (IC): & 0,01 \\
\hline Índice de Vigencia (IV): & 0,00 \\
\hline
\end{tabular}

Obtención: silvestre

Vigencia: abandonado

\section{Conocimientos:}

\section{ECOLOGÍA}

Aparecen en el entorno de paredes umbrosas. "Siguen como el estilo del musgo y se dan por los muros de piedra. Son raquíticos y pequeños".

Usos:

ORNAMENTAL

- Adornos florales y plantas de interior (1): Se empleaban las frondes en Valcobero como arreglo floral decorativo para el hogar en algún florero, como base o relleno de flor cortada. "Gustaba llevarlos de verde para florero y acompañar a alguna rosa".

\section{DENNSTAEDTIACEAE}

Pteridium aquilinum (L.) Kuhn

Helecho (49), halecho (21)

27P, 131P; 30F; 60V, 169V, 170V, 432V

\begin{tabular}{lc} 
Frecuencia de citación (FC): & 70 \\
Número de usos (UN): & 6 \\
\hline Número registros de uso (RU): & 82 \\
Frecuencia Relativa de Citación (FRC): & 0,50 \\
Índice de Importancia Cultural (IC): & 0,59 \\
Índice de Vigencia (IV): & 0,00
\end{tabular}

Obtención: silvestre

Vigencia: abandonado

Conocimientos:

ECOLOGÍA

La presencia de helechos indica a los lugareños prados pobres, descuidados y de poco interés agrícola.

\section{LÉXICO:}

Encontramos como fitotopónimo el pago "Helechar" en el término de Gramedo y el "Paraje Helechar" en Barruelo de Santullán.

Usos:

COMBUSTIBLE

- Para chamuscar (10): Para quemar los pelos o serdas del cerdo se usaban frondes de helechos, dejaban la piel más dorada y con 
mejor sabor que otras técnicas más modernas, "Al quemarlos con el soplete sabe a medicina". En La Lastra señalan que al haber abandonado el cultivo del centeno, se inclinaban por esta especie.

\section{CONSTRUCCIÓN}

- Casas, edificios e instalaciones agropecuarias (49): En las techumbres de las viviendas principales o de instalaciones secundarias como cuadras, pajares, chozos o tenadas, se empleaban las frondes como cama para asentar las tejas sobre la ripia. En el argot local se conoce como "mullía o mullida" de la teja, y aunque era una práctica muy común en toda la comarca, se señala como inconveniente que se trituran y se pulverizan con facilidad.

\section{INDUSTRIA Y ARTESANÍA}

- Herramientas y utensilios (6): Con las frondes verdes de helechos se elaboraban escobas vegetales para solventar la necesidad de retirar las brasas y cenizas del horno, de este modo al introducir los panes no se manchan, ni se queman. En ocasiones se mojaba previamente en agua para que no se incendiaran.

\section{MEDIOAMBIENTAL}

- Mejora del suelo (10): La planta servía para extender por el cubil del cerdo como mullida y cama, también se ha citado como cama del ganado vacuno. La mezcla del excremento animal con la cama vegetal proporcionaba abono destinado a los cultivos.

- Malas hierbas (2): El helecho es considerado como una mala hierba, el carácter invasor de sus rizomas lo convierte en objetivo para erradicar en los prados de siega y en las tierras de cultivo.

\section{ORNAMENTAL}

- Adorno floral y plantas de interior (2): Las frondes se utilizan como acompañamiento en centros ornamentales de flor seca para engalanar alguna estancia en las viviendas.

\section{SOCIAL, SIMBÓLICO Y RITUAL}

- Ritual de ciclo anual (2): Para decorar como fondo verde en alguna fiesta religiosa o patronal, por ejemplo en Resoba se adornan con helechos las carrozas que desfilan en Cervera de Pisuerga en la festividad de San Cristóbal.

- Literatura popular (1): En San Salvador de Cantamuda se recoge el dicho "Tierra de helecho, tierra de poco provecho", en alusión a la mala calidad de los terrenos donde aparece esta especie.

\section{DRYOPTERIDACEAE}

Dryopteris affinis Fraser-Jenk.

D. filix-mas (L.) Schott

Helecha (2), helecho (2)

D. affinis: 81P, 318P; 137F; 229V, 403V, 553V

D. filix-max: $378 \mathrm{P}$

\begin{tabular}{lc}
\hline Frecuencia de citación (FC): & 4 \\
\hline Número de usos (UN): & 2 \\
\hline Número registros de uso (RU): & 4 \\
\hline Frecuencia Relativa de Citación (FRC): & 0,03 \\
\hline Índice de Importancia Cultural (IC): & 0,03 \\
\hline Índice de Vigencia (IV): & 0,02 \\
\hline
\end{tabular}

Obtención: silvestre

Vigencia: vigente (75\%)

Conocimientos:

ECOLOGÍA

Crece en terrenos húmedos, orillas de río y calares umbrías. "La helecha siempre sale en sitios con mucha sombra".

\section{LÉXICO:}

El nombre genérico de helecha se emplea en la zona para denominar a los helechos cuyas frondes presentan pinnas desde abajo sin diferenciar un peciolo, diferente al caso del helecho común Pteridium aquilinum. "La helecha es individual, diferente al helecho".

\section{Usos: \\ CONSTRUCCIÓN}

- Casas, edificios e instalaciones agropecuarias (1): Al igual que el helecho más común (Pteridium aquilinum) las frondes servían como cama para asentar las tejas en diferentes construcciones. "Se traía un carro de helechos para hacer el tejado cuando se hacía una casa nueva en La Lastra".

\section{ORNAMENTAL}

- Patios, huertos y jardines (1): Se ha señalado su uso decorativo en Villanueva de la Torre, en patios por la vistosidad de sus frondes. "Este helecho lo traje del monte porque me gusta, lo pelo todos los años y vuelve a echar".

- Adornos florales y plantas de interior (2): Utilizada como acompañamiento en arreglos florales en el interior de las casas, con fines decorativos. "Siempre he tenido la helecha como cosa decorativa, es fina y decorativa. 
Cuando era joven y cogía flores, metía un poco de helecha en el florero".

Observaciones: Entre las especies testimoniadas con el nombre de helecha encontramos: Dryopteris affinis, D. filix-mas y Botrychium lunaria, la última mencionada pero sin uso reconocido.

EQUISETACEAE

Equisetum arvense $\mathrm{L}$.

Cola de caballo (18), pinillo (5), escobilla (4)

56P, 134P; 166F; 110V, 155V, 573V

\begin{tabular}{lc}
\hline Frecuencia de citación (FC): & 31 \\
\hline Número de usos (UN): & 3 \\
\hline Número registros de uso (RU): & 33 \\
\hline Frecuencia Relativa de Citación (FRC): & 0,22 \\
\hline Índice de Importancia Cultural (IC): & 0,24 \\
\hline Índice de Vigencia (IV): & 0,05 \\
\hline
\end{tabular}

Obtención: silvestre

Vigencia: vigente (20\%)

\section{Conocimientos:}

\section{ECOLOGÍA}

Frecuente en terrenos húmedos y ricos en nutrientes, "Hay mucho a la orilla del pantano y cerca de las fuentes", "Abunda en los huertos y en las tierras removidas de patatas".

\section{LÉXICO:}

Los nombres comunes escobilla y pinillo se derivan del aspecto morfológico de la planta y se han mencionado con mayor frecuencia como malas hierbas, mientras que el nombre de cola de caballo se asocia al de planta medicinal.

Usos:

ALIMENTACIÓN ANIMAL

- Pasto (1): Afirman en Roscales de la Peña que se trata de una planta apetecida por las yeguas y los burros.

\section{MEDICINA}

- Sistema circulatorio (7): La cocción en agua de la parte aérea se recomienda para el tratamiento de diferentes problemas circulatorios, así como para purificar la sangre. En Camasobres se señala la adicción de ortigas en la cocción para reunir las cualidades beneficiosas de las dos plantas.

- Sistema genito-urinario (14): En forma de infusión se menciona el uso para afecciones derivadas de la próstata, y para las infecciones vaginales se realizaban lavados con una cocción tibia.

- Musculatura y esqueleto (3): Para atenuar dolores reumáticos se toma la infusión de la parte aérea.

- Otros usos medicinales (2): Sola o mezclada con otras plantas se emplea como sanalotodo, siendo considerada una planta panacea.

\section{MEDIOAMBIENTAL}

- Malas hierbas (6): Es una planta perjudicial al invadir los cultivos en los huertos $\mathrm{y}$ en las mejores tierras de labor.

Observaciones: Es probable que se englobe a otras especies del mismo genero con el mismo nombre común en la zona, como Equisetum fluviatile o E. palustre.

\section{OPHIOGLOSSACEAE}

\section{Botrychium lunaria (L.) Sw.}

Helecha (1)

425P

\begin{tabular}{|ll}
\hline Frecuencia de citación (FC): & 1 \\
\hline Número de usos (UN): & 0 \\
\hline Número registros de uso (RU): & 0 \\
\hline
\end{tabular}

\section{Conocimientos:}

\section{ECOLOGÍA}

"Suelen salir entre la roca o la caliza, la hoja es como un helecho pequeño, pero da como una mazorca" (Alba de los Cardaños).

\section{GIMNOSPERMAS}

CUPRESSACEAE

Chamaecyparis lawsoniana (A.Murray bis) Parl.

\begin{tabular}{ll|}
\hline Frecuencia de citación (FC): & 1 \\
\hline Número de usos (UN): & 1 \\
\hline Número registros de uso (RU): & 1 \\
\hline
\end{tabular}

Obtención: cultivada

Vigencia: vigente (100\%)

Usos:

ORNAMENTAL

- Patios, huertos y jardines (1): Se cultiva en las últimas décadas como arbusto ornamental de jardín. 
Juniperus communis $\mathrm{L}$.

Enebro (7), corveño (3)

177P, 358P; 207F; 161V

\begin{tabular}{lc}
\hline Frecuencia de citación (FC): & 8 \\
\hline Número de usos (UN): & 4 \\
\hline Número registros de uso (RU): & 10 \\
\hline Frecuencia Relativa de Citación (FRC): & $\mathbf{0 , 0 6}$ \\
\hline Índice de Importancia Cultural (IC): & $\mathbf{0 , 0 7}$ \\
\hline Índice de Vigencia (IV): & $\mathbf{0 , 0 0}$ \\
\hline
\end{tabular}

Obtención: silvestre

Vigencia: abandonado

Conocimientos:

ECOLOGÍA

Se desarrollan en calares y roquedos, formando extensos mantos postrados.

\section{Usos:}

\section{COMBUSTIBLE}

- Leña (1): La madera se cortaba para usar la leña en la lumbre. En Traspeña de la Peña emplean esta madera para cocer las morcillas, tras la matanza del cerdo.

- Para ahumar (1): En Villanueva de Arriba la resina que segregan las ramas se utiliza, una vez seco y reducido a polvo, a modo de incienso para quemar en alguna ceremonia religiosa, al quemarlo desprende un agradable olor

\section{INDUSTRIA Y ARTESANÍA}

- Herramientas y utensilios (2): La madera posee una gran dureza y resistencia, útil para la fabricación de pequeños objetos como cucharas.

- Vestimenta y adornos personales (1): La madera es apreciada para las machorras de las albarcas.

\section{SOCIAL, SIMBÓLICO Y RITUAL}

- Ritual de ciclo anual (4): En algunas localidades las enramadas anuales se hacen con ramas de corveño, preferido por su mayor duración.

- Uso recreativo (1): Los niños en Santibáñez de la Peña jugaban a saltar sobre ellos semejando camas elásticas.

\section{CUPRESSACEAE}

\section{Juniperus sabina $\mathrm{L}$.} Corveño (4)

76P; 39F; 233V

\begin{tabular}{lc}
\hline Frecuencia de citación (FC): & 4 \\
\hline Número de usos (UN): & 3 \\
\hline Número registros de uso (RU): & 6 \\
\hline Frecuencia Relativa de Citación (FRC): & $\mathbf{0 , 0 3}$ \\
\hline Índice de Importancia Cultural (IC): & $\mathbf{0 , 0 4}$ \\
\hline Índice de Vigencia (IV): & $\mathbf{0 , 0 0}$ \\
\hline
\end{tabular}

Obtención: silvestre

Vigencia: abandonado

\section{LÉXICO:}

En Camporredondo aparece el fitotopónimo del pago "Corveñera".

Usos:

COMBUSTIBLE

- Leña (2): Su madera no se solía quemar en la lumbre del hogar, era más habitual quemarla en hogueras en el campo, aunque el mismo informante desaconsejaba su uso porque saltan muchas chispas cuando arde.

- Para ahumar (1): El humo producido por la madera quemada se utilizaba en Vidrieros para ahumar a las abejas en las colmenas, de este modo se atontaban, abandonaban el panal y se podía extraer la miel.

- Luz (1): Los palos secos llamados teos se utilizaban en el pasado como antorcha para iluminar alguna estancia.

\section{MEDIOAMBIENTAL}

- Malas hierbas (1): Cuando invadían algún prado, en Vidrieros se les quemaba para que no se redujese la superficie del pasto.

\section{SOCIAL, SIMBÓLICO Y RITUAL}

- Ritual de ciclo anual (1): Con las ramas verdes se hacían enramadas para las fiestas locales más señaladas.

PINACEAE

Cedrus libani A.Rich.

Cedro de los Orioles (1)

$126 \mathrm{~F}$

\begin{tabular}{ll}
\hline Frecuencia de citación (FC): & 1 \\
Número de usos (UN): & 1 \\
Número registros de uso (RU): & 1 \\
\hline
\end{tabular}

Usos:

SOCIAL, SIMBÓLICO Y RITUAL

- Árboles singulares (1): En una finca particular de Vallejo de Orbó se puede admirar la presencia de un cedro excepcional por la gran dimensión que alcanza su copa. 
Observaciones: En la zona se conoce este famoso árbol de unos $25 \mathrm{~m}$ de altura, como cedro de los Orioles, familia a la que perteneció. Sobrevivió al impacto de un obús durante la Guerra Civil y se encuentra incluido en el catalogo de Árboles Singulares de Castilla y León.

PINACEAE

Pinus nigra Fraser-Jenk.

\section{$P$. sylvestris L.}

Pino (36)

P. nigra: 41P; $165 \mathrm{~F}$

P. sylvestris: $153 \mathrm{P}, 174 \mathrm{~F}$

\begin{tabular}{lc}
\hline Frecuencia de citación (FC): & 36 \\
\hline Número de usos (UN): & 4 \\
\hline Número registros de uso (RU): & 44 \\
\hline Frecuencia Relativa de Citación (FRC): & $\mathbf{0 , 2 6}$ \\
\hline Índice de Importancia Cultural (IC): & $\mathbf{0 , 3 2}$ \\
\hline Índice de Vigencia (IV): & $\mathbf{0 , 0 5}$ \\
\hline
\end{tabular}

Obtención: cultivada y comprada (madera).

Vigencia: vigente (16\%)

Usos:

\section{COMBUSTIBLE}

- Encendido (1): Las piñas se recogen para realizar el encendido de la hornacha, además el tamaño de la piña es pequeña y solo en unas pocas ocasiones sustituye a las escobas, preferidas por su fácil obtención.

\section{CONSTRUCCIÓN}

- Infraestructuras (10): La madera de pino se empleaba en las minas de la zona y era junto a la de eucalipto de las más demandadas para la entibación, procedía de otras provincias. Las rampas o ramplas se construían con tabla de pino, además según varios informantes las propiedades de la madera del pino son especiales para el posteo, "Si la mina se hunde al apretar el pino te avisa, otras maderas no".

\section{MEDIOAMBIENTAL}

- Mejora del suelo (14): En diversas localidades se hicieron repoblaciones con pino en terrenos poco productivos o de gran pendiente. Varios informantes participaron como mano de obra de estas repoblaciones que datan de mediados del siglo pasado, en Camporredondo recuerdan como "En el pinar pagaban 16 pesetas para hacer pistas y poner pinos, sin maquinaria, hacíamos a tanto céntimo cada hoyo".

\section{SOCIAL, SIMBÓLICO Y RITUAL}

- Ritual de ciclo anual (18): Una de las tradiciones más arraigadas el primer día de mayo, fue el pinado del mayo, también establecido en acontecimientos solemnes extraordinarios, como la ordenación de un sacerdote o alguna fiesta patronal. Los mozos ojeaban previamente el árbol más apropiado, lo cortaban, lo desmochaban y transportaban hasta el lugar donde finalmente se levantaba, preparado para ser trepado por cualquier mozo que insistiera en conseguir tal hazaña. Se coronan con algún premio como dulces, frutas o algo de dinero. De este modo lo recuerdan en Velilla del Río Carrión "el primero de mayo era una de las fiestas mayores, la sociedad de mozos ya días antes iba a revisar el pino autóctono más grande que hubiera, según se va a Valcobero es un pino natural autóctono que va de la Colonia del Brezo hasta la Ermita de Cristo Sierra, es natural y de aquí se traía el pino con vacas, se ponía en la plaza del pueblo, se limpiaba y se pinaba, después se vendía el pino y se sacaba para las comidas de hermandad".

Las ramas de pino se han utilizado para ser bendecidas por el cura durante la festividad del Domingo de Ramos, en algunas localidades ha sustituido al acebo cuando en el año 1991 se reguló su aprovechamiento. La rama bendecida permanecía el resto del año en la cuadra como símbolo de buena suerte.

Ramos de pino grandes se empleaban para decorar las portadas de las casas como agasajo a las mozas del pueblo en la víspera del primer domingo de mayo.

- Árboles singulares (1): En Vallejo de Orbó también se puede contemplar un pino de porte recto admirable que supera los $30 \mathrm{~m}$ de altura, conocido como el Pino de Don Luis y que se encuentra incluido en el catalogo de Árboles Singulares de Castilla y León, como Pinus pinaster subsp. salzmannii.

Observaciones: Los datos de las dos especies se encuentran agrupados al no poder determinar exactamente a cual de ellas se han referido los informantes.

Se han recogido quejas respecto a las repoblaciones realizadas, fueron polémicas dado que los pinares restaban terreno útil para el pasto.

La madera de pino no es apreciada porque la resina que desprende se adhiere en la chimenea y la obstruye.

En Velilla del Río Carrión existe un pinar centenario autóctono único en la Montaña Palentina. 
La procesionaria (Thaumetopoea pityocampa) daña a los pinos provocando una defoliación intensa en los árboles, en Aguilar de Campoo aseguran que "Hay pinos que se están secando por una enfermedad, hay dos tipos de pino uno el que coge la enfermedad y otro no".

TAXACEAE

Taxus baccata L.

Tejo (38)

PALAB1982, 82P, 531P; 71F; 332V, 333V, 544V

\begin{tabular}{lc}
\hline Frecuencia de citación (FC): & 38 \\
\hline Número de usos (UN): & 5 \\
\hline Número registros de uso (RU): & 64 \\
\hline Frecuencia Relativa de Citación (FRC): & $\mathbf{0 , 2 7}$ \\
\hline Índice de Importancia Cultural (IC): & $\mathbf{0 , 4 6}$ \\
\hline Índice de Vigencia (IV): & $\mathbf{0 , 0 4}$ \\
\hline
\end{tabular}

Obtención: silvestre

Vigencia: vigente (9\%)

\section{Conocimientos:}

\section{LÉXICO}

En Lebanza aparece como fitotopónimo el pago "Los Tejos", en Resoba "El Tejo Bajero", y en el Valle de los Redondos "El Tejo la Peña".

\section{Usos:}

\section{ALIMENTACIÓN HUMANA}

- Frutas y frutos dulces (2): La envoltura roja carnosa (arilo) que recubre la semilla es comestible, es la única parte de la planta que no resulta tóxica. Esa cubierta carnosa posee un sabor dulce y textura algo viscosa. En San Juan de Redondo se indica que "la carne del tejo eso está divino, cuando están maduros, se quita la piel y la pepita del fruto y la carne está muy rica".

\section{TÓXICO Y NOCIVO}

- Tóxico para humanos y animales (8): Es venenosa para personas y para animales, aunque no a todos ellos afecta de igual modo.. En las localidades con presencia de tejo se reconoce su toxicidad y se manifiesta de forma habitual con esta expresión "Dicen que es venenoso".

\section{CONSTRUCCIÓN}

- Casas, edificios e instalaciones agropecuarias (1): La madera de tejo es valorada por su dureza y resistencia, empleada ocasionalmente como material estructural en viviendas.

\section{INDUSTRIA Y ARTESANÍA}

- Herramientas y utensilios (4): La madera de tejo es rojiza, de buena calidad, densa, muy dura y apreciada para la talla y para algún utensilio necesitado de estas propiedades. Se han recogido en la comarca testimonios sobre elaboración de pipas para fumar, cucharas, carracas, mangos de herramientas, e incluso herramientas como el rodillo para extraer el abono o las brasas del horno.

\section{ORNAMENTAL}

- Patios, huertos y jardines (5): Se ha cultivado como ornamento en jardines y a la entrada de casas e iglesias. Es un árbol decorativo que soporta bien la poda y puede formar fácilmente setos. Se señala su cultivo a partir de esquejes obtenidos de ejemplares ubicados en el monte.

\section{SOCIAL, SIMBÓLICO Y RITUAL}

- Ritual de ciclo anual (28): En la festividad del Domingo de Ramos, el ramo bendecido por el sacerdote solía ser de tejo. En algunos pueblos donde no aparece este árbol, los mozos recorrían largas distancias para cortar lo suficiente y de esta manera abastecer a todos los vecinos de la localidad. Tras la bendición del ramo en esta festividad, se conservaba hasta el año siguiente en alguna estancia de la vivienda, pues se consideraba protector de la casa y símbolo de buena suerte.

Las ramas de tejo también se usaron en festividades locales como elemento decorativo en las tradicionales enramadas y en otras fiestas religiosas como el Corpus Christi o la Navidad.

- Ritual de ciclo de vida (11): El ramo de tejo se empleaba para coronar y engalanar el tradicional mayo alzado en caso de celebración de un cantamisas. También servía de ornamento el día de la boda sobre la puerta de la casa de la novia.

- Ritual de incertidumbre, protección y aflicción (1): En la localidad de Lebanza se recuerda como con la rama bendecida el Domingo de Ramos se recorría todas las estancias de la vivienda para eliminar el mal de ojo y que durante todo el año la buena suerte estuviera presente en el núcleo familiar.

- Literatura oral popular (1): En Rebanal de las Llantas se recoge el dicho: "Debajo de tu ventana un tejo plantado vi, nadie daba con el tejo y yo con el tejo di". Al parecer forma parte de alguna estrofa de un cantico popular o rabelada (pequeña copla de carácter pícaro y jocoso), en ella se hace referencia al ramo de tejo que se colocaba en la clave de la enramada hecha en la casa de la novia el día de la boda. 
- Árboles singulares (3): Varios informantes de localidades próximas a la Tejeda de Tosande señalaron la popularidad y peculiaridad de varios ejemplares de este bosque.

Observaciones: En la singular Tejeda de Tosande ubicada en el término de Dehesa de Montejo se encuentran 3 ejemplares catalogados como especies singulares de Castilla y León, destacando por su porte y longevidad. Además, la Tejeda es excepcional por el gran número de ejemplares que se conservan, ya que por lo general en la Montaña Palentina se encuentran dispersos y son escasos.

\section{ANGIOSPERMAS MONOCOTILEDÓNEAS}

AMARYLLIDACEAE

\section{Allium ampeloprasum L.}

Puerro (13)

\begin{tabular}{|c|c|}
\hline Frecuencia de citación (FC): & 13 \\
\hline Número de usos (NU): & 2 \\
\hline Número registros de uso (RU): & 14 \\
\hline
\end{tabular}

Obtención: cultivada

Vigencia: vigente (100\%)

Usos:

\section{ALIMENTACIÓN HUMANA}

- Verduras y hortalizas (13): Las hojas enterradas blancas se emplean en sopas $y$ cocidos.

\section{SOCIAL, SIMBÓLICO Y RITUAL}

- Literatura oral popular (1): En Verdeña nos citan el refrán "Por San Pedro saca tu ajo y siembra tu puerro", aludiendo a la fecha idónea de siembra.

AMARYLLIDACEAE

\section{Allium cepa $\mathrm{L}$.}

Cebolla (48)

$80 \mathrm{~F}$

\begin{tabular}{lc}
\hline Frecuencia de citación (FC): & 48 \\
\hline Número de usos (NU): & 5 \\
\hline Número registros de uso (RU): & 53 \\
\hline
\end{tabular}

Obtención: cultivada

Vigencia: vigente (88\%)

\section{Conocimientos:}

\section{LÉXICO:}

Cuando la cebolla se utiliza en crudo cambia su nombre por el de cebolleta. Las hojas carnosas del bulbo se denominan cascos.

\section{Usos:}

\section{ALIMENTACIÓN HUMANA}

- Raíces, bulbos, tubérculos y rizomas (45): Forma parte del huerto tradicional y es un ingrediente fundamental que nunca falta en la cocina, se emplea en multitud de guisos, para la elaboración de las típicas morcillas y cruda en ensaladas o sola simplemente con pan.

\section{MEDICINA}

- Sistema respiratorio (2): Para curar el catarro y para aliviar la tos se toma el cocimiento de cebolla, manzana y limón, endulzado con un requemado de azúcar.

- Piel y tejido celular subcutáneo (5): Los cascos de la cebolla se asan o fríen con un poco de aceite al calor de la lumbre para que ablanden y se aplican directamente o mediante cataplasma sobre diviesos o forúnculos, también sobre heridas infectadas que supuren pus, calma el dolor y desinfecta. En Salinas de Pisuerga encima de la cebolla se ponía un poco de tocino y se cubría con una venda.

\section{VETERINARIO}

- Sistema digestivo (1): Para purgar a las vacas en San Martín de Perapertú se daba a beber la mezcla de cebollas podridas cocidas con manzanilla de lastra. "Cuando picaban los tábanos, las vacas corrían y corrían, cogían sed y bebían frío, y luego cagaban como sangre, para purgarlas era este el remedio".

Observaciones: Existen muchas variedades de cebolla y desde hace años los hortelanos no conservan la semilla de un año para otro. Lo que sí hemos podido distinguir son dos tipos de cebolla, una más fina y poco picante válida para ensaladas de verano y otra más carnosa y jugosa para guisos y matanzas, que según un informante de Santa María de Nava se trata de la variedad Horcal.

\section{Allium oleraceum L.} Ajo (1), ajo pío (2) 


\begin{tabular}{lc}
\hline Frecuencia de citación (FC): & 3 \\
\hline Número de usos (NU): & 1 \\
\hline Número registros de uso (RU): & 3 \\
\hline Frecuencia Relativa de Citación (FRC): & $\mathbf{0 , 0 2}$ \\
\hline Índice de Importancia Cultural (IC): & $\mathbf{0 , 0 2}$ \\
\hline Índice de Vigencia (IV): & $\mathbf{0 , 0 0}$ \\
\hline
\end{tabular}

Obtención: silvestre

Vigencia: abandonado

Usos:

\section{ALIMENTACIÓN HUMANA}

- Golosinas y masticatorias (3): Se come el bulbo en fresco directamente en el campo, con un sabor a ajo muy intenso.

AMARYLLIDACEAE

\section{Allium sativum $\mathrm{L}$. \\ Ajo (13)}

\begin{tabular}{lc}
\hline Frecuencia de citación (FC): & 13 \\
\hline Número de usos (NU): & 4 \\
\hline Número registros de uso (RU): & 13 \\
\hline
\end{tabular}

Obtención: cultivada

Vigencia: vigente (83\%)

Usos:

\section{ALIMENTACIÓN HUMANA}

- Condimentos y conservantes (9): Se trata de otro ingrediente básico en cualquier cocina de la comarca, empleado para dar sabor a sopas, guisos, cocidos y matanzas.

\section{MEDICINA}

- Sistema respiratorio (1): Para mejorar los síntomas de la bronquitis y descongestionar, se toman vahos de la siguiente mezcla: ajo, eucalipto, orégano y tomillo.

\section{VETERINARIO}

- Enfermedades "culturales" (1): En Salcedillo explican como curar a las vacas que "se toman" (enfermedad del ganado vacuno bien conocida por los ganaderos cuyos síntomas eran nerviosismo, rabia, ansiedad e hinchazón), quemando las trenzas de las ristras de ajos en un puchero con brasas y ahumando por el vientre y por el morro al animal.

\section{SOCIAL, SIMBÓLICO Y RITUAL}

- Ritual de incertidumbre, protección y aflicción (1): Las ristras de los ajos se colocaban en alguna estancia de la casa en Barruelo de Santullán, ya que de este modo se evitaba el mal de ojo y ejercía de elemento protector contra las brujas.

- Literatura oral popular (1): La época idónea de recolección del ajo se señala en el siguiente dicho popular "Por San Pedro saca tu ajo y siembra tu puerro".

AMARYLLIDACEAE

Allium sphaerocephalon L.

Ajestrín (3), ajo (4), cebolleta (3)

65P; 95F; 3V, 95V, 268V

\begin{tabular}{lc}
\hline Frecuencia de citación (FC): & 10 \\
\hline Número de usos (NU): & 4 \\
\hline Número registros de uso (RU): & 10 \\
\hline Frecuencia Relativa de Citación (FRC): & 0,07 \\
\hline Índice de Importancia Cultural (IC): & 0,07 \\
\hline Índice de Vigencia (IV): & 0,00 \\
\hline
\end{tabular}

Obtención: silvestre

Vigencia: abandonado

Conocimientos:

\section{ECOLOGÍA:}

Crecen tanto en camperas, como en las lastras y en las orillas de los caminos.

Usos:

\section{ALIMENTACIÓN HUMANA}

- Golosinas y masticatorias (6): El bulbo en fresco se comía directamente en el campo y en seco añadido como condimento a las sopas en sustitución del ajo cultivado, pues se señala un sabor similar aunque más concentrado debido a su menor tamaño.

\section{ALIMENTACIÓN ANIMAL}

- Pasto (1): Las vacas pacen con gusto esta especie.

\section{TóxICO Y NOCIVO}

- Tóxicos para personas o animales (1): EI bulbo no es tóxico pero las vacas que lo comían transmitían el sabor característico del ajo a la leche, por lo que en las vecerías se trataba de impedir su consumo.

\section{ORNAMENTAL}

- Adorno floral y planta de interior (2): La inflorescencia de atractivo color rojo se incluye en centros decorativos de flor seca, solos o acompañados de otras especies, que tienen por característica su gran persistencia en el tiempo. 


\section{AMARYLLIDACEAE}

Narcissus asturiensis (Jord.) Pugsley

Lira (3), lirón (2), campanilla (1)

\begin{tabular}{lc} 
98P; 202F; 49V & \\
\hline Frecuencia de citación (FC): & 6 \\
\hline Número de usos (NU): & 1 \\
\hline Número registros de uso (RU): & 6 \\
\hline Frecuencia Relativa de Citación (FRC): & $\mathbf{0 , 0 4}$ \\
Índice de Importancia Cultural (IC): & $\mathbf{0 , 0 4}$ \\
\hline Índice de Vigencia (IV): & $\mathbf{0 , 0 0}$ \\
\hline
\end{tabular}

Obtención: silvestre

Vigencia: vigente (9\%)

Conocimientos:

ECOLOGÍA:

Son las primeras flores en aparecer en primavera, a principios de marzo si la nieve se ha retirado de los prados.

\section{LÉXICO:}

El tamaño de las diferentes especies de Narcissus es diferenciado con el lenguaje popular, lira es el diminutivo de lirón. También se nombra la especie por su morfología, la flor con forma de campana determina la denominación de campanilla.

Usos:

\section{ORNAMENTAL}

- Adorno floral y plantas de interior (6): Con las flores pequeñas pero bellas se confeccionan ramilletes de flor cortada como aderezo en el hogar.

AMARYLLIDACEAE

Narcissus bulbocodium $\mathrm{L}$.

Lirón (4), lirona (1), cantarujil (1)

241P, 484P

\begin{tabular}{lc}
\hline Frecuencia de citación (FC): & 6 \\
\hline Número de usos (NU): & 2 \\
\hline Número registros de uso (RU): & 6 \\
\hline Frecuencia Relativa de Citación (FRC): & 0,04 \\
\hline Índice de Importancia Cultural (IC): & 0,04 \\
\hline Índice de Vigencia (IV): & 0,00 \\
\hline
\end{tabular}

Obtención: silvestre

Vigencia: vigente (9\%)

\section{Usos:}

\section{ALIMENTACIÓN HUMANA}

- Golosinas y masticatorias (1): Los más jóvenes chupaban la flor como entretenimiento intentando extraer el néctar contenido en ella.

\section{ORNAMENTAL}

- Adorno floral y plantas de interior (5): Para decoración del hogar se recolectan las flores y se emplazan en pequeños frascos con agua. "Los lirones que salen por aquí son pequeñitos, por arriba (más al Norte) son grandes, se cogen para jarrones" (Matamorisca).

AMARYLLIDACEAE

Narcissus pseudonarcissus L.

Lirón (77), lirón de Pineda (1), lirio (1), cancarico (1), cantarillo (1), campanilla (1)

91P, 277P; 42F

\begin{tabular}{lc}
\hline Frecuencia de citación (FC): & $\mathbf{8 2}$ \\
\hline Número de usos (NU): & 3 \\
\hline Número registros de uso (RU): & 91 \\
\hline Frecuencia Relativa de Citación (FRC): & $\mathbf{0 , 5 9}$ \\
\hline Índice de Importancia Cultural (IC): & $\mathbf{0 , 6 5}$ \\
\hline Índice de Vigencia (IV): & $\mathbf{0 , 1 0}$ \\
\hline
\end{tabular}

Obtención: silvestre

Vigencia: vigente (16\%)

Conocimientos:

ECOLOGÍA:

Los lirones salen en prados húmedos y sotobosques, lugares de abundante floración en la comarca son: Brañosera, Camasobres, Estalaya, Lores, Resoba y Triollo.

\section{LÉXICO:}

En Arbejal denominan a esta especie lirón de Pineda, lugar que solían visitar para recogerlos (Valle de Pineda). El nombre de cantarillo se recoge en la localidad de Santibañez de la Peña y cancarico en la zona de Santullán.

En Brañosera aparece el fitotopónimo del pago "Lirones".

Usos:

ALIMENTACIÓN ANIMAL

- Plantas melíferas (1): Afirman en Matabuena que las abejas muestran inclinación por la temprana floración de los lirones, de los que extraen el néctar para elaborar la miel.

\section{ORNAMENTAL}

- Patios, huertos y jardines (6): Se trasplantan ejemplares en primavera del campo a los jardines y macetas, con fines decorativos.

- Adorno floral y plantas de interior (78): Se recogen ramos como adorno de flor fresca cortada para decoración. Se conservan en jarrones con agua en el interior de las 
viviendas, el colegio, la iglesia. De ello se encargaban principalmente las mujeres o los niños, tradicionalmente encomendados para este fin. Con las flores trenzadas también se elaboran coronas ornamentales.

\section{SOCIAL, SIMBÓLICO Y RITUAL}

- Ritual de ciclo anual (4): Era tradicional adornar los altares y las calles durante la festividad religiosa del Corpus Christi con flores atractivas disponibles en el campo, entre ellas destacaban los lirones.

- Uso recreativo (2): El lirón era utilizado en los juegos infantiles del momento, la flor presenta una corona en forma de trompeta, por la que los niños solían soplar a través de ella consiguiendo un sonido agudo.

Observaciones: Durante los años 80/90 del siglo pasado acontecieron recolecciones masivas de lirones por parte de particulares y floristerías para comerciar con ellos, procedentes en muchos casos de provincias limítrofes, hoy en día su recolección ha sido regulada mediante el Decreto 63/2007 de 14 de junio, por la que se crean el Catálogo de Flora Protegida de Castilla y León y la figura de protección denominada Microrreserva de Flora, limitándose la recolección a 24 unidades por persona.

AMARYLLIDACEAE

\section{Narcissus triandrus L.}

Pipa (2), lira (1)

334P, 442P; 118F; 50V, 51V

\begin{tabular}{lc}
\hline Frecuencia de citación (FC): & 3 \\
\hline Número de usos (NU): & 1 \\
\hline Número registros de uso (RU): & 3 \\
\hline Frecuencia Relativa de Citación (FRC): & 0,02 \\
\hline Índice de Importancia Cultural (IC): & 0,02 \\
\hline Índice de Vigencia (IV): & $\mathbf{0 , 0 0}$ \\
\hline
\end{tabular}

Obtención: silvestre

Vigencia: abandonado

\section{Conocimientos:}

ECOLOGÍA:

Son iguales que los lirones pequeños pero blancos, salen también en primavera.

Usos:

ORNAMENTAL

- Adorno floral y plantas de interior (3): Se hacen ramilletes de flor cortada como adorno en el hogar.

\section{ARACEAE}

Arum italicum L.

Hierba de la culebra (2), raíz de la culebra (3), planta de la culebra (1), veneno de culebra (2)

102P, 302P; 316F; 7V

\begin{tabular}{lc}
\hline Frecuencia de citación (FC): & 11 \\
\hline Número de usos (NU): & 2 \\
\hline Número registros de uso (RU): & 13 \\
\hline Frecuencia Relativa de Citación (FRC): & $\mathbf{0 , 0 8}$ \\
\hline Índice de Importancia Cultural (IC): & $\mathbf{0 , 0 9}$ \\
\hline Índice de Vigencia (IV): & $\mathbf{0 , 0 0}$ \\
\hline
\end{tabular}

Obtención: silvestre

Vigencia: abandonado

\section{Conocimientos:}

\section{ECOLOGÍA:}

La raíz de la culebra se cría entre linderas y orilla de muros.

\section{LÉXICO:}

Se asocia su nombre a la culebra un animal detestado y que advierte de la peligrosidad de la misma. Denominan gargolitas a los redondeados frutos rojos.

Usos:

\section{VETERINARIA}

- Piel y tejido celular subcutáneo (4): Se extraía la raíz, útil para curar la hinchazón de las pezuñas del ganado, popularmente conocida como enfermedad del "babón". Se machaca la raíz o se cuece hasta que alcanza una textura un tanto gelatinosa y suave que se acomodaba en la pezuña directamente o mediante cataplasma.

\section{TÓXICA Y NOCIVA}

- Tóxica para humanos o animales (9): Planta reconocida como tóxica en toda la comarca.

Observaciones: En Otero de Guardo se recoge el siguiente testimonio que hemos dejado como dudoso a pesar de ser un informante de confianza: "La raíz de la culebra es bajita y da como una piña de bolas rojitas, era veneno y sin embargo se tomaba cuando te picaba algo, se cocía la raíz y el agua de eso se daba a las personas a beber, me acuerdo de verlo a mi padre dárselo a alguno".

Con el nombre adyacente de "culebra" atestiguamos las siguientes especies: Arum italicum, Bryonia cretica, Helleborus foetidus, $H$. viridis y Dracunculus vulgaris, todas ellas consideradas tóxicas. 


\section{ARACEAE}

Dracunculus vulgaris Schot

Hierba de la culebra (3)

\begin{tabular}{ll}
\hline $357 V$ & \\
\hline Frecuencia de citación (FC): & 3 \\
\hline Número de usos (NU): & 2 \\
\hline Número registros de uso (RU): & 4 \\
\hline
\end{tabular}

Obtención: cultivada

Vigencia: vigente (25\%)

LÉXICO:

En Salinas de Pisuerga la denominan hierba de la culebra porque su tallo salteado de manchas evoca a la piel de un ofidio.

Usos:

TÓXICO Y NOCIVO

- Venenos, insecticidas y plaguicidas (2): En Polentinos aseguran que posee la capacidad de ahuyentar a las culebras.

\section{ORNAMENTAL}

- Patios, huertos y jardines (2): Emplazan esta planta en patios o jardines cercanos de las casas.

ASPARAGACEAE

Chlorophytum comosum (Thunb.) Jacques Cinta (1)

\begin{tabular}{ll}
\hline Frecuencia de citación (FC): & 1 \\
\hline Número de usos (NU): & 1 \\
\hline Número registros de uso (RU): & 1 \\
\hline
\end{tabular}

Obtención: cultivada

Vigencia: vigente (100\%)

Usos:

ORNAMENTAL

- Adorno floral y plantas de interior (1): Se cultiva en macetas en el interior de la vivienda.

\section{ASPARAGACEAE}

\section{Muscari racemosum $\mathrm{L}$.}

Vino (1)

\begin{tabular}{lc} 
157P, 493P; 317F & \\
\hline Frecuencia de citación (FC): & 1 \\
\hline Número de usos (NU): & 1 \\
\hline Número registros de uso (RU): & 1 \\
\hline Frecuencia Relativa de Citación (FRC): & $\mathbf{0 , 0 1}$ \\
Índice de Importancia Cultural (IC): & $\mathbf{0 , 0 1}$ \\
\hline Índice de Vigencia (IV): & $\mathbf{0 , 0 0}$ \\
\hline
\end{tabular}

Obtención: silvestre

Vigencia: abandonado

Usos:

SOCIAL, SIMBÓLICO Y RITUAL

- Uso recreativo (1): Los vinos se utilizaban en juegos infantiles donde simulaban algún producto del tradicional juego de las comiditas.

\section{ASPARAGACEAE}

Polygonatum odoratum (Mill.) Druce

Pendientes de la reina (1)

377P, 467P; 326F

\begin{tabular}{|lc|}
\hline Frecuencia de citación (FC): & 1 \\
\hline Número de usos (NU): & 1 \\
\hline Número registros de uso (RU): & 11 \\
\hline Frecuencia Relativa de Citación (FRC): & $\mathbf{0 , 0 1}$ \\
\hline Índice de Importancia Cultural (IC): & $\mathbf{0 , 0 1}$ \\
\hline
\end{tabular}

Obtención: Silvestre

Usos:

TÓXICO Y NOCIVO

- Tóxica para personas y animales (1): En Verdeña consideran a esta especie tóxica porque no la comen los animales.

\section{COLCHICACEAE}

Colchicum montanum L.

Quitameriendas (22), cucubilla (1)

40P, 274P; 67F

\begin{tabular}{|lc|}
\hline Frecuencia de citación (FC): & 23 \\
\hline Número de usos (NU): & 2 \\
\hline Número registros de uso (RU): & 24 \\
\hline Frecuencia Relativa de Citación (FRC): & 0,17 \\
\hline Índice de Importancia Cultural (IC): & 0,17 \\
\hline Índice de Vigencia (IV): & 0,00 \\
\hline
\end{tabular}

Obtención: silvestre

Vigencia: abandonado

Conocimientos:

LÉXICO:

El nombre quitameriendas significa que cuando florecen las tardes se acortan y se suprime la merienda en el campo, ya que se cena antes de hacerse de noche.

Usos:

\section{ALIMENTACIÓN HUMANA}

- Golosinas y masticatorias (10): Las flores se chupaban para tratar de obtener el néctar 
dulce. Los jóvenes escarbaban la tierra para extraer el bulbo, que consumían directamente en el campo tras limpiarlo.

\section{MEDIOAMBIENTAL}

- Bioindicadores (14): Conocida por su peculiar forma de florecer a finales del verano, anunciando la proximidad del otoño y el acortamiento de los días.

\section{CYPERACEAE}

\section{Eriophorum latifolium Hoppe}

Hierba de algodón (1)

443P; 224F; 97V

\begin{tabular}{|lc|}
\hline Frecuencia de citación (FC): & 1 \\
\hline Número de usos (NU): & 1 \\
\hline Número registros de uso (RU): & 1 \\
\hline Frecuencia Relativa de Citación (FRC): & 0,01 \\
\hline Índice de Importancia Cultural (IC): & 0,01 \\
\hline Índice de Vigencia (IV): & 0,01 \\
\hline
\end{tabular}

Obtención: silvestre

Vigencia: vigente (100\%)

Usos:

ORNAMENTAL

- Adorno floral y plantas de interior (1): En San Felices de Castillería se utiliza esta especie para decorar centros de flores secas, en ocasiones incluso se tiñe la inflorescencia de colores para destacar su belleza.

\section{CYPERACEAE}

Scirpoides holoschoenus (L.) Soják

Junco (3)

\begin{tabular}{lc} 
79P; 96F & \\
\hline Frecuencia de citación (FC): & $\mathbf{3}$ \\
\hline Número de usos (NU): & $\mathbf{1}$ \\
\hline Número registros de uso (RU): & $\mathbf{3}$ \\
Frecuencia Relativa de Citación (FRC): & $\mathbf{0 , 0 2}$ \\
\hline Índice de Importancia Cultural (IC): & $\mathbf{0 , 0 2}$ \\
\hline Índice de Vigencia (IV): & $\mathbf{0 , 0 0}$ \\
\hline
\end{tabular}

Obtención: silvestre

Vigencia: abandonado

Conocimientos:

ECOLOGÍA:

Se da en suelos húmedos.

Usos:

CONSTRUCCIÓN
- Casas, edificios e instalaciones agropecuarias (3): Se emplean en los tejados como mullida para asentar las tejas y como aislante.

IRIDACEAE

\section{Gladiolus communis L.}

Gladiolo (2)

\begin{tabular}{ll}
\hline $227 \mathrm{~F}$ & \\
\hline Frecuencia de citación (FC): & 2 \\
\hline Número de usos (NU): & 1 \\
\hline Número registros de uso (RU): & 2 \\
\hline
\end{tabular}

Obtención: cultivada

Vigencia: vigente (50\%)

Usos:

ORNAMENTAL

- Patios, huertos y jardines (2): Cultivada en jardines y huertos como ornamental.

IRIDACEAE

Iris pseudacorus L.

Lirio amarillo (2)

221P, 397P; 154F

Frecuencia de citación (FC): 2

Número de usos (NU): $\quad 1$

Número registros de uso (RU): 2

Frecuencia Relativa de Citación (FRC): $\quad 0,01$

Índice de Importancia Cultural (IC): $\quad 0,01$

Índice de Vigencia (IV): $\quad \mathbf{0 , 0 0}$

Obtención: silvestre

Vigencia: abandonado

Usos:

ORNAMENTAL

- Adorno floral y plantas de interior (2): Se cortan ramos en época de floración para decorar el hogar en jarrones con agua.

IRIDACEAE

Iris X germanica L.

Lirio (6)

\begin{tabular}{ll}
\hline $194 \mathrm{~F}$ & \\
\hline Frecuencia de citación (FC): & 6 \\
\hline Número de usos (NU): & 1 \\
\hline Número registros de uso (RU): & 7 \\
\hline
\end{tabular}

Obtención: cultivada

Vigencia: vigente (72\%) 
Usos:

\section{ORNAMENTAL}

- Patios, huertos y jardines (3): Se cultivan en jardines, huertos e incluso cementerios como ornamental.

- Adorno floral y plantas de interior (4): Se cortan flores como adorno en el hogar.

IRIDACEAE

Iris latifolia (Mill.) Voss

Lirio (7), lirio azul (2)

179P; 319F

\begin{tabular}{lc}
\hline Frecuencia de citación (FC): & 9 \\
Número de usos (NU): & 1 \\
\hline Número registros de uso (RU): & 9 \\
\hline Frecuencia Relativa de Citación (FRC): & 0,06 \\
Índice de Importancia Cultural (IC): & 0,06 \\
Índice de Vigencia (IV): & 0,00 \\
\hline
\end{tabular}

Obtención: silvestre

Vigencia: abandonado

Usos:

ORNAMENTAL

- Adorno floral y plantas de interior (9): Se llevan ramos de flor para adornar jarrones en el hogar, "fui a llevar una vaca a los pies del Curavacas y baje un brazao de lirios preciosos", Vidrieros.

\section{IRIDACEAE}

Romulea bulbocodium (L.) Sebast. \& Mauri Cucubilla (8), ceringueña (2), cerindeña (1), celingueña (1), amacuca (1)

\begin{tabular}{lc} 
148P, 208P; 102F; 62V & \\
\hline Frecuencia de citación (FC): & 13 \\
\hline Número de usos (NU): & 2 \\
Número registros de uso (RU): & 15 \\
\hline Frecuencia Relativa de Citación (FRC): & 0,09 \\
Índice de Importancia Cultural (IC): & 0,11 \\
Índice de Vigencia (IV): & 0,00 \\
\hline
\end{tabular}

Obtención: silvestre

Vigencia: abandonado

Conocimientos:

ECOLOGÍA:

Sale en camperas pobres.

\section{LÉXICO:}

El bulbo se reconoce con los siguientes nombres: cucubilla, camorrita o cebollita.
Usos:

\section{ALIMENTACIÓN HUMANA}

- Golosinas y masticatorias (14): El bulbo era consumido por los más jóvenes en el inicio de la primavera, "suelen salir en marzo en cuanto sale el sol", y de la flor se chupaba el néctar de sabor dulce.

\section{ALIMENTACIÓN ANIMAL}

- Pasto (1): Los jabalíes buscan con anhelo los bulbos de esta especie.

JUNCACEAE

\section{Juncus articulatus L. \\ J. conglomeratus $\mathrm{L}$. \\ J. effusus L. \\ J. inflexus $\mathrm{L}$. \\ Junco (12)}

Juncus articulatus: 78P, 347P; 420V, 484V

J. conglomeratus: $117 \mathrm{P}, 352 \mathrm{P}$

J. effusus: 376P, 508P; 220F

J. inflexus: 160P

\begin{tabular}{lc}
\hline Frecuencia de citación (FC): & 12 \\
Número de usos (NU): & 1 \\
\hline Número registros de uso (RU): & 14 \\
Frecuencia Relativa de Citación (FRC): & 0,09 \\
Índice de Importancia Cultural (IC): & 0,06 \\
Índice de Vigencia (IV): & 0,00
\end{tabular}

Obtención: silvestre

Vigencia: abandonado

Conocimientos:

ECOLOGÍA:

Se da en las inmediaciones de suelos húmedos.

\section{LÉXICO:}

Encontramos el pago "El Juncal" en Matabuena y en Valsadornín.

Usos:

\section{CONSTRUCCIÓN}

- Casas, edificios e instalaciones agropecuarias (8): En las techumbres se utilizaron como mullida para asentar las tejas y como aislante encima de la ripia, tiene la ventaja de que dura más que el helecho, y como inconveniente que resbala la teja.

\section{INDUSTRIA Y ARTESANÍA}

- Juguetes $e$ instrumentos deportivos $y$ musicales (5): Los tallos de los juncos se han trenzado en juegos infantiles para hacer sonajeros, porras y varilletas, que son el 
sustento sobre el que se colocaba la liga para cazar pájaros.

- Cuerdas y ataduras (1): En Villanueva de Arriba con los juncos trenzados se fabricaba un látigo para arrear al ganado.

\section{Luzula lactea (Link) E.Mey. Purrino (1)}

\begin{tabular}{lc} 
333P, 468P; 305F; 163V, 164V & \\
\hline Frecuencia de citación (FC): & 1 \\
\hline Número de usos (NU): & 1 \\
\hline Número registros de uso (RU): & 1 \\
\hline Frecuencia Relativa de Citación (FRC): & $\mathbf{0 , 0 1}$ \\
\hline Índice de Importancia Cultural (IC): & $\mathbf{0 , 0 1}$ \\
\hline Índice de Vigencia (IV): & $\mathbf{0 , 0 1}$ \\
\hline
\end{tabular}

Obtención: silvestre

Vigencia: vigente (100\%)

Usos:

ORNAMENTAL

- Adorno floral y plantas de interior (1): En Resoba se hacen floreros con esta especie para decorar alguna estancia del hogar, manteniéndose vistosos durante al menos un año.

\section{LILIACEAE}

\section{Erythronium dens-canis L.}

Campanilla (1)

\begin{tabular}{lc} 
164P, 492P; 318F; 24V & \\
\hline Frecuencia de citación (FC): & 1 \\
\hline Número de usos (NU): & 1 \\
\hline Número registros de uso (RU): & 1 \\
\hline Frecuencia Relativa de Citación (FRC): & $\mathbf{0 , 0 1}$ \\
\hline Índice de Importancia Cultural (IC): & $\mathbf{0 , 0 1}$ \\
\hline Índice de Vigencia (IV): & $\mathbf{0 , 0 0}$ \\
\hline
\end{tabular}

Obtención: silvestre

Vigencia: abandonado

Usos:

ORNAMENTAL

- Patios, huertos y jardines (1): En la localidad de Verdeña se extraen los bulbos del monte y se ponen en macetas para decorar los patios.

\section{LILIACEAE}

Fritillaria lusitanica Wikstr.

\section{F. pyrenaica L.}

Calderón (5), campanilla (4), cencerrón (1), campánula (1)

Fritillaria lusitanica: $242 \mathrm{P}$

F. pyrenaica: $225 \mathrm{P} ; 111 \mathrm{~F}$

\begin{tabular}{lc|}
\hline Frecuencia de citación (FC): & 11 \\
\hline Número de usos (NU): & 2 \\
\hline Número registros de uso (RU): & 11 \\
\hline Frecuencia Relativa de Citación (FRC): & $\mathbf{0 , 0 8}$ \\
\hline Índice de Importancia Cultural (IC): & $\mathbf{0 , 0 8}$ \\
\hline Índice de Vigencia (IV): & $\mathbf{0 , 0 0}$ \\
\hline
\end{tabular}

Obtención: silvestre

Vigencia: abandonado

Conocimientos:

ECOLOGÍA:

Se dan en prados frescos.

Usos:

\section{ALIMENTACIÓN HUMANA}

- Golosinas y masticatorias (10): Durante la primavera se chupaba la flor con intención de extraer el sabor dulce del néctar que produce. Los más jóvenes comían los tépalos de la flor, directamente en el campo sin ninguna preparación, en ocasiones se lavaban en agua antes de ingerirlos.

\section{ORNAMENTAL}

- Adorno floral y plantas de interior (1): Se ponen las flores en jarrones con agua como ornamento en el hogar.

\section{Lilium candidum L.}

LILIACEAE

Vara de San José (1), azucena (1)

\begin{tabular}{ll}
\hline $219 \mathrm{~V}$ & \\
\hline Frecuencia de citación (FC): & $\mathbf{2}$ \\
\hline Número de usos (NU): & 1 \\
\hline Número registros de uso (RU): & 2 \\
\hline
\end{tabular}

Obtención: cultivada

Vigencia: vigente (100\%)

Usos:

ORNAMENTAL

- Patios, huertos y jardines (2): Se cultivan como ornamentales en huertos y jardines.

\section{LILIACEAE}

\section{Lilium martagon L.}

Antojil (2), campanilla de monte (1), azucena (1) 
400P, 469P; 78F; 214V

\begin{tabular}{lc}
\hline Frecuencia de citación (FC): & 5 \\
\hline Número de usos (NU): & 2 \\
\hline Número registros de uso (RU): & 7 \\
\hline Frecuencia Relativa de Citación (FRC): & 0,04 \\
\hline Índice de Importancia Cultural (IC): & 0,05 \\
\hline Índice de Vigencia (IV): & 0,01 \\
\hline
\end{tabular}

Obtención: silvestre

Vigencia: vigente (14\%)

Usos:

\section{VETERINARIA}

- Piel y tejido celular subcutáneo (2): El bulbo de esta especie se aconseja para la cura de heridas en los animales domésticos, atribuyéndose la capacidad de favorecer la rápida cicatrización y desinfección de las mismas. La extracción del bulbo se prolonga durante la época de verano y se almacena en lugar seco para conservar sus propiedades. En caso de necesidad se cocía unos minutos en agua y con el líquido resultante se lavaba cualquier tipo de herida.

\section{ORNAMENTAL}

- Patios, huertos y jardines (2): Se cultivan en huertos y jardines, trasplantadas desde el monte, por la vistosidad de sus flores.

- Adorno floral y plantas de interior (3): Se recogen para uso ornamental en la realización de arreglos florales en el hogar con la flor fresca.

LILIACEAE

Tulipa gesneriana $\mathrm{L}$.

Tulipán (2)

\begin{tabular}{ll}
\hline $274 \mathrm{~F}$ & \\
\hline Frecuencia de citación (FC): & 2 \\
\hline Número de usos (NU): & 1 \\
\hline Número registros de uso (RU): & 2 \\
\hline
\end{tabular}

Obtención: cultivada

Vigencia: vigente (50\%)

Usos:

ORNAMENTAL

- Patios, huertos y jardines (2): Se cultivan en exterior por la vistosidad de sus flores, en maceta o jardín.

\section{ORCHIDACEAE}

Anacamptis morio

(L.) R.M.Bateman,
Clavel (1)

\begin{tabular}{lc}
\hline $444 \mathrm{P} ; 4 \mathrm{~V}$ & \\
\hline Frecuencia de citación (FC): & 1 \\
\hline Número de usos (NU): & 1 \\
\hline Número registros de uso (RU): & $\mathbf{0 , 0 1}$ \\
\hline Frecuencia Relativa de Citación (FRC): & $\mathbf{0 , 0 1}$ \\
\hline Índice de Importancia Cultural (IC): & $\mathbf{0 , 0 0}$ \\
\hline Índice de Vigencia (IV): &
\end{tabular}

Obtención: silvestre

Vigencia: abandonado

Usos:

ORNAMENTAL

- Adorno floral y plantas de interior (1): Se colocan las flores en jarrones con agua para adornar alguna estancia del hogar, aunque perduran pocos días.

\section{ORCHIDACEAE}

Orchis pallens $\mathrm{L}$.

Clavel (1)

319P; 158F; 52V

\begin{tabular}{lc|}
\hline Frecuencia de citación (FC): & 1 \\
\hline Número de usos (NU): & 1 \\
\hline Número registros de uso (RU): & 1 \\
\hline Frecuencia Relativa de Citación (FRC): & 0,01 \\
\hline Índice de Importancia Cultural (IC): & 0,01 \\
\hline Índice de Vigencia (IV): & 0,00 \\
\hline
\end{tabular}

Obtención: silvestre

Vigencia: abandonado

Usos:

ORNAMENTAL

- Patios, huertos y jardines (1): En Verdeña se sacan del campo con una azadilla y se ubican en macetas en el exterior de la vivienda.

\section{POACEAE}

Agrostis delicatula Pourr. ex Lapeyr. Risas y coscas (1)

239P; 389V, 390V, 391V

\begin{tabular}{lc}
\hline Frecuencia de citación (FC): & 1 \\
\hline Número de usos (NU): & 2 \\
\hline Número registros de uso (RU): & 2 \\
\hline Frecuencia Relativa de Citación (FRC): & 0,01 \\
\hline Índice de Importancia Cultural (IC): & 0,01 \\
\hline Índice de Vigencia (IV): & 0,01 \\
\hline
\end{tabular}

Obtención: silvestre

Vigencia: vigente (50\%) 
Usos:

\section{ORNAMENTAL}

- Adorno floral y plantas de interior (1): Inflorescencia empleada en centros de flor seca para decoración interior.

\section{SOCIAL, SIMBÓLICO Y RITUAL}

- Uso recreativo (1): Los niños en Valcobero se restregaban la planta por la cara para hacerse cosquillas unos a otros.

\section{POACEAE}

\section{Aira caryophyllea L.}

Heno (1)

\begin{tabular}{lc} 
426P; 318V & \\
\hline Frecuencia de citación (FC): & 1 \\
\hline Número de usos (NU): & 1 \\
\hline Número registros de uso (RU): & 1 \\
\hline Frecuencia Relativa de Citación (FRC): & $\mathbf{0 , 0 1}$ \\
\hline Índice de Importancia Cultural (IC): & $\mathbf{0 , 0 1}$ \\
Índice de Vigencia (IV): & $\mathbf{0 , 0 0}$ \\
\hline
\end{tabular}

Obtención: silvestre

Vigencia: abandonado

Usos:

ORNAMENTAL

- Adorno floral y plantas de interior (1): Incluida en ornamentos y centros de flores secas.

\section{POACEAE}

Arrhenatherum elatius (L.) P.Beauv. ex J.Presl \& C.Presl.

Grama (2)

401P, 470P; 145V

\begin{tabular}{lc}
\hline Frecuencia de citación (FC): & 2 \\
\hline Número de usos (NU): & 2 \\
\hline Número registros de uso (RU): & 2 \\
\hline Frecuencia Relativa de Citación (FRC): & 0,01 \\
\hline Índice de Importancia Cultural (IC): & 0,01 \\
\hline Índice de Vigencia (IV): & 0,01 \\
\hline
\end{tabular}

Obtención: silvestre

Vigencia: vigente (50\%)

Usos:

MEDIOAMBIENTAL

- Malas hierbas (1): Se quitaba de los cultivos.

\section{ORNAMENTAL}

- Adorno floral y plantas de interior (1): Válida la inflorescencia en ornamentación de flor seca.
Observaciones: Nos encontramos ante otra de las especies denominada grama, junto con: Cynodon dactylon, Dactylis glomerata, Elymus repens y Lolium multiflorum.

POACEAE

Avena fatua $\mathrm{L}$.

A. sterilis L.

Avena loca (1), avena seca (1), hierba loca (1)

Avena fatua: $402 \mathrm{P} ; 185 \mathrm{~F}$

A. sterilis: $172 \mathrm{P} ; 106 \mathrm{~F}$

\begin{tabular}{lc|}
\hline Frecuencia de citación (FC): & 3 \\
\hline Número de usos (NU): & $\mathbf{2}$ \\
\hline Número registros de uso (RU): & $\mathbf{3}$ \\
\hline Frecuencia Relativa de Citación (FRC): & $\mathbf{0 , 0 2}$ \\
\hline Índice de Importancia Cultural (IC): & $\mathbf{0 , 0 2}$ \\
\hline Índice de Vigencia (IV): & $\mathbf{0 , 0 1}$ \\
\hline
\end{tabular}

Obtención: silvestre

Vigencia: vigente (33\%)

Usos:

MEDIOAMBIENTAL

- Malas hierbas (2): Crece en los cultivos de cereal, de donde se escarda.

\section{ORNAMENTAL}

- Adorno floral y plantas de interior (1): En San Salvador de Cantamuda se utiliza para decorar en centros de flor seca.

POACEAE

Avena sativa $\mathrm{L}$.

Avena (57)

$330 \mathrm{~F}$

\begin{tabular}{|lc|}
\hline Frecuencia de citación (FC): & 57 \\
\hline Número de usos (NU): & 1 \\
\hline Número registros de uso (RU): & 67 \\
\hline
\end{tabular}

Obtención: cultivada

Vigencia: vigente (3\%)

Usos:

ALIMENTACIÓN ANIMAL

- Forraje verde o seco (5): La paja se servía a las vacas y los burros.

- Pienso (62): Se cultivaba para todo tipo de animales domésticos, vacas, cerdos, conejos, gallinas, burros y caballos, que lo consumían generalmente en grano, salvo los cerdos a los que se les administraba molido para digerirlo mejor. 
Observaciones: Las tierras consideradas más flojas eran las destinadas al cultivo de avena, donde no se daba bien el trigo.

\section{POACEAE}

Brachypodium phoenicoides (L.) Roem. \& Schult

Hierba perruna (2)

\begin{tabular}{lc}
\hline $320 \mathrm{P}, 535 \mathrm{P} ;$ 256F; 147V & \\
\hline Frecuencia de citación (FC): & $\mathbf{2}$ \\
\hline Número de usos (NU): & $\mathbf{2}$ \\
\hline Número registros de uso (RU): & $\mathbf{3}$ \\
\hline Frecuencia Relativa de Citación (FRC): & $\mathbf{0 , 0 1}$ \\
\hline Índice de Importancia Cultural (IC): & $\mathbf{0 , 0 2}$ \\
\hline Índice de Vigencia (IV): & $\mathbf{0 , 0 0}$ \\
\hline
\end{tabular}

Obtención: silvestre

Vigencia: abandonado

Usos:

\section{VETERINARIA}

- Otros usos veterinarios (2): Los perros ingieren esta planta y después la vomitan como automedicación, purgándose de este modo cuando se encuentran mal.

\section{MEDIOAMBIENTAL}

- Malas hierbas (1): Se quitan de los prados.

Observaciones: Es probable que tuvieran el mismo uso las siguientes especies del mismo género también presentes en la zona: Brachypodium distachyon, B. pinnatum y $B$. sylvaticum.

\section{Briza media L.}

Corazones (5), corazoncitos (1)

\begin{tabular}{lc} 
183P, 419P; 290F; 10V, 148V, 149V & \\
\hline Frecuencia de citación (FC): & $\mathbf{6}$ \\
\hline Número de usos (NU): & $\mathbf{2}$ \\
\hline Número registros de uso (RU): & $\mathbf{7}$ \\
\hline Frecuencia Relativa de Citación (FRC): & $\mathbf{0 , 0 4}$ \\
\hline Índice de Importancia Cultural (IC): & $\mathbf{0 , 0 5}$ \\
\hline Índice de Vigencia (IV): & $\mathbf{0 , 0 1}$ \\
\hline
\end{tabular}

Obtención: silvestre

Vigencia: vigente (14\%)

Usos:

ORNAMENTAL

- Adorno floral y plantas de interior (6): La inflorescencia con forma de corazón se emplea en la confección de ramos de flor seca paral decorar la vivienda.

SOCIAL, SIMBÓLICO Y RITUAL

- Uso recreativo (1): LoS niños jugaban sujetando con la boca el tallo con la inflorescencia y tirando por el extremo se desmontaban las espiguillas y se adherían a los labios.

POACEAE

Cynodon dactylon (L.) Pers.

Grama (9), hierba de la grama (3)

\begin{tabular}{lc} 
42P, 344P; 130F \\
\hline Frecuencia de citación (FC): & 12 \\
\hline Número de usos (NU): & 1 \\
\hline Número registros de uso (RU): & 12 \\
\hline Frecuencia Relativa de Citación (FRC): & 0,09 \\
\hline Índice de Importancia Cultural (IC): & 0,09 \\
\hline Índice de Vigencia (IV): & 0,00 \\
\hline
\end{tabular}

Obtención: silvestre

Vigencia: abandonado

Usos:

MEDIOAMBIENTAL

- Malas hierbas (12): Se trata una de las especies más difíciles de erradicar de huertos y tierras de cultivo por su capacidad de multiplicación vegetativa.

POACEAE

Cynosurus cristatus L.

Cola de perro (1)

\begin{tabular}{lc} 
375P; $572 \mathrm{~V}$ & \\
\hline Frecuencia de citación (FC): & 1 \\
\hline Número de usos (NU): & 1 \\
\hline Número registros de uso (RU): & 1 \\
\hline Frecuencia Relativa de Citación (FRC): & $\mathbf{0 , 0 1}$ \\
Índice de Importancia Cultural (IC): & $\mathbf{0 , 0 1}$ \\
\hline Índice de Vigencia (IV): & $\mathbf{0 , 0 1}$ \\
\hline
\end{tabular}

Obtención: silvestre

Vigencia: vigente (100\%)

Usos:

ORNAMENTAL

- Adorno floral y plantas de interior (1): Presente en algún centro de flor seca para el ornamento de interiores. 
Dactylis glomerata L.

Grama (1)

\section{P; 253F; 552V}

\begin{tabular}{lc}
\hline Frecuencia de citación (FC): & 1 \\
\hline Número de usos (NU): & 2 \\
\hline Número registros de uso (RU): & 2 \\
\hline Frecuencia Relativa de Citación (FRC): & $\mathbf{0 , 0 1}$ \\
\hline Índice de Importancia Cultural (IC): & $\mathbf{0 , 0 1}$ \\
\hline Índice de Vigencia (IV): & $\mathbf{0 , 0 0}$ \\
\hline
\end{tabular}

Obtención: silvestre

Vigencia: abandonado

Usos:

VETERINARIA

- Sistema genito-urinario (1): La raíz de la grama se cocía junto con el fruto de la agayuba (Arctostaphylos uva-ursi) y el líquido resultante con cualidades diuréticas se suministra a las vacas con dificultades para orinar.

\section{MEDIOAMBIENTAL}

- Malas hierbas (1): Considerada mala hierba "es una hierba muy basta que se mete por todos laos".

\section{POACEAE}

\section{Elymus repens (L.) Gould}

Grama (2)

\begin{tabular}{lc} 
243P; 230F; 404V & \\
\hline Frecuencia de citación (FC): & 2 \\
\hline Número de usos (NU): & 2 \\
\hline Número registros de uso (RU): & 2 \\
\hline Frecuencia Relativa de Citación (FRC): & 0,01 \\
\hline Índice de Importancia Cultural (IC): & 0,01 \\
\hline Índice de Vigencia (IV): & 0,01 \\
\hline
\end{tabular}

Obtención: silvestre

Vigencia: vigente (50\%)

Usos:

MEDIOAMBIENTAL

- Malas hierbas (1): Se escarda en las tierras de cereal, "se quitaba mucho del centeno".

\section{ORNAMENTAL}

- Adorno floral y plantas de interior (1): Empleada la caña fructificada en ramos decorativos de flor seca.

\section{POACEAE}

Holcus mollis L. Yerbancho (1)

382P; 327F; 419V

\begin{tabular}{lc}
\hline Frecuencia de citación (FC): & 1 \\
\hline Número de usos (NU): & 2 \\
\hline Número registros de uso (RU): & 2 \\
\hline Frecuencia Relativa de Citación (FRC): & 0,01 \\
\hline Índice de Importancia Cultural (IC): & 0,01 \\
\hline Índice de Vigencia (IV): & 0,01 \\
\hline
\end{tabular}

Obtención: silvestre

Vigencia: vigente (50\%)

Usos:

ALIMENTACIÓN ANIMAL

- Forraje verde o seco (1): Se cortan las hojas para servir a los conejos como forraje, sobre todo en invierno, pues se mantiene verde durante esta época.

\section{ORNAMENTAL}

- Adorno floral y plantas de interior (1): En Valcobero se hacen floreros con las ramas floridas de esta especie, "quedan muy bonitas, parecen espigas de centeno".

\section{POACEAE}

Hordeum vulgare $\mathrm{L}$.

Cebada (61), ladilla (7), comuña (2)

\begin{tabular}{|c|c|}
\hline Frecuencia de citación (FC): & 70 \\
\hline Número de usos (NU): & 5 \\
\hline Número registros de uso (RU): & 83 \\
\hline
\end{tabular}

Obtención: cultivada

Vigencia: vigente (2\%)

LÉXICO:

En Estalaya se encuentra el fitotopónimo del pago "El Cebadal".

Usos:

\section{ALIMENTACIÓN HUMANA}

- Cereales (1): En caso de escasez de harina de trigo para elaborar el pan se añadía o mezclaba harina de cebada.

\section{ALIMENTACIÓN ANIMAL}

- Forraje verde o seco (6): La paja se daba como forraje a las ovejas y vacas, aunque no todos la consideraban buena en el pasado "la paja de cebada no se utilizaba antaño porque tiene mucha garabasta, es muy áspera y al comerlo 
se le quedaba al ganado en la garganta. Ahora la cosechadora quita la garabasta y queda muy suave y ya se puede usar".

- Pienso (72): La cebada se servía en verde como forraje, aunque su uso más destacado fue en grano entero o molido para todo tipo de animales: cerdos, conejos, gallinas, ovejas y vacas.

\section{COMBUSTIBLE}

- Para chamuscar (1): La paja de cebada se usa para quemar el pelo del cerdo en la matanza.

\section{CONSTRUCCIÓN}

- Casas, edificios e instalaciones agropecuarias (1): Para elaborar adobes la paja de cebada bien picada se mezclaba con tierra y agua para dar consistencia y cohesión a los mismos.

\section{MEDIOAMBIENTAL}

- Mejora del suelo (2): Las pajas del cereal en general se utilizan como cama para el ganado.

Observaciones: La cebada podía cultivarse mezclada con otros cereales y leguminosas, en cuyo caso recibía el nombre de comuña.

La ladilla era un tipo de cebada de dos carreras.

\section{POACEAE}

\section{Lolium multiflorum Lam.}

Grama (1)

407P, 539P; $125 \mathrm{~F}$

\begin{tabular}{lc}
\hline Frecuencia de citación (FC): & 1 \\
\hline Número de usos (NU): & 1 \\
\hline Número registros de uso (RU): & 1 \\
\hline Frecuencia Relativa de Citación (FRC): & 0,01 \\
\hline Índice de Importancia Cultural (IC): & 0,01 \\
\hline Índice de Vigencia (IV): & 0,00 \\
\hline
\end{tabular}

Obtención: silvestre

Vigencia: abandonado

Usos:

\section{MEDIOAMBIENTAL}

- Malas hierbas (1): En Arbejal es considerada una de las malas hierbas más difíciles de erradicar de los cultivos.

Observaciones: Se han identificado en la comarca bajo el nombre de grama las siguientes especies: Arrhenatherum elatius, Cynodon dactylon, Dactylis glomerata, Elymus repens y Lolium multiflorum.

\section{POACEAE}

Lolium perenne L.

Vallico (3), valluco (2), avallico (3)

\begin{tabular}{lc}
\hline $184 \mathrm{P} ; 251 \mathrm{~F}$ \\
\hline Frecuencia de citación (FC): & $\mathbf{8}$ \\
\hline Número de usos (NU): & $\mathbf{2}$ \\
\hline Número registros de uso (RU): & $\mathbf{1 1}$ \\
\hline Frecuencia Relativa de Citación (FRC): & $\mathbf{0 , 0 6}$ \\
\hline Índice de Importancia Cultural (IC): & $\mathbf{0 , 0 8}$ \\
\hline Índice de Vigencia (IV): & $\mathbf{0 , 0 0}$ \\
\hline
\end{tabular}

Obtención: silvestre

Vigencia: abandonado

Usos:

ALIMENTACIÓN ANIMAL

- Forraje verde o seco (3): Se daba como forraje principalmente a cerdos y vacas, antes de servir se lavaban para quitar la tierra adherida.

\section{MEDIOAMBIENTAL}

- Malas hierbas (8): Se escardaban con una azadilla de los cultivos de cereal y de patatas.

\section{POACEAE}

\section{Oryza sativa $\mathrm{L}$.} Arroz (2)

\begin{tabular}{ll}
\hline Frecuencia de citación (FC): & 2 \\
\hline Número de usos (NU): & 1 \\
\hline Número registros de uso (RU): & 2 \\
\hline
\end{tabular}

Obtención: comprada

Vigencia: abandonado

Usos:

\section{MEDICINA}

- Sistema digestivo (2): El arroz hervido o el agua donde se cuece se tomaba para detener la diarrea.

\section{POACEAE}

Secale cereale $\mathrm{L}$.

Centeno (97), sirvendo (6), servendo (2)

90F; 305V, 306V, 312V, 313V, 314V, 346V, 445V, $446 \mathrm{~V}, 493 \mathrm{~V}, 542 \mathrm{~V}, 561 \mathrm{~V}$

\begin{tabular}{lc}
\hline Frecuencia de citación (FC): & 99 \\
\hline Número de usos (NU): & 8 \\
\hline Número registros de uso (RU): & 235 \\
\hline
\end{tabular}

Obtención: cultivada

Vigencia: vigente (2\%) 


\section{Conocimientos:}

\section{LÉXICO:}

Existían en la zona dos tipos de cultivo, el de ciclo largo con siembra en otoño y recolección en verano, y el de ciclo corto llamado sirvendo o servendo, con siembra al final del invierno y recogida también en verano.

Los haces de paja de centeno se conocen con los siguientes nombres: bálagos, colmos, gavijones, gavillas o manojos.

Usos:

\section{ALIMENTACIÓN HUMANA}

- Cereales (17): El destino final del centeno era la molienda del grano del que se obtenía la harina de centeno, sólamente en casos de necesidad se empleaba para elaborar el pan. Este fue el caso en la posguerra, donde el hambre obligó a usar esta harina sola o mezclada con la de trigo. Comer pan de centeno era síntoma de pobreza.

La harina de centeno proporciona un cierto sabor amargo y una miga más oscura que la tradicional del trigo.

\section{ALIMENTACIÓN ANIMAL}

- Forraje verde o seco (9): Se trata del cereal forrajero por excelencia en la comarca, se cultivaba junto con alguna leguminosa para dar al ganado como forraje verde. La paja seca se suministraba al ganado lanar y vacuno como forraje.

- Pienso (85): Se cultivaba como alimento del ganado en general, ovejas, cabras, vacas, cerdos y gallinas, se servía en grano o más comúnmente se molía la producción para suministrarlo en forma de harina.

\section{MEDICINA}

- Sistema digestivo (2): Para combatir el dolor de muelas se elaboraba una pasta con agua y harina de centeno que se aplicaba directamente sobre los dientes, o con un paño de tela sobre la mejilla a modo de cataplasma.

\section{COMBUSTIBLE}

- Para chamuscar (50): La materia prima preferida para chamuscar el pelo del cerdo en la matanza, era la paja de centeno. Antes de trillar la paja en la era, se seleccionaban varios haces, se golpeaban (majar) para separar la espiga de la caña y se conservaban en lugar seco hasta la fecha de la matanza.

\section{CONSTRUCCIÓN}

- Casas, edificios e instalaciones agropecuarias (22): La paja de centeno se ha empleado antiguamente como cubierta vegetal sobre armadura de madera en diferentes construcciones.

En Valcobero se recuerda la construcción en las eras de casetas conocidas con el nombre de "cuchas" con los haces de centeno ya desgranados o majados, con el fin de proporcionar sombra durante las labores agrícolas.

También se incluye la paja trillada de centeno en la fabricación de adobes empleados en la construcción de paredes y tapias. Asimismo, con la paja muy picada se elaboraba una argamasa típica hecha con tierra y agua, con la que en ocasiones se revocaban las paredes de piedra y los entramados vegetales (sietos).

\section{INDUSTRIA Y ARTESANÍA}

- Sustancias tintóreas y pinturas (1): Como tinte se recoge un uso curioso en Verdeña, donde un vecino recuerda quemar paja de centeno y mezclarla con agua para impregnar y teñir la cuerda del tiralíneas o bota de marcar empleada por los albañiles.

- Juguetes $e$ instrumentos musicales y deportivos (1): Con la caña del centeno los niños en la localidad de Santa María de Nava fabricaban un instrumento rústico a modo de flauta o chiflito.

- Mobiliario y enseres domésticos (1): Se menciona en San Martín de Perapertú el uso de la paja de centeno como relleno para los jergones que hacían de colchón en las camas.

- Cestos, recipientes y envoltorios (17): En la artesanía tradicional se ha empleado paja de centeno para la fabricación de cestas funcionales de diferentes tamaños, popularmente conocidas como escriños o escriñas. Para su elaboración se meten las cañas de centeno a través de un aro y se cosen con tiras de zarza (Rosa spp. o Rubus spp.) o salguera (Salix spp.), moldeando hasta obtener la forma y el tamaño deseado.

\section{MEDIOAMBIENTAL}

- Mejora del suelo (27): La paja de centeno era considerada la de peor calidad forrajera por lo tanto era la más empleada para mullir en el establo. Mezclada con los excrementos se incorporaba posteriormente como abono en las tierras de cultivo y en los pastos.

\section{ORNAMENTAL}

- Adorno floral y plantas de interior (3): Las cañas floridas de centeno se usan como adorno floral en centros de ornamentación de flor seca para decorar en el hogar o la iglesia local. 
Observaciones: El centeno era uno de los cultivos más importantes en la Montaña Palentina a mediados del siglo $X X$, paulatinamente fue perdiendo superficie hasta casi su desaparición. Se desarrolla bien en suelos ácidos, poco exigentes y además soporta las temperaturas frías mejor que el trigo.

En la actualidad, el único ejemplo de arquitectura popular que conserva la techumbre realizada con colmos de paja es la casa de "La Benina", en la localidad de Valcobero.

La cestería con paja de centeno aún se practica de modo residual por los hombres más mayores, en alguna localidad como Nava de Santullán.

Existió un prolijo comercio con el centeno en comarcas próximas, se ha citado la venta de paja en Tierra de Campos, donde los albarderos la usaban como relleno de los collares del ganado. También se intercambió centeno por nueces con los vecinos lebaniegos.

POACEAE

\section{Stipa iberica Martinovský}

Hierba plumera (1), peluso (1)

203P; 233F

\begin{tabular}{lc}
\hline Frecuencia de citación (FC): & 2 \\
\hline Número de usos (NU): & 1 \\
\hline Número registros de uso (RU): & 2 \\
\hline Frecuencia Relativa de Citación (FRC): & 0,01 \\
\hline Índice de Importancia Cultural (IC): & 0,01 \\
\hline Índice de Vigencia (IV): & 0,01 \\
\hline
\end{tabular}

Obtención: silvestre

Vigencia: vigente (50\%)

Usos:

ORNAMENTAL

- Adorno floral y plantas de interior (2): Las cañas floridas se usan en decoración formando parte en composiciones de flores secas.

POACEAE

Triticum aestivum $\mathrm{L}$.

Trigo (110), mesino (7), tremesino (9)

91F; 268V, 542V

\begin{tabular}{lc}
\hline Frecuencia de citación (FC): & 110 \\
Número de usos (NU): & 10 \\
Número registros de uso (RU): & 194 \\
\hline
\end{tabular}

Obtención: cultivada

Vigencia: vigente (4\%)

\section{Conocimientos:}

\section{LÉXICO:}

En la zona se han cultivado dos tipos de trigo, uno de ciclo largo que se sembraba sobre el mes de octubre y otro de ciclo corto que se sembraba alrededor del mes de marzo y que recibía los nombres de mesino o tremesino porque en unos tres meses completa su ciclo.

\section{Usos:}

\section{ALIMENTACIÓN HUMANA}

- Cereales (64): El grano de trigo se destinaba a la molienda para la elaboración del pan, producto fundamental en la dieta del núcleo familiar. El molinero descontaba una parte proporcional del producto para cobrarse la molienda (maquila). Cada $10-15$ días se preparaba una hornada de entre 15-20 panes, aprovechando el tamaño del horno, que podía ser familiar o comunal. Primeramente se echaba en la artesa media talega de harina y sal según la cantidad de panes a hornear, aproximadamente 5 puñados de sal para 18 panes según receta recogida en Valcobero. Después se añadía el retiento (levadura), el agua y se amasaba hasta dejar la mezcla a gusto, tras este proceso se colocaba la masa en la trébede tapada para que soltara el exceso de agua, iniciara la fermentación y estuviera lista ya para cocer.

Con harina además del pan, también se preparaban tradicionales rosquillas en días festivos señalados. Y con el pan se elaboraban sopas de pan en agua y también en leche como desayuno.

- Golosinas y masticatorias (2): Los niños masticaban varios granos de trigo en verde, separando el salvado, y con ello se formaba una masa que semejaba la textura de un chicle.

\section{ALIMENTACIÓN ANIMAL}

- Forraje verde o seco (7): La paja de trigo era para las vacas, burros, cabras y ovejas.

- Pienso (63): Una vez cubierta la producción para la elaboración anual del pan, el trigo se destinaba a la alimentación animal. El grano entero lo consumen gallinas y conejos y los subproductos obtenidos en el molino en las sucesivas etapas del cernido (tercerilla y salvados) se daba a los cerdos, en ocasiones mezclado con algo de harina y con otros alimentos como hojas verdes cocidas o patatas pequeñas.

\section{MEDICINA}

- Sistema circulatorio (1): En Resoba los salvados se calentaban en un saco de tela y se 
colocaban como asiento de un paciente con hemorroides.

- Sistema digestivo (1): En Salinas de Pisuerga se mezclaba harina de trigo con un poco de agua para formar una masa que se situaba sobre la sien para aliviar el dolor de muelas.

\section{VETERINARIA}

- Sistema digestivo (1): Para curar a las vacas indigestadas o empachadas, en Lebanza se cocían granos de trigo que se introducían directamente en la boca del animal.

\section{COMBUSTIBLE}

- Para chamuscar (17): La paja de trigo servía como combustible para chamuscar el pelo del cerdo en la matanza.

\section{CONSTRUCCIÓN}

- Casas, edificios e instalaciones agropecuarias (14): La paja trillada de trigo se empleó en la fabricación de adobes para paredes y tapias.

\section{INDUSTRIA Y ARTESANÍA}

- Juguetes $e$ instrumentos musicales $y$ deportivos (1): Con la caña un poco aplastada del trigo los niños de Santibáñez de la Peña fabricaban flautas y chiflitos.

- Cestos, recipientes y envoltorios (2): La cestería tradicional emplea para fabricar escriños la paja de trigo insertada a través de un pequeño dedal o tubo y cosida después con zarzas.

\section{MEDIOAMBIENTAL}

- Mejora del suelo (15): La paja de trigo trillada se emplea como cama del ganado, absorbe los excrementos y mantiene limpio el establo. Cuando se retiran los excrementos se amontonan en el abonero (mudadal) hasta el momento de extenderlos por las tierras para mejorar su fertilidad.

\section{ORNAMENTAL}

- Adorno floral y plantas de interior (3): Se realizan adornos florales en jarrones o centros de flor seca con las cañas floridas de trigo para decorar alguna estancia.

\section{SOCIAL, SIMBÓLICO Y RITUAL}

- Uso recreativo (3): Los niños marcaban un grano de trigo de entre varios de un puñado. Después iban cogiendo de uno en uno hasta que aparecía el marcado que determinaba el perdedor. En la localidad de Monasterio este juego se denomina "reviéntame cuca".
Observaciones: Las mejores tierras de labor se reservaban para el cultivo del trigo.

En Arbejal se pagaba al herrero local que atendía la herramienta de trabajo, con un cuarto de trigo $(21 \mathrm{~kg})$, sirviendo de moneda de intercambio. También se cambiaba trigo por manzanas con los vecinos lebaniegos.

En la zona se ha mencionado el cultivo de estas variedades: Blanquilla, Colorao, Royón, Rojo Basto, Rojomocho y Lebaniego.

En la época más dura de la posguerra, los molinos estaban intervenidos y había que ingeniárselas para no perder la producción de trigo al entregarlo a la autoridad, por ello se iba a moler por la noche de estraperlo y conseguir la harina imprescindible para hacer el pan.

POACEAE

Zea mays L.

Maíz (6)

\begin{tabular}{ll}
\hline Frecuencia de citación (FC): & 6 \\
\hline Número de usos (NU): & 3 \\
\hline Número registros de uso (RU): & 8 \\
\hline
\end{tabular}

Obtención: cultivada, comprada

Vigencia: abandonado

Conocimientos:

LÉXICO:

Denominan pelos a los estigmas del maíz.

Usos:

ALIMENTACIÓN ANIMAL

- Pienso (3): Se cultiva para obtener el grano que entero o molido consumían cerdos, gallinas o vacas.

\section{VETERINARIA}

- Sistema genito-urinario (1): En Resoba recuerdan que el cocimiento de los estigmas en agua se lo daban a las vacas con una botella, como remedio diurético cuando tenían retención de orina.

\section{INDUSTRIA Y ARTESANÍA}

- Mobiliario y enseres domésticos (4): Las brácteas que envuelven a la infrutescencia y las hojas se empleaban para rellenar los jergones y los colchones.

Observaciones: En Polentinos señalan que el cultivo del maíz no era común en la zona y que desde la vecina Liébana traían manzanas y brácteas para colmar los colchones. 
TYPHACEAE

Typha angustifolia $\mathrm{L}$.

Puro (6), cuete (2)

194P, 283P; 108F; 94V

\begin{tabular}{lc}
\hline Frecuencia de citación (FC): & 8 \\
\hline Número de usos (NU): & 2 \\
\hline Número registros de uso (RU): & 9 \\
\hline Frecuencia Relativa de Citación (FRC): & 0,06 \\
\hline Índice de Importancia Cultural (IC): & 0,06 \\
\hline Índice de Vigencia (IV): & $\mathbf{0 , 0 1}$ \\
\hline
\end{tabular}

Obtención: silvestre

Vigencia: vigente (14\%)

Usos:

INDUSTRIA Y ARTESANÍA

- Cestería, recipientes y envoltorios (1): En la elaboración de las cubas, se usaban las hojas de los puros a modo de junta entre tabla y tabla, y de esta forma sellar los huecos.

\section{ORNAMENTAL}

- Adorno floral y plantas de interior (8): Las mujeres recogían la inflorescencia antes de que madurara, con parte del tallo, para elaborar jarrones decorativos de flor seca.

Observaciones: Es probable que Thypa latifolia y $T$. domingensis tengan los mismo usos en la zona.

\section{XANTHORRHOEACEAE}

\section{Asphodelus albus Mill.}

Gamón (90), gamonita (4)

PALAB1445, 66P, 135P; 18F; 146V, 210V, 454V

\begin{tabular}{lc}
\hline Frecuencia de citación (FC): & 92 \\
\hline Número de usos (NU): & 6 \\
\hline Número registros de uso (RU): & 110 \\
Frecuencia Relativa de Citación (FRC): & 0,66 \\
Índice de Importancia Cultural (IC): & 0,79 \\
Índice de Vigencia (IV): & 0,00 \\
\hline
\end{tabular}

Obtención: silvestre

Vigencia: abandonado

\section{Conocimientos:}

\section{ECOLOGÍA}

Se encuentra en bosques y en terrenos quemados o pastoreados.

\section{LÉXICO:}

Se denomina gamonita al escapo o tallo floral. El fitotopónimo "gamonal" define los lugares donde se crían gamones y en la Montaña
Palentina existen varios parajes con esta denominación en las localidades de: Cillamayor, Verdeña y Vergaño.

Usos:

\section{ALIMENTACIÓN ANIMAL}

- Forraje verde o seco (92): Durante la primavera y antes de que floreciera, se recolectaban hojas de gamones como alimento silvestre para la cría del cerdo, a menudo se acompañaban mezcladas con pienso molido, salvados $\mathrm{e}$ incluso con otros productos vegetales como: patatas pequeñas, peladuras, hojas de berza, etc. Habitualmente antes de servirlos se cocían durante un corto periodo de tiempo para que los pudieran digerir mejor.

Una vez pasada la floración las hojas secas se destinaban para alimento de ovejas y cabras.

- Plantas melíferas (2): La floración primaveral resulta de gran interés para las abejas, obteniendo néctar para la elaboración de miel.

\section{COMBUSTIBLE}

- Luz (6): Al escapo o tallo florido del gamón seco, se empleaba como mecha para encender el candil, también para iluminar en la noche alguna estancia a modo de pequeña antorcha o tea.

\section{INDUSTRIA Y ARTESANÍA}

- Vestimenta y adornos personales (1): LoS frutos poseen forma esférica y eran utilizados por los más jóvenes para elaborar pulseras y collares, engarzando varios con un hilo.

\section{MEDIOAMBIENTAL}

- Malas hierbas (4): A pesar de ser una planta apreciada por su utilidad, se trataba de erradicar su presencia en las praderas al presentar varios inconvenientes, el tallo robusto dificulta la siega de los prados y el ganado vacuno evita su consumo.

- Bioindicadores (1): Su presencia es indicadora de pastos de mala calidad.

\section{ORNAMENTAL}

- Adorno floral y plantas de interior (2): El racimo floral es muy vistoso durante la primavera, se cortaban las varas para destinarlas a la decoración en fresco de jarrones u otros recipientes.

\section{SOCIAL, SIMBÓLICO Y RITUAL}

- Uso recreativo (2): Los niños hacían uso de los gamones en típicos juegos infantiles como el de las comiditas, el fruto se asimilaba a algún alimento o comida. El tallo verde también se 
empleó en la fabricación de silbatos como entretenimiento infantil.

Observaciones: Es posible que también tuviera un uso medicinal en la Montaña, así lo apunta Gordaliza (1991) "el agua de hervir las hojas se usaba para curar los granos de la cara", empleo que no se ha podido contrastar.

\section{ANGIOSPERMAS DICOTILEDÓNEAS}

ADOXACEAE

\section{Sambucus ebulus L.}

Nuezgo (2), yezgo (2)

321P, 471P; 116F

\begin{tabular}{lc}
\hline Frecuencia de citación (FC): & 4 \\
\hline Número de usos (NU): & 4 \\
Número registros de uso (RU): & 4 \\
\hline Frecuencia Relativa de Citación (FRC): & 0,03 \\
Índice de Importancia Cultural (IC): & 0,03 \\
\hline Índice de Vigencia (IV): & 0,00 \\
\hline
\end{tabular}

Obtención: silvestre

Vigencia: abandonado

Conocimientos:

ECOLOGÍA

Aparece en los bordes de carreteras, cultivos y muros. En San Juan de Redondo nos advierten de que son muy abundantes, "son altas como los budaños (Conium maculatum) y echa una pandereta de flor blanca".

\section{LÉXICO:}

La inflorescencia de esta especie es un corimbo y se conoce popularmente como pandereta.

\section{Usos:}

\section{MEDICINA}

- Musculatura y esqueleto (1): La planta con o sin flor se cuece en agua y con el caldo obtenido se dan friegas en zonas con dolores reumáticos, también señalada como funcional para dolores de huesos y torceduras.

\section{VETERINARIA}

- Musculatura y esqueleto (1): La cocción de la planta es útil para tratar los golpes de los animales domésticos (ovejas y vacas). Con un trapo se aplicaba una cataplasma en la zona afectada.

\section{TÓXICO Y NOCIVO}

- Tóxica para humanos y animales (1): Se la reconoce como planta venenosa.

\section{MEDIOAMBIENTAL}

- Malas hierbas (1): En Verdeña la señalan como mala hierba que sale cerca de las paredes de los huertos y en los bordes de cultivos.

Observaciones: En la Sierra Norte de Madrid llaman venenales a varias especies, entre ellas el yezgo (Aceituno Mata, 2010).

\section{ADOXACEAE}

Sambucus nigra $\mathrm{L}$.

Saúco (46), saúgo (32), sabúgo (1), taco (1)

PALAB 2608, 24P, 385P; 10F; 129V, 183V, 184V, $185 \mathrm{~V}, 252 \mathrm{~V}, 261 \mathrm{~V}, 348 \mathrm{~V}, 383 \mathrm{~V}, 443 \mathrm{~V}, 539 \mathrm{~V}, 540 \mathrm{~V}$

\begin{tabular}{lc}
\hline Frecuencia de citación (FC): & 80 \\
\hline Número de usos (NU): & 8 \\
\hline Número registros de uso (RU): & 120 \\
\hline Frecuencia Relativa de Citación (FRC): & $\mathbf{0 , 5 8}$ \\
\hline Índice de Importancia Cultural (IC): & $\mathbf{0 , 8 6}$ \\
\hline Índice de Vigencia (IV): & $\mathbf{0 , 0 0}$ \\
\hline
\end{tabular}

Obtención: silvestre

Vigencia: vigente (12\%)

\section{Conocimientos:}

\section{ECOLOGÍA}

Se encuentra en bordes de caminos y cultivos, orillas de cursos de agua y junto a edificios derruidos o abandonados.

Para mejorar la eficacia de los remedios se aconsejó en Rebanal de las Llantas recoger antes de la salida del sol, la mañana del día de San Juan.

\section{LÉXICO:}

En la Montaña Palentina se usa indistintamente como nombre vulgar saúco o saúgo, en Triollo se recoge la derivación sabúgo y en Valcobero también se reconoce con el nombre de taco cuando su empleo se vincula a la fabricación de ciertos juguetes infantiles.

Algunos informantes llaman a la planta flor de saúco o flor de saúgo, haciendo alusión a la parte utilizada en los remedios.

Los frutos se identifican con el popular nombre de reventones cuando su uso es asociado a toxicidad, "Los reventones que salen en el saúgo dicen de no comerles por venenosos". (Tremaya).

Se documentan los fitotopónimos de los siguientes pagos: "El Sahúgo" en Aguilar de 
Campoo, "Sahugal" en Santibáñez de la Peña, y "Sahúco" en Verdeña

Usos:

\section{ALIMENTACIÓN HUMANA}

- Verduras y hortalizas (1): La inflorescencia es comestible, se recoge a primeros de junio en plena floración y se cocina en forma de sabrosas frituras. Una vecina nonagenaria de Vidrieros nos reveló que su uso comestible es reciente y antes no se comía en la zona. "Se corta la flor, se la reboza en huevo y harina, y está muy rica, lo he sabido después, pero está muy bueno".

- Frutas y frutos dulces (10): Se recogen los frutos bien maduros, desde principios de septiembre, momento en el adquieren un color casi negruzco. Se cuece la fruta y se mezcla con azúcar. También resulta reciente en el tiempo el conocimiento del uso de los frutos en la elaboración de mermeladas y confituras, ya que por lo general, no se aprovechaban en la zona al ser considerados venenosos.

- Bebidas alcohólicas (2): En Herreruela de Castillería y San Felices de Castillería se recogieron los únicos testimonios sobre la elaboración de licor, macerando un tiempo los frutos maduros en orujo.

\section{MEDICINA}

- Sistema digestivo (4): Para contrarrestar los dolores de muelas se han recogido varios remedios, desde inhalar por la boca los vahos producidos al quemar las flores en unas brasas, hasta hervir las flores en leche y miga de pan, con la que se realizaba una cataplasma aplicada sobre los flemones y muelas doloridas.

El licor obtenido con la maceración de los frutos del saúco en orujo, se recomienda en San Felices de Castillería, para favorecer la digestión y calmar el dolor de estomago.

- Sistema respiratorio (32): Destaca en la comarca el uso frecuente de las flores como remedio clásico en el tratamiento de catarros, resfriados o gripes, para los que se recogen distintas formas de administración: tomada en infusión con agua o leche, aplicada mediante cataplasma en el pecho mojando un paño o toalla en la infusión, en sahumerios y en vahos inhalados por la nariz. También válida para dolores de garganta o ronqueras mediante enjuagues con la infusión.

- Musculatura y esqueleto (20): Las flores de saúco se han utilizado de forma habitual como remedio vulnerario, para golpes, torceduras o hinchazones musculares, aplicado mediante friegas con aceite, en baños de agua caliente $o$ mediante cataplasma embadurnada en la cocción de las flores. En algunas ocasiones se aconseja mezclarlo con árnica (Inula montana), para potenciar sus propiedades antiinflamatorias.

- Piel y tejido celular subcutáneo (11): La infusión de las flores se emplea para lavar pequeñas heridas superficiales, y en el caso de producirse quemaduras se utiliza el parénquima cortical para preparar una crema con propiedades cicatrizantes y regeneradoras, cómo así nos detallan en Resoba: "La crema de saúco es un remedio que hacían de antiguo las abuelas con aceite de oliva y cera virgen. Se pela la corteza del saúco, lo leñoso y se coge la segunda capa, que es verde y blandita. Lo frío en aceite de oliva, después deshago un poco de cera que aparto cuando catamos y en caliente lo hecho a los tarros. Se usa de siempre para las quemaduras, te quita el dolor y no te queda ni una cicatriz". En esta misma localidad, se indica que la crema también es eficaz para curar eccemas, granos y diviesos.

- Sistema nervioso (1): Una vecina de Celada de Roblecedo nos aconsejó para aliviar el dolor de cabeza, un paño caliente en la frente, empapado en la infusión de flores de saúco.

- Órganos de los sentidos (5): Se emplea la infusión de las flores de saúco, solas o mezcladas con manzanilla (Chamaemelun nobile), para lavar los ojos aquejados por alguna afección ocular.

\section{VETERINARIA}

- Sistema respiratorio (1): En Rebanal de las Llantas se recoge un testimonio sobre el uso de las flores quemadas para tratar el catarro del ganado vacuno. "Los sahumerios de saúco eran para aspirar los animales con catarro. Lo quemabas en una vasija la flor, con unas brasas y aspiraban los humos".

- Musculatura y esqueleto (6): Al igual que para personas, es remedio vulnerario válido para animales con golpes e hinchazones. La infusión de la inflorescencia se aplica mediante compresas calientes, en la zona afectada.

En el caso de que la hinchazón no procediera de un golpe, se ahumaba la parte inflamada con los vapores procedentes de quemar unas pocas flores.

- Piel y tejido celular subcutáneo (3): Las heridas de los animales (cabras, ovejas y vacas) se lavaban y desinfectaban con la infusión de las flores. "Saúgo se tenía siempre en casa, para cuando mordía el lobo a las ovejas", Roscales de la Peña. 


\section{TóXICO Y NOCIVO}

- Venenos, insecticidas y plaguicidas (2): En San Salvador de Cantamuda un pequeño horticultor nos mostró su uso como plaguicida. El líquido resultante del cocimiento de flores y hojas lo emplea como repelente general contra roedores y topos.

- Tóxicas para humanos o animales (3): En la Montaña Palentina se recogen varias citas sobre la toxicidad de los frutos (reventones), que por lo general, advierten a los más jóvenes sobre su consumo prohibido.

\section{COMBUSTIBLE}

- Leña (1): En circunstancias ocasionales (restos de poda, desbroce de linderas...) se utiliza el saúco como combustible para quemar en la lumbre. Su madera es menos apreciada que la de roble o haya, además menos abundante y con menor poder calorífico.

\section{INDUSTRIA Y ARTESANÍA}

- Sustancias tintóreas y pinturas (1): Los frutos del saúco una vez maduros tienen propiedades colorantes, con gran facilidad para teñir de negro. En Verdeña se recuerda como los carpinteros en el pasado, teñían con frutos muy maduros las cuerdas que servían como marca para hacer el corte.

- Herramientas y utensilios (4): La madera de saúco se menciona apropiada por su duración, para la confección de rastros.

En Valcobero se fabricaba con las hojas de saúco una escoba para barrer las cenizas del horno del pan. En esta misma localidad, se usaban ramos de hojas a modo de hisopo para aplicar a las vacas el zotal (compuesto fenólico de color azulado y olor intenso, empleado como desinfectante de heridas y como repelente de insectos).

- Juguetes $e$ instrumentos deportivos $y$ musicales (10): Las principales características de la madera de saúco son su ligereza y fragilidad, excelente para elaborar silbatos o chiflos a partir de ramas a las que se extrae la médula para obtener la forma de flauta deseada.

También con las ramas, los niños tenían por costumbre fabricar juguetes que funcionaban a modo de jeringuilla, introduciendo un trozo de rama que se ajustaba al diámetro hueco de la rama de saúco, pudiendo disparar agua, pequeños trozos de tela o de estopa, y que recibían nombres diversos como: chirote, tiragüas o tiratacos.

\section{ORNAMENTAL}

- Adorno floral (2): Su uso ornamental no es muy frecuente, solamente en Cillamayor se refiere el uso decorativo de las inflorescencias, como elemento decorativo de interior en jarrones de flor.

\section{SOCIAL, SIMBÓLICA Y RITUAL}

- Ritual de ciclo anual (1): En la localidad de Matabuena se señala su uso para realizar la tradicional enramada en la festividad de San Juan. Los ramos floridos destacaban como ornamento en las casas de las mozas, en ocasiones se combinaban con ramas del olmo.

Observaciones: Los usos alimentarios del saúco han aumentado en la actualidad en la zona, al evolucionar la valoración negativa y tóxica que se tenía en el pasado de sus propiedades.

La recolección de las flores para uso medicinal se realiza tradicionalmente el día de San Juan, juntando los racimos en manojos o atadillos dispuestos para su secado y conservación.

Según López González (2002), las hojas, los frutos verdes y la corteza fresca son ligeramente tóxicos debido a la sambunigrina, un heterósido cianogénico, no así flores y frutos maduros que son comestibles.

En Santibáñez de la Peña se recordaba el uso de un producto conocido como: "Bálsamo de Lucatello", según varios vecinos lo elaboraban los boticarios de Guardo, se aplicaba sobre los golpes y estaba compuesto por los siguientes ingredientes: médula de saúgo, cera de abeja y aceite.

Diversos usos coinciden con los documentados en la comarca del Cerrato Palentino (Pascual et al., 2016) para elaborar mermeladas, como medicinal en el tratamiento de heridas $y$ eczemas, como tintórea para teñir el textil de negro, para fabricar chiflos y jeringas, como adorno floral de interior y para decorar en varias fiestas populares tradicionales $y$ religiosas.

ADOXACEAE

Viburnum lantana L.

Barbadillo (2), petruco (1), petrujo (1), sangricio (1)

PALAB2506, 192P; 235F; 602V

\begin{tabular}{lc}
\hline Frecuencia de citación (FC): & 5 \\
\hline Número de usos (NU): & 2 \\
\hline Número registros de uso (RU): & 6 \\
\hline Frecuencia Relativa de Citación (FRC): & $\mathbf{0 , 0 4}$ \\
\hline Índice de Importancia Cultural (IC): & $\mathbf{0 , 0 4}$ \\
\hline Índice de Vigencia (IV): & $\mathbf{0 , 0 0}$ \\
\hline
\end{tabular}


Obtención: silvestre

Vigencia: abandonado

\section{Conocimientos:}

\section{ECOLOGÍA}

"Son como árboles pero pequeños que salen en las linderas de los montes, echan muchas ramas bien cargadas de flores y cuando echa el fruto primero es verde, luego rojo y después negro" (Cubillo de la Peña).

\section{LÉXICO:}

El nombre vulgar barbadillo describe a la planta, sin embargo el resto de nombres recogidos (petruco, petrujo y sangricio) hace referencia tanto a la planta como a los frutos.

Usos:

\section{ALIMENTACIÓN HUMANA}

- Frutas y frutos dulces (4): Los frutos bien maduros son comestibles, su punto óptimo para el consumo se detecta por el color negruzco que adquieren.

\section{INDUSTRIA Y ARTESANÍA}

- Herramientas y utensilios (2): Las ramas más rectas sirven para algún utensilio. En concreto, en Verdeña recuerdan el palo de la rueca y las varas de arrear el ganado de madera barbadillo.

Observaciones: Los nombres de los frutos son naturales de la Montaña Palentina, no encontrándose referencias similares en la bibliografía consultada.

ADOXACEAE

Viburnum opulus L.

Copo de nieve (3)

332P; 161F; 194V, 253V

\begin{tabular}{|ll|}
\hline Frecuencia de citación (FC): & 4 \\
\hline Número de usos (NU): & 2 \\
\hline Número registros de uso (RU): & 5 \\
\hline
\end{tabular}

Obtención: cultivada

Vigencia: vigente (40\%)

Conocimientos:

LÉXICO:

Los frutos se denominan popularmente copos.

Usos:

ORNAMENTAL

- Patios, huertos y jardines (3): Se cultiva en jardines.
SOCIAL, SIMBÓLICO Y RITUAL

- Ritual de ciclo anual (2): Las flores blancas y muy vistosas servían para adornar la iglesia local durante el mes de mayo y los altares dispuestos en las calles en la celebración de la fiesta del Corpus Christi.

Observaciones: Se han obtenido solo dos citas de su cultivo como ornamental en jardín, pero se ha observado de modo reiterado su implantación en los jardines de la zona.

AMARANTHACEAE

Beta vulgaris var. altissima Döll

Remolacha (6), remolacha forrajera (2)

\begin{tabular}{|lc|}
\hline Frecuencia de citación (FC): & 8 \\
\hline Número de usos (NU): & 3 \\
\hline Número registros de uso (RU): & 10 \\
\hline
\end{tabular}

Obtención: cultivada

Vigencia: vigente (25\%)

Usos:

\section{ALIMENTACIÓN HUMANA}

- Raíces, bulbos, tubérculos y rizomas (1): Se consume la raíz de la remolacha como hortaliza de mesa.

\section{ALIMENTACIÓN ANIMAL}

- Forraje verde o seco (8): Cultivada esta especie para servir las hojas cocidas a vacas y cerdos. La remolacha se cultivaba como forraje para vacas y cerdos. Para las vacas en crudo y para los cerdos cocidas, en ocasiones junto con patatas pequeñas y hojas de berza.

\section{SOCIAL, SIMBÓLICO Y RITUAL}

- Alucinógenas, narcóticas y fumatorias (1): En Santibáñez de la Peña afirman que las hojas de la remolacha forrajera se fumaban secas, cuando el tabaco escaseaba.

Observaciones: Solo en Resoba y en San Felices de Castillería se mencionó el uso de la remolacha azucarera frente a la forrajera, mucho más común.

La variedad roja de consumo en mesa se ha ido incluyendo en el huerto de la casa ya que no era tradicional su cultivo, un surco o dos para abastecimiento particular.

Se recoge el testimonio en Salinas de Pisuerga sobre la plantación de remolacha forrajera para la obtención de semilla que se vendía a cooperativas. 


\section{AMARANTHACEAE}

Beta vulgaris var. cicla $\mathrm{L}$.

Acelga (2)

\begin{tabular}{ll}
\hline $226 \mathrm{~F}$ & \\
\hline Frecuencia de citación (FC): & 2 \\
\hline Número de usos (NU): & 1 \\
\hline Número registros de uso (RU): & 2 \\
\hline
\end{tabular}

Obtención: cultivada, comprada

Vigencia: vigente (50\%)

Usos:

\section{ALIMENTACIÓN HUMANA}

- Verduras y hortalizas (2): Se cultiva para aprovechar las hojas, de normal consumidas cocidas como acompañamiento en guisos.

Observaciones: Incorporada con lentitud, en la actualidad es un cultivo habitual en los huertos de la comarca.

\section{AMARANTHACEAE}

Chenopodium album $\mathrm{L}$.

Ramagón (5), sallo (2), layo (1), ceñilgo (1), cenizo (1)

\begin{tabular}{lc} 
44P; 300F; 354V & \\
\hline Frecuencia de citación (FC): & 10 \\
\hline Número de usos (NU): & 2 \\
\hline Número registros de uso (RU): & 11 \\
Frecuencia Relativa de Citación (FRC): & $\mathbf{0 , 0 7}$ \\
Índice de Importancia Cultural (IC): & $\mathbf{0 , 0 8}$ \\
\hline Índice de Vigencia (IV): & $\mathbf{0 , 0 0}$ \\
\hline
\end{tabular}

Obtención: silvestre

Vigencia: abandonado

Conocimientos:

ECOLOGÍA:

Aparece de modo asiduo en huertos y patateras. "Sale en tierra removida, en huertos sí, en camperas no. Produce mucha grana y cuesta mucho arrancarla".

\section{LÉXICO:}

El nombre vulgar sallo deriva del verbo sallar que significa escardar, por tanto el sallo define a todas las plantas que han de ser eliminadas de los cultivos. Pero también se denomina sallo a las plantas que se dan como forraje al ganado y que proceden de la escarda.

Usos:

ALIMENTACIÓN ANIMAL
- Forraje verde o seco (1): En la localidad de Camporredondo se recoge el testimonio sobre el uso de los glomérulos como forraje para los cerdos, "Los cenizos que salían entre las patatas se ordeñaban, se cogían las bolitas finitas y pa los cerdos".

\section{MEDIOAMBIENTAL}

- Malas hierbas (10): Considerada mala hierba, perseverante en huertos y cultivos de patata.

Observaciones: En la zona también se encuentran Chenopodium bonus-henricus y $C$. vulvaria, con probabilidad también mencionadas con los mismos nombres vulgares.

AMARANTHACEAE

\section{Spinacia oleracea L.}

Espinaca (1)

\begin{tabular}{ll|}
\hline Frecuencia de citación (FC): & 1 \\
\hline Número de usos (NU): & 1 \\
\hline Número registros de uso (RU): & 1 \\
\hline
\end{tabular}

Obtención: cultivada, comprada

Vigencia: vigente $(100 \%)$

Usos:

ALIMENTACIÓN HUMANA

- Verduras y hortalizas (1): Se consumen las hojas cocidas como hortaliza de mesa.

Observaciones: Introducida en los huertos desde hace unos pocos años, incrementándose su cultivo en la actualidad.

APIACEAE

Angelica sylvestris L.

Angélica (1), chiflato (1)

265P, 312P; 229F; 224V

\begin{tabular}{lc}
\hline Frecuencia de citación (FC): & 2 \\
\hline Número de usos (NU): & 4 \\
\hline Número registros de uso (RU): & 5 \\
\hline Frecuencia Relativa de Citación (FRC): & 0,01 \\
\hline Índice de Importancia Cultural (IC): & 0,04 \\
\hline Índice de Vigencia (IV): & 0,00 \\
\hline
\end{tabular}

Obtención: silvestre

Vigencia: abandonado

Conocimientos:

ECOLOGÍA:

Son altos y salen en los prados. 
LÉXICO:

El nombre vulgar chiflato deriva del uso atribuido en Vidrieros.

Usos:

\section{ALIMENTACIÓN HUMANA}

- Golosinas y masticatorias (1): El tallo pelado en sus primeras fases de desarrollo lo consumían los más jóvenes, en Vidrieros señalan que "el tallito corto y tiernecito es cuando sabe mejor, muy parecido al apio".

\section{MEDICINA}

- Sistema circulatorio (1): La infusión de las flores hervidas en agua se toma como remedio purificador, sobre todo cuando aparecen granos en la piel derivados de trastornos generales del aparato circulatorio.

\section{VETERINARIA}

- Sistema digestivo (1): Con la inflorescencia hervida en agua se prepara un caldo que se administra tibio en una botella a las vacas que están empachadas o con gases, síntomas principales del timpanismo.

- Enfermedades "culturales" (1): La enfermedad de "la traidora", señalan en Arbejal, se observa en el ganado vacuno con síntomas de nerviosismo, rabia, ansiedad e hinchazón, para tratar estos síntomas, se cocía un puchero con la inflorescencia y se administraba por la boca con una botella.

\section{INDUSTRIA Y ARTESANÍA}

- Juguetes e instrumentos deportivos $y$ musicales (1): Con el tallo hueco seco se hacían chiflos o silbatos.

Observaciones: Un informante de Arbejal nos advierte del parecido existente entre la cicuta (Conium maculatum) que es venenosa y la angélica.

\section{APIACEAE}

Anthriscus sylvestris (L.) Hoffm.

Canuto (1)

\begin{tabular}{lc}
\hline 244P, 483P; 323F & \\
\hline Frecuencia de citación (FC): & 1 \\
\hline Número de usos (NU): & 1 \\
\hline Número registros de uso (RU): & 1 \\
\hline Frecuencia Relativa de Citación (FRC): & $\mathbf{0 , 0 1}$ \\
\hline Índice de Importancia Cultural (IC): & $\mathbf{0 , 0 1}$ \\
\hline Índice de Vigencia (IV): & $\mathbf{0 , 0 0}$ \\
\hline
\end{tabular}

Obtención: silvestre
Vigencia: abandonado

\section{Conocimientos:}

\section{LÉXICO:}

El nombre vulgar canuto deriva de la forma del tallo hueco. Son varias las especies reconocidas por el mismo nombre popular: Anthriscus sylvestris, Chaerophyllum aureum, C. hirsutum y Conium maculatum.

Usos:

ALIMENTACIÓN ANIMAL

- Forraje verde o seco (1): Se recoge para el ganado vacuno como forraje.

APIACEAE

\section{Apium graveolens $\mathrm{L}$.}

Apio (5)

\begin{tabular}{ll}
\hline $188 \mathrm{~F}$ & \\
\hline Frecuencia de citación (FC): & 5 \\
\hline Número de usos (NU): & 2 \\
\hline Número registros de uso (RU): & 5 \\
\hline
\end{tabular}

Obtención: cultivada, comprada

Vigencia: vigente (60\%)

Usos:

ALIMENTACIÓN HUMANA

- Verduras y hortalizas (4): Se usa como verdura para guisos o purés y en menor medida para ensaladas.

\section{MEDICINA}

- Enfermedades infecciosas y parasitarias (1): El apio machacado y hervido con un poco de leche se administraba a los niños que padecían lombrices.

Observaciones: Incluida en el huerto de la casa en las últimas décadas ya que no era tradicional su cultivo.

Apium nodiflorum (L.) Lag. Berra (2)

\begin{tabular}{lc}
\hline $445 \mathrm{P} ; 264 \mathrm{~F}$ \\
\hline Frecuencia de citación (FC): & $\mathbf{2}$ \\
\hline Número de usos (NU): & $\mathbf{1}$ \\
\hline Número registros de uso (RU): & $\mathbf{2}$ \\
\hline Frecuencia Relativa de Citación (FRC): & $\mathbf{0 , 0 1}$ \\
\hline Índice de Importancia Cultural (IC): & $\mathbf{0 , 0 1}$ \\
\hline
\end{tabular}

Obtención: silvestre 
Conocimientos:

\section{ECOLOGÍA:}

Se desarrolla en ríos, arroyos y fuentes, en los mismos lugares que el berro.

\section{LÉXICO:}

El nombre vulgar berro en masculino es comestible, en femenino la berra no lo es.

\section{Usos:}

\section{TÓXICO Y NOCIVO}

- Tóxica para personas y animales (2): Al recoger los berros había que distinguirlos bien para no confundir estas dos especies, las indicaciones advierten que no son comestibles.

Observaciones: En Pisón de Castrejón saben como diferenciarlas por su morfología, "el berro tiene la hoja redonda y la berra un poco picuda".

APIACEAE

\section{Carum carvi L.}

Anís (1)

\begin{tabular}{lc}
\hline $81 \mathrm{~F}$ & \\
\hline Frecuencia de citación (FC): & 1 \\
\hline Número de usos (NU): & 1 \\
\hline Número registros de uso (RU): & 1 \\
\hline Frecuencia Relativa de Citación (FRC): & $\mathbf{0 , 0 1}$ \\
\hline Índice de Importancia Cultural (IC): & $\mathbf{0 , 0 1}$ \\
\hline Índice de Vigencia (IV): & $\mathbf{0 , 0 0}$ \\
\hline
\end{tabular}

Obtención: silvestre

Vigencia: abandonado

Usos:

\section{MEDICINA}

- Sistema respiratorio (1): Se toma la infusión de los frutos para el tratamiento de catarros y para descongestionar las vías respiratorias.

\section{APIACEAE}

\section{Caucalis platycarpos L.} Cadillo (6)

185P, 490P; 209F

\begin{tabular}{lc}
\hline Frecuencia de citación (FC): & 6 \\
\hline Número de usos (NU): & 3 \\
\hline Número registros de uso (RU): & 7 \\
\hline Frecuencia Relativa de Citación (FRC): & 0,04 \\
\hline Índice de Importancia Cultural (IC): & 0,05 \\
\hline
\end{tabular}

Obtención: silvestre

\section{Conocimientos:}

\section{ECOLOGÍA:}

Orillas de caminos y cultivos de cereal.

\section{LÉXICO:}

En la zona se reconoce por cadillos a los frutos de Arctium minus, Caucalis platycarpos y Ranunculus arvensis, todos tienen la capacidad de adherirse mediante pequeños ganchos a tejidos o pelos.

Usos:

\section{MEDIOAMBIENTAL}

- Malas hierbas (6): Considerada una de las especies más invasivas de los cultivos de cereales, se procuraba su escarda.

\section{SOCIAL, SIMBÓLICO Y RITUAL}

- Literatura oral popular (1): "Al trigo, el cadillo lo da brillo, el amapol le da color y la lapa lo agazapa".

Observaciones: En la comarca del Cerrato denominan cadillo a las siguientes especies: Anthriscus caucalis, Arctium minus, Galium aparine, Torilis arvensis y Xanthium spinosum.

APIACEAE

\section{Chaerophyllum aureum $\mathrm{L}$. Canuto (1)}

465P; 270V

\begin{tabular}{lc}
\hline Frecuencia de citación (FC): & 1 \\
\hline Número de usos (NU): & 2 \\
\hline Número registros de uso (RU): & 2 \\
\hline Frecuencia Relativa de Citación (FRC): & $\mathbf{0 , 0 1}$ \\
\hline Índice de Importancia Cultural (IC): & 0,01 \\
\hline Índice de Vigencia (IV): & $\mathbf{0 , 0 0}$ \\
\hline
\end{tabular}

Obtención: silvestre

Vigencia: abandonado

Usos:

ALIMENTACIÓN ANIMAL

- Forraje verde o seco (1): Se añade como suplemento alimenticio en los comederos de las vacas.

\section{ORNAMENTAL}

- Adorno floral y plantas de interior (1): Ramos de inflorescencias se llevan a la iglesia con motivo ornamental. 
APIACEAE

Chaerophyllum hirsutum L.

Perejil (1), canuto (1)

509P; 96V

\begin{tabular}{lc}
\hline Frecuencia de citación (FC): & 2 \\
\hline Número de usos (NU): & 1 \\
\hline Número registros de uso (RU): & 2 \\
\hline Frecuencia Relativa de Citación (FRC): & 0,01 \\
\hline Índice de Importancia Cultural (IC): & 0,01 \\
\hline Índice de Vigencia (IV): & 0,00 \\
\hline
\end{tabular}

Obtención: silvestre

Vigencia: abandonado

Usos:

ORNAMENTAL

- Adorno floral y plantas de interior (2): La inflorescencia forma parte de centros decorativos de flor seca, en el hogar y en la iglesia.

APIACEAE

Conium maculatum L.

Budaño (13), muzgaño (1), cañiguerra (2), canuto (1), cicuta (2)

PALAB1322, 70P, 501P; 135F; 14V, 102V, 271V, 374V, 459V

\begin{tabular}{lc}
\hline Frecuencia de citación (FC): & 21 \\
\hline Número de usos (NU): & 6 \\
\hline Número registros de uso (RU): & 25 \\
\hline Frecuencia Relativa de Citación (FRC): & 0,15 \\
Índice de Importancia Cultural (IC): & 0,18 \\
\hline Índice de Vigencia (IV): & 0,01 \\
\hline
\end{tabular}

Obtención: silvestre

Vigencia: vigente (4\%)

Conocimientos:

ECOLOGÍA:

Sale en márgenes de tierras, linderas y a orillas de muros.

\section{LÉXICO:}

Tanto cañiguerra como canuto hacen alusión a plantas con el tallo hueco, sin embargo cicuta se cita para señalarla como planta tóxica.

Usos:

\section{ALIMENTACIÓN ANIMAL}

- Forraje verde o seco (6): Se segaban para servir como forraje de vacas y conejos.

- Pasto (6): El ganado vacuno pace con avidez la planta tierna.

\section{TÓXICA Y NOCIVA}

- Tóxica para personas y animales (5): Si las vacas pacían muchos budaños se acumulaban gases en el estomago y se hinchaban, por lo que se procuraba vigilar que no lo comieran en exceso.

"Les dejaba pacer algo, pero se implaban sobre todo si lo comían mojado con el rocío" (Lores). También se reconoce como tóxica para las personas.

\section{CONSTRUCCIÓN}

- Casas, edificios e instalaciones agropecuarias (2): Para asentar la teja se siegan y se colocan sobre la ripia de las construcciones.

\section{INDUSTRIA Y ARTESANÍA}

- Juguetes $e$ instrumentos deportivos $y$ musicales (2): Aprovechando el tallo hueco seco se hacían chiflos o silbatos.

\section{MEDIOAMBIENTAL}

- Mejora del suelo (1): Cuando escaseaba la paja de cereal se echaban budaños como mullida para cerdos o vacas.

- Malas hierbas (1): Se considera mala hierba a erradicar de hortales y huertas ya que se propaga con facilidad.

\section{ORNAMENTAL}

- Adorno floral y plantas de interior (2): Incluida la inflorescencia en algún centro de flor seca.

Observaciones: Estamos ante una especie un tanto contradictoria en sus usos, algunos informantes la sirven como forraje, mientras que otros la consideran tóxica o restringen su consumo. Font Quer (1961) al respecto dice de ella que los alcaloides se encuentran principalmente en los frutos aun no maduros y que las hojas contienen cuatro veces menos. Como la planta fructifica a partir de julio, y su consumo es normalmente anterior, quizás sea esta la causa de que fuera posible un cierto consumo.

Debido al parecido morfológico de varias especies de esta familia, es probable que bajo el nombre budaño también se englobaran Anthriscus sylvestris y alguna especie del género Chaerophyllum.

\section{APIACEAE}

Conopodium majus (Gouan) Loret

C. pyrenaeum (Loisel.) Miégev. 
Ajuérjano (38), caguergano (1), pera de la vega (1), mantecón (2)

Conopodium majus: 109P; $247 \mathrm{~F}$

C. pyrenaeum: PALAB1617, 167P, 138P; 149F; 15V, $355 \mathrm{~V}, 455 \mathrm{~V}$

\begin{tabular}{lc}
\hline Frecuencia de citación (FC): & 41 \\
\hline Número de usos (NU): & 2 \\
\hline Número registros de uso (RU): & 42 \\
\hline Frecuencia Relativa de Citación (FRC): & $\mathbf{0 , 2 9}$ \\
\hline Índice de Importancia Cultural (IC): & $\mathbf{0 , 3 0}$ \\
\hline Índice de Vigencia (IV): & $\mathbf{0 , 0 0}$ \\
\hline
\end{tabular}

Obtención: silvestre

Vigencia: abandonado

\section{Conocimientos:}

\section{ECOLOGÍA:}

Los jóvenes buscaban esta planta con avidez en prados, bosques y sobre todo en las tierras que se araban, momento en el cual afloraba a la superficie el deseado tubérculo. Otra forma de obtención era escarbar la tierra alrededor con un palo o navaja hasta hallarlo en la profundidad.

\section{LÉXICO:}

Se denomina del mismo modo tanto el tubérculo como a toda la planta.

El término ajuérjano, es propio y endémico de la Montaña Palentina. Como excepción, en San Martín de los Herreros recibe el nombre de pera de la vega, en Cillamayor y Salinas de Pisuerga el nombre de mantecón.

Usos:

\section{ALIMENTACIÓN HUMANA}

- Golosinas y masticatorias (39): El tubérculo era estimado en tiempos de escasez y necesidad.

La época propicia para la recolección es la primavera y la forma tradicional de consumo era directamente en el campo, una vez extraído, se pelaba retirando la cáscara que lo recubre, se limpiaba un poco y ya estaba listo para degustarlo. En ocasiones, se dejaban secar al sol unas horas, ya que de este modo se potencia el sabor, que es similar al de una castaña o una avellana

\section{ALIMENTACIÓN ANIMAL}

- Pasto (3): Varios informantes señalaron la apetencia de animales como la cigüeña, el jabalí o el cerdo por el tubérculo.

Observaciones: Aunque Conopodium majus produce tubérculos un poco más grandes que
C. pyrenaeum, son dos especies difíciles de diferenciar en campo.

En la tradición o romance de la "Despoblación de Carracedo" publicada por el ilustre don Matías Barrio y Mier en 1908, ya se recogía un fragmento en el que aparecen "En sus tiempos oportunos gustó endrinas, amajuelas... y ajuérjanos de las tierras".

\section{APIACEAE}

\section{Daucus carota L.} Zanahoria (10)

\begin{tabular}{|lc|}
\hline Frecuencia de citación (FC): & 10 \\
\hline Número de usos (NU): & 2 \\
\hline Número registros de uso (RU): & 10 \\
\hline
\end{tabular}

Obtención: cultivada, comprada

Vigencia: vigente (100\%)

Usos:

\section{ALIMENTACIÓN HUMANA}

- Raíces, bulbos, tubérculos y rizomas (9): Se cultiva por su raíz que se consume por lo general cocida en guisos o purés y en menor medida cruda en ensaladas. En la actualidad, con los excedentes de la producción algunas amas de casa realizan mermeladas.

\section{ALIMENTACIÓN ANIMAL}

- Raíces y tubérculos (1): Las zanahorias más imperfectas en tamaño y forma se apartaban para el sustento de los conejos.

Observaciones: Este cultivo, hoy en día común, no formaba parte del huerto tradicional hasta hace unas pocas décadas.

\section{APIACEAE}

Eryngium bourgatii Gouan.

Cardo azul (10), cardo morado (6), cardo (5), cardo burriquero (1), cardo santo (1), cardo del ejido (1)

93P, 453P; 43F; 157V, 410V

\begin{tabular}{lc}
\hline Frecuencia de citación (FC): & 24 \\
\hline Número de usos (NU): & 2 \\
\hline Número registros de uso (RU): & 25 \\
\hline Frecuencia Relativa de Citación (FRC): & 0,17 \\
\hline Índice de Importancia Cultural (IC): & 0,18 \\
\hline Índice de Vigencia (IV): & 0,03 \\
\hline
\end{tabular}

Obtención: silvestre

Vigencia: vigente (15\%) 
Usos:

\section{ALIMENTACIÓN ANIMAL}

- Pasto (1): En Vidrieros una vecina señala esta especie como pasto de burros y cabras.

\section{ORNAMENTAL}

- Adorno floral y plantas de interior (24): Se ha utilizado tradicionalmente en centros de flor seca, sola o acompañando a otras especies, para decorar el interior del hogar o la iglesia. Florece durante el verano y una vez recogido tiene la virtud de ser resistente y mantener su coloración azul en perfectas condiciones durante un largo tiempo.

APIACEAE

\section{Eryngium campestre L.}

Cardo (9), cardo borriquero (1)

\begin{tabular}{lc} 
46P, 434P; 198F; 483V & \\
\hline Frecuencia de citación (FC): & 10 \\
\hline Número de usos (NU): & 2 \\
\hline Número registros de uso (RU): & 10 \\
\hline Frecuencia Relativa de Citación (FRC): & 0,07 \\
Índice de Importancia Cultural (IC): & 0,07 \\
\hline Índice de Vigencia (IV): & $\mathbf{0 , 0 0}$ \\
\hline
\end{tabular}

Obtención: silvestre

Vigencia: abandonado

Usos:

ALIMENTACIÓN ANIMAL

- Pasto (1): Los comen los burros cuando están tiernos.

\section{MEDIOAMBIENTAL}

- Bioindicadores (9): A este cardo se asocia la seta Pleurotus eryngii, de ahí que sea un buen indicador para su búsqueda en el campo.

Foeniculum vulgare Mill.

Hinojo (3), anís, (1), comino (1)

\begin{tabular}{lc} 
163P; 147F \\
\hline Frecuencia de citación (FC): & 4 \\
\hline Número de usos (NU): & 2 \\
\hline Número registros de uso (RU): & 4 \\
Frecuencia Relativa de Citación (FRC): & $\mathbf{0 , 0 3}$ \\
Índice de Importancia Cultural (IC): & $\mathbf{0 , 0 3}$ \\
\hline Índice de Vigencia (IV): & $\mathbf{0 , 0 1}$ \\
\hline
\end{tabular}

Obtención: silvestre, cultivada

Vigencia: vigente (25\%)

\section{Conocimientos:}

\section{ECOLOGÍA:}

Se puede encontrar esta especie tanto de forma silvestre como cultivada en huertos.

\section{LÉXICO:}

Comino sirve para denominar a la planta, a los frutos o semillas se los llama grana en el argot popular.

Usos:

\section{ALIMENTACIÓN HUMANA}

- Golosinas y masticatorias (3): Las hojas se chupan para obtener un sabor dulce anisado en la boca.

\section{MEDICINA}

- Sistema digestivo (1): Con los frutos se preparaba una infusión para eliminar los gases del estomago.

Observaciones: En San Juan de Redondo citan esta planta como un ingrediente empleado en las comidas de los gitanos ambulantes.

APIACEAE

Heracleum sphondylium L.

Hoja de patacaballo (1), patacaballo (1)

\begin{tabular}{lc} 
222P, 517P; 322F; 113V, 114V & \\
\hline Frecuencia de citación (FC): & $\mathbf{2}$ \\
\hline Número de usos (NU): & $\mathbf{1}$ \\
Número registros de uso (RU): & $\mathbf{2}$ \\
Frecuencia Relativa de Citación (FRC): & $\mathbf{0 , 0 1}$ \\
Índice de Importancia Cultural (IC): & $\mathbf{0 , 0 1}$ \\
\hline Índice de Vigencia (IV): & $\mathbf{0 , 0 0}$ \\
\hline
\end{tabular}

Obtención: silvestre

Vigencia: abandonado

Usos:

\section{ALIMENTACIÓN ANIMAL}

- Forraje verde o seco (2): Las hojas de gran tamaño sirven de alimento a cerdos y conejos.

Petroselinum crispum (Mill.) Fuss

Perejil (22)

271F; 288V

\begin{tabular}{|lc|}
\hline Frecuencia de citación (FC): & 22 \\
\hline Número de usos (NU): & 1 \\
\hline Número registros de uso (RU): & 22 \\
\hline
\end{tabular}

Obtención: cultivada 
Vigencia: vigente (100\%)

Usos:

\section{ALIMENTACIÓN HUMANA}

- Condimentos y conservantes (22): Las hojas se utilizan como condimento en multitud de recetas de cocina.

Observaciones: Se cultiva en muchos huertos y en pequeñas macetas próximas a las viviendas, para disponer de ello de forma accesible, llegando a asilvestrarse con facilidad en las cercanías del cultivo.

APIACEAE

Scandix australis L.

Anís (36), anís de lastra (3)

PALAB2407, 178P; 48F; 66V

\begin{tabular}{|lc|}
\hline Frecuencia de citación (FC): & 39 \\
\hline Número de usos (NU): & 5 \\
\hline Número registros de uso (RU): & 44 \\
\hline Frecuencia Relativa de Citación (FRC): & $\mathbf{0 , 2 8}$ \\
\hline Índice de Importancia Cultural (IC): & $\mathbf{0 , 3 2}$ \\
\hline Índice de Vigencia (IV): & $\mathbf{0 , 0 2}$ \\
\hline
\end{tabular}

Obtención: silvestre

Vigencia: vigente (6\%)

Conocimientos:

ECOLOGÍA:

Esta especie se distribuye en pastizales pedregosos sobre calizas, hecho bien conocido por todos los informantes que señalan su presencia en peñas, calares o lastras, y de la cual deriva uno de los nombres recogidos: "anís de lastra".

Usos:

\section{ALIMENTACIÓN HUMANA}

- Condimentos y conservantes (2): Esta especie posee un agradable sabor dulzón que recuerda al del anís, se consume la parte aérea (tallos y hojas) como condimento principalmente en guisos, aunque también se añade para aromatizar en otras recetas, como sopas.

- Golosinas y masticatorias (32): La parte aprovechada son los tallos tiernos con hojas, en ocasiones también los frutos. Se recolecta durante la primavera $y$ se consume directamente en el campo, cruda, chupando o masticando hojas, tallos o frutos, de los cuales se obtiene un delicioso sabor anisado.

\section{MEDICINA}

- Sistema digestivo (2): La parte aérea incluidos los frutos o solo los frutos, se aconseja como un buen tratamiento digestivo en caso de malestar estomacal, con propiedades carminativas para aliviar los gases. Se toman los frutos en crudo directamente sin preparación alguna o se hace una infusión con la parte aérea.

- Sistema respiratorio (1): La infusión de la parte aérea se toma en Triollo como remedio anticatarral.

\section{VETERINARIA}

- Sistema digestivo (1): La acumulación de gases en el estomago del ganado vacuno provoca hinchazón y malestar, llegando a causar en los casos más severos la muerte del animal. Para tratar este problema se suministraba al animal afectado orujo con anís macerado, por vía oral. Este remedio fue recogido en San Felices de Castillería.

\section{INDUSTRIA Y ARTESANÍA}

- Cosmética, perfumería y limpieza (2): Se cita en Estalaya el uso de la parte aérea como ambientador para el hogar. Los ramilletes recolectados durante la primavera desprenden un agradable aroma persistente durante varias semanas.

\section{SOCIAL, SIMBÓLICO Y RITUAL}

- Alucinógenas, narcóticas y fumatorias (4): Las hojas secas y picaditas se usaron como sustituto del tabaco, utilizado por jóvenes que se iniciaban en el consumo del tabaco como un juego.

APIACEAE

\section{Thapsia villosa $\mathrm{L}$.}

Tagarno (5), tagarnio (2)

103P, 202P; 141F

\begin{tabular}{lc}
\hline Frecuencia de citación (FC): & $\mathbf{7}$ \\
\hline Número de usos (NU): & $\mathbf{1}$ \\
\hline Número registros de uso (RU): & $\mathbf{7}$ \\
\hline Frecuencia Relativa de Citación (FRC): & $\mathbf{0 , 0 5}$ \\
\hline Índice de Importancia Cultural (IC): & $\mathbf{0 , 0 5}$ \\
\hline Índice de Vigencia (IV): & $\mathbf{0 , 0 0}$ \\
\hline
\end{tabular}

Obtención: silvestre

Vigencia: abandonado

Conocimientos:

ECOLOGÍA:

Aparece en terrenos malos, pedregales calizos y pastizales secos. 
LÉXICO:

Se denomina caña al tallo de esta especie. "Sale una caña alta que echa unas copas de flores amarillas".

Usos:

TÓXICO Y NOCIVO

- Tóxica para personas y animales (7): La planta machacada o picada, o solo la raíz se utilizó para la pesca furtiva, desprende de este modo un líquido lechoso que es ictiotóxico y atontaba o mataba a los peces. Se empantanaba artificialmente una zona del río y se echaba el resultado del machado en el interior de un saco.

Observaciones: El tagarno forma parte del grupo de plantas ictiotóxicas (tóxicas para los peces), utilizadas en el pasado en la Montaña Palentina para la pesca furtiva, junto con la hoja mora (Scrophularia canina) y el gordolobo (Verbascum spp.).

APOCYNACEAE

\section{Vinca major L.}

Judío (1)

\begin{tabular}{lc}
\hline $245 \mathrm{P} ; 254 \mathrm{~F}$ & \\
\hline Frecuencia de citación (FC): & $\mathbf{1}$ \\
\hline Número de usos (NU): & 1 \\
\hline Número registros de uso (RU): & $\mathbf{1}$ \\
\hline Frecuencia Relativa de Citación (FRC): & $\mathbf{0 , 0 1}$ \\
\hline Índice de Importancia Cultural (IC): & $\mathbf{0 , 0 1}$ \\
\hline Índice de Vigencia (IV): & $\mathbf{0 , 0 1}$ \\
\hline
\end{tabular}

Obtención: silvestre, cultivada

Vigencia: vigente (100\%)

Usos:

ORNAMENTAL

- Patios, huertos y jardines (1): Se cultiva como trepadora ornamental en jardines y patios. En Celada de Roblecedo señalan además que decora las paredes del cementerio.

Observaciones: Se extienden con facilidad y se asilvestra en los alrededores urbanos.

AQUIFOLIACEAE

Ilex aquifolium $\mathrm{L}$.

Acebo (108), aceba (6)

PALAB1333, 22P, 224P; 23F; 35V, 281V, 325V

\begin{tabular}{lc}
\hline Frecuencia de citación (FC): & 108 \\
\hline Número de usos (NU): & 6 \\
\hline Número registros de uso (RU): & 233 \\
\hline Frecuencia Relativa de Citación (FRC): & 0,78 \\
\hline Índice de Importancia Cultural (IC): & 1,68 \\
\hline Índice de Vigencia (IV): & 0,07 \\
\hline
\end{tabular}

Obtención: silvestre

Vigencia: vigente (4\%)

\section{Conocimientos:}

\section{LÉXICO:}

Se denomina acebo al ejemplar que posee hoja con pinchos y aceba al que no los tiene, aunque este no es un carácter que diferencie los pies masculinos de los femeninos.

Encontramos fitotopónimos relacionados en la zona: "Arroyo de la Aceba" en Cardaño de Abajo, y pago "El Acebal" en Estalaya, Lebanza y Vañes.

Usos:

\section{ALIMENTACIÓN ANIMAL}

- Forraje verde o seco (47): Cuando llegado el invierno el pasto escaseaba o las reservas de hierba almacenada en el pajar menguaban, se solía cortar hoja de acebo, muy apreciada como alimento para el ganado, indicado como forraje para vacas y conejos, aunque igualmente formaba parte del menú de cabras y ovejas. Si la necesidad de forraje verde era grande, incluso se disponía del carro para obtener mayor provisión. Para conejos, cabras y ovejas se servían ramas con hojas, sin embargo, para las vacas se pelaba la hoja, se picaba o se machacaba si ésta resultaba muy pinchuda.

- Pasto (5): Se recogen varios testimonios sobre el consumo de hoja por parte de cabras, yeguas y venados, además los frutos tienen gran importancia en la alimentación de algunos animales como osos y urogallos, por el hecho de tener una fructificación invernal.

\section{TÓXICO Y NOCIVO}

- Trampas atrayentes (19): En el pasado la caza de pájaros era una de las diversiones infantiles más populares. Para apresar pequeños pajarillos se elaboraba liga, una sustancia pegajosa y espesa obtenida con la corteza del acebo. Para ello se introduce la corteza en agua varios días, o se machaca y masca pacientemente hasta conseguir una masa gelatinosa de un color grisáceo que tiene un gran poder adherente. Esta liga se coloca sobre juncos, cañas de cereal o pequeñas varillas vegetales en sitios frecuentados por las aves, como abrevaderos de agua, nidos, etc. 
- Tóxicas para personas y animales (5): LoS frutos del acebo poseen alta toxicidad, advertida en varias localidades visitadas.

\section{COMBUSTIBLE}

- Leña (9): Se cortaba algo de madera de acebo, tiene un gran poder calorífico y es considerada buena leña para cocer el pan en el horno. También se aprovechaban para la lumbre los ramos limpios de hoja, una vez consumidos por el ganado.

- Luz (8): Los palos secos de acebo resultan muy eficaces para iluminar, al ser largos y de madera muy dura. Esta vara se denomina comúnmente teo y a la brasa que produce, se la conoce con el nombre de moco.

\section{INDUSTRIA Y ARTESANÍA}

- Herramientas y utensilios (23): Las principales características de la madera de acebo son su dureza, resistencia y verticalidad, bondades necesarias para la fabricación de varas, cachavas o mangos.

La madera también es empleada para elaborar aperos como el dental del arado.

- Vestimenta y adornos personales (2): Las principales características de la madera de acebo son Idónea para la elaboración de los tarugos o machorras de las albarcas.

\section{ORNAMENTAL}

- Patios, huertos y jardines (2): Resulta habitual encontrar acebos procedentes del monte, en jardines y patios de muchas viviendas de la comarca. Se planta como árbol ornamental, teniendo preferencia por los pies femeninos que destacan por su colorida fructificación invernal.

- Adorno floral y plantas de interior (10): Algunas mujeres de la zona cortan ramos fructificados durante el invierno para decorar el interior de la vivienda.

\section{SOCIAL, SOMBÓLICO Y RITUAL}

- Ritual de ciclo anual (87): En un gran número de localidades, los mozos cortaban brazados de ramas de acebo para ser bendecidas por el cura en la festividad del Domingo de Ramos. Las ramas sobrantes permanecían en la iglesia dispuestas para quemar y obtener ceniza que el sacerdote imponía en la misa del miércoles de ceniza.

El acebo también está presente como ornamento en la tradicional fiesta del Corpus Christi, en las enramadas por San Juan y San Pedro y en alguna fiesta local, como la del Santo Cristo de las Batallas o Cristo del Río (segundo domingo del mes de Junio), en Alba de los Cardaños.

En algunas casas se cortaban pequeños acebos para decorar como árbol de Navidad.

- Ritual de ciclo de vida (9): Empleado el acebo para realizar los arcos vegetales que engalanaban las portadas de las casas de las novias casaderas.

- Ritual de incertidumbre, protección y aflicción (7): El ramo bendecido de acebo transmite buena suerte durante el año $y$ además existe la creencia generalizada de poseer propiedades curativas sobre el ganado vacuno, por ello era común su presencia en las cuadras.

- Uso recreativo (1): En Santibáñez de la Peña se cita el uso de las hojas de acebo para realizar molinetes, con los que los más pequeños se entretenían.

Observaciones: En el libro de Montería de Alfonso XI (s. XIV) se citan dos acebales palentinos: Azebeda de Salcedillo y el Azebal de San Salvador de Cantamuda.

Para mejorar su regeneración en San Cebrián de Mudá consideran: "un error no cortarlo porque antes tenían bravura y ahora no se ven más que acebos muertos".

ARALIACEAE

Hedera helix L.

Hiedra (12), yedra (9), enredadera (1)

85P, 454P; 97F; 31V, 281V, 325V

\begin{tabular}{lc}
\hline Frecuencia de citación (FC): & 22 \\
\hline Número de usos (NU): & 4 \\
\hline Número registros de uso (RU): & 27 \\
\hline Frecuencia Relativa de Citación (FRC): & 0,16 \\
\hline Índice de Importancia Cultural (IC): & 0,19 \\
\hline Índice de Vigencia (IV): & 0,08 \\
\hline
\end{tabular}

Obtención: silvestre, cultivada

Vigencia: vigente (42\%)

Usos:

MEDICINA

- Piel y tejido celular subcutáneo (1): Recuerdan en Aguilar de Campoo utilizar las hojas fritas en un poco de aceite para tratar infecciones en la piel o granos con pus.

\section{MEDIOAMBIENTAL}

- Malas hierbas (1): Su carácter invasor y trepador hace que logre ahogar a las especies sobre las que se sustenta, por lo que se 
impedía que abrazara a los frutales de los huertos.

- Setos y cortavientos (2): La hiedra se plantaba en muretes para darles más consistencia o como barrera divisoria entre fincas, aprovechando su rápido desarrollo y defoliación tardía.

\section{ORNAMENTAL}

- Patios, huertos y jardines (2): Se cultiva como ornamental en los jardines.

- Otros adornos (1): Se ha referenciado el uso de la madera de hiedra para realizar algún trabajo decorativo, aprovechando sus formas caprichosas e intrincadas.

\section{SOCIAL, SIMBÓLICO Y RITUAL}

- Ritual ciclo anual (10): En diferentes fiestas patronales se adornaba al santo local con ramas de hiedra. También en la fiesta del Corpus Christi se adornaban los altares de las calles con ramas de hiedra y en las tradicionales enramadas por San Juan o San Pedro.

- Ritual ciclo de vida (9): Con ramas de hiedra se confeccionaban arcos decorativos para engalanar la visita de alguna autoridad civil o eclesial. Es una de las especies empleadas en las enramadas a las novias.

- Alucinógenas, narcóticas y fumatorias (1): EI tallo hueco servía de boquilla para la elaboración de cigarrillos en Estalaya.

\section{BALSAMINACEAE}

Impatiens balsamina $\mathrm{L}$.

Alegría (2)

\begin{tabular}{ll}
\hline Frecuencia de citación (FC): & 2 \\
\hline Número de usos (NU): & 2 \\
\hline Número registros de uso (RU): & 3 \\
\hline
\end{tabular}

Obtención: cultivada

Vigencia: vigente (66\%)

Usos:

ORNAMENTAL

- Adorno floral y plantas de interior (2): Se cultiva en macetas como ornamento de interiores.

\section{SOCIAL, SIMBÓLICO Y RITUAL}

- Ritual de ciclo anual (1): En la fiesta del Corpus Christi las mujeres decoraban los altares emplazados en las calles con plantas silvestres y con tiestos de sus mejores y más vistosas plantas de interior, entre ellos la alegría.

\section{Begonia spp. Conchita (2)}

\begin{tabular}{ll}
\hline Frecuencia de citación (FC): & 2 \\
\hline Número de usos (NU): & 2 \\
\hline Número registros de uso (RU): & 3 \\
\hline
\end{tabular}

Obtención: cultivada

Vigencia: vigente (66\%)

Usos:

ORNAMENTAL

- Adorno floral y plantas de interior (2): Se cultivan diversas especies en macetas para decorar el hogar.

\section{SOCIAL, SIMBÓLICO Y RITUAL}

- Ritual de ciclo anual (1): Se llevan begonias para engalanar los altares en la fiesta del Corpus Christi.

BERBERIDACEAE

Berberis vulgaris $\mathrm{L}$.

Hoja maldita (2), borrachín (6)

PALAB2408, 171P, 395P; 236

\begin{tabular}{lc}
\hline Frecuencia de citación (FC): & $\mathbf{8}$ \\
\hline Número de usos (NU): & 2 \\
\hline Número registros de uso (RU): & 9 \\
\hline Frecuencia Relativa de Citación (FRC): & $\mathbf{0 , 0 6}$ \\
\hline Índice de Importancia Cultural (IC): & $\mathbf{0 , 0 6}$ \\
\hline Índice de Vigencia (IV): & $\mathbf{0 , 0 0}$ \\
\hline
\end{tabular}

Obtención: silvestre

Vigencia: abandonado

Conocimientos:

ECOLOGÍA:

Aparecen en el monte en las zonas donde hay brezal y calar, en los hayedos no prosperan.

\section{LÉXICO:}

En la zona se conoce a los frutos como borrachines y a la planta por sinécdoque también.

El nombre de hoja maldita se menciona en Otero de Guardo con la explicación de que el arbusto con muchas espinas rasgó el manto de la Virgen.

Usos:

\section{ALIMENTACIÓN HUMANA}

- Frutas o frutos dulces (6): Los frutos, de sabor acídulo y con gran cantidad de vitamina $C$, se recogen en otoño en plena maduración y se 
consumen en fresco directamente de la planta o se recolectan para elaborar confitura.

- Golosinas y masticatorias (2): Las hojas con sabor ácido similar a las populares aceras se comían o chupaban como refrescantes.

\section{ALIMENTACIÓN ANIMAL}

- Pasto (1): Los corzos aprovechan los frutos con avidez.

Observaciones: En Triollo aseguran que si se comen muchos borrachines entra dolor de cabeza, es como si emborracharan.

BETULACEAE

\section{Betula pubescens Ehrh.}

Abedul (58)

PALAB2902, 17P, 464P; 63F; 319V, 587V

\begin{tabular}{lc}
\hline Frecuencia de citación (FC): & 58 \\
\hline Número de usos (NU): & 7 \\
\hline Número registros de uso (RU): & 92 \\
\hline Frecuencia Relativa de Citación (FRC): & 0,42 \\
\hline Índice de Importancia Cultural (IC): & 0,66 \\
\hline Índice de Vigencia (IV): & 0,00 \\
\hline
\end{tabular}

Obtención: silvestre

Vigencia: abandonado

\section{Conocimientos:}

\section{ECOLOGÍA:}

Se desarrolla bien en fondos de valles y riberas húmedas. Salcedillo, Lebanza y Carracedo son lugares referenciados donde se pueden encontrar con facilidad.

\section{LÉXICO:}

En Herreruela de Castillería encontramos como fitotopónimos la "Fuente el Abedul" y el pago "El Abedul", en Cardaño de Abajo la "Fuente de los Abidulares", y en Camporredondo "Abidulares".

Usos:

\section{ALIMENTACIÓN ANIMAL}

- Forraje verde o seco (3): El ramón suponía un valioso suplemento alimenticio para el ganado, sobre todo cuando los rigores del invierno no permitían que los animales salieran del establo. Por ello, a finales del verano, en algunos pueblos donde más presencia tenía el abedul, se podaba y se metían las ramas con hojas en el pajar junto a la hierba. Se dedicaba principalmente a la alimentación de cabras y ovejas, que las consumen con avidez, y para vacas.

\section{MEDICINA}

- Sistema genito-urinario (1): Cuando aparecían problemas en la retención de líquidos se elaboraban remedios "para ayudar a orinar", según denominación local. En Celada de Roblecedo detallaron como uno de estos remedios consistía en el cocimiento en agua de las hojas jóvenes de abedul. La infusión resultante se administraba como un buen diurético, en trastornos de próstata y riñón.

- Musculatura y esqueleto (1): En Resoba se citó esta misma infusión para combatir dolores reumáticos, manifestando que la planta posee propiedades diuréticas útiles en tratamientos de artrosis y artritis, al reducir la inflamación de las articulaciones.

\section{VETERINARIA}

- Sistema genito-urinario (1): Los trastornos de orina en el ganado vacuno se trataban con el cocimiento de las hojas jóvenes en agua. El caldo previamente colado se administraba con una botella que se introducía en la boca del animal, de esta manera se facilitaba la eliminación de líquidos.

\section{COMBUSTIBLE}

- Leña (2): El abedul podía emplearse esporádicamente para quemar, su madera, de escaso poder calorífico, era más valorada y se reservaba para la fabricación de herramientas y utensilios.

\section{CONSTRUCCIÓN}

- Casas, edificios e instalaciones agropecuarias (1): La tabla obtenida de la corta de un abedul se podía emplear en la estructura de alguna edificación, pero debido a su escasez predominaban en la construcción otras especies (roble, haya o chopo).

\section{INDUSTRIA Y ARTESANÍA}

- Herramientas y utensilios (59): Es considerada madera de buena calidad. Entre sus usos se menciona la fabricación de yugos, mangos y útiles varios.

Un uso generalizado fue la elaboración de las típicas baleas, escobas hechas con las ramas finas, con ellas se barría el grano de la era.

- Juguetes $e$ instrumentos musicales $y$ deportivos (6): Al ser buena madera, ligera y de fácil trabajo, los bolos del juego tradicional en ocasiones podían ser fabricados con abedul. Aprovechando estas mismas propiedades, también se ha citado el uso de la madera en Salcedillo y Néstar para la fabricación del rabel (instrumento tradicional de cuerda). 
- Vestimenta y adornos personales (17): Una de las principales utilidades de la madera, fue la elaboración de albarcas o almadreñas (calzado de madera que protege de la humedad). Se cortaban los tajos (pieza de madera gruesa sobre la que se talla la albarca) en función del tamaño final deseado. Las albarcas de abedul tenían la ventaja de ser más ligeras frente a las de haya, sin embargo se desgastaban más rápidamente y eran más frías. Los pueblos de la Montaña más destacados en este trabajo artesanal fueron Lores, Polentinos y Salcedillo, donde nos relataron su elaboración " $A$ por la madera de abedul se iba en otoño o en la primavera, según hiciera falta, pero siempre en buena luna, en cuarto menguante. Se cortaba el tamaño de la albarca y había quien las traía ya medio hechas. La albarca se elaboraba bastante en casa, se la daba una aproximación y después se metía entre sacos o algo de tela, para que no se abriera de golpe la madera, para que no se venteara decíamos. Una vez hechas se podían dibujar con la navaja y luego se untaban con el calostro de la vaca, como tenía buena grasa, la daba color y cogía dureza. El abedul es madera buena, porque el haya se abre más".

\section{SOCIAL, SIMBÓLICA Y RITUAL}

- Alucinógenas, narcóticas y fumatorias (1): En Vidrieros nos detallaron la abundancia de abedules en su entorno y como en épocas de escasez, tras la guerra civil española, la semilla seca se disponía sobre un papel de fumar para liar cigarrillos.

Observaciones: En Salcedillo se fabricaban baleas que llevaban a vender al mercado de Aguilar de Campoo el día de San Pedro.

BETULACEAE

\section{Corylus avellana L.}

Avellano (117)

PALAB2743, 9P, 294P; 61F; 103V, 104V, 105V, 209V, 279V, 301V, 356V, 375V

\begin{tabular}{lc}
\hline Frecuencia de citación (FC): & 117 \\
\hline Número de usos (NU): & 6 \\
\hline Número registros de uso (RU): & 296 \\
\hline Frecuencia Relativa de Citación (FRC): & 0,84 \\
\hline Índice de Importancia Cultural (IC): & 2,13 \\
\hline Índice de Vigencia (IV): & 0,26 \\
\hline
\end{tabular}

Obtención: silvestre

Vigencia: vigente (12\%)

\section{ECOLOGÍA}

Existen años mejores y peores en el rendimiento de los avellanos, si el año era bueno, se almacenan para consumir a lo largo del tiempo.

\section{LÉXICO}

"El avellanal" es un fitotopónimo que encontramos para nombrar un pago en Celada de Roblecedo y un paraje en Verdeña.

Usos:

\section{ALIMENTACIÓN HUMANA}

- Frutos secos y oleaginosos (90): Se aprovechan los frutos, las avellanas, que se recogen una vez maduras a finales de septiembre. Se pueden consumir crudas, secas y también crudas en leche, cuando no se deja completar su maduración.

En Salinas de Pisuerga se señala el cultivo del avellano en huerta.

\section{ALIMENTACIÓN ANIMAL}

- Forraje verde o seco (23): La hoja de avellano se desmochaba y se empleaba como forraje para alimentar al ganado. Para conejos, ovejas, cabras y vacas se servía en fresco sin mayor preparación, sin embargo, para cerdos había que cocerlas en agua caliente.

\section{COMBUSTIBLE}

- Encendido (5): Los sobrantes de los ramos destinados para el forraje o para algún uso tecnológico se aprovechan como leña fina para la lumbre.

\section{CONSTRUCCIÓN}

- Carros y otros vehículos (4): Para realizar el transporte de la paja trillada desde la era, de la manera más eficiente posible, el carro tradicional era agrandado con una estructura denominada zarzo, formada por palos de avellano entretejidos.

- Casas, edificios e instalaciones agropecuarias (15): Las varas de avellano se han empleado con frecuencia en la arquitectura popular para construir cerramientos denominados "setos, sietos o sietus". La técnica consiste en entrelazar varas de avellanos sobre montantes verticales. Se emplean estos cerramientos tanto en interior como en exterior para separar estancias que permiten la ventilación y la iluminación, aunque en alguna otra ocasión se revocaba con tierra barrial mezclada con paja para que el cierre fuera total.

\section{INDUSTRIA Y ARTESANÍA}


- Herramientas y utensilios (113): El avellano produce ramas largas y flexibles empleadas como: tutores para legumbres, varas para dirigir el ganado (hijada-ahijada), palos para varear colchones de lana, cachavas, varales para colgar la matanza, etc.

Su madera ligera se estima en la elaboración de mangos para rastros, rastrillos, azadillas, hachas, horcones, picachos o incluso para fabricar horcas y garios.

En San Juan de Redondo se indica la utilidad del avellano para las machorras (piezas de madera sobre las que se apoyan las albarcas y que permiten recambio tras el desgaste) de las albarcas.

Para las cebillas o collares que amarraban el ganado al pesebre.

- Juguetes $e$ instrumentos deportivos $y$ musicales (6): Se menciona el avellano en elementos de diferentes juegos tradicionales como: los bolos, el pite o bigarda, la chita y la palma.

- Cestos, recipientes y envoltorios (7): En la confección de los típicos cestos (cestas, corras, garrotas) se incluye el avellano para hacer el aro y las costillas.

- Cuerdas y ataduras (1): Las ramas más flexibles servían a modo de cuerda para atar cualquier cosa, en Salcedillo se amarraban las ramas de abedul de los escobones.

- Vestimenta y adornos personales (1): En San Juan de Redondo se indica la utilidad del avellano para las machorras (piezas de madera sobre las que se apoyan las albarcas y que permiten recambio tras el desgaste) de las albarcas.

\section{SOCIAL, SIMBÓLICO Y RITUAL}

- Ritual de ciclo anual (4): Las enramadas son una antigua tradición donde los jóvenes en la festividad de San Juan o San Pedro iban a recoger ramas al bosque para ornamentar la ventana de alguna moza en edad casadera. Podían ser de avellano, acebo, chopo, haya, olmo o tejo.

- Ritual de ciclo de vida (7): Cuando la moza se casaba, se enramaba su casa con ramas de avellano. También se empleaban ramas para ornamentar el carro con el que se finalizaba la recogida de la hierba y para confeccionar varas que sustentaban flores y otras ramas, en caso de que el obispo o alguna autoridad importante visitara una localidad.

- Literatura oral popular (1): En Herreruela de Castillería, recogemos el siguiente refrán que alude a la predicción en la producción de frutos secos: "La avellana que en agosto no grana, cata la vana".

- Alucinógenas, narcóticas y fumatorias (19): Muy generalizado el uso de la corteza del avellano pelada y picada como sustituto del tabaco en épocas de escasez.

BIGNONIACEAE

Campsis radicans (L.) Seem.

Enredadera (1)

403P

\begin{tabular}{ll}
\hline Frecuencia de citación (FC): & 1 \\
\hline Número de usos (NU): & 1 \\
\hline Número registros de uso (RU): & 1 \\
\hline
\end{tabular}

Obtención: cultivada

Vigencia: vigente (100\%)

Usos:

ORNAMENTAL

- Patios, huertos y jardines (1): Se localiza en patios y jardines como planta ornamental trepadora tapizante de muros y vallas divisoras de fincas.

BORAGINACEAE

Borago officinalis L.

Borraja (2)

246P; 285F

\begin{tabular}{ll}
\hline Frecuencia de citación (FC): & 2 \\
\hline Número de usos (NU): & 1 \\
\hline Número registros de uso (RU): & 2 \\
\hline
\end{tabular}

Obtención: cultivada

Vigencia: vigente (50\%)

Usos:

ALIMENTACIÓN HUMANA

- Verduras y hortalizas (2): Se cultiva por sus hojas que se consumen cocidas.

Observaciones: Se trata de una verdura introducida en los huertos recientemente.

BORAGINACEAE

Echium vulgare $\mathrm{L}$.

Gardincha (1)

229P; 88V 


\begin{tabular}{lc}
\hline Frecuencia de citación (FC): & 3 \\
\hline Número de usos (NU): & 3 \\
\hline Número registros de uso (RU): & 3 \\
\hline Frecuencia Relativa de Citación (FRC): & $\mathbf{0 , 0 2}$ \\
\hline Índice de Importancia Cultural (IC): & $\mathbf{0 , 0 2}$ \\
\hline Índice de Vigencia (IV): & $\mathbf{0 , 0 0}$ \\
\hline
\end{tabular}

Obtención: silvestre

Vigencia: abandonado

Conocimientos:

ECOLOGÍA:

Se da en orillas de caminos y calles.

Usos:

MEDICINA

- Sistema digestivo (1): En Valcobero se utilizaba el cocimiento de la parte aérea para calmar dolores de estomago y detener la diarrea.

\section{VETERINARIA}

- Sistema digestivo (1): Entre manteca de cerdo se envolvían los frutos y se suministraba a las vacas que tenían el estómago hinchado. Los gases desaparecían y continuaban rumiando.

\section{ORNAMENTAL}

- Adorno floral y plantas de interior (1): La rama florida se emplea en San Salvador de Cantamuda en centros decorativos de flor seca.

\section{BORAGINACEAE}

Glandora diffusa (Lag.) D.C.Thomas

Hierba de las 7 sangrías (6), siete sangrías (1)

223P, 309P; 112F; 43V, 204V

\begin{tabular}{lc}
\hline Frecuencia de citación (FC): & 7 \\
Número de usos (NU): & 2 \\
\hline Número registros de uso (RU): & 8 \\
\hline Frecuencia Relativa de Citación (FRC): & 0,05 \\
\hline Índice de Importancia Cultural (IC): & 0,06 \\
\hline Índice de Vigencia (IV): & 0,00 \\
\hline
\end{tabular}

Obtención: silvestre

Vigencia: abandonado

Conocimientos:

ECOLOGÍA

Es una pequeña matita.

LÉXICO:

Se denominan chupas a las flores.

Usos:

ALIMENTACIÓN HUMANA
- Golosinas y masticatorias (1): Las flores se chupaban para extraer su néctar dulce.

\section{MEDICINA}

- Sistema circulatorio (6): La infusión de la parte aérea se tomaba para mejorar problemas de circulación de la sangre como varices y como remedio depurativo de la sangre.

- Sistema respiratorio (1): Se recomienda en Santibáñez de la Peña tomar la infusión como remedio para la bronquitis.

\section{BORAGINACEAE}

Pentaglottis sempervirens (L.) Tausch ex
L.H.Bailey
Borraja (1)

381P; 259F

\begin{tabular}{lc}
\hline Frecuencia de citación (FC): & 1 \\
\hline Número de usos (NU): & 2 \\
\hline Número registros de uso (RU): & 2 \\
\hline Frecuencia Relativa de Citación (FRC): & 0,01 \\
\hline Índice de Importancia Cultural (IC): & 0,01 \\
\hline Índice de Vigencia (IV): & 0,00 \\
\hline
\end{tabular}

Obtención: silvestre

Vigencia: abandonado

ALIMENTACIÓN ANIMAL

- Forraje verde o seco (1): Las hojas cocidas sirven de forraje para los cerdos.

\section{MEDICINA}

- Sistema respiratorio (1): En Vidrieros recomiendan tomar el cocimiento de las hojas para el tratamiento del catarro.

Observaciones: El uso medicinal no se ha podido contrastar en la bibliografía consultada.

\section{BORAGINACEAE}

\section{Pulmonaria longifolia (Bastard) Boreau} Pulmonaria (1)

\begin{tabular}{lc} 
374P; 307F & \\
\hline Frecuencia de citación (FC): & 2 \\
\hline Número de usos (NU): & 1 \\
\hline Número registros de uso (RU): & 2 \\
\hline Frecuencia Relativa de Citación (FRC): & 0,01 \\
\hline Índice de Importancia Cultural (IC): & 0,01 \\
\hline Índice de Vigencia (IV): & 0,00 \\
\hline
\end{tabular}

Obtención: silvestre

Vigencia: abandonado 
Usos:

\section{MEDICINA}

- Sistema respiratorio (2): En Celada de Roblecedo se emplea la infusión de sus hojas para aliviar los síntomas del catarro, se suele mezclar con otras especies como malva (Malva sylvestris) y malvarisco (Althaea officinalis) para potenciar sus efectos beneficiosos.

Observaciones: Se recomienda secarla bien para que no tome un color negruzco y se pudra.

\section{BRASSICACEAE}

\section{Barbarea intermedia Boreau} Naviza (1)

235P, 485P; 214F; 8V

\begin{tabular}{lc}
\hline Frecuencia de citación (FC): & 1 \\
\hline Número de usos (NU): & 2 \\
\hline Número registros de uso (RU): & 2 \\
\hline Frecuencia Relativa de Citación (FRC): & 0,01 \\
\hline Índice de Importancia Cultural (IC): & 0,01 \\
\hline Índice de Vigencia (IV): & 0,00 \\
\hline
\end{tabular}

Obtención: silvestre

Vigencia: abandonado

Conocimientos:

\section{ECOLOGÍA}

Salen en primavera en la época de siembra, en orillas de caminos y huertos. "Las hojas son como las del nabo pero no echa nabo".

Usos:

ALIMENTACIÓN ANIMAL

- Forraje verde o seco (1): Se arrancaba la planta entera y se echaba como forraje a las vacas.

\section{MEDIOAMBIENTAL}

- Malas hierbas (1): Se escarda de tierras y huertos.

BRASSICACEAE

\section{Brassica napus L.} Nabo (15)

\begin{tabular}{|c|c|}
\hline Frecuencia de citación (FC): & 15 \\
\hline Número de usos (NU): & 3 \\
\hline Número registros de uso (RU): & 21 \\
\hline
\end{tabular}

Obtención: cultivada

Vigencia: vigente (10\%)
Conocimientos:

\section{LÉXICO:}

A los habitantes de Valberzoso se les conoce en los pueblos vecinos de Cantabria como nabucos, porque se hacía venta ambulante con ellos.

\section{Usos:}

\section{ALIMENTACIÓN HUMANA}

- Raíces, bulbos, tubérculos y rizomas (12): En el huerto se reservaban unos surcos para sembrar nabos que se comían crudos y más corriente cocidos por lo general junto con patatas.

\section{ALIMENTACIÓN ANIMAL}

- Raíces y tubérculos (7): Se dispensaban cocidos a los cerdos.

\section{SOCIAL, SIMBÓLICO Y RITUAL}

- Literatura popular (2): Se recogen estos dos refranes, referentes a la época de siembra: "Para Santa Marina siembra tu nabina" y a la de recolección: "Las cosas a su tiempo y los nabos en Adviento".

\section{BRASSICACEAE}

\section{Brassica nigra (L.) K.Koch}

Gébene (3)

427P; 278F

\begin{tabular}{lc|}
\hline Frecuencia de citación (FC): & $\mathbf{3}$ \\
\hline Número de usos (NU): & $\mathbf{1}$ \\
\hline Número registros de uso (RU): & $\mathbf{3}$ \\
\hline Frecuencia Relativa de Citación (FRC): & $\mathbf{0 , 0 2}$ \\
\hline Índice de Importancia Cultural (IC): & $\mathbf{0 , 0 2}$ \\
\hline
\end{tabular}

Obtención: silvestre

Conocimientos:

\section{ECOLOGÍA}

Aparece en los cultivos de cereal.

Usos:

MEDIOAMBIENTAL

- Malas hierbas (3): Se limpiaba de los cultivos de cereal.

BRASSICACEAE

Brassica oleracea var. acephala DC.

Berza (50), col (4)

277V 


\begin{tabular}{lc}
\hline Frecuencia de citación (FC): & 54 \\
\hline Número de usos (NU): & 2 \\
\hline Número registros de uso (RU): & 74 \\
\hline
\end{tabular}

Obtención: cultivada, comprada

Vigencia: vigente (32\%)

Usos:

\section{ALIMENTACIÓN HUMANA}

- Verduras y hortalizas (49): Verdura de invierno fundamental en el huerto tradicional, se cocinaban las hojas acompañando a titos o garbanzos.

\section{ALIMENTACIÓN ANIMAL}

- Forraje verde o seco (25): En las berzas, todas las hojas exteriores y las de peor calidad servían de forraje en crudo para el ganado domestico, vacas y gallinas. Para los cerdos previamente se las cocía en agua junto con peladuras de patatas, patatas pequeñas, ortigas, etc.

\section{BRASSICACEAE}

Brassica oleracea var. botrytis L.

Coliflor (1)

$190 \mathrm{~F}$

\begin{tabular}{|ll}
\hline Frecuencia de citación (FC): & 1 \\
\hline Número de usos (NU): & 1 \\
\hline Número registros de uso (RU): & 1 \\
\hline
\end{tabular}

Obtención: cultivada

Vigencia: vigente (100\%)

Usos:

ALIMENTACIÓN HUMANA

- Verduras y hortalizas (1): Cultivo introducido en las últimas décadas.

BRASSICACEAE

Brassica oleracea var. capitata $\mathrm{L}$.

Repollo (1), lombarda (1)

189F; $277 \mathrm{~V}$

\begin{tabular}{|ll|}
\hline Frecuencia de citación (FC): & 2 \\
\hline Número de usos (NU): & 1 \\
\hline Número registros de uso (RU): & 2 \\
\hline
\end{tabular}

Obtención: cultivada, comprada

Vigencia: vigente (100\%)

Usos:

\section{ALIMENTACIÓN HUMANA}

- Verduras y hortalizas (2): Se consumen las hojas cocinadas en guisos y potajes. La lombarda se ha introducido como cultivo en las últimas décadas en el huerto familiar.

BRASSICACEAE

Brassica oleracea var. gemmifera (DC.)

Zenker

Col de Bruselas (1)

\begin{tabular}{ll}
\hline $191 \mathrm{~F}$ & \\
\hline Frecuencia de citación (FC): & 1 \\
\hline Número de usos (NU): & 1 \\
\hline Número registros de uso (RU): & 1 \\
\hline
\end{tabular}

Obtención: cultivada, comprada

Vigencia: vigente (100\%)

Usos:

ALIMENTACIÓN HUMANA

- Verduras y hortalizas (1): Introducida recientemente en los huertos, se consumen las yemas laterales cocinadas.

BRASSICACEAE

Capsella bursa-pastoris (L.) Medik.

Bolsa de pastor (3)

\begin{tabular}{lc} 
233P; 179F & \\
\hline Frecuencia de citación (FC): & $\mathbf{3}$ \\
\hline Número de usos (NU): & $\mathbf{1}$ \\
\hline Número registros de uso (RU): & $\mathbf{3}$ \\
\hline Frecuencia Relativa de Citación (FRC): & $\mathbf{0 , 0 2}$ \\
\hline Índice de Importancia Cultural (IC): & $\mathbf{0 , 0 2}$ \\
\hline Índice de Vigencia (IV): & $\mathbf{0 , 0 0}$ \\
\hline
\end{tabular}

Obtención: silvestre

Vigencia: abandonado

Usos:

MEDICINA

- Sistema digestivo (2): La parte aérea de la planta administrada mediante infusión se recomienda para detener las diarreas.

- Sistema genito-urinario (1): Empleada en infusión para dolores menstruales. "Yo aconsejaba un puñadito de planta picada en agua y era muy bueno para mujeres que tenían problemas con la regla y esas cosas". (Celada de Roblecedo).

BRASSICACEAE

Hirschfeldia incana (L.) Lagr.-Foss.

Gébene (1) 
404P, 510P; 260F; 514V

\begin{tabular}{lc}
\hline Frecuencia de citación (FC): & 1 \\
\hline Número de usos (NU): & 1 \\
\hline Número registros de uso (RU): & 1 \\
\hline Frecuencia Relativa de Citación (FRC): & 0,01 \\
\hline Índice de Importancia Cultural (IC): & 0,01 \\
\hline
\end{tabular}

Obtención: silvestre

Usos:

MEDIOAMBIENTAL

- Malas hierbas (1): Especie considerada mala hierba de los cultivos de cereal.

\section{BRASSICACEAE}

Lepidium campestre $\mathrm{L}$.

Rábano (1)

545P; 42V

\begin{tabular}{lc|}
\hline Frecuencia de citación (FC): & 1 \\
\hline Número de usos (NU): & 2 \\
\hline Número registros de uso (RU): & 2 \\
\hline Frecuencia Relativa de Citación (FRC): & 0,01 \\
\hline Índice de Importancia Cultural (IC): & 0,01 \\
\hline Índice de Vigencia (IV): & 0,00
\end{tabular}

Obtención: silvestre

Vigencia: abandonado

Usos:

ALIMENTACIÓN ANIMAL

- Forraje verde o seco (1): Las plantas escardadas en las tierras se llevaban para dar como forraje verde a las vacas.

MEDIOAMBIENTAL

- Malas hierbas (1): Se quitaban con una azadilla de las tierras de cultivo.

BRASSICACEAE

Lepidium latifolium L.

Rompepiedras (1)

472P; 311F

Frecuencia de citación (FC):

Número de usos (NU): 1

Número registros de uso (RU):

Obtención: cultivada

Vigencia: vigente (100\%)

Usos:

MEDICINA

- Sistema genito-urinario (1): En Dehesa de Montejo se cultiva y se usan las hojas en infusión, ya que ayuda a expulsar las piedras del riñón.

BRASSICACEAE

\section{Lunaria annua L.}

Hoja de la plata (5), flor de la plata (2)

182P, 307P; 250F; 162V, 265V, 320V, 548V, 549V

\begin{tabular}{lc}
\hline Frecuencia de citación (FC): & 7 \\
Número de usos (NU): & 1 \\
Número registros de uso (RU): & 10
\end{tabular}

Obtención: cultivada

Vigencia: vigente (100\%)

Conocimientos:

LÉXICO:

El nombre deriva de la apariencia del tabique de sus frutos.

\section{Usos:}

\section{ORNAMENTAL}

- Patios, huertos y jardines (4): Cultivada en huertos y patios por su vistosa floración.

- Adorno floral y plantas de interior (6): Se emplean los racimos con los frutos secos en centros para decoración de flor seca, una vez fructificados queda el tabique central de aspecto cristalino y color plateado.

\section{BRASSICACEAE}

\section{Matthiola incana L.}

$119 \mathrm{~V}$

\begin{tabular}{ll}
\hline Frecuencia de citación (FC): & 1 \\
\hline Número de usos (NU): & 1 \\
\hline Número registros de uso (RU): & 1 \\
\hline
\end{tabular}

Obtención: cultivada

Vigencia: vigente (100\%)

Usos:

ORNAMENTAL

- Patios, huertos y jardines (1): Se cultiva en exterior por la belleza de sus flores moradas.

BRASSICACEAE

\section{Nasturtium officinale R.Br.}

Berro (34)

PALAB1643, 156P, 281P; 250F; 162V, 265V, 320V, $548 \mathrm{~V}, 549 \mathrm{~V}$ 


\begin{tabular}{lc}
\hline Frecuencia de citación (FC): & $\mathbf{3 4}$ \\
\hline Número de usos (NU): & 2 \\
\hline Número registros de uso (RU): & 36 \\
\hline Frecuencia Relativa de Citación (FRC): & $\mathbf{0 , 2 4}$ \\
\hline Índice de Importancia Cultural (IC): & $\mathbf{0 , 2 6}$ \\
\hline Índice de Vigencia (IV): & $\mathbf{0 , 0 1}$ \\
\hline
\end{tabular}

Obtención: silvestre

Vigencia: vigente (5\%)

Conocimientos:

ECOLOGÍA

Los berros se crían en fuentes o arroyos de agua clara y limpia. El abandono de los trabajos comunales en los pueblos ha provocado la pérdida de muchas fuentes en las que se recogía esta especie.

Usos:

\section{ALIMENTACIÓN HUMANA}

- Verduras y hortalizas (34) Se recolectan los tallos tiernos con hojas desde el mes de enero hasta el comienzo de la primavera, antes de que florezcan y se comen crudos en ensalada, refiriendo un sabor un tanto picante.

\section{ALIMENTACIÓN ANIMAL}

- Pasto (2): Las vacas, las cabras y las ovejas se detenían en las fuentes para pacer los berros.

\section{Sinapis alba L.}

BRASSICACEAE Mostaza (3)

\begin{tabular}{ll}
\hline Frecuencia de citación (FC): & 3 \\
\hline Número de usos (NU): & 1 \\
\hline Número registros de uso (RU): & 3 \\
\hline
\end{tabular}

Obtención: comprada

Vigencia: abandonado

Usos:

\section{MEDICINA}

- Sistema respiratorio (3): En las boticas se obtenían semillas de mostaza que mezcladas con linaza y agua formaban una pasta que se acomodaba envuelta en un trapo a modo de cataplasma sobre el pecho cuando aparecían resfriados.

BRASSICACEAE

Sinapis arvensis $\mathrm{L}$.

Gébene (6)

186P, 522P; 151F; 517V

\begin{tabular}{lc}
\hline Frecuencia de citación (FC): & $\mathbf{6}$ \\
\hline Número de usos (NU): & $\mathbf{2}$ \\
\hline Número registros de uso (RU): & $\mathbf{7}$ \\
\hline Frecuencia Relativa de Citación (FRC): & $\mathbf{0 , 0 4}$ \\
\hline Índice de Importancia Cultural (IC): & $\mathbf{0 , 0 5}$ \\
\hline Índice de Vigencia (IV): & $\mathbf{0 , 0 0}$ \\
\hline
\end{tabular}

Obtención: silvestre

Vigencia: abandonado

Usos:

\section{ALIMENTACIÓN ANIMAL}

- Forraje verde o seco (2): Las hojas basales se recogen en primavera como forraje para los conejos.

\section{MEDIOAMBIENTAL}

- Malas hierbas (5): Se retira este especie de los cultivos de cereal, principalmente en el trigo.

\section{CAMPANULACEAE}

\section{Campanula rapunculus $\mathrm{L}$.}

Campanilla (4)

331P, 536P; $12 \mathrm{~V}$

\begin{tabular}{lc}
\hline Frecuencia de citación (FC): & 4 \\
\hline Número de usos (NU): & 1 \\
\hline Número registros de uso (RU): & 4 \\
\hline Frecuencia Relativa de Citación (FRC): & 0,03 \\
\hline Índice de Importancia Cultural (IC): & 0,03 \\
\hline Índice de Vigencia (IV): & 0,01 \\
\hline
\end{tabular}

Obtención: silvestre

Vigencia: vigente (25\%)

Usos:

\section{ORNAMENTAL}

- Adorno floral y plantas de interior (4): Durante la primavera se recogen las flores que se introducen en jarrones con agua como decoración en el hogar.

CAPRIFOLIACEAE

\section{Dipsacus fullonum L.}

Cardo cardador (5), cardo de hisopo (3), cardo santo (2), cardo (14), cardón (3), cardo burriquero (1), cardencha (3), cardincha (1)

\begin{tabular}{lc} 
92P; 200F; 22V, 109V, 376V, 482V & \\
\hline Frecuencia de citación (FC): & 32 \\
\hline Número de usos (NU): & 4 \\
\hline Número registros de uso (RU): & 35 \\
Frecuencia Relativa de Citación (FRC): & $\mathbf{0 , 2 3}$ \\
\hline Índice de Importancia Cultural (IC): & $\mathbf{0 , 2 5}$ \\
Índice de Vigencia (IV): & $\mathbf{0 , 0 3}$ \\
\hline
\end{tabular}


Obtención: silvestre

Vigencia: vigente (11\%)

Conocimientos:

LÉXICO

En Rabanal de las Llantas se denomina espantacabras al juguete que fabricaban los niños con el tallo.

Usos:

ALIMENTACIÓN ANIMAL

- Plantas melíferas (1): En Polentinos afirman que las abejas visitan con asiduidad esta especie para pecorear el néctar de las flores.

\section{INDUSTRIA Y ARTESANÍA}

- Juguetes $e$ instrumentos deportivos $y$ musicales (3): Con un trozo de tallo con entrenudo y un pequeño palo, se fabrica un juguete a modo de matraca para hacer ruido haciéndolo girar con rapidez.

\section{ORNAMENTAL}

- Adorno floral y plantas de interior (28): Se recoge la inflorescencia y parte del tallo y se dejan secar para adornar en alguna maceta o florero, junto con alguna otra especie. En ocasiones se suelen teñir con algún colorante para darlos mayor vistosidad.

\section{SOCIAL, SIMBÓLICO Y RITUAL}

- Ritual de incertidumbre, protección e incertidumbre (1): El agua acumulado entre las axilas de sus grandes hojas, se considera con propiedades cosméticas especiales para la piel y además tiene la capacidad de rizar el pelo.

- Uso recreativo (2): Las niñas usaban la inflorescencia a modo de peine para las muñecas y los niños como un hisopo que mojaban en agua y asperjaban.

\section{CAPRIFOLIACEAE}

Knautia arvensis (L.) Coult

Flor de la corona (1)

\begin{tabular}{lc} 
247P, 515P; 181F; 90V & \\
\hline Frecuencia de citación (FC): & 1 \\
\hline Número de usos (NU): & 1 \\
Número registros de uso (RU): & 1 \\
\hline Frecuencia Relativa de Citación (FRC): & $\mathbf{0 , 0 1}$ \\
Índice de Importancia Cultural (IC): & $\mathbf{0 , 0 1}$ \\
\hline Índice de Vigencia (IV): & $\mathbf{0 , 0 0}$ \\
\hline
\end{tabular}

Obtención: silvestre

Vigencia: abandonado
Conocimientos:

\section{ECOLOGÍA}

Muy frecuente en prados y eras.

\section{LÉXICO}

Con el nombre de flor de las coronas se han identificado 3 especies: Knautia arvensis, Scabiosa columbaria y Armeria pubinervis, con todas ellas los niños hacían pequeñas coronas.

Usos:

SOCIAL, SIMBÓLICO Y RITUAL

- Uso recreativo (1): Los más jóvenes confeccionaban coronas trenzando los tallos flexibles en la primavera.

CAPRIFOLIACEAE

Lonicera japonica Thunb.

Mariselva (1)

473P; 266F

Frecuencia de citación (FC):

Número de usos (NU):

Número registros de uso (RU):

Número registros de uso (RU):

Obtención: cultivada

Vigencia: vigente (100\%)

Usos:

ORNAMENTAL

- Patios, huertos y jardines (1): Aparece como trepadora ornamental en el vallado de jardines.

CAPRIFOLIACEAE

Lonicera periclymenum L.

Mariselva (2), madreselva (1)

248P, 415P; 304F; 45V

\begin{tabular}{lc}
\hline Frecuencia de citación (FC): & 3 \\
\hline Número de usos (NU): & 2 \\
\hline Número registros de uso (RU): & 2 \\
\hline Frecuencia Relativa de Citación (FRC): & $\mathbf{0 , 0 2}$ \\
\hline Índice de Importancia Cultural (IC): & $\mathbf{0 , 0 1}$ \\
\hline Índice de Vigencia (IV): & $\mathbf{0 , 0 0}$ \\
\hline
\end{tabular}

Obtención: silvestre

Vigencia: abandonado

Usos:

ALIMENTACIÓN HUMANA

- Golosinas y masticatorias (1): Se chupaba la flor para succionar el néctar de sabor dulce.

INDUSTRIA Y ARTESANÍA 
- Herramientas y utensilios (1): El tallo hueco servía como boquilla para liar cigarrillos.

Observaciones: También están presentes en la zona Lonicera etrusca y L. xylosteum.

CAPRIFOLIACEAE

Scabiosa columbaria L.

Flor de la corona (1)

428P; $123 \mathrm{~F}$

\begin{tabular}{lc|}
\hline Frecuencia de citación (FC): & 1 \\
\hline Número de usos (NU): & 1 \\
\hline Número registros de uso (RU): & 1 \\
\hline Frecuencia Relativa de Citación (FRC): & 0,01 \\
\hline Índice de Importancia Cultural (IC): & 0,01 \\
\hline Índice de Vigencia (IV): & 0,00 \\
\hline
\end{tabular}

Obtención: silvestre

Vigencia: abandonado

Usos:

SOCIAL, SIMBÓLICO Y RITUAL

- Uso recreativo (1): Se trenzaban los tallos con flor para elaborar pequeñas coronas con las que jugaban los niños.

CAPRIFOLIACEAE

Symphoricarpos albus (L.) S.F.Blake

Lágrimas de Judas (1), nevada (1), bola de nieve (1)

\begin{tabular}{ll}
\hline $373 \mathrm{P} ; 58 \mathrm{~F}$ & \\
\hline Frecuencia de citación (FC): & $\mathbf{3}$ \\
\hline Número de usos (NU): & $\mathbf{1}$ \\
\hline Número registros de uso (RU): & $\mathbf{3}$ \\
\hline
\end{tabular}

Obtención: cultivada

Vigencia: vigente (100\%)

Usos:

ORNAMENTAL

- Patios, huertos y jardines (3): Se cultiva como ornamental en los jardines, destacando la belleza de su fruto redondeado y de color blanco.

CAPRIFOLIACEAE

\section{Valeriana montana $\mathrm{L}$.}

Valeriana (2)

446P; 310F

\begin{tabular}{lc|}
\hline Frecuencia de citación (FC): & $\mathbf{2}$ \\
\hline Número de usos (NU): & $\mathbf{1}$ \\
\hline Número registros de uso (RU): & 2 \\
\hline Frecuencia Relativa de Citación (FRC): & $\mathbf{0 , 0 1}$ \\
\hline Índice de Importancia Cultural (IC): & $\mathbf{0 , 0 1}$ \\
\hline Índice de Vigencia (IV): & $\mathbf{0 , 0 0}$ \\
\hline
\end{tabular}

Obtención: silvestre

Vigencia: abandonado

Conocimientos:

ECOLOGÍA

Se recoge en la Sierra de Celada de Roblecedo.

Usos:

MEDICINA

- Sistema nervioso (2): La raíz es un buen tranquilizante, se usa la infusión para estados de nerviosismo y para trastornos del sueño o simplemente para mejorar el sueño.

CAPRIFOLIACEAE

Valeriana pyrenaica $\mathrm{L}$.

Valeriana (1)

249P; 284F

\begin{tabular}{ll}
\hline Frecuencia de citación (FC): & 1 \\
Número de usos (NU): & 1 \\
\hline Número registros de uso (RU): & 1 \\
\hline
\end{tabular}

Obtención: cultivada

Vigencia: vigente (100\%)

Usos:

ORNAMENTAL

- Patios, huertos y jardines (1): Se menciona su cultivo ornamental en jardín, en la localidad de Arbejal.

CARYOPHYLLACEAE

Agrostemma githago L.

Neguilla (1), neguillón (1), clavel (2)

\begin{tabular}{lc} 
187P; 301F & \\
\hline Frecuencia de citación (FC): & 5 \\
\hline Número de usos (NU): & $\mathbf{1}$ \\
\hline Número registros de uso (RU): & 6 \\
\hline Frecuencia Relativa de Citación (FRC): & $\mathbf{0 , 0 4}$ \\
\hline Índice de Importancia Cultural (IC): & $\mathbf{0 , 0 4}$ \\
\hline Índice de Vigencia (IV): & $\mathbf{0 , 0 0}$ \\
\hline
\end{tabular}

Obtención: silvestre

Vigencia: abandonado

Conocimientos: 


\section{ECOLOGÍA}

Extendida en el pasado en los cultivos de cereal, en la actualidad se observa una menor aparición debido al cambio de prácticas agrícolas y a los herbicidas empleados.

Usos:

ALIMENTACIÓN ANIMAL

- Forraje verde o seco (1): Las plantas que se escardaban se echaban como forraje verde a las vacas.

\section{MEDIOAMBIENTAL}

- Malas hierbas (5): Se trata de la mala hierba por excelencia para los agricultores de cereal. Se tenía especial cuidado en la escarda de esta planta, ya que si se mezclaba la semilla con el cereal, el Servicio Nacional de Productos Agrarios (SENPA) rechazaba la producción.

\section{CARYOPHYLLACEAE}

Dianthus caryophyllus L.

Clavel (1)

330P; $217 \mathrm{~F}$

\begin{tabular}{|ll|}
\hline Frecuencia de citación (FC): & 1 \\
\hline Número de usos (NU): & 1 \\
\hline Número registros de uso (RU): & 1 \\
\hline
\end{tabular}

Obtención: cultivada

Vigencia: vigente (100\%)

\section{ORNAMENTAL}

- Patios, huertos y jardines (1): Se cultiva con fines decorativos en jardines y en macetas en el exterior de la vivienda.

\section{CARYOPHYLLACEAE}

Dianthus hyssopifolius L.

Clavelina (4), clavel (3)

195P, 521P; 320F; 20V

\begin{tabular}{lc}
\hline Frecuencia de citación (FC): & $\mathbf{7}$ \\
\hline Número de usos (NU): & 3 \\
\hline Número registros de uso (RU): & $\mathbf{8}$ \\
\hline Frecuencia Relativa de Citación (FRC): & $\mathbf{0 , 0 5}$ \\
\hline Índice de Importancia Cultural (IC): & $\mathbf{0 , 0 6}$ \\
\hline Índice de Vigencia (IV): & $\mathbf{0 , 0 0}$ \\
\hline
\end{tabular}

Obtención: silvestre

Vigencia: abandonado

Conocimientos:

ECOLOGÍA

Salen en terrenos calizos.
Usos:

INDUSTRIA Y ARTESANÍA

- Cosmética, perfumería y limpieza (1): En Verdeña se usan como ambientador, su fragancia perdura hasta que la planta se seca.

\section{ORNAMENTAL}

- Adorno floral y plantas de interior (5): Las flores se cortan para hacer pequeños ramilletes decorativos sobre jarrones con agua para decoración del hogar.

\section{SOCIAL, SIMBÓLICA Y RITUAL}

- Ritual de ciclo anual (2): Era una de las flores que se cortaban para tirar por las calles el día del Corpus Christi o para decorar los altares dispuestos para la fiesta.

CARYOPHYLLACEAE

Paronychia kapela (Hacq.) A.Kern

Sanguinaria (28), flor de papel (2)

\begin{tabular}{lc} 
55P; $36 \mathrm{~F}$ & \\
\hline Frecuencia de citación (FC): & $\mathbf{3 0}$ \\
\hline Número de usos (NU): & $\mathbf{2}$ \\
\hline Número registros de uso (RU): & $\mathbf{3 0}$ \\
\hline Frecuencia Relativa de Citación (FRC): & $\mathbf{0 , 2 2}$ \\
\hline Índice de Importancia Cultural (IC): & $\mathbf{0 , 2 2}$ \\
\hline Índice de Vigencia (IV): & $\mathbf{0 , 0 0}$ \\
\hline
\end{tabular}

Obtención: silvestre

Vigencia: abandonado

Conocimientos:

\section{ECOLOGÍA}

Aparece en calares, castros y terrenos con cascajo.

\section{LÉXICO}

En la nomenclatura popular se denomina flor de papel, por su aspecto quebradizo y sus brácteas de color pajizo, casi transparente.

Usos:

MEDICINA

- Sistema circulatorio (26): Especialmente recomendada como depurativo para "rebajar la sangre" y para cualquier otro trastorno circulatorio. Recolectada a principios del verano, se administran las sumidades florales en infusión.

- Sistema nervioso (1): La infusión de flores se empleó como remedio contra el dolor de cabeza. 
- Otros usos medicinales (2): Se mezclan con otras 10 especies locales (manzanilla, té, orégano, malva, hierbabuena, escaramujo, cola de caballo, tila, llantél y tomillo) para elaborar un sanalotodo general, válida para casi cualquier enfermedad.

\section{VETERINARIA}

- Sistema genito-urinario (1): El cocimiento de sanguinaria se empleaba en San Salvador de Cantamuda como diurético para el ganado vacuno que tenían dificultades para orinar.

Observaciones: Es probable que también se recolectara para los mismo usos Paronychia capitata, también presente en la zona.

\section{CARYOPHYLLACEAE}

Saponaria ocymoides L.

Jabonera de lastra (1)

405P; 308F; 560V

\begin{tabular}{lc}
\hline Frecuencia de citación (FC): & 1 \\
\hline Número de usos (NU): & 1 \\
\hline Número registros de uso (RU): & 1 \\
\hline Frecuencia Relativa de Citación (FRC): & 0,01 \\
\hline Índice de Importancia Cultural (IC): & 0,01 \\
\hline Índice de Vigencia (IV): & 0,01 \\
\hline
\end{tabular}

Obtención: silvestre

Vigencia: vigente (100\%)

\section{ECOLOGÍA}

Prefiere terrenos pedregosos y lastras.

Usos:

ORNAMENTAL

- Patios, huertos y jardines (1): En Villanueva de la Torre se cultiva esta especie en jardines como ornamental, trasplantada desde las calares.

\section{CARYOPHYLLACEAE}

Saponaria officinalis $\mathrm{L}$.

Jabonera (7), planta del jabón (3)

89P, 349P; 138F; 329V, 444V, 541V

\begin{tabular}{lc}
\hline Frecuencia de citación (FC): & 10 \\
\hline Número de usos (NU): & 2 \\
\hline Número registros de uso (RU): & 11 \\
\hline Frecuencia Relativa de Citación (FRC): & $\mathbf{0 , 0 7}$ \\
\hline Índice de Importancia Cultural (IC): & $\mathbf{0 , 0 8}$ \\
\hline Índice de Vigencia (IV): & $\mathbf{0 , 0 1}$ \\
\hline
\end{tabular}

Vigencia: vigente (10\%)

Conocimientos:

LÉXICO

Jabonera y planta de jabón son nombres obtenidos en base al uso aplicado a la especie.

Usos:

ORNAMENTAL

- Adorno floral y plantas de interior (1): Se colocan flores frescas en jarrones con agua como ornamento en la vivienda.

\section{SOCIAL, SIMBÓLICO Y RITUAL}

- Uso recreativo (10): Servía como juego infantil, ya que al frotarla entre las manos producía una especie de espuma que suavizaba las manos y semejaba la sensación de haberse lavado con jabón.

\section{CARYOPHYLLACEAE}

Silene vulgaris (Moench) Garcke

Colleja (4), cuete (3)

\begin{tabular}{lc} 
PALAB1618, 176P; 107F; 450V & \\
\hline Frecuencia de citación (FC): & $\mathbf{7}$ \\
\hline Número de usos (NU): & $\mathbf{3}$ \\
\hline Número registros de uso (RU): & $\mathbf{9}$ \\
\hline Frecuencia Relativa de Citación (FRC): & $\mathbf{0 , 0 5}$ \\
\hline Índice de Importancia Cultural (IC): & $\mathbf{0 , 0 6}$ \\
\hline Índice de Vigencia (IV): & $\mathbf{0 , 0 1}$ \\
\hline
\end{tabular}

Obtención: silvestre

Vigencia: vigente (22\%)

Conocimientos:

ECOLOGÍA

Se desarrolla tanto en orillas de caminos como en prados húmedos.

\section{LÉXICO}

Se recogen los nombres cuete y chacleo para denominar a las flores que se explotaban.

Usos:

\section{ALIMENTACIÓN HUMANA}

- Verduras y hortalizas (3): Las hojas tiernas se recolectan desde el principio de la primavera hasta que aparece el tallo floral, momento en que la planta se vuelve menos palatable. Se añade en tortillas, revueltos, guisos, también como verdura en el cocido o en el relleno.

\section{ORNAMENTAL}

Obtención: silvestre 
- Adorno floral y plantas de interior (1): En Valle de Santullán se añade la parte aérea florecida en centros ornamentales de flor seca.

\section{SOCIAL, SIMBÓLICO Y RITUAL}

- Uso recreativo (5): Los niños jugaban a aplastar las flores, ya que su cáliz globoso permitía explotarlo o chascarlo de forma brusca contra la mano.

\section{CARYOPHYLLACEAE}

Stellaria media (L.) Vill.

Paulina (3), pamplina (2)

439P, 505P; 186F; 331V

\begin{tabular}{lc}
\hline Frecuencia de citación (FC): & 5 \\
\hline Número de usos (NU): & 2 \\
\hline Número registros de uso (RU): & 5 \\
\hline Frecuencia Relativa de Citación (FRC): & $\mathbf{0 , 0 4}$ \\
Índice de Importancia Cultural (IC): & $\mathbf{0 , 0 4}$ \\
\hline Índice de Vigencia (IV): & $\mathbf{0 , 0 0}$
\end{tabular}

Obtención: silvestre

Vigencia: abandonado

Conocimientos:

ECOLOGÍA

Se deja ver con frecuencia en los huertos y en las fincas abonadas.

Usos:

\section{ALIMENTACIÓN ANIMAL}

- Forraje verde o seco (2): Se escardaba y se añadía como forraje verde a las vacas y a los cerdos.

\section{MEDIOAMBIENTAL}

- Malas hierbas (3): Muy corriente en el huerto, "No es muy alta pero se hace muy tupida y es malísima".

CELASTRACEAE

\section{Euonymus europaeus L.}

Husera (1), bonetero (2)

\section{P, 342P; 199F}

\begin{tabular}{lc}
\hline Frecuencia de citación (FC): & 4 \\
\hline Número de usos (NU): & 2 \\
\hline Número registros de uso (RU): & 5 \\
\hline Frecuencia Relativa de Citación (FRC): & 0,03 \\
\hline Índice de Importancia Cultural (IC): & 0,04 \\
\hline Índice de Vigencia (IV): & 0,01 \\
\hline
\end{tabular}

Obtención: silvestre

Vigencia: vigente (20\%)
Usos:

INDUSTRIA Y ARTESANÍA

- Herramientas y utensilios (3): Su madera es de gran calidad y muy valorada, con ella se elaboraban cubiertos (cacillos, cucharas y tenedores).

- Vestimenta y adornos personales (1): LoS frutos de esta especie se engarzaban con un hilo para elaborar collares con los que jugaban las niñas.

\section{ORNAMENTAL}

- Patios, huertos y jardines (1): Destaca en jardinería por la vistosidad de sus frutos rosas durante el otoño.

CELASTRACEAE

Euonymus japonicus Thunb.

Bonetero (1)

Frecuencia de citación (FC):

Número de usos (NU): 1

Número registros de uso (RU):

Obtención: cultivada

Vigencia: vigente (100\%)

Usos:

ORNAMENTAL

- Patios, huertos y jardines (1): Es idóneo en jardinería para formar setos.

COMPOSITAE

Achillea ageratum L. Rosón (1)

187F; 254V

\begin{tabular}{ll}
\hline Frecuencia de citación (FC): & 1 \\
\hline Número de usos (NU): & 1 \\
Número registros de uso (RU): & 1 \\
\hline
\end{tabular}

Obtención: cultivada

Vigencia: abandonado

Usos:

ORNAMENTAL

- Adorno floral y plantas de interior (1): En Traspeña de la Peña se recoge para adornar la vivienda, sobre jarrones de flores secas. 


\section{COMPOSITAE}

Achillea millefolium $\mathrm{L}$.

Milenrama (13), mielenrama (1), birlenda (2), hierba del morro (1), balsamina (1), margarita (1), savia (1)

59P, 275P; 16F; 1V, 2V, 84V, 98V, 197V, 201V, 268V, $368 \mathrm{~V}, 500 \mathrm{~V}, 518 \mathrm{~V}, 569 \mathrm{~V}$

\begin{tabular}{lc}
\hline Frecuencia de citación (FC): & 20 \\
\hline Número de usos (NU): & 5 \\
\hline Número registros de uso (RU): & 28 \\
\hline Frecuencia Relativa de Citación (FRC): & 0,14 \\
\hline Índice de Importancia Cultural (IC): & 0,20 \\
\hline Índice de Vigencia (IV): & 0,02 \\
\hline
\end{tabular}

Obtención: silvestre

Vigencia: vigente (9\%)

Usos:

\section{ALIMENTACIÓN HUMANA}

- Bebidas no alcohólicas (1): En Verdeña se mezcla milenrama y melisa para tomar como infusión alimentaria después de las comidas. La época idónea de recolección son los meses de junio y julio principalmente.

\section{MEDICINA}

- Sistema circulatorio (3): Las sumidades florales se toman en infusión aconsejado como purificador de la sangre y regulador de la tensión.

Otra de sus virtudes destacadas son sus propiedades como buen antihemorroidal, se aplica cataplasma o se lavan las almorranas, con el cocimiento de las sumidades florales.

- Sistema digestivo (10): Su acción más conocida para las personas es la antidiarreica, mediante cocimiento de la planta, con unas pocas tazas se ataja el problema. Del mismo modo también tiene la capacidad de combatir el exceso de gases en el estomago.

- Sistema genito-urinario (2): Se cita en Herreruela de Castillería para aliviar dolores menstruales y para hacer lavados vaginales en casos de infecciones o algún otro tipo de afección. $Y$ en San Salvador de Cantamuda aluden a ella como un buen diurético.

- Sistema respiratorio (1): En la localidad de Ventanilla indican esta planta para curar los catarros de pecho administrada en infusión.

- Musculatura y esqueleto (2): El cocimiento de la inflorescencia se toma para tratar la artrosis y los dolores reumáticos.

- Síntomas estados de origen indefinido (1): Para estados de cansancio y astenia se añaden unas sumidades florales en un litro de agua y se toma el líquido resultante.
- Otros usos medicinales (1): Tiene tantos usos medicinales que se considera una panacea válida para casi cualquier enfermedad, puede mezclarse con una gran cantidad de especies para potenciar sus beneficios.

\section{VETERINARIO}

- Sistema digestivo (3): Los cólicos de las vacas se trataban dando a beber en una botella el cocimiento de varias inflorescencias.

- Sistema genito-urinario (1): Como diurético se aconseja "para las vacas que no podían orinar bien".

\section{ORNAMENTAL}

- Adorno floral y plantas de interior (2): Las inflorescencias secas se incluyen en jarrones y centros decorativos.

\section{SOCIAL, SIMBÓLICO Y RITUAL}

- Ritual de incertidumbre, protección o aflicción (1): Una mujer de Celada de Roblecedo aconseja tomarla repetidamente para ayudar a embarazarse.

\section{COMPOSITAE}

Anacyclus clavatus (Desf.) Pers. Margarita (3)

\section{P; 279F}

\begin{tabular}{lc}
\hline Frecuencia de citación (FC): & 3 \\
\hline Número de usos (NU): & 2 \\
\hline Número registros de uso (RU): & 3 \\
\hline Frecuencia Relativa de Citación (FRC): & $\mathbf{0 , 0 2}$ \\
\hline Índice de Importancia Cultural (IC): & $\mathbf{0 , 0 2}$ \\
\hline Índice de Vigencia (IV): & $\mathbf{0 , 0 1}$ \\
\hline
\end{tabular}

Obtención: silvestre

Vigencia: vigente (33\%)

Usos:

ORNAMENTAL

- Adorno floral y plantas de interior (1): Se usa la inflorescencia en decoración de jarrones con agua en el hogar.

\section{SOCIAL, SIMBÓLICA Y RITUAL}

- Ritual de ciclo anual (2): Las flores se utilizan para decorar altares y calles en la tradicional fiesta del Corpus Christi.

\section{COMPOSITAE}

Anthemis arvensis $\mathrm{L}$. Margarita (18), manzanilla (3), manzanillón (4), lirada (6) 
96P, 137P; 98F; 300V

\begin{tabular}{|lc|}
\hline Frecuencia de citación (FC): & 30 \\
\hline Número de usos (NU): & 4 \\
\hline Número registros de uso (RU): & 30 \\
\hline Frecuencia Relativa de Citación (FRC): & 0,22 \\
\hline Índice de Importancia Cultural (IC): & 0,22 \\
\hline Índice de Vigencia (IV): & 0,02 \\
\hline
\end{tabular}

Obtención: silvestre

Vigencia: vigente (9\%)

Conocimientos:

LÉXICO

Se distingue el manzanillón de la manzanilla (Chamaemelum nobile) porque es más alta y basta y con mayor número de capítulos, la manzanilla solo tiene uno por tallo. Todos los informantes que la citaron con el nombre de lirada lo hicieron despectivamente como mala hierba y los que la denominaron margarita fue con uso ornamental o ritual.

\section{Usos:}

\section{VETERINARIA}

- Sistema digestivo (12): Se usa el cocimiento de la planta como digestivo para las vacas cuando están empachadas y tienen hinchazón de estomago.

- Sistema genito-urinario (1): Tiene propiedades vulnerarias para tratar heridas e infecciones en la piel del ganado vacuno, la administración se realiza mediante cataplasma previamente untada en el refrito de aceite con unos pocos capítulos.

\section{MEDIOAMBIENTAL}

- Malas hierbas (7): Se escardaba de forma corriente y sencilla en los trigales.

\section{ORNAMENTAL}

- Adorno floral y plantas de interior (7): En primavera servían de adorno como flor cortada para floreros y jarrones con agua.

\section{SOCIAL, SIMBÓLICO Y RITUAL}

- Ritual de ciclo anual (1): Es una de las especies que se incluía en la recogida de flores para la decoración de altares y calles en el Corpus Christi.

- Uso recreativo (2): Los niños arrancaban las flores blancas liguladas en el juego tradicional del "me quiere, no me quiere".

\section{COMPOSITAE}

Arctium minus (Hill.) Bernh.
Amargacho (1), amargaza (2), capacho (16), capachera (1), lapa (1), pegote (1), cadillo (1)

\begin{tabular}{lc}
\hline $84 \mathrm{P}, 348 \mathrm{P} ; 314 \mathrm{~F} ; 100 \mathrm{~V}, 140 \mathrm{~V}, 370 \mathrm{~V}, 393 \mathrm{~V}, 520 \mathrm{~V}$ \\
\hline Frecuencia de citación (FC): & $\mathbf{2 3}$ \\
\hline Número de usos (NU): & $\mathbf{5}$ \\
\hline Número registros de uso (RU): & $\mathbf{2 6}$ \\
Frecuencia Relativa de Citación (FRC): & $\mathbf{0 , 1 7}$ \\
\hline Índice de Importancia Cultural (IC): & $\mathbf{0 , 1 9}$ \\
\hline Índice de Vigencia (IV): & $\mathbf{0 , 0 0}$ \\
\hline
\end{tabular}

Obtención: silvestre

Vigencia: abandonado

Conocimientos:

LÉXICO

Se reconocen a los capítulos por los nombres de capacho, pegote o cadillo.

Usos:

ALIMENTACIÓN ANIMAL

- Forraje verde o seco (1): Las hojas de gran tamaño se cocían en un puchero para servir a los cerdos.

\section{MEDICINA}

- Sistema endocrino-metabólico (2): En Herreruela de Castillería recomiendan la infusión de las hojas para tratar la diabetes.

\section{VETERINARIO}

- Piel y tejido celular subcutáneo (1): Para curar la herida infectada provocada al capar (extracción de los testículos) los cerdos, se lavaba la sutura con el cocimiento de la raíz. En Villanueva de la Torre recuerdan cómo "se compraba el cerdo por San Miguel y se les capaba por San Martín. Si no se les capaba no hacían buena carne".

\section{TóXICO Y NOCIVO}

- Otros nocivos y repelentes (2): Las edificaciones tradicionales de piedra, son propicias para que entre sus huecos puedan introducirse ratones, para evitarlo se colocaban capachos obstruyendo los agujeros.

\section{SOCIAL, SIMBÓLICO Y RITUAL}

- Uso recreativo (20): Los niños jugaban a menudo con el capítulo que tenía la capacidad de adherirse a la ropa y al pelo.

\section{Artemisia absinthium L.}

COMPOSITAE Ajenjo (1) 
406P, 537P; 269V

\begin{tabular}{ll}
\hline Frecuencia de citación (FC): & 1 \\
Número de usos (NU): & 0 \\
Número registros de uso (RU): & 0
\end{tabular}

Obtención: silvestre

Vigencia: abandonado

Observaciones: Solo hemos podido recoger de esta especie su uso comercial en Roscales de la Peña "Desde Cornón íbamos a Guardo a por ello, el ajenjo decían que era para hacer medicina, lo cogíamos, hacíamos montones y luego venían a por ellos, un cura lo compraba, después se lo llevaba un camión".

\section{COMPOSITAE}

\section{Bellis perennis $\mathrm{L}$.}

B. sylvestris Cirillo

Margarita (10), flor de Nuestra Señora (1)

Bellis perennis: 90P, 499P; 139F; 9V

B. sylvestris: 329P

\begin{tabular}{lc|}
\hline Frecuencia de citación (FC): & 11 \\
\hline Número de usos (NU): & 3 \\
\hline Número registros de uso (RU): & 12 \\
\hline Frecuencia Relativa de Citación (FRC): & $\mathbf{0 , 0 8}$ \\
\hline Índice de Importancia Cultural (IC): & $\mathbf{0 , 0 9}$ \\
\hline Índice de Vigencia (IV): & $\mathbf{0 , 0 1}$ \\
\hline
\end{tabular}

Obtención: silvestre

Vigencia: vigente (16\%)

\section{Conocimientos:}

\section{ECOLOGÍA}

Extendida en el pasado en los cultivos de cereal, en la actualidad se observa una menor aparición debido al cambio de prácticas agrícolas y a los herbicidas empleados.

Usos:

INDUSTRIA Y ARTESANÍA

- Vestimenta y adornos personales (2): Las niñas buscaban las margaritas con el escapo más largo para trenzarlas y elaborar collares y pulseras.

\section{ORNAMENTAL}

- Adorno floral y plantas de interior (2): Se hacían pequeños ramilletes de flores para decorar en algún jarrón.

\section{SOCIAL, SIMBÓLICO Y RITUAL}

- Ritual de ciclo anual (7): En la fiesta del Corpus Christi las niñas vestidas de comunión tiraban por las calles margaritas.
- Uso recreativo (1): Para jugar los niños al típico "me quiere, no me quiere".

COMPOSITAE

Bidens aurea (Aiton) Sherff

Té de huerta (1)

234P, 416P

\begin{tabular}{|ll|}
\hline Frecuencia de citación (FC): & 1 \\
\hline Número de usos (NU): & 1 \\
\hline Número registros de uso (RU): & 1 \\
\hline
\end{tabular}

Obtención: cultivada

Vigencia: vigente $(100 \%)$

Conocimientos:

ECOLOGÍA

Se cría bien en huertos y zonas húmedas o de regadío.

Usos:

\section{ALIMENTACIÓN HUMANA}

- Bebidas no alcohólicas (1): Las hojas y tallos de esta planta se utilizan para elaborar infusiones que se suelen tomar después de las comidas o en el desayuno. La recolección se suele realizar durante el otoño cuando la planta está alta, las hojas y tallos bien picaditos se dejan secar y se reserva en tarros. El resultante del cocimiento en agua es una bebida de sabor agradable empleada como sustituto del té comercial (Camellia sinensis).

\section{COMPOSITAE}

\section{Calendula officinalis L.}

Maravilla (7), caléndula (1), clavel (4)

95P, 452P; 201F; 495V, 550V, 571V

\begin{tabular}{lc}
\hline Frecuencia de citación (FC): & 12 \\
\hline Número de usos (NU): & 4 \\
\hline Número registros de uso (RU): & 14 \\
\hline Frecuencia Relativa de Citación (FRC): & 0,09 \\
\hline Índice de Importancia Cultural (IC): & 0,10 \\
\hline Índice de Vigencia (IV): & 0,06 \\
\hline
\end{tabular}

Obtención: cultivada, silvestre

Vigencia: vigente (64\%)

Usos:

ALIMENTACIÓN ANIMAL

- Plantas melíferas (1): La floración de esta especie es muy atrayente para las abejas, como así nos confirman en Lebanza.

MEDICINA 
- Musculatura y esqueleto (1): Para el hinchazón muscular se elabora una crema con cera de abeja y el aceite resultante de freír unos pocos capítulos en una sartén.

- Piel y tejido celular subcutáneo (2): Se maceran capítulos de caléndula en aceite de oliva y se mezcla con cera de abejas, el ungüento se aconseja para las heridas y grietas en la piel.

\section{VETERINARIA}

- Sistema genito-urinario (1): En La Lastra se usaba para tratar la mamitis de las vacas. En una sartén se deshacía un poco de grasa o manteca de cerdo con unas cabezas de caléndula, se dejaba reposar tapado un día entero, y se calentaba poco antes de ser usado.

\section{ORNAMENTAL}

- Patios, huertos y jardines (9): Se cultiva en huertos y jardines, y además aparece de modo espontáneo por las calles.

COMPOSITAE

Carduus crispus Guirão ex Nyman

Cardo (4), cardo negrero (1)

170P, 537P; 206F; 85V

\begin{tabular}{lc}
\hline Frecuencia de citación (FC): & 5 \\
\hline Número de usos (NU): & 2 \\
\hline Número registros de uso (RU): & $\mathbf{7}$ \\
\hline Frecuencia Relativa de Citación (FRC): & $\mathbf{0 , 0 4}$ \\
\hline Índice de Importancia Cultural (IC): & $\mathbf{0 , 0 5}$ \\
\hline Índice de Vigencia (IV): & $\mathbf{0 , 0 0}$ \\
\hline
\end{tabular}

Obtención: silvestre

Vigencia: abandonado

Conocimientos:

\section{ECOLOGÍA}

Extendida en el pasado en los cultivos de cereal, en la actualidad se observa en menor medida debido al cambio de prácticas agrícolas y a los herbicidas empleados.

\section{Usos:}

\section{ALIMENTACIÓN ANIMAL}

- Forraje verde o seco (2): Se llevaban como forraje verde a las vacas al principio de la primavera, antes incluso de que se araran las tierras.

\section{MEDIOAMBIENTAL}

- Malas hierbas (5): Los cardos se limpian de las tierras de labor, consideradas malas hierbas.
Observaciones: En la zona podemos encontrar diversas especies del género Carduus que quizás fueron empleadas como forraje verde para los animales, entre ellas: Carduus carpetanus, C. pycnocephalus o C. tenuiflorus.

\section{COMPOSITAE}

\section{Carlina vulgaris $\mathrm{L}$.} Cardo (1)

429P; $277 \mathrm{~F}$

\begin{tabular}{lc}
\hline Frecuencia de citación (FC): & 1 \\
\hline Número de usos (NU): & 1 \\
\hline Número registros de uso (RU): & 1 \\
\hline Frecuencia Relativa de Citación (FRC): & 0,01 \\
\hline Índice de Importancia Cultural (IC): & 0,01 \\
\hline Índice de Vigencia (IV): & 0,00 \\
\hline
\end{tabular}

Obtención: silvestre

Vigencia: abandonado

\section{ORNAMENTAL}

- Adorno floral y plantas de interior (1): En Verdeña, cuando la planta comienza a secarse a mediados del verano, se cortan para hacer jarrones de flor seca, "en el tardío aguantan mucho y no tienen mucha pelusa".

\section{COMPOSITAE}

\section{Carthamus mitissimus $\mathrm{L}$. \\ Arzolla (1)}

\begin{tabular}{lc} 
250P; $56 \mathrm{~F}$ & \\
\hline Frecuencia de citación (FC): & 1 \\
\hline Número de usos (NU): & 1 \\
\hline Número registros de uso (RU): & 1 \\
\hline Frecuencia Relativa de Citación (FRC): & $\mathbf{0 , 0 1}$ \\
\hline Índice de Importancia Cultural (IC): & $\mathbf{0 , 0 1}$ \\
\hline Índice de Vigencia (IV): & $\mathbf{0 , 0 0}$ \\
\hline
\end{tabular}

Obtención: silvestre

Vigencia: abandonado

\section{Conocimientos: \\ ECOLOGÍA}

Solo sale en sitios secos como lastras, nunca en praderas.

\section{Usos:}

\section{MEDICINA}

- Piel y tejido celular subcutáneo (1): Con el cocimiento de la planta se lavan las heridas para que cicatricen más rápido y no se infecten en San Felices de Castillería. 
Observaciones: Con el nombre de arzolla hemos documentado en la comarca las siguientes especies: Carthamus mitissimus, Centaurea calcitrapa, C. lagascana y Jurinea humilis, todas ellas con uso vulnerario.

\section{COMPOSITAE}

\section{Centaurea calcitrapa L.}

Cardo de arzolla (1)

447P, 538P; 276F; 373V

\begin{tabular}{lc|}
\hline Frecuencia de citación (FC): & 1 \\
\hline Número de usos (NU): & 1 \\
\hline Número registros de uso (RU): & 2 \\
\hline Frecuencia Relativa de Citación (FRC): & 0,01 \\
\hline Índice de Importancia Cultural (IC): & 0,01 \\
\hline Índice de Vigencia (IV): & 0,00 \\
\hline
\end{tabular}

Obtención: silvestre

Vigencia: abandonado

\section{Conocimientos:}

\section{LÉXICO}

Se denomina alcachofa a la inflorescencia de la planta.

Usos:

\section{VETERINARIA}

- Musculatura y esqueleto (1): El cocimiento de la inflorescencia se aplica con una compresa en los golpes del ganado (equino, ovino, vacuno). Según testimonio recogido en Rabanal de las Llantas "hay que recoger la alcachofa del cardo de arzolla cuando está empezando a brotar y antes de que espigue".

- Piel y tejido celular subcutáneo (1): En la misma localidad se lavan las heridas de los animales con la cocción de la inflorescencia.

\section{Centaurea lagascana Graells}

COMPOSITAE

Arzolla (22), cardo de arzolla (2)

114P; 44F; 101V, 150V, 151V, 395V, 595V

\begin{tabular}{lc}
\hline Frecuencia de citación (FC): & 24 \\
\hline Número de usos (NU): & 2 \\
\hline Número registros de uso (RU): & 29 \\
\hline Frecuencia Relativa de Citación (FRC): & 0,17 \\
\hline Índice de Importancia Cultural (IC): & 0,21 \\
\hline Índice de Vigencia (IV): & 0,01 \\
\hline
\end{tabular}

Obtención: silvestre

Vigencia: vigente (4\%)

Conocimientos:

\section{ECOLOGÍA}

"Se cría en camperas a ras de suelo, es una cepa con flores amarillas y todo pinchos".

Usos:

\section{MEDICINA}

- Sistema digestivo (1): En Cubillo de la Peña un informante nos muestra una tintura hecha macerando arzolla en orujo, asegura que cura el dolor de estomago bebiendo un vasito pequeño "con menos de un chupito alivia el dolor fuerte de estomago".

- Musculatura y esqueleto (6): La arzolla es una planta de uso convencional para el tratamiento de esguinces, contusiones, fracturas o dolores producidos por golpes. El momento idóneo para su recolección es durante la floración, hacia el final de la primavera o principio del verano, se arrancaba la planta entera y se almacenaba en tarros o cajas. Cuando se precisaba, se cocía la planta entera en agua durante varios minutos, después se mojaban paños en el líquido resultante y se colocaban sobre la zona afectada, a modo de emplasto.

- Piel y tejido celular subcutáneo (6): Tiene reputación como remedio vulnerario (curar heridas) y desinfectante. Las heridas se lavaban con el cocimiento en agua de la planta entera.

\section{VETERINARIA}

- Musculatura y esqueleto (2): Todo tipo de traumatismos en los animales domésticos se combatían con la cocción de arzolla administrada mediante cataplasma.

- Piel y tejido celular subcutáneo (14): Para la desinfección y cicatrización de heridas en animales su uso es preferente. La zona afectada se lavaba con el cocimiento de la planta o se aplicaban compresas empapadas en el mismo.

Observaciones: Se utiliza el término arzolla para denominar plantas empleadas como vulnerarias o para tratar diversos traumatismos, tanto en personas como en animales. Nos encontramos ante el caso particular, de que la nomenclatura popular atiende a un sistema clasificatorio basado en la utilidad de la planta, por ello son varias las especies denominadas bajo el mismo nombre. En la zona de La Pernía, Valle de Castillería y Valle Estrecho designan arzolla a Centaurea lagascana. Hacia el este, en la zona de Santullán, bajo ese mismo nombre se identifica a Jurinea humilis. Por último, en el Cerrato refieren arzolla o raíz de arzolla a Centaurea ornata. 


\section{COMPOSITAE}

\section{Centaurea nigra L.}

Garbanzón (1)

371P; 258F

\begin{tabular}{lc}
\hline Frecuencia de citación (FC): & 1 \\
\hline Número de usos (NU): & 1 \\
\hline Número registros de uso (RU): & 1 \\
\hline Frecuencia Relativa de Citación (FRC): & 0,01 \\
\hline Índice de Importancia Cultural (IC): & 0,01 \\
\hline Índice de Vigencia (IV): & 0,00 \\
\hline
\end{tabular}

Obtención: silvestre

Vigencia: abandonado

Usos:

MEDICINA

- Órganos de los sentidos (1): En Celada de Roblecedo se emplea la infusión de los capítulos para lavar los ojos enrojecidos por conjuntivitis o con legañas.

COMPOSITAE

\section{Centaurea scabiosa $\mathrm{L}$.}

Amapera (3), humarra (3)

169P; 105F; 86V, 479V

\begin{tabular}{lc}
\hline Frecuencia de citación (FC): & 6 \\
\hline Número de usos (NU): & 2 \\
\hline Número registros de uso (RU): & 10 \\
\hline Frecuencia Relativa de Citación (FRC): & 0,03 \\
Índice de Importancia Cultural (IC): & 0,05 \\
Índice de Vigencia (IV): & 0,00
\end{tabular}

Obtención: silvestre

Vigencia: abandonado

\section{Conocimientos:}

\section{ECOLOGÍA}

En Matabuena afirman que "solo sale en las tierras trigales, nunca en las ceñales que son más areniscas".

Usos:

\section{ALIMENTACIÓN ANIMAL}

- Forraje verde o seco (6): Se aprovechan la parte aérea en fresco como forraje para vacas y cerdos.

\section{MEDIOAMBIENTAL}

- Malas hierbas (4): Considerada mala hierba que se escarda de los cultivos de cereal.
Manzanilla (106), manzanilla campera (7)

PALAB2902, 47P, 503P; 35F; 135V, 225V, 255V, 335V, 480V, 588V, 591V

\begin{tabular}{lc}
\hline Frecuencia de citación (FC): & 113 \\
Número de usos (NU): & 4 \\
\hline Número registros de uso (RU): & 142 \\
\hline Frecuencia Relativa de Citación (FRC): & 0,81 \\
Índice de Importancia Cultural (IC): & 1,02 \\
\hline Índice de Vigencia (IV): & 0,57 \\
\hline
\end{tabular}

Obtención: silvestre

Vigencia: vigente (56\%)

\section{Conocimientos:}

\section{ECOLOGÍA}

Extendida por prados, cañadas algo húmedas y vaguadas. "Sale en la cabecera de los pantanos".

\section{LÉXICO}

Denominada con el binomio manzanilla campera, para diferenciarla de la manzanilla bastarda o manzanillón (Anthemis arvensis) y de la manzanilla calar (Helichrysum stoechas).

Usos:

\section{ALIMENTACIÓN HUMANA}

- Bebidas alcohólicas (2): En los preparados de diversos licores (endrinas, maíllas, etc.) se suelen añadir unas cabezuelas de manzanilla para aromatizar los orujos, pues se afirma mejora el sabor.

- Bebidas no alcohólicas (7): Resulta común tomar infusiones no solo por sus propiedades medicinales, tanto en el desayuno como después de las comidas.

\section{MEDICINA}

- Sistema digestivo (97): Ampliamente utilizada ante cualquier problema de origen digestivo (empacho, cólico, diarrea, indigestión, gases, dolor estomacal, etc.). Se recolecta la parte aérea de la planta a principios del mes de julio, se ata y se seca en manojos. La preparación se realiza en forma de infusión con unos pocos capítulos florales.

- Sistema respiratorio (4): La infusión se toma caliente para aliviar los síntomas del catarro.

- Musculatura y esqueleto (1): Para combatir los ataques de reuma se describe en Herreruela de Castillería, el empleo de infusión de flores de manzanilla, mezcladas con la segunda corteza (floema) del fresno.

- Sistema nervioso (1): La infusión caliente servía para el tratamiento de cefaleas.

Chamaemelum nobile (L.) All. 
- Órganos de los sentidos (19): En casos de trastornos oculares leves como conjuntivitis o picor y dolor de ojos, la infusión tibia de manzanilla resulta un remedio popular.

- Otros usos medicinales (1): En Ventanilla se usa como panacea, en infusión mezclada con otras especies, con las cuales se asegura no caer en enfermedad alguna. "Se mezcla grama que sale en los praos, tila, te, orégano, milenrama, cola de caballo, manzanilla de las dos clases, la de campera y la calar, sanguinaria y tomillo".

\section{VETERINARIA}

- Sistema digestivo (5): Eficaz en infusión ante diversos problemas digestivos del ganado vacuno, principalmente cólicos. En ocasiones se mezclaba la infusión con aceite, según señalan en Camporredondo.

También era útil la infusión cuando se manifestaban problemas en el rumio,

- Sistema genito-urinario (3): En Celada de Roblecedo se señaló la utilidad de la manzanilla ante casos de retención de orina en el ganado.

Para tratar inflamaciones en las ubres se empleaba esta receta recogida en Herreruela de Castillería "Se cogen unas cabezas de manzanilla, se echan en el sartén, se fríen con un poquitín de aceite y después con un trapo se da a las vacas cuando tienen inflamación en las ubres. Quita las inflamaciones".

- Órganos de los sentidos (1): En Camasobres se detalla cómo, en ocasiones, a los animales les lloraban los ojos y se los lavaban mojando un trapo en una infusión de manzanilla.

\section{INDUSTRIA Y ARTESANÍA}

- Cosmética, perfumería y limpieza (1): Afirma una informante de Estalaya cómo se lavaban siempre el pelo con agua cocida con manzanillas, que servía para aclarar el pelo.

Observaciones: Varios informantes señalan que el abandono de los usos ganaderos en muchos pueblos ha provocado la desaparición o disminución de las poblaciones de esta especie.

COMPOSITAE

\section{Cichorium endivia $\mathrm{L}$.}

Escarola (1)

\begin{tabular}{ll}
$266 P ; 283 F$ & \\
\hline Frecuencia de citación (FC): & 1 \\
\hline Número de usos (NU): & 1 \\
Número registros de uso (RU): & 1 \\
\hline
\end{tabular}

Obtención: cultivada, comprada

Vigencia: vigente (100\%)

Usos:

\section{ALIMENTACIÓN HUMANA}

- Verduras y hortalizas (1): Se consumen las hojas en ensalada, sola o junto con ajo picado. Su cultivo es reciente y poco frecuente en los huertos de la zona.

COMPOSITAE

Cirsium arvense (L.) Scop.

\section{C. vulgare (Savi) Ten.}

Cardo (59), cardo negrero (1), cardo triguero (2), cardo borriquero (2)

Cirsium arvense: 35P, 388P; 66F; 397V

C. vulgare: 168P, 306P; 104F; $87 \mathrm{~V}$

\begin{tabular}{lc}
\hline Frecuencia de citación (FC): & 64 \\
\hline Número de usos (NU): & 2 \\
\hline Número registros de uso (RU): & 91 \\
\hline Frecuencia Relativa de Citación (FRC): & $\mathbf{0 , 4 6}$ \\
\hline Índice de Importancia Cultural (IC): & 0,65 \\
\hline Índice de Vigencia (IV): & $\mathbf{0 , 0 0}$ \\
\hline
\end{tabular}

Obtención: silvestre

Vigencia: abandonado

Conocimientos:

ECOLOGÍA

Se dan en cultivos de cereal, patateras y tierras abandonadas.

\section{LÉXICO:}

En Celada de Roblecedo aparece el fitotopónimo del pago "El Cardo" y en La Lastra la "Fuente el Cardo".

\section{Usos:}

\section{ALIMENTACIÓN ANIMAL}

- Forraje verde o seco (44): Se daban como forraje verde a las vacas, las yeguas y los cerdos, en este último caso podían ser cocidos previamente para que fuera más sencillo su consumo.

- Plantas melíferas (1): Las abejas visitan las flores.

\section{MEDIOAMBIENTAL}

- Malas hierbas (46): Los cardos se limpiaban con frecuencia de las tierras de cereal y cultivos de patata.

Observaciones: Varias especies se han identificado con el nombre de cardo, en la zona: Carduus crispus, Cirsium arvense, $C$. 
eriophorum C. vulgare, Eryngium bourgatii, $E$. campestre, Dipsacus fullonum, Lactuca serriola, Onopordum acanthium y Sonchus oleraceus. Algunas otras especies, presentes en la comarca posiblemente tengan los mismos usos, como: Cirsium palustre, $C$. helenioides, Carduus bourgeanus, Lactuca viminea, L. virosa o Sonchus asper.

\section{COMPOSITAE}

\section{Cirsium eriophorum (L.) Scop.}

Cardo (3), cardo burriquero (2), cardo burrero (2)

\begin{tabular}{lc}
\hline 340P; 219F; 398V \\
\hline Frecuencia de citación (FC): & $\mathbf{7}$ \\
\hline Número de usos (NU): & $\mathbf{3}$ \\
\hline Número registros de uso (RU): & $\mathbf{7}$ \\
Frecuencia Relativa de Citación (FRC): & $\mathbf{0 , 0 5}$ \\
\hline Índice de Importancia Cultural (IC): & $\mathbf{0 , 0 5}$ \\
\hline Índice de Vigencia (IV): & $\mathbf{0 , 0 0}$ \\
\hline
\end{tabular}

Obtención: silvestre

Vigencia: abandonado

Conocimientos:

LÉXICO

Las espinas duras y fuertes se denominan guinchos.

Usos:

\section{ALIMENTACIÓN ANIMAL}

- Pasto (2): Los burros son los únicos animales que pastan este tipo de cardos con unas espinas tan fuertes.

- Plantas melíferas (1): La flor es buena para las abejas, "en el tardío las moscas van a los cardos".

\section{VETERINARIA}

- Sistema respiratorio (1): El líquido resultante de la cocción de la inflorescencia en agua se empleaba para tratar a las vacas con tos en la localidad de Néstar.

\section{MEDIOAMBIENTAL}

- Malas hierbas (3): Se retiran de los prados.

\section{COMPOSITAE}

Cyanus segetum Hill

Azulina (1), clavelina azul (2), clavel (2), molino de color (1), azulejo (1)

231P; 286F; 226V, 513V

\begin{tabular}{lc}
\hline Frecuencia de citación (FC): & $\mathbf{7}$ \\
\hline Número de usos (NU): & 4 \\
\hline Número registros de uso (RU): & $\mathbf{8}$ \\
\hline Frecuencia Relativa de Citación (FRC): & $\mathbf{0 , 0 5}$ \\
\hline Índice de Importancia Cultural (IC): & $\mathbf{0 , 0 6}$ \\
\hline Índice de Vigencia (IV): & $\mathbf{0 , 0 0}$ \\
\hline
\end{tabular}

Obtención: silvestre

Vigencia: abandonado

Usos:

\section{ALIMENTACIÓN ANIMAL}

- Forraje verde o seco (1): Útil como forraje verde para los conejos.

\section{MEDICINA}

- Órganos de los sentidos (4): Con la infusión de las flores se lavan los ojos malos, enrojecidos o legañosos.

\section{MEDIOAMBIENTAL}

- Malas hierbas (1): En los trigos y otros cultivos de cereal se escardan las azulinas.

\section{SOCIAL, SIMBÓLICO Y RITUAL}

- Ritual de ciclo anual (2): La flor de esta planta se recogía para decorar los altares en la fiesta del Corpus Christi o para tirarlas por las calles por las que discurría la procesión.

COMPOSITAE

\section{Cynara scolymus L.}

Alcachofa (1)

\begin{tabular}{ll} 
380P; $120 \mathrm{~F}$ & \\
\hline Frecuencia de citación (FC): & 1 \\
\hline Número de usos (NU): & 1 \\
\hline Número registros de uso (RU): & 1 \\
\hline
\end{tabular}

Obtención: cultivada, comprada

Vigencia: vigente (100\%)

Usos:

\section{ALIMENTACIÓN HUMANA}

- Verduras y hortalizas (1): Se trata de una verdura poco cultivada en el huerto tradicional, se consume cocinada con frecuencia acompañada de trozos de jamón.

\section{COMPOSITAE}

Dahlia x hortensis Guillaumin

D. pinnata Cav.

Dalia (2)

Dahlia pinnata: $192 \mathrm{~F}$ 
D. hortensis: $584 \mathrm{~V}$

\begin{tabular}{ll}
\hline Frecuencia de citación (FC): & 2 \\
\hline Número de usos (NU): & 2 \\
\hline Número registros de uso (RU): & 2 \\
\hline
\end{tabular}

Obtención: cultivada

Vigencia: vigente (100\%)

Usos:

ORNAMENTAL

- Patios, huertos y jardines (2): Se cultivan en patios y jardines como ornamentales.

COMPOSITAE

\section{Helianthus annuus $\mathrm{L}$.}

Girasol (2)

24P; 35,37F; 112V

\begin{tabular}{ll}
\hline Frecuencia de citación (FC): & 2 \\
\hline Número de usos (NU): & 1 \\
Número registros de uso (RU): & 2 \\
\hline
\end{tabular}

Obtención: cultivada

Vigencia: vigente (50\%)

Usos:

ALIMENTACIÓN ANIMAL

- Frutos secos y oleaginosos (2): En alguna huerta se sembraba girasol, de la inflorescencia llamada gigantea se aprovechan las semillas que se pueden comer crudas o tostadas.

Observaciones: Se ha observado el cultivo de girasol en las zonas más meridionales de la comarca.

COMPOSITAE

\section{Helichrysum stoechas (L.) Moench}

Manzanilla (54), manzanilla de peña (8), manzanilla de lastra (5), manzanilla calar (4), manzanilla de roca (1)

PALAB2609, 50P; 246F; 112V, 198V, 244V, 308V, 339V, 498V, 501V, 502V, 554V

\begin{tabular}{|lc|}
\hline Frecuencia de citación (FC): & $\mathbf{7 2}$ \\
\hline Número de usos (NU): & 3 \\
\hline Número registros de uso (RU): & $\mathbf{8 2}$ \\
\hline Frecuencia Relativa de Citación (FRC): & $\mathbf{0 , 5 2}$ \\
\hline Índice de Importancia Cultural (IC): & $\mathbf{0 , 5 9}$ \\
\hline Índice de Vigencia (IV): & $\mathbf{0 , 1 0}$ \\
\hline
\end{tabular}

Obtención: silvestre

Vigencia: vigente (17\%)

Conocimientos:

\section{ECOLOGÍA}

Se recolecta esta planta en las llamadas calares o lastras, lugares donde abunda la piedra caliza.

\section{LÉXICO}

Los adyacentes que acompañan a las denominaciones de esta especie derivan de las zonas donde se recolecta "de peña, lastra, roca y calar".

Usos:

\section{ALIMENTACIÓN HUMANA}

- Bebidas no alcohólicas (9): La infusión de la parte aérea se toma como bebida para después de las comidas, o como señalan en Rebanal de las Llantas simplemente "para pasar la pastilla".

\section{MEDICINA}

- Sistema digestivo (64): Utilizada como digestiva y estomacal. Su forma de administración es mediante tisanas hechas a partir de tallos y capítulos florales. Se dice, que además de servir como digestivo después de las comidas, puede calmar los dolores estomacales producidos por empachos o malas digestiones

- Sistema respiratorio (5): Para los catarros se toma la infusión de la inflorescencia bien caliente.

- Órganos de los sentidos (1): En Traspeña de la Peña se indica la infusión para curar los ojos enrojecidos o con alguna infección.

- Otros usos medicinales (2): Considerada una panacea válida para casi cualquier enfermedad, se mezcla con otras especies para mejorar sus propiedades curativas.

\section{VETERINARIA}

- Sistema digestivo (1): La cocción de cebollas podridas y manzanilla se administraba a las vacas como purgante.

COMPOSITAE

Inula helvetica Grauer

Árnica (1)

161P, 356P; 249F

\begin{tabular}{|lc|}
\hline Frecuencia de citación (FC): & 1 \\
\hline Número de usos (NU): & 2 \\
\hline Número registros de uso (RU): & 4 \\
\hline Frecuencia Relativa de Citación (FRC): & 0,01 \\
\hline Índice de Importancia Cultural (IC): & 0,03 \\
\hline Índice de Vigencia (IV): & 0,02 \\
\hline
\end{tabular}

Obtención: silvestre

Vigencia: vigente (75\%) 
Usos:

\section{MEDICINA}

- Sistema circulatorio (1): El macerado en orujo de la parte aérea se aplica con un trapo sobre las hemorroides "si aguantas dátelo mejor en orujo, sino rebájalo con una cucharada en agua", Cubillo de la Peña.

- Sistema digestivo (1): El mismo preparado se emplea para enjuagar la boca cuando aparecen llagas.

- Piel y tejido celular subcutáneo (1): Para cicatrizar las heridas se lavan con el orujo resultante de macerar la parte aérea durante un tiempo.

\section{VETERINARIA}

- Piel y tejido celular subcutáneo (1): A los animales también se les lavaba las heridas con el macerado de la planta en orujo.

Observaciones: Para que la planta conserve todas sus propiedades se ha de recolectar en la luna menguante de julio, agosto o septiembre.

COMPOSITAE

\section{Inula montana $\mathrm{L}$.}

Árnica (101)

$48 \mathrm{P}, 502 \mathrm{P} ; 12 \mathrm{~F} ; 36 \mathrm{~V}, 115 \mathrm{~V}, 160 \mathrm{~V}, 247 \mathrm{~V}, 341 \mathrm{~V}, 378 \mathrm{~V}$, 504V, 528V, 556V

\begin{tabular}{lc}
\hline Frecuencia de citación (FC): & 101 \\
\hline Número de usos (NU): & 3 \\
\hline Número registros de uso (RU): & 120 \\
\hline Frecuencia Relativa de Citación (FRC): & 0,73 \\
\hline Índice de Importancia Cultural (IC): & 0,86 \\
\hline Índice de Vigencia (IV): & 0,02 \\
\hline
\end{tabular}

Obtención: silvestre

Vigencia: vigente (2\%)

Conocimientos:

ECOLOGÍA

Aparece en laderas pedregosas y áridas sobre suelos calcáreos.

Usos:

MEDICINA

- Sistema respiratorio (2): Se recoge el uso de la inflorescencia administrada en infusión, como tratamiento eficaz para combatir la pulmonía.

- Musculatura y esqueleto (83): Se aconseja para los dolores e inflamaciones producidas por contusiones o golpes, fracturas o cualquier tipo de traumatismo, siendo considerada panacea para este tipo de contratiempos. La parte útil son las inflorescencias que se recogen desde el principio del verano. Los modos de aplicación varían bastante, desde maceraciones en alcohol o aceite para friccionar las zonas doloridas, hasta cocimientos en agua para cataplasmas o compresas, así como baños de la parte afectada en agua hirviendo.

- Piel y tejido celular subcutáneo (16): Se señala el cocimiento en agua de las flores para curar heridas. Se aplica un paño húmedo para lavar la zona afectada.

\section{VETERINARIO}

- Musculatura y esqueleto (17): Utilizada como vulneraria y antiinflamatoria en tratamientos para aliviar traumatismos en todo tipo de animales. Se recomienda hervir la planta en agua, sola o mezclada con otras plantas como el saúco para potenciar su acción curativa y aplicar mediante cataplasma sobre la zona contusionada.

\section{TÓXICO Y NOCIVO}

- Tóxico para humanos y animales (2): Se recoge en Tarilonte de la Peña la advertencia de no utilizar la infusión para uso interno, debido a su toxicidad.

Observaciones: En la zona de estudio hemos identificado Inula montana, sin poder precisar si Inula helenioides e Inula salicina, también presentes, tienen los mismos usos.

COMPOSITAE

Jacobaea vulgaris Gaertn.

Hierba bujanera (1), bujanera (1), hierba gusanera (1), hierba del gusano (1), hierba piojera (1), hierba de Santiago (1)

104P, 530P; 242F; 37V, 379V, 596V

\begin{tabular}{lc}
\hline Frecuencia de citación (FC): & $\mathbf{8}$ \\
\hline Número de usos (NU): & 4 \\
\hline Número registros de uso (RU): & 10 \\
\hline Frecuencia Relativa de Citación (FRC): & $\mathbf{0 , 0 6}$ \\
\hline Índice de Importancia Cultural (IC): & $\mathbf{0 , 0 7}$ \\
\hline Índice de Vigencia (IV): & $\mathbf{0 , 0 0}$ \\
\hline
\end{tabular}

Obtención: silvestre

Vigencia: abandonado

Conocimientos:

\section{ECOLOGÍA}

Aparece en bordes de caminos y prados pobres.

LÉXICO 
Es conocida como bujanera, hierba gusanera o hierba del gusano porque esta planta hospeda la oruga de la mariposa cinabrio (Thyria jacobaea).

Usos:

MEDICINA

- Musculatura y esqueleto (1): Se cuece la parte aérea junto con hojas de gordolobo y se aplica una cataplasma sobre hinchazones $y$ moratones.

- Síntomas y estados de origen indefinido (1): Para combatir el sudor y mal olor de los pies, se meten los pies en agua templada previamente cocida con la parte aérea.

\section{VETERINARIA}

- Otras enfermedades infecciosas y parasitarias (2): La pediculosis en el ganado más joven (corderos y terneros) se combatía mojándoles con el agua resultante de cocer la planta. También era útil para lavar las heridas infectadas por larvas de mosca.

\section{TóxICO Y NOCIVO}

- Tóxica para personas y animales (4): Se considera tóxica por observación, ya que el ganado no la pace.

\section{MEDIOAMBIENTAL}

- Malas hierbas (2): Se quitan de los prados.

Observaciones: Rivera y Obón (1991) comentan que todas las especies de este genero son venenosas al contener alcaloides.

\section{COMPOSITAE}

Jurinea humilis (Desf.) DC.

Arzolla (8)

474P; 312F; 342V, 556V

\begin{tabular}{lc}
\hline Frecuencia de citación (FC): & 8 \\
\hline Número de usos (NU): & 2 \\
\hline Número registros de uso (RU): & 9 \\
\hline Frecuencia Relativa de Citación (FRC): & 0,06 \\
\hline Índice de Importancia Cultural (IC): & 0,06 \\
\hline Índice de Vigencia (IV): & 0,00 \\
\hline
\end{tabular}

Obtención: silvestre

Vigencia: abandonado

Usos:

MEDICINA

- Piel y tejido celular subcutáneo (5): Utilizada como vulneraria y desinfectante. El modo de uso señalado fue el cocimiento de la planta entera en agua, para después aplicarla con emplastos o lavados sobre heridas.

\section{VETERINARIA}

- Piel y tejido celular subcutáneo (4): Para animales también es empleada como vulneraria y para tratar infecciones y heridas en la piel. Se aplican cataplasmas o se realizan lavados sobre la zona afectada con el cocimiento de la planta en agua, mejora y acelera la cicatrización de los tejidos. El principal destino fue el lavado de las heridas provocadas por la mordedura del lobo.

Observaciones: La nomenclatura popular atiende a un sistema clasificatorio basado en la utilidad de la planta, por ello son varias las especies denominadas bajo el nombre de arzolla. (Carthamus mitissimus, Centaurea calcitrapa, C. lagascana y Jurinea humilis).

COMPOSITAE

\section{Lactuca sativa $\mathrm{L}$.}

Lechuga (41)

\begin{tabular}{l}
\hline $268 \mathrm{~F}$ \\
\hline Frecuencia de citación (FC): \\
\hline Número de usos (NU):
\end{tabular}

Obtención: cultivada, comprada

Vigencia: vigente (100\%)

Usos:

ALIMENTACIÓN HUMANA

- Verduras y hortalizas (41): Verdura muy frecuente en los huertos, empleada para ensaladas de acompañamiento en las comidas.

\section{ALIMENTACIÓN ANIMAL}

- Forraje verde o seco (1): En Alba de los Cardaños las hojas exteriores y las menos aprovechables se echaban como forraje para los cerdos y las gallinas.

Observaciones: Se advierte que las variedades más utilizadas en el pasado fueron las de tipo rizado, derivando con el paso del tiempo hacia la variedad de oreja de mulo.

\section{COMPOSITAE}

\section{Lactuca serriola L.}

Lecherín (2), cardo lecherín (2), cardo lechero (2) 


\begin{tabular}{lc}
\hline Frecuencia de citación (FC): & $\mathbf{6}$ \\
\hline Número de usos (NU): & $\mathbf{2}$ \\
\hline Número registros de uso (RU): & $\mathbf{7}$ \\
\hline Frecuencia Relativa de Citación (FRC): & $\mathbf{0 , 0 4}$ \\
\hline Índice de Importancia Cultural (IC): & $\mathbf{0 , 0 5}$ \\
\hline Índice de Vigencia (IV): & $\mathbf{0 , 0 0}$ \\
\hline
\end{tabular}

Obtención: silvestre

Vigencia: abandonado

Conocimientos:

ECOLOGÍA

Salen en carreteras y orillas de caminos.

Usos:

ALIMENTACIÓN ANIMAL

- Forraje verde o seco (6): Se recogen en su estado más tierno y se sirven a cerdos, conejos y también a gallinas.

\section{MEDIOAMBIENTAL}

- Malas hierbas (1): Se considera mala hierba en las huertas.

COMPOSITAE

Lactuca virosa Habl.

Achicoria (1)

\begin{tabular}{lc}
\hline 440P, 506P; 79F; 421V & \\
\hline Frecuencia de citación (FC): & 1 \\
\hline Número de usos (NU): & 1 \\
\hline Número registros de uso (RU): & 1 \\
\hline Frecuencia Relativa de Citación (FRC): & $\mathbf{0 , 0 1}$ \\
\hline Índice de Importancia Cultural (IC): & $\mathbf{0 , 0 1}$ \\
\hline Índice de Vigencia (IV): & $\mathbf{0 , 0 0}$ \\
\hline
\end{tabular}

Obtención: silvestre

Vigencia: abandonado

Usos:

ALIMENTACIÓN ANIMAL

- Forraje verde o seco (1): En Valcobero utilizan esta planta para servir como forraje verde para los cerdos.

COMPOSITAE

Leucanthemum maximum (Ramond) DC. Margarita (1)

430P; 309F

\begin{tabular}{ll}
\hline Frecuencia de citación (FC): & 1 \\
\hline Número de usos (NU): & 1 \\
\hline Número registros de uso (RU): & 1 \\
\hline
\end{tabular}

Obtención: cultivada
Vigencia: vigente (100\%)

\section{ORNAMENTAL}

- Patios, huertos y jardines (1): Se cultiva en jardines por la belleza de sus inflorescencias.

COMPOSITAE

Leucanthemum vulgare (Vaill.) Lam.

Margarita (9)

\begin{tabular}{lc} 
175P; 150F & \\
\hline Frecuencia de citación (FC): & 9 \\
\hline Número de usos (NU): & $\mathbf{2}$ \\
\hline Número registros de uso (RU): & 9 \\
Frecuencia Relativa de Citación (FRC): & $\mathbf{0 , 0 6}$ \\
Índice de Importancia Cultural (IC): & $\mathbf{0 , 0 6}$ \\
\hline Índice de Vigencia (IV): & $\mathbf{0 , 0 0}$ \\
\hline
\end{tabular}

Obtención: silvestre

Vigencia: abandonado

Usos:

INDUSTRIA Y ARTESANÍA

- Vestimenta y adornos personales (1): LOS tallos largos con inflorescencia se trenzaban para elaborar collares en Villanueva de Arriba.

SOCIAL, SIMBÓLICO Y RITUAL

- Ritual de ciclo anual (7): En la fiesta del Corpus Christi se tiraban flores para ornamentar las calles al paso de la procesión.

- Uso recreativo (1): Los más jóvenes jugaban al tradicional "me quiere, no me quiere", arrancando las flores liguladas.

Observaciones: En la zona también se encuentra Leucanthemum pallens, quizás empleada con los mismos usos.

COMPOSITAE

Matricaria discoidea DC.

Lirada (2), manzanillón (2), margarita (1)

\begin{tabular}{lc} 
322P; 216F & \\
\hline Frecuencia de citación (FC): & 5 \\
\hline Número de usos (NU): & 3 \\
\hline Número registros de uso (RU): & 5 \\
\hline Frecuencia Relativa de Citación (FRC): & 0,04 \\
Índice de Importancia Cultural (IC): & 0,04 \\
\hline Índice de Vigencia (IV): & 0,01 \\
\hline
\end{tabular}

Obtención: silvestre

Vigencia: vigente (20\%)

Conocimientos: 


\section{LÉXICO}

En general denominan lirada a las plantas con aspecto de margarita y que son consideradas malas hierbas (Anthemis arvensis y Matricaria discoidea).

Usos:

\section{MEDIOAMBIENTAL}

- Malas hierbas (3): Se considera mala hierba a erradicar de los cultivos de cereal.

\section{ORNAMENTAL}

- Adorno floral y plantas de interior (1): La inflorescencia se usa para decoración de floreros y jarrones con agua.

\section{SOCIAL, SIMBÓLICO Y RITUAL}

- Ritual de ciclo anual (1): Es una de las flores que se recoge para decorar altares y calles en el Corpus Christi.

\section{COMPOSITAE}

\section{Onopordum acanthium L.}

Cardo borriquero (2), toba (1)

216P, 487P; 287F; 275V, 326V

\begin{tabular}{lc}
\hline Frecuencia de citación (FC): & 3 \\
\hline Número de usos (NU): & 2 \\
\hline Número registros de uso (RU): & 3 \\
\hline Frecuencia Relativa de Citación (FRC): & 0,02 \\
\hline Índice de Importancia Cultural (IC): & 0,02 \\
\hline Índice de Vigencia (IV): & $\mathbf{0 , 0 0}$ \\
\hline
\end{tabular}

Obtención: silvestre

Vigencia: abandonado

Usos:

ALIMENTACIÓN ANIMAL

- Pasto (1): El único animal que pace esta especie son los burros.

MEDIOAMBIENTAL

- Malas hierbas (2): Se quitan de los trigales.

\section{COMPOSITAE}

\section{Rhaponticum coniferum (L.) Greuter}

Cucharilla (1)

\begin{tabular}{lc} 
408P, 475P; 328F; 199V & \\
\hline Frecuencia de citación (FC): & 1 \\
\hline Número de usos (NU): & 1 \\
Número registros de uso (RU): & 1 \\
\hline Frecuencia Relativa de Citación (FRC): & 0,01 \\
\hline Índice de Importancia Cultural (IC): & $\mathbf{0 , 0 1}$ \\
Índice de Vigencia (IV): & $\mathbf{0 , 0 1}$ \\
\hline
\end{tabular}

Obtención: silvestre

Vigencia: vigente (100\%)

Usos:

ORNAMENTAL

- Adorno floral y plantas de interior (1): Cuando los capítulos florales se abren y se secan, son utilizados en Aguilar de Campoo como ornamento en jarrones para decorar las viviendas.

\section{COMPOSITAE}

Scorzonera humilis $\mathrm{L}$.

Chamorro (4), camorro (1), lecherina (1)

PALAB1619, 251P; 155F; 67V, 68V

\begin{tabular}{lc}
\hline Frecuencia de citación (FC): & $\mathbf{7}$ \\
\hline Número de usos (NU): & 1 \\
\hline Número registros de uso (RU): & $\mathbf{7}$ \\
\hline Frecuencia Relativa de Citación (FRC): & $\mathbf{0 , 0 5}$ \\
\hline Índice de Importancia Cultural (IC): & $\mathbf{0 , 0 5}$ \\
\hline Índice de Vigencia (IV): & $\mathbf{0 , 0 1}$ \\
\hline
\end{tabular}

Obtención: silvestre

Vigencia: vigente (12\%)

\section{Conocimientos:}

LÉXICO

Bajo la denominación de chamorro no se ha encontrado ninguna referencia bibliográfica, posiblemente sea un término citado únicamente en el área del Valle de Castillería.

Usos:

\section{ALIMENTACIÓN HUMANA}

- Golosinas y masticatorias (7): Planta consumida generalmente en crudo $y$ directamente en el campo, aunque puede incluso ser ingrediente de ensaladas. La parte aprovechada es el tallo con un sabor un tanto dulzón y la época de recolección es durante la primavera cuando los tallos están más tiernos.

Observaciones: Se pueden encontrar en la zona otras especies del género Scorzonera, entre ellas probablemente Scorzonera laciniata también tuviera un uso comestible.

\section{COMPOSITAE}

Sonchus asper (L.) Hill

Cardo lecherín (8)

267P, 364P; 57F 


\begin{tabular}{lc}
\hline Frecuencia de citación (FC): & $\mathbf{8}$ \\
\hline Número de usos (NU): & $\mathbf{2}$ \\
\hline Número registros de uso (RU): & $\mathbf{8}$ \\
\hline Frecuencia Relativa de Citación (FRC): & $\mathbf{0 , 0 6}$ \\
\hline Índice de Importancia Cultural (IC): & $\mathbf{0 , 0 6}$ \\
\hline Índice de Vigencia (IV): & $\mathbf{0 , 0 0}$ \\
\hline
\end{tabular}

Obtención: silvestre

Vigencia: abandonado

Usos:

\section{ALIMENTACIÓN ANIMAL}

- Forraje verde o seco (6): Empleado como alimento de cerdos y conejos.

\section{MEDIOAMBIENTAL}

- Malas hierbas (2): Se escardan de los trigales.

COMPOSITAE

\section{Sonchus oleraceus (L.) L}

Cardo lecherín (19), cardo lecherito (1), cardo lechero (2), lecherín (17), lecherina (2)

\begin{tabular}{lc} 
PALAB2155, 43P, 252P; 11F; 366V, 471V & \\
\hline Frecuencia de citación (FC): & $\mathbf{4 1}$ \\
\hline Número de usos (NU): & $\mathbf{2}$ \\
Número registros de uso (RU): & $\mathbf{4 5}$ \\
Frecuencia Relativa de Citación (FRC): & $\mathbf{0 , 2 9}$ \\
Índice de Importancia Cultural (IC): & $\mathbf{0 , 3 2}$ \\
\hline Índice de Vigencia (IV): & $\mathbf{0 , 0 0}$ \\
\hline
\end{tabular}

Obtención: silvestre

Vigencia: abandonado

Usos:

ALIMENTACIÓN ANIMAL

- Forraje verde o seco (34): El uso dado a esta especie era como forrajera, sobre todo para los cerdos y apreciada para los conejos. Se administraba la planta entera en crudo, a veces sola y a veces junto con salvado o harina de algún cereal.

\section{MEDIOAMBIENTAL}

- Malas hierbas (11): Especie frecuente entre los trigales, se hacía la escarda en las tierras de cereal o patatas, e incluso en huertos.

COMPOSITAE

\section{Tagetes erecta L.}

\section{Frecuencia de citación (FC):}

Número de usos (NU):

Número registros de uso (RU):
Obtención: cultivada

Vigencia: vigente (100\%)

\section{ORNAMENTAL}

- Patios, huertos y jardines (1): Las flores de gran belleza se cultivan sobre macetas, en jardines y en patios de las viviendas.

COMPOSITAE

\section{Tanacetum corymbosum (L.) Sch.Bip}

Margarita (4)

\begin{tabular}{lc}
$123 \mathrm{P}$ & \\
\hline Frecuencia de citación (FC): & 4 \\
\hline Número de usos (NU): & $\mathbf{1}$ \\
\hline Número registros de uso (RU): & 4 \\
\hline Frecuencia Relativa de Citación (FRC): & $\mathbf{0 , 0 3}$ \\
\hline Índice de Importancia Cultural (IC): & $\mathbf{0 , 0 3}$ \\
\hline Índice de Vigencia (IV): & $\mathbf{0 , 0 2}$ \\
\hline
\end{tabular}

Obtención: silvestre

Vigencia: vigente (75\%)

Usos:

ORNAMENTAL

- Adorno floral y plantas de interior (4): En el mes de mayo se cortan para decorar sobre jarrones, sobre todo en la iglesia local.

COMPOSITAE

Tanacetum parthenium (L.) Sch.Bip

Margarita (2)

\begin{tabular}{ll}
\hline $196 \mathrm{~F}$ & \\
\hline Frecuencia de citación (FC): & 2 \\
\hline Número de usos (NU): & 1 \\
\hline Número registros de uso (RU): & $\mathbf{2}$ \\
\hline
\end{tabular}

Obtención: cultivada

Vigencia: vigente (100\%)

Usos:

ORNAMENTAL

- Patios, huertos y jardines (2): Se cultiva como ornamental en patios y jardines.

\section{COMPOSITAE}

Taraxacum campylodes G.E.Haglund Achicoria (38), diente de león (9), lecherina (3), lecherín (2), lechuga (4), meacamas (2)

PALAB1203, 68P, 532P; 19F; 72V, 73V 


\begin{tabular}{lc}
\hline Frecuencia de citación (FC): & 58 \\
\hline Número de usos (NU): & 5 \\
\hline Número registros de uso (RU): & 70 \\
\hline Frecuencia Relativa de Citación (FRC): & $\mathbf{0 , 4 2}$ \\
\hline Índice de Importancia Cultural (IC): & $\mathbf{0 , 5 0}$ \\
\hline Índice de Vigencia (IV): & $\mathbf{0 , 0 2}$ \\
\hline
\end{tabular}

Obtención: silvestre

Vigencia: vigente (4\%)

Usos:

\section{ALIMENTACIÓN HUMANA}

- Verduras y hortalizas (22): Las hojas frescas se consumen en ensalada como verdura a principios de la primavera, más tarde amargan. También se pueden tomar cocidas acompañando algún guiso a modo de verdura.

- Bebidas no alcohólicas (1): Se testimonia además un uso particular de las flores para elaborar un producto similar a la miel, en Herreruela se detalla la siguiente receta "se cuece como un kilo de flores y después se hecha un kilo de azúcar moreno. De que está bien cocido se cuela y lo usas para lo que quieras, untao en pan, por ejemplo".

\section{ALIMENTACIÓN ANIMAL}

- Forraje verde o seco (26): Se recogen las hojas como forraje silvestre complementario, sobre todo para cerdos, conejos y vacas. En el caso de los cerdos era habitual cocer las hojas previamente.

\section{MEDICINA}

- Sistema genito-urinario (10): Bien conocidas sus virtudes diuréticas y depurativas. Considerada también un buen remedio para afecciones hepáticas. Se utilizaban las hojas en cocimiento y se bebía como una tisana.

- Sistema endocrino-metabólico (1): Un informante de confianza de Verdeña afirma que es muy bueno tomar la infusión para rebajar el nivel de colesterol.

- Musculatura y esqueleto (1): En San Juan de Redondo se emplea la infusión de la parte aérea para tratar dolores reumáticos.

- Piel y tejido celular subcutáneo (3): El látex que desprende el tallo se aplica sobre las verrugas para hacerlas desaparecer.

\section{MEDIOAMBIENTAL}

- Malas hierbas (5): Se eliminan de los huertos y tierras de labor.

\section{SOCIAL, SIMBÓLICO Y RITUAL}

- Fobias y filias (1): En la localidad de Guardo se aconsejaba a los niños no jugar con estas plantas ya que podían mear la cama por la noche.

\section{COMPOSITAE}

\section{Tragopogon castellanus Levier}

Cantarujil (1)

337P; 257F; 263V

\begin{tabular}{lc}
\hline Frecuencia de citación (FC): & 1 \\
\hline Número de usos (NU): & 1 \\
\hline Número registros de uso (RU): & 1 \\
\hline Frecuencia Relativa de Citación (FRC): & $\mathbf{0 , 0 1}$ \\
\hline Índice de Importancia Cultural (IC): & 0,01 \\
\hline Índice de Vigencia (IV): & 0,00 \\
\hline
\end{tabular}

Obtención: silvestre

Vigencia: abandonado

Usos:

ALIMENTACIÓN HUMANA

- Golosinas y masticatorias (1): Los niños comían el tallo en su estado más tierno del que se desprendía un látex de sabor dulce.

COMPOSITAE

\section{Tragopogon dubius Scop.}

\section{T. pratensis $\mathrm{L}$.}

Lecherina (28), lecherín (13), lechuga (15), lecherita (2), acompango (3), borraja (6), forraja (1), burrialón (2), currialón (2), culebrón (1) tallo de borrega (1)

Tragopogon dubius: PALAB1443, 125P; 45F; 134V

T. pratensis: 12P, 287P, 436P; 27F; 76V, 93V, 241V

\begin{tabular}{lc|}
\hline Frecuencia de citación (FC): & 74 \\
\hline Número de usos (NU): & 1 \\
\hline Número registros de uso (RU): & 74 \\
\hline Frecuencia Relativa de Citación (FRC): & $\mathbf{0 , 5 3}$ \\
\hline Índice de Importancia Cultural (IC): & $\mathbf{0 , 5 3}$ \\
\hline Índice de Vigencia (IV): & $\mathbf{0 , 0 0}$ \\
\hline
\end{tabular}

Obtención: silvestre

Vigencia: abandonado

Conocimientos:

ECOLOGÍA

Extendida por prados y pastos.

\section{LÉXICO}

Los nombres lecherina, lecherín y lecherita, bien pueden derivar del látex que desprende el tallo al cortarlo.

Usos:

ALIMENTACIÓN HUMANA 
- Golosinas y masticatorias (74): La parte aprovechable es el tallo, que se consume en crudo directamente en el campo. La época propicia de recolección es la primavera, momento en el que son más tiernas y sabrosas al paladar, antes de consumirlas se retiran las hojas exteriores. Al cortarla desprende un líquido lechoso blanco y pegajoso que al oxidarse toma una coloración marrón, tiznando los labios de los que los consumían.

En el pasado los niños buscaban con avidez esta planta, que apreciaban por su sabor dulzón, se acostumbraba a recogerlas en manojos cuando se acompañaba al ganado a pastar al monte $y$ podían servir como merienda infantil.

COMPOSITAE

Tussilago farfara $\mathrm{L}$.

Hoja de chupón (1)

\begin{tabular}{lc}
\hline $370 \mathrm{P}$ & \\
\hline Frecuencia de citación (FC): & 2 \\
\hline Número de usos (NU): & 1 \\
\hline Número registros de uso (RU): & 2 \\
\hline Frecuencia Relativa de Citación (FRC): & $\mathbf{0 , 0 1}$ \\
\hline Índice de Importancia Cultural (IC): & $\mathbf{0 , 0 1}$ \\
\hline Índice de Vigencia (IV): & $\mathbf{0 , 0 0}$ \\
\hline
\end{tabular}

Obtención: silvestre

Vigencia: abandonado

Usos:

MEDICINA

- Sistema respiratorio (1): La infusión de las hojas se emplea en Ventanilla como antitusivo para calmar la tos.

- Piel y tejido celular subcutáneo (1): Las hojas se aplican directamente sobre las pequeñas heridas ayudando a mejorar la cicatrización de las mismas.

CONVOLVULACEAE

Convolvulus arvensis $\mathrm{L}$.

Correyuela (7), corrigüela (2), carriyuela (3), carrigüela (2)

PALAB1431, 45P, 461P; 34F

\begin{tabular}{lc}
\hline Frecuencia de citación (FC): & 14 \\
\hline Número de usos (NU): & 3 \\
\hline Número registros de uso (RU): & 16 \\
\hline Frecuencia Relativa de Citación (FRC): & 0,10 \\
\hline Índice de Importancia Cultural (IC): & 0,12 \\
\hline Índice de Vigencia (IV): & 0,00 \\
\hline
\end{tabular}

Vigencia: abandonado

Usos:

ALIMENTACIÓN HUMANA

- Verduras y hortalizas (2): Sus hojas se usan como alimento en fresco para ensaladas o cocidas en potajes de garbanzos o titos.

\section{ALIMENTACIÓN ANIMAL}

- Forraje verde o seco (4): Aprovechando la escarda se administraban de forraje verde a cerdos, conejos y vacas.

\section{MEDIOAMBIENTAL}

- Malas hierbas (10): Perjudican mucho a los cultivos ya que se extienden con facilidad y se enredan y tumban los trigos y las patatas, por tanto, se escardan de las tierras de labor y de las huertas.

CRASSULACEAE

\section{Sedum album L.}

\section{S. sediforme (Jacq.) Pau}

Pan de los pajaritos (3), comida de pajaritos (2), arroz de pajaritos (1)

\begin{tabular}{lc} 
204P, 520P; 130V, 385V, 447V & \\
\hline Frecuencia de citación (FC): & 6 \\
\hline Número de usos (NU): & 1 \\
\hline Número registros de uso (RU): & 7 \\
\hline Frecuencia Relativa de Citación (FRC): & 0,04 \\
\hline Índice de Importancia Cultural (IC): & $\mathbf{0 , 0 4}$ \\
\hline Índice de Vigencia (IV): & $\mathbf{0 , 0 0}$ \\
\hline
\end{tabular}

Obtención: silvestre

Vigencia: abandonado

Conocimientos:

\section{LÉXICO}

Todos los nombres derivan de la observación sobre el uso que los pájaros hacen de ella, pan, comida y arroz de pajaritos.

Usos:

ALIMENTACIÓN ANIMAL

- Pasto (6): Los pájaros visitan esta especie para alimentarse de las hojas, que al parecer las consideran muy sabrosas.

\section{SOCIAL, SIMBÓLICO Y RITUAL}

- Uso recreativo (1): Los niños jugaban al juego de las comiditas con las hojas suculentas de esta especie.

Obtención: silvestre 


\section{CRASSULACEAE}

\section{Sempervivum vicentei Pau}

Siempreviva (11), suelda (1), sanalotodo (1), hoja chupona (1)

180P, 523; 49F; 317V, 448V, 562V

\begin{tabular}{lc|}
\hline Frecuencia de citación (FC): & 14 \\
\hline Número de usos (NU): & 3 \\
\hline Número registros de uso (RU): & 15 \\
\hline Frecuencia Relativa de Citación (FRC): & 0,10 \\
\hline Índice de Importancia Cultural (IC): & 0,11 \\
\hline Índice de Vigencia (IV): & 0,09 \\
\hline
\end{tabular}

Obtención: silvestre, cultivada

Vigencia: vigente $(80 \%)$

Conocimientos:

ECOLOGÍA

Se desarrolla en muros, tejados y lastras de montaña, incluso "cuando no llueve".

Usos:

MEDICINA

- Piel y tejido celular subcutáneo (6): La planta posee hojas carnosas que deprenden un jugo de propiedades vulnerarias, útil para curar heridas, cortaduras, quemaduras, picaduras, y en general pequeñas afecciones en la piel. Resulta popular su uso específico en el tratamiento de clavos, diviesos, verrugas o granos, así como un remedio casero eficaz y rápido al encontrarse con frecuencia cultivada en macetas y jardines. Para administrarlo se arranca una hoja y se exprime el jugo que desprende o se retira la epidermis de la cara superior y se aplica directamente sobre la zona afectada. En Róscales de la Peña se aconseja colocar la hoja sobre los diviesos previamente calentada en una sartén con aceite

\section{VETERINARIA}

- Piel y tejido celular subcutáneo (1): Las hojas machacadas también se recomiendan como remedio vulnerario para curar pequeñas heridas y llagas en animales, aplicadas directamente o mediante cataplasma.

\section{ORNAMENTAL}

- Patios, huertos y jardines (8): Se trata de una especie muy empleada en jardinería popular, considerada no solo por la vistosidad de la floración en verano, sino también por los rosetones que forman las hojas suculentas. Su cultivo es sencillo debido a su resistencia al frío, su adaptación a suelos pobres, la escasez de cuidados necesarios y su rápida propagación. Es frecuente encontrarla decorando en patios, jardines, macetas de exterior y sobre todo en muros divisorios, donde se extiende fácilmente.

CRASSULACEAE

Umbilicus rupestris (Salisb.) Dandy

Sombrerillos (1)

253P, 363P; 113F; 564V

\begin{tabular}{lc|}
\hline Frecuencia de citación (FC): & 2 \\
\hline Número de usos (NU): & 2 \\
\hline Número registros de uso (RU): & 2 \\
\hline Frecuencia Relativa de Citación (FRC): & 0,01 \\
\hline Índice de Importancia Cultural (IC): & 0,01 \\
\hline Índice de Vigencia (IV): & 0,00 \\
\hline
\end{tabular}

Obtención: silvestre

Vigencia: abandonado

Usos:

MEDICINA

- Piel y tejido celular subcutáneo (1): En San Martín de los Herreros el jugo resultante de machacar las hojas suculentas se emplea como cicatrizante de pequeñas heridas.

\section{VETERINARIA}

- Piel y tejido celular subcutáneo (1): En la misma localidad también es válido el jugo de las hojas para cauterizar las heridas de los animales.

\section{CUCURBITACEAE}

\section{Bryonia cretica $\mathrm{L}$.}

Uva de perro (17), nueza (1), parra de culebra (1), enredadera (2), muegueda (1)

99P, 393P; 140F; 334V

\begin{tabular}{lc}
\hline Frecuencia de citación (FC): & 22 \\
\hline Número de usos (NU): & 3 \\
\hline Número registros de uso (RU): & 22 \\
\hline Frecuencia Relativa de Citación (FRC): & $\mathbf{0 , 1 6}$ \\
\hline Índice de Importancia Cultural (IC): & $\mathbf{0 , 1 6}$ \\
\hline Índice de Vigencia (IV): & $\mathbf{0 , 0 0}$ \\
\hline
\end{tabular}

Obtención: silvestre

Vigencia: abandonado

Conocimientos:

LÉXICO

Se han recogido varios nombres para denominar sus frutos: uvas de perro, reventones y gargolitas.

Usos:

VETERINARIA 
- Piel y tejido celular subcutáneo (2): El cocimiento de la raíz se usa en Otero de Guardo y Cillamayor para poner emplastos en las patas de las vacas con hinchazón o cojera.

\section{TÓXICA Y NOCIVA}

- Tóxica para personas y animales (19): LoS frutos se reconocen como tóxicos y se advertía a los niños que evitaran su consumo.

\section{MEDIOAMBIENTAL}

- Malas hierbas (1): Su carácter trepador e invasivo la convierten en una especie a erradicar si aparecía en algún cultivo.

Observaciones: Se han recogido dos testimonios de fallecimientos en la zona por causa del consumo de un fruto silvestre al parecer asociado a este especie, uno de ellos en Villabellaco y otro en Nava de Santullán.

\section{CUCURBITACEAE}

\section{Cucumis sativus $\mathrm{L}$.}

Pepino (4)

\begin{tabular}{ll}
\hline $82 \mathrm{~F}$ & \\
\hline Frecuencia de citación (FC): & 4 \\
\hline Número de usos (NU): & 1 \\
\hline Número registros de uso (RU): & 4 \\
\hline
\end{tabular}

Obtención: cultivada, comprada

Vigencia: vigente $(100 \%)$

Usos:

\section{ALIMENTACIÓN HUMANA}

- Verduras y hortalizas (4): Se cultiva en las últimas décadas en los huertos locales, se consume en ensaladas.

\section{Cucurbita moschata Duchesne}

\section{CUCURBITACEAE}

\section{Calabaza (2)}

\begin{tabular}{ll}
\hline Frecuencia de citación (FC): & 2 \\
\hline Número de usos (NU): & 1 \\
\hline Número registros de uso (RU): & 2 \\
\hline
\end{tabular}

Obtención: cultivada, comprada

Vigencia: vigente (100\%)

Usos:

\section{ALIMENTACIÓN HUMANA}

- Verduras y hortalizas (2): Su cultivo ha sido introducido recientemente en las huertas, se usa en purés y otros guisos.

\section{CUCURBITACEAE}

\section{Cucurbita pepo L.}

Calabacín (5)

\begin{tabular}{ll}
\hline $83 \mathrm{~F}$ \\
\hline Frecuencia de citación (FC): \\
\hline Número de usos (NU): & 5 \\
\hline Número registros de uso (RU): & 2 \\
\hline
\end{tabular}

Obtención: cultivada, comprada

Vigencia: vigente (100\%)

Usos:

\section{ALIMENTACIÓN HUMANA}

- Verduras y hortalizas (4): Se ha convertido en la actualidad en un cultivo común en las huertas, se consume en purés y guisos.

\section{ALIMENTACIÓN ANIMAL}

- Plantas melíferas (1): En Ruesga indican como las abejas visitan las vistosas flores del calabacín para extraer el néctar y elaborar la miel.

\section{ERICACEAE}

Arctostaphylos uva-ursi (L.) Spreng. Gayuga (4), agayuga (17), gayuba (3), agayuba (4)

\begin{tabular}{lc}
$28 \mathrm{P} ; 65 \mathrm{~F}$ & \\
\hline Frecuencia de citación (FC): & $\mathbf{2 8}$ \\
\hline Número de usos (NU): & 6 \\
\hline Número registros de uso (RU): & 34 \\
Frecuencia Relativa de Citación (FRC): & $\mathbf{0 , 2 0}$ \\
Índice de Importancia Cultural (IC): & $\mathbf{0 , 2 4}$ \\
\hline Índice de Vigencia (IV): & $\mathbf{0 , 0 0}$ \\
\hline
\end{tabular}

Obtención: silvestre

Vigencia: abandonado

Conocimientos:

\section{LÉXICO}

Todos los nombres recogidos para esta especie denominan tanto a la planta entera como a los frutos.

Usos:

\section{ALIMENTACIÓN HUMANA}

- Frutas y frutos dulces (22): Los frutos carnosos maduros se consumen directamente en el campo, poseen una pulpa seca un tanto insípida y de textura harinosa.

\section{ALIMENTACIÓN ANIMAL}


- Pasto (2): Las ovejas y las cabras aprovechaban con gusto los frutos durante el pastoreo.

\section{MEDICINA}

- Sistema genito-urinario (1): En la localidad de Triollo se recomienda tomar infusión de hojas de gayuga para tratar infecciones urinarias $y$ como diurético.

\section{VETERINARIA}

- Sistema genito-urinario (3): Los frutos y las hojas se cocían y se daba el líquido resultante a las vacas con dificultades para orinar.

\section{TÓXICA Y NOCIVA}

- Tóxica para personas y animales (1): En Alba de los Cardaños un ganadero señala que las ovejas que comen muchas agayugas tienen más posibilidad de abortar.

\section{INDUSTRIA Y ARTESANÍA}

- Vestimenta y adornos personales (5): Los más jóvenes insertaban frutos a través de un hilo, para elaborar collares y pulseras decorativos.

Observaciones: En Roscales de la Peña se recoge el testimonio de un informante que asegura que recolectaba agayuga en sacos para comercializar, sin poder confirmar cual era el destino final de la misma.

\section{ERICACEAE}

Calluna vulgaris (L.) Hull.

Brezo (12), graspo (5), brecina (1),

74P; 20F; 11V, 394V

\begin{tabular}{lc}
\hline Frecuencia de citación (FC): & 14 \\
\hline Número de usos (NU): & 5 \\
\hline Número registros de uso (RU): & 20 \\
\hline Frecuencia Relativa de Citación (FRC): & 0,10 \\
\hline Índice de Importancia Cultural (IC): & 0,14 \\
\hline Índice de Vigencia (IV): & 0,01 \\
\hline
\end{tabular}

Obtención: silvestre

Vigencia: vigente (10\%)

\section{Conocimientos:}

\section{LÉXICO}

El diminutivo brecina define los brezos de menor porte. Algunos informantes diferencian el graspo por tener un porte menor que el brezo.

En Casavegas y en Herreruela de Castillería encontramos los pagos denominados "EI Graspal".
Usos:

ALIMENTACIÓN ANIMAL

- Plantas melíferas (6): Se considera una excelente planta melífera y la miel obtenida es muy apreciada.

\section{MEDICINA}

- Sistema genito-urinario (1): El cocimiento de las sumidades florales se toma como un buen diurético y también para afecciones relacionadas con la próstata.

\section{COMBUSTIBLE}

- Leña (9): Las cepas de esta especie se utilizan para quemar en la lumbre ya que poseen un gran poder calorífico.

- Carbón (1): También se aprovecha esta especie para hacer carbón vegetal de excelente calidad.

\section{ORNAMENTAL}

- Adorno floral y plantas de interior (1): Las flores se colocan en jarrones de flor seca como ornamento.

- Otros adornos (1): Las cepas de gran belleza se usan en interiores para engalanar algún salón o estancia.

\section{SOCIAL, SIMBÓLICO Y RITUAL}

- Alucinógenas, narcóticas y fumatorias (1): Las flores secas se machacaban en Casavegas y servían para fumar envueltas en papel de liar.

\section{ERICACEAE}

\section{Erica arborea $\mathrm{L}$.}

E. australis $\mathrm{L}$.

E. cinerea $\mathrm{L}$.

E. tetralix L.

E. vagans $L$.

Brezo (70), urz (14), ayuz (4) graspo (2), graspillo (1), berezo (2)

Erica arborea: 34P; 22F; 156V, 405V, 406

E. australis: 21P, 228P; $29 \mathrm{~F}$

E. cinerea: 61P, 390P; $167 \mathrm{~F}$

E. tetralix: 165P, 305P; 205F; 230V, 409V

E. vagans: $115 \mathrm{P}, 496 \mathrm{P} ; 143 \mathrm{~F}$

Erica spp.: 23V, 264V, 407V, 408V, 461V, 462V, $587 \mathrm{~V}$

\begin{tabular}{lc}
\hline Frecuencia de citación (FC): & 93 \\
Número de usos (NU): & 8 \\
\hline Número registros de uso (RU): & 162 \\
Frecuencia Relativa de Citación (FRC): & 0,67 \\
\hline Índice de Importancia Cultural (IC): & 1,17 \\
\hline Índice de Vigencia (IV): & 0,15 \\
\hline
\end{tabular}

Obtención: silvestre 
Vigencia: vigente (13\%)

\section{Conocimientos: \\ LÉXICO}

Los nombres recogidos para las distintas especies se entremezclan y en muchos casos denominan varias especies. En general, se puede diferenciar como urz o ayuz a las especies de mayor porte: Erica arborea y $E$. australis; y como brezo o berezo a las especies de menor porte: Erica cinerea, E. tetralix, E. vagans. Las denominaciones berezo y ayuz fueron recogidas en la zona oriental de la comarca, en localidades limítrofes con la provincia de Cantabria cómo Salcedillo, Valberzoso y Néstar.

Bajo el nombre de graspo se señaló a Erica tetralix y $E$. cinerea, y como graspillo a $E$. tetralix en la localidad de Vidrieros.

Diversos lugares tienen fitotopónimos asociados al brezo, entre ellos el popular Santuario de Nuestra Señora del Brezo ubicado en Villafría de la Peña, también los pagos de "EI Brezal" en Estalaya, Los Llazos, Rebanal de los Caballeros y Velilla del Río Carrión, y "Los Brezales" en Lebanza.

\section{Usos:}

\section{ALIMENTACIÓN ANIMAL}

- Pasto (3): Cabras, ovejas y ganado vacuno se alimentan de los brotes más verdes y tiernos, en periodos de escasez de recursos alimenticios más apetecibles.

- Plantas melíferas (20): El brezo es una excelente planta melífera y goza de una gran reputación en toda la comarca. Las abejas producen a partir del néctar de las flores de brezo, una miel con un tono rojizo oscuro, disponiendo de una larga floración entre las distintas especies.

\section{MEDICINA}

- Sistema genito-urinario (3): La infusión de la parte aérea se menciona en San Martín de los Herreros para el tratamiento de la infecciones de orina.

\section{COMBUSTIBLE}

- Leña (39): El poder calorífico del brezo es bien conocido y se destaca como un excelente combustible para calentar tanto el hogar, como el horno de cocer el pan. Los brezales se rozaban (eliminar la parte aérea de la vegetación) y se extraían las cepas, en algunas ocasiones previamente se quemaban, con dos finalidades: eliminar la vegetación para facilitar la extracción de la cepa o aumentar la superficie de cultivo o pasto.

- Encendido (3): Las ramas se cortaban y una vez secas quedaban dispuestas para su empleo como leña fina en el encendido de la lumbre.

- Carbón (26): Con las cepas de los brezos más altos (Erica arborea, E. australis) se elabora el carbón vegetal, indicado especialmente para el trabajo de templar el hierro en la fragua. En una hoya realizada en el suelo, se introducen las cepas, se tapan con ramas y tierra, procurando dejar un agujero a modo de chimenea que permite que la leña se queme lentamente hasta obtener carbón. Estos trabajos se ejecutaban en el monte y podían llevarlo a cabo carboneros itinerantes especializados, el herrero del pueblo o algún vecino en particular.

- Para chamuscar (1): En Riosmenudos de la Peña se cita el uso de ramas de brezo para chamuscar los pelos del cerdo en la matanza.

- Luz (10): Los más mayores aún recuerdan la época en la que para iluminar una estancia se utilizaban los teos, antorchas hechas con ramas muy secas de brezo.

\section{CONSTRUCCIÓN}

- Casas, edificios e instalaciones agropecuarias (4): Edificaciones como tenadas, cuadras, o chozos, se remataban tradicionalmente con cubierta vegetal, más extendida esta práctica en la parte más occidental de la comarca. Entre los cabrios se coloca la ripia (latas), encima de ella se montan ramas de brezo y rematando la cubierta, césped con la misión de impermeabilizar la construcción.

\section{INDUSTRIA Y ARTESANÍA}

- Herramientas y utensilios (35): La madera de brezo posee la propiedad de ser muy dura, compacta, pesada y buena para trabajar, ideal para la realización de cucharas, pipas para fumar, badajos para los cencerros o campanos y llaves para las cebillas.

Otro uso muy citado es la fabricación de escobas para barrer la cuadra, la era o las portadas de las casas.

\section{MEDIOAMBIENTAL}

- Mejora del suelo (2): Las ramas más finas y verdes se extendían como mullida para los animales domésticos (vacas y cerdos).

\section{ORNAMENTAL}

- Adorno floral y plantas de interior (10): El brezo es un arbusto muy utilizado en la realización de composiciones florales 
decorativas, en solitario o combinado con otras especies. La floración es de gran belleza, con vivos colores que perduran en el tiempo.

- Otros adornos (3): Las caprichosas formas de las cepas servían de escultura decorativa en los portales de algunas casas.

\section{SOCIAL, SIMBÓLICO Y RITUAL}

- Alucinógenas, narcóticas y fumatorias (4): Las flores secas se machacaban y servían para fumar, envueltas en un papel de liar.

Observaciones: Se ha optado por tratar todas las especies del genero Erica en una misma ficha por la dificultad que entraña separar los usos de cada una y por la similitud de usos en todas ellas.

\section{ERICACEAE}

Vaccinium myrtillus $\mathrm{L}$.

Arráspano (58), ráspano (28), arándano (7), arraspanera (1), raspanera (1)

PALAB1607, 6P, 128P; 24F; 77V

\begin{tabular}{lc}
\hline Frecuencia de citación (FC): & 95 \\
\hline Número de usos (NU): & $\mathbf{3}$ \\
Número registros de uso (RU): & 105 \\
\hline Frecuencia Relativa de Citación (FRC): & $\mathbf{0 , 6 8}$ \\
Índice de Importancia Cultural (IC): & $\mathbf{0 , 7 6}$ \\
Índice de Vigencia (IV): & $\mathbf{0 , 1 1}$ \\
\hline
\end{tabular}

Obtención: silvestre

Vigencia: vigente (14\%)

\section{Conocimientos:}

\section{LÉXICO}

Tanto el fruto como la planta son referidos de igual modo, dando lugar a la figura literaria de la sinécdoque, por la que se designa la parte por el todo.

Usos:

\section{ALIMENTACIÓN HUMANA}

- Frutas y frutos dulces (96): Los frutos en forma de baya son comestibles y se aprovechan en fresco directamente en el campo o se recogen para elaborar con ellos mermeladas y postres. Se pueden recolectar desde finales de julio hasta finales de agosto, momento en el cual alcanzan un tono negro azulado que indica su madurez. Resulta ser una planta muy reconocida y valorada por su exquisito sabor.

- Bebidas alcohólicas (2): Macerando los frutos maduros en orujo o anís, se han elaborado licores en Polentinos o Valcobero.

\section{ALIMENTACIÓN ANIMAL}

- Pasto (4): Animales silvestres como osos y venados, e incluso las vacas, gustan de los sabrosos frutos.

\section{MEDICINA}

- Sistema genito-urinario (2): En Vidrieros y Herreruela de Castillería se aconsejó el fruto consumido en fresco, para tratar y prevenir las infecciones del tracto urinario en general (cistitis, infección renal y genital).

- Órganos de los sentidos (1): Los frutos también poseen propiedades beneficiosas para mejorar problemas en la vista.

EUPHORBIACEAE

\section{Euphorbia amygdaloides L. \\ Lechetrezna (1)}

227P, 362P; 54F

$\begin{array}{ll}\text { Frecuencia de citación (FC): } & 1 \\ \text { Número de usos (NU): } & 0 \\ \text { Número registros de uso (RU): } & 0\end{array}$

Obtención: silvestre

\section{EUPHORBIACEAE}

Euphorbia hyberna L. Hierba de la leche (1)

323P, 476P; 282F; 25V

\begin{tabular}{lc}
\hline Frecuencia de citación (FC): & 1 \\
\hline Número de usos (NU): & 1 \\
\hline Número registros de uso (RU): & 1 \\
\hline Frecuencia Relativa de Citación (FRC): & 0,01 \\
\hline Índice de Importancia Cultural (IC): & 0,01 \\
\hline
\end{tabular}

Obtención: silvestre

Usos:

TÓXICA Y NOCIVA

- Irritantes, urticantes y fotosensibilizantes (1):

El látex que se desprende al cortar el tallo se reconoce como irritante para la piel.

\section{Euphorbia serrata L. Lechetrezna (1)}

142P, 494P; 295F; 158V 


\begin{tabular}{lc}
\hline Frecuencia de citación (FC): & 1 \\
\hline Número de usos (NU): & 1 \\
\hline Número registros de uso (RU): & 1 \\
\hline Frecuencia Relativa de Citación (FRC): & 0,01 \\
\hline Índice de Importancia Cultural (IC): & 0,01 \\
\hline
\end{tabular}

Obtención: silvestre

Usos:

\section{TÓXICA Y NOCIVA}

- Irritantes, urticantes y fotosensibilizantes (1): En la localidad de Resoba se cita a la planta como irritante, los niños que jugaban con ella se arriesgaban a impregnarse con el látex y a provocarse enrojecimientos en la piel.

\section{EUPHORBIACEAE}

Ricinus communis $\mathrm{L}$. Ricino (6)

\begin{tabular}{ll}
\hline Frecuencia de citación (FC): & 6 \\
\hline Número de usos (NU): & 1 \\
\hline Número registros de uso (RU): & 6 \\
\hline
\end{tabular}

Obtención: comprada

Vigencia: abandonado

Usos:

\section{MEDICINA}

- Sistema digestivo (6): El aceite de ricino que se compraba en las farmacias se administraba como un eficaz laxante. Tiene un sabor desagradable y una cucharadita pequeña de café era suficiente para provocar el efecto purgante.

FAGACEAE

Castanea sativa Mill.

Castaño (1)

\begin{tabular}{ll}
\hline Frecuencia de citación (FC): & 1 \\
\hline Número de usos (NU): & 1 \\
\hline Número registros de uso (RU): & 1 \\
\hline
\end{tabular}

Obtención: cultivada, comprada

Vigencia: abandonado

Usos:

\section{ALIMENTACIÓN HUMANA}

- Frutos secos y oleaginosos (1): Los castañas se pueden consumir en crudo, aunque se prefieren asadas.

Observaciones: Aunque en Barruelo de Santullán aseguran que recogían castañas de un ejemplar, en la actualidad ya desaparecido, se trata de una especie que no se adapta bien al clima de la zona.

FAGACEAE

Fagus sylvatica L. Haya (103)

PALAB1605, 14P, 288P, 384P; 4F; 278V, 279V, 301V, $323 \mathrm{~V}, 324 \mathrm{~V}, 337 \mathrm{~V}, 532 \mathrm{~V}, 585 \mathrm{~V}$

\begin{tabular}{lc}
\hline Frecuencia de citación (FC): & 103 \\
\hline Número de usos (NU): & 7 \\
\hline Número registros de uso (RU): & 324 \\
\hline Frecuencia Relativa de Citación (FRC): & 0,74 \\
\hline Índice de Importancia Cultural (IC): & 2,33 \\
\hline Índice de Vigencia (IV): & 0,14 \\
\hline
\end{tabular}

Obtención: silvestre

Vigencia: vigente (6\%)

\section{Conocimientos:}

\section{ECOLOGÍA}

Aparece en laderas umbrosas de montaña. "EI roble sale donde da el sol por la tarde, el haya al revés".

\section{LÉXICO}

Los frutos se denominan hayucos.

Encontramos fitotopónimos relacionados: en Lebanza "Hayedo del Pando", Camasobres y San Cebrián de Mudá "Fuente el Haya", Celada de Roblecedo "Haya Grande", Dehesa de Montejo "Monte el Hayedo", Valsadornín "El Haya", y Ligüérzana, Casavegas, Camporredondo y Verdeña "El Hayedo".

Usos:

\section{ALIMENTACIÓN HUMANA}

- Frutos secos y oleaginosos (59): La parte comestible son los frutos que se consumen en crudo o más comúnmente tostados, de esta forma la cáscara se desprende más sencillamente. La fructificación comienza a finales de septiembre y se extiende durante el otoño.

- Grasas alimentarias (4): De las semillas se obtenía aceite mediante prensado, en los molinos de oilo de Lores y Fresno del Río, hoy en día ya desaparecidos. Se empleaba en la cocina y era considerado de buena calidad y resistente al paso del tiempo

- Bebidas no alcohólicas (2): Los hayucos tostados y molidos servían como sucedáneo del café.

\section{ALIMENTACIÓN ANIMAL}


- Pasto (2): En otoño los venados, los jabalíes y los osos aprovechan los hayucos caídos al suelo.

\section{TóxICO Y NOCIVO}

- Tóxica para personas y animales (1): La ingesta excesiva de hayucos provoca dolor de cabeza.

\section{COMBUSTIBLE}

- Leña (49): La madera es muy empleada como combustible en la lumbre del hogar y en el horno de cocer los panes, su uso varía en función del tipo de monte existente en cada localidad. La leña de haya es apreciada como combustible, aunque tiene como inconveniente su rápida combustión.

- Carbón (7): El carbón vegetal de haya era un combustible empleado en la fragua del herrero, elaborado carbonizando su madera.

- Luz (1): En Lores señalan la utilización del aceite de hayuco como combustible de alumbrado en los candiles.

\section{CONSTRUCCIÓN}

- Carros y otros vehículos terrestres (18): Algunas partes del típico carro de tiro de vacas, se emplea la madera de haya para fabricar las agujas, las taleras de la armadura, la barandilla - las tablas del piso. El haya presenta ventajas frente al roble, aguanta mejor la humedad, se trabaja mejor y aligera el peso del carro.

- Casas, edificios e instalaciones agropecuarias (29): Utilizada la madera en los tejados de las edificaciones para tablas de ripia e incluso para cabrios o vigas de mayor relevancia en la construcción. Los chozos próximos a bosques de haya también incluyen esta madera en su cubierta. Presenta el inconveniente de ser fácilmente atacado por xilófagos de la madera, por ello el roble es preferido en el levantamiento de estructuras.

- Infraestructuras (2): Un minero de San Juan de Redondo destaca la funcionalidad de la madera de haya en la mina para postear "Si caía una nevada y no quedaba madera, íbamos a cortarlo al monte. Para postear en las galerías era mejor el haya porque avisaba cuando la cosa apretaba".

\section{INDUSTRIA Y ARTESANÍA}

- Herramientas y utensilios (83): La madera de haya es muy apreciada en carpintería y ebanistería, al ser fácil de trabajar (tallar, tornear o pulir). Fue común su uso en la elaboración de piezas de aperos como la esteva y la camba del arado que requiere una curvatura especial.

También útil para la fabricación de yugos, yuguetas, escaleras, garios, bieldos, astiles y mangos de diversas herramientas. En este apartado destacan pueblos como San Martín de los Herreros, Rebanal de las Llantas y Ventanilla, con fama de poseer buenos carpinteros.

- Juguetes e instrumentos deportivos y musicales (7): Los bolos del tradicional juego pueden confeccionarse con haya, aportando la madera atributos como ligereza y posibilidad de talla. Empleado también para la fabricación de esquís en la localidad de Polentinos.

- Vestimenta y adornos personales (21): Un uso muy frecuente de la madera de haya fue la confección del tradicional calzado rústico, conocido como albarca o madreña.

- Otros usos industriales (1): En Velilla del Río Carrión describieron la forma de obtener antiguamente alquitrán con madera de haya, destinado a la impermeabilización "Al hacer carbón vegetal de haya, los humos en vez de echarlos a la atmosfera iban a una charca y la sustancia que quedaba era alquitrán".

\section{SOCIAL, SIMBÓLICO Y RITUAL}

- Ritual de ciclo anual (12): Las ramas de haya se empleaban para decorar los altares y las calles en la fiesta del Corpus Christi y también en la festividad de San Juan o San Pedro como agasajo a las mozas del pueblo..

- Ritual de ciclo de vida (17): Una de las tradiciones más arraigadas para solemnizar acontecimientos extraordinarios, como la ordenación de un sacerdote o resaltar una fiesta patronal, fue el pinado del mayo. Los mozos ojeaban previamente el haya más apropiado, lo cortaban, lo desmochaban y transportaban hasta el lugar donde finalmente se alzaba, preparado para ser trepado por cualquier mozo que insistiera en conseguir tal hazaña. Se coronan con algún premio como dulces, frutas o algo de dinero.

- Literatura popular (8): "El haya para cuando más no haya", es un dicho popular recogido en toda la comarca, alude a la obligación de uso, cuando escasea otro tipo de madera y apunta las desventajas de la madera: atacada por parásitos y de rápida combustión.

- Alucinógenas, narcóticas y fumatorias (1): En Casavegas, se cita el empleo de las hojas secas de haya como sustituto del tabaco.

Observaciones: En los años 40 y 50 del siglo pasado, algunos habitantes de zonas con 
amplias superficies de hayedo, bajaban con sus carros a las zonas cerealistas para vender o intercambiar sus mercancías (escaleras, herramientas, utensilios, etc.) por cereales, legumbres $\mathrm{u}$ otros productos.

También se han recogido testimonios de la venta de hayucos para obtener un aporte económico extraordinario.

El haya forma densos bosques, con representación destacada en Brañosera, La Pernía y Velilla del Río Carrión.

FAGACEAE

Quercus petraea (Matt.) Liebl.

Q. pyrenaica Willd.

Q. robur L.

Roble (129), cajigo (1), cajiga (1), matorro (9), roble albar (1), roble matorrizo (1), roble matiego (1), roble enciniego (1)

Quercus petraea: PALAB2706, 16P, 129P, 292P; 5F

Q. pyrenaica: PALAB2707, 63P, 210P; 245F

Q. robur: 119P, 528P; $171 \mathrm{~F}$

Quercus spp: 171V, 205V, 236V, 302V, 327V, 343V, $362 \mathrm{~V}, 434 \mathrm{~V}, 435 \mathrm{~V}, 436 \mathrm{~V}, 437 \mathrm{~V}, 438 \mathrm{~V}, 508 \mathrm{~V}, 533 \mathrm{~V}$

Frecuencia de citación (FC): 138

Número de usos (NU):

Número registros de uso (RU):

Frecuencia Relativa de Citación (FRC): $\quad 0,99$

Índice de Importancia Cultural (IC): $\quad 4,60$

Índice de Vigencia (IV):

0,46

Obtención: silvestre

Vigencia: vigente (10\%)

\section{Conocimientos:}

\section{ECOLOGÍA}

Por lo general los informantes no identifican las distintas especies de roble, los únicos datos al respecto se recogen en las localidades de: Vidrieros donde diferencian el roble matorrizo (Quercus pyrenaica) del roble albar (Quercus petraea) por que el primero tarda más en echar la hoja y más en caerse, en Valcobero donde nos explican que la hoja del roble albar (Quercus petraea) es grande y verde y la del roble matiego (Quercus pyrenaica) es más pequeña, grisácea y algo aterciopelada, y en Salcedillo donde diferencian la hoja del roble enciniego (Quercus pyrenaica) más suave y tardía en su desarrollo que la del roble albar (Quercus petraea).

\section{LÉXICO}

En alguna localidad de la comarca, como San Salvador de Cantamuda, reconocen la especie
Quercus petraea como cajigo o cajiga. Bajo la denominación de matorro se identifican los ejemplares jóvenes de porte arbustivo, pudiendo pertenecer a cualquiera de las 3 especies señaladas.

Marnioso es un roble cuando es nudoso y difícil de trabajar.

Las agallas esféricas presentes en el roble se producen como respuesta a picaduras de himenópteros, popularmente se conocen con el nombre de gallaritas o gollerotas las más pequeñas y gallarones o frailes, las de mayor tamaño.

Varios fitotopónimos encontramos en la zona, el pago: "El Roblón” en Estalaya y Lebanza, “EI Robledo" en Casavegas, "Prado del Robledo" en El Campo, y "Robledo" en Cervera de Pisuerga.

Usos:

\section{ALIMENTACIÓN HUMANA}

- Frutos secos y oleaginosos (13): La parte comestible son los frutos que se recolectan durante el otoño. Se pueden consumir en crudo directamente en el campo, o se conservan en casa durante un corto periodo de tiempo para permitir su completa maduración y así mejorar su sabor, también se pueden tostar o asar, proceso que atenuaba el amargor de las bellotas.

- Bebidas alcohólicas (2): Un uso reciente es la elaboración de licores obtenidos macerando bellotas en licor.

- Golosinas y masticatorias (1): En Rabanal de los Caballeros se señala cómo los más jóvenes chupaban la savia de los robles recién cortados, "sabía un poco a whisky, así como una cosa seca de madera".

\section{ALIMENTACIÓN ANIMAL}

- Forraje verde o seco (117): Una de las labores imperativas durante la época del tardío (otoño) era la recogida de hoja de roble, estimada como suplemento alimenticio para el ganado en el rigor invernal. El destino principal era ovejas y cabras, pero también se suministraba al ganado vacuno en verde, y al porcino, previamente cocidas y acompañado de un poco de harina de cereal o leguminosa. Los niños ayudaban en esta tarea, arrancando (esmochando, repelando) hojas de los robles más bajos (matorros) y acarreando en momentos de necesidad puntual pequeños sacos o cestos (zamanzos, gamanzos o capachos).

- Pienso (91): Las bellotas se han recolectado como complemento en la alimentación del 
ganado, destinadas para cerdos, ovejas, vacas y cabras. El uso más frecuente fue como engorde del cerdo en semanas próximas a la matanza. Se servían de ordinario en crudo, aunque en ocasiones se transformaban en pienso en el molino más cercano.

La recogida se realiza durante el otoño y se aprovechan las bellotas caídas al suelo por sí solas o se varean los árboles que se advierten con mayor producción. En algunas localidades se menciona el comercio de bellota como fuente de ingresos extra en el núcleo familiar.

- Pasto (2): La actividad ganadera en el pasado obligaba al pastoreo de ovejas y vacas, que se beneficiaban de las bellotas caídas en el monte durante el otoño. En Matabuena se indica la competencia del ganado lanar por conseguir las bellotas maduras.

- Plantas melíferas (3): Al final del verano y en otoño los robles producen mielatos que las abejas transforman en miel. Se trata de secreciones azucaradas producidas por el árbol para eliminar el exceso de savia o como respuesta ante el ataques de insectos. Se obtiene una miel densa de color oscuro.

\section{COMBUSTIBLE}

- Leña (113): La madera de roble posee un gran poder calorífico, es la más empleada como combustible para el hogar y antiguamente para cocer el pan en el horno. La leña se obtiene en la parcelas de monte (suertes) señaladas por el guarda, de la cual se entresacan los ejemplares que posteriormente se trocean y se colocan en los leñeros dispuestos para quemar durante los duros inviernos.

- Encendido (20): Para el encendido de la lumbre se aprovechan las ramas más finas, obtenidas del despiece de los ejemplares asignados en las suertes o del sobrante del ramoneo.

- Carbón (18): El carbón elaborado con roble resulta de gran calidad, tenía como destino habitual la fragua. En Velilla del Río Carrión se recuerda la construcción de gran cantidad de hornos y la comercialización en comarcas vecinas.

\section{CONSTRUCCIÓN}

- Carros y otros vehículos terrestres (25): La madera de roble ofrece ventajas frente a otras maderas de la zona, por su mayor resistencia y durabilidad. Se empleaba en la fabricación del armazón o de alguna otra parte (ejes, radios...) del carro de tiro de vacas, también en la construcción de pequeñas carretillas para el transporte de abono.
- Casas, edificios e instalaciones agropecuarias (56): el roble se integra en la arquitectura popular tradicional, se emplea tanto en vigas principales para sujeción de estructuras, como en otras secundarias para dinteles y apeos, en la construcción de la cubierta (cumbrial, cabrios, cuartones y ripia), en el solado, en puertas, ventanas y marcos de viviendas, tenadas, chozos, corrales, etc.

En caso de necesidad puntual se pedía permiso al guarda para resolver la carencia. En algunos pueblos con abundante superficie de bosque se realizaban subastas para comercializar la madera.

- Infraestructuras (8): En las minas de la comarca se empleaba puntualmente madera de roble procedente de subastas locales, también se destinó la madera a la fabricación de traviesas para el tren.

\section{INDUSTRIA Y ARTESANÍA}

- Curtientes (1): La corteza del roble rica en taninos fue empleada antiguamente por los pastores para curtir las pieles de su ganado. Mediante el curtido, las pieles quedan limpias y adquieren solidez y resistencia.

- Sustancias tintóreas y pinturas (3): EI propietario de una antigua serrería en San Felices de Castillería explica la obtención de pintura con la savia desprendida al cortar los robles jóvenes. "Cuando cortábamos los robles para sacar tabla, echaba una savia, ese líquido era una pintura azul, casi negra, te manchaba las manos, si te mojabas los dedos con la savia ya no se quitaba con nada. Se usaba para pintar luego, cualquier cosa".

Se recoge también el uso tintóreo tanto de las agallas, como de la corteza de roble. Los taninos presentes producen tonalidades grisáceas y negras capaces de teñir tejidos. En otros tiempos, la demanda de ropa negra resultaba habitual, tanto en la vida cotidiana como en ceremonias religiosas (bodas $y$ defunciones).

- Herramientas y utensilios (60): La dureza de la madera se aprovecha para la confección de mangos de herramientas que soportan golpes violentos y continuados (azadones, porrillas y picos). También se dedicaba la madera para confeccionar cebillas o collares para el ganado, cachavas, escaleras e incluso en algún caso excepcional, yugos. En Salinas de Pisuerga señalan la fabricación de pipas para fumar con las agallas que aparecen en los robles.

- Juguetes $e$ instrumentos deportivos $y$ musicales (13): El empleo de la madera se cita en la confección de bolas y bolos del tradicional 
juego popular, resultando pesados y por lo tanto más difíciles de derribar. También útil para fabricar peonzas o trompas y para otros juegos infantiles del momento. En Villanueva de Arriba rememoran la fabricación de zancos sobre los que los niños se sustentaban a cierta altura.

- Mobiliario y enseres (2): Se refiere el uso de la madera de roble en la fabricación de mobiliario de interior: mesas, mesillas, alacenas, camas y sillas.

- Cestos, recipientes y envoltorios (15): LoS troncos de roble han tenido un aprovechamiento tradicional como recipientes de gran capacidad para conservar el grano de cereal cosechado y como habitáculo para las colmenas (dujo). Se solían conseguir troncos en el monte con la parte central ahuecada o podrida, completándose el vaciado con las herramientas adecuadas hasta alcanzar en las paredes el grosor deseado, normalmente entre 5 y $10 \mathrm{~cm}$, dependiendo del diámetro y altura final del recipiente. En el caso de los dujos, se colocaban dos listones a modo de cruz en el centro del tronco para que las abejas pudieran asegurar los panales en ellos y se taladraban tres agujeros en un rebaje que servían de acceso al interior. Por último se colocaban y tapaban con lanchas (losa de piedra lisa).

Otro uso importante del roble hasta bien entrado el siglo XX fue la elaboración de duelas (tablillas curvas empleadas en tonelería). Las propiedades de esta madera son valoradas en la fabricación de cubas y en la zona del valle de Castillería especialmente, esta actividad alcanzó gran importancia, desarrollándose un comercio ordinario con comarcas vecinas. Para la elaboración se serraban y pulían las duelas, se armaban con aros y se cocían con agua caliente, entre tabla y tabla a modo de junta se empleaba hoja de espadaña o puro (Typha angustifolia).

También se menciona la fabricación de comederos para el ganado porcino, a partir de grandes troncos de roble que se iban vaciando hasta conseguir la forma cóncava necesaria del recipiente.

- Vestimenta y adornos (4): Los tarugos o machorras de las albarcas se hacían con madera de roble.

- Otros usos industriales (1): Se obtenía alquitrán destinado a la impermeabilización, a partir del residuo desprendido en la combustión de leña verde de roble.

\section{MEDIOAMBIENTAL}

- Mejora del suelo (9): La hoja seca de roble sustituía a la paja de cereal como acolchado de los animales domésticos en épocas de escasez, y tenía también utilidad una vez descompuesta como abono para las tierras de labor.

- Bioindicador (4): El hongo yesquero (Fomes fomentarius) se desarrolla de forma habitual sobre la corteza del roble, esta especie se recogía como sustituto del tabaco en la zona y se señala que para encontrarlo se debe inspeccionar los troncos de los robles.

\section{SOCIAL, SIMBÓLICO Y RITUAL}

- Ritual de ciclo anual (11): El mayo por el que trepaban los jóvenes en la primavera habitualmente era de roble, la ventaja de emplear roble en vez de haya o chopo, es que los mozos obtenían mayor beneficio económico para luego celebrar el festín.

Las ramas de roble también se usaron en las tradicionales enramadas de San Juan y San Pedro, para engalanar las viviendas de las mozas del lugar durante la fiesta. Asimismo era tradicional colocar un ramo en el último carro de recogida de la hierba, éste señalaba el fin de la época de recolección.

- Ritual de ciclo de vida (9): La colocación del tradicional mayo fue muy popular cuando un vecino se ordenaba sacerdote. La forma de actuación era similar a la llevada a cabo en la fiesta de San Juan o San Pedro. Mientras los mozos trataban de trepar, las mozas del pueblo recitaban cantares.

- Literatura popular (1): En la localidad de Valcobero, las mozas del pueblo visitaban un viejo roble para consultar su futuro, recitando este estribillo. "Roble cucubillo, ramo de cuchar, dime cuantos años me quedan, para poderme casar". El roble hoy en día talado, poseía forma cóncava en la base del tronco semejante a una cuchara.

- Uso recreativo (7): Las gallaritas, gallarones o frailes se empleaban en múltiples juegos que atendían a la imaginación infantil, como las canicas.

- Alucinógenas, narcóticas y fumatorias (19): La hoja de roble seca y molida sirvió como sustituto del tabaco en épocas de carestía.

- Árboles singulares (11): Existen robles albares longevos con diámetro y porte excepcional, de entre todos el más conocido es el "Roblón de Estalaya" con casi 500 años de antigüedad. Otros interesantes ejemplos se pueden observar en Lebanza "Roble de Lebanza" y en Resoba "Roble de la Tenada", donde era tradicional descansar y sentarse a almorzar cobijado bajo su extensa sombra. 
Los tres ejemplares se incluyen en el catálogo de Árboles singulares de Castilla y León.

En Valberzoso se encuentra el "Roble del Escurridero", que servía como punto de encuentro del ganado de los dos barrios de la localidad, y en Pisón de Castrejón el "Roble de Matarraposera" de gran tamaño, situado en una cañada por donde pasaba el ganado de vecería.

Observaciones: Se recomienda realizar la tala con la luna propicia, durante el cuarto menguante. En este periodo se asegura la adecuada conservación de la madera.

FAGACEAE

\section{Quercus rotundifolia Lam.}

Encina (15), ancina (1)

73P; 455F; 21V

\begin{tabular}{lc}
\hline Frecuencia de citación (FC): & 16 \\
\hline Número de usos (NU): & 5 \\
\hline Número registros de uso (RU): & 28 \\
\hline Frecuencia Relativa de Citación (FRC): & 0,12 \\
Índice de Importancia Cultural (IC): & 0,20 \\
\hline Índice de Vigencia (IV): & 0,01 \\
\hline
\end{tabular}

Obtención: silvestre

Vigencia: vigente (3\%)

Conocimientos:

LÉXICO

El "Camino del Encinal" se encuentra en Nestar y el pago de "Encinal" en Guardo.

Usos:

ALIMENTACIÓN HUMANA

- Frutos secos y oleaginosos (4): El fruto se puede consumir en crudo directamente en el campo o se puede tostar o asar. La bellota de encina es más dulce y apetecible que la de roble.

\section{ALIMENTACIÓN ANIMAL}

- Forraje verde o seco (2): La hoja de encina se destinaba como forraje para ovejas y cabras, de entre ellas se procuraba escoger las hojas con el borde no espinoso.

- Pienso (3): Se recolectaban bellotas como complemento alimenticio de cabras, cerdos, ovejas y vacas. Se podían administrar enteras y en algunos casos se molían junto con el cereal.

\section{COMBUSTIBLE}

- Leña (9): La madera de encina es considerada de muy buena calidad para la lumbre, "da una brasa muy buena y aguanta bien el rescoldo".

- Carbón (3): Se hacía carbón vegetal con la madera de encina.

\section{CONSTRUCCIÓN}

- Carros y otros vehículos terrestres (6): Las propiedades en cuanto a dureza y resistencia de la madera de encina la hacían adecuada para la fabricación de los radios del tradicional carro de tiro de vacas.

\section{INDUSTRIA Y ARTESANÍA}

- Juguetes $e$ instrumentos deportivos $y$ musicales (1): Se cita la madera de encina para fabricar peonzas en Villanueva de Arriba, "eran las más duras".

Observaciones: La presencia de encina en la comarca se concentra en las laderas con exposición sur.

GENTIANACEAE

\section{Centaurium erythraea Rafn}

Hierba de las 7 sangrías (1)

\begin{tabular}{lc} 
232P; 213F; 551V & \\
\hline Frecuencia de citación (FC): & 1 \\
\hline Número de usos (NU): & 1 \\
\hline Número registros de uso (RU): & 2 \\
\hline Frecuencia Relativa de Citación (FRC): & $\mathbf{0 , 0 1}$ \\
\hline Índice de Importancia Cultural (IC): & $\mathbf{0 , 0 1}$ \\
\hline Índice de Vigencia (IV): & $\mathbf{0 , 0 1}$ \\
\hline
\end{tabular}

Obtención: silvestre

Vigencia: vigente (50\%)

Usos:

MEDICINA

- Sistema circulatorio (1): En Villanueva de la Torre se usa la infusión de la parte aérea de esta planta para purificar la sangre, de 3 a 4 tazas diarias. Útil cuando aparecen diviesos en la piel problema asociado con la necesidad de limpiar y renovar la sangre.

- Sistema digestivo (1): La misma preparación se tomaba para los dolores de muelas.

\section{GENTIANACEAE}

Gentiana lutea L. Junciana (47), genciana (29)

52P, 534P; 69F; 136V, 159V, 417V, 418V, 592V 


\begin{tabular}{lc}
\hline Frecuencia de citación (FC): & 76 \\
\hline Número de usos (NU): & 3 \\
\hline Número registros de uso (RU): & 98 \\
\hline Frecuencia Relativa de Citación (FRC): & $\mathbf{0 , 5 5}$ \\
\hline Índice de Importancia Cultural (IC): & $\mathbf{0 , 7 1}$ \\
\hline Índice de Vigencia (IV): & $\mathbf{0 , 0 0}$ \\
\hline
\end{tabular}

Obtención: silvestre

Vigencia: abandonado

\section{Conocimientos:}

ECOLOGÍA

Se desarrolla en pastizales y claros de bosques a gran altura.

Usos:

\section{MEDICINA}

- Sistema digestivo (52): Su uso más reputado es para el tratamiento de desórdenes digestivos, como dolores de tripa, úlceras, digestiones pesadas y especialmente útil en la pérdida de apetito. Los preparados a base de rizoma, podían llevarse a cabo a través de cocimiento, infusión, maceración en vino, orujo o agua, e incluso directamente chupado.

- Sistema respiratorio (10): La junciana es reconocida tradicionalmente por su uso medicinal. El rizoma se emplea para el tratamiento de catarros, resfriados, gripes o cualquier otra afección de tipo respiratorio. Se puede administrar mediante infusión, previamente cocido en agua y también mediante maceración en vino.

- Otras enfermedades infecciosas y parasitarias (1): El cocimiento del rizoma tiene propiedades vermífugas, recomendado para eliminar las lombrices de los niños.

- Intoxicaciones y envenenamientos (1): En Piedrasluengas se avala su uso como tratamiento del tabaquismo, chupando el rizoma.

\section{VETERINARIA}

- Sistema digestivo (20): Es de uso común para problemas digestivos en animales, empleado el rizoma para facilitar la digestión de las vacas empanzadas y especialmente útil para abrir el apetito del ganado (cerdos y vacas).

- Sistema respiratorio (8): Se describe la utilización del rizoma para combatir afecciones respiratorias (catarro, tos o pulmonía) del ganado vacuno.

- Otras enfermedades infecciosas y parasitarias (5): Su virtud vermífuga es mencionada para tratamientos contra las lombrices en los animales, sobre todo para los cerdos.

\section{TÓXICO Y NOCIVO}

- Otros elementos nocivos y repelentes (1): En la localidad de Valcobero se recuerda el uso de la junciana para inducir a los niños el abandono del chupete. Se frotaba con un trozo de rizoma pelado y el amargor provocaba en los niños el rechazo del habito de succión del chupete.

Observaciones: Todos los informantes que tomaron esta planta señalaron que se trataba de un remedio difícil de digerir por su amargor. La economía de subsistencia de esta sociedad tradicionalmente rural, favoreció la recolección de esta planta hasta aproximadamente los años 80 , era vendida a intermediarios encargados de comercializarlo a la industria farmacéutica. En la posguerra, su aprovechamiento ayudó a muchos pueblos de estas zonas de montaña, ya que se obtenían ingresos extra para las familias sin alterar las actividades habituales de la agricultura y la ganadería. La recolección libre de la genciana derivó en un mal uso, lo que ha puesto en peligro la supervivencia de esta especie, llevándola en algunas zonas de la Montaña Palentina a su desaparición. Por ello fue incluida en el Catalogo de Flora Protegida de Castilla y León (Decreto 63/2007, de 14 de junio), bajo la figura de aprovechamiento regulado.

La recolección de rizoma de genciana se realizaba en el otoño una vez acabadas las labores anuales habituales del campo, extrayéndose la parte superior del rizoma con un azadón y dejando los más profundos para que siguiera su desarrollo y permitiera la recuperación de la planta.

\section{Pelargonium zonale (L.) L'Hér. ex Aiton Geranio (5)}

\begin{tabular}{|ll|}
\hline Frecuencia de citación (FC): & 5 \\
\hline Número de usos (NU): & 2 \\
\hline Número registros de uso (RU): & 6 \\
\hline
\end{tabular}

Obtención: cultivada

Vigencia: vigente (83\%)

Usos:

ORNAMENTAL

- Adorno floral y plantas de interior (5): Se cultiva en macetas para ornamentación de balcones, así como de estancias interiores.

SOCIAL, SIMBÓLICO Y RITUAL 
- Ritual de ciclo anual (1): Las macetas de los geranios más majestuosas se llevaban a los altares que se colocaban en las calles por la tradicional fiesta del Corpus Christi.

Observaciones: Posiblemente en la zona se cultiven también en macetas Pelargonium grandiflorum y $P$. peltatum.

\section{GROSSULARIACEAE}

Ribes alpinum L.

Abubillo (5), abubillo montesino (7), amacuco (3), agüillo (3), aguvillo (1), plumillo (4), agrión (5), espuma (4)

\begin{tabular}{lc} 
PALAB2151, 189P; 50F; 61V, 488V & \\
\hline Frecuencia de citación (FC): & 32 \\
\hline Número de usos (NU): & $\mathbf{2}$ \\
\hline Número registros de uso (RU): & 33 \\
\hline Frecuencia Relativa de Citación (FRC): & $\mathbf{0 , 2 3}$ \\
\hline Índice de Importancia Cultural (IC): & $\mathbf{0 , 2 4}$ \\
\hline Índice de Vigencia (IV): & $\mathbf{0 , 0 1}$ \\
\hline
\end{tabular}

Obtención: silvestre

Vigencia: vigente (6\%)

Conocimientos:

LÉXICO

Se han documentado varios nombres comunes y aunque no existe una separación estricta, si podemos confirmar que en la parte oriental de la comarca recibe el nombre de plumillo o espuma, en la occidental agrión y en la parte septentrional abubillo.

Los nombres compuestos recogidos hacen alusión al lugar donde encontrar esta especie: abubillo de monte, abubillo montesino.

Los frutos se conocen con los siguientes nombres: abubilla, agüilla, aguvilla, agrión, plumilla y espuma, coincidiendo varios con el nombre de la planta.

Usos:

\section{ALIMENTACIÓN HUMANA}

- Frutos y frutas dulces (30): La parte aprovechable son los frutos recolectados a partir del mes julio, momento en el que alcanzan su maduración, tomando un color rojo intenso. Suelen consumirse directamente en el campo sin ninguna preparación. Los frutos son de pequeño tamaño y se refiere un sabor un tanto dulce y gustoso al paladar.

\section{INDUSTRIA Y ARTESANÍA}

- Herramientas y utensilios (3): Con las ramas se fabrican escobas para barrer zonas irregulares como portadas, cuadras o patios. Se cortan varias ramas y se unen abrazadas por un alambre o presilla vegetal, en ocasiones se remata con un palo central. Una vez seca, destaca su flexibilidad y resistencia.

\section{GROSSULARIACEAE}

Ribes petraeum Wulfen

Abubillo (4), abubillo montesino (1)

209P, 519P

\begin{tabular}{lc}
\hline Frecuencia de citación (FC): & 5 \\
\hline Número de usos (NU): & 2 \\
\hline Número registros de uso (RU): & 6 \\
\hline Frecuencia Relativa de Citación (FRC): & $\mathbf{0 , 0 4}$ \\
\hline Índice de Importancia Cultural (IC): & $\mathbf{0 , 0 4}$ \\
\hline Índice de Vigencia (IV): & $\mathbf{0 , 0 1}$ \\
\hline
\end{tabular}

Obtención: silvestre

Vigencia: vigente (16\%)

Usos:

\section{ALIMENTACIÓN HUMANA}

- Frutos y frutas dulces (5): Se consumen los frutos rojos y maduros, directamente en el campo.

\section{INDUSTRIA Y ARTESANÍA}

- Herramientas y utensilios (1): Juntando varias ramas con una presilla se fabrican escobas.

\section{GROSSULARIACEAE}

Ribes rubrum L.

Abubillo (4), agüillo (3), ovillo (1) , acubillo (1), escándalo (3), grosellero (5)

272F; 173V, 221V, 535V

\begin{tabular}{lc}
\hline Frecuencia de citación (FC): & 17 \\
\hline Número de usos (NU): & 1 \\
\hline Número registros de uso (RU): & 17 \\
\hline
\end{tabular}

Obtención: cultivada

Vigencia: vigente (66\%)

Usos:

ALIMENTACIÓN HUMANA

- Frutos y frutas dulces (17): Se cultiva en huertos y se consiguen frutos de mayor tamaño y dulzor que los obtenidos en el campo se consumen en fresco o se elabora con ellos mermelada. 


\section{GROSSULARIACEAE}

Ribes uva-crispa L.

Abubillo (19), agüillo (9), aguvillo (6), escándalo (5), plumillar (13), espuma (5)

PALAB781, 106P; 296F; 174V, 303V, 489V, 496V

\begin{tabular}{lc}
\hline Frecuencia de citación (FC): & 59 \\
\hline Número de usos (NU): & 2 \\
\hline Número registros de uso (RU): & 61 \\
\hline Frecuencia Relativa de Citación (FRC): & 0,42 \\
\hline Índice de Importancia Cultural (IC): & 0,44 \\
\hline Índice de Vigencia (IV): & 0,02 \\
\hline
\end{tabular}

Obtención: silvestre, cultivada

Vigencia: vigente (4\%)

Conocimientos:

ECOLOGÍA

Aunque aparece silvestre en orlas de bosques, también se cultiva en los huertos.

Usos:

\section{ALIMENTACIÓN HUMANA}

- Frutos y frutas dulces (59): Los frutos de color verde casi trasparente se recolectan alrededor del mes de agosto y se consumen en fresco.

\section{INDUSTRIA Y ARTESANÍA}

- Herramientas y utensilios (2): Con las ramas pinchudas se elaboran escobas pequeñas para barrer.

\section{HYDRANGEACEAE}

Hydrangea macrophylla (Thunb.) Ser.

Hortensia (2)

\begin{tabular}{ll}
\hline $280 \mathrm{~V}$ & \\
\hline Frecuencia de citación (FC): & 2 \\
\hline Número de usos (NU): & 1 \\
\hline Número registros de uso (RU): & 2 \\
\hline
\end{tabular}

Obtención: cultivada

Vigencia: vigente (50\%)

Usos:

ORNAMENTAL

- Patios, huertos y jardines (2): Es cultivada con fines ornamentales en huertos y jardines.

\section{HYDRANGEACEAE}

Philadelphus coronarius L.

Ramo de azahar (1)

\begin{tabular}{ll}
\hline Frecuencia de citación (FC): & 1 \\
\hline Número de usos (NU): & 1 \\
\hline Número informes de uso (RU): & 1 \\
\hline
\end{tabular}

Obtención: cultivada

Vigencia: vigente (100\%)

Usos:

ORNAMENTAL

- Patios, huertos y jardines (1): Se cultiva en huertos y jardines como arbusto ornamental.

\section{HYPERICACEAE}

Hypericum perforatum $\mathrm{L}$.

Hipérico (12), bergaula (3), pericón (3), pericol (1), flor de orina (2), hierba de la orina (1), hierba alpericón (1), hierba de San Juan (2)

57P, 457P; 15F; 32V, 244V, 246V, 257V, 340V, 377V, 503V, 527V

\begin{tabular}{lc}
\hline Frecuencia de citación (FC): & 25 \\
\hline Número de usos (NU): & 3 \\
\hline Número registros de uso (RU): & 33 \\
\hline Frecuencia Relativa de Citación (FRC): & $\mathbf{0 , 1 8}$ \\
\hline Índice de Importancia Cultural (IC): & $\mathbf{0 , 2 4}$ \\
\hline Índice de Vigencia (IV): & 0,04 \\
\hline
\end{tabular}

Obtención: silvestre

Vigencia: vigente (15\%)

Conocimientos:

LÉXICO

El nombre de bergaula se cita solamente en Polentinos y en Rabanal de las Llantas, resultando un nombre inédito y propio de la Montaña Palentina, no recogido con anterioridad en la bibliografía consultada.

Los nombres compuestos hierba de la orina y flor de orina hacen referencia al uso diurético de la planta.

Usos:

MEDICINA

- Sistema genito-urinario (7): Posee un creciente valor en la zona como planta medicinal. Se usa como excelente diurético, empleado para tratar la retención de orina y las infecciones urinarias. Se recolecta la parte aérea en pleno estado de floración, desde el final de la primavera hasta la mitad del verano y se administra mediante infusión.

- Musculatura y esqueleto (6): Para tratar dolores musculares y óseos se aconseja el tratamiento con aceite de hipérico, en Cervera de Pisuerga se recoge "primero los tallos con flor y se secan un poco. En una botella con 
aceite de oliva se meten y se deja la botella 40 días en la calle. Después ya se cuela y se pone en un sitio oscuro. Este aceite es para dolores, de los pies, de los tobillos y para el reuma".

- Piel y tejido celular subcutáneo (3): Es reconocido como un buen cicatrizante de pequeñas heridas (vulnerario). Se aplica sobre las heridas en forma de aceite o se lavan las heridas con el agua resultante de cocer la parte aérea.

- Sistema nervioso (5): La infusión de flores se recomienda para atender estados de nerviosismo, estrés, ansiedad, depresión y para dolores de cabeza.

- Otras enfermedades infecciosas y parasitarias (2): En Alba de los Cardaños se refiere el empleo de aceite de hipérico para combatir la tiña (infección fúngica) de la piel.

\section{VETERINARIO}

- Sistema genito-urinario (5): Las virtudes diuréticas también se aconsejan para el tratamiento de la retención de orina en el ganado vacuno. Se cuecen en agua los tallos con flor y se da a beber el líquido resultante.

- Piel y tejido celular subcutáneo (2): Las heridas que presentan los animales domésticos se lavan con la cocción de hipérico. Muy eficaz para cerrar pequeñas heridas.

- Otras enfermedades infecciosas y parasitarias (2): Útil para combatir la tiña, enfermedad infecciosa en los animales domésticos. Se usa el hiperíco macerado en aceite.

\section{INDUSTRIA Y ARTESANÍA}

- Cosmética, perfumería y limpieza (1): En Celada de Roblecedo se recoge el empleo del aceite de hipérico como bronceador corporal "la hierba fresca se mete en aceite, se deja al sol unos días hasta que se pone rojo y luego se daba en la piel".

Observaciones: En humanos, el contacto de esta planta con la piel húmeda o aplicada de forma tópica produce eritemas y ulceraciones si existe una exposición al sol, por lo que ponemos en duda su empleo como bronceador, a pesar de ser transmitido por una persona sabia de las plantas.

En la Montaña Palentina existen otras especies del mismo género como: Hypericum hirsutum, $H$. hyssopifolium, $H$. pulchrum o $H$. undulatum, pudiendo tener algún uso común con Hypericum perforatum.

\section{Juglans regia $\mathrm{L}$. Nogal (28)}

PALAB483, 188P, 359P; 252F; 213V, 359V

\begin{tabular}{lc}
\hline Frecuencia de citación (FC): & 28 \\
\hline Número de usos (NU): & 6 \\
\hline Número registros de uso (RU): & 34 \\
\hline
\end{tabular}

Obtención: cultivada

Vigencia: vigente (14\%)

Usos:

\section{ALIMENTACIÓN HUMANA}

- Frutos secos y oleaginosos (20): Los años que las heladas respetaban la cosecha se podían recoger unas pocas nueces que se consumían en crudo, aunque por lo general la producción era escasa.

- Bebidas alcohólicas (1): En la localidad de Gramedo se elaboraba orujo de nueces macerando la semilla en aguardiente o licor.

\section{MEDICINA}

- Sistema digestivo (1): Se toma una copita de orujo de nueces para calmar el dolor de estómago.

- Musculatura y esqueleto (1): La cataplasma con la cocción de las hojas de nogal se aconseja para el tratamiento de inflamaciones provocadas por golpes y dolores musculares.

- Piel y tejido celular subcutáneo (3): La cocción de las hojas de nogal se emplea como cicatrizante de pequeñas heridas o grietas en la piel, aplicada mediante cataplasma o baño directo. En San Martín de los Herreros también recomiendan lavarse el pelo con el cocimiento de las hojas pues evitaba la caída del pelo.

\section{VETERINARIA}

- Piel y tejido celular subcutáneo (2): También para cicatrizar heridas de los animales se utilizan cataplasmas con la cocción de las hojas.

\section{COMBUSTIBLE}

- Leña (1): Los restos de poda o cortas puntuales servían para quemar en la lumbre.

\section{INDUSTRIA Y ARTESANÍA}

- Juguetes $e$ instrumentos deportivos $y$ musicales (1): Con la madera de nogal en Arbejal se fabricaban las bolas del típico juego de los bolos.

- Mobiliario y enseres (2): Su madera es muy apreciada, de gran calidad para fabricar muebles y fácil de trabajar en la talla. 
SOCIAL, SIMBÓLICA Y RITUAL

- Ritual de incertidumbre, protección y aflicción (1): En Recueva de la Peña afirman que la mejor sombra que existe es la de un nogal, por la frescura que ofrece y por la ausencia de insectos, pero sin embargo se prohíbe dormir debajo de un nogal advirtiendo la posibilidad de morir.

- Alucinógenas, narcóticas y fumatorias (1): Las hojas de nogal secas y machacadas se utilizaban en San Martín de los Herreros como sustituto del tabaco.

Observaciones: En Camporredondo nos informan que los vecinos cántabros de la comarca de La Liébana comerciaban al trueque con nueces y manzanas por centeno local.

LAMIACEAE

\section{Ajuga pyramidalis $\mathrm{L}$.}

\begin{tabular}{lc} 
448P; 127F; 142V \\
\hline Frecuencia de citación (FC): & 1 \\
\hline Número de usos (NU): & 1 \\
\hline Número registros de uso (RU): & 1 \\
\hline Frecuencia Relativa de Citación (FRC): & 0,01 \\
\hline Índice de Importancia Cultural (IC): & 0,01 \\
\hline Índice de Vigencia (IV): & 0,01 \\
\hline
\end{tabular}

Obtención: silvestre

Vigencia: vigente (100\%)

Usos:

ORNAMENTAL

- Adorno floral y plantas de interior (1): En Resoba se ponen ramilletes floridos de esta planta sobre jarrones con agua para decorar.

\section{LAMIACEAE}

\section{Ballota nigra $\mathrm{L}$.}

Chupona (1)

\begin{tabular}{lc} 
379P, 507P; 221F; 372V & \\
\hline Frecuencia de citación (FC): & 1 \\
\hline Número de usos (NU): & 1 \\
\hline Número registros de uso (RU): & 1 \\
\hline Frecuencia Relativa de Citación (FRC): & 0,01 \\
Índice de Importancia Cultural (IC): & 0,01 \\
\hline Índice de Vigencia (IV): & 0,00 \\
\hline
\end{tabular}

Obtención: silvestre

Vigencia: abandonado

Usos:

ALIMENTACIÓN HUMANA
- Golosinas y masticatorias (1): Se chupaban las flores para extraer el dulce néctar.

Observaciones: Varias especies cuyo principal entretenimiento era chupar las flores por el sabor dulce obtenido reciben el nombre de chupa, chupón o chupona, Ballota nigra, Pedicularis comosa, P. sylvatica, Primula veris, Prunella grandiflora, $P$. vulgaris y Trifolium pratense.

LAMIACEAE

\section{Lamium album L.}

Ortiga blanca (1), chupón (1)

\begin{tabular}{lc}
\hline $254 \mathrm{P}$ & \\
\hline Frecuencia de citación (FC): & $\mathbf{2}$ \\
\hline Número de usos (NU): & $\mathbf{1}$ \\
\hline Número registros de uso (RU): & $\mathbf{2}$ \\
\hline Frecuencia Relativa de Citación (FRC): & $\mathbf{0 , 0 1}$ \\
\hline Índice de Importancia Cultural (IC): & $\mathbf{0 , 0 1}$ \\
\hline Índice de Vigencia (IV): & $\mathbf{0 , 0 0}$ \\
\hline
\end{tabular}

Obtención: silvestre

Vigencia: abandonado

Usos:

\section{ALIMENTACIÓN HUMANA}

- Golosinas y masticatorias (1): En Valsurbio los niños chupaban las flores para extraer su néctar dulce.

\section{VETERINARIA}

- Piel y tejido celular subcutáneo (1): En Tremaya recomienda la infusión de ortiga blanca para lavar las pequeñas heridas de los animales, después se les ponía un poco de cera de abejas sobre la herida para que cicatrizara más rápidamente.

\section{Lavandula latifolia Medik.}

LAMIACEAE Lavanda (1)

409P, 512P; 261F

\begin{tabular}{lc}
\hline Frecuencia de citación (FC): & 1 \\
\hline Número de usos (NU): & 1 \\
\hline Número registros de uso (RU): & 1 \\
\hline Frecuencia Relativa de Citación (FRC): & 0,01 \\
\hline Índice de Importancia Cultural (IC): & 0,01 \\
\hline Índice de Vigencia (IV): & 0,01 \\
\hline
\end{tabular}

Obtención: silvestre

Vigencia: vigente (100\%) 
Usos:

ORNAMENTAL

- Adorno floral y plantas de interior (1): Se menciona su uso para decorar algún centro de flor seca en Aguilar de Campoo.

LAMIACEAE

Marrubium vulgare L.

Marrubio (2)

219P, 417P; 321F

\begin{tabular}{lc}
\hline Frecuencia de citación (FC): & 2 \\
\hline Número de usos (NU): & 1 \\
\hline Número registros de uso (RU): & 3 \\
\hline Frecuencia Relativa de Citación (FRC): & $\mathbf{0 , 0 1}$ \\
\hline Índice de Importancia Cultural (IC): & $\mathbf{0 , 0 2}$ \\
\hline Índice de Vigencia (IV): & $\mathbf{0 , 0 0}$ \\
\hline
\end{tabular}

Obtención: silvestre

Vigencia: abandonado

Conocimientos:

ECOLOGÍA

Sale en terrenos incultos y en márgenes de caminos, "al pie de paredones y muros".

Usos:

MEDICINA

- Sistema respiratorio (2): La infusión de la parte aérea se toma para mejorar los síntomas de los procesos catarrales.

- Piel y tejido celular subcutáneo (1): Se cuece la planta y se hacen pediluvios para reblandecer las durezas y los callos, según se recoge en la localidad de Polentinos.

LAMIACEAE

Melissa officinalis L.

Melisa (1)

$341 \mathrm{~F}$

Frecuencia de citación (FC): 1

Número de usos (NU): $\quad 1$

Número registros de uso (RU): 1

Obtención: cultivada

Vigencia: vigente (100\%)

\section{MEDICINA}

- Sistema digestivo (1): Se cultiva en exterior y se utiliza la parte aérea para hacer infusiones digestivas.
Melittis melissophyllum L.

Melisa (5)

\begin{tabular}{lc} 
158P; $175 \mathrm{~F} ; 47 \mathrm{~V}, 48 \mathrm{~V}$ \\
\hline Frecuencia de citación (FC): & $\mathbf{5}$ \\
\hline Número de usos (NU): & $\mathbf{2}$ \\
\hline Número registros de uso (RU): & $\mathbf{6}$ \\
Frecuencia Relativa de Citación (FRC): & $\mathbf{0 , 0 4}$ \\
\hline Índice de Importancia Cultural (IC): & $\mathbf{0 , 0 4}$ \\
\hline Índice de Vigencia (IV): & $\mathbf{0 , 0 2}$ \\
\hline
\end{tabular}

Obtención: silvestre

Vigencia: vigente (40\%)

Conocimientos:

ECOLOGÍA

Se da bien en bosques densos, "por donde hay roble y matas".

Usos:

\section{ALIMENTACIÓN HUMANA}

- Bebidas no alcohólicas (1): En Verdeña se hacen tisanas tomadas después de las comidas a modo de café, como una simple bebida.

\section{MEDICINA}

- Sistema digestivo (1): Se recolecta la parte aérea cuando está a punto de florecer hacia finales de primavera, y la forma de administración es mediante infusión, empleada para favorecer la digestión.

- Sistema nervioso (4): La infusión también se toma antes de ir a la cama como relajante, antiespasmódico y calmante de los nervios.

LAMIACEAE

Mentha aquatica L.

Hierbabuena (4), menta (3)

338P; 218F; 250V

\begin{tabular}{lc}
\hline Frecuencia de citación (FC): & 7 \\
\hline Número de usos (NU): & 2 \\
\hline Número registros de uso (RU): & 7 \\
\hline Frecuencia Relativa de Citación (FRC): & 0,05 \\
\hline Índice de Importancia Cultural (IC): & 0,05 \\
\hline Índice de Vigencia (IV): & 0,01 \\
\hline
\end{tabular}

Obtención: silvestre

Vigencia: vigente (29\%)

Usos:

ALIMENTACIÓN HUMANA

- Condimentos y conservantes (3): Se emplean las hojas como condimento en diferentes guisos, carnes y postres. 


\section{MEDICINA}

- Sistema digestivo (1): La infusión se recomienda en Santa María de Redondo para los dolores de estomago.

- Sistema respiratorio (3): La parte aérea en infusión se toma para aliviar los síntomas de los catarros, también se hacen vahos para descongestionar, en ocasiones mezcladas con otras plantas como tomillo y orégano.

LAMIACEAE

\section{Mentha longifolia (L.) L.}

Poleo del río (1), poleo (15), té de menta (1), menta poleo (1), menta (3), hortelana (1)

29P, 386P, 435P; 31F; 166V, 380V, 422V, 423V, 598V

\begin{tabular}{lc}
\hline Frecuencia de citación (FC): & 22 \\
\hline Número de usos (NU): & 3 \\
\hline Número registros de uso (RU): & 23 \\
\hline Frecuencia Relativa de Citación (FRC): & 0,16 \\
Índice de Importancia Cultural (IC): & 0,17 \\
\hline Índice de Vigencia (IV): & 0,03 \\
\hline
\end{tabular}

Obtención: silvestre

Vigencia: vigente (18\%)

Conocimientos:

\section{ECOLOGÍA}

Se desarrolla en terrenos húmedos, arroyos y orillas de ríos.

\section{Usos:}

MEDICINA

- Sistema digestivo (9): Se toma la infusión caliente de la planta para calmar los dolores de estomago o incluso para aliviar gases.

- Sistema respiratorio (4): Se recolecta en época de floración y se toma en infusión o en sahumerios para respirar. Útil para los catarros y para mitigar la tos seca.

\section{TóxICO Y NOCIVO}

- Venenos, insecticidas y plaguicidas (4): El olor que desprende previene de insectos y pulgas. Se ponía un hatillo debajo de las camas o colgado en las cuadras como repelente natural antipulgas.

\section{INDUSTRIA Y ARTESANÍA}

- Cosmética, perfumería y limpieza (2): La planta se machacaba un poco y se frotaban los muebles y el suelo de madera hasta conseguir un brillo llamativo.

- Herramientas y utensilios (3): Juntando varios manojos se hacían hisopos para sulfatar las patatas y escobas para barrer el horno del pan. En Verdeña esa escoba se empapaba en leche con miel para limpiar el interior de las colmenas.

\section{SOCIAL, SIMBÓLICA Y RITUAL}

- Alucinógenas, narcóticas y fumatorias (1): Las hojas secas y machacadas se utilizaban en Valcobero como sustituto del tabaco.

LAMIACEAE

Mentha x piperita L.

Hierbabuena (7), menta (4)

120V, 287V, 424V, 557V

\begin{tabular}{lc}
\hline Frecuencia de citación (FC): & 11 \\
Número de usos (NU): & 2 \\
Número registros de uso (RU): & 12 \\
\hline
\end{tabular}

Obtención: cultivada

Vigencia: vigente (38\%)

Usos:

\section{ALIMENTACIÓN HUMANA}

- Bebidas no alcohólicas (1): La infusión se toma en Villanueva de la Torre simplemente por placer después de las comidas.

- Condimentos y conservantes (8): Se emplean las hojas para condimentar o dar aroma a algún guiso o postre.

\section{ORNAMENTAL}

- Patios, huertos y jardines (3): Se cultiva tanto en huertos como en macetas decorativas en patios y exteriores de las viviendas.

\section{LAMIACEAE}

Mentha pulegium $\mathrm{L}$.

Té de menta (9), hierba de menta (1), menta poleo (9), poleo (5)

\begin{tabular}{lc} 
58P, 533P; 70F; 311V, 589V & \\
\hline Frecuencia de citación (FC): & 24 \\
\hline Número de usos (NU): & 3 \\
\hline Número registros de uso (RU): & 26 \\
\hline Frecuencia Relativa de Citación (FRC): & $\mathbf{0 , 1 7}$ \\
\hline Índice de Importancia Cultural (IC): & $\mathbf{0 , 1 9}$ \\
\hline Índice de Vigencia (IV): & $\mathbf{0 , 0 4}$ \\
\hline
\end{tabular}

Obtención: silvestre

Vigencia: vigente (24\%)

Conocimientos:

ECOLOGÍA 
Nace en lugares húmedos, por ello los vecinos de pueblos limítrofes a los pantanos de la comarca, señalaron que las cabeceras de los pantanos es el lugar más adecuado para su recolección.

Usos:

\section{ALIMENTACIÓN HUMANA}

- Bebidas no alcohólicas (6): La infusión se toma en varias localidades como bebida de acompañamiento en el desayuno, la merienda - después de las principales comidas, simplemente por el placer de disfrutar un brebaje caliente. Se emplea la sumidad florida, recolectada en plena floración hacia la mitad del mes de julio.

\section{MEDICINA}

- Sistema digestivo (16): Se administra en forma de infusión para combatir trastornos digestivos varios, como dolores estomacales, cólicos o indigestiones, también se señala su efectividad en el tratamiento de gases 0 aerofagia y como remedio antidiarreico.

- Sistema respiratorio (2): En la localidad de Salcedillo, se menciona el empleo del té de menta administrado en infusión para atender enfermedades respiratorias leves, como resfriados o catarros.

\section{TóXICO Y NOCIVO}

- Venenos, insecticidas y plaguicidas (1): Entre sus propiedades destaca la de ahuyentar a las pulgas, por ello se colocan manojos en lugares frecuentados por estos insectos (camas, cuadras, caseta del perro...).

\section{SOCIAL, SIMBÓLICA Y RITUAL}

- Ritual de incertidumbre, protección y aflicción (1): Aseguran en Rebanal de las Llantas que la infusión de menta poleo se administraba al toro semental para mejorar el apareamiento con las vacas, con ella se favorece la monta y cubrición. "Es la viagra de los pobres, se lo dábamos a beber al toro para que cogiera a la vaca".

LAMIACEAE

Mentha suaveolens Ehrh.

Poleo (3)

190P, 314P; 210F

\begin{tabular}{lc}
\hline Frecuencia de citación (FC): & 3 \\
\hline Número de usos (NU): & 1 \\
\hline Número registros de uso (RU): & 3 \\
\hline Frecuencia Relativa de Citación (FRC): & $\mathbf{0 , 0 2}$ \\
\hline Índice de Importancia Cultural (IC): & $\mathbf{0 , 0 2}$ \\
\hline Índice de Vigencia (IV): & $\mathbf{0 , 0 0}$ \\
\hline
\end{tabular}

Obtención: silvestre

Vigencia: abandonado

Usos:

INDUSTRIA Y ARTESANÍA

- Herramientas y utensilios (3): Se fabrican escobas para limpiar el horno del pan, reuniendo varios manojos a los que se les añade un palo suficientemente largo para recorrer toda la superficie del horno.

LAMIACEAE

Ocimum basilicum L.

Albahaca (2)

\begin{tabular}{ll}
\hline $88 \mathrm{~F}$ & \\
\hline Frecuencia de citación (FC): & 2 \\
\hline Número de usos (NU): & 1 \\
\hline Número registros de uso (RU): & 2 \\
\hline
\end{tabular}

Obtención: cultivada

Vigencia: vigente (100\%)

Usos:

TÓXICA Y NOCIVA

- Venenos, insecticidas y plaguicidas (2): Introducida recientemente en cultivo de macetas que se colocan en las repisas de las ventanas como un efectivo repelente de moscas y mosquitos.

LAMIACEAE

Origanum vulgare $\mathrm{L}$.

Orégano (102)

PALAB1437, 11P, 293P; 62F; 138V, 167V, 196V, $235 \mathrm{~V}, 244 \mathrm{~V}, 258 \mathrm{~V}, 273 \mathrm{~V}, 321 \mathrm{~V}, 499 \mathrm{~V}, 529 \mathrm{~V}, 530 \mathrm{~V}$, $590 \mathrm{~V}, 594 \mathrm{~V}$

\begin{tabular}{lc}
\hline Frecuencia de citación (FC): & 102 \\
\hline Número de usos (NU): & 5 \\
\hline Número registros de uso (RU): & 146 \\
\hline Frecuencia Relativa de Citación (FRC): & 0,73 \\
\hline Índice de Importancia Cultural (IC): & 1,05 \\
\hline Índice de Vigencia (IV): & 0,64 \\
\hline
\end{tabular}

Obtención: cultivada, silvestre

Vigencia: vigente (61\%) 
Conocimientos:

\section{ECOLOGÍA}

Aunque se encuentra como especie silvestre, resulta común su cultivo en el huerto para disponer de ello de forma inmediata.

\section{LÉXICO:}

El proceso de desmenuzar el orégano seco se conoce en algunas localidades con el nombre de esgamar.

Usos:

\section{ALIMENTACIÓN HUMANA}

- Condimentos y conservantes (79): Ampliamente utilizada en la cocina para dar sabor a todo tipo de platos y guisos. Su principal empleo fue en la tradicional matanza, para la elaboración de morcillas, chorizos y adobo de carnes. Se utilizan las sumidades florales una vez secas, conservadas en ramilletes 0 desmenuzadas en botes, recolectadas en los meses de julio o agosto, momento de plena floración.

\section{MEDICINA}

- Sistema digestivo (2): La infusión de las sumidades florales se aconseja para aliviar las molestias causadas por digestiones pesadas. Se toma caliente después de las comidas como digestivo y tónico estomacal.

- Sistema respiratorio (57): Se usa como anticatarral, antitusivo y en general en afecciones respiratorias. Se hierve la planta en agua, sola o mezclada con alguna otra planta que potencie sus virtudes, en la zona se recogen combinaciones con malva, tomillo, manzanilla, menta, raíz de malvavisco, eucalipto, cebolla o zumo de limón. Se toma la infusión varias veces al día o se inhalan los vahos cubriendo la cabeza con una toalla.

- Otras enfermedades infecciosas o parasitarias (1): En Velilla del Río Carrión se describe el empleo del orégano para combatir las lombrices con orégano macerado en orujo, que se frotaba sobre la garganta y la nariz, "después te servían una copita, ibas a hacer de cuerpo y salían cantidad de lombrices".

- Otros usos medicinales (2): El orégano se considera panacea para no enfermar, se mezcla con otras plantas y se toma en infusión preferentemente por las mañanas en ayunas.

\section{VETERINARIA}

- Sistema genito-urinario (1): En Alba de los Cardaños se refiere el empleo de orégano mezclado con leche azucarada para cuando los terneros no admiten bien la leche de la madre.
- Sistema respiratorio (1): En la misma localidad también se indica el empleo de infusión de orégano para combatir la tos de los terneros. Se levanta la cabeza del animal, se introduce una botella en la boca, conduciendo la infusión hacia la faringe.

\section{TóxICO Y NOCIVO}

- Venenos, insecticidas y plaguicidas (1): Se elabora en Estalaya una mixtura con orégano, aceite y sal, como ahuyentador de insectos, aplicada con un brochón por la cabeza y las patas de las vacas.

\section{SOCIAL, SIMBÓLICA Y RITUAL}

- Alucinógenas, narcóticas y fumatorias (2): Las hojas secas de orégano, bien picadas y molidas, servían como sustituto del tabaco, en ocasiones mezcladas con otras especies.

Observaciones: En San Martín de los Herreros recuerdan recoger hatillos de orégano y llevarlos a Cervera preparados para la venta. EI orégano se comercializaba en toda la comarca al ser un producto con gran demanda. En Piedrasluengas se evoca el paso de los Lebaniegos por el puerto con productos para comercializar, entre ellos el orégano.

\section{LAMIACEAE}

\section{Plectranthus scutellarioides (L.) R.Br.} Cóleo (1)

\begin{tabular}{ll|}
\hline Frecuencia de citación (FC): & 1 \\
\hline Número de usos (NU): & 2 \\
\hline Número registros de uso (RU): & 2 \\
\hline
\end{tabular}

Obtención: cultivada

Vigencia: vigente (50\%)

Usos:

ORNAMENTAL

- Adorno floral y plantas de interior (1): Se cultiva en macetas para decorar el hogar.

SOCIAL, SIMBÓLICO Y RITUAL

- Ritual de ciclo anual (1): Las mejores macetas se llevan a engalanar los altares en la fiesta del Corpus Christi.

LAMIACEAE

\section{Prunella grandiflora L.}

\section{$P$. vulgaris $\mathrm{L}$.}

Chupa (5), chupete de grillo (1) 
Prunella grandiflora: 268P, 514P

P. vulgaris: PALAB1448, 211P; 178F; 55V, 56V

Frecuencia de citación (FC):

Número de usos (NU):

Número registros de uso (RU): 13

Frecuencia Relativa de Citación (FRC): $\quad 0,08$

Índice de Importancia Cultural (IC): $\quad 0,09$

Índice de Vigencia (IV):

0,00

Obtención: silvestre

Vigencia: abandonado

\section{Conocimientos:}

\section{LÉXICO}

El nombre compuesto chupete de grillo se recoge en Matabuena y lo atribuyen a la frecuente presencia de este insecto en la planta. Otras especies reciben el mismo nombre de chupa: Ballota nigra, Pedicularis comosa, $P$. sylvatica, Primula veris y Trifolium pratense.

Usos:

ALIMENTACIÓN HUMANA

- Golosinas y masticatorias (11): Las flores se chupaban por el dulce sabor del néctar.

\section{ALIMENTACIÓN ANIMAL}

- Plantas melíferas (2): Las abejas visitan con frecuencia las flores de esta planta.

LAMIACEAE

\section{Rosmarinus officinalis $\mathrm{L}$.}

Romero (17)

146P, 394P; 173F; 119V

\begin{tabular}{lc}
\hline Frecuencia de citación (FC): & 17 \\
\hline Número de usos (NU): & 5 \\
Número registros de uso (RU): & 21 \\
\hline
\end{tabular}

Obtención: cultivada

Vigencia: vigente (33\%)

Usos:

\section{ALIMENTACIÓN HUMANA}

- Condimentos y conservantes (1): Los tallos y hojas más jóvenes y tiernas se utilizan para condimentar guisos de carne, de pollo, cerdo, conejo, paellas y sobre todo en el asado de lechazo.

\section{ALIMENTACIÓN ANIMAL}

- Plantas melíferas (4): Las abejas aprovechan el amplio periodo de floración de esta especie, es reconocida como una buena planta melífera cultivada cerca de los colmenares.

\section{MEDICINA}

- Sistema circulatorio (1): En Roscales de la Peña se indica la infusión de romero para tratar trastornos generales del aparato circulatorio.

- Sistema respiratorio (2): Para el tratamiento de catarros, gripes y resfriados se empleaba el romero en infusión o vahos.

- Musculatura y esqueleto (2): Recomendado para tratar golpes, contusiones, traumatismos o dolores de las articulaciones. Se hacían cataplasmas con la decocción de la parte aérea del romero y también se maceraba en alcohol durante unos meses para realizar friegas con el producto resultante.

\section{VETERINARIA}

- Sistema genito-urinario (4): El remedio sugerido cuando las vacas orinaban sangre era cocer romero con vino tinto y dárselo a beber al animal.

\section{ORNAMENTAL}

- Patios, huertos y jardines (7): Suele cultivarse para embellecer huertos y jardines por su vistosa y abundante floración de color azul.

LAMIACEAE

\section{Salvia officinalis L.}

Salvia (2)

369P; 119F; 119V, 251V

\begin{tabular}{|ll|}
\hline Frecuencia de citación (FC): & 2 \\
\hline Número de usos (NU): & 2 \\
\hline Número registros de uso (RU): & 4 \\
\hline
\end{tabular}

Obtención: cultivada

Vigencia: vigente (50\%)

Usos:

MEDICINA

- Sistema respiratorio (2): Con la infusión de las hojas se hacen gárgaras para aplacar el dolor de garganta, también se toma una taza en procesos catarrales.

\section{ORNAMENTAL}

- Patios, huertos y jardines (2): Posee una floración atractiva y se cultiva para la ornamentación de huertos. 
LAMIACEAE

Salvia pratensis $\mathrm{L}$.

Salvia (1)

477P, 540P; $275 \mathrm{~F}$

\begin{tabular}{lc}
\hline Frecuencia de citación (FC): & 1 \\
\hline Número de usos (NU): & 1 \\
\hline Número registros de uso (RU): & 1 \\
\hline Frecuencia Relativa de Citación (FRC): & 0,01 \\
\hline Índice de Importancia Cultural (IC): & 0,01 \\
\hline Índice de Vigencia (IV): & 0,00 \\
\hline
\end{tabular}

Obtención: silvestre

Vigencia: abandonado

Usos:

\section{MEDICINA}

- Piel y tejido celular subcutáneo (1): La parte aérea se macera durante una temporada en aceite de oliva y se aplica para cicatrizar pequeñas heridas, calmar el dolor derivado de ellas y en quemaduras leves.

LAMIACEAE

Salvia verbenaca $\mathrm{L}$.

Hierba de Santa Lucía (2), balsamina (2)

122P; 241F; 127V, 128V, 182V

\begin{tabular}{lc}
\hline Frecuencia de citación (FC): & 4 \\
\hline Número de usos (NU): & 1 \\
\hline Número registros de uso (RU): & 4 \\
\hline Frecuencia Relativa de Citación (FRC): & 0,03 \\
\hline Índice de Importancia Cultural (IC): & 0,03 \\
\hline Índice de Vigencia (IV): & 0,01 \\
\hline
\end{tabular}

Obtención: silvestre

Vigencia: vigente (25\%)

Conocimientos:

LÉXICO

El nombre de Hierba de Santa Lucía nos desvela su posible uso oftálmico, ya que Santa Lucía es la patrona de los ciegos y abogada de los problemas de la vista.

\section{Usos:}

\section{MEDICINA}

- Sistema circulatorio (1): Para la pesadez en las piernas derivada de una deficiente circulación de la sangre se toma la infusión de la parte aérea o se dan friegas con el macerado en aceite, recetas recogidas en Resoba.

- Piel y tejido celular subcutáneo (1): La parte aérea macerada en aceite se aplica como remedio cicatrizante de pequeñas heridas.
- Órganos de los sentidos (2): La semilla de esta especie tiene bastante mucilago que en contacto con el fluido del ojo se ablanda y limpia toda la superficie, eliminando alguna broza, paja o elemento extraño del mismo.

La infusión de la planta también se utiliza para lavar los ojos.

LAMIACEAE

\section{Sideritis hyssopifolia L.}

Té (83), té de roca (9), té de lastra (6), té de peña (4), té de calar (1)

PALAB1435, 49P, 133P, 460P; 68F; 131V, 186V, 195V, 200V, 240V, 244V, 276V, 299V, 308V, 349V, 449V

\begin{tabular}{lc}
\hline Frecuencia de citación (FC): & 103 \\
\hline Número de usos (NU): & 4 \\
\hline Número registros de uso (RU): & 119 \\
\hline Frecuencia Relativa de Citación (FRC): & 0,74 \\
\hline Índice de Importancia Cultural (IC): & 0,86 \\
\hline Índice de Vigencia (IV): & 0,59 \\
\hline
\end{tabular}

Obtención: silvestre

Vigencia: vigente (69\%)

\section{Conocimientos:}

LÉXICO

Se recogen varios denominaciones cuyos complementos de nombre hacen alusión al hábitat en el que se desarrolla esta especie: de roca, de lastra, de peña y de calar.

\section{Usos:}

\section{ALIMENTACIÓN HUMANA}

- Bebidas no alcohólicas (25): La parte útil son las inflorescencias que alcanzan su momento óptimo de recolección durante el mes de agosto. Con las inflorescencias se confeccionan pequeños ramilletes (atadillos) que se disponen en lugares apropiados para su secado hasta el momento de su utilización. Tradicionalmente se han empleado en forma de infusión caliente para consumirlo como bebida de desayuno o de sobremesa, siendo usuales las citas que lo comparan con la bebida del café.

En la localidad de Valcobero se recoge el testimonio del empleo del té como ingrediente base en la elaboración de una peculiar receta de sopas de pan con té "Primero migaba el pan y lo echaba en una taza. Hervía el té, lo colaba y lo juntaba con el pan y con un poco de azúcar. Lo dejaba enfriar un poco y así lo tomaba".

\section{ALIMENTACIÓN HUMANA}

- Pasto (1): Se menciona cómo los venados consumen en primavera y verano esta planta, 
provocando la disminución de las poblaciones y la reducción de la recolección disponible para los lugareños.

\section{MEDICINA}

- Sistema digestivo (85): El té es empleado para el tratamiento medicinal de cualquier mal relacionado con el aparato digestivo, útil para empachos, dolores o pesadez de estomago, gases o cólicos. Se prepara una infusión de la parte aérea de la planta y se toma una taza caliente después de las comidas para mejorar la digestión o en el momento en el que aparece el malestar.

- Sistema respiratorio (6): De igual manera, se elaboran infusiones con propiedades anticatarrales.

- Otros usos medicinales (1): En Ventanilla se aconseja como panacea la infusión de té, combinada con otras plantas (cola de caballo, grama, manzanilla calar, manzanilla campera, milenrama, orégano, sanguinaria, te, tila y tomillo) como remedio al que se le atribuyen propiedades preventivas y curativas para sobreponerse ante cualquier trastorno.

\section{VETERINARIA}

- Sistema digestivo (1): Se sugiere en Tremaya el uso de té para el tratamiento de los cólicos que afectaban a los terneros. Para ello se cocía en agua té mezclado con manzanilla (Chamaemelum nobile), una vez colado, se introducía en una botella y se administraba con gran habilidad del ganadero por la boca del animal.

Observaciones: Se trata de una especie recogida en el Catalogo de Especies Protegidas de Castilla y León, asignada en la categoría con aprovechamiento regulado, decreto 63/2007 de la Junta de Castilla y León.

En la comarca se identifican dos especies más del mismo género, Sideritis chamaedryfolia y $S$. hirsuta, sin haber podido imputarlas empleo alguno.

LAMIACEAE

Thymus mastichina (L.) L. Tomillo (11), mejorana (4)

197P, 353P; 109F; 262V, 293V

\begin{tabular}{lc}
\hline Frecuencia de citación (FC): & 15 \\
\hline Número de usos (NU): & 5 \\
\hline Número registros de uso (RU): & 20 \\
\hline Frecuencia Relativa de Citación (FRC): & $\mathbf{0 , 1 1}$ \\
\hline Índice de Importancia Cultural (IC): & $\mathbf{0 , 1 4}$ \\
\hline Índice de Vigencia (IV): & $\mathbf{0 , 0 2}$ \\
\hline
\end{tabular}

Obtención: silvestre

Vigencia: vigente (15\%)

Conocimientos:

ECOLOGÍA

Prospera en terrenos calizos.

Usos:

\section{ALIMENTACIÓN HUMANA}

- Condimentos y conservantes (5): LaS sumidades floridas se recogen en el mes de julio y una vez secas y desmenuzadas se usan para condimentar asados y guisos, común en los de conejo y en la carne de caza, dando buen olor y sabor a las comidas.

\section{MEDICINA}

- Sistema digestivo (3): La parte aérea de la planta se emplea en infusión como un buen digestivo después de las comidas.

- Sistema genito-urinario (1): En la localidad de Arbejal recomiendan tomar la infusión de la planta para trastornos y dolores menstruales.

- Sistema respiratorio (8): La parte aérea en infusión se indica para tratamiento general de resfriados y catarros.

\section{TÓXICO Y NOCIVO}

- Venenos, insecticidas y plaguicidas (1): Para ahuyentar los chinches en los nidos de las palomas se colocaba unas ramitas de tomillo dentro de ellos.

\section{COMBUSTIBLE}

- Para ahumar (1): Cuando escaseaba el incienso en la iglesia de Arbejal, el cura ordenaba al monaguillo durante la consagración quemar la parte aérea desmenuzada en una pequeña naveta, desprendiendo un intenso olor similar al incienso.

\section{MEDIOAMBIENTAL}

- Mejora del suelo (1): Se cortaban unas ramas para que las palomas pudieran acomodarse los nidos. 
LAMIACEAE

Thymus praecox Opiz

Tomillo (6), hierba de la sabina (1), té (1)

124P, 353P; 77F; 74V, 75V, 187V, 188V, 189V, 350V

\begin{tabular}{lc}
\hline Frecuencia de citación (FC): & 8 \\
\hline Número de usos (NU): & 3 \\
\hline Número registros de uso (RU): & 11 \\
\hline Frecuencia Relativa de Citación (FRC): & 0,06 \\
\hline Índice de Importancia Cultural (IC): & 0,08 \\
Índice de Vigencia (IV): & 0,01 \\
\hline
\end{tabular}

Obtención: silvestre

Vigencia: vigente (18\%)

Usos:

ALIMENTACIÓN HUMANA

- Condimentos y conservantes (3): Se reconoce como una planta condimentaria de uso popular, que se incorpora como ingrediente para aromatizar y condimentar en diferentes recetas de cocina, sobre todo guisos y asados. Se utiliza la parte aérea, recolectada desde principios de verano aprovechando la plena floración de la planta. Una vez recolectada, se seca y se tritura, dispuesta en tarros para su conservación.

\section{ALIMENTACIÓN ANIMAL}

- Plantas melíferas (1): Se observa a las abejas frecuentar esta especie en la época de floración.

\section{MEDICINA}

- Sistema digestivo (5): Empleada la parte aérea en el tratamiento general de problemas digestivos. Se ha mencionado su administración mediante infusión para aliviar dolores estomacales e indigestiones.

- Sistema genito-urinario (2): En Resoba, la infusión de esta planta se emplea para combatir el dolor del periodo o para cualquier otro desarreglo menstrual.

En Nava de Santullán se denomina hierba de la sabina y se utiliza en infusión para tratar infecciones urinarias.

Thymus pulegioides L.

Hierba de la cólica (1)

201P, 308P; 51F; 133V, 545V

\begin{tabular}{lc}
\hline Frecuencia de citación (FC): & 1 \\
\hline Número de usos (NU): & 1 \\
\hline Número registros de uso (RU): & 1 \\
\hline Frecuencia Relativa de Citación (FRC): & 0,01 \\
\hline Índice de Importancia Cultural (IC): & 0,01 \\
\hline Índice de Vigencia (IV): & 0,00 \\
\hline
\end{tabular}

Obtención: silvestre

Vigencia: abandonado

Conocimientos:

LÉXICO

El nombre recogido en la localidad de Ventanilla, hierba de la cólica, ya hace alusión a sus virtudes digestivas.

\section{Usos:}

MEDICINA

- Sistema digestivo (1): Se administran 2 o 3 tazas de infusión caliente de la parte aérea para mitigar dolores digestivos fuertes, indigestiones o cólicos.

\section{LAMIACEAE}

Thymus zygis $\mathrm{L}$.

Tomillo (29), cepico (1)

112P; 203F; 44V, 207V, 351V, 472V, 563V

\begin{tabular}{lc}
\hline Frecuencia de citación (FC): & 30 \\
\hline Número de usos (NU): & 5 \\
\hline Número registros de uso (RU): & 44 \\
\hline Frecuencia Relativa de Citación (FRC): & $\mathbf{0 , 2 2}$ \\
\hline Índice de Importancia Cultural (IC): & $\mathbf{0 , 3 2}$ \\
\hline Índice de Vigencia (IV): & $\mathbf{0 , 0 9}$ \\
\hline
\end{tabular}

Obtención: silvestre

Vigencia: vigente (28\%)

Conocimientos:

LÉXICO

En Otero de Guardo se reconoce esta planta con el nombre de zepico.

Usos:

ALIMENTACIÓN HUMANA

- Condimentos y conservantes (21): Valorado como condimento para asados y guisos. Se recolecta la parte aérea tras la floración, se deja secar, se desmenuza y se guarda en tarros para su mejor conservación.

\section{MEDICINA}

- Sistema genito-urinario (1): En Villanueva de Arriba recomiendan la infusión de la planta para prevenir afecciones prostáticas. 
- Sistema respiratorio (17): Se emplea para combatir catarros y dolores de garganta, mediante infusiones $o$ sahumerios para descongestionar los bronquios.

- Otros usos medicinales (1): Mezclada con otras plantas para potenciar sus virtudes, se considera panacea para prevenir y curar cualquier dolencia.

\section{TóXICO Y NOCIVO}

- Venenos, insecticidas y plaguicidas (1): En Polentinos aconsejan colocar ramas de tomillo cerca de los comederos de los cerdos, pues servían como ahuyentador de las ratas.

\section{COMBUSTIBLE}

- Para ahumar (2): Para ahumar las colmenas se quemaba tomillo, de este modo las abejas descuidaban el panal y se podía catar la miel. En San Martín de los Herreros se hacía el día de San Pedro (29 junio).

\section{MEDIOAMBIENTAL}

- Mejora del suelo (1): Se cortaban ramas para los nidos de las palomas.

\section{LAURACEAE}

\section{Cinnamomum verum J.Pres|}

Canela (3)

\begin{tabular}{ll}
\hline Frecuencia de citación (FC): & 3 \\
\hline Número de usos (NU): & 1 \\
\hline Número registros de uso (RU): & 3 \\
\hline
\end{tabular}

Obtención: comprada

Vigencia: vigente (100\%)

Usos:

\section{ALIMENTACIÓN HUMANA}

- Condimentos y conservantes (3): Se emplea para dar sabor a los orujos, ingrediente habitual del licor de endrinas. También se utiliza en repostería.

\section{LAURACEAE}

Laurus nobilis L.

Laurel (28)

86P; 243F; 116V, 234V

\begin{tabular}{|lc|}
\hline Frecuencia de citación (FC): & 30 \\
\hline Número de usos (NU): & 4 \\
\hline Número registros de uso (RU): & 36 \\
\hline
\end{tabular}

Obtención: cultivada, comprada
Vigencia: vigente (42\%)

Usos:

\section{ALIMENTACIÓN HUMANA}

- Condimentos y conservantes (12): Las hojas secas se utilizan como condimento en la cocina tradicional, presente en numerosas recetas de guisos, sopas, cocidos, etc.

\section{INDUSTRIA Y ARTESANÍA}

- Sustancias tintóreas y pinturas (1): En Polentinos se cita el cocimiento de hojas de laurel para desteñir la ropa, se sumerge la prenda en un barreño con la cocción tibia y se deja unas horas hasta que desaparece.

\section{ORNAMENTAL}

- Patios, huertos y jardines (3): Aparece en huertos $\mathrm{y}$ en macetas en los patios como ornamental.

\section{SOCIAL, SIMBÓLICA Y RITUAL}

- Ritual de ciclo anual (20): El ramo de laurel ha sustituido en la actualidad a otras plantas como acebo o tejo, menos accesibles y en algunos casos con limitaciones de aprovechamiento, como planta para bendecir en la iglesia el día de Domingo de Ramos.

LEGUMINOSAE

\section{Adenocarpus complicatus (L.) Gay}

Ulaga (3), ulaja (1)

\begin{tabular}{lc} 
31P, 387P; 32F; 388V & \\
\hline Frecuencia de citación (FC): & 4 \\
\hline Número de usos (NU): & 1 \\
\hline Número registros de uso (RU): & 4 \\
\hline Frecuencia Relativa de Citación (FRC): & $\mathbf{0 , 0 3}$ \\
\hline Índice de Importancia Cultural (IC): & 0,03 \\
\hline Índice de Vigencia (IV): & 0,01 \\
\hline
\end{tabular}

Obtención: silvestre

Vigencia: vigente (25\%)

Usos:

INDUSTRIA Y ARTESANÍA

- Cosmética, perfumería y limpieza (1): Una mujer de Recueva de la Peña cuelga ramos florecidos de esta planta en el patio de su casa, por el olor intenso y agradable que desprenden.

- Herramientas y utensilios (3): Con las ramas de las ulagas se elaboran excelentes escobas resistentes y duraderas para barrer el grano, el patio, la cuadra, etc. 
LEGUMINOSAE

Anthyllis vulneraria $\mathrm{L}$.

\begin{tabular}{lc}
\hline 511P; 99V & \\
\hline Frecuencia de citación (FC): & 1 \\
\hline Número de usos (NU): & 1 \\
\hline Número registros de uso (RU): & 1 \\
Frecuencia Relativa de Citación (FRC): & 0,01 \\
\hline Índice de Importancia Cultural (IC): & 0,01 \\
\hline Índice de Vigencia (IV): & 0,00 \\
\hline
\end{tabular}

Obtención: silvestre

Vigencia: abandonado

Usos:

ALIMENTACIÓN HUMANA

- Golosinas y masticatorias (1): En San Salvador de Cantamuda afirman que las flores se chupaban porque tenían un sabor dulce, aunque desconocen el nombre de la planta.

LEGUMINOSAE

\section{Cicer arietinum L.}

Garbanzo (64)

\begin{tabular}{lc}
$85 \mathrm{P} ; 512 \mathrm{~V}$ \\
\hline Frecuencia de citación (FC): & 64 \\
\hline Número de usos (NU): & 3 \\
\hline Número registros de uso (RU): & 71 \\
\hline
\end{tabular}

Obtención: cultivada

Vigencia: vigente (25\%)

Conocimientos:

LÉXICO

El fruto recibe el nombe de jaruga.

Usos:

\section{ALIMENTACIÓN HUMANA}

- Legumbres (65): El garbanzo era un alimento muy importante en la cocina tradicional de la zona, consumidos de forma común en cocidos, acompañados de berza y carne. Se preparan el día anterior remojándolos en agua para reducir su periodo de cocción. Se tomaba el cocido un día asignado en la semana y sobre todo días especiales de celebraciones o fiestas locales y religiosas.

Los más jóvenes gustaban de comer los garbanzos en verde sin dejarlos madurar por completo.

\section{ALIMENTACIÓN ANIMAL}

- Forraje verde o seco (5): La paja de garbanzos se consideraba muy nutritiva y se servía a ovejas y vacas.

\section{CONSTRUCCIÓN}

- Casas, edificios e instalaciones agropecuarias (1): En Matabuena una vez hecha la recolección se utilizaban los matas secas para asentar las tejas en las edificaciones.

Observaciones: La recolección se realizaba a mano y por lo general no se trillaban, sino que se arrancaba y abría la vaina a mano, proceso denominado "esjerugar".

LEGUMINOSAE

\section{Cytisus oromediterraneus (Boiss.) Ball}

Escoba hornil (10), escoba (3)

72P, 346P; 299F; 153V, 154V, 227V, 228V, 400V, 401V

\begin{tabular}{|lc|}
\hline Frecuencia de citación (FC): & 13 \\
\hline Número de usos (NU): & 4 \\
\hline Número registros de uso (RU): & 21 \\
\hline Frecuencia Relativa de Citación (FRC): & 0,09 \\
\hline Índice de Importancia Cultural (IC): & 0,15 \\
\hline Índice de Vigencia (IV): & 0,02 \\
\hline
\end{tabular}

Obtención: silvestre

Vigencia: vigente (11\%)

\section{Conocimientos:}

LÉXICO

Las ramas verdes empleadas para forraje del ganado se llaman ramón o rohíjo.

Usos:

ALIMENTACIÓN ANIMAL

- Forraje verde o seco (4): Se cortaban ramas al final del verano para servir como forraje durante el invierno tanto a ovejas como a cabras.

- Pasto (1): El día de San Lorenzo (10/08) en Valcobero se llevaban al monte las ovejas para que pacieran la legumbre de esta especie, pues la consideraban de gran calidad para el engorde del animal.

\section{COMBUSTIBLE}

- Encendido (13): Las ramas secas se usan para encender la lumbre. En Otero de Guardo recuerdan la preferencia por esta especie para el encendido por parte de los panaderos y de los pastores en los chozos.

- Para chamuscar (1): En Alba de los Cardaños se emplean las ramas secas para quemar el pelo de la piel del cerdo durante la matanza.

\section{CONSTRUCCIÓN}


- Casas, edificios e instalaciones agropecuarias (1): La techumbre de los chozos de pastor situados en los puertos de montaña se realizaba a base de escoba hornil, más tupida y compacta que el resto de escobas.

\section{ORNAMENTAL}

- Adorno floral y plantas de interior (1): Los ramos florecidos desprenden un agradable olor y en Vidrieros se ubican en las viviendas como ambientador natural.

Observaciones: La escoba hornil (Cytisus oromediterraneus) tiene mayor presencia en la zona occidental de la comarca. Algunas diferencias mencionadas por los informantes entre este tipo de escoba y el resto (Cytisus scoparius, Genista florida y G. obtusiramea) presentes en la zona son : flores más pequeñas y de aroma agradable, y porte más bajo y compacto de la planta.

LEGUMINOSAE

Cytisus scoparius (L.) Link.

Escoba (92), ramo (26), escoba balera (3), escoba barredera (2), escoba serraniega (2), escoba chiflona (1)

PALAB1432, 20P, 130P; 7F; 17V, 18V, 19V, 107V, $211 \mathrm{~V}, 212 \mathrm{~V}, 310 \mathrm{~V}, 336 \mathrm{~V}, 460 \mathrm{~V}, 481 \mathrm{~V}, 522 \mathrm{~V}, 581 \mathrm{~V}$

\begin{tabular}{lc}
\hline Frecuencia de citación (FC): & 126 \\
\hline Número de usos (NU): & 7 \\
\hline Número registros de uso (RU): & 243 \\
\hline Frecuencia Relativa de Citación (FRC): & $\mathbf{0 , 9 1}$ \\
\hline Índice de Importancia Cultural (IC): & 1,75 \\
\hline Índice de Vigencia (IV): & $\mathbf{0 , 4 2}$ \\
\hline
\end{tabular}

Obtención: silvestre

Vigencia: vigente (24\%)

\section{Conocimientos:}

\section{LÉXICO}

Bajo el nombre de escoba, se reconoce en la zona varias especies, todas ellas de aspecto arbustivo retamoide (Cytisus cantabricus, C. oromediterraneus, C. scoparius, Genista florida y G. obtusiramea).

El nombre de escoba serraniega solo fue mencionado en la localidad de Salcedillo y el de escoba chiflona en la localidad de Alba de los Cardaños.

Las flores se conocen con el nombre de "zapatitos de la Virgen". Ordeñar las flores significaba recolectarlas rodeando el ramo con la mano y haciéndolas correr a lo largo del mismo hasta desprenderlas.
En la zona encontramos varios fitotopónimos: "Arroyo del Escobar" en Vallejo de Orbó y Cillamayor, los pagos de "Los Escobales" en Villabellaco, "Escobal" en Barruelo de Santullán, Brañosera y Salinas de Pisuerga, "El Escobal de la Gallega" en San Salvador de Cantamuda, y "Los Escobalones" en San Felices de Castillería.

Usos:

ALIMENTACIÓN ANIMAL

- Pasto (2): Las cabras aprovechan los brotes verdes más tiernos en el inicio de la primavera. Otros animales consumen las semillas en el momento en el que la legumbre se seca y se abre.

- Plantas melíferas (6): La abundante floración primaveral de la escoba es explotada por las abejas. En Villanueva de Arriba, indican que es de las primeras plantas en florecer en primavera y de las más productivas y beneficiosas para las abejas.

\section{COMBUSTIBLE}

- Leña (2): Los ejemplares más grandes se destinan para quemar en la lumbre o para el horno de cocer el pan. En Salvador de Cantamuda, nos explican cómo en ocasiones se echaban, incluso, ramas verdes al horno para mantener controlado el fuego y no quemar los panes.

- Encendido (107): Las ramas secas de esta especie tienen la cualidad de prender rápidamente y se procura tener siempre disponibles para encender el fuego de la cocina o el horno del pan. Se recogían por lo común en el mes de septiembre, una vez terminadas las tareas del campo.

- Para chamuscar (10):. Una vez desangrado el cerdo en la matanza, se le quema con escobas, que tienen la ventaja de producir buena llama y no trasmitir olor a la carne.

\section{CONSTRUCCIÓN}

- Casas, edificios e instalaciones agropecuarias (10): Los chozos son construcciones que empleaban los pastores como refugio, la techumbre de ellos se fabricaba a base de un entramado de escobas.

\section{INDUSTRIA Y ARTESANÍA}

- Herramientas y utensilios (44): La escoba artesanal es uno de los utensilios más demandados en cualquier hogar de la comarca. Especialmente útil para barrer zonas irregulares como las portadas de las casas, patios, cuadras, etc. Para su confección, primero se corta un 
manojo de ramas y se prensan por uno de los extremos, posteriormente con un alambre o con una ramita larga y flexible de la propia escoba se abraza el extremo prensado, anudando de esta forma las ramas, por último se corta por encima de la atadura y se introduce en el centro un palo de la medida deseada, a modo de mango. Una vez se seca, queda lista para su uso.

\section{MEDIOAMBIENTAL}

- Malas hierbas (1): Se indica a la escoba como objetivo a erradicar en tierras en barbecho $y$ pastos cercanos al monte, terrenos propicios para su expansión y consiguiente reducción de la superficie de cultivo.

- Predicción del tiempo (1): La floración invernal de esta planta, por otro lado inusual, predice nevadas abundantes, según un informante de Valsurbio.

\section{ORNAMENTAL}

- Adorno floral y plantas de interior (5): Las escobas producen abundantes y espléndidas floraciones de color amarillo durante la primavera, señaladas para adornar jarrones en el cementerio o en el interior de la vivienda.

\section{SOCIAL, SIMBÓLICA Y RITUAL}

- Ritual de ciclo anual (55): Todos los años coincidiendo con la festividad del Corpus Christi, muchos vecinos se volcaban en la recolección de flores, entre ellas las de la escoba, para engalanar las calles al paso de la procesión religiosa. En algunas zonas, las flores se conocen con el nombre de "zapatitos de la Virgen".

Observaciones: En Ventanilla se señala que las personas con pocos recursos económicos, cortaban escobas que se vendían en Cervera de Pisuerga, como leña de encendido.

LEGUMINOSAE

\section{Genista florida L.}

Escoba (29), escoba albar (14), escoba albera (6), ramón (3), ramón albar (2)

\begin{tabular}{lc} 
PALAB1444, 25P, 290P; 9F; 27V, 203V, 463V, & $525 \mathrm{~V}$ \\
\hline Frecuencia de citación (FC): & 54 \\
\hline Número de usos (NU): & 6 \\
Número registros de uso (RU): & $\mathbf{8 2}$ \\
\hline Frecuencia Relativa de Citación (FRC): & $\mathbf{0 , 3 9}$ \\
Índice de Importancia Cultural (IC): & $\mathbf{0 , 5 9}$ \\
Índice de Vigencia (IV): & $\mathbf{0 , 1 3}$ \\
\hline
\end{tabular}

Obtención: silvestre

Vigencia: vigente (22\%)

\section{Conocimientos:}

\section{LÉXICO}

Las ramas verdes utilizadas como forraje verde se conocen popularmente con el nombre de rohíjo y servía además para que los animales realizaran una masticación más pausada.

Usos:

\section{ALIMENTACIÓN ANIMAL}

- Forraje verde o seco (11): Al final del verano se cortan ramas verdes como complemento a la alimentación del ganado, principalmente ovejas y cabras. Se almacenaba en el pajar, dispuesto para su utilización en los meses más fríos.

- Plantas melíferas (2): La especie resulta de gran interés apícola, pudiéndose observar con frecuencia la presencia de abejas, entre la copiosa producción floral de esta especie.

\section{COMBUSTIBLE}

- Leña (12): La escoba albar desarrolla un tronco robusto que es mencionado como leña para el hogar y especialmente valorado para el horno de cocer el pan por su poder calorífico.

- Encendido (34): Se emplean las ramas secas para el encendido de la lumbre.

\section{CONSTRUCCIÓN}

- Casas, edificios e instalaciones agropecuarias (5): Esta especie de escoba era estimada por los pastores de la zona. Por un lado, empleaban los ramos en verde, como aislante para mullir el suelo $o$ el camastro del chozo donde pernoctaban, era preferida a las escobas del género Cytisus, menos confortables para descansar. Por otro lado, los ramos servían para cubrir el chozo y aislarlo del agua, en algunos casos se remataban las techumbres con planchas de césped para mejorar la impermeabilización. También se empleó para techar otras construcciones como corrales o tenadas

\section{INDUSTRIA Y ARTESANÍA}

- Herramientas y utensilios (4): Se confeccionan escobas rudimentarias con las ramas verdes, una vez secas son útiles para barrer suelos con tierra.

En Resoba señalan la calidad de la madera para elaborar los dientes de los rastros y cachavas.

- Vestimenta y adornos personales (9): La madera de escoba albar posee la cualidad de ser muy dura, referida para la elaboración de los tarugos o machorras (piezas de madera 
sobre las que se apoyan las albarcas y que permiten recambio tras el desgaste).

\section{ORNAMENTAL}

- Adorno floral y plantas de interior (1): Durante la primavera, la floración de la escoba albar tiñe de amarillo amplias áreas. En Triollo se cortan ramos de flores frescas para decoración de la vivienda.

\section{SOCIAL, SIMBÓLICA Y RITUAL}

- Ritual de ciclo anual (4): Las flores se utilizaban en la festividad anual del Corpus Christi para ornamentar las calles y altares.

LEGUMINOSAE

\section{Genista hispanica L.}

Argoma (3), ulaga (3)

\begin{tabular}{lc} 
83P, 136P; 298F; 28V, 29V & \\
\hline Frecuencia de citación (FC): & 6 \\
\hline Número de usos (NU): & 3 \\
\hline Número registros de uso (RU): & $\mathbf{8}$ \\
\hline Frecuencia Relativa de Citación (FRC): & $\mathbf{0 , 0 4}$ \\
\hline Índice de Importancia Cultural (IC): & $\mathbf{0 , 0 6}$ \\
\hline Índice de Vigencia (IV): & $\mathbf{0 , 0 0}$ \\
\hline
\end{tabular}

Obtención: silvestre

Vigencia: abandonado

\section{ALIMENTACIÓN ANIMAL}

- Plantas melíferas (1): Las abejas visitan las flores de esta especie.

\section{COMBUSTIBLE}

- Leña (5): Se corta la planta para quemar en la lumbre, especialmente indicado para calentar el horno del pan por su gran poder calorífico.

- Para ahumar (1): El humo desprendido al encender una rama es muy denso y se utiliza en Lores para ahumar trabajos o tallas en madera, quedando de este modo impreso el diseño deseado.

\section{INDUSTRIA Y ARTESANÍA}

- Herramientas y utensilios (1): Con las ramas se fabrican en Alba de los Cardaños escobas fuertes y resistentes.

\section{Genista obtusiramea Spach}

LEGUMINOSAE

Escoba cabrera (4), escoba de la cuesta (1), escoba de rohíjo (1)

\begin{tabular}{lc}
\hline Frecuencia de citación (FC): & 6 \\
\hline Número de usos (NU): & 3 \\
\hline Número registros de uso (RU): & 10 \\
\hline Frecuencia Relativa de Citación (FRC): & $\mathbf{0 , 0 4}$ \\
\hline Índice de Importancia Cultural (IC): & $\mathbf{0 , 0 7}$ \\
\hline Índice de Vigencia (IV): & $\mathbf{0 , 0 1}$ \\
\hline
\end{tabular}

Obtención: silvestre

Vigencia: vigente (20\%)

Conocimientos:

LÉXICO

Los palos secos se denominan sarojos en la localidad de Valcobero.

Usos:

\section{ALIMENTACIÓN ANIMAL}

- Forraje verde o seco (4): Cuando se finalizaba la temporada de laboreo en el campo, hacia finales de septiembre, se iba a por ramas de este tipo de escobas porque servían durante el invierno como forraje a ovejas y cabras.

\section{COMBUSTIBLE}

- Leña (4): Arden muy bien las ramas secas para encender la lumbre. En Valcobero recuerdan cocer las morcillas con la leña de esta especie.

\section{CONSTRUCCIÓN}

- Casas, edificios e instalaciones agropecuarias (2): La cubierta de los chozos de pastores se realizaba con un entramado de ramas, y los camastros que utilizaban para dormir se acolchaban con ramas verdes de esta especie.

LEGUMINOSAE

Genista scorpius L.

Ulaga (7), abrojo (4)

\begin{tabular}{lc} 
75P, 301P; 136F; 338V, 464V & \\
\hline Frecuencia de citación (FC): & 11 \\
\hline Número de usos (NU): & $\mathbf{2}$ \\
\hline Número registros de uso (RU): & 11 \\
\hline Frecuencia Relativa de Citación (FRC): & $\mathbf{0 , 0 8}$ \\
\hline Índice de Importancia Cultural (IC): & $\mathbf{0 , 0 8}$ \\
\hline Índice de Vigencia (IV): & $\mathbf{0 , 0 0}$ \\
\hline
\end{tabular}

Obtención: silvestre

Vigencia: abandonado

\section{Conocimientos:}

\section{LÉXICO}

En Porquera de Santullán se encuentra el pago "Los Abrojales" y en Recueva de la Peña el de "Los Abrojos". 


\section{COMBUSTIBLE}

- Leña (10): Servía de leña de buena calidad para la lumbre y para los hornos de los panaderos ya que la llama que desprendía tenía mucha viveza y calentaba el horno rápidamente. A pesar del inconveniente que supone su carácter espinoso para ser recolectada, tiene muy buena consideración por su gran poder calorífico.

\section{CONSTRUCCIÓN}

- Cercas, tapias y vallas (1): Al ser una especie muy espinosa, en Nava de Santullán en los remates de las tapias de patios o corrales se solían poner sujetas con barro, para evitar que personas o animales accedieran al interior.

LEGUMINOSAE

\section{Genista tridentata L.}

\section{Carquesa (1)}

269P, 313P; 157F; 433V

\begin{tabular}{lc}
\hline Frecuencia de citación (FC): & 1 \\
\hline Número de usos (NU): & 1 \\
Número registros de uso (RU): & 2 \\
\hline Frecuencia Relativa de Citación (FRC): & 0,01 \\
Índice de Importancia Cultural (IC): & 0,01 \\
\hline Índice de Vigencia (IV): & 0,00 \\
\hline
\end{tabular}

Obtención: silvestre

Vigencia: abandonado

Usos:

ALIMENTACIÓN ANIMAL

- Forraje verde o seco (1): En Valcolbero se cortaba esta especie para forraje de ovejas y cabras durante el invierno.

- Pasto (1): Lo pastan tanto ovejas como vacas.

\section{LEGUMINOSAE}

\section{Lathyrus cicera $\mathrm{L}$.} Titarro (13)

\begin{tabular}{lc}
\hline Frecuencia de citación (FC): & 13 \\
\hline Número de usos (NU): & 3 \\
\hline Número registros de uso (RU): & 18 \\
\hline
\end{tabular}

Obtención: cultivada

Vigencia: abandonado

Usos:

ALIMENTACIÓN HUMANA

- Legumbres (2): Los años de escasez de harina de trigo, se elaboraba en Villanueva de la Torre la masa del pan con mezclas de otras harinas, entre ellas la de titarro.

Los niños comían las semillas en verde, sin dejar completar su maduración.

\section{ALIMENTACIÓN ANIMAL}

- Forraje verde o seco (2): La paja para ovejas y vacas era muy valorada, de las de mayor aporte alimenticio, denominada paja negra.

- Pienso (14): Se cultivaban titarros que se servían en crudo para ovejas y molidos para vacas y ovejas.

\section{LEGUMINOSAE}

\section{Lathyrus latifolius L.}

Arvejana (2)

\begin{tabular}{lc}
\hline $410 \mathrm{P}$ & \\
\hline Frecuencia de citación (FC): & $\mathbf{2}$ \\
\hline Número de usos (NU): & $\mathbf{1}$ \\
\hline Número registros de uso (RU): & $\mathbf{2}$ \\
\hline Frecuencia Relativa de Citación (FRC): & $\mathbf{0 , 0 1}$ \\
\hline Índice de Importancia Cultural (IC): & $\mathbf{0 , 0 1}$ \\
\hline Índice de Vigencia (IV): & $\mathbf{0 , 0 0}$ \\
\hline
\end{tabular}

Obtención: silvestre

Vigencia: abandonado

Conocimientos:

ECOLOGÍA

Se desarrolla en cunetas, linderas y orillas de caminos.

Usos:

ORNAMENTAL

- Adorno floral y plantas de interior (2): Se recogen ramos durante la época de floración para colocar en jarrones con agua. Las flores rosas son de gran belleza pero tienen como inconveniente una corta duración.

LEGUMINOSAE

Lathyrus sativus L.

Tito (47), tito esquinado (10), muela (4)

67P; 38F; 516V

\begin{tabular}{|lc|}
\hline Frecuencia de citación (FC): & 61 \\
\hline Número de usos (NU): & 2 \\
\hline Número registros de uso (RU): & 97 \\
\hline
\end{tabular}

Obtención: cultivada

Vigencia: vigente (3\%)

Usos:

ALIMENTACIÓN HUMANA 
- Legumbres (57): Los más mayores recuerdan ir al titar en su juventud a recogerlos en verde, se aprovechaban los granos inmaduros, apreciados por su agradable sabor un tanto dulce.

Su empleo principal en la cocina fueron las semillas o granos secos, servidos en forma de potajes, con un sabor parecido al garbanzo. En épocas de escasez pasó a formar un elemento fundamental en la dieta diaria de las familias más humildes y se asociaba su consumo a pobreza, ya que el destino principal del cultivo era convertirse en pienso para el ganado.

Se siembran en el mes de mayo y se recogen en octubre, si la superficie de cultivo era grande se trillaban, sino se desgranaban manualmente, poco a poco, durante el invierno.

\section{ALIMENTACIÓN ANIMAL}

- Forraje verde o seco (8): La paja aunque de escasa producción también se aprovecha como alimento, se aprecia por su alto valor proteico, y en la comarca se la conoce como paja negra (paja de leguminosas: arvejas, titarros, titos, yeros...). Con ella se afirma que las ovejas aumentaban la producción de leche.

- Pienso (32): El principal aprovechamiento lo constituyen las semillas que enteras o molidas sirven de pienso a los animales, principalmente para vacas, ovejas, cabras y ocasionalmente cerdos

Observaciones: Esta leguminosa resultó ser un cultivo importante en la zona en la época de la posguerra española, desde entonces ha ido retrocediendo paulatinamente su transcendencia, hasta convertirse en la actualidad en un cultivo residual prácticamente perdido. Su ingestión prolongada produce latirismo, enfermedad que provoca parálisis y trastornos en el sistema nervioso. Se manifiesta a causa del consumo casi exclusivo de esta legumbre en la dieta diaria de una persona. En la época posterior a la Guerra Civil se produjeron muchos casos en distintas zonas de España, lo que llevó al gobierno de entonces a prohibir su consumo. Paradójicamente, los casos de latirismo documentados en las provincias Burgos y Palencia fueron reducidos. Se ha observado en algún huerto de Cillamayor y Matabuena, donde se dedica algún pequeño surco para su cultivo.

LEGUMINOSAE

\section{Lathyrus tuberosus L.}

Lonceja (6), castaña pilonga (3), pilonga (3), castaña (1)

255P; 482F; 38V, 39V, 40V, 41V

\begin{tabular}{lc}
\hline Frecuencia de citación (FC): & 13 \\
\hline Número de usos (NU): & 1 \\
\hline Número registros de uso (RU): & 13 \\
\hline Frecuencia Relativa de Citación (FRC): & 0,09 \\
\hline Índice de Importancia Cultural (IC): & 0,09 \\
\hline Índice de Vigencia (IV): & 0,00 \\
\hline
\end{tabular}

Obtención: silvestre

Vigencia: abandonado

\section{Conocimientos:}

\section{ECOLOGÍA}

Aparece en las orillas de las lastras, en linderas y en las tierras que se araban, pero sobre todo se cita su presencia en los cultivos de lino.

\section{LÉXICO}

Los nombres de castaña y pilonga se recogen en la parte más septentrional de la comarca, mientras que lonceja en la más meridional, resultando además un término propio y endémico de esta zona.

Usos:

\section{ALIMENTACIÓN HUMANA}

- Golosinas y masticatorias (13): Se recolecta el tubérculo en primavera, aprovechando las labores agrícolas en las tierras de cultivo. Se consume directamente en el campo, previamente se limpia la tierra y se pela, recordando su aspecto a pequeñas patatas arrugadas y su sabor al de una castaña dulce.

LEGUMINOSAE

Lens culinaris Medik. Lenteja (19)

\begin{tabular}{lc|}
\hline Frecuencia de citación (FC): & 19 \\
\hline Número de usos (NU): & 1 \\
\hline Número registros de uso (RU): & 19 \\
\hline
\end{tabular}

Obtención: cultivada, comprada

Vigencia: vigente (21\%)

Usos:

ALIMENTACIÓN HUMANA

- Legumbres (19): Se sembraban unos pocos surcos de lentejas en algunas huertas de la zona para autoconsumo en el núcleo familiar. Se emplean en guisos acompañados con morcilla o/y chorizo. 
LEGUMINOSAE

Lotus corniculatus L.

Zapatitos del Niño Jesús (1)

\begin{tabular}{lc}
\hline $339 P$ & \\
\hline Frecuencia de citación (FC): & 1 \\
\hline Número de usos (NU): & 1 \\
\hline Número registros de uso (RU): & 1 \\
\hline Frecuencia Relativa de Citación (FRC): & $\mathbf{0 , 0 1}$ \\
\hline Índice de Importancia Cultural (IC): & $\mathbf{0 , 0 1}$ \\
\hline Índice de Vigencia (IV): & $\mathbf{0 , 0 0}$ \\
\hline
\end{tabular}

Obtención: silvestre

Vigencia: abandonado

Conocimientos:

LÉXICO

Denominan zapatitos de Jesús a la planta y sobre todo a las flores por su forma que recuerda al de un pequeño zapato.

Usos:

ALIMENTACIÓN ANIMAL

- Pasto (1): La planta en verde la consumen vacas y ovejas.

LEGUMINOSAE

Lupinus albus L. Chocho (24)

\begin{tabular}{|lc|}
\hline Frecuencia de citación (FC): & 24 \\
\hline Número de usos (NU): & 4 \\
\hline Número registros de uso (RU): & 34 \\
\hline
\end{tabular}

Obtención: cultivada

Vigencia: abandonado

Usos:

ALIMENTACIÓN HUMANA

- Legumbres (8): Se consumen las semillas cocidas o crudas, previamente desamargadas.

\section{ALIMENTACIÓN ANIMAL}

- Pienso (24): Los granos con alto valor proteico son muy valorados para el engorde del ganado, se sirven en forma de grano seco una vez desamargado o molido en forma de harina.

\section{MEDICINA}

- Otras enfermedades infecciosas y parasitarias (2): El líquido resultante de la cocción de los chochos se empleaba para combatir las infecciones provocadas por piojos, se diluía con un poco de agua para reducir su concentración y se aclaraba el cabello, desapareciendo los parásitos de inmediato.
Observaciones: El proceso de desamargado, por lo general, se llevaba a cabo en el río o arroyo más cercano a la vivienda, se rellenaba un saco con granos y se sumergía al menos un par de días en el agua.

\section{LEGUMINOSAE}

Medicago sativa $\mathrm{L}$.

Mielga (11), alfalfa (8)

110P, 529P; 142F; 466V

\begin{tabular}{lc}
\hline Frecuencia de citación (FC): & 19 \\
\hline Número de usos (NU): & 1 \\
\hline Número registros de uso (RU): & 20 \\
\hline Frecuencia Relativa de Citación (FRC): & 0,14 \\
\hline Índice de Importancia Cultural (IC): & 0,14 \\
\hline Índice de Vigencia (IV): & 0,01 \\
\hline
\end{tabular}

Obtención: silvestre, cultivada

Vigencia: vigente (10\%)

Conocimientos:

LÉXICO

Aunque se trata de la misma especie, cuando es cultivada se denomina alfalfa y cuando aparece silvestre mielga.

En Ligüerzana se encuentra el pago “Melgares”.

Usos:

ALIMENTACIÓN ANIMAL

- Forraje verde o seco (19): Se cultiva como una excelente planta forrajera para vacas.

Silvestre se recoge de linderas y orillas de caminos y sirve también como forraje, para conejos y gallinas.

- Plantas melíferas (1): Las abejas pecorean el néctar de las flores.

\section{LEGUMINOSAE}

Melilotus officinalis (L.) Pall. Meliloto (1)

449P, 541P; $128 \mathrm{~F}$

\begin{tabular}{lc}
\hline Frecuencia de citación (FC): & 1 \\
\hline Número de usos (NU): & 1 \\
\hline Número registros de uso (RU): & 1 \\
\hline Frecuencia Relativa de Citación (FRC): & 0,01 \\
\hline Índice de Importancia Cultural (IC): & 0,01 \\
\hline Índice de Vigencia (IV): & 0,00 \\
\hline
\end{tabular}

Obtención: silvestre

Vigencia: abandonado

Usos:

MEDICINA 
- Sistema respiratorio (1): La parte aérea se usa en Celada de Roblecedo para hacer infusiones que alivian el catarro.

LEGUMINOSAE

Onobrychis viciifolia Scop.

Esparceta (3)

228F

Frecuencia de citación (FC): 3

Número de usos (NU):

Número registros de uso (RU):

1

Obtención: cultivada

Vigencia: abandonado

Usos:

\section{ALIMENTACIÓN ANIMAL}

- Forraje verde o seco (4): Se cultiva como forraje verde para las vacas y también, según señalan en Pisón de Castrejón, para los cerdos.

LEGUMINOSAE

\section{Ononis spinosa $\mathrm{L}$.}

Gatuña (22)

PALAB731, 37P, 462P; 33F; 425V, 467V, 486V

\begin{tabular}{lc}
\hline Frecuencia de citación (FC): & 22 \\
Número de usos (NU): & 2 \\
\hline Número registros de uso (RU): & 25 \\
\hline Frecuencia Relativa de Citación (FRC): & 0,16 \\
\hline Índice de Importancia Cultural (IC): & 0,18 \\
Índice de Vigencia (IV): & 0,00
\end{tabular}

Obtención: silvestre

Vigencia: abandonado

Conocimientos:

LÉXICO

En Aviñante de la Peña aparece el fitotopónimo del pago "El Gatuñal”.

Usos:

\section{ALIMENTACIÓN ANIMAL}

- Forraje verde o seco (2): Las plantas se cavaban de las tierras y se metían en un saco para emplearlas posteriormente como alimento en verde para las vacas.

\section{MEDIOAMBIENTAL}

- Malas hierbas (22): Reconocida como negativa, además de resultar perjudicial para las tierras de cultivo y los prados por sus densas raíces que dificultan el laboreo, posee pequeños pinchos que hacían aún más difícil su escarda.

- Bioindicadores (1): Las tierras con gatuñas indica terrenos de poca productividad.

Observaciones: En Lebanza comentan la anécdota de un agricultor que quiso comprar una tierra preguntando por si ésta tenía gatuñas, al responder el vendedor que no, se canceló la venta, pues la tierra con gatuñas aseguraba el comprador era muy buena para sembrar trigo. Es probable que esta decisión estuviese relacionada con la fijación de nitrógeno que proporcionan las leguminosas.

LEGUMINOSAE

Phaseolus vulgaris $\mathrm{L}$.

Fréjol (24), alubia (8), vaina (8), judía (4)

87F; 361V, 468V, 599V

\begin{tabular}{lc}
\hline Frecuencia de citación (FC): & 39 \\
Número de usos (NU): & 1 \\
Número registros de uso (RU): & 41 \\
\hline
\end{tabular}

Obtención: cultivada, comprada

Vigencia: vigente (73\%)

\section{Conocimientos:}

\section{LÉXICO}

Las semillas secas refieren los fréjoles y las alubias, aunque hay diversas denominaciones según la localidad, fréjoles son las semillas pintas o coloradas y alubias son blancas. El nombre de vaina o judía refiere siempre al fruto inmaduro.

Usos:

\section{ALIMENTACIÓN HUMANA}

- Legumbres (41): Se consumen las semillas secas o los frutos verdes. Las semillas secas se preparan en guisos a menudo acompañados de chorizo o carne. Los frutos verdes se cuecen y se toman de modo común con un refrito de ajo, aceite y pimentón.

Observaciones: El cultivo de alubias es tradicional en la zona y se realiza en la huerta familiar. El cultivo de vainas requiere de tutores para mantener erectos los tallos, mientras que el cultivo de alubias no los necesita al ser de mata baja. 
LEGUMINOSAE

Pisum sativum L.

Arveja (35), guisante (8), tito redondo (6), morita (7)

\begin{tabular}{lc}
\hline Frecuencia de citación (FC): & 54 \\
\hline Número de usos (NU): & 3 \\
\hline Número registros de uso (RU): & 92 \\
\hline
\end{tabular}

Obtención: cultivada, comprada

Vigencia: vigente (29\%)

\section{Conocimientos:}

\section{LÉXICO}

Para muchos informantes la arveja y el guisante es lo mismo y para otros la diferencia es el tamaño menor de la arveja. Existían en el pasado arvejas blancas y otras de color oscuro que recibían el nombre de moritas, según se cita en San Juan de Redondo, las blancas eran para alimento humano y las más oscuras solo para forraje.

La jaruga es el fruto que contiene las semillas.

Usos:

\section{ALIMENTACIÓN HUMANA}

- Legumbres (39): Se consumen las semillas verdes en crudo sin dejar terminar su proceso de maduración. Era un entretenimiento para los más jóvenes, ir al cultivo a merendar desgranando las legumbres. También se consumen las semillas secas cocidas en guisos junto con unas patatas o con algo de carne, en algunos casos se refiere un sabor un tanto amargo, "se decía que aleaban las arvejas".

\section{ALIMENTACIÓN ANIMAL}

- Forraje verde o seco (10): La paja producida se aportaba a ovejas y vacas.

- Pienso (41): El cultivo de arvejas tenía como destino principal la molienda del grano para obtener una harina muy nutritiva de la que se beneficiaban las vacas. El grano en seco se servía a los cerdos previamente remojados para favorecer su ingesta.

\section{SOCIAL, SIMBÓLICA Y RITUAL}

- Uso recreativo (2): Con los granos los niños jugaban, de modo que marcaban uno de ellos y por turnos se iban comiendo, el que cogiera el marcado perdía el turno.

Robinia pseudoacacia $\mathrm{L}$.

Acacia (8)
191P, 489P; 176F; 266V

\begin{tabular}{|ll|}
\hline Frecuencia de citación (FC): & $\mathbf{8}$ \\
\hline Número de usos (NU): & 3 \\
\hline Número registros de uso (RU): & $\mathbf{8}$ \\
\hline
\end{tabular}

Obtención: cultivada.

Vigencia: vigente (25\%)

Conocimientos:

\section{LÉXICO}

En Villanueva de Arriba se llaman pan y quesillo a las flores.

Usos:

ALIMENTACIÓN HUMANA

- Golosinas y masticatorias (3): Las flores de la acacia se consumen en fresco, aludiendo un sabor dulce.

\section{INDUSTRIA Y ARTESANÍA}

- Herramientas y utensilios (2): Aunque su madera no resulta muy valorada, se usa para elaborar mangos de herramientas.

\section{ORNAMENTAL}

- Calles y caminos (2): Se plantan en alineaciones urbanas y en el exterior de edificios públicos y religiosos como árbol de sombra.

- Adorno floral y plantas de interior (1): Ramos de inflorescencias se llevan en Nestar a la iglesia para adornar durante los oficios religiosos sobre jarrones con agua.

LEGUMINOSAE

\section{Trifolium alpinum $\mathrm{L}$.}

Regaliz (38)

PALAB2744, 263P, 481P; 182F

\begin{tabular}{lc}
\hline Frecuencia de citación (FC): & 38 \\
\hline Número de usos (NU): & 1 \\
\hline Número registros de uso (RU): & 38 \\
\hline Frecuencia Relativa de Citación (FRC): & 0,27 \\
\hline Índice de Importancia Cultural (IC): & 0,27 \\
\hline Índice de Vigencia (IV): & 0,03 \\
\hline
\end{tabular}

Obtención: silvestre

Vigencia: vigente (10\%)

\section{Conocimientos:}

\section{ECOLOGÍA}

Se recolecta en los montes más altos, se ha citado su presencia en todos estos lugares de la comarca: Sierra de Celada, El Cueto, Pico Lezna, Peñalabra y el puerto de Lores. 
Usos:

\section{ALIMENTACIÓN HUMANA}

- Golosinas y masticatorias (38): Las raíces de esta planta se recolectaban con una pequeña azadilla, se limpiaba la tierra que la rodeaba y se reservaba para chuparlas en el momento apetecido ya que poseen un sabor muy dulce y gustoso.

Observaciones: En ocasiones, se aprovechaba la ascensión a los puertos para recolectar a la vez regaliz y junciana.

\section{LEGUMINOSAE}

Trifolium pratense $\mathrm{L}$.

$T$. repens $\mathrm{L}$.

Trébol (11), chupa (2), chupón (1), hierba nube (1)

Trifolium pratense: PALAB2151, 126P, 495P; 101F; 546V

T. repens: 368P; 306F; 458V

\begin{tabular}{|lc|}
\hline Frecuencia de citación (FC): & 15 \\
\hline Número de usos (NU): & 5 \\
\hline Número registros de uso (RU): & 15 \\
\hline Frecuencia Relativa de Citación (FRC): & 0,11 \\
\hline Índice de Importancia Cultural (IC): & 0,10 \\
\hline Índice de Vigencia (IV): & 0,00 \\
\hline
\end{tabular}

Obtención: silvestre

Vigencia: abandonado

Conocimientos:

LÉXICO

Hierba nube solo denomina a Trifolium pratense, mientras que trébol, chupa y chupa designa a las dos especies.

\section{Usos:}

\section{ALIMENTACIÓN HUMANA}

- Verduras y hortalizas (1): En Areños se asegura que las hojas verdes tiernas se añaden en ensaladas, bien lavadas y aliñadas con aceite y vinagre.

- Golosinas y masticatorias (7): La flor se chupaba, pues de ella se obtenía una diminuta gota de néctar de sabor dulce.

\section{ALIMENTACIÓN ANIMAL}

- Forraje verde o seco (1): En Valsadornín recolectan esta planta para llevar forraje verde a los conejos.

- Pasto (2): Se considera buen pasto para las vacas.

MEDICINA
- Órganos de los sentidos (1): La infusión de la parte aérea se recomienda en Polentinos para lavar los ojos enrojecidos, secos o con picazón.

\section{TóxICO Y NOCIVO}

- Tóxica para personas y animales (2): Se aconseja tener precaución con el consumo excesivo de trébol pues las vacas podían hincharse.

\section{LEGUMINOSAE}

Trigonella foenum-graecum L.

Alholva (7)

\begin{tabular}{|ll|}
\hline Frecuencia de citación (FC): & 7 \\
\hline Número de usos (NU): & 1 \\
\hline Número registros de uso (RU): & 7 \\
\hline
\end{tabular}

Obtención: cultivada

Vigencia: abandonado

Usos:

\section{ALIMENTACIÓN ANIMAL}

- Forraje verde o seco (2): Servía como forraje verde para ovejas y vacas.

- Pienso (5): El grano es excelente para el ganado, se administraba a ovejas y vacas. Con el paso del tiempo se dejó de usar pues trasmitía amargor y mal sabor a la leche.

LEGUMINOSAE

\section{Ulex europaeus $\mathrm{L}$.}

Arguma (1)

\begin{tabular}{lc} 
198P, 360P; 289F & \\
\hline Frecuencia de citación (FC): & $\mathbf{1}$ \\
\hline Número de usos (NU): & 1 \\
\hline Número registros de uso (RU): & $\mathbf{1}$ \\
Frecuencia Relativa de Citación (FRC): & $\mathbf{0 , 0 1}$ \\
\hline Índice de Importancia Cultural (IC): & $\mathbf{0 , 0 1}$ \\
\hline Índice de Vigencia (IV): & $\mathbf{0 , 0 0}$ \\
\hline
\end{tabular}

Obtención: silvestre

Vigencia: abandonado

Usos:

COMBUSTIBLE

- Leña (1): Se recuerda en Salcedillo como los tejeros rozaban (cortar desde la base) las argumas con pinchos, hasta completar la carga de un carro. Con ellas calentaban muy bien el horno de cocer las tejas. 
LEGUMINOSAE

Vicia articulata $\mathrm{L}$. Algarroba (7)

\begin{tabular}{ll}
\hline Frecuencia de citación (FC): & 7 \\
\hline Número de usos (NU): & 2 \\
\hline Número registros de uso (RU): & 9 \\
\hline
\end{tabular}

Obtención: cultivada

Vigencia: abandonado

Usos:

ALIMENTACIÓN HUMANA

- Legumbres (1): En Salinas de Pisuerga se recuerda el consumo de algarrobas cocidas, en épocas de escasez de otras legumbres.

\section{ALIMENTACIÓN ANIMAL}

- Forraje verde o seco (1): La paja de algarroba se aprovecha para dar de comer a las vacas.

- Pienso (7): El destino principal del cultivo de algarrobas era la molienda del grano para consumo de las vacas.

LEGUMINOSAE

Vicia cracca L.

V. pannonica $\mathrm{L}$.

Arvejana (23)

Vicia cracca: PALAB737, 38P; 131F; 80V, 494V

V. pannonica: 256P; 114F; 81V

\begin{tabular}{lc|}
\hline Frecuencia de citación (FC): & 23 \\
\hline Número de usos (NU): & 3 \\
\hline Número registros de uso (RU): & 33 \\
\hline Frecuencia Relativa de Citación (FRC): & $\mathbf{0 , 1 7}$ \\
\hline Índice de Importancia Cultural (IC): & $\mathbf{0 , 2 4}$ \\
\hline Índice de Vigencia (IV): & $\mathbf{0 , 0 0}$ \\
\hline
\end{tabular}

Obtención: silvestre

Vigencia: abandonado

Usos:

ALIMENTACIÓN ANIMAL

- Forraje verde o seco (8): Se cortaba la planta para llevar en verde a los comederos de las vacas y los conejos.

- Pasto (2): Cuando están tiernas en la primavera las vacas pacen esta especie.

\section{MEDIOAMBIENTAL}

- Malas hierbas (21): Era habitual la escarda en las tierras cultivadas de patatas y cereal, se temía a esta planta porque ahogaba y tumbaba el cereal y porque además podían mezclarse las semillas y manchar la harina en la molienda.
SOCIAL, SIMBÓLICA Y RITUAL

- Ritual de ciclo anual (2): En la fiesta del Corpus Christi se adornaban las calles con flores azules de arvejanas.

LEGUMINOSAE

Vicia ervilia (L.) Willd Yero (46)

\begin{tabular}{lc}
\hline Frecuencia de citación (FC): & 46 \\
\hline Número de usos (NU): & 2 \\
\hline Número registros de uso (RU): & 54 \\
\hline
\end{tabular}

Obtención: cultivada

Vigencia: abandonado

Usos:

\section{ALIMENTACIÓN HUMANA}

- Legumbres (1): Los yeros en Santa María de Nava se comían en verde sin dejarlos completar la maduración.

\section{ALIMENTACIÓN ANIMAL}

- Forraje verde o seco (6): La paja de yeros era denominada paja negra, por el gran valor alimenticio que tenía para el engorde del ganado vacuno y lanar.

- Pienso (47): Se trata de uno de los alimentos mejor valorados por los ganaderos para el engorde del ganado "si querías vender un jato le dabas yeros", el grano se servía molido para vacas y sobre todo para terneros jóvenes.

LEGUMINOSAE

\section{Vicia faba L.} Haba (11)

\begin{tabular}{lc}
\hline Frecuencia de citación (FC): & 11 \\
\hline Número de usos (NU): & 2 \\
\hline Número registros de uso (RU): & 15 \\
\hline
\end{tabular}

Obtención: cultivada

Vigencia: abandonado

Usos:

ALIMENTACIÓN HUMANA

- Legumbres (8): Se cultivaban habas para autoconsumo en el núcleo familiar, cocinadas las semillas secas en cocidos o purés. También los niños como entretenimiento comían las semillas verdes inmaduras.

\section{ALIMENTACIÓN ANIMAL}


- Pienso (7): La harina obtenida a partir de las semillas secas es un pienso excelente para las vacas, "muy bueno para las vacas de leche", Villaverde de la Peña.

\section{LEGUMINOSAE}

Vicia sativa $\mathrm{L}$.

Arrica (14), franco (4), rica (1), veza (1)

\begin{tabular}{lc}
\hline Frecuencia de citación (FC): & 20 \\
\hline Número de usos (NU): & 1 \\
\hline Número registros de uso (RU): & 30 \\
\hline
\end{tabular}

Obtención: cultivada

Vigencia: abandonado

Usos:

\section{ALIMENTACIÓN ANIMAL}

- Forraje verde o seco (6): Las vacas aprovechan la planta como forraje verde e incluso la paja se emplea para alimentar a ovejas y vacas.

- Pienso (24): Se sirve a las vacas la harina obtenida de la molienda del grano, apreciada por su gran valor nutritivo.

\section{LENTIBURIACEAE}

\section{Pinguicula grandiflora Lam.}

Tiraña (2), hoja de la tiraña (2), hoja de la tiraina (1)

214P; $153 \mathrm{~F}$

\begin{tabular}{lc}
\hline Frecuencia de citación (FC): & $\mathbf{5}$ \\
\hline Número de usos (NU): & 2 \\
\hline Número registros de uso (RU): & 5 \\
\hline Frecuencia Relativa de Citación (FRC): & $\mathbf{0 , 0 4}$ \\
\hline Índice de Importancia Cultural (IC): & $\mathbf{0 , 0 4}$ \\
\hline Índice de Vigencia (IV): & $\mathbf{0 , 0 0}$ \\
\hline
\end{tabular}

Obtención: silvestre

Vigencia: abandonado

\section{Conocimientos:}

\section{ECOLOGÍA}

"La tiraña está agazapada en el fresco, donde hay agua, húmedos y manantiales".

Usos:

\section{VETERINARIA}

- Sistema digestivo (1): Las hojas pegajosas con las que la planta caza insectos se emplean como potente laxante para el ganado vacuno. Se prepara una cocción de las hojas y el líquido viscoso que se produce se da a beber provocando la evacuación del intestino.
- Concepción, embarazo y parto (1): La cocción de las hojas se indica en Camasobres útil para el ganado vacuno en el caso de retención de placenta o cuando no se expulsa completamente horas después del parto.

\section{TóxICO Y NOCIVO}

- Tóxica para personas y animales (3): Se advierte en Santa María de Redondo que la planta es perjudicial, "si te tomas un vaso de la fuente te entra una cagalera que no veas".

Cuentan en Salcedillo, cómo un vecino del pueblo hizo una apuesta con Gasparín vecino de Izara (Cantabria), por ver quién segaba antes un prado, y para entorpecer su avance le echaron hoja de tiraña en la comida, lo que le provocó una gran diarrea, que a pesar de ello no le impidió por ello ganar la apuesta.

LINACEAE

Linum narbonense $\mathrm{L}$.

Flor de lino (1), lino montesino (1)

431P, 542P; 223F; 44V

\begin{tabular}{lc|}
\hline Frecuencia de citación (FC): & 2 \\
\hline Número de usos (NU): & 1 \\
\hline Número registros de uso (RU): & 2 \\
\hline Frecuencia Relativa de Citación (FRC): & $\mathbf{0 , 0 1}$ \\
\hline Índice de Importancia Cultural (IC): & 0,01 \\
\hline Índice de Vigencia (IV): & 0,01 \\
\hline
\end{tabular}

Obtención: silvestre

Vigencia: vigente (50\%)

Usos:

ORNAMENTAL

- Adorno floral y plantas de interior (2): Aunque sus pétalos no son muy persistentes, se cortaban unas cuantas ramas floridas hasta formar un pequeño ramo que se colocaba sobre un jarrón con agua para decoración de interiores.

\section{Linum usitatissimum L.}

LINACEAE Lino (22)

\begin{tabular}{l}
$92 \mathrm{~F}$ \\
\hline Frecuencia de citación (FC): \\
\hline Número de usos (NU):
\end{tabular}

Obtención: cultivada

Vigencia: abandonado 


\section{Conocimientos: \\ ECOLOGÍA}

El cultivo se desarrollaba en las cercanías de sitios húmedos, arroyos o ríos, pues el agua era necesaria para el cultivo y en el proceso de obtención de la fibra de lino.

\section{LÉXICO}

Los cultivos de lino se denominan linares y las semillas se conocen como linaza. Estos cultivos han dado lugar a varios fitotopónimos recogidos en la zona: el pago de "Los Linares del Río" en Villabellaco, "Los Linares" en Areños, Bustillo de Santullán, Camporredondo, Castrejón de la Peña, Menaza, Polentinos, Resoba, San Cebrian de Mudá, Tarilonte de la Peña, Traspeña de la Peña y Vallespinoso de Cervera.

Usos:

\section{ALIMENTACIÓN HUMANA}

- Grasas alimentarias (1): En Santibáñez de la Peña recuerdan portear semillas de lino hasta Pino de Viduerna, donde existía un molino de oilo del que obtenían aceite de linaza para cocinar.

\section{MEDICINA}

- Sistema respiratorio (1): En la misma localidad se preparaban cataplasmas con aceite de linaza que se colocaban sobre el pecho para combatir catarros y afecciones pulmonares.

\section{VETERINARIA}

- Sistema digestivo (1): Para las vacas empachadas en Estalaya se daba a beber la cocción de semillas de linaza.

\section{INDUSTRIA Y ARTESANÍA}

- Vestimenta y adornos personales (22): EI cultivo de lino textil tuvo gran importancia en la comarca hasta aproximadamente los años 40 del s. XX. El proceso para conseguir la fibra resultaba muy laborioso, se remojaba en agua unos cuantos días, se machacaba (majar), se cardaba, se lavaba en ceniza de roble (cernada) y se hilaba por último. Existían telares en varias localidades en los que se elaboraban telas para sabanas o ropa.

\section{LYTHRACEAE}

Lythrum salicaria $\mathrm{L}$.

Hierba de la colitis (1), salicaria (1)

159P, 315P; 327F; 245V, 597V

\begin{tabular}{lc}
\hline Frecuencia de citación (FC): & 2 \\
\hline Número de usos (NU): & 1 \\
\hline Número registros de uso (RU): & 2 \\
\hline Frecuencia Relativa de Citación (FRC): & $\mathbf{0 , 0 1}$ \\
\hline Índice de Importancia Cultural (IC): & $\mathbf{0 , 0 1}$ \\
\hline Índice de Vigencia (IV): & $\mathbf{0 , 0 1}$ \\
\hline
\end{tabular}

Obtención: silvestre

Vigencia: vigente (50\%)

Conocimientos:

ECOLOGÍA

Sale en las orillas de ríos y arroyos.

Usos:

MEDICINA

- Sistema digestivo (2): Se utiliza la parte aérea recolectada durante la época de floración para hacer una infusión que se recomienda en casos de gastroenteritis, "se toma uno o dos vasos calientes cuando tienes colitis".

\section{MALVACEAE}

\section{Alcea rosea $\mathrm{L}$}

Malva real (1), malvarisco (1)

\begin{tabular}{ll}
\hline $89 \mathrm{~F}$ & \\
\hline Frecuencia de citación (FC): & 2 \\
\hline Número de usos (NU): & 1 \\
\hline Número registros de uso (RU): & 2 \\
\hline
\end{tabular}

Obtención: cultivada

Vigencia: vigente (100\%)

Usos:

ORNAMENTAL

- Patios, huertos y jardines (2): Se cultiva en patios y jardines por la belleza de sus grandes flores que pueden llegar a tener distintas tonalidades.

MALVACEAE

Althaea officinalis L.

Malvarisco (5), malvavisco (3), malvalisco (1)

450P; 329F

\begin{tabular}{lc|}
\hline Frecuencia de citación (FC): & 9 \\
\hline Número de usos (NU): & 3 \\
\hline Número registros de uso (RU): & 11 \\
\hline
\end{tabular}

Obtención: cultivada

Vigencia: vigente (18\%)

Usos:

MEDICINA 
- Sistema respiratorio (7): La especie tiene buena reputación en el tratamiento del catarro y la congestión de pecho. Se utilizan flores y hojas para respirar los vahos producidos por su cocción. En Santa María de Nava las hojas más grandes cocidas se colocaban calientes sobre el pecho en forma de cataplasma. Otra parte de la planta empleada es la raíz, que se toma en infusión para tratar las mismas afecciones. En Triollo se elaboraba una especie de jarabe cociendo la raíz junto con higos y orégano, una vez colado se servía una cucharadita durante unos días para tratar el catarro de los más pequeños.

\section{ORNAMENTAL}

- Patios, huertos y jardines (3): Se cultiva en patios y jardines por la vistosidad de sus flores.

\section{SOCIAL, SIMBÓLICO Y RITUAL}

- Alucinógenas, narcóticas y fumatorias (1): En Camporredondo de Alba se recuerda cómo el día de Santa Águeda, se permitía a los niños fumar tallos huecos de malvavisco, alrededor de la hoguera que se realizaba en esta fiesta local.

MALVACEAE

Malva moschata L.

Malva (1)

399P; 222F

\begin{tabular}{lc}
\hline Frecuencia de citación (FC): & 1 \\
\hline Número de usos (NU): & 2 \\
\hline Número registros de uso (RU): & 2 \\
\hline Frecuencia Relativa de Citación (FRC): & 0,01 \\
Índice de Importancia Cultural (IC): & 0,01 \\
\hline Índice de Vigencia (IV): & 0,00 \\
\hline
\end{tabular}

Obtención: silvestre

Vigencia: abandonado

Conocimientos:

ECOLOGÍA

En San Salvador de Cantamuda diferencian esta especie del resto de malvas, pues "es más grande y tiene un color más fuerte".

\section{LÉXICO}

Se conoce popularmente a los frutos con el nombre de panecitos.

Usos:

ALIMENTACIÓN HUMANA

- Golosinas y masticatorias (1): Los niños comían los frutos de la malva.

\section{MEDICINA}

- Musculatura y esqueleto (1): La parte aérea se machaca bien y se envuelve en un trozo de manteca que se usa como cataplasma para tratar golpes e hinchazones.

Observaciones: Es probable que esta especie tenga los mismo usos que Malva sylvestris ya que solo en San Salvador de Cantamuda se identificaron como diferentes.

MALVACEAE

Malva sylvestris $\mathrm{L}$.

Malva (54), flor de malva (21)

PALAB2636, 51P, 389P, 459P; 13F; 91V, 117V, 118V, 137V, 165V, 286V, 360V, 465V, 593V

\begin{tabular}{lc}
\hline Frecuencia de citación (FC): & 75 \\
\hline Número de usos (NU): & 6 \\
\hline Número registros de uso (RU): & 94 \\
\hline Frecuencia Relativa de Citación (FRC): & 0,54 \\
\hline Índice de Importancia Cultural (IC): & 0,68 \\
\hline Índice de Vigencia (IV): & 0,13 \\
\hline
\end{tabular}

Obtención: silvestre

Vigencia: vigente (19\%)

Conocimientos:

ECOLOGíA

Aparecen en prados y márgenes de caminos.

LÉXICO

Se recogen los nombres de panecitos o panecillos para denominar a los frutos

Usos:

ALIMENTACIÓN HUMANA

- Golosinas y masticatorias (18): En primavera cuando coexisten flores y frutos verdes, se consumen estos frutos inmaduros, sobre todo por los niños como entretenimiento o golosina, directamente sin preparación alguna, "se pelaban y se comían unos gajos que echaba".

\section{ALIMENTACIÓN ANIMAL}

- Forraje verde o seco (1): La planta se recoge y se sirve como forraje verde para conejos.

\section{MEDICINA}

- Sistema digestivo (2): Se cita el uso de las flores de malva en infusión para temperar los dolores de estomago. También se menciona en Triollo el uso de hojas y flores machacadas para aliviar los dolores de muelas, de tal manera que se colocaban sobre la zona dolorida envueltas en un trapo. 
- Sistema respiratorio (55): El cocimiento de las flores solas o mezcladas con otras hierbas sirve de remedio contra catarros o cualquier otro tipo de afección respiratoria, tomado en forma de infusión caliente o mediante vahos para respirar. En Celada de Roblecedo se cuecen las flores de malva junto con las de saúco en leche y se añade un poco de azúcar, potenciándose de este modo las virtudes para acortar el periodo de recuperación.

- Musculatura y esqueleto (4): Hojas y flores tienen uso vulnerario, se cuecen y se mojan paños, a modo de cataplasma, que se acomodan sobre golpes, torceduras e hinchazones. También es adecuado para estos problemas el machacado de la planta envuelto en manteca.

- Piel y tejido celular subcutáneo (5): Empleado como desinfectante para lavar heridas con el cocimiento de las flores.

\section{VETERINARIA}

- Sistema digestivo (1): En Triollo se envuelve en manteca unas pocas flores cocidas y se hace una bola que se introduce en la boca de las vacas cuando tienen el estomago hinchado, "que se les pega las hojas del estomago, de la primanuera".

- Sistema respiratorio (1): La cocción de flores de malva se administraba por la boca a las vacas con pulmonía.

- Piel y tejido celular subcutáneo (2): Las heridas de los animales domésticos se desinfectaban lavandolas con el cocimiento tibio de flores y hojas.

\section{MEDIOAMBIENTAL}

- Malas hierbas (3): La malva es una mala hierba que se escarda de cultivos y huertas.

\section{SOCIAL, SIMBÓLICO Y RITUAL}

- Uso recreativo (2): Las niñas jugaban con los panecillos de las malvas en los tradicionales juegos de las comiditas.

Observaciones: Muriel Martín (2008) cita esta especie mezclada con romero y tomillo, como remedio anticatarral en Guardo.

MALVACEAE

Tilia platyphylos Scop.

Tilo (48)

53P, 299P; 14F; 190V, 352V

\begin{tabular}{lc}
\hline Frecuencia de citación (FC): & 48 \\
\hline Número de usos (NU): & 2 \\
\hline Número registros de uso (RU): & 51 \\
\hline Frecuencia Relativa de Citación (FRC): & $\mathbf{0 , 3 5}$ \\
\hline Índice de Importancia Cultural (IC): & $\mathbf{0 , 3 7}$ \\
\hline Índice de Vigencia (IV): & $\mathbf{0 , 0 4}$ \\
\hline
\end{tabular}

Obtención: silvestre, cultivada

Vigencia: vigente (12\%)

Usos:

MEDICINA

- Sistema digestivo (7): Las flores del tilo poseen propiedades antiespasmódicas útiles en tratamientos de problemas digestivos, sobre todo dolores estomacales de origen diverso (gases, menstruación, empachos...). La recolección de flores con sus brácteas se realiza de forma manual desde principios del verano y se conservan tras su secado en envases en lugar fresco y seco hasta la administración, que se realiza mediante infusión en agua caliente.

Algunas recetas recogidas en la zona combinan plantas como el té (Sideritis hyssopifolia) o la manzanilla (Chamaemelum nobile), para potenciar los efectos terapéuticos de la infusión.

- Sistema respiratorio (3): Empleadas las flores con sus brácteas en afecciones respiratorias leves (tos, catarro o gripe), administradas en forma de infusión o mediante vahos respiratorios.

- Sistema nervioso (39): Su principal uso es como tranquilizante y relajante. Recomendado para conciliar el sueño, para tratar estados de nerviosismo, ansiedad o estrés y para calmar el dolor de cabeza. Se administran dos o tres tazas al día de la infusión de las flores.

- Otros usos medicinales (1): La tila se indica en Ventanilla como panacea con propiedades curativas múltiples, mezclada en infusión con otras plantas (cola de caballo, grama, manzanilla calar, manzanilla campera, milenrama, orégano, sanguinaria, té, tila y tomillo).

\section{ORNAMENTAL}

- Patios, huertos y jardines (1): Se ha observado en varias localidades de la comarca cultivada en huertos, jardines y en bordes de caminos o senderos.

Observaciones: Varios informantes señalaron, como en el pasado los vecinos lebaniegos comerciaban con esta especie, debido a la escasez de ejemplares en la zona de la estudio. 
También es conocida la tila por las populares bolsitas de infusión de tila comercializadas, que han facilitado su difusión y utilización.

Se ha observado cómo las abejas visitan con frecuencia esta especie en plena época de floración, momento en el que las flores desprenden un agradable aroma, sin embargo, no se ha obtenido ninguna cita como planta melífera, de la cual se extrae una miel excelente.

Un vecino de Valcobero indicó la mayor presencia de tilos en el despoblado de Valsurbio, lugar al que se solía ir a recoger. En Resoba existe un rodal significativo de tilos en el paraje de Milares.

\section{MORACEAE}

Ficus carica L.

Higuera (1)

336P; 280F

Frecuencia de citación (FC): 1

Número de usos (NU):

1

Número registros de uso (RU):

1

Obtención: cultivada

Vigencia: vigente (100\%)

Usos:

ALIMENTACIÓN HUMANA

- Frutos y frutas dulces (1): A pesar de la climatología adversa de la zona para la maduración de la fruta, en Barruelo de Santullán recuerdan recoger higos para comer en la higuera situada en la escuela de la localidad.

MORACEAE

\section{Morus alba L.}

Moral (1)

217P

\begin{tabular}{ll}
\hline Frecuencia de citación (FC): & 1 \\
Número de usos (NU): & 1 \\
Número registros de uso (RU): & 1 \\
\hline
\end{tabular}

Obtención: cultivada

Vigencia: abandonado

Usos:

ALIMENTACIÓN HUMANA

- Frutas y frutos dulces (1): Se consume el fruto una vez maduro directamente del árbol. En
Aguilar de Campoo se recogían de un ejemplar situado al lado del colegio de San Gregorio.

MORACEAE

\section{Morus nigra L.}

Morera (1)

398P; $121 \mathrm{~F}$

\begin{tabular}{ll}
\hline Frecuencia de citación (FC): & 1 \\
Número de usos (NU): & 1 \\
Número registros de uso (RU): & 1 \\
\hline
\end{tabular}

Obtención: cultivada

Vigencia: abandonado

Usos:

ALIMENTACIÓN HUMANA

- Frutas y frutos dulces (1): En el centro de la localidad de Salinas de Pisuerga existe una morera de la que los más jóvenes aprovechaban una vez maduras, las dulces moras negras.

\section{MYRTACEAE}

Eucalyptus globulus Labill.

Eucalipto (7), eucalito (9)

\begin{tabular}{lc}
\hline Frecuencia de citación (FC): & 16 \\
\hline Número de usos (NU): & 3 \\
\hline Número registros de uso (RU): & 19 \\
\hline
\end{tabular}

Obtención: comprada

Vigencia: vigente (5\%)

Usos:

MEDICINA

- Sistema respiratorio (9): Las hojas de eucalipto se toman en infusiones o vahos como tratamiento anticatarral. Se mezcla en ocasiones con otras hierbas de propiedades similares para potenciar sus virtudes, entre ellas, la malva y el orégano.

\section{CONSTRUCCIÓN}

- Infraestructuras (9): La madera de eucalipto era la preferida para postear las galerías en las minas de la comarca. Se trata de una madera compacta de gran resistencia y aguante para solventar las necesidades requeridas en la explotación minera.

\section{INDUSTRIA Y ARTESANÍA}

- Juguetes, instrumentos deportivos $y$ musicales (1): En Salinas de Pisuerga se 
fabricaban bolas del tradicional juego de los bolos, con restos de madera obtenida en las minas cercanas.

Observaciones: Esta especie no existe en la zona, sin embargo se ha importado desde las provincias de Cantabria y Asturias. Los lebaniegos comerciaban con hojas de eucalipto que vendían o cambian al trueque por otros productos. La madera para las minas se traía por lo general desde Asturias.

\section{NYCTAGINACEAE}

Mirabilis jalapa L.

Dondiego (1)

69P

\begin{tabular}{ll}
\hline Frecuencia de citación (FC): & 1 \\
\hline Número de usos (NU): & 1 \\
\hline Número registros de uso (RU): & 1 \\
\hline
\end{tabular}

Obtención: cultivada

Vigencia: vigente (100\%)

Usos:

\section{ORNAMENTAL}

- Patios, huertos y jardines (1): Planta sencilla de cultivar en patios y jardines como ornamental, con bellas flores de intensos $y$ variados colores.

OLEACEAE

\section{Fraxinus excelsior $\mathrm{L}$.}

Fresno (81)

PALAB1984, 15P, 505P; 28F; 358V, 524V, 574V

\begin{tabular}{lc}
\hline Frecuencia de citación (FC): & 81 \\
\hline Número de usos (NU): & 6 \\
\hline Número registros de uso (RU): & 166 \\
\hline Frecuencia Relativa de Citación (FRC): & 0,58 \\
\hline Índice de Importancia Cultural (IC): & 1,19 \\
\hline Índice de Vigencia (IV): & 0,01 \\
\hline
\end{tabular}

Obtención: silvestre

Vigencia: vigente (1\%)

\section{Conocimientos:}

\section{LÉXICO}

El fitotopónimo "El Fresno" aparece en San Juan de Redondo, "Fresnedo" en Vergaño, y el de "Los Fresnos" en Quintanaluengos.

Usos:

ALIMENTACIÓN HUMANA
- Forraje verde o seco (33): De todas las posibles hojas empleadas como ramón, la de fresno es de las más valoradas, se considera buen forraje para cabras, ovejas, conejos, vacas y especialmente indicada para terneros que empezaban a rumiar. Se procede al desmoche del fresno a partir de septiembre, una vez terminadas las labores del campo y se guarda en el pajar hasta su utilización durante el largo invierno. El inconveniente para su recogida es la presencia aislada de ejemplares y la escasez en su número

\section{MEDICINA}

- Musculatura y esqueleto (2): En Herreruela de Castillería recuerdan como realizar una infusión antirreumática empleando el floema, "Se cuece en agua unos minutos la segunda corteza del fresno y manzanilla, se toma cuando te dan ataques de reuma".

También se aconseja como remedio para tratar las inflamaciones y los dolores musculares, colocando en el lugar dolorido, cataplasmas humedecidas en la cocción de las hojas.

- Piel y tejido celular subcutáneo (1): Para tratar pequeñas heridas se indica la decocción de la corteza de fresno en San Salvador de Cantamuda.

- Sintomas y estados de origen indefinido (1): La infusión de hojas de fresno es febrífuga, siendo usada en decocción para bajar la fiebre.

\section{COMBUSTIBLE}

- Leña (5): Si se cortaba un árbol y no había necesidad para algún uso tecnológico, se aprovechaba la leña como combustible, aunque era norma reservarlo por la calidad de su madera para mejor ocasión.

- Encendido (1): Las ramas cortadas de fresno, una vez consumida la hoja, se aprovechaban para leña fina del hogar.

\section{CONSTRUCCIÓN}

- Carros y otros vehículos (4): En la zona de Triollo y Otero de Guardo se afirma que las piezas de la armadura del carro se realizaban con madera de fresno.

\section{INDUSTRIA Y ARTESANÍA}

- Herramientas y utensilios (86): La madera de fresno es pesada, dura y elástica, difícil de agrietar y fácil de pulir y doblar al vapor, por ello es apreciada en la fabricación de yugos y yuguetas, rastros y pinos para los rastros, cachavas, varas, astiles y mangos de diversas herramientas 
- Juguetes e instrumentos deportivos $y$ musicales (12): Aprovechando las excelentes propiedades de la madera, se han descrito en la comarca usos para la fabricación de bolos, esquís, peonzas, rabeles, chiflas, chiflitas y cornetas.

- Vestimenta y adornos personales (2): La confección de albarcas también se llevó a cabo con madera de fresno en Alba de los Cardaños y Otero de Guardo, donde aseguran que "Casi la fuerza de las casas había quien hacia albarcas con fresno".

\section{ORNAMENTAL}

- Calles y caminos (2): El fresno posee un porte bello, capaz de alcanzar hasta los $20 \mathrm{~m}$ de altura, por ello se puede admirar como árbol de sombra en algún paseo, plaza o portada de iglesia, como por ejemplo, en Verdeña, en Estalaya o en Celada de Roblecedo.

\section{SOCIAL, SIMBÓLICO Y RITUAL}

- Ritual de ciclo anual (9): En la festividad de San Juan o San Pedro los mozos adornaban las ventanas de las mozas pretendidas con ramos de fresno y en la festividad del Corpus Christi se engalanaban los distintos altares distribuidos por las calles de la localidad.

- Ritual de ciclo de vida (8): Se emplean los ramos de fresno en el ornamento de la casa de la novia el día de la boda, en Arbejal lo narran de este modo: "La mocedad se encargaba de cortar los ramos y de pedir los derechos de los que se casaban. La víspera de la boda se cantaba la enhorabuena y se hacía un arco de ramos de fresno, rosas y otras flores. El día de la boda por la mañana, iban los mozos y las mozas a la puerta de la casa de la novia a cantar la enhorabuena, los novios se ponían debajo del arco".

Observaciones: El fresno de hoja estrecha (Fraxinus angustifolia) se encuentra en la comarca de forma escasa en su área más meridional.

OLEACEAE

\section{Ligustrum vulgare $\mathrm{L}$.}

Varillo (6)

\begin{tabular}{lc} 
26P; 163F; 248V, 249V, 283V & \\
\hline Frecuencia de citación (FC): & $\mathbf{6}$ \\
\hline Número de usos (NU): & $\mathbf{3}$ \\
\hline Número registros de uso (RU): & $\mathbf{8}$ \\
\hline Frecuencia Relativa de Citación (FRC): & $\mathbf{0 , 0 4}$ \\
\hline Índice de Importancia Cultural (IC): & $\mathbf{0 , 0 6}$ \\
\hline Índice de Vigencia (IV): & $\mathbf{0 , 0 1}$ \\
\hline
\end{tabular}

Obtención: silvestre

Vigencia: vigente (13\%)

Usos:

INDUSTRIA Y ARTESANÍA

- Cosmética, perfumería y limpieza (1): En Villanueva de Arriba se llevan ramos floridos para ambientar el salón de la vivienda, pues las flores desprenden un agradable olor.

- Herramientas y utensilios (5): Uniendo varias ramas se elaboraban escobas que se empleaban como baleas para barrer el grano de la era o para limpiar cuadras o portales.

\section{ORNAMENTAL}

- Adorno floral y plantas de interior (1): Alrededor del mes de julio la planta florece con intensidad, cortándose ramas para decorar en interiores.

\section{SOCIAL, SIMBÓLICO Y RITUAL}

- Ritual de ciclo anual (1): En Santibáñez de la Peña se incorporan ramas de varillo en los arcos y enramadas tradicionales por San Juan y San Pedro.

\section{OLEACEAE}

\section{Syringa vulgaris L.}

Lilar (2)

\begin{tabular}{ll}
\hline $273 F$ & \\
\hline Frecuencia de citación (FC): & 2 \\
\hline Número de usos (NU): & 2 \\
\hline Número registros de uso (RU): & 2 \\
\hline
\end{tabular}

Obtención: cultivada

Vigencia: vigente (50\%)

Usos:

ORNAMENTAL

- Patios, huertos y jardines (1): Se cultiva como arbusto decorativo por su floración de intensa y agradable fragancia y de colores variados.

\section{SOCIAL, SIMBÓLICO Y RITUAL}

- Ritual de ciclo anual (1): En Villanueva de Arriba los más jóvenes "desgranaban flores" que tiraban por las calles el día del Corpus Christi.

\section{Fuchsia magellanica L.}

Pendientes de la reina (2) 
413V

\begin{tabular}{|ll|}
\hline Frecuencia de citación (FC): & 2 \\
\hline Número de usos (NU): & 1 \\
\hline Número registros de uso (RU): & 2 \\
\hline
\end{tabular}

Obtención: cultivada

Vigencia: vigente (100\%)

Usos:

ORNAMENTAL

- Adorno floral y plantas de interior (2): Se cultiva en macetas como planta de interior por su espectacular floración.

OROBANCHACEAE

Bellardia trixago (L.) All.

Cencerrada (1)

257P, 311P; 477V

\begin{tabular}{lc|}
\hline Frecuencia de citación (FC): & 1 \\
\hline Número de usos (NU): & 1 \\
\hline Número registros de uso (RU): & 1 \\
\hline Frecuencia Relativa de Citación (FRC): & 0,01 \\
\hline Índice de Importancia Cultural (IC): & 0,01 \\
\hline
\end{tabular}

Obtención: silvestre

Usos:

MEDIOAMBIENTAL

- Malas hierbas (1): En Matabuena se la considera mala hierba.

OROBANCHACEAE

Melampyrum pratense $\mathrm{L}$.

Hierba morena (1), hierba negreal (1)

218P, 284P; 110F

\begin{tabular}{lc}
\hline Frecuencia de citación (FC): & 2 \\
\hline Número de usos (NU): & 2 \\
\hline Número registros de uso (RU): & 3 \\
\hline Frecuencia Relativa de Citación (FRC): & $\mathbf{0 , 0 1}$ \\
\hline Índice de Importancia Cultural (IC): & $\mathbf{0 , 0 2}$ \\
\hline Índice de Vigencia (IV): & $\mathbf{0 , 0 0}$ \\
\hline
\end{tabular}

Obtención: silvestre

Vigencia: abandonado

Usos:

ALIMENTACIÓN ANIMAL

- Pasto (2): Esta especie era especialmente llamativa para ovejas y vacas que la pacían con avidez.

TÓXICA Y NOCIVA
- Tóxica para personas y animales (1): En Roscales de la Peña aseguran que pacer demasiada hierba negreal producía diarreas en las vacas.

OROBANCHACEAE

Pedicularis comosa $\mathrm{L}$.

$P$. sylvatica $\mathrm{L}$.

Chupa (4), chupón (9), chupete (2)

Pedicularis comosa: 155P; $103 \mathrm{~F}$

P. sylvatica: 215P, 361P; 288F; 168V

\begin{tabular}{|lc|}
\hline Frecuencia de citación (FC): & 15 \\
\hline Número de usos (NU): & 2 \\
\hline Número registros de uso (RU): & 16 \\
\hline Frecuencia Relativa de Citación (FRC): & 0,11 \\
\hline Índice de Importancia Cultural (IC): & 0,12 \\
\hline Índice de Vigencia (IV): & 0,00 \\
\hline
\end{tabular}

Obtención: silvestre

Vigencia: abandonado

Conocimientos:

ECOLOGÍA

Aparecen en los prados.

Usos:

ALIMENTACIÓN HUMANA

- Golosinas y masticatorias (15): El néctar dulce lo aprovechaban los más jóvenes chupando las flores directamente en el campo.

\section{ALIMENTACIÓN ANIMAL}

- Plantas melíferas (1): Las abejas visitan con frecuencia esta planta durante la floración primaveral.

OROBANCHACEAE

Rhinanthus minor L.

Cencerrada (10), cencerra (2), encantadera (4), cencellada (1)

\begin{tabular}{lc} 
39P, 298P, 343P; 132F; 487V, 534V & \\
\hline Frecuencia de citación (FC): & 17 \\
\hline Número de usos (NU): & $\mathbf{3}$ \\
\hline Número registros de uso (RU): & 19 \\
\hline Frecuencia Relativa de Citación (FRC): & $\mathbf{0 , 1 2}$ \\
\hline Índice de Importancia Cultural (IC): & $\mathbf{0 , 1 4}$ \\
\hline Índice de Vigencia (IV): & $\mathbf{0 , 0 0}$ \\
\hline
\end{tabular}

Obtención: silvestre

Vigencia: abandonado

Usos:

ALIMENTACIÓN HUMANA 
- Golosinas y masticatorias (1): Las flores se chupan para intentar extraer su néctar.

\section{MEDIOAMBIENTAL}

- Malas hierbas (16): Los informantes reconocen esta especie como mala hierba presente en los prados

- Bioindicadores (1): Su presencia advierte de prados pobres y con poca producción de hierba.

\section{ORNAMENTAL}

- Adorno floral y plantas de interior (1): Se utiliza en San Salvador de Cantamuda en ornamentación floral, se recogían ramos floridos para centros de flores secas, acompañando de forma habitual a gramíneas.

Observaciones: En Verdeña señalan que esta planta prospera cuando se producen muchas heladas.

El nombre recogido de cencerrada quizás se deba al ruido que hacían los cálices pajizos y secos, cuando alguien pasaba por un prado con formaciones de Rhinantus. "Cuando se secan es como que tienen un sonajero".

\section{OXALIDACEAE}

\section{Oxalis pes-caprae L.}

\begin{tabular}{lc}
\hline Frecuencia de citación (FC): & 1 \\
\hline Número de usos (NU): & 1 \\
\hline Número registros de uso (RU): & 2 \\
\hline Frecuencia Relativa de Citación (FRC): & 0,01 \\
\hline Índice de Importancia Cultural (IC): & 0,01 \\
\hline
\end{tabular}

Obtención: silvestre (naturalizada)

Usos:

\section{MEDIOAMBIENTAL}

- Malas hierbas (2): Se señala en varias localidades el problema provocado en el invernadero por esta planta, antaño desconocida, pues se desarrolla muy rápido y es difícil de erradicar, "es como un que tiene un nabo, que no hay quien pueda con ello, no se si ha venido con algún pienso", Valberzoso.

PAEONIACEAE

Paeonia lactiflora Pall. Peonía (25)

324P; 159F; 53V, 575V

\begin{tabular}{lc}
\hline Frecuencia de citación (FC): & 25 \\
\hline Número de usos (NU): & 4 \\
\hline Número registros de uso (RU): & 32 \\
\hline
\end{tabular}

Obtención: cultivada

Vigencia: vigente (63\%)

Usos:

ALIMENTACIÓN ANIMAL

- Plantas melíferas (1): Se trata de una especie que florece alrededor del mes de mayo y en la cual las abejas obtienen néctar con el que fabricar miel.

\section{INDUSTRIA Y ARTESANÍA}

- Vestimenta y adornos personales (1): Los más pequeños empleaban las semillas redondas de la peonía para engarzarlas y confeccionar collares decorativos.

\section{ORNAMENTAL}

- Patios, huertos y jardines (12): Las peonías producen flores muy vistosas y atractivas. Se cultiva tradicionalmente como planta ornamental en huertos o jardines. En Tremaya se emplea con fines decorativos en el cementerio.

- Adorno floral y plantas de interior (10): En la primavera coincidiendo con la hermosa floración de las peonías, se recogen flores para confeccionar jarrones decorativos en fresco y también para incluir en centros de flor seca.

Se destinaban los floreros para las viviendas y frecuentemente para emplazar en el altar de la iglesia durante el mes de mayo, en el que se cantaban versos y se realizaban ofrendas florales a la Virgen. En Polentinos los niños recitaban estos versos en el ofrecimiento "María te regalo esta peonía, te la pongo en el altar, recíbela madre mía, que esta niña te la $d a^{\prime \prime}$.

\section{SOCIAL, SIMBÓLICA Y RITUAL}

- Ritual de ciclo anual (7): En la Festividad del Corpus Christi se colocaban peonías como ornamento en los altares tradicionales que se instalaban en el recorrido de la procesión. Los más jóvenes además tiraban pétalos al paso de la comitiva religiosa.

- Ritual de incertidumbre, protección y aflicción (1): En Alba de los Cardaños señalan a esta planta como supersticiosa, desaconsejando el empleo para el decoro en el cementerio. 


\section{PAEONIACEAE}

Paeonia officinalis $\mathrm{L}$.

Peonía (8), roso (3), amaperro (2), clavel (1)

88P; 72F; 576V, 577V

\begin{tabular}{lc}
\hline Frecuencia de citación (FC): & 9 \\
\hline Número de usos (NU): & 2 \\
\hline Número registros de uso (RU): & 15 \\
\hline Frecuencia Relativa de Citación (FRC): & 0,06 \\
\hline Índice de Importancia Cultural (IC): & $\mathbf{0 , 1 1}$ \\
\hline Índice de Vigencia (IV): & 0,01 \\
\hline
\end{tabular}

Obtención: silvestre

Vigencia: vigente (13\%)

Conocimientos:

\section{ECOLOGÍA}

Se encuentra de forma silvestre entre matorrales aclarados.

\section{LÉXICO}

En la zona de Triollo, Alba de los Cardaños y La Lastra se recoge el nombre de roso. En Santibáñez de la Peña y Villanueva de la Peña se denominan amaperros y en San Martín de los Herreros se conocen con el nombre de claveles.

Usos:

ORNAMENTAL

- Patios, huertos y jardines (4): Se traen del monte para cultivar cultivar en huertos o jardines como planta ornamental.

- Adorno floral y plantas de interior (6): Se cogen flores para decorar las viviendas y el altar de la iglesia local.

\section{SOCIAL, SIMBÓLICA Y RITUAL}

- Ritual de ciclo anual (5): Los más jóvenes recogen pétalos de peonías para decorar las calles durante la procesión del Corpus Christi.

\section{Chelidonium majus L.}

PAPAVERACEAE

Planta del yodo (10), celidonia (4), celedonia (3), cerigüeña (2), centidonia (1)

60P, 345P; 197F; 13V, 202V, 396V

\begin{tabular}{lc}
\hline Frecuencia de citación (FC): & 20 \\
\hline Número de usos (NU): & 2 \\
\hline Número registros de uso (RU): & 21 \\
\hline Frecuencia Relativa de Citación (FRC): & 0,14 \\
Índice de Importancia Cultural (IC): & 0,15 \\
Índice de Vigencia (IV): & 0,03 \\
\hline
\end{tabular}

Vigencia: vigente (23\%)

\section{Conocimientos:} ECOLOGÍA

Asociada a muros, paredones, y caminos circundantes.

\section{LÉXICO}

El característico color de su látex hace que se asimile su uso al del yodo para la desinfección de heridas, derivando además el nombre de planta del yodo.

Usos:

\section{MEDICINA}

- Piel y tejido celular subcutáneo (20): El látex que desprende el tallo al cortarlo se aplica en uso externo sobre las verrugas, también se extiende sobre cortaduras y pequeñas heridas como cicatrizante. En Polentinos recomiendan el látex sobre los callos para ablandarlos y eliminarlos y en Valcobero para eliminar los clavos de la piel.

\section{VETERINARIA}

- Piel y tejido celular subcutáneo (1): El látex se aplica sobre las heridas que se provocan las gallinas al picarse unas a otras.

PAPAVERACEAE

Eschscholzia californica Cham.

Amapola (2)

411P, 478P; 261F

\begin{tabular}{|ll|}
\hline Frecuencia de citación (FC): & 2 \\
\hline Número de usos (NU): & 1 \\
\hline Número registros de uso (RU): & 2 \\
\hline
\end{tabular}

Obtención: cultivada

Vigencia: vigente (100\%)

Usos:

ORNAMENTAL

- Patios, huertos y jardines (2): Se cultiva como planta ornamental de exterior en parterres de jardines o en macetas.

PAPAVERACEAE

Papaver rhoeas L.

Amapola (44), pirigallo (3)

36P, 132P; 133F; 121V, 381V

Obtención: silvestre 


\begin{tabular}{lc}
\hline Frecuencia de citación (FC): & 44 \\
\hline Número de usos (NU): & 5 \\
\hline Número registros de uso (RU): & 58 \\
\hline Frecuencia Relativa de Citación (FRC): & $\mathbf{0 , 3 2}$ \\
\hline Índice de Importancia Cultural (IC): & $\mathbf{0 , 4 2}$ \\
\hline Índice de Vigencia (IV): & $\mathbf{0 , 0 1}$ \\
\hline
\end{tabular}

Obtención: silvestre

Vigencia: vigente (3\%)

Conocimientos:

LÉXICO

Todas las citas obtenidas en Rabanal de las Llantas fueron bajo la denominación de pirigallo.

Usos:

\section{ALIMENTACIÓN ANIMAL}

- Forraje verde o seco (9): Empleada la planta entera como forraje verde para las vacas y especialmente citada para los conejos. En Pisón de Castrejón se recomienda dosificar el consumo en conejos, pues el abuso les produce diarrea.

\section{MEDICINA}

- Sistema respiratorio (4): Los pétalos de las flores se indican mediante infusión para el tratamiento de resfriados, catarros y tos convulsiva.

- Sistema nervioso (3): Utilizada la infusión de las flores por sus virtudes tranquilizantes, sedantes y antiespasmódicas. Ayuda a dormir y apaciguar estados nerviosos.

- Órganos de los sentidos (1): La cocción de pétalos se emplea en lavados de ojos, cuando se encontraban legañosos o enrojecidos.

\section{MEDIOAMBIENTAL}

- Malas hierbas (25): Planta reconocida como mala hierba, se escardaba sobre todo de los cultivos de cereal.

\section{ORNAMENTAL}

- Adorno floral y plantas de interior (4): Se hacían ramilletes para adornar en jarrones el interior de las casas. "Se ponían en un tarro, pero duraban muy poco".

\section{SOCIAL, SIMBÓLICO Y RITUAL}

- Ritual de ciclo anual (8): En mayo, mes de la Virgen según la cultura católica, se producía el máximo esplendor en la floración de la amapola. Las flores se utilizaban en ornamentación en fiestas religiosas como el Corpus Christi o en fiestas locales y en ofrendas los domingos de mayo en la iglesia local.
- Literatura oral popular (1): El dicho: "el cadillo le da brillo, el amapol le da color y la lapa lo agazapa", refiere al color que adquieren los cultivos con presencia de amapolas.

- Uso recreativo (3): Cuando la floración estaba a punto de suceder, los más jóvenes se entretenían inventando diversos juegos con los capullos florales. El más popular era el "titirifraile" que consistía en acertar el color del capullo floral, "si sale rojo era fraile, rosa titirifraile y blanco monja".

Observaciones: En el Partido Judicial de Saldaña, Macho Tomé (1892) indica el uso sedante de la amapola.

PAPAVERACEAE

Papaver somniferum $\mathrm{L}$.

Amapola (14), amapola real (2), flor de la droga (2)

94P, 392P; 315F; 274V

\begin{tabular}{lc}
\hline Frecuencia de citación (FC): & 18 \\
\hline Número de usos (NU): & 3 \\
\hline Número registros de uso (RU): & 28 \\
\hline
\end{tabular}

Obtención: cultivada

Vigencia: vigente (7\%)

Usos:

TÓXICO Y NOCIVO

- Tóxica para personas y animales (12): El látex de la cápsula verde es un líquido tóxico y narcótico, este hecho se conoce por los lugareños a través de un boca a boca, que provocó que en los años $80-90$ se erradicaran como cultivo.

\section{ORNAMENTAL}

- Patios, huertos y jardines (14): Cultivada en jardines, huertos y patios como planta ornamental por la extraordinaria belleza de sus flores. En diversas localidades de la zona la Guardia Civil prohibió su cultivo y ordenó su retirada, "me dijeron que ya podía quitar todas, que eso era droga", Cervera de Pisuerga.

- Adorno floral y plantas de interior (1): Las ramas con cápsulas se emplean en la elaboración de ramos y centros de flores secas.

\section{SOCIAL, SIMBÓLICO Y RITUAL}

- Uso recreativo (1): Los niños de Santibáñez de la Peña usaban las cápsulas secas como sonajeros. 


\section{PASSIFLORACEAE}

Passiflora caeruela L.

Pasiflora (1)

$195 \mathrm{~F}$

\begin{tabular}{|ll|}
\hline Frecuencia de citación (FC): & 1 \\
\hline Número de usos (NU): & 1 \\
\hline Número registros de uso (RU): & 1 \\
\hline
\end{tabular}

Obtención: cultivada

Vigencia: vigente (100\%)

Usos:

ORNAMENTAL

- Patios, huertos y jardines (1): En Aguilar de Campoo se cultiva en patios y jardines para tapizar tapias o muros, posee un tupido follaje y hermosas flores.

PLANTAGINACEAE

Antirrhinum majus L.

Boca de dragón (1)

\begin{tabular}{ll}
\hline Frecuencia de citación (FC): & 1 \\
\hline Número de usos (NU): & 1 \\
\hline Número registros de uso (RU): & 1 \\
\hline
\end{tabular}

Obtención: cultivada

Vigencia: vigente (100\%)

Usos:

ORNAMENTAL

- Patios, huertos y jardines (1): Se cultiva en parterres de jardines y macetas por su colorida y bella floración.

PLANTAGINACEAE

Digitalis purpurea L.

Dedalera (14), campanilla (3), cuete (5), chacleo (1)

87P, 500P; 41F; 21V, 108V, 402V

\begin{tabular}{lc}
\hline Frecuencia de citación (FC): & 23 \\
\hline Número de usos (NU): & 3 \\
\hline Número registros de uso (RU): & 38 \\
\hline Frecuencia Relativa de Citación (FRC): & $\mathbf{0 , 1 7}$ \\
\hline Índice de Importancia Cultural (IC): & $\mathbf{0 , 2 7}$ \\
Índice de Vigencia (IV): & $\mathbf{0 , 0 0}$ \\
\hline
\end{tabular}

Obtención: silvestre

Vigencia: abandonado

Usos:

TÓXICA Y NOCIVA
- Tóxica para personas y animales (14): Se trata de una planta muy venenosa, en algunos casos reconocida como tal, aunque en otros casos, apenas se daba importancia a su peligro, "Las campanillas son venenosas, pero jugábamos con ellas de pequeñas", El Campo. Otras veces se descubre su toxicidad por observación, como en San Martín de los Herreros "Una vez llevé hojas de cuetes para los conejos, porque no había otra cosa de verde (forraje) y se me murieron todos".

\section{ORNAMENTAL}

- Adorno floral y plantas de interior (5): Desde mayo hasta agosto es posible disfrutar de la espléndida floración rosada de esta planta, empleada con frecuencia para la confección de ramos de flor fresca, como ornamento en el hogar o en la iglesia local.

\section{SOCIAL, SIMBÓLICO Y RITUAL}

- Uso recreativo (19): Uno de los juegos más arraigados en el pasado, entre los niños de la comarca, consistía en soplar las flores, taparlas por la boca y hacerlas explotar contra la mano, este modo de actuación se conoce como chaclear, hacer pedorretas o tirar pedos.

Otros juegos mencionados se sirven de las flores simulando dedales, paracaídas, etc.

Observaciones: En la comarca se encuentra presente otra especie del mismo género, Digitalis parviflora, de propiedades también tóxicas, pero sin uso reconocido.

\section{PLANTAGINACEAE}

Plantago lanceolata L.

Hoja de lentén (5), hoja de llantel (2), llantén (5), lentel (1), lantel (2), alentel (1)

\begin{tabular}{lc} 
113P, 497P; 170F & \\
\hline Frecuencia de citación (FC): & 16 \\
\hline Número de usos (NU): & $\mathbf{3}$ \\
\hline Número registros de uso (RU): & $\mathbf{1 8}$ \\
Frecuencia Relativa de Citación (FRC): & $\mathbf{0 , 1 2}$ \\
\hline Índice de Importancia Cultural (IC): & $\mathbf{0 , 1 3}$ \\
\hline Índice de Vigencia (IV): & $\mathbf{0 , 0 1}$ \\
\hline
\end{tabular}

Obtención: silvestre

Vigencia: vigente (5\%)

Usos:

MEDICINA

- Sistema circulatorio (1): En Matabuena se aplican las hojas directamente sobre las almorranas para curarlas. 
- Sistema digestivo (2): En Recueva de la Peña se hace una infusión con las hojas de esta especie para detener la diarrea.

- Sistema respiratorio (5): Las hojas se preparan en infusión para tratamientos anticatarrales, es común mezclarla con otras especies que potencien sus virtudes como: verbena, romero, malva, manzanilla, orégano, tila o escaramujos. En Brañosera se cuecen las hojas con granos de cebada y se realizan gárgaras para suavizar la garganta.

- Piel y tejido celular subcutáneo (5): Tiene buena reputación como cicatrizante, las hojas aplicadas directamente o machadas sobre las heridas tienen la propiedad de suturar con rapidez rozaduras y cortes en la piel.

En Estalaya se fríen las hojas con un poco de aceite y se colocan con un trapo sobre los diviesos y los granos infectados.

- Órganos de los sentidos (2): Se lavan los ojos enfermos con la infusión de la parte aérea de la planta, según remedio recogido en Celada de Roblecedo.

\section{VETERINARIO}

- Sistema genito-urinario (1): En Resoba se describe el cocimiento de las hojas de lentén como remedio para tratar a las vacas que orinaban sangre, el líquido se introducía por la boca con una botella.

- Piel y tejido celular subcutáneo (1): Las heridas de los animales se curaban aplicando directamente sobre ellas, hojas machacadas.

\section{MEDIOAMBIENTAL}

- Malas hierbas (1): Reconocida en San Salvador de Cantamuda como mala hierba de los prados.

Observaciones: Los informantes diferencian las especies de este género por el tamaño de las hojas, en concreto, $P$. lanceolata es la que posee las hojas más estrechas.

\section{PLANTAGINACEAE}

Plantago major L.

Hoja mantequera (1)

152P; 294F; 215V, 457V

\begin{tabular}{lc}
\hline Frecuencia de citación (FC): & 1 \\
\hline Número de usos (NU): & 1 \\
\hline Número registros de uso (RU): & 1 \\
\hline Frecuencia Relativa de Citación (FRC): & 0,01 \\
\hline Índice de Importancia Cultural (IC): & 0,01 \\
\hline Índice de Vigencia (IV): & 0,00 \\
\hline
\end{tabular}

Obtención: silvestre

Vigencia: abandonado

Usos:

ALIMENTACIÓN ANIMAL

- Forraje verde o seco (1): En Brañosera se utilizan las hojas como forraje verde para los conejos.

Observaciones: Es probable que Plantago media, presente en la zona, se utilice también como forraje.

\section{PLANTAGINACEAE}

Veronica beccabunga $\mathrm{L}$. Berraza (1)

328P; 160F

\begin{tabular}{lc}
\hline Frecuencia de citación (FC): & 1 \\
\hline Número de usos (NU): & 1 \\
\hline Número registros de uso (RU): & 1 \\
\hline Frecuencia Relativa de Citación (FRC): & 0,01 \\
\hline Índice de Importancia Cultural (IC): & 0,01 \\
\hline
\end{tabular}

Obtención: silvestre

\section{Conocimientos:}

LÉXICO

El nombre despectivo de berraza refiere especies no comestibles, al igual que las berras (Apium nodiflurum).

Usos:

\section{TÓXICA Y NOCIVA}

- Tóxica para personas y animales (1): Esta especie aparece en las fuentes junto con los berros y se advierte en Santa María de Redondo no confundirlas ya que no es comestible.

\section{PLUMBAGINACEAE}

Armeria pubinervis Boiss. Flor de las coronas (3)

\begin{tabular}{lc} 
237P, 516P; 55F; 6V, 144V & \\
\hline Frecuencia de citación (FC): & 5 \\
\hline Número de usos (NU): & 2 \\
\hline Número registros de uso (RU): & 6 \\
\hline Frecuencia Relativa de Citación (FRC): & $\mathbf{0 , 0 4}$ \\
Índice de Importancia Cultural (IC): & $\mathbf{0 , 0 4}$ \\
\hline Índice de Vigencia (IV): & $\mathbf{0 , 0 1}$ \\
\hline
\end{tabular}

Obtención: silvestre

Vigencia: vigente (33\%) 
Conocimientos:

LÉXICO

El nombre deriva del uso al que se destinan sus flores, "de las coronas".

Usos:

ORNAMENTAL

- Adorno floral y plantas de interior (4): Las flores se utilizan en centros de flores secas para decoración.

\section{SOCIAL, SIMBÓLICA Y RITUAL}

- Uso recreativo (2): LoS niños jugaban trenzando tallos florecidos con los que confeccionaban coronas. Los tallos resultan más flexibles y dóciles para entretejerlos al principio de la primavera.

POLYGONACEAE

Fallopia baldschuanica (Regel) Holub

Enredadera (2)

\begin{tabular}{ll}
\hline Frecuencia de citación (FC): & 2 \\
\hline Número de usos (NU): & 2 \\
\hline Número registros de uso (RU): & 4 \\
\hline
\end{tabular}

Obtención: cultivada

Vigencia: vigente (50\%)

Usos:

ALIMENTACIÓN HUMANA

- Golosinas y masticatorias (2): Los brotes tiernos de los tallos se mastican y de ellos se obtiene un sabor ácido apetecible.

\section{ORNAMENTAL}

- Patios, huertos y jardines (2): Se cultiva en muros y paredes de jardines y huertos como trepadora tapizante.

\section{POLYGONACEAE}

Persicaria bistorta (L.) Samp.

Cornicabra (4)

154P, 421P; 238F; $92 \mathrm{~V}$

\begin{tabular}{lc}
\hline Frecuencia de citación (FC): & 4 \\
\hline Número de usos (NU): & 1 \\
\hline Número registros de uso (RU): & 4 \\
\hline Frecuencia Relativa de Citación (FRC): & 0,03 \\
Índice de Importancia Cultural (IC): & 0,03 \\
\hline Índice de Vigencia (IV): & 0,01 \\
\hline
\end{tabular}

Obtención: silvestre

Vigencia: vigente (25\%)
Conocimientos:

\section{ECOLOGÍA}

Se dan en prados húmedos.

Usos:

\section{ALIMENTACIÓN HUMANA}

- Verduras y hortalizas (4): Las hojas tiernas se comen directamente en el campo o se recogen para cocinar como verdura de acompañamiento en diversos guisos, cocidos y potajes. "Las cocía con garbanzos o con unas patatas, cuando no tenía berza", Herreruela de Castillería.

\section{POLYGONACEAE}

\section{Rumex acetosa $\mathrm{L}$.}

Tallos (51), acera (32), ancera (14), acedera (10), acidera (1), acerón (3), ancerón (2), cornicabra (1), grana (1)

PALAB2634, 4P, 271P; 60F; 63V, 178V, 206V, 216V, 217V, 218V, 491V

\begin{tabular}{lc|}
\hline Frecuencia de citación (FC): & 102 \\
\hline Número de usos (NU): & 2 \\
\hline Número registros de uso (RU): & 110 \\
\hline Frecuencia Relativa de Citación (FRC): & 0,73 \\
\hline Índice de Importancia Cultural (IC): & 0,79 \\
\hline Índice de Vigencia (IV): & 0,03 \\
\hline
\end{tabular}

Obtención: silvestre

Vigencia: vigente (4\%)

Conocimientos:

ECOLOGÍA

Se recolectan en los prados.

Usos:

\section{ALIMENTACIÓN HUMANA}

- Verduras y hortalizas (16): Las hojas tiernas al principio de la primavera se añaden en ensaladas que se aliñan con aceite, vinagre, sal o azúcar. Se refiere un exquisito sabor ácido.

- Golosinas y masticatorias (93): Los más jóvenes gustan de chupar e incluso masticar los tallos, de los que se disfruta su acidez. Una vez florece el tallo se pone correoso y se aconseja no consumir.

\section{SOCIAL, SIMBÓLICO Y RITUAL}

- Uso recreativo (1): En el popular juego de las comiditas las hojas eran los filetes, en San Cebrián de Mudá.

Observaciones: Se han agrupado los usos comestibles en la especie identificada Rumex acetosa, sin embargo es probable que otras 
especies del mismo género se hayan utilizado también para alimentación humana, como $R$. acetosella o $R$. scutatus.

POLYGONACEAE

\section{Rumex conglomeratus Murray}

Chuma (2)

\begin{tabular}{lc}
\hline $206 \mathrm{P} ; 52 \mathrm{~F}$ & \\
\hline Frecuencia de citación (FC): & 2 \\
\hline Número de usos (NU): & $\mathbf{1}$ \\
\hline Número registros de uso (RU): & $\mathbf{2}$ \\
\hline Frecuencia Relativa de Citación (FRC): & $\mathbf{0 , 0 1}$ \\
\hline Índice de Importancia Cultural (IC): & $\mathbf{0 , 0 1}$ \\
\hline Índice de Vigencia (IV): & $\mathbf{0 , 0 0}$ \\
\hline
\end{tabular}

Obtención: silvestre

Vigencia: abandonado

Usos:

SOCIAL, SIMBÓLICO Y RITUAL

- Alucinógenas, narcóticas y fumatorias (2): Los frutos y las hojas una vez secos se desmenuzan entre las manos y se lían en papel de fumar, sustituían al tabaco en época de escasez.

POLYGONACEAE

\section{Rumex crispus $\mathrm{L}$.}

R. obtusifolius $\mathrm{L}$.

Amargaza (7), margaza (1), acerón (5), ancerón (1), ramagón (2), planta del tabaco (2), tabaco silvestre (2)

Rumex crispus: 71P, 300P; 168F; 64V, 139V, 179V, 275V, 600V

R. obtusifolius: $145 \mathrm{P}$

\begin{tabular}{|lc|}
\hline Frecuencia de citación (FC): & 20 \\
\hline Número de usos (NU): & 6 \\
\hline Número registros de uso (RU): & 26 \\
\hline Frecuencia Relativa de Citación (FRC): & 0,14 \\
\hline Índice de Importancia Cultural (IC): & 0,19 \\
\hline Índice de Vigencia (IV): & 0,00 \\
\hline
\end{tabular}

Obtención: silvestre

Vigencia: abandonado

Conocimientos:

LÉXICO

Se denomina ordeñar a la acción de recolectar los frutos rodeando el tallo con la mano, y recorriéndolo hasta desprenderlos.

Usos:

ALIMENTACIÓN ANIMAL
- Forraje verde o seco (8): Se cita el uso de las hojas como forraje verde para vacas, conejos y gallinas. En Camasobres empleaban los frutos verdes en estado inmaduro como alimento para los cerdos.

\section{MEDICINA}

- Sistema digestivo (1): Los frutos en infusión se toman en Resoba como tratamiento antidiarreico.

\section{VETERINARIA}

- Piel y tejido celular subcutáneo (1): EI cocimiento de la raíz se utiliza en Villanueva de la Torre para lavar las heridas infectadas del ganado.

\section{MEDIOAMBIENTAL}

- Malas hierbas (3): Los tallos endurecidos dificultan la siega, por ello son considerados mala hierba en los prados.

\section{ORNAMENTAL}

- Adorno floral y plantas de interior (1): En Santa María de Redondo testimonian el uso de los tallos secos granados, en centros ornamentales.

\section{SOCIAL, SIMBÓLICO Y RITUAL}

- Uso recreativo (4): Los frutos simulaban el arroz en el popular juego infantil de las comiditas.

- Alucinógenas, narcóticas y fumatorias (8): Las hojas secas de las amargazas secas se utilizan como sustitutivo del tabaco en caso de escasez.

POLYGONACEAE

\section{Rumex longifolius DC. \\ Cornicabra (1)}

\begin{tabular}{lc} 
120P, 303P, 316P; 172F; 238V & \\
\hline Frecuencia de citación (FC): & $\mathbf{1}$ \\
\hline Número de usos (NU): & 1 \\
\hline Número registros de uso (RU): & 1 \\
\hline Frecuencia Relativa de Citación (FRC): & $\mathbf{0 , 0 1}$ \\
\hline Índice de Importancia Cultural (IC): & $\mathbf{0 , 0 1}$ \\
\hline Índice de Vigencia (IV): & $\mathbf{0 , 0 0}$ \\
\hline
\end{tabular}

Obtención: silvestre

Vigencia: abandonado

Usos:

\section{ALIMENTACIÓN HUMANA}

- Verduras y hortalizas (1): Se recolectan las hojas tiernas durante la primavera y se utilizan 
como verdura en potajes o guisos, "se cuecen como las acelgas y se echaban a los garbanzos y a los titos", Vidrieros.

POLYGONACEAE

\section{Rumex pulcher $\mathrm{L}$.}

Ramagón (1)

432P; 124F; 558V, 559V

\begin{tabular}{lc}
\hline Frecuencia de citación (FC): & 1 \\
\hline Número de usos (NU): & 1 \\
\hline Número registros de uso (RU): & 1 \\
\hline Frecuencia Relativa de Citación (FRC): & 0,01 \\
\hline Índice de Importancia Cultural (IC): & 0,01 \\
\hline Índice de Vigencia (IV): & 0,00
\end{tabular}

Obtención: silvestre

Vigencia: abandonado

Usos:

\section{VETERINARIA}

- Sistema digestivo (1): Se recoge en Villanueva de la Torre el uso de la cocción de la raíz para empachos del ganado vacuno y también se daba a beber este cocimiento cuando el rumio se paralizaba.

\section{PRIMULACEAE}

\section{Primula veris $\mathrm{L}$.}

Cuquillo (8), chupete (3), chupa (2), bragas de cucubillo (2), bragas de cuco (1)

PALAB2624, 212P, 518P; 53F; 45V

\begin{tabular}{lc}
\hline Frecuencia de citación (FC): & 18 \\
\hline Número de usos (NU): & 3 \\
\hline Número registros de uso (RU): & 20 \\
Frecuencia Relativa de Citación (FRC): & 0,13 \\
\hline Índice de Importancia Cultural (IC): & 0,14 \\
\hline Índice de Vigencia (IV): & 0,01 \\
\hline
\end{tabular}

Obtención: silvestre

Vigencia: vigente (10\%)

Conocimientos:

LÉXICO

En Santibáñez de la Peña recibe el nombre de bragas de cucubillo y en Matabuena el de bragas de cuco, similar al que se menciona en la comarca vecina de Campoo.

Usos:

\section{ALIMENTACIÓN HUMANA}

- Golosinas y masticatorias (14): La floración del cuquillo acontece al comienzo de la primavera, alrededor del mes de abril. Un entretenimiento extendido en el pasado entre los niños consistía en chupar el néctar de las flores. Los niños también comían el tallo en los primeros momentos de la primavera, cuando se encuentra tierno y fresco, se refiere un sabor azucarado que se mascaba a modo de golosina.

\section{MEDICINA}

- Sistema respiratorio (1): Se indica en Celada de Roblecedo el cocimiento de la raíz para combatir infecciones respiratorias y como tratamiento anticatarral.

- Sistema nervioso (1): En la misma localidad, se señala el empleo de la infusión del tallo con flores como tratamiento para aliviar dolores de cabeza.

\section{ORNAMENTAL}

- Adorno floral y plantas de interior (4): La planta es muy estimada por su temprana y esplendida floración. Durante la primavera las mujeres de la zona recogen con frecuencia esta planta con el fin de realizar arreglos florales de flor cortada. El principal destino de los ramilletes de flores eran jarrones para el interior de las viviendas.

Observaciones: En la zona se ha observado también la presencia de Primula elatior.

RANUNCULACEAE

Aconitum napellus $\mathrm{L}$.

A. vulparia Rchb.

Hierba piojera (4), acónito (5), aconito (1)

Aconitum napellus: 139P, 280P; 46F; 369V

A. vulparia: $240 \mathrm{P} ; 231 \mathrm{~F}$

\begin{tabular}{lc}
\hline Frecuencia de citación (FC): & 9 \\
\hline Número de usos (NU): & 4 \\
\hline Número registros de uso (RU): & 12 \\
\hline Frecuencia Relativa de Citación (FRC): & 0,06 \\
Índice de Importancia Cultural (IC): & 0,09 \\
\hline Índice de Vigencia (IV): & 0,01 \\
\hline
\end{tabular}

Obtención: silvestre

Vigencia: vigente (16\%)

Conocimientos:

ECOLOGÍA

Aparece en las orillas de los arroyos y bordes de ríos, tanto la especie de flor azul (Aconitum napellus), como la de flor amarilla (A. vulparia),

Usos:

MEDICINA 
- Otras enfermedades infecciosas y parasitarias (2): Se recoge el uso del acónito para tratamiento de las afecciones cutáneas provocadas por infestación de piojos en el cabello humano. Con frecuencia esta enfermedad parasitaria (pediculosis) afectaba en la edad infantil, resultando muy contagiosa y con cierto impacto social, al asociarse erróneamente a personas con escasa higiene. Cuando se detectaba la presencia de liendres o de individuos adultos, se procedía a la recolección de la planta, cortando o arrancando la vara entera con o sin flores, dependiendo de la época del año en que se requiriera su provecho.

Para su preparación se hervía agua en un caldero de cobre o en un puchero grande y se introducía la planta fresca recién recogida, manteniendo unos diez minutos la cocción. Se dejaba reposar hasta disminuir la temperatura y resultar adecuada para verter el líquido sobre el pelo y el cuero cabelludo.

\section{VETERINARIA}

- Sistema digestivo (1): El mismo tratamiento que el indicado para personas se aconsejó para animales, principalmente para los terneros más jóvenes, al parecer más propensos a padecer esta afección según los testimonios recopilados. Con el cocimiento de las hojas se lavaba bien al animal, desapareciendo los piojos al poco tiempo.

\section{TóXICO Y NOCIVO}

- Tóxica para personas y animales (4): Se trata de una planta muy tóxica por su contenido en alcaloides que resultan mortales. En la comarca se reconoce la toxicidad de la planta por la simple observación del medio: "Las vacas pacen todo de alrededor, pero esta no la comen", Herreruela de Castillería. "Si llevaban a pacer los corderos por bajo del puente, a veces alguno se moría porque decían que comían esto venenoso", Tremaya.

\section{ORNAMENTAL}

- Adorno floral y plantas de interior (5): La floración de la planta acontece entre los meses de julio y septiembre, resulta muy atractiva y de gran vistosidad por su coloración azul, violeta ( $A$. napellus) o amarilla (A. vulparia). Se ha empleado para la confección de ramos de flor fresca en la decoración de alguna estancia en el hogar.
RANUNCULACEAE

Anemone nemorosa $\mathrm{L}$. Campanilla (1)

238P, 310P; 180F; 3V, 4V

\begin{tabular}{ll}
\hline Frecuencia de citación (FC): & 1 \\
Número de usos (NU): & 0 \\
\hline Número registros de uso (RU): & 0 \\
\hline
\end{tabular}

Obtención: silvestre

Conocimientos:

ECOLOGÍA

Aparece en bosques de robles.

\section{RANUNCULACEAE}

Aquilegia vulgaris $\mathrm{L}$.

Aguileña (3), flor de riachino (1), campanilla (1), cucubillo (1)

\begin{tabular}{lc} 
97P, 350P; 297F; 5V, 143V, 519V & \\
\hline Frecuencia de citación (FC): & $\mathbf{7}$ \\
\hline Número de usos (NU): & $\mathbf{1}$ \\
\hline Número registros de uso (RU): & $\mathbf{7}$ \\
\hline Frecuencia Relativa de Citación (FRC): & $\mathbf{0 , 0 5}$ \\
\hline Índice de Importancia Cultural (IC): & $\mathbf{0 , 0 5}$ \\
\hline Índice de Vigencia (IV): & $\mathbf{0 , 0 3}$ \\
\hline
\end{tabular}

Obtención: silvestre

Vigencia: vigente (57\%)

Usos:

ORNAMENTAL

- Patios, huertos y jardines (3): La aguileña se transplanta desde el monte a parterres de jardines y a macetas en el exterior de la vivienda.

- Adorno floral y plantas de interior (4): Sus flores azules son muy vistosas, sirviendo para decorar algún jarrón en el interior de las viviendas.

RANUNCULACEAE

Consolida ajacis (L.) Schur

Espuela de caballero (1)

\begin{tabular}{ll}
\hline $84 \mathrm{~F}$ & \\
\hline Frecuencia de citación (FC): & 1 \\
\hline Número de usos (NU): & 1 \\
\hline Número registros de uso (RU): & 1 \\
\hline
\end{tabular}

Obtención: cultivada

Vigencia: vigente (100\%)

Usos: 


\section{ORNAMENTAL}

- Patios, huertos y jardines (1): Se cultiva en jardines y macetas en el exterior de la vivienda como ornamental.

\section{RANUNCULACEAE}

\section{Helleborus foetidus $\mathrm{L}$.}

\section{$H$. viridis $\mathrm{L}$.}

Hierba de las culebras (1), planta de las culebras (1), mantecón (1)

Helleborus foetidus: 116P, 423P; $100 \mathrm{~F}$

H. viridis: 365P; 325F; 33V, 456V

\begin{tabular}{lc}
\hline Frecuencia de citación (FC): & 3 \\
\hline Número de usos (NU): & $\mathbf{2}$ \\
\hline Número registros de uso (RU): & 3 \\
\hline Frecuencia Relativa de Citación (FRC): & $\mathbf{0 , 0 2}$ \\
\hline Índice de Importancia Cultural (IC): & $\mathbf{0 , 0 2}$ \\
\hline Índice de Vigencia (IV): & $\mathbf{0 , 0 0}$ \\
\hline
\end{tabular}

Obtención: silvestre

Vigencia: abandonado

Conocimientos:

ECOLOGÍA

Suele encontrarse "entre robledal y matorral".

\section{LÉXICO}

La semilla e incluso la planta se denomina mantecón. Se menciona el nombre adyacente "de las culebras" en sentido de repudio hacia la planta.

\section{Usos:}

\section{ALIMENTACIÓN HUMANA}

- Golosinas y masticatorias (1): Asegura un informante de Arbejal que siendo niños se comían las semillas de esta planta, se cogían unas cuantas y después se pelaban, refiriendo un sabor parecido al de una legumbre verde.

\section{TóxICO Y NOCIVO}

- Tóxicas para personas y animales (2): Se reconoce como planta venenosa, apuntando que los animales no las comen y que su olor resulta muy desagradable.

Observaciones: Para Font Quer (1961) la planta posee heleborina, tóxico cardíaco de propiedades drásticas, sin embargo, se testimonia el uso comestible de las semillas.

RANUNCULACEAE

\section{Ranunculus arvensis L.} Cadillo (2)
451P, 543P; 265F

\begin{tabular}{lc}
\hline Frecuencia de citación (FC): & 2 \\
\hline Número de usos (NU): & 1 \\
\hline Número registros de uso (RU): & 2 \\
\hline Frecuencia Relativa de Citación (FRC): & 0,01 \\
\hline Índice de Importancia Cultural (IC): & 0,01 \\
\hline
\end{tabular}

Obtención: silvestre

Usos:

MEDIOAMBIENTAL

- Malas hierbas (2): Se escardan de las tierras de cultivo, sobre todo de patatales y trigales.

\section{RANUNCULACEAE}

Trollius europaeus $\mathrm{L}$.

Botón (4), capricho del cielo (1), flor del tobar (1)

\begin{tabular}{lc} 
181P; 208F; 191V & \\
\hline Frecuencia de citación (FC): & $\mathbf{7}$ \\
\hline Número de usos (NU): & $\mathbf{1}$ \\
Número registros de uso (RU): & $\mathbf{7}$ \\
\hline Frecuencia Relativa de Citación (FRC): & $\mathbf{0 , 0 5}$ \\
Índice de Importancia Cultural (IC): & $\mathbf{0 , 0 5}$ \\
\hline Índice de Vigencia (IV): & $\mathbf{0 , 0 2}$
\end{tabular}

Obtención: silvestre, cultivada

Vigencia: vigente (47\%)

Conocimientos:

\section{ECOLOGÍA}

Se desarrolla bien en prados húmedos de montaña.

\section{LÉXICO}

El nombre de botón refiere a la planta y a la flor, que posee aspecto de capullo cerrado. El nombre de capricho del cielo se recoge en Resoba y en Vidrieros el de flor del tobar, porque salía en tierra calcárea muy porosa.

Usos:

\section{ORNAMENTAL}

- Patios, huertos y jardines (3): Se extraen cuidadosamente del monte y se plantan en orillas de huertas, jardines y patios de las viviendas como ornamental.

- Adorno floral y plantas de interior (4): Desde mediados de primavera a mediados de verano florecen los botones, hecho aprovechado por mujeres para hacer ramos decorativos en floreros para las viviendas. 
Observaciones: De la Fuente Sanz (1987) la señala como ornamental, observando que se presenta únicamente en la Montaña, en prados y zonas húmedas.

Se indica presencia abundante en el valle de Pineda.

\section{RESEDACEAE}

\section{Reseda lutea $\mathrm{L}$ \\ Gualda (1)}

\begin{tabular}{lc} 
149P; 204F & \\
\hline Frecuencia de citación (FC): & 1 \\
\hline Número de usos (NU): & 1 \\
\hline Número registros de uso (RU): & 1 \\
Frecuencia Relativa de Citación (FRC): & $\mathbf{0 , 0 1}$ \\
Índice de Importancia Cultural (IC): & $\mathbf{0 , 0 1}$ \\
\hline Índice de Vigencia (IV): & $\mathbf{0 , 0 1}$ \\
\hline
\end{tabular}

Obtención: silvestre

Vigencia: vigente (100\%)

Usos:

ORNAMENTAL

- Adorno floral y plantas de interior (1): En San Felices de Castillería se incluyen las inflorescencias en centros de flor seca para decoración de interiores.

RHAMNACEAE

Frangula alnus Mill.

Meaperro (1), uva de perro (1)

141P, 354P; 248F; 411V, 412V

\begin{tabular}{lc}
\hline Frecuencia de citación (FC): & $\mathbf{2}$ \\
\hline Número de usos (NU): & 1 \\
\hline Número registros de uso (RU): & 2 \\
\hline Frecuencia Relativa de Citación (FRC): & $\mathbf{0 , 0 1}$ \\
\hline Índice de Importancia Cultural (IC): & $\mathbf{0 , 0 1}$ \\
\hline
\end{tabular}

Obtención: silvestre

Conocimientos:

LÉXICO

Los nombres recogidos meaperros y uva de perro refieren tanto al arbusto como a los frutos. Resultan nombres de alusión despectiva y que sugiere una advertencia para no llevarse a la boca.

Usos:

TÓXICA Y NOCIVA

- Tóxica para personas y animales (2): Se advierte que los frutos son tóxicos y no se deben consumir.

\section{Rhamnus alpina L.}

\section{RHAMNACEAE}

Teja blanca (1), uva de oso (1), pudio (1)

\begin{tabular}{lc} 
424P, 466P; 122F; 172V, 237V & \\
\hline Frecuencia de citación (FC): & $\mathbf{2}$ \\
\hline Número de usos (NU): & $\mathbf{2}$ \\
\hline Número registros de uso (RU): & $\mathbf{2}$ \\
Frecuencia Relativa de Citación (FRC): & $\mathbf{0 , 0 1}$ \\
\hline Índice de Importancia Cultural (IC): & $\mathbf{0 , 0 1}$ \\
\hline Índice de Vigencia (IV): & $\mathbf{0 , 0 0}$ \\
\hline
\end{tabular}

Obtención: silvestre

Vigencia: abandonado

Usos:

ALIMENTACIÓN ANIMAL

- Pasto (1): Los osos aprecian con gusto los frutos maduros de esta especie.

\section{INDUSTRIA Y ARTESANÍA}

- Herramientas y utensilios (1): Se señala en Resoba que la madera de la teja blanca es adecuada para elaborar mangos de herramientas.

ROSACEAE

Amelanchier ovalis Medik.

Amilloma (9), amijoma (3), sorbo (6), anietano (2)

\begin{tabular}{lc} 
173P, 282P; 291F; 570V & \\
\hline Frecuencia de citación (FC): & 20 \\
\hline Número de usos (NU): & 1 \\
\hline Número registros de uso (RU): & 20 \\
\hline Frecuencia Relativa de Citación (FRC): & 0,14 \\
\hline Índice de Importancia Cultural (IC): & 0,14 \\
\hline Índice de Vigencia (IV): & 0,01 \\
\hline
\end{tabular}

Obtención: silvestre

Vigencia: vigente (10\%)

Conocimientos:

LÉXICO

El mismo nombre sirve para designar tanto a la especie, como al fruto. En el valle de los Redondos se recoge el nombre de sorbo, en el valle de Castillería lo conocen como anietano y en el valle Estrecho se denomina amilloma, excepto en Alba de los Cardaños que deriva a amijoma.

Usos:

\section{ALIMENTACIÓN HUMANA}

- Frutas y frutos dulces (20): La parte aprovechable son los frutos y el momento 
óptimo de recolección suele ser a final del verano o principios del otoño. Se consumen directamente en crudo en el campo una vez han madurado, momento en el cual los frutos tornan hacia un color azul oscuro, casi negro y elevan su nivel de azúcar, resultando más apetecibles. El color, la forma e incluso el sabor recuerda en cierto modo al de los conocidos ráspanos (arándanos).

ROSACEAE

Crataegus monogyna Jacq.

Espino (41), espino albar (6), espino blanco (6), espino majolero (1), majueto (32), amajueto (15)

PALAB2623, 8P, 258P; 3F; 16V, 106V, 152V, 507V, $521 \mathrm{~V}, 565 \mathrm{~V}$

\begin{tabular}{lc}
\hline Frecuencia de citación (FC): & 99 \\
\hline Número de usos (NU): & 9 \\
\hline Número registros de uso (RU): & 179 \\
\hline Frecuencia Relativa de Citación (FRC): & $\mathbf{0 , 7 1}$ \\
\hline Índice de Importancia Cultural (IC): & 1,29 \\
\hline Índice de Vigencia (IV): & 0,03 \\
\hline
\end{tabular}

Obtención: silvestre

Vigencia: vigente (2\%)

Conocimientos:

LÉXICO

Los frutos se conocen con el nombre de majuetas o amajuetas.

Usos:

ALIMENTACIÓN HUMANA

- Verduras y hortalizas (4): Las primeras hojas salen en primavera se comen en crudo directamente en el campo.

- Frutas y frutos dulces (83): Se aprovecha el fruto que se recoge una vez madura a principio del otoño y se consumen en crudo. Aunque algo insípido, se come frecuentemente.

- Bebidas alcohólicas (2): Se elabora un licor macerando los frutos en aguardiente.

- Golosinas y masticatorias (2): Los brotes tiernos del espino que aparecen en primavera son apreciados para su consumo directo en el campo.

\section{ALIMENTACIÓN ANIMAL}

- Forraje verde o seco (1): Las ramas con hojas se cortan y se sirven como forraje para los conejos.

- Pasto (2): Las ovejas y las cabras gustaban de aprovechar las hojas del espino. También los pájaros consumen los frutos.
- Plantas melíferas (1): Planta de interés melífero por la extraordinaria floración que explotan las abejas.

\section{MEDICINA}

- Sistema circulatorio (6): Se utilizan sus flores en infusión, apuntándose beneficios y mejoras para el sistema circulatorio, además de rebajar y regular la tensión.

- Sistema respiratorio (6): La infusión de las flores se emplea para aliviar los síntomas del catarro y de los resfriados.

\section{COMBUSTIBLE}

- Leña (16): Utilizado como combustible puntual en la cocción del pan, recomendado para atizar el horno por su gran poder calorífico.

- Carbón (1): En Rabanal de las Llantas recuerdan utilizar leña de espino albar para elaborar carbón vegetal.

\section{CONSTRUCCIÓN}

- Cercas, tapias y vallas (17): Se cortaban ramas de espino para servir de cerramiento en fincas, hortales o eras. Sus espinas y ramas lo convierten en una buena barrera para impedir el paso de personas y animales.

\section{INDUSTRIA Y ARTESANÍA}

- Herramientas y utensilios (26): La madera del espino es dura y resistente, por ello se utilizó para cachavas, mangos de herramientas, badajos para los cencerros, cubiertos, etc.

- Cestería, recipientes y envoltorios (4): Los aros y las costillas de las típicas cestas se realizaban con madera de espino, de verdes eran dóciles y se domaban bien a la forma deseada.

\section{MEDIOAMBIENTAL}

- Injerto (1): En Villanueva de Arriba se injertaban los perales sobre patrones de espino.

\section{ORNAMENTAL}

- Adorno floral y plantas de interior (5): Las flores desprenden un agradable olor, por lo que se llevaban ramos a las casas para adornar en algún jarrón.

\section{SOCIAL, SIMBÓLICO Y RITUAL}

- Ritual de ciclo anual (1): Se llevaban ramos floridos en Resoba a los altares del Corpus Christi.

- Uso recreativo (1): Los niños incorporaban las espinas en juegos infantiles, como el de pinchar 
granos de cereal y acertar cual de ellos era el marcado.

\section{ROSACEAE}

Filipendula ulmaria (L.) Maxim.

Reina de los prados (1)

479P; 129F; 523V

\begin{tabular}{lc}
\hline Frecuencia de citación (FC): & 2 \\
\hline Número de usos (NU): & 1 \\
\hline Número registros de uso (RU): & 3 \\
\hline Frecuencia Relativa de Citación (FRC): & 0,01 \\
\hline Índice de Importancia Cultural (IC): & 0,02 \\
\hline Índice de Vigencia (IV): & 0,00 \\
\hline
\end{tabular}

Obtención: silvestre

Vigencia: abandonado

Conocimientos:

\section{ECOLOGÍA}

Sale "al pie de los ríos y de las carreteras".

Usos:

MEDICINA

- Sistema genito-urinario (1): En Celada de Roblecedo se señala la infusión de la parte aérea como diurético.

- Sistema nervioso (2): Se utiliza la infusión de las flores para aplacar el dolor de cabeza.

Observaciones: Comentan en Ventanilla que en el pasado no se hacía uso de esta especie.

\section{ROSACEAE}

\section{Filipendula vulgaris Moench}

226P; 232F; 26V

\begin{tabular}{lc}
\hline Frecuencia de citación (FC): & 2 \\
\hline Número de usos (NU): & 1 \\
\hline Número registros de uso (RU): & 2 \\
\hline Frecuencia Relativa de Citación (FRC): & 0,01 \\
\hline Índice de Importancia Cultural (IC): & 0,01 \\
\hline Índice de Vigencia (IV): & 0,01 \\
\hline
\end{tabular}

Obtención: silvestre

Vigencia: vigente (50\%)

Usos:

ORNAMENTAL

- Adorno floral y plantas de interior (2): Se cortan ramos de flores, que se ubican en jarrones con agua para decoración de interiores.
ROSACEAE

Fragaria $\mathrm{x}$ ananassa (Duchesne ex Weston) Duchesne ex Rozier

Fresa (4)

\begin{tabular}{|ll|}
\hline $193 F$ & \\
\hline Frecuencia de citación (FC): & 4 \\
\hline Número de usos (NU): & 1 \\
\hline Número registros de uso (RU): & 4 \\
\hline
\end{tabular}

Obtención: cultivada

Vigencia: vigente (100\%)

Usos:

\section{ALIMENTACIÓN HUMANA}

- Frutas y frutos dulces (4): Se cultivan en algunas huertas por sus exquisitos frutos, que se consumen una vez alcanzan la madurez.

ROSACEAE

Fragaria vesca $\mathrm{L}$.

Amiérgano (59), miérgano (7), fresa (4), abijano (3)

PALAB2622, 13P, 272P; 164F; 111V

\begin{tabular}{lc}
\hline Frecuencia de citación (FC): & 73 \\
\hline Número de usos (NU): & 2 \\
\hline Número registros de uso (RU): & 75 \\
\hline Frecuencia Relativa de Citación (FRC): & 0,53 \\
\hline Índice de Importancia Cultural (IC): & 0,54 \\
\hline Índice de Vigencia (IV): & $\mathbf{0 , 0 2}$ \\
\hline
\end{tabular}

Obtención: silvestre

Vigencia: vigente (4\%)

\section{Conocimientos:}

\section{LÉXICO}

En la localidad de Rebanal de las Llantas se reconoce a esta especie con el singular nombre de abijano. En el resto de citas obtenidas, denominaron a esta especie amiérgano o su derivación miérgano, nombre por el que se conoce a los frutos y que se extiende también para nombrar a la planta entera.

En Casavegas se encuentra el pago "Los Amiérganos".

Usos:

\section{ALIMENTACIÓN HUMANA}

- Frutas y frutos dulces (73): La parte comestible es el fruto y el momento óptimo de recolección se produce en el mes de julio, cuando adquiere un color rojo intenso. Lo más usual es consumir los frutos recién recogidos en el campo, aunque en ocasiones, si el acopio de frutos resulta abundante, se llevan a casa como 
postre o para acompañar algún plato de repostería.

Su aspecto es más pequeño que la conocida fresa cultivada, pero con un sabor muy intenso y sabroso.

\section{ALIMENTACIÓN ANIMAL}

- Pasto (2): En el verano los venados, los osos y otros animales silvestres buscan ávidamente los frutos.

ROSACEAE

\section{Geum urbanum L.}

Hierba de San Benito (1)

327P, 480P; 117F; 30V

\begin{tabular}{lc}
\hline Frecuencia de citación (FC): & 1 \\
\hline Número de usos (NU): & 1 \\
\hline Número registros de uso (RU): & 1 \\
\hline Frecuencia Relativa de Citación (FRC): & 0,01 \\
\hline Índice de Importancia Cultural (IC): & 0,01 \\
\hline Índice de Vigencia (IV): & 0,00 \\
\hline
\end{tabular}

Obtención: silvestre

Vigencia: abandonado

Usos:

\section{MEDICINA}

- Sistema digestivo (1): En la localidad de Verdeña se toma la infusión de esta planta para detener la diarrea. Si la indisposición surge en medio del campo, se pueden usar las hojas para limpiarse el culo y tratar de cortar la diarrea.

ROSACEAE

Malus domestica Borkh.

Manzano (37)

\begin{tabular}{lc}
\hline $269 F$ \\
\hline Frecuencia de citación (FC): & 37 \\
\hline Número de usos (NU): & 5 \\
\hline Número registros de uso (RU): & 46 \\
\hline
\end{tabular}

Obtención: cultivada

Vigencia: vigente (100\%)

\section{Conocimientos:}

\section{LÉXICO}

Los frutos son las manzanas. Se denomina camuesa a la variedad de manzana enana.

Usos:

\section{ALIMENTACIÓN HUMANA}

- Frutas y frutos dulces (38): Se cultiva en las huertas por sus frutos, de los que se han testimoniado las variedades Reineta y Golden. Para conservarlas durante más tiempo se guardaban entre paja o se colocaban en el desván o debajo de las camas sin que se tocaran unas con otras.

Otra variedad también muy presente en la zona son las Camuesas, una manzana de tamaño muy pequeño y con un sabor un poco ácido. En Camporredondo estas manzanitas se introducían en un tarro con manteca para conservarlas durante más tiempo y mejorar además su sabor.

\section{ALIMENTACIÓN ANIMAL}

- Frutas y frutos dulces (1): Las manzanas sobremaduradas y más defectuosas se echaban en el pesebre de los cerdos.

- Plantas melíferas (4): La abundante floración de los manzanos durante la primavera es aprovechada por las abejas en la elaboración de la miel.

\section{MEDICINA}

- Sistema respiratorio (1): En San Juan de Redondo se cuece manzana junto con orégano, cebolla y limón, resultando un líquido recomendado como tratamiento anticatarral.

\section{COMBUSTIBLE}

- Leña (1): La madera originada de la poda de estos frutales se destina para quemar en la lumbre.

\section{MEDIOAMBIENTAL}

- Injerto (1): Los manzanos son buenos patrones portainjertos de distintas variedades $y$ de otras especies.

ROSACEAE

Malus sylvestris (L.) Mill.

Maíllo (50), amaíllo (25), maello (13), amaello (4)

PALAB2844, 3P, 296P, 437P; 1F; 46V, 284V, 285V

\begin{tabular}{lc}
\hline Frecuencia de citación (FC): & 92 \\
\hline Número de usos (NU): & 2 \\
\hline Número registros de uso (RU): & 105 \\
\hline Frecuencia Relativa de Citación (FRC): & $\mathbf{0 , 6 6}$ \\
\hline Índice de Importancia Cultural (IC): & $\mathbf{0 , 7 6}$ \\
\hline Índice de Vigencia (IV): & $\mathbf{0 , 1 1}$ \\
\hline
\end{tabular}

Obtención: silvestre

Vigencia: vigente (15\%)

\section{LÉXICO}


Los frutos se denominan popularmente maíllas o amaíllas. El color marrón alcanzado en la maduración se reconoce como tonizo.

Usos:

\section{ALIMENTACIÓN ANIMAL}

- Frutas y frutos dulces (86): La parte que se consume son los frutos. Se pueden comer directamente en crudo en el campo, aunque lo más común es conservarlas hasta llegar a la sobremaduración. Las maíllas se extienden en arcones, entre paja, grano o hierba, incluso debajo de la cama, hasta que finaliza su maduración, momento en el cual torna su piel hacia un color marrón, el aspecto de la piel se arruga, pierden la acidez y se vuelven dulces y con un agradable olor y sabor. Se recolectan en otoño y la sobremaduración transcurre durante el invierno.

- Bebidas alcohólicas (13): Mezclando orujo con maíllas se preparan licores, también conocidos como pacharanes. Se introduce la fruta troceada en una botella y se añade orujo o aguardiente, en algunas recetas descritas se incluye un almíbar a base de una cocción de agua con abundante azúcar. La mezcla queda lista para servir al cabo de unos meses.

- Bebidas no alcohólicas (4): Con los frutos macerados en azúcar se elabora una bebida dulce. Se trocean las maíllas, se introducen en un tarro y se cubren posteriormente con azúcar. Pasados unos días se filtra la mezcla, de la cual se obtiene un líquido de color amarillo con un sabor cercano a una sidra azucarada.

\section{MEDIOAMBIENTAL}

- Injertos (2): Esta especie se emplea como portainjerto de variedades más productivas de manzana y pera.

Observaciones: No queda claro si el licor de maíllas es de uso tradicional o no, en varias localidades señalaron que en el pasado no se realizaba, sin embargo en otras como en Valsadornín, recuerdan desde siempre su elaboración.

ROSACEAE

Prunus avium (L.) L. Cerezo (22)

PALAB2840, 33P, 273P; 8F; 260V, 426V, 427V, 428V

\begin{tabular}{lc}
\hline Frecuencia de citación (FC): & 22 \\
\hline Número de usos (NU): & 4 \\
\hline Número registros de uso (RU): & 29 \\
\hline Frecuencia Relativa de Citación (FRC): & $\mathbf{0 , 1 6}$ \\
\hline Índice de Importancia Cultural (IC): & $\mathbf{0 , 2 1}$ \\
\hline Índice de Vigencia (IV): & 0,06 \\
\hline
\end{tabular}

Obtención: cultivada, silvestre

Vigencia: vigente (28\%)

\section{LÉXICO}

Los frutos son las cerezas. La goma que suelta la corteza se llama carralón.

En Celada de Roblecedo y en Villalbeto encontramos el fitotopónimo "El Cerezal".

\section{Usos:}

\section{ALIMENTACIÓN HUMANA}

- Frutas y frutos dulces (19): Se consumen los frutos, que una vez alcanzan la madurez a principios de julio, tienen un sabor muy dulce apreciado por los lugareños. No todos los años prospera bien la fruta, pues las heladas podían estropear la cosecha o impedir su fructificación.

- Bebidas alcohólicas (2): Mezclando cerezas con aguardiente y un poco de azúcar, se elaboran licores.

- Golosinas y masticatorias (1): En Valcobero los más jóvenes comían la goma que segregan los cerezos por alguna grieta en la corteza.

\section{ALIMENTACIÓN ANIMAL}

- Forraje verde o seco (1): Las hojas crudas se servían a los cerdos, consideradas un magnifico alimento.

- Plantas melíferas (1): Las abejas pecorean el néctar de la abundante floración de los cerezos.

\section{INDUSTRIA Y ARTESANÍA}

- Herramientas y utensilios (3): La madera de cerezo se ha mencionado como útil para la fabricación de mangos, cachavas y cucharas.

- Juguetes $e$ instrumentos deportivos $y$ musicales (1): Con la madera se elaboran las bolas del tradicional juego de los bolos.

\section{SOCIAL, SIMBÓLICO Y RITUAL}

- Ritual de ciclo anual (1): Las ramas de cerezo se incluyen en las tradicionales enramadas por San Juan y San Pedro, en Celada de Roblecedo.

ROSACEAE

Prunus cerasus $\mathrm{L}$.

Guindal (31)

PALAB2154, 143P, 304P; 145F; 57V, 58V, 429V 


\begin{tabular}{lc}
\hline Frecuencia de citación (FC): & 31 \\
\hline Número de usos (NU): & 5 \\
\hline Número registros de uso (RU): & 45 \\
\hline Frecuencia Relativa de Citación (FRC): & $\mathbf{0 , 2 2}$ \\
\hline Índice de Importancia Cultural (IC): & $\mathbf{0 , 3 2}$ \\
\hline Índice de Vigencia (IV): & $\mathbf{0 , 1 2}$ \\
\hline
\end{tabular}

Obtención: cultivada, silvestre

Vigencia: vigente (37\%)

\section{LÉXICO}

El fruto es la guinda.

Usos:

\section{ALIMENTACIÓN HUMANA}

- Frutas y frutos dulces (27): Se consumen los frutos directamente en el campo, se refiere un tamaño menor que las cerezas y un sabor más ácido.

- Bebidas alcohólicas (10): Con los frutos se prepara un licor tradicional, mezclando en una botella guindas, aguardiente y azúcar, composición que puede conservarse durante años.

\section{MEDICINA}

- Sistema digestivo (2): Se toma un chupito de licor de guindas o se come una de las guindas maceradas en el orujo para aliviar el dolor de estomago.

\section{TóxICO Y NOCIVO}

- Trampas atrayentes (1): En Verdeña, el exudado pegajoso que rezuma el árbol por la corteza lo empleaban los niños a modo de liga para cazar pequeños pájaros.

\section{COMBUSTIBLE}

- Leña (1): Se cita el uso de la leña de guindal en el supuesto de una poda anual o corta extraordinaria.

\section{INDUSTRIA Y ARTESANÍA}

- Herramientas y utensilios (3): Su madera compacta y dura se aconseja para la fabricación de cachavas, rastros y para el dental del arado romano.

- Juguetes e instrumentos deportivos y musicales (1): Se fabrican las bolas del juego de los bolos con su madera.

ROSACEAE

\section{Prunus domestica $\mathrm{L}$.}

Ciruelo (52), mijuelo (5), pruno (1)

\begin{tabular}{lc}
\hline Frecuencia de citación (FC): & 58 \\
\hline Número de usos (NU): & 4 \\
\hline Número registros de uso (RU): & 63 \\
\hline Frecuencia Relativa de Citación (FRC): & $\mathbf{0 , 4 2}$ \\
\hline Índice de Importancia Cultural (IC): & $\mathbf{0 , 4 5}$ \\
\hline Índice de Vigencia (IV): & $\mathbf{0 , 2 7}$ \\
\hline
\end{tabular}

Obtención: cultivada, silvestre

Vigencia: vigente (60\%)

\section{LÉXICO}

Se denomina mijuelo al árbol y a los frutos obtenidos de ejemplares asilvestrados. En Villanueva de Arriba denominan pruno al ciruelo silvestre.

\section{Usos:}

\section{ALIMENTACIÓN HUMANA}

- Frutas y frutos dulces (57): Se aprecian los frutos, que se consumen directamente en el campo o se recogen para consumo en el hogar o elaboración de mermeladas. La maduración de las ciruelas sucede durante el verano y se conocen ejemplares asilvestrados que producen fruta de menor tamaño y algo más ácida que la de los cultivados.

- Bebidas alcohólicas (1): En Tremaya se elabora licor de ciruelas, macerando los frutos en orujo durante un tiempo.

\section{ALIMENTACIÓN ANIMAL}

- Forraje verde o seco (1): Las hojas del ciruelo se sirven en crudo en Valcobero, como forraje para los cerdos.

- Plantas melíferas (2): Las abejas visitan con asiduidad las flores en la primavera.

\section{MEDIOAMBIENTAL}

- Injerto (1): El ciruelo se emplea como patrón portainjerto para cambiar la variedad de los frutos.

\section{ORNAMENTAL}

- Adorno floral y plantas de interior (1): En San Juan de Redondo recuerdan utilizar ramos floridos de ciruelo para adornar y dar buen aroma a alguna estancia de la vivienda.

ROSACEAE

Prunus domestica subsp. insitia (L.) Bonnier \& Layens Andrino real (4), andriniego (2)

PALAB2153, 259P; 364V 


\begin{tabular}{lc}
\hline Frecuencia de citación (FC): & 6 \\
\hline Número de usos (NU): & 1 \\
\hline Número registros de uso (RU): & 6 \\
\hline Frecuencia Relativa de Citación (FRC): & 0,04 \\
\hline Índice de Importancia Cultural (IC): & 0,04 \\
\hline Índice de Vigencia (IV): & 0,01 \\
\hline
\end{tabular}

Obtención: cultivada, silvestre

Vigencia: vigente (33\%)

Conocimientos:

LÉXICO

Sus frutos se denominan andrinas reales 0 andriniegas.

Usos:

\section{ALIMENTACIÓN HUMANA}

- Frutas y frutos dulces (5): Los frutos se aprovechan al alcanzar la maduración. En Aviñante de la Peña se indica como, en ocasiones, se conservaban los frutos secos y a la hora de consumir se metían en agua caliente para hidratarlos y consumirlos. Las andriniegas son de mayor tamaño y dulzor que las andrinas.

- Bebidas alcohólicas (1): Se elabora licor en Salinas de Pisuerga macerando los frutos en aguardiente.

ROSACEAE

Prunus padus L.

Ceresuela (2)

151P, 525P; 47F; 430V, 431V

\begin{tabular}{lc}
\hline Frecuencia de citación (FC): & 2 \\
\hline Número de usos (NU): & 4 \\
\hline Número registros de uso (RU): & 6 \\
\hline Frecuencia Relativa de Citación (FRC): & $\mathbf{0 , 0 1}$ \\
\hline Índice de Importancia Cultural (IC): & $\mathbf{0 , 0 4}$ \\
\hline Índice de Vigencia (IV): & $\mathbf{0 , 0 0}$ \\
\hline
\end{tabular}

Obtención: silvestre

Vigencia: abandonado

Conocimientos:

LÉXICO

En Cardaño de Abajo se localiza el fitotopónimo "Arroyo de la Ceresuela", en Camporredondo el pago "Las Ceresuelas", y en Cardaño de Arriba y Rebanal de las Llantas el de "La Cerezuela".

\section{Usos:}

COMBUSTIBLE

- Leña (1): La madera de ceresuela procedente de las podas posee utilidad como leña del hogar. No es una madera de las más apreciadas como combustible, pero se aprovechaban todos los restos de las podas, éstas tenían por finalidad eliminar el follaje que invadía los prados de siega.

\section{INDUSTRIA Y ARTESANÍA}

- Cuerdas y ataduras (2): Los tallos retoñados son flexibles y adecuados para tejer la paja de centeno con la que se elaboraban los escriños (cestas de paja). Para ello se recogen ramas jóvenes, las cuales se cortan longitudinalmente utilizando una navaja, obteniendo tiras maleables, a modo de cuerdas. Una vez secas, adquieren gran resistencia.

\section{ORNAMENTAL}

- Adorno floral y plantas de interior (2): Se trata de una planta muy valorada en ornamentación, con una vistosa floración primaveral de color blanco. Las flores se emplean con fines decorativos en la elaboración de jarrones de flor fresca para el hogar, la escuela o la iglesia.

\section{SOCIAL, SIMBÓLICA Y RITUAL}

- Ritual de ciclo de vida (1): Esta especie de ramas flexibles se utilizaba para dar forma a los arcos vegetales decorativos que por tradición se presentaban en actos ceremoniales destacados, como una boda, la recepción de alguna autoridad importante o la ordenación de un cura (cantamisas). A estos arcos vegetales se les añadían flores de temporada para mejorar la composición.

Observaciones: Todas las citas obtenidas de esta especie fueron en la localidad de Valcobero, a pesar de extenderse esta especie por otras localidades.

En la actualidad, se encuentran muchos ejemplares atacados por la mariposa Argyresthia pruniella, cuyas orugas están provocando la muerte de muchos individuos.

ROSACEAE

\section{Prunus persica (L.) Batsch Melocotón (1)}

\begin{tabular}{ll}
\hline Frecuencia de citación (FC): & 1 \\
\hline Número de usos (NU): & 1 \\
\hline Número registros de uso (RU): & 1 \\
\hline
\end{tabular}

Obtención: comprada

Usos:

ALIMENTACIÓN HUMANA 
- Frutas y frutos dulces (1): El melocotón se come en crudo. En el pasado, se recuerda en La Lastra, que se comerciaba con los lebaniegos que cambiaban o vendían esta fruta.

ROSACEAE

\section{Prunus spinosa $\mathrm{L}$.}

Endrino (30), andrino (63), espino (18)

1P, 438P; 25F; 59V, 123V, 220V, 289V, 505V

\begin{tabular}{lc}
\hline Frecuencia de citación (FC): & 111 \\
\hline Número de usos (NU): & 6 \\
\hline Número registros de uso (RU): & 177 \\
\hline Frecuencia Relativa de Citación (FRC): & $\mathbf{0 , 8 0}$ \\
\hline Índice de Importancia Cultural (IC): & 1,27 \\
\hline Índice de Vigencia (IV): & 0,32 \\
\hline
\end{tabular}

Obtención: silvestre

Vigencia: vigente (25\%)

\section{LÉXICO}

Se denomina cornito al brote tierno del tallo que surge en la primavera.

Encontramos los fitotóponimos de los pagos: "El Andrinal" en Salcedillo y Traspeña de la Peña, y "Endrinal" en Pisón de Castrejón.

Usos:

\section{ALIMENTACIÓN HUMANA}

- Frutas y frutos dulces (91): Se consumen los frutos directamente en el campo o se recogen dejándolos secar en arcones o entre el grano hasta que se convierten en pasas, listas para degustar en cualquier momento. Se recolectan en el mes de septiembre y el sabor referido es un tanto amargo en fresco y algo más dulces en pasa.

- Bebidas alcohólicas (45): Se maceran los frutos en aguardiente durante unos meses para obtener licor de endrinas, que tradicionalmente se conoce como pacharán.

- Golosinas y masticatorias (3): Los brotes tiernos de los tallos en primavera se mastican y eran apreciados por los más jóvenes.

\section{ALIMENTACIÓN ANIMAL}

- Plantas melíferas (2): Las abejas se aplican en obtener néctar de la copiosa floración del endrino.

\section{MEDICINA}

- Sistema circulatorio (1): Las flores del espino se usaron en San Felices de Castillería para hacer una infusión con propiedades beneficiosas para el aparato circulatorio, recomendada para regular la tensión.

\section{COMBUSTIBLE}

- Leña (11): La madera del endrino se consideraba ideal para caldear el horno del pan ya que tiene gran poder calorífico.

\section{CONSTRUCCIÓN}

- Cercas, tapias y vallas (23): En los cercados como cerramiento provisional de las fincas y como remate de tapias se colocan endrinos por su carácter espinoso para impedir el paso de personas y animales.

\section{ORNAMENTAL}

- Adorno floral y plantas de interior (1): En San Juan de Redondo se colocan ramos florecidos de endrino para decorar el interior de la vivienda.

Observaciones: El endrino ha sido mencionado como espino, y siempre que así fue, tratamos de discriminarlo del resto de especies que se agrupan bajo esta denominación popular, en concreto de Crataegus monogyna y de Rosa sp.

ROSACEAE

Pyrus communis L.

Peral (27)

\begin{tabular}{lc}
\hline Frecuencia de citación (FC): & 27 \\
\hline Número de usos (NU): & 2 \\
\hline Número registros de uso (RU): & 30 \\
\hline
\end{tabular}

Obtención: cultivada

Vigencia: vigente (100\%)

Usos:

ALIMENTACIÓN HUMANA

- Frutas y frutos dulces (27): Los frutos se consumen en crudo o se elaboran, en ocasiones, mermeladas con los excedentes de la producción.

\section{ALIMENTACIÓN ANIMAL}

- Plantas melíferas (3): El peral presenta una abundante floración en primavera aprovechada por las abejas.

ROSACEAE

Pyrus cordata Desv.

Peral de monte (2), peral silvestre (3), perujo (9)

PALAB2312, 150P, 355P; 239F 


\begin{tabular}{lc}
\hline Frecuencia de citación (FC): & 14 \\
\hline Número de usos (NU): & 2 \\
\hline Número registros de uso (RU): & 15 \\
\hline Frecuencia Relativa de Citación (FRC): & $\mathbf{0 , 1 0}$ \\
\hline Índice de Importancia Cultural (IC): & $\mathbf{0 , 1 1}$ \\
\hline Índice de Vigencia (IV): & $\mathbf{0 , 0 0}$ \\
\hline
\end{tabular}

Obtención: silvestre

Vigencia: abandonado

\section{Conocimientos:}

\section{LÉXICO}

Se conoce a la especie y a los frutos por el nombre de perujos.

Aparecen los fitotopónimos del "Arroyo de Perales" en Salcedillo, de los pagos "Perujales" en Brañosera, "El Perujal" en Lebanza y San Martín de los Herreros, y "Peral" en Cubillo de Castrejón y San Felices de Castillería.

Usos:

\section{ALIMENTACIÓN HUMANA}

- Frutas y frutos dulces (14): Se consumen los perujos como fruta silvestre, de aspecto similar a las peras cultivadas pero de menor tamaño.

\section{ALIMENTACIÓN ANIMAL}

- Plantas melíferas (1): Las abejas visitan las flores del peral silvestre.

\section{ROSACEAE}

\section{Rosa canina L.}

\section{R. micrantha Borrer ex Sm \\ R. pendulina $\mathrm{L}$. \\ R. pouzinii Tratt. \\ R. rubiginosa $\mathrm{L}$. \\ R. villosa $\mathrm{L}$.}

Zarza (25), espino (17), rosal (3), calambrojo (16), calambroto (3), escalambrojo (7), escaramujo (3), escaramojo (4), garamujo (5), garamojo (1), jaramojo (3), garamocho (9), garameto (2), tapaculo (1)

Rosa canina: $5 \mathrm{P}, 295 \mathrm{P}, 383 \mathrm{P} ; 2 \mathrm{~F}$

R. micrantha: 207P; $212 \mathrm{~F}$

R. pendulina: $118 \mathrm{P}$

R. pouzinii: 259P; $156 \mathrm{~F}$

R. rubiginosa: $433 \mathrm{P}$

R. villosa: 366P, 544P; $184 \mathrm{~F}$

Rosa spp: 125V; $175 \mathrm{~V}, 222 \mathrm{~V}, 316 \mathrm{~V}, 322 \mathrm{~V}, 344 \mathrm{~V}$, 439V, 470V, 490V, 536V

\begin{tabular}{lc}
\hline Frecuencia de citación (FC): & 79 \\
\hline Número de usos (NU): & 6 \\
\hline Número registros de uso (RU): & 181 \\
\hline Frecuencia Relativa de Citación (FRC): & 0,57 \\
\hline Índice de Importancia Cultural (IC): & 1,30 \\
\hline Índice de Vigencia (IV): & 0,04 \\
\hline
\end{tabular}

Obtención: silvestre

Vigencia: vigente (3\%)

\section{Conocimientos:}

\section{LÉXICO}

La figura lingüística de la sinécdoque implica nombrar a la parte por el todo. Se han recogido en la comarca los siguientes nombres: escaramujo, escaramojo, calambrojo, calambroto, escalambrojo, garamujo, garamojo, jaramojo, garamocho, garameto y tapaculo, que en ocasiones denominan al fruto y en otras a la planta entera. Otro aspecto de la nomenclatura conlleva que se denomine a la planta por alguna característica, en este caso espino o zarza, al igual que otras plantas con espinas.

También se han recogido varios nombres que identifican al fruto en el momento de sobremaduración: paturra, pachurra, papucha o papuja.

Los brotes tiernos del tallo se denominan carneros.

Aparecen los fitotopónimos de los pagos: "La Zarza" en Salcedillo y Villalbeto, y "Las Zarzas" en Cubillo de Castrejón y Villanueva de Arriba.

Usos:

\section{ALIMENTACIÓN HUMANA}

- Frutas y frutos dulces (77): El consumo de las infrutescencias se referencia de forma generalizada. Se aprovechan en crudo en el campo cuando alcanzan la sobremadurez, recolectados durante el otoño. Al apretarlos con los dedos por un extremo desprenden una pasta espesa de sabor dulce muy apreciado, quedando separadas las partes más molestas para consumir: frutos, pelos y piel.

También se ha testimoniado la recolección de infrutescencias para embotar y elaborar mermeladas. El proceso para separar la parte carnosa útil resulta muy laborioso.

- Bebidas alcohólicas (3): Se elaboran licores mezclando las infrutescencias con orujo $y$ azúcar, responde a una tendencia reciente, no vinculada a un uso tradicional en el pasado.

- Golosinas y masticatorias (26): En primavera se comen los brotes tiernos. Se corta la parte terminal del tallo, a una distancia aproximada de $15 \mathrm{~cm}$ y se pelan retirando una fina capa externa de carácter menos palatable. Se consumen en crudo y se refiere un sabor un tanto ácido muy apetitoso.

\section{ALIMENTACIÓN ANIMAL}

- Frutas y frutos dulces (6): La infrutescencia se recolectó en algunas localidades para utilizarlo 
como alimento de engorde para las cabras y en menor medida para los cerdos.

- Pasto (2): Se indica como las cabras y los venados consumen en el campo con gran avidez las infrutescencias durante el otoño.

- Plantas melíferas (2): La floración primaveral atrae a las abejas, que extraen el néctar necesario para elaborar la miel.

\section{MEDICINA}

- Sistema genito-urinario (1): En Villanueva de la Torre se señala el uso de la infrutescencia para tratamientos depurativos del riñón. Se cuecen en agua y se toma el líquido resultante.

- Sistema respiratorio (14): Para combatir enfermedades de las vías respiratorias se emplean las infrutescencias, aconsejados sobre todo como un eficaz remedio anticatarral. Se recogen a finales de septiembre, antes de que maduren en exceso, se cuecen en agua y se toma la infusión resultante, alivio sintomático del catarro y la ronquera.

Otro método de administración recogido en la localidad de Polentinos, se practica tomando una cucharada de una especie de jarabe, que se elabora mezclando azúcar, anís e infrutescencias, macerados en un tarro por un tiempo.

- Órganos de los sentidos (3): La cocción de pétalos de rosa y de las hojas, se recomienda para lavar los ojos con alguna molestia (conjuntivitis, inflamación, legañas...).

\section{VETERINARIA}

- Sistema digestivo (1): Ante la picadura de avispas de la familia Cynipidae, el rosal reacciona formando una agalla, que tiene el aspecto de una bola de pelusa. Según nos informan en la localidad de Polentinos, esta bola se introducía en la boca de las vacas cuando presentaban algún problema con el rumio, ya que en ocasiones las dejaba de funcionar normalmente y con la bola recuperaban el ritmo digestivo. En términos veterinarios esta alteración digestiva se denomina meteorismo o timpanismo rumial.

También se mencionó cómo tratar la indigestión de las vacas, administrando con una botella, el agua resultante de cocer la raíz de esta planta.

\section{CONSTRUCCIÓN}

- Cercas, tapias y vallas (14): Utilizada debido a su carácter espinoso, de barrera o seto, para separar fincas e impedir que el ganado penetrara en ellas.

\section{INDUSTRIA Y ARTESANÍA}

- Cosmética, perfumería y limpieza (3): En el pasado las niñas solían elaborar agua de rosas, macerando pétalos en agua, en algunos casos se hervían previamente para absorber mejor la fragancia. Servía este preparado a modo de perfume o tónico de limpieza.

- Cestería, recipientes y envoltorios (23): En la confección de las tradicionales cestas se utilizan materiales vegetales bien diferenciados, para el armazón (aro y costillas) se escogen ramas de zarza, flexibles y fáciles de domar.

- Vestimenta y adornos personales (6): Como un juego infantil, las niñas en el pasado engarzaban las infrutescencias con un hilo, confeccionando collares con los que se embellecían.

Observaciones: Se ha tratado de discriminar los usos de las especies silvestres frente a los usos de las cultivadas, en el primer grupo hemos identificado: Rosa canina, $R$. micrantha, $R$. pendulina, $R$. pouzinii, $R$. rubiginosa y $R$. villosa, pero es probable que otras especies también presentes en la zona tengan los mismos usos, como Rosa agrestis, $R$. corymbifera o $R$. tomentosa. En general se trata de especies difíciles de diferenciar.

ROSACEAE

\section{Rosa spp. (cultivadas) \\ Rosal (21)}

\begin{tabular}{lc}
\hline $313 \mathrm{~F}$ \\
\hline Frecuencia de citación (FC): & 28 \\
\hline Número de usos (NU): & 4 \\
\hline Número registros de uso (RU): & 37 \\
\hline
\end{tabular}

Obtención: cultivada

Vigencia: vigente (38\%)

Usos:

MEDICINA

- Órganos de los sentidos (3): Se deshojan pétalos de rosa que se cuecen para lavar los ojos enrojecidos o con alguna infección. Referido a este uso se recoge en Arbejal el dicho popular "A tu madre, hija, la llaman la legañosa y no sabe que en la botica hay agua de rosas".

\section{INDUSTRIA Y ARTESANÍA}

- Cosmética, perfumería y limpieza (9): Los pétalos se deshojan y se maceran en agua durate un tiempo, solos o junto con pétalos de 
violetas (Viola spp.), consiguiendo agua de rosas o colonia con propiedades aromáticas.

\section{ORNAMENTAL}

- Patios, huertos y jardines (7): Cultivada tradicionalmente en jardinería de exterior y patios, destacando la belleza de las flores y el agradable aroma que desprenden.

- Adorno floral y plantas de interior (6): Se cortan ramos de flores para decoración en jarrones en el hogar o en la iglesia.

\section{SOCIAL, SIMBÓLICO Y RITUAL}

- Ritual de ciclo anual (9): Los pétalos de las flores se tiraban por las calles y los altares el día del Corpus Christi. Las flores se añadían como decoración en los arcos vegetales que se confeccionaban para alguna fiesta local.

- Ritual de ciclo de vida (2): En las bodas se preparaban arcos vegetales con diferentes especies (chopo, hiedra, acebo, etc.) y entre ellos se integraban rosas para engalanar el paso de los novios.

- Uso recreativo (1): Los niños jugaban a colocarse las espinas de los rosales en la frente con un poco de saliva.

Observaciones: De los rosales cultivados los informantes destacan el rosal de Alejandría y el rosal de cien hojas, ambos con números pétalos en sus flores.

ROSACEAE

\section{Rosa spinosissima L.}

Zarzaparrilla (16), rosal espinoso (1)

\begin{tabular}{lc}
\hline PALAB1981, 147P; 146F; 124V, 176V, 177V \\
\hline Frecuencia de citación (FC): & $\mathbf{2 0}$ \\
\hline Número de usos (NU): & $\mathbf{3}$ \\
\hline Número registros de uso (RU): & $\mathbf{2 4}$ \\
\hline Frecuencia Relativa de Citación (FRC): & $\mathbf{0 , 1 4}$ \\
\hline Índice de Importancia Cultural (IC): & $\mathbf{0 , 1 7}$ \\
\hline Índice de Vigencia (IV): & $\mathbf{0 , 0 0}$ \\
\hline
\end{tabular}

Obtención: silvestre

Vigencia: abandonado

\section{Conocimientos:}

\section{LÉXICO}

Se recogen los nombres de calambrojos, escaramujos y garamojos para denominar a las infrutescencias, que en su estado más maduro se conocen como papujas.

Usos:

ALIMENTACIÓN HUMANA
- Frutas y frutos dulces (3): Las infrutescencias son comestibles, poseen una tonalidad más rojiza y de sabor más dulzón que las de otras especies del género Rosa, siendo consideradas más apetecibles en su estado sobremadurado hacia finales de verano e incluso otoño. Se tomaban aplastándolas entre los dedos y chupando la pasta espesa que desprende.

\section{MEDICINA}

- Sistema circulatorio (14): Un remedio popular fue el uso de la raíz de esta especie como depurativo del cuerpo y de la sangre. La raíz se cuece con agua, el líquido resultante se administraba en forma de tisana. En Resoba señalan que la cocción, en ocasiones, se hacía con la raíz y otras con el tallo, además se recomienda para los calambres, el dolor en las extremidades $y$ en general para mejorar cualquier problema circulatorio.

- Sistema digestivo (1): En San Juan de Redondo se recomienda tomar la cocción de la raíz cuando existe dolor de muelas, "te tomabas un vaso por la mañana, era tan fuerte que te dejaba baldao".

- Sistema respiratorio (2): Las infrutescencias se tomaban en infusión para aliviar los catarros. - Piel y tejido celular subcutáneo (2): Para granos infectados y diviesos se ponen cataplasmas con la cocción de la raíz.

- Otras enfermedades infecciosas y parasitarias (1): El cocimiento de infrutescencias de esta especie es considerado un buen remedio para la sarna. En Verdeña recuerdan como al terminar la Guerra Civil mucha personas contrajeron la sarna, y para tratarla se bañaban en baldes de gran tamaño con la cocción de los escaramujos.

\section{SOCIAL, SIMBÓLICO Y RITUAL}

- Literatura popular (1): En San Salvador de Cantamuda se documenta el siguiente dicho "La zarzaparrilla y unas cataplasmas pa las pantorrillas", que puede aludir a alguno de los remedios medicinales señalados.

ROSACEAE

Rubus caesius L.

Moral (1), morito (1)

\begin{tabular}{lc} 
264P; 255F; 440V & \\
\hline Frecuencia de citación (FC): & 2 \\
\hline Número de usos (NU): & 1 \\
\hline Número registros de uso (RU): & 2 \\
\hline Frecuencia Relativa de Citación (FRC): & $\mathbf{0 , 0 1}$ \\
\hline Índice de Importancia Cultural (IC): & $\mathbf{0 , 0 1}$ \\
\hline Índice de Vigencia (IV): & $\mathbf{0 , 0 1}$ \\
\hline
\end{tabular}


Obtención: silvestre

Vigencia: vigente (100\%)

Conocimientos:

\section{ECOLOGÍA}

Para diferenciar la especie del moral (Rubus ulmifolius), se explica que los tallos son rastreros y más delgados, y los frutos tienen bolitas de mayor tamaño y también con un mayor dulzor.

\section{LÉXICO}

Las infrutescencias se denominan moras. El nombre vulgar de morito se recoge en la localidad de Matabuena.

Usos:

\section{ALIMENTACIÓN HUMANA}

- Frutas y frutos dulces (2): La fruta se consume en el campo a partir de finales de agosto cuando alcanza su maduración.

ROSACEAE

Rubus idaeus L.

Antimora (13), gatimora (8), amamora (1), mora montesina (8), mora de la reina (4), frambueso (14)

PALAB1983, 108P; 75F; 328V, 535V

\begin{tabular}{lc}
\hline Frecuencia de citación (FC): & 48 \\
\hline Número de usos (NU): & 2 \\
\hline Número registros de uso (RU): & 48 \\
\hline Frecuencia Relativa de Citación (FRC): & 0,35 \\
\hline Índice de Importancia Cultural (IC): & 0,35 \\
\hline Índice de Vigencia (IV): & 0,07 \\
\hline
\end{tabular}

Obtención: cultivada, silvestre

Vigencia: vigente (20\%)

\section{Conocimientos:}

\section{LÉXICO}

El nombre de antimora se recoge en la zona occidental de la Montaña Palentina (Velilla del Río Carrión, Otero de Guardo, Alba de los Cardaños, Triollo y La Lastra), el de gatimora en la zona oriental y septentrional (Brañosera, Barruelo de Santullán, San Juan de Redondo y Verdeña) y el de mora montesina en Resoba, Ventanilla, San Martín de los Herreros y Rebanal de las Llantas. El binomio mora montesina alude al lugar donde se pueden encontrar, el nombre mora de la reina, tal vez haga referencia a la exquisitez del fruto.

Los informantes citan a la planta con el mismo nombre que al fruto, haciendo uso de la figura lingüística denominada sinécdoque.
Usos:

\section{ALIMENTACIÓN HUMANA}

- Frutas y frutos dulces (47): La parte aprovechable son los frutos que se consumen por lo general en crudo, una vez han madurado, directamente en el campo. Otras veces, se recolectan para preparar mermeladas o como acompañamiento en repostería casera. La época optima de recolección se produce a últimos del mes de junio, en ese momento el fruto provisto de pilosidad, tiene un color rojo pálido casi rosáceo muy característico. El sabor referido es intenso y muy dulce.

\section{ALIMENTACIÓN ANIMAL}

- Pasto (1): Los venados también disfrutan con los frutos durante el verano.

ROSACEAE

Rubus ulmifolius L.

Zarza (48), zarzamora (5), moral (31), amoral (10), espino (11)

PALAB1987, 2P, 285P; 59F; 126V, 304V, 305V, 306V, $312 \mathrm{~V}, 313 \mathrm{~V}, 314 \mathrm{~V}, 345 \mathrm{~V}, 346 \mathrm{~V}, 365 \mathrm{~V}, 441 \mathrm{~V}, 537 \mathrm{~V}$

\begin{tabular}{lc}
\hline Frecuencia de citación (FC): & 104 \\
\hline Número de usos (NU): & 4 \\
\hline Número registros de uso (RU): & 131 \\
\hline Frecuencia Relativa de Citación (FRC): & 0,75 \\
\hline Índice de Importancia Cultural (IC): & 0,94 \\
Índice de Vigencia (IV): & 0,57 \\
\hline
\end{tabular}

Obtención: silvestre

Vigencia: vigente (60\%)

\section{Conocimientos:}

\section{LÉXICO}

Los brotes tiernos de los tallos se denominan carneros, y los agregados de frutos son las populares moras.

Usos:

\section{ALIMENTACIÓN HUMANA}

- Frutas y frutos dulces (94): Las polidrupas se consumen directamente, o se recolectan para mezclarlas con vino y azúcar, o solo azúcar. Su recolección se hace a finales de verano y principios de otoño. Una costumbre más reciente en el tiempo es la elaboración de mermeladas.

- Bebidas alcohólicas (4): El licor de mora se elabora con los frutos macerados en aguardiente.

- Golosinas y masticatorias (20): Las puntas de los brotes se pelan y se comen en crudo a 
principios de la primavera, que es cuando resultan más tiernas, su sabor resulta un tanto ácido y amargo.

\section{CONSTRUCCIÓN}

- Cercas, tapias y vallas (1): Los tallos más gruesos y espinosos se cortaban para servir de cierre rústico en huertos, corrales, lindes o cercados.

\section{INDUSTRIA Y ARTESANÍA}

- Cuerdas y ataduras (11): Las ramas más largas y flexibles se limpiaban de espinas, se pelaban y la corteza se empleaba como atadura para tejer cestos y recipientes de diversos tamaños, como los escriños.

\section{SOCIAL, SIMBÓLICO Y RITUAL}

- Uso recreativo (1): Las espinas de las zarzas se usaban en algún juego infantil. Adornaban la cara y servían para el desarrollo imaginativo en los juegos de los niños.

ROSACEAE

\section{Sanguisorba officinalis $\mathrm{L}$.}

Escalerilla (1)

\begin{tabular}{lc} 
205P; 177F & \\
\hline Frecuencia de citación (FC): & 1 \\
\hline Número de usos (NU): & 1 \\
\hline Número registros de uso (RU): & 1 \\
\hline Frecuencia Relativa de Citación (FRC): & 0,01 \\
\hline Índice de Importancia Cultural (IC): & $\mathbf{0 , 0 1}$ \\
\hline Índice de Vigencia (IV): & $\mathbf{0 , 0 0}$ \\
\hline
\end{tabular}

Obtención: silvestre

Vigencia: abandonado

Usos:

ALIMENTACIÓN ANIMAL

- Pasto (1): Especie apreciada en el pasto por vacas y ovejas.

ROSACEAE

Sorbus aria (L.) Crantz

Mostajo (59), amostajo (34)

PALAB1984, 10P, 286P; 26F; 70V, 71V, 132V, 386V, $543 \mathrm{~V}$

\begin{tabular}{lc}
\hline Frecuencia de citación (FC): & 93 \\
\hline Número de usos (NU): & 7 \\
\hline Número registros de uso (RU): & 106 \\
\hline Frecuencia Relativa de Citación (FRC): & $\mathbf{0 , 6 7}$ \\
\hline Índice de Importancia Cultural (IC): & $\mathbf{0 , 7 7}$ \\
\hline Índice de Vigencia (IV): & $\mathbf{0 , 0 4}$ \\
\hline
\end{tabular}

Obtención: silvestre

Vigencia: vigente (5\%)

Conocimientos:
LÉXICO
El fruto es conocido popularmente como
mostaja, o amostaja. Encontramos el
fitotopónimo "El Amostajo" en un pago de la
localidad de Camporredondo de Alba,
"Mostajo" en Valle de Santullán, y "El
Amostalejo" en Velilla del Río Carrión.

Usos:

\section{ALIMENTACIÓN HUMANA}

- Frutas y frutos dulces (80): La parte aprovechable son los frutos que se consumen en crudo directamente en el campo o se conservan entre paja para disponer de ellos a lo largo del invierno. "Traíamos cantidad de amostajas del monte y las metíamos a madurar entre paja", Lebanza.

La madurez de los frutos acontece a lo largo del otoño, tornando hacia un color naranja-rojizo. El sabor de la pulpa es dulce y la textura algo harinosa.

\section{ALIMENTACIÓN ANIMAL}

- Forraje verde o seco (16): La hoja procedente de la poda otoñal de las ramas, servía como suplemento alimenticio al ganado lanar en el invierno. También los conejos apreciaban como forraje las hojas y los frutos.

- Pasto (1): En la localidad de Valsadornín se indica cómo el oso consume los frutos en el bosque durante el otoño.

\section{COMBUSTIBLE}

- Leña (2): La madera se ha empleado como combustible para quemar en la lumbre. En Ruesga aseguran que aunque el roble es la principal especie, de los ejemplares con mayor porte se obtenía madera de buena calidad para utilizar en la tradicional hornacha (cavidad bajo una trébede donde se hace lumbre).

- Carbón (1): Como combustible proporciona un buen carbón vegetal, en Rebanal de las Llantas recuerdan como: "en el monte de Ventanilla se hacía carbón con haya y mostajo. El carbón que salía era bueno y sonaba como metálico".

\section{INDUSTRIA Y ARTESANÍA}

- Herramientas y utensilios (3): El mostajo goza de buen prestigio por tener una madera dura, pesada y de veta recta. Se utilizó con frecuencia para elaborar mangos de herramientas. 
- Vestimenta y adornos personales (1): Para la confección de las albarcas (calzado rústico de madera) se utilizaba la madera de mostajo, considerada fácil de tallar por su textura fina

\section{MEDIOAMBIENTAL}

- Injerto (1): El mostajo es un árbol tolerante al rigor climático y poco exigente a nivel edáfico, por lo que se adapta bien a los suelos poco fértiles de la zona. Esta interacción con el terreno es conocida en Alba de los Cardaños, donde se señala la idoneidad de esta especie como portainjerto, empleándose como patrón de manzanos.

\section{ORNAMENTAL}

- Calles y caminos (1): Se emplea en varios pueblos de la zona como árbol ornamental en plazas, jardines y alineaciones de calles. Durante la primavera y el verano resulta llamativo su follaje, verde por el haz $y$ blanquecino por el envés, y durante el otoño presenta frutos rojos muy vistosos que añaden una atractiva nota de color al paisaje urbano en el que se instalan.

\section{SOCIAL, SIMBÓLICO Y RITUAL}

- Ritual de ciclo de vida (1): Las ramas de mostajo se utilizaron para el ornamento de las portadas de las casas de las mozas que contraían matrimonio. La víspera del enlace matrimonial, los mozos agasajaban a la novia colocando en la puerta de entrada de su casa una enramada, elaborada con ramas de mostajo y de otras especies como avellano, fresno, saúco, olmo, etc.

Observaciones: Algunas de las especies identificadas en ornamentación urbana son híbridos de especies silvestres procedentes de viveros comerciales.

ROSACEAE

Sorbus aucuparia L.

Amargoso (22), serbal (9), argamón (2), drío (1), drido (1)

\begin{tabular}{lc}
\hline 30P, 463P; 162F; 32V, 451V, 452V & \\
\hline Frecuencia de citación (FC): & 35 \\
\hline Número de usos (NU): & $\mathbf{7}$ \\
\hline Número registros de uso (RU): & 45 \\
\hline Frecuencia Relativa de Citación (FRC): & $\mathbf{0 , 2 5}$ \\
\hline Índice de Importancia Cultural (IC): & $\mathbf{0 , 3 2}$ \\
\hline Índice de Vigencia (IV): & $\mathbf{0 , 0 5}$ \\
\hline
\end{tabular}

Obtención: silvestre
Vigencia: vigente (14\%)

\section{Conocimientos: \\ LÉXICO}

Solamente en Polentinos y Rebanal de las Llantas se recogió el peculiar nombre de drío o drido para denominar a esta especie. Los frutos se conocen popularmente como reventones 0 argamones.

Usos:

ALIMENTACIÓN ANIMAL

- Forraje verde o seco (1): En Lebanza se recoge el testimonio del empleo de la hoja como forraje para los terneros, "se recogía hoja para echar a los terneros cuando tenían 2-3 meses, decían que era muy buena".

- Pasto (5): Las aves y los osos buscan con avidez los frutos del serbal, son un excelente reclamo alimenticio para ellos, además abundan en el invierno cuando escasea otro tipo de alimento. Este hecho no pasa desapercibido para la sabiduría popular, que identifica esta especie como adecuada para su alimentación.

\section{TóxICO Y NOCIVO}

- Tóxica para personas y animales (20): En algunas localidades se identifican como tóxicos los frutos rojos, siendo los niños advertidos del peligro de su consumo. En otras localidades donde no se reconocen como tóxicos, se hace referencia a la imposibilidad de su consumo por su extrema acidez.

\section{COMBUSTIBLE}

- Leña (1): La leña del amargoso es considerada un buen combustible con gran poder calorífico. A pesar de esta propiedad, solo en casos excepcionales su madera se empleaba para quemar, ya que se destinaba a otros fines más valorados (herramientas).

\section{INDUSTRIA Y ARTESANÍA}

- Herramientas y utensilios (4): Su madera pesada y difícil de agrietar es muy dura y resistente, utilizada para elaborar los mangos de alguna herramienta de golpeo. También se menciona el uso para confeccionar varas largas, fuertes y sólidas.

- Vestimenta y adornos personales (1): En Santa María de Redondo se aconseja la madera de amargoso para confeccionar las machorras de las albarcas, aprovechando su característica dureza.

\section{MEDIOAMBIENTAL}


- Injerto (2): Al igual que sucedía con el mostajo, el amargoso también es adecuado como patrón para injertar manzanos, según explican en Alba de los Cardaños.

\section{ORNAMENTAL}

- Calles y caminos (4): Se trata de una especie ornamental, tanto por la vistosidad de su floración primaveral, así como por sus frutos colorados durante parte del verano y el otoño. Se ha convertido en la actualidad en un árbol decorativo empleado en la zona en alineaciones urbanas, jardines y plazas.

\section{SOCIAL, SIMBÓLICO Y RITUAL}

- Ritual de ciclo anual (7): Los ramos florecidos de serbal, se utilizan para adornar en festividades locales, para decorar la imagen del patrón o patrona que se pasea en procesión por las calles.

En épocas pasadas también servía para confeccionar arcos vegetales ornamentales con los que recibir a alguna personalidad eminente.

Observaciones: Algunas de las especies identificadas en ornamentación urbana son híbridos de especies silvestres procedentes de viveros.

Los frutos contienen vitamina $\mathrm{C}$ y se han consumido en la antigüedad en forma de mermeladas, aunque son ligeramente tóxicos por su contenido en parasorbina, sustancia que provoca irritación gástrica, sin embargo este efecto desaparece con la cocción (López Gonzalez, 2002).

RUBIACEAE

\section{Coffea arabica L.}

Café (11)

\begin{tabular}{lc}
\hline Frecuencia de citación (FC): & 11 \\
\hline Número de usos (NU): & 1 \\
\hline Número registros de uso (RU): & 11 \\
\hline
\end{tabular}

Obtención: comprada

Vigencia: vigente (100\%)

Usos:

\section{ALIMENTACIÓN HUMANA}

- Bebidas no alcohólicas (8): Se toma el café después de las comidas y como bebida para el desayuno.

- Condimentos y conservantes (3): Los granos de café se añadían en las recetas de elaboración de diferentes licores, pues mejora el sabor final de los mismos.
Galium aparine L.

Pegamanos (2), ensallo (1), lapa (3)

\begin{tabular}{lc} 
162P, 524P; 515V & \\
\hline Frecuencia de citación (FC): & $\mathbf{6}$ \\
\hline Número de usos (NU): & $\mathbf{2}$ \\
\hline Número registros de uso (RU): & $\mathbf{7}$ \\
Frecuencia Relativa de Citación (FRC): & $\mathbf{0 , 0 4}$ \\
\hline Índice de Importancia Cultural (IC): & $\mathbf{0 , 0 5}$ \\
\hline Índice de Vigencia (IV): & $\mathbf{0 , 0 0}$ \\
\hline
\end{tabular}

Obtención: Silvestre

Vigencia: abandonado

\section{Conocimientos:}

\section{LÉXICO}

El nombre de lapa deriva de la morfología de la planta, posee unos ganchos con los que se adhiere a otras plantas, "la lapa se pegaba".

\section{Usos:}

\section{MEDIOAMBIENTAL}

- Malas hierbas (6): Mala hierba temida en los cultivos de cereal, pues el carácter trepador de los tallos "tumbaba los trigos".

\section{SOCIAL, SIMBÓLICO Y RITUAL}

- Literatura popular (1): Se cita en Matabuena el dicho "el cadillo le da brillo, el amapol le da color y la lapa lo agazapa".

\section{RUBIACEAE}

Galium verum $\mathrm{L}$.

Hierba del cuajo (1), cuajaleche (1), hierba de la pulmonía (1)

\begin{tabular}{lc}
\hline 260P, 513P; 115F; 231V, 232V, 256V & \\
\hline Frecuencia de citación (FC): & $\mathbf{7}$ \\
\hline Número de usos (NU): & $\mathbf{3}$ \\
\hline Número registros de uso (RU): & $\mathbf{7}$ \\
\hline Frecuencia Relativa de Citación (FRC): & $\mathbf{0 , 0 5}$ \\
\hline Índice de Importancia Cultural (IC): & $\mathbf{0 , 0 5}$ \\
\hline Índice de Vigencia (IV): & $\mathbf{0 , 0 0}$ \\
\hline
\end{tabular}

Obtención: silvestre

Vigencia: abandonado

Usos:

ALIMENTACIÓN HUMANA

- Condimentos y conservantes (2): Se cita esta especie para sustituir el cuajo o presura en el proceso de cuajado del queso.

MEDICINA 
- Sistema respiratorio (2): La infusión de la parte aérea se toma en Vidrieros en casos de pulmonía.

- Piel y tejido celular subcutáneo (2): En Valsurbio se indica como se machacaba la planta, se juntaba con agua y se ponía la mezcla sobre las heridas.

Con el cocimiento de la planta se hacen pediluvios en Recueva de la Peña, cuando se tienen molestias o cansancio en los pies.

\section{ORNAMENTAL}

- Adorno floral y plantas de interior (1): En Verdeña se ponen ramos de flores sobre jarrones con agua, además desprenden un agradable olor.

RUTACEAE

Citrus limon (L.) Osbeck

Limón (3)

\begin{tabular}{ll}
\hline Frecuencia de citación (FC): & 3 \\
\hline Número de usos (NU): & 1 \\
\hline Número registros de uso (RU): & 3 \\
\hline
\end{tabular}

Obtención: comprada

Vigencia: vigente (33\%)

Usos:

MEDICINA

- Sistema digestivo (1): Para atajar la diarrea se aconseja tomar agua de limón (un vaso de agua mezclado con zumo de limón).

- Sistema respiratorio (2): El zumo de limón se añade en infusiones anticatarrales, de malva o de orégano y cebolla.

RUTACEAE

\section{Citrus sinensis (L.) Osbeck Naranja (1)}

\begin{tabular}{ll}
\hline Frecuencia de citación (FC): & 1 \\
\hline Número de usos (NU): & 1 \\
\hline Número registros de uso (RU): & 1 \\
\hline
\end{tabular}

Obtención: comprada

Vigencia: abandonado

Usos:

INDUSTRIA Y ARTESANÍA

- Cosmética, perfumería y limpieza (1): La cáscara de naranja se macera en agua junto con pétalos de rosa y violeta, para elaborar un agua oloroso que los niños usaban a modo de colonia.

RUTACEAE

Ruta montana L.

Ruda (2)

325P; 281F; 208V

\begin{tabular}{lc}
\hline Frecuencia de citación (FC): & $\mathbf{2}$ \\
\hline Número de usos (NU): & 2 \\
\hline Número registros de uso (RU): & 2 \\
\hline Frecuencia Relativa de Citación (FRC): & $\mathbf{0 , 0 1}$ \\
\hline Índice de Importancia Cultural (IC): & $\mathbf{0 , 0 1}$ \\
\hline Índice de Vigencia (IV): & $\mathbf{0 , 0 0}$ \\
\hline
\end{tabular}

Obtención: silvestre

Vigencia: abandonado

Usos:

MEDICINA

- Piel y tejido celular subcutáneo (1): En Matabuena se prepara una crema para las quemaduras con la cocción de la planta y cera de abejas.

\section{VETERINARIA}

- Sistema genito-urinario (1): Para curar las ubres de las vacas, se fríe la planta de la ruda con un poco de aceite y se unta sobre el área afectada, remedio recopilado en San Martín de Perapertú.

SALICACEAE

Populus alba L.

P. nigra L.

Chopo (122)

Populus alba: 19P, 297P; 6F

P. nigra: PALAB1247, 62P, 213P, 456P; 17F; 469V, $531 \mathrm{~V}$

\begin{tabular}{lc}
\hline Frecuencia de citación (FC): & 122 \\
\hline Número de usos (NU): & 6 \\
\hline Número registros de uso (RU): & 335 \\
\hline Frecuencia Relativa de Citación (FRC): & $\mathbf{0 , 8 8}$ \\
\hline Índice de Importancia Cultural (IC): & $\mathbf{2 , 4 1}$ \\
\hline Índice de Vigencia (IV): & $\mathbf{0 , 2 7}$ \\
\hline
\end{tabular}

Obtención: cultivada, silvestre

Vigencia: vigente (11\%)

Usos:

\section{ALIMENTACIÓN ANIMAL}

- Forraje verde o seco (59): Los chopos se podaban para aprovisionar en invierno de hoja para comer el ganado. Sobre todo se cortaba 
para ovejas y cabras, y especialmente para los corderos, aunque también podía administrarse a vacas, cerdos y conejos, estos últimos aprovechaban hasta la corteza de las ramas.

\section{COMBUSTIBLE}

- Leña (37): Como combustible no es muy apreciado por su baja capacidad calorífica, pero sí se aprovechan los restos de poda para hacer lumbre rápida y los troncos para calentar en la lumbre.

\section{CONSTRUCCIÓN}

- Carros y otros vehículos terrestres (4): En la construcción del tradicional carro tirado por vacas se empleaba la madera de chopo por su ligereza, para las tablas del suelo y de los zarzos (extensión del carro para aumentar la capacidad de carga).

- Casas, edificios e instalaciones agropecuarias (74): Utilizada su madera en algunos elementos de construcción, sobre todo para techar en tablas para la ripia. Se suelen usar las tablas que quedan del primer corte, que son las de peor calidad al tener una de sus caras convexa o con parte de corteza. También para vigas de poca carga, suelos o ventanas.

\section{INDUSTRIA Y ARTESANÍA}

- Herramientas y utensilios (12): La madera blanda y ligera, se utiliza para confeccionar alguna herramienta y mangos para ellas.

- Juguetes $e$ instrumentos deportivos $y$ musicales (28): Se fabricaban flautas rústicas con una rama ahuecada de chopo, se realizaban en primavera y era un juego tradicional en la zona. La raíz del chopo se usaba para fabricar las bolas del juego de los bolos.

- Mobiliario y enseres (6): Se empleó la madera en mobiliario variado como mesas, bancos, sillas, e incluso ataúdes, también para enseres, tablas de lavar, jaulas, etc.

\section{MEDIOAMBIENTAL}

- Mejora del suelo (5): Las hojas se emplearon como cama del ganado, citada con frecuencia para mullir el cubil del cerdo.

\section{SOCIAL, SIMBÓLICO Y RITUAL}

- Ritual de ciclo anual (61): Destaca el uso de ramas de chopo en las típicas enramadas por San Juan o San Pedro, en las cuales se colgaban ramos de este árbol en balcones o ventanas de las mozas a las que se pretendía. Asimismo se utilizaba para adornar el día del Corpus, y en las fiestas patronales.
Por último el uso del chopo era tradicional para plantar el mayo. A la llegada de mayo los jóvenes del pueblo cortaban un chopo para después de pelarlo, trepar por él y conseguir algún obsequio.

- Ritual de ciclo de vida (46): La colocación del mayo también fue popular en las ordenaciones de sacerdotes. Las enramadas y arcos decorativos de chopo eran tradicionales también en acontecimientos religiosos como las bodas o la visita ocasional de alguna personalidad de notoria importancia como el obispo o el gobernador.

- Alucinógenas, narcóticas y fumatorias (3): Las hojas secas y bien picaditas servían de sustituto del tabaco.

SALICACEAE

Populus tremula L.

Álamo (7)

77P, 276P; 40F

\begin{tabular}{ll|}
\hline Frecuencia de citación (FC): & 7 \\
\hline Número de usos (NU): & 4 \\
\hline Número registros de uso (RU): & 8 \\
\hline
\end{tabular}

Obtención: cultivada

Vigencia: vigente (20\%)

Conocimientos:

LÉXICO

En Salcedillo encontramos el pago "Los Álamos" y en Traspeña de la Peña el de "Álamo Llano".

Usos:

COMBUSTIBLE

- Leña (3): Las ramas caídas y alguna tala puntual se aprovechaba como combustible en la lumbre de las casas.

\section{CONSTRUCCIÓN}

- Casas, edificios e instalaciones agropecuarias (1): En Valsurbio se preparaban vigas para la estructura de las casas o las cuadras.

\section{MEDIOAMBIENTAL}

- Mejora del suelo (1): Las hojas se extienden sobre el cubil del cerdo como mullida de la cama para estuvieran limpios y bien dispuestos.

\section{SOCIAL, SIMBÓLICO Y RITUAL}

- Ritual de ciclo anual (3): En la fiesta del primero de mayo se pinaba un álamo descortezado y limpio de ramas, la juventud trataba de treparlo para conseguir llegar hasta 
el extremo, donde se colocaba algún premio como recompensa.

Observaciones: Las citas obtenidas como árbol empleado en la fiesta del mayo se recogieron todas en el mismo área: Valcobero, Valsurbio y Velilla del Río Carrión.

SALICACEAE

Salix atrocinerea Brot.

Salce gatillo (3)

121P, 527P; 76F; 180V

\begin{tabular}{lc|}
\hline Frecuencia de citación (FC): & 3 \\
\hline Número de usos (NU): & 1 \\
\hline Número registros de uso (RU): & 3 \\
\hline Frecuencia Relativa de Citación (FRC): & $\mathbf{0 , 0 2}$ \\
\hline Índice de Importancia Cultural (IC): & $\mathbf{0 , 0 2}$ \\
\hline Índice de Vigencia (IV): & $\mathbf{0 , 0 0}$ \\
\hline
\end{tabular}

Obtención: silvestre

Vigencia: abandonado

Conocimientos:

LÉXICO

Bajo el binomio salce gatillo se diferencia a la especie $S$. atrocinerea.

Usos:

INDUSTRIA Y ARTESANÍA

- Herramientas y utensilios (3): Se recomienda la madera especialmente por la resistencia y ligereza de su madera en la construcción de mangos, hastiles y piezas específicas del arado tradicional.

SALICACEAE

\section{Salix spp.}

Salguero (24), zalguero (2), salguera (13), zalguera (8), sota (22), sota lombarda (1), salce (35), zalce (1), mimbrera (2), mimbre (14)

64P, 144P, 317P, 414P, 418P, 488P ; 37F; 65V, 141V, 181V, 209V, 239V, 267V, 290V, 291V, 307V, 315V, $316 \mathrm{~V}, 347 \mathrm{~V}, 382 \mathrm{~V}, 442 \mathrm{~V}, 492 \mathrm{~V}, 506 \mathrm{~V}, 509 \mathrm{~V}, 510 \mathrm{~V}$, 533V, 538V, 566V, 578V, 579V, 583V, 601V

\begin{tabular}{lc}
\hline Frecuencia de citación (FC): & 110 \\
\hline Número de usos (NU): & 5 \\
\hline Número registros de uso (RU): & 205 \\
\hline Frecuencia Relativa de Citación (FRC): & 0,79 \\
\hline Índice de Importancia Cultural (IC): & 1,47 \\
\hline Índice de Vigencia (IV): & 0,03 \\
\hline
\end{tabular}

Obtención: silvestre

Vigencia: vigente (2\%)

\section{Conocimientos:}

\section{ECOLOGÍA}

Se encuentra en bosques húmedos, setos y riberas de los ríos.

\section{LÉXICO}

En Villaverde de la Peña se recoge el nombre de sota lombarda.

Mimbre sirve para denominar tanto a las ramas flexibles con las que se elaboran cestas, como a toda la planta.

Para los recipientes de cestería se documentaron los siguientes nombres: cestas, cestos, corras, coladeras o garrotas.

Se documentan los siguientes fitotopónimos en la zona, los pagos: "La Salguera" en Villabellaco, "El Salcedo" en Polentinos, San Salvador de Cantamuda y Vergaño, "La Salceda" en Salcedillo, del cual podría deriva el nombre de la localidad, y "Las Mimbreras" en Ruesga.

\section{Usos:}

\section{ALIMENTACIÓN ANIMAL}

- Forraje verde o seco (2): Las ramas con hojas se dedicaban con frecuencia a la alimentación de cabras, ovejas y conejos. Se cortaban durante el otoño y se dejaban secar atadas en manojos (gavillas, capachos o zamanzos), que después se colocaban en el pajar hasta su utilización. Suponía un apreciado suplemento alimenticio para el ganado durante el invierno, cuando el pastoreo no era posible por las condiciones meteorológicas adversas.

- Plantas melíferas (1): Las abejas aprovechan la floración primaveral de estas especies.

\section{COMBUSTIBLE}

- Leña (11): La leña producida por esta especie, se emplea de forma esporádica en algunos pueblos como combustible para la lumbre. A pesar de su abundancia, no goza de gran aprecio, al tratarse de una madera con poco poder calorífico y de engorroso rendimiento final, "es malo pa la lumbre porque iPega unos petardazos!", San Juan de Redondo.

\section{CONSTRUCCIÓN}

- Carros y otros vehículos terrestres (3): Con varas entretejidas de salguero se fabricaban zarzos, que servían para ampliar la capacidad del carro tradicional. Se colocaban en los costados del mismo, principalmente para el transporte de la paja desde la era, de este modo se reducía el número final de viajes al pajar.

- Casas, edificios e instalaciones agropecuarias (4): Las varas entretejidas de salguero, se han 
empleado en la arquitectura popular para levantar cerramientos exteriores o separar compartimentos interiores. La técnica es similar a la empleada para la construcción de los típicos sietos de avellano, e incluso se revocaban con una argamasa a base de tierra y agua.

\section{INDUSTRIA Y ARTESANÍA \\ - Herramientas y utensilios (38): La madera de este género se caracteriza por su ligereza y suavidad, apropiada para elaborar mangos de herramientas, cachavas y varas. Indicada también para la confección de escobas y especialmente para el tiro o arrastradero del arado romano, ya que aligeraba su peso final.}

- Juguetes $e$ instrumentos deportivos $y$ musicales (34): Los niños conocían la forma de elaborar todo tipo de silbatos, chiflos o flautas con la madera del salguero. Para la realización de estos instrumentos rústicos, se tomaba en primavera un trozo de rama del tamaño deseado, se desprendía la corteza golpeándola suavemente y entonando algún cántico cómo el recogido en Arbejal ,"Suda, suda, suda la manta peluda, el burro pide pan y no se lo dan, si a las 24 no parte, te parto, te parto, te parto, te parto y te partí", aunque pueden variar dependiendo de la localidad. Posteriormente, se hacían las muescas necesarias en el xilema para concluir la boquilla y se finalizaba el proceso acoplando el canuto de corteza en la rama.

Otro instrumento infantil típico era la corneta o trompeta, obtenida descortezando en espiral con una navaja un trozo de rama y uniendo nuevamente el tirabuzón.

Por último, en Camasobres se recoge la forma de confeccionar las combas que se empleaban en los juegos infantiles.

- Mobiliario y enseres (1): Únicamente en la localidad de Valsadornín se ha citado el singular empleo de la madera de salce para la fabricación de muebles de salón, combinado con madera de chopo.

- Cestería, recipientes y envoltorios (92): Con los rebrotes, de propiedades flexibles y consistentes, se confeccionan todo tipo de cestas en cuanto a tamaños y formas, su función está asociada a tareas de transporte en el ámbito agrícola y doméstico, muy útiles como recipientes para acarrear forraje, patatas, hortalizas, huevos, etc. Para obtener la materia prima se cortan los tallos nuevos de los ejemplares silvestres, normalmente mantenidos gracias a la poda anual a la que se someten. La confección de la cesta comienza con la preparación de un armazón de madera de avellano (Corylus avellana) o zarza (Rosa spp.), que consta de aro y costillas, sobre las que se trenzan las mimbres dóciles, previamente deshojadas.

Además, con mimbres se confeccionaban otro tipo de utensilios, uno de los más comunes fue la cagadera, con la que se recogían las heces del ganado durante la trilla y que evitaba ensuciar el grano.

- Cuerdas y ataduras (12): La flexibilidad de los tallos jóvenes y la dureza que adquieren tras el secado, son cualidades aprovechadas para hacer ataduras sólidas y resistentes, empleadas por ejemplo, para amarrar las ramas de las escobas vegetales a modo de presilla, para atar los manojos del ramón (capachos, gamanzos o zamanzos) o para sujetar la ripia del tejado.

En Santa María de Nava, la corteza de los tallos jóvenes se pela y se divide en pequeñas tiras útiles para atar las cañas de centeno con las que se elaboran los escriños

\section{SOCIAL, SIMBÓLICO Y RITUAL}

- Ritual de ciclo anual (2): En la localidad de Recueva de la Peña recuerdan el empleo de las ramas jóvenes, que eran bendecidas el Domingo de Ramos.

- Ritual de ciclo de vida (5): Para solemnizar momentos importantes se decoraba y se engalanaba con enramadas de salguero, podían utilizarse tanto en bodas como en conmemoraciones religiosas (cantamisas, visitas obispales, etc.) o civiles.

Observaciones: En la Montaña Palentina el género Salix está representado por más de una decena de especies, junto con sus formas híbridas. Encontramos sauces arbóreos (S. alba y $S$. $\mathrm{x}$ fragilis), y otro grupo más numeroso de especies arbustivas (S. atrocinerea, S. bicolor, $S$. caprea, S. eleagnos, S. neotricha, S. purpurea, S. salviifolia, S. triandra, S. viminalis).

SANTALACEAE

Viscum album L.

Muérdago (9), maraojo (2), marajojo (1), mingojo (1), milgojo (1)

105P, 498P; 99F; 135V

\begin{tabular}{lc}
\hline Frecuencia de citación (FC): & 13 \\
\hline Número de usos (NU): & 6 \\
\hline Número registros de uso (RU): & 18 \\
\hline Frecuencia Relativa de Citación (FRC): & 0,09 \\
Índice de Importancia Cultural (IC): & 0,13 \\
\hline Índice de Vigencia (IV): & 0,06 \\
\hline
\end{tabular}


Obtención: silvestre

Vigencia: vigente (44\%)

Conocimientos:

\section{ECOLOGÍA}

Puede encontrarse como parásito sobre todo en chopos y frutales.

\section{LÉXICO}

El fruto traslucido en su madurez se conoce con el nombre de barbolita.

Usos:

MEDICINA

- Sistema circulatorio (1): Se recomienda en Polentinos dar friegas con el cocimiento de la planta en las varices de las piernas.

\section{VETERINARIO}

- Concepción, embarazo y parto (1): EI cocimiento tibio de la planta se da a beber a las vacas, para ayudar a expulsar la placenta tras el parto, remedio recogido en Piedrasluengas.

- Piel y tejido celular subcutáneo (1): En Polentinos se cita el uso de la cocción de la planta, administrada en forma de cataplasma para cicatrizar las heridas de los animales domésticos.

\section{TóxICO Y NOCIVO}

- Tóxica para personas y animales (2): Se considera especie tóxica.

\section{MEDIOAMBIENTAL}

- Malas hierbas (1): En Otero de Guardo se señala que su presencia en los frutales acaba provocando la muerte por secado de los mismos.

\section{ORNAMENTAL}

- Adorno floral y plantas de interior (4): La planta se utiliza para adornar belenes navideños.

\section{SOCIAL, SIMBÓLICO Y RITUAL}

- Ritual de incertidumbre, protección y aflicción (8): Se ha incorporado como una costumbre reciente en el tiempo, la ubicación de muérdago en las puertas de cuadras y casas, como amuleto para ayudar a expulsar la negatividad y atraer la buena suerte.

\section{SAPINDACEAE}

Acer campestre L.

Barbaleña (2)
196P, 396P; 234F; 475V, 476V

\begin{tabular}{lc}
\hline Frecuencia de citación (FC): & 3 \\
\hline Número de usos (NU): & 3 \\
\hline Número registros de uso (RU): & 4 \\
\hline Frecuencia Relativa de Citación (FRC): & 0,02 \\
\hline Índice de Importancia Cultural (IC): & 0,03 \\
\hline Índice de Vigencia (IV): & 0,01 \\
\hline
\end{tabular}

Obtención: silvestre

Vigencia: vigente (25\%)

Usos:

COMBUSTIBLE

- Leña (2): Se utilizan ramas y tronco como combustible para la lumbre.

\section{INDUSTRIA Y ARTESANÍA}

- Herramientas y utensilios (1): En Villanueva de la Torre se indica la madera de barbaleña para la fabricación de rastros.

\section{ORNAMENTAL}

- Calles y caminos (1): En Herreruela de Castillería indican su presencia ornamental en la plaza de la iglesia.

SAPINDACEAE

\section{Aesculus hippocastanum L.}

Castaño de Indias (3)

174P, 491P; 292F

\begin{tabular}{|ll|}
\hline Frecuencia de citación (FC): & 4 \\
\hline Número de usos (NU): & 3 \\
\hline Número registros de uso (RU): & 5 \\
\hline
\end{tabular}

Obtención: cultivada

Vigencia: vigente (40\%)

Conocimientos:

LÉXICO

La semilla se conoce como castaña pilonga.

Usos:

MEDICINA

- Piel y tejido celular subcutáneo (1): En Verdeña se cita el uso de la semilla macerada en alcohol para desinfectar heridas.

\section{TÓXICO Y NOCIVO}

- Tóxicas para personas y animales (2): Las semillas no son comestibles, denominándose castañas pilongas. En Barruelo de Santullán incluso se afirma que comer castañas pilongas deriva en locura.

ORNAMENTAL 
- Calles y caminos (2): Se señala su presencia en plazas y jardines como decoración urbana.

\section{SCROPHULARIACEAE}

Scrophularia canina L.

Hoja mora (3), jamora (2)

140P, 422P; 240F; 330V, 384V

\begin{tabular}{lc}
\hline Frecuencia de citación (FC): & 5 \\
Número de usos (NU): & 1 \\
\hline Número registros de uso (RU): & 5 \\
\hline Frecuencia Relativa de Citación (FRC): & 0,04 \\
\hline Índice de Importancia Cultural (IC): & 0,04 \\
\hline Índice de Vigencia (IV): & 0,00
\end{tabular}

Obtención: silvestre

Vigencia: abandonado

Usos:

TÓXICO Y NOCIVO

- Venenos, insecticidas y plaguicidas (5): Planta ictiotóxica usada para pescar truchas, pues machando su fruto e incluso la planta entera, y echándolo en una zona empantanada artificialmente, provocaba el aturdimiento de la pesca. De esta manera se recogían las piezas fácilmente.

SCROPHULARIACEAE

\section{Verbascum lychnitis L.}

V. pulverulentum Vill.

V. thapsus $\mathrm{L}$.

Gordolobo (15), guardalobo (13)

Verbascum lychnitis: 261P; 215F; 193V

V. pulverulentum: 127P, 526P; 144F; 242V, 243V

V. thapsus: 100P, 278P; 73F; 453V, 580V

\begin{tabular}{lc|}
\hline Frecuencia de citación (FC): & 28 \\
\hline Número de usos (NU): & 4 \\
\hline Número registros de uso (RU): & 34 \\
\hline Frecuencia Relativa de Citación (FRC): & $\mathbf{0 , 2 0}$ \\
\hline Índice de Importancia Cultural (IC): & $\mathbf{0 , 2 4}$ \\
\hline Índice de Vigencia (IV): & $\mathbf{0 , 0 2}$ \\
\hline
\end{tabular}

Obtención: silvestre

Vigencia: vigente (9\%)

Conocimientos:

ECOLOGÍA

Aparece en bordes de caminos y áreas degradadas.

Usos:

MEDICINA
- Sistema circulatorio (7): Las hojas de gordolobo han sido mencionadas como un remedio eficaz contra las hemorroides. Poseen efectos emolientes que provocan la reducción de la inflamación y la cicatrización de la zona afectada. Se recogen formas diferentes de administración, aplicando directamente las hojas machacadas o previamente cocidas a modo de cataplasma, también mediante baños de asiento realizados con la cocción de las hojas.

- Sistema respiratorio (3): Para el tratamiento de catarros se utilizan las flores en infusión, que además tienen la cualidad de aliviar la tos.

- Musculatura y esqueleto (3): Se recomienda la cocción de hojas para el tratamiento de golpes o contusiones que provocan hinchazón, eficaz como antiinflamatorio y administrado en forma de cataplasma o baño de la zona afectada.

\section{VETERINARIA}

- Sistema digestivo (1): En Verdeña se evoca el uso del gordolobo como aperitivo del ganado vacuno joven, de esta manera, "Las hojas eran para abrir el apetito de los novillos que se encontraban sin ganas de comer. Se cocían las hojas y después se les daba en una botella el agua".

- Concepción, embarazo y parto (1): Tras un parto, las vacas pueden expulsar la matriz, suceso conocido con el nombre de esmadronar. En estos casos se procedía a la limpieza y reintroducción con habilidad del mismo. En la localidad de Resoba se aconseja la cocción de hojas de gordolobo para lavar e higienizar el útero desprendido antes de reintroducirse.

- Intoxicaciones y envenenamientos (1): Resulta un buen antiinflamatorio natural, se ha empleado la cocción de las hojas en cataplasma, para rebajar la inflamación producida por la picadura de algún insecto. Se recoge en Resoba esta receta, "se cuecen hojas de guardalobo en agua, se moja un paño y se pone a las ovejas cuando las pica algún bicho".

\section{TóXICO Y NOCIVO}

- Venenos, insecticidas y plaguicidas (17): Machacando frutos y semillas, en ocasiones toda la planta, se obtenía una especie de pasta, que se arrojaba en los remansos de los ríos trucheros, con el objetivo de atontar a la pesca y recoger fácilmente las piezas. Resulta una práctica de pesca tradicional muy antigua en las localidades por las que discurrían ríos con actividad pesquera. 


\section{ORNAMENTAL}

- Adorno floral y plantas de interior (1): Se ha documentado de forma ocasional, el uso ornamental de varas con la floración ya finalizada, en centros de flores secas.

Observaciones: No existe distinción de usos para los informantes entre Verbascum lychnitis, $V$. pulverulentum y $V$. thapsus.

El arte de pescar con gordolobo, dio lugar al verbo enverbascar (envenenar el agua con verbasco $u$ otra sustancia análoga para atontar a los peces).

El gordolobo forma parte del grupo de plantas ictiotóxicas (tóxicas para los peces), utilizadas en el pasado en la Montaña Palentina para la pesca furtiva, junto con la hoja mora (Scrophularia canina) y el tagarnio (Thapsia villosa).

\section{SOLANACEAE}

\section{Capsicum annuum L.} Pimiento (3)

\begin{tabular}{ll}
\hline Frecuencia de citación (FC): & 6 \\
\hline Número de usos (NU): & 2 \\
\hline Número registros de uso (RU): & 9 \\
\hline
\end{tabular}

Obtención: cultivada, comprada

Vigencia: vigente (25\%)

Usos:

ALIMENTACIÓN HUMANA

- Verduras y hortalizas (2): Cultivado en huertos, se consume frito, asado o en diversos guisos.

- Condimentos y conservantes (6): El pimentón es un condimento esencial para el adobo de la matanza, se compraba y se añadía en el chorizo, las jijas, la morcilla, etc. También en guisos que tienen como ingrediente las patatas y en otro tipo de recetas culinarias.

\section{VETERINARIA}

- Sistema digestivo (1): En Resoba se unta tocino en pimentón y se introduce en la boca de las vacas cuando se encontraban infladas por gases en el estomago, "fermenta en el estomago y se desinflan solas".

\section{Datura stramonium L.}

SOLANACEAE

Estramonio (3), trompeta (1)
413P; 263F

\begin{tabular}{lc}
\hline Frecuencia de citación (FC): & 5 \\
\hline Número de usos (NU): & 1 \\
\hline Número registros de uso (RU): & 5 \\
\hline Frecuencia Relativa de Citación (FRC): & $\mathbf{0 , 0 4}$ \\
\hline Índice de Importancia Cultural (IC): & $\mathbf{0 , 0 4}$ \\
\hline
\end{tabular}

Obtención: silvestre

\section{Conocimientos:}

\section{ECOLOGÍA}

Se da en terrenos fertilizados, en aboneros (mudadales) y huertas.

Usos:

\section{TÓXICO Y NOCIVO}

- Tóxico para humanos y animales (4): Se la reconoce como una planta altamente tóxica tanto para el ganado como para las personas.

- Otros elementos nocivos y repelentes (1): En Villanueva de Arriba afirman que se solía ubicar en el pasado un par de plantas cerca de las colmenas, para ahuyentar por su desagradable olor a las hormigas y otros insectos, "huele peor que los huevos podridos".

SOLANACEAE

\section{Hyoscyamus niger L.}

Beleño (27)

\begin{tabular}{lc} 
101P; 74F; 555V \\
\hline Frecuencia de citación (FC): & $\mathbf{2 7}$ \\
\hline Número de usos (NU): & $\mathbf{3}$ \\
\hline Número registros de uso (RU): & $\mathbf{3 7}$ \\
\hline Frecuencia Relativa de Citación (FRC): & $\mathbf{0 , 1 9}$ \\
\hline Índice de Importancia Cultural (IC): & $\mathbf{0 , 2 7}$ \\
\hline Índice de Vigencia (IV): & $\mathbf{0 , 0 0}$ \\
\hline
\end{tabular}

Obtención: silvestre

Vigencia: abandonado

\section{Conocimientos:}

\section{ECOLOGÍA}

Se encuentra en escombreras, cunetas y márgenes de huertos.

Usos:

\section{MEDICINA}

- Sistema digestivo (8): Las semillas del beleño son mencionadas en remedios para el tratamiento de los dolores de muelas y las caries. Las formas de administración recogidas son varias, colocar una cataplasma en la zona dolorida con las semillas previamente hervidas, tomar vapores de su cocimiento, o ahumar la 
muela con el humo que desprenden las semillas en una brasa.

En Polentinos señalaron esta especie para combatir dolores estomacales "se fríe la grana en un sartén con un poco de aceite y se unta en la tripa cuando te duele la barriga".

- Musculatura y esqueleto (3): Empleadas como antiinflamatorias, las semillas sirven para combatir los dolores y las inflamaciones derivadas de traumatismos o golpes. Se fríen con un poco de aceite y se aplica mediante cataplasma.

\section{VETERINARIA}

- Sistema genito-urinario (4): Un buen tratamiento de la mamitis (inflamación de las ubres de las vacas) era el que se realizaba con el aceite resultante de freír las semillas, "se daba con un algodón cuando tenían el ubre inflamada".

- Musculatura y esqueleto (1): Eficaz como antiinflamatorio, se aplica a los animales en la parte afectada un poco de aceite frito con las semillas de beleño.

- Intoxicaciones y envenenamientos (6): El remedio más popular para tratar las inflamaciones provocadas al ganado por mordeduras (de culebra, de comadreja, etc.) se elaboraba con semillas de beleño. Así se detalla en la localidad de Verdeña "cuando está seca la grana se cuece en el puchero, se quita el agua, se da vuelta en una sartén mala y se fríe un poco. Con una vedija de lana se da en la picadura, es contraveneno para si pica a la vaca, una culebra o una mostolilla".

\section{TóxICO Y NOCIVO}

- Tóxico para humanos y animales (15): A pesar de su uso corriente como planta medicinal y veterinaria, son varias las personas que advierten su potente toxicidad.

Observaciones: Se ha comprobado que esta planta es muy popular entre los vecinos de Polentinos, de la que se han recogido varios remedios medicinales.

SOLANACEAE

Nicotiana tabacum L. Tabaco (13)

\begin{tabular}{lc}
\hline Frecuencia de citación (FC): & 13 \\
\hline Número de usos (NU): & 1 \\
\hline Número registros de uso (RU): & 14 \\
\hline
\end{tabular}

Obtención: cultivada
Vigencia: abandonado

Usos:

VETERINARIA

- Enfermedades infecciosas y parasitarias (2): Las hojas se cuecen en agua y con el líquido resultante se lava a los terneros para eliminar los piojos. Se colocaba el bozal para que no se lamieran durante el tratamiento.

SOCIAL, SIMBÓLICO Y RITUAL

- Alucinógenas, narcóticas y fumatorias (12): Se cultivaban unas pocas plantas para autoconsumo, las hojas secas y desmenuzadas se fumaban.

SOLANACEAE

Petunia hybrida Vilm.

Petunia (1)

\begin{tabular}{|ll|}
\hline Frecuencia de citación (FC): & 1 \\
Número de usos (NU): & 1 \\
\hline Número registros de uso (RU): & 1 \\
\hline
\end{tabular}

Obtención: cultivada

Vigencia: vigente (100\%)

Usos:

ORNAMENTAL

- Patios, huertos y jardines (1): Se cultiva en parterres y macetas como flor ornamental de temporada.

SOLANACEAE

Solanum lycopersicon Mill.

Tomate (10)

262P

\begin{tabular}{lc}
\hline Frecuencia de citación (FC): & 10 \\
\hline Número de usos (NU): & 1 \\
\hline Número registros de uso (RU): & 10 \\
\hline
\end{tabular}

Obtención: cultivada, comprada

Vigencia: vigente (100\%)

Usos:

ALIMENTACIÓN HUMANA

- Verduras y hortalizas (10): Se cultivan principalmente para utilizar en crudo en ensaladas $y$ en menor medida como ingrediente de algunos guisos. En la actualidad es común su presencia en las huertas, pero en el pasado no era así, ya que no resultaba sencillo conseguir una correcta maduración. 
SOLANACEAE

Solanum melongena $\mathrm{L}$. Berenjena (1)

\begin{tabular}{ll}
\hline Frecuencia de citación (FC): & 1 \\
\hline Número de usos (NU): & 1 \\
\hline Número registros de uso (RU): & 1 \\
\hline
\end{tabular}

Obtención: cultivada, comprada

Vigencia: vigente (100\%)

Usos:

ALIMENTACIÓN HUMANA

- Verduras y hortalizas (1): Introducida en los años noventa como cultivo en la zona. Se utiliza como verdura presente en diversos guisos $y$ sofritos.

SOLANACEAE

Solanum tuberosum L.

Patata (95)

\begin{tabular}{lc} 
7P; $94 \mathrm{~F}$ \\
\hline Frecuencia de citación (FC): & 95 \\
\hline Número de usos (NU): & 3 \\
\hline Número registros de uso (RU): & 151 \\
\hline
\end{tabular}

Obtención: cultivada, comprada

Vigencia: vigente (61\%)

Usos:

\section{ALIMENTACIÓN HUMANA}

- Raíces, bulbos, tubérculos y rizomas (92): Se trata de un cultivo de vital importancia en la dieta de los habitantes de la comarca. Se toman de ordinario cocinadas en diferentes guisos, junto con chorizo, carne o solo con pimentón, aceite o tocino, también en forma de tortilla y en otras múltiples recetas.

\section{ALIMENTACIÓN ANIMAL}

- Raíces y tubérculos (42): Las patatas defectuosas y las más pequeñas se servían a los cerdos, también las peladuras se incluían en su dieta. Se cocían previamente en un puchero en el que se añadían de forma corriente otras verduras cultivadas o silvestres como berza, ortigas, cardos, hojas de ramón, etc. En Valsurbio se cocían patatas a las vacas, servidas con un poco de harina de centeno, y en Arbejal aseguran que los terneros engordan cuando comen patatas cocidas con harina de cebada.

SOCIAL, SIMBÓLICO Y RITUAL
- Alucinógenas, narcóticas y fumatorias (17): Las hojas secas se fumaban desmenuzadas en momentos de escasez de tabaco.

Observaciones: Al resultar un cultivo que se desarrolla bien en la zona se asignaban tierras de gran tamaño para obtener una producción mayor. Las tierras de peor calidad se dedicaban al cultivo de la patata.

Si la producción del año resultaba escasa, para optimizar en la siembra se cortaban los tubérculos en trozos dispuestos para plantar. Por lo general las patatas grandes eran para comer, las medianas para plantar y las pequeñas para el ganado.

Las patatas se han comercializado y han servido para intercambiar por otros productos más difíciles de conseguir en la comarca.

THYMELAEACEAE

Daphne laureola L.

166P, 420P; 148F

\begin{tabular}{lc|}
\hline Frecuencia de citación (FC): & 1 \\
\hline Número de usos (NU): & 1 \\
\hline Número registros de uso (RU): & 1 \\
\hline Frecuencia Relativa de Citación (FRC): & 0,01 \\
\hline Índice de Importancia Cultural (IC): & 0,01 \\
\hline Índice de Vigencia (IV): & 0,00 \\
\hline
\end{tabular}

Obtención: silvestre

Vigencia: abandonado

Usos:

VETERINARIA

- Sistema digestivo (1): En Alba de los Cardaños recuerdan que cuando las ovejas tenían diarrea se las ataba esta planta al rabo para que se detuviera la colitis.

ULMACEAE

Ulmus glabra Huds.

Olmo monte (1)

\begin{tabular}{lc}
\hline $441 \mathrm{P}$ & \\
\hline Frecuencia de citación (FC): & 1 \\
\hline Número de usos (NU): & 1 \\
\hline Número registros de uso (RU): & 1 \\
\hline Frecuencia Relativa de Citación (FRC): & 0,01 \\
\hline Índice de Importancia Cultural (IC): & 0,01 \\
\hline Índice de Vigencia (IV): & 0,00 \\
\hline
\end{tabular}

Obtención: silvestre

Vigencia: abandonado 
Usos:

\section{ALIMENTACIÓN ANIMAL}

- Forraje verde o seco (1): En Nava de Santullán se cuecen las hojas y se sirven como alimento a los cerdos.

\section{ULMACEAE}

\section{Ulmus minor Mill.} Olmo (59)

PALAB1346, 18P, 291P; 93F; 294V, 295V, 309V, 353V, 473V, 474V, 510V, 511V, 568V

\begin{tabular}{lc}
\hline Frecuencia de citación (FC): & 59 \\
\hline Número de usos (NU): & 5 \\
\hline Número registros de uso (RU): & 144 \\
Frecuencia Relativa de Citación (FRC): & 0,42 \\
\hline Índice de Importancia Cultural (IC): & 1,04 \\
\hline Índice de Vigencia (IV): & 0,00 \\
\hline
\end{tabular}

Obtención: silvestre

Vigencia: abandonado

\section{Conocimientos:}

\section{ECOLOGÍA}

La enfermedad de la grafiosis causada por el hongo Ceratocystis ulmi ha mermado considerablemente su población, causando el secado del árbol. Según varios informantes afecta a los olmos y no a las olmas.

\section{LÉXICO}

El entretejido de ramas de olmo se denomina gamanzo o zamanzo.

Olmiza refiere a los ejemplares que no llegan a prosperar hacia un porte arbóreo. Olma es un árbol longevo. "La grafiosis ha terminado con todos, ahora solo hay olmizas, olma llamábamos a un olmo antiquísimo", Santa María de Nava.

Varios fitotopónimos se encuentran en la zona, los pagos de: "Los Olmos" en Salcedillo, "Olmeras" en Matabuena y Nestar, "Las Olmedas" en Dehesa de Montejo, "La Olmeda" en Cervera de Pisuerga, y "El Olmo" en Recueva de la Peña.

\section{Usos:}

\section{ALIMENTACIÓN ANIMAL}

- Forraje verde o seco (52): La hoja de olmo era recogida al terminar el verano y se llevaba para el consumo del ganado en el invierno. Gustaban de ella cabras, cerdos, conejos, ovejas y vacas, en el caso de los cerdos, se cocían un poco en agua para facilitar su ingesta. Para cabras y ovejas se entretejían varias ramas y se servían como forraje seco, además de alimento ejercía de entretenimiento a los animales en la cuadra.

\section{COMBUSTIBLE}

- Leña (8): Las ramas procedentes de desmoches se echaban a la lumbre así como la madera no aprovechada en artesanía, "hacíamos lumbre, aunque tenía más merito para madera", Roscales de la Peña.

\section{CONSTRUCCIÓN}

- Carros y otros vehículos (12): La madera del olmo resiste bien los golpes y la tracción, por ello fue apreciado en la fabricación de carros. Destaca la elaboración de las ruedas del carro con este tipo de madera, la maza, así como otras piezas que configuraban la estructura y el armazón del carro.

- Casas, edificios e instalaciones agropecuarias (8): Se emplea la madera de olmo en vigas para la estructura de las construcciones, en ripia para el tejado, y en puertas y ventanas.

\section{INDUSTRIA Y ARTESANÍA}

- Herramientas y utensilios (43): Se cita el uso de la madera para la construcción de yugos y yuguetas, rastros, horcas, collares para el ganado, cachavas, piezas de aperos como el dental del arado romano, y mangos para todo tipo de herramientas.

- Juguetes $e$ instrumentos deportivos $y$ musicales (5): Se fabricaban con su madera las bolas del juego tradicional de los bolos y peonzas para los más jóvenes.

- Mobiliario y enseres (3): Excelente madera para la construcción de muebles, sillas, mesas, armarios, etc.

- Cestos, recipientes y envoltorios (1): Los troncos de viejos olmos huecos se empleaban en Matabuena como habitáculo para las abejas (dujo) donde elaboraban la miel.

- Cuerdas y ataduras (1): En Salinas de Pisuerga se hacían una especie de cuerdas con las ramas más flexibles del olmo con las que se ataban los manojos de ramos con hojas que se acarreaban hasta el pajar.

\section{SOCIAL, SIMBÓLICO Y RITUAL}

- Ritual de ciclo anual (2): Los típicos arcos y enramadas para engalanar en alguna fiesta local se confeccionaban con ramas de olmo.

- Alucinógenas, narcóticas y fumatorias (8): Las hojas secas y muy picadas se envuelven en papel de fumar y sirven como sustituto del tabaco.

- Árboles singulares (1): El olmo ubicado en la plaza de Camporredondo de Alba posee un 
gran porte y era lugar de reunión de la mocedad del lugar, denominado olma por su gran porte.

URTICACEAE

Urtica dioica L.

Ortiga (67)

PALAB 1446, 54P, 458P; 134F; 192V, 296V, 367V, 497V, 547V

\begin{tabular}{lc}
\hline Frecuencia de citación (FC): & 67 \\
\hline Número de usos (NU): & 5 \\
\hline Número registros de uso (RU): & 101 \\
\hline Frecuencia Relativa de Citación (FRC): & $\mathbf{0 , 4 8}$ \\
\hline Índice de Importancia Cultural (IC): & $\mathbf{0 , 7 2}$ \\
\hline Índice de Vigencia (IV): & $\mathbf{0 , 0 4}$ \\
\hline
\end{tabular}

Obtención: silvestre

Vigencia: vigente $(6 \%)$

Conocimientos:

ECOLOGÍA

Caminos, setos, muros y herbazales.

Usos:

\section{ALIMENTACIÓN HUMANA}

- Verduras y hortalizas (3): Se toman ortigas cocidas en forma de sopas, la parte aprovechable son los brotes más tiernos recogidos en primavera o en otoño, "mi abuela la cocía un minuto y a tapar, la colaba y la tomaba fría". En Polentinos se tomaba el caldo de cocer las ortigas, recomendado por los minerales y vitaminas que contiene.

\section{ALIMENTACIÓN ANIMAL}

- Forraje verde o seco (43): La parte aérea tiene uso forrajero como alimento para los cerdos, cocida o picada, y también para las vacas en fresco. Se recolectaban con guantes para evitar la irritación.

- Pasto (3): Las vacas pacen con avidez las ortigas, y los cerdos también cuando se les dejaba salir del cubil.

\section{MEDICINA}

- Sistema circulatorio (26): Considerada depurativa. Resulta habitual tomar el cocimiento de la planta para mejorar la circulación, la tensión y purificar la sangre.

- Sistema genito-urinario (1): La infusión alivia los dolores provocados por la menstruación.

- Sistema respiratorio (1): En Estalaya se preparara la infusión de la planta para combatir el resfriado.
- Musculatura y esqueleto (4): Se toma infusión de la parte aérea como tratamiento de dolores reumáticos. En Piedrasluengas las ortigas machacadas y con un poco de aceite se envuelven en un paño que se coloca a modo de cataplasma para templar el dolor de espalda.

- Piel y tejido celular subcutáneo (3): Macerada en alcohol se utiliza contra la caspa, dermatitis o eczemas, se aplicaba con un algodón el preparado en las zonas afectadas. Para los mismos problemas e incluso para la caída del pelo se ha recogido también el uso del cocimiento en el aclarado del pelo.

\section{TÓXICO Y NOCIVO}

- Irritantes, urticantes y fotosensibles (11): Al tocarlas causan irritación y enrojecimiento en la piel. Se indica que si se contiene la respiración se pueden tocar.

- Venenos, insecticidas y plaguicidas (3): EI caldo resultante del cocimiento de ortigas se usa como insecticida antipulgón.

\section{INDUSTRIA Y ARTESANÍA}

- Cosmético, perfumería y limpieza (2): En San Felices de Castillería se recomienda lavar el pelo con el agua de cocer las ortigas como tratamiento de belleza, señalando que fortalece y da brillo al cabello.

\section{URTICACEAE}

Urtica urens $\mathrm{L}$.

Ortiga (5), ortiga meña (1)

\begin{tabular}{lc} 
270P; 324F & \\
\hline Frecuencia de citación (FC): & 6 \\
\hline Número de usos (NU): & 2 \\
\hline Número registros de uso (RU): & 6 \\
Frecuencia Relativa de Citación (FRC): & $\mathbf{0 , 0 4}$ \\
Índice de Importancia Cultural (IC): & $\mathbf{0 , 0 5}$ \\
Índice de Vigencia (IV): & $\mathbf{0 , 0 0}$ \\
\hline
\end{tabular}

Obtención: silvestre

Vigencia: abandonado

Conocimientos:

\section{ECOLOGÍA}

"Las ortigas meñas son más pequeñas y pican más que las normales", Polentinos.

Usos:

ALIMENTACIÓN ANIMAL

- Forraje verde o seco (2): Se cortan para añadir como alimento en verde a cerdos y vacas.

MEDICINA 
- Sistema circulatorio (4): La cocción de ortigas se aconseja en casos de trastornos circulatorios, pesadez de piernas y limpieza general de la sangre.

\section{TÓXICO Y NOCIVO}

- Irritantes, urticantes y fotosensibles (1): Al tocarlas causan irritación y enrojecimiento en la piel, resultando su picadura más agresiva que la de la ortiga común, según recogemos en la localidad de Polentinos.

VERBENACEAE

\section{Verbena officinalis $\mathrm{L}$.}

Verbena (13)

200P; 302F; 78V, 79V, 387V

\begin{tabular}{lc}
\hline Frecuencia de citación (FC): & 13 \\
\hline Número de usos (NU): & 2 \\
\hline Número registros de uso (RU): & 15 \\
\hline Frecuencia Relativa de Citación (FRC): & 0,09 \\
\hline Índice de Importancia Cultural (IC): & 0,11 \\
\hline Índice de Vigencia (IV): & 0,00 \\
\hline
\end{tabular}

Obtención: silvestre

Vigencia: abandonado

Conocimientos:

\section{ECOLOGÍA}

Se da por la orilla de carreteras y caminos.

Usos:

MEDICINA

- Sistema circulatorio (2): La parte aérea en infusión se aconseja para rebajar la sangre.

- Sistema digestivo (2): Para detener la diarrea se toma una taza de infusión de verbena. $Y$ en San Martín de los Herreros, para reducir el tamaño de las hemorroides se prepara el cocimiento de la planta que se echa sobre un orinal y con los vahos se toman baños de asiento.

- Sistema respiratorio (10): Un remedio muy común para aliviar la sinusitis consiste en freir la planta picada en una sartén y añadir un huevo batido, consiguiendo una tortilla que se coloca a modo de cataplasma sobre la frente. En algunas citas se envuelve la tortilla en un trapo.

También se toma infusión de la parte aérea de la planta como tratamiento anticatarral.

\section{SOCIAL, SIMBÓLICO Y RITUAL}

- Literatura popular (1): En Rebanal de las Llantas se recoge el dicho "cogiendo la verbena en la mañanita de San Juan no te picará culebra ni bicho que te haga mal".

VIOLACEAE

Viola alba Besser

V. bubanii Timb.-Lagr.

V. palustris $\mathrm{L}$.

V. reichenbachiana Jord. ex Boreau

V. riviniana Rchb.

Violeta (14), pensamiento (1)

Viola alba: $199 \mathrm{P} ; 211 \mathrm{~F}$

V. bubanii: 367P

V. palustris: $262 \mathrm{P}$

V. reichebachiana: $326 \mathrm{P}$

V. riviniana: 23P, 289P; 64F; 82V, $83 \mathrm{~V}$

\begin{tabular}{lc}
\hline Frecuencia de citación (FC): & 24 \\
\hline Número de usos (NU): & 3 \\
\hline Número registros de uso (RU): & 27 \\
\hline Frecuencia Relativa de Citación (FRC): & $\mathbf{0 , 1 7}$ \\
\hline Índice de Importancia Cultural (IC): & $\mathbf{0 , 1 9}$ \\
\hline Índice de Vigencia (IV): & $\mathbf{0 , 0 2}$ \\
\hline
\end{tabular}

Obtención: silvestre

Vigencia: vigente (11\%)

\section{Conocimientos:}

\section{ECOLOGÍA}

Se encuentran por las orillas de los caminos en el bosque.

Usos:

MEDICINA

- Sistema respiratorio (2): Se recomienda la infusión de flores de violetas y malvas para aliviar el dolor de garganta y la tos bronquial.

\section{INDUSTRIA Y ARTESANÍA}

- Cosmética, perfumería y limpieza (20): Los pétalos de violeta se mezclan con agua, a veces con agua y alcohol y se dejan macerar al menos un mes para preparar colonia, en ocasiones, se añadían otras especies olorosas como pétalos de rosa o cáscara de naranja. Existía la creencia de que la fragancia de las flores se conservaba mejor de este modo en pequeños tarros de cristal.

\section{ORNAMENTAL}

- Patios, huertos y jardines (2): Se traslada la belleza de las flores del monte al jardín de la vivienda.

- Adorno floral y plantas de interior (3): Con las flores se hacen pequeños ramilletes decorativos para el interior de las viviendas e 
incluso para la iglesia local, destacando su excelente aroma.

Observaciones: Otras especies del genero Viola, como $V$. arvensis, V. biflora, V. canina, $V$. odorata, $V$. pyrenaica o $V$. rupestris, se han podido utilizar de la misma manera que las recogidas en esta ficha.

VIOLACEAE

Viola tricolor L.

Pensamiento (2)

412P

Frecuencia de citación (FC): $\quad 2$

Número de usos (NU):

Número registros de uso (RU):

2

Obtención: cultivada

Vigencia: vigente $(100 \%)$

Usos:

ORNAMENTAL

- Patios, huertos y jardines (2): Se cultiva en macetas para decoración en exterior de viviendas y en parterres de jardines.

VITACEAE

Vitis vinifera $\mathrm{L}$.

Parra (8)

193P; 152F; 297V, 298V, 567V

\begin{tabular}{lc}
\hline Frecuencia de citación (FC): & 18 \\
Número de usos (NU): & 6 \\
\hline Número registros de uso (RU): & 23
\end{tabular}

Obtención: cultivada, comprada

Vigencia: vigente (61\%)

Usos:

\section{ALIMENTACIÓN HUMANA}

- Frutas y frutos dulces (12): Los frutos de las parras se destinan al consumo de uva de mesa, el problema es conseguir que maduren completamente, pues las condiciones meteorológicas de la zona no son las más idóneas para el desarrollo de fruta en perfectas condiciones para su consumo. Si el año era bueno se deshidrataba parte de la producción para hacer uva pasa.

- Golosinas y masticatorias (2): Los brotes tiernos y los zarcillos de las viñas eran muy apetecidos para consumirlos por su sabor un tanto ácido, como refrescantes y como entretenimiento. A primeros de mayo se cogían los tallos más tiernos, se pelaban quitándolos la piel fina que los rodea y se consumían en crudo sin preparación alguna.

\section{MEDICINA}

- Sistema respiratorio (1): En San Felices de Castillería se cocía vino con azúcar, que se tomaba como remedio anticatarral.

\section{VETERINARIA}

- Concepción, embarazo y parto (1): Para expulsar por completo la placenta de una vaca tras el parto, en Vidrieros se las administraba vino caliente con miel por medio de una botella introducida en la boca del animal.

- Sistema respiratorio (3): El vino se servía a las vacas con un poco de pan o grasa de cerdo para curar los catarros.

\section{COMBUSTIBLE}

- Leña (1): En Arbejal se utilizaban ramas con hojas verdes para controlar la temperatura del horno. Si aumentaba mucho el calor, se atemperaba con hojas verdes y de esta forma se conseguía la temperatura deseada para el horno.

\section{INDUSTRIA Y ARTESANÍA}

- Herramientas y utensilios (1): La madera de parra se empleó ocasionalmente para fabricar pipas para fumar.

\section{MEDIOAMBIENTAL}

- Sombra y protección (2): Las fachadas de muchos patios de viviendas en la zona tienen parras trepadoras que servían como sombreo.

\section{HONGOS}

AGARICACEAE

Agaricus arvensis L.:Fr.

A. campestris L.:Fr.

Champiñón (4), champiñón campero (2), hongo (9), hongo silvestre (1)

\begin{tabular}{lc}
\hline Frecuencia de citación (FC): & 16 \\
\hline Número de usos (NU): & 1 \\
\hline Número registros de uso (RU): & 16 \\
\hline Frecuencia Relativa de Citación (FRC): & $\mathbf{0 , 1 2}$ \\
\hline Índice de Importancia Cultural (IC): & 0,12 \\
\hline Índice de Vigencia (IV): & 0,12 \\
\hline
\end{tabular}

Obtención: silvestre

Vigencia: vigente (100\%) 
Usos:

\section{ALIMENTACIÓN HUMANA}

- Setas y otros hongos (16): Destacan por su olor y por ser considerada una de las setas más sabrosas de la zona, se recogen en primavera y otoño y se cocinan o se comen troceados y calentados sobre unas brasas.

\section{AGARICACEAE}

\section{Macrolepiota procera (Scop.:Fr.) Sing}

Parasol (1)

\begin{tabular}{lc}
\hline Frecuencia de citación (FC): & 1 \\
\hline Número de usos (NU): & 1 \\
\hline Número registros de uso (RU): & 1 \\
\hline Frecuencia Relativa de Citación (FRC): & 0,01 \\
\hline Índice de Importancia Cultural (IC): & 0,01 \\
\hline Índice de Vigencia (IV): & 0,01 \\
\hline
\end{tabular}

Obtención: silvestre

Vigencia: vigente (100\%)

Usos:

ALIMENTACIÓN HUMANA

- Setas y otros hongos (1): De gran tamaño se consumen asados o fritos, en el pasado no se reconocían como comestibles.

\section{BOLBITIACEAE}

Agrocybe aegerita (Brig.)Fayod

Seta de chopo (1)

\begin{tabular}{lc}
\hline Frecuencia de citación (FC): & 1 \\
\hline Número de usos (NU): & 1 \\
\hline Número registros de uso (RU): & 1 \\
\hline Frecuencia Relativa de Citación (FRC): & 0,01 \\
\hline Índice de Importancia Cultural (IC): & 0,01 \\
\hline Índice de Vigencia (IV): & 0,01 \\
\hline
\end{tabular}

Obtención: silvestre

Vigencia: vigente (100\%)

Usos:

ALIMENTACIÓN HUMANA

- Setas y otros hongos (1): Se recolecta en tocones o viejos troncos de chopo, de uso reciente en el tiempo.

\section{BOLETACEAE}

Boletus edulis Bull.:Fr.

B. pinophilus Pilat \& Dermek Boletus (6)

\begin{tabular}{lc}
\hline Frecuencia de citación (FC): & 6 \\
\hline Número de usos (NU): & 1 \\
\hline Número registros de uso (RU): & 6 \\
\hline Frecuencia Relativa de Citación (FRC): & $\mathbf{0 , 0 4}$ \\
\hline Índice de Importancia Cultural (IC): & $\mathbf{0 , 0 4}$ \\
\hline Índice de Vigencia (IV): & $\mathbf{0 , 0 4}$ \\
\hline
\end{tabular}

Obtención: silvestre

Vigencia: vigente (100\%)

Usos:

\section{ALIMENTACIÓN HUMANA}

- Setas y otros hongos (6): Considerada exquisita, se cocina o se come cruda fileteada. Se ha empezado a consumir en los últimos años.

\section{CANTHARELLACEAE}

\section{Cantarellus cibarius Fr.}

Cantarellus (1)

\begin{tabular}{lc}
\hline Frecuencia de citación (FC): & 1 \\
\hline Número de usos (NU): & 1 \\
\hline Número registros de uso (RU): & 1 \\
\hline Frecuencia Relativa de Citación (FRC): & $\mathbf{0 , 0 1}$ \\
\hline Índice de Importancia Cultural (IC): & $\mathbf{0 , 0 1}$ \\
\hline Índice de Vigencia (IV): & $\mathbf{0 , 0 1}$ \\
\hline
\end{tabular}

Obtención: silvestre

Vigencia: vigente (100\%)

Usos:

ALIMENTACIÓN HUMANA

- Setas y otros hongos (1): Se cita su consumo en Salinas de Pisuerga de forma reciente, a partir de los años noventa.

\section{CLAVICIPETACEAE}

Claviceps purpurea (Fr.) Tul.

Cornezuelo (8)

\begin{tabular}{lc}
\hline $582 \mathrm{~V}$ & \\
\hline Frecuencia de citación (FC): & 8 \\
\hline Número de usos (NU): & 1 \\
\hline Número registros de uso (RU): & 8 \\
\hline Frecuencia Relativa de Citación (FRC): & $\mathbf{0 , 0 6}$ \\
\hline Índice de Importancia Cultural (IC): & 0,06 \\
\hline Índice de Vigencia (IV): & 0,00 \\
\hline
\end{tabular}

Obtención: silvestre

Vigencia: abandonado

Conocimientos:

ECOLOGÍA

En el centeno se desarrolla el cornezuelo. 
Usos:

\section{VETERINARIA}

- Concepción, embarazo y parto (8): EI cornezuelo es un hongo parásito que se manifiesta como una estructura compacta de color negro en los granos del cereal. Los alcaloides que contienen son empleados para expulsar la placenta de las vacas después del parto. Se daba a beber al animal la cocción de cornitos. También tienen efectos abortivos.

Observaciones: A mediados del siglo $X X$, la recolección del cornezuelo del centeno sirvió en la comarca, para la obtención de recursos extraordinarios dentro del núcleo familiar. Sin dejar de ser un estorbo para los cultivadores, se podía vender a los farmacéuticos.

\section{COPRINACEAE}

Coprinus comatus (Mül.I) S.F.Gray

Borracha (2), seta del vino (1)

\begin{tabular}{lc}
\hline Frecuencia de citación (FC): & 3 \\
\hline Número de usos (NU): & 1 \\
\hline Número registros de uso (RU): & 3 \\
\hline Frecuencia Relativa de Citación (FRC): & $\mathbf{0 , 0 2}$ \\
\hline Índice de Importancia Cultural (IC): & $\mathbf{0 , 0 2}$ \\
\hline Índice de Vigencia (IV): & $\mathbf{0 , 0 2}$ \\
\hline
\end{tabular}

Obtención: silvestre

Vigencia: vigente (100\%)

Usos:

ALIMENTACIÓN HUMANA

- Setas y otros hongos (3): Se indica su uso comestible cocinada o guisada.

\section{CORIOLACEAE}

Fomes fomentarius (L.:Fr.) Fr.

Yesca (3), yezca (3)

\begin{tabular}{lc}
\hline $586 \mathrm{~V}$ & \\
\hline Frecuencia de citación (FC): & 6 \\
\hline Número de usos (NU): & 3 \\
\hline Número registros de uso (RU): & 6 \\
\hline Frecuencia Relativa de Citación (FRC): & $\mathbf{0 , 0 4}$ \\
\hline Índice de Importancia Cultural (IC): & $\mathbf{0 , 0 4}$ \\
\hline Índice de Vigencia (IV): & $\mathbf{0 , 0 1}$ \\
\hline
\end{tabular}

Obtención: silvestre

Vigencia: vigente (17\%)

Conocimientos:

ECOLOGÍA

Sale en chopos y robles.
Usos:

\section{COMBUSTIBLE}

- Encendido (2): Se recogen testimonios de cómo en el pasado se usó este hongo como mecha.

\section{ORNAMENTAL}

- Otros adornos (1): En la localidad de Lores se muestran varios ejemplares con fines decorativos en el interior de la vivienda.

\section{SOCIAL, SIMBÓLICA Y RITAL}

- Alucinógenas, narcóticas y fumatorias (3): Se machacaba en pequeños trocitos y se fumaba directamente. En Barruelo de Santullán afirman que "casi nos quedamos en el sitio al fumar la yesca, nos tuvieron que dar leche de cabra porque nos habíamos medio envenenado".

Observaciones: En otros lugares de España también se usó la yesca cocida en agua y ceniza. Después se machacaban hasta obtener unas hebras que se encendían con la chispa procedente del golpeo del pedernal (Aceituno Mata, 2010).

\section{Lycoperdon perlatum Pers.:Pers} Pedo de lobo (2)

\begin{tabular}{|lc|}
\hline Frecuencia de citación (FC): & $\mathbf{2}$ \\
\hline Número de usos (NU): & $\mathbf{2}$ \\
\hline Número registros de uso (RU): & $\mathbf{2}$ \\
\hline Frecuencia Relativa de Citación (FRC): & $\mathbf{0 , 0 1}$ \\
\hline Índice de Importancia Cultural (IC): & $\mathbf{0 , 0 1}$ \\
\hline Índice de Vigencia (IV): & $\mathbf{0 , 0 0}$ \\
\hline
\end{tabular}

Obtención: silvestre

Vigencia: abandonado

\section{Conocimientos:}

\section{LÉXICO}

Polvillo son las esporas con las que se dispersa este hongo.

Usos: MEDICINA

- Piel y tejido celular subcutáneo (1): Se asegura en San Juan de Redondo que las esporas secas se echaban sobre las heridas para acelerar la cicatrización.

SOCIAL, SIMBÓLICO Y RITUAL

- Uso recreativo (1): Los niños jugaban a lanzarse o patear el hongo para espolvorear las esporas. 


\section{MARASMIACEAE}

Marasmius oreades (Jacq.:Fr.) Fr.

Seta rojilla (27), roja (1), senderilla (3), senderina (12), senderuela (1), carrerilla (3)

\begin{tabular}{lc}
$69 \mathrm{~V}$ & \\
\hline Frecuencia de citación (FC): & $\mathbf{4 3}$ \\
\hline Número de usos (NU): & 1 \\
\hline Número registros de uso (RU): & 43 \\
\hline Frecuencia Relativa de Citación (FRC): & $\mathbf{0 , 3 1}$ \\
\hline Índice de Importancia Cultural (IC): & $\mathbf{0 , 3 1}$ \\
\hline Índice de Vigencia (IV): & $\mathbf{0 , 3 1}$ \\
\hline
\end{tabular}

Obtención: silvestre

Vigencia: vigente (100\%)

Usos:

ALIMENTACIÓN HUMANA

- Setas y otros hongos (43): Se trata de la seta más apreciada en la comarca, se recolecta en primavera y otoño, y se consume en tortillas y revueltos.

\section{PLEUROTACEAE}

Pleurotus eryngii (DC.:Fr.) Quél.

Seta de cardillo (3), seta de cardo (11)

\begin{tabular}{lc}
\hline Frecuencia de citación (FC): & 14 \\
\hline Número de usos (NU): & 1 \\
\hline Número registros de uso (RU): & 14 \\
\hline Frecuencia Relativa de Citación (FRC): & $\mathbf{0 , 1 0}$ \\
\hline Índice de Importancia Cultural (IC): & $\mathbf{0 , 1 0}$ \\
\hline Índice de Vigencia (IV): & $\mathbf{0 , 1 0}$ \\
\hline
\end{tabular}

Obtención: silvestre

Vigencia: vigente (100\%)

Usos:

\section{ALIMENTACIÓN HUMANA}

- Setas y otros hongos (14): Se recogen en primavera y otoño y se consumen en guisos y preparadas a la plancha.

\section{Lactarius deliciosus (L.:Fr.) S.F.Gray}

RUSSULACEAE Níscalo (8)

\begin{tabular}{lc}
\hline Frecuencia de citación (FC): & 8 \\
\hline Número de usos (NU): & 1 \\
\hline Número registros de uso (RU): & $\mathbf{8}$ \\
\hline Frecuencia Relativa de Citación (FRC): & 0,06 \\
\hline Índice de Importancia Cultural (IC): & 0,06 \\
\hline Índice de Vigencia (IV): & 0,06 \\
\hline
\end{tabular}

Obtención: silvestre
Vigencia: vigente (100\%)

Conocimientos:

ECOLOGÍA

Aparece en los pinares de la zona.

Usos:

ALIMENTACIÓN HUMANA

- Setas y otros hongos (8): Se recolectan en otoño y se consumen en guisos, con patatas y con chorizo.

TRICHOLOMATACEAE

Calocybe gambosa (Fr.) Donk

Seta blanca (38), seta de la buena (1)

\begin{tabular}{lc}
\hline $478 \mathrm{~V}$ \\
\hline Frecuencia de citación (FC): & 39 \\
\hline Número de usos (NU): & 1 \\
\hline Número registros de uso (RU): & 39 \\
\hline Frecuencia Relativa de Citación (FRC): & $\mathbf{0 , 2 8}$ \\
\hline Índice de Importancia Cultural (IC): & $\mathbf{0 , 2 8}$ \\
\hline Índice de Vigencia (IV): & $\mathbf{0 , 2 8}$ \\
\hline
\end{tabular}

Obtención: silvestre

Vigencia: vigente (100\%)

Conocimientos:

LÉXICO

El nombre tradicional en la comarca es seta blanca, aunque varios informantes están admitiendo e incorporando el nombre de perro chico o seta de San Jorge, denominaciones procedentes del País Vasco.

Usos:

\section{ALIMENTACIÓN HUMANA}

- Setas y otros hongos (39): Son muy valoradas por su exquisito sabor, son setas de primavera, que se consumen de forma tradicional.

\section{TRICHOLOMATACEAE}

Lepista nuda (Bull.:Fr.) Cke. Seta de pie azul (8), seta de rabo azul (1), seta de mango azul (1), seta de pezón azul (1)

\begin{tabular}{lc}
\hline Frecuencia de citación (FC): & 12 \\
\hline Número de usos (NU): & 1 \\
\hline Número registros de uso (RU): & 12 \\
\hline Frecuencia Relativa de Citación (FRC): & 0,09 \\
\hline Índice de Importancia Cultural (IC): & 0,09 \\
\hline Índice de Vigencia (IV): & 0,09 \\
\hline
\end{tabular}

Obtención: silvestre

Vigencia: vigente (100\%) 
Usos:

\section{ALIMENTACIÓN HUMANA}

- Setas y otros hongos (12): De color azul, es una seta carnosa que se consume cocinada.

TRICHOLOMATACEAE

Lepista rickenii Sing.

Seta de brezo (3), seta de berezo (1)

\begin{tabular}{lc}
\hline Frecuencia de citación (FC): & 4 \\
\hline Número de usos (NU): & 1 \\
\hline Número registros de uso (RU): & 4 \\
\hline Frecuencia Relativa de Citación (FRC): & 0,03 \\
\hline Índice de Importancia Cultural (IC): & 0,03 \\
\hline Índice de Vigencia (IV): & 0,03 \\
\hline
\end{tabular}

Obtención: silvestre

Vigencia: vigente (100\%)

Usos:

ALIMENTACIÓN HUMANA

- Setas y otros hongos (4): De agradable sabor, se recolecta en otoño.

TRICHOLOMATACEAE

Lepista sordida (Fr.:Fr.) Sing

Seta morada (1)

\begin{tabular}{lc}
\hline Frecuencia de citación (FC): & 1 \\
\hline Número de usos (NU): & 1 \\
\hline Número registros de uso (RU): & 1 \\
\hline Frecuencia Relativa de Citación (FRC): & 0,01 \\
\hline Índice de Importancia Cultural (IC): & 0,01 \\
\hline Índice de Vigencia (IV): & 0,01 \\
\hline
\end{tabular}

Obtención: silvestre

Vigencia: vigente (100\%)

Usos:

ALIMENTACIÓN HUMANA

- Setas y otros hongos (1): En Salinas de Pisuerga se señala su consumo de forma reciente.

\section{PLANTAS DUDOSAS}

A continuación se señalan los testimonios de ciertas plantas que no hemos podido asignar a un género o especie concreta, por no haber podido obtener una muestra vegetal.
Ahujón: "Son los que buscan los jabalines en las fincas, donde estén los jabalines lo ves enseguida porque levantan una tierra entera si hay esto. Era parecido a un ajo pequeño, escarbabas con la navaja, no sabe casi a nada, pero estaba bueno. Da como una roseta de flor blanca, así al terminar, con flores pequeñitas". (Silverio, Otero de Guardo).

Amargacho: "Es una verdura para los cerdos que sale en el campo, con hoja ancha, flor casi no echa, es la hoja como la palma la mano. No tiene el botón que se tira y se pega, eso es otra cosa". (Salomón, Velilla del Río Carrión).

Arzanda: "Eran unas hojas que olían muy bien y que se sembraban en la huerta o en un tiesto. Subía unos $40 \mathrm{~cm}$ y no da flor. La recogíamos antes, la echábamos en infusión, una taza de ello con un poco de azúcar. Para el dolor de cabeza era muy buena". (Rosario, Recueva).

Ascua: "Era una hoja por un lado verdosina y por otro lado era como arenusca, así blanquecino, tenía un poco de pico la hoja, no se hacía árbol, era como una zarza que se cría en el suelo y va corriendo la rama, daba muchas hojas. No lo había en todos sitios, pero donde iba mi madre si, estaba lleno de piedras, una canchalera., No era el guardalobo, no daba tallo ni nada, más que corría por el suelo. Lo echábamos a los potajes, se comía todo, lo picaba como si fuera berza, con los titos o los garbanzos". (Amalia, Valcobero).

Canijuela: "Es una planta silvestre verdosa que echa un tallo retorcido $\mathrm{y}$ hojas pequeñitas alrededor, salía un tallo, con hojas. Se da en las mojoneras al pie de una piedra o así y en las tierras donde se araba. Se comía la hoja y el tronco de tierno, la hoja era pequeña y el color de la flor ablancada tirando a grisáceo, lo más que levantaba $40 \mathrm{~cm}$. Las hojas lo preparaba en ensalada con vinagre, aceite y sal, no son las aceras son diferentes. Mi madre las comía también en ensalada". (Victorino, Valcobero).

Chinchirrilla: "Echa la flor morada, no levanta, va agazapada al suelo, echa muchos tallos, pequeñita la flor, había que cavarlo porque tenía buena raíz, abultaba mucho y sacabas buen sayo para los animales. Salía en los trigos, en la huerta no". (Emilia, Velilla de la Peña).

Comino: "Lo hay solo en un sitio, se da en zona de secano. Echa un tallo como grande $y$ después una grana, levanta $15 \mathrm{~cm}$, echa un 
color agrisao oscuro, la flor como marrón claro. Era para los cólicos, se daba cocido, y eso era para cuando los animales en primavera con el verdín se hinchan". (Andrés, Salcedillo).

Corona de fraile: "Es como una estrellita azul, se traía para tener un jarrón o para decir versos en mayo en la escuela. También el día del Corpus iban los hombres al monte a por un carro de ramas de haya y las chavalas íbamos a por flores, se hacían casetas que adorábamos, echábamos amapolas, la de escoba, peonias y la corona de fraile". (Prudencia, San Martín de los Herreros).

Garbanzo silvestre: "Es una planta que sale parecida al garbanzo natural y se da en la peña caliza. Era para curar los hinchazones y se hacía igual que el árnica, se daba solo en esas peñas, levantaba unos $30 \mathrm{~cm}$, la flor de color verde, daba una vaina muy pequeña más pequeña que la de las escobas, un parecido a la vaina de la alverjana. Se cogía toda la planta, sacada de raíz, que era donde tenía la cosa curativa, pero se cocía toda la planta incluida la raíz en agua y se aplicaba a la inflamación de una pierna o de un brazo, con una tela se mojaba bien caliente y bajaba el hinchazón. Se usaban paños calientes para los animales, para las hinchazones, igual que para las personas. Se recogía a últimos de julio sobre la fiesta de Santiago que se recogía el té, la sanguinaria. Una hija mía se rompió una pierna, mi madre la puso paños de garbanzo silvestre". (Salomón, Velilla del Río Carrión).

Halecha: "Se cría en los hayedos donde hay bastante humedad, echa bastantes hojas así rameada, es más baja y echa las hojas del suelo, excavas y tiene una raíz grande. Era remedio para heridas o accidentes". (Mariano, San Juan de Redondo".

Hierba colobrera: "Es una planta bajita, un poco parecido al trébol, suelta grana y se daba para comer a las ovejas". (Marina, Triollo).

Hierba lichonera: “Cuando salían los niños de la escuela se les mandaba a por hierba lichonera para dar de comer a el cerdo. Solo se daba a los cerdos. Era una cosa amarrada a ras de suelo, no echaba flor, las hojas eran estrechas, muy menuditas y amarrao al suelo". (Sagrario, Vidrieros).

Hujón: "Tira un estilo al perejil, pero no es igual. El hujón es como verde, echa varios tallos con la grana y la flor ablancada. Era una mala hierba y el ganao tampoco lo come". (Gregorio, Matabuena).

"El hujon es mala. La hoja es parecida a la zanahoria y salía como unos picos en la flor, más pequeña que la zanahoria, y medía sobre $15 \mathrm{~cm}$ ". (Saturnina, Matabuena).

Jujarra: "Es una planta chiquitilla con las hojas redondas, de unos $10 \mathrm{~cm}$, de flor amarilla, que después echa una vaina chiquitina con granos chiquitines, chiquitines negros. Lo quitábamos, lo excavabas y todavía se volvía a reproducir. Se lo dábamos de ensayo a las vacas". (Miguel, Matabuena).

"Salía en la humedad, en los trigos. La flor de momento era verde claro, pero luego se quedaban rojas, y después tiraban y dejaban una vaina chiquitina, que da bolinas". (Saturnina, Matabuena).

Lombricina: "Es una planta que hay a la orilla de las lastras, es más chiquitina que el anís, y las dos salen en la lastra. Se cogía en mayo, junio o algo más tarde. Echaba las hojucas pequeñas igual que una lombriz, el color de la hoja es como el de la piedra de lastra, es un tallo relativamente grueso y luego es como un ciempiés. No echaba flor, no levanta mucho. Lo hervías igual que haces un té, echabas azúcar para tomarla para que supiera mejor es para las personas y mata la lombriz porque los chavales de pequeños teníamos lombrices". (Miguel, Matabuena).

Mantecón: "Salen en primavera entre hayas y avellanos, echan como una cebolla y al nacer echa una hojilla que se abre, la flor es morada y levanta unos $10 \mathrm{~cm}$. La cebolleta la comíamos, picaba un poco y sabía como a rábano". (Paulino, Rebanal de las Llantas).

"Era una planta que cuando íbamos al monte, los hombres con la navaja sacaban la raíz que era ovalada y la flor era morada. Salían en las matas, se pelaban y se comían". (Prudencia, San Martín de los Herreros).

"Los mantecones tienen unos $20 \mathrm{~cm}$ y abajo llevan una bola. Se pelaba la bola y se comía, sabía dulce". (Bonifacio, Cillamayor).

Queso pan y vino: "Echaba un cacharrito para arriba por una lao eran moradas por otro lao mas coloradillo y por bajo blancas, por eso decíamos queso pan y vino, es parecido a las amargazas que llamamos, ahora no las veo, se han perdido, la flor era morada pero pequeñuca, la flor se caía y quedaba el vino que 
llamábamos, morao, eso era para jugar de chavalillos cogíamos un montonzuco y como que íbamos a merendar. Sale en la primavera y echaba la flor bastante pronto" (Victorino, Verdeña).

Pastorcilla: "En tiempo de flores se cogían en las praderas unas flores bonitas que llamábamos pastorcillas y que las echábamos para el Corpus". (Agustina, Camporredondo de Alba).

Pescuenda: "Recuerdo ir a coger para los cerdos pescuendas. La pescuenda sale plana con 4-6 hojas alrededor, la hoja es compacta, toda la periferia de la planta en redondo, a ras de suelo, se sacaban con un cuchillo, no tenían flor. Es en primavera cuando salen. " (José Luis, Brañosera).

"Cuando pasábamos hambre se comían pescuendas. Son hojas verdes muy anchas, no echa flor. Era planta baja. Se dan en abril y es para comer". (Jesús, Barruelo).

Tinaco: "Nace en los praos igual en el mes de mayo, salía una vara que se pelaba en tiras y la comíamos. Me parece que salía solo una flor o una pa cada lao, algo amarilla, de unos $40 \mathrm{~cm}$. La flor ya talluda no se podía comer, era antes de que diera la flor, no daba leche. Lo comíamos cuando está la yerba más tierna". (Amalia, Valcobero).

Reventón: "Les bajábamos para hacer medicina y los pagaban bien. Se cogían en unos árboles de alto como avellanos, y eran negros así como los arráspanos. El boticario nos daba dinero por bajar un balde de ellos “. (Jesús, Barruelo). 


\subsection{ANÁLISIS DE LOS DATOS}

El catálogo aporta información de 447 taxones pertenecientes a 101 familias botánicas, 429 taxones de plantas vasculares y 18 de hongos. De ellos, 327 son de obtención silvestre, representando el $73,15 \%$ del total, 113 son cultivados, el $25,28 \%$ y 7 son comprados, el $1,57 \%$.

Casi la totalidad de los taxones del catálogo (443) poseen una utilidad, aunque se han recogido 4 taxones (Anemone nemorosa, Artemisia absinthium Botrychium lunaria y Euphorbia amygdaloides) sin ningún uso conocido y que aparecen en él por el conocimiento de su nombre vulgar.

Comparamos nuestros resultados en la comarca de la Montaña Palentina con una superficie de $1326 \mathrm{~km}^{2}$, con las aportaciones de los trabajos señalados en la tabla 10, en ella se indica el autor, la zona de estudio, la extensión $\left(\mathrm{km}^{2}\right)$ y el número de taxones.

TABLA 10: Listado de estudios etnobotánicos consultados, señalando el autor, la zona de estudio, la extensión (km² ) y el número de taxones.

\begin{tabular}{|c|c|c|c|}
\hline Autor/año & Zona de estudio & $\begin{array}{c}\text { Extensión } \\
\text { (km2) }\end{array}$ & $\begin{array}{c}\text { No de } \\
\text { taxones }\end{array}$ \\
\hline Aceituno Mata, 2010 & Sierra Norte de Madrid & 1261 & 420 \\
\hline Anllo, 2011 & Terra Chá (Lugo) & 1823 & 136 \\
\hline Benítez, 2009 & Poniente Granadino (Granada) & 2042 & 442 \\
\hline Blanco, 1996 & El Caurel (Lugo) & 260 & 223 \\
\hline Blanco, 1998 & Segovia & 6921 & 303 \\
\hline Blanco, 2005 & Sanabria, Carballeda y los Valles (Zamora) & - & 170 \\
\hline Bonet, 2001 & Montseny (Barcelona, Gerona) & 826 & 593 \\
\hline Casana, 1993 & Subbética, campiña y vega del Guadalquivir (Córdoba) & 3909 & 172 \\
\hline Fajardo et al., 2000 & Albacete & 14858 & 414 \\
\hline Galán, 1993 & Pedroches, Sierra y vega del Guadalquivir (Córdoba) & - & 181 \\
\hline García Jiménez, 2007 & Palacios del Sil & 200 & 218 \\
\hline Gil Pinilla, 1995 & Cantalojas (Guadalajara) & 134 & 137 \\
\hline González-Tejero, 1989 & Granada & 12531 & 230 \\
\hline Guzmán, 1997 & Jaén & 13489 & 320 \\
\hline Lastra, 2003 & Parque Nacional Picos de Europa & 650 & 300 \\
\hline Latorre, 2008 & La Coruña & 7950 & 190 \\
\hline Martínez Lirola et al., 1997 & Cabo de Gata (Almeria) & 380 & 253 \\
\hline Mesa, 1996 & Sierra Mágina (Jaén) & 1236 & 360 \\
\hline Mulet, 1991 & Castellón & 6679 & 350 \\
\hline Muntané, 1994 & Cerdanya (Gerona) & 1139 & 234 \\
\hline Obón \& Rivera, 1991 & Murcia & 11313 & 115 \\
\hline Ortuño, 2003 & Los Villares y Valdepeñas (Jaén) & 271 & 463 \\
\hline Pardo de Santayana, 2008 & Campoo (Cantabria) & 1012 & 469 \\
\hline Pascual, 2013 & La Pernía, Polentinos y Valle de Castillería (Palencia) & 233 & 200 \\
\hline Pascual, 2016 & Cerrato (Palencia) & 1529 & 310 \\
\hline San Miguel, 2005 & Piloña (Asturias) & 282 & 473 \\
\hline Tardío et al., 2002 & Madrid & 8022 & 139 \\
\hline Velasco et al., & Salamanca & 12349 & 626 \\
\hline Verde et al., 1998 & Sierras de Segura y Alcaraz (Albacete) & - & 511 \\
\hline Villar et al., 1987 & Pirineo Aragonés & 15671 & 406 \\
\hline
\end{tabular}

El cotejo de los resultados con otras zonas de similar extensión revela que es mayor el número de taxones en la comarca de la Montaña Palentina, que el recogido en otras zonas de la Península Ibérica como: Cerdanya (Muntané, 1991), Sierra Mágina (Mesa, 1996), Sierra Norte de Madrid (Aceituno Mata, 2010) o el Cerrato Palentino (Pascual et al., 2016). Incluso es mayor el número de taxones que en zonas de mayor extensión como: Granada (González-Tejero, 1989), Murcia (Obón \& Rivera, 1991), Jaén (Guzmán, 1997), Segovia (Blanco, 1998) o Albacete (Fajardo et al., 2000). 


\subsubsection{ANÁLISIS POR FAMILIAS}

Se han obtenido datos de 101 familias botánicas, 87 familias de especies de obtención silvestre, 47 familias de especies cultivadas y 5 familias de especies compradas. De las 101 familias, 45 están representadas por una sola especie. Las familias con 5 o más especies se describen en la figura 20 , indicando además, el número de especies dependiendo del modo de obtención.

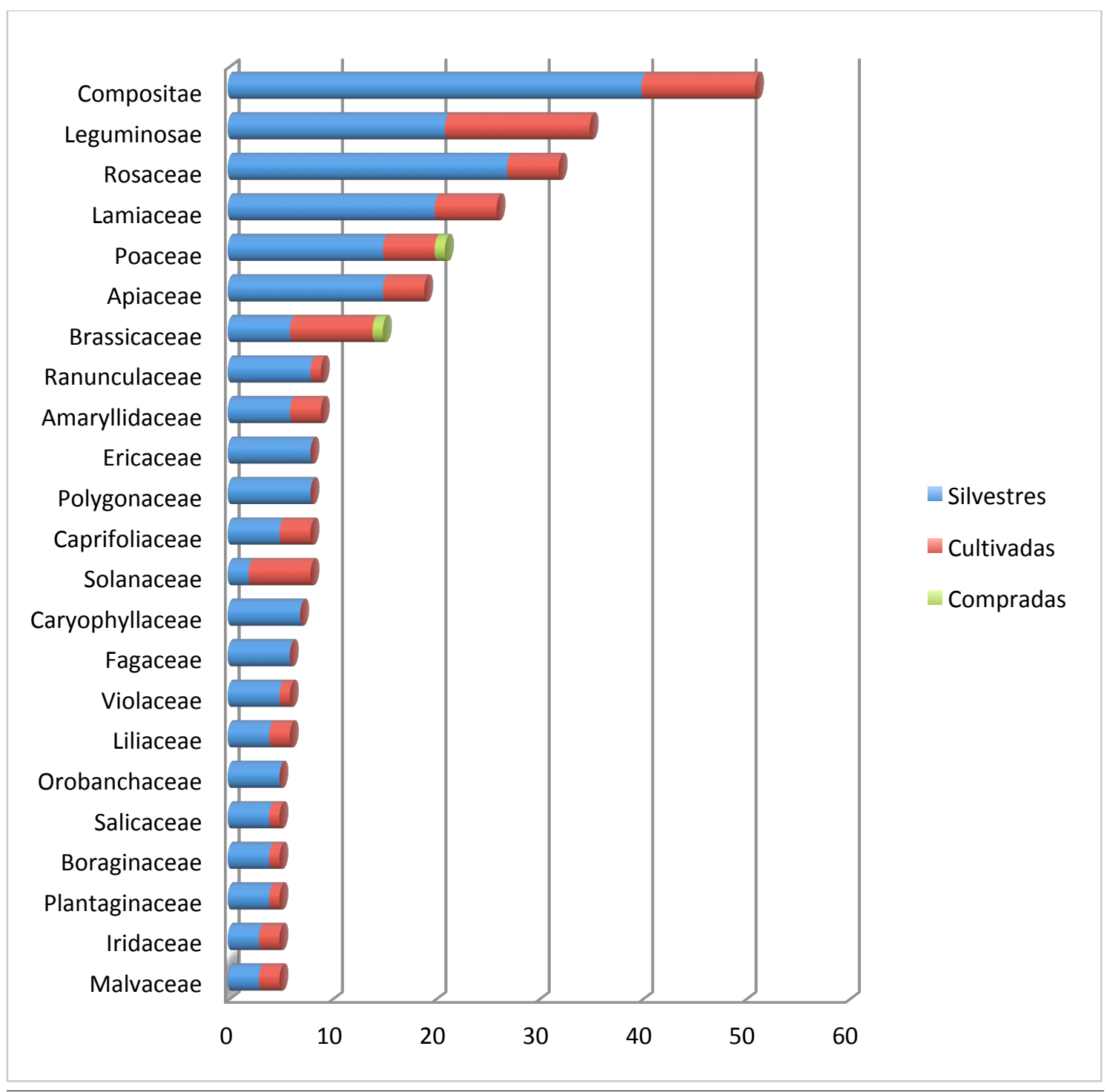

FIGURA 20: Listado de familias con 5 o más especies, teniendo en cuenta el modo de obtención.

Encabeza el listado la familia Compositae con 40 especies silvestres y 11 cultivadas, destaca por su valor alimentario, medicinal, medioambiental y ornamental. Le siguen las familias Leguminosae con 21 especies silvestres y 14 cultivadas, y Rosaceae con 27 especies silvestres y 5 cultivadas, ambas familias se distinguen por su importancia alimentaria, Leguminosae en alimentación animal y Rosaceae en alimentación humana.

Los datos obtenidos coinciden con otros estudios etnobotánicos realizados en la Península Ibérica (Mesa, 1996; Carvalho, 2005; Pardo de Santayana, 2008; Aceituno Mata, 2010), donde estas 3 familias son también las que están representadas por un mayor número de especies. 


\subsubsection{ANÁLISIS POR CATEGORÍAS DE USO}

En el análisis por categorías de uso se han incluido los 443 taxones con alguna utilidad o conocimiento registrado, pertenecientes a 100 familias botánicas, siendo distribuidos en 11 categorías de uso, que recogen los conocimientos relacionados con los usos de la biodiversidad, tanto materiales como simbólicos.

La elección de dichas categorías se ha hecho siguiendo los criterios establecidos en el Inventario Español de los Conocimientos Tradicionales relativos a la Biodiversidad (Pardo de Santayana et al., 2014), obteniendo referencias en las 11 categorías indicadas en la tabla 11.

TABLA 11: Clasificación de categorías de uso.

\begin{tabular}{l}
\hline Categorías: \\
\hline Alimentación humana \\
Alimentación animal \\
Medicina \\
Veterinaria \\
Uso tóxico y nocivo \\
Uso combustible \\
Construcción \\
Industria y artesanía \\
Uso medioambiental \\
Uso ornamental \\
Uso social, simbólico y ritual \\
\hline
\end{tabular}

En la Montaña Palentina se han obtenido un total 10438 registros de uso, repartidos en las 11 categorías tal y como señala la figura 21, resultando que Alimentación humana es la que recibió mayor número de registros con 2988, un 28,63\%, seguido de Alimentación animal con 1608 , un $15,41 \%$, y Medicina con 1248 , un $11,96 \%$.

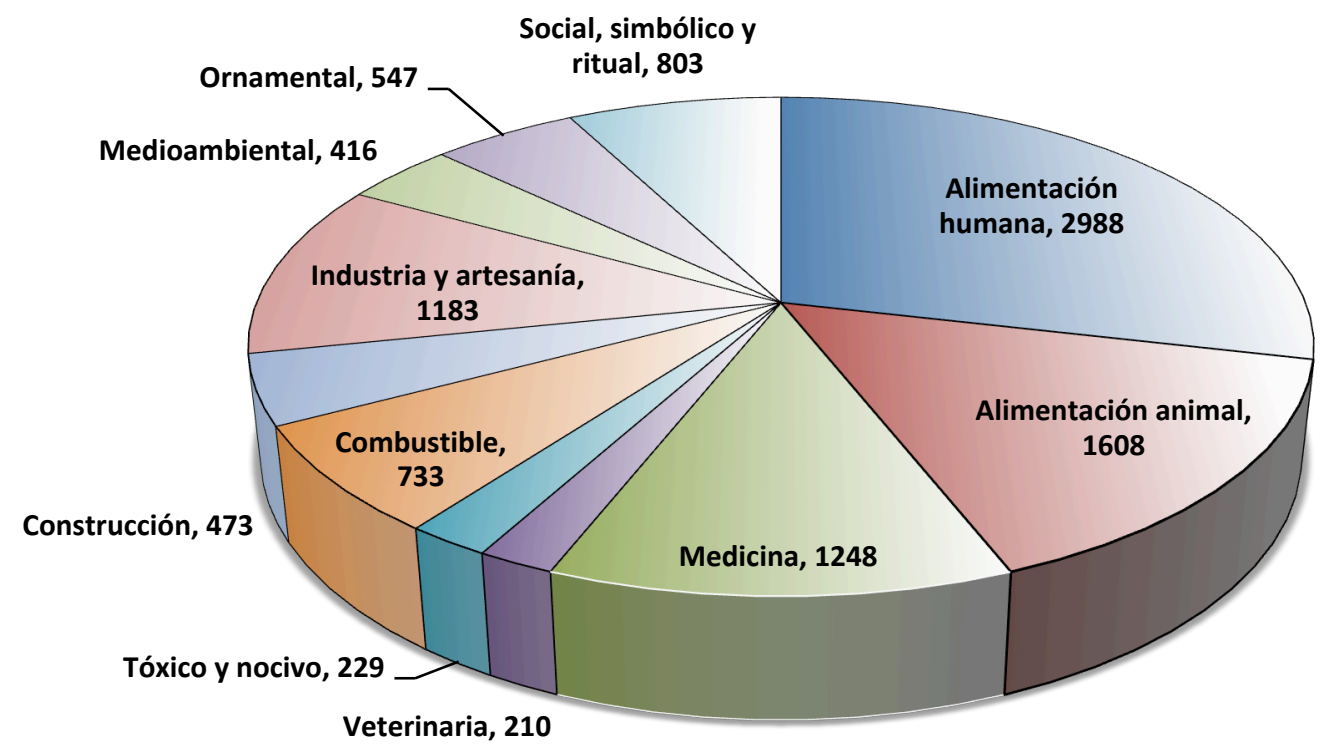

FIGURA 21: Categorías y número total de registros de uso (RU) obtenidos en el estudio. 
En la tabla 12 se describe la información recogida para las distintas categorías de uso, incluyendo todos los taxones, tanto los de obtención silvestre como los cultivados (sumatorio de cultivados y comprados).

TABLA 12: Resumen de las categorías de uso, mostrando SU: número de subcategorías de uso; RU: número de registros de uso; Tax: número de taxones; Fam: número de familias; RUs: número de registros de uso de obtención silvestre; \%Rus: porcentaje de registros de uso de taxones de obtención silvestre respecto al total; Taxs: número de taxones de obtención silvestre; Fams: número de familias de obtención silvestre; RUc: número de registros de uso cultivados; \%Ruc: porcentaje de registros de uso de taxones cultivados respecto al total; Taxc: número de taxones cultivados; Famc: número de familias cultivadas; \%RU: porcentaje de registros de uso respecto del total.

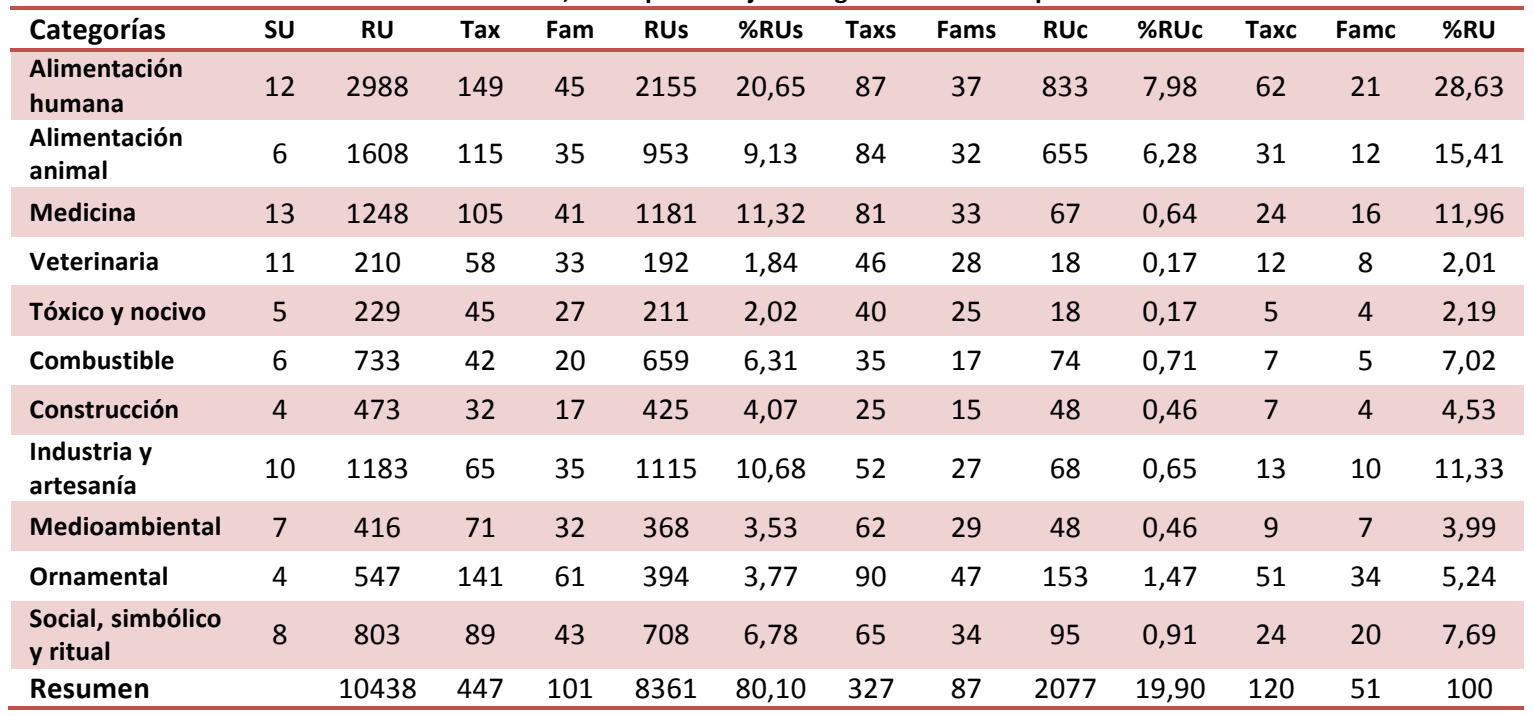

La importancia de las especies silvestres frente a las cultivadas es variable dependiendo de la categoría de uso. La representatividad de las especies cultivadas es destacable en las categorías alimentación humana y animal, alcanzando un porcentaje de registros de uso respecto del total de $7,98 \%$ y $6,28 \%$, respectivamente, seguida a continuación de la categoría ornamental con un resultado de un 1,47\%. Dentro de la categoría ornamental se emplean 51 taxones cultivados, casi un tercio del total, y en la categoría alimentación humana 62 taxones cultivados, el mayor número en el total de todas las categorías.

En cuanto a especies silvestres señalar que su representatividad es máxima en las categorías veterinaria, tóxica y nociva, y medioambiental, en este último caso resulta evidente al incluir la misma, las especies consideradas malas hierbas. Estos resultados se pueden contrastar con los obtenidos en la Sierra Norte de Madrid (Aceituno Mata, 2010), donde estas mismas categorías también obtuvieron gran representatividad de especies silvestres.

El orden del análisis de las categorías se establece en la tabla 11, correspondiente a la clasificación de las categorías de uso según los criterios del Inventario Nacional de los Conocimientos Tradicionales relativos a la Biodiversidad. Prevío a este análisis se incluye en el presente trabajo el artículo "Wild food plants gathered in the upper Pisuerga river basin, Palencia, Spain" publicado en Botany letters, (Pascual \& Herrero, 2017), que detalla los resultados en las categorías Alimentación humana y animal. 
BOTANY LETTERS, 2017

https://doi.org/10.1080/23818107.2017.1328314

Taylor \& Francis

Jor \& Francis Group

(A) Check for updates

Wild food plants gathered in the upper Pisuerga river basin, Palencia, Spain

Juan Cruz Pascual ${ }^{\mathrm{a}}$ and Baudilio Herrero ${ }^{\mathrm{b}}$

aAsociación Etnobotánica Palentina, Palencia, Spain; bDepartamento de Ciencias Agroforestales, Universidad de Valladolid, Palencia, Spain

ABSTRACT

This paper presents the results of an ethnobotanical study in the upper region of the Pisuerga River in Palencia, Spain. The study was carried out by conducting semi-structured interviews of 50 residents above the age of 52 . The total number of use reports was 2,$879 ; 839$ refer to plants used in human food and 247 are related to plants used in animal feed. Forty-two wild species have been cited for human consumption: $45.2 \%$ of them are exploited for their fruit, $33.3 \%$ are eaten as vegetables, and $28.6 \%$ are used to produce liqueurs. Twenty wild species have been eaten as vegetables, and $28.6 \%$ are used to produce liqueurs. Twenty wild species have been fodd ar a fodder or hay. Of the species, $20 \%$ are used for their fruit, whether fresh or dried. The species of the highest interest for human consumption in the region were Corylus avellana, Prunus spinosa, Fragaria vesca and Sorbus aria. The plants that were cited most often as animal feed are Asphodelus albus, Quercus petraea and Q, pyrenaica. Conopodium pyrenaeum, locally called ajuérjano in Spanish, a common name unique to the region ("pignut" in English), was cited by more than $50 \%$ of interviewees. Conopodium majus is consumed in nearby regions. Conclusion: Wild food plants gathered in the region are not the population's main source of nutrients, but they are important resources that can be used to diversify recipes.
ARTICLE HISTOR Received 3 January 2017 Accepted 2 May 2017

KEYWORDS

Animal feed; ethnobotany; Palencia; Spain wild food

\section{Introduction}

Rural areas in inland Spain usually have a low population density and a high rate of aging, in part due to emigration that began in the mid-twentieth century. This migration has mostly affected young people, causing social disruption, making it difficult for parents to pass down traditional knowledge to children, thus creating a rupture in the generational transmission. This difficulty is evident in changes in land use; the region has lost traditional grazing practices that in the past helped to reduce the frequency and severity of forest fires in the region, and to preserve biological diversity.

In recent years, various studies have shown that gathered non-cultivated wild plants play an important role in supplying seasonal food to rural communities (Molina et al. 2014, 2005; Pardo-de-Santayana et al. 2007; Pieroni et al. 2002; Serrasolses et al. 2016; Tardío, Pardo-de-Santayana, and Morales 2006; Tardío, Pascual, and Morales 2002). Wild weedy greens that are gathered, largely comprising vegetables and salads, are an especially important aspect of local dietary traditions. Non-cultivated plants grow spontaneously in self-maintaining populations in natural or semi-natural ecosystems and can exist without direct human interaction (Heywood 1999). In practice, distinguishing between cultivated and non-cultivated species and plant varieties is not easy because they exist on a continuous spectrum that spans from completely wild to fully domesticated species (Harlan 1992; Heywood 1999).

According to Etkin (1996), "Wild foods are consumed not only for caloric value, but also for other nutrient and pharmacological potential". Etkin refers to a number of plants (Origanum virens, Rosmarinus officinalis, Thymus mastichina and T. vulgaris among others) that are used today as food, but were first appreciated for their medicinal qualities.

Indeed, food is far more than a mere means of nutrition or a pivotal part of culinary art. The relationship between diet and the condition of the human body and psyche has been a subject of discussion since at least Plato's times. The ancient Greeks believed that following a proper diet was a prerequisite for corporeal and intellectual well-being. Many passages in Platonic texts recognized the importance of nutrition in corporeal development (Skiadas and Lascaratos 2001). It is now generally accepted that many plants can be used as both medicine and food and it is often difficult to draw a dividing line between these two categories (Etkin 1996).

In Spain, there are still many regions unexplored with regard to ethnobotany, and the upper Pisuerga River basin in Palencia is one of them. This study is being undertaken as part of a national inventory of traditional knowledge in Spain that aims to document and preserve traditional knowledge to plan the sustainable use of

CONTACT Baudilio Herrero baudilio@agro.uva.es

@ 2017 Société botanique de France 


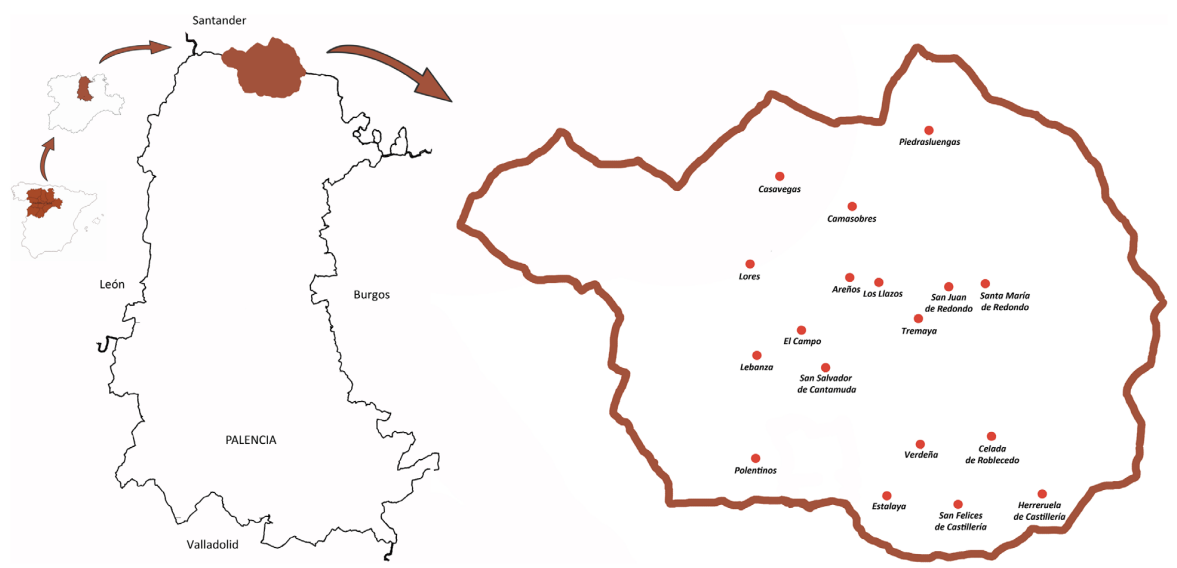

Figure 1. Location of the study area.

biodiversity. The first ethnobotanical work to be carried out in the upper Pisuerga River basin, our study aims to detail the various wild plants edible to human and animal. Additionally, we present information on how to use these plants as well as the cultural significance they have to the region.

\section{Material and methods}

\section{Study area}

The study area occupies the municipalities of La Pernía, Polentinos and Valle de Castillería, the latter of which is integrated into the town of Cervera de Pisuerga. This study region is located between the coordinates $42^{\circ} 54^{\prime}$ and $43^{\circ} 03^{\prime}$ latitude north, $4^{\circ} 28^{\prime}$ and $4^{\circ} 34^{\prime}$ longitude west, northwest Spain, southeast of the Cantabrian Mountains (Figure 1). It occupies an area of $232.7 \mathrm{~km}^{2}$. The terrain is mountainous with an altitude ranging from 1,000 to 2,208 $\mathrm{m}$ (Pico Lezna). The most common geological substrate is limestone, deposited between the Devonian and Carboniferous Periods. The climate is in transition between the Oceanic and the Mediterranean climate, with an average annual temperature of $8.3^{\circ} \mathrm{C}$ and average annual rainfall of $1,154 \mathrm{~mm}$. The natural vegetation is dominated by oak (Quercus petraea (Matt.) Liebl., Q. pyrenaica Wild.) and beech forests (Fagus sylvatica L.), which are replaced by heather (Erica arborea L., E. australis L.) and broom (Cytisus scoparius (L.) Link) in more degraded areas. Forest occupies $35.6 \%$ of the region's surface area, bushes cover $11.7 \%$, and pastures occupy $48.4 \%$.

This area was settled in the early ninth century A.D. by the combined action of monks, counts and residents of the nearby regions of Cantabria and Asturias. Some of these individuals descended from people from the Meseta del Duero who had left their home towns because battles between Christians and Muslims had broken out in the region (Basterra 2009). The population is currently 540, corresponding to a population density of three inhabitants per $\mathrm{km}^{2}$ (Pascual 2013). The primary language spoken is Castilian. The main economic activity is extensive cattle ranching, with horses to a lesser extent. Until the 1990s, the coal-mining sector brought the greatest wealth to the region.

\section{Data collection procedures}

The study was conducted through semi-structured interviews with 50 people living in the study area. The interviews were recorded on a laptop, and the information was input into Excel 2010 Database.

Furthermore, to assess the recognition of the plants used in the area, four indexes were calculated according to the criteria of Tardío and Pardo-de-Santayana (2008). The indexes calculated were as follows: relative citation frequency (RCF), relative importance (RI), cultural importance $(\mathrm{CI})$ and cultural value $(\mathrm{CV})$. The RFC, ranges from 0 , when no one considered the species useful, to 1 , in the event that all informants mentioned using it. The RFC does not take into account the number of different uses for a species or the categories in which a species is mentioned, only the number of informants that mention it, based on the total number of informants in the study. The index of RI takes into account categories of use and frequency of citation. This index varies from 0 , when no one mentions using the plant, to 1 in the case that a plant is mentioned as been useful in the maximum number of categories of use. The values in $\mathrm{CI}$ index range from 0 to the total number of categories (10 in this study). The CV index reaches the theoretical maximum value if all informants mention the use of a species in all categories considered in the study. 


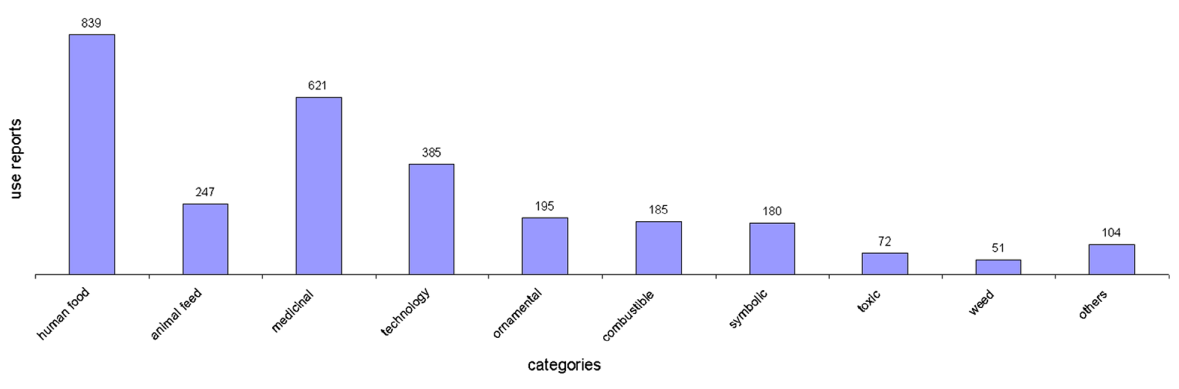

Figure 2. Use reports of wild plants in terms of the use categories considered.

The uses were categorized into 10 use-groups in accordance with Pardo-de-Santayana (2008) criteria.

The interviews were conducted between April 2010 and October 2011. All 18 localities in the study area were visited. At least two informants were interviewed from each town, selected in most cases on the advice of the local people from the area, who informed which residents had the best knowledge of uses and benefits of local wild plants.

Semi-structured, semi-open interviews were used to gather information. The interviews lasted between 45 min and $10 \mathrm{~h}$, with an average duration of two hours, and many interviews were conducted over more than one session.

Of the 50 interviewees, $72 \%$ were interviewed alone, $22 \%$ were interviewed in pairs and $6 \%$ of the interviews were carried out collectively. Of all informants, $51 \%$ were male, and $49 \%$ were female. The age of the informants was between 52 and 97 years, with an average age of 75 .

Plant specimens from the region were collected and deposited in the herbarium of the Botany area, PALAB, at the Palencia campus of the University of Valladolid. The scientific names of the plants were then updated to the currently accepted names listed in the public taxonomic database The Plant List (2013), and we followed the APG IV (2016) for the names of botanical families. Hereafter, we use the term "species" understanding that in some cases, we also speak of several species of one genus, which are used interchangeably.

\section{Results}

Figure 2 shows the number of use reports distributed in 10 use-categories. Out of a total of 2879 use reports, $29.1 \%$ were in the category of plants used in human food, and $8.6 \%$ correspond to plants that have been used in domestic livestock feed. The category "other uses" constitutes $3.1 \%$ of the citations; plants included in this category are used to make packaging, sports, vehicles, etc.

Table 1 lists the wild plants recorded as being traditionally used as human food. The species are ordered alphabetically by families, and the table includes the most common local names used, the part(s) of the plant consumed in each food use, the most common use of the plant and its frequency of citation (CF).

A total of 44 species of vascular plants belonging to 20 families were recorded, representing $4.6 \%$ of the species of the mountain flora of Palencia province, estimated at 912 taxa (Herrero 1989). In terms of the number of species, the most important family was the Rosaceae with 14 species. These were mainly consumed as fresh fruits and for making jams and liqueurs. The Asteraceae, with five species, were mostly used as vegetables, whereas three Lamiaceae species were used for seasonings. Thirty-six species were listed as unprocessed foods; 11 species were mentioned as being used in the production of liqueurs, three species were listed as seasonings and eight species were used as treats.

Food use was categorized into seven groups (i.e. consumption as vegetables, fleshy fruit, dried fruits, infusions, liqueurs, condiments, and sweets) to help analyze the results. Some species were included in more than one category. For example, Taraxacum sect. Ruderalia was identified as being used as both vegetable (leaves) and sweets (inflorescences).

Table 2 describes the wild species used in cattle feed; 20 species were collected, belonging to 14 families. When these plants were easily accessible they were used as dietary supplements; it was common to cut the leaves of woody species such as oak (Quercus petraea (Matt.) Liebl., Q. pyrenaica Willd.), holly (Ilex aquifolium L.), poplar (Populus nigra L.), ash (Fraxinus excelsior L.), and hazel (Corylus avellana L.), which allowed the food that was harvested to be better managed and stored for the winter. Wild plants that were grazed by livestock and not selectively collected by farmers were not considered.

Species that were weeded from fields of grains, potatoes, or other vegetables were also used as feed for domestic livestock. These include Sonchus oleraceus (L.) L., Vicia cracca L., and Convolvulus arvensis L.

Asphodelus albus Mill. deserves a special mention; it was gathered frequently in the area and used to clean pastures and feed pigs. 
Table 1. List of wild plants used in human food, in the upper Pisuerga region.

\begin{tabular}{|c|c|c|c|c|c|}
\hline Botanical family & Plant species & Local name & Part used & Mode of consumption & CF \\
\hline Adoxaceae & Sambucus nigra L. PALAB 2608 & Saúco & Ripe fruits & Jam, liqueurs & 6 \\
\hline Adoxaceae & Viburnum lantana L. PALAB 2506 & Petruco & Ripe fruits & Fresh, jam & 2 \\
\hline Apiaceae & $\begin{array}{l}\text { Conopodium pyrenaeum (Loisel.) Miégev. } \\
\text { PALAB } 1617\end{array}$ & Ajuérjano & Tubers & Fresh & 27 \\
\hline Apiaceae & Scandix australis L. PALAB 2407 & Anis & Aerial part & Fresh & 18 \\
\hline \multirow[t]{6}{*}{ Asteraceae } & Chamaemelum nobile (L.) All. PALAB 2902 & Manzanilla campera & Capitula & LiqueursInfusions & 2 \\
\hline & $\begin{array}{l}\text { Helichrysum stoechas (L.) Moench PALAB } \\
2609\end{array}$ & Manzanilla de peña & Capitula & Infusions & 8 \\
\hline & Scorzonera humilis L. PALAB 1619 & Chamorro & Stems & SaladFresh & 6 \\
\hline & Taraxacum sect. Ruderalia PALAB 1203 & Achicoria & Leaves & Salad, boiled & 7 \\
\hline & & & Inflorescences & Treats & 2 \\
\hline & Tragopogon dubius Scop. PALAB 1443 & Lecherina & Stems & Fresh & 31 \\
\hline Berberidaceae & Berberis vulgaris L. PALAB 2408 & Borrachín & Ripe fruits & Fresh, jam & 3 \\
\hline Betulaceae & Corylus avellana L. PALAB 2743 & Avellano & Ripe fruits & Dry fruit & 45 \\
\hline Brassicaceae & Nasturtium officinale R.Br. PALAB 1643 & Berro & Stem with leaves & Salad & 20 \\
\hline \multirow[t]{2}{*}{ Caryophyllaceae } & $\begin{array}{l}\text { Silene vulgaris (Moench) Garcke PALAB } \\
1618\end{array}$ & Colleja & Tender stems & Salad & 1 \\
\hline & & & Leaves & Boiled & 1 \\
\hline Convolvulaceae & Convolvulus arvensis L. PALAB 1431 & Correhuela & Leaves & Salad, boiled & 1 \\
\hline Ericaceae & Vaccinium myrtillus L. PALAB 1607 & Ráspanos & Fruits & Fresh, jam, liqueurs & 48 \\
\hline \multirow[t]{2}{*}{ Fabaceae } & Trifolium alpinum L. PALAB 2744 & Regaliz & Rhizomes & Treats & 29 \\
\hline & Trifolium pratense L. PALAB 2151 & Trébol & Flowers & Salad, nectar & 5 \\
\hline \multirow[t]{3}{*}{ Fagaceae } & Fagus sylvatica L. PALAB 1605 & Haya & Fruits & Fresh, toasted, infusions & 33 \\
\hline & $\begin{array}{l}\text { Quercus petraea (Matt.) Liebl. PALAB } 2706 \\
\text { Quercus pyrenaica Willd. PALAB } 2707\end{array}$ & Roble & Fruits & Fresh, roasted, liqueurs & 8 \\
\hline & & & Sap & Treats & 2 \\
\hline Grossulariaceae & Ribes alpinum L. PALB 2151 & Abubillo montesino & Fruits & Fresh, liqueurs & 32 \\
\hline Grossulariaceae & Ribes uva-crispa L. PALAB 781 & Abubillo & Ripe fruits & Fresh & 32 \\
\hline Juglandaceae & Juglans regia L. PALAB 483 & Nogal & Fruits & Dry fruit & 4 \\
\hline \multirow{5}{*}{ Lamiaceae } & Origanum vulgare L. PALAB 1437 & Orégano & Flowering top & Seasoning & 39 \\
\hline & Mentha spp. & Menta & Leaves & Seasoning, marinate & 9 \\
\hline & Prunella vulgaris L. PALAB 1448 & Chupas & Flower & Nectar & 9 \\
\hline & Sideritis hyssopifolia L. PALAB 1435 & Té de roca & Aerial part & Liqueurs, Infusions & 4 \\
\hline & Thymus spp. & Tomillo & Aerial part & Seasoning & 9 \\
\hline Malvaceae & Malva sylvestris (L.) Mill. PALAB 2636 & Malva & Immature fruits & Treats & 6 \\
\hline \multirow{2}{*}{ Polygonaceae } & Rumex acetosa L. PALAB 2634 & Tallos & Leaves & Salad & 33 \\
\hline & & & Tender stems & Refreshing candy & 3 \\
\hline \multirow{2}{*}{ Primulaceae } & Primula veris L. PALAB 2624 & Cuquillo & Flowers & Nectar & 6 \\
\hline & & & Stem & Fresh & 2 \\
\hline \multirow[t]{18}{*}{ Rosaceae } & Crataegus monogyna Jacq. PALAB 2623 & Espino blanco & Fruits & Fresh & 31 \\
\hline & & & Leaves & Salad & 1 \\
\hline & & & Tender stems & Fresh & 2 \\
\hline & Fragaria vesca L. PALAB 2622 & Amiérgano & Fruits & Fresh & 45 \\
\hline & Malus sylvestris (L.) Mill. PALAB 2844 & Maillo & Fruits & Fresh, overripe, liqueurs & 43 \\
\hline & Prunus avium (L.) L. PALAB 2840 & Cerezo & Fruits & Fresh & 7 \\
\hline & Prunus cerasus L. PALAB 2154 & Guindal & Fruits & Fresh, liqueurs & 11 \\
\hline & Prunus insititia L. PALB 2153 & mijuelo & Fruits & Fresh, liqueurs & 20 \\
\hline & Prunus spinosa L. PALAB 2152 & Endrino & Fruits & Fresh, raisin, liqueurs & 45 \\
\hline & & & Tender stems & Fresh & 2 \\
\hline & Pyrus cordata Desv. PALAB 2312 & Perujo & Fruits & Fresh, overripe & 6 \\
\hline & Rosa spp. & Rosal & Ripe fruits & Fresh, jam, liqueurs & 29 \\
\hline & & & Tender stems & Fresh & 6 \\
\hline & Rosa spinosissima L. PALAB 1981 & Zarzaparrilla & Ripe fruits & Fresh & 1 \\
\hline & Rubus idaeus L. PALAB 1983 & Mora de la reina & Ripe fruits & Fresh, jam & 18 \\
\hline & Rubus ulmifolius Schott PALAB 1987 & Zarza & Ripe fruits & Fresh, jam, liqueurs, treats, wine & 39 \\
\hline & & & Tender stems & Fresh & 4 \\
\hline & Sorbus aria (L.) Crantz PALAB 1984 & Mostajo & Ripe fruits & Fresh, overripe & 44 \\
\hline Taxaceae & Taxus baccata L. PALAB 1982 & Tejo & Seed coats & Fresh & 2 \\
\hline
\end{tabular}

Note: $\mathrm{CF}=$ citation frequency $(\mathrm{x} / \mathrm{50})$.

The last block is made up of herbaceous species that are not considered weeds by the informants. They were reported to be gathered as vegetables, most notably Urtica dioica L. and Conium maculatum L. The main use for wild species is as fodder (i.e. they were consumed fresh or slightly dehydrated). The species consumed as hay represents $23 \%$ of the use reports.

Figure 3 shows the number of species of food plants distributed into sub-categories, notably the use as fresh fruit in human food and the use of plants as fodder for animal feed.
The results are presented below in terms of the categories considered in human and animal food, respectively.

\section{Human food}

Wild fresh fruits

This group, with 19 species (45.2\%), is the first in terms of the number of species cited. The most frequently eaten fruits in the region were those of Prunus spinosa L., Fragaria vesca L., Malus sylvestris (L.) Mill. and Sorbus 
Table 2. List of plant species used in livestock feed, in the upper Pisuerga region.

\begin{tabular}{|c|c|c|c|c|c|c|}
\hline Botanical family & Plant species & Local name & Part used & Administration & Target domestic animals & CF \\
\hline Apiaceae & $\begin{array}{l}\text { Conium maculatum L. PALAB } \\
1322\end{array}$ & Budaño & Aerial parts & Fodder & Cows & 7 \\
\hline Aquifoliaceae & Ilex aquifolium L. PALAB 1333 & Acebo & Leaves & Fresh & Goats, cows, sheep, rabbits & 25 \\
\hline \multirow[t]{2}{*}{ Asteraceae } & $\begin{array}{l}\text { Sonchus oleraceus (L.) L. PALAB } \\
2155\end{array}$ & Cardo lecherín & Aerial parts & Fodder & Pigs, rabbits & 20 \\
\hline & $\begin{array}{l}\text { Taraxacum sect. Ruderalia } \\
\text { PALAB } 1203\end{array}$ & Achicoria & Leaves & Fodder & Cows, pigs, rabbits & 13 \\
\hline \multirow[t]{2}{*}{ Betulaceae } & $\begin{array}{l}\text { Betula pubescens Ehrh. PALAB } \\
2902\end{array}$ & Abedul & Leaves & Fresh & Goats, sheep & 1 \\
\hline & Corylus avellana L. PALAB 2743 & Avellano & Leaves & Fodder & Pigs, rabbits & 10 \\
\hline Convolvulaceae & $\begin{array}{l}\text { Convolvulus arvensis L. PALAB } \\
1431\end{array}$ & Correhuela & Aerial parts & Fodder & Cows & 1 \\
\hline \multirow[t]{4}{*}{ Fabaceae } & $\begin{array}{l}\text { Cytisus scoparius (L.) Link PALAB } \\
1432\end{array}$ & Escoba & Young branches & Fodder & Goats, sheep & 3 \\
\hline & Genista florida L. PALAB 1444 & Escoba albar & Young branches & Fodder & Goats, sheep & 4 \\
\hline & Ononis spinosa L. PALAB 731 & Gatuña & Aerial parts & Fodder & Rabbits & 2 \\
\hline & Vicia cracca L. PALAB 737 & Arvejana & Aerial parts & Fodder & Cows, rabbits & 3 \\
\hline \multirow[t]{3}{*}{ Fagaceae } & $\begin{array}{l}\text { Quercus petraea (Matt.) Liebl. } \\
\text { PALAB 2706, Q. pyrenaica } \\
\text { Willd. PALAB 2707 }\end{array}$ & Roble & Leaves & Fodder & Goats, sheep & 6 \\
\hline & & & Leaves & Boiled & Pigs & 9 \\
\hline & & & Fruits & Fresh, ground & Goats, sheep, pigs, cows & 34 \\
\hline Oleaceae & Fraxinus excelsior L. PALAB 425 & Fresno & Leaves & Hay & Goats, rabbits, sheep, cows & 11 \\
\hline Polygonaceae & Rumex crispus L. PALAB 983 & Amargaza & Fruits & Dry & Pigs & 1 \\
\hline \multirow[t]{3}{*}{ Rosaceae } & Rosa spp. & Zarza & Fruits & Fresh & Goats & 7 \\
\hline & $\begin{array}{l}\text { Sorbus aria (L.) Crantz PALAB } \\
1984\end{array}$ & Amostajo & Leaves & Fodder & Rabbits & 7 \\
\hline & & & Fruits & Fresh & Pigs & 3 \\
\hline Salicaceae & Populus nigra L. PALAB 1247 & Chopo & Branches with leaves & Fodder & Goats, sheep, cows, pigs & 19 \\
\hline & Ulmus minor Mill. PALAB 1346 & Olmo & Leaves & Hay & Goats, sheep, cows & 4 \\
\hline \multirow[t]{2}{*}{ Urticaceae } & Urtica dioica L. PALAB 1446 & Ortiga & Aerial parts & Boiled & Pigs & 7 \\
\hline & & & Aerial parts & Fodder & Cows & 9 \\
\hline \multirow{2}{*}{$\begin{array}{l}\text { Xanthorrhoeace- } \\
\text { ae }\end{array}$} & Asphodelus albus Mill. PALAB & Gamón & Fruits & Boiled & Pigs & 35 \\
\hline & & & Leaves & Fodder & Goats, sheep & 8 \\
\hline
\end{tabular}

Note: $C F=$ citation frequency $(\mathrm{x} / 50)$.

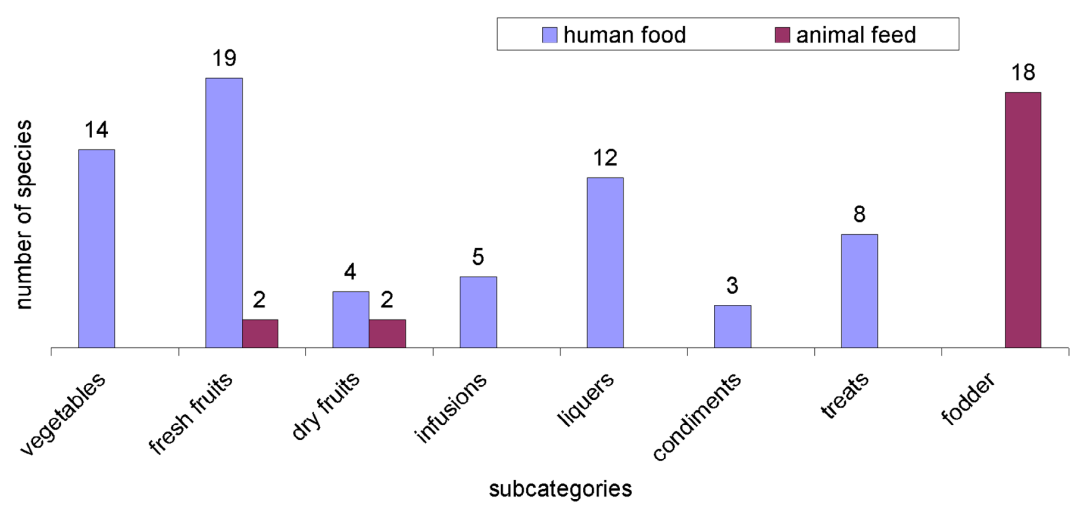

Figure 3. Number of species mentioned in the use subcategories of edible plants.

aria (L.) Crantz. These fruits are well known and appreciated for their high vitamin content.

The use of the fruits of Ribes uva-crispa L. and $R$. alpinum L. was also usual; these fruits are called abubillo and abubillo montesino, respectively.

Malus sylvestris and Prunus spinosa, which fruits are often unpalatable when eaten raw, were reported to be stored for several months before being eaten, a process that allowed them to sweeten. In the production of jams, the part of the plant utilized is primarily the fruit; which is used in eight of the species mentioned.

Wild vegetables

The second most important group was made up of 14 species $(33.3 \%)$. This group includes species of which the tubers, stems, leaves, flowers, or the whole plant are consumed. Using the tuber of Conopodium pyrenaeum (Loisel.) Miégev, known locally as ajuérjano, is popular 
in the region. Wild vegetables are often consumed in the form of mixed salads, composed of several wild and cultivated species, such as tomatoes and onions, in addition to a small amount of tuna or sardines. The Asteraceae family contributes species such as Tragopogon dubius Scop., Scorzonera humilis L. and Taraxacum sect. Ruderalia. Peeled young shoots of different species of Rubus and Rosa as well as shoots of Tragopogon, Rumex Scorzonera, Silene, Prunus spinosa and Crataegus monogyna Jacq. were used as ingredients in salads or as snacks.

\section{Dried fruits}

The fruit of Corylus avellana, collected in late summer, is very popular in the region. Next in importance are the fruits of Fagus sylvatica and Quercus petraea. Quercus petraea acorns, according to some reports, were roasted before eating. The informants say that eating too many acorns caused headaches. The presence of Juglans regia L. is scarce, given how difficult it is for it to produce fruit because of the region's adverse climate.

\section{Infusions}

This group consists of five species that are used to make non-alcoholic beverages such as herbal teas. An infusion made with roasted acorns is a new use found in thi study. The most appreciated of all of the herbal teas is the te de roca-infusion, made with Sideritis hyssopifolia $\mathrm{L}$.

Liqueurs

Another important group, with 12 species (28.6\%) is plants used in the production of liqueurs.

Among the plants used to make liqueurs, the most popular was Prunus spinosa. Also noted were Prunus cerasus, L. Prunus insititia L., Malus sylvestris, Rubus idaeus L., Rubus ulmifolius Schott. and Ribes alpinum.

Although the interviewees indicated that it has some toxic properties, the fruits of Sambucus nigra L. were used to produce liqueurs. The part used to produce the liqueur was always the fruit, except in liqueurs made with Sideritis hyssopifolia for which the aerial part of the plant is used.

\section{Condiments and preservatives}

This group had three species $(7.1 \%)$ belonging to the Lamiaceae family, Mentha spp., Origanum vulgare L., Thymus praecox Opiz and T. zygis L. Origanum vulgare was widely used as a condiment for seasoning pork, mainly in chorizo and other meat dishes.

Treats

The flowers of four species $(9.52 \%)$ were reported as sweets. The flowers of Prunella vulgaris, Primula veris L., Trifolium pratense L. and Taraxacum sect. Ruderalia were commonly consumed by children, who suck the nectar from the corolla. The rhizome of Trifolium alpinum L., the stem of Rumex acetosa $\mathrm{L}$., and the fruits of Malva sylvestris (L.) Mill. were also consumed by chil dren as sweets. Finally, the sap of Quercus spp. was also mentioned as being consumed as a treat.

\section{Animal feed}

Wild fresh fruits

The fleshy fruits of Rosa spp. and Sorbus aria were used in livestock feed. The fruits of roses were used to feed goats intended for the production of the salt-cured meat cecina (dehydrated and seasoned meat that does not come from pigs)

\section{Dried fruits}

The dried fruits of Rumex crispus L., Quercus petraea and $Q$. pyrenaica were used as pig feed. Acorns were also used to feed goats and cows; for the latter ground acorns were also used.

\section{Fodder}

There were 18 species included in this category, $90 \%$ of which being used for animal feed. Most-used were the leaves of Asphodelus albus and Ilex aquifolium as well as the entire plant of Sonchus oleraceus.

New or rarely reported food plants

Making tea with roasted acorns is not referenced in the bibliography, and the use tuber of Conopodium pyrenaeum is not mentioned in other studied areas (Blanco 1998; González, García-Barriuso, and Amich 2011a Pardo-de-Santayana 2008; Tardío, Pardo-de-Santayana, and Morales 2006). Using the dried fruits of Rumex crispus as feed for pigs is another observation that we have not seen referenced in other studies.

\section{Cultural indexes}

Table 3 shows the rates of RFC, RI, CI, and CV of the plants for human and animal food use recorded in this study, as well as the number of categories of use (CU) and the number of reports of use (RU).

Four species Quercus petraea, Q. pyrenaica., Sideritis hyssopifolia, and Chamaemelum nobile (L.) Al. had the highest CF, being cited by $98 \%$ of informants.

The species that had the highest rates of citation according to the RI index were Ilex aquifolium, Quercus spp., Corylus avellana and Cytisus scoparius. Oak was cited in six categories of use and hazel in five. These two species had CFs of 49 and 48 , respectively.

The species with the highest CIs included tree species (e.g. oak, hazel, beech), shrubs such as holly, broom, rose (Rosa spp.), and hawthorn (Crataegus monogyna). The oak had the highest CI value, at 3.40, and oregano (Origanum vulgare) with a value of 1.42 , was a noteworthy herbaceous species.

Oak had the highest value, with a CV index of 1.99 due to its CF (49), high CU (6), and high value in number of reported uses $(\mathrm{RU}=170)$. Other species that showed notable CVs were Corylus avellana, Ilex aquifolium, and Cytisus scoparius. Comparing hazel and broom (Cytisus scoparius), both species had the same citation frequency $(\mathrm{CF}=48)$, and the same number of use categories $(C U=6)$, but hazel had 112 use reports, being 
Table 3. Values of the cultural indexes of the species of food used in the upper Pisuerga region.

\begin{tabular}{|c|c|c|c|c|c|c|}
\hline Species & FRC & $\mathrm{RI}$ & $\mathrm{Cl}$ & VC & CU & $\mathrm{RU}$ \\
\hline Asphodelus albus Mill. (2) & 0.86 & 0.65 & 0.94 & 0.24 & 3 & 47 \\
\hline Berberis vulgaris $\mathrm{L}$. & 0.06 & 0.10 & 0.06 & 0.01 & 1 & 3 \\
\hline Betula pubescens Ehrh. (2) & 0.58 & 0.51 & 0.62 & 0.11 & 3 & 31 \\
\hline Chamaemelum nobile (L.) All. & 0.98 & 0.64 & 1.02 & 0.20 & 2 & 51 \\
\hline Conium maculatum $\mathrm{L}$. & 0.24 & 0.34 & 0.28 & 0.02 & 3 & 14 \\
\hline Conopodium pyrenaeum (Loisel.) Miégev. & 0.54 & 0.35 & 0.54 & 0.03 & 1 & 27 \\
\hline Convolvulus arvensis L. (1) & 0.12 & 0.28 & 0.14 & 0.01 & 3 & 7 \\
\hline Corylus avellana L. (1) & 0.96 & 0.92 & 2.24 & 1.29 & 6 & 112 \\
\hline Crataegus monogyna Jacq. & 0.80 & 0.77 & 1.16 & 0.46 & 5 & 58 \\
\hline Cytisus scoparius (L.) Link (2) & 0.96 & 0.92 & 1.74 & 1.00 & 6 & 87 \\
\hline Fagus sylvatica $\mathrm{L}$. & 0.88 & 0.81 & 2.10 & 0.92 & 5 & 105 \\
\hline Fragaria vesca $\mathrm{L}$. & 0.90 & 0.53 & 0.90 & 0.08 & 1 & 45 \\
\hline Fraxinus excelsior L. (2) & 0.62 & 0.67 & 0.92 & 0.28 & 5 & 46 \\
\hline Genista florida L. (2) & 0.24 & 0.34 & 0.26 & 0.02 & 3 & 13 \\
\hline Helichrysum stoechas (L.) Moench & 0.70 & 0.43 & 0.70 & 0.05 & 1 & 35 \\
\hline Ilex aquifolium L. (2) & 0.86 & 0.94 & 1.78 & 1.07 & 7 & 89 \\
\hline Juglans regia $\mathrm{L}$. & 0.12 & 0.28 & 0.12 & 0.01 & 3 & 6 \\
\hline Malus sylvestris (L.) Mill. & 0.86 & 0.51 & 0.86 & 0.07 & 1 & 43 \\
\hline Malva sylvestris $\mathrm{L}$. & 0.62 & 0.53 & 0.76 & 0.14 & 3 & 38 \\
\hline Mentha spp. & 0.44 & 0.51 & 0.70 & 0.12 & 4 & 35 \\
\hline Nasturtium oficinale R.Br. & 0.40 & 0.28 & 0.40 & 0.02 & 1 & 20 \\
\hline Ononis spinosa L. (2) & 0.14 & 0.21 & 0.18 & 0.01 & 2 & 9 \\
\hline Origanum vulgare $\mathrm{L}$. & 0.94 & 0.69 & 1.42 & 0.40 & 3 & 71 \\
\hline Populus nigra L. (2) & 0.90 & 0.74 & 1.80 & 0.65 & 4 & 90 \\
\hline Primula veris $\mathrm{L}$. & 0.24 & 0.34 & 0.28 & 0.02 & 3 & 14 \\
\hline Prunella vulgaris $\mathrm{L}$. & 0.20 & 0.24 & 0.22 & 0.01 & 2 & 11 \\
\hline Prunus cerasus L. & 0.36 & 0.40 & 0.42 & 0.04 & 3 & 21 \\
\hline Prunus insititia L. & 0.40 & 0.28 & 0.40 & 0.02 & 1 & 20 \\
\hline Prunus spinosa $\mathrm{L}$. & 0.94 & 0.62 & 0.96 & 0.18 & 2 & 48 \\
\hline Pyrus cordata Desv. & 0.12 & 0.13 & 0.12 & 0.01 & 1 & 6 \\
\hline Quercus spp. (1) & 0.98 & 0.93 & 3.40 & 1.99 & 6 & 170 \\
\hline Ribes alpinum $\mathrm{L}$. & 0.64 & 0.40 & 0.64 & 0.04 & 1 & 32 \\
\hline Ribes uva-crispa $\mathrm{L}$. & 0.64 & 0.40 & 0.64 & 0.04 & 1 & 32 \\
\hline Rosa spp. (1) & 0.80 & 0.84 & 1.18 & 0.57 & 6 & 59 \\
\hline Rosa spinosissima $\mathrm{L}$. & 0.22 & 0.26 & 0.24 & 0.01 & 2 & 12 \\
\hline Rubus idaeus L. & 0.36 & 0.26 & 0.36 & 0.01 & 1 & 18 \\
\hline Rubus ulmifolius Schott & 0.86 & 0.58 & 0.88 & 0.15 & 2 & 44 \\
\hline Rumex acetosa $\mathrm{L}$. & 0.72 & 0.44 & 0.72 & 0.05 & 1 & 36 \\
\hline Rumex crispus L. (2) & 0.12 & 0.28 & 0.14 & 0.01 & 3 & 7 \\
\hline Sambucus nigra $\mathrm{L}$. & 0.84 & 0.71 & 1.08 & 0.36 & 4 & 54 \\
\hline Scandix australis L. & 0.42 & 0.43 & 0.46 & 0.06 & 3 & 23 \\
\hline Scorzonera humilis L. & 0.12 & 0.13 & 0.12 & 0.01 & 1 & 6 \\
\hline Sideritis hyssopifolia L. & 0.98 & 0.64 & 1.02 & 0.20 & 2 & 51 \\
\hline Silene vulgaris (Moench) Garcke & 0.04 & 0.16 & 0.06 & 0.01 & 2 & 3 \\
\hline Sonchus oleraceus (L.) L. (2) & 0.52 & 0.41 & 0.58 & 0.06 & 2 & 29 \\
\hline Sorbus aria (L.) Crantz (1) & 0.88 & 0.81 & 1.20 & 0.53 & 5 & 60 \\
\hline Taraxacum sect. Ruderalia (1) & 0.58 & 0.51 & 0.64 & 0.11 & 3 & 32 \\
\hline Taxus baccata L. & 0.36 & 0.54 & 0.50 & 0.09 & 2 & 25 \\
\hline Thymus spp. & 0.38 & 0.34 & 0.52 & 0.04 & 2 & 26 \\
\hline Tragopogon dubius Scop. & 0.62 & 0.39 & 0.62 & 0.04 & 1 & 31 \\
\hline Trifolium alpinum L. & 0.62 & 0.46 & 0.62 & 0.08 & 2 & 31 \\
\hline Trifolium pratense $\mathrm{L}$. & 0.19 & 0.21 & 0.14 & 0.01 & 2 & 7 \\
\hline Ulmus minor Mill. (2) & 0.22 & 0.26 & 0.26 & 0.01 & 2 & 13 \\
\hline Urtica dioica L. (2) & 0.66 & 0.55 & 0.84 & 0.17 & 3 & 42 \\
\hline Vaccinium myrtillus L. & 0.96 & 0.63 & 1.00 & 0.19 & 2 & 50 \\
\hline Viburnum lantana $\mathrm{L}$. & 0.04 & 0.09 & 0.04 & 0.01 & 1 & 2 \\
\hline Vicia cracca L. (2) & 0.24 & 0.34 & 0.40 & 0.03 & 3 & 20 \\
\hline
\end{tabular}

Note: RCF (relative citation frequency), RI (relative importance), Cl (cultural importance), CV (cultural value), CU (number of use categories), RU (number of use reports). (1). Species used for human and animal food; (2). Species used as animal feed.

cited 45 times in the category of human food and 10 times in that of animal feed. Broom had 87 use reports with only one report in the category of animal feed.

\section{Discussion}

Regarding the novel results, the informants said that Conopodium pyrenaeum is a well-known tuber among the population, and is consumed fresh, its flavor reminiscent of the hazelnut. It is a common practice to pick it from fields and eat it after removing the dry outer covering. In nearby regions, another species, Conopodium majus (Gouan) Loret is consumed in a similar way (Blanco 1998; González, García-Barriuso, and Amich 2011a). Using oak acorns as human and animal food is frequent among the inhabitants who live where these species grow (Menendez-Baceta et al. 2012). The acorns were reported to be consumed fresh, toasted, or ground to make flour. Using roasted acorns to make digestive tea, however, has not been referenced in other works. Using the fruits of Rumex crispus as animal feed is also a new finding, given that the more common use 
of these fruits in other regions is medicinal (Fajardo et al. 2007).

Regarding the cultural indexes, the species that had the highest values were Quercus spp., Corylus avellana, Ilex aquifolium, and Fagus sylvatica. The RU was high for all of these species and they presented a high diversity of use categories. It is significant that all of these plants are trees or shrubs; indeed, the cultural importance of tree species has been highlighted in other studies (Tardío and Pardo-de-Santayana 2008). Moerman (1994) indicated that trees have many different parts (e.g. wood, bark, leaves, fruits, seeds, and roots) and are more likely to be used as medicinal plants than as herbs. Their dominance in the landscape and versatility of use confirm this observation. The most important species in the study area is Quercus spp., which has a slight secondary importance to human consumption, reaching only 10 reports of use (1.2\%). However, in the case of animal feed, this species reached 49 reports of use (19.7\%). The species Rubus ulmifolius had the highest cultural index value in the Arribes de Duero region in western Spain and in several regions of Southern and Eastern Europe (González, García-Barriuso, and Amich 2011a; Łuczaj et al. 2015).

Other species that had high values in the cultural indexes evaluated are Sideritis hyssopifolia and Chamaemelum nobile. The latter, in addition to its importance in making liqueurs, is noteworthy for being used as tea, for which it is more well-known in this region than in other regions such as Campoo (Tardío and Pardode-Santayana 2008). Proof of its use is that its collection has been limited by an environmental management regulatory order, which still remains in effect today. In the Arribes del Duero region, Chamaemelum nobile is the most consumed herbal tea (González, García-Barriuso, and Amich 2011a)

The number of reports of plants used for human consumption is much higher than those referenced for animal feed. These data coincide with findings in other works (Parada, Carrió, and Vallès 2011; Pardode-Santayana 2008). However, it should be noted that the plants gathered are not the region's main source of food; rather, they are used as food supplements. The plants are gathered in the phenological stage that coincides with the time when the organs that are going to be used are conveniently developed. For plants used as animal feed, the parts generally used are branches, leaves, and fruits. On the other hand, for human food, the diversity of plant organs used is greater as is the variety of recipes. Most plants gathered for animal feed are used for pigs; in the region, it is common practice to raise domesticated pigs, to supply families with meat for much of the year. Before the use of herbicides became common, this omnivorous animal was fed mostly with food waste generated in the home and other plants collected from the environs near homes and orchards. A very significant plant associated with slaughtering pigs is Origanum vulgare, which is commonly used in seasoning products made from the animals' meat, an observation that has also been noted in other studies (Fajardo et al. 2007; Reyes-García et al. 2015).

The number of species used in animal feed is lower than that recorded in other regions such as Arribes del Duero (González, García-Barriuso, and Amich 2011b), where numerous plants are collected to feed donkeys. This type of animal is not found in the study region. The species Urtica dioica and Sonchus oleraceus, which are not used in human food in this region, are widely used in human food in other regions such as Southern and Eastern Europe, forming part of their traditional recipes (Guarrera and Savo 2016; Pieroni, Nedelcheva, and Dogan 2015). Furthermore, Foeniculum vulgare Mill., which does not appear in this region but is available close by, is not cited, despite its accumulating a high percentage of uses in many other regions of Spain and other European countries (Łuczaj, Fressel, and Perković 2013; Tardío, Pardo-de-Santayana, and Morales 2006; Velasco, Criado, and Blanco 2010).

Among the plants mentioned as being used as human food in this region, the subcategory that had the largest number of species was fresh fruits, whereas in other regions we found that the subcategory wild vegetables had the highest number of species (González García-Barriuso, and Amich 2011a; Guarrera and Savo 2016). This result may be due to the predominance of livestock farming in the region, an activity that is influenced by a lesser tradition in the harvesting of wild vegetables. The category that has the highest risk of abandonment is that of plants used as treats due to the low birth rate in the region, the flavors and sensations of consuming these plants may soon be a memory of the past.

\section{Conclusion}

Wild edible plants have a secondary role in nourishing inhabitants of the region, forming part of their desserts, drinks to complement meals or vegetables to accompany main dishes. No main courses were described as being composed mainly of these plants.

Regarding food used for livestock, these plants are used in times of abundant plant biomass, exploiting the waste material from weeding farms or cleaning ruderal areas, an activity known in Spanish as "sallar" (meaning "weeding using a hoe"). This food also comes from pruning trees and shrubs.

The territory's physiognomic characteristics have meant that subsistence farming has been practiced in the area, dedicated to cultivating grains and small plots of legumes for self-sufficient farmers.

Although their consumption was common in the past, wild vegetables are in sharp decline and disuse, with very few people continuing to consume them. 
The plants gathered from the wild have been used to feed stabled animals for domestic use such as pigs, chickens, and rabbits.

\section{Acknowledgements}

We would like to thank the informants who collaborated generously, sharing their knowledge about the traditional use of plants with us.

\section{Disclosure statement}

No potential conflict of interest was reported by the authors.

\section{Notes on contributors}

Juan Cruz Pascual, Agricultural engineer. Master in Biodiversity by the Autonomous University of Madrid (2016). Currently, preparing his doctoral thesis on ethnobotany in the province of Palencia.

Baudilio Herrero, Doctor of Biological Sciences (1994) Professor of Botany at the University of Valladolid. Ethnobotany investigates. Collaborator in Spanish Inventory of Traditional Knowledge relating to Biodiversity.

\section{References}

APG IV. 2016. "An Update of the Angiosperm Phylogeny Gropus Classification for the Orders and Families of Flowering Plants: APG IV." Botanical Journal of the Linnean Society 181: 1-20.

Basterra, M. V. 2009. "Las antiguas vías de comunicación de la montaña palentina [The ancient roads of the Palencia mountain]." Publicaciones de la Institución Tello Téllez de Meneses 21: 109-149.

Blanco, E. 1998. Diccionario de etnobotánica segoviana [Segoviana Dictionary Ethnobotany]. Segovia: Ayuntamiento de Segovia.

Etkin N L 1996. "Medicinal Cuisines: Diet and Ethnopharmacology." International Journal of Pharmacognosy 34: 313-326.

Fajardo, J., A. Verde, D. Rivera, and C. Obón. 2007. Etnobotánica en la Serranía de Cuenca: Las plantas y el hombre [Ethnobotany in the Serranía de Cuenca: Plants and Man]. Cuenca: Diputación Provincial de Cuenca.

González, J. A., M. García-Barriuso, and F. Amich. 2011a. "The Consumption of Wild and Semi-Domesticated Edible Plants in the Arribes del Duero (SalamancaZamora, Spain): An Analysis of Traditional Knowledge." Genetic Resources and Crop Evolution 58: 991-1006.

González, J. A., M. García-Barriuso, and F. Amich. 2011b. "Ethnoveterinary Medicine in the Arribes del Duero, Western Spain." Veterinary Research Communications 35: 283-310.

Guarrera, P. M., and V. Savo. 2016. "Wild Food Plants Used in Traditional Vegetable Mixtures in Italy." Journal of Ethnopharmacology 185: 202-234.

Harlan, J. R. 1992. Crops and Man. Wisconsin: American Society of Agronomy-Madison.

Herrero, L. 1989. "Flora y vegetación en la margen izquierd de la cuenca alta del río Pisuerga, Palencia [Flora and Vegetation on the Left Bank of the Upper Reaches of the River Pisuerga]." PhD diss., Universidad de León.
Heywood, V. 1999. Use and Potential of Wild Plants in Farm Households. Rome: FAO Farm Systems Management Series 15

Łuczaj, Ł., N. Fressel, and S. Perković. 2013. "Wild Food Plants Used in the Villages of the Lake Vrana Nature Park (Northern Dalmatia, Croatia)." Acta Societatis Botanicorum Poloniae 82 (4): 275-281.

Łuczaj, Ł., K. Stawarczyk, T. Kosiek, M. Pietras, and A. Kujawa. 2015. "Wild Food Plants and Fungi Used by Ukranians in the Western Part of the Maramures Region in Romania." Acta Societatis Botanicorum Poloniae 84 (3): 339-346.

Menendez-Baceta, G., L. Aceituno-Mata, J. Tardío, V. ReyesGarcía, and M. Pardo-de-Santayana. 2012. "Wild Edible Plants Traditionally Gathered in Gorbeialdea (Biscay, Basque Country)." Genetic Resources and Crop Evolution 59 (7): 1329-1347.

Moerman, D. E. 1994. "North American Food and Drus Plants." In Eating on the Wild Side, edited by N. L. Etkin, 166-181. Tucson, AZ: University of Arizona Press.

Molina, M., J. Tardío, L. Aceituno-Mata, R. Morales, V. Reyes-García, and M. Pardo-de-Santayana. 2014. "Weed and Food Diversity: Natural Yield Assessment and Future Alternatives for Traditionally Consumed Wild Vegetables.' Journal of Ethnobiology 34 (1): 44-67.

Parada, M., E. Carrió, and J. Vallès. 2011. "Ethnobotany of Food Plants in the Alt Empordà Region (Catalonia Iberian Peninsula)." Journal of Applied Botany and Food Quality 84: 11-25.

Pardo-de-Santayana, M. 2008. Estudios etnobotánicos en Campoo: Conocimiento $y$ uso tradicional de plantas [Ethnobotanical Studies in Campoo: Knowledge and Traditional Use of Plants]. Madrid: CSIC

Pardo-de-Santayana, M., J. Tardío, E. Blanco, A. M. Carvalho, J. J. Lastra, E. San Miguel, and R. Morales. 2007. "Traditional Knowledge of Wild Edible Plants Used in the Northwest of the Iberian Peninsula (Spain and Portugal): A Comparative Study." Journal of Ethnobiology and Ethnomedicine 3: 27-37.

Pascual, J. C. 2013. Estudio etnobotánico de La Pernía Polentinos y Castillería [Ethnobotanical Study of La Pernía, Polentinos and Castillería]. Palencia: Trabajo Fin de Carrera, Universidad de Valladolid.

Pieroni, A., S. Nebel, C. Quave, H. Münz, and M. Heinrich. 2002. "Ethnopharmacology of Liakra: Traditional Weedy Vegetables of the Abërëshe of the Vulture Area in Southern Italy." Journal of Ethnopharmacology 81: 165-185.

Pieroni, A., A. Nedelcheva, and Y. Dogan. 2015. "Local Knowledge of Medicinal Plants and Wild Food Plants among Tatars and Romanians in Dobruja (South-East Romania)." Genetic Resources and Crop Evolution 62 (4) $605-620$

Reyes-García, V., G. Menendez-Baceta, L. Aceituno-Mata R. Acosta-Naranjo, L. Calvet-Mir, P. Domínguez, T Garnatje, et al. 2015. "From Famine Foods to Delicatessen Interpreting Trends in the Use of Wild Edible Plants through Cultural Ecosystem Services." Ecological Economics 120: 303-311.

Serrasolses, G., L. Calvet-Mir, E. Carrió, U. D’Ambrosio, T. Garnatje, M. Parada, J. Vallès, and V. Reyes-García 2016. "A Matter of Taste: Local Explanations for the Consumption of Wild Food Plants in the Catalan Pyrenees and the Balearic Island." Economic Botany 70 (2): 176-189.

Skiadas, P. K., and J. G. Lascaratos. 2001. "Dietetics in Ancient Greek Philosophy: Plato's Concepts of Healthy Diet." European Journal of Clinical Nutrition 55: 532-537. 
$272 \odot$ J.C. PASCUAL AND B. HERRERO

Tardío, J., and M. Pardo-de-Santayana. 2008. "Cultural Importance Indices: A Comparative Analysis Based on the Useful Wild Plants in Southern Cantabria (Northern Spain)." Economic Botany 62 (1): 24-39.

Tardío, J., H. Pascual, and R. Morales. 2002. Alimentos silvestres de Madrid [Wild Food of Madrid]. Madrid: Real Jardín Botánico de Madrid-CSIC.

Tardío, J., H. Pascual, and R. Morales. 2005. "Wild Food Plants Traditionally Used in the Province of Madrid, Central Spain." Economic Botany 59 (2): 122-136.
Tardío, J., M. Pardo-de-Santayana, and R. Morales. 2006 "Ethnobotanical Review of Wild Edible Plants in Spain." Botanical Journal of the Linnean Society 152: 27-71.

The Plant List. 2013. The Plant List. Version 1.1. Accessed May 15, 2016. www.theplantlist.org

Velasco, J. M., J. Criado, and E. Blanco. 2010. Usos tradicionales de las plantas en la provincia de Salamanca [Traditional Uses of Plants in the Province of Salamanca]. Salamanca: Diputación de Salamanca.

A continuación se realiza un examen detallado de las categorías Alimentación humana y Alimentación animal, teniendo en cuenta la extensión total de la comarca de la Montaña Palentina. Se justifica este añadido ya que el área prospectado se ha incrementado considerablemente, abarcando la superficie total de la comarca de la Montaña Palentina y no solo las zonas de la Pernía, Polentinos y el Valle de Castillería, incluidas en el artículo "Wild food plants gathered in the upper Pisuerga river basin, Palencia, Spain" publicado en Botany letters, (Pascual \& Herrero, 2017). Se ha incorporado la información obtenida de 89 nuevas entrevistas realizadas por todo el territorio, así como la información procedente de las especies cultivadas, logrando aumentar de forma notable el número de datos obtenidos. 


\section{Alimentación Humana:}

La categoría Alimentación humana reúne todos los productos de carácter alimentario, desde productos comestibles, bebidas, condimentos, grasas, aceites, hasta plantas que se mastican, tanto si se emplean con o sin elaboración. En la Montaña Palentina se menciona el uso de 149 taxones correspondientes a 45 familias botánicas, para los que se han recogido un total de 2988 registros de uso (RU). De ellos, 87 taxones son de obtención silvestre, 60 cultivados y 2 comprados. Los taxones con mayor número de registros de uso en la categoría "Alimentación humana" se representan en la figura 22.

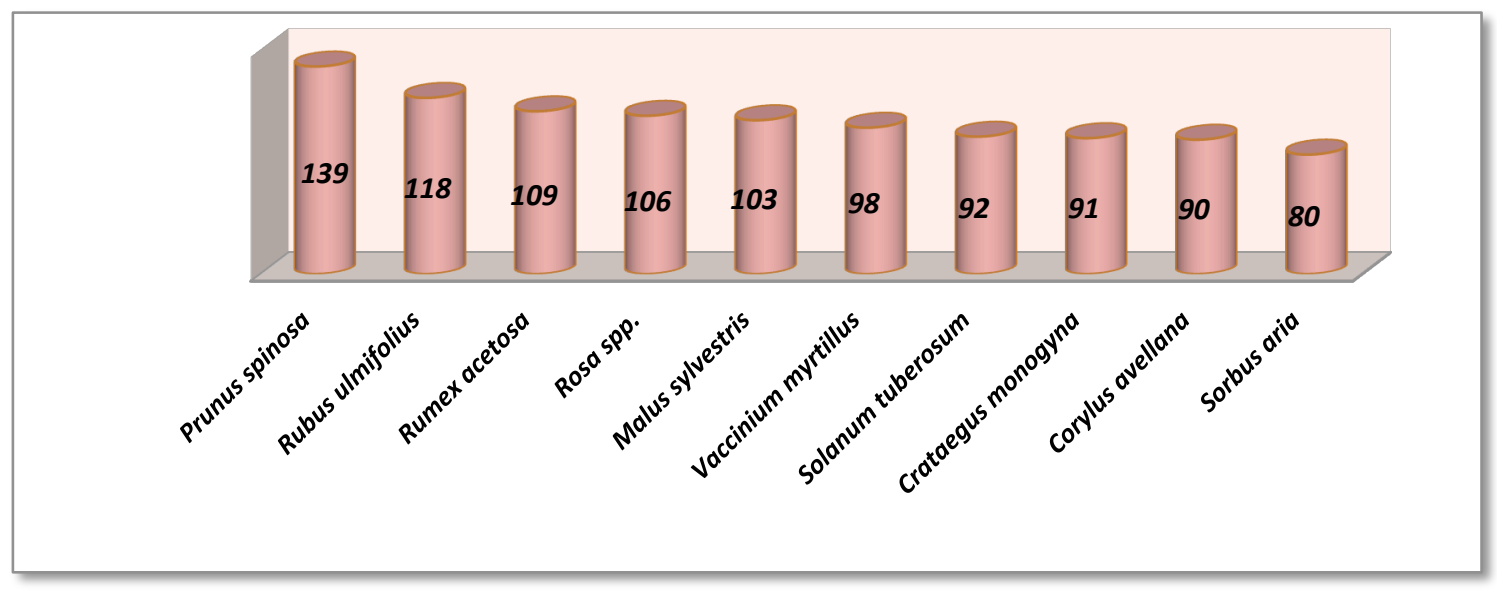

FIGURA 22: Taxones con mayor número de registros de uso en Alimentación humana.

Las familias con mayor representación en cuanto a número de especies fueron: Rosaceae, Leguminosae y Lamiaceae con 20, 15 y 13 especies respectivamente, según se señala en la figura 23.

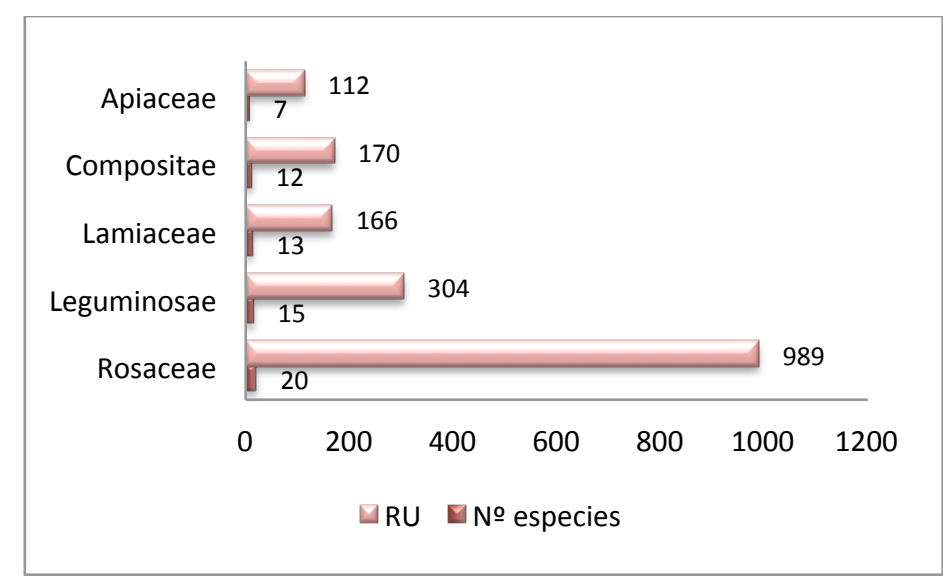

FiguRA 23: Familias con mayor representación de especies y número de registros de uso (RU), en Alimentación humana.

Las familia más destacada en esta categoría en cuanto a número de registros de uso es Rosaceae con 989 registros, justificado por la gran cantidad de citas obtenidas de las especies pertenecientes a esta familia, las más destacadas: endrino (Prunus spinosa) y moral (Rubus ulmifolius) con 139 y 118 registros, respectivamente. Otra familia importante es Leguminosae con 304 registros de uso, con varias especies cultivadas para alimentación, las más relevantes: garbanzo (Cicer arietinum), tito (Lathyrus sativus) y fréjol (Phaseolus vulgaris), con 65, 57 y 41 registros de uso, respectivamente. 
Los usos se han agrupado en subcategorías siguiendo los criterios establecidos en el Inventario Español de los Conocimientos Tradicionales relativos a la Biodiversidad (Pardo de Santayana et al., 2014), obteniendo referencias en las 12 subcategorías indicadas en la tabla 13.

\begin{tabular}{l}
$\begin{array}{l}\text { TABLA 13: Subcategorías con representación en la categoría } \\
\text { Alimentación humana. }\end{array}$ \\
\hline Subcategorías : \\
\hline Verduras y hortalizas \\
Raíces, bulbos, tubérculos y rizomas \\
Frutas y frutos dulces \\
Frutos secos y oleaginosos \\
Cereales \\
Legumbres \\
Setas y otros hongos \\
Grasas alimentarias \\
Bebidas alcohólicas \\
Bebidas no alcohólicas \\
Condimentos y conservantes \\
Golosinas y masticatorias \\
\hline
\end{tabular}

Los 2988 registros de uso obtenidos en la categoría Alimentación humana, se reparten en 12 subcategorías tal y como señala la figura 24, resultando que Frutas y frutos dulces es la que recibió el mayor número de registros con 1114 , un $37,28 \%$ del total en esta categoría, seguido de Golosinas y masticatorias con 482 , un $16,13 \%$, y Verduras y hortalizas con 232 , un $7,76 \%$.

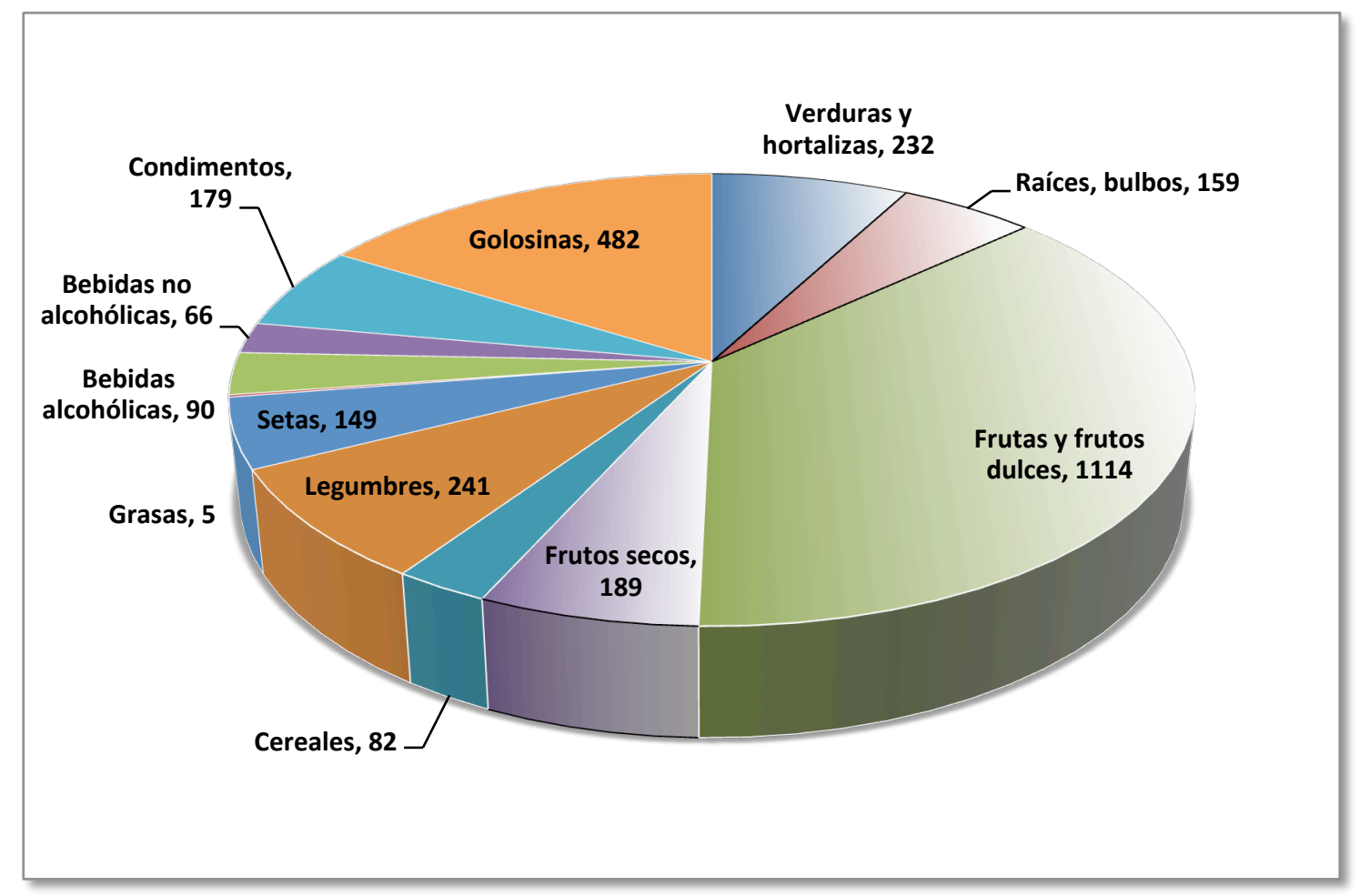

FIGURA 24: Registros de Uso (RU) de las subcategorías representadas en Alimentación humana.

A continuación se presentan los usos agrupados por subcategorías de Alimentación humana, señalando los taxones que han obtenido citas en los mismos, el número de registros de uso de cada taxón, la parte usada y el empleo. 


\section{Verduras y hortalizas:}

Se han recogido 232 registros de uso, correspondientes a 29 taxones de 15 familias botánicas diferentes, 11 taxones de obtención silvestre y 18 cultivados, representando un 7,76\% del total de registros de uso para la categoría Alimentación humana.

TABLA 14: Relación de especies empleadas en la subcategoría Verduras y hortalizas, ordenadas alfabéticamente por familia, indicando número de registros de uso (RU), parte usada y empleo.

\begin{tabular}{|c|c|c|c|c|}
\hline Familia & $\begin{array}{l}\text { Nombre científico } \\
\text { Nombre vulgar }\end{array}$ & RU & Parte usada & Empleo \\
\hline Adoxaceae & $\begin{array}{l}\text { Sambucus nigra } \\
\text { Saúco, saúgo, sabúgo, taco }\end{array}$ & 1 & Inflorescencia & Fritura \\
\hline \multirow[t]{2}{*}{ Amaranthaceae } & $\begin{array}{l}\text { Beta vulgaris var. cicla } \\
\text { Acelga }\end{array}$ & 2 & Hojas & Guisos \\
\hline & $\begin{array}{l}\text { Spinacia oleracea } \\
\text { Espinaca }\end{array}$ & 1 & Hojas & Guisos \\
\hline Amaryllidaceae & $\begin{array}{l}\text { Allium ampeloprasum } \\
\text { Puerro }\end{array}$ & 13 & Tallo & Ensalada, guisos \\
\hline Apiaceae & $\begin{array}{l}\text { Apium graveolens } \\
\text { Apio }\end{array}$ & 4 & Tallo, hojas & Guisos \\
\hline Boraginaceae & $\begin{array}{l}\text { Borago officinalis } \\
\text { Borraja }\end{array}$ & 2 & Hojas & Cocinada \\
\hline \multirow[t]{5}{*}{ Brassicaceae } & $\begin{array}{l}\text { Brassica oleracea var. acephala } \\
\text { Berza, col }\end{array}$ & 49 & Hojas & Cocinada \\
\hline & $\begin{array}{l}\text { Brassica oleracea var. botrytis } \\
\text { Coliflor }\end{array}$ & 1 & Inflorescencia & Cocinada \\
\hline & $\begin{array}{l}\text { Brassica oleracea var. capitata } \\
\text { Repollo, lombarda }\end{array}$ & 2 & Hojas & Cocinada \\
\hline & $\begin{array}{l}\text { Brassica oleracea var. } \\
\text { gemmifera } \\
\text { Col de Bruselas }\end{array}$ & 1 & Yemas axilares & Cocinada \\
\hline & $\begin{array}{l}\text { Nasturtium officinale } \\
\text { Berro }\end{array}$ & 34 & Hojas & Ensalada \\
\hline Caryophyllaceae & $\begin{array}{l}\text { Silene vulgaris } \\
\text { Colleja, cuete }\end{array}$ & 3 & Hojas & Guisos \\
\hline \multirow[t]{4}{*}{ Compositae } & $\begin{array}{l}\text { Cichorium endivia } \\
\text { Escarola }\end{array}$ & 1 & Hojas & Ensalada \\
\hline & $\begin{array}{l}\text { Cynara scolymus } \\
\text { Alcachofa }\end{array}$ & 1 & Inflorescencia & Cocinada \\
\hline & $\begin{array}{l}\text { Lactuca sativa } \\
\text { Lechuga }\end{array}$ & 41 & Hojas & Ensalada \\
\hline & $\begin{array}{l}\text { Taraxacum campylodes } \\
\text { Achicoria, diente de león }\end{array}$ & 22 & Hojas & Ensalada \\
\hline Convolvulaceae & $\begin{array}{l}\text { Convolvulus arvensis } \\
\text { Correyuela, corrigüela }\end{array}$ & 2 & Hojas & Cocinada \\
\hline \multirow[t]{3}{*}{ Cucurbitaceae } & $\begin{array}{l}\text { Cucumis sativus } \\
\text { Pepino }\end{array}$ & 4 & Fruto & Ensalada \\
\hline & $\begin{array}{l}\text { Cucurbita moschata } \\
\text { Calabaza }\end{array}$ & 2 & Fruto & Cocinada \\
\hline & $\begin{array}{l}\text { Cucurbita pepo } \\
\text { Calabacín }\end{array}$ & 4 & Fruto & Cocinada \\
\hline Leguminosae & $\begin{array}{l}\text { Trifolium pratense } \\
\text { Trébol, chupa, chupón }\end{array}$ & 1 & Hojas & Ensalada \\
\hline \multirow[t]{3}{*}{ Polygonaceae } & $\begin{array}{l}\text { Persicaria bistorta } \\
\text { Cornicabra }\end{array}$ & 4 & Hojas & Guisos \\
\hline & $\begin{array}{l}\text { Rumex acetosa } \\
\text { Tallos, acera, acerón, cornicabra }\end{array}$ & 16 & Hojas & Fresco, ensalada \\
\hline & $\begin{array}{l}\text { Rumex longifolius } \\
\text { Cornicabra }\end{array}$ & 1 & Hojas & Guisos \\
\hline
\end{tabular}




\begin{tabular}{lllll}
\hline TABLA 14: & $\begin{array}{l}\text { (Continuación) } \\
\text { alfabéticamente por familia, indicando número de registros de uso (RU), parte usada y empleo. }\end{array}$ & Empleo \\
\hline Familia & $\begin{array}{l}\text { Nombre científico } \\
\text { Nombre vulgar }\end{array}$ & RU & Parte usada & Fresco \\
\hline Rosaceae & $\begin{array}{l}\text { Crataegus monogyna } \\
\text { Espino, espino albar, majueto }\end{array}$ & 4 & Hojas & Guisos \\
\hline Solanaceae & $\begin{array}{l}\text { Capsicum annuum } \\
\text { Pimiento }\end{array}$ & 2 & Fruto & Ensalada \\
\hline $\begin{array}{l}\text { Solanum lycopersicon } \\
\text { Tomate }\end{array}$ & $\begin{array}{l}\text { Solanum melongena } \\
\text { Berenjena } \\
\text { Urtica dioica }\end{array}$ & 10 & Fruto & Cocinada \\
\hline Ortiga & 1 & Fruto & Guisos \\
\hline
\end{tabular}

Dentro del análisis etnobotánico de las plantas de uso alimentario como verduras y hortalizas, cabe reseñar las diferencias entre plantas cultivadas y silvestres. Entre las primeras, las variedades han ido evolucionando con el paso del tiempo y hasta hace unos pocos años en el que la introducción de semilla seleccionada se impuso como modelo, los cultivos hortícolas fueron el resultado de una selección genética llevada a cabo por los propios agricultores de la zona, conservando las mejores semillas de un año para otro.

En el típico huerto de mediados del siglo XX, se cultivaban unas pocas verduras y hortalizas, básicamente berza (Brassica oleracea var. acephala), y lechuga (Lactuca sativa), bien adaptados a la climatología de la zona, en ocasiones puerro (Allium ampeloprasum) y acelga (Beta vulgaris var. cicla). Hoy en día la variedad de verduras se ha incrementado y aparecen cultivadas en la huerta especies como: tomate (Solanum lycopersicon), calabacín (Cucurbita pepo), calabaza (Cucurbita moschata), pepino (Cucumis sativus) o pimiento (Capsicum annuum).

Resulta significativa la cantidad de especies silvestres comestibles en la zona como verduras, desde las que acompañaban a cocidos o guisos, como cornicabras (Persicaria bistorta, Rumex longifolius), ortigas (Urtica dioica), collejas (Silene vulgaris) y correyuelas (Convolvulus arvensis), hasta las que se utilizaban para realizar ensaladas como achicorias (Taraxacum campylodes), berros (Nasturtium officinale) o aceras (Rumex acetosa). El uso de verduras silvestres es generalizado en la Península Ibérica, consumiéndose en un gran número de regiones. Se documenta el uso como verdura de la colleja en: Monzón (Ferrández \& Sanz, 1993), La Calabria (Blanco \& Cuadrado, 2000), Carcabuey (Molina, 2001), Madrid (Tardío et al., 2002), la Vall de Campodron (Rigat, 2005) y el Poniente Granadino (Benítez, 2009).

\section{Raíces, bulbos, tubérculos y rizomas:}

Se han recogido 159 registros de uso, correspondientes a 5 taxones cultivados de 5 familias botánicas diferentes, representando un $5,32 \%$ del total de registros de uso para la categoría Alimentación humana. 
TABLA 15: Relación de especies empleadas en la subcategoría Raíces, bulbos, tubérculos y rizomas, ordenadas alfabéticamente por familia, indicando número de registros de uso (RU), parte usada y empleo.

\begin{tabular}{llccc}
\hline Familia & $\begin{array}{l}\text { Nombre científico } \\
\text { Nombre vulgar }\end{array}$ & RU & Parte usada & Empleo \\
\hline Amaranthaceae & $\begin{array}{l}\text { Beta vulgaris var. altissima } \\
\text { Remolacha }\end{array}$ & 1 & Raíz & Ensalada \\
\hline Amaryllidaceae & $\begin{array}{l}\text { Allium cepa } \\
\text { Cebolla } \\
\text { Daucus carota } \\
\text { Zanahoria }\end{array}$ & 45 & Bulbo & $\begin{array}{c}\text { Ensalada, guisos, } \\
\text { fresco }\end{array}$ \\
\hline Apraceae & $\begin{array}{l}\text { Brassica napus } \\
\text { Nabo }\end{array}$ & 9 & Raíz & Cocinada, fresco \\
\hline Solanaceae & $\begin{array}{l}\text { Solanum tuberosum } \\
\text { Patata }\end{array}$ & 12 & Raíz & Cocinado \\
\hline
\end{tabular}

La subcategoría incluye las especies utilizadas por sus raíces, bulbos o tubérculos. Todas las especies mencionadas son obtenidas mediante cultivo. Para muchos habitantes de la zona, la patata (Solanum tuberosum) resultó un cultivo primordial para resolver la escasez de alimento en épocas de hambruna como la posguerra, y a ella podían dedicar terrenos más extensos para aumentar la producción, o pequeñas huertas, dependiendo del tamaño familiar. Se toman de ordinario cocinadas en diferentes guisos, junto con chorizo, carne o solo con pimentón, aceite o tocino, también en forma de tortilla y en otras múltiples recetas.

En la huerta tradicional también se sembraban cebollas (Allium cepa), zanahorias (Daucus carota) y nabos (Brassica napus), se reservaban unos pocos surcos para los nabos, y aunque su principal destino era para la alimentación de los cerdos, también servían para consumo humano como hortaliza de mesa, consumidos de forma habitual cocidos junto con patatas. En la provincia de Salamanca se referencian también ambos consumos (Velasco et al., 2010).

\section{Frutas y frutos dulces:}

Se han recogido 1114 registros de uso, correspondientes a 29 taxones de 15 familias botánicas diferentes, 11 taxones de obtención silvestre y 18 cultivados, representando un $37,28 \%$ del total de registros de uso para la categoría Alimentación humana.

TABLA 16: Relación de taxones empleados en la subcategoría Frutas y frutos dulces, ordenados alfabéticamente por familia, indicando número de registros de uso (RU), parte usada y empleo.

\begin{tabular}{llccc}
\hline Familia & $\begin{array}{l}\text { Nombre científico } \\
\text { Nombre vulgar }\end{array}$ & RU & Parte usada & Empleo \\
\hline Adoxaceae & $\begin{array}{l}\text { Sambucus nigra } \\
\text { Saúco, saúgo, sabúgo, taco } \\
\text { Viburnum lantana } \\
\text { Barbadillo, petruco, sangricio }\end{array}$ & 10 & Fruto & Mermelada \\
\hline Berberis vulgaris & 4 & Fruto & Fresco, maduro \\
\hline Ericaceae & $\begin{array}{l}\text { Hoja maldita, borrachín } \\
\text { Arctostaphylos uva-ursi } \\
\text { Gayuga, agayuga, gayuba } \\
\text { Vaccinium myrtillus } \\
\text { Arráspano, ráspano, arándano } \\
\text { Ribes alpinum } \\
\text { Abubillo, agüillo, plumillo }\end{array}$ & 6 & Fruto & Fresco, maduro \\
\hline $\begin{array}{l}\text { Ribes petraeum } \\
\text { Abubillo, abubillo montesino }\end{array}$ & 96 & Fruto & Fresco, mermelada \\
\hline
\end{tabular}




\begin{tabular}{|c|c|c|c|c|}
\hline Familia & $\begin{array}{l}\text { Nombre científico } \\
\text { Nombre vulgar }\end{array}$ & RU & Parte usada & Empleo \\
\hline \multirow[t]{2}{*}{ Grossulariaceae } & $\begin{array}{l}\text { Ribes rubrum } \\
\text { Abubillo, agüillo, escándalo }\end{array}$ & 17 & Fruto & Fresco \\
\hline & $\begin{array}{l}\text { Ribes uva-crispa } \\
\text { Abubillo, escándalo, plumillar }\end{array}$ & 59 & Fruto & Fresco \\
\hline \multirow[t]{3}{*}{ Moraceae } & $\begin{array}{l}\text { Ficus carica } \\
\text { Higuera }\end{array}$ & 1 & Fruto & Fresco \\
\hline & $\begin{array}{l}\text { Morus alba } \\
\text { Moral }\end{array}$ & 1 & Fruto & Fresco, maduro \\
\hline & $\begin{array}{l}\text { Morus nigra } \\
\text { Morera }\end{array}$ & 1 & Fruto & Fresco, maduro \\
\hline \multirow[t]{20}{*}{ Rosaceae } & $\begin{array}{l}\text { Amelanchier ovalis } \\
\text { Amilloma, sorbo, anietano }\end{array}$ & 20 & Fruto & Fresco, maduro \\
\hline & $\begin{array}{l}\text { Crataegus monogyna } \\
\text { Espino, espino albar, majueto }\end{array}$ & 83 & Fruto & Fresco \\
\hline & $\begin{array}{l}\text { Fragaria } \mathrm{x} \text { ananassa } \\
\text { Fresa }\end{array}$ & 4 & Fruto & Fresco \\
\hline & $\begin{array}{l}\text { Fragaria vesca } \\
\text { Amiérgano, fresa, abijano }\end{array}$ & 73 & Fruto & Fresco \\
\hline & $\begin{array}{l}\text { Malus domestica } \\
\text { Manzano }\end{array}$ & 38 & Fruto & Fresco \\
\hline & $\begin{array}{l}\text { Malus sylvestris } \\
\text { Maíllo, maello, amaello }\end{array}$ & 86 & Fruto & Fresco, maduro \\
\hline & $\begin{array}{l}\text { Prunus avium } \\
\text { Cerezo }\end{array}$ & 19 & Fruto & Fresco \\
\hline & $\begin{array}{l}\text { Prunus cerasus } \\
\text { Guindal }\end{array}$ & 27 & Fruto & Fresco \\
\hline & $\begin{array}{l}\text { Prunus domestica } \\
\text { Ciruelo, mijuelo, pruno }\end{array}$ & 57 & Fruto & Fresco, mermelada \\
\hline & $\begin{array}{l}\text { Prunus domestica subsp. insitia } \\
\text { Andrino real, andriniego }\end{array}$ & 5 & Fruto & Fresco, secos \\
\hline & $\begin{array}{l}\text { Prunus persica } \\
\text { Melocotón }\end{array}$ & 1 & Fruto & Fresco \\
\hline & $\begin{array}{l}\text { Prunus spinosa } \\
\text { Endrino, andrino, espino }\end{array}$ & 91 & Fruto & Fresco \\
\hline & $\begin{array}{l}\text { Pyrus communis } \\
\text { Peral }\end{array}$ & 27 & Fruto & Fresco, mermeladas \\
\hline & $\begin{array}{l}\text { Pyrus cordata } \\
\text { Peral de monte, perujo }\end{array}$ & 14 & Fruto & Fresco \\
\hline & $\begin{array}{l}\text { Rosa spp. } \\
\text { Zarza, espino, rosal, calambrojo }\end{array}$ & 77 & Fruto & $\begin{array}{l}\text { Fresco, maduro, } \\
\text { mermeladas }\end{array}$ \\
\hline & $\begin{array}{l}\text { Rosa spinosissima } \\
\text { Zarzaparrilla, rosal espinoso }\end{array}$ & 3 & Fruto & Fresco, maduro \\
\hline & $\begin{array}{l}\text { Rubus caesius } \\
\text { Moral, morito }\end{array}$ & 2 & Fruto & Fresco \\
\hline & $\begin{array}{l}\text { Rubus idaeus } \\
\text { Antimora, mora de la reina }\end{array}$ & 47 & Fruto & Fresco \\
\hline & $\begin{array}{l}\text { Rubus ulmifolius } \\
\text { Zarza, moral, espino }\end{array}$ & 94 & Fruto & Fresco, mermeladas \\
\hline & $\begin{array}{l}\text { Sorbus aria } \\
\text { Mostajo, amostajo }\end{array}$ & 80 & Fruto & Fresco \\
\hline Taxaceae & $\begin{array}{l}\text { Taxus baccata } \\
\text { Tejo }\end{array}$ & 2 & Fruto & Fresco \\
\hline Vitaceae & $\begin{array}{l}\text { Vitis vinifera } \\
\text { Parra }\end{array}$ & 12 & Fruto & Fresco \\
\hline
\end{tabular}


Se recogen todas las especies con frutos carnosos consumidos normalmente como postre, diferenciando los frutos silvestres de los cultivados.

Los rigores climáticos de la zona limitan el cultivo de frutales, en las huertas se puede encontrar manzano (Malus domestica), ciruelo (Prunus domestica), guindal (Prunus cerasus), cerezo (Prunus avium) y peral (Pyrus communis), aunque las heladas tardías de determinados años provocan que la cosecha no prospere. En la zona sur de la comarca, con clima un poco más benévolo se puede localizar cultivado algún ejemplar de higuera (Ficus carica), morera (Morus alba y M. nigra), andrino real (Prunus domestica subsp. insitia) o melocotón (Prunus persica).

El consumo de frutos silvestres continúa en muchos casos aún vigente, sobre todo los relacionados con la recolección de frutas, de las cuales se atesora un gran conocimiento entre los habitantes de la zona. En la actualidad, a pequeña escala se recolecta un gran número de especies por sus frutos carnosos: arráspanos (Vaccinium myrtillus), maíllas (Malus sylvestris), endrinas (Prunus spinosa), moras (Rubus ulmifolius), escalambrojos (Rosa spp.), majuetas (Crataegus monogyna), mostajas (Sorbus aria), amiérganos (Fragaria vesca), abubillas (Ribes alpinum, R. petraeum y R. uva-crispa), gatimoras (Rubus idaeus), agayugas (Arctostaphylos uva-ursi), perujos (Pyrus cordata), borrachines (Berberis vulgaris), petrucos (Viburnum lantana) y amillomas (Amelanchier ovalis), estos últimos apreciados por su sabor dulce también en: Cerdanya (Muntané, 1991), Montsant (Ledesma, 2004), y la provincia de Albacete (Rivera et al., 2006). El consumo de frutos silvestres se suele realizar en el propio campo, también pueden elaborarse mermeladas con arráspanos, moras, escalambrojos y frutos del saúco (Sambucus nigra), o conservarse hasta su adecuada maduración, como es el caso de las maíllas.

\section{Frutos secos y oleaginosos:}

Se han recogido 189 registros de uso, correspondientes a 7 taxones de 4 familias botánicas diferentes, 4 taxones de obtención silvestre y 3 cultivados, representando un 6,33\% del total de registros de uso para la categoría Alimentación humana.

TABLA 17: Relación de especies empleadas en la subcategoría Frutos secos y oleaginosos, ordenadas alfabéticamente por familia, indicando número de registros de uso (RU), parte usada y empleo.

\begin{tabular}{|c|c|c|c|c|}
\hline Familia & $\begin{array}{l}\text { Nombre científico } \\
\text { Nombre vulgar }\end{array}$ & RU & Parte usada & Empleo \\
\hline Betulaceae & $\begin{array}{l}\text { Corylus avellana } \\
\text { Avellano }\end{array}$ & 90 & Fruto seco & Crudo, en leche \\
\hline Compositae & $\begin{array}{l}\text { Helianthus annuus } \\
\text { Girasol }\end{array}$ & 2 & Fruto seco & Crudo, tostado \\
\hline \multirow[t]{4}{*}{ Fagaceae } & $\begin{array}{l}\text { Castanea sativa } \\
\text { Castaño }\end{array}$ & 1 & Fruto seco & Asado, crudo \\
\hline & $\begin{array}{l}\text { Fagus sylvatica } \\
\text { Haya }\end{array}$ & 59 & Fruto seco & Crudo, tostado \\
\hline & $\begin{array}{l}\text { Quercus petraea } \\
\text { Q. pyrenaica } \\
\text { Q. robur } \\
\text { Roble, cajigo, matorro }\end{array}$ & 13 & Fruto seco & Asado, crudo, tostado \\
\hline & $\begin{array}{l}\text { Quercus rotundifolia } \\
\text { Encina, ancina }\end{array}$ & 4 & Fruto seco & Asado, crudo, tostado \\
\hline Juglandaceae & $\begin{array}{l}\text { Juglans regia } \\
\text { Nogal }\end{array}$ & 20 & Fruto seco & Crudo \\
\hline
\end{tabular}


Entre los frutos secos y oleaginosos sobresale el fruto del avellano (Corylus avellana) con 90 registros de uso, el mayor de esta subcategoría alimentaria. Las avellanas se pueden consumir crudas, secas y también crudas en leche, cuando no se deja completar su maduración.

Otro destacado fruto seco es el hayuco procedente del haya (Fagus sylvatica), se consumen en crudo o más comúnmente tostados, de esta forma la cáscara se desprende más sencillamente. Su ingesta está muy extendida por aquellas regiones en las que este árbol se desarrolla de forma espontánea, como en Asturias (San Miguel, 2004), Navarra (Pérez Altamira, 2007), Cantabria (Pardo de Santayana, 2008) o el País Vasco (Menendez Baceta et al., 2012).

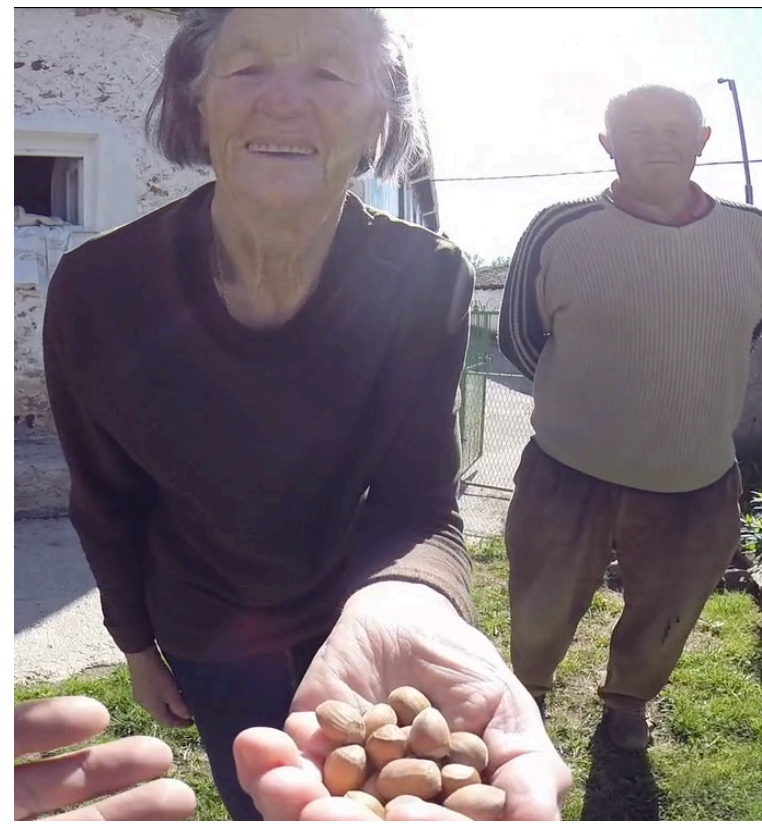

FIGURA 25: Victorina de San Salvador ofreciendo avellanas.

Con menor frecuencia se consumen nueces del nogal (Juglans regia) y bellotas, las de encina (Quercus rotundifolia) eran más apreciadas por ser más dulces y sabrosas que las del roble (Quercus petraea, $Q$. pyrenaica, $Q$. robur) y se podían tomar asadas, crudas o tostadas.

\section{Cereales:}

Se han recogido 82 registros de uso, correspondientes a 3 taxones cultivados de la familia Poaceae, representando un $2,74 \%$ del total de registros de uso para la categoría Alimentación humana.

TABLA 18: Relación de especies empleadas en la subcategoría Cereales, ordenadas alfabéticamente por familia, indicando número de registros de uso (RU), parte usada y empleo.

\begin{tabular}{llccc}
\hline Familia & $\begin{array}{l}\text { Nombre científico } \\
\text { Nombre vulgar }\end{array}$ & RU & Parte usada & Empleo \\
\hline Poaceae & $\begin{array}{l}\text { Hordeum vulgare } \\
\text { Cebada, ladilla, comuña }\end{array}$ & 1 & Fruto & Harina \\
\hline $\begin{array}{l}\text { Secale cereale } \\
\text { Centeno, sirvendo, servendo }\end{array}$ & 17 & Fruto & Harina \\
\hline $\begin{array}{l}\text { Triticum aestivum } \\
\text { Trigo, mesino, tremesino }\end{array}$ & 64 & Fruto & Harina \\
\hline
\end{tabular}

Se incluyen en la subcategoría todos los cereales silvestres o cultivados y sus derivados. El cultivo del trigo (Triticum aestivum) resultaba imprescindible para obtener harina con la que elaborar el pan. El grano se llevaba a moler a los molinos más cercanos y casi todas las casas disponían de horno tradicional donde cocer unos cuantos panes con los que abastecer a la familia durante un tiempo. En casos de necesidad se mezclaba con harina de centeno (Secale cereale), y las menos con harina de cebada (Hordeum vulgare), aunque no era del aprecio de los lugareños y además se consideraba síntoma de pobreza. 


\section{Legumbres:}

Se han recogido 189 registros de uso, correspondientes a 7 taxones cultivados de la familia Leguminosae, representando un 6,33\% del total de registros de uso para la categoría Alimentación humana.

TABLA 19: Relación de especies empleadas en la subcategoría Legumbres, ordenadas alfabéticamente por familia, indicando número de registros de uso (RU), parte usada y empleo.

\begin{tabular}{|c|c|c|c|c|}
\hline Familia & $\begin{array}{l}\text { Nombre científico } \\
\text { Nombre vulgar }\end{array}$ & RU & Parte usada & Empleo \\
\hline \multirow[t]{10}{*}{ Leguminosae } & $\begin{array}{l}\text { Cicer arietinum } \\
\text { Garbanzo }\end{array}$ & 65 & $\begin{array}{l}\text { Semilla seca } \\
\text { Semilla verde }\end{array}$ & $\begin{array}{l}\text { Cocinada } \\
\text { Crudo }\end{array}$ \\
\hline & $\begin{array}{l}\text { Lathyrus cicera } \\
\text { Titarro }\end{array}$ & 2 & $\begin{array}{l}\text { Semilla seca } \\
\text { Semilla verde }\end{array}$ & $\begin{array}{l}\text { Harina } \\
\text { Crudo }\end{array}$ \\
\hline & $\begin{array}{l}\text { Lathyrus sativus } \\
\text { Tito, tito esquinado, muela }\end{array}$ & 57 & $\begin{array}{l}\text { Semilla seca } \\
\text { Semilla verde }\end{array}$ & $\begin{array}{c}\text { Cocinada } \\
\text { Crudo }\end{array}$ \\
\hline & $\begin{array}{l}\text { Lens culinaris } \\
\text { Lenteja }\end{array}$ & 19 & Semilla seca & Cocinada \\
\hline & $\begin{array}{l}\text { Lupinus albus } \\
\text { Chocho }\end{array}$ & 8 & Semilla seca & $\begin{array}{l}\text { Cocinada } \\
\text { Crudo }\end{array}$ \\
\hline & $\begin{array}{l}\text { Phaseolus vulgaris } \\
\text { Fréjol, alubia, vaina, judía }\end{array}$ & 41 & $\begin{array}{l}\text { Semilla seca } \\
\text { Fruto verde }\end{array}$ & Cocinada \\
\hline & $\begin{array}{l}\text { Pisum sativum } \\
\text { Arveja, guisante, morita }\end{array}$ & 39 & $\begin{array}{l}\text { Semilla seca } \\
\text { Semilla verde }\end{array}$ & $\begin{array}{l}\text { Cocinada } \\
\text { Crudo }\end{array}$ \\
\hline & $\begin{array}{l}\text { Vicia articulata } \\
\text { Algarroba }\end{array}$ & 1 & Semilla seca & Cocinada \\
\hline & $\begin{array}{l}\text { Vicia ervilia } \\
\text { Yero }\end{array}$ & 1 & Semilla verde & Crudo \\
\hline & $\begin{array}{l}\text { Vicia faba } \\
\text { Haba }\end{array}$ & 8 & $\begin{array}{l}\text { Semilla seca } \\
\text { Semilla verde }\end{array}$ & $\begin{array}{c}\text { Cocinada } \\
\text { Crudo }\end{array}$ \\
\hline
\end{tabular}

En cuanto a los cultivos de legumbres, su destino principal fue el uso de las semillas o granos secos en la cocina servidos en forma de potajes, los más frecuentes son garbanzos (Cicer arietinum), titos (Lathyrus sativus), arvejas (Pisum sativum) y fréjoles (Phaseolus vulgaris), que se incorporaban en la dieta diaria y se solían preparar cocidos. Se referencia el cultivo de titos en la provincia de Segovia (Blanco, 1998), de Salamanca (Velasco et al., 2010) o de Avila (Blanco, 2015). En la Montaña Palentina, en épocas de escasez pasó a formar un elemento fundamental en la dieta diaria de las familias más humildes y se asociaba su consumo a pobreza, ya que el destino principal del cultivo era convertirse en pienso para el ganado.

También se cultivan pequeñas superficies de lenteja (Lens culinaris) y haba (Vicia faba), cuyo destino final es el autoconsumo en el núcleo familiar. Una legumbre como el chocho (Lupinus albus) cultivada para uso ganadero, gustaba reservar una pequeña cantidad de semilla para consumir una vez desamargada.

Los más mayores recuerdan en su juventud recoger legumbres en verde, se aprovechaban los granos inmaduros, apreciados por su agradable sabor un tanto dulce. Se menciona el consumo de este modo de: garbanzos, titos, chochos, arvejas y habas. 


\section{Setas y otros hongos:}

Se han recogido 149 registros de uso, correspondientes a 13 taxones de obtención silvestre de 9 familias botánicas diferentes, representando un $4,99 \%$ del total de registros de uso para la categoría Alimentación humana.

TABLA 20: Relación de especies empleadas en la subcategoría Setas y otros hongos, ordenadas alfabéticamente por familia, indicando número de registros de uso (RU), parte usada y empleo.

\begin{tabular}{|c|c|c|c|c|}
\hline Familia & $\begin{array}{l}\text { Nombre científico } \\
\text { Nombre vulgar }\end{array}$ & RU & Parte usada & Empleo \\
\hline \multirow[t]{3}{*}{ Agaricaceae } & Agaricus arvensis & & & \\
\hline & $\begin{array}{l}\text { A. campestris } \\
\text { Champiñón, hongo }\end{array}$ & 16 & Cuerpo fructífero & Cocinada \\
\hline & $\begin{array}{l}\text { Macrolepiota procera } \\
\text { Parasol }\end{array}$ & 1 & Cuerpo fructífero & Cocinada \\
\hline Bolbitiaceae & $\begin{array}{l}\text { Agrocybe aegerita } \\
\text { Seta de chopo }\end{array}$ & 1 & Cuerpo fructífero & Cocinada \\
\hline Boletaceae & $\begin{array}{l}\text { Boletus edulis } \\
\text { B. pinophilus } \\
\text { Boletus }\end{array}$ & 6 & Cuerpo fructífero & $\begin{array}{c}\text { Cocinada } \\
\text { Cruda }\end{array}$ \\
\hline Cantharellaceae & $\begin{array}{l}\text { Cantarellus cibarius } \\
\text { Cantarellus }\end{array}$ & 1 & Cuerpo fructífero & Cocinada \\
\hline Coprinaceae & $\begin{array}{l}\text { Coprinus comatus } \\
\text { Borracha, seta del vino }\end{array}$ & 3 & Cuerpo fructífero & Cocinada \\
\hline Marasmiaceae & $\begin{array}{l}\text { Marasmius oreades } \\
\text { Seta rojilla, roja, senderilla }\end{array}$ & 43 & Cuerpo fructífero & Cocinada \\
\hline Pleurotaceae & $\begin{array}{l}\text { Pleurotus eryngii } \\
\text { Seta de cardillo, seta de cardo }\end{array}$ & 14 & Cuerpo fructífero & Cocinada \\
\hline Russulaceae & $\begin{array}{l}\text { Lactarius deliciosus } \\
\text { Níscalo }\end{array}$ & 8 & Cuerpo fructífero & Cocinada \\
\hline \multirow[t]{4}{*}{ Tricholomataceae } & $\begin{array}{l}\text { Calocybe gambosa } \\
\text { Seta blanca, seta de la buena }\end{array}$ & 39 & Cuerpo fructífero & Cocinada \\
\hline & $\begin{array}{l}\text { Lepista nuda } \\
\text { Seta de pie azul }\end{array}$ & 4 & Cuerpo fructífero & Cocinada \\
\hline & $\begin{array}{l}\text { Lepista rickenii } \\
\text { Seta de brezo, seta de berezo }\end{array}$ & 1 & Cuerpo fructífero & Cocinada \\
\hline & $\begin{array}{l}\text { Lepista sordida } \\
\text { Seta morada }\end{array}$ & 1 & Cuerpo fructífero & Cocinada \\
\hline
\end{tabular}

En la comarca se recolectan setas de modo tradicional de unas pocas especies para autoconsumo, la más apreciada es la seta rojilla (Marasmius oreades) recolectada en primavera y otoño, se consume en tortillas y revueltos, le siguen a continuación la seta blanca (Calocybe gambosa) y el hongo (Agaricus arvensis y A. campestris). En general, se tenía miedo a consumir las setas y hasta los años 90 del pasado siglo no se ha puesto de moda su aprovechamiento, incorporando a la cesta otras especies (Boletus edulis, B. pinophilus, Lactarius deliciosus, Lepista nuda o Pleurotus eryngii), antes conocidas solo por unos pocos eruditos locales.

\section{Grasas alimentarias:}

Se han recogido 5 registros de uso, correspondientes a 2 taxones de 2 familias botánicas diferentes, 1 taxón de obtención silvestre y 1 cultivado, representando un 0,17\% del total de registros de uso para la categoría Alimentación humana. 
TABLA 21: Relación de especies empleadas en la subcategoría Grasas alimentarias, ordenadas alfabéticamente por familia, indicando número de registros de uso (RU), parte usada y empleo.

\begin{tabular}{llccc}
\hline Familia & $\begin{array}{l}\text { Nombre cientifico } \\
\text { Nombre vulgar }\end{array}$ & RU & Parte usada & Empleo \\
\hline Linaceae & $\begin{array}{l}\text { Linum usitatissimum } \\
\text { Lino }\end{array}$ & 1 & Semilla & Aceite cocinar \\
Fagaceae & $\begin{array}{l}\text { Fagus sylvatica } \\
\text { Haya }\end{array}$ & 4 & Semilla & Aceite cocinar \\
\hline
\end{tabular}

La manteca procedente del cerdo y de la oveja fue empleada de forma habitual en el pasado, como ingrediente de ciertas recetas y como de elemento graso para freir alimentos, sustituido de forma gradual por aceites vegetales comerciales.

Otra forma de obtener aceite de uso culinario fue a partir de las semillas de lino (Linum usitatissimum) y de las de haya (Fagus sylvatica). En la comarca se han mencionado dos molinos denominados "de oilo" ya desaparecidos, en Lores y en Fresno del Río, donde se llevaban las semillas a moler para extraer pequeñas cantidades de aceite.

\section{Bebidas alcohólicas:}

Se han recogido 90 registros de uso, correspondientes a 14 taxones de 6 familias botánicas diferentes, 9 taxones de obtención silvestre y 5 cultivados, representando un 3,01\% del total de registros de uso para la categoría Alimentación humana.

TABLA 22: Relación de taxones empleados en la subcategoría Bebidas alcohólicas, ordenados alfabéticamente por familia, indicando número de registros de uso (RU), parte usada y empleo.

\begin{tabular}{|c|c|c|c|c|}
\hline Familia & $\begin{array}{l}\text { Nombre científico } \\
\text { Nombre vulgar }\end{array}$ & RU & Parte usada & Empleo \\
\hline Adoxaceae & $\begin{array}{l}\text { Sambucus nigra } \\
\text { Saúco, saúgo, sabúgo, taco }\end{array}$ & 2 & Fruto & Licor \\
\hline Compositae & $\begin{array}{l}\text { Chamaemelum nobile } \\
\text { Manzanilla, manzanilla campera }\end{array}$ & 2 & Capítulo & Licor \\
\hline Ericaceae & $\begin{array}{l}\text { Vaccinium myrtillus } \\
\text { Arráspano, ráspano, arándano }\end{array}$ & 2 & Fruto & Licor \\
\hline Fagaceae & $\begin{array}{l}\text { Quercus petraea } \\
\text { Q. pyrenaica } \\
\text { Q. robur } \\
\text { Roble, cajigo, matorro }\end{array}$ & 2 & Fruto seco & Licor \\
\hline Juglandaceae & $\begin{array}{l}\text { Juglans regia } \\
\text { Nogal }\end{array}$ & 1 & Semilla & Licor \\
\hline \multirow[t]{7}{*}{ Rosaceae } & $\begin{array}{l}\text { Crataegus monogyna } \\
\text { Espino, espino albar, majueto }\end{array}$ & 2 & Fruto & Licor \\
\hline & $\begin{array}{l}\text { Malus sylvestris } \\
\text { Maíllo, maello, amaello }\end{array}$ & 13 & Fruto & Licor \\
\hline & $\begin{array}{l}\text { Prunus avium } \\
\text { Cerezo }\end{array}$ & 2 & Fruto & Licor \\
\hline & $\begin{array}{l}\text { Prunus cerasus } \\
\text { Guindal }\end{array}$ & 10 & Fruto & Licor \\
\hline & $\begin{array}{l}\text { Prunus domestica } \\
\text { Ciruelo, mijuelo, pruno }\end{array}$ & 1 & Fruto & Licor \\
\hline & $\begin{array}{l}\text { Prunus domestica subsp. insitia } \\
\text { Andrino real, andriniego }\end{array}$ & 1 & Fruto & Licor \\
\hline & $\begin{array}{l}\text { Prunus spinosa } \\
\text { Endrino, andrino, espino }\end{array}$ & 45 & Fruto & Licor \\
\hline
\end{tabular}




\begin{tabular}{llcccc}
\hline TABLA 22: (Continuación) Relación de taxones empleados en la subcategoría Bebidas alcohólicas, ordenados alfabéticamente \\
por familia, indicando número de registros de uso (RU), parte usada y empleo.
\end{tabular}

Es tradicional en la comarca la elaboración de bebidas alcohólicas a base de macerados de frutos en orujo o aguardiente, a los que en ocasiones se les suele añadir unos capítulos de manzanilla (Chamaemelum nobile), unos granos de café o una rama de canela para mejorar el sabor. Al cabo de unos dos o tres meses se puede colar para dejar el líquido resultante limpio de restos vegetales, o se pueden conservar los frutos en el líquido.

Predomina el aprovechamiento de frutas, con las endrinas (Prunus spinosa) se elabora la conocida bebida denominada pacharán, también ampliamente referenciada por toda la geografía de la Península Ibérica: en la provincia de Córdoba (Casana, 1993), de Jaén (Ortuño, 2003), de Toledo (Criado et al., 2008), de La Coruña (Latorre, 2008) y de Navarra (Akerreta, 2009).

Otras especies útiles para elaboración de licores son maíllos (Malus sylvestris), morales (Rubus ulmifolius) o rosales (Rosa spp.), sus frutos se maceran junto con aguardiente o anís, y en todos estos casos continua vigente su uso. Los licores de guindas (Prunus cerasus) y de cerezas (Prunus avium) tenían además propiedades medicinales digestivas y su elaboración estaba ligado principalmente a este uso. En la actualidad se preparan licores variados de todo tipo, con bellotas de roble (Quercus spp.), con majuetas del espino albar (Crataegus monogyna), con frutos de saúco (Sambucus nigra), con nueces (Juglans regia), e incluso se ha citado la utilización de ciertas hierbas que no se han podido identificar.

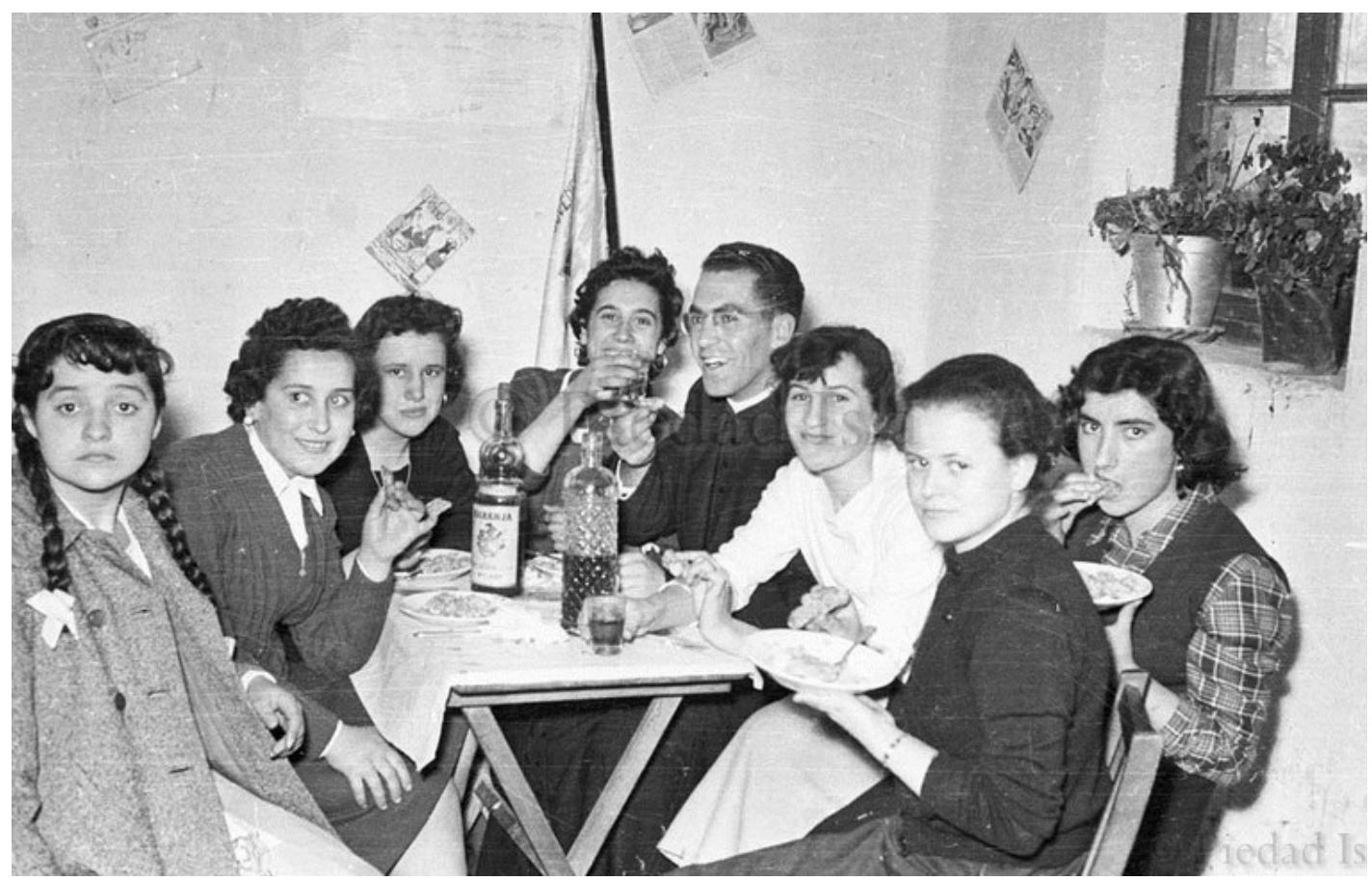

FIGURA 26: Reunión en torno al orujo, Cervera de Pisuerga (1969). Foto: Piedad Isla. 


\section{Bebidas no alcohólicas:}

Se han recogido 66 registros de uso, correspondientes a 12 taxones de 5 familias botánicas diferentes, 9 taxones de obtención silvestre, 2 cultivados y 1 comprado, representando un $2,21 \%$ del total de registros de uso para la categoría Alimentación humana.

TABLA 23: Relación de especies empleadas en la subcategoría Bebidas no alcohólicas, ordenadas alfabéticamente por familia, indicando número de registros de uso (RU), parte usada y empleo.

\begin{tabular}{|c|c|c|c|c|}
\hline Familia & $\begin{array}{l}\text { Nombre científico } \\
\text { Nombre vulgar }\end{array}$ & RU & Parte usada & Empleo \\
\hline \multirow[t]{5}{*}{ Compositae } & $\begin{array}{l}\text { Achillea millefolium } \\
\text { Milenrama, birlenda, balsamina }\end{array}$ & 1 & Parte aérea & Infusión \\
\hline & $\begin{array}{l}\text { Bidens aurea } \\
\text { Té de huerta }\end{array}$ & 1 & Hojas & Infusión \\
\hline & $\begin{array}{l}\text { Chamaemelum nobile } \\
\text { Manzanilla, manzanilla campera }\end{array}$ & 7 & Sumidad floral & Infusión \\
\hline & $\begin{array}{l}\text { Helichrysum stoechas } \\
\text { Manzanilla, manzanilla de peña }\end{array}$ & 9 & Parte aérea & Infusión \\
\hline & $\begin{array}{l}\text { Taraxacum campylodes } \\
\text { Achicoria, diente de león }\end{array}$ & 1 & Capítulo & Bebida dulce \\
\hline Fagaceae & $\begin{array}{l}\text { Fagus sylvatica } \\
\text { Haya }\end{array}$ & 2 & Semilla tostada & Café \\
\hline \multirow[t]{4}{*}{ Lamiaceae } & $\begin{array}{l}\text { Melittis melissophyllum } \\
\text { Melisa }\end{array}$ & 1 & Parte aérea & Infusión \\
\hline & $\begin{array}{l}\text { Mentha x piperita } \\
\text { Hierbabuena, menta }\end{array}$ & 1 & Parte aérea & Infusión \\
\hline & $\begin{array}{l}\text { Mentha pulegium } \\
\text { Té de menta, menta poleo, poleo }\end{array}$ & 6 & Parte aérea & Infusión \\
\hline & $\begin{array}{l}\text { Sideritis hyssopifolia } \\
\text { Té, té de lastra, té de peña }\end{array}$ & 25 & Parte aérea & Infusión \\
\hline Rosaceae & $\begin{array}{l}\text { Malus sylvestris } \\
\text { Maíllo, maello, amaello }\end{array}$ & 4 & Fruto & Bebida dulce \\
\hline Rubiaceae & $\begin{array}{l}\text { Coffea arabica } \\
\text { Café }\end{array}$ & 8 & Semilla & Café \\
\hline
\end{tabular}

Incluidas aquellas especies empleadas en infusiones de tipo alimentario, no consumidas por sus propiedades medicinales, en bebidas refrescantes o dulces y sustitutos del café.

En la zona resulta habitual tomar alguna bebida en forma de tisana después de las comidas por simple deleite, distinguiéndose con 25 registros la infusión de té de roca (Sideritis hyssopyfolia), seguida de las infusiones: de manzanilla de lastra (Helichrysum stoechas), de manzanilla (Chamaemelum nobile), y de té de menta (Mentha pulegium), con 9, 7 y 6 registros, respectivamente. La infusión de té de menta también es apreciada como bebida no alcohólica en: la provincia de Córdoba (Galán, 1993), en la de Jaén (Guzmán, 1997), en las Sierras de Cazorla, Segura y las Vilas (Fernández Ocaña, 2000), en el Montseny (Bonet, 2001), en L'Alt Empordà (Parada, 2008), en los Arribes del Duero (González et al., 2011a) y en la Sierra de Avila (Díaz Fernández \& del Monte, 2012).

Otro tipo de bebidas documentadas en la comarca son las de tipo dulce, elaboradas mezclando maíllas (Malus sylvestris) o capítulos de achicorias (Taraxacum campylodes) con azúcar.

En cuanto a los sustitutos del café se ha referenciado el uso del fruto tostado y molido del haya (Fagus sylvatica) como un sucedáneo del café, empleo no referenciado en la bibliografía consultada. 


\section{Condimentos y conservantes:}

Se han recogido 179 registros de uso, correspondientes a 15 taxones de 6 familias botánicas diferentes, 6 taxones de obtención silvestre, 7 cultivados y 2 comprados, representando un $5,99 \%$ del total de registros de uso para la categoría Alimentación humana.

TABLA 24: Relación de especies empleadas en la subcategoría Condimentos y conservantes, ordenadas alfabéticamente por familia, indicando número de registros de uso (RU), parte usada y empleo.

\begin{tabular}{|c|c|c|c|c|}
\hline Familia & $\begin{array}{l}\text { Nombre científico } \\
\text { Nombre vulgar }\end{array}$ & RU & Parte usada & Empleo \\
\hline Amaryllidaceae & $\begin{array}{l}\text { Allium sativum } \\
\text { Ajo }\end{array}$ & 9 & Bulbo & $\begin{array}{l}\text { Embutidos, guisos, } \\
\text { sopas }\end{array}$ \\
\hline \multirow[t]{2}{*}{ Apiaceae } & $\begin{array}{l}\text { Petroselinum crispum } \\
\text { Perejil }\end{array}$ & 22 & Hojas & Guisos \\
\hline & $\begin{array}{l}\text { Scandix australis } \\
\text { Anís, anís de lastra }\end{array}$ & 2 & Parte aérea & Guisos, sopas \\
\hline \multirow[t]{7}{*}{ Lamiaceae } & $\begin{array}{l}\text { Mentha aquatica } \\
\text { Hierbabuena, menta }\end{array}$ & 3 & Hojas & Carnes, guisos, postres \\
\hline & $\begin{array}{l}\text { Menta x piperita } \\
\text { Hierbabuena, menta }\end{array}$ & 8 & Hojas & Guisos, postres \\
\hline & $\begin{array}{l}\text { Origanum vulgare } \\
\text { Orégano }\end{array}$ & 79 & Sumidad florida & Embutidos, guisos \\
\hline & $\begin{array}{l}\text { Rosmarinus officinalis } \\
\text { Romero }\end{array}$ & 1 & Hojas & Asados, guisos \\
\hline & $\begin{array}{l}\text { Thymus mastichina } \\
\text { Tomillo, mejorana }\end{array}$ & 5 & Sumidad florida & Asados, guisos \\
\hline & $\begin{array}{l}\text { Thymus praecox } \\
\text { Tomillo, hierba de la sabina, té }\end{array}$ & 3 & Parte aérea & Asados, guisos \\
\hline & $\begin{array}{l}\text { Thymus zygis } \\
\text { Tomillo, cepico }\end{array}$ & 21 & Parte aérea & Asados, guisos \\
\hline \multirow[t]{2}{*}{ Lauraceae } & $\begin{array}{l}\text { Cinnamomum verum } \\
\text { Canela }\end{array}$ & 3 & Corteza & Licores, postres \\
\hline & $\begin{array}{l}\text { Laurus nobilis } \\
\text { Laurel }\end{array}$ & 12 & Hojas & Guisos \\
\hline \multirow[t]{2}{*}{ Rubiaceae } & $\begin{array}{l}\text { Galium verum } \\
\text { Hierba del cuajo, cuajaleche }\end{array}$ & 3 & Parte aérea & Cuajaleche \\
\hline & $\begin{array}{l}\text { Coffea arabica } \\
\text { Café }\end{array}$ & 2 & Semilla & Licores \\
\hline Solanaceae & $\begin{array}{l}\text { Capsicum annuum } \\
\text { Pimiento }\end{array}$ & 6 & Fruto molido & Embutidos, guisos \\
\hline
\end{tabular}

La subcategoría condimentos y conservantes agrupa a las especies empleadas para dar sabor, olor y color a las comidas, así como cuajaleches.

Las principales especies cultivadas como condimentos son el perejil (Petroselinum crispum) y la hierbabuena (Mentha x piperita), utilizadas sus hojas en diferentes comidas, también el bulbo del ajo (Allium sativum) empleado para dar sabor a sopas, guisos y embutidos.

Destaca el popular orégano (Origanum vulgare), aunque aparece de forma silvestre en la comarca, se maneja de modo frecuente como cultivo aún vigente, para uso inmediato en diferentes recetas de cocina, y empleado sobre todo de modo tradicional en el adobo de la matanza.

Además del orégano, se citan como condimentos a la menta (Mentha aquatica) utilizada en carnes, guisos y postres, a los tomillos (Thymus praecox y T. zygis) y a la mejorana (Thymus mastichina), todos ellos para condimentar guisos y asados. El empleo de la mejorana como 
condimento también se referencia hasta en siete áreas circundantes al mar Mediterráneo (Hadjichambis et al., 2008).

En la localidad de Matabuena y en San Juan de Redondo, fruto del antiguo legado de los pastores trashumantes, todavía se recuerda el uso de la hierba del cuajo (Galium verum) para cuajar la leche en la elaboración del queso o para conseguir cuajadas con una textura cremosa.

\section{Golosinas y masticatorias:}

Se han recogido 482 registros de uso, correspondientes a 40 taxones de 20 familias botánicas diferentes, 36 taxones de obtención silvestre y 4 cultivados, representando un 16,13\% del total de registros de uso para la categoría Alimentación humana.

TABLA 25: Relación de especies empleadas en la subcategoría Golosinas y masticatorias, ordenadas alfabéticamente por familia, indicando número de registros de uso (RU), parte usada y empleo.

\begin{tabular}{|c|c|c|c|c|}
\hline Familia & $\begin{array}{l}\text { Nombre científico } \\
\text { Nombre vulgar }\end{array}$ & RU & Parte usada & Empleo \\
\hline \multirow[t]{3}{*}{ Amaryllidaceae } & $\begin{array}{l}\text { Allium oleraceum } \\
\text { Ajo, ajo pío }\end{array}$ & 3 & Bulbo & $\begin{array}{l}\text { Fresco } \\
\text { Directo }\end{array}$ \\
\hline & $\begin{array}{l}\text { Allium sphaerocephalon } \\
\text { Ajestrín, ajo, cebolleta }\end{array}$ & 6 & Bulbo & $\begin{array}{l}\text { Fresco } \\
\text { Directo }\end{array}$ \\
\hline & $\begin{array}{l}\text { Narcissus bulbocodium } \\
\text { Lirón, lirona, cantarujil }\end{array}$ & 1 & Néctar & $\begin{array}{l}\text { Fresco } \\
\text { Chupado }\end{array}$ \\
\hline \multirow[t]{4}{*}{ Apiaceae } & $\begin{array}{l}\text { Angelica sylvestris } \\
\text { Angélica, chiflato }\end{array}$ & 1 & Tallo tierno & $\begin{array}{l}\text { Fresco } \\
\text { Directo }\end{array}$ \\
\hline & $\begin{array}{l}\text { Conopodium majus } \\
\text { C. pyrenaeum } \\
\text { Ajuérjano, mantecón }\end{array}$ & 39 & Tubérculo & $\begin{array}{l}\text { Fresco } \\
\text { Directo }\end{array}$ \\
\hline & $\begin{array}{l}\text { Foeniculum vulgare } \\
\text { Hinojo, anís, comino }\end{array}$ & 3 & Hojas & $\begin{array}{c}\text { Fresco } \\
\text { Directo o chupado }\end{array}$ \\
\hline & $\begin{array}{l}\text { Scandix australis } \\
\text { Anís, anís de lastra }\end{array}$ & 32 & Parte aérea & $\begin{array}{c}\text { Fresco } \\
\text { Directo o chupado }\end{array}$ \\
\hline Berberidaceae & $\begin{array}{l}\text { Berberis vulgaris } \\
\text { Hoja maldita, borrachín }\end{array}$ & 2 & Hojas & $\begin{array}{c}\text { Fresco } \\
\text { Directo o chupado }\end{array}$ \\
\hline Boraginaceae & $\begin{array}{l}\text { Glandora diffusa } \\
\text { Hierba } 7 \text { sangrías, } 7 \text { sangrías }\end{array}$ & 1 & Néctar & $\begin{array}{l}\text { Fresco } \\
\text { Chupado }\end{array}$ \\
\hline Caprifoliaceae & $\begin{array}{l}\text { Lonicera periclymenum } \\
\text { Mariselva, madreselva }\end{array}$ & 1 & Néctar & $\begin{array}{l}\text { Fresco } \\
\text { Chupado }\end{array}$ \\
\hline Colchicaceae & $\begin{array}{l}\text { Colchicum montanum } \\
\text { Quitameriendas, cucubilla }\end{array}$ & 10 & $\begin{array}{l}\text { Bulbo } \\
\text { Néctar }\end{array}$ & $\begin{array}{l}\text { Fresco } \\
\text { Directo }\end{array}$ \\
\hline \multirow[t]{3}{*}{ Compositae } & $\begin{array}{l}\text { Scorzonera humilis } \\
\text { Chamorro, camorro, lecherina }\end{array}$ & 7 & Tallo & $\begin{array}{l}\text { Fresco } \\
\text { Directo }\end{array}$ \\
\hline & $\begin{array}{l}\text { Tragopogon castellanus } \\
\text { Cantarujil }\end{array}$ & 1 & Tallo & $\begin{array}{l}\text { Fresco } \\
\text { Directo }\end{array}$ \\
\hline & $\begin{array}{l}\text { Tragopogon dubius } \\
\text { T. pratensis } \\
\text { Lecherina, lechuga, borraja }\end{array}$ & 74 & Tallo & $\begin{array}{l}\text { Fresco } \\
\text { Directo }\end{array}$ \\
\hline Fagaceae & $\begin{array}{l}\text { Quercus petraea } \\
\text { Q. pyrenaica } \\
\text { Q. robur } \\
\text { Roble, cajigo, matorro }\end{array}$ & 1 & Savia & Bebida \\
\hline Iridaceae & $\begin{array}{l}\text { Romulea bulbocodium } \\
\text { Cucubilla, ceringueña, amacuca }\end{array}$ & 14 & Bulbo & $\begin{array}{l}\text { Fresco } \\
\text { Directo }\end{array}$ \\
\hline
\end{tabular}




\begin{tabular}{|c|c|c|c|c|}
\hline Familia & $\begin{array}{l}\text { Nombre científico } \\
\text { Nombre vulgar }\end{array}$ & RU & Parte usada & Empleo \\
\hline \multirow[t]{3}{*}{ Lamiaceae } & $\begin{array}{l}\text { Ballota nigra } \\
\text { Chupona }\end{array}$ & 1 & Néctar & $\begin{array}{l}\text { Fresco } \\
\text { Chupado }\end{array}$ \\
\hline & $\begin{array}{l}\text { Lamium album } \\
\text { Ortiga blanca, chupón }\end{array}$ & 1 & Néctar & $\begin{array}{l}\text { Fresco } \\
\text { Chupado }\end{array}$ \\
\hline & $\begin{array}{l}\text { Prunella grandiflora } \\
\text { P. vulgaris } \\
\text { Chupa, chupete de grillo }\end{array}$ & 11 & Néctar & $\begin{array}{l}\text { Fresco } \\
\text { Chupado }\end{array}$ \\
\hline \multirow[t]{5}{*}{ Leguminosae } & Anthyllis vulneraria & 1 & Néctar & $\begin{array}{l}\text { Fresco } \\
\text { Chupado }\end{array}$ \\
\hline & $\begin{array}{l}\text { Lathyrus tuberosus } \\
\text { Lonceja, castaña, pilonga }\end{array}$ & 13 & Tubérculo & $\begin{array}{l}\text { Fresco } \\
\text { Directo }\end{array}$ \\
\hline & $\begin{array}{l}\text { Robinia pseudoacacia } \\
\text { Acacia }\end{array}$ & 3 & Inflorescencia & $\begin{array}{l}\text { Fresco } \\
\text { Directo }\end{array}$ \\
\hline & $\begin{array}{l}\text { Trifolium alpinum } \\
\text { Regaliz }\end{array}$ & 38 & Raíz & $\begin{array}{c}\text { Seca } \\
\text { Chupado }\end{array}$ \\
\hline & $\begin{array}{l}\text { Trifolium pratense } \\
T \text {. repens } \\
\text { Trébol, chupa, chupón }\end{array}$ & 7 & Néctar & $\begin{array}{l}\text { Fresco } \\
\text { Chupado }\end{array}$ \\
\hline Liliaceae & $\begin{array}{l}\text { Fritillaria lusitanica } \\
\text { F. pyrenaica } \\
\text { Calderón, campanilla, cencerrón }\end{array}$ & 10 & Flor & $\begin{array}{l}\text { Fresco } \\
\text { Directo }\end{array}$ \\
\hline \multirow[t]{2}{*}{ Malvaceae } & $\begin{array}{l}\text { Malva moschata } \\
\text { Malva }\end{array}$ & 1 & $\begin{array}{l}\text { Fruto } \\
\text { inmaduro }\end{array}$ & $\begin{array}{l}\text { Fresco } \\
\text { Directo }\end{array}$ \\
\hline & $\begin{array}{l}\text { Malva sylvestris } \\
\text { Malva, flor de malva }\end{array}$ & 18 & $\begin{array}{l}\text { Fruto } \\
\text { inmaduro }\end{array}$ & $\begin{array}{l}\text { Fresco } \\
\text { Directo }\end{array}$ \\
\hline \multirow[t]{2}{*}{ Orobanchaceae } & $\begin{array}{l}\text { Pedicularis comosa } \\
\text { P. sylvatica } \\
\text { Chupa, chupón, chupete }\end{array}$ & 15 & Néctar & Fresco \\
\hline & $\begin{array}{l}\text { Rhinanthus minor } \\
\text { Cencerrada, encantadera }\end{array}$ & 1 & Néctar & $\begin{array}{l}\text { Fresco } \\
\text { Chupado }\end{array}$ \\
\hline Poaceae & $\begin{array}{l}\text { Triticum aestivum } \\
\text { Trigo, mesino, tremesino }\end{array}$ & 2 & Grano verde & $\begin{array}{l}\text { Chicle } \\
\text { Mascado }\end{array}$ \\
\hline \multirow[t]{2}{*}{ Polygonaceae } & $\begin{array}{l}\text { Fallopia baldschuanica } \\
\text { Enredadera }\end{array}$ & 2 & Tallo joven & $\begin{array}{l}\text { Fresco } \\
\text { Directo }\end{array}$ \\
\hline & $\begin{array}{l}\text { Rumex acetosa } \\
\text { Tallos, acera, acedera, acerón }\end{array}$ & 93 & Tallo & $\begin{array}{l}\text { Fresco } \\
\text { Directo }\end{array}$ \\
\hline Primulaceae & $\begin{array}{l}\text { Primula veris } \\
\text { Cuquillo, chupa, bragas de cuco }\end{array}$ & 14 & Tallo & $\begin{array}{l}\text { Fresco } \\
\text { Directo }\end{array}$ \\
\hline Ranunculaceae & $\begin{array}{l}\text { Helleborus viridis } \\
\text { Hierba de las culebras }\end{array}$ & 1 & Semilla & $\begin{array}{l}\text { Fresco } \\
\text { Directo }\end{array}$ \\
\hline \multirow[t]{5}{*}{ Rosaceae } & $\begin{array}{l}\text { Crataegus monogyna } \\
\text { Espino, espino albar, majueto }\end{array}$ & 2 & Tallo joven & $\begin{array}{l}\text { Fresco } \\
\text { Directo }\end{array}$ \\
\hline & $\begin{array}{l}\text { Prunus avium } \\
\text { Cerezo }\end{array}$ & 1 & Secrección & $\begin{array}{l}\text { Fresco } \\
\text { Chupado }\end{array}$ \\
\hline & $\begin{array}{l}\text { Prunus spinosa } \\
\text { Endrino, andrino, espino }\end{array}$ & 3 & Tallo joven & $\begin{array}{l}\text { Fresco } \\
\text { Directo }\end{array}$ \\
\hline & $\begin{array}{l}\text { Rosa spp. } \\
\text { Zarza, espino, rosal, calambrojo }\end{array}$ & 26 & Tallo joven & $\begin{array}{l}\text { Fresco } \\
\text { Directo }\end{array}$ \\
\hline & $\begin{array}{l}\text { Rubus ulmifolius } \\
\text { Zarza, moral, espino }\end{array}$ & 20 & Tallo joven & $\begin{array}{l}\text { Fresco } \\
\text { Directo }\end{array}$ \\
\hline Vitaceae & $\begin{array}{l}\text { Vitis vinifera } \\
\text { Parra }\end{array}$ & 2 & $\begin{array}{l}\text { Tallo joven } \\
\text { Zarcillo }\end{array}$ & $\begin{array}{l}\text { Fresco } \\
\text { Directo }\end{array}$ \\
\hline
\end{tabular}


Dentro de la subcategoría Golosinas y masticatorias se alude a las especies de consumo directo en el campo de distintas partes vegetales que se chupan o mastican para refrescarse, quitar el hambre, como entretenimiento o por su sabor agradable.

Existe un importante grupo de especies silvestres comestibles que no tienen uso vigente en la actualidad, pero que en el pasado durante épocas de escasez tuvieron gran relevancia, sobre todo entre los más pequeños que buscaban con avidez este tipo de suplementos alimenticios en una mezcla de entretenimiento y modo de saciar el hambre.

Era común mascar tallos por su gustosa acidez, por su látex dulce o por su agradable sabor, algunos ejemplos encontramos en lecherinas (Tragopogon dubius y T. pratrensis), cuquillos (Primula veris), tallos (Rumex acetosa), chamorros (Scorzonera humilis), enredaderas (Fallopia baldschuanica) o chiflatos (Angelica sylvestris).

También se comían hojas, de anís (Scandix australis), de hinojo (Foeniculum vulgare) y de hoja maldita (Berberis vulgaris), se chupaban las flores de chupa (Ballota nigra, Lamium maculatum, Pedicularis comosa, P. sylvatica, Prunella grandiflora y P. vulgaris), de quitameriendas (Colchicum montanum), de trébol (Trifolium pratense, T. repens), lirones (Narcissus bulbocodium) o de cencerrada (Rhinanthus minor), se comían los pétalos de calderón (Fritillaria lusitanica, F. pyrenaica), los brotes tiernos de varias especies: Prunus spinosa, Rosa spp., Rubus ulmifolius y Vitis vinifera, conocidos con el nombre de carneros y los frutos inmaduros de la malva (Malva moschata, M. sylvestris).

A pesar del carácter tóxico del mantecón (Helleborus viridis), en la localidad de Arbejal aseguran que los más pequeños comían los frutos inmaduros de esta especie. Este uso como golosina infantil no se describe en la bibliografía consultada.

La raíz del regaliz (Trifolium alpinum) se recolectaba con una pequeña azadilla, se limpiaba la tierra que la rodeaba y se reservaba para chuparla en el momento apetecido ya que posee un sabor muy dulce y gustoso. Este mismo uso se ha registrado en la provincia de Cantabria (Pardo de Santayana, 2004), en la comarca de Sanabria (Blanco \& Díez, 2005) y en el Valle del río Ter (Rigat et al., 2009).

Se consumía también el tubérculo del popular ajuérjano (Conopodium majus, C. pyrenaeum), de la lonceja (Lathyrus tuberosus) y de la cucubilla (Romulea bulbocodium), así como el bulbo del ajo (Allium oleraceum, A. sphaerocephalon), los más jóvenes escarbaban la tierra para extraerlos o rastreaban las tierras recién aradas.

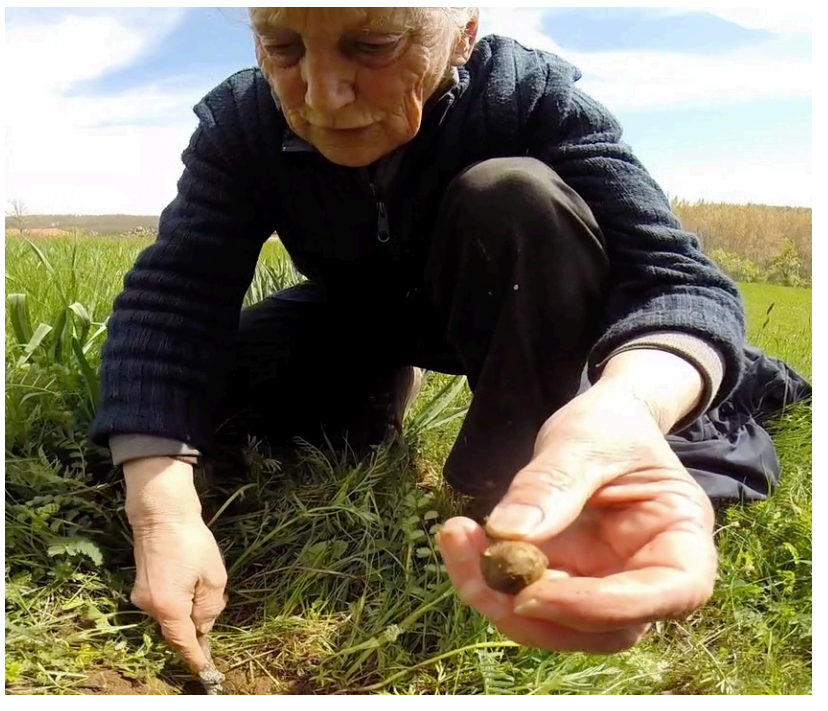

FIgURA 27: Máxima de Verdeña extrayendo ajuérjanos. 


\section{Alimentación ANimal:}

La categoría Alimentación animal agrupa los alimentos que consumen los animales, tanto de forma directa como porque se los provisionan las personas. La categoría contiene también las plantas en cuyas flores las abejas liban el néctar para hacer la miel. En la Montaña Palentina se menciona el uso de 115 taxones correspondientes a 35 familias botánicas, para los que se han recogido un total de 1608 registros de uso (RU). De ellos, 84 taxones son de obtención silvestre y 31 cultivados. Los taxones con mayor número de registros de uso en la categoría "Alimentación animal" se representan en la figura 28.

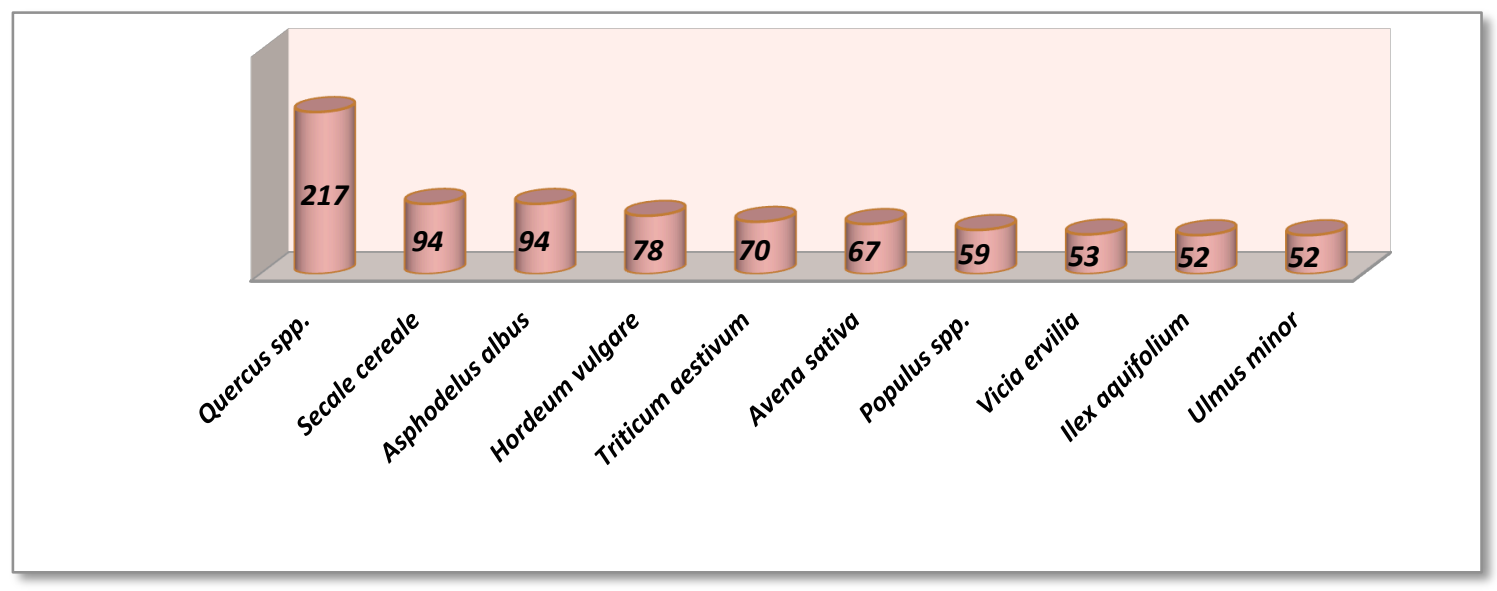

FIGURA 28: Taxones con mayor número de registros de uso en Alimentación animal.

Las familias con mayor representación en cuanto a número de especies fueron: Leguminosae, Compositae y Rosaceae con 22, 14 y 13 especies respectivamente, según se señala en la figura 29.

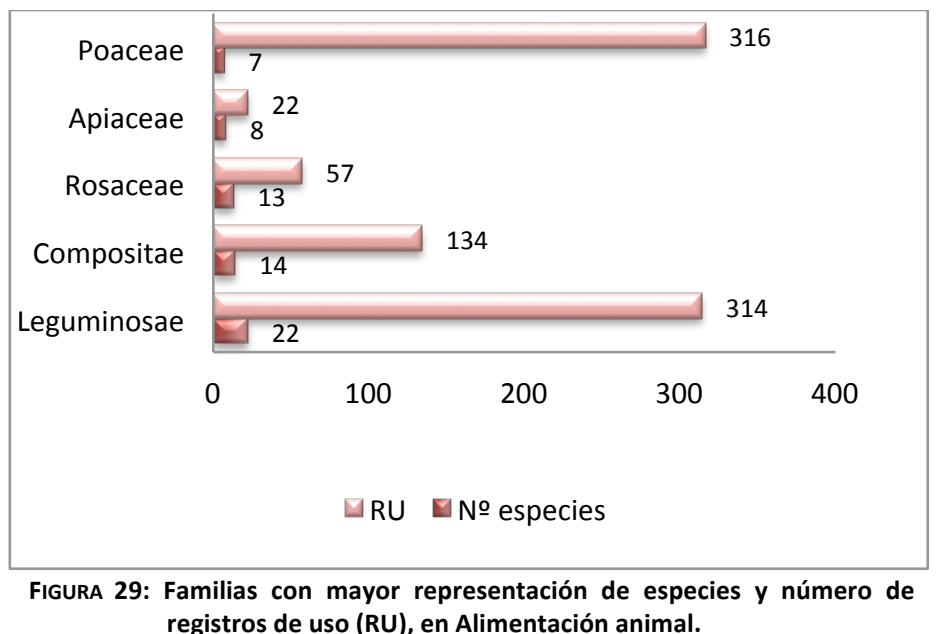

Las familias más destacadas en esta categoría en cuanto a número de registros de uso son Poaceae con 316 registros y Leguminosae con 314 registros, ambas familias están representadas por cereales como: centeno (Secale cereale), cebada (Hordeum vulgare) o avena (Avena sativa), y por legumbres como: yeros (Vicia ervilia), titos (Lathyrus sativus) o arricas (Vicia sativa), empleados como base de la alimentación del ganado. 
Los usos se han agrupado en subcategorías siguiendo los criterios establecidos en el Inventario Español de los Conocimientos Tradicionales relativos a la Biodiversidad (Pardo de Santayana et al., 2014), obteniendo referencias en las 6 subcategorías indicadas en la tabla 26.

\begin{tabular}{l}
$\begin{array}{l}\text { TABLA 26: Subcategorías con representación en la categoría } \\
\text { Alimentación animal. }\end{array}$ \\
\hline Subcategorías : \\
\hline Forraje verde o seco \\
Raíces y tubérculos \\
Frutas y frutos dulces \\
Pienso \\
Pasto \\
Plantas melíferas \\
\hline
\end{tabular}

Los 1608 registros de uso obtenidos, en la categoría Alimentación animal, se reparten en 6 subcategorías tal y como señala la figura 30, resultando que Forraje verde o seco es la que recibió el mayor número de registros con 824 , un $51,24 \%$ del total en esta categoría, seguido de Pienso con 580 , un $36,07 \%$, y Pasto con 74 , un $4,60 \%$.

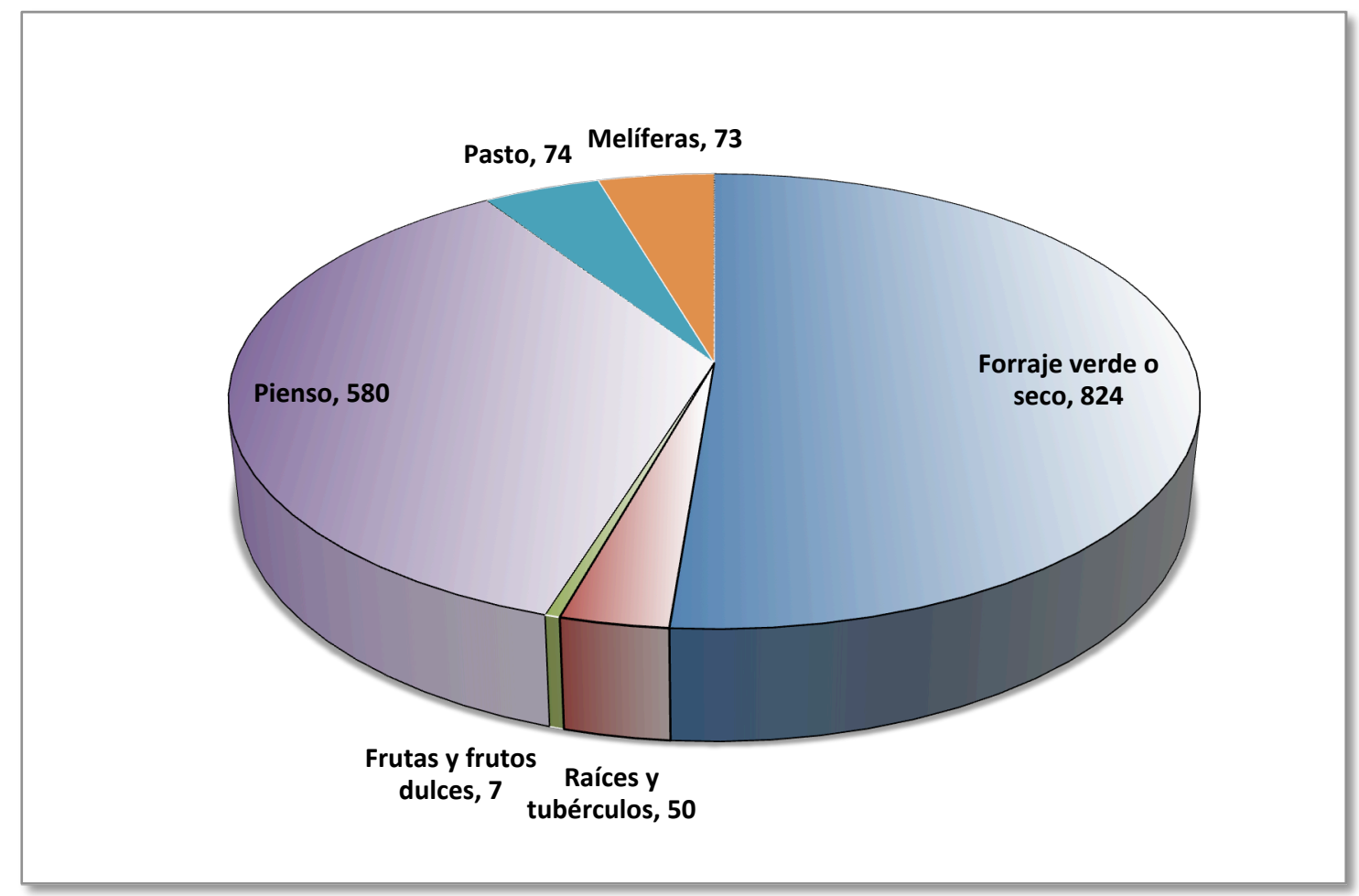

FIGURA 30: Registros de Uso (RU) de las subcategorías representadas en Alimentación animal.

A continuación se presentan los usos agrupados por subcategorías de Alimentación animal, señalando los taxones que han obtenido citas en los mismos, el número de registros de uso de cada taxón, la parte usada y el empleo.

\section{Forraje verde o seco:}

Se han recogido 824 registros de uso, correspondientes a 70 taxones de 22 familias botánicas diferentes, 51 taxones de obtención silvestre y 19 cultivados, representando un $51,24 \%$ del total de registros de uso para la categoría Alimentación animal. 
TABLA 27: Relación de especies empleadas en la subcategoría Forraje verde o seco, ordenadas alfabéticamente por familia, indicando número de registros de uso (RU), parte usada, empleo y ganado ( $\mathrm{a}=\mathrm{avícola;} \mathrm{c}=$ caprino; $c u$ = cunícula; $\mathrm{e}=$ equino; $\mathrm{o}=$ ovino; $\mathrm{p}=$ porcino; $\mathrm{v}$ = vacuno).

\begin{tabular}{|c|c|c|c|c|c|}
\hline Familia & $\begin{array}{l}\text { Nombre científico } \\
\text { Nombre vulgar }\end{array}$ & RU & Parte usada & Empleo & Ganado \\
\hline \multirow[t]{2}{*}{ Amaranthaceae } & $\begin{array}{l}\text { Beta vulgaris var. altissima } \\
\text { Remolacha }\end{array}$ & 8 & $\begin{array}{l}\text { Hojas } \\
\text { Raíz }\end{array}$ & $\begin{array}{l}\text { Cocinado y } \\
\text { fresco }\end{array}$ & $p, v$ \\
\hline & $\begin{array}{l}\text { Chenopodium album } \\
\text { Ramagón, sallo, layo, ceñilgo }\end{array}$ & 1 & Fruto & Fresco & $p$ \\
\hline \multirow[t]{4}{*}{ Apiaceae } & $\begin{array}{l}\text { Anthryscus sylvestris } \\
\text { Canuto }\end{array}$ & 1 & Parte aérea & Fresco & v \\
\hline & $\begin{array}{l}\text { Chaerophyllum aureum } \\
\text { Canuto }\end{array}$ & 1 & Parte aérea & Fresco & v \\
\hline & $\begin{array}{l}\text { Conium maculatum } \\
\text { Budaño, cañiguerra, canuto }\end{array}$ & 6 & Parte aérea & Fresco & $\mathrm{cu}, \mathrm{v}$ \\
\hline & $\begin{array}{l}\text { Heracleum sphondylium } \\
\text { Hoja de patacaballo }\end{array}$ & 2 & Hojas & Fresco & $c u, p$ \\
\hline Aquifoliaceae & $\begin{array}{l}\text { Ilex aquifolium } \\
\text { Acebo, aceba }\end{array}$ & 47 & Hojas & Fresco & $\begin{array}{c}\mathrm{c}, \mathrm{cu}, \mathrm{o}, \\
\mathrm{v}\end{array}$ \\
\hline \multirow[t]{2}{*}{ Betulaceae } & $\begin{array}{l}\text { Betula pubescens } \\
\text { Abedul }\end{array}$ & 3 & Hojas & Fresco & $c, 0, v$ \\
\hline & $\begin{array}{l}\text { Corylus avellana } \\
\text { Avellano }\end{array}$ & 23 & Hojas & $\begin{array}{l}\text { Cocinado } \\
\text { Fresco }\end{array}$ & $\begin{array}{c}\mathrm{p} \\
\mathrm{cu}, \mathrm{o}, \mathrm{v}\end{array}$ \\
\hline Boraginaceae & $\begin{array}{l}\text { Pentaglotis sempervirens } \\
\text { Borraja }\end{array}$ & 1 & Hojas & Cocinado & $p$ \\
\hline \multirow[t]{4}{*}{ Brassicaceae } & $\begin{array}{l}\text { Barbarea intermedia } \\
\text { Naviza }\end{array}$ & 1 & Parte aérea & Fresco & v \\
\hline & $\begin{array}{l}\text { Brassica oleracea var. } \\
\text { acephala } \\
\text { Berza, col }\end{array}$ & 25 & Hojas & $\begin{array}{l}\text { Cocinado } \\
\text { Fresco }\end{array}$ & $\mathrm{p}$ \\
\hline & $\begin{array}{l}\text { Lepidium campestre } \\
\text { Rábano }\end{array}$ & 1 & Parte aérea & Fresco & v \\
\hline & $\begin{array}{l}\text { Sinapis arvensis } \\
\text { Gébene }\end{array}$ & 2 & Hojas & Fresco & $\mathrm{cu}$ \\
\hline \multirow[t]{2}{*}{ Caryophyllaceae } & $\begin{array}{l}\text { Agrostemma githago } \\
\text { Neguilla, neguillón, clavel }\end{array}$ & 1 & Parte aérea & Fresco & v \\
\hline & $\begin{array}{l}\text { Stellaria media } \\
\text { Paulina, pamplina }\end{array}$ & 2 & Parte aérea & Fresco & $p, v$ \\
\hline \multirow[t]{10}{*}{ Compositae } & $\begin{array}{l}\text { Arctium minus } \\
\text { Amargacho, capacho, pegote }\end{array}$ & 1 & Hojas & Cocinado & $p$ \\
\hline & $\begin{array}{l}\text { Carduus crispus } \\
\text { Cardo, cardo negrero }\end{array}$ & 2 & Parte aérea & Fresco & v \\
\hline & $\begin{array}{l}\text { Centaurea scabiosa } \\
\text { Amapera, humarra }\end{array}$ & 6 & Parte aérea & Fresco & $p, v$ \\
\hline & $\begin{array}{l}\text { Cirsium arvense } \\
\text { C. vulgare } \\
\text { Cardo, cardo negrero }\end{array}$ & 44 & Parte aérea & $\begin{array}{l}\text { Cocinado } \\
\text { Fresco }\end{array}$ & $\begin{array}{l}p \\
e, v\end{array}$ \\
\hline & $\begin{array}{l}\text { Cyanus segetum } \\
\text { Azulina, clavel, azulejo }\end{array}$ & 1 & Parte aérea & Fresco & $\mathrm{cu}$ \\
\hline & $\begin{array}{l}\text { Lactuca sativa } \\
\text { Lechuga }\end{array}$ & 1 & Hojas & Fresco & $a, p$ \\
\hline & $\begin{array}{l}\text { Lactuca serriola } \\
\text { Lecherín, cardo lechero }\end{array}$ & 6 & Hojas & Fresco & $a, c u, p$ \\
\hline & $\begin{array}{l}\text { Lactuca virosa } \\
\text { Achicoria }\end{array}$ & 1 & Hojas & Fresco & $p$ \\
\hline & $\begin{array}{l}\text { Sonchus asper } \\
\text { Cardo lecherín }\end{array}$ & 6 & Parte aérea & Fresco & $c u, p$ \\
\hline & $\begin{array}{l}\text { Sonchus oleraceus } \\
\text { Cardo lecherín, lecherín }\end{array}$ & 34 & Parte aérea & Fresco & $c u, p$ \\
\hline
\end{tabular}




\begin{tabular}{|c|c|c|c|c|c|}
\hline Familia & $\begin{array}{l}\text { Nombre científico } \\
\text { Nombre vulgar }\end{array}$ & RU & Parte usada & Empleo & Ganado \\
\hline & $\begin{array}{l}\text { Taraxacum campylodes } \\
\text { Achicoria, diente de león }\end{array}$ & 26 & Hojas & $\begin{array}{l}\text { Cocinado } \\
\text { Fresco }\end{array}$ & $\begin{array}{c}\mathrm{p} \\
\mathrm{cu}, \mathrm{v}\end{array}$ \\
\hline Convolvulaceae & $\begin{array}{l}\text { Convolvulus arvensis } \\
\text { Correyuela, corrigüela }\end{array}$ & 4 & Parte aérea & Fresco & $c u, p, v$ \\
\hline \multirow[t]{2}{*}{ Fagaceae } & $\begin{array}{l}\text { Quercus petraea } \\
\text { Q. pyrenaica } \\
\text { Q. robur } \\
\text { Roble, cajigo, matorro }\end{array}$ & 117 & Hojas & $\begin{array}{l}\text { Cocinado } \\
\text { Fresco }\end{array}$ & $\begin{array}{c}p \\
c, o\end{array}$ \\
\hline & $\begin{array}{l}\text { Quercus rotundifolia } \\
\text { Encina, ancina }\end{array}$ & 2 & Hojas & Fresco & $c, 0$ \\
\hline \multirow[t]{17}{*}{ Leguminosae } & $\begin{array}{l}\text { Cicer arietinum } \\
\text { Garbanzo }\end{array}$ & 5 & Paja & Seca & $0, v$ \\
\hline & $\begin{array}{l}\text { Cytisus oromediterraneus } \\
\text { Escoba hornil, escoba }\end{array}$ & 4 & Hojas & Fresco & $c, 0$ \\
\hline & $\begin{array}{l}\text { Genista florida } \\
\text { Escoba, escoba albar, ramón }\end{array}$ & 11 & Hojas & Fresco y seco & $c, 0$ \\
\hline & $\begin{array}{l}\text { Genista obtusiramea } \\
\text { Escoba cabrera }\end{array}$ & 4 & Hojas & Fresco y seco & c, o \\
\hline & $\begin{array}{l}\text { Genista tridentata } \\
\text { Carquesa }\end{array}$ & 1 & Hojas & Fresco y seco & $c, 0$ \\
\hline & $\begin{array}{l}\text { Lathyrus cicera } \\
\text { Titarro }\end{array}$ & 2 & Paja & Seco & $o, v$ \\
\hline & $\begin{array}{l}\text { Lathyrus sativus } \\
\text { Tito, tito esquinado, muela }\end{array}$ & 8 & Paja & Seco & $0, v$ \\
\hline & $\begin{array}{l}\text { Medicago sativa } \\
\text { Mielga, alfalfa }\end{array}$ & 19 & Parte aérea & Fresco & $a, c u, v$ \\
\hline & $\begin{array}{l}\text { Onobrychis viciifolia } \\
\text { Esparceta }\end{array}$ & 4 & Parte aérea & Fresco & $p, v$ \\
\hline & $\begin{array}{l}\text { Ononis spinosa } \\
\text { Gatuña }\end{array}$ & 2 & Parte aérea & Fresco & v \\
\hline & $\begin{array}{l}\text { Pisum sativum } \\
\text { Arveja, guisante, morita }\end{array}$ & 10 & Paja & Seco & $0, v$ \\
\hline & $\begin{array}{l}\text { Trifolium pratense } \\
\text { Trébol, chupa, hierba nube }\end{array}$ & 1 & Parte aérea & Fresco & $\mathrm{cu}$ \\
\hline & $\begin{array}{l}\text { Trigonella foenum-graecum } \\
\text { Alholva }\end{array}$ & 2 & Parte aérea & Fresco & $o, v$ \\
\hline & $\begin{array}{l}\text { Vicia articulata } \\
\text { Algarroba }\end{array}$ & 1 & Paja & Seco & v \\
\hline & $\begin{array}{l}\text { Vicia cracca/V. pannonica } \\
\text { Arvejana }\end{array}$ & 8 & Parte aérea & Fresco & $\mathrm{cu}, \mathrm{v}$ \\
\hline & $\begin{array}{l}\text { Vicia ervilia } \\
\text { Yero }\end{array}$ & 6 & Paja & Seco & $\mathrm{o}, \mathrm{v}$ \\
\hline & $\begin{array}{l}\text { Vicia sativa } \\
\text { Arrica, franco, rica, veza }\end{array}$ & 6 & Paja & Seco & $0, v$ \\
\hline Malvaceae & $\begin{array}{l}\text { Malva sylvestris } \\
\text { Malva, flor de malva }\end{array}$ & 1 & Parte aérea & Fresco & $\mathrm{cu}$ \\
\hline Oleaceae & $\begin{array}{l}\text { Fraxinus excelsior } \\
\text { Fresno }\end{array}$ & 33 & Hojas & Fresco & $\begin{array}{c}\mathrm{c}, \mathrm{cu}, \mathrm{o}, \\
\mathrm{v}\end{array}$ \\
\hline Papaveraceae & $\begin{array}{l}\text { Papaver rhoeas } \\
\text { Amapola, pirigallo }\end{array}$ & 9 & Parte aérea & Fresco & $\mathrm{cu}, \mathrm{v}$ \\
\hline Plantaginaceae & $\begin{array}{l}\text { Plantago major } \\
\text { Hoja mantequera }\end{array}$ & 1 & Parte aérea & Fresco & $\mathrm{cu}$ \\
\hline Poaceae & $\begin{array}{l}\text { Avena sativa } \\
\text { Avena }\end{array}$ & 5 & Paja & Seca & $e, v$ \\
\hline
\end{tabular}




\begin{tabular}{|c|c|c|c|c|c|}
\hline Familia & $\begin{array}{l}\text { Nombre científico } \\
\text { Nombre vulgar }\end{array}$ & RU & Parte usada & Empleo & Ganado \\
\hline \multirow[t]{5}{*}{ Poaceae } & $\begin{array}{l}\text { Holcus mollis } \\
\text { Yerbancho }\end{array}$ & 1 & Parte aérea & Fresco & $\mathrm{cu}$ \\
\hline & $\begin{array}{l}\text { Hordeum vulgare } \\
\text { Cebada, ladilla, comuña }\end{array}$ & 6 & Paja & Seco & $0, v$ \\
\hline & $\begin{array}{l}\text { Lolium perenne } \\
\text { Vallico, valluco, avallico }\end{array}$ & 3 & Parte aérea & Fresco & $p, v$ \\
\hline & $\begin{array}{l}\text { Secale cereale } \\
\text { Centeno }\end{array}$ & 9 & Paja & Seco & $0, v$ \\
\hline & $\begin{array}{l}\text { Triticum aestivum } \\
\text { Trigo, mesino, tremesino }\end{array}$ & 7 & Paja & Seco & $c, e, 0, v$ \\
\hline Polygonaceae & $\begin{array}{l}\text { Rumex crispus } \\
\text { Amargaza, acerón, ramagón }\end{array}$ & 8 & Hojas & Fresco & $\begin{array}{c}a, c u, p, \\
v\end{array}$ \\
\hline \multirow[t]{5}{*}{ Rosaceae } & $\begin{array}{l}\text { Crataegus monogyna } \\
\text { Espino, espino albar, majueto }\end{array}$ & 1 & Hojas & Fresco & $\mathrm{cu}$ \\
\hline & $\begin{array}{l}\text { Prunus avium } \\
\text { Cerezo }\end{array}$ & 1 & Hojas & Fresco & $p$ \\
\hline & $\begin{array}{l}\text { Prunus domestica } \\
\text { Ciruelo, mijuelo, pruno }\end{array}$ & 1 & Hojas & Fresco & $p$ \\
\hline & $\begin{array}{l}\text { Sorbus aria } \\
\text { Mostajo, amostajo }\end{array}$ & 16 & Hojas & Fresco & $\mathrm{cu}, \mathrm{O}$ \\
\hline & $\begin{array}{l}\text { Sorbus aucuparia } \\
\text { Amargoso, serbal, drío, drido }\end{array}$ & 1 & Hojas & Fresco & v \\
\hline Salicaceae & $\begin{array}{l}\text { Populus alba } \\
\text { P. nigra } \\
\text { Chopo }\end{array}$ & 59 & Hojas & Fresco & $\begin{array}{c}c, c u, o, \\
p, v\end{array}$ \\
\hline \multirow[t]{2}{*}{ Ulmaceae } & $\begin{array}{l}\text { Ulmus glabra } \\
\text { Olmo monte }\end{array}$ & 1 & Hojas & Cocinado & $p$ \\
\hline & $\begin{array}{l}\text { Ulmus minor } \\
\text { Olmo }\end{array}$ & 52 & Hojas & Fresco & $\begin{array}{c}c, c u, p, \\
o, v\end{array}$ \\
\hline \multirow[t]{2}{*}{ Urticaceae } & $\begin{array}{l}\text { Urtica dioica } \\
\text { Ortiga }\end{array}$ & 43 & Parte aérea & $\begin{array}{l}\text { Cocinado } \\
\text { Fresco }\end{array}$ & $\begin{array}{c}p \\
p, v\end{array}$ \\
\hline & $\begin{array}{l}\text { Urtica urens } \\
\text { Ortiga, ortiga meña }\end{array}$ & 2 & Parte aérea & Fresco & $p, v$ \\
\hline Xanthorrhoeaceae & $\begin{array}{l}\text { Asphodelus albus } \\
\text { Gamón, gamonita }\end{array}$ & 92 & Hojas & $\begin{array}{l}\text { Cocinado } \\
\text { Seco }\end{array}$ & $\begin{array}{c}p \\
c, 0\end{array}$ \\
\hline
\end{tabular}

Se han agrupado en esta subcategoría las especies que se siegan o recolectan y se sirven a los animales verdes, ensiladas o secas, también se incluye el ramón que son las ramas con hojas $u$ hojas que se dan a los animales como forraje, verdes o secas.

En la Montaña Palentina la base de la alimentación animal eran los pastos, que se complementaba con la recolección de recursos silvestres, era costumbre podar al final del verano las hojas tiernas de roble (Quercus petraea, Q. pyrenaica y Q. robur), chopo (Populus alba, P. nigra), acebo (llex aquifolium), olmo (Ulmus minor), fresno (Fraxinus excelsior), avellano (Corylus avellana) o mostajo (Sorbus aria). Lo más común era almacenar la hoja en el pajar junto con la hierba y recurrir a ella a lo largo del duro invierno. También se cortaban varias escobas (Cytisus oromediterraneus, Genista florida y G. obtusiramea) como ramón que se servía en fresco o seco a cabras y ovejas.

Otro recurso alimenticio interesante era la paja de cereal y de leguminosas, entre las primeras destacan la avena (Avena sativa), la cebada (Hordeum vulgare), el centeno (Secale cereale) y el 
trigo (Triticum aestivum), y entre las segundas se distinguen, el yero (Vicia ervilia), la arrica (Vicia sativa), el tito (Lathyrus sativus) y la arveja (Pisum sativum), cuya paja seca servía como complemento alimenticio, fundamentalmente a ovejas y vacas. La paja de leguminosas se conoce con el nombre de paja negra, y aunque es de escasa producción, es muy apreciada por su alto valor proteico.

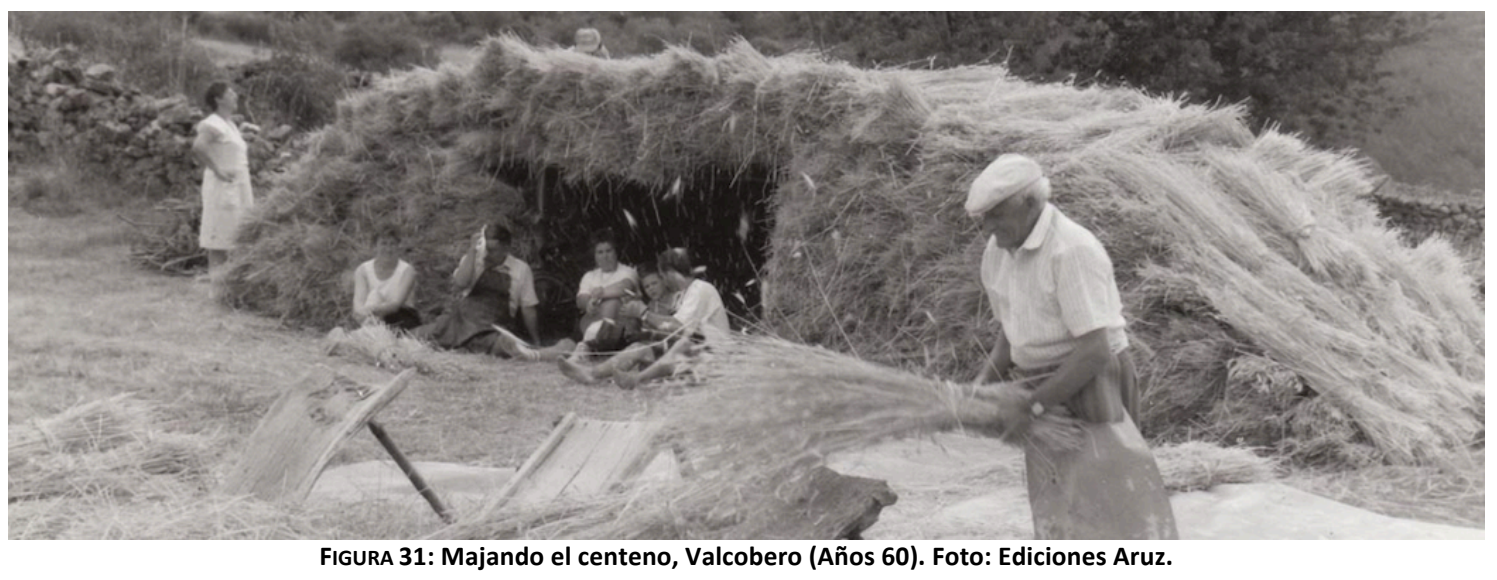

Entre las verduras silvestres administradas como suplemento alimenticio fueron de especial relevancia los gamones (Asphodelus albus), las hojas secas se destinaban para alimento de ovejas y cabras, y las hojas verdes se recolectaban como alimento silvestre para los cerdos. Antes de servirlos se cocían durante un corto periodo de tiempo para que los pudieran digerir mejor, proceso conocido como: amoragar, amoratar, cocer o encallar. El uso de gamones como forraje se documenta ampliamente en toda la Península Ibérica, en el Pirineo Aragonés (Villar et al., 1987), El Caurel (Blanco, 1996), Zamora (Krause et al., 2006), La Coruña (Latorre, 2008), El Aliste (Gallego, 2009), Sierra Norte de Madrid (Aceituno Mata, 2010), Los Arribes del Duero (González et al., 2011b), Ávila (Blanco, 2015) o el Cerrato Palentino (Pascual et al., 2016).

Otras destacadas verduras silvestres fueron las ortigas (Urtica dioica) y los cardos (Cirsium arvense, Lactuca serriola y Sonchus oleraceus), empleadas todas ellas cocidas, sobre todo en la cría del cerdo. También resultaba común alimentar al cerdo con las hojas exteriores y de peor calidad de la berza (Brassica oleracea var. acephala), y en ocasiones se podían destinar a gallinas y vacas.

Muchas especies forrajeras son malas hierbas escardadas de las tierras de cultivo y de los huertos, que se incorporaban como forraje para el ganado, se llenaba un saco con el sallo en verde y se añadía en los comederos de los animales. Las más conocidas eran la arvejana (Vicia cracca, V. pannonica), la amapola (Papaver rhoeas), la amapera (Centaurea scabiosa) y la correyuela (Convolvulus arvensis).

Cierta vegetación ruderal era muy deseada como forraje verde, entre los ejemplos más significativos podemos señalar la mielga (Medicago sativa), la achicoria (Taraxacum campylodes) y la amargaza (Rumex crispus) para conejos, gallinas y vacas, también el budaño (Conium maculatum) para conejos y vacas, y la hoja de patacaballo (Heracleum sphondylium) y el amargacho (Arctium minus) para los cerdos. 


\section{Raíces y tubérculos:}

Se han recogido 50 registros de uso, correspondientes a 3 taxones cultivados de 3 familias botánicas diferentes, representando un $3,11 \%$ del total de registros de uso para la categoría Alimentación animal.

TABLA 28: Relación de especies empleadas en la subcategoría Raíces y tubérculos, ordenadas alfabéticamente por familia, indicando número de registros de uso (RU), parte usada, empleo y ganado (cu = cunícula; $p=$ porcino; $v$ = vacuno).

\begin{tabular}{llcccc}
\hline Familia & $\begin{array}{l}\text { Nombre científico } \\
\text { Nombre vulgar }\end{array}$ & RU & Parte usada & Empleo & Ganado \\
\hline Apiaceae & $\begin{array}{l}\text { Daucus carota } \\
\text { Zanahoria }\end{array}$ & 1 & Raíz & Fresco & cu \\
Brassicaceae & $\begin{array}{l}\text { Brassica napus } \\
\text { Nabo }\end{array}$ & 7 & Raíz & Cocinado & $\mathrm{p}$ \\
Solanaceae & $\begin{array}{l}\text { Solanum tuberosum } \\
\text { Patata }\end{array}$ & 42 & Tubérculo & Cocinado & $\mathrm{p}, \mathrm{v}$ \\
\hline
\end{tabular}

Las patatas (Solanum tuberosum) defectuosas y las más pequeñas, así como las peladuras se incluían en la dieta de los cerdos. Se cocían previamente en un puchero en el que se añadían de forma corriente otras verduras cultivadas o silvestres. En la localidad de Valsurbio se cocían patatas para las vacas, servidas con un poco de harina de centeno, y en Arbejal aseguran que los terneros engordan cuando comen patatas cocidas con harina de cebada.

En algunos pueblos existía la tradición de sembrar nabos (Brassica napus), apreciados para alimentar al cerdo. Este uso también es referenciado en La Calabria (Blanco \& Cuadrado, 2000) y en Piloña (San Miguel, 2004).

Otra raíz empleada en alimentación animal es la zanahoria (Daucus carota), aunque la finalidad del cultivo era la alimentación humana, las más imperfectas en tamaño y forma, o destríos, se apartaban para el sustento de los conejos.

\section{Frutas y frutos dulces:}

Se han recogido 7 registros de uso, correspondientes a 2 taxones de la familia Rosaceae, 1 de obtención silvestre y 1 cultivado, representando un $0,44 \%$ del total de registros de uso para la categoría Alimentación animal.

TABLA 29: Relación de especies empleadas en la subcategoría Frutas y frutos dulces, ordenadas alfabéticamente por familia, indicando número de registros de uso (RU), parte usada, empleo y ganado $(c=$ caprino; $p=$ porcino).

\begin{tabular}{llcccc}
\hline Familia & $\begin{array}{l}\text { Nombre científico } \\
\text { Nombre vulgar }\end{array}$ & RU & Parte usada & Empleo & Ganado \\
\hline Rosaceae & $\begin{array}{l}\text { Malus domestica } \\
\text { Manzano }\end{array}$ & 1 & Fruto & Fresco & $\mathrm{p}$ \\
& $\begin{array}{l}\text { Rosa spp. } \\
\text { Zarza, espino, rosal, calambrojo }\end{array}$ & 6 & Infrutescencia & Fresco & $\mathrm{C}, \mathrm{p}$ \\
\hline
\end{tabular}

Son pocos los frutos recolectados útiles para la alimentación animal, se han citado por un lado las manzanas (Malus domestica) sobremaduradas y defectuosas que se echaban en el pesebre a los cerdos, y por otro, los calambrojos recolectados de la zarza (Rosa spp.) utilizados como 
alimento de engorde para los cerdos y sobre todo para las cabras, asegurando que mejora sustancialmente el sabor de la cecina.

\section{Pienso:}

Se han recogido 580 registros de uso, correspondientes a 16 taxones de 3 familias botánicas diferentes, 2 taxones de obtención silvestre y 14 cultivados, representando un $36,07 \%$ del total de registros de uso para la categoría Alimentación animal.

TABLA 30: Relación de especies empleadas en la subcategoría Pienso, ordenadas alfabéticamente por familia, indicando número de registros de uso ( $\mathrm{RU})$, parte usada, empleo y ganado (a = avícola; $c$ = caprino; $c u$ = cunícula; $\mathrm{e}=$ equino; $\mathrm{o}=$ ovino; $\mathrm{p}=$ porcino; $\mathrm{v}=$ vacuno).

\begin{tabular}{|c|c|c|c|c|c|}
\hline Familia & $\begin{array}{l}\text { Nombre científico } \\
\text { Nombre vulgar }\end{array}$ & RU & $\begin{array}{l}\text { Parte } \\
\text { usada }\end{array}$ & Empleo & Ganado \\
\hline \multirow[t]{4}{*}{ Fagaceae } & Quercus petraea & & & & \\
\hline & Q. pyrenaica & 91 & Fruto & Pienso y seco & $c, o, p, v$ \\
\hline & $\begin{array}{l}\text { Q. robur } \\
\text { Roble, cajigo, matorro }\end{array}$ & ז & (1) & (10 & (2, \\
\hline & $\begin{array}{l}\text { Quercus rotundifolia } \\
\text { Encina, ancina }\end{array}$ & 3 & Fruto & Pienso y seco & $c, o, p, v$ \\
\hline \multirow[t]{12}{*}{ Leguminosae } & Lathyrus cicera & & & Fresco & 0 \\
\hline & Titarro & 14 & semilla & Pienso & $0, v$ \\
\hline & Lathyrus sativus & 32 & Semilla & Pienso & $c, o, p, v$ \\
\hline & Tito, tito esquinado, muela & 32 & senimía & rictiso & 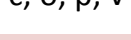 \\
\hline & $\begin{array}{l}\text { Lupinus albus } \\
\text { Chocho }\end{array}$ & 24 & Semilla & Pienso y seco & $0, v$ \\
\hline & Pisum sativum & & & Pienso & $\mathrm{v}$ \\
\hline & Arveja, guisante, morita & 41 & semilla & Seco & $p$ \\
\hline & $\begin{array}{l}\text { Trigonella foenum-graecum } \\
\text { Alholva }\end{array}$ & 5 & Semilla & Seco & $0, v$ \\
\hline & $\begin{array}{l}\text { Vicia articulata } \\
\text { Algarroba }\end{array}$ & 7 & Semilla & Pienso & $\mathrm{v}$ \\
\hline & $\begin{array}{l}\text { Vicia ervilia } \\
\text { Yero }\end{array}$ & 47 & Semilla & Pienso & $v$ \\
\hline & $\begin{array}{l}\text { Vicia faba } \\
\text { Haba }\end{array}$ & 7 & Semilla & Pienso & $v$ \\
\hline & $\begin{array}{l}\text { Vicia sativa } \\
\text { Arrica, franco, rica, veza }\end{array}$ & 24 & Semilla & Pienso & $v$ \\
\hline \multirow[t]{8}{*}{ Poaceae } & Avena sativa & & & & a, cu, e, \\
\hline & Avena & 62 & Fruto & Pienso y seco & $p, v$ \\
\hline & Hordeum vulgare & 72 & Fruto & Pienso y seco & a, cu, o, \\
\hline & Cebada, ladilla, comuña & 12 & ricto & & $p, v$ \\
\hline & $\begin{array}{l}\text { Secale cereale } \\
\text { Centeno }\end{array}$ & 85 & Fruto & Pienso y seco & $\begin{array}{c}a, c, o, p, \\
v\end{array}$ \\
\hline & Triticum aestivum & & & Seco & $\mathrm{a}, \mathrm{cu}$ \\
\hline & Trigo, mesino, tremesino & 63 & Fruto & Pienso & $\mathrm{p}$ \\
\hline & $\begin{array}{l}\text { Zea mays } \\
\text { Maíz }\end{array}$ & 3 & Fruto & Pienso y seco & $a, p, v$ \\
\hline
\end{tabular}

Se incluyen en la subcategoría Pienso, los granos maduros de cereales y leguminosas que se consumen enteros o molidos, así como el salvado de los cereales. También los frutos secos empleados en alimentación animal. 
Los cultivos de cereal en la Montaña Palentina destinados a la alimentación animal fueron el centeno (Secale cereale), la cebada (Hordeum vulgare), el trigo (Triticum aestivum) y la avena (Avena sativa), empleados todos ellos enteros o molidos para complementar la dieta de cabras, cerdos, conejos, gallinas, ovejas y vacas. Entre todos los cultivos cabe destacar la importancia en la zona del centeno por su resistencia a las frías temperaturas.

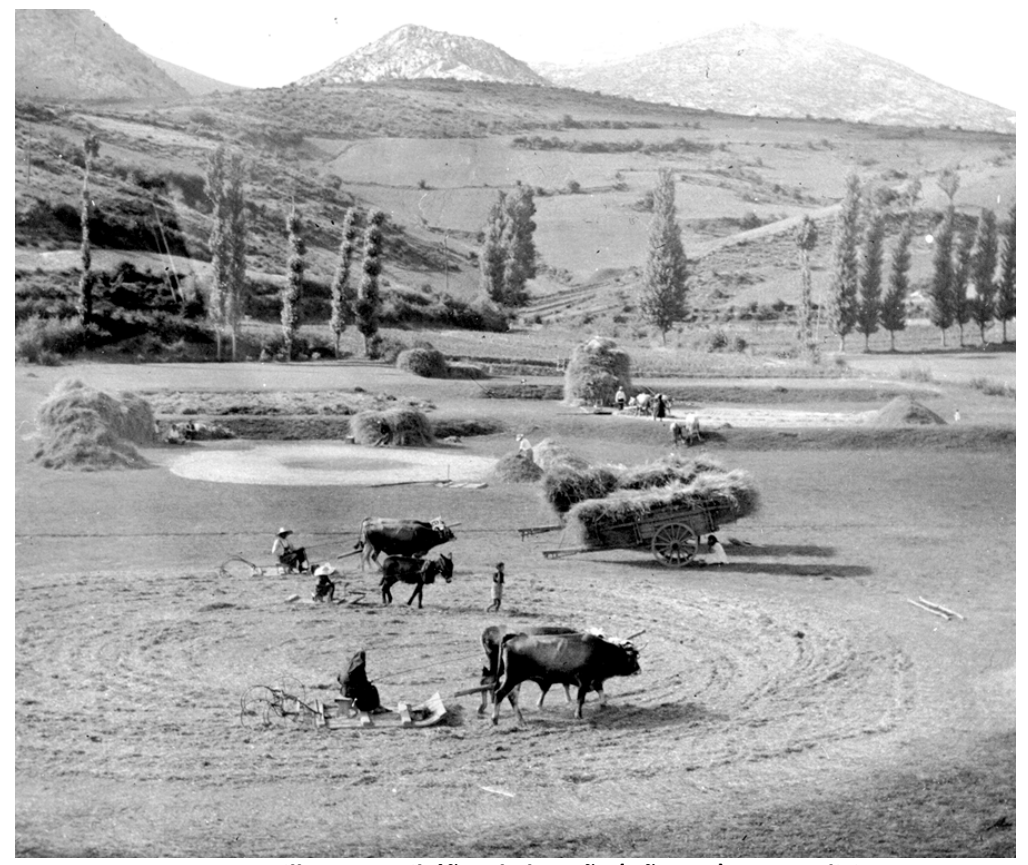

Figura № X: La trilla en Santibáñez de la Peña (Años 60). Foto: Ediciones Aruz.

Otros cultivos muy apreciados por ser una excelente fuente de proteínas para el engorde del ganado eran las leguminosas, los más citados en la zona fueron los yeros (Vicia ervilia) indicados para los terneros más jóvenes, seguidos por arvejas (Pisum sativum), titos (Lathyrus sativus), arricas (Vicia sativa) y chochos (Lupinus albus), y de menor importancia titarro (Lathyrus cicera), algarroba (Vicia articulata) y alholva (Trigonella foenum-graecum), ésta última se fue descartando como cultivo ya que transmitía mal sabor a la leche y a la carne de las vacas. Era habitual sembrar una mezcla de ellas, en ocasiones junto con cereal, mixtura conocida con el nombre de comuña.

Las bellotas de roble (Quercus petraea, Q. pyrenaica y Q. robur) y de encina (Quercus rotundifolia) se han recolectado como complemento en la alimentación del ganado, destinadas a cabras, cerdos, ovejas y vacas. En la localidad de La Lastra incluso manifiestan que su consumo aumentaba la producción de leche de las ovejas y las vacas, aunque su uso más frecuente fue como engorde del cerdo en semanas próximas a la matanza. Se servían de ordinario en crudo, aunque en ocasiones se transformaban en pienso en el molino más cercano. La recogida se realizaba durante el otoño y se aprovechan las bellotas caídas al suelo por sí solas o se varean los árboles con mayor producción. El uso de bellotas para consumo animal se recoge en otras zonas de la Península Ibérica como en Campoo (Pardo de Santayana, 2008), en el Poniente Granadino (Benítez, 2009) o en la provincia de Salamanca (Velasco et al., 2010). 
Pasto:

Se han recogido 74 registros de uso, correspondientes a 35 taxones de obtención silvestre, de 17 familias botánicas diferentes, representando un $4,60 \%$ del total de registros de uso para la categoría Alimentación animal.

TABLA 31: Relación de taxones empleados en la subcategoría Pasto, ordenados alfabéticamente por familia, indicando número de registros de uso $(\mathrm{RU})$, parte usada, empleo y animal $(a=a v e ; b=$ burro; $c=c a b r a ;$ $c i$ = cigüeña; $c o=$ corzo; $e=$ caballo; $j$ = jabalí; $o=$ oveja; os = oso; $p=$ cerdo; $p a=$ pájaro; $v$ = vaca; ve= venado).

\begin{tabular}{|c|c|c|c|c|c|}
\hline Familia & $\begin{array}{l}\text { Nombre científico } \\
\text { Nombre vulgar }\end{array}$ & RU & Parte usada & Empleo & Animal \\
\hline Amaryllidaceae & $\begin{array}{l}\text { Allium sphaerocephalon } \\
\text { Ajestrín, ajo, cebolleta }\end{array}$ & 1 & Parte aérea & Fresco & $v$ \\
\hline \multirow[t]{4}{*}{ Apiaceae } & $\begin{array}{l}\text { Conium maculatum } \\
\text { Budaño, cañiguerra, canuto }\end{array}$ & 6 & Parte aérea & Fresco & $v$ \\
\hline & $\begin{array}{l}\text { Conopodium majus } \\
\text { C. pyrenaeum } \\
\text { Ajuérjano, mantecón }\end{array}$ & 3 & Tubérculo & Fresco & $c i, j, p$ \\
\hline & $\begin{array}{l}\text { Eryngium bourgatii } \\
\text { Cardo azul, cardo, cardo morado }\end{array}$ & 1 & Parte aérea & Fresco & $b$ \\
\hline & $\begin{array}{l}\text { Eryngium campestre } \\
\text { Cardo, cardo borriquero }\end{array}$ & 1 & Parte aérea & Fresco & $b$ \\
\hline Aquifoliaceae & $\begin{array}{l}\text { Ilex aquifolium } \\
\text { Acebo, aceba }\end{array}$ & 5 & Hojas y fruto & Fresco & c, os, ve \\
\hline Berberidaceae & $\begin{array}{l}\text { Berberis vulgaris } \\
\text { Hoja maldita, borrachín }\end{array}$ & 1 & Frutos & Fresco & CO \\
\hline Brassicaceae & $\begin{array}{l}\text { Nasturtium officinale } \\
\text { Berro }\end{array}$ & 2 & Parte aérea & Fresco & $c, 0, v$ \\
\hline \multirow[t]{2}{*}{ Compositae } & $\begin{array}{l}\text { Cirsium eriophorum } \\
\text { Cardo, cardo burriquero }\end{array}$ & 2 & Parte aérea & Fresco & b \\
\hline & $\begin{array}{l}\text { Onopordum acanthium } \\
\text { Cardo borriquero, toba }\end{array}$ & 1 & Parte aérea & Fresco & $b$ \\
\hline Crassulaceae & $\begin{array}{l}\text { Sedum album } \\
\text { S. sediforme } \\
\text { Pan de los pajaritos }\end{array}$ & 6 & Hojas & Fresco & pa \\
\hline Equisetaceae & $\begin{array}{l}\text { Equisetum arvense } \\
\text { Cola de caballo, pinillo, escobilla }\end{array}$ & 1 & Parte aérea & Fresco & $b, e$ \\
\hline \multirow[t]{3}{*}{ Ericaceae } & $\begin{array}{l}\text { Arctostaphylos uva-ursi } \\
\text { Gayuga, agayuga, gayuba }\end{array}$ & 2 & Frutos & Fresco & $c, 0$ \\
\hline & $\begin{array}{l}\text { Erica spp. } \\
\text { Brezo, urz, ayuz, graspo }\end{array}$ & 3 & Brotes & Fresco & $c, 0, v$ \\
\hline & $\begin{array}{l}\text { Vaccinium myrtillus } \\
\text { Arráspano, ráspano, arándano }\end{array}$ & 4 & Frutos & Fresco & os, v, ve \\
\hline \multirow[t]{2}{*}{ Fagaceae } & $\begin{array}{l}\text { Fagus sylvatica } \\
\text { Haya }\end{array}$ & 2 & Frutos & Fresco & j, os, ve \\
\hline & $\begin{array}{l}\text { Quercus petraea } \\
\text { Q. pyrenaica } \\
\text { Q. robur } \\
\text { Roble, cajigo, matorro }\end{array}$ & 2 & Frutos & $\begin{array}{l}\text { Fresco } \\
\text { y seco }\end{array}$ & $0, v$ \\
\hline Iridaceae & $\begin{array}{l}\text { Romulea bulbocodium } \\
\text { Cucubilla, ceringueña, amacuca }\end{array}$ & 1 & Bulbo & Fresco & j \\
\hline Lamiaceae & $\begin{array}{l}\text { Sideritis hyssopifolia } \\
\text { Té, té de roca, té de lastra }\end{array}$ & 1 & Parte aérea & Fresco & ve \\
\hline \multirow[t]{2}{*}{ Leguminosae } & $\begin{array}{l}\text { Cytisus oromediterraneus } \\
\text { Escoba hornil, escoba }\end{array}$ & 1 & Fruto & Fresco & o \\
\hline & $\begin{array}{l}\text { Cytisus scoparius } \\
\text { Escoba, ramo, escoba balera }\end{array}$ & 2 & Brotes y frutos & Fresco & c \\
\hline
\end{tabular}




\begin{tabular}{|c|c|c|c|c|c|}
\hline \multirow[t]{5}{*}{ Familia } & $\begin{array}{l}\text { Nombre cientifico } \\
\text { Nombre vulgar }\end{array}$ & RU & Parte usada & Empleo & Animal \\
\hline & $\begin{array}{l}\text { Genista tridentata } \\
\text { Carquesa }\end{array}$ & 1 & Parte aérea & Fresco & $0, v$ \\
\hline & $\begin{array}{l}\text { Lotus corniculatus } \\
\text { Zapatitos del niño Jesús }\end{array}$ & 1 & Parte aérea & Fresco & $0, v$ \\
\hline & $\begin{array}{l}\text { Trifolium pratense } \\
T \text {. repens } \\
\text { Trébol, chupa, hierba nube }\end{array}$ & 2 & Parte aérea & Fresco & $v$ \\
\hline & $\begin{array}{l}\text { Vicia cracca } \\
\text { V. pannonica } \\
\text { Arvejana }\end{array}$ & 2 & Parte aérea & Fresco & v \\
\hline Orobanchaceae & $\begin{array}{l}\text { Melampyrum pratense } \\
\text { Hierba morena, hierba negreal }\end{array}$ & 2 & Parte aérea & Fresco & $0, v$ \\
\hline Rhamnaceae & $\begin{array}{l}\text { Rhamnus alpina } \\
\text { Teja blanca, uva de oso, pudio }\end{array}$ & 1 & Frutos & Fresco & os \\
\hline \multirow[t]{7}{*}{ Rosaceae } & $\begin{array}{l}\text { Crataegus monogyna } \\
\text { Espino, espino albar, majueto }\end{array}$ & 2 & Hojas y frutos & Fresco & c, pa, o \\
\hline & $\begin{array}{l}\text { Fragaria vesca } \\
\text { Amiérgano, fresa, abijano }\end{array}$ & 2 & Frutos & Fresco & os, ve \\
\hline & $\begin{array}{l}\text { Rosa spp. } \\
\text { Zarza, espino, rosal, calambrojo }\end{array}$ & 2 & Infrutescencia & Fresco & c, ve \\
\hline & $\begin{array}{l}\text { Rubus idaeus } \\
\text { Antimora, mora de la reina }\end{array}$ & 1 & Frutos & Fresco & ve \\
\hline & $\begin{array}{l}\text { Sanguisorba officinalis } \\
\text { Escalerilla }\end{array}$ & 1 & Parte aérea & Fresco & $0, v$ \\
\hline & $\begin{array}{l}\text { Sorbus aria } \\
\text { Mostajo, amostajo }\end{array}$ & 1 & Frutos & Fresco & os \\
\hline & $\begin{array}{l}\text { Sorbus aucuparia } \\
\text { Amargoso, serbal, drío, drido }\end{array}$ & 5 & Frutos & Fresco & a, os \\
\hline Urticaceae & $\begin{array}{l}\text { Urtica dioica } \\
\text { Ortiga }\end{array}$ & 3 & Parte aérea & Fresco & $p, v$ \\
\hline
\end{tabular}

Las especies pastadas son numerosas, suponen un conocimiento adquirido fruto de la observación y rara vez se produce un manejo humano, las ovejas aprecian en el pastoreo la hierba negreal (Melampyrum pratense) y la gayuga (Arctostaphylos uva-ursi), también referenciado el pastoreo de la gayuga en la Sierra Norte de Madrid (Aceituno Mata, 2010).

Un ejemplo de manejo curioso, lo documentamos en la localidad de Valcobero, donde el día de San Lorenzo guiaban las ovejas a pastar la legumbre de la escoba hornil (Cytisus oromediterraneus), considerada de mucho alimento.

Los capítulos de los cardos más bastos (Cirsium eriophorum, Eryngium bourgatii, E. campestre y Onopordum acanthium) gustaban a burros y caballos, y por ello reciben el nombre de borriqueros.

Durante las vecerías las vacas estiman especies herbáceas en sus primeros estados de desarrollo, cuando más tiernas y apetecibles resultan, se han citado: ajestrín (Allium sphaerocephalon), arvejana (Vicia cracca, V. pannonica), budaño (Conium maculatum), escalerilla (Sanguisorba officinalis), ortiga (Urtica dioica) o trébol (Trifolium pratense, $T$. repens).

Varios informantes de la zona señalaron cómo la fauna silvestre aprovecha entre otros, los frutos del acebo (Ilex aquifolium), del amargoso (Sorbus aucuparia), del amiérgano (Fragaria 
vesca), del haya (Fagus sylvatica), de la uva de oso (Rhamnus alpina) o del arráspano (Vaccinium myrtillus), también la observación de la naturaleza incluye el conocimiento del consumo por parte de los pájaros de pan de pajaritos (Sedum album, S. sediforme), y de tubérculos de ajuérjanos (Conopodium majus, C. pyrenaeum) o bulbos de cucubillas (Romulea bulbocodium) que extraen del suelo los jabalíes.

\section{Plantas melíferas:}

Se han recogido 73 registros de uso, correspondientes a 28 taxones de 13 familias botánicas diferentes, 21 de obtención silvestre y 7 cultivados, representando un 4,54\% del total de registros de uso para la categoría Alimentación animal.

TABLA 32: Relación de taxones empleados en la subcategoría Plantas melíferas, ordenados alfabéticamente por familia, indicando número de registros de uso (RU), parte usada y empleo.

\begin{tabular}{|c|c|c|c|c|}
\hline Familia & $\begin{array}{l}\text { Nombre científico } \\
\text { Nombre vulgar }\end{array}$ & RU & Parte usada & Empleo \\
\hline Amaryllidaceae & $\begin{array}{l}\text { Narcissus pseudonarcissus } \\
\text { Lirón, lirio, cancarico, campanilla }\end{array}$ & 1 & Flor & Néctar, polen \\
\hline Caprifoliaceae & $\begin{array}{l}\text { Dipsacus fullonum } \\
\text { Cardo cardador, cardo }\end{array}$ & 1 & Flor & Néctar, polen \\
\hline \multirow[t]{3}{*}{ Compositae } & $\begin{array}{l}\text { Calendula officinalis } \\
\text { Maravilla, caléndula, clavel }\end{array}$ & 1 & Flor & Néctar, polen \\
\hline & $\begin{array}{l}\text { Cirsium arvense } \\
\text { C. vulgare } \\
\text { Cardo, cardo negrero }\end{array}$ & 1 & Flor & Néctar, polen \\
\hline & $\begin{array}{l}\text { Cirsium eriophorum } \\
\text { Cardo, cardo burriquero }\end{array}$ & 1 & Flor & Néctar, polen \\
\hline Cucurbitaceae & $\begin{array}{l}\text { Cucurbita pepo } \\
\text { Calabacín }\end{array}$ & 1 & Flor & Néctar, polen \\
\hline \multirow[t]{2}{*}{ Ericaceae } & $\begin{array}{l}\text { Calluna vulgaris } \\
\text { Brezo, graspo, brecina }\end{array}$ & 6 & Flor & Néctar, polen \\
\hline & $\begin{array}{l}\text { Erica spp. } \\
\text { Brezo, urz, ayuz, graspo }\end{array}$ & 20 & Flor & Néctar, polen \\
\hline Fagaceae & $\begin{array}{l}\text { Quercus petraea } \\
\text { Q. pyrenaica } \\
\text { Q. robur } \\
\text { Roble, cajigo, matorro }\end{array}$ & 3 & Exudado & Melaza \\
\hline \multirow[t]{3}{*}{ Lamiaceae } & $\begin{array}{l}\text { Prunella grandiflora } \\
\boldsymbol{P} \text {. vulgaris } \\
\text { Chupa, chupete de grillo }\end{array}$ & 2 & Flor & Néctar, polen \\
\hline & $\begin{array}{l}\text { Rosmarinus officinalis } \\
\text { Romero }\end{array}$ & 4 & Flor & Néctar, polen \\
\hline & $\begin{array}{l}\text { Thymus praecox } \\
\text { Tomillo, hierba de la sabina }\end{array}$ & 1 & Flor & Néctar, polen \\
\hline \multirow[t]{4}{*}{ Leguminosae } & $\begin{array}{l}\text { Cytisus scoparius } \\
\text { Escoba, ramo, escoba balera }\end{array}$ & 6 & Flor & Néctar, polen \\
\hline & $\begin{array}{l}\text { Genista florida } \\
\text { Escoba, escoba albar, ramón }\end{array}$ & 2 & Flor & Néctar, polen \\
\hline & $\begin{array}{l}\text { Genista hispanica } \\
\text { Argoma, ulaga }\end{array}$ & 1 & Flor & Néctar, polen \\
\hline & $\begin{array}{l}\text { Medicago sativa } \\
\text { Mielga, alfalfa }\end{array}$ & 1 & Flor & Néctar, polen \\
\hline Orobanchaceae & $\begin{array}{l}\text { Pedicularis comosa } \\
\text { P. sylvatica } \\
\text { Chupa, chupón, chupete }\end{array}$ & 1 & Flor & Néctar, polen \\
\hline
\end{tabular}




\begin{tabular}{|c|c|c|c|c|}
\hline Familia & $\begin{array}{l}\text { Nombre científico } \\
\text { Nombre vulgar }\end{array}$ & RU & Parte usada & Empleo \\
\hline Paeoniaceae & $\begin{array}{l}\text { Paeonia lactiflora } \\
\text { Peonía }\end{array}$ & 1 & Flor & Néctar, polen \\
\hline \multirow[t]{8}{*}{ Rosaceae } & $\begin{array}{l}\text { Crataegus monogyna } \\
\text { Espino, espino albar, majueto }\end{array}$ & 1 & Flor & Néctar, polen \\
\hline & $\begin{array}{l}\text { Malus domestica } \\
\text { Manzano }\end{array}$ & 4 & Flor & Néctar, polen \\
\hline & $\begin{array}{l}\text { Prunus avium } \\
\text { Cerezo }\end{array}$ & 1 & Flor & Néctar, polen \\
\hline & $\begin{array}{l}\text { Prunus domestica } \\
\text { Ciruelo, mijuelo, pruno }\end{array}$ & 2 & Flor & Néctar, polen \\
\hline & $\begin{array}{l}\text { Prunus spinosa } \\
\text { Endrino, andrino, espino }\end{array}$ & 2 & Flor & Néctar, polen \\
\hline & $\begin{array}{l}\text { Pyrus communis } \\
\text { Peral }\end{array}$ & 3 & Flor & Néctar, polen \\
\hline & $\begin{array}{l}\text { Pyrus cordata } \\
\text { Peral de monte, perujo }\end{array}$ & 1 & Flor & Néctar, polen \\
\hline & $\begin{array}{l}\text { Rosa spp. } \\
\text { Zarza, espino, rosal, calambrojo }\end{array}$ & 2 & Flor & Néctar, polen \\
\hline Salicaceae & $\begin{array}{l}\text { Salix spp. } \\
\text { Salguero, sota, salce, mimbrera }\end{array}$ & 1 & Flor & Néctar, polen \\
\hline Xanthorrhoeaceae & $\begin{array}{l}\text { Asphodelus albus } \\
\text { Gamón, gamonita }\end{array}$ & 2 & Flor & Néctar, polen \\
\hline
\end{tabular}

En la comarca se recoge una importante tradición apícola, aprovechando la flora silvestre para obtener miel de buena calidad para su uso dentro del núcleo familiar. Los lugareños se refieren a las abejas por el nombre vulgar de "moscas", y el habitáculo donde se albergan las colmenas "dujo".

Las especies más notables son sin duda las de la familia Ericaceae, brezos (Erica spp.) y graspos (Calluna vulgaris) con una interesante floración escalonada, seguidas por las escobas (Cytisus scoparius y Genista florida) que presentan una abundante floración. Otras especies interesantes son los frutales pertenecientes a la familia Rosaceae, se menciona el manzano (Malus domestica), el cerezo (Prunus avium), el ciruelo (Prunus domestica), el peral (Pyrus communis) e incluso el endrino (Prunus spinosa).

Los árboles del género Quercus: roble (Quercus petraea, Q. pyrenaica y $Q$. robur) y encina (Quercus rotundifolia) producen una sustangia pegajosa, secreciones dulces con las que las abejas se alimentan en el final del verano y con las que elaboran una miel de color oscuro. También se señalan como plantas melíferas a especies con una floración vistosa, entre ellas, las chupas (Prunella grandiflora, P. vulgaris, Pedicularis comosa, P. sylvatica), los cardos (Cirsium arvense, C. eriophorum, C. vulgare, Dipsacus fullonum), los lirones (Narcissus pseudonarcissus) o los gamones (Asphodelus albus). La utilidad melífera de los gamones se describe también en la provincia de León (García Jiménez, 2007) y en la de Cantabria (Pardo de Santayana, 2004).

El romero (Rosmarinus officinalis) que se cultiva en huertos y jardines se considera una buena especie melífera obteniendo 4 registros de uso en la presente subcategoría, de su néctar se obtiene una miel clara y suave, uso también documentado en Sierra Magina (Mesa, 1996), La Calabria (Blanco \& Cuadrado, 2000), el Montseny (Bonet, 2001), provincia de Jaén (Ortuño, 2003), La Coruña (Latorre, 2008), las Tablas de Daimiel (Consuegra, 2009), la Sierra Norte de Madrid (Aceituno Mata, 2010) y el Cerrato Palentino (Pascual et al., 2016). 


\section{Medicina:}

En la categoría Medicina se incluyen todas las especies empleadas para tratar, prevenir o curar enfermedades en personas. En la comarca de la Montaña Palentina se menciona el uso de 105 taxones vegetales correspondientes a 41 familias botánicas, para los que se han recogido un total de 1248 registros de uso (RU). De ellos, 81 taxones son de obtención silvestre, 19 cultivados y 5 comprados. Los taxones con mayor número de registros de uso en la categoría Medicina se representan en la figura 33.

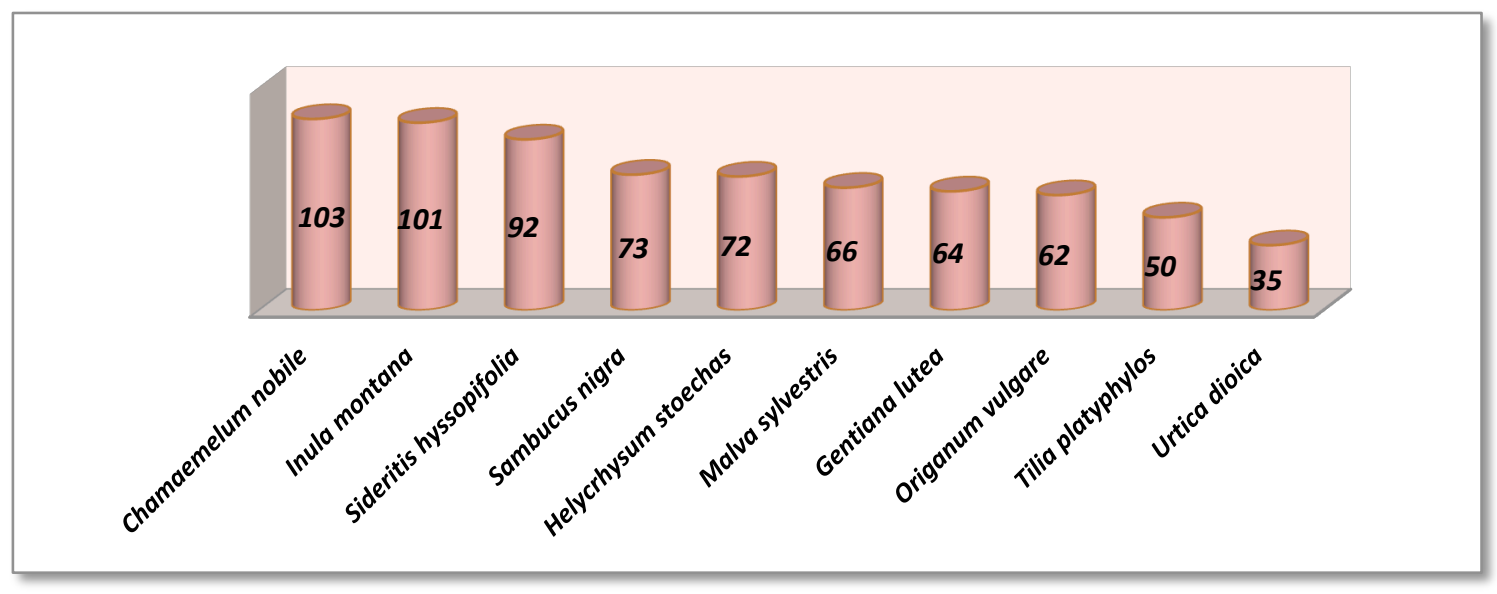

FIGURA 33: Especies con mayor número de registros de uso empleadas en Medicina.

Las familias con mayor representación en cuanto a número de especies fueron: Lamiaceae, Compositae y Rosaceae, con 16, 15 y 9 especies respectivamente, y la familia con mayor número de registros de uso fue Compositae con 354, según se señala en la figura 34.

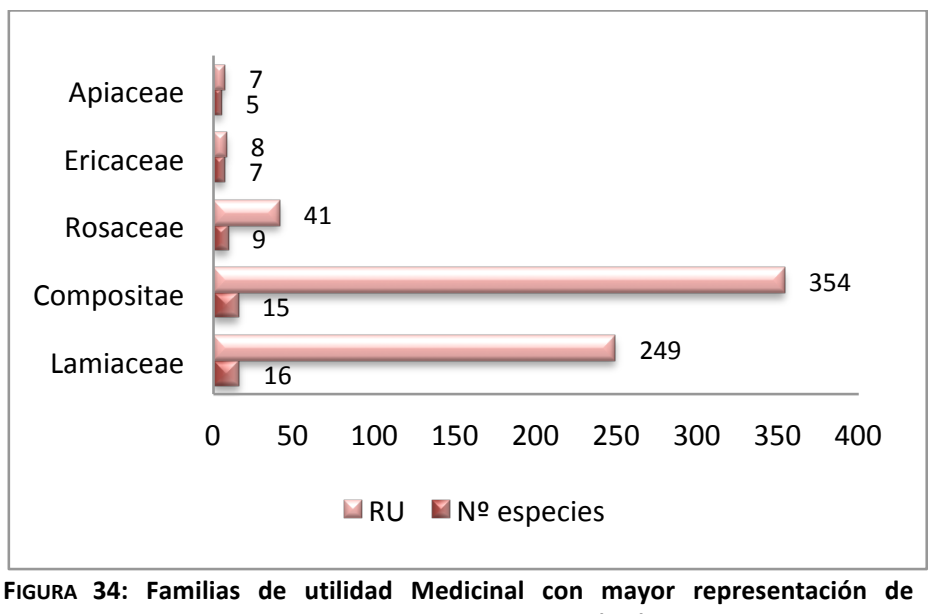
especies y número de registros de uso (RU).

Las plantas empleadas como medicinales sirven para resolver múltiples dolencias, la mayoría son plantas abundantes y comunes, también empleadas en la medicina popular de otras zonas de la Península Ibérica. Este amplio conocimiento responde a la necesidad imperiosa de solventar problemas y trastornos ante la dificultad en el pasado de acceder a un médico, ya fuera por no poder afrontar sus honorarios o por incomunicación debida a las malas condiciones meteorológicas que por lo general acaecían en el invierno. 
Los usos se han agrupado en subcategorías atendiendo al aparato o sistema corporal sobre el que actúan, siguiendo los criterios establecidos en el Inventario Español de los Conocimientos Tradicionales relativos a la Biodiversidad (Pardo de Santayana et al., 2014), obteniendo referencias en las 13 subcategorías indicadas en la tabla 33.

\begin{tabular}{l}
$\begin{array}{l}\text { TABLA 33: Subcategorías con representación en la categoría } \\
\text { Medicina. }\end{array}$ \\
\hline Subcategorías : \\
\hline Sistema circulatorio \\
Sistema digestivo \\
Sistema genito-urinario \\
Sistema respiratorio \\
Sistema endocrino-metabólico \\
Musculatura y esqueleto \\
Piel y tejido celular subcutáneo \\
Sistema nervioso \\
Órganos de los sentidos \\
Enfermedades infecciosas y parasitarias \\
Síntomas y estados de origen indefinido \\
Intoxicaciones y envenenamientos \\
Otros usos medicinales
\end{tabular}

Los 1248 registros de uso obtenidos, en la categoría Medicina, se reparten en 13 subcategorías tal y como señala la figura 35, resultando que el Sistema digestivo es la que recibió mayor número de registros con 401 , un $32,13 \%$ del total en esta categoría, seguido del Sistema respiratorio con 300 , un $24,04 \%$, y Musculatura y esqueleto con 146 , un $11,70 \%$.

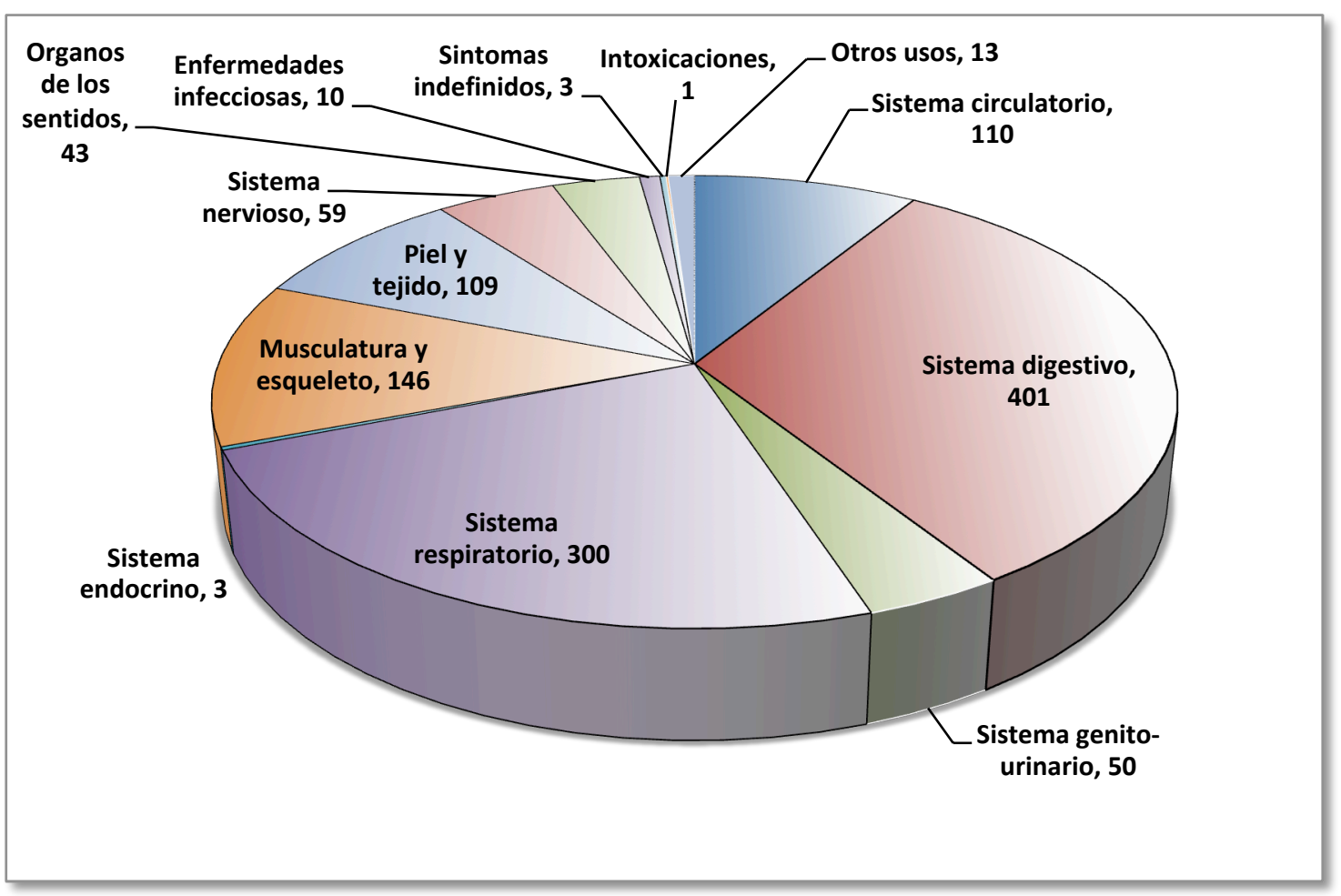

FIGURA 35: Registros de Uso (RU) de las subcategorías representadas en Medicina.

A continuación se presentan las utilidades agrupadas por subcategorías medicinales, señalando los taxones que han obtenido citas en los mismos, el número de registros de uso de cada taxón, la parte usada y el empleo. 


\section{Sistema circulatorio:}

Se han recogido 110 registros de uso, correspondientes a 19 taxones de 15 familias botánicas diferentes, 17 taxones de obtención silvestre y 2 cultivados, representando un 8,81\% del total de registros de uso para la categoría Medicina.

TABLA 34: Relación de especies empleadas en la subcategoría Sistema circulatorio, ordenadas alfabéticamente por familia, indicando número de registros de uso (RU), parte usada y empleo (modo de preparación y finalidad de uso).

\begin{tabular}{|c|c|c|c|c|}
\hline Familia & $\begin{array}{l}\text { Nombre cientifico } \\
\text { Nombre vulgar }\end{array}$ & RU & Parte usada & Empleo \\
\hline Apiaceae & $\begin{array}{l}\text { Angelica sylvestris } \\
\text { Angélica, chiflato }\end{array}$ & 1 & Frutos & $\begin{array}{c}\text { Infusión } \\
\text { Depurativo sangre }\end{array}$ \\
\hline Boraginaceae & $\begin{array}{l}\text { Glandora diffusa } \\
\text { Hierba } 7 \text { sangrías, } 7 \text { sangrías }\end{array}$ & 6 & Parte aérea & $\begin{array}{l}\text { Infusión } \\
\text { Depurativo sangre }\end{array}$ \\
\hline Caryophyllaceae & $\begin{array}{l}\text { Paronychia kapela } \\
\text { Sanguinaria, flor de papel }\end{array}$ & 26 & Parte aérea & $\begin{array}{l}\text { Infusión } \\
\text { Depurativo sangre }\end{array}$ \\
\hline \multirow[t]{2}{*}{ Compositae } & $\begin{array}{l}\text { Achillea millefolium } \\
\text { Milenrama, birlenda, balsamina }\end{array}$ & 3 & Parte aérea & $\begin{array}{l}\text { Infusión } \\
\text { Depurativo sangre }\end{array}$ \\
\hline & $\begin{array}{l}\text { Inula helvetica } \\
\text { Árnica }\end{array}$ & 1 & Parte aérea & $\begin{array}{l}\text { Maceración alcohol } \\
\text { Hemorroides }\end{array}$ \\
\hline Equisetaceae & $\begin{array}{l}\text { Equisetum arvense } \\
\text { Cola de caballo, pinillo, escobilla }\end{array}$ & 14 & Parte aérea & $\begin{array}{c}\text { Infusión } \\
\text { Mala circulación }\end{array}$ \\
\hline Gentianaceae & $\begin{array}{l}\text { Centaurium erythraea } \\
\text { Hierba de las } 7 \text { sangrías }\end{array}$ & 1 & Parte aérea & $\begin{array}{c}\text { Infusión } \\
\text { Depurativo sangre }\end{array}$ \\
\hline \multirow[t]{2}{*}{ Lamiaceae } & $\begin{array}{l}\text { Rosmarinus officinalis } \\
\text { Romero }\end{array}$ & 1 & Parte aérea & $\begin{array}{l}\text { Maceración alcohol } \\
\text { Mala circulación }\end{array}$ \\
\hline & $\begin{array}{l}\text { Salvia verbenaca } \\
\text { Hierba de Santa Lucía, balsamina }\end{array}$ & 1 & Parte aérea & $\begin{array}{l}\text { Maceración aceite } \\
\text { Mala circulación }\end{array}$ \\
\hline Plantaginaceae & $\begin{array}{l}\text { Plantago lanceolata } \\
\text { Hoja de lentén, Ilantén, lentel }\end{array}$ & 1 & Hojas & $\begin{array}{c}\text { Directa } \\
\text { Hemorroides }\end{array}$ \\
\hline Poaceae & $\begin{array}{l}\text { Triticum aestivum } \\
\text { Trigo, mesino, tremesino }\end{array}$ & 1 & Salvado & $\begin{array}{l}\text { Directo } \\
\text { Hemorroides }\end{array}$ \\
\hline \multirow[t]{3}{*}{ Rosaceae } & $\begin{array}{l}\text { Crataegus monogyna } \\
\text { Espino, espino albar, majueto }\end{array}$ & 6 & Hojas y flores & $\begin{array}{l}\text { Infusión } \\
\text { Regulador tensión }\end{array}$ \\
\hline & $\begin{array}{l}\text { Prunus spinosa } \\
\text { Endrino, andrino, espino }\end{array}$ & 1 & Hojas y flores & $\begin{array}{l}\text { Infusión } \\
\text { Regulador tensión }\end{array}$ \\
\hline & $\begin{array}{l}\text { Rosa spinosissima } \\
\text { Zarzaparrilla, rosal espinoso }\end{array}$ & 7 & Raíz & $\begin{array}{l}\text { Cocción } \\
\text { Depurativo sangre }\end{array}$ \\
\hline Santalaceae & $\begin{array}{l}\text { Viscum album } \\
\text { Muerdago, maraojo, mingojo }\end{array}$ & 1 & Planta & $\begin{array}{l}\text { Cataplasma } \\
\text { Varices }\end{array}$ \\
\hline Scrophulariaceae & $\begin{array}{l}\text { Verbascum lychnitis } \\
\text { V. pulverulentum } \\
\text { V. thapsus } \\
\text { Gordolobo, guardalobo }\end{array}$ & 7 & Hojas & $\begin{array}{c}\text { Cocción y cataplasma } \\
\text { Hemorroides }\end{array}$ \\
\hline \multirow[t]{2}{*}{ Urticaceae } & $\begin{array}{l}\text { Urtica dioica } \\
\text { Ortiga }\end{array}$ & 26 & Parte aérea & $\begin{array}{l}\text { Cocción } \\
\text { Mala circulación }\end{array}$ \\
\hline & $\begin{array}{l}\text { Urtica urens } \\
\text { Ortiga, ortiga meña }\end{array}$ & 4 & Parte aérea & $\begin{array}{c}\text { Cocción } \\
\text { Mala circulación }\end{array}$ \\
\hline Verbenaceae & $\begin{array}{l}\text { Verbena officinalis } \\
\text { Verbena }\end{array}$ & 2 & Parte aérea & $\begin{array}{c}\text { Infusión } \\
\text { Mala circulación }\end{array}$ \\
\hline
\end{tabular}

Las patologías que afectan al aparato circulatorio se resumen en varios bloques, en primer lugar los que tienen que ver con la limpieza y depuración de la sangre, según la terminología popular "rebajar la sangre, tener la sangre gorda o espesa", tratamientos procedentes de 
antiguas prácticas médicas que podrían derivar de las teorías de Hipócrates sobre el equilibrio de los cuatro humores. Este diagnóstico de la medicina popular alude a una serie de afecciones que generalmente se manifiestan mediante pruritos, enrojecimientos de la piel y la cara, erupciones cutáneas, eccemas o espinillas, entre otros, y que de forma generalizada los informantes relacionan con problemas circulatorios con la sangre (Pardo de Santayana et al., 2018). En la comarca se consideraba necesaria la depuración de la sangre para conseguir un buen estado de salud, ya que podía ser el origen además de otros males, para ello se utilizan plantas que llevan en su nombre vulgar el uso para el que se recomienda, este es el caso de la hierba de las 7 sangrías, identificada en la zona septentrional de la comarca como Glandora diffusa y en el Valle de Santullán como Centaurium erythraea. Glandora diffusa se usa para tratar afecciones similares en otros estudios consultados (Pardo de Santayana, 2008; Velasco et al., 2010). Centaurium erythraea tiene un uso similar en la provincia de Navarra (Akerreta, 2009) y en La Calabria (Blanco \& Cuadrado, 2000), y es referenciada como desintoxicante del hígado en el Pirineo Aragonés (Villar et al., 1987) y en la Serranía de Cuenca (Fajardo et al., 2007).

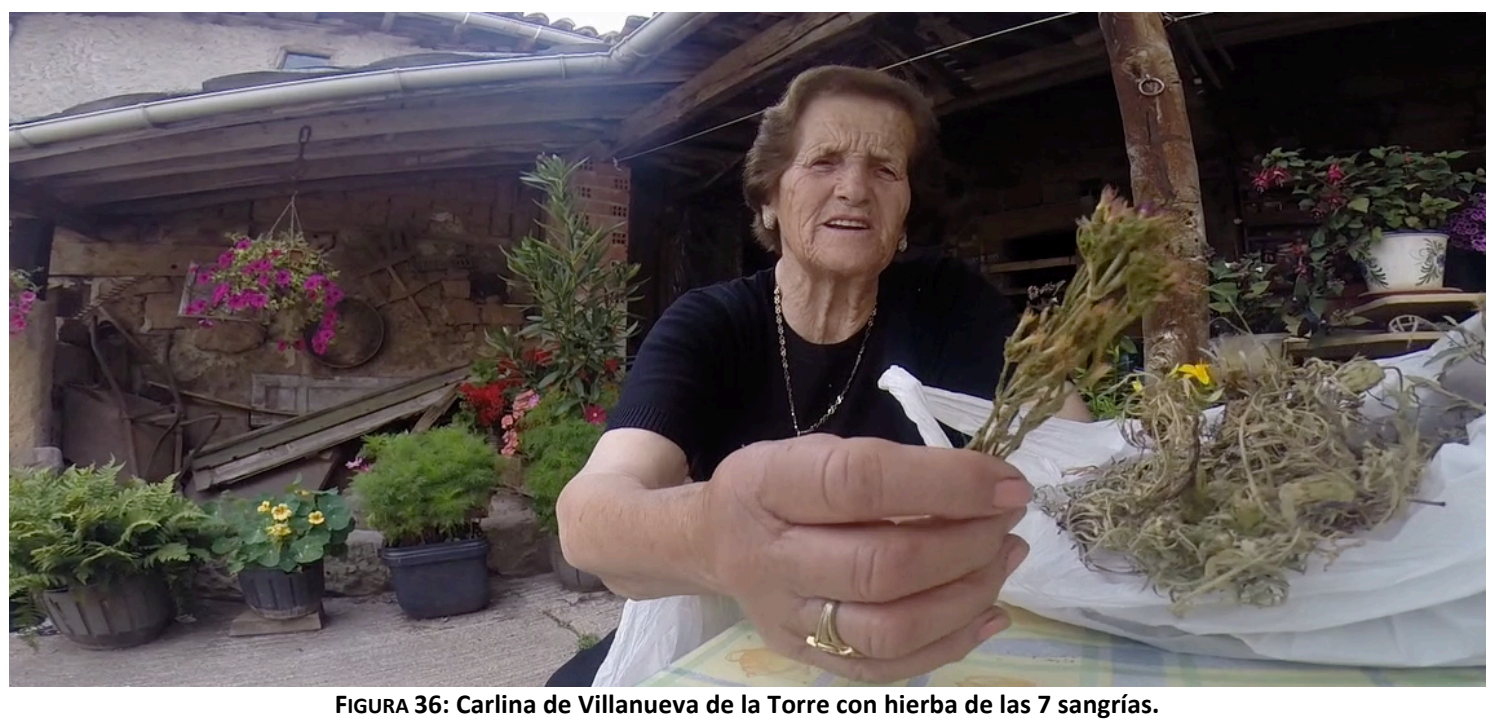

La planta más utilizada en la comarca para adelgazar la sangre y purificarla es Paronychia kapela, con 26 registros de uso, y destacada también es la cocción de la raíz de la zarzaparrilla (Rosa spinosissima), no habiendo encontrado esta utilidad en la bibliografía consultada, Fajardo et al. (2007), recogen el uso de la zarzaparrilla (Smilax aspera) para rebajar la sangre.

En el segundo bloque, se distinguen las especies empleadas en trastornos generales del aparato circulatorio, como ortigas (Urtica dioica, U. urens) y cola de caballo (Equisetum arvense), ampliamente utilizadas por toda la Península Ibérica (Mulet, 1991; Rivera et al., 1994; Guzmán, 1997; Benítez, 2009; Tejerina, 2010), y las especies recomendadas para regular la tensión, entre las que destaca el majueto (Crataegus monogyna), del que se usan hojas y flores en infusión.

Por último, el bloque de tratamientos antihemorroidales, para aliviar y curar las almorranas que provocan molestias más o menos leves como picor, inflamación de la piel, dolor, ardor o pequeños sangrados. Para estos casos se utiliza en la zona con frecuencia las hojas de gordolobo (Verbascum spp.) ya sean aplicadas previa cocción o a modo de cataplasma, o también mediante baños de asiento. Idéntico empleo se referencia en la comarca de Pallars (Agelet, 1999), en la provincia de Salamanca (Velasco et al., 2010) o en la de Navarra (Akerreta et al., 2013). 


\section{Sistema digestivo:}

Se han recogido 401 registros de uso, correspondientes a 38 taxones de 17 familias botánicas diferentes, 30 taxones de obtención silvestre, 5 cultivados y 3 comprados, representando un $32,13 \%$ del total de registros de uso para la categoría medicina, se corresponde con la subcategoría medicinal que acumula mayor número de registros de uso.

TABLA 35: Relación de especies empleadas en la subcategoría Sistema digestivo, ordenadas alfabéticamente por familia, indicando número de registros de uso (RU), parte usada y empleo (modo de preparación y finalidad de uso).

\begin{tabular}{|c|c|c|c|c|}
\hline Familia & $\begin{array}{l}\text { Nombre cientifico } \\
\text { Nombre vulgar }\end{array}$ & RU & Parte usada & Empleo \\
\hline Adoxaceae & $\begin{array}{l}\text { Sambucus nigra } \\
\text { Saúco, saúgo, sabúgo, taco }\end{array}$ & 4 & Inflorescencia & $\begin{array}{l}\text { Cataplasma y vahos } \\
\text { Dolor de muelas }\end{array}$ \\
\hline \multirow[t]{2}{*}{ Apiaceae } & $\begin{array}{l}\text { Foeniculum vulgare } \\
\text { Hinojo, anís, comino }\end{array}$ & 1 & Parte aérea & $\begin{array}{c}\text { Infusión } \\
\text { Gases }\end{array}$ \\
\hline & $\begin{array}{l}\text { Scandix australis } \\
\text { Anís, anís de lastra }\end{array}$ & 2 & Parte aérea & $\begin{array}{c}\text { Infusión } \\
\text { Dolor estomacal y gases }\end{array}$ \\
\hline Boraginaceae & $\begin{array}{l}\text { Echium vulgare } \\
\text { Gardincha }\end{array}$ & 1 & Parte aérea & $\begin{array}{c}\text { Infusión } \\
\text { Dolor estomacal }\end{array}$ \\
\hline Brassicaceae & $\begin{array}{l}\text { Capsella bursa-pastoris } \\
\text { Bolsa de pastor }\end{array}$ & 2 & Parte aérea & $\begin{array}{l}\text { Infusión } \\
\text { Diarreas }\end{array}$ \\
\hline \multirow[t]{5}{*}{ Compositae } & $\begin{array}{l}\text { Achillea millefolium } \\
\text { Milenrama, birlenda, balsamina }\end{array}$ & 10 & Parte aérea & $\begin{array}{c}\text { Infusión } \\
\text { Diarrea y gases }\end{array}$ \\
\hline & $\begin{array}{l}\text { Centaurea lagascana } \\
\text { Arzolla, cardo de arzolla }\end{array}$ & 1 & Inflorescencia & $\begin{array}{l}\text { Maceración en orujo } \\
\text { Dolor estomago }\end{array}$ \\
\hline & $\begin{array}{l}\text { Chamaemelum nobile } \\
\text { Manzanilla, manzanilla campera }\end{array}$ & 97 & Sumidad floral & $\begin{array}{l}\text { Infusión } \\
\text { Indigestión, diarrea y gases }\end{array}$ \\
\hline & $\begin{array}{l}\text { Helichrysum stoechas } \\
\text { Manzanilla, manzanilla de peña }\end{array}$ & 64 & Sumidad floral & $\begin{array}{c}\text { Infusión } \\
\text { Dolor estomacal }\end{array}$ \\
\hline & $\begin{array}{l}\text { Inula helvetica } \\
\text { Árnica }\end{array}$ & 1 & Parte aérea & $\begin{array}{l}\text { Maceración en licor } \\
\text { Enjuague bucal }\end{array}$ \\
\hline Euphorbiaceae & $\begin{array}{l}\text { Ricinus communis } \\
\text { Ricino }\end{array}$ & 6 & Comprada & $\begin{array}{l}\text { Aceite } \\
\text { Purga }\end{array}$ \\
\hline \multirow[t]{2}{*}{ Gentianaceae } & $\begin{array}{l}\text { Centaurium erythraea } \\
\text { Hierba de las } 7 \text { sangrías }\end{array}$ & 1 & Parte aérea & $\begin{array}{c}\text { Infusión } \\
\text { Dolor de muelas }\end{array}$ \\
\hline & $\begin{array}{l}\text { Gentiana lutea } \\
\text { Junciana, genciana }\end{array}$ & 52 & Rizoma & $\begin{array}{c}\text { Cocción } \\
\text { Pérdida apetito, dolor estomacal }\end{array}$ \\
\hline Juglandaceae & $\begin{array}{l}\text { Juglans regia } \\
\text { Nogal }\end{array}$ & 1 & Fruto & $\begin{array}{c}\text { Licor } \\
\text { Dolor estomacal }\end{array}$ \\
\hline \multirow[t]{7}{*}{ Lamiaceae } & $\begin{array}{l}\text { Melissa officinalis } \\
\text { Melisa }\end{array}$ & 1 & Parte aérea & $\begin{array}{l}\text { Infusión } \\
\text { Indigestión }\end{array}$ \\
\hline & $\begin{array}{l}\text { Melittis melissophyllum } \\
\text { Melisa }\end{array}$ & 1 & Parte aérea & $\begin{array}{l}\text { Infusión } \\
\text { Indigestión }\end{array}$ \\
\hline & $\begin{array}{l}\text { Mentha aquatica } \\
\text { Hierbabuena, menta }\end{array}$ & 1 & Parte aérea & $\begin{array}{c}\text { Infusión } \\
\text { Indigestión }\end{array}$ \\
\hline & $\begin{array}{l}\text { Mentha longifolia } \\
\text { Poleo, té de menta, menta } \\
\text { poleo }\end{array}$ & 9 & Parte aérea & $\begin{array}{c}\text { Infusión } \\
\text { Dolor estomacal y gases }\end{array}$ \\
\hline & $\begin{array}{l}\text { Mentha pulegium } \\
\text { Té de menta, menta poleo, } \\
\text { poleo }\end{array}$ & 16 & Parte aérea & $\begin{array}{l}\text { Infusión } \\
\text { Indigestión, diarrea y gases }\end{array}$ \\
\hline & $\begin{array}{l}\text { Origanum vulgare } \\
\text { Orégano }\end{array}$ & 2 & Sumidad floral & $\begin{array}{l}\text { Infusión } \\
\text { Indigestión }\end{array}$ \\
\hline & $\begin{array}{l}\text { Sideritis hyssopifolia } \\
\text { Té, té de roca, té de lastra }\end{array}$ & 85 & Sumidad floral & $\begin{array}{c}\text { Infusión } \\
\text { Indigestión, diarrea y gases }\end{array}$ \\
\hline
\end{tabular}




\begin{tabular}{|c|c|c|c|c|}
\hline Familia & $\begin{array}{l}\text { Nombre científico } \\
\text { Nombre vulgar }\end{array}$ & RU & Parte usada & Empleo \\
\hline \multirow[t]{3}{*}{ Lamiaceae } & $\begin{array}{l}\text { Thymus mastichina } \\
\text { Tomillo, mejorana }\end{array}$ & 3 & Parte aérea & $\begin{array}{c}\text { Infusión } \\
\text { Dolor estomacal y gases }\end{array}$ \\
\hline & $\begin{array}{l}\text { Thymus pulegioides } \\
\text { Hierba de la cólica }\end{array}$ & 1 & Parte aérea & $\begin{array}{c}\text { Infusión } \\
\text { Indigestión y gases }\end{array}$ \\
\hline & $\begin{array}{l}\text { Thymus praecox } \\
\text { Tomillo, hierba la sabina, té }\end{array}$ & 5 & Parte aérea & $\begin{array}{l}\text { Infusión } \\
\text { Indigestión }\end{array}$ \\
\hline Lythraceae & $\begin{array}{l}\text { Lythrum salicaria } \\
\text { Hierba de la colitis, salicaria }\end{array}$ & 2 & Parte aérea & $\begin{array}{l}\text { Infusión } \\
\text { Diarrea }\end{array}$ \\
\hline \multirow[t]{2}{*}{ Malvaceae } & $\begin{array}{l}\text { Malva sylvestris } \\
\text { Malva, flor de malva }\end{array}$ & 2 & Parte aérea & $\begin{array}{l}\text { Infusión } \\
\text { Dolor estomacal }\end{array}$ \\
\hline & $\begin{array}{l}\text { Tilia platyphylos } \\
\text { Tilo }\end{array}$ & 7 & Flor & $\begin{array}{l}\text { Infusión } \\
\text { Dolor estomacal }\end{array}$ \\
\hline Plantaginaceae & $\begin{array}{l}\text { Plantago lanceolata } \\
\text { Hoja de lentén, Ilantén, lentel }\end{array}$ & 2 & Hojas & $\begin{array}{l}\text { Directa } \\
\text { Diarrea }\end{array}$ \\
\hline \multirow[t]{3}{*}{ Poaceae } & $\begin{array}{l}\text { Oryza sativa } \\
\text { Arroz }\end{array}$ & 2 & Grano & $\begin{array}{l}\text { Cocción } \\
\text { Diarrea }\end{array}$ \\
\hline & $\begin{array}{l}\text { Secale cereale } \\
\text { Centeno, sirvendo, servendo }\end{array}$ & 2 & Grano & $\begin{array}{l}\text { Cataplasma } \\
\text { Dolor de muelas }\end{array}$ \\
\hline & $\begin{array}{l}\text { Triticum aestivum } \\
\text { Trigo, mesino, tremesino }\end{array}$ & 1 & Grano & $\begin{array}{c}\text { Cataplasma } \\
\text { Dolor de muelas }\end{array}$ \\
\hline Polygonaceae & $\begin{array}{l}\text { Rumex crispus } \\
\text { Amargaza, acerón, ramagón }\end{array}$ & 1 & Fruto & $\begin{array}{l}\text { Cocción } \\
\text { Diarrea }\end{array}$ \\
\hline \multirow[t]{3}{*}{ Rosaceae } & $\begin{array}{l}\text { Geum urbanum } \\
\text { Hierba de San Benito }\end{array}$ & 1 & Parte aérea & $\begin{array}{l}\text { Infusión } \\
\text { Diarrea }\end{array}$ \\
\hline & $\begin{array}{l}\text { Prunus cerasus } \\
\text { Guindal }\end{array}$ & 2 & Fruto & $\begin{array}{l}\text { Maceración licor } \\
\text { Dolor estomacal }\end{array}$ \\
\hline & $\begin{array}{l}\text { Rosa spinosissima } \\
\text { Zarzaparrilla, rosal espinoso }\end{array}$ & 1 & Raíz & $\begin{array}{c}\text { Cocción } \\
\text { Dolor de muelas }\end{array}$ \\
\hline Rutaceae & $\begin{array}{l}\text { Citrus limon } \\
\text { Limón }\end{array}$ & 1 & Fruto & $\begin{array}{c}\text { Zumo } \\
\text { Diarreas }\end{array}$ \\
\hline Solanaceae & $\begin{array}{l}\text { Hyoscyamus niger } \\
\text { Beleño }\end{array}$ & 8 & Semilla & $\begin{array}{l}\text { Cataplasma y vahos } \\
\text { Dolor de muelas }\end{array}$ \\
\hline Verbenaceae & $\begin{array}{l}\text { Verbena officinalis } \\
\text { Verbena }\end{array}$ & 2 & Parte aérea & $\begin{array}{l}\text { Infusión } \\
\text { Diarrea }\end{array}$ \\
\hline
\end{tabular}

Son varios los trastornos del aparato digestivo resueltos a base de plantas, diferenciándose los remedios que intervienen en el propio proceso digestivo, los que sirven para calmar dolores gástricos e intestinales, los que eliminan gases acumulados en el estomago, los laxantes y astringentes, los aperitivos y los relacionados con la salud dental.

En el apartado de los remedios empleados para favorecer el proceso digestivo, se describen los que facilitan la digestión en caso de empacho, con síntomas más o menos acusados e incluso los que se utilizan simplemente para evitar la indigestión, para "asentar el estomago o la comida" según denominación popular. Se utilizan de modo frecuente, tés (Sideritis hyssopifolia, Thymus praecox), manzanillas (Chamaemelum nobile, Helichrysum stoechas) y poleos (Mentha longifolia, M. pulegium), administrados siempre en forma de infusión, después de comidas copiosas o como digestivo ordinario, que continúa con plena vigencia en la actualidad. 
Los casos que presentan síntomas con dolores gástricos o intestinales, mencionados como "dolor de barriga, tripa o vientre", además de las plantas citadas anteriormente, se utilizan el tilo (Tilia platyphylos), el tomillo (Thymus mastichina) o el anís (Scandix australis), administradas mediante infusiones calientes que alivian los dolores. Otro modo común de administración para este tipo de inconvenientes se realiza mediante licores digestivos, elaborados a base de mezclar orujos de alta graduación con frutos como guindas (Prunus cerasus) o nueces (Juglans regia).

Para eliminar gases molestos acumulados en el estomago se indican las mismas especies que para los dolores gástricos, debido a que el origen del malestar en ocasiones no queda bien definido, además se recomienda la milenrama (Achillea millefolium), el hinojo (Foeniculum vulgare) o la hierba de la cólica (Thymus pulegioides), que en su nombre ya señala la relevancia de su uso contra los cólicos.

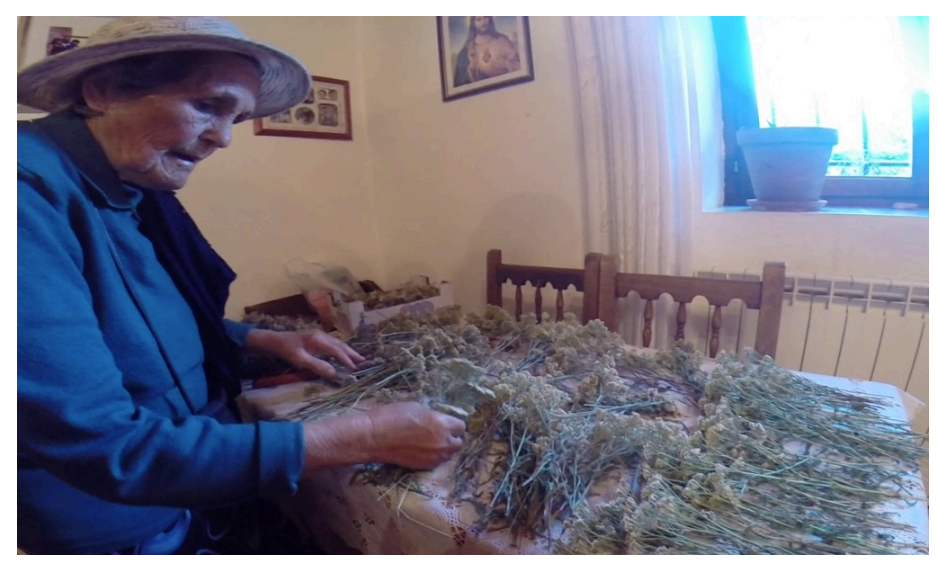

FIGURA 37: Oliva de La Lastra secando milenrama.

En cuanto a remedios laxantes destaca el aceite de ricino (Ricinus communis) conocido purgante que se obtenía en las boticas, y como remedios astringentes se señalan nuevamente las infusiones de tés, manzanillas, poleos o milenrama, además la hierba de la colitis (Lythrum salicaria), o remedios más contemporáneos como cocer arroz (Oryza sativa) o tomar jugo de limón (Citrus limon).

Todas las especies hasta el momento referenciadas son muy apreciadas también en multitud de zonas de la Península Ibérica: Pirineo Aragonés (Villar et al., 1987), Campoo (Pardo de Santayana, 2008), Sierra Norte de Madrid (Aceituno Mata, 2010), Salamanca (Velasco et al., 2010) y Ávila (Blanco, 2015).

Resulta interesante el uso aperitivo que se daba a la genciana (Gentiana lutea), los preparados a base del rizoma, podían llevarse a cabo a través de infusión, cocimiento, maceración en vino, orujo o agua, e incluso directamente chupado, difíciles de digerir por los más jóvenes por el intenso amargor referido, pero que estimulaban el apetito de forma eficaz.

En la sección de plantas empleadas en salud dental se distingue el beleño (Hyoscyamus niger) cuyas semillas hervidas y colocadas mediante cataplasma en el carrillo sobre la pieza dolorida ejercían un efecto narcótico, también los vahos producidos por las semillas sobre brasas tenían efectos calmantes, creyéndose que las caries desaparecían con este método. Según Villar et al. (1987), se trata de un típico ejemplo de curación mimética dado el parecido del fruto con una pieza dentaria, señalando que en el Pirineo Aragonés se aspiraban los humos haciéndolos incidir en el lugar dolorido, usando tanto el beleño como el saúco (Sambucus nigra), idénticas especies y prácticas que las de nuestra zona de estudio. También con los granos de centeno (Secale cereale) o trigo (Triticum aestivum) se preparaba una pasta que se disponía sobre las muelas doloridas. 


\section{Sistema genito-urinario:}

Se han recogido 50 registros de uso, correspondientes a 17 taxones de 9 familias botánicas diferentes, 16 de obtención silvestre y 1 cultivado, representando un 4,01\% del total de registros de uso para la categoría medicina.

TABLA 36: Relación de taxones empleados en la subcategoría Sistema genito-urinario, ordenados alfabéticamente por familia, indicando número de registros de uso (RU), parte usada y empleo (modo de preparación y finalidad de uso).

\begin{tabular}{|c|c|c|c|c|}
\hline Familia & $\begin{array}{l}\text { Nombre científico } \\
\text { Nombre vulgar }\end{array}$ & RU & Parte usada & Empleo \\
\hline Betulaceae & $\begin{array}{l}\text { Betula pubescens } \\
\text { Abedul }\end{array}$ & 1 & Hojas & $\begin{array}{l}\text { Cocción } \\
\text { Diurético }\end{array}$ \\
\hline \multirow[t]{2}{*}{ Brassicaceae } & $\begin{array}{l}\text { Capsella bursa-pastoris } \\
\text { Bolsa de pastor }\end{array}$ & 1 & Parte aérea & $\begin{array}{l}\text { Infusión } \\
\text { Dolor menstrual }\end{array}$ \\
\hline & $\begin{array}{l}\text { Lepidium Iatifolium } \\
\text { Rompepiedras }\end{array}$ & 1 & Hojas & $\begin{array}{l}\text { Infusión } \\
\text { Diurética }\end{array}$ \\
\hline \multirow[t]{2}{*}{ Compositae } & $\begin{array}{l}\text { Achillea millefolium } \\
\text { Milenrama, birlenda, balsamina }\end{array}$ & 2 & Parte aérea & $\begin{array}{l}\text { Infusión, lavado } \\
\text { Infección vaginal }\end{array}$ \\
\hline & $\begin{array}{l}\text { Taraxacum campylodes } \\
\text { Achicoria, diente de león }\end{array}$ & 10 & Parte aérea & $\begin{array}{l}\text { Infusión } \\
\text { Diurética }\end{array}$ \\
\hline Equisetaceae & $\begin{array}{l}\text { Equisetum arvense } \\
\text { Cola de caballo, pinillo, escobilla }\end{array}$ & 14 & Parte aérea & $\begin{array}{c}\text { Infusión } \\
\text { Diurética, próstata }\end{array}$ \\
\hline \multirow[t]{4}{*}{ Ericaceae } & $\begin{array}{l}\text { Arctostaphylos uva-ursi } \\
\text { Gayuga, agayuga, gayuba }\end{array}$ & 1 & Fruto & $\begin{array}{l}\text { Directo } \\
\text { Diurético }\end{array}$ \\
\hline & $\begin{array}{l}\text { Calluna vulgaris } \\
\text { Brezo, graspo, brecina }\end{array}$ & 1 & Parte aérea & $\begin{array}{l}\text { Infusión } \\
\text { Diurética }\end{array}$ \\
\hline & $\begin{array}{l}\text { Erica spp. } \\
\text { Brezo, urz, ayuz, graspo }\end{array}$ & 3 & Parte aérea & $\begin{array}{l}\text { Infusión } \\
\text { Diurética }\end{array}$ \\
\hline & $\begin{array}{l}\text { Vaccinium myrtillus } \\
\text { Arráspano, ráspano, arándano }\end{array}$ & 2 & Fruto & $\begin{array}{c}\text { Directo } \\
\text { Infección urinaria }\end{array}$ \\
\hline Hypericaceae & $\begin{array}{l}\text { Hypericum perforatum } \\
\text { Hipérico, bergaula, pericón }\end{array}$ & 7 & Parte aérea & $\begin{array}{c}\text { Infusión } \\
\text { Retención, infección orina }\end{array}$ \\
\hline \multirow[t]{3}{*}{ Lamiaceae } & $\begin{array}{l}\text { Thymus mastichina } \\
\text { Tomillo, mejorana }\end{array}$ & 1 & Parte aérea & $\begin{array}{c}\text { Infusión } \\
\text { Dolor menstrual }\end{array}$ \\
\hline & $\begin{array}{l}\text { Thymus praecox } \\
\text { Tomillo, hierba la sabina, té }\end{array}$ & 2 & Parte aérea & $\begin{array}{l}\text { Infusión } \\
\text { Dolor menstrual }\end{array}$ \\
\hline & $\begin{array}{l}\text { Thymus zygis } \\
\text { Tomillo, cepico }\end{array}$ & 1 & Parte aérea & $\begin{array}{l}\text { Infusión } \\
\text { Próstata }\end{array}$ \\
\hline \multirow[t]{2}{*}{ Rosaceae } & $\begin{array}{l}\text { Filipendula ulmaria } \\
\text { Reina de los prados }\end{array}$ & 1 & Parte aérea & $\begin{array}{l}\text { Infusión } \\
\text { Diurética }\end{array}$ \\
\hline & $\begin{array}{l}\text { Rosa spp. } \\
\text { Zarza, espino, rosal, calambrojo }\end{array}$ & 1 & Fruto & $\begin{array}{l}\text { Cocción } \\
\text { Diurética }\end{array}$ \\
\hline Urticaceae & $\begin{array}{l}\text { Urtica dioica } \\
\text { Ortiga }\end{array}$ & 1 & Parte aérea & $\begin{array}{l}\text { Cocción } \\
\text { Dolor menstrual }\end{array}$ \\
\hline
\end{tabular}

Se incluyen en esta subcategoría las enfermedades relacionadas con el aparato excretor como la retención o incontinencia urinaria, infecciones renales y genitales, afecciones prostáticas y vaginales, así como dolencias del aparato reproductor, tanto masculino como femenino.

Varias especies coinciden en virtudes con las indicadas para el aparato circulatorio debido a la doble función que desempeñan depurativas y diuréticas. En el apartado de plantas diuréticas destacan la cola de caballo (Equisetum arvense), el diente de león (Taraxacum campylodes) y el hipérico (Hypericum perforatum), también denominado hierba de la orina en alusión a sus 
bondades para favorecer la eliminación de líquidos a través del riñón. El modo ordinario de administración en este orden es la infusión.

Cabe reseñar la importancia de la familia Ericaceae en este sistema, pues se utilizan brezos (Erica spp.), arráspanos (Vaccinium myrtillus), gayugas (Arctostaphylos uva-ursi) y graspos (Calluna vulgaris), las especies de esta familia también son destacados en la provincia de Castellón (Mulet, 1991) y en el municipio de Piloña (San Miguel, 2004). Las infecciones de orina se trababan con plantas con principios antibacterianos como el hipérico, y las propias relacionadas con el género femenino se indican lavados vaginales con infusión de milenrama (Achillea millefolium).

Para las alteraciones del ciclo menstrual y los dolores derivados del mismo se aconsejan los tomillos (Thymus mastichina, T. praecox), especies también recomendadas para problemas digestivos, manifestándose en ambos sistemas síntomas similares. Otra especie citada dentro de este grupo es la bolsa de pastor (Capsella bursa-pastoris), que ayuda a detener las menstruaciones abundantes.

No son muchas las especies recogidas para solventar afecciones genitales femeninas, quizás debido a un cierto secretismo, a la dificultad de empatía entre entrevistador e informante, o a que se citaran estas dolencias dentro de los síntomas del aparato digestivo.

\section{Sistema respiratorio:}

Se han recogido 300 registros de uso, correspondientes a 45 taxones de 23 familias botánicas diferentes, 32 taxones son de obtención silvestre, 10 cultivados y 3 comprados, representando un $24,04 \%$ del total de registros de uso para la categoría medicina.

TABLA 37: Relación de taxones empleados en la subcategoría Sistema respiratorio, ordenados alfabéticamente por familia, indicando número de registros de uso (RU), parte usada y empleo (modo de preparación y finalidad de uso).

\begin{tabular}{|c|c|c|c|c|}
\hline Familia & $\begin{array}{l}\text { Nombre cientifico } \\
\text { Nombre vulgar }\end{array}$ & RU & Parte usada & Empleo \\
\hline Adoxaceae & $\begin{array}{l}\text { Sambucus nigra } \\
\text { Saúco, saúgo, sabúgo, taco }\end{array}$ & 32 & Inflorescencia & $\begin{array}{l}\text { Infusión, vahos } \\
\text { Catarro y gripe }\end{array}$ \\
\hline \multirow[t]{2}{*}{ Amaryllidaceae } & $\begin{array}{l}\text { Allium cepa } \\
\text { Cebolla }\end{array}$ & 2 & Bulbo & $\begin{array}{l}\text { Cocción } \\
\text { Catarro }\end{array}$ \\
\hline & $\begin{array}{l}\text { Allium sativum } \\
\text { Ajo }\end{array}$ & 1 & Bulbo & $\begin{array}{c}\text { Vahos } \\
\text { Infección respiratoria }\end{array}$ \\
\hline \multirow[t]{2}{*}{ Apiaceae } & $\begin{array}{l}\text { Carum carvi } \\
\text { Anís }\end{array}$ & 1 & Inflorescencia & $\begin{array}{l}\text { Infusión } \\
\text { Catarro }\end{array}$ \\
\hline & $\begin{array}{l}\text { Scandix australis } \\
\text { Anís, anís de lastra }\end{array}$ & 1 & Parte aérea & $\begin{array}{l}\text { Infusión } \\
\text { Catarro }\end{array}$ \\
\hline \multirow[t]{3}{*}{ Boraginaceae } & $\begin{array}{l}\text { Glandora diffusa } \\
\text { Hierba } 7 \text { sangrías, } 7 \text { sangrías }\end{array}$ & 1 & Parte aérea & $\begin{array}{l}\text { Infusión } \\
\text { Bronquitis }\end{array}$ \\
\hline & $\begin{array}{l}\text { Pentaglotis sempervirens } \\
\text { Borraja }\end{array}$ & 1 & Hojas & $\begin{array}{l}\text { Cocción } \\
\text { Catarro }\end{array}$ \\
\hline & $\begin{array}{l}\text { Pulmonaria longifolia } \\
\text { Pulmonaria }\end{array}$ & 2 & Hojas & $\begin{array}{l}\text { Infusión } \\
\text { Pulmonía }\end{array}$ \\
\hline Brassicaceae & $\begin{array}{l}\text { Sinapis alba } \\
\text { Mostaza }\end{array}$ & 3 & Comprada & $\begin{array}{l}\text { Cataplasma } \\
\text { Gripe }\end{array}$ \\
\hline Compositae & $\begin{array}{l}\text { Achillea millefolium } \\
\text { Milenrama, birlenda, balsamina }\end{array}$ & 1 & Parte aérea & $\begin{array}{l}\text { Infusión } \\
\text { Catarro }\end{array}$ \\
\hline
\end{tabular}




\begin{tabular}{|c|c|c|c|c|}
\hline \multirow{2}{*}{$\begin{array}{ll}\text { TABLA 37: } & \begin{array}{l}\text { (Contin } \\
\text { alfabéti } \\
\text { prepara }\end{array} \\
\text { Familia } & \end{array}$} & \multirow{2}{*}{$\begin{array}{l}\text { n) Relación de taxones empleado } \\
\text { ente por familia, indicando número d } \\
\text { y finalidad de uso). } \\
\text { Nombre científico } \\
\text { Nombre vulgar }\end{array}$} & \multirow{2}{*}{$\begin{array}{l}\text { en la } \\
\text { registrc } \\
\text { RU }\end{array}$} & \multicolumn{2}{|c|}{$\begin{array}{l}\text { subcategoría Sistema respiratorio, ordenados } \\
\text { ss de uso (RU), parte usada y empleo (modo de }\end{array}$} \\
\hline & & & Parte usada & Empleo \\
\hline \multirow[t]{4}{*}{ Compositae } & $\begin{array}{l}\text { Chamaemelum nobile } \\
\text { Manzanilla, manzanilla campera }\end{array}$ & 4 & Sumidad floral & $\begin{array}{l}\text { Infusión } \\
\text { Catarro }\end{array}$ \\
\hline & $\begin{array}{l}\text { Helichrysum stoechas } \\
\text { Manzanilla, manzanilla de peña }\end{array}$ & 5 & Sumidad floral & $\begin{array}{l}\text { Infusión } \\
\text { Catarro }\end{array}$ \\
\hline & $\begin{array}{l}\text { Inula montana } \\
\text { Árnica }\end{array}$ & 2 & Inflorescencia & $\begin{array}{l}\text { Infusión } \\
\text { Pulmonía }\end{array}$ \\
\hline & $\begin{array}{l}\text { Tussilago farfara } \\
\text { Hoja de chupón }\end{array}$ & 1 & Hojas & $\begin{array}{l}\text { Infusión } \\
\text { Antitusivo }\end{array}$ \\
\hline Gentianaceae & $\begin{array}{l}\text { Gentiana lutea } \\
\text { Junciana, genciana }\end{array}$ & 10 & Rizoma & $\begin{array}{c}\text { Cocción } \\
\text { Infección respiratoria }\end{array}$ \\
\hline \multirow[t]{10}{*}{ Lamiaceae } & $\begin{array}{l}\text { Marrubium vulgare } \\
\text { Marrubio }\end{array}$ & 2 & Parte aérea & $\begin{array}{l}\text { Infusión } \\
\text { Catarro }\end{array}$ \\
\hline & $\begin{array}{l}\text { Mentha aquatica } \\
\text { Hierbabuena, menta }\end{array}$ & 3 & Parte aérea & $\begin{array}{l}\text { Infusión } \\
\text { Catarro }\end{array}$ \\
\hline & $\begin{array}{l}\text { Mentha longifolia } \\
\text { Poleo, té de menta, menta poleo }\end{array}$ & 4 & Parte aérea & $\begin{array}{l}\text { Infusión } \\
\text { Catarro }\end{array}$ \\
\hline & $\begin{array}{l}\text { Mentha pulegium } \\
\text { Té de menta, menta poleo, poleo }\end{array}$ & 2 & Parte aérea & $\begin{array}{l}\text { Infusión } \\
\text { Catarro }\end{array}$ \\
\hline & $\begin{array}{l}\text { Origanum vulgare } \\
\text { Orégano }\end{array}$ & 57 & Sumidad floral & $\begin{array}{c}\text { Infusión, vahos } \\
\text { Catarro }\end{array}$ \\
\hline & $\begin{array}{l}\text { Rosmarinus officinalis } \\
\text { Romero }\end{array}$ & 2 & Parte aérea & $\begin{array}{l}\text { Infusión } \\
\text { Catarro }\end{array}$ \\
\hline & $\begin{array}{l}\text { Salvia officinalis } \\
\text { Salvia }\end{array}$ & 2 & Parte aérea & $\begin{array}{l}\text { Infusión } \\
\text { Dolor garganta }\end{array}$ \\
\hline & $\begin{array}{l}\text { Sideritis hyssopifolia } \\
\text { Té, té de roca, té de lastra }\end{array}$ & 6 & Sumidad floral & $\begin{array}{l}\text { Infusión } \\
\text { Catarro }\end{array}$ \\
\hline & $\begin{array}{l}\text { Thymus mastichina } \\
\text { Tomillo, mejorana }\end{array}$ & 8 & Parte aérea & $\begin{array}{l}\text { Infusión } \\
\text { Catarro }\end{array}$ \\
\hline & $\begin{array}{l}\text { Thymus zygis } \\
\text { Tomillo, cepico }\end{array}$ & 17 & Parte aérea & $\begin{array}{l}\text { Infusión, vahos } \\
\text { Catarro, garganta }\end{array}$ \\
\hline Leguminosae & $\begin{array}{l}\text { Melilotus officinalis } \\
\text { Meliloto }\end{array}$ & 1 & Parte aérea & $\begin{array}{l}\text { Infusión } \\
\text { Catarro }\end{array}$ \\
\hline Linaceae & $\begin{array}{l}\text { Linum usitatissimum } \\
\text { Lino }\end{array}$ & 1 & Semilla & $\begin{array}{l}\text { Cataplasma } \\
\text { Catarro }\end{array}$ \\
\hline \multirow[t]{3}{*}{ Malvaceae } & $\begin{array}{l}\text { Althaea officinalis } \\
\text { Malvarisco, malvavisco }\end{array}$ & 7 & Raíz & $\begin{array}{l}\text { Infusión, vahos, jarabe } \\
\text { Catarro }\end{array}$ \\
\hline & $\begin{array}{l}\text { Malva sylvestris } \\
\text { Malva, flor de malva }\end{array}$ & 55 & Parte aérea & $\begin{array}{l}\text { Infusión, vahos } \\
\text { Catarro }\end{array}$ \\
\hline & $\begin{array}{l}\text { Tilia platyphylos } \\
\text { Tilo }\end{array}$ & 3 & Flor & $\begin{array}{l}\text { Infusión } \\
\text { Catarro }\end{array}$ \\
\hline Myrtaceae & $\begin{array}{l}\text { Eucalyptus globulus } \\
\text { Eucalipto, eucalito }\end{array}$ & 9 & Hojas & $\begin{array}{c}\text { Vahos } \\
\text { Infección respiratoria }\end{array}$ \\
\hline Papaveraceae & $\begin{array}{l}\text { Papaver rhoeas } \\
\text { Amapola, pirigallo }\end{array}$ & 4 & Parte aérea & $\begin{array}{l}\text { Infusión } \\
\text { Catarro }\end{array}$ \\
\hline Plantaginaceae & $\begin{array}{l}\text { Plantago lanceolata } \\
\text { Hoja de lentén, Ilantén, lentel }\end{array}$ & 5 & Hojas & $\begin{array}{l}\text { Infusión } \\
\text { Catarro }\end{array}$ \\
\hline Primulaceae & $\begin{array}{l}\text { Primula veris } \\
\text { Cuquillo, chupa, bragas de cuco }\end{array}$ & 1 & Raíz & $\begin{array}{l}\text { Cocción } \\
\text { Infección respiratoria }\end{array}$ \\
\hline \multirow[t]{2}{*}{ Rosaceae } & $\begin{array}{l}\text { Crataegus monogyna } \\
\text { Espino, espino albar, majueto }\end{array}$ & 6 & Flor & $\begin{array}{l}\text { Infusión } \\
\text { Catarro }\end{array}$ \\
\hline & $\begin{array}{l}\text { Malus domestica } \\
\text { Manzano }\end{array}$ & 1 & Fruto & $\begin{array}{l}\text { Infusión } \\
\text { Catarro }\end{array}$ \\
\hline
\end{tabular}




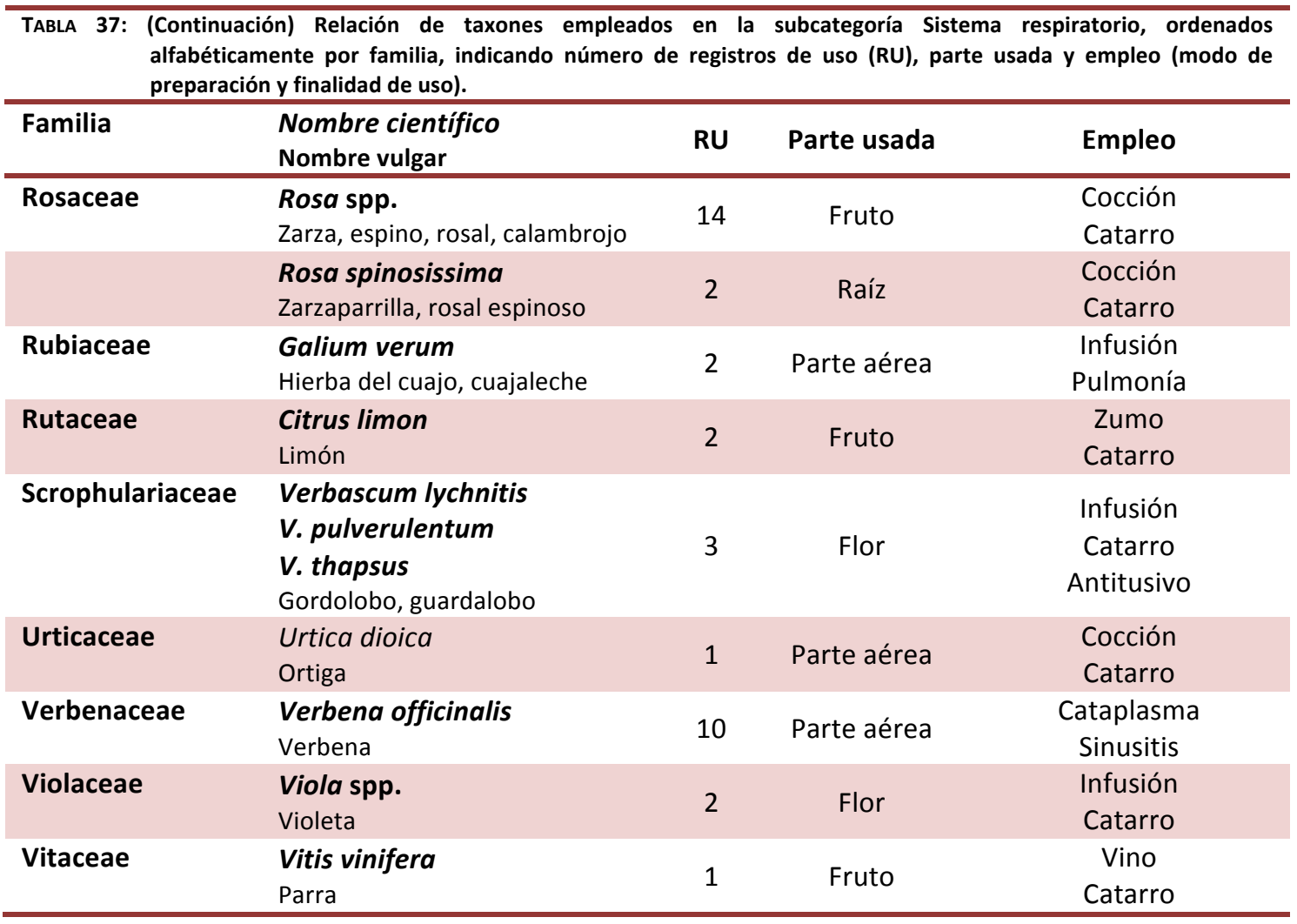

Dentro del sistema respiratorio se agrupan todas las posibles afecciones respiratorias, desde las más leves como catarro, resfriado, gripe, tos, ronquera o faringitis, hasta las más severas como bronquitis o pulmonía, algunas de ellas no son propiamente de las vías respiratorias pero el tratamiento es similar.

Para combatir las más leves se toman multitud de remedios caseros con plantas, resultando el orégano (Origanum vulgare), la malva (Malva sylvestris) y el saúco (Sambucus nigra) las especies que mayores registros de uso han obtenido en esta subcategoría, y que además se toman generalmente en infusión o a través de vahos, para curar los catarros. Se trata de especies muy populares y con un uso tradicional en la zona contrastado, en ocasiones se combinan entre ellas y con otras plantas para potenciar sus efectos anticatarrales. También se distinguen otras especies como los tomillos (Thymus mastichina, T. zygis), el calambrojo (Rosa spp.), el té (Sideritis hyssopifolia) o el gordobolobo (Verbascum spp.), todas ellas administradas mediante infusiones, cocciones o vahos, y que muestran la gran cantidad de remedios y especies recopilados en este apartado.

En la localidad de Triollo se elaboraba una especie de jarabe cociendo la raíz de malvarisco (Althaea officinalis) junto con higos y orégano, una vez colado se servía una cucharadita durante unos días para tratar el catarro de los más pequeños.

Las infecciones respiratorias se atendían aspirando los vapores resultantes del cocimiento de plantas con propiedades antisépticas, como el eucalipto (Eucaliptus globulus), aunque no es una planta autóctona, si se comerciaba con ella desde las cercanas provincias de Asturias y Cantabria.

Infecciones más severas de tipo bronquial o pulmonar se tratan con genciana (Gentiana lutea), a través de cocciones o macerados en agua, orujo o vino, al igual que en los Picos de Europa 
(Lastra, 2004). También se utiliza en estos casos, la hierba del cuajo (Galium verum) conocida para este uso medicinal como hierba de la pulmonía y el árnica (Inula montana).

Otro método extendido en el pasado para las afecciones respiratorias fueron las cataplasmas de semillas de mostaza (Sinapis alba), adquiridas en las boticas y colocadas dentro de una bolsa caliente sobre el pecho. También la cataplasma de verbena (Verbena officinalis) resultaba eficaz para combatir la sinusitis, para conseguirla se fríe la parte aérea en una clara de huevo y se coloca esta especie de tortilla sobre la frente.

En cuanto a los problemas derivados de la garganta se utilizan varias de las plantas ya mencionadas, como el tomillo (Thymus zygis) o el gordobolobo (Verbascum spp.), y significar también la hoja de chupón (Tussilago farfara) como antitusivo, ya que según Font Quer (1961) se consideró planta eficaz para la tos desde tiempos remotos e incluso su nombre procede del latín tussis que significa tos.

\section{Sistema endocrino-metabólico:}

Se han recogido 3 registros de uso, correspondientes a 2 taxones de obtención silvestre de la familia Compositae, representando un $0,24 \%$ del total de registros de uso para la categoría medicina.

TABLA 38: Relación de especies empleadas en la subcategoría Sistema endocrino-metabólico, ordenadas alfabéticamente por familia, indicando número de registros de uso (RU), parte usada y empleo (modo de preparación y finalidad de uso).

\begin{tabular}{|c|c|c|c|c|}
\hline Familia & $\begin{array}{l}\text { Nombre científico } \\
\text { Nombre vulgar }\end{array}$ & RU & Parte usada & Empleo \\
\hline \multirow[t]{2}{*}{ Compositae } & $\begin{array}{l}\text { Arctium minus } \\
\text { Amargacho, capacho, pegote }\end{array}$ & 2 & Hojas & $\begin{array}{l}\text { Infusión } \\
\text { Diabetes }\end{array}$ \\
\hline & $\begin{array}{l}\text { Taraxacum campylodes } \\
\text { Achicoria, diente de león }\end{array}$ & 1 & Parte aérea & $\begin{array}{l}\text { Infusión } \\
\text { Colesterol }\end{array}$ \\
\hline
\end{tabular}

Se tratan en este apartado trastornos del metabolismo y la nutrición, encontrando dos registros de uso del amargacho (Arctium minus) como reductor del nivel de azúcar en la sangre ante problemas diabéticos. En la Península Ibérica no hemos encontrado similitud de uso para esta especie, si en Francia, que se describe como antidiabético por Delaveau et al. (1981).

Solamente un registro de uso se ha recogido para tratar el colesterol, con la infusión del diente de león (Taraxacum campylodes). La explicación a este escaso número de registros es que en el pasado no se tenía información sobre este tipo de afecciones, en algunos casos ligadas a cambios en los hábitos de alimentación de la sociedad moderna actual.

\section{Musculatura y esqueleto:}

Se han recogido 146 registros de uso, correspondientes a 20 taxones de 12 familias botánicas diferentes, 18 taxones de obtención silvestre y 2 cultivados, representando un $11,70 \%$ del total de registros de uso para la categoría medicina. 
TABLA 39: Relación de especies empleadas en la subcategoría Musculatura y esqueleto, ordenadas alfabéticamente por familia, indicando número de registros de uso (RU), parte usada y empleo (modo de preparación y finalidad de uso).

\begin{tabular}{|c|c|c|c|c|}
\hline Familia & $\begin{array}{l}\text { Nombre científico } \\
\text { Nombre vulgar }\end{array}$ & $\mathbf{R U}$ & Parte usada & Empleo \\
\hline \multirow[t]{2}{*}{ Adoxaceae } & $\begin{array}{l}\text { Sambucus ebulus } \\
\text { Nuezgo, yezgo }\end{array}$ & 1 & Planta & $\begin{array}{l}\text { Cocción } \\
\text { Reuma }\end{array}$ \\
\hline & $\begin{array}{l}\text { Sambucus nigra } \\
\text { Saúco, saúgo, sabúgo, taco }\end{array}$ & 20 & Inflorescencia & $\begin{array}{l}\text { Cataplasma } \\
\text { Traumatismos }\end{array}$ \\
\hline Betulaceae & $\begin{array}{l}\text { Betula pubescens } \\
\text { Abedul }\end{array}$ & 1 & Hojas & $\begin{array}{l}\text { Cocción } \\
\text { Reuma }\end{array}$ \\
\hline \multirow[t]{7}{*}{ Compositae } & $\begin{array}{l}\text { Achillea millefolium } \\
\text { Milenrama, birlenda, balsamina }\end{array}$ & 2 & Parte aérea & $\begin{array}{l}\text { Infusión } \\
\text { Artrosis }\end{array}$ \\
\hline & $\begin{array}{l}\text { Calendula officinalis } \\
\text { Maravilla, caléndula, clavel }\end{array}$ & 1 & Inflorescencia & $\begin{array}{c}\text { Crema } \\
\text { Dolor muscular }\end{array}$ \\
\hline & $\begin{array}{l}\text { Centaurea lagascana } \\
\text { Arzolla, cardo de arzolla }\end{array}$ & 6 & Parte aérea & $\begin{array}{l}\text { Cataplasma } \\
\text { Traumatismos }\end{array}$ \\
\hline & $\begin{array}{l}\text { Chamaemelum nobile } \\
\text { Manzanilla, manzanilla } \\
\text { campera }\end{array}$ & 1 & Sumidad floral & $\begin{array}{l}\text { Infusión } \\
\text { Reuma }\end{array}$ \\
\hline & $\begin{array}{l}\text { Inula montana } \\
\text { Árnica }\end{array}$ & 83 & Inflorescencia & $\begin{array}{c}\text { Maceración alcohol o } \\
\text { aceite, baños. } \\
\text { Traumatismos }\end{array}$ \\
\hline & $\begin{array}{l}\text { Jacobaea vulgaris } \\
\text { Bujanera, hierba de Santiago }\end{array}$ & 1 & Parte aérea & $\begin{array}{c}\text { Cataplasma } \\
\text { Golpes }\end{array}$ \\
\hline & $\begin{array}{l}\text { Taraxacum campylodes } \\
\text { Achicoria, diente de león }\end{array}$ & 1 & Parte aérea & $\begin{array}{l}\text { Infusión } \\
\text { Reuma }\end{array}$ \\
\hline Equisetaceae & $\begin{array}{l}\text { Equisetum arvense } \\
\text { Cola de caballo, pinillo, } \\
\text { escobilla }\end{array}$ & 3 & Parte aérea & $\begin{array}{l}\text { Infusión } \\
\text { Reuma }\end{array}$ \\
\hline Hypericaceae & $\begin{array}{l}\text { Hypericum perforatum } \\
\text { Hipérico, bergaula, pericón }\end{array}$ & 6 & Parte aérea & $\begin{array}{l}\text { Maceración aceite } \\
\text { Dolor muscular }\end{array}$ \\
\hline Juglandaceae & $\begin{array}{l}\text { Juglans regia } \\
\text { Nogal }\end{array}$ & 1 & Hojas & $\begin{array}{c}\text { Cataplasma } \\
\text { Golpes }\end{array}$ \\
\hline Lamiaceae & $\begin{array}{l}\text { Rosmarinus officinalis } \\
\text { Romero }\end{array}$ & 2 & Parte aérea & $\begin{array}{c}\text { Cocción, cataplasma, } \\
\text { alcohol } \\
\text { Golpes }\end{array}$ \\
\hline \multirow[t]{2}{*}{ Malvaceae } & $\begin{array}{l}\text { Malva moschata } \\
\text { Malva }\end{array}$ & 1 & Fruto & $\begin{array}{c}\text { Directo } \\
\text { Inflamación muscular }\end{array}$ \\
\hline & $\begin{array}{l}\text { Malva sylvestris } \\
\text { Malva, flor de malva }\end{array}$ & 4 & Parte aérea & $\begin{array}{c}\text { Cataplasma } \\
\text { Traumatismos }\end{array}$ \\
\hline Oleaceae & $\begin{array}{l}\text { Fraxinus excelsior } \\
\text { Fresno }\end{array}$ & 2 & $\begin{array}{l}\text { Corteza y } \\
\text { hojas }\end{array}$ & $\begin{array}{c}\text { Cataplasma } \\
\text { Reuma y dolor muscular }\end{array}$ \\
\hline Scrophulariaceae & $\begin{array}{l}\text { Verbascum lychnitis } \\
\text { V. pulverulentum } \\
\text { V. thapsus } \\
\text { Gordolobo, guardalobo }\end{array}$ & 3 & Hojas & $\begin{array}{l}\text { Cataplasma } \\
\text { Golpes }\end{array}$ \\
\hline Solanaceae & $\begin{array}{l}\text { Hyoscyamus niger } \\
\text { Beleño }\end{array}$ & 3 & Semilla & $\begin{array}{c}\text { Cataplasma } \\
\text { Traumatismos }\end{array}$ \\
\hline Urticaceae & $\begin{array}{l}\text { Urtica dioica } \\
\text { Ortiga }\end{array}$ & 4 & Parte aérea & $\begin{array}{c}\text { Cocción y maceración } \\
\text { aceite } \\
\text { Reuma }\end{array}$ \\
\hline
\end{tabular}

En la subcategoría Musculatura y esqueleto se engloban afecciones inflamatorias musculares y articulares, dolores musculares y óseos, contusiones, luxaciones y traumatismos, también reúma, ciática o lumbalgia. 
Para el tratamiento de contusiones, golpes, moratones, etc, el árnica (Inula montana) destaca como un antiinflamatorio, empleado de forma tradicional en múltiples aplicaciones, macerado en aceite o alcohol, en cocción con cataplasmas o directamente en baños sobre la zona afectada. Se han recopilado hasta 83 registros de uso sobre el empleo de esta planta, dando idea de la enorme popularidad que posee en la zona de estudio. Le siguen en importancia el saúco (Sambucus nigra) y la arzolla (Centaurea lagascana) para tratar la misma problemática.

Los dolores musculares se combaten con plantas con propiedades analgésicas, además del árnica, el aceite de hipérico (Hypericum perforatum) y el alcohol de romero (Rosmarinus officinalis) resultan las más indicadas. También las semillas de beleño (Hyoscyamus niger) fritas en aceite y aplicadas en cataplasma sirven como analgésicas y antiinflamatorias, en la comarca zamorana del Sayago son las hojas y no las semillas las que se fríen para el mismo tratamiento (Gallego \& Gallego, 2008).

En cuanto a dolores articulares del tipo artritis o reuma, se tratan con ortiga (Urtica dioica), cola de caballo (Equisetum arvense), milenrama (Achillea millefolium) y fresno (Fraxinus angustifolia).

\section{Piel y tejido celular subcutáneo:}

Se han recogido 109 registros de uso, correspondientes a 28 taxones de 18 familias botánicas diferentes, 25 taxones de obtención silvestre y 3 cultivados, representando un $8,73 \%$ del total de registros de uso para la categoría medicina.

TABLA 40: Relación de especies empleadas en la subcategoría Piel y tejido celular subcutáneo, ordenadas alfabéticamente por familia, indicando número de registros de uso (RU), parte usada y empleo (modo de preparación y finalidad de uso).

\begin{tabular}{|c|c|c|c|c|}
\hline Familia & $\begin{array}{l}\text { Nombre científico } \\
\text { Nombre vulgar }\end{array}$ & RU & Parte usada & Empleo \\
\hline Adoxaceae & $\begin{array}{l}\text { Sambucus nigra } \\
\text { Saúco, saúgo, sabúgo, taco }\end{array}$ & 11 & $\begin{array}{l}\text { Inflorescencia } \\
\text { y parénquima }\end{array}$ & $\begin{array}{l}\text { Infusión y crema } \\
\text { Heridas y quemaduras }\end{array}$ \\
\hline Amaryllidaceae & $\begin{array}{l}\text { Allium cepa } \\
\text { Cebolla }\end{array}$ & 5 & Bulbo & $\begin{array}{l}\text { Cataplasma } \\
\text { Diviesos }\end{array}$ \\
\hline Araliaceae & $\begin{array}{l}\text { Hedera helix } \\
\text { Hiedra, yedra, enredadera }\end{array}$ & 1 & Hojas & $\begin{array}{l}\text { Cataplasma } \\
\text { Heridas }\end{array}$ \\
\hline \multirow[t]{8}{*}{ Compositae } & $\begin{array}{l}\text { Calendula officinalis } \\
\text { Maravilla, caléndula, clavel }\end{array}$ & 2 & Inflorescencia & $\begin{array}{c}\text { Maceración aceite } \\
\text { Heridas }\end{array}$ \\
\hline & $\begin{array}{l}\text { Carthamus mitissimus } \\
\text { Arzolla }\end{array}$ & 1 & Parte aérea & $\begin{array}{l}\text { Maceración orujo } \\
\text { Heridas }\end{array}$ \\
\hline & $\begin{array}{l}\text { Centaurea lagascana } \\
\text { Arzolla, cardo de arzolla }\end{array}$ & 6 & Parte aérea & $\begin{array}{l}\text { Cocción } \\
\text { Heridas profundas }\end{array}$ \\
\hline & $\begin{array}{l}\text { Inula helvetica } \\
\text { Árnica }\end{array}$ & 1 & Parte aérea & $\begin{array}{l}\text { Maceración orujo } \\
\text { Heridas }\end{array}$ \\
\hline & $\begin{array}{l}\text { Inula montana } \\
\text { Árnica }\end{array}$ & 16 & Inflorescencia & $\begin{array}{l}\text { Cocción } \\
\text { Heridas }\end{array}$ \\
\hline & $\begin{array}{l}\text { Jurinea humilis } \\
\text { Arzolla }\end{array}$ & 5 & Parte aérea & $\begin{array}{l}\text { Cataplasma } \\
\text { Heridas }\end{array}$ \\
\hline & $\begin{array}{l}\text { Taraxacum campylodes } \\
\text { Achicoria, diente de león }\end{array}$ & 3 & Látex & $\begin{array}{l}\text { Directo } \\
\text { Verrugas }\end{array}$ \\
\hline & $\begin{array}{l}\text { Tussilago farfara } \\
\text { Hoja de chupón }\end{array}$ & 1 & Hojas & $\begin{array}{l}\text { Directa } \\
\text { Heridas }\end{array}$ \\
\hline Crassulaceae & $\begin{array}{l}\text { Sempervivum vicentei } \\
\text { Siempreviva, suelda, sanalotodo }\end{array}$ & 6 & Hojas & $\begin{array}{c}\text { Directo } \\
\text { Heridas y quemaduras }\end{array}$ \\
\hline
\end{tabular}




\begin{tabular}{|c|c|c|c|c|}
\hline \multicolumn{5}{|c|}{$\begin{array}{l}\text { TABLA 40: (Continuación) Relación de especies empleadas en la subcategoría Piel y tejido celular subcutáneo, ordenadas } \\
\text { alfabéticamente por familia, indicando número de registros de uso (RU), parte usada y empleo (modo de } \\
\text { preparación y finalidad de uso). }\end{array}$} \\
\hline Familia & $\begin{array}{l}\text { Nombre científico } \\
\text { Nombre vulgar }\end{array}$ & RU & Parte usada & Empleo \\
\hline Crassulaceae & $\begin{array}{l}\text { Umbilicus rupestris } \\
\text { Sombrerillos }\end{array}$ & 1 & Hojas & $\begin{array}{l}\text { Directa } \\
\text { Heridas }\end{array}$ \\
\hline Hypericaceae & $\begin{array}{l}\text { Hypericum perforatum } \\
\text { Hipérico, bergaula, pericón }\end{array}$ & 3 & Parte aérea & $\begin{array}{c}\text { Maceración aceite o } \\
\text { cocción } \\
\text { Heridas }\end{array}$ \\
\hline Juglandaceae & $\begin{array}{l}\text { Juglans regia } \\
\text { Nogal }\end{array}$ & 3 & Hojas & $\begin{array}{l}\text { Cocción } \\
\text { Grietas y heridas }\end{array}$ \\
\hline \multirow[t]{3}{*}{ Lamiaceae } & $\begin{array}{l}\text { Marrubium vulgare } \\
\text { Marrubio }\end{array}$ & 1 & Parte aérea & $\begin{array}{l}\text { Baños } \\
\text { Callos }\end{array}$ \\
\hline & $\begin{array}{l}\text { Salvia pratensis } \\
\text { Salvia }\end{array}$ & 1 & Parte aérea & $\begin{array}{l}\text { Maceración aceite } \\
\text { Heridas }\end{array}$ \\
\hline & $\begin{array}{l}\text { Salvia verbenaca } \\
\text { Hierba de Santa Lucía, balsamina }\end{array}$ & 1 & Parte aérea & $\begin{array}{l}\text { Maceración aceite } \\
\text { Heridas }\end{array}$ \\
\hline Malvaceae & $\begin{array}{l}\text { Malva sylvestris } \\
\text { Malva, flor de malva }\end{array}$ & 5 & Parte aérea & $\begin{array}{l}\text { Cocción } \\
\text { Heridas }\end{array}$ \\
\hline Oleaceae & $\begin{array}{l}\text { Fraxinus excelsior } \\
\text { Fresno }\end{array}$ & 1 & Corteza & $\begin{array}{l}\text { Cataplasma } \\
\text { Heridas }\end{array}$ \\
\hline Papaveraceae & $\begin{array}{l}\text { Chelidonium majus } \\
\text { Planta del yodo, celidonia }\end{array}$ & 20 & Látex & $\begin{array}{l}\text { Directo } \\
\text { Heridas }\end{array}$ \\
\hline Plantaginaceae & $\begin{array}{l}\text { Plantago lanceolata } \\
\text { Hoja de lentén, Ilantén, lentel }\end{array}$ & 5 & Hojas & $\begin{array}{l}\text { Directa } \\
\text { Heridas }\end{array}$ \\
\hline Rosaceae & $\begin{array}{l}\text { Rosa spinosissima } \\
\text { Zarzaparrilla, rosal espinoso }\end{array}$ & 2 & Raíz & $\begin{array}{c}\text { Cocción } \\
\text { Diviesos y granos }\end{array}$ \\
\hline Rubiaceae & $\begin{array}{l}\text { Galium verum } \\
\text { Hierba del cuajo, cuajaleche }\end{array}$ & 2 & Parte aérea & $\begin{array}{c}\text { Directa machacada } \\
\text { Heridas }\end{array}$ \\
\hline Rutaceae & $\begin{array}{l}\text { Ruta montana } \\
\text { Ruda }\end{array}$ & 1 & Parte aérea & $\begin{array}{c}\text { Crema } \\
\text { Quemaduras }\end{array}$ \\
\hline Sapindaceae & $\begin{array}{l}\text { Aesculus hippocastanum } \\
\text { Castaño de indias }\end{array}$ & 1 & Fruto & $\begin{array}{c}\text { Maceración alcohol } \\
\text { Heridas }\end{array}$ \\
\hline Urticaceae & $\begin{array}{l}\text { Urtica dioica } \\
\text { Ortiga }\end{array}$ & 3 & Planta & $\begin{array}{l}\text { Cocción } \\
\text { Dermatitis, alopecia }\end{array}$ \\
\hline Lycoperdaceae & $\begin{array}{l}\text { Lycoperdon perlatum } \\
\text { Pedo de lobo }\end{array}$ & 1 & Esporas & $\begin{array}{l}\text { Directo } \\
\text { Heridas }\end{array}$ \\
\hline
\end{tabular}

Los problemas relacionados con la piel son diversos, desde los más evidentes como heridas, quemaduras, rozaduras o granos, hasta trastornos capilares, dermatitis, verrugas o callos.

En la sección de heridas se emplean plantas vulnerarias para la limpieza, desinfección o cicatrización de la piel, entre ellas destaca el látex de la planta del yodo (Chelidonium majus) para la cicatrización de pequeñas heridas, también es recurrente el lavado de heridas con la cocción de ciertas especies como el árnica (Inula montana), la malva (Malva sylvestris) o el hipérico (Hypericum perforatum). Uno de los remedios infalibles para la cicatrización según Serafina Fuente informante de Celada de Roblecedo, dedicada durante años a la recogida y venta de plantas medicinales, era la cocción de hojas de nogal (Juglans regia).

Los casos de heridas profundas que requieren una cicatrización más aguda se atienden con las arzollas (Carthamus mitissimus, Centaurea lagascana y Jurinea humilis). En la zona de La Pernía, Valle de Castillería y Valle Estrecho designan arzolla a Centaurea lagascana, en San Felices de Castillería arzolla se identifica como Carthamus mitissimus, y hacia el este de la comarca, en la zona de Santullán, bajo ese mismo nombre se identifica a Jurinea humilis. En general, se utiliza el termino arzolla para denominar plantas empleadas como vulnerarias o 
para tratar diversos traumatismos, tanto en personas como en animales. Nos encontramos ante el caso particular, de que la nomenclatura popular atiende a un sistema clasificatorio basado en la utilidad de la planta. En la comarca vecina de Campoo arzolla refiere Carthamus mitissimus, (Pardo de Santayana, 2008), en la Sierra Norte de Madrid (Aceituno Mata, 2010) y en el Cerrato Palentino (Pascual et al., 2016) denominan arzolla a Centaurea ornata.

Otros remedios vulnerarios se realizan colocando hojas directamente sobre la herida, es el caso de la siempreviva (Sempervivum vicentei), de los sombrerillos (Umbilicus rupestris), y también la hoja del llantén (Plantago lanceolata) que actúa como cicatrizante de emergencia en el campo. Observamos que las hojas suculentas de la familia Crassulaceae son apreciadas para este tipo de remedios.

El parénquima cortical del saúco (Sambucus nigra) se emplea para elaborar una eficiente crema con propiedades cicatrizantes y regeneradoras para aliviar las quemaduras. La receta además incluye cera virgen de abeja y aceite de oliva, y en otras ocasiones la manteca es el ingrediente base de la crema. El tratamiento de quemaduras se realiza con este tipo de untos y cremas, pues en Matabuena se elabora una crema a base de ruda (Ruta montana), documentada también en otras zonas por varios autores (Villar et al., 1987; Mulet, 1991; Bonet, 2001).

Un remedio popular para madurar los molestos diviesos consiste en ablandarlos con cascos de cebolla (Allium cepa) fritos en un poco de aceite o mediante una cataplasma con la cocción de zarzaparrilla (Rosa spinosissima).

En el apartado tratamiento de las verrugas, se utiliza para cauterizarlas el látex de la planta del yodo (Chelidonium majus) o del diente de león (Taraxacum campylodes), métodos que en algunos casos no resultan eficaces si no se perseveran en el tiempo.

Destaca el empleo de ortigas (Urtica dioica) para detener la caída del cabello mediante baños con la cocción de la planta y macerada en alcohol ayuda a eliminar la caspa, eccemas o descamaciones derivadas de dermatitis.

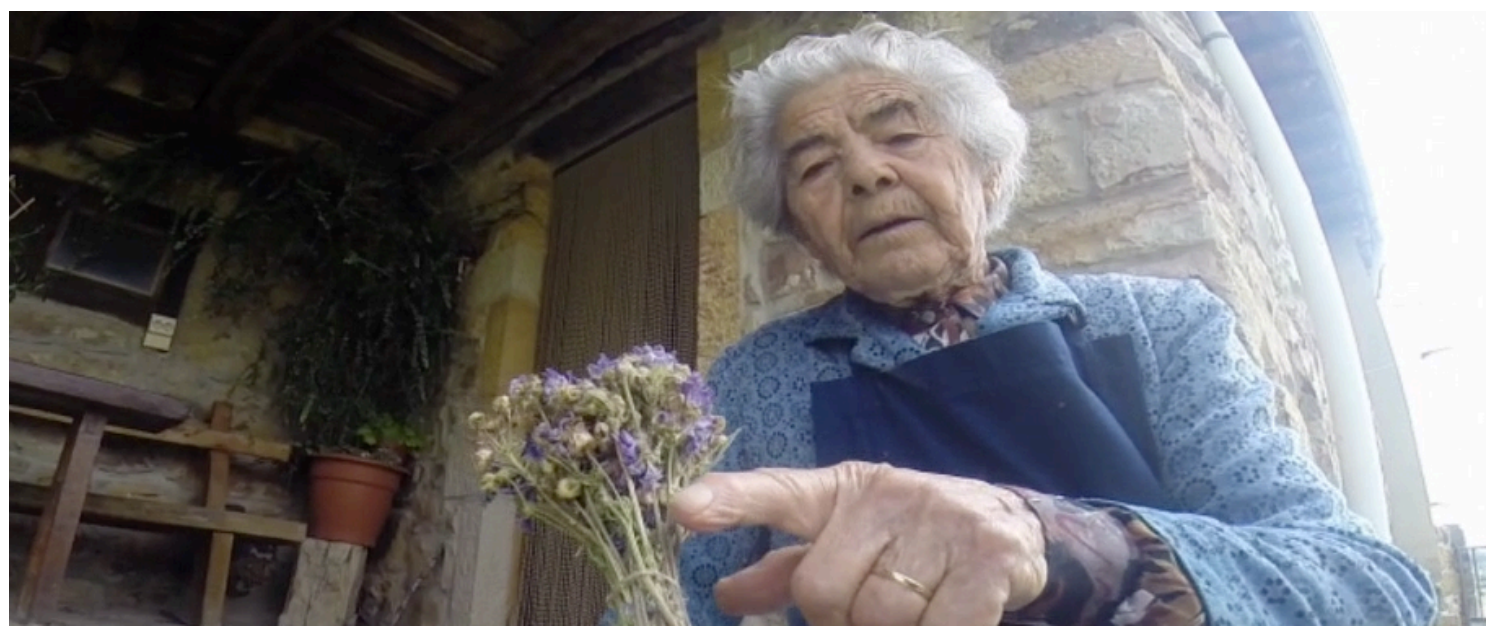

FIGURA 38: Edelmira de Celada de Roblecedo con atadillo de malvas. 


\section{Sistema nervioso y enfermedades mentales:}

Se han recogido 59 registros de uso, correspondientes a 10 taxones de obtención silvestre, de 10 familias botánicas diferentes, representando un $4,73 \%$ del total de registros de uso para la categoría medicina.

TABLA 41: Relación de especies empleadas en la subcategoría Sistema nervioso y enfermedades mentales, ordenadas alfabéticamente por familia, indicando número de registros de uso (RU), parte usada y empleo (modo de preparación y finalidad de uso).

\begin{tabular}{|c|c|c|c|c|}
\hline Familia & $\begin{array}{l}\text { Nombre cientifico } \\
\text { Nombre vulgar }\end{array}$ & RU & Parte usada & Empleo \\
\hline Adoxaceae & $\begin{array}{l}\text { Sambucus nigra } \\
\text { Saúco, saúgo, sabúgo, taco }\end{array}$ & 1 & Inflorescencia & $\begin{array}{c}\text { Cataplasma } \\
\text { Dolor de cabeza }\end{array}$ \\
\hline Caprifoliaceae & $\begin{array}{l}\text { Valeriana montana } \\
\text { Valeriana }\end{array}$ & 2 & Parte aérea & $\begin{array}{l}\text { Infusión } \\
\text { Insomnio }\end{array}$ \\
\hline Caryophyllaceae & $\begin{array}{l}\text { Paronychia kapela } \\
\text { Sanguinaria, flor de papel }\end{array}$ & 1 & Parte aérea & $\begin{array}{c}\text { Infusión } \\
\text { Dolor de cabeza }\end{array}$ \\
\hline Compositae & $\begin{array}{l}\text { Chamaemelum nobile } \\
\text { Manzanilla, manzanilla campera }\end{array}$ & 1 & Sumidad floral & $\begin{array}{l}\text { Infusión } \\
\text { Cefalea }\end{array}$ \\
\hline Hypericaceae & $\begin{array}{l}\text { Hypericum perforatum } \\
\text { Hipérico, bergaula, pericón }\end{array}$ & 5 & Parte aérea & $\begin{array}{c}\text { Infusión } \\
\text { Nervios y dolor de } \\
\text { cabeza }\end{array}$ \\
\hline Lamiaceae & $\begin{array}{l}\text { Melittis melissophyllum } \\
\text { Melisa }\end{array}$ & 4 & Parte aérea & $\begin{array}{c}\text { Infusión } \\
\text { Tranquilizante }\end{array}$ \\
\hline Malvaceae & $\begin{array}{l}\text { Tilia platyphylos } \\
\text { Tilo }\end{array}$ & 39 & Flor & $\begin{array}{l}\text { Infusión } \\
\text { Nerviosismo }\end{array}$ \\
\hline Papaveraceae & $\begin{array}{l}\text { Papaver rhoeas } \\
\text { Amapola, pirigallo }\end{array}$ & 3 & Parte aérea & $\begin{array}{l}\text { Infusión } \\
\text { Insomnio }\end{array}$ \\
\hline Primulaceae & $\begin{array}{l}\text { Primula veris } \\
\text { Cuquillo, chupa, bragas de cuco }\end{array}$ & 1 & Parte aérea & $\begin{array}{c}\text { Infusión } \\
\text { Dolor de cabeza }\end{array}$ \\
\hline Rosaceae & $\begin{array}{l}\text { Filipendula ulmaria } \\
\text { Reina de los prados }\end{array}$ & 2 & Parte aérea & $\begin{array}{l}\text { Infusión } \\
\text { Dolor de cabeza }\end{array}$ \\
\hline
\end{tabular}

Las patologías asociadas a este sistema se pueden resumir en nerviosismo, ansiedad o estrés, insomnio, y neuralgias o dolores más o menos intensos de cabeza.

Entre los remedios para tratar el nerviosismo, la ansiedad o el estrés se distingue con 39 registros de uso la muy conocida tila, administrada mediante infusión, popularizada además por su disponibilidad en el mercado a través de bolsitas infusionables. Otras especies también empleadas en esta sección son el hipérico (Hypericum perforatum) y la melisa (Melittis melissophyllum), de esta última Villar et al. (1987) comentan que a esta planta se la han encontrado virtudes sedantes y antisépticas.

Para conciliar el sueño se han recomendado dos plantas, la amapola (Papaver rhoeas) y la valeriana (Valeriana montana), aunque la especie más reconocida por su eficacia en la medicina popular en esta categoría a nivel nacional es Valeriana officinalis, también presente en la zona de estudio, en la Castillería se identificó a Valeriana montana para favorecer el sueño mediante infusión, resultando un uso inédito no documentado en la bibliografía consultada.

En cuanto a los dolores de cabeza se han atendido con infusiones de hipérico, reina de los prados (Filipendula ulmaria), sanguinaria (Paronychia kapela) o manzanilla (Chamaemelum nobile), y con cataplasmas sobre la frente con la cocción de saúco (Sambucus nigra). 


\section{Órganos de los sentidos:}

Se han recogido 43 registros de uso, correspondientes a 12 taxones de 8 familias botánicas diferentes, 11 taxones de obtención silvestre y 1 cultivado, representando un 3,45\% del total de registros de uso para la categoría medicina.

TABLA 42: Relación de taxones empleados en la subcategoría Órganos de los sentidos, ordenados alfabéticamente por familia, indicando número de registros de uso (RU), parte usada y empleo (modo de preparación y finalidad de uso).

\begin{tabular}{|c|c|c|c|c|}
\hline Familia & $\begin{array}{l}\text { Nombre científico } \\
\text { Nombre vulgar }\end{array}$ & RU & Parte usada & Empleo \\
\hline Adoxaceae & $\begin{array}{l}\text { Sambucus nigra } \\
\text { Saúco, saúgo, sabúgo, taco }\end{array}$ & 5 & Inflorescencia & $\begin{array}{c}\text { Infusión } \\
\text { Infección ocular }\end{array}$ \\
\hline \multirow[t]{4}{*}{ Compositae } & $\begin{array}{l}\text { Centaurea nigra } \\
\text { Garbanzón }\end{array}$ & 1 & Parte aérea & $\begin{array}{c}\text { Infusión } \\
\text { Infección ocular }\end{array}$ \\
\hline & $\begin{array}{l}\text { Chamaemelum nobile } \\
\text { Manzanilla, manzanilla campera }\end{array}$ & 19 & Sumidad floral & $\begin{array}{c}\text { Infusión } \\
\text { Infección ocular }\end{array}$ \\
\hline & $\begin{array}{l}\text { Cyanus segetum } \\
\text { Azulina, clavel, azulejo }\end{array}$ & 4 & Inflorescencia & $\begin{array}{c}\text { Infusión } \\
\text { Infección ocular }\end{array}$ \\
\hline & $\begin{array}{l}\text { Helichrysum stoechas } \\
\text { Manzanilla, manzanilla de peña }\end{array}$ & 1 & Sumidad floral & $\begin{array}{c}\text { Infusión } \\
\text { Infección ocular }\end{array}$ \\
\hline Ericaceae & $\begin{array}{l}\text { Vaccinium myrtillus } \\
\text { Arráspano, ráspano, arándano }\end{array}$ & 1 & Fruto & $\begin{array}{c}\text { Directo } \\
\text { Infección ocular }\end{array}$ \\
\hline Lamiaceae & $\begin{array}{l}\text { Salvia verbenaca } \\
\text { Hierba de Santa Lucía, balsamina }\end{array}$ & 2 & Semilla & $\begin{array}{c}\text { Directa } \\
\text { Limpiar ojos }\end{array}$ \\
\hline Leguminosae & $\begin{array}{l}\text { Trifolium pratense } \\
\text { Trébol, chupa, hierba nube }\end{array}$ & 1 & Parte aérea & $\begin{array}{c}\text { Infusión } \\
\text { Infección ocular }\end{array}$ \\
\hline Papaveraceae & $\begin{array}{l}\text { Papaver rhoeas } \\
\text { Amapola, pirigallo }\end{array}$ & 1 & Flor & $\begin{array}{c}\text { Infusión } \\
\text { Infección ocular }\end{array}$ \\
\hline Plantaginaceae & $\begin{array}{l}\text { Plantago lanceolata } \\
\text { Hoja de lentén, llantén, lentel }\end{array}$ & 2 & Hojas & $\begin{array}{c}\text { Infusión } \\
\text { Infección ocular }\end{array}$ \\
\hline \multirow[t]{2}{*}{ Rosaceae } & $\begin{array}{l}\text { Rosa spp. cultivadas } \\
\text { Rosal }\end{array}$ & 3 & Pétalos & $\begin{array}{c}\text { Infusión } \\
\text { Infección ocular }\end{array}$ \\
\hline & $\begin{array}{l}\text { Rosa spp. silvestres } \\
\text { Zarza, espino, rosal, calambrojo }\end{array}$ & 3 & Pétalos & $\begin{array}{c}\text { Infusión } \\
\text { Infección ocular }\end{array}$ \\
\hline
\end{tabular}

En la subcategoría Órganos de los sentidos se incluyen plantas empleadas para tratar enfermedades relacionadas con la vista, el olfato o el oído, pero solo se han recogido datos del sentido de la vista, los que más se citan son los relacionados con las infecciones oculares: ojos irritados o conjuntivitis, y los remedios empleados para expulsar partículas introducidas de forma involuntaria en el ojo.

Para el grupo de las infecciones oculares cuyos síntomas se describen con ojos irritados, rojos, con legañas, picor o lagrimeo, se realizan lavados oculares con infusiones tibias de flores de manzanilla (Chamaemelum nobile), de saúco (Sambucus nigra) o azulina (Cyanus segetum), o con pétalos de rosas (Rosa spp.) tanto cultivadas como silvestres. En Vidrieros aconsejan consumir arándanos (Vaccinium myrtillus) para prevenir y mejorar afecciones de la vista.

En cuanto a los remedios para limpiar los ojos se señala el curioso empleo a modo de colirio de la semilla de la hierba de Santa Lucía (Salvia verbenaca), que se coloca debajo del párpado para limpiar alguna partícula extraña introducida en el ojo, para Blanco \& Díaz (2005) la semilla tiene abundante mucílago, que en contacto con el fluido del ojo se ablanda y limpia toda la superficie, para reabsorberse poco a poco. 


\section{Enfermedades infecciosas y parasitarias:}

Se han recogido 10 registros de uso, correspondientes a 7 taxones de 7 familias botánicas diferentes, 4 taxones de obtención silvestre y 3 cultivados, representando un 0,80\% del total de registros de uso para la categoría medicina.

TABLA 43: Relación de especies empleadas en la subcategoría Enfermedades infecciosas y parasitarias, ordenadas alfabéticamente por familia, indicando número de registros de uso (RU), parte usada y empleo (modo de preparación y finalidad de uso).

\begin{tabular}{|c|c|c|c|c|}
\hline Familia & $\begin{array}{l}\text { Nombre científico } \\
\text { Nombre vulgar }\end{array}$ & RU & Parte usada & Empleo \\
\hline Apiaceae & $\begin{array}{l}\text { Apium graveolens } \\
\text { Apio }\end{array}$ & 1 & Parte aérea & $\begin{array}{c}\text { Maceración en leche } \\
\text { Lombrices }\end{array}$ \\
\hline Gentianaceae & $\begin{array}{l}\text { Gentiana lutea } \\
\text { Junciana, genciana }\end{array}$ & 1 & Rizoma & $\begin{array}{c}\text { Cocción } \\
\text { Lombrices }\end{array}$ \\
\hline Hypericaceae & $\begin{array}{l}\text { Hypericum perforatum } \\
\text { Hipérico, bergaula, pericón }\end{array}$ & 2 & Parte aérea & $\begin{array}{l}\text { Maceración aceite } \\
\text { Tiña }\end{array}$ \\
\hline Lamiaceae & $\begin{array}{l}\text { Origanum vulgare } \\
\text { Orégano }\end{array}$ & 1 & Sumidad floral & $\begin{array}{l}\text { Infusión } \\
\text { Lombrices }\end{array}$ \\
\hline Leguminosae & $\begin{array}{l}\text { Lupinus albus } \\
\text { Chocho }\end{array}$ & 2 & Semilla & $\begin{array}{c}\text { Cocción } \\
\text { Pediculosis }\end{array}$ \\
\hline Ranunculaceae & $\begin{array}{l}\text { Aconitum napellus } \\
\text { A. vulparia } \\
\text { Hierba piojera, acónito, aconito }\end{array}$ & 2 & Parte aérea & $\begin{array}{l}\text { Cocción } \\
\text { Pediculosis }\end{array}$ \\
\hline Rosaceae & $\begin{array}{l}\text { Rosa spinosissima } \\
\text { Zarzaparrilla, rosal espinoso }\end{array}$ & 1 & Fruto & $\begin{array}{l}\text { Baños } \\
\text { Sarna }\end{array}$ \\
\hline
\end{tabular}

Se recogen datos en esta subcategoría relacionados con enfermedades provocadas por parásitos, hongos, bacterias o virus.

El tratamiento de las afecciones cutáneas provocadas por infestación de piojos en el cabello humano se combatían lavando el pelo con el agua de cocer los chochos (Lupinus albus) o con la cocción de la hierba piojera (Aconitum napellus, A. vulparia), no se referencia este uso en la bibliografía consultada, a pesar de que incluso el nombre vasco de esta planta es sorribelarr, o hierba piojera. Con frecuencia esta enfermedad parasitaria (pediculosis) afectaba en la edad infantil, resultando muy contagiosa y con cierto estigma social, al asociarse erróneamente a personas con escasa higiene.

La helmintiasis es la enfermedad producida por gusanos parásitos (lombrices) que viven alojados en el intestino, afectaba de modo frecuente a los niños y para tratarla se tomaba el macerado de apio en leche (Apium graveolens), la infusión de orégano (Origanum vulgare) o la cocción de genciana (Gentiana lutea), muy común este uso en el Pirineo Aragonés (Villar et al., 1987), en Pallars (Agelet, 1999), en el Montseny (Bonet, 2001) y en Cantabria (Pardo de Santayana, 2004).

Otros remedios recogidos en la zona, son el aceite de hipérico (Hypericum perforatum) para la infección fúngica de la tiña, transmitida a través del ganado, y el baño con zarzaparrilla (Rosa spinosissima) para tratar la sarna, enfermedad causada por ácaros que infectaban la piel y provocaban una gran picazón. 


\section{Síntomas de origen indefinido:}

Se han recogido 3 registros de uso, correspondientes a 3 taxones de obtención silvestre, de 2 familias botánicas diferentes, representando un $0,24 \%$ del total de registros de uso para la categoría medicina.

TABLA 44: Relación de especies empleadas en la subcategoría Síntomas de origen indefinido, ordenadas alfabéticamente por familia, indicando número de registros de uso (RU), parte usada y empleo (modo de preparación y finalidad de uso).

\begin{tabular}{llccc}
\hline Familia & $\begin{array}{l}\text { Nombre científico } \\
\text { Nombre vulgar }\end{array}$ & RU & Parte usada & Empleo \\
\hline Compositae & $\begin{array}{l}\text { Achillea millefolium } \\
\text { Milenrama, birlenda, balsamina }\end{array}$ & 1 & Sumidad floral & $\begin{array}{c}\text { Infusión } \\
\text { Cansancio }\end{array}$ \\
& $\begin{array}{l}\text { Jacobaea vulgaris } \\
\text { Bujanera, hierba de Santiago }\end{array}$ & 1 & Parte aérea & $\begin{array}{c}\text { Pediluvio } \\
\text { Sudoración } \\
\text { Oleaceae }\end{array}$ \\
$\begin{array}{l}\text { Fraxinus excelsior } \\
\text { Fresno }\end{array}$ & 1 & Hojas & $\begin{array}{c}\text { Cocción } \\
\text { Fiebre }\end{array}$ \\
\hline
\end{tabular}

Reunidos los síntomas que provienen de un origen incierto o no definidos en otros estados. Para la fatiga general se tomaba la infusión de milenrama (Achillea millefolium), se hacían pediluvios para combatir el sudor de los pies con bujanera (Jacobaea vulgaris) y cuando una enfermedad cursaba con fiebre sin otros síntomas aparentes, se controlaban con la decocción de hojas de fresno (Fraxinus excelsior). Según Villar et al. (1987) el agua de cocimiento de la corteza del fresno se ingiere para quitar la fiebre, aunque no se ha confirmado su acción febrífuga. En la comarca nos han citado las hojas, pero no se ha podido contrastar la eficacia de su acción en la bibliografía consultada.

\section{Intoxicaciones y envenenamientos:}

Se ha recogido 1 registro de uso, correspondiente a 1 taxón de obtención silvestre, de la familia Gentianaceae, representando un $0,08 \%$ del total de registros de uso para la categoría medicina.

TABLA 45: Relación de especies empleadas en la subcategoría Intoxicaciones y envenenamientos, indicando familia, número de registros de uso (RU), parte usada y empleo (modo de preparación y finalidad de uso).

\begin{tabular}{llccc}
\hline Familia & $\begin{array}{l}\text { Nombre científico } \\
\text { Nombre vulgar }\end{array}$ & RU & Parte usada & Empleo \\
\hline Gentianaceae & $\begin{array}{l}\text { Gentiana lutea } \\
\text { Junciana, genciana }\end{array}$ & 1 & Rizoma & $\begin{array}{c}\text { Directo } \\
\text { Tabaquismo }\end{array}$ \\
\hline
\end{tabular}

Únicamente se ha obtenido un registro de uso para el tratamiento del tabaquismo, según un informante de Piedrasluengas se chupaba el rizoma de genciana (Gentiana lutea) para abandonar el habito de fumar, uso inédito localizado en esta zona de estudio. 


\section{Otros usos medicinales:}

Se han recogido 13 registros de uso, correspondientes a 9 taxones de 5 familias botánicas diferentes, 8 taxones de obtención silvestre y 1 cultivado, representando un 1,04\% del total de registros de uso para la categoría medicina.

TABLA 46: Relación de especies empleadas en la subcategoría Otros usos medicinales, ordenadas alfabéticamente por familia, indicando número de registros de uso (RU), parte usada y empleo (modo de preparación y finalidad de uso).

\begin{tabular}{|c|c|c|c|c|}
\hline Familia & $\begin{array}{l}\text { Nombre científico } \\
\text { Nombre vulgar }\end{array}$ & RU & Parte usada & Empleo \\
\hline Caryophyllaceae & $\begin{array}{l}\text { Paronychia kapela } \\
\text { Sanguinaria, flor de papel }\end{array}$ & 2 & Parte aérea & $\begin{array}{l}\text { Infusión } \\
\text { Panacea }\end{array}$ \\
\hline \multirow[t]{3}{*}{ Compositae } & $\begin{array}{l}\text { Achillea millefolium } \\
\text { Milenrama, birlenda, balsamina }\end{array}$ & 1 & Parte aérea & $\begin{array}{l}\text { Infusión } \\
\text { Panacea }\end{array}$ \\
\hline & $\begin{array}{l}\text { Chamaemelum nobile } \\
\text { Manzanilla, manzanilla campera }\end{array}$ & 1 & Sumidad floral & $\begin{array}{l}\text { Infusión } \\
\text { Panacea }\end{array}$ \\
\hline & $\begin{array}{l}\text { Helichrysum stoechas } \\
\text { Manzanilla, manzanilla de peña }\end{array}$ & 2 & Sumidad floral & $\begin{array}{l}\text { Infusión } \\
\text { Panacea }\end{array}$ \\
\hline Equisetaceae & $\begin{array}{l}\text { Equisetum arvense } \\
\text { Cola de caballo, pinillo, escobilla }\end{array}$ & 2 & Parte aérea & $\begin{array}{l}\text { Infusión } \\
\text { Panacea }\end{array}$ \\
\hline \multirow[t]{3}{*}{ Lamiaceae } & $\begin{array}{l}\text { Origanum vulgare } \\
\text { Orégano }\end{array}$ & 2 & Sumidad floral & $\begin{array}{l}\text { Infusión } \\
\text { Panacea }\end{array}$ \\
\hline & $\begin{array}{l}\text { Sideritis hyssopifolia } \\
\text { Té, té de roca, té de lastra }\end{array}$ & 1 & Sumidad floral & $\begin{array}{l}\text { Infusión } \\
\text { Panacea }\end{array}$ \\
\hline & $\begin{array}{l}\text { Thymus zygis } \\
\text { Tomillo, cepico }\end{array}$ & 1 & Parte aérea & $\begin{array}{l}\text { Infusión } \\
\text { Panacea }\end{array}$ \\
\hline Malvaceae & $\begin{array}{l}\text { Tilia platyphylos } \\
\text { Tilo }\end{array}$ & 1 & Flor & $\begin{array}{l}\text { Infusión } \\
\text { Panacea }\end{array}$ \\
\hline
\end{tabular}

Existen varias plantas consideradas como "sanalotodo", capaces de utilizarse ante cualquier patología. En general, son plantas muy populares y reconocidas con facilidad, empleadas en varios sistemas, solas o mezcladas entre ellas para potenciar sus virtudes y siempre administradas mediante infusión. Distinguimos con mayor registros de uso la cola de caballo (Equisetum arvense), la sanguinaria (Paronychia kapela), la manzanilla (Helichrysum stoechas) y el orégano (Origanum vulgare). 


\section{VETERINARIA:}

En la categoría Veterinaria se incluyen todas las especies empleadas para tratar, prevenir o curar enfermedades del ganado. En la comarca de la Montaña Palentina se menciona el uso de 58 taxones vegetales correspondientes a 33 familias botánicas, para los que se han recogido un total de 210 registros de uso (RU). De ellos, 46 taxones son de obtención silvestre y 12 cultivados. Los taxones con mayor número de registros de uso en la categoría veterinaria se representan en la figura 39.

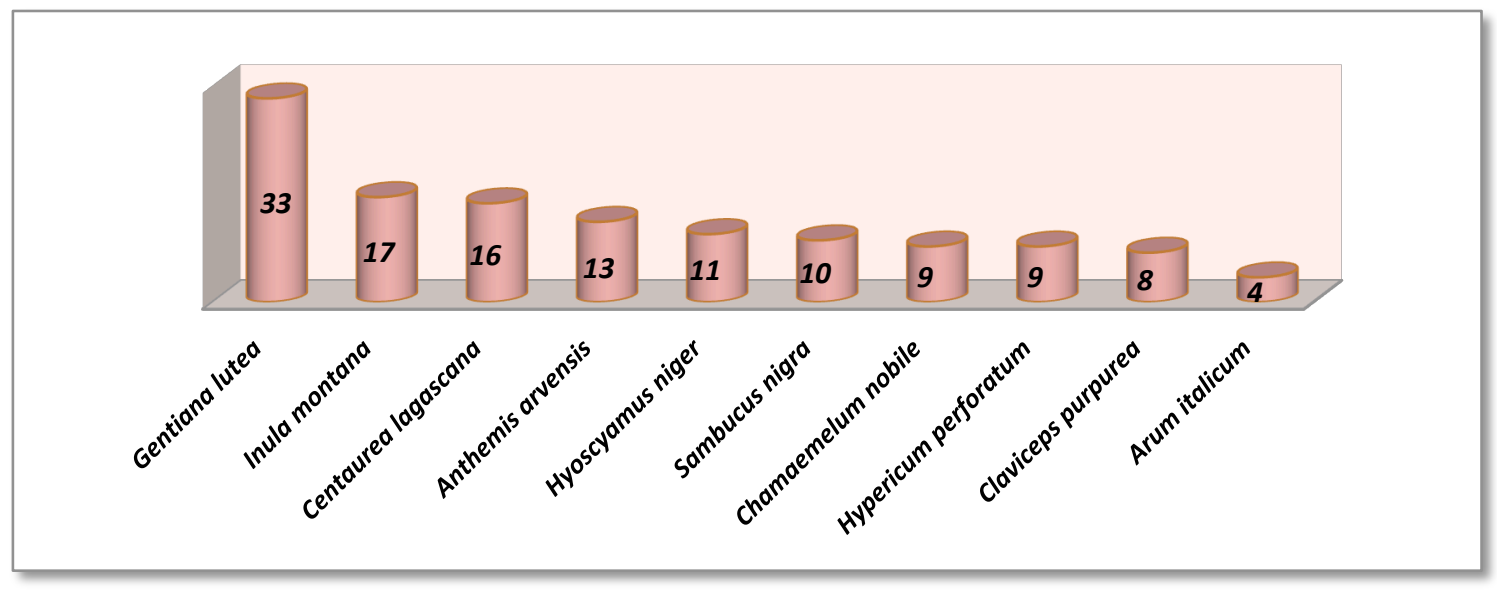

FIGURA 39: Especies con mayor número de registros de uso empleadas en Veterinaria.

Las familias con mayor representación en cuanto a número de especies fueron: Compositae, Lamiaceae y Poaceae, con 13, 4 y 4 especies respectivamente, y la familia con mayor número de registros de uso fue Compositae con 72 , según se señala en la figura 40 .

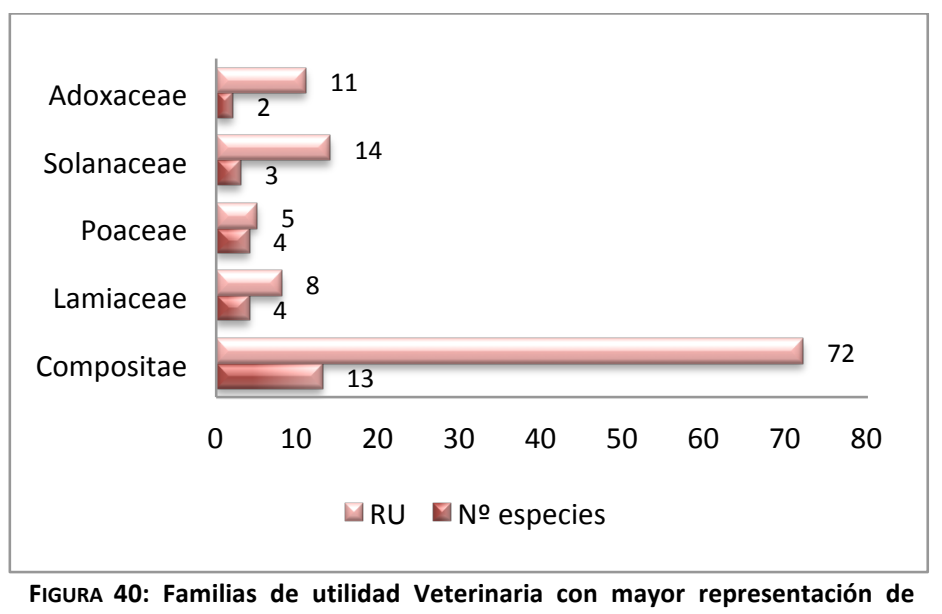
especies y número de registros de uso (RU).

Las plantas empleadas como veterinarias sirven para resolver enfermedades del ganado, su salud era un asunto de importancia vital dentro del núcleo familiar, dado que resultaban imprescindibles para realizar las tareas del campo y suministrar alimentos, por lo que se consideraban miembros de la propia familia. Muchas de las plantas que se utilizaron para resolver problemas humanos fueron también aplicadas a los animales domésticos. En la comarca se recurrió al veterinario progresivamente en el tiempo ya que hasta la época de la posguerra la salud del ganado recaía en el conocimiento de los dueños o en los más sabios de 
cada localidad. Todos los conocimientos recogidos no son vigentes en la actualidad, pues sólo quedan trazas de recuerdos en la memoria de los más mayores.

Los usos se han agrupado en subcategorías atendiendo al aparato o sistema corporal sobre el que actúan, siguiendo los criterios establecidos en el Inventario Español de los Conocimientos Tradicionales relativos a la Biodiversidad (Pardo de Santayana et al., 2014), obteniendo referencias en las 11 subcategorías indicadas en la tabla 47.

\begin{tabular}{l}
$\begin{array}{l}\text { TABLA 47: Subcategorías con representación en la categoría } \\
\text { Veterinaria. }\end{array}$ \\
\hline Subcategorías : \\
\hline Sistema digestivo \\
Sistema genito-urinario \\
Concepción, embarazo y parto \\
Sistema respiratorio \\
Musculatura y esqueleto \\
Piel y tejido celular subcutáneo \\
Órganos de los sentidos \\
Enfermedades infecciosas y parasitarias \\
Enfermedades "culturales" \\
Intoxicaciones y envenenamientos \\
Otros usos veterinarios \\
\hline
\end{tabular}

Los 210 registros de uso obtenidos, en la categoría Veterinaria, se reparten en 11 subcategorías tal y como señala la figura 41 , resultando que el Sistema digestivo es la que recibió mayor número de registros con 56 , un $26,67 \%$ del total en esta categoría, seguido de Piel y tejido celular subcutáneo con 44 , un $20,95 \%$, y Musculatura y esqueleto con 28 , un $13,33 \%$.

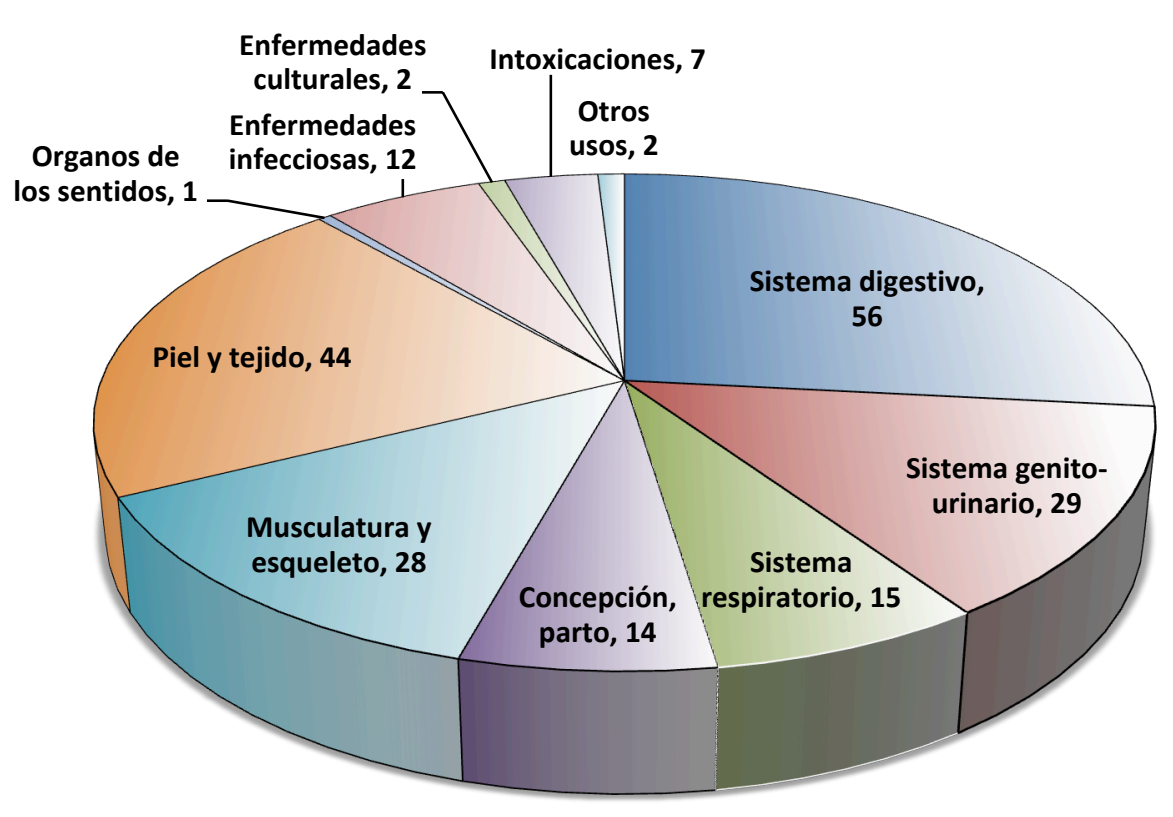

FIGURA 41: Registros de Uso (RU) de las subcategorías representadas en Veterinaria. 
A continuación se presentan las utilidades agrupadas por subcategorías veterinarias, señalando los taxones que han obtenido citas en los mismos, el número de registros de uso de cada taxón, la parte usada y el empleo.

\section{Sistema digestivo:}

Se han recogido 56 registros de uso, correspondientes a 20 taxones de 16 familias botánicas diferentes, 16 taxones de obtención silvestre y 4 cultivados, representando un $26,67 \%$ del total de registros de uso para la categoría Veterinaria.

TABLA 48: Relación de taxones empleados en la subcategoría Sistema digestivo, ordenados alfabéticamente por familia, indicando número de registros de uso (RU), parte usada, empleo (modo de preparación y finalidad de uso) y ganado ( $o=$ ovino; $p=$ porcino; $v=$ vacuno).

\begin{tabular}{|c|c|c|c|c|c|}
\hline Familia & $\begin{array}{l}\text { Nombre científico } \\
\text { Nombre vulgar }\end{array}$ & RU & Parte usada & Empleo & Ganado \\
\hline Amaryllidaceae & $\begin{array}{l}\text { Allium cepa } \\
\text { Cebolla }\end{array}$ & 1 & Bulbo & $\begin{array}{l}\text { Cocción } \\
\text { Purga }\end{array}$ & $v$ \\
\hline \multirow[t]{2}{*}{ Apiaceae } & $\begin{array}{l}\text { Angelica sylvestris } \\
\text { Angélica, chiflato }\end{array}$ & 1 & Inflorescencia & $\begin{array}{c}\text { Cocción } \\
\text { Indigestión, gases }\end{array}$ & $v$ \\
\hline & $\begin{array}{l}\text { Scandix australis } \\
\text { Anís, anís de lastra }\end{array}$ & 1 & Parte aérea & $\begin{array}{c}\text { Infusión } \\
\text { Gases }\end{array}$ & $v$ \\
\hline Boraginaceae & $\begin{array}{l}\text { Echium vulgare } \\
\text { Gardincha }\end{array}$ & 1 & Fruto & $\begin{array}{l}\text { Directo } \\
\text { Gases }\end{array}$ & $v$ \\
\hline \multirow[t]{4}{*}{ Compositae } & $\begin{array}{l}\text { Achillea millefolium } \\
\text { Milenrama, birlenda }\end{array}$ & 3 & Parte aérea & $\begin{array}{l}\text { Cocción } \\
\text { Cólicos }\end{array}$ & $v$ \\
\hline & $\begin{array}{l}\text { Anthemis arvensis } \\
\text { Margarita, manzanilla }\end{array}$ & 12 & Inflorescencia & $\begin{array}{c}\text { Cocción } \\
\text { Indigestión }\end{array}$ & $v$ \\
\hline & $\begin{array}{l}\text { Chamaemelum nobile } \\
\text { Manzanilla }\end{array}$ & 5 & Inflorescencia & $\begin{array}{l}\text { Cocción } \\
\text { Cólicos }\end{array}$ & $v$ \\
\hline & $\begin{array}{l}\text { Helichrysum stoechas } \\
\text { Manzanilla }\end{array}$ & 1 & Sumidad floral & $\begin{array}{l}\text { Cocción } \\
\text { Purga }\end{array}$ & $v$ \\
\hline Gentianaceae & $\begin{array}{l}\text { Gentiana lutea } \\
\text { Junciana, genciana }\end{array}$ & 20 & Rizoma & $\begin{array}{c}\text { Cocción } \\
\text { Pérdida de apetito }\end{array}$ & $p, v$ \\
\hline Lamiaceae & $\begin{array}{l}\text { Sideritis hyssopifolia } \\
\text { Té, té de roca, té de lastra }\end{array}$ & 1 & Parte aérea & $\begin{array}{l}\text { Infusión } \\
\text { Cólicos }\end{array}$ & $v$ \\
\hline Lentiburiaceae & $\begin{array}{l}\text { Pinguicula grandiflora } \\
\text { Tiraña, hoja de la tiraña }\end{array}$ & 1 & Hojas & $\begin{array}{l}\text { Cocción } \\
\text { Laxante }\end{array}$ & $v$ \\
\hline Linaceae & $\begin{array}{l}\text { Linum usitatissimum } \\
\text { Lino }\end{array}$ & 1 & Semillas & $\begin{array}{c}\text { Cocción } \\
\text { Indigestión }\end{array}$ & $v$ \\
\hline Malvaceae & $\begin{array}{l}\text { Malva sylvestris } \\
\text { Malva, flor de malva }\end{array}$ & 1 & Parte aérea & $\begin{array}{l}\text { Infusión } \\
\text { Gases }\end{array}$ & $v$ \\
\hline Poaceae & $\begin{array}{l}\text { Triticum aestivum } \\
\text { Trigo, mesino, tremesino }\end{array}$ & 1 & Grano & $\begin{array}{c}\text { Cocción } \\
\text { Indigestión }\end{array}$ & $v$ \\
\hline Polygonaceae & $\begin{array}{l}\text { Rumex pulcher } \\
\text { Ramagón }\end{array}$ & 1 & Raíz & $\begin{array}{c}\text { Cocción } \\
\text { Indigestión }\end{array}$ & v \\
\hline Rosaceae & $\begin{array}{l}\text { Rosa spp. } \\
\text { Zarza, espino, rosal }\end{array}$ & 1 & Agalla & $\begin{array}{c}\text { Directo } \\
\text { Trastorno rumio }\end{array}$ & $v$ \\
\hline Scrophulariaceae & $\begin{array}{l}\text { Verbascum lychnitis } \\
\text { V. pulverulentum } \\
\text { V. thapsus } \\
\text { Gordolobo, guardalobo }\end{array}$ & 1 & Hojas & $\begin{array}{l}\text { Cocción } \\
\text { Pérdida de apetito }\end{array}$ & $v$ \\
\hline Solanaceae & $\begin{array}{l}\text { Capsicum annuum } \\
\text { Pimiento }\end{array}$ & 1 & Fruto molido & $\begin{array}{l}\text { Directo } \\
\text { Gases }\end{array}$ & $v$ \\
\hline Thymelaeaceae & Daphne laureola & 1 & Parte aérea & $\begin{array}{l}\text { Directo } \\
\text { Colitis }\end{array}$ & 0 \\
\hline
\end{tabular}


Los trastornos digestivos se pueden agrupar en indigestiones o empachos, cólicos, diarreas, gases, trastornos del rumio, laxantes y pérdida del apetito.

Los más comunes en el ganado vacuno son los trastornos derivados de indigestiones, empachos o cólicos que provocan dolores intensos en la cavidad abdominal, se tratan con cocciones de manzanillas (Anthemis arvensis, Chamaemelum nobile), de té (Sideritis hyssopifolia), de lino (Linum usitatissimum) o de ramagón (Rumex pulcher), que se servían tibias con gran habilidad por parte del ganadero colocando una botella debajo de la lengua del animal.

Una de las enfermedades que más inquietaba a los ganaderos era el timpanismo, que es la hinchazón del abdomen del ganado vacuno causada por la acumulación de gases producidos durante la fermentación microbiana en el rumen y que si no se expulsaban a tiempo podía provocar la muerte del animal. Varios informantes culpan a ciertas plantas de desencadenar este proceso, una de ellas el trébol (Trifolium pratense), o también al tipo de pasto que pace el ganado. Para que el animal expulsara el acúmulo de gas se han recogido varios métodos, desde introducir una bola de tocino con malva (Malva sylvestris), gardincha (Echium vulgare) o pimentón (Capsicum annuum), una agalla desarrollada sobre las zarzas (Rosa spp.) de avispa Cynipidae, o infusión de anís (Scandix australis). En caso de no disminuir el hinchazón, se disponía de un cuerno de corzo para clavarlo con destreza en el abdomen y desalojar de esta forma violenta el gas, sin tener que solicitar por tanto los servicios de un veterinario.

En cuanto a los remedios laxantes, se recurre a la cocción de cebollas (Allium cepa) podridas con manzanilla (Helychrisum stoechas) o a la cocción de la hoja de la tiraña (Pinguicula grandiflora), este remedio también se referencia en el municipio asturiano de Piloña (San Miguel, 2004).

Sin embargo, para detener la diarrea del ganado ovino se recoge un curioso método, atando en la base del rabo del animal afectado, un ramo de la especie Daphne laureola. Otra especie del mismo genero Daphne gnidium tiene el mismo uso en la Serranía de Cuenca (Fajardo et al., 2007).

La especie con mayor número de registros de usos fue la genciana (Gentiana lutea), por tanto, al igual que en Asturias es la planta más popular para el tratamiento de problemas digestivos en el ganado (Dopico et al., 2008). Fue usada de modo frecuente como aperitivo del ganado, ya que era normal la pérdida de apetito en animales recién destetados.

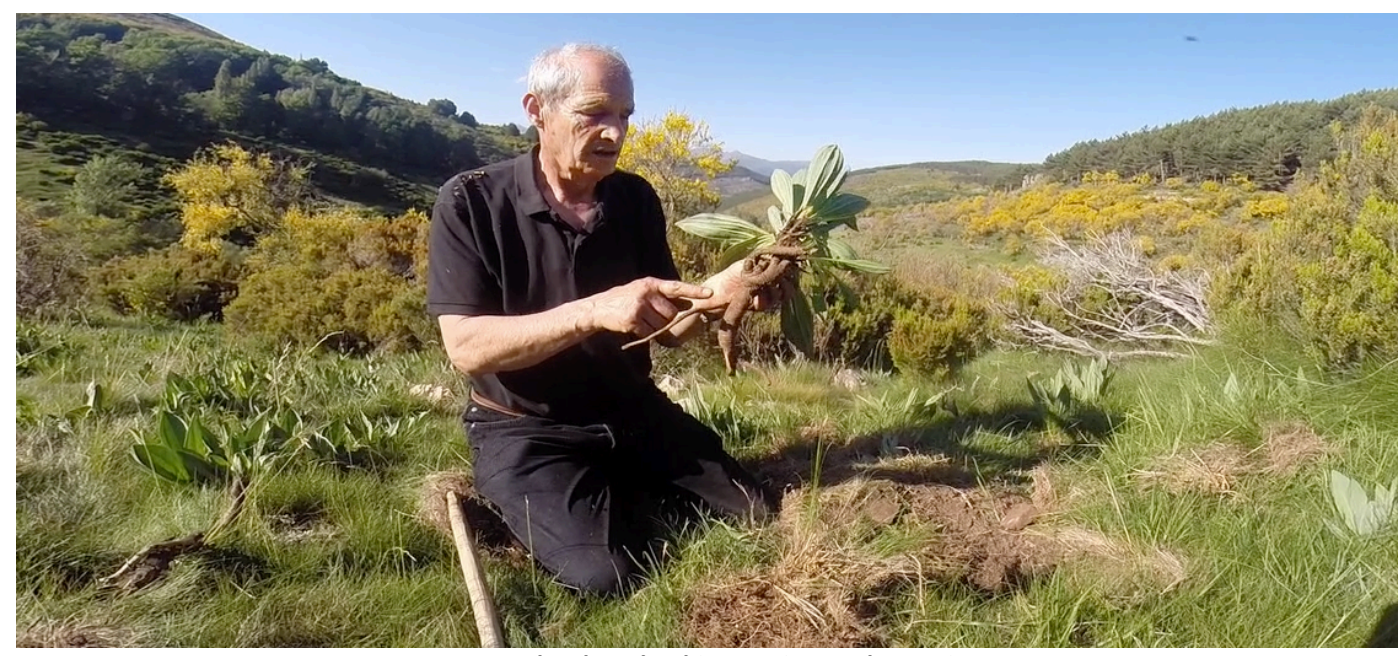

FIGURA 42: Pedro de Valsurbio con rizoma de genciana. 


\section{Sistema genito-urinario:}

Se han recogido 29 registros de uso, correspondientes a 15 taxones de 11 familias botánicas diferentes, 12 taxones de obtención silvestre y 3 cultivados, representando un 13,81\% del total de registros de uso para la categoría Veterinaria.

TABLA 49: Relación de especies empleadas en la subcategoría Sistema genito-urinario, ordenadas alfabéticamente por familia, indicando número de registros de uso (RU), parte usada, empleo (modo de preparación y finalidad de uso) y ganado ( $v$ = vacuno).

\begin{tabular}{|c|c|c|c|c|c|}
\hline Familia & $\begin{array}{l}\text { Nombre cientifico } \\
\text { Nombre vulgar }\end{array}$ & RU & Parte usada & Empleo & Ganado \\
\hline Betulaceae & $\begin{array}{l}\text { Betula pubescens } \\
\text { Abedul }\end{array}$ & 1 & Hojas & $\begin{array}{l}\text { Cocción } \\
\text { Diurética }\end{array}$ & $\mathrm{v}$ \\
\hline Caryophyllaceae & $\begin{array}{l}\text { Paronychia kapela } \\
\text { Sanguinaria, flor de papel }\end{array}$ & 1 & Parte aérea & $\begin{array}{l}\text { Cocción } \\
\text { Retención orina }\end{array}$ & v \\
\hline \multirow[t]{4}{*}{ Compositae } & $\begin{array}{l}\text { Achillea millefolium } \\
\text { Milenrama, birlenda }\end{array}$ & 1 & Parte aérea & $\begin{array}{l}\text { Infusión } \\
\text { Diurética }\end{array}$ & v \\
\hline & $\begin{array}{l}\text { Anthemis arvensis } \\
\text { Margarita, manzanilla }\end{array}$ & 1 & Inflorescencia & $\begin{array}{l}\text { Frita } \\
\text { Mamitis }\end{array}$ & v \\
\hline & $\begin{array}{l}\text { Calendula officinalis } \\
\text { Maravilla, caléndula, clavel }\end{array}$ & 1 & Inflorescencia & $\begin{array}{l}\text { Frita } \\
\text { Mamitis }\end{array}$ & v \\
\hline & $\begin{array}{l}\text { Chamaemelum nobile } \\
\text { Manzanilla }\end{array}$ & 3 & Inflorescencia & $\begin{array}{c}\text { Infusión } \\
\text { Diurética, mamitis }\end{array}$ & $v$ \\
\hline Ericaceae & $\begin{array}{l}\text { Arctostaphylos uva-ursi } \\
\text { Gayuga, agayuga, gayuba }\end{array}$ & 3 & Hojas y fruto & $\begin{array}{l}\text { Cocción } \\
\text { Retención orina }\end{array}$ & v \\
\hline Hypericaceae & $\begin{array}{l}\text { Hypericum perforatum } \\
\text { Hipérico, bergaula, pericón }\end{array}$ & 5 & Parte aérea & $\begin{array}{l}\text { Infusión } \\
\text { Retención orina }\end{array}$ & v \\
\hline \multirow[t]{2}{*}{ Lamiaceae } & $\begin{array}{l}\text { Origanum vulgare } \\
\text { Orégano }\end{array}$ & 1 & Sumidad floral & $\begin{array}{l}\text { Infusión en leche } \\
\text { Rechazo lactancia }\end{array}$ & v \\
\hline & $\begin{array}{l}\text { Rosmarinus officinalis } \\
\text { Romero }\end{array}$ & 4 & Parte aérea & $\begin{array}{l}\text { Cocción en vino } \\
\text { Sangre en la orina }\end{array}$ & v \\
\hline Plantaginaceae & $\begin{array}{l}\text { Plantago lanceolata } \\
\text { Hoja de lentén, Ilantén, lentel }\end{array}$ & 1 & Parte aérea & $\begin{array}{c}\text { Cocción } \\
\text { Sangre en la orina }\end{array}$ & v \\
\hline \multirow[t]{2}{*}{ Poaceae } & $\begin{array}{l}\text { Dactylis glomerata } \\
\text { Grama }\end{array}$ & 1 & Raíz & $\begin{array}{l}\text { Cocción } \\
\text { Diurética }\end{array}$ & v \\
\hline & $\begin{array}{l}\text { Zea mays } \\
\text { Maíz }\end{array}$ & 1 & Estigmas & $\begin{array}{l}\text { Cocción } \\
\text { Retención orina }\end{array}$ & v \\
\hline Rutaceae & $\begin{array}{l}\text { Ruta montana } \\
\text { Ruda }\end{array}$ & 1 & Parte aérea & $\begin{array}{l}\text { Frita } \\
\text { Mamitis }\end{array}$ & v \\
\hline Solanaceae & $\begin{array}{l}\text { Hyoscyamus niger } \\
\text { Beleño }\end{array}$ & 4 & Semillas & $\begin{array}{l}\text { Frita } \\
\text { Mamitis }\end{array}$ & v \\
\hline
\end{tabular}

Se incluyen en este apartado la hematuria o sangre en la orina, retención de orina, mamitis y los trastornos relacionados con la lactancia y el destete.

Para solventar la hematuria, enfermedad del ganado vacuno cuyo síntoma dominante y característico era la emisión de orina sanguinolenta, se describen dos especies, el cocimiento en vino de la parte aérea del romero (Rosmarinus officinalis) y el cocimiento del llantén (Plantago lanceolata).

Las plantas con propiedades diuréticas se aconsejan para los trastornos generales de orina y en especial para la retención de orina, con frecuencia descrita en el ganado vacuno. Se administra infusión de hipérico (Hypericum perforatum) del mismo modo que en Lérida (Agelet, 1999), cocción de gayuga (Arctostaphylos uva-ursi) al igual que en Huesca (Villar et al., 1987), infusión de manzanilla (Chamaemelum nobile), raíz de la grama (Dactylis glomerata), los 
estigmas del maíz (Zea mays) o las hojas de abedul (Betula pubescens), estos últimos remedios similares a los empleados en la zona de Campoo (Pardo de Santayana, 2008).

En cuanto a la mamitis, se trataba de una enfermedad temida por los ganaderos pues pocos remedios podían evitar la pérdida de la teta afectada y por tanto la producción de leche, entre ellos se describen frituras en aceite de semillas de beleño (Hyoscyamus niger), de flores de margaritas (Anthemis arvensis), manzanillas (Chamaemelum nobile) o de maravillas (Calendula officinalis), o de la parte aérea de la ruda (Ruta montana), con un trapo o un algodón se untaba el aceite en las ubres inflamadas.

En Alba de los Cardaños se recoge el empleo de orégano (Origanum vulgare) mezclado con leche azucarada para cuando los terneros no admiten bien la leche y rechazaban mamar de la ubre de la madre, uso no documentado en la bibliografía consultada.

\section{Concepción, embarazo y parto:}

Se han recogido 14 registros de uso, correspondientes a 6 taxones de 6 familias botánicas diferentes, 5 taxones de obtención silvestre y 1 cultivado, representando un 6,67\% del total de registros de uso para la categoría Veterinaria.

TABLA 50: Relación de especies empleadas en la subcategoría Concepción, embarazo y parto, ordenadas alfabéticamente por familia, indicando número de registros de uso (RU), parte usada, empleo (modo de preparación y finalidad de uso) y ganado ( $v$ = vacuno).

\begin{tabular}{|c|c|c|c|c|c|}
\hline Familia & $\begin{array}{l}\text { Nombre científico } \\
\text { Nombre vulgar }\end{array}$ & RU & Parte usada & Empleo & Ganado \\
\hline Aspleniaceae & $\begin{array}{l}\text { Asplenium trichomanes } \\
\text { Golondrillo, golondrino }\end{array}$ & 2 & Frondes & $\begin{array}{c}\text { Cocción } \\
\text { Expulsar placenta }\end{array}$ & v \\
\hline Lentiburiaceae & $\begin{array}{l}\text { Pinguicula grandiflora } \\
\text { Tiraña, hoja de la tiraña }\end{array}$ & 1 & Frondes & $\begin{array}{c}\text { Cocción } \\
\text { Expulsar placenta }\end{array}$ & $v$ \\
\hline Santalaceae & $\begin{array}{l}\text { Viscum album } \\
\text { Muérdago, maraojo, mingojo }\end{array}$ & 1 & Planta & $\begin{array}{c}\text { Cocción } \\
\text { Expulsar placenta }\end{array}$ & $v$ \\
\hline Scrophulariaceae & $\begin{array}{l}\text { Verbascum lychnitis } \\
\text { V. pulverulentum } \\
\text { V. thapsus } \\
\text { Gordolobo, guardalobo }\end{array}$ & 1 & Planta & $\begin{array}{c}\text { Cocción } \\
\text { Lavado placenta }\end{array}$ & $v$ \\
\hline Vitaceae & $\begin{array}{l}\text { Vitis vinifera } \\
\text { Parra }\end{array}$ & 1 & Fruto & $\begin{array}{c}\text { Vino } \\
\text { Expulsar placenta }\end{array}$ & v \\
\hline Clavicipitaceae & $\begin{array}{l}\text { Claviceps purpurea } \\
\text { Cornezuelo }\end{array}$ & 8 & Hongo & $\begin{array}{l}\text { Cocción } \\
\text { Expulsar placenta }\end{array}$ & v \\
\hline
\end{tabular}

Se pueden agrupar en esta subcategoría los tratamientos realizados ante trastornos o complicaciones del parto, por un lado la necesidad de expulsión de la placenta tras un parto o un aborto, y por otro la limpieza de la matriz.

Hasta 5 especies se documentan para ayudar a que las vacas expulsaran la placenta, también denominada en el argot popular "limpia o paria", se trata en general de especies con cierta toxicidad y que la ingestión de los cocimientos provocaba la purga del animal, entre ellas el más citado el hongo del cornezuelo (Claviceps purpurea), también se utiliza el golondrillo (Asplenium trichomanes), la tiraña (Pinguicula grandiflora), el muérdago (Viscum album) y el vino caliente de uva (Vitis vinifera), según Pardo de Santayana (2008), algunos emborrachaban al animal para soportar mejor el doloroso trance. 
En ocasiones, las vacas sufrían un desprendimiento de la matriz (esmadronarse) y antes de ser hábilmente reintroducida, se lavaba con la cocción de gordolobo (Verbascum spp.). En Pallars (Agelet, 1999) se utilizaba el gordolobo para expulsar la placenta, pero no se menciona su empleo para la limpieza de la matriz.

\section{Sistema respiratorio:}

Se han recogido 15 registros de uso, correspondientes a 6 taxones de 6 familias botánicas diferentes, 4 taxones de obtención silvestre y 2 cultivados, representando un 7,14\% del total de registros de uso para la categoría Veterinaria.

TABLA 51: Relación de especies empleadas en la subcategoría Sistema respiratorio, ordenadas alfabéticamente por familia, indicando número de registros de uso (RU), parte usada, empleo (modo de preparación y finalidad de uso) y ganado ( $v=$ vacuno).

\begin{tabular}{|c|c|c|c|c|c|}
\hline Familia & $\begin{array}{l}\text { Nombre científico } \\
\text { Nombre vulgar }\end{array}$ & $\mathbf{R U}$ & Parte usada & Empleo & Ganado \\
\hline Adoxaceae & $\begin{array}{l}\text { Sambucus nigra } \\
\text { Saúco, saúgo, sabúgo, taco }\end{array}$ & 1 & Inflorescencia & $\begin{array}{l}\text { Sahumerio } \\
\text { Catarro }\end{array}$ & $v$ \\
\hline Compositae & $\begin{array}{l}\text { Cirsium eriophorum } \\
\text { Cardo, cardo burriquero }\end{array}$ & 1 & Inflorescencia & $\begin{array}{l}\text { Cocción } \\
\text { Tos }\end{array}$ & $v$ \\
\hline Gentianaceae & $\begin{array}{l}\text { Gentiana lutea } \\
\text { Junciana, genciana }\end{array}$ & 8 & Rizoma & $\begin{array}{c}\text { Cocción. Directo } \\
\text { Catarro, tos, pulmonía }\end{array}$ & $v$ \\
\hline Lamiaceae & $\begin{array}{l}\text { Origanum vulgare } \\
\text { Orégano }\end{array}$ & 1 & Sumidad floral & $\begin{array}{c}\text { Infusión } \\
\text { Tos }\end{array}$ & $v$ \\
\hline Malvaceae & $\begin{array}{l}\text { Malva sylvestris } \\
\text { Malva, flor de malva }\end{array}$ & 1 & Parte aérea & $\begin{array}{l}\text { Infusión } \\
\text { Pulmonía }\end{array}$ & v \\
\hline Vitaceae & $\begin{array}{l}\text { Vitis vinifera } \\
\text { Parra }\end{array}$ & 3 & Fruto & $\begin{array}{l}\text { Vino } \\
\text { Catarro }\end{array}$ & $v$ \\
\hline
\end{tabular}

Las enfermedades relacionadas con el sistema respiratorio se reducen a catarro, pulmonía, tos o gripe. Es probable que todas las especies documentadas sirvan para todas las patologías respiratorias, pues en muchos casos, los síntomas son comunes y no resulta fácil distinguir un catarro de una gripe. La mayoría de remedios se describen en el ganado vacuno.

La especie con mayor número de registros de uso es la genciana (Gentiana lutea), útil para casi cualquier trastorno respiratorio, se administraba la cocción del rizoma o se picaba directamente mezclada con un poco de pienso.

Otro remedio popular fue hacer respirar a las vacas los vahos de saúco (Sambucus nigra), producidos al quemar las flores sobre unas brasas, este uso es similar en otras zonas del norte de la Península Ibérica como Navarra (Akerreta, 2009) o Cantabria (Pardo de Santayana, 2008). Se mencionan para aliviar la tos, las cocciones de cardo (Cirsium eriophorum), o las infusiones de orégano (Origanum vulgare), y para tratar la pulmonía la infusión de malva (Malva sylvestris). También por vía interna se daba a beber vino para tratar de mitigar el catarro del animal.

\section{Musculatura y esqueleto:}

Se han recogido 28 registros de uso, correspondientes a 7 taxones de 3 familias botánicas diferentes, todos los taxones de obtención silvestre, representando un $13,33 \%$ del total de registros de uso para la categoría Veterinaria. 
TABLA 52: Relación de especies empleadas en la subcategoría Musculatura y esqueleto, ordenadas alfabéticamente por familia, indicando número de registros de uso (RU), parte usada, empleo (modo de preparación y finalidad de uso) y ganado (c = caprino; e = equino; o = ovino; v = vacuno).

\begin{tabular}{|c|c|c|c|c|c|}
\hline Familia & $\begin{array}{l}\text { Nombre científico } \\
\text { Nombre vulgar }\end{array}$ & $\mathbf{R U}$ & Parte usada & Empleo & Ganado \\
\hline \multirow[t]{2}{*}{ Adoxaceae } & $\begin{array}{l}\text { Sambucus ebulus } \\
\text { Nuezgo, yezgo }\end{array}$ & 1 & Parte aérea & $\begin{array}{c}\text { Cataplasma } \\
\text { Golpes }\end{array}$ & $0, v$ \\
\hline & $\begin{array}{l}\text { Sambucus nigra } \\
\text { Saúco, saúgo, sabúgo, taco }\end{array}$ & 6 & Inflorescencia & $\begin{array}{l}\text { Cataplasma, sahumerio } \\
\text { Golpes, hinchazones }\end{array}$ & $\mathrm{o}, \mathrm{v}$ \\
\hline \multirow[t]{3}{*}{ Compositae } & $\begin{array}{l}\text { Centaurea calcitrapa } \\
\text { Cardo de arzolla }\end{array}$ & 1 & Inflorescencia & $\begin{array}{c}\text { Cataplasma } \\
\text { Golpes }\end{array}$ & $e, o, v$ \\
\hline & $\begin{array}{l}\text { Centaurea lagascana } \\
\text { Arzolla, cardo de arzolla }\end{array}$ & 2 & Planta & $\begin{array}{l}\text { Cataplasma } \\
\text { Traumatismos }\end{array}$ & $c, e, o, v$ \\
\hline & $\begin{array}{l}\text { Inula montana } \\
\text { Árnica }\end{array}$ & 17 & Parte aérea & $\begin{array}{c}\text { Cataplasma } \\
\text { Traumatismos }\end{array}$ & $c, e, o, v$ \\
\hline Solanaceae & $\begin{array}{l}\text { Hyoscyamus niger } \\
\text { Beleño }\end{array}$ & 1 & Semillas & $\begin{array}{c}\text { Frita } \\
\text { Inflamaciones }\end{array}$ & $c, e, o, v$ \\
\hline
\end{tabular}

La subcategoría Musculatura y esqueleto recoge información para el tratamiento de golpes, contusiones, fracturas o inflamaciones de origen indeterminado, se aconsejan las mismas especies sin tener en cuenta la contrariedad acaecida.

La terapia aplicada con mayor frecuencia es la colocación de cataplasmas en la zona afectada con el cocimiento de alguna de las plantas recomendadas, árnica (Inula montana), saúco (Sambucus nigra), arzollas (Centaurea calcitrapa, C. lagascana) o nuezgo (Sambucus ebulus), comprobando que dos familias Compositae y Adoxaceae son las que monopolizan la mayoría de especies en esta subcategoría.

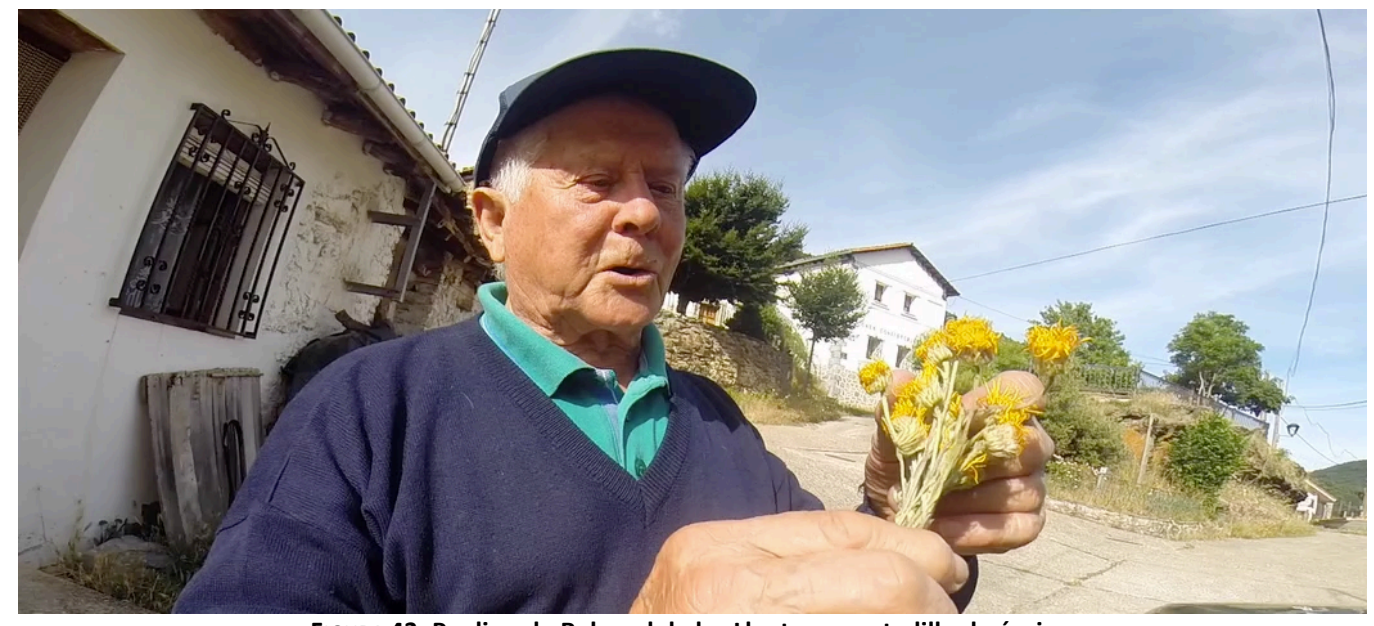

FIGURA 43: Paulino de Rebanal de las Llantas con atadillo de árnica.

Para tratar las hinchazones de origen indefinido se ahumaba la parte afectada con los vapores de la inflorescencia de saúco (Sambucus nigra), de modo similar al realizado en la provincia de Albacete (Fajardo et al., 2000), o se frotaba con el aceite de freír semillas de beleño (Hyoscyamus niger).

Las fracturas se resolvían inmovilizando el miembro afectado mediante sistemas rudimentarios de sujeción, con palos o estaquillas que se ataban con cuerda o trapos, en un intento de curar y recuperar el animal lesionado. 


\section{Piel y tejido celular subcutáneo:}

Se han recogido 44 registros de uso, correspondientes a 18 taxones de 13 familias botánicas diferentes, 17 taxones de obtención silvestre y 1 cultivado, representando un 20,95\% del total de registros de uso para la categoría Veterinaria.

TABLA 53: Relación de especies empleadas en la subcategoría Piel y tejido celular subcutáneo, ordenadas alfabéticamente por familia, indicando número de registros de uso (RU), parte usada, empleo (modo de preparación y finalidad de uso) y ganado ( $a=$ avícola; $c=$ caprino; $c u=$ cunícula; $e=$ equino; $o=$ ovino; $p=$ porcino; $v$ = vacuno).

\begin{tabular}{|c|c|c|c|c|c|}
\hline Familia & $\begin{array}{l}\text { Nombre cientifico } \\
\text { Nombre vulgar }\end{array}$ & RU & Parte usada & Empleo & Ganado \\
\hline Adoxaceae & $\begin{array}{l}\text { Sambucus nigra } \\
\text { Saúco, saúgo, sabúgo, taco }\end{array}$ & 3 & Inflorescencia & $\begin{array}{l}\text { Infusión } \\
\text { Heridas }\end{array}$ & $c, 0, v$ \\
\hline Araceae & $\begin{array}{l}\text { Arum italicum } \\
\text { Hierba de la culebra }\end{array}$ & 4 & Raíz & $\begin{array}{l}\text { Cataplasma } \\
\text { Babón }\end{array}$ & $e, v$ \\
\hline \multirow[t]{5}{*}{ Compositae } & $\begin{array}{l}\text { Arctium minus } \\
\text { Amargacho, capacho, pegote }\end{array}$ & 1 & Raíz & $\begin{array}{l}\text { Cocción } \\
\text { Heridas }\end{array}$ & $p$ \\
\hline & $\begin{array}{l}\text { Centaurea calcitrapa } \\
\text { Cardo de arzolla }\end{array}$ & 1 & Inflorescencia & $\begin{array}{c}\text { Cocción } \\
\text { Lavar heridas }\end{array}$ & $c, 0, v$ \\
\hline & $\begin{array}{l}\text { Centaurea lagascana } \\
\text { Arzolla, cardo de arzolla }\end{array}$ & 14 & Planta & $\begin{array}{l}\text { Cocción } \\
\text { Heridas }\end{array}$ & $\begin{array}{l}a, c, c u \\
e, o, p, v\end{array}$ \\
\hline & $\begin{array}{l}\text { Inula helvetica } \\
\text { Árnica }\end{array}$ & 1 & Parte aérea & $\begin{array}{l}\text { Maceración } \\
\text { Lavar heridas }\end{array}$ & $\begin{array}{l}a, c, c u \\
e, o, p, v\end{array}$ \\
\hline & $\begin{array}{l}\text { Jurinea humilis } \\
\text { Arzolla }\end{array}$ & 4 & Parte aérea & $\begin{array}{c}\text { Cocción } \\
\text { Lavar heridas }\end{array}$ & $c, 0$ \\
\hline \multirow[t]{2}{*}{ Crassulaceae } & $\begin{array}{l}\text { Sempervivum vicentei } \\
\text { Siempreviva, suelda }\end{array}$ & 1 & Hojas & $\begin{array}{l}\text { Cataplasma } \\
\text { Heridas }\end{array}$ & $\begin{array}{l}a, c, c u \\
e, o, p, v\end{array}$ \\
\hline & $\begin{array}{l}\text { Umbilicus rupestris } \\
\text { Sombrerillos }\end{array}$ & 1 & Hojas & $\begin{array}{l}\text { Directo } \\
\text { Heridas }\end{array}$ & $\begin{array}{l}a, c, c u \\
e, o, p, v\end{array}$ \\
\hline Cucurbitaceae & $\begin{array}{l}\text { Bryonia cretica } \\
\text { Uva de perro, nueza }\end{array}$ & 2 & Raíz & $\begin{array}{l}\text { Cocción } \\
\text { Cojera }\end{array}$ & v \\
\hline Hypericaceae & $\begin{array}{l}\text { Hypericum perforatum } \\
\text { Hipérico, bergaula, pericón }\end{array}$ & 2 & Parte aérea & $\begin{array}{l}\text { Infusión } \\
\text { Lavar heridas }\end{array}$ & $\begin{array}{l}a, c, c u \\
e, o, p, v\end{array}$ \\
\hline Juglandaceae & $\begin{array}{l}\text { Juglans regia } \\
\text { Nogal }\end{array}$ & 2 & Hojas & $\begin{array}{c}\text { Cocción } \\
\text { Lavar heridas }\end{array}$ & $\begin{array}{l}a, c, c u \\
e, o, p, v\end{array}$ \\
\hline Lamiaceae & $\begin{array}{l}\text { Lamium album } \\
\text { Ortiga blanca, chupón }\end{array}$ & 1 & Parte aérea & $\begin{array}{l}\text { Infusión } \\
\text { Heridas }\end{array}$ & $\begin{array}{l}a, c, c u \\
e, o, p, v\end{array}$ \\
\hline Liliaceae & $\begin{array}{l}\text { Lilium martagon } \\
\text { Antojil, azucena }\end{array}$ & 2 & Bulbo & $\begin{array}{l}\text { Cocción } \\
\text { Heridas }\end{array}$ & $c, 0$ \\
\hline Malvaceae & $\begin{array}{l}\text { Malva sylvestris } \\
\text { Malva, flor de malva }\end{array}$ & 2 & Parte aérea & $\begin{array}{l}\text { Cocción } \\
\text { Heridas }\end{array}$ & $\begin{array}{l}a, c, c u \\
e, o, p, v\end{array}$ \\
\hline Papaveraceae & $\begin{array}{l}\text { Chelidonium majus } \\
\text { Planta del yodo, celidonia }\end{array}$ & 1 & Látex & $\begin{array}{l}\text { Directo } \\
\text { Heridas }\end{array}$ & $\mathrm{a}$ \\
\hline Plantaginaceae & $\begin{array}{l}\text { Plantago lanceolata } \\
\text { Saúco, saúgo, sabúgo, taco }\end{array}$ & 1 & Hojas & $\begin{array}{l}\text { Directo } \\
\text { Heridas }\end{array}$ & $\begin{array}{l}a, c, c u \\
e, o, p, v\end{array}$ \\
\hline Polygonaceae & $\begin{array}{l}\text { Rumex crispus } \\
\text { Hoja de lentén, llantén, lentel }\end{array}$ & 1 & Raíz & $\begin{array}{l}\text { Cocción } \\
\text { Heridas }\end{array}$ & $\begin{array}{l}a, c, c u \\
e, o, p, v\end{array}$ \\
\hline Santalaceae & $\begin{array}{l}\text { Viscum album } \\
\text { Muérdago, maraojo, mingojo }\end{array}$ & 1 & Planta & $\begin{array}{l}\text { Cataplasma } \\
\text { Heridas }\end{array}$ & $\begin{array}{l}a, c, c u \\
e, o, p, v\end{array}$ \\
\hline
\end{tabular}

En esta subcategoría se incluyen los tratamientos para curar heridas superficiales, profundas o causadas por castración. También trastornos comunes en las pezuñas del ganado para los que se emplean remedios vulnerarios. 
Se recurre a plantas con propiedades desinfectantes para tratar heridas superficiales con las que se hacen lavados, como el saúco (Sambucus nigra), el hipérico (Hypericum perforatum), el nogal (Juglans regia) o la malva (Malva sylvestris), y a plantas con propiedades cicatrizantes para situaciones que han provocado heridas más profundas y que necesitan además regenerar el tejido, se aconsejan en estos casos las conocidas arzollas (Centaurea calcitrapa, C. lagascana y Jurinea humilis). Varios informantes señalaron estas especies para lavar las profundas heridas que provocaba la mordedura del lobo, además de desinfectar el área afectado, "criaba carne" con rapidez. Para este mismo empleo se citó el bulbo del antojil (Lilium martagon), este remedio vulnerario también se ha referenciado en Palacios del Sil (García Jiménez, 2007).

Otros remedios citados para heridas de carácter leve consisten en colocar las hojas suculentas sobre pequeñas heridas o escoceduras, de especies de la familia Crassulaceae, como la siempreviva (Sempervivum vicentei) o los sombrerillos (Umbilicus rupestris), y también el látex de la planta del yodo (Chelidonium majus) que se dispone sobre las heridas provocadas por picotazos entre las gallinas.

En Villanueva de la Torre, las heridas causadas por castración a los cerdos se lavaban con la cocción de la raíz del amargacho (Arctium minus), Font Quer (1961) señala para esta especie propiedades vulnerarias en uso externo.

Podemos destacar para las cojeras del ganado, el emplasto con la raíz de la hierba de la culebra (Arum italicum) para curar el "babón", herida en la pezuña de la vaca que provocaba cojera y un fuerte hinchazón, o el emplasto de la raíz de uva de perro (Bryonia cretica), también se citaron remedios animales machacando babosas que se disponían en el espacio interdigital de la pezuña.

En la zona se hace referencia a la enfermedad del "lamparón" de las vacas, en la que solían aparecer bultos en el cuello, según Pardo de Santayana (2008) provocados por ganglios infectados. Se trataban en la localidad de Arbejal de este modo: "cogíamos en el pajar una bolsa de grana, de lo que dejaba la hierba y se cocía todo junto, casi hirviendo en un saco se ponía lo que pudiera aguantar la vaca, y el caldo lo usabas cada poco para que el saco estuviera siempre húmedo, y así se quitaba la inflamación".

\section{Órganos de los sentidos:}

Se ha recogido 1 registro de uso, correspondiente a 1 taxón de obtención silvestre de la familia Compositae, representando un $0,48 \%$ del total de registros de uso para la categoría Veterinaria.

TABLA 54: Relación de especies empleadas en la subcategoría Órganos de los sentidos, indicando familia, número de registros de uso $(\mathrm{RU})$, parte usada, empleo (modo de preparación y finalidad de uso) y ganado $(\mathrm{c}=$ caprino; $\mathrm{e}=$ equino; $\mathrm{o}=$ ovino; $\mathrm{v}=$ vacuno).

\begin{tabular}{llllll}
\hline Familia & $\begin{array}{l}\text { Nombre científico } \\
\text { Nombre vulgar }\end{array}$ & RU & Parte usada & Empleo & Ganado \\
\hline Compositae & $\begin{array}{l}\text { Chamaemelum nobile } \\
\text { Manzanilla, manzanilla campera }\end{array}$ & 1 & Inflorescencia & $\begin{array}{l}\text { Infusión } \\
\text { Lavado ojos }\end{array}$ & c, e, o, v \\
\hline
\end{tabular}

El único registro de uso en la subcategoría Órganos de los sentidos es el referente al uso de la infusión de manzanilla (Chamaemelum nobile) para lavar los ojos llorosos del ganado, cabras, yeguas, ovejas y vacas. 
Consideramos probable que la hierba nube (Trifolium pratense) se haya utilizado para tratar la nube (cataratas) de los animales, ya que su nombre vulgar aporta información sobre el uso, aunque solo se referenció el empleo en personas para tratar las infecciones oculares. Font Quer (1961) recoge su uso contra las cataratas.

\section{Enfermedades infecciosas y parasitarias:}

Se han recogido 12 registros de uso, correspondientes a 5 taxones de 5 familias botánicas diferentes, 4 taxones de obtención silvestre y 1 cultivado, representando un 5,71\% del total de registros de uso para la categoría Veterinaria.

TABLA 55: Relación de especies empleadas en la subcategoría Enfermedades infecciosas y parasitarias, ordenadas alfabéticamente por familia, indicando número de registros de uso (RU), parte usada, empleo (modo de preparación y finalidad de uso) y ganado ( $c$ = caprino; $c u=$ cunícula; $o=0 v i n o ; ~ p=$ porcino; $v$ = vacuno).

\begin{tabular}{|c|c|c|c|c|c|}
\hline Familia & $\begin{array}{l}\text { Nombre cientifico } \\
\text { Nombre vulgar }\end{array}$ & RU & Parte usada & Empleo & Ganado \\
\hline Compositae & $\begin{array}{l}\text { Jacobaea vulgaris } \\
\text { Bujanera }\end{array}$ & 2 & Parte aérea & $\begin{array}{c}\text { Cocción } \\
\text { Pediculosis y picaduras }\end{array}$ & $0, v$ \\
\hline Gentianaceae & $\begin{array}{l}\text { Gentiana lutea } \\
\text { Junciana, genciana }\end{array}$ & 5 & Rizoma & $\begin{array}{l}\text { Cocción, directo } \\
\text { Lombrices }\end{array}$ & $p$ \\
\hline Hypericaceae & $\begin{array}{l}\text { Hypericum perforatum } \\
\text { Hipérico, bergaula, pericón }\end{array}$ & 2 & Parte aérea & $\begin{array}{c}\text { Macerado en aceite } \\
\text { Tiña }\end{array}$ & $\begin{array}{c}\text { c, cu, o, } \\
\text { pe }\end{array}$ \\
\hline Ranunculaceae & $\begin{array}{l}\text { Aconitum napellus } \\
\text { A. vulparia } \\
\text { Hierba piojera, acónito }\end{array}$ & 1 & Parte aérea & $\begin{array}{c}\text { Cocción } \\
\text { Pediculosis }\end{array}$ & $v$ \\
\hline Solanaceae & $\begin{array}{l}\text { Nicotiana tabacum } \\
\text { Tabaco }\end{array}$ & 2 & Parte aérea & $\begin{array}{l}\text { Cocción } \\
\text { Pediculosis }\end{array}$ & v \\
\hline
\end{tabular}

Se recogen remedios para tratar las infecciones fúngicas, las infecciones por piojos (pediculosis), por lombrices (helmintiasis), o por picaduras de larvas de moscas (miasis).

La pediculosis no solo afecta a las personas, también es común en otros mamíferos. El mismo tratamiento con hierba piojera (Aconitum napellus, A. vulparia) que el indicado para personas se aconsejó para animales, principalmente para los terneros más jóvenes, propensos a padecer esta infección. Con el cocimiento se lavaba bien al animal, desapareciendo los piojos al poco tiempo. Otras plantas idóneas son la bujanera (Jacobaea vulgaris) y la planta del tabaco (Nicotiana tabacum), administradas de forma similar a la hierba piojera.

La virtud vermífuga de la genciana (Gentiana lutea) es bien conocida en la zona de estudio, siendo la especie con mayor número de registro de uso en esta subcategoría, las lombrices solían afectar en mayor medida a los cerdos, a los que se les servía fragmentos de rizoma de genciana directamente con la comida o se les cocía previamente, remedio recogido también en el Montseny (Bonet, 2001).

En cuanto a la miasis, es una enfermedad parasitaria ocasionada por larvas de mosca que afecta a los tejidos, provocando bultos e hinchazones que se trataban con la bujanera (Jacobaea vulgaris). En la provincia de Segovia, Blanco Castro (1998) recoge el uso de esta especie en veterinaria popular para curar el "gusano del ganao", por aplicación directa en la herida, cuando se secaba la hierba, caían muertos los gusanos. 
Para infecciones fúngicas como la tiña, se aplica aceite de hipérico (Hypericum perforatum) sobre la zona afectada, se recogen referencias de contagio en ovejas, cerdos y conejos.

\section{Enfermedades "culturales":}

Se han recogido 2 registros de uso, correspondientes a 2 taxones de 2 familias botánicas diferentes, 1 taxón de obtención silvestre y 1 cultivado, representando un 0,95\% del total de registros de uso para la categoría Veterinaria.

TABLA 56: Relación de especies empleadas en la subcategoría Enfermedades "culturales", ordenadas alfabéticamente por familia, indicando número de registros de uso (RU), parte usada, empleo (modo de preparación y finalidad de uso) y ganado ( $v=$ vacuno).

\begin{tabular}{llcccc}
\hline Familia & $\begin{array}{l}\text { Nombre científico } \\
\text { Nombre vulgar }\end{array}$ & RU & Parte usada & Empleo & Ganado \\
\hline Amaryllidaceae & $\begin{array}{l}\text { Allium sativum } \\
\text { Ajo }\end{array}$ & 1 & Tallo seco & $\begin{array}{c}\text { Sahumerio } \\
\text { Traidora }\end{array}$ & v \\
Apiaceae & $\begin{array}{l}\text { Angelica sylvestris } \\
\text { Angélica, chiflato }\end{array}$ & 1 & Inflorescencia & $\begin{array}{c}\text { Cocción } \\
\text { Traidora }\end{array}$ & $v$ \\
\hline
\end{tabular}

La "traidora" es la única enfermedad de tipo cultural recogida en la zona de estudio. Se trata de una enfermedad del ganado vacuno bien conocida por los ganaderos, también se decía que se "tomaban" las vacas por el hecho de no concederlas un capricho, los síntomas eran nerviosismo, rabia, ansiedad e hinchazón. La angélica (Angelica sylvestris) y el ajo (Allium sativum) trataban de disminuir los síntomas purificando al animal, en el primer caso se servía la cocción de la inflorescencia, y en segundo caso se ahumaba al animal con el humo de quemar las ristras de los ajos. En la comarca de Campoo (Pardo de Santayana, 2008) la traidora es conocida con el nombre de solengua y refiere los mismos síntomas que los señalados en la zona de estudio.

\section{Intoxicaciones y envenenamientos:}

Se han recogido 7 registros de uso, correspondientes a 2 taxones de obtención silvestre de 2 familias botánicas diferentes, representando un 3,33\% del total de registros de uso para la categoría Veterinaria.

TABLA 57: Relación de especies empleadas en la subcategoría Intoxicaciones y envenenamientos, ordenadas alfabéticamente por familia, indicando número de registros de uso (RU), parte usada, empleo (modo

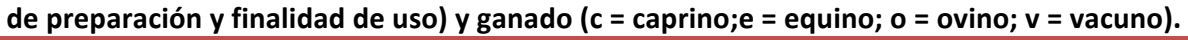

\begin{tabular}{llcccc}
\hline Familia & $\begin{array}{l}\text { Nombre científico } \\
\text { Nombre vulgar }\end{array}$ & RU & Parte usada & Empleo & Ganado \\
\hline Scrophulariaceae & $\begin{array}{l}\text { Verbascum lychnitis } \\
\text { V. pulverulentum } \\
\text { V. thapsus } \\
\text { Gordolobo, guardalobo } \\
\text { Hyoscyamus niger } \\
\text { Beleño }\end{array}$ & 1 & Hojas & $\begin{array}{c}\text { Cataplasma } \\
\text { Picaduras insectos }\end{array}$ & o \\
Solanaceae & 6 & Semillas & Frita & C, e, o, v \\
\hline
\end{tabular}

El remedio más popular en la comarca para tratar las inflamaciones provocadas al ganado por mordeduras (de culebra, de comadreja, etc.) se elaboraba con semillas de beleño (Hyoscyamus niger). Así lo detallan en la localidad de Verdeña "Cuando está seca la grana se cuece en el 
puchero, se quita el agua, se da vuelta en una sartén mala y se fríe un poco. Con una vedija de lana se da en la picadura, es contraveneno para si pica a la vaca, una culebra o una mostolilla". Este mismo remedio se cita en la subcategoría musculatura y esqueleto para el tratamiento general de inflamaciones, y en los Picos de Europa (Lastra, 2003) se señala el poder analgésico de las semillas.

Para las picaduras de insectos se colocaba una cataplasma mojada en la cocción de hojas de gordolobo (Verbascum spp.).

\section{Otros usos veterinarios:}

Se han recogido 2 registros de uso, correspondientes a 1 taxón de obtención silvestre de la familia Poaceae, representando un $0,95 \%$ del total de registros de uso para la categoría Veterinaria.

TABLA 58: Relación de especies empleadas en la subcategoría Otros usos veterinarios, indicando familia, número de registros de uso (RU), parte usada, empleo (modo de uso y finalidad) y animal (pe = perros).

\begin{tabular}{llcccc}
\hline Familia & $\begin{array}{l}\text { Nombre científico } \\
\text { Nombre vulgar }\end{array}$ & RU & Parte usada & Empleo & Animal \\
\hline Poaceae & $\begin{array}{l}\text { Brachypodium phoenicoides } \\
\text { Hierba perruna }\end{array}$ & 2 & Hojas & $\begin{array}{l}\text { Directa } \\
\text { Purga }\end{array}$ & pe \\
\hline
\end{tabular}

En otros usos veterinarios se incluyen plantas que utilizan los animales como automedicación, como es el caso de la hierba perruna (Brachypodium phoenicoides), que utilizan los perros para purgarse. En El Caurel (Blanco, 1996) se indica que los perros comen Brachypodium pinnatum cuando se indigestan. 


\section{Uso Tóxıco y Nocivo:}

En la categoría de Uso Tóxico y Nocivo se incluye el conocimiento sobre la toxicidad de las plantas y otras sustancias como venenos o repelentes. También se recogen productos nocivos e incluso plantas utilizadas como cebo o reclamo para atraer o atrapar animales. En la comarca de la Montaña Palentina se menciona el uso de 45 taxones vegetales correspondientes a 27 familias botánicas, para los que se han recogido un total de 229 registros de uso (RU). De ellos, 40 taxones son de obtención silvestre y 5 cultivados. Los taxones con mayor número de registros de uso en la categoría Uso Tóxico y Nocivo se representan en la figura 44.

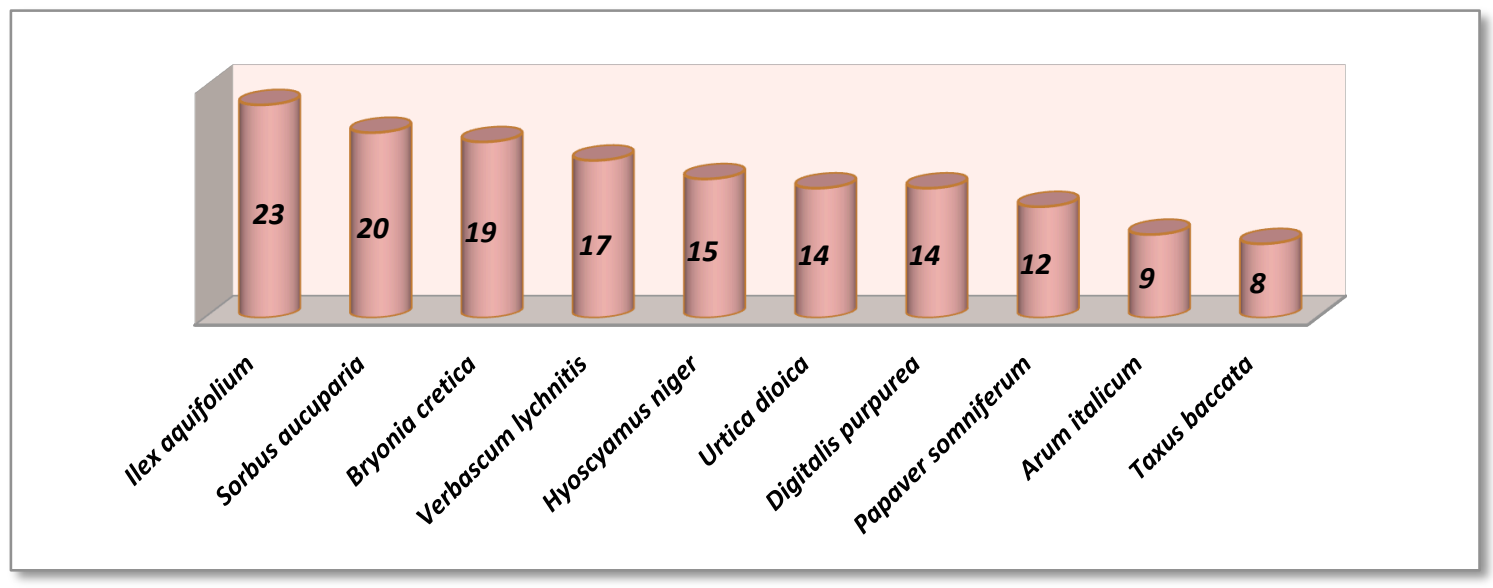

FIGURA 44: Especies con mayor número de registros de uso de carácter Tóxico y Nocivo.

Las familias con mayor representación en cuanto a número de especies fueron: Lamiaceae, Scrophulariacea y Apiaceae, con 6,4 y 3 especies respectivamente, y la familia con mayor número de registros de uso fue Scrophulariaceae con 22, según se señala en la figura 45.

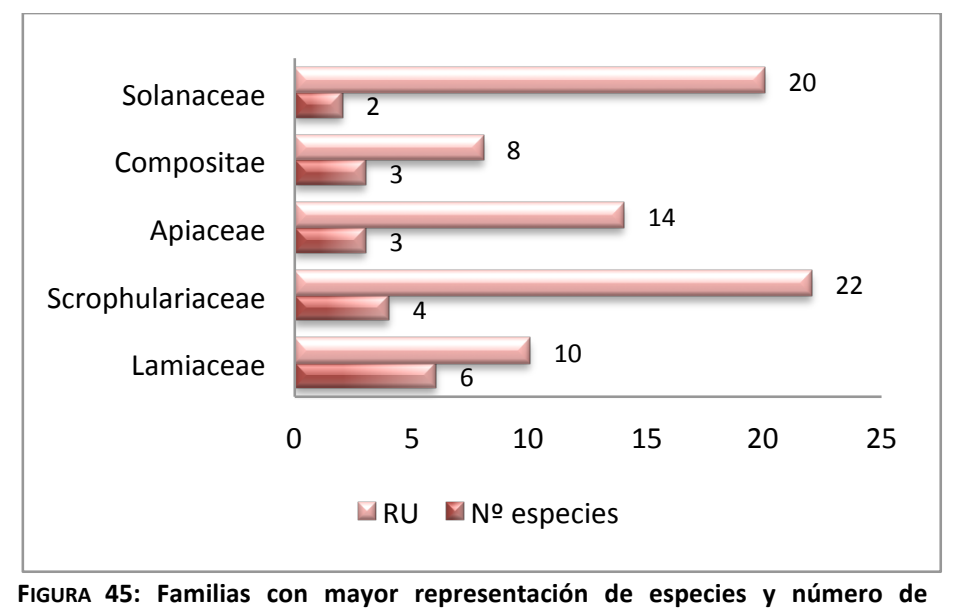
registros de uso (RU) de carácter Tóxico y nocivo.

La importancia del conocimiento relacionado con esta categoría resulta vital, ya que distingue entre las especies que se pueden consumir, de las que su uso puede causar graves problemas para la salud por consumo o contacto, tanto para los animales como para las personas. Otra parte significativa del conocimiento se centra en la forma de controlar las plagas, tanto en el hogar como en los cultivos, así como distintos métodos de caza o pesca. 
Los usos se han agrupado en subcategorías siguiendo los criterios establecidos en el Inventario Español de los Conocimientos Tradicionales relativos a la Biodiversidad (Pardo de Santayana et al., 2014), obteniendo referencias en las 5 subcategorías indicadas en la tabla 59.

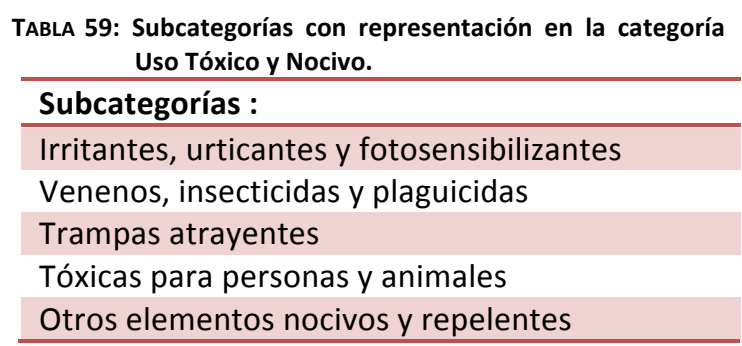

Los 229 registros de uso obtenidos, en la categoría Uso Tóxico y Nocivo, se reparten en 5 subcategorías tal y como señala la figura 46, resultando que Tóxicos para personas y animales es la que recibió mayor número de registros con 147, un $64,19 \%$ del total en esta categoría, seguido de Venenos, insecticidas y plaguicidas con 45 , un $19,65 \%$, y Trampas atrayentes con 20 , un $8,73 \%$.

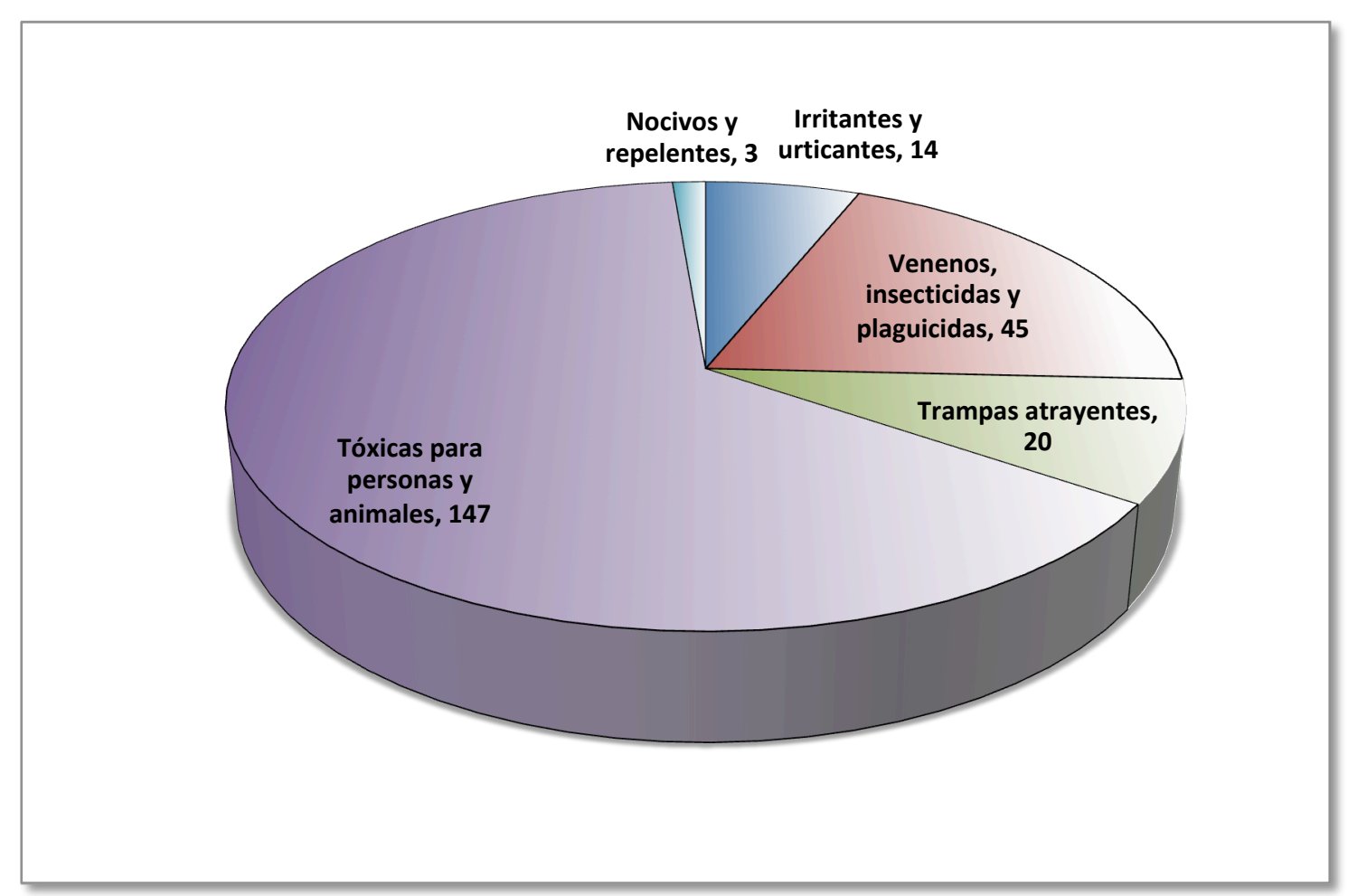

FIGURA 46: Registros de Uso (RU) de las subcategorías representadas en Uso Tóxico y Nocivo.

A continuación se presentan las utilidades agrupadas por subcategorías de Uso Tóxico y Nocivo, señalando los taxones que han obtenido citas en los mismos, el número de registros de uso de cada taxón, la parte usada y la finalidad.

\section{Irritantes, urticantes y fotosensibilizantes:}

Se han recogido 14 registros de uso, correspondientes a 4 taxones de 2 familias botánicas diferentes, todos los taxones son de de obtención silvestre, representando un 6,11\% del total de registros de uso para la categoría Uso Tóxico y Nocivo. 
TABLA 60: Relación de especies empleadas en la subcategoría Irritantes, urticantes y fotosensibilizantes, ordenadas alfabéticamente por familia, indicando número de registros de uso (RU), parte usada y finalidad.

\begin{tabular}{llccc}
\hline Familia & $\begin{array}{l}\text { Nombre científico } \\
\text { Nombre vulgar }\end{array}$ & RU & Parte usada & Finalidad \\
\hline Euphorbiaceae & $\begin{array}{l}\text { Euphorbia hyberna } \\
\text { Hierba de la leche } \\
\text { Euphorbia serrata } \\
\text { Lechetrezna }\end{array}$ & 1 & Látex & Lersonas \\
\hline $\begin{array}{l}\text { Urtica dioica } \\
\text { Ortiga }\end{array}$ & 11 & Parte aérea & Personas \\
\hline $\begin{array}{l}\text { Urtica urens } \\
\text { Ortiga, ortiga meña }\end{array}$ & 1 & Parte aérea & Personas \\
\hline
\end{tabular}

Se incluyen todos aquellos registros de uso relativos a especies que al tocarlas causan irritación, enrojecimiento y otros efectos perjudiciales para la piel.

Las ortigas (Urtica dioica, U. urens) son reconocidas por su efecto urticante sobre la piel y se evita su contacto. Existe la leyenda popular que asegura que no pican cuando se contiene la respiración, recogido también en otras zonas de la Península Ibérica como: los Picos de Europa (Lastra, 2003), Vasconia (Barandiaran \& Manterola, 2004) y Campoo (Pardo de Santayana, 2008). Entre las especies de ortigas, destaca la ortiga meña (Urtica urens) por la agresividad de su picadura.

En cuanto a especies irritantes se mencionan la hierba de la leche (Euphobia hyberna) y la lechetrezna (Euphorbia serrata), cuyo látex causa enrojecimientos e irritación al contacto con la piel.

\section{Venenos, insecticidas y plaguicidas:}

Se han recogido 45 registros de uso, correspondientes a 12 taxones de 6 familias botánicas diferentes, 10 taxones de obtención silvestre y 2 cultivados, representando un 19,65\% del total de registros de uso para la categoría Uso Tóxico y Nocivo.

TABLA 61: Relación de especies empleadas en la subcategoría Venenos, insecticidas y plaguicidas, ordenadas alfabéticamente por familia, indicando número de registros de uso (RU), parte usada y finalidad.

\begin{tabular}{llccc}
\hline Familia & $\begin{array}{l}\text { Nombre científico } \\
\text { Nombre vulgar }\end{array}$ & RU & Parte usada & Finalidad \\
\hline Adoxaceae & $\begin{array}{l}\text { Sambucus nigra } \\
\text { Saúco, saúgo, sabúgo, taco }\end{array}$ & 1 & Parte aérea & Roedores \\
\hline Apiaceae & $\begin{array}{l}\text { Thapsia villosa } \\
\text { Tagarno, tagarnio } \\
\text { Dracunculus vulgaris } \\
\text { Hierba de la culebra }\end{array}$ & 2 & Raíz & Pesca trucha \\
\hline Lamiaceae & $\begin{array}{l}\text { Mentha longifolia } \\
\text { Poleo, té de menta, menta poleo } \\
\text { Mentha pulegium } \\
\text { Té de menta, menta poleo, poleo }\end{array}$ & 4 & Parte aérea & Culebras \\
\hline $\begin{array}{l}\text { Ocimum basilicum } \\
\text { Albahaca } \\
\text { Origanum vulgare } \\
\text { Orégano } \\
\text { Thymus mastichina } \\
\text { Tomillo, mejorana }\end{array}$ & 2 & Planta viva & Pulgas \\
\hline
\end{tabular}




\begin{tabular}{|c|c|c|c|c|}
\hline Familia & $\begin{array}{l}\text { Nombre científico } \\
\text { Nombre vulgar }\end{array}$ & RU & Parte usada & Finalidad \\
\hline Lamiaceae & $\begin{array}{l}\text { Thymus zygis } \\
\text { Tomillo, cepico }\end{array}$ & 1 & Parte aérea & Ratas \\
\hline \multirow[t]{2}{*}{ Scrophulariaceae } & $\begin{array}{l}\text { Scrophularia canina } \\
\text { Hoja mora, jamora }\end{array}$ & 5 & Parte aérea & Pesca trucha \\
\hline & $\begin{array}{l}\text { Verbascum lychnitis } \\
\text { V. pulverulentum } \\
\text { V. thapsus } \\
\text { Gordolobo, guardalobo }\end{array}$ & 17 & Planta entera & Pesca trucha \\
\hline Urticaceae & $\begin{array}{l}\text { Urtica dioica } \\
\text { Ortiga }\end{array}$ & 3 & Parte aérea & Pulgón \\
\hline
\end{tabular}

Distinguimos dos grupos diferenciados en esta subcategoría, por un lado los venenos y repelentes empleados para controlar las plagas del hogar, del establo o de los cultivos, y por otro, los venenos empleados para cazar o pescar.

En el primer grupo destacan las especies de la familia Lamiaceae, sus propiedades aromáticas resultan indicadas como repelentes. Se ha citado al poleo (Mentha longifolia, M. pulegium) contra las pulgas, a la mejorana (Thymus mastichina) contra los chinches, al tomillo (Thymus zygis) para ahuyentar ratas, y a la albahaca (Ocimum basilicum) y al orégano (Origanum vulgare) para alejar los insectos del hogar.

Aparece como tendencia en las últimas décadas, cultivada en los jardines de las casas, la hierba de la culebra (Dracunculus vulgaris), asegurando que ahuyenta a las temidas culebras, sin poder confirmar si es su desagradable olor o el parecido de su tallo moteado con la piel de una culebra, lo que ha derivado su uso como repelente.

Entre las técnicas de pesca furtiva de la trucha en las cabeceras de los ríos, documentamos el envenenamiento de zonas remansadas con 3 taxones diferentes: gordolobo (Verbascum spp.), hoja mora (Scrophularia canina) o tagarno (Thapsia villosa), se trata del grupo de plantas ictiotóxicas (tóxicas para los peces). Resulta una práctica de pesca tradicional muy antigua y que ya solo recuerdan los más mayores, en las localidades por las que discurrían ríos con actividad pesquera. Machacando frutos y semillas, en ocasiones toda la planta, se obtenía una especie de pasta, que se arrojaba en los remansos de los ríos trucheros, con el objetivo de atontar a la pesca y recoger fácilmente las piezas. Este arte de pesca se llevó a cabo en muchas otras zonas de la Península Ibérica como: Segovia (Blanco, 1998), Toledo (Criado et al., 2008), Castilla-La Mancha (Verde et al., 2008), Aliste (Gallego, 2009), Monfragüe (Tejerina, 2010) o Salamanca (Velasco et al., 2010).

\section{Trampas atrayentes:}

Se han recogido 20 registros de uso, correspondientes a 2 taxones de 2 familias botánicas diferentes, 1 taxón de obtención silvestre y 1 cultivado, representando un 8,73\% del total de registros de uso para la categoría Uso Tóxico y Nocivo. 
TABLA 62: Relación de especies empleadas en la subcategoría Trampas atrayentes, ordenadas alfabéticamente por familia, indicando número de registros de uso (RU), parte usada y finalidad.

\begin{tabular}{llccc}
\hline Familia & $\begin{array}{l}\text { Nombre científico } \\
\text { Nombre vulgar }\end{array}$ & RU & Parte usada & Finalidad \\
\hline Aquifoliaceae & $\begin{array}{l}\text { llex aquifolium } \\
\text { Acebo, aceba }\end{array}$ & 19 & $\begin{array}{l}\text { Corteza y } \\
\text { parénquima }\end{array}$ & Pájaros \\
Rosaceae & $\begin{array}{l}\text { Prunus cerasus } \\
\text { Guindal }\end{array}$ & 1 & Exudado & Pájaros \\
\hline
\end{tabular}

La subcategoría Trampas atrayentes agrupa plantas utilizadas como reclamos para atraer, atrapar o matar animales con distintos fines.

La caza de pájaros en el pasado era una de las diversiones infantiles más populares. Para apresar pequeños pajarillos se elaboraba liga, una sustancia pegajosa y espesa obtenida con la corteza y el parénquima cortical del acebo (llex aquifolium). Se introduce la corteza en agua varios días, o se machaca y masca pacientemente hasta conseguir una masa gelatinosa de un color grisáceo que tiene un gran poder adherente. La liga se colocaba sobre juncos, cañas de cereal o pequeñas varillas vegetales en sitios frecuentados por las aves, como abrevaderos de agua, nidos, etc. Similar método de caza se ha documentado entre otras zonas en: Cantalojas (Gil Pinilla, 1995), Castellón (Mulet, 1991), Picos de Europa (Lastra, 2003), Sierra de Montsant (Ledesma, 2004), Sanabria (Blanco \& Díez, 2005), Campoo (Pardo de Santayana, 2008) o Castilla La-Mancha (Verde et al., 2008). También con el exudado pegajoso del guindal (Prunus cerasus) se conseguía atrapar pequeños pájaros.

\section{Tóxicas para personas y animales:}

Se han recogido 147 registros de uso, correspondientes a 28 taxones de 22 familias botánicas diferentes, 26 taxones de obtención silvestre y 2 cultivados, representando un $64,19 \%$ del total de registros de uso para la categoría Uso Tóxico y Nocivo.

TABLA 63: Relación de especies empleadas en la subcategoría Tóxicas para personas y animales, ordenadas alfabéticamente por familia, indicando número de registros de uso (RU), parte usada y afectados.

\begin{tabular}{|c|c|c|c|c|}
\hline Familia & $\begin{array}{l}\text { Nombre científico } \\
\text { Nombre vulgar }\end{array}$ & RU & Parte usada & Afectados \\
\hline \multirow[t]{2}{*}{ Adoxaceae } & $\begin{array}{l}\text { Sambucus ebulus } \\
\text { Nuezgo, yezgo }\end{array}$ & 1 & Planta & Personas \\
\hline & $\begin{array}{l}\text { Sambucus nigra } \\
\text { Saúco, saúgo, sabúgo, taco }\end{array}$ & 4 & Fruto & Personas \\
\hline Amaryllidaceae & $\begin{array}{l}\text { Allium sphacerocephalon } \\
\text { Ajestrín, ajo, cebolleta }\end{array}$ & 1 & Bulbo & Animales \\
\hline \multirow[t]{2}{*}{ Apiaceae } & $\begin{array}{l}\text { Apium nodiflorum } \\
\text { Berra }\end{array}$ & 2 & Tallos y hojas & Personas \\
\hline & $\begin{array}{l}\text { Conium maculatum } \\
\text { Budaño, cañiguerra, canuto }\end{array}$ & 5 & Parte aérea & Animales \\
\hline Aquifoliaceae & $\begin{array}{l}\text { Ilex aquifolium } \\
\text { Acebo, aceba }\end{array}$ & 4 & Fruto & Personas \\
\hline Araceae & $\begin{array}{l}\text { Arum italicum } \\
\text { Hierba de la culebra }\end{array}$ & 9 & Planta & Personas \\
\hline Asparagaceae & $\begin{array}{l}\text { Polygonatum odoratum } \\
\text { Pendientes de la reina }\end{array}$ & 1 & Parte aérea & Personas \\
\hline \multirow[t]{2}{*}{ Compositae } & $\begin{array}{l}\text { Inula montana } \\
\text { Árnica }\end{array}$ & 2 & Parte aérea & Personas \\
\hline & $\begin{array}{l}\text { Jacobaea vulgaris } \\
\text { Bujanera, hierba piojera }\end{array}$ & 4 & Parte aérea & Animales \\
\hline
\end{tabular}




\begin{tabular}{|c|c|c|c|c|}
\hline Familia & $\begin{array}{l}\text { Nombre científico } \\
\text { Nombre vulgar }\end{array}$ & RU & Parte usada & Afectados \\
\hline Cucurbitaceae & $\begin{array}{l}\text { Bryonia cretica } \\
\text { Uva de perro, nueza, enredadera }\end{array}$ & 19 & Fruto & Personas \\
\hline Ericaceae & $\begin{array}{l}\text { Arctostaphylos uva-ursi } \\
\text { Gayuga, agayuga, gayuba }\end{array}$ & 1 & Fruto & Animales \\
\hline Fagaceae & $\begin{array}{l}\text { Fagus sylvatica } \\
\text { Haya }\end{array}$ & 1 & Fruto & Personas \\
\hline Leguminosae & $\begin{array}{l}\text { Trifolium pratense } \\
\text { Trébol, chupa, hierba nube }\end{array}$ & 2 & Parte aérea & Animales \\
\hline Lentiburiaceae & $\begin{array}{l}\text { Pinguicula grandiflora } \\
\text { Tiraña, hoja de la tiraña }\end{array}$ & 3 & Hojas & Personas \\
\hline Orobanchaceae & $\begin{array}{l}\text { Melampyrum pratense } \\
\text { Hierba morena, hierba negreal }\end{array}$ & 1 & Parte aérea & Animales \\
\hline Papaveraceae & $\begin{array}{l}\text { Papaver somniferum } \\
\text { Amapola, flor de la droga }\end{array}$ & 12 & Planta & Personas \\
\hline \multirow[t]{2}{*}{ Plantaginaceae } & $\begin{array}{l}\text { Digitalis purpurea } \\
\text { Dedalera, campanilla, cuete }\end{array}$ & 14 & Planta & Personas y animales \\
\hline & $\begin{array}{l}\text { Veronica beccabunga } \\
\text { Berraza }\end{array}$ & 1 & Tallos y hojas & Personas \\
\hline \multirow[t]{4}{*}{ Ranunculaceae } & Aconitum napellus & & & \\
\hline & $\begin{array}{l}\text { A. vulparia } \\
\text { Hierba piojera, acónito }\end{array}$ & 4 & Parte aérea & Personas y animales \\
\hline & Helleborus foetidus & & & \\
\hline & $\begin{array}{l}\text { H. viridis } \\
\text { Hierba de las culebras, mantecón }\end{array}$ & 2 & Planta & Personas y animales \\
\hline Rhamnaceae & $\begin{array}{l}\text { Frangula alnus } \\
\text { Meaperro, uva de perro }\end{array}$ & 2 & Fruto & Personas \\
\hline Rosaceae & $\begin{array}{l}\text { Sorbus aucuparia } \\
\text { Amargoso, serbal, drío, drido }\end{array}$ & 20 & Fruto & Personas \\
\hline Santalaceae & $\begin{array}{l}\text { Viscum album } \\
\text { Muérdago, maraojo, mingojo }\end{array}$ & 2 & Planta & Personas \\
\hline Sapindaceae & $\begin{array}{l}\text { Aesculus hippocastanum } \\
\text { Castaño de Indias }\end{array}$ & 2 & Fruto & Personas \\
\hline \multirow[t]{2}{*}{ Solanaceae } & $\begin{array}{l}\text { Datura stramonium } \\
\text { Estramonio, trompeta }\end{array}$ & 5 & Planta & Personas \\
\hline & $\begin{array}{l}\text { Hyoscyamus niger } \\
\text { Beleño }\end{array}$ & 15 & Planta & Personas \\
\hline Taxaceae & $\begin{array}{l}\text { Taxus baccata } \\
\text { Tejo }\end{array}$ & 8 & Ramas y hojas & Personas \\
\hline
\end{tabular}

Las plantas cuyo consumo debe evitarse por su toxicidad tanto para personas como animales se recogen es este apartado. Además engloba aquellas especies de las que se advierte que un consumo prolongado puede ser perjudicial.

Dentro del conocimiento recopilado sobre las plantas cuyo consumo debe evitarse por su toxicidad para las personas, destacan especies como beleño (Hyoscyamus niger), dedalera (Digitalis purpurea) y tejo (Taxus baccata). Se recuerdan fallecimientos en la localidad de Villabellaco, debido a la ingestión de las temidas uvas de perro, nombre vulgar por el que se reconoce en la zona a los frutos de varias especies (Bryonia cretica, Frangula alnus). Los frutos rojos del amargoso (Sorbus aucuparia) o del acebo (Ilex aquifolium) también se consideran tóxicos, denominados vulgarmente reventones, ya que su consumo "te hacía reventar". 
En la comarca, la hierba de las culebras (Helleborus foetidus, H. viridis) y la raíz de la culebra (Arum italicum) asocian su nombre común a un animal detestado para advertir su posible peligrosidad, también se la reconoce su toxicidad en: el Pirineo Aragonés (Villar et al., 1987), Monzón (Ferrández \& Sanz, 1993), El Caurel (Blanco, 1996), o Piloña (San Miguel, 2005). Del mismo modo, la flor de la droga o amapola (Papaver somniferum) fue erradicada casi en su totalidad de los jardines con la creencia de provocar alguna intoxicación o servir para el trafico de drogas tóxicas contra la salud publica.

Existe un grupo de plantas que sin ser considerado peligroso para las personas, al menos se advierte sobre ellos que su consumo puede producir algún efecto adverso no deseado, comer muchos frutos de haya (Fagus sylvatica) produce dolor de cabeza, probar la tiraña (Pinguicula grandiflora) deriva en diarrea o confundir el sabroso berro con la berra (Apium nodiflorum) o con las berraza (Veronica beccabunga) de menor palatabilidad.

En cuanto al ganado, se vigilaba durante la vecería la ingesta excesiva de trébol (Trifolium pratense) y de budaño (Conium maculatum) que provocaban hinchazón y gases, la de hierba negreal (Melampyrum pratense) para impedir diarreas y la de ajestrín (Allium sphaerocephalon) al traspasar un sabor desagradable a la leche. En Tremaya cuidaban a los corderos con especial atención cuando se acercaban al río para impedir el consumo de acónito (Aconitum napellus, A. vulparia), recordándose alguna desgracia relacionada al respecto.

\section{Elementos nocivos y repelentes:}

Se han recogido 3 registros de uso, correspondientes a 2 taxones de 2 familias botánicas diferentes, los 2 taxones de obtención silvestre, representando un 1,31\% del total de registros de uso para la categoría Uso Tóxico y Nocivo.

TABLA 64: Relación de especies empleadas en la subcategoría Elementos nocivos y repelentes, ordenadas alfabéticamente por familia, indicando número de registros de uso (RU), parte usada y finalidad.

\begin{tabular}{llccc}
\hline Familia & $\begin{array}{l}\text { Nombre científico } \\
\text { Nombre vulgar }\end{array}$ & RU & Parte usada & Finalidad \\
\hline Compositae & $\begin{array}{l}\text { Arctium minus } \\
\text { Amargacho, capacho, pegote }\end{array}$ & 2 & Fruto & Ratones \\
\hline Gentianaceae & $\begin{array}{l}\text { Gentiana lutea } \\
\text { Junciana, genciana }\end{array}$ & 1 & Rizoma & Niños \\
\hline
\end{tabular}

Se agrupan a las especies empleadas en el control biológico de plagas y otros elementos nocivos o repelentes no recogidos en anteriores subcategorías.

En control biológico de plagas se mencionan los frutos del amargacho (Arctium minus) para tapar agujeros en las paredes y evitar la presencia de ratones. En Palacios del Sil (García Jiménez, 2007) señala el uso del fruto para tapar los agujeros de arcas y arcones y así impedir el paso de los ratones.

Y en la localidad de Valcobero, recuerdan utilizar el intenso amargor del rizoma de genciana (Gentiana lutea) para inducir a los niños el abandono del chupete. Se frotaba con un trozo de rizoma pelado y el amargor provocaba en los niños el rechazo del habito de succión del chupete, este uso no se encuentra referenciado en la bibliografía consultada. 


\section{USO COMBUSTIBLE:}

En la categoría de Uso Combustible se incluyen las especies usadas para calentar, cocinar, iluminar o ahumar, otras indicadas para chamuscar el cerdo en la matanza y las que se utilizaron para elaborar carbón vegetal. En la comarca de la Montaña Palentina se menciona el uso de 42 taxones vegetales correspondientes a 20 familias botánicas, para los que se han recogido un total de 733 registros de uso (RU). De ellos, 35 taxones son de obtención silvestre y 7 cultivados. Los taxones con mayor número de registros de uso en la categoría Uso Combustible se representan en la figura 47.

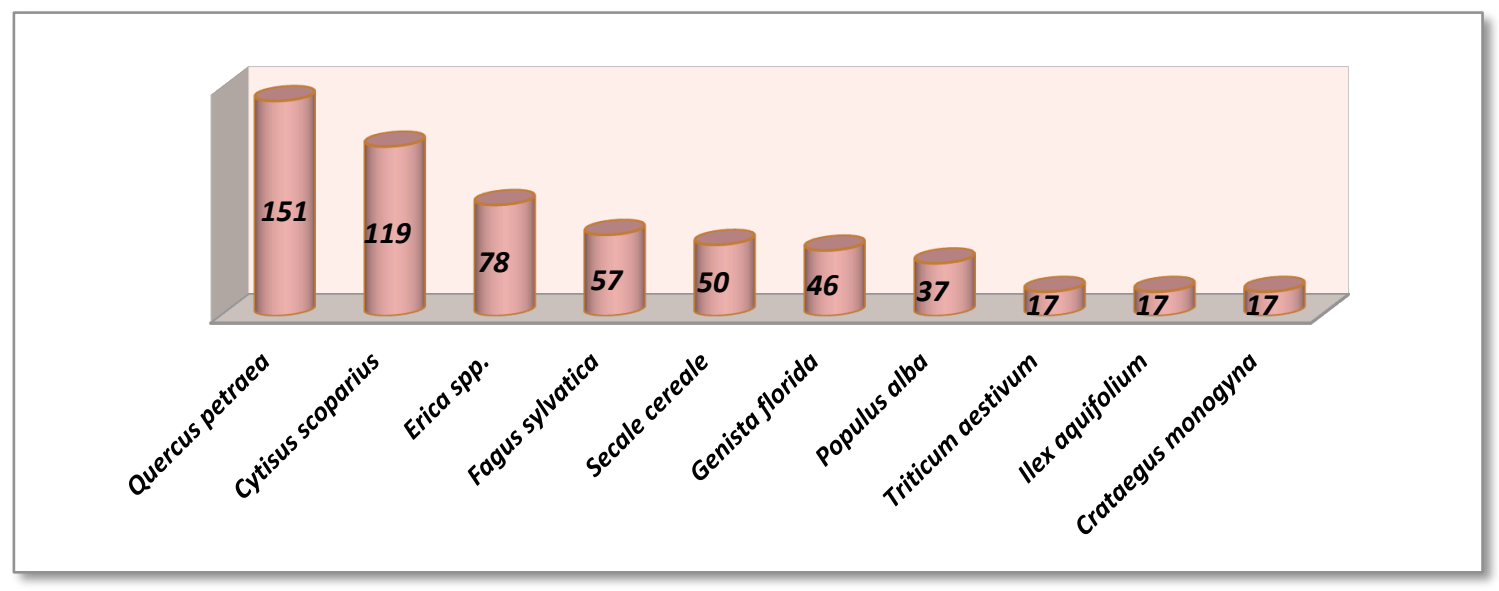

FIGURA 47: Especies con mayor número de registros de uso empleadas como Combustible.

Las familias con mayor representación en cuanto a número de especies fueron: Leguminosae, Rosaceae y Fagaceae, con 7, 6 y 5 especies respectivamente, y la familia con mayor número de registros de uso fue Fagaceae con 220, según se muestra en la figura 48.

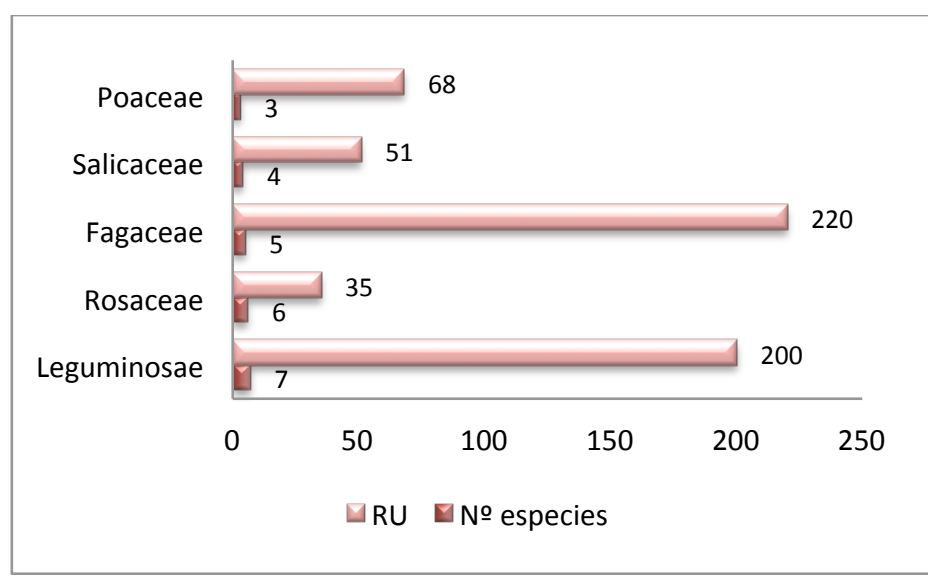

FIGURA 48: Familias con mayor representación de especies y número de registros de uso (RU), de utilidad Combustible.

Las familias más destacadas en esta categoría son Leguminosae y Fagaceae, resulta lógico ya que engloban en el caso de Leguminosae todas las especies arbustivas que se han empleado de forma tradicional para el encendido de la lumbre, y en el caso de Fagaceae por la importancia de sus especies arbóreas como leña o para carbón vegetal. 
Los usos se han agrupado en subcategorías siguiendo los criterios establecidos en el Inventario Español de los Conocimientos Tradicionales relativos a la Biodiversidad (Pardo de Santayana et al., 2014), obteniendo referencias en las 6 subcategorías indicadas en la tabla 65.

\begin{tabular}{l} 
TABLA 65: Subcategorías con representación en la categoría \\
Uso Combustible. \\
\hline Subcategorías : \\
\hline Leña \\
Encendido o leña fina \\
Carbón \\
Para chamuscar \\
Para ahumar \\
\hline Luz \\
\hline
\end{tabular}

Los 733 registros de uso obtenidos, en la categoría Uso Combustible, se reparten en 6 subcategorías tal y como señala la figura 49, resultando que Leña es la que recibió el mayor número de registros con 369 , un 50,34\% del total en esta categoría, seguido de Encendido o leña fina con 186 , un $25,38 \%$, y Para chamuscar con 90 , un $12,28 \%$.

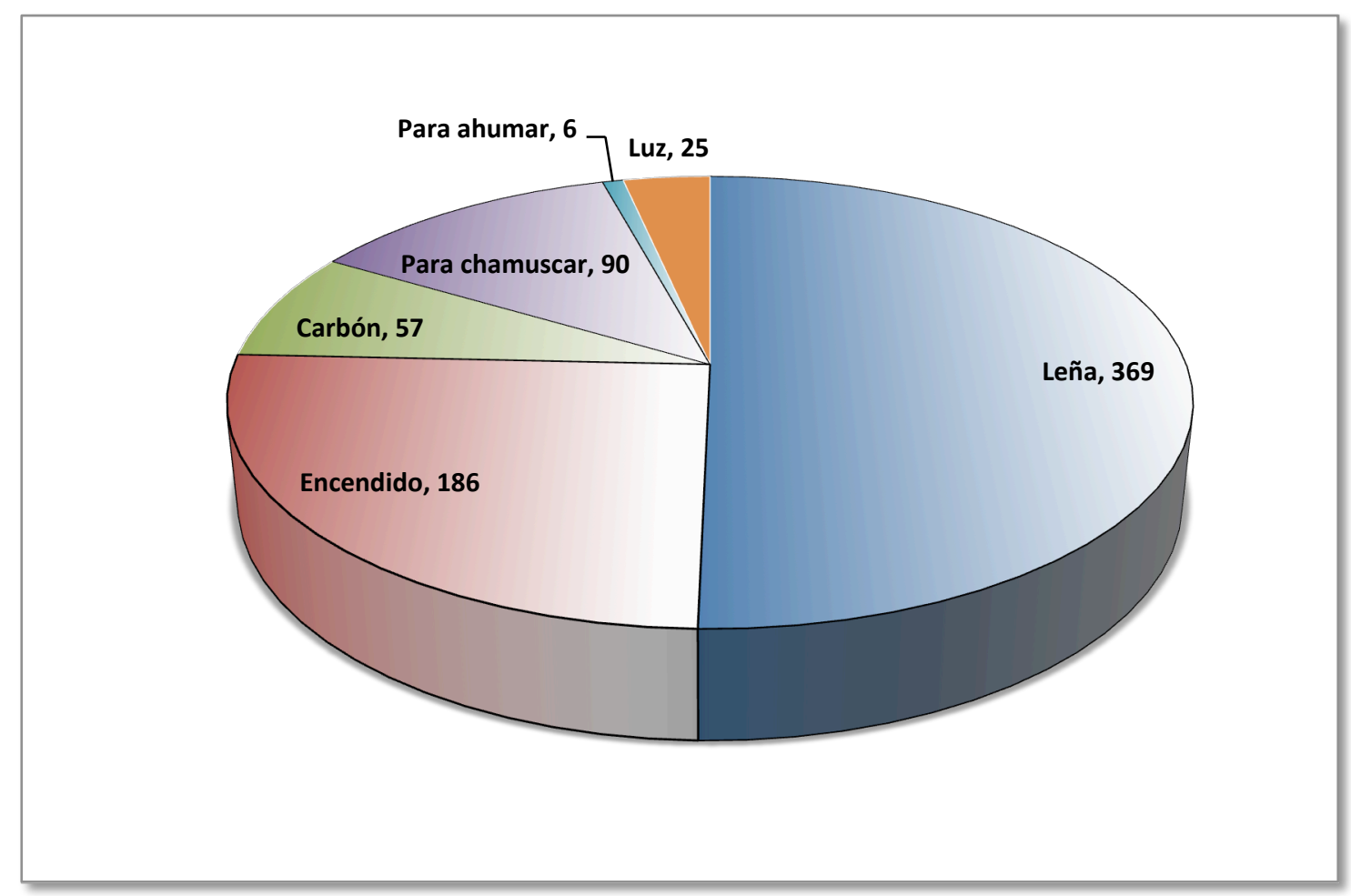

FIGURA 49: Registros de Uso (RU) de las subcategorías representadas en Uso Combustible.

A continuación se presentan las utilidades agrupadas por subcategorías de Uso Combustible, señalando los taxones que han obtenido citas en los mismos, el número de registros de uso de cada taxón, la parte usada y el empleo.

\section{Leña:}

Se han recogido 369 registros de uso, correspondientes a 31 taxones de 20 familias botánicas diferentes, 27 taxones de obtención silvestre y 4 cultivados, representando un 50,34\% del total de registros de uso para la categoría Uso Combustible. 
TABLA 66: Relación de taxones empleados en la subcategoría Leña, ordenados alfabéticamente por familia, indicando número de registros de uso (RU), parte usada y empleo.

\begin{tabular}{|c|c|c|c|c|}
\hline Familia & $\begin{array}{l}\text { Nombre científico } \\
\text { Nombre vulgar }\end{array}$ & RU & Parte usada & Empleo \\
\hline Adoxaceae & $\begin{array}{l}\text { Sambucus nigra } \\
\text { Saúco, saúgo, sabúgo, taco }\end{array}$ & 1 & Tronco, ramas & Leña \\
\hline Aquifoliaceae & $\begin{array}{l}\text { Ilex aquifolium } \\
\text { Acebo, aceba }\end{array}$ & 9 & Tronco, ramas & Leña \\
\hline Betulaceae & $\begin{array}{l}\text { Betula pubescens } \\
\text { Abedul }\end{array}$ & 2 & Tronco, ramas & Leña \\
\hline \multirow[t]{2}{*}{ Cupressaceae } & $\begin{array}{l}\text { Juniperus commnunis } \\
\text { Enebro, corveño }\end{array}$ & 1 & Parte aérea & Leña \\
\hline & $\begin{array}{l}\text { Juniperus sabina } \\
\text { Corveño }\end{array}$ & 2 & Parte aérea & Leña \\
\hline \multirow[t]{2}{*}{ Ericaceae } & $\begin{array}{l}\text { Calluna vulgaris } \\
\text { Brezo, graspo, brecina }\end{array}$ & 9 & Parte aérea & Leña \\
\hline & $\begin{array}{l}\text { Erica spp. } \\
\text { Brezo, urz, ayuz, graspo }\end{array}$ & 39 & Parte aérea & Leña \\
\hline \multirow[t]{3}{*}{ Fagaceae } & $\begin{array}{l}\text { Fagus sylvatica } \\
\text { Haya }\end{array}$ & 49 & Tronco, ramas & Leña \\
\hline & $\begin{array}{l}\text { Quercus petraea } \\
\text { Q. pyrenaica } \\
\text { Q. robur } \\
\text { Roble, cajigo, matorro }\end{array}$ & 113 & Tronco, ramas & Leña \\
\hline & $\begin{array}{l}\text { Quercus rotundifolia } \\
\text { Encina, ancina }\end{array}$ & 9 & Tronco, ramas & Leña \\
\hline Junglandaceae & $\begin{array}{l}\text { Juglans regia } \\
\text { Nogal }\end{array}$ & 1 & Tronco, ramas & Leña \\
\hline \multirow[t]{6}{*}{ Leguminosae } & $\begin{array}{l}\text { Cytisus scoparius } \\
\text { Escoba, ramo, escoba balera }\end{array}$ & 2 & Tronco & Leña \\
\hline & $\begin{array}{l}\text { Genista florida } \\
\text { Escoba, escoba albar }\end{array}$ & 12 & Tronco & Leña \\
\hline & $\begin{array}{l}\text { Genista hispanica } \\
\text { Argoma, ulaga }\end{array}$ & 5 & Tronco & Leña \\
\hline & $\begin{array}{l}\text { Genista obtusiramea } \\
\text { Escoba cabrera }\end{array}$ & 4 & Tronco & Leña \\
\hline & $\begin{array}{l}\text { Genista scorpius } \\
\text { Ulaga, abrojo }\end{array}$ & 10 & Parte aérea & Leña \\
\hline & $\begin{array}{l}\text { Ulex europaeus } \\
\text { Arguma }\end{array}$ & 1 & Parte aérea & Leña \\
\hline Oleaceae & $\begin{array}{l}\text { Fraxinus excelsior } \\
\text { Fresno }\end{array}$ & 5 & Tronco, ramas & Leña \\
\hline \multirow[t]{7}{*}{ Rosaceae } & $\begin{array}{l}\text { Crataegus monogyna } \\
\text { Espino, espino albar, majueto }\end{array}$ & 16 & Tronco, ramas & Leña \\
\hline & $\begin{array}{l}\text { Malus domestica } \\
\text { Manzano }\end{array}$ & 1 & Tronco, ramas & Leña \\
\hline & $\begin{array}{l}\text { Prunus cerasus } \\
\text { Guindal }\end{array}$ & 1 & Tronco, ramas & Leña \\
\hline & $\begin{array}{l}\text { Prunus padus } \\
\text { Ceresuela }\end{array}$ & 1 & Tronco, ramas & Leña \\
\hline & $\begin{array}{l}\text { Prunus spinosa } \\
\text { Endrino, andrino, espino }\end{array}$ & 11 & Parte aérea & Leña \\
\hline & $\begin{array}{l}\text { Sorbus aria } \\
\text { Mostajo, amostajo }\end{array}$ & 2 & Tronco, ramas & Leña \\
\hline & $\begin{array}{l}\text { Sorbus aucuparia } \\
\text { Amargoso, serbal, drío, drido }\end{array}$ & 1 & Tronco, ramas & Leña \\
\hline Sapindaceae & $\begin{array}{l}\text { Acer campestre } \\
\text { Barbaleña }\end{array}$ & 2 & Tronco, ramas & Leña \\
\hline
\end{tabular}




\begin{tabular}{lllll}
\hline $\begin{array}{l}\text { TABLA 66: (Continuación) } \\
\text { indicando número de registros de uso (RU), parte usada y empleo. }\end{array}$ & RU & Parte usada & Empleo \\
\hline Familia & $\begin{array}{l}\text { Nombre científico } \\
\text { Nombre vulgar }\end{array}$ & 37 & Tronco, ramas & Leña \\
\hline Salicaceae & $\begin{array}{l}\text { Populus alba } \\
\text { P. nigra } \\
\text { Chopo }\end{array}$ & 3 & Tronco, ramas & Leña \\
\hline Salicaceae & $\begin{array}{l}\text { Populus tremula } \\
\text { Álamo }\end{array}$ & 11 & Tronco, ramas & Leña \\
\hline $\begin{array}{l}\text { Salix spp. } \\
\text { Salguero, sota, salce, mimbrera }\end{array}$ & $\begin{array}{l}\text { Ulmus minor } \\
\text { Olmo }\end{array}$ & 8 & Tronco, ramas & Leña \\
\hline Vitaceae & $\begin{array}{l}\text { Vitis vinifera } \\
\text { Parra }\end{array}$ & 1 & Ramas & Leña \\
\hline
\end{tabular}

La subcategoría Leña agrupa a todas aquellas especies cuya madera es empleada como leña para el hogar, en hogueras para calentar o para el horno de pan.

La madera es la principal fuente de energía en la comarca, empleada aún como combustible para calentar el hogar durante el invierno y para cocinar. La leña la extraen los vecinos de los montes públicos en el invierno o la primavera de las parcelas de monte señaladas por el guarda, y que en el argot popular se denominan suertes. En el pasado se entresacaban los ejemplares más grandes con una pareja de vacas y se bajaba la leña en el carro, una vez en casa se troceaba y los troncos más gruesos se abrían con el hacha o con cuñas de hierro.

Las especies con mayor número de registros son el roble (Quercus petraea, $Q$. pyrenaica, $Q$. robur), de gran poder calorífico y el haya (Fagus sylvatica), con 113 y 49 registros respectivamente. El uso de una especie u otra depende en gran medida del tipo de monte de cada localidad. Comprobamos como el haya es apreciado como leña en diversos lugares del norte de la Península Ibérica como: El Caurel (Blanco, 1996), Picos de Europa (Lastra, 2003), Euskal Herria atlántica (Zapata \& Peña, 2003), Urdaibai (Meaza et al., 2004), Piloña (San Miguel, 2004) o Izal (Palacios \& Urtasun, 2011).

En la zona de La Peña donde aparece la encina (Quercus rotundifolia) se recomienda como un buen combustible, y en otras zonas donde escasea el bosque se emplean todo tipo de especies arbustivas, como los brezos (Erica spp., Calluna vulgaris) o diferentes tipos de escobas (Cytisus scoparius, Genista florida, G. obtusiramea), de las que se aprovecha el tronco o tocón, también de gran poder calorífico y muy valoradas en el pasado para cocer en el horno del pan. Asimismo, se mencionan especies espinosas para este mismo destino, es el caso del endrino (Prunus spinosa), las ulagas (Genista hispanica, G. scorpius) o la arguma (Ulex europaeus). En Valcobero aconsejan específicamente los palos secos o sarojos de la escoba cabrera (Genista obtusiramea) para cocer las morcillas.

De otras especies arbóreas como el chopo (Populus alba, P. nigra) o el salguero (Salix spp.) se ha aprovechado la madera por su alta frecuencia en la zona, pero ambas de escaso poder calorífico y poco valoradas, al igual que el álamo (Populus tremula) o la barbaleña (Acer campestre), consideradas maderas flojas.

Todas las especies empleadas como forraje arbóreo proporcionaban leña extra, las más citadas fueron el acebo (Ilex aquifolium), el olmo (Ulmus minor), el fresno (Fraxinus excelsior), el avellano (Corylus avellana) o el mostajo (Sorbus aria). 


\section{Encendido o leña fina:}

Se han recogido 186 registros de uso, correspondientes a 10 taxones de 7 familias botánicas diferentes, 9 taxones de obtención silvestre y 1 cultivado, representando un 25,38\% del total de registros de uso para la categoría Uso Combustible.

TABLA 67: Relación de taxones empleados en la subcategoría Encendido o leña fina, ordenados alfabéticamente por familia, indicando número de registros de uso (RU), parte usada y empleo.

\begin{tabular}{|c|c|c|c|c|}
\hline Familia & $\begin{array}{l}\text { Nombre científico } \\
\text { Nombre vulgar }\end{array}$ & RU & Parte usada & Empleo \\
\hline Betulaceae & $\begin{array}{l}\text { Corylus avellana } \\
\text { Avellano }\end{array}$ & 5 & Ramas & Encendido \\
\hline Ericaceae & $\begin{array}{l}\text { Erica spp. } \\
\text { Brezo, urz, ayuz, graspo }\end{array}$ & 3 & Parte aérea & Encendido \\
\hline Fagaceae & $\begin{array}{l}\text { Quercus petraea } \\
\text { Q. pyrenaica } \\
\text { Q. robur } \\
\text { Roble, cajigo, matorro }\end{array}$ & 20 & Ramas & Encendido \\
\hline \multirow[t]{3}{*}{ Leguminosae } & $\begin{array}{l}\text { Cytisus oromediterraneus } \\
\text { Escoba hornil, escoba }\end{array}$ & 13 & Parte aérea & Encendido \\
\hline & $\begin{array}{l}\text { Cytisus scoparius } \\
\text { Escoba, ramo, escoba balera }\end{array}$ & 107 & Parte aérea & Encendido \\
\hline & $\begin{array}{l}\text { Genista florida } \\
\text { Escoba, escoba albar }\end{array}$ & 34 & Parte aérea & Encendido \\
\hline Oleaceae & $\begin{array}{l}\text { Fraxinus excelsior } \\
\text { Fresno }\end{array}$ & 1 & Ramas & Encendido \\
\hline Pinaceae & $\begin{array}{l}\text { Pinus nigra } \\
\text { P. sylvestris } \\
\text { Pino }\end{array}$ & 1 & $\begin{array}{c}\text { Cono } \\
\text { femenino }\end{array}$ & Encendido \\
\hline Coriolaceae & $\begin{array}{l}\text { Fomes fomentarius } \\
\text { Yesca, yezca }\end{array}$ & 2 & $\begin{array}{l}\text { Cuerpo } \\
\text { fructífero }\end{array}$ & Encendido \\
\hline
\end{tabular}

Incluidos los elementos usados para el encendido del fuego, tales como ramas finas o pequeñas matas, así como la yesca.

Varias especies empleadas como forraje arbóreo proporcionaban ramas finas para el encendido una vez consumidas las hojas por el ganado, fueron citadas: el roble (Quercus petraea, Q. pyrenaica y Q. robur), el avellano (Corylus avellana) y el fresno (Fraxinus excelsior), aunque es posible que otras especies con uso forrajero no mencionadas, como el chopo, el mostajo o el olmo, también fueran utilizadas en el encendido.

Para comenzar el fuego se usan especies que una vez secas prenden con facilidad, entre ellas podemos señalar todo tipo de escobas (Cytisus oromediterraneus, C. scoparius, Genista florida) y en menor medida los brezos (Erica spp.), también se indicó el uso de piñas en alguna localidad con plantación de pinos (Pinus nigra, P. sylvestris).

Un trozo de yesca (Fomes fomentarius) sirvió en el pasado como mecha de encendido, según los testimonios recogidos la chispa producida por el choque entre un trozo de metal y una piedra provocaban con facilidad el encendido de la mecha. Esta especie se ha usado en otros lugares de la Península Ibérica para hacer fuego, como en la Serranía de Cuenca (Fajardo et al., 2007) y en la provincia de Salamanca (Velasco et al., 2010). 
Carbón:

Se han recogido 57 registros de uso, correspondientes a 7 taxones de obtención silvestre, de 3 familias botánicas diferentes, representando un $7,78 \%$ del total de registros de uso para la categoría Uso Combustible.

TABLA 68: Relación de taxones empleados en la subcategoría Carbón, ordenados alfabéticamente por familia, indicando número de registros de uso (RU), parte usada y empleo.

\begin{tabular}{llccc}
\hline Familia & $\begin{array}{l}\text { Nombre científico } \\
\text { Nombre vulgar }\end{array}$ & RU & Parte usada & Empleo \\
\hline Ericaceae & $\begin{array}{l}\text { Calluna vulgaris } \\
\text { Brezo, graspo, brecina } \\
\text { Erica spp. } \\
\text { Brezo, urz, ayuz, graspo }\end{array}$ & 1 & Cepa & Carboneo \\
\hline $\begin{array}{l}\text { Fagus sylvatica } \\
\text { Haya }\end{array}$ & $\begin{array}{l}\text { Quercus petraea } \\
\text { Q. pyrenaica } \\
\text { Q. robur } \\
\text { Roble, cajigo, matorro }\end{array}$ & 7 & Tronco, ramas & Carboneo \\
\hline $\begin{array}{l}\text { Quercus rotundifolia } \\
\text { Encina, ancina }\end{array}$ & 18 & Tronco, ramas & Carboneo \\
\hline $\begin{array}{l}\text { Crataegus monogyna } \\
\text { Espino, espino albar, majueto }\end{array}$ & 1 & Tronco, ramas & Carboneo \\
\hline $\begin{array}{l}\text { Sorbus aria } \\
\text { Mostajo, amostajo }\end{array}$ & 3 & Tronco, ramas & Carboneo \\
\hline
\end{tabular}

La subcategoría Carbón agrupa a todas aquellas especies empleadas en la elaboración de carbón a partir de madera y restos vegetales.

En varios pueblos de la comarca se elaboró carbón vegetal principalmente con troncos de roble (Quercus petraea, Q. pyrenaica y Q. robur), de haya (Fagus sylvatica), o con cepas (raíces leñosas) de brezo (Erica spp.), empleado para comercializar y deseado por los herreros locales para templar el hierro en las fraguas. En una hoya realizada en el suelo, se introduce la madera, se tapa con tierra y ramas, procurando dejar un agujero a modo de chimenea que permite que la madera se queme lentamente hasta obtener carbón. Estos trabajos se ejecutaban en el monte y podían llevarlo a cabo carboneros itinerantes especializados, el herrero del pueblo o algún vecino en particular.

Otra especie valorada para el carboneo fue la encina (Quercus rotundifolia), pero su presencia se limita a la zona meridional de la comarca, sin embargo, su uso fue muy común en la comarca palentina del Cerrato (Pascual et al., 2016). Con menor frecuencia se emplearon especies como el majueto (Crataegus monogyna) o el mostajo (Sorbus aria).

\section{Para chamuscar:}

Se han recogido 90 registros de uso, correspondientes a 7 taxones de 4 familias botánicas diferentes, 4 taxones de obtención silvestre y 3 cultivados, representando un 12,28\% del total de registros de uso para la categoría Uso Combustible. 
TABLA 69: Relación de taxones empleados en la subcategoría Para chamuscar, ordenados alfabéticamente por familia, indicando número de registros de uso (RU), parte usada y empleo.

\begin{tabular}{llccc}
\hline Familia & $\begin{array}{l}\text { Nombre científico } \\
\text { Nombre vulgar }\end{array}$ & RU & Parte usada & Empleo \\
\hline Dennstaedtiaceae & $\begin{array}{l}\text { Pteridium aquilinum } \\
\text { Helecho, halecho }\end{array}$ & 10 & Frondes & Chamuscar \\
\hline Lricaceae & $\begin{array}{l}\text { Erica spp. } \\
\text { Brezo, urz, ayuz, graspo } \\
\text { Cytisus oromediterraneus }\end{array}$ & 1 & Parte aérea & Chamuscar \\
$\begin{array}{l}\text { Escoba hornil, escoba } \\
\text { Cytisus scoparius } \\
\text { Escoba, ramo, escoba balera } \\
\text { Hordeum vulgare }\end{array}$ & 10 & Parte aérea & Chamuscar \\
Cebada, ladilla, comuna & 1 & Paja & Chamuscar \\
\hline $\begin{array}{l}\text { Secale cereale } \\
\text { Centeno, sirvendo, servendo }\end{array}$ & 50 & Paja & Chamuscar \\
\hline $\begin{array}{l}\text { Triticum aestivum } \\
\text { Trigo, mesino, tremesino }\end{array}$ & 17 & Paja & Chamuscar \\
\hline
\end{tabular}

Se recogen todas aquellas especies que servían como combustible para chamuscar el cerdo en la matanza tradicional.

La materia prima más adecuada para chamuscar los pelos del cerdo era la paja de centeno (Secale cereale), antes de trillar la paja en la era, se seleccionaban varios haces (bálagos, colmos, gavijones, gavillas, manojos), se golpeaban (majar) para separar la espiga de la caña y se conservaban en lugar seco hasta la fecha de la matanza.

En menor medida se utilizaba la paja de trigo (Triticum aestivum) o de cebada (Hordeum vulgare), los helechos (Pteridium aquilinum), las ramas de escoba (Cytisus scoparius y $C$. oromediterranus) o de brezo (Erica spp.), todas ellas no transmiten sabor a la carne y producen una llama duradera. También se documenta el uso de la escoba (Cytisus scoparius) para chamuscar, en la Sierra Norte de Madrid (Aceituno Mata, 2010) y en los Arribes del Duero (González et al., 2013).

\section{Para ahumar:}

Se han recogido 6 registros de uso, correspondientes a 5 taxones de obtención silvestre, de 3 familias botánicas diferentes, representando un $0,82 \%$ del total de registros de uso para la categoría Uso Combustible.

TABLA 70: Relación de especies empleadas en la subcategoría Para ahumar, ordenadas alfabéticamente por familia, indicando número de registros de uso (RU), parte usada y empleo.

\begin{tabular}{llccc}
\hline Familia & $\begin{array}{l}\text { Nombre científico } \\
\text { Nombre vulgar }\end{array}$ & RU & Parte usada & Empleo \\
\hline Cupressaceae & $\begin{array}{l}\text { Juniperus communis } \\
\text { Enebro, corveño } \\
\text { Juniperus sabina } \\
\text { Corveño }\end{array}$ & 1 & Parte aérea & Incienso \\
\hline Lamiaceae & $\begin{array}{l}\text { Thymus mastichina } \\
\text { Tomillo, mejorana }\end{array}$ & 1 & Parte aérea & Ahumar colmenas \\
\hline $\begin{array}{l}\text { Thymus zygis } \\
\text { Tomillo, cepico } \\
\text { Legumista hispanica } \\
\text { Argoma, ulaga }\end{array}$ & 1 & Parte aérea & Incienso \\
\hline
\end{tabular}


Se incluyen especies que al quemarlas producen humo, empleado en diversas actividades. El más común fue el ahumado de las colmenas, antes de catar la miel o como simple método de inspección de las mismas, se quemaban ramas de tomillo (Thymus zygis) o corveño (Juniperus sabina) en un recipiente, para que el abundante humo desprendido confundiera y dispersara a las abejas, pudiendo el apicultor de este modo realizar la labor deseada con mayor comodidad. Cuando escaseaba el incienso en la iglesia, según relatan en la localidad de Arbejal, el cura ordenaba al monaguillo durante la consagración quemar la parte aérea del tomillo (Thymus mastichina) desmenuzada en una pequeña naveta, desprendiendo un intenso olor similar al incienso empleado durante las ceremonias religiosas. Similar método, pero con la resina que desprende el enebro (Juniperus commnis) se hacía en la localidad de Villanueva de Arriba.

En Lores, el humo desprendido al encender una rama de argoma (Genista hispanica) se utilizó para ahumar trabajos o tallas en madera, quedando de este modo impreso el diseño deseado. No se han encontrado coincidencias de uso en ninguna de las publicaciones consultadas con alguno de los registros documentados en esta subcategoría.

Luz:

Se han recogido 25 registros de uso, correspondientes a 5 taxones de obtención silvestre, de 5 familias botánicas diferentes, representando un $3,41 \%$ del total de registros de uso para la categoría Uso Combustible.

TABLA 71: Relación de taxones empleados en la subcategoría Luz, ordenados alfabéticamente por familia, indicando número de registros de uso (RU), parte usada y empleo.

\begin{tabular}{lllll}
\hline Familia & $\begin{array}{l}\text { Nombre científico } \\
\text { Nombre vulgar }\end{array}$ & RU & Parte usada & Empleo \\
\hline Aquifoliaceae & $\begin{array}{l}\text { llex aquifolium } \\
\text { Acebo, aceba }\end{array}$ & 8 & Ramas secas & Antorcha (teo) \\
\hline Cunpressaceae & $\begin{array}{l}\text { Juniperus sabina } \\
\text { Corveño } \\
\text { Erica spp. } \\
\text { Brezo, urz, ayuz, graspo }\end{array}$ & 1 & Ramas secas & Antorcha (teo) \\
\hline Fagaceae & $\begin{array}{l}\text { Fagus sylvatica } \\
\text { Haya } \\
\text { Asphodelus albus } \\
\text { Gamón, gamonita }\end{array}$ & 1 & Ramas secas & Antorcha (teo) \\
\hline Xanthorrhoeaceae & 6 & Escapo floral & Antorcha (teo) \\
\hline
\end{tabular}

Dentro de la subcategoría Luz se agrupan especies empleadas en lámparas, velas, antorchas o teas. En el pasado, ante la falta de luz eléctrica se recurría a antorchas vegetales, conocidas en el argot popular como teos, empleados para iluminar la cocina, lugar donde transcurre la velada y bajo cuya luz acostumbraban a pasar el tiempo conversando, hilando o tallando. Los que mejor luz proporcionaban eran los teos de brezo (Erica spp.), de acebo (Ilex aquifolium), y las gamonitas (Asphodelus albus) secas, también utilizadas para transportar el fuego. Se ha documentado el uso similar de las gamonitas en otras zonas de la Península Ibérica como el Sayago (Panero, 2000), Picos de Europa (Lastra, 2003), Cantabria (Pardo de Santayana, 2004) o la provincia de Salamanca (Velasco et al., 2010).

El aceite de los hayucos se extraía en los molinos de "oilo" que en la antigüedad existían distribuidos por la comarca, con él se encendían candiles y lámparas para iluminar alguna estancia. 


\section{CONSTRUCCIÓN:}

La categoría Construcción contiene las especies empleadas en la construcción de casas, edificios, refugios temporales para pastores, animales o herramientas, así como los vallados y aquellas utilizadas en todo tipo de medios de transporte. En la comarca de la Montaña Palentina se menciona el uso de 32 taxones vegetales correspondientes a 17 familias botánicas, para los que se han recogido un total de 473 registros de uso (RU). De ellos, 25 taxones son de obtención silvestre, 6 cultivados y 1 comprado. Los taxones con mayor número de registros de uso en la categoría Construcción se representan en la figura 50.

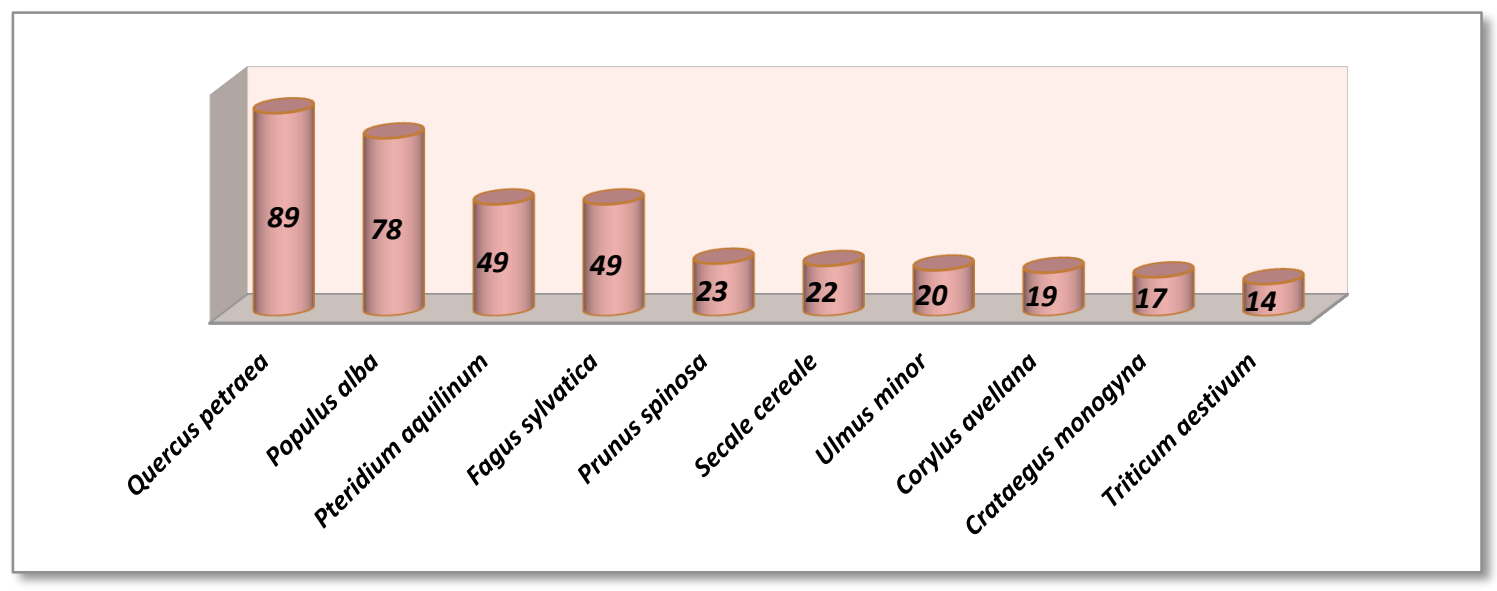

FIGURA 50: Especies con mayor número de registros de uso empleadas en Construcción.

Las familias con mayor representación en cuanto a número de especies fueron: Leguminosae, Fagaceae y Salicaceae, con 6,5 y 4 especies respectivamente, y la familia con mayor número de registros de uso fue Fagaceae con 144, según se señala en la figura 51.

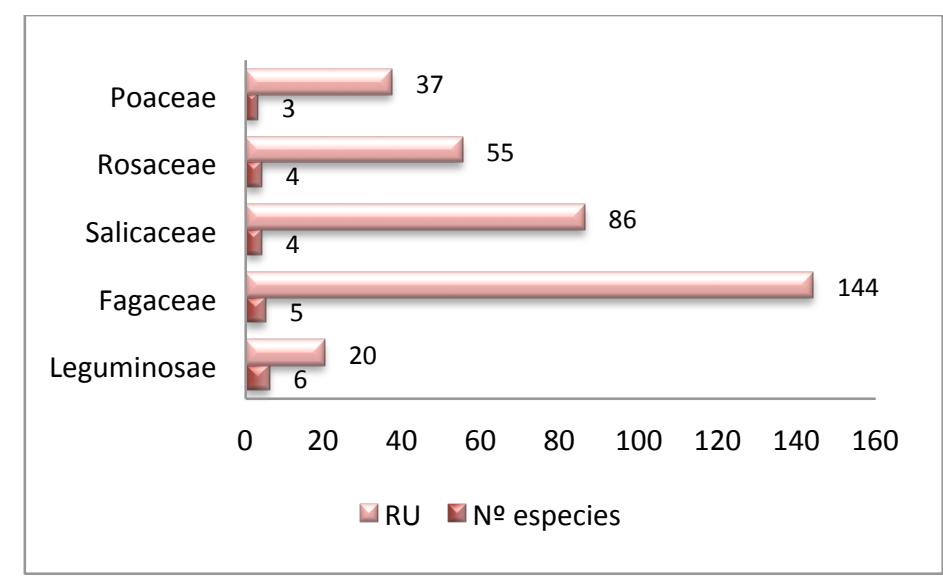

FiguRA 51: Familias con mayor representación de especies y número de registros de uso (RU), en Construcción.

Las familia más destacada en esta categoría en cuanto a número de registros de uso es Fagaceae alcanzando 144 registros y representada por 5 especies de porte arbóreo, todas ellas de gran importancia en la construcción de carros y vehículos, en las edificaciones e infraestructuras. 
Los usos se han agrupado en subcategorías siguiendo los criterios establecidos en el Inventario Español de los Conocimientos Tradicionales relativos a la Biodiversidad (Pardo de Santayana et al., 2014), obteniendo referencias en las 4 subcategorías indicadas en la tabla 72.

\begin{tabular}{l}
$\begin{array}{l}\text { TABLA 72: Subcategorías con representación en la categoría } \\
\text { Construcción. }\end{array}$ \\
\hline Subcategorías : \\
\hline Carros y otros vehículos terrestres \\
Casas, edificios e instalaciones agropecuarias \\
Cercas, tapias y vallas \\
Infraestructuras \\
\hline
\end{tabular}

Los 473 registros de uso obtenidos, en la categoría Construcción, se reparten en las 4 subcategorías tal y como señala la figura 52, resultando que Casas, edificios e instalaciones agropecuarias es la que recibió el mayor número de registros con 312, un 65,96\% del total en esta categoría, seguido de Carros y otros vehículos terrestres con 76, un 16,07\%, y Cercas, tapias y vallas con 56 , un $11,84 \%$.

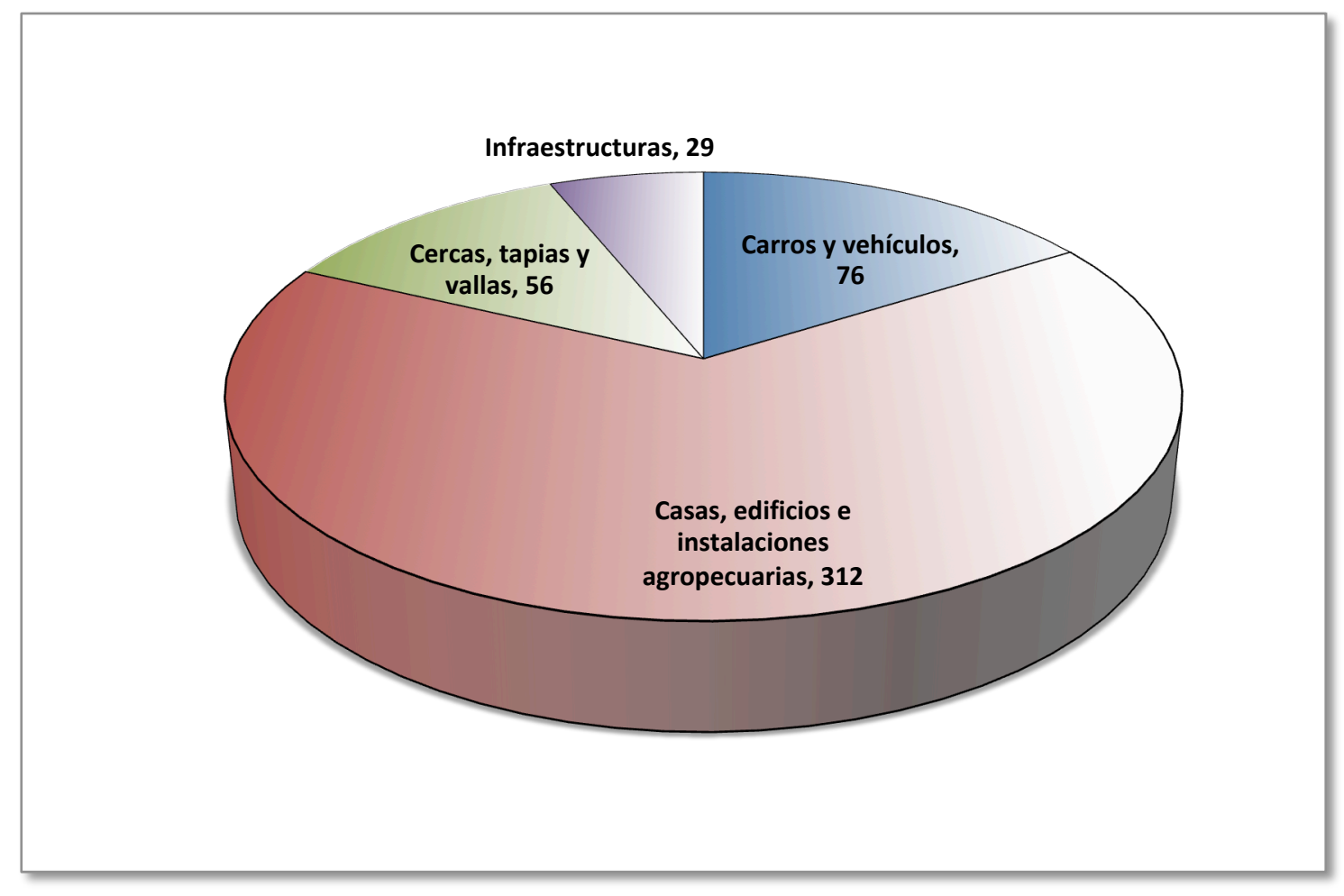

FIGURA 52: Registros de Uso (RU) de las subcategorías representadas en Construcción.

A continuación se presentan las utilidades agrupadas por subcategorías de Construcción, señalando los taxones que han obtenido citas en los mismos, el número de registros de uso de cada taxón, la parte usada y el empleo.

\section{Carros y otros vehículos terrestres:}

Se han recogido 76 registros de uso, correspondientes a 8 taxones de 5 familias botánicas diferentes, 7 taxones de obtención silvestre y 1 cultivado, representando un 16,07\% del total de registros de uso para la categoría Construcción. 
TABLA 73: Relación de taxones empleados en la subcategoría Carros y otros vehículos terrestres, ordenados alfabéticamente por familia, indicando número de registros de uso (RU), parte usada y empleo.

\begin{tabular}{|c|c|c|c|c|}
\hline Familia & $\begin{array}{l}\text { Nombre cientifico } \\
\text { Nombre vulgar }\end{array}$ & RU & Parte usada & Empleo \\
\hline Betulaceae & $\begin{array}{l}\text { Corylus avellana } \\
\text { Avellano }\end{array}$ & 4 & Ramas & Armadura \\
\hline \multirow[t]{3}{*}{ Fagaceae } & $\begin{array}{l}\text { Fagus sylvatica } \\
\text { Haya }\end{array}$ & 18 & Madera & Piezas carro \\
\hline & $\begin{array}{l}\text { Quercus petraea } \\
\text { Q. pyrenaica } \\
\text { Q. robur } \\
\text { Roble, cajigo, matorro }\end{array}$ & 25 & Madera & Piezas carro \\
\hline & $\begin{array}{l}\text { Quercus rotundifolia } \\
\text { Encina, ancina }\end{array}$ & 6 & Madera & Piezas carro \\
\hline Oleaceae & $\begin{array}{l}\text { Fraxinus excelsior } \\
\text { Fresno }\end{array}$ & 4 & Madera & Piezas carro \\
\hline \multirow[t]{2}{*}{ Salicaceae } & $\begin{array}{l}\text { Populus alba } \\
\text { P. nigra } \\
\text { Chopo }\end{array}$ & 4 & Madera & Tablas \\
\hline & $\begin{array}{l}\text { Salix spp. } \\
\text { Salguero, sota, salce, mimbrera }\end{array}$ & 3 & Madera & Piezas carro \\
\hline Ulmaceae & $\begin{array}{l}\text { Ulmus minor } \\
\text { Olmo }\end{array}$ & 12 & Madera & Piezas carro \\
\hline
\end{tabular}

Se incluyen en la presente subcategoría todas aquellas especies empleadas para la elaboración de carros, o las piezas necesarias para su construcción final como: ruedas, ejes, armazón, etc., también otro tipo de vehículos como carretes o carretillas, útiles para desarrollar actividades agrícolas o ganaderas propias de la zona de estudio.

En toda la comarca existieron carreteros especializados en el oficio, que manejaban diferentes maderas para la construcción del tradicional carro tirado por vacas. Las partes del carro toman distintos nombres según la localidad, pero de forma general, la viga del carro se hacía de roble (Quercus petraea, Q. pyrenaica, Q. robur) o de olmo (Ulmus minor), al igual que la maza, los radios y cambones de encina (Quercus rotundifolia), y para agujas, taleras y resto de piezas se menciona el haya (Fagus sylvatica), el fresno (Fraxinus excelsior), nuevamente el olmo y de forma ocasional el chopo (Populus alba, P. nigra) para las tablas. El zarzo, pieza especial para aumentar el volumen del carro y transportar la paja del cereal, estaba hecho a base de varas de avellano (Corylus avellana) o salguero (Salix spp.), o con tabla de chopo, este tipo de estructura también se documenta en Picos de Europa (Lastra, 2003) y la comarca cántabra de Campoo (Pardo de Santayana, 2008).

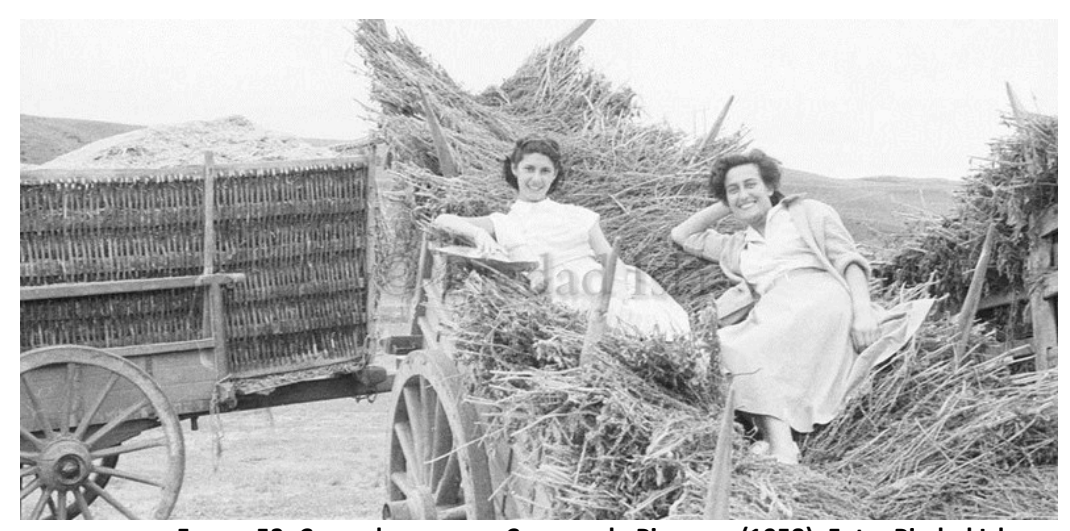

Figura 53: Carro de zarzo en Cervera de Pisuerga (1958). Foto: Piedad Isla. 


\section{Casas, edificios e instalaciones agropecuarias:}

Se han recogido 312 registros de uso, correspondientes a 23 taxones de 13 familias botánicas diferentes, 17 taxones de obtención silvestre y 6 cultivados, representando un 65,96\% del total de registros de uso para la categoría Construcción.

TABLA 74: Relación de taxones empleados en la subcategoría Casas, edificios e instalaciones agropecuarias, ordenados alfabéticamente por familia, indicando número de registros de uso (RU), parte usada y empleo.

\begin{tabular}{|c|c|c|c|c|}
\hline Familia & $\begin{array}{l}\text { Nombre científico } \\
\text { Nombre vulgar }\end{array}$ & RU & Parte usada & Empleo \\
\hline Apiaceae & $\begin{array}{l}\text { Conium maculatum } \\
\text { Budaño, cañiguerra, canuto }\end{array}$ & 2 & Parte aérea & Asentar tejado \\
\hline \multirow[t]{2}{*}{ Betulaceae } & $\begin{array}{l}\text { Betula pubescens } \\
\text { Abedul }\end{array}$ & 1 & Madera & Tablas \\
\hline & $\begin{array}{l}\text { Corylus avellana } \\
\text { Avellano }\end{array}$ & 15 & Ramas & Pared \\
\hline Cyperaceae & $\begin{array}{l}\text { Scirpoides holoschoenus } \\
\text { Junco }\end{array}$ & 3 & Parte aérea & Asentar tejado \\
\hline Dennstaedtiaceae & $\begin{array}{l}\text { Pteridium aquilinum } \\
\text { Helecho, halecho }\end{array}$ & 49 & Frondes & Asentar tejado \\
\hline Dryopteridaceae & $\begin{array}{l}\text { Dryopteris affinis } \\
\text { D. filix-mas } \\
\text { Helecha, helecho }\end{array}$ & 1 & Frondes & Asentar tejado \\
\hline Ericaceae & $\begin{array}{l}\text { Erica spp. } \\
\text { Brezo, urz, ayuz, graspo }\end{array}$ & 4 & Parte aérea & Asentar tejado \\
\hline \multirow[t]{2}{*}{ Fagaceae } & $\begin{array}{l}\text { Fagus sylvatica } \\
\text { Haya }\end{array}$ & 29 & Madera & Vigas, tablas \\
\hline & $\begin{array}{l}\text { Quercus petraea } \\
\text { Q. pyrenaica } \\
\text { Q. robur } \\
\text { Roble, cajigo, matorro }\end{array}$ & 56 & Madera & Vigas, tablas \\
\hline Juncaceae & $\begin{array}{l}\text { Juncus articulatus } \\
\text { J. conglomeratus } \\
\text { J. effusus } \\
\text { J. inflexus } \\
\text { Junco }\end{array}$ & 8 & Parte aérea & Asentar tejado \\
\hline \multirow[t]{5}{*}{ Leguminosae } & $\begin{array}{l}\text { Cicer arietinum } \\
\text { Garbanzo }\end{array}$ & 1 & Paja & Asentar tejado \\
\hline & $\begin{array}{l}\text { Cytisus oromediterraneus } \\
\text { Escoba hornil, escoba }\end{array}$ & 1 & Ramas & Tejado \\
\hline & $\begin{array}{l}\text { Cytisus scoparius } \\
\text { Escoba, ramo, escoba balera }\end{array}$ & 10 & Ramas & Tejado \\
\hline & $\begin{array}{l}\text { Genista florida } \\
\text { Escoba, escoba albar }\end{array}$ & 5 & Ramas & Tejado \\
\hline & $\begin{array}{l}\text { Genista obtusiramea } \\
\text { Escoba cabrera }\end{array}$ & 2 & Ramas & Tejado \\
\hline \multirow[t]{3}{*}{ Poaceae } & $\begin{array}{l}\text { Hordeum vulgare } \\
\text { Cebada, ladilla, comuna }\end{array}$ & 1 & Paja & Adobes \\
\hline & $\begin{array}{l}\text { Secale cereale } \\
\text { Centeno, sirvendo, servendo }\end{array}$ & 22 & Paja & Adobes, tejado \\
\hline & $\begin{array}{l}\text { Triticum aestivum } \\
\text { Trigo, mesino, tremesino }\end{array}$ & 14 & Paja & Adobes \\
\hline \multirow[t]{2}{*}{ Salicaceae } & $\begin{array}{l}\text { Populus alba } \\
\text { P. nigra } \\
\text { Chopo }\end{array}$ & 74 & Madera & Vigas, tablas \\
\hline & $\begin{array}{l}\text { Populus tremula } \\
\text { Álamo }\end{array}$ & 1 & Madera & Vigas, tablas \\
\hline
\end{tabular}




\begin{tabular}{llccc}
\hline $\begin{array}{l}\text { TABLA 74: (Continuación) } \\
\text { ordenados alfabéticamente por familia, indicando número de registros de uso (RU), parte usada y empleo. }\end{array}$ \\
\hline Familia & $\begin{array}{l}\text { Nombre cientifico } \\
\text { Nombre vulgar }\end{array}$ & RU & Parte usada & Empleo \\
\hline Salicaceae & $\begin{array}{l}\text { Salix spp. } \\
\text { Salguero, sota, salce, mimbrera }\end{array}$ & 4 & Ramas & Pared \\
\hline $\begin{array}{l}\text { Taxus baccata } \\
\text { Taxaceae }\end{array}$ & 1 & Madera & Vigas \\
\hline Ulmaceae & $\begin{array}{l}\text { Ulmus minor } \\
\text { Olmo }\end{array}$ & 8 & Madera & Vigas, tablas \\
\hline
\end{tabular}

Descritos aquellos materiales empleados para la estructura de las casas, ya sean muros, tabiques, techos, techumbres, dinteles, tabiques, puertas, ventanas, etc. Asimismo los materiales destinados para construcciones agropecuarias necesarios para la edificación de corrales, pajares, molinos, abrevaderos, tenadas..., o refugios temporales como chozos o cabañas.

En la arquitectura tradicional, las vigas y la estructura del tejado eran siempre de madera procedente del bosque más cercano. El entramado del tejado está formado por una compleja estructura de vigas, cumbrial, cuartones, cabrios y ripia, con nombres diversos según la localidad. Destaca en la carpintería de obra el roble (Quercus petraea, Q. pyrenaica, Q. robur) frente al haya (Fagus sylvatica), siendo común el dicho "El haya para cuando más no haya" en alusión a su menor dureza y resistencia a los xilófagos. Otras maderas más débiles como la del chopo (Populus alba, P. nigra), eran interesantes para tabla de construcción y ripia, resultando además el taxón con mayor número de registros en esta subcategoría.

Para asentar la teja se utilizan diversos materiales vegetales, los más frecuentes son a base de helechos (Pteridium aquilinum, Dryopteris affinis), seguido de juncos (Juncus spp., Scirpoides holoschoenus), brezos (Erica spp.) o budaños (Conium maculatum).

En cuanto a cubiertas vegetales cabe reseñar la importancia que en tiempos pasados tuvo el centeno (Secale cereale), sustituido progresivamente por la teja de barro y del que ya solo se puede contemplar el ejemplo de La Benina en la localidad de Valcobero, un almacen rectangular que conserva tejado vegetal. Las construcciones menores como tenadas o chozos de pastor, éstas últimas, reliquias del pasado pastoril de la zona, ejecutaban la cubierta con escobas (Cytisus oromediterraneus, C. scoparius, Genista florida, G. obtusiramea), así como los camastros de los pastores. Vielba (2012) señala el uso de escobas para elaborar camastros en los chozos del norte de la provincia de Palencia.

Aunque el principal material para levantar paredes y muros era la piedra, también el adobe acompaña a ciertas construcciones, hecho con barro y paja picada de centeno (Secale cereale), de trigo (Triticum aestivum) o de cebada (Hordeum vulgare).

En las divisiones fue tradicional el cerramiento de sieto, entramado a base de varas entrelazadas de avellano (Corylus avellana) o de salguero (Salix spp.). La técnica consiste en entrelazar varas sobre montantes verticales. Se emplean estos cerramientos tanto en exterior como en interior para separar estancias que permiten la ventilación y la iluminación, aunque en alguna otra ocasión se revocaba con tierra barrial mezclada con paja para que el cierre fuera total. 


\section{Cercas, tapias y vallas:}

Se han recogido 56 registros de uso, correspondientes a 5 taxones de obtención silvestre, de 2 familias botánicas diferentes, representando un $11,84 \%$ del total de registros de uso para la categoría Construcción.

TABLA 75: Relación de taxones empleados en la subcategoría Cercas, tapias y vallas, ordenados alfabéticamente por familia, indicando número de registros de uso (RU), parte usada y empleo.

\begin{tabular}{|c|c|c|c|c|}
\hline Familia & $\begin{array}{l}\text { Nombre cientifico } \\
\text { Nombre vulgar }\end{array}$ & $\mathbf{R U}$ & Parte usada & Empleo \\
\hline Leguminosae & $\begin{array}{l}\text { Genista scorpius } \\
\text { Ulaga, abrojo }\end{array}$ & 1 & $\begin{array}{l}\text { Ramas } \\
\text { espinosas }\end{array}$ & Remate tapias \\
\hline \multirow[t]{4}{*}{ Rosaceae } & $\begin{array}{l}\text { Crataegus monogyna } \\
\text { Espino, espino albar, majueto }\end{array}$ & 17 & $\begin{array}{l}\text { Ramas } \\
\text { espinosas }\end{array}$ & Paso animales \\
\hline & $\begin{array}{l}\text { Prunus spinosa } \\
\text { Endrino, andrino, espino }\end{array}$ & 23 & $\begin{array}{c}\text { Ramas } \\
\text { espinosas }\end{array}$ & $\begin{array}{l}\text { Paso animales } \\
\text { Remate tapias }\end{array}$ \\
\hline & $\begin{array}{l}\text { Rosa spp. silvestres } \\
\text { Zarza, espino, rosal, calambrojo }\end{array}$ & 14 & $\begin{array}{c}\text { Ramas } \\
\text { espinosas }\end{array}$ & Pasos animales \\
\hline & $\begin{array}{l}\text { Rubus ulmifolius } \\
\text { Zarza, moral, espino }\end{array}$ & 1 & $\begin{array}{l}\text { Ramas } \\
\text { espinosas }\end{array}$ & Pasos animales \\
\hline
\end{tabular}

Dentro de la subcategoría "Cercas, tapias y vallas" se agrupan especies para realizar vallados de madera, tapias, o entramados para encerrar el ganado, así como plantas espinosas que se colocan sobre muros para dificultar o impedir el paso de animales o personas.

Varias especies sirvieron para rematar las tapias de las paredes y dificultar el paso de animales no deseados, las más citadas fueron el endrino (Prunus spinosa) y la ulaga (Genista scorpius), también señalada en el Cerrato Palentino como remate de tapias y corrales (Pascual et al., 2016).

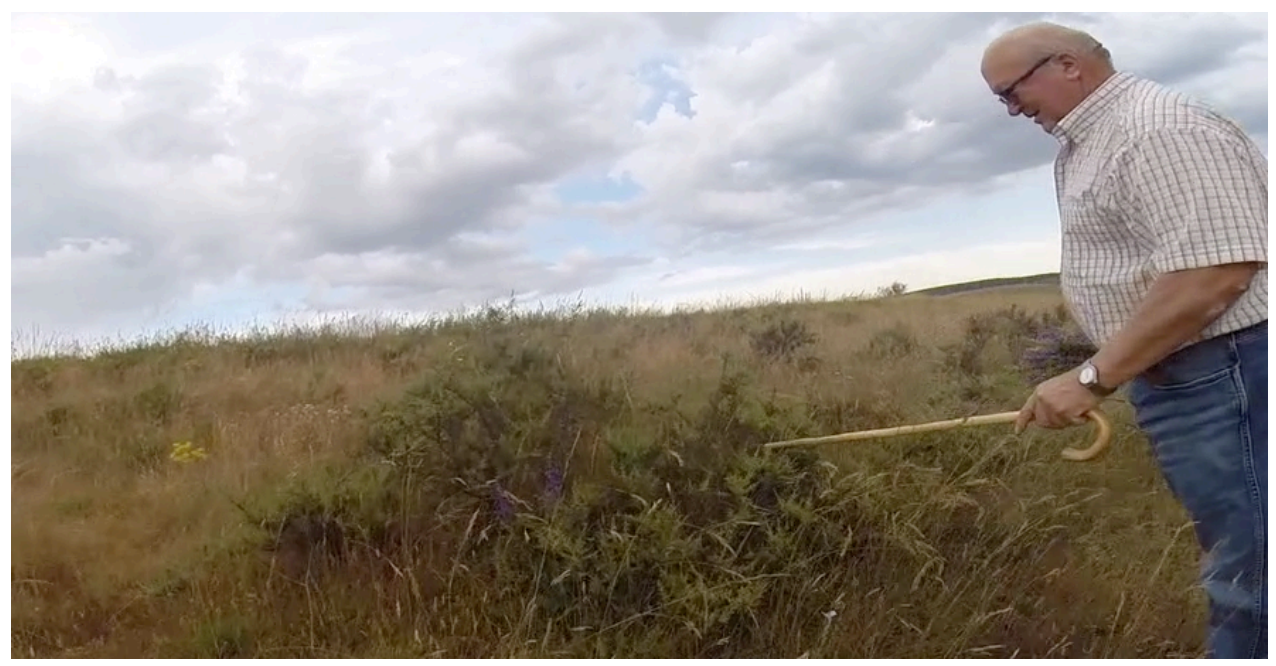

FIGURA 54: Andrés de Monasterio mostrando ulagas.

Para impedir el paso en fincas o cercados, y para separar parcelas mediante vallados generalmente provisionales se citaron el espino (Crataegus monogyna) y las zarzas (Rosa spp., Rubus ulmifolius). 


\section{Infraestructuras:}

Se han recogido 29 registros de uso, correspondientes a 4 taxones de 3 familias botánicas diferentes, 2 taxones de obtención silvestre y 2 comprados, representando un 6,13\% del total de registros de uso para la categoría Construcción.

TABLA 76: Relación de especies empleadas en la subcategoría Infraestructuras, ordenadas alfabéticamente por familia, indicando número de registros de uso (RU), parte usada y empleo.

\begin{tabular}{llccc}
\hline Familia & $\begin{array}{l}\text { Nombre científico } \\
\text { Nombre vulgar }\end{array}$ & RU & Parte usada & Empleo \\
\hline Fagaceae & $\begin{array}{l}\text { Fagus sylvatica } \\
\text { Haya } \\
\text { Quercus petraea } \\
\begin{array}{l}\text { Q. pyrenaica } \\
\text { Roble, cajigo, matorro } \\
\text { Eucalyptus globulus } \\
\text { Eucalipto, eucalito }\end{array}\end{array}$ & 2 & Madera & Vigas mina \\
\hline Myrtaceae & $\begin{array}{l}\text { Pinus nigra } \\
\text { P. sylvestris } \\
\text { Pino }\end{array}$ & 9 & Madera & Vigas mina \\
& & 10 & Madera & Vigas mina \\
\hline
\end{tabular}

Recogidas aquellas especies empleadas en diferentes infraestructuras como puentes, traviesas del tren, postes de teléfono o minas.

En relación a las infraestructuras, se señala el uso puntual de madera de roble (Quercus petraea, Q. pyrenaica) y en ocasiones de haya (Fagus sylvatica), procedentes de subastas locales, para posteado en las minas locales y para la fabricación de las traviesas del tren de la vía del norte que unía Bilbao con La Robla, en el caso del roble.

Aunque por lo general, la madera empleada en las minas distribuidas por toda la comarca se compraba y se importaba de provincias cercanas como Asturias o Cantabria, las especies más destacadas y con mayor número de registro de uso en esta subcategoría fueron el pino (Pinus nigra, P. sylvestris) y el eucalipto (Eucalyptus globulus), con 10 y 9 registros de uso respectivamente. En el concejo de Piloña (Asturias), las plantaciones de eucalipto son frecuentes, se han implantado como cultivos forestales (San Miguel, 2004). 


\section{INDUSTRIA Y ARTESANÍA:}

Las plantas relacionadas con el uso tecnológico popular se encuadran en una categoría muy amplia que incluye, desde la fabricación de herramientas, aperos, pintura, mobiliario, cestos, juguetes, vestimenta o cualquier elemento empleado en las distintas actividades humanas realizadas en la comarca. En la Montaña Palentina se menciona el uso de 65 taxones vegetales correspondientes a 35 familias botánicas, para los que se han recogido un total de 1183 registros de uso (RU). De ellos, 52 taxones son de obtención silvestre, 11 cultivados y 2 comprados. Los taxones con mayor número de registros de uso en la categoría Industria y Artesanía se representan en la figura 55.

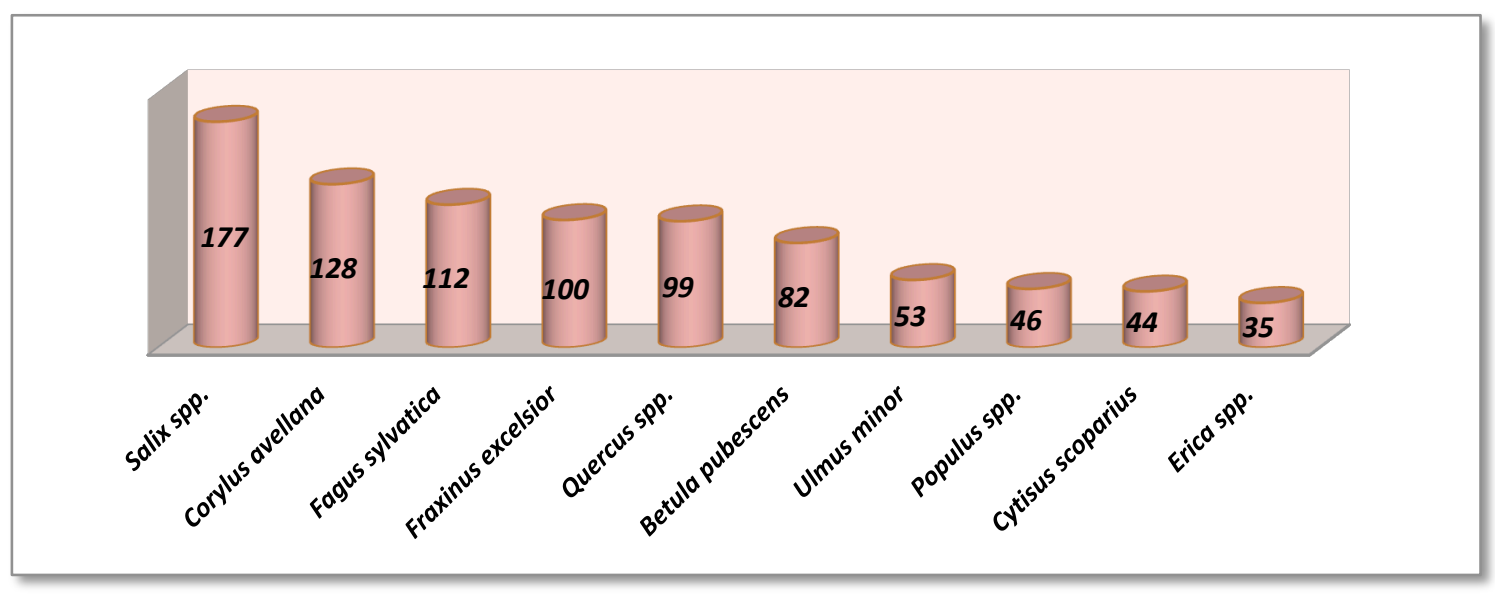

FIGURA 55: Taxones con mayor número de registros de uso empleadas en Industria y Artesanía.

Las familias con mayor representación en cuanto a número de especies fueron: Rosaceae, Fagaceae y Leguminosae, con 9, 5 y 5 especies respectivamente, según se señala en la figura 56.

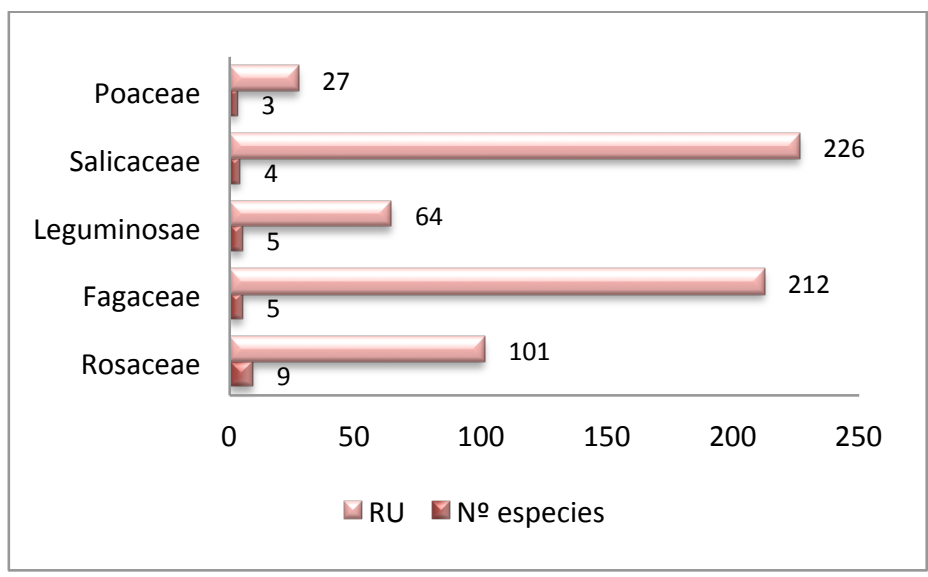

FIGURA 56: Familias con mayor representación de especies y número de registros de uso (RU), en Industria y artesanía.

Las familia más destacada en esta categoría en cuanto a número de registros de uso es Salicaceae alcanzando 226 registros, seguida de Fagaceae con 212, ambas familias representadas por especies de porte arbóreo o arbustivo, esta es una de las razones de estos valores elevados, al resultar una categoría con múltiples usos para las maderas. 
Los usos se han agrupado en subcategorías siguiendo los criterios establecidos en el Inventario Español de los Conocimientos Tradicionales relativos a la Biodiversidad (Pardo de Santayana et al., 2014), obteniendo referencias en las 10 subcategorías indicadas en la tabla 77.

\begin{tabular}{l}
$\begin{array}{l}\text { TABLA 77: Subcategorías con representación en la categoría } \\
\text { Industria y artesanía. }\end{array}$ \\
\hline Subcategorías : \\
\hline Cosmética, perfumería y limpieza \\
Curtientes \\
Sustancias tintóreas y pinturas \\
Herramientas y utensilios \\
Juguetes e instrumentos deportivos y musicales \\
Mobiliario y enseres domésticos \\
Cestos, recipientes y envoltorios \\
Cuerdas y ataduras \\
Vestimenta y adornos personales \\
Otros usos industriales y artesanales \\
\hline
\end{tabular}

Los 1183 registros de uso obtenidos, en la categoría Industria y Artesanía, se reparten en 10 subcategorías tal y como señala la figura 57, resultando que Herramientas y utensilios es la que recibió el mayor número de registros con 690 , un $58,33 \%$ del total en esta categoría, seguido de Cestos, recipientes y envoltorios con 162, un 13,69\%, y Juguetes e instrumentos deportivos y musicales con 134 , un $11,33 \%$.

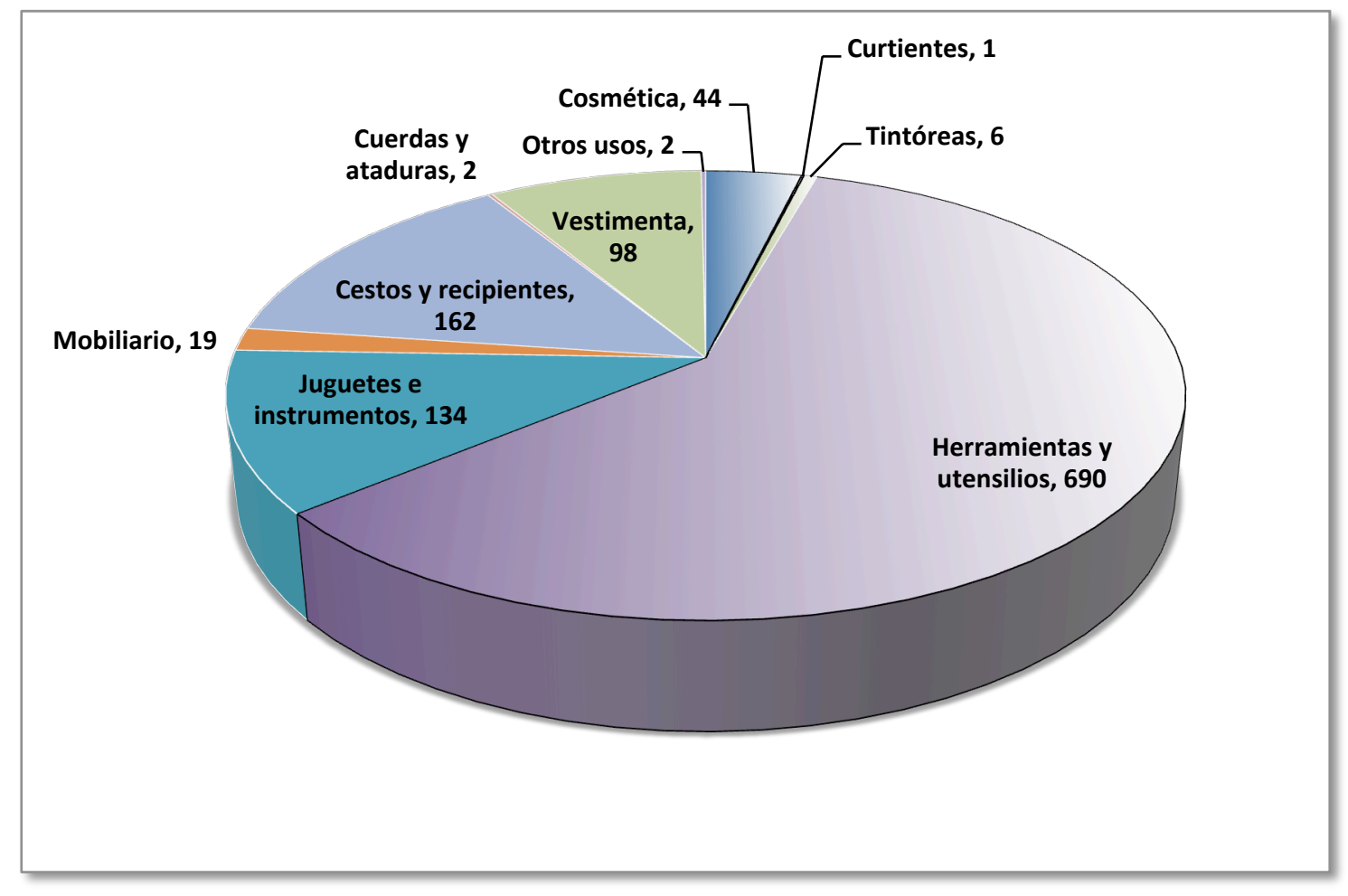

FIGURA 57: Registros de Uso (RU) de las subcategorías representadas en Industria y Artesanía.

A continuación se presentan las utilidades agrupadas por subcategorías de Industria y Artesanía, señalando los taxones que han obtenido citas en los mismos, el número de registros de uso de cada taxón, la parte usada y el empleo. 


\section{Cosmética, perfumería y limpieza:}

Se han recogido 44 registros de uso, correspondientes a 12 taxones de 11 familias botánicas diferentes, 10 taxones de obtención silvestre, 1 cultivado y 1 comprado, representando un $3,72 \%$ del total de registros de uso para la categoría Industria y Artesanía.

TABLA 78: Relación de taxones empleados en la subcategoría Cosmética, perfumería y limpieza, ordenados alfabéticamente por familia, indicando número de registros de uso (RU), parte usada y empleo.

\begin{tabular}{|c|c|c|c|c|}
\hline Familia & $\begin{array}{l}\text { Nombre cientiffico } \\
\text { Nombre vulgar }\end{array}$ & RU & Parte usada & Empleo \\
\hline Apiaceae & $\begin{array}{l}\text { Scandix australis } \\
\text { Anís, anís de lastra }\end{array}$ & 2 & Parte aérea & $\begin{array}{c}\text { Directo } \\
\text { Ambientador }\end{array}$ \\
\hline Caryophyllaceae & $\begin{array}{l}\text { Dianthus hyssopifolius } \\
\text { Clavelina, clavel }\end{array}$ & 1 & Parte aérea & $\begin{array}{c}\text { Directo } \\
\text { Ambientador }\end{array}$ \\
\hline Compositae & $\begin{array}{l}\text { Chamaemelum nobile } \\
\text { Manzanilla, manzanilla campera }\end{array}$ & 1 & Inflorescencia & $\begin{array}{l}\text { Cocción } \\
\text { Aclarar pelo }\end{array}$ \\
\hline Hypericaceae & $\begin{array}{l}\text { Hypericum perforatum } \\
\text { Hipérico, bergaula, pericón }\end{array}$ & 1 & Parte aérea & $\begin{array}{l}\text { Macerado aceite } \\
\text { Bronceador }\end{array}$ \\
\hline Lamiaceae & $\begin{array}{l}\text { Mentha longifolia } \\
\text { Poleo, té de menta, menta poleo }\end{array}$ & 2 & Parte aérea & $\begin{array}{c}\text { Directo } \\
\text { Abrillantador madera }\end{array}$ \\
\hline Leguminosae & $\begin{array}{l}\text { Adenocarpus complicatus } \\
\text { Ulaga, ulaja }\end{array}$ & 1 & Ramas floridas & $\begin{array}{c}\text { Directo } \\
\text { Ambientador }\end{array}$ \\
\hline Oleaceae & $\begin{array}{l}\text { Ligustrum vulgare } \\
\text { Varillo }\end{array}$ & 1 & Ramas floridas & $\begin{array}{c}\text { Directo } \\
\text { Ambientador }\end{array}$ \\
\hline \multirow[t]{2}{*}{ Rosaceae } & $\begin{array}{l}\text { Rosa spp. cultivadas } \\
\text { Rosal }\end{array}$ & 9 & Pétalos & $\begin{array}{c}\text { Macerado agua o } \\
\text { alcohol } \\
\text { Colonia }\end{array}$ \\
\hline & $\begin{array}{l}\text { Rosa spp. silvestres } \\
\text { Zarza, espino, rosal, calambrojo }\end{array}$ & 3 & Pétalos & $\begin{array}{c}\text { Macerado agua o } \\
\text { alcohol } \\
\text { Colonia }\end{array}$ \\
\hline Rutaceae & $\begin{array}{l}\text { Citrus sinensis } \\
\text { Naranja }\end{array}$ & 1 & Cáscara fruto & $\begin{array}{l}\text { Macerado agua } \\
\text { Colonia }\end{array}$ \\
\hline Urticaceae & $\begin{array}{l}\text { Urtica dioica } \\
\text { Ortiga }\end{array}$ & 2 & Parte aérea & $\begin{array}{l}\text { Cocción } \\
\text { Brillo pelo }\end{array}$ \\
\hline Violaceae & $\begin{array}{l}\text { Viola spp. } \\
\text { Violeta }\end{array}$ & 20 & Flor & $\begin{array}{c}\text { Macerado agua o } \\
\text { alcohol } \\
\text { Colonia }\end{array}$ \\
\hline
\end{tabular}

Se incluyen aquellas especies empleadas por un lado, para el cuidado de la piel y el pelo, tales como colonias, perfumes o aclarados de pelo, y por otro lado, productos de limpieza y ambientadores para el hogar.

Casi como un juego del pasado, las niñas mezclaban especies olorosas con agua o alcohol en frascos de cristal, en un intento de elaborar colonia, las flores de las violetas (Viola spp.) y los pétalos de las rosas (Rosa spp.) tanto silvestres como cultivadas en los jardines, fueron las más usadas para esta finalidad, en algunos ocasiones se añadían cáscaras de naranja (Citrus sinensis).

Como tratamiento de belleza y cuidado del cabello se menciona el uso de manzanilla (Chamaemelum nobile) para aclarar el pelo, y de ortiga (Urtica dioica) para enjuagar el cabello después de lavarlo, con el propósito de mejorar su fortaleza y brillo, este empleo también se ha referenciado en Jaén (Guzmán, 1997) y en Castilla-La Mancha (Verde, 2002). 
Otras especies olorosas se usaban en época de floración como ambientador temporal en el hogar, es el caso del anís (Scandix australis), la clavelina (Dianthus hyssopifolius), la ulaga (Adenocarpus complicatus) y el varillo (Ligustrum vulgare).

En el ámbito de la limpieza del hogar recogemos el uso del poleo (Mentha longifolia) para frotar los suelos de madera y obtener un brillo intenso.

\section{Curtientes:}

Se ha recogido 1 registro de uso, correspondientes a 1 taxón de obtención silvestre, de la familia Fagaceae, representando un $0,08 \%$ del total de registros de uso para la categoría Industria y Artesanía.

TABLA 79: Relación de especies empleadas en la subcategoría Curtientes, indicando familia, número de registros de uso (RU), parte usada y empleo.

\begin{tabular}{lllll}
\hline Familia & $\begin{array}{l}\text { Nombre científico } \\
\text { Nombre vulgar }\end{array}$ & RU & Parte usada & Empleo \\
\hline Fagaceae & $\begin{array}{l}\text { Quercus petraea } \\
\text { Q. pyrenaica } \\
\text { Q. robur } \\
\text { Roble, cajigo, matorro }\end{array}$ & 1 & Corteza & Curtir piel \\
\hline
\end{tabular}

En la subcategoría Curtientes se incluyen las especies utilizadas para curtir pieles y cueros.

En la zona de estudio hemos recogido un solo registro sobre el uso de la corteza de roble (Quercus petraea, $Q$. pyrenaica, $Q$. robur), la riqueza en taninos al igual que otras especies del genero Quercus fueron empleadas en el pasado como curtientes también en los Picos de Europa (Lastra, 2003).

\section{Sustancias tintóreas y pinturas:}

Se han recogido 6 registros de uso, correspondientes a 4 taxones de 4 familias botánicas diferentes, 2 taxones de obtención silvestre y 2 cultivados, representando un 0,51\% del total de registros de uso para la categoría Industria y Artesanía.

TABLA 80: Relación de especies empleadas en la subcategoría Sustancias tintóreas y pinturas, ordenadas alfabéticamente por familia, indicando número de registros de uso (RU), parte usada y empleo.

\begin{tabular}{|c|c|c|c|c|}
\hline Familia & $\begin{array}{l}\text { Nombre científico } \\
\text { Nombre vulgar }\end{array}$ & RU & Parte usada & Empleo \\
\hline Adoxaceae & $\begin{array}{l}\text { Sambucus nigra } \\
\text { Saúco, saúgo, sabúgo, taco }\end{array}$ & 1 & Fruto maduro & $\begin{array}{c}\text { Directo } \\
\text { Tinte negro }\end{array}$ \\
\hline Fagaceae & $\begin{array}{l}\text { Quercus petraea } \\
\text { Q. pyrenaica } \\
\text { Q. robur } \\
\text { Roble, cajigo, matorro }\end{array}$ & 3 & $\begin{array}{l}\text { Agallas } \\
\text { Corteza }\end{array}$ & $\begin{array}{l}\text { Directo } \\
\text { Pintura } \\
\text { Cocción } \\
\text { Teñir ropa }\end{array}$ \\
\hline Lauraceae & $\begin{array}{l}\text { Laurus nobilis } \\
\text { Laurel }\end{array}$ & 1 & Hojas & $\begin{array}{l}\text { Cocción } \\
\text { Teñir ropa }\end{array}$ \\
\hline Poaceae & $\begin{array}{l}\text { Secale cereale } \\
\text { Centeno, sirvendo, servendo }\end{array}$ & 1 & Paja & $\begin{array}{c}\text { Ceniza y agua } \\
\text { Tinte }\end{array}$ \\
\hline
\end{tabular}


Las sustancias de origen vegetal empleadas para teñir distintos materiales o tejidos, y la pintura se agrupan en la presente subcategoría.

En otros tiempos, la demanda de ropa negra resultaba habitual, tanto en la vida cotidiana como en ceremonias religiosas (bodas y defunciones), por ello ciertas especies se indicaron para teñir la ropa, se señalan las agallas y la corteza del roble (Quercus petraea, Q. pyrenaica, Q. robur), así como las hojas de laurel (Laurus nobilis).

Otro uso tintóreo fue impregnar y teñir la cuerda del tiralíneas o bota de marcar empleada por los albañiles, siendo citado el centeno (Secale cereale) y el saúco (Sambucus nigra), descrito también con la misma utilidad tintórea en otras zonas como la provincia de Toledo (Criado et al., 2008), o la de Murcia (Rivera et al., 2008).

El propietario de una antigua serrería situada en San Felices de Castillería nos detalló la obtención de pintura con la savia desprendida al cortar los robles jóvenes (Quercus petraea, Q. pyrenaica, Q. robur). "Cuando cortábamos los robles para sacar tabla, echaba una savia, ese líquido era una pintura azul, casi negra, te manchaba las manos, si te mojabas los dedos con la savia ya no se quitaba con nada. Se usaba para pintar luego, cualquier cosa". Este uso no se ha podido contrastar en la bibliografía consultada.

\section{Herramientas y utensilios:}

Se han recogido 690 registros de uso, correspondientes a 37 taxones de 20 familias botánicas diferentes, 34 taxones de obtención silvestre y 3 cultivados, representando un 58,33\% del total de registros de uso para la categoría Industria y Artesanía.

TABLA 81: Relación de taxones empleados en la subcategoría Herramientas y utensilios, ordenados alfabéticamente por familia, indicando número de registros de uso (RU), parte usada y empleo.

\begin{tabular}{|c|c|c|c|c|}
\hline Familia & $\begin{array}{l}\text { Nombre científico } \\
\text { Nombre vulgar }\end{array}$ & RU & Parte usada & Empleo \\
\hline \multirow[t]{2}{*}{ Adoxaceae } & $\begin{array}{l}\text { Sambucus nigra } \\
\text { Saúco, saúgo, sabúgo, taco }\end{array}$ & 4 & Ramas & Escobas y mangos \\
\hline & $\begin{array}{l}\text { Viburnum Iantana } \\
\text { Barbadillo, petruco, sangricio }\end{array}$ & 2 & Ramas & Rueca \\
\hline Aquifoliaceae & $\begin{array}{l}\text { Ilex aquifolium } \\
\text { Acebo, aceba }\end{array}$ & 23 & $\begin{array}{l}\text { Madera, } \\
\text { ramas }\end{array}$ & $\begin{array}{c}\text { Aperos, varas, cachavas, } \\
\text { y herramientas }\end{array}$ \\
\hline \multirow[t]{2}{*}{ Betulaceae } & $\begin{array}{l}\text { Betula pubescens } \\
\text { Abedul }\end{array}$ & 59 & $\begin{array}{l}\text { Madera, } \\
\text { ramas }\end{array}$ & Aperos y escobas \\
\hline & $\begin{array}{l}\text { Corylus avellana } \\
\text { Avellano }\end{array}$ & 113 & $\begin{array}{l}\text { Tronco, } \\
\text { ramas }\end{array}$ & $\begin{array}{c}\text { Aperos, varas, cachavas } \\
\text { y herramientas }\end{array}$ \\
\hline Caprifoliaceae & $\begin{array}{l}\text { Lonicera periclymenum } \\
\text { Mariselva, madreselva }\end{array}$ & 1 & Tallo & Pipas de fumar \\
\hline Celastraceae & $\begin{array}{l}\text { Euonymus europaeus } \\
\text { Husera, bonetero }\end{array}$ & 3 & Madera & Cubiertos \\
\hline Cupressaceae & $\begin{array}{l}\text { Juniperus communis } \\
\text { Enebro, corveño }\end{array}$ & 2 & Madera & Cucharas \\
\hline Dennstaedtiaceae & $\begin{array}{l}\text { Pteridium aquilinum } \\
\text { Helecho, halecho }\end{array}$ & 6 & Frondes & Escobas \\
\hline Ericaceae & $\begin{array}{l}\text { Erica spp. } \\
\text { Brezo, urz, ayuz, graspo }\end{array}$ & 35 & $\begin{array}{l}\text { Madera, } \\
\text { parte aérea }\end{array}$ & $\begin{array}{c}\text { Escobas, pipas de fumar } \\
\text { y cucharas }\end{array}$ \\
\hline Fagaceae & $\begin{array}{l}\text { Fagus sylvatica } \\
\text { Haya }\end{array}$ & 83 & Madera & Aperos y herramientas \\
\hline
\end{tabular}




\begin{tabular}{|c|c|c|c|c|}
\hline Familia & $\begin{array}{l}\text { Nombre científico } \\
\text { Nombre vulgar }\end{array}$ & RU & Parte usada & Empleo \\
\hline Fagaceae & $\begin{array}{l}\text { Quercus petraea } \\
\text { Q. pyrenaica; Q. robur } \\
\text { Roble, cajigo, matorro }\end{array}$ & 60 & $\begin{array}{l}\text { Madera } \\
\text { Agallas }\end{array}$ & $\begin{array}{l}\text { Mangos, aperos y } \\
\text { cebillas } \\
\text { Pipas de fumar }\end{array}$ \\
\hline \multirow[t]{3}{*}{ Grossulariaceae } & $\begin{array}{l}\text { Ribes alpinum } \\
\text { Abubillo, plumillo, espuma }\end{array}$ & 3 & Ramas & Escobas \\
\hline & $\begin{array}{l}\text { Ribes petraeum } \\
\text { Abubillo, abubillo montesino }\end{array}$ & 1 & Ramas & Escobas \\
\hline & $\begin{array}{l}\text { Ribes uva-crispa } \\
\text { Abubillo, escándalo, plumillar }\end{array}$ & 2 & Ramas & Escobas \\
\hline \multirow[t]{2}{*}{ Lamiaceae } & $\begin{array}{l}\text { Mentha longifolia } \\
\text { Poleo, té de menta }\end{array}$ & 3 & Parte aérea & Escobas \\
\hline & $\begin{array}{l}\text { Mentha suaveolens } \\
\text { Poleo }\end{array}$ & 3 & Parte aérea & Escobas \\
\hline \multirow[t]{5}{*}{ Leguminosae } & $\begin{array}{l}\text { Adenocarpus complicatus } \\
\text { Ulaga, ulaja }\end{array}$ & 3 & Ramas & Escobas \\
\hline & $\begin{array}{l}\text { Cytisus scoparius } \\
\text { Escoba, ramo, escoba balera }\end{array}$ & 44 & Ramas & Escobas \\
\hline & $\begin{array}{l}\text { Genista florida } \\
\text { Escoba, escoba albar, ramón }\end{array}$ & 4 & Ramas & Escobas \\
\hline & $\begin{array}{l}\text { Genista hispanica } \\
\text { Argoma, ulaga }\end{array}$ & 1 & Ramas & Escobas \\
\hline & $\begin{array}{l}\text { Robinia pseudoacacia } \\
\text { Acacia }\end{array}$ & 2 & Madera & Mangos \\
\hline \multirow[t]{2}{*}{ Oleaceae } & $\begin{array}{l}\text { Fraxinus excelsior } \\
\text { Fresno }\end{array}$ & 86 & $\begin{array}{l}\text { Tronco, } \\
\text { ramas }\end{array}$ & $\begin{array}{l}\text { Aperos, cachavas y } \\
\text { herramientas }\end{array}$ \\
\hline & $\begin{array}{l}\text { Ligustrum vulgare } \\
\text { Varillo }\end{array}$ & 5 & Ramas & Escobas \\
\hline Rhamnaceae & $\begin{array}{l}\text { Rhamnus alpina } \\
\text { Teja blanca, uva de oso, pudio }\end{array}$ & 1 & Madera & Mangos \\
\hline \multirow[t]{5}{*}{ Rosaceae } & $\begin{array}{l}\text { Crataegus monogyna } \\
\text { Espino, espino albar, majueto }\end{array}$ & 26 & $\begin{array}{l}\text { Madera, } \\
\text { ramas }\end{array}$ & $\begin{array}{c}\text { Mangos, cachavas y } \\
\text { cucharas }\end{array}$ \\
\hline & $\begin{array}{l}\text { Prunus avium } \\
\text { Cerezo }\end{array}$ & 3 & $\begin{array}{l}\text { Madera y } \\
\text { ramas }\end{array}$ & $\begin{array}{c}\text { Mangos, cachavas y } \\
\text { cucharas }\end{array}$ \\
\hline & $\begin{array}{l}\text { Prunus cerasus } \\
\text { Guindal }\end{array}$ & 3 & $\begin{array}{l}\text { Madera y } \\
\text { ramas }\end{array}$ & $\begin{array}{c}\text { Mangos, cachavas y } \\
\text { cucharas }\end{array}$ \\
\hline & $\begin{array}{l}\text { Sorbus aria } \\
\text { Mostajo, amostajo }\end{array}$ & 3 & Madera & Mangos \\
\hline & $\begin{array}{l}\text { Sorbus aucuparia } \\
\text { Amargoso, serbal, drío, drido }\end{array}$ & 4 & Ramas & Varas \\
\hline \multirow[t]{3}{*}{ Salicaceae } & $\begin{array}{l}\text { Populus alba } \\
\text { P. nigra } \\
\text { Chopo }\end{array}$ & 12 & Madera & Mangos y herramientas \\
\hline & $\begin{array}{l}\text { Salix atrocinerea } \\
\text { Salce gatillo }\end{array}$ & 3 & Madera & Aperos y mangos \\
\hline & $\begin{array}{l}\text { Salix spp. } \\
\text { Salguero, sota, salce, mimbrera }\end{array}$ & 38 & $\begin{array}{l}\text { Tronco, } \\
\text { ramas }\end{array}$ & $\begin{array}{l}\text { Aperos, cachavas y } \\
\text { herramientas }\end{array}$ \\
\hline Sapindaceae & $\begin{array}{l}\text { Acer campestre } \\
\text { Barbaleña }\end{array}$ & 1 & Madera & Mangos \\
\hline Taxaceae & $\begin{array}{l}\text { Taxus baccata } \\
\text { Tejo }\end{array}$ & 4 & Madera & $\begin{array}{c}\text { Mangos, pipas de fumar } \\
\text { y cucharas }\end{array}$ \\
\hline Ulmaceae & $\begin{array}{l}\text { Ulmus minor } \\
\text { Olmo }\end{array}$ & 43 & $\begin{array}{l}\text { Tronco, } \\
\text { ramas }\end{array}$ & $\begin{array}{l}\text { Aperos, cachavas y } \\
\text { herramientas }\end{array}$ \\
\hline Vitaceae & $\begin{array}{l}\text { Vitis vinifera } \\
\text { Parra }\end{array}$ & 1 & Madera & Pipas de fumar \\
\hline
\end{tabular}


La subcategoría Herramientas y utensilios es muy amplia y engloba aperos de labranza como guadañas, horcas, palas, yugos, rastros, arados, mangos, varas y cachavas. También utensilios para el ganado como badajos, collares, albardas, etc, distintas herramientas, escobas, utensilios específicos para hilar, cucharas u otros cubiertos para cocinar, y pipas de fumar.

La madera es clave como materia prima de uso tecnológico, con ella se han fabricado aperos de labranza imprescindibles para el desarrollo del modo de vida eminentemente agrícola y ganadero de la zona. Los pueblos con mejor zona boscosa surtían a los mercados locales de Aguilar, Cervera y Guardo, con todo tipo de objetos, destacando en este aspecto las localidades de San Martín de los Herreros, Rebanal de las Llantas, Polentinos o Salcedillo.

Entre las maderas más valoradas para elaborar garios, bieldos, horcas, rastros, astiles, yugos, etc., están, avellano (Corylus avellana), fresno (Fraxinus excelsior), haya (Fagus sylvatica) y abedul (Betula pubescens). Para los mangos de herramientas, además de los anteriormente señalados, se aconseja también el roble (Quercus petraea, Q. pyrenaica, Q. robur), el olmo (Ulmus minor) y el acebo (Ilex aquifolium).

Las varas más rectas para arrear el ganado (ahijada) o para "pinar las vainas" se obtienen de avellano, acebo y amargoso (Sorbus aucuparia), especies también señaladas con la misma finalidad en los Picos de Europa (Lastra, 2003).

Las cualidades de la madera son bien conocidas y cada objeto a fabricar precisa de una madera características más adecuadas. Por ello, en la construcción del clásico arado romano intervienen distintas especies, para la camba y la esteva se recomienda haya, en ocasiones también para el dental, junto con guindal (Prunus cerasus) o encina (Quercus rotundifolia) si aparece en la zona, los tiros o arrastraderos de salguero (Salix spp.) o abedul de características más ligeras.

Son muchas las especies vegetales empleadas para fabricar escobas para barrer calles, cuadras y corrales, todas ellas de aspecto arbustivo, las más citadas fueron la escoba (Cytisus scoparius, Genista florida), el abubillo (Ribes alpinum, R. petraeum y R. uva-crispa), el brezo (Erica spp.), la ulaga (Adenocarpus complicatus) y la argoma (Genista hispanica).

Con helechos (Pteridium aquilinum) o con poleos (Mentha longifolia, M. suaveolens) se fabricaba una escoba especial para barrer las brasas del horno de cocer el pan, el mejor baleo para barrer el grano de la era solía ser de abedul o de varillo (Ligustrum vulgare) y con un manojo también de poleos (Mentha longifolia) se frotaban las colmenas para atraer a las abejas.

Destacan las especies señaladas para la fabricación de pipas para fumar, entre ellas el brezo, el tejo (Taxus baccata) o el acebo, todos ellos con madera de propiedades muy duras. Con las agallas del roble y un trozo de tallo hueco a modo de boquilla de mariselva (Lonicera periclymenun), también se fabricaba una rústica pipa para fumar.

Otra artesanía de interés es la elaboración de cubiertos para la cocina, los más citados, cucharas y cucharones, para los que se usaban maderas muy duras capaces de aguantar los contrastes de calor, como el majueto (Crataegus monogyna), la husera (Euonymus europaeus) y el tejo, estas maderas también se han empleado en la fabricación de cubiertos en la provincia de León (García Jiménez, 2007). 


\section{Juguetes e instrumentos deportivos y musicales:}

Se han recogido 134 registros de uso, correspondientes a 19 taxones de 12 familias botánicas diferentes, 14 taxones de obtención silvestre, 4 cultivados y 1 comprado, representando un $11,33 \%$ del total de registros de uso para la categoría Industria y Artesanía.

TABLA 82: Relación de taxones empleados en la subcategoría Juguetes e instrumentos deportivos y musicales, ordenados alfabéticamente por familia, indicando número de registros de uso (RU), parte usada y empleo.

\begin{tabular}{|c|c|c|c|c|}
\hline Familia & $\begin{array}{l}\text { Nombre científico } \\
\text { Nombre vulgar }\end{array}$ & RU & Parte usada & Empleo \\
\hline Adoxaceae & $\begin{array}{l}\text { Sambucus nigra } \\
\text { Saúco, saúgo, sabúgo, taco }\end{array}$ & 10 & Ramas & $\begin{array}{l}\text { Chiflos } \\
\text { Jeringas }\end{array}$ \\
\hline \multirow[t]{2}{*}{ Apiaceae } & $\begin{array}{l}\text { Angelica sylvestris } \\
\text { Angélica, chiflato }\end{array}$ & 1 & Tallo & Chiflos \\
\hline & $\begin{array}{l}\text { Conium maculatum } \\
\text { Budaño, cañiguerra, canuto }\end{array}$ & 2 & Tallo & Chiflos \\
\hline \multirow[t]{2}{*}{ Betulaceae } & $\begin{array}{l}\text { Betula pubescens } \\
\text { Abedul }\end{array}$ & 6 & Madera & $\begin{array}{l}\text { Bolos y bolas } \\
\text { Rabel }\end{array}$ \\
\hline & $\begin{array}{l}\text { Corylus avellana } \\
\text { Avellano }\end{array}$ & 6 & Madera & $\begin{array}{l}\text { Bolos y bolas } \\
\text { Juegos populares }\end{array}$ \\
\hline Caprifoliaceae & $\begin{array}{l}\text { Dipsacus fullonum } \\
\text { Cardo cardador, cardo, cardón }\end{array}$ & 3 & Tallo & Matraca \\
\hline \multirow[t]{3}{*}{ Fagaceae } & $\begin{array}{l}\text { Fagus sylvatica } \\
\text { Haya }\end{array}$ & 7 & Madera & $\begin{array}{l}\text { Bolos y bolas } \\
\text { Esquís }\end{array}$ \\
\hline & $\begin{array}{l}\text { Quercus petraea } \\
\text { Q. pyrenaica } \\
\text { Q. robur } \\
\text { Roble, cajigo, matorro }\end{array}$ & 13 & Madera & $\begin{array}{l}\text { Bolos y bolas } \\
\text { Peonzas } \\
\text { Zancos }\end{array}$ \\
\hline & $\begin{array}{l}\text { Quercus rotundifolia } \\
\text { Encina, ancina }\end{array}$ & 1 & Madera & Peonzas \\
\hline Juglandaceae & $\begin{array}{l}\text { Juglans regia } \\
\text { Nogal }\end{array}$ & 1 & Madera & Bolos y bolas \\
\hline Myrtaceae & $\begin{array}{l}\text { Eucalyptus globulus } \\
\text { Eucalipto, eucalito }\end{array}$ & 1 & Madera & Bolos y bolas \\
\hline Oleaceae & $\begin{array}{l}\text { Fraxinus excelsior } \\
\text { Fresno }\end{array}$ & 12 & Madera & $\begin{array}{l}\text { Bolos y bolas, chiflos, } \\
\text { rabel, peonzas y esquís }\end{array}$ \\
\hline \multirow[t]{2}{*}{ Poaceae } & $\begin{array}{l}\text { Secale cereale } \\
\text { Centeno, sirvendo, servendo }\end{array}$ & 1 & Paja & Flautas \\
\hline & $\begin{array}{l}\text { Triticum aestivum } \\
\text { Trigo, mesino, tremesino }\end{array}$ & 1 & Paja & Flautas \\
\hline \multirow[t]{2}{*}{ Rosaceae } & $\begin{array}{l}\text { Prunus avium } \\
\text { Cerezo }\end{array}$ & 1 & Madera & Bolos y bolas \\
\hline & $\begin{array}{l}\text { Prunus cerasus } \\
\text { Guindal }\end{array}$ & 1 & Madera & Bolos y bolas \\
\hline \multirow[t]{2}{*}{ Salicaceae } & $\begin{array}{l}\text { Populus alba } \\
\text { P. nigra } \\
\text { Chopo }\end{array}$ & 28 & $\begin{array}{l}\text { Madera y } \\
\text { ramas }\end{array}$ & $\begin{array}{l}\text { Bolos y bolas } \\
\text { Chiflos }\end{array}$ \\
\hline & $\begin{array}{l}\text { Salix spp. } \\
\text { Salguero, sota, salce, mimbrera }\end{array}$ & 34 & Ramas & $\begin{array}{l}\text { Chiflos } \\
\text { Combas }\end{array}$ \\
\hline Ulmaceae & $\begin{array}{l}\text { Ulmus minor } \\
\text { Olmo }\end{array}$ & 5 & Madera & $\begin{array}{l}\text { Bolos y bolas } \\
\text { Peonzas }\end{array}$ \\
\hline
\end{tabular}

Descritas aquellas especies empleadas en la fabricación de juguetes, en útiles para deportes o en instrumentos musicales. 
En el apartado de fabricación de juguetes destacan la elaboración de peonzas con madera de roble (Quercus petraea, Q. pyrenaica, Q. robur), fresno (Fraxinus excelsior) olmo (Ulmus minor) o encina (Quercus rotundifolia), de jeringas (chirotes, tiragüas o tiratacos) construidas con las ramas de saúco (Sambucus nigra), donde los niños tenían por costumbre fabricar este artefacto introduciendo un trozo de rama ajustada al diámetro hueco de la rama del saúco, pudiendo disparar agua, pequeños trozos de tela o de estopa.

Otro tipo de juegos infantiles consistían en caminar sobre zancos de madera de roble, saltar la comba con las delgadas y flexibles ramas del salguero (Salix spp.), o diferentes juegos populares como el pite, la bigarda, el chite, etc., en los que se mencionó la necesidad de algún elemento de madera, a veces no especificado. Por último, con un trozo de tallo con entrenudo de cardo cardador (Dipsacus fullonum) y un pequeño palo, se fabricaba un juguete a modo de matraca para hacer ruido haciéndolo girar con rapidez, ingenio también referenciado en la provincia de Ciudad Real (Molero Mesa et al., 2001) y en el Cerrato Palentino (Pascual et al., 2016).

El juego más predominante y popular en la zona es el de los bolos, con múltiples variantes de juego, consta de diez bolos y bolas con dos orificios o un asa, construidas principalmente con maderas de chopo (Populus alba, P. nigra), roble, fresno, haya (Fagus sylvatica) y alguna otra, dependiendo de las características deseadas de peso y volumen.

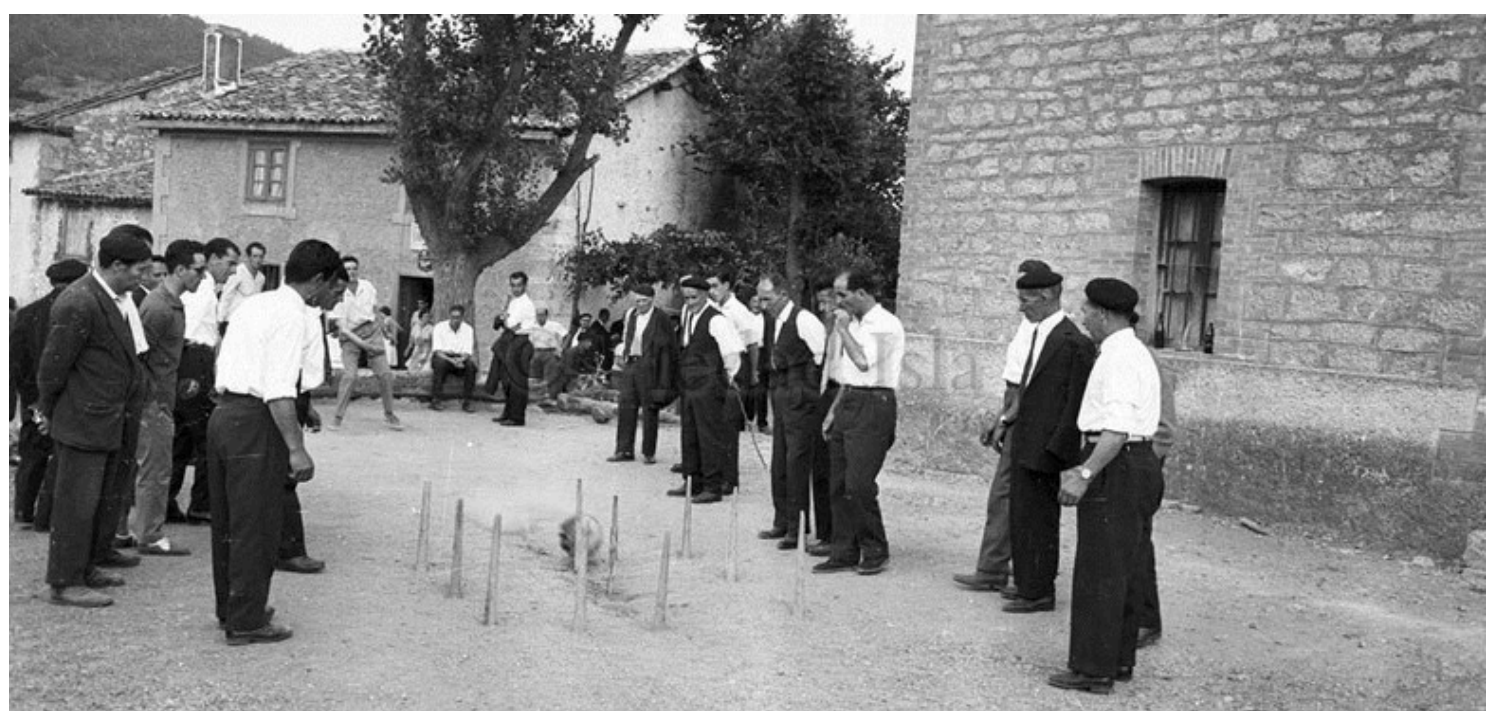

FIGURA 58: Juego de los bolos en Ruesga (1961). Foto: Piedad Isla.

En la zona más septentrional de la comarca, propicia a recibir mayores precipitaciones en forma de nieve, se mostraron rústicos esquís construidos con madera de fresno y haya, aprovechando las excelentes propiedades de esta madera.

En cuanto a instrumentos musicales, se fabricaban sencillas flautas o chiflos a partir de ramas de chopo, saúco o fresno, a las que se extrae la médula para obtener la forma de flauta deseada. Más elementales aún eran las flautas a base de cañas huecas de budaño (Conium maculatum), centeno (Secale cereale), trigo (Triticum aestivum) o chiflato (Angelica sylvestris). Aunque el instrumento tradicional más significativo en la zona fue el rabel, construido con madera de abedul (Betula pubescens) o haya, el cual se frotaba con un arco y servía de acompañamiento para recitar coplas y romances. 


\section{Mobiliario y enseres domésticos:}

Se han recogido 19 registros de uso, correspondientes a 7 taxones de 6 familias botánicas diferentes, 3 taxones de obtención silvestre y 4 cultivados, representando un 1,61\% del total de registros de uso para la categoría Industria y Artesanía.

TABLA 83: Relación de taxones empleados en la subcategoría Mobiliario y enseres domésticos, ordenados alfabéticamente por familia, indicando número de registros de uso (RU), parte usada y empleo.

\begin{tabular}{llccc}
\hline Familia & $\begin{array}{l}\text { Nombre científico } \\
\text { Nombre vulgar }\end{array}$ & RU & Parte usada & Empleo \\
\hline Fagaceae & $\begin{array}{l}\text { Juglans regia } \\
\text { Nogal }\end{array}$ & 2 & Madera & Muebles \\
\hline Juglandaceae & $\begin{array}{l}\text { Secale cereale } \\
\text { Centeno, sirvendo, servendo }\end{array}$ & 2 & Madera & Muebles \\
\hline Poaceae & $\begin{array}{l}\text { Zea mays } \\
\text { Maíz }\end{array}$ & 1 & Paja & Jergones \\
\hline $\begin{array}{l}\text { Populus alba } \\
\text { P. nigra } \\
\text { Chopo }\end{array}$ & $\begin{array}{l}\text { Salix spp. } \\
\text { Salguero, sota, salce, mimbrera }\end{array}$ & 6 & Madera & Jergones \\
\hline $\begin{array}{l}\text { Ulmus } \text { minor } \\
\text { Olmo } \\
\text { Juglans regia } \\
\text { Nogal }\end{array}$ & 1 & Madera & Muebles \\
\hline Ulmaceae & \begin{tabular}{l} 
Nogeras \\
\hline
\end{tabular} & 3 & Madera & Muebles \\
\hline
\end{tabular}

Incluidas las especies recomendadas para la fabricación de todo tipo de muebles: sillas, mesas, armarios, estantes, cunas, etc., así como rellenos de jergones y colchones.

El mobiliario tradicional de la casa era de madera, así como interesantes utensilios domésticos que elaboraban los lugareños más diestros en el oficio. El chopo (Populus alba, P. nigra) obtuvo 6 registros de uso, el mayor número en esta subcategoría, posee una madera blanda y ligera, mencionado su uso en mesas, bancos, sillas, e incluso ataúdes, también para enseres, tablas de lavar y jaulas.

También se refiere el uso de la madera de roble (Quercus petraea, Q. pyrenaica, Q. robur), en la fabricación de mobiliario de interior: mesas, mesillas, alacenas, camas y sillas. Su madera es más basta y engorrosa de trabajar que la de olmo (Ulmus minor) o la de nogal (Juglans regia) que se consideraban las mejores para este tipo de trabajos. La madera del olmo fue apreciada también para fabricar muebles en Cantabria (Pardo de Santayana, 2004), en Doñana (Cobo \& Tijera, 2011) y en la provincia de Mallorca (Carrió, 2013).

El uso de las hojas de maíz (Zea mays) y el de la paja de centeno (Secale cerale) como relleno para los jergones que hacían de colchón en las camas, es bien conocido en toda la comarca.

\section{Cestos, recipientes y envoltorios:}

Se han recogido 162 registros de uso, correspondientes a 9 taxones de 7 familias botánicas diferentes, 7 taxones de obtención silvestre y 2 cultivados, representando un 13,69\% del total de registros de uso para la categoría Industria y Artesanía. 
TABLA 84: Relación de taxones empleados en la subcategoría Cestos, recipientes y envoltorios, ordenados alfabéticamente por familia, indicando número de registros de uso (RU), parte usada y empleo.

\begin{tabular}{|c|c|c|c|c|}
\hline Familia & $\begin{array}{l}\text { Nombre científico } \\
\text { Nombre vulgar }\end{array}$ & RU & Parte usada & Empleo \\
\hline Betulaceae & $\begin{array}{l}\text { Corylus avellana } \\
\text { Avellano }\end{array}$ & 7 & Tallo & Armazón cesta \\
\hline Fagaceae & $\begin{array}{l}\text { Quercus petraea } \\
\text { Q. pyrenaica } \\
\text { Q. robur } \\
\text { Roble, cajigo, matorro }\end{array}$ & 15 & Tronco & Colmenas y recipientes \\
\hline \multirow[t]{2}{*}{ Poaceae } & $\begin{array}{l}\text { Secale cereale } \\
\text { Centeno, sirvendo, servendo }\end{array}$ & 17 & Paja & Escriños \\
\hline & $\begin{array}{l}\text { Triticum aestivum } \\
\text { Trigo, mesino, tremesino }\end{array}$ & 2 & Paja & Escriños \\
\hline \multirow[t]{2}{*}{ Rosaceae } & $\begin{array}{l}\text { Crataegus monogyna } \\
\text { Espino, espino albar, majueto }\end{array}$ & 4 & Tallo & Armazón cesta \\
\hline & $\begin{array}{l}\text { Rosa spp. silvestres } \\
\text { Zarza, espino, rosal, calambrojo }\end{array}$ & 23 & Ramas & Armazón cesta \\
\hline Salicaceae & $\begin{array}{l}\text { Salix spp. } \\
\text { Salguero, sota, salce, mimbrera }\end{array}$ & 92 & Tallo & Cestas \\
\hline Typhaceae & $\begin{array}{l}\text { Typha angustifolia } \\
\text { Puro, cuete }\end{array}$ & 1 & Hojas & Sellar juntas cubas \\
\hline Ulmaceae & $\begin{array}{l}\text { Ulmus minor } \\
\text { Olmo }\end{array}$ & 1 & Tronco & Colmenas \\
\hline
\end{tabular}

Agrupadas aquellas especies empleadas en la elaboración de cestos con materiales vegetales, y recipientes de madera para alimentos, para líquidos como cubas o toneles, y para colmenas. Especial interés tiene la utilización de la mimbre del salguero (Salix spp.) como base de la cestería. Se trata de una actividad temporal que aprovecha las ramas de crecimiento del año y que aún encontramos ejemplos de vigencia en su elaboración en la localidad de La Lastra. Con los rebrotes, de propiedades flexibles y consistentes, se confeccionan todo tipo de cestas en cuanto a tamaños y formas, su función está asociada a tareas de transporte en el ámbito agrícola y doméstico, muy útiles como recipientes para acarrear forraje, patatas, hortalizas, huevos, etc. Para obtener la materia prima se cortan los tallos nuevos de los ejemplares silvestres, normalmente mantenidos gracias a la poda anual a la que se someten. La confección de la cesta comienza con la preparación de un armazón de madera de avellano (Corylus avellana), zarza (Rosa spp.) o espino (Crataegus monogyna), que consta de aro y costillas, sobre las que se trenzan las mimbres dóciles, previamente deshojadas. Además, con mimbres se confeccionaban otro tipo de utensilios, uno de los más comunes fue la cagadera, con la que se recogían las heces del ganado durante la trilla y que evitaba ensuciar el grano.

También destaca en cestería la fabricación de escriños a base de paja de centeno (Secale cereale) o trigo (Triticum aestivum), enrollada en espiral y cosida con tiras de zarza (Rosa spp., Rubus ulmifolius), este procedimiento también se referencia en muchas otras zonas de la Península Ibérica: Sanabria (Blanco \& Díez, 2005), La Gomera (Perera López, 2006), el Sayago (Gallego \& Gallego, 2008), provincia de La Coruña (Latorre, 2008), Campoo (Pardo de Santayana, 2008), Sierra de Madrid (Aceituno Mata, 2010), Monfragüe (Tejerina, 2010) o Tenerife (Álvarez Escobar, 2011).

Hasta los años 60 del siglo XX se elaboraron en ciertos pueblos de la zona cubas o toneles con madera de roble (Quercus petraea, $Q$. pyrenaica, $Q$. robur), y otros recipientes de gran tamaño llamados dujos, utilizados para conservar el grano de cereal y como habitáculo para albergar las colmenas de abejas. 


\section{Cuerdas y ataduras:}

Se han recogido 27 registros de uso, correspondientes a 5 taxones de obtención silvestre, de 4 familias botánicas diferentes, representando un $2,28 \%$ del total de registros de uso para la categoría Industria y Artesanía.

TABLA 85: Relación de taxones empleados en la subcategoría Cuerdas y ataduras, ordenados alfabéticamente por familia, indicando número de registros de uso (RU), parte usada y empleo.

\begin{tabular}{llccc}
\hline Familia & $\begin{array}{l}\text { Nombre científico } \\
\text { Nombre vulgar }\end{array}$ & RU & Parte usada & Empleo \\
\hline Betulaceae & $\begin{array}{l}\text { Corylus avellana } \\
\text { Avellano }\end{array}$ & 1 & Tallo joven & Atadura \\
\hline Rosaceae & $\begin{array}{l}\text { Prunus padus } \\
\text { Ceresuela } \\
\text { Rubus ulmifolius } \\
\text { Zarza, moral, espino }\end{array}$ & 11 & Ramas & Cuerda \\
\hline Salicaceae & $\begin{array}{l}\text { Salix spp. } \\
\text { Salguero, sota, salce, mimbrera } \\
\text { Ulmus minor }\end{array}$ & 12 & Tallo & Cuerda \\
\hline Olmo & 1 & Ramas & Atadura \\
\hline
\end{tabular}

Se describen en esta subcategoría las plantas empleadas para hacer cuerdas y ataduras. La flexibilidad de los tallos jóvenes de ciertas especies y la dureza que adquieren tras el secado, son cualidades aprovechadas para hacer ataduras sólidas y resistentes, empleadas por ejemplo, para amarrar las ramas de las escobas vegetales a modo de presilla, para atar los manojos del ramón (capachos, gamanzos o zamanzos) o para sujetar la ripia del tejado. En la comarca se han destinado para dichos usos: el salguero (Salix spp.), el avellano (Corylus avellana) y el olmo (Ulmus minor).

Las ramas más largas y flexibles de la zarza (Rubus ulmifolius) se limpiaban de espinas, se pelaban y la corteza servía como atadura para tejer cestos y recipientes de diversos tamaños, como los escriños, una vez secas, adquieren gran resistencia. En la provincia de Cantabria (Pardo de Santayana, 2004) y en la de Salamanca (Velasco et al., 2010), también documentan este mismo uso.

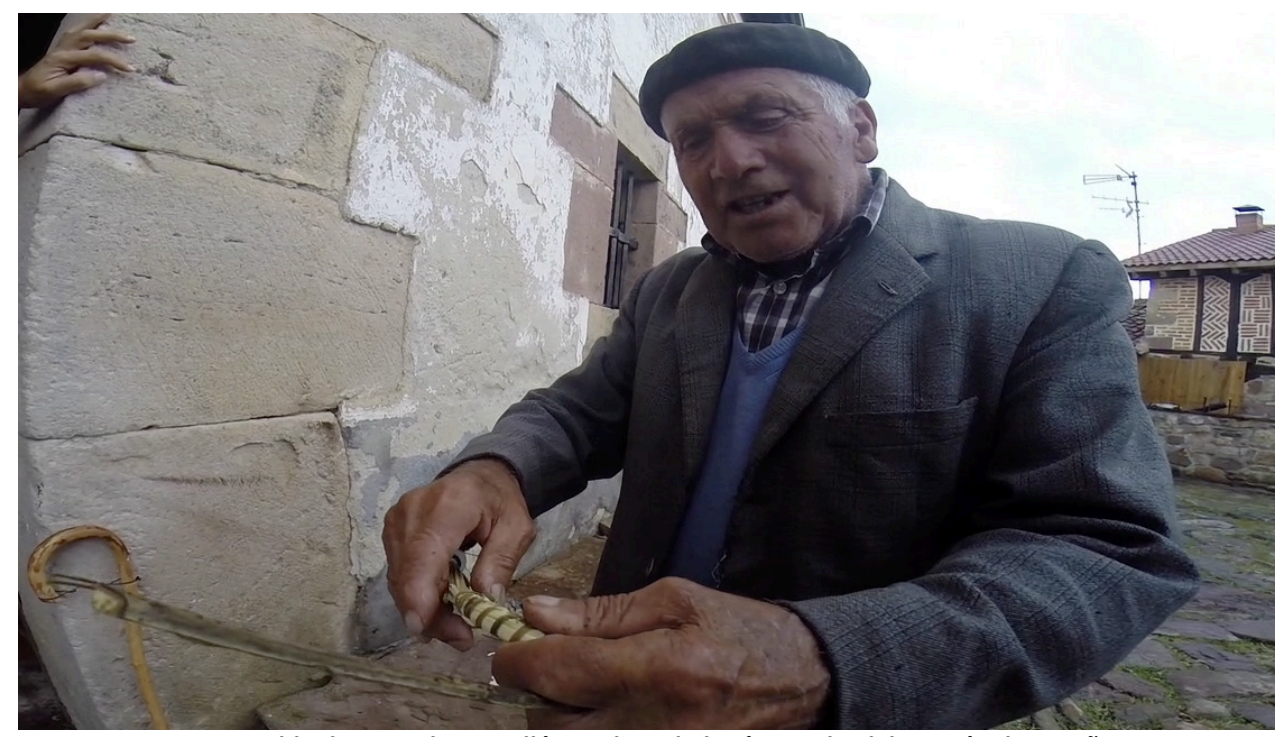

FIGURA 59: Pablo de Nava de Santullán explicando la técnica de elaboración de escriños con zarzas. 


\section{Vestimenta y adornos personales:}

Se han recogido 98 registros de uso, correspondientes a 18 taxones de 13 familias botánicas diferentes, 16 taxones de obtención silvestre y 2 cultivados, representando un 8,28\% del total de registros de uso para la categoría Industria y Artesanía.

TABLA 86: Relación de taxones empleados en la subcategoría Vestimenta y adornos personales, ordenados alfabéticamente por familia, indicando número de registros de uso (RU), parte usada y empleo.

\begin{tabular}{|c|c|c|c|c|}
\hline Familia & $\begin{array}{l}\text { Nombre científico } \\
\text { Nombre vulgar }\end{array}$ & RU & Parte usada & Empleo \\
\hline Aquifoliaceae & $\begin{array}{l}\text { Ilex aquifolium } \\
\text { Acebo, aceba }\end{array}$ & 2 & Madera & Tarugos \\
\hline \multirow[t]{2}{*}{ Betulaceae } & $\begin{array}{l}\text { Betula pubescens } \\
\text { Abedul }\end{array}$ & 17 & Madera & Albarcas \\
\hline & $\begin{array}{l}\text { Corylus avellana } \\
\text { Avellano }\end{array}$ & 1 & Madera & Tarugos \\
\hline Celastraceae & $\begin{array}{l}\text { Euonymus europaeus } \\
\text { Husera, bonetero }\end{array}$ & 1 & Fruto & Collares \\
\hline \multirow[t]{2}{*}{ Compositae } & $\begin{array}{l}\text { Bellis perennis } \\
\text { Margarita }\end{array}$ & 2 & Inflorescencia & Collares \\
\hline & $\begin{array}{l}\text { Leucanthemum vulgare } \\
\text { Margarita }\end{array}$ & 1 & Inflorescencia & Collares \\
\hline Cupressaceae & $\begin{array}{l}\text { Juniperus communis } \\
\text { Enebro, corveño }\end{array}$ & 1 & Madera & Tarugos \\
\hline Ericaceae & $\begin{array}{l}\text { Arctostaphylos uva-ursi } \\
\text { Gayuga, agayuga, gayuba }\end{array}$ & 5 & Fruto & Collares \\
\hline \multirow[t]{2}{*}{ Fagaceae } & $\begin{array}{l}\text { Fagus sylvatica } \\
\text { Haya }\end{array}$ & 21 & Madera & Albarcas \\
\hline & $\begin{array}{l}\text { Quercus petraea } \\
\text { Q. pyrenaica } \\
\text { Q. robur } \\
\text { Roble, cajigo, matorro }\end{array}$ & 4 & Madera & Tarugos \\
\hline Leguminosae & $\begin{array}{l}\text { Genista florida } \\
\text { Escoba, escoba albar, ramón }\end{array}$ & 9 & Madera & Tarugos \\
\hline Linaceae & $\begin{array}{l}\text { Linum usitatissimum } \\
\text { Lino }\end{array}$ & 22 & Fibras tallo & Textil \\
\hline Oleaceae & $\begin{array}{l}\text { Fraxinus excelsior } \\
\text { Fresno }\end{array}$ & 2 & Madera & Albarcas \\
\hline Paeoniaceae & $\begin{array}{l}\text { Paeonia lactiflora } \\
\text { Peonía }\end{array}$ & 1 & Semillas & Collares \\
\hline \multirow[t]{3}{*}{ Rosaceae } & $\begin{array}{l}\text { Rosa spp. silvestres } \\
\text { Zarza, espino, rosal, calambrojo }\end{array}$ & 6 & Fruto & Collares \\
\hline & $\begin{array}{l}\text { Sorbus aria } \\
\text { Mostajo, amostajo }\end{array}$ & 1 & Madera & Albarcas \\
\hline & $\begin{array}{l}\text { Sorbus aucuparia } \\
\text { Amargoso, serbal, drío, drido }\end{array}$ & 1 & Madera & Tarugos \\
\hline Xanthorrhoeaceae & $\begin{array}{l}\text { Asphodelus albus } \\
\text { Gamón, gamonita }\end{array}$ & 1 & Fruto & Collares \\
\hline
\end{tabular}

Referente a la subcategoría Vestimenta y adornos personales se indican las especies utilizadas para fabricar calzado, todo tipo de ropa y adornos como collares, pulseras y otros elementos.

Gran importancia tuvo en épocas pasadas el cultivo del lino (Linum usitatissimum) del que se hicieron todo tipo de tejidos una vez extraídas sus fibras. A pesar del abandono del cultivo hace muchos años, se conservan muchos topónimos diseminados por toda la comarca. En la provincia de Segovia se cultivaba el lino en las zonas con clima de montaña (Blanco, 1998). 
También destacó la realización de albarcas, tradicional calzado de madera hecho de una sola pieza de haya (Fagus sylvatica), abedul (Betula pubescens), fresno (Fraxinus excelsior) - mostajo (Sorbus aria). Los tarugos o machorras se tallaban con maderas duras como la de escoba (Genista florida), roble (Quercus petraea, Q. pyrenaica, Q. robur), o acebo (Ilex aquifolium).

Por otro lado, las niñas en el pasado engarzaban los frutos del rosal (Rosa spp.), del gamón (Asphodelus albus), de la gayuga (Arctostaphylos uva-ursi) o de la husera (Euonymus europaeus) para elaborar collares $y$ adornos personales.

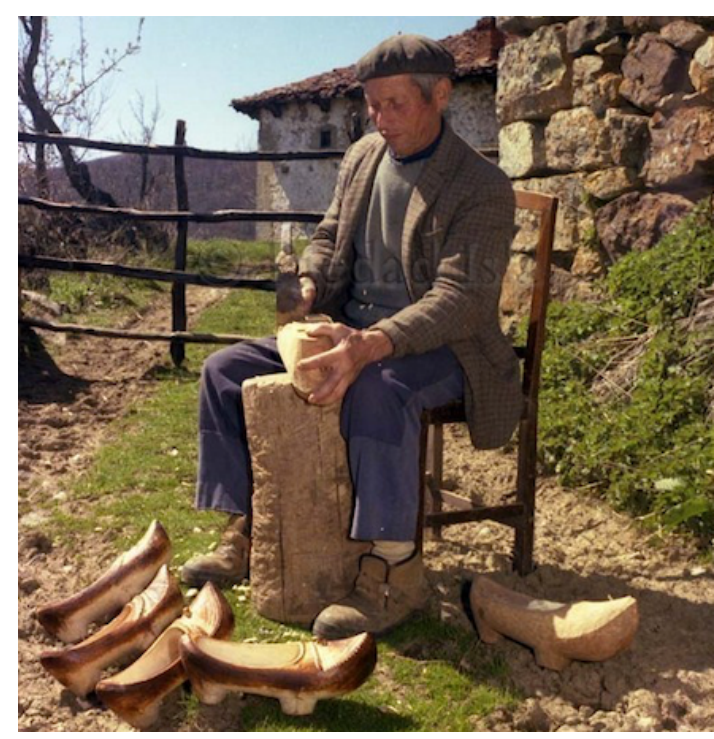

FiguRA 60: Elaboración tradicional de albarcas (Años 80). Foto: Piedad Isla.

\section{Otros usos industriales:}

Se han recogido 2 registros de uso, correspondientes a 2 taxones de obtención silvestre, de la familia Fagaceae, representando un $0,17 \%$ del total de registros de uso para la categoría Industria y Artesanía.

TABLA 87: Relación de especies empleadas en la subcategoría Otros usos industriales, ordenadas alfabéticamente por familia, indicando número de registros de uso (RU), parte usada y empleo.

\begin{tabular}{lllll}
\hline Familia & $\begin{array}{l}\text { Nombre cientifico } \\
\text { Nombre vulgar }\end{array}$ & RU & Parte usada & Empleo \\
\hline Fagaceae & $\begin{array}{l}\text { Fagus sylvatica } \\
\text { Haya }\end{array}$ & 1 & Tronco y ramas & Alquitrán \\
$\begin{array}{l}\text { Quercus petraea } \\
\text { Q. pyrenaica } \\
\text { Q. robur } \\
\text { Roble, cajigo, matorro }\end{array}$ & 1 & Tronco y ramas & Alquitrán \\
\hline
\end{tabular}

Se incluyen las especies con las que se obtienen resinas, brea o alquitrán para impermeabilizar. En Velilla del Río Carrión un informante nonagenario recuerda la forma de obtener antiguamente alquitrán destinado a la impermeabilización, con madera de roble (Quercus petraea, Q. pyrenaica, Q. robur) y de haya (Fagus sylvatica) de la siguiente manera: "Al hacer carbón vegetal con leña verde de roble o haya se criaba mucho humo y en vez de echarlo a la atmósfera iba a una charca y la sustancia que quedaba era alquitrán que quedaba hirviendo. Incluso me acuerdo de un vecino que de chaval tropezó y cayo a la laguna de alquitrán, se quemo y no le quedó carne". Este uso no ha podido contrastarse en la bibliografía consultada. 


\section{USO MedioAmBIENTAL:}

En la categoría de Uso Medioambiental se incluyen las plantas o conocimientos sobre ellas, referidos al manejo y mantenimiento de ecosistemas explotados por los humanos, así como aquellas especies consideradas malas hierbas que son objeto de conocimiento y control. En la Montaña Palentina se menciona el uso de 71 taxones vegetales correspondientes a 32 familias botánicas, para los que se han recogido un total de 416 registros de uso (RU). De ellos, 62 taxones son de obtención silvestre y 9 cultivados. Los taxones con mayor número de registros de uso en la categoría Uso Medioambiental se representan en la figura 61.

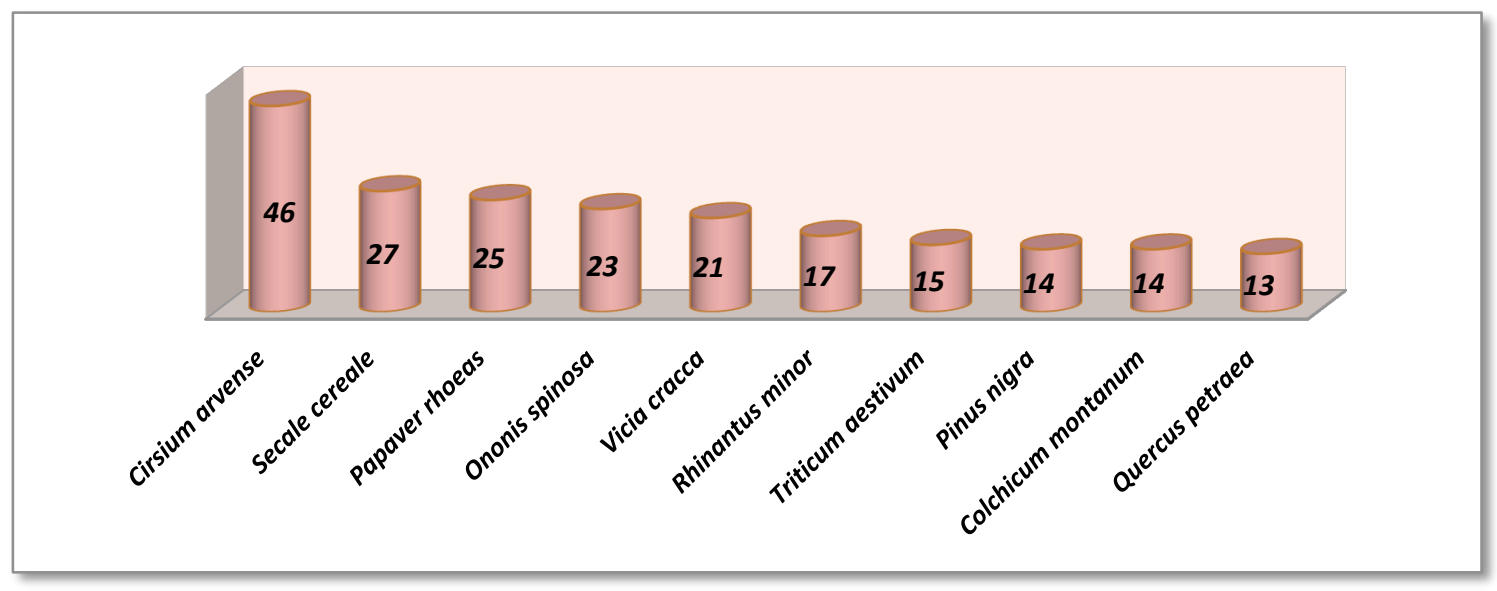

FIGURA 61: Especies con mayor número de registros de uso de carácter Medioambiental.

Las familias con mayor representación en cuanto a número de especies fueron: Compositae, Poaceae y Rosaceae, con 12, 11 y 6 especies respectivamente, según se señala en la figura 62.

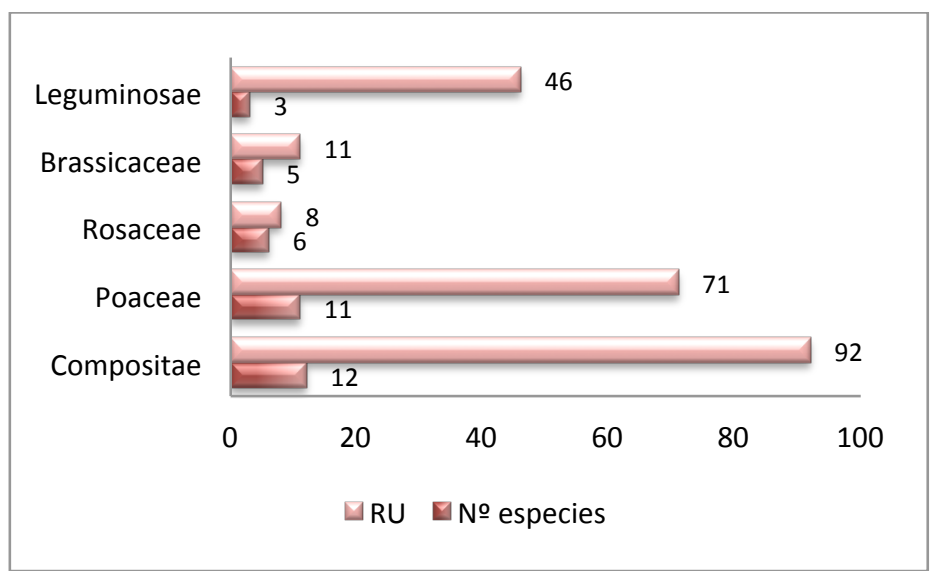

FIGURA 62: Familias de utilidad Medioambiental con mayor representación de especies y número de registros de uso (RU).

Las familia más destacada en esta categoría en cuanto a número de registros de uso es Compositae alcanzando 92 registros, seguida de Poaceae con 71, ambas familias representadas por especies herbáceas susceptibles de ser manejadas y controladas como malas hierbas en los cultivos.

Los usos se han agrupado en subcategorías siguiendo los criterios establecidos en el Inventario Español de los Conocimientos Tradicionales relativos a la Biodiversidad (Pardo de Santayana et al., 2014), obteniendo referencias en las 7 subcategorías indicadas en la tabla 88: 
TABLA 88: Subcategorías con representación en la categoría Uso Medioambiental.

\begin{tabular}{l}
\hline Subcategorías : \\
\hline Mejora del suelo \\
\hline Setos y cortavientos \\
\hline Sombra y protección \\
Injerto \\
\hline Malas hierbas \\
Bioindicadores \\
\hline Predicción del tiempo \\
\hline
\end{tabular}

Los 416 registros de uso obtenidos, en la categoría Uso Medioambiental, se reparten en 7 subcategorías tal y como señala la figura 63 , resultando que Malas hierbas es la que recibió el mayor número de registros con 285 , un $68,51 \%$ del total en esta categoría, seguido de Mejora del suelo con 88 , un $21,15 \%$, y Bioindicadores con 30 , un $7,21 \%$.

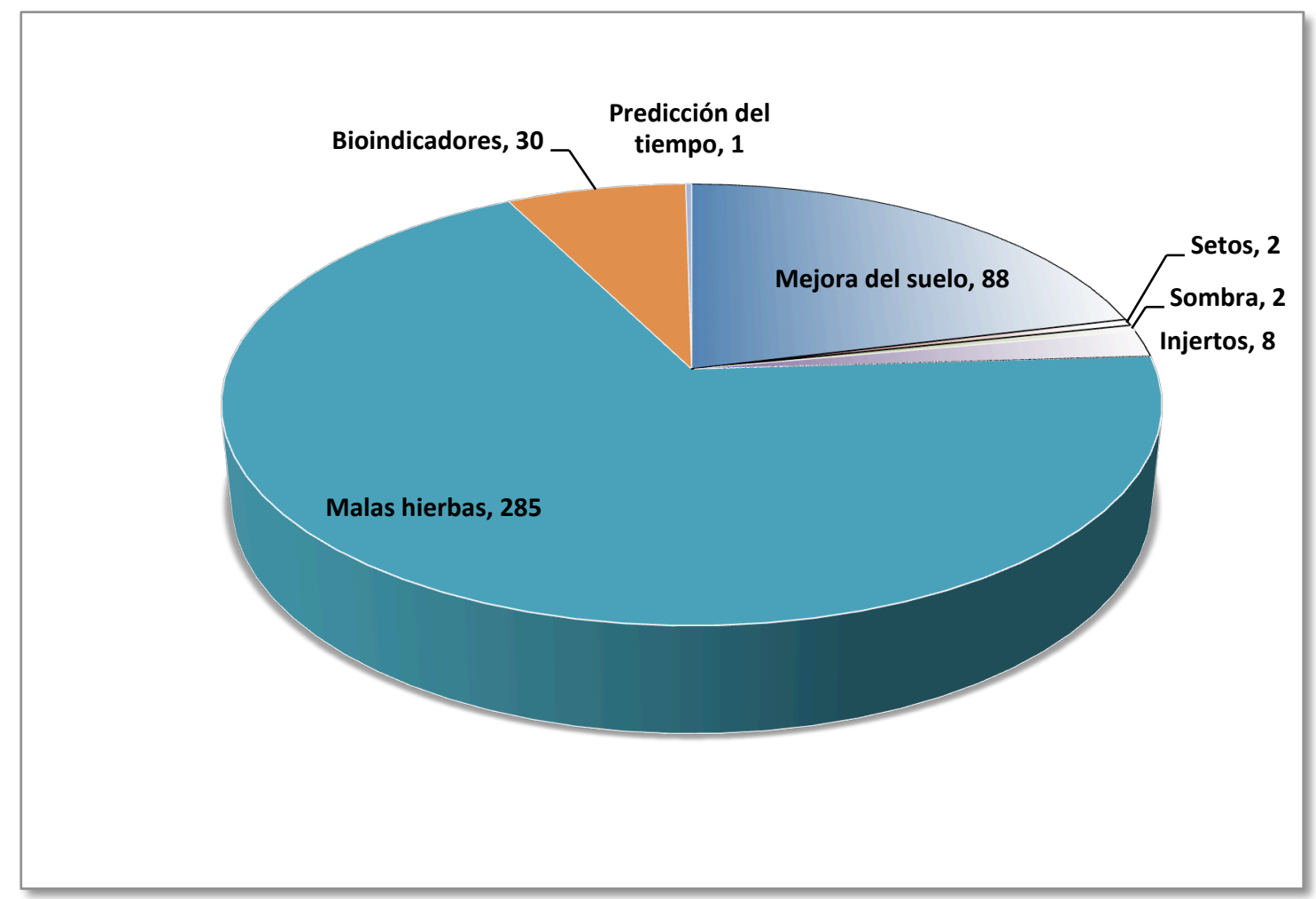

FIGURA 63: Registros de Uso (RU) de las subcategorías representadas en Uso Medioambiental.

A continuación se presentan las utilidades agrupadas por subcategorías de Uso Medioambiental, señalando los taxones que han obtenido citas en los mismos, el número de registros de uso de cada taxón, la parte usada y el empleo. 


\section{Mejora del suelo:}

Se han recogido 88 registros de uso, correspondientes a 12 taxones de 8 familias botánicas diferentes, 6 taxones de obtención silvestre y 6 cultivados, representando un 21,15\% del total de registros de uso para la categoría Uso Medioambiental.

TABLA 89: Relación de taxones empleados en la subcategoría Mejora del suelo, ordenados alfabéticamente por familia, indicando número de registros de uso (RU), parte usada y empleo.

\begin{tabular}{|c|c|c|c|c|}
\hline Familia & $\begin{array}{l}\text { Nombre científico } \\
\text { Nombre vulgar }\end{array}$ & RU & Parte usada & Empleo \\
\hline Apiaceae & $\begin{array}{l}\text { Conium maculatum } \\
\text { Budaño, cañiguerra, canuto }\end{array}$ & 1 & Parte aérea & $\begin{array}{l}\text { Cama ganado } \\
\text { Vacuno y porcino }\end{array}$ \\
\hline Dennstaedtiaceae & $\begin{array}{l}\text { Pteridium aquilinum } \\
\text { Helecho, halecho }\end{array}$ & 10 & Frondes & $\begin{array}{c}\text { Cama ganado } \\
\text { Vacuno y porcino }\end{array}$ \\
\hline Ericaceae & $\begin{array}{l}\text { Erica spp. } \\
\text { Brezo, urz, ayuz, graspo }\end{array}$ & 2 & Parte aérea & $\begin{array}{c}\text { Cama ganado } \\
\text { Vacuno y porcino }\end{array}$ \\
\hline Fagaceae & $\begin{array}{l}\text { Quercus petraea } \\
\text { Q. pyrenaica } \\
\text { Q. robur } \\
\text { Roble, cajigo, matorro }\end{array}$ & 9 & Hojas & $\begin{array}{l}\text { Cama ganado } \\
\text { Vacuno y porcino }\end{array}$ \\
\hline \multirow[t]{2}{*}{ Lamiaceae } & $\begin{array}{l}\text { Thymus mastichina } \\
\text { Tomillo, mejorara }\end{array}$ & 1 & Parte aérea & $\begin{array}{l}\text { Cama ganado } \\
\text { Palomas }\end{array}$ \\
\hline & $\begin{array}{l}\text { Thymus zygis } \\
\text { Tomillo, cepico }\end{array}$ & 1 & Parte aérea & $\begin{array}{l}\text { Cama ganado } \\
\text { Palomas }\end{array}$ \\
\hline Pinaceae & $\begin{array}{l}\text { Pinus nigra } \\
\text { P. sylvestris } \\
\text { Pino }\end{array}$ & 14 & Árbol & Repoblación \\
\hline \multirow[t]{3}{*}{ Poaceae } & $\begin{array}{l}\text { Hordeum vulgare } \\
\text { Cebada, ladilla, comuña }\end{array}$ & 2 & Paja & $\begin{array}{c}\text { Cama ganado } \\
\text { Vacuno, ovino y porcino }\end{array}$ \\
\hline & $\begin{array}{l}\text { Secale cereale } \\
\text { Centeno, sirvendo, servendo }\end{array}$ & 27 & Paja & $\begin{array}{c}\text { Cama ganado } \\
\text { Vacuno, ovino y porcino }\end{array}$ \\
\hline & $\begin{array}{l}\text { Triticum aestivum } \\
\text { Trigo, mesino, tremesino }\end{array}$ & 15 & Paja & $\begin{array}{c}\text { Cama ganado } \\
\text { Vacuno, ovino y porcino }\end{array}$ \\
\hline \multirow[t]{2}{*}{ Salicaceae } & $\begin{array}{l}\text { Populus alba } \\
\text { P. nigra } \\
\text { Chopo }\end{array}$ & 5 & Hojas & $\begin{array}{l}\text { Cama ganado } \\
\text { Porcino }\end{array}$ \\
\hline & $\begin{array}{l}\text { Populus tremula } \\
\text { Álamo }\end{array}$ & 1 & Hojas & $\begin{array}{l}\text { Cama ganado } \\
\text { Porcino }\end{array}$ \\
\hline
\end{tabular}

En la presente subcategoría se mencionan plantas para abonar o hacer abono, plantas empleadas como cama para animales domésticos y que posteriormente se aprovechan como abono, así como las plantas para proteger el suelo.

Para preparar la cama del ganado ovino, porcino o vacuno, destaca la paja de los cereales cultivados en la zona: el centeno (Secale cereale), el trigo (Triticum aestivum) o la cebada (Hordeum vulgare), una vez trillada la paja se emplea para absorber los excrementos y mantener limpio el establo. Cuando se retiran los excrementos se amontonan en el abonero (mudadal) hasta el momento de extenderlos por las tierras o praderas para mejorar su fertilidad.

Las hojas de roble (Quercus petraea, Q. pyrenaica, Q. robur), de chopo (Populus alba, P. nigra) y las frondes de los helechos (Pteridium aquilinum) sustituyen a la paja de cereal como acolchado del ganado vacuno y porcino. Los helechos también han servido como cama de ganado en El Caurel (Blanco, 1996), Urdaibai (Meaza et al., 2004), La Gomera (Perera López, 2005), La Coruña (Latorre, 2008) o La Mancha (Consuegra, 2009). 
En el caso de los nidos de las palomas, encamaban con ramas de tomillo (Thymus mastichina, T. zygis), idóneas además por su propiedad repelente de parásitos. Todas ellas una vez pisoteadas y mezcladas con los excrementos forman un abono excelente con destino a esparcir en prados de siega, huertos o cultivos.

En varias zonas de la Montaña Palentina se hicieron repoblaciones forestales en la segunda mitad del siglo $\mathrm{XX}$, principalmente con pino (Pinus nigra y $P$. sylvestris) en terrenos poco productivos o de gran pendiente.

\section{Setos y cortavientos:}

Se han recogido 2 registros de uso, correspondientes a 1 taxón de la familia Araliaceae, representando un $0,48 \%$ del total de registros de uso para la categoría Uso Medioambiental.

TABLA 90: Relación de especies empleadas en la subcategoría Setos y cortavientos, indicando familia, número de registros de uso (RU), parte usada y empleo.

\begin{tabular}{llccc}
\hline Familia & $\begin{array}{l}\text { Nombre científico } \\
\text { Nombre vulgar }\end{array}$ & RU & Parte usada & Empleo \\
\hline Araliaceae & $\begin{array}{l}\text { Hedera helix } \\
\text { Hiedra, yedra, enredadera }\end{array}$ & 2 & Planta & Seto \\
\hline
\end{tabular}

Se incluyen las especies utilizadas como setos vivos para separar fincas, impedir el paso del ganado o proteger los cultivos más sensibles en los huertos.

La especie empleada en la comarca como seto vivo es la hiedra (Hedera helix), plantada en muretes para darles más consistencia o como barrera divisoria entre fincas, aprovechando su rápido desarrollo y defoliación tardía. El mismo uso se documenta en la comarca de Campoo, donde se deja crecer en los muros de piedra para darles resistencia (Pardo de Santayana, 2008).

\section{Sombra y protección:}

Se han recogido 2 registros de uso, correspondientes a 1 taxón de la familia Vitaceae, representando un $0,48 \%$ del total de registros de uso para la categoría Uso Medioambiental.

TABLA 91: Relación de especies empleadas en la subcategoría Sombra y protección, indicando familia, número de registros de uso (RU), parte usada y empleo.

\begin{tabular}{llccc}
\hline Familia & $\begin{array}{l}\text { Nombre científico } \\
\text { Nombre vulgar }\end{array}$ & RU & Parte usada & Empleo \\
\hline Vitaceae & $\begin{array}{l}\text { Vitis vinifera } \\
\text { Parra }\end{array}$ & 2 & Planta & Sombra \\
\hline
\end{tabular}

La subcategoría "Sombra y protección" agrupa a las especies empleadas para proteger al ganado, los cultivos a las personas del sol y el frío.

En la comarca se han observado parras (Vitis vinifera) en las fachadas de las viviendas de muchos patios, dos informantes señalaron su utilidad como sombreo durante los días más calurosos del verano. Este uso es muy común en la cercana comarca del Cerrato Palentino (Pascual et al., 2016). 


\section{Injerto:}

Se han recogido 8 registros de uso, correspondientes a 6 taxones de la familia Rosaceae, 4 taxones de obtención silvestre y 2 cultivados, representando un 1,92\% del total de registros de uso para la categoría Uso Medioambiental.

TABLA 92: Relación de especies empleadas en la subcategoría Injerto, ordenados alfabéticamente por familia, indicando número de registros de uso (RU), parte usada y empleo.

\begin{tabular}{|c|c|c|c|c|}
\hline Familia & $\begin{array}{l}\text { Nombre científico } \\
\text { Nombre vulgar }\end{array}$ & RU & Parte usada & Empleo \\
\hline \multirow[t]{6}{*}{ Rosaceae } & $\begin{array}{l}\text { Crataegus monogyna } \\
\text { Espino, espino albar, majueto }\end{array}$ & 1 & Árbol & $\begin{array}{l}\text { Patrón injerto } \\
\text { Pera }\end{array}$ \\
\hline & $\begin{array}{l}\text { Malus domestica } \\
\text { Manzano }\end{array}$ & 1 & Árbol & $\begin{array}{l}\text { Patrón injerto } \\
\text { Manzana y pera }\end{array}$ \\
\hline & $\begin{array}{l}\text { Malus sylvestris } \\
\text { Maíllo, amaíllo, maello, amaello }\end{array}$ & 2 & Árbol & $\begin{array}{l}\text { Patrón injerto } \\
\text { Manzana y pera }\end{array}$ \\
\hline & $\begin{array}{l}\text { Prunus domestica } \\
\text { Ciruelo, mijuelo, pruno }\end{array}$ & 1 & Árbol & $\begin{array}{l}\text { Patrón injerto } \\
\text { Ciruela }\end{array}$ \\
\hline & $\begin{array}{l}\text { Sorbus aria } \\
\text { Mostajo, amostajo }\end{array}$ & 1 & Árbol & $\begin{array}{l}\text { Patrón injerto } \\
\text { Manzana }\end{array}$ \\
\hline & $\begin{array}{l}\text { Sorbus aucuparia } \\
\text { Amargoso, serbal, drío, drido }\end{array}$ & 2 & Árbol & $\begin{array}{l}\text { Patrón injerto } \\
\text { Manzana }\end{array}$ \\
\hline
\end{tabular}

Contenidas aquellas especies útiles como portainjertos o patrones de injerto, observando como todas las especies de esta subcategoría pertenecen a la familia Rosaceae.

En el huerto tradicional de la comarca suele haber un espacio reservado a los frutales, sobre los que en ocasiones, se realizaban diferentes técnicas de injerto. Existen varias especies indicadas como patrón portainjerto por su mejor adaptación y resistencia a las condiciones meteorológicas, sobresalen el maíllo (Malus sylvestris) y el espino albar (Crataegus monogyna), sobre los que se injertaban variedades de manzana o pera, mejor adaptadas a las condiciones climáticas de la zona. El mostajo (Sorbus aria) y el amargoso (Sorbus aucuparia) son especies tolerantes a los rigores climáticos y poco exigentes a nivel edáfico, por lo que se adaptan bien a los suelos poco fértiles de la zona. Esta interacción con el terreno es conocida, señalándose la idoneidad de estas especies como patrones de manzanos. Se ha documentado también el empleo ocasional del mostajo como patrón para injertar manzana en la Sierra Norte de Madrid (Aceituno Mata, 2010). La mejora de variedades de ciruela se realizaba sobre patrones de ciruelo (Prunus domestica).

\section{Malas hierbas:}

Se han recogido 285 registros de uso, correspondientes a 52 taxones de obtención silvestre, de 24 familias botánicas diferentes, representando un $68,51 \%$ del total de registros de uso para la categoría Uso Medioambiental. 
TABLA 93: Relación de especies empleadas en la subcategoría Malas hierbas, ordenadas alfabéticamente por familia, indicando número de registros de uso (RU), parte usada y hábitat.

\begin{tabular}{|c|c|c|c|c|}
\hline Familia & $\begin{array}{l}\text { Nombre científico } \\
\text { Nombre vulgar }\end{array}$ & RU & Parte usada & Hábitat \\
\hline Adoxaceae & $\begin{array}{l}\text { Sambucus ebulus } \\
\text { Nuezgo, yezgo }\end{array}$ & 1 & Planta & $\begin{array}{c}\text { Huerta } \\
\text { Tierras de cultivo }\end{array}$ \\
\hline Amaranthaceae & $\begin{array}{l}\text { Chenopodium album } \\
\text { Ramagón, sallo, ceñilgo }\end{array}$ & 10 & Planta & $\begin{array}{c}\text { Huerta } \\
\text { Tierras de cultivo }\end{array}$ \\
\hline \multirow[t]{2}{*}{ Apiaceae } & $\begin{array}{l}\text { Caucalis platycarpos } \\
\text { Cadillo }\end{array}$ & 6 & Planta & Tierras de cultivo \\
\hline & $\begin{array}{l}\text { Conium maculatum } \\
\text { Budaño, cañiguerra, canuto }\end{array}$ & 1 & Planta & Huerta \\
\hline Araliaceae & $\begin{array}{l}\text { Hedera helix } \\
\text { Hiedra, yedra, enredadera }\end{array}$ & 1 & Planta & Invasora frutales \\
\hline \multirow[t]{5}{*}{ Brassicaceae } & $\begin{array}{l}\text { Barbarea intermedia } \\
\text { Naviza }\end{array}$ & 1 & Planta & $\begin{array}{c}\text { Huerta } \\
\text { Tierras de cultivo }\end{array}$ \\
\hline & $\begin{array}{l}\text { Brassica nigra } \\
\text { Gébene }\end{array}$ & 3 & Planta & Tierras de cultivo \\
\hline & $\begin{array}{l}\text { Hirschfeldia incana } \\
\text { Gébene }\end{array}$ & 1 & Planta & Tierras de cultivo \\
\hline & $\begin{array}{l}\text { Lepidium campestre } \\
\text { Rábano }\end{array}$ & 1 & Planta & Tierras de cultivo \\
\hline & $\begin{array}{l}\text { Sinapis arvensis } \\
\text { Gébene }\end{array}$ & 5 & Planta & Tierras de cultivo \\
\hline \multirow[t]{2}{*}{ Caryophyllaceae } & $\begin{array}{l}\text { Agrostemma githago } \\
\text { Neguilla, neguillón, clavel }\end{array}$ & 5 & Semillas & Tierras de cultivo \\
\hline & $\begin{array}{l}\text { Stellaria media } \\
\text { Paulina, pamplina }\end{array}$ & 3 & Planta & Huerta \\
\hline \multirow[t]{13}{*}{ Compositae } & $\begin{array}{l}\text { Anthemis arvensis } \\
\text { Margarita, manzanilla, lirada }\end{array}$ & 7 & Planta & Tierras de cultivo \\
\hline & $\begin{array}{l}\text { Carduus crispus } \\
\text { Cardo, cardo negrero }\end{array}$ & 5 & Planta & Tierras de cultivo \\
\hline & $\begin{array}{l}\text { Centaurea scabiosa } \\
\text { Amapera, humarra }\end{array}$ & 4 & Planta & Tierras de cultivo \\
\hline & $\begin{array}{l}\text { Cirsium arvense } \\
\text { C. vulgare } \\
\text { Cardo, cardo negrero }\end{array}$ & 46 & Planta & Tierras de cultivo \\
\hline & $\begin{array}{l}\text { Cirsium eriophorum } \\
\text { Cardo, cardo burriquero }\end{array}$ & 3 & Planta & Prados \\
\hline & $\begin{array}{l}\text { Cyanus segetum } \\
\text { Azulina, clavel, azulejo }\end{array}$ & 1 & Planta & Tierras de cultivo \\
\hline & $\begin{array}{l}\text { Jacobaea vulgaris } \\
\text { Bujanera, hierba del gusano }\end{array}$ & 2 & Planta & Prados \\
\hline & $\begin{array}{l}\text { Lactuca serriola } \\
\text { Lecherín, cardo lecherín }\end{array}$ & 1 & Planta & Huerta \\
\hline & $\begin{array}{l}\text { Matricaria discoidea } \\
\text { Lirada, manzanillón, margarita }\end{array}$ & 3 & Planta & Tierras de cultivo \\
\hline & $\begin{array}{l}\text { Onopordum acanthium } \\
\text { Cardo borriquero, toba }\end{array}$ & 2 & Planta & Tierras de cultivo \\
\hline & $\begin{array}{l}\text { Sonchus asper } \\
\text { Cardo lecherín }\end{array}$ & 2 & Planta & Tierras de cultivo \\
\hline & $\begin{array}{l}\text { Sonchus oleraceus } \\
\text { Cardo lecherín, lecherín }\end{array}$ & 11 & Planta & $\begin{array}{c}\text { Huerta } \\
\text { Tierras de cultivo }\end{array}$ \\
\hline & $\begin{array}{l}\text { Taraxacum campylodes } \\
\text { Achicoria, diente de león }\end{array}$ & 5 & Planta & $\begin{array}{c}\text { Huerta } \\
\text { Tierras de cultivo }\end{array}$ \\
\hline Convolvulaceae & $\begin{array}{l}\text { Convolvulus arvensis } \\
\text { Correyuela, corrigüela }\end{array}$ & 10 & Planta & $\begin{array}{c}\text { Huerta } \\
\text { Tierras de cultivo }\end{array}$ \\
\hline Cucurbitaceae & $\begin{array}{l}\text { Bryonia cretica } \\
\text { Uva de perro, nueza, enredadera }\end{array}$ & 1 & Planta & Tierras de cultivo \\
\hline
\end{tabular}




\begin{tabular}{|c|c|c|c|c|}
\hline Familia & $\begin{array}{l}\text { Nombre científico } \\
\text { Nombre vulgar }\end{array}$ & RU & Parte usada & Hábitat \\
\hline Cupressaceae & $\begin{array}{l}\text { Juniperus sabina } \\
\text { Corveño }\end{array}$ & 1 & Planta & Prados \\
\hline Dennstaedtiaceae & $\begin{array}{l}\text { Pteridium aquilinum } \\
\text { Helecho, halecho }\end{array}$ & 2 & Planta & $\begin{array}{c}\text { Prados } \\
\text { Tierras de cultivo }\end{array}$ \\
\hline Equisetaceae & $\begin{array}{l}\text { Equisetum arvense } \\
\text { Cola de caballo, pinillo, escobilla }\end{array}$ & 6 & Planta & $\begin{array}{c}\text { Huerta } \\
\text { Tierras de cultivo }\end{array}$ \\
\hline \multirow[t]{3}{*}{ Leguminosae } & $\begin{array}{l}\text { Cytisus scoparius } \\
\text { Escoba, ramo, escoba balera }\end{array}$ & 1 & Planta & Prados \\
\hline & $\begin{array}{l}\text { Ononis spinosa } \\
\text { Gatuña }\end{array}$ & 22 & Planta & $\begin{array}{l}\text { Prados } \\
\text { Tierras de cultivo }\end{array}$ \\
\hline & $\begin{array}{l}\text { Vicia cracca } \\
\text { V. pannonica } \\
\text { Arvejana }\end{array}$ & 21 & Planta & Tierras de cultivo \\
\hline Malvaceae & $\begin{array}{l}\text { Malva sylvestris } \\
\text { Malva, flor de malva }\end{array}$ & 3 & Planta & $\begin{array}{c}\text { Huerta } \\
\text { Tierras de cultivo }\end{array}$ \\
\hline \multirow[t]{2}{*}{ Orobanchaceae } & $\begin{array}{l}\text { Bellardia trixago } \\
\text { Cencerrada }\end{array}$ & 1 & Planta & Prados \\
\hline & $\begin{array}{l}\text { Rhinanthus minor } \\
\text { Cencerrada, encantadera }\end{array}$ & 16 & Planta & Prados \\
\hline Oxalidaceae & Oxalis pes-caprae & 2 & Planta & Huerta \\
\hline Papaveraceae & $\begin{array}{l}\text { Papaver rhoeas } \\
\text { Amapola, pirigallo }\end{array}$ & 25 & Planta & Tierras de cultivo \\
\hline Plantaginaceae & $\begin{array}{l}\text { Plantago lanceolata } \\
\text { Hoja de lentén, llantén, lentel }\end{array}$ & 1 & Planta & Prados \\
\hline \multirow[t]{8}{*}{ Poaceae } & $\begin{array}{l}\text { Arrhenatherum elatius } \\
\text { Grama }\end{array}$ & 1 & Planta & Tierras de cultivo \\
\hline & $\begin{array}{l}\text { Avena fatua } \\
\text { A. sterilis } \\
\text { Avena loca, hierba loca }\end{array}$ & 2 & Planta & Tierras de cultivo \\
\hline & $\begin{array}{l}\text { Brachypodium phoenicoides } \\
\text { Hierba perruna }\end{array}$ & 1 & Planta & Prados \\
\hline & $\begin{array}{l}\text { Cynodon dactylon } \\
\text { Grama, hierba de la grama }\end{array}$ & 12 & Planta & $\begin{array}{c}\text { Huerta } \\
\text { Tierras de cultivo }\end{array}$ \\
\hline & $\begin{array}{l}\text { Dactylis glomerata } \\
\text { Grama }\end{array}$ & 1 & Planta & Tierras de cultivo \\
\hline & $\begin{array}{l}\text { Elymus repens } \\
\text { Grama }\end{array}$ & 1 & Planta & Tierras de cultivo \\
\hline & $\begin{array}{l}\text { Lolium multiflorum } \\
\text { Grama }\end{array}$ & 1 & Planta & Tierras de cultivo \\
\hline & $\begin{array}{l}\text { Lolium perenne } \\
\text { Vallico, valluco, avallico }\end{array}$ & 8 & Planta & Tierras de cultivo \\
\hline Polygonaceae & $\begin{array}{l}\text { Rumex crispus } \\
\text { Amargaza, acerón, ramagón }\end{array}$ & 3 & Planta & Prados \\
\hline Ranunculaceae & $\begin{array}{l}\text { Ranunculus arvensis } \\
\text { Cadillo }\end{array}$ & 2 & Planta & Tierras de cultivo \\
\hline Rubiaceae & $\begin{array}{l}\text { Galium aparine } \\
\text { Pegamanos, ensayo, lapa }\end{array}$ & 6 & Planta & Huerta \\
\hline Santalaceae & $\begin{array}{l}\text { Viscum album } \\
\text { Muérdago, maraojo, mingojo }\end{array}$ & 1 & Planta & Invasora frutales \\
\hline Xanthorrhoeaceae & $\begin{array}{l}\text { Asphodelus albus } \\
\text { Gamón, gamonita }\end{array}$ & 4 & Planta & Prados \\
\hline
\end{tabular}


La subcategoría Malas hierbas agrupa las malezas de los cultivos y las malas hierbas de los prados que son objeto de conocimiento, control y manejo.

Gran importancia tiene la escarda o eliminación de malas hierbas en los cultivos, en el pasado esta práctica agrícola era realizada a mano, por lo que se temía especialmente a la gatuña (Ononis spinosa) y al cardo (Cirsium arvense, C. vulgare) por su carácter espinoso. También se cuidaba de que las semillas de la neguilla (Agrostemma githago) no se mezclaran con las de trigo ya que inutilizaban la harina.

Otras especies citadas con frecuencia en este apartado y que además servían como forraje o sallo para el ganado fueron: amapola (Papaver rhoeas), arvejana (Vicia cracca, V. pannonica), cardo lecherín (Sonchus oleraceus), ceñilgo (Chenopodium album), correyuela (Convolvulus arvensis), lapa (Galium aparine), lirada (Anthemis arvensis, Matricaria discoidea) y paulina (Stellaria media).

Con cierto odio se menciona a especies difíciles de erradicar como grama (Arrhenaterum elatius, Cynodon dactylon, Dactylis glomerata, Elymus repens, Lolium multiflorum), vallico (Lolium perenne), pinillo (Equisetum arvense), gébene (Brassica nigra, Hirschfeldia incana, Sinapis arvensis) o cadillo (Caucalis platycarpos, Ranunculus arvensis), aunque son hasta 52 los taxones considerados malas hierbas.

Se menciona a la hiedra (Hedera helix) por su carácter invasor ya que consigue ahogar a las especies sobre las que se sustenta, vigilando que no abrazara los frutales de los huertos, también el muérdago (Viscum album) que provocaba el secado de los mismos. En la provincia de Asturias se considera una plaga que infecta el manzanal terminando por secarlos (Lastra, 2003).

\section{Bioindicadores:}

Se han recogido 30 registros de uso, correspondientes a 6 taxones de obtención silvestre, de 6 familias botánicas diferentes, representando un $7,21 \%$ del total de registros de uso para la categoría Uso Medioambiental.

TABLA 94: Relación de especies empleadas en la subcategoría Bioindicadores, ordenadas alfabéticamente por familia, indicando número de registros de uso (RU), parte usada e indicador.

\begin{tabular}{llccc}
\hline Familia & $\begin{array}{l}\text { Nombre científico } \\
\text { Nombre vulgar }\end{array}$ & RU & Parte usada & Indicador \\
\hline Apiaceae & $\begin{array}{l}\text { Eryngium campestre } \\
\text { Cardo, cardo borriquero }\end{array}$ & 9 & Planta & Setas \\
\hline Colchicaceae & $\begin{array}{l}\text { Colchicum montanum } \\
\text { Quitameriendas, cucubilla } \\
\text { Quercus petraea } \\
\text { Q. pyrenaica } \\
\text { Q. robur } \\
\text { Roble, cajigo, matorro }\end{array}$ & 14 & Planta & Estación \\
\hline Lnonis spinosa & 4 & Planta & Hongo yesquero \\
Gatuña & $\begin{array}{l}\text { Rhinanthus minor } \\
\text { Cencerrada, encantadera }\end{array}$ & 1 & Planta & Terrenos pobres \\
\hline Xsphodelus albus & 1 & Planta & Prados poca calidad \\
\hline
\end{tabular}


Dentro de esta subcategoría se reúnen las especies que indican la presencia de otras plantas, de hongos, cambios de estación, tipos de suelo, etc.

En general, el agricultor conocía la calidad de la tierra o el prado identificando determinadas especies bioindicadoras. La cencerrada (Rhinantus minor) y el gamón (Asphodelus albus) advierten de suelos pobres y pastos poco productivos, mientras que la presencia de gatuñas (Ononis spinosa) sugiere tierras de cultivo de poca calidad.

Otras especies bioindicadoras señalan la presencia de hongos, en el roble (Quercus petraea, $Q$. pyrenaica, $Q$. robur) se puede encontrar la yesca (Fomes fomentarius), y el cardo (Eryngium campestre) se asocia con la aparición de la seta de cardo (Pleurotus eryngii).

Por último, la floración del quitameriendas (Colchicum montanum), señala el acortamiento de los días y la proximidad del otoño, este uso bioindicativo es recogido por Blanco (1998) en la provincia de Segovia, y por Blanco \& Díez (2005) en la zona de Sanabria, donde testimonian que cuando florece esta planta ya no es época de merendar.

\section{Predicción del tiempo:}

Se ha recogido 1 registro de uso, correspondientes a 1 taxón de obtención silvestre, de la familia Leguminosae, representando un $0,24 \%$ del total de registros de uso para la categoría Uso Medioambiental.

TABLA 95: Relación de especies empleadas en la subcategoría Predicción del tiempo, indicando familia, número de registros de uso (RU), parte usada y empleo.

\begin{tabular}{llccc}
\hline Familia & $\begin{array}{l}\text { Nombre científico } \\
\text { Nombre vulgar }\end{array}$ & RU & Parte usada & Empleo \\
\hline Leguminosae & $\begin{array}{l}\text { Cytisus scoparius } \\
\text { Escoba, ramo, escoba balera }\end{array}$ & 1 & Flor & Nieve \\
\hline
\end{tabular}

Documentamos una interesante curiosidad en la localidad de Valsurbio, donde aseguran que la extraña e inusual presencia de algún ejemplar de escoba (Cytisus scoparius) florido en invierno, promete nevadas abundantes en el año. "Mi madre siempre decía, si en el campo encuentras una escoba florida solitaria en pleno invierno, es que va a nevar mucho. Paseando un 23 de diciembre, vi una escoba florida igual que si fuera junio y efectivamente, al mes fue la nevada grande, ésta que hubo en el 2015". No se ha encontrado referencia bibliográfica del valor predictivo del tiempo para la escoba. 


\section{USO ORNAMENTAL:}

En la categoría de Uso Ornamental se incluyen las plantas cuya función es el adorno o decoración del hogar y otros espacios como casas, patios, balcones y jardines. También árboles de sombra de calles y caminos con función ornamental. En la Montaña Palentina se menciona el uso de 141 taxones vegetales correspondientes a 61 familias botánicas, para los que se han recogido un total de 547 registros de uso (RU). De ellos, 90 taxones son de obtención silvestre y 51 cultivados. Los taxones con mayor número de registros de uso en la categoría Uso Ornamental se representan en la figura 64.

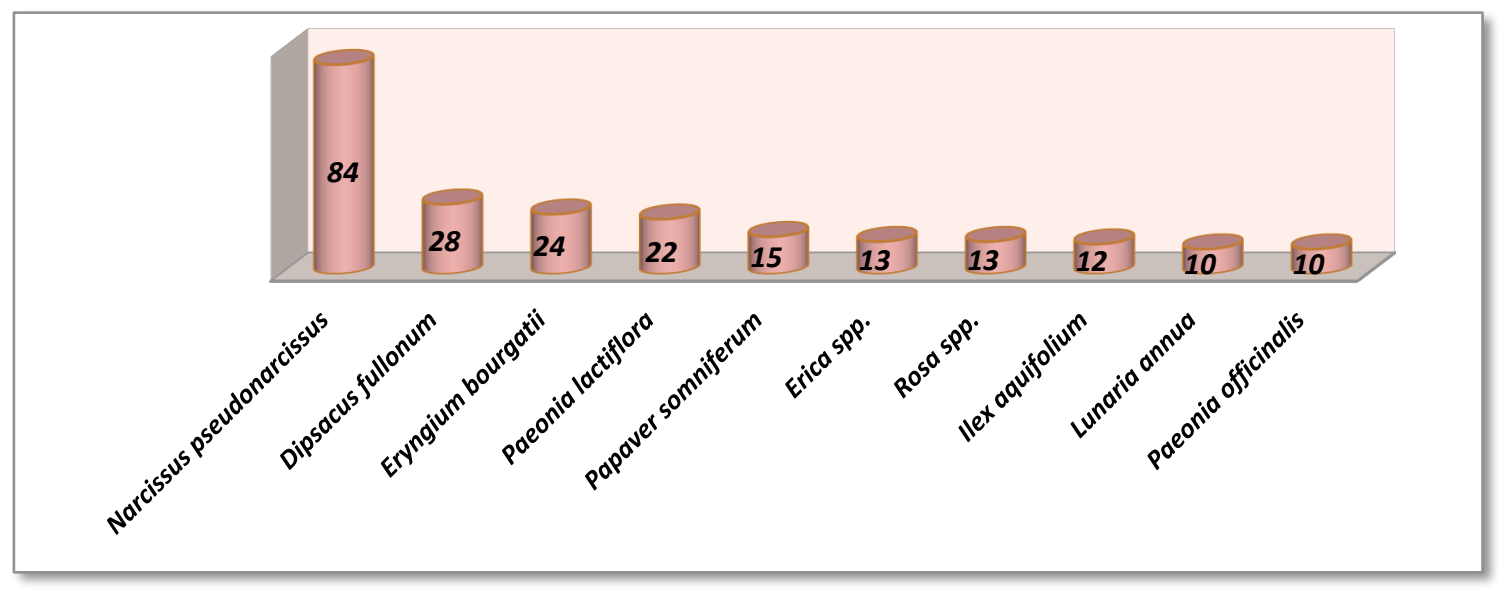

FIGURA 64: Taxones con mayor número de registros de uso empleados como Ornamental.

Las familias con mayor representación en cuanto a número de especies fueron: Compositae, Poaceae y Rosaceae, con 14, 11 y 8 especies respectivamente, según se señala en la figura 65.

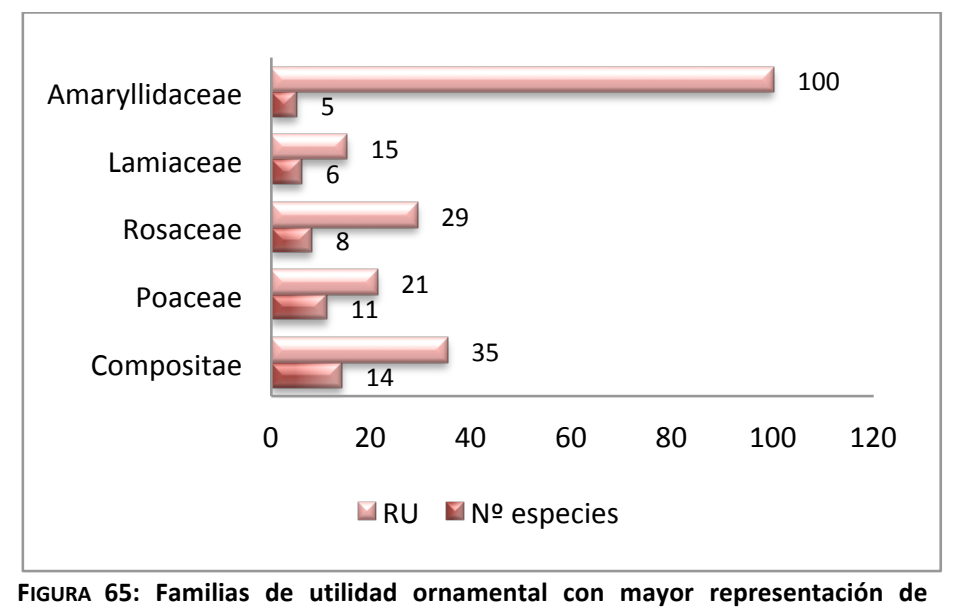
especies y número de registros de uso (RU),

La familia más destacada en esta categoría en cuanto a número de registros de uso es Amaryllidaceae con 100 registros, debido a la popularidad de los lirones (Narcissus spp.) como adorno floral tanto de exterior como de interior. Le sigue la familia Compositae con 35 registros de uso, representada por especies herbáceas como: milenrama (Achillea millefolium), margaritas (Anthemis arvensis, Matricaria discoidea, Leucanthemum maximum, Tanacetum corymbosum), maravilla (Calendula officinalis), dalia (Dahlia pinnata)..., empleadas en jardinería y en ornamentación floral de interiores. 
Los usos se han agrupado en subcategorías siguiendo los criterios establecidos en el Inventario Español de los Conocimientos Tradicionales relativos a la Biodiversidad (Pardo de Santayana et al., 2014), obteniendo referencias en las 4 subcategorías indicadas en la tabla 96.

\begin{tabular}{l} 
TABLA 96: Subcategorías con representación en la categoría \\
Uso Ornamental. \\
\hline Subcategorías : \\
\hline Patios, huertos y jardines \\
Calles y caminos \\
Adornos florales y plantas de interior \\
Otros adornos \\
\hline
\end{tabular}

Los 547 registros de uso obtenidos, en la categoría Uso Ornamental, se reparten en 4 subcategorías tal y como señala la figura 66, resultando que Adorno floral y plantas de interior es la que recibió el mayor número de registros con 374 , un $68,37 \%$ del total en esta categoría, seguido de Patios, huertos y jardines con 154 , un $28,34 \%$, y Calles y caminos con 12 , un $2,19 \%$.

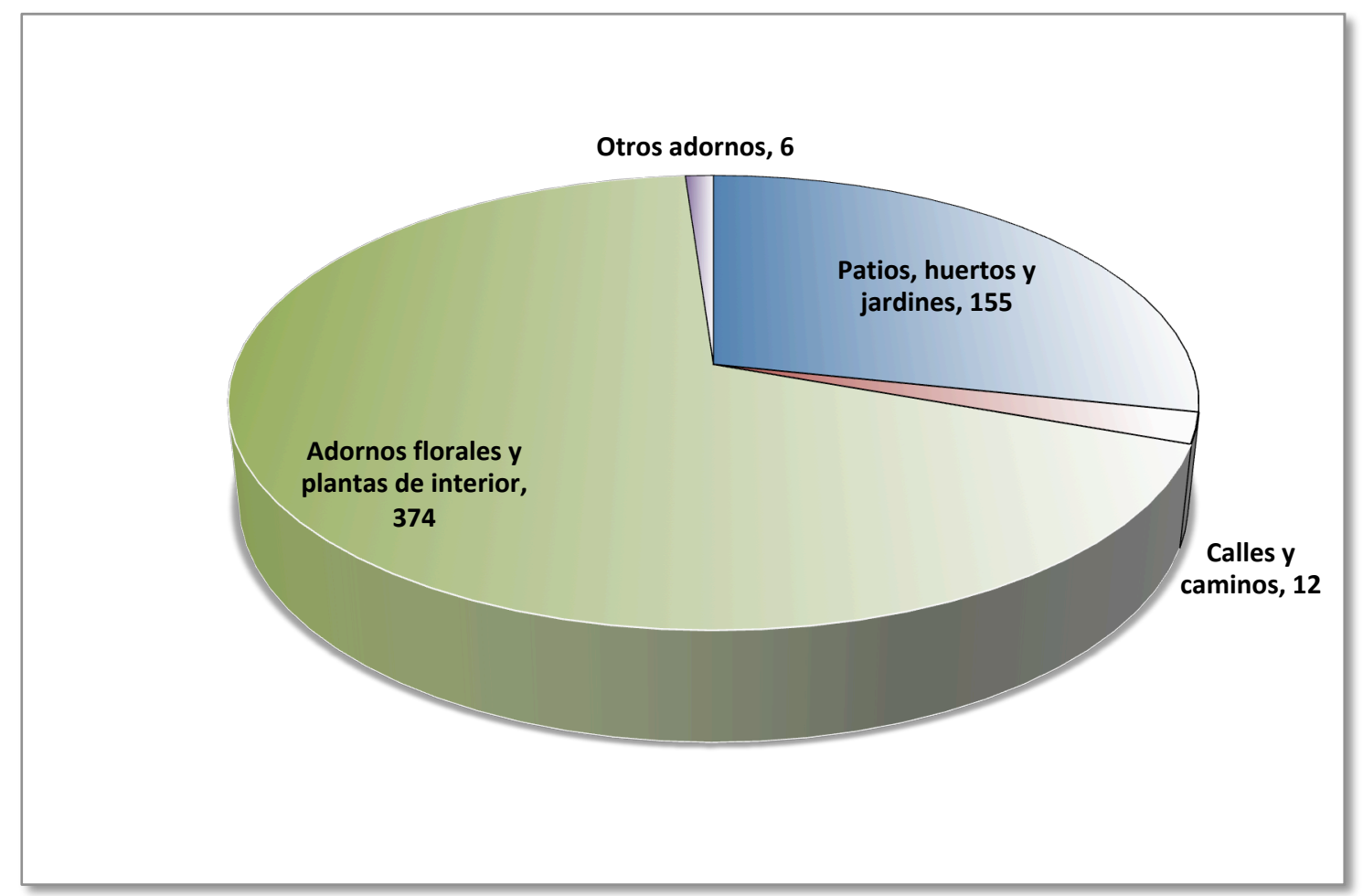

FIGURA 66: Registros de Uso (RU) de las subcategorías representadas en Uso Ornamental.

A continuación se presentan los usos agrupados por subcategorías de Uso Ornamental, señalando los taxones que han obtenido citas en los mismos, el número de registros de uso de cada taxón, la parte usada y el empleo. 


\section{Patios, huertos y jardines:}

Se han recogido 155 registros de uso, correspondientes a 57 taxones de 34 familias botánicas diferentes, 19 taxones de obtención silvestre y 38 cultivados, representando un $28,34 \%$ del total de registros de uso para la categoría Uso Ornamental.

TABLA 97: Relación de taxones empleados en la subcategoría Patios, huertos y jardines, ordenados alfabéticamente por familia, indicando número de registros de uso (RU), parte usada y empleo.

\begin{tabular}{|c|c|c|c|c|}
\hline Familia & $\begin{array}{l}\text { Nombre científico } \\
\text { Nombre vulgar }\end{array}$ & RU & Parte usada & Empleo \\
\hline Adoxaceae & $\begin{array}{l}\text { Viburnum opulus } \\
\text { Copo de nieve }\end{array}$ & 3 & Planta & Jardinería exterior \\
\hline Amaryllidaceae & $\begin{array}{l}\text { Narcissus pseudonarcissus } \\
\text { Lira, lirón, campanilla }\end{array}$ & 6 & Planta & Jardinería exterior \\
\hline Aquifoliaceae & $\begin{array}{l}\text { Ilex aquifolium } \\
\text { Acebo, aceba }\end{array}$ & 2 & Planta & Jardinería exterior \\
\hline Apocynaceae & $\begin{array}{l}\text { Vinca major } \\
\text { Judío }\end{array}$ & 1 & Planta & Jardinería exterior \\
\hline Araceae & $\begin{array}{l}\text { Dracunculus vulgaris } \\
\text { Hierba de la culebra }\end{array}$ & 2 & Planta & Jardinería exterior \\
\hline Araliaceae & $\begin{array}{l}\text { Hedera helix } \\
\text { Hiedra, yedra, enredadera }\end{array}$ & 2 & Planta & Jardinería exterior \\
\hline Bignoniaceae & $\begin{array}{l}\text { Campsis radicans } \\
\text { Enredadera }\end{array}$ & 1 & Planta & Jardinería exterior \\
\hline \multirow[t]{2}{*}{ Brassicaceae } & $\begin{array}{l}\text { Lunaria annua } \\
\text { Hoja de la plata, flor de la plata }\end{array}$ & 4 & Planta & Jardinería exterior \\
\hline & Matthiola incana & 1 & Planta & Jardinería exterior \\
\hline \multirow[t]{3}{*}{ Caprifoliaceae } & $\begin{array}{l}\text { Lonicera japonica } \\
\text { Mariselva }\end{array}$ & 1 & Planta & Jardinería exterior \\
\hline & $\begin{array}{l}\text { Symphoricarpos albus } \\
\text { Lágrimas de Judas, bola de nieve }\end{array}$ & 3 & Planta & Jardinería exterior \\
\hline & $\begin{array}{l}\text { Valeriana pyrenaica } \\
\text { Valeriana }\end{array}$ & 1 & Planta & Jardinería exterior \\
\hline \multirow[t]{2}{*}{ Caryophyllaceae } & $\begin{array}{l}\text { Dianthus caryophyllus } \\
\text { Clavel }\end{array}$ & 1 & Planta & Jardinería exterior \\
\hline & $\begin{array}{l}\text { Saponaria ocymoides } \\
\text { Jabonera de lastra }\end{array}$ & 1 & Planta & Jardinería exterior \\
\hline \multirow[t]{2}{*}{ Celastraceae } & $\begin{array}{l}\text { Euonymus europaeus } \\
\text { Husera, bonetero }\end{array}$ & 1 & Planta & Jardinería exterior \\
\hline & $\begin{array}{l}\text { Euonymus japonicus } \\
\text { Bonetero }\end{array}$ & 1 & Planta & Jardinería exterior \\
\hline \multirow[t]{5}{*}{ Compositae } & $\begin{array}{l}\text { Calendula officinalis } \\
\text { Maravilla, caléndula, clavel }\end{array}$ & 9 & Planta & Jardinería exterior \\
\hline & $\begin{array}{l}\text { Dahlia pinnata } \\
\text { Dalia }\end{array}$ & 2 & Planta & Jardinería exterior \\
\hline & $\begin{array}{l}\text { Leucanthemum maximum } \\
\text { Margarita }\end{array}$ & 1 & Planta & Jardinería exterior \\
\hline & Tagetes erecta & 1 & Planta & Jardinería exterior \\
\hline & $\begin{array}{l}\text { Tanacetum parthenium } \\
\text { Margarita }\end{array}$ & 2 & Planta & Jardinería exterior \\
\hline Crassulaceae & $\begin{array}{l}\text { Sempervivum vicentei } \\
\text { Siempreviva, suelda, sanalotodo }\end{array}$ & 8 & Planta & Jardinería exterior \\
\hline Cupressaceae & Chamaecyparis lawsoniana & 1 & Planta & Jardinería exterior \\
\hline Dryopteridaceae & $\begin{array}{l}\text { Dryopteris affinis } \\
\text { Helecha, helecho }\end{array}$ & 1 & Planta & Jardinería exterior \\
\hline
\end{tabular}




\begin{tabular}{|c|c|c|c|c|}
\hline Familia & $\begin{array}{l}\text { Nombre científico } \\
\text { Nombre vulgar }\end{array}$ & RU & Parte usada & Empleo \\
\hline \multirow[t]{2}{*}{ Hydrangeaceae } & $\begin{array}{l}\text { Hydrangea macrophylla } \\
\text { Hortensia }\end{array}$ & 2 & Planta & Jardinería exterior \\
\hline & $\begin{array}{l}\text { Philadelphus coronarius } \\
\text { Ramo de azahar }\end{array}$ & 1 & Planta & Jardinería exterior \\
\hline \multirow[t]{2}{*}{ Iridaceae } & $\begin{array}{l}\text { Gladiolus communis } \\
\text { Gladiolo }\end{array}$ & 2 & Planta & Jardinería exterior \\
\hline & $\begin{array}{l}\text { Iris x germanica } \\
\text { Lirio }\end{array}$ & 3 & Planta & Jardinería exterior \\
\hline \multirow[t]{3}{*}{ Lamiaceae } & $\begin{array}{l}\text { Mentha x piperita } \\
\text { Hierbabuena, menta }\end{array}$ & 3 & Planta & Jardinería exterior \\
\hline & $\begin{array}{l}\text { Rosmarinus officinalis } \\
\text { Romero }\end{array}$ & 7 & Planta & Jardinería exterior \\
\hline & $\begin{array}{l}\text { Salvia officinalis } \\
\text { Salvia }\end{array}$ & 2 & Planta & Jardinería exterior \\
\hline Lauraceae & $\begin{array}{l}\text { Laurus nobilis } \\
\text { Laurel }\end{array}$ & 3 & Planta & Jardinería exterior \\
\hline \multirow[t]{4}{*}{ Liliaceae } & $\begin{array}{l}\text { Erythronium dens-canis } \\
\text { Campanilla }\end{array}$ & 1 & Planta & Jardinería exterior \\
\hline & $\begin{array}{l}\text { Lilium candidum } \\
\text { Vara de San José, azucena }\end{array}$ & 2 & Planta & Jardinería exterior \\
\hline & $\begin{array}{l}\text { Lilium martagon } \\
\text { Antojil, azucena }\end{array}$ & 2 & Planta & Jardinería exterior \\
\hline & $\begin{array}{l}\text { Tulipa gesneriana } \\
\text { Tulipán }\end{array}$ & 2 & Planta & Jardinería exterior \\
\hline \multirow[t]{3}{*}{ Malvaceae } & $\begin{array}{l}\text { Alcea rosea } \\
\text { Malva real, malvarisco }\end{array}$ & 2 & Planta & Jardinería exterior \\
\hline & $\begin{array}{l}\text { Althaea officinalis } \\
\text { Malvarisco, malvavisco }\end{array}$ & 3 & Planta & Jardinería exterior \\
\hline & $\begin{array}{l}\text { Tilia platyphylos } \\
\text { Tilo }\end{array}$ & 1 & Planta & Jardinería exterior \\
\hline Nyctaginaceae & $\begin{array}{l}\text { Mirabilis jalapa } \\
\text { Dondiego }\end{array}$ & 1 & Planta & Jardinería exterior \\
\hline Oleaceae & $\begin{array}{l}\text { Syringa vulgaris } \\
\text { Lilar }\end{array}$ & 1 & Planta & Jardinería exterior \\
\hline Orchidaceae & $\begin{array}{l}\text { Orchis pallens } \\
\text { Clavel }\end{array}$ & 1 & Planta & Jardinería exterior \\
\hline \multirow[t]{2}{*}{ Paeoniaceae } & $\begin{array}{l}\text { Paeonia lactiflora } \\
\text { Peonía }\end{array}$ & 12 & Planta & Jardinería exterior \\
\hline & $\begin{array}{l}\text { Paeonia officinalis } \\
\text { Peonía, roso, amaperro }\end{array}$ & 4 & Planta & Jardinería exterior \\
\hline \multirow[t]{2}{*}{ Papaveraceae } & $\begin{array}{l}\text { Eschscholzia californica } \\
\text { Amapola }\end{array}$ & 2 & Planta & Jardinería exterior \\
\hline & $\begin{array}{l}\text { Papaver somniferum } \\
\text { Amapola, flor de la droga }\end{array}$ & 14 & Planta & Jardinería exterior \\
\hline Passifloraceae & $\begin{array}{l}\text { Passiflora caeruela } \\
\text { Pasiflora }\end{array}$ & 1 & Planta & Jardinería exterior \\
\hline Plantaginaceae & $\begin{array}{l}\text { Antirrhinum majus } \\
\text { Boca de dragón }\end{array}$ & 1 & Planta & Jardinería exterior \\
\hline Polygonaceae & $\begin{array}{l}\text { Fallopia baldschuanica } \\
\text { Enredadera }\end{array}$ & 2 & Planta & Jardinería exterior \\
\hline \multirow[t]{3}{*}{ Ranunculaceae } & $\begin{array}{l}\text { Aquilegia vulgaris } \\
\text { Aguileña, campanilla }\end{array}$ & 3 & Planta & Jardinería exterior \\
\hline & $\begin{array}{l}\text { Consolida ajacis } \\
\text { Espuela de caballero }\end{array}$ & 1 & Planta & Jardinería exterior \\
\hline & $\begin{array}{l}\text { Trollius europaeus } \\
\text { Botón, capricho del cielo }\end{array}$ & 3 & Planta & Jardinería exterior \\
\hline
\end{tabular}




\begin{tabular}{llccc}
\hline TABLA 97: (Continuación) Relación de taxones empleados en la subcategoría Patios, huertos y jardines, ordenados \\
alfabéticamente por familia, indicando número de registros de uso (RU), parte usada y empleo.
\end{tabular}

Se agrupan en esta subcategoría las especies empleadas para adornar el acceso de la casa, los patios, balcones, terrazas, huertos o jardines.

Las plantas ornamentales tienen como principal función la decoración de diferentes espacios relacionados con los entornos exteriores del hogar, el huerto o el jardín. Por lo general, las mujeres son las encargadas de estos asuntos estéticos y una vivienda ornamentada con flores o un jardín cuidado se asociaba a un hogar bien administrado, a una mujer trabajadora y preocupada por el hogar.

En los jardines y portadas de las casas traían árboles pequeños del monte como el tejo (Taxus baccata) o el acebo (Ilex aquifolium) y herbáceas silvestres de floración vistosa como la peonía (Paeonia officinalis), el botón (Trollius europaeus) o la campanilla (Aquilegia vulgaris), en un intento de trasladar la belleza de la naturaleza al jardín. El número de especies introducidas en los jardines de la zona cada vez es más abundante, incrementado por el habitual intercambio de esquejes y semillas. Son frecuentes arbustos como el romero (Rosmarinus officinalis), el copo de nieve (Viburnum opulus), las lágrimas de Judas (Symphoricarpos albus), el lilar (Syringa vulgaris) y el ramo de azahar (Philadelphus coronarius), también especies herbáceas como la maravilla (Calendula officinalis), la hoja de la plata (Lunnaria annua), el malvarisco (Althaea officinalis), el dondiego (Mirabilis jalapa), la vara de San José (Lilium candidum) o la peonía (Paeonia lactiflora), ajardinada y con numerosos pétalos de color rojo.

En casi todos los jardines de la comarca aparecían amapolas (Papaver somniferum), hasta que la Guardia Civil aconsejó su erradicación a partir de los años 80 del siglo pasado, por considerarla planta productora de droga, acción un tanto desproporcionada para el conocimiento local. Esta situación fue común también en la comarca vecina de Campoo (Pardo de Santayana, 2008) y en la provincia de Murcia (Rivera et al., 2008).

En muros y en macetas para exteriores se cultivan siemprevivas (Sempervivum vicentei) traídas del campo y de gran resistencia a los rigores climatológicos.

\section{Calles y caminos:}

Se han recogido 12 registros de uso, correspondientes a 6 taxones de 4 familias botánicas diferentes, 4 taxones de obtención silvestre y 2 cultivados, representando un 2,19\% del total de registros de uso para la categoría Uso Ornamental. 
TABLA 98: Relación de especies empleadas en la subcategoría Calles y caminos, ordenados alfabéticamente por familia, indicando número de registros de uso (RU), parte usada y empleo.

\begin{tabular}{llccc}
\hline Familia & $\begin{array}{l}\text { Nombre científico } \\
\text { Nombre vulgar }\end{array}$ & RU & Parte usada & Empleo \\
\hline Leguminosae & $\begin{array}{l}\text { Robinia pseudoacacia } \\
\text { Acacia }\end{array}$ & 2 & Planta & Calles, plazas e iglesias \\
\hline Oleaceae & $\begin{array}{l}\text { Fraxinus excelsior } \\
\text { Fresno }\end{array}$ & 2 & Planta & Calles e iglesias \\
\hline Rosaceae & $\begin{array}{l}\text { Sorbus aria } \\
\text { Mostajo, amostajo }\end{array}$ & 1 & Planta & Calles y plazas \\
\hline $\begin{array}{l}\text { Sorbus aucuparia } \\
\text { Amargoso, serbal, drío, drido }\end{array}$ & 4 & Planta & Calles y plazas \\
& $\begin{array}{l}\text { Acer campestre } \\
\text { Barbaleña } \\
\text { Aesculus hippocastanum } \\
\text { Castaño de indias }\end{array}$ & 1 & Planta & Iglesias \\
\hline
\end{tabular}

Incluidas todas aquellas especies arbóreas susceptibles de ser empleadas en alineaciones urbanas, como árboles de paseo y de sombra.

Con el objetivo de sombreo y ornamentación urbana aparecen en plazas y alineaciones especies silvestres, pero empleadas en la actualidad en jardinería como son el amargoso (Sorbus aucuparia) y el mostajo (Sorbus aria). El interés ornamental del amargoso se documenta también en en el Pirineo Aragonés (Villar et al., 1987), en El Caurel (Blanco, 1998), y en Piloña (San Miguel, 2004).

En las portadas de las iglesias se plantan especies arbóreas que aseguren sombra protectora del sol los días de celebración religiosa, es el ejemplo del fresno (Fraxinus excelsior) en las iglesias de varios pueblos de la Castillería, de la acacia (Robinia pseudoacacia) y de la barbaleña (Acer campestre).

\section{Adornos florales y plantas de interior:}

Se han recogido 374 registros de uso, correspondientes a 91 taxones de 45 familias botánicas diferentes, 74 taxones de obtención silvestre y 17 cultivados, representando un $68,37 \%$ del total de registros de uso para la categoría Uso Ornamental.

TABLA 99: Relación de taxones empleados en la subcategoría Adornos florales y plantas de interior, ordenados alfabéticamente por familia, indicando número de registros de uso (RU), parte usada y empleo.

\begin{tabular}{|c|c|c|c|c|}
\hline Familia & $\begin{array}{l}\text { Nombre científico } \\
\text { Nombre vulgar }\end{array}$ & RU & Parte usada & Empleo \\
\hline Adoxaceae & $\begin{array}{l}\text { Sambucus nigra } \\
\text { Saúco, saúgo, sabúgo, taco }\end{array}$ & 2 & Ramas florecidas & Adorno floral \\
\hline \multirow[t]{5}{*}{ Amaryllidaceae } & $\begin{array}{l}\text { Allium sphaerocephalon } \\
\text { Ajestrín, ajo, cebolleta }\end{array}$ & 2 & Parte aérea & Flor seca \\
\hline & $\begin{array}{l}\text { Narcissus asturiensis } \\
\text { Lira, lirón, campanilla }\end{array}$ & 6 & Flor & Adorno floral \\
\hline & $\begin{array}{l}\text { Narcissus bulbocodium } \\
\text { Lirón, lirona, cantarujil }\end{array}$ & 5 & Flor & Adorno floral \\
\hline & $\begin{array}{l}\text { Narcissus pseudonarcissus } \\
\text { Lirón, cantarillo, campanilla }\end{array}$ & 78 & Flor & Adorno floral \\
\hline & $\begin{array}{l}\text { Narcissus triandrus } \\
\text { Pipa, lira }\end{array}$ & 3 & Flor & Adorno floral \\
\hline
\end{tabular}




\begin{tabular}{|c|c|c|c|c|}
\hline Familia & $\begin{array}{l}\text { Nombre científico } \\
\text { Nombre vulgar }\end{array}$ & $\mathbf{R U}$ & Parte usada & Empleo \\
\hline \multirow[t]{4}{*}{ Apiaceae } & $\begin{array}{l}\text { Chaerophyllum aureum } \\
\text { Canuto }\end{array}$ & 1 & Parte aérea & Flor seca \\
\hline & $\begin{array}{l}\text { Chaerophyllum hirsutum } \\
\text { Perejil, canuto }\end{array}$ & 2 & Parte aérea & Flor seca \\
\hline & $\begin{array}{l}\text { Conium maculatum } \\
\text { Budaño, cañiguerra, canuto }\end{array}$ & 2 & Parte aérea & Adorno floral \\
\hline & $\begin{array}{l}\text { Eryngium bourgatii } \\
\text { Cardo azul, cardo morado, cardo }\end{array}$ & 24 & Parte aérea & Adorno floral \\
\hline Aquifoliaceae & $\begin{array}{l}\text { Ilex aquifolium } \\
\text { Acebo, aceba }\end{array}$ & 10 & Hojas y frutos & Adorno floral \\
\hline Asparagaceae & $\begin{array}{l}\text { Chlorophytum comosum } \\
\text { Cinta }\end{array}$ & 1 & Planta & Planta interior \\
\hline Balsaminaceae & $\begin{array}{l}\text { Impatiens balsamina } \\
\text { Alegría }\end{array}$ & 2 & Planta & Planta interior \\
\hline Begoniaceae & $\begin{array}{l}\text { Begonia spp. } \\
\text { Conchita }\end{array}$ & 2 & Planta & Planta interior \\
\hline Boraginaceae & $\begin{array}{l}\text { Echium vulgare } \\
\text { Gardincha }\end{array}$ & 1 & Parte aérea & Flor seca \\
\hline Brassicaceae & $\begin{array}{l}\text { Lunaria annua } \\
\text { Hoja de la plata, flor de la plata }\end{array}$ & 6 & Parte aérea & Flor seca \\
\hline Campanulaceae & $\begin{array}{l}\text { Campanula rapunculus } \\
\text { Campanilla }\end{array}$ & 4 & Parte aérea & Adorno floral \\
\hline Caprifoliaceae & $\begin{array}{l}\text { Dipsacus fullonum } \\
\text { Cardo cardador, cardo }\end{array}$ & 28 & Parte aérea & Flor seca \\
\hline \multirow[t]{3}{*}{ Caryophyllaceae } & $\begin{array}{l}\text { Dianthus hyssopifolius } \\
\text { Clavelina, clavel }\end{array}$ & 5 & Parte aérea & Adorno floral \\
\hline & $\begin{array}{l}\text { Saponaria officinalis } \\
\text { Jabonera, planta del jabón }\end{array}$ & 1 & Parte aérea & Adorno floral \\
\hline & $\begin{array}{l}\text { Silene vulgaris } \\
\text { Colleja, cuete }\end{array}$ & 1 & Parte aérea & Adorno floral \\
\hline \multirow[t]{9}{*}{ Compositae } & $\begin{array}{l}\text { Achillea ageratum } \\
\text { Rosón }\end{array}$ & 1 & Parte aérea & Flor seca \\
\hline & $\begin{array}{l}\text { Achillea millefolium } \\
\text { Milenrama, birlenda, balsamina }\end{array}$ & 2 & Parte aérea & Flor seca \\
\hline & $\begin{array}{l}\text { Anacyclus clavatus } \\
\text { Margarita }\end{array}$ & 1 & Parte aérea & Adorno floral \\
\hline & $\begin{array}{l}\text { Anthemis arvensis } \\
\text { Margarita, manzanilla, lirada }\end{array}$ & 7 & Parte aérea & Adorno floral \\
\hline & $\begin{array}{l}\text { Bellis perennis } \\
\text { B. sylvestris } \\
\text { Margarita }\end{array}$ & 2 & Parte aérea & Adorno floral \\
\hline & $\begin{array}{l}\text { Carlina vulgaris } \\
\text { Cardo }\end{array}$ & 1 & Parte aérea & Flor seca \\
\hline & $\begin{array}{l}\text { Matricaria discoidea } \\
\text { Lirada, manzanillón, margarita }\end{array}$ & 1 & Parte aérea & Adorno floral \\
\hline & $\begin{array}{l}\text { Rhaponticum coniferum } \\
\text { Cucharilla }\end{array}$ & 1 & Parte aérea & Flor seca \\
\hline & $\begin{array}{l}\text { Tanacetum corymbosum } \\
\text { Margarita }\end{array}$ & 4 & Parte aérea & Adorno floral \\
\hline Cyperaceae & $\begin{array}{l}\text { Eriophorum latifolium } \\
\text { Hierba de algodón }\end{array}$ & 1 & Parte aérea & Flor seca \\
\hline Cystopteridaceae & $\begin{array}{l}\text { Cystopteris fragilis } \\
\text { Helecho }\end{array}$ & 1 & Frondes & Adorno floral \\
\hline Dennstaedtiaceae & $\begin{array}{l}\text { Pteridium aquilinum } \\
\text { Helecho, halecho }\end{array}$ & 2 & Frondes & Adorno floral \\
\hline
\end{tabular}




\begin{tabular}{|c|c|c|c|c|}
\hline Familia & $\begin{array}{l}\text { Nombre científico } \\
\text { Nombre vulgar }\end{array}$ & RU & Parte usada & Empleo \\
\hline Dryopteridaceae & $\begin{array}{l}\text { Dryopteris affinis } \\
\text { Helecha, helecho }\end{array}$ & 2 & Frondes & Adorno floral \\
\hline \multirow[t]{2}{*}{ Ericaceae } & $\begin{array}{l}\text { Calluna vulgaris } \\
\text { Brezo, graspo, graspillo }\end{array}$ & 1 & Parte aérea & Flor seca \\
\hline & $\begin{array}{l}\text { Erica spp. } \\
\text { Brezo, urz, ayuz, graspo }\end{array}$ & 10 & Parte aérea & Flor seca \\
\hline Geraniaceae & $\begin{array}{l}\text { Pelargonium zonale } \\
\text { Geranio }\end{array}$ & 5 & Planta & Planta interior \\
\hline \multirow[t]{3}{*}{ Iridaceae } & $\begin{array}{l}\text { Iris } \mathrm{x} \text { germanica } \\
\text { Lirio }\end{array}$ & 4 & Parte aérea & Adorno floral \\
\hline & $\begin{array}{l}\text { Iris latifolia } \\
\text { Lirio, lirio azul }\end{array}$ & 9 & Parte aérea & Adorno floral \\
\hline & $\begin{array}{l}\text { Iris pseudacorus } \\
\text { Lirio amarillo }\end{array}$ & 2 & Parte aérea & Adorno floral \\
\hline Juncaceae & $\begin{array}{l}\text { Luzula lactea } \\
\text { Purrino }\end{array}$ & 1 & Parte aérea & Adorno floral \\
\hline \multirow[t]{3}{*}{ Lamiaceae } & Ajuga pyramidalis & 1 & Parte aérea & Adorno floral \\
\hline & $\begin{array}{l}\text { Lavandula latifolia } \\
\text { Lavanda }\end{array}$ & 1 & Parte aérea & Flor seca \\
\hline & $\begin{array}{l}\text { Plectranthus scutellarioides } \\
\text { Cóleo }\end{array}$ & 1 & Planta & Planta de interior \\
\hline \multirow[t]{5}{*}{ Leguminosae } & $\begin{array}{l}\text { Cytisus oromediterraneus } \\
\text { Escoba hornil, escoba }\end{array}$ & 1 & Ramas florecidas & Adorno floral \\
\hline & $\begin{array}{l}\text { Cytisus scoparius } \\
\text { Escoba, ramo, escoba balera }\end{array}$ & 5 & Ramas florecidas & Adorno floral \\
\hline & $\begin{array}{l}\text { Genista florida } \\
\text { Escoba, escoba albar, ramón }\end{array}$ & 1 & Ramas florecidas & Adorno floral \\
\hline & $\begin{array}{l}\text { Lathyrus latifolius } \\
\text { Arvejana }\end{array}$ & 2 & Parte aérea & Adorno floral \\
\hline & $\begin{array}{l}\text { Robinia pseudoacacia } \\
\text { Acacia }\end{array}$ & 1 & Ramas florecidas & Adorno floral \\
\hline \multirow[t]{2}{*}{ Liliaceae } & $\begin{array}{l}\text { Fritillaria lusitanica } \\
\text { Calderón, campanilla, cencerrón }\end{array}$ & 1 & Flor & Adorno floral \\
\hline & $\begin{array}{l}\text { Lilium martagon } \\
\text { Antojil, azucena }\end{array}$ & 3 & Parte aérea & Adorno floral \\
\hline Linaceae & $\begin{array}{l}\text { Linum narbonense } \\
\text { Flor de lino, lino montesino }\end{array}$ & 2 & Parte aérea & Adorno floral \\
\hline Oleaceae & $\begin{array}{l}\text { Ligustrum vulgare } \\
\text { Varillo }\end{array}$ & 1 & Ramas florecidas & Adorno floral \\
\hline Onagraceae & $\begin{array}{l}\text { Fuchsia magellanica } \\
\text { Pendientes de la reina }\end{array}$ & 2 & Planta & Planta interior \\
\hline Orchidaceae & $\begin{array}{l}\text { Anacamptis morio } \\
\text { Clavel }\end{array}$ & 1 & Parte aérea & Adorno floral \\
\hline Orobanchaceae & $\begin{array}{l}\text { Rhinanthus minor } \\
\text { Cencerrada, encantadera }\end{array}$ & 1 & Parte aérea & Adorno floral \\
\hline \multirow[t]{2}{*}{ Paeoniaceae } & $\begin{array}{l}\text { Paeonia lactiflora } \\
\text { Peonía }\end{array}$ & 10 & Parte aérea & Adorno floral \\
\hline & $\begin{array}{l}\text { Paeonia officinalis } \\
\text { Peonía, roso, amaperro }\end{array}$ & 6 & Parte aérea & Adorno floral \\
\hline \multirow[t]{2}{*}{ Papaveraceae } & $\begin{array}{l}\text { Papaver rhoeas } \\
\text { Amapola, pirigallo }\end{array}$ & 4 & Parte aérea & Adorno floral \\
\hline & $\begin{array}{l}\text { Papaver somniferum } \\
\text { Amapola, flor de la droga }\end{array}$ & 1 & Parte aérea & Adorno floral \\
\hline
\end{tabular}




\begin{tabular}{|c|c|c|c|c|}
\hline Familia & $\begin{array}{l}\text { Nombre científico } \\
\text { Nombre vulgar }\end{array}$ & RU & Parte usada & Empleo \\
\hline Plantaginaceae & $\begin{array}{l}\text { Digitalis purpurea } \\
\text { Dedalera, campanilla, cuete }\end{array}$ & 5 & Parte aérea & Adorno floral \\
\hline Plumbaginaceae & $\begin{array}{l}\text { Armeria pubinervis } \\
\text { Flor de las coronas }\end{array}$ & 4 & Parte aérea & Flor seca \\
\hline \multirow[t]{11}{*}{ Poaceae } & $\begin{array}{l}\text { Agrostis delicatula } \\
\text { Risas y coscas }\end{array}$ & 1 & Parte aérea & Flor seca \\
\hline & $\begin{array}{l}\text { Aira caryophyllea } \\
\text { Heno }\end{array}$ & 1 & Parte aérea & Flor seca \\
\hline & $\begin{array}{l}\text { Arrhenatherum elatius } \\
\text { Grama }\end{array}$ & 1 & Parte aérea & Flor seca \\
\hline & $\begin{array}{l}\text { Avena fatua } \\
\text { A. sylvestris } \\
\text { Avena loca, hierba loca }\end{array}$ & 1 & Inflorescencia & Flor seca \\
\hline & $\begin{array}{l}\text { Briza media } \\
\text { Corazones, corazoncitos }\end{array}$ & 6 & Inflorescencia & Flor seca \\
\hline & $\begin{array}{l}\text { Cynosurus cristatus } \\
\text { Heno }\end{array}$ & 1 & Parte aérea & Flor seca \\
\hline & $\begin{array}{l}\text { Elymus repens } \\
\text { Grama }\end{array}$ & 1 & Parte aérea & Flor seca \\
\hline & $\begin{array}{l}\text { Holcus mollis } \\
\text { Yerbancho }\end{array}$ & 1 & Parte aérea & Flor seca \\
\hline & $\begin{array}{l}\text { Secale cereale } \\
\text { Centeno, sirvendo, servendo }\end{array}$ & 3 & Inflorescencia & Flor seca \\
\hline & $\begin{array}{l}\text { Stipa iberica } \\
\text { Hierba plumera, peluso }\end{array}$ & 2 & Parte aérea & Flor seca \\
\hline & $\begin{array}{l}\text { Triticum aestivum } \\
\text { Trigo, mesino, tremesino }\end{array}$ & 3 & Inflorescencia & Flor seca \\
\hline Polygonaceae & $\begin{array}{l}\text { Rumex crispus } \\
\text { Amargaza, acerón, ramagón }\end{array}$ & 1 & Parte aérea & Adorno floral \\
\hline Primulaceae & $\begin{array}{l}\text { Primula veris } \\
\text { Cuquillo, chupa, bragas de cuco }\end{array}$ & 4 & Parte aérea & Adorno floral \\
\hline \multirow[t]{3}{*}{ Ranunculaceae } & $\begin{array}{l}\text { Aconitum napellus } \\
\text { A. vulparia } \\
\text { Hierba piojera, acónito }\end{array}$ & 5 & Parte aérea & Adorno floral \\
\hline & $\begin{array}{l}\text { Aquilegia vulgaris } \\
\text { Aguileña, campanilla }\end{array}$ & 4 & Parte aérea & Adorno floral \\
\hline & $\begin{array}{l}\text { Trollius europaeus } \\
\text { Botón, capricho del cielo }\end{array}$ & 4 & Parte aérea & Adorno floral \\
\hline Resedaceae & $\begin{array}{l}\text { Reseda lutea } \\
\text { Gualda }\end{array}$ & 1 & Parte aérea & Adorno floral \\
\hline \multirow[t]{6}{*}{ Rosaceae } & $\begin{array}{l}\text { Crataegus monogyna } \\
\text { Espino, espino albar, majueto }\end{array}$ & 5 & Ramas florecidas & Adorno floral \\
\hline & Filipendula vulgaris & 2 & Parte aérea & Adorno floral \\
\hline & $\begin{array}{l}\text { Prunus domestica } \\
\text { Ciruelo, mijuelo, pruno }\end{array}$ & 1 & Ramas florecidas & Adorno floral \\
\hline & $\begin{array}{l}\text { Prunus padus } \\
\text { Ceresuela }\end{array}$ & 2 & Ramas florecidas & Adorno floral \\
\hline & $\begin{array}{l}\text { Prunus spinosa } \\
\text { Endrino, andrino, espino }\end{array}$ & 1 & Ramas florecidas & Adorno floral \\
\hline & $\begin{array}{l}\text { Rosa spp. cultivadas } \\
\text { Rosal }\end{array}$ & 6 & Flor & Adorno floral \\
\hline Rubiaceae & $\begin{array}{l}\text { Galium verum } \\
\text { Hierba del cuajo, cuajaleche }\end{array}$ & 1 & Parte aérea & Adorno floral \\
\hline
\end{tabular}




\begin{tabular}{|c|c|c|c|c|}
\hline Familia & $\begin{array}{l}\text { Nombre científico } \\
\text { Nombre vulgar }\end{array}$ & RU & Parte usada & Empleo \\
\hline Santalaceae & $\begin{array}{l}\text { Viscum album } \\
\text { Muérdago, maraojo, mingojo }\end{array}$ & 4 & Planta & Adorno floral \\
\hline Scrophulariaceae & $\begin{array}{l}\text { Verbascum lychnitis } \\
\text { V. pulverulentum } \\
\text { V. thapsus } \\
\text { Gordolobo, guardalobo }\end{array}$ & 1 & Parte aérea & Adorno floral \\
\hline Typhaceae & $\begin{array}{l}\text { Typha angustifolia } \\
\text { Puro, cuete }\end{array}$ & 8 & Parte aérea & Adorno floral \\
\hline Violaceae & $\begin{array}{l}\text { Viola spp. } \\
\text { Violeta }\end{array}$ & 3 & Flor & Adorno floral \\
\hline Xanthorrhoeaceae & $\begin{array}{l}\text { Asphodelus albus } \\
\text { Gamón, gamonita }\end{array}$ & 2 & Parte aérea & Adorno floral \\
\hline
\end{tabular}

Se describen en esta subcategoría las plantas vivas de interior, los ramos de flores secas o frescas y los arreglos florales para adornar el hogar, la iglesia, el lugar de trabajo, etc.

En el pasado, las labores del campo permitían poco tiempo para el esmero en estos quehaceres ornamentales, que suponían un sobresfuerzo que añadir a las tareas obligatorias. Los niños también recolectaban plantas para ornamentar el colegio durante el mes de mayo y que servían de ofrecimiento a la Virgen.

Aprovechando los paseos al campo se recogen muchas especies herbáceas que sobresalen por su olor y por su vistosidad, como adorno floral en fresco se cortan los célebres lirones (Narcissus pseudonarcissus), liras (Narcissus asturiensis, N. bulbocodium), dedaleras (Digitalis purpurea), margaritas (Anacyclus clavatus, Anthemis arvensis, Bellis perennis, Matricaria discoidea, Tanacetum corymbosum), clavelinas (Dianthus hyssopifolius) y muchas más, en algunos casos se desconoce su nombre pero se recogen por su belleza singular. A pesar del pequeño tamaño de las liras, se recogen preparando pequeños ramilletes que se colocan sobre jarrones para adornar la casa, encontrando un uso similar en la provincia de Salamanca (Velasco et al., 2010).

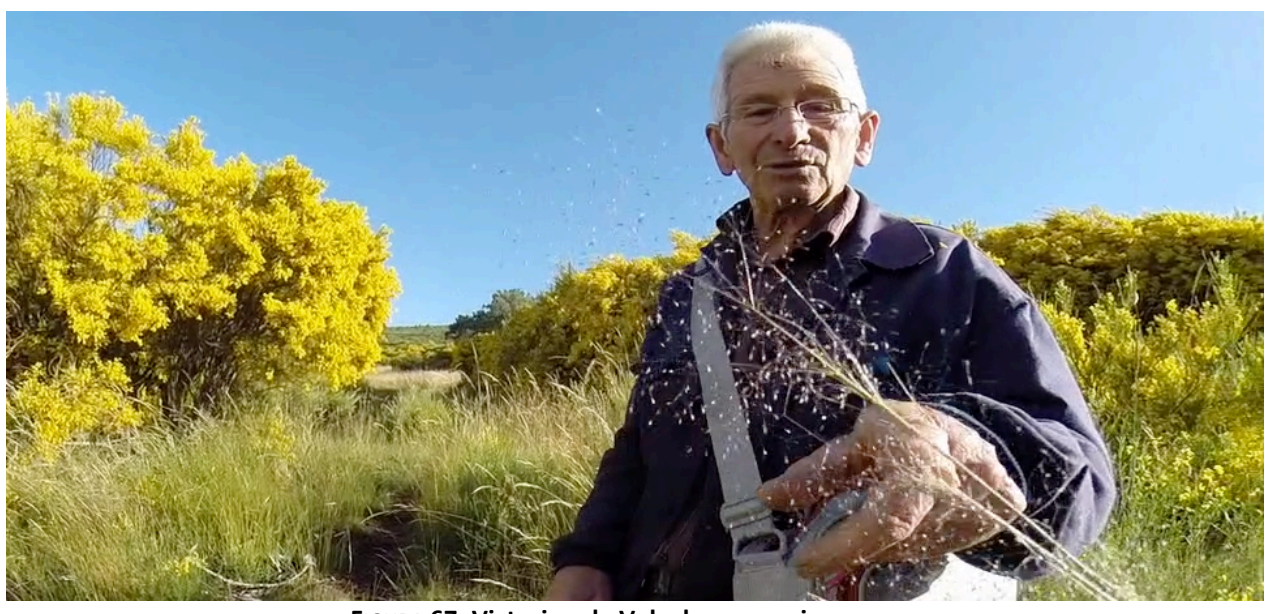

FIGURA 67: Victorino de Valcobero con risas y coscas.

Las ramas floridas o fructificadas de ciertas especies arbustivas o arbóreas también se utilizan como adornos florales, es el caso del acebo (Ilex aquifolium), las escobas (Cytisus 
oromediterraneus, C. scoparius, Genista florida), el majueto (Crataegus monogyna), el saúco (Sambucus nigra) o la ceresuela (Prunus padus).

Algunas plantas son valoradas como ornamento de flor seca, entre las más mencionadas se encuentran, el cardo azul (Eryngium bourgatii), el cardo cardador (Dipsacus fullonum), el brezo (Erica spp.), el puro (Typha angustifolia) o la hoja de la plata (Lunaria annua). Existen varias especies de la familia Poaceae que se han empleado en la decoración para centros de flor seca, silvestres como los corazones (Briza media), la hierba plumera (Stipa iberica), las risas y coscas (Agrostis delicatula), etc., y cultivadas como el centeno (Secale cereale) o el trigo (Triticum aestivum).

Sin duda la planta más frecuente en la decoración exterior de balcones y portadas es el geranio (Pelargonium zonale), de vistosos colores y fácil cultivo en maceta. Las especies más valoradas en cultivo interior son los pendientes de la reina (Fuchsia magellanica), la alegría (Impatiens balsamina) y la conchita (Begonia spp.).

\section{Otros adornos:}

Se han recogido 6 registros de uso, correspondientes a 4 taxones de obtención silvestre, de 3 familias botánicas diferentes, representando un $1,10 \%$ del total de registros de uso para la categoría Uso Ornamental.

TABLA 100: Relación de taxones empleados en la subcategoría Otros adornos, ordenados alfabéticamente por familia, indicando número de registros de uso (RU), parte usada y empleo.

\begin{tabular}{llccc}
\hline Familia & $\begin{array}{l}\text { Nombre científico } \\
\text { Nombre vulgar }\end{array}$ & RU & Parte usada & Empleo \\
\hline Araliaceae & $\begin{array}{l}\text { Hedera helix } \\
\text { Hiedra, yedra, enredadera }\end{array}$ & 1 & Ramas secas & Adornos \\
\hline Ericaceae & $\begin{array}{l}\text { Calluna vulgaris } \\
\text { Brezo, graspo, brecina }\end{array}$ & 1 & Cepa & Adornos \\
Ericaceae & $\begin{array}{l}\text { Erica spp. } \\
\text { Brezo, urz, ayuz, graspo } \\
\text { Fomes fomentarius } \\
\text { Yesca, yezca }\end{array}$ & 3 & Cepas & Adornos \\
\hline
\end{tabular}

Dentro de la subcategoría "Otros adornos" se incluyen especies para realizar tallas, imágenes, esculturas y cualquier otro adorno. Son varios los adornos de carácter natural que se pueden encontrar en las viviendas tradicionales de la comarca, en primer lugar son frecuentes las cornamentas de ciervos y corzos decorando las paredes, también se ha documentado el uso de la yesca (Fomes fomentarius) como decoración sobre vigas de madera.

En cuanto a los adornos vegetales, se citaron las cepas de brezo (Erica spp., Calluna vulgaris), las caprichosas formas que adquieren se aprecian como escultura decorativa en los portales de algunas casas. Por último, se cita el uso de la madera de hiedra para algún trabajo decorativo, aprovechando sus formas intrincadas. 


\section{USO SOCIAL, SIMBÓLICO Y RITUAL:}

La categoría de Uso social, simbólico y ritual representa a un grupo muy heterogéneo de usos. Se incluyen en ella aquellos elementos con un papel central o simbólico en las fiestas de carácter anual o vital, especies citadas en la literatura oral popular, las empleadas en usos recreativos, fumatorios, así como aquellos árboles singulares o legendarios existentes en la comarca. Las plantas no solo satisfacen estrictas necesidades materiales, sino que desempeñan un importante papel en las relaciones sociales, adquiriendo protagonismo en multitud de ritos, celebraciones y fiestas que forman parte de la identidad de sus habitantes. En la Montaña Palentina se menciona el uso de 89 taxones correspondientes a 43 familias botánicas, para los que se han recogido un total de 803 registros de uso (RU). De ellos, 65 taxones son de obtención silvestre y 24 cultivados. Los taxones con mayor número de registros de uso en la categoría Uso social, simbólico y ritual se representan en la figura 68.

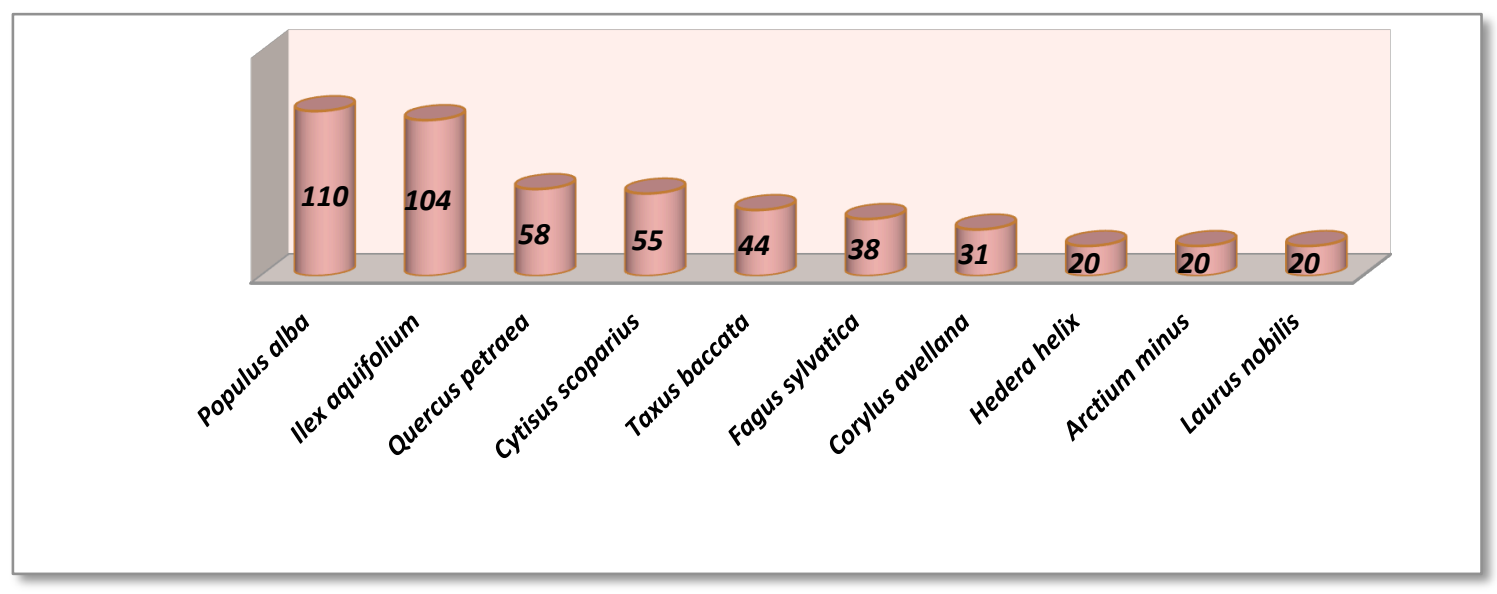

FIGURA 68: Taxones con mayor número de registros de uso Social, simbólico y ritual.

Las familias con mayor representación en cuanto a número de especies fueron: Compositae, Rosaceae y Leguminosae con 9,8 y 4 especies respectivamente, según se señala en la figura 69.

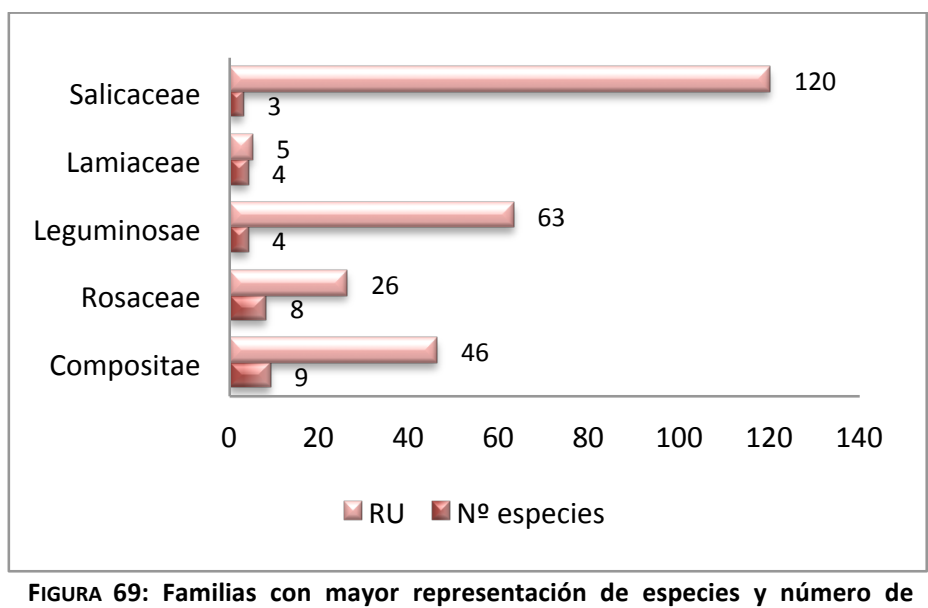
registros de uso (RU), de uso Social, simbólico y ritual.

La familia más destacada en esta categoría en cuanto a número de registros de uso es Salicaceae con 120 registros, debido principalmente al uso de las ramas de chopo (Populus $a l b a, P$. nigra) y de salguero (Salix spp.) en las tradicionales enramadas y en la confección de 
arcos decorativos en fiestas religiosas o civiles. Otra familia destacada es Leguminosae con 63 registros de uso, las flores de todo tipo de escobas se empleaban en la fiesta religiosa del Corpus Christi para engalanar las calles al paso de la procesión religiosa.

Los usos se han agrupado en subcategorías siguiendo los criterios establecidos en el Inventario Español de los Conocimientos Tradicionales relativos a la Biodiversidad (Pardo de Santayana et al., 2014), obteniendo referencias en las 8 subcategorías indicadas en la tabla 101.

TABLA 101: Subcategorías con representación en la categoría
Uso social, simbólico y ritual.

Los 803 registros de uso obtenidos, en la categoría Uso social, simbólico y ritual, se reparten en 8 subcategorías tal y como señala la figura 70 , resultando que Ritual de ciclo anual es la que recibió el mayor número de registros con 408 , un $50,81 \%$ del total en esta categoría, seguido de Ritual de ciclo de vida con 125, un 15,57\%, y Alucinógenas, narcóticas y fumatorias con 109, un $13,57 \%$.

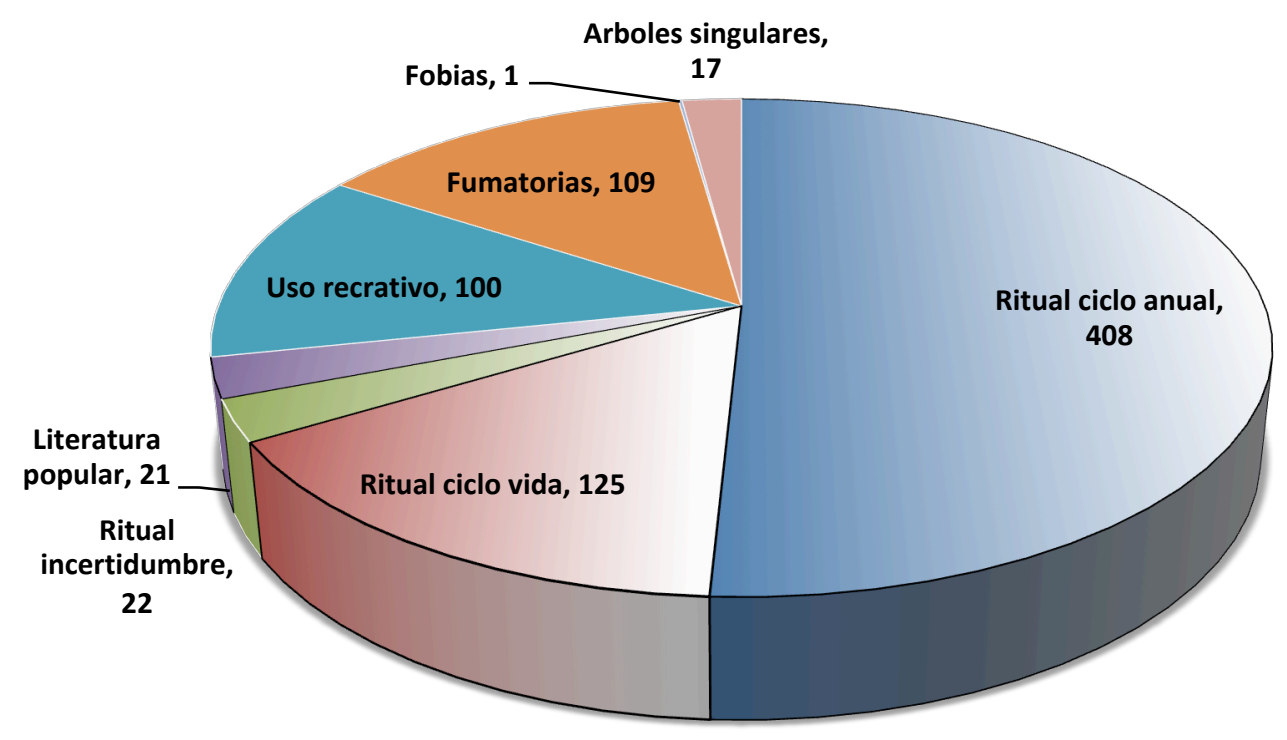

FIGURA 70: Registros de Uso (RU) de las subcategorías representadas en Uso social, simbólico o ritual.

A continuación se presentan los usos agrupados por subcategorías de Uso social, simbólico y ritual, señalando los taxones que han obtenido citas en los mismos, el número de registros de uso de cada taxón, la parte usada y el empleo. 


\section{Ritual de ciclo anual:}

Se han recogido 408 registros de uso, correspondientes a 42 taxones de 24 familias botánicas diferentes, 31 taxones de obtención silvestre y 11 cultivados, representando un 50,81\% del total de registros de uso para la categoría Uso social, simbólico y ritual.

TABLA 102: Relación de taxones empleados en la subcategoría Ritual de ciclo anual, ordenados alfabéticamente por familia, indicando número de registros de uso (RU), parte usada y empleo.

\begin{tabular}{|c|c|c|c|c|}
\hline Familia & $\begin{array}{l}\text { Nombre cientifico } \\
\text { Nombre vulgar }\end{array}$ & RU & Parte usada & Empleo \\
\hline \multirow[t]{2}{*}{ Adoxaceae } & $\begin{array}{l}\text { Sambucus nigra } \\
\text { Saúco, saúgo, sabúgo, taco }\end{array}$ & 1 & Ramas & Enramadas \\
\hline & $\begin{array}{l}\text { Viburnum opulus } \\
\text { Copo de nieve }\end{array}$ & 2 & $\begin{array}{l}\text { Ramas } \\
\text { florecidas }\end{array}$ & Corpus \\
\hline Amaryllidaceae & $\begin{array}{l}\text { Narcissus pseudonarcissus } \\
\text { Lirón, cantarillo, campanilla }\end{array}$ & 4 & Flor & Corpus \\
\hline Aquifoliaceae & $\begin{array}{l}\text { Ilex aquifolium } \\
\text { Acebo, aceba }\end{array}$ & 87 & Ramas & $\begin{array}{c}\text { Corpus, Domingo } \\
\text { Ramos y fiestas locales }\end{array}$ \\
\hline Araliaceae & $\begin{array}{l}\text { Hedera helix } \\
\text { Hiedra, yedra, enredadera }\end{array}$ & 10 & Ramas & $\begin{array}{l}\text { Corpus, enramadas S. } \\
\text { Juan y S. Pedro }\end{array}$ \\
\hline Balsaminaceae & $\begin{array}{l}\text { Impatiens balsamina } \\
\text { Alegría }\end{array}$ & 1 & Planta & Corpus \\
\hline Begoniaceae & $\begin{array}{l}\text { Begonia spp. } \\
\text { Conchita }\end{array}$ & 1 & Planta & Corpus \\
\hline Betulaceae & $\begin{array}{l}\text { Corylus avellana } \\
\text { Avellano }\end{array}$ & 4 & Ramas & $\begin{array}{l}\text { Enramadas San Juan y } \\
\text { San Pedro }\end{array}$ \\
\hline Caryophyllaceae & $\begin{array}{l}\text { Dianthus hyssopifolius } \\
\text { Clavelina, clavel }\end{array}$ & 2 & Flor & Corpus \\
\hline \multirow[t]{6}{*}{ Compositae } & $\begin{array}{l}\text { Anacyclus clavatus } \\
\text { Margarita }\end{array}$ & 2 & Inflorescencia & Corpus \\
\hline & $\begin{array}{l}\text { Anthemis arvensis } \\
\text { Margarita, manzanilla, lirada }\end{array}$ & 1 & Inflorescencia & Corpus \\
\hline & $\begin{array}{l}\text { Bellis perennis } \\
\text { Margarita }\end{array}$ & 7 & Inflorescencia & Corpus \\
\hline & $\begin{array}{l}\text { Cyanus segetum } \\
\text { Azulina, clavel }\end{array}$ & 2 & Flor & Corpus \\
\hline & $\begin{array}{l}\text { Leucanthemum vulgare } \\
\text { Margarita }\end{array}$ & 7 & Inflorescencia & Corpus \\
\hline & $\begin{array}{l}\text { Matricaria discoidea } \\
\text { Lirada, manzanillón, margarita }\end{array}$ & 1 & Inflorescencia & Corpus \\
\hline \multirow[t]{2}{*}{ Cupressaceae } & $\begin{array}{l}\text { Juniperus communis } \\
\text { Enebro, corveño }\end{array}$ & 4 & Ramas & Enramadas \\
\hline & $\begin{array}{l}\text { Juniperus sabina } \\
\text { Corveño }\end{array}$ & 1 & Ramas & Enramadas \\
\hline Dennstaedtiaceae & $\begin{array}{l}\text { Pteridium aquilinum } \\
\text { Helecho, halecho }\end{array}$ & 2 & Frondes & Fiesta local \\
\hline \multirow[t]{2}{*}{ Fagaceae } & $\begin{array}{l}\text { Fagus sylvatica } \\
\text { Haya }\end{array}$ & 12 & Ramas & $\begin{array}{l}\text { Corpus, enramadas S. } \\
\text { Juan y S. Pedro }\end{array}$ \\
\hline & $\begin{array}{l}\text { Quercus petraea } \\
\text { Q. pyrenaica } \\
\text { Q. robur } \\
\text { Roble, cajigo, matorro }\end{array}$ & 11 & $\begin{array}{c}\text { Ramas y } \\
\text { tronco } \\
\text { descortezado }\end{array}$ & $\begin{array}{l}\text { Enramadas y fiesta } \\
\text { local }\end{array}$ \\
\hline Geraniaceae & $\begin{array}{l}\text { Pelargonium zonale } \\
\text { Geranio }\end{array}$ & 1 & Planta & Corpus \\
\hline Lamiaceae & $\begin{array}{l}\text { Plectranthus scutellarioides } \\
\text { Cóleo }\end{array}$ & 1 & Planta & Corpus \\
\hline Lauraceae & $\begin{array}{l}\text { Laurus nobilis } \\
\text { Laurel }\end{array}$ & 20 & Ramas & Domingo de Ramos \\
\hline
\end{tabular}




\begin{tabular}{|c|c|c|c|c|}
\hline Familia & $\begin{array}{l}\text { Nombre científico } \\
\text { Nombre vulgar }\end{array}$ & RU & Parte usada & Empleo \\
\hline \multirow[t]{3}{*}{ Leguminosae } & $\begin{array}{l}\text { Cytisus scoparius } \\
\text { Escoba, ramo, escoba balera }\end{array}$ & 55 & Flor & Corpus \\
\hline & $\begin{array}{l}\text { Genista florida } \\
\text { Escoba, escoba albar, ramón }\end{array}$ & 4 & Flor & Corpus \\
\hline & $\begin{array}{l}\text { Vicia cracca } \\
\text { V. pannonica } \\
\text { Arvejana }\end{array}$ & 2 & Flor & Corpus \\
\hline \multirow[t]{3}{*}{ Oleaceae } & $\begin{array}{l}\text { Fraxinus excelsior } \\
\text { Fresno }\end{array}$ & 9 & Ramas & $\begin{array}{l}\text { Enramadas S. Juan y S. } \\
\text { Pedro }\end{array}$ \\
\hline & $\begin{array}{l}\text { Ligustrum vulgare } \\
\text { Varillo }\end{array}$ & 1 & $\begin{array}{l}\text { Ramas } \\
\text { florecidas }\end{array}$ & Corpus \\
\hline & $\begin{array}{l}\text { Syringa vulgaris } \\
\text { Lilar }\end{array}$ & 1 & Flor & Corpus \\
\hline \multirow[t]{2}{*}{ Paeoniaceae } & $\begin{array}{l}\text { Paeonia lactiflora } \\
\text { Peonía }\end{array}$ & 7 & Flor & Corpus \\
\hline & $\begin{array}{l}\text { Paeonia officinalis } \\
\text { Peonía, roso, amaperro, clavel }\end{array}$ & 5 & Flor & Corpus \\
\hline Papaveraceae & $\begin{array}{l}\text { Papaver rhoeas } \\
\text { Amapola, pirigallo }\end{array}$ & 8 & Flor & Corpus \\
\hline Pinaceae & $\begin{array}{l}\text { Pinus nigra } \\
\text { P. sylvestris } \\
\text { Pino }\end{array}$ & 18 & $\begin{array}{c}\text { Ramas y } \\
\text { tronco } \\
\text { descortezado }\end{array}$ & $\begin{array}{l}\text { Domingo de Ramos y } \\
\text { fiestas locales }\end{array}$ \\
\hline \multirow[t]{4}{*}{ Rosaceae } & $\begin{array}{l}\text { Crataegus monogyna } \\
\text { Espino, espino albar, majueto }\end{array}$ & 1 & $\begin{array}{c}\text { Ramas } \\
\text { florecidas }\end{array}$ & Corpus \\
\hline & $\begin{array}{l}\text { Prunus avium } \\
\text { Cerezo }\end{array}$ & 1 & Ramas & $\begin{array}{l}\text { Enramadas S. Juan y S. } \\
\text { Pedro }\end{array}$ \\
\hline & $\begin{array}{l}\text { Rosa spp. cultivadas } \\
\text { Rosal }\end{array}$ & 9 & Flor & Corpus \\
\hline & $\begin{array}{l}\text { Sorbus acucaparia } \\
\text { Amargoso, serbal, drío, drido }\end{array}$ & 7 & Ramas & Fiesta local \\
\hline \multirow[t]{3}{*}{ Salicaceae } & $\begin{array}{l}\text { Populus alba } \\
\text { P. nigra } \\
\text { Chopo }\end{array}$ & 61 & $\begin{array}{c}\text { Ramas y } \\
\text { tronco } \\
\text { descortezado }\end{array}$ & $\begin{array}{l}\text { Corpus, enramadas y } \\
\text { fiestas locales }\end{array}$ \\
\hline & $\begin{array}{l}\text { Populus tremula } \\
\text { Álamo }\end{array}$ & 3 & $\begin{array}{c}\text { Tronco } \\
\text { descortezado }\end{array}$ & Fiesta local \\
\hline & $\begin{array}{l}\text { Salix spp. } \\
\text { Salguero, sota, salce }\end{array}$ & 2 & Ramas & Domingo de Ramos \\
\hline Taxaceae & $\begin{array}{l}\text { Taxus baccata } \\
\text { Tejo }\end{array}$ & 28 & Ramas & $\begin{array}{l}\text { Corpus, Domingo } \\
\text { Ramos y enramadas }\end{array}$ \\
\hline Ulmaceae & $\begin{array}{l}\text { Ulmus minor } \\
\text { Olmo }\end{array}$ & 2 & Ramas & Enramada, fiesta local \\
\hline
\end{tabular}

Incluidas aquellas especies que forman parte de ceremonias y fiestas del ciclo anual: fiestas locales y patronales, Carnaval, Domingo de Ramos, Semana Santa, Corpus, Mayos y fiestas del árbol, San Juan u otros santos a los que se colocan enramadas, Navidad, y celebraciones ligadas a trabajos comunales.

En el ciclo anual festivo se incorporan elementos vegetales que cumplen un papel simbólico especial, incluso sagrado en las diversas celebraciones religiosas. El Domingo de Ramos en el pasado se bendicían ramilletes recogidos por los vecinos de tejo (Taxus baccata), de pino (Pinus sylvestris) y sobre todo de acebo (Ilex aquifolium). En los años 80 del siglo pasado estas especies fueron sustituidas por el laurel (Laurus nobilis) o el romero (Rosmarinus officinalis), más fáciles de obtener al presentarse de forma cultivada en patios o jardines. El acebo 
también se incorporó en los años 60 como elemento decorativo en el tradicional árbol de Navidad.

Durante la fiesta del Corpus Christi celebrada en la mayoría de los pueblos, se adornaban pequeños altares, cubriendo con flores las calles por las que discurría la procesión religiosa. Los niños se encargaban de recolectar todo tipo de flores que lanzaban a modo de alfombra durante el paso del Santísimo, las más buscadas eran los zapatitos de la Virgen, nombre vulgar de la flor de las escobas (Cytisus spp., Genista spp.), los pétalos de rosas (Rosa spp.), de peonías (Paeonia lactiflora, P. officinalis), capítulos de margaritas (Anacyclus clavatus, Anthemis arvensis, Bellis perennis, Leucanthemum vulgare, Matricaria discoidea) y en general cualquier otro tipo de flor presente en el momento de la fiesta. En los altares colocados en las calles al paso de la procesión, las mujeres llevaban sus mejores macetas de flores, adornándose para la ocasión con geranios (Pelargonium zonale), alegrías (Impatiens balsamina), cóleos (Plectranthus scutellarioides), begonias (Begonia spp.) o pendientes de la reina (Fuchsia magellanica).

Una fiesta destacada en el ciclo anual por su popularidad fue San Juan, el 24 de junio, donde era tradicional la enramada adornando las ventanas de la casa de las mozas solteras. Los mozos preparaban ramos lustrosos de chopo (Populus spp.), de fresno (Fraxinus excelsior), de avellano (Corylus avellana), de yedra (Hedera helix), etc., significando su amor por alguna muchacha. En algún pueblo de la comarca también era costumbre enramar por San Pedro o en la festividad local.

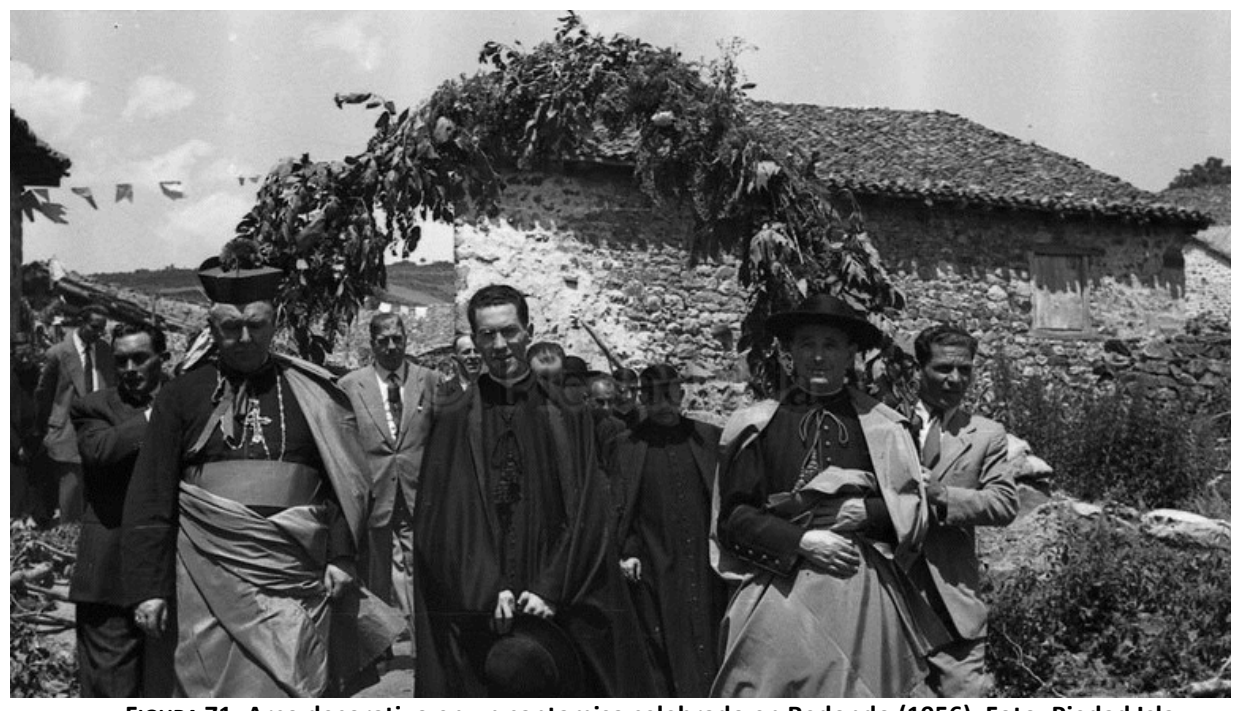

FIGURA 71: Arco decorativo en un cantamisa celebrado en Redondo (1956). Foto: Piedad Isla.

Coincidiendo con la festividad de San Juan, la celebración del patrón local o con el primero de mayo, tuvo gran interés el pinado del mayo, en el que los mozos trataban de trepar el tronco desmochado de: un haya (Fagus sylvatica), un roble (Quercus petraea), un chopo o un pino (Pinus sylvestris), mientras las mozas acompañaban recitando cantos en torno al "mayo". De forma similar el día de San Juan en muchos pueblos del País Vasco y Navarra se colocaba un gran haya en el centro del pueblo (Garmendia, 2009). 


\section{Ritual de ciclo de vida:}

Se han recogido 125 registros de uso, correspondientes a 12 taxones de 8 familias botánicas diferentes, 10 taxones de obtención silvestre y 2 cultivados, representando un 15,57\% del total de registros de uso para la categoría Uso social, simbólico y ritual.

TABLA 103: Relación de taxones empleados en la subcategoría Ritual de ciclo de vida, ordenados alfabéticamente por familia, indicando número de registros de uso (RU), parte usada y empleo.

\begin{tabular}{|c|c|c|c|c|}
\hline Familia & $\begin{array}{l}\text { Nombre cientifico } \\
\text { Nombre vulgar }\end{array}$ & RU & Parte usada & Empleo \\
\hline Aquifoliaceae & $\begin{array}{l}\text { Ilex aquifolium } \\
\text { Acebo, aceba }\end{array}$ & 9 & Ramas & Bodas \\
\hline Araliaceae & $\begin{array}{l}\text { Hedera helix } \\
\text { Hiedra, yedra, enredadera }\end{array}$ & 9 & Ramas & $\begin{array}{l}\text { Bodas y visitas } \\
\text { autoridades }\end{array}$ \\
\hline Betulaceae & $\begin{array}{l}\text { Corylus avellana } \\
\text { Avellano }\end{array}$ & 7 & Ramas & Bodas y fin de cosecha \\
\hline \multirow[t]{2}{*}{ Fagaceae } & $\begin{array}{l}\text { Fagus sylvatica } \\
\text { Haya }\end{array}$ & 17 & $\begin{array}{c}\text { Tronco } \\
\text { descortezado }\end{array}$ & Cantamisas \\
\hline & $\begin{array}{l}\text { Quercus petraea } \\
\text { Q. pyrenaica } \\
\text { Q. robur } \\
\text { Roble, cajigo, matorro }\end{array}$ & 9 & $\begin{array}{c}\text { Tronco } \\
\text { descortezado }\end{array}$ & Cantamisas \\
\hline Oleaceae & $\begin{array}{l}\text { Fraxinus excelsior } \\
\text { Fresno }\end{array}$ & 8 & Ramas & Bodas \\
\hline \multirow[t]{3}{*}{ Rosaceae } & $\begin{array}{l}\text { Prunus padus } \\
\text { Ceresuela }\end{array}$ & 1 & $\begin{array}{l}\text { Ramas } \\
\text { florecidas }\end{array}$ & $\begin{array}{l}\text { Bodas y visitas } \\
\text { autoridades }\end{array}$ \\
\hline & $\begin{array}{l}\text { Rosa spp. cultivadas } \\
\text { Rosal }\end{array}$ & 2 & Flor & Bodas \\
\hline & $\begin{array}{l}\text { Sorbus aria } \\
\text { Mostajo, amostajo }\end{array}$ & 1 & Ramas & Bodas \\
\hline \multirow[t]{2}{*}{ Salicaceae } & $\begin{array}{l}\text { Populus alba } \\
\text { P. nigra } \\
\text { Chopo }\end{array}$ & 46 & $\begin{array}{l}\text { Ramas, tronco } \\
\text { descortezado }\end{array}$ & $\begin{array}{l}\text { Bodas, cantamisas y } \\
\text { visitas autoridades }\end{array}$ \\
\hline & $\begin{array}{l}\text { Salix spp. } \\
\text { Salguero, sota, salce }\end{array}$ & 5 & Ramas & Bodas y cantamisas \\
\hline Taxaceae & $\begin{array}{l}\text { Taxus baccata } \\
\text { Tejo }\end{array}$ & 11 & Ramas & Bodas y cantamisas \\
\hline
\end{tabular}

En los rituales del ciclo de vida se describen aquellas especies empleadas en ritos de paso como nacimientos, matrimonios o muertes, también en ceremonias de ordenación de sacerdotes, y las empleadas en actos de bienvenida o agasajo a autoridades civiles o religiosas de relevancia.

Durante los enlaces matrimoniales es representativo enramar la puerta de la casa de la novia, significando el amor del novio, para estas ocasiones se empleaban las mismas especies que durante las enramadas realizadas por la festividad de San Juan, como el chopo (Populus spp.), tejo (Taxus baccata), acebo (Ilex aquifolium), hiedra (Hedera helix) o fresno (Fraxinus excelsior), también empleado en Piloña (San Miguel, 2004) y en la comarca de Campoo (Pardo de Santaya, 2008) para las típicas enramadas.

En el caso de recibir la visita de alguna autoridad importante se elaboraban arcos con ramas de las especies antes señaladas a las que se añadían lazos, flores de rosal (Rosa spp.), de ceresuela (Prunus padus) o algún otro adorno. La comitiva de recibimiento se colocaba a la 
entrada de localidad y acompañaba a las autoridades bajo estos arcos vegetales en un acto de agasajo y bienvenida.

El pinado del mayo no fue exclusivo de festividades anuales, ya que el ordenamiento de un sacerdote de la localidad era motivo de celebración. Tras el cantamisa (primera misa del sacerdote ordenado) en la que todo el pueblo se unía a la familia y a las amistades, los más jóvenes trepaban el "mayo" colocado siempre que fuera posible en frente de la casa del sacerdote y preparado con el tronco descortezado de chopo, haya (Fagus sylvatica), o roble (Quercus petraea).

\section{Ritual de incertidumbre, protección y aflicción:}

Se han recogido 22 registros de uso, correspondientes a 9 taxones de 9 familias botánicas diferentes, 6 taxones de obtención silvestre y 3 cultivados, representando un 2,74\% del total de registros de uso para la categoría Uso social, simbólico y ritual.

TABLA 104: Relación de especies empleadas en la subcategoría Ritual de incertidumbre, protección y aflicción, ordenados alfabéticamente por familia, indicando número de registros de uso (RU), parte usada y empleo.

\begin{tabular}{|c|c|c|c|c|}
\hline Familia & $\begin{array}{l}\text { Nombre científico } \\
\text { Nombre vulgar }\end{array}$ & RU & Parte usada & Empleo \\
\hline Amaryllidaceae & $\begin{array}{l}\text { Allium sativum } \\
\text { Ajo }\end{array}$ & 1 & Bulbo & Protector mal de ojo \\
\hline Aquifoliaceae & $\begin{array}{l}\text { Ilex aquifolium } \\
\text { Acebo, aceba }\end{array}$ & 7 & Ramas & Protector hogar \\
\hline Caprifoliaceae & $\begin{array}{l}\text { Dipsacus fullonum } \\
\text { Cardo cardador, cardo }\end{array}$ & 1 & Hojas & Agua para rizar el pelo \\
\hline Compositae & $\begin{array}{l}\text { Achillea millefolium } \\
\text { Milenrama, birlenda, balsamina }\end{array}$ & 1 & Parte aérea & $\begin{array}{l}\text { Infusión } \\
\text { Ayuda al embarazo }\end{array}$ \\
\hline Juglandaceae & $\begin{array}{l}\text { Juglans regia } \\
\text { Nogal }\end{array}$ & 1 & Planta & Mala suerte \\
\hline Lamiaceae & $\begin{array}{l}\text { Mentha pulegium } \\
\text { Té de menta, menta poleo, poleo }\end{array}$ & 1 & Parte aérea & $\begin{array}{l}\text { Cocción } \\
\text { Mejora fertilidad toros }\end{array}$ \\
\hline Paeoniaceae & $\begin{array}{l}\text { Paeonia lactiflora } \\
\text { Peonía }\end{array}$ & 1 & Flor & Mala suerte \\
\hline Santalaceae & $\begin{array}{l}\text { Viscum album } \\
\text { Muérdago, maraojo, mingojo }\end{array}$ & 8 & Planta & Protector hogar \\
\hline Taxaceae & $\begin{array}{l}\text { Taxus baccata } \\
\text { Tejo }\end{array}$ & 1 & Ramas & Protector hogar \\
\hline
\end{tabular}

Dentro de los rituales de incertidumbre, protección y aflicción se mencionan especies útiles como amuletos y elementos usados como protector, para evitar el mal de ojo, a personas, animales, cosechas o casas, como protector de tormentas, malos espiritus, o para lograr atraer la suerte, así como árboles que dan mala sombra.

La especie con mayor número de registros de uso en esta subcategoría, con 8, es el muérdago (Viscum album), sus ramos se colocan en el hogar o en la cuadra para ahuyentar la mala suerte, se trata de un ritual importado que se ha incorporado en los años 80 en la zona. Se ha documentado este mismo uso en Les Guileries (Selga, 1998), en Navarra (Akerreta, 2008), en L'Alt Emporda (Parada, 2008) y en Campoo (Pardo de Santayana, 2008). 
Otras especies utilizadas en el pasado como símbolo transmisor de buena suerte y protector del ganado, colocados en la cuadra, son el acebo (Ilex aquifolium) y el tejo (Taxus baccata). Existen rituales relacionados con la fertilidad, para favorecer al embarazo se toman infusiones de milenrama (Achillea millefolium) y para mejorar la fertilidad de los toros sementales se les suministra cocciones de té de menta (Mentha pulegium), ambos remedios no se referencian en la bibliografía consultada.

En Recueva de la Peña afirman que la mejor sombra que existe es la de un nogal (Juglans regia), por la frescura que ofrece y por la ausencia de insectos, pero sin embargo se prohíbe dormir debajo de un nogal advirtiendo sobre la posibilidad de morir. Otra planta de carácter supersticioso es la peonía (Paeonia lactiflora), en Alba de los Cardaños desaconsejan su utilización para decorar en el cementerio, pudiendo atraer nuevas muertes.

\section{Literatura oral popular:}

Se han recogido 21 registros de uso, correspondientes a 13 taxones de 11 familias botánicas diferentes, 10 taxones de obtención silvestre y 3 cultivados, representando un 2,62\% del total de registros de uso para la categoría Uso social, simbólico y ritual.

TABLA 105: Relación de especies mencionadas en la subcategoría Literatura oral popular, ordenadas alfabéticamente por familia, indicando número de registros de uso (RU), parte usada y empleo.

\begin{tabular}{|c|c|c|c|c|}
\hline Familia & $\begin{array}{l}\text { Nombre cientifico } \\
\text { Nombre vulgar }\end{array}$ & RU & $\begin{array}{l}\text { Parte } \\
\text { usada }\end{array}$ & Empleo \\
\hline \multirow[t]{2}{*}{ Amaryllidaceae } & $\begin{array}{l}\text { Allium ampeloprasum } \\
\text { Puerro }\end{array}$ & 1 & Refrán & $\begin{array}{l}\text { Por San Pedro saca tu ajo y siembra } \\
\text { tu puerro }\end{array}$ \\
\hline & $\begin{array}{l}\text { Allium sativum } \\
\text { Ajo }\end{array}$ & 1 & Refrán & $\begin{array}{l}\text { Por San Pedro saca tu ajo y siembra } \\
\text { tu puerro }\end{array}$ \\
\hline Apiaceae & $\begin{array}{l}\text { Caucalis platycarpos } \\
\text { Cadillo }\end{array}$ & 1 & Dicho & $\begin{array}{l}\text { El cadillo le da brillo, el amapol le da } \\
\text { color y la lapa lo agazapa }\end{array}$ \\
\hline Betulaceae & $\begin{array}{l}\text { Corylus avellana } \\
\text { Avellano }\end{array}$ & 1 & Refrán & $\begin{array}{l}\text { La avellana que en agosto no grana, } \\
\text { catala vana }\end{array}$ \\
\hline Brassicaceae & $\begin{array}{l}\text { Brassica napus } \\
\text { Nabo }\end{array}$ & 2 & Refrán & Para Santa Marina siembra tu nabina \\
\hline Dennstaedtiaceae & $\begin{array}{l}\text { Pteridium aquilinum } \\
\text { Helecho, halecho }\end{array}$ & 1 & Dicho & $\begin{array}{l}\text { Tierra de helecho, tierra de poco } \\
\text { provecho }\end{array}$ \\
\hline \multirow[t]{2}{*}{ Fagaceae } & $\begin{array}{l}\text { Fagus sylvatica } \\
\text { Haya }\end{array}$ & 8 & Refrán & El haya para cuando más no haya \\
\hline & $\begin{array}{l}\text { Quercus petraea } \\
\text { Q. pyrenaica } \\
\text { Q. robur } \\
\text { Roble, cajigo, matorro }\end{array}$ & 1 & Dicho & $\begin{array}{l}\text { Roble cucubillo, ramo de cuchar, } \\
\text { dime cuantos años me quedan, para } \\
\text { poderme casar }\end{array}$ \\
\hline Papaveraceae & $\begin{array}{l}\text { Papaver rhoeas } \\
\text { Amapola, pirigallo }\end{array}$ & 1 & Dicho & $\begin{array}{l}\text { El cadillo le da brillo, el amapol le da } \\
\text { color y la lapa lo agazapa }\end{array}$ \\
\hline Rosaceae & $\begin{array}{l}\text { Rosa spinosissima } \\
\text { Zarzaparrilla, rosal espinoso }\end{array}$ & 1 & Dicho & $\begin{array}{l}\text { La zarzaparrilla y unas cataplasmas pa } \\
\text { las pantorrillas }\end{array}$ \\
\hline Rubiaceae & $\begin{array}{l}\text { Galium aparine } \\
\text { Pegamanos, ensayo, lapa }\end{array}$ & 1 & Dicho & $\begin{array}{l}\text { El cadillo le da brillo, el amapol le da } \\
\text { color y la lapa lo agazapa }\end{array}$ \\
\hline Taxaceae & $\begin{array}{l}\text { Taxus baccata } \\
\text { Tejo }\end{array}$ & 1 & Dicho & $\begin{array}{c}\text { Debajo de tu ventana un tejo } \\
\text { plantado vi, nadie daba con el tejo y } \\
\text { yo con el tejo di }\end{array}$ \\
\hline Verbenaceae & $\begin{array}{l}\text { Verbena officinalis } \\
\text { Verbena }\end{array}$ & 1 & Dicho & $\begin{array}{c}\text { Cogiendo la verbena en la mañanita } \\
\text { de San Juan no te picará culebra ni } \\
\text { bicho que te haga mal }\end{array}$ \\
\hline
\end{tabular}


Se recopilan en la subcategoría Literatura oral popular, canciones, cuentos, leyendas, dichos, refranes y adivinanzas.

La especie con mayor número de registros (8) es el haya (Fagus sylvatica), aparece en el popular refrán: "el haya para cuando más no haya", que alude a la obligación de su uso cuando escasea otro tipo de madera y apunta las desventajas de su madera frente a la del roble, por ser más vulnerable a los parásitos y de rápida combustión. Otros refranes señalan épocas idóneas de cultivo o recolección, son los casos del nabo (Brassica napus), el puerro (Allium ampeloprasum), el ajo (Allium sativum) o el avellano (Corylus avellana).

También son significativos los dichos relacionados con las malas hierbas de los cultivos, donde han sido mencionadas especies como el cadillo (Caucalis platycarpos), la amapola (Papaver rhoeas) o la lapa (Galium aparine), o con la calidad del terreno en el caso del helecho (Pteridium aquilinum). Existen multitud de dichos y refranes populares en toda la Península Ibérica referentes a las especies anteriormente citadas, pero no se han registrado coincidencias en la bibliografía consultada.

\section{Uso recreativo:}

Se han recogido 100 registros de uso, correspondientes a 30 taxones de 18 familias botánicas diferentes, 26 taxones de obtención silvestre y 4 cultivados, representando un 12,45\% del total de registros de uso para la categoría Uso social, simbólico y ritual.

TABLA 106: Relación de taxones empleados en la subcategoría Uso recreativo, ordenados alfabéticamente por familia, indicando número de registros de uso (RU), parte usada y empleo.

\begin{tabular}{|c|c|c|c|c|}
\hline Familia & $\begin{array}{l}\text { Nombre científico } \\
\text { Nombre vulgar }\end{array}$ & RU & Parte usada & Empleo \\
\hline Amaryllidaceae & $\begin{array}{l}\text { Narcissus pseudonarcissus } \\
\text { Lirón, cantarillo, campanilla }\end{array}$ & 2 & Flor & Chiflo \\
\hline Aquifoliaceae & $\begin{array}{l}\text { Ilex aquifolium } \\
\text { Acebo, aceba }\end{array}$ & 1 & Hojas & Molinillos \\
\hline Asparagaceae & $\begin{array}{l}\text { Muscari racemosum } \\
\text { Vino }\end{array}$ & 1 & Flor & Comiditas \\
\hline \multirow[t]{3}{*}{ Caprifoliaceae } & $\begin{array}{l}\text { Dipsacus fullonum } \\
\text { Cardo cardador, cardo }\end{array}$ & 2 & Inflorescencia & Juego infantil \\
\hline & $\begin{array}{l}\text { Knautia arvensis } \\
\text { Flor de la corona }\end{array}$ & 1 & Flor & Coronas \\
\hline & $\begin{array}{l}\text { Scabiosa columbaria } \\
\text { Flor de la corona }\end{array}$ & 1 & Flor & Coronas \\
\hline \multirow[t]{2}{*}{ Caryophyllaceae } & $\begin{array}{l}\text { Saponaria officinalis } \\
\text { Jabonera, planta del jabón }\end{array}$ & 10 & Planta & Juego infantil \\
\hline & $\begin{array}{l}\text { Silene vulgaris } \\
\text { Colleja, cuete }\end{array}$ & 5 & Flor & Juego infantil \\
\hline \multirow[t]{4}{*}{ Compositae } & $\begin{array}{l}\text { Anthemis arvensis } \\
\text { Margarita, manzanilla, lirada }\end{array}$ & 2 & Capítulo & Adivinación \\
\hline & $\begin{array}{l}\text { Arctium minus } \\
\text { Amargacho, capacho, lapa }\end{array}$ & 20 & Fruto & Pegotes \\
\hline & $\begin{array}{l}\text { Bellis perennis } \\
\text { B. sylvestris } \\
\text { Margarita }\end{array}$ & 1 & Capítulo & Adivinación \\
\hline & $\begin{array}{l}\text { Leucanthemum vulgare } \\
\text { Margarita }\end{array}$ & 1 & Capítulo & Adivinación \\
\hline Cupressaceae & $\begin{array}{l}\text { Juniperus communis } \\
\text { Enebro, corveño }\end{array}$ & 1 & Planta & Saltos \\
\hline
\end{tabular}




\begin{tabular}{|c|c|c|c|c|}
\hline Familia & $\begin{array}{l}\text { Nombre científico } \\
\text { Nombre vulgar }\end{array}$ & RU & Parte usada & Empleo \\
\hline Fagaceae & $\begin{array}{l}\text { Quercus petraea } \\
\text { Q. pyrenaica } \\
\text { Q. robur } \\
\text { Roble, cajigo, matorro }\end{array}$ & 7 & Agalla & Canicas \\
\hline Leguminosae & $\begin{array}{l}\text { Pisum sativum } \\
\text { Arveja, guisante, morita }\end{array}$ & 2 & Semilla verde & Juego infantil \\
\hline Malvaceae & $\begin{array}{l}\text { Malva sylvestris } \\
\text { Malva, flor de malva }\end{array}$ & 2 & Fruto & Comiditas \\
\hline \multirow[t]{2}{*}{ Papaveraceae } & $\begin{array}{l}\text { Papaver rhoeas } \\
\text { Amapola, pirigallo }\end{array}$ & 3 & Flor & Juego infantil \\
\hline & $\begin{array}{l}\text { Papaver somniferum } \\
\text { Amapola, flor de la droga }\end{array}$ & 1 & Cápsulas & Sonajeros \\
\hline Plantaginaceae & $\begin{array}{l}\text { Digitalis purpurea } \\
\text { Dedalera, campanilla, cuete }\end{array}$ & 19 & Flor & Juego infantil \\
\hline Plumbaginaceae & $\begin{array}{l}\text { Armeria pubinervis } \\
\text { Flor de la corona }\end{array}$ & 2 & Flor & Coronas \\
\hline \multirow[t]{3}{*}{ Poaceae } & $\begin{array}{l}\text { Agrostis delicatula } \\
\text { Risas y coscas }\end{array}$ & 1 & Inflorescencia & Juego infantil \\
\hline & $\begin{array}{l}\text { Briza media } \\
\text { Corazones, corazoncitos }\end{array}$ & 1 & Parte aérea & Juego infantil \\
\hline & $\begin{array}{l}\text { Triticum aestivum } \\
\text { Trigo, mesino, tremesino }\end{array}$ & 3 & Semilla verde & Juego infantil \\
\hline \multirow[t]{2}{*}{ Polygonaceae } & $\begin{array}{l}\text { Rumex acetosa } \\
\text { Tallos, acera, acidera, cornicabra }\end{array}$ & 1 & Fruto & Comiditas \\
\hline & $\begin{array}{l}\text { Rumex crispus } \\
\text { Amargaza, acerón, ramagón }\end{array}$ & 4 & Fruto & Comiditas \\
\hline \multirow[t]{3}{*}{ Rosaceae } & $\begin{array}{l}\text { Crataegus monogyna } \\
\text { Espino, espino albar, majueto }\end{array}$ & 1 & Espinas & Juego infantil \\
\hline & $\begin{array}{l}\text { Rosa spp. cultivadas } \\
\text { Rosal }\end{array}$ & 1 & Espinas & Juego infantil \\
\hline & $\begin{array}{l}\text { Rubus ulmifolius } \\
\text { Zarza, moral, espino }\end{array}$ & 1 & Espinas & Juego infantil \\
\hline Xanthorrhoeaceae & $\begin{array}{l}\text { Asphodelus albus } \\
\text { Gamón, gamonita }\end{array}$ & 2 & Fruto & Comiditas \\
\hline Lycoperdaceae & $\begin{array}{l}\text { Lycoperdon perlatum } \\
\text { Pedo de lobo }\end{array}$ & 1 & $\begin{array}{l}\text { Cuerpo } \\
\text { fructífero }\end{array}$ & Juego infantil \\
\hline
\end{tabular}

La subcategoría Uso recreativo agrupa las plantas empleadas en todo tipo de juegos infantiles. El juego infantil es una actividad que sirve de ejemplo para mostrar el cambio de nuestra relación con la naturaleza. En el pasado los niños estaban familiarizados con las plantas y utilizaban lo que tenían a mano como entretenimiento.

Los juegos populares más citados fueron lanzar capachos (Arctium minus), explotar dedales (Digitalis purpurea), o insertarlos en los dedos, uso muy extendido por la Península Ibérica, con referencias en Cantalojas (Gil Pinilla, 1995), El Caurel (Blanco, 1996), Sanabria (Blanco \& Díez, 2005) o Los Arribes del Duero (González, 2009).

Otro juego generalizado fue utilizar gallarones (Quercus petraea, Q. pyrenaica, Q. robur) empleados en múltiples juegos que atendían a la imaginación infantil, como las canicas. También sacar jabón con la jabonera (Saponaria officinalis), al frotarla entre las manos producía una especie de espuma que suavizaba las manos y semejaba la sensación de haberse lavado con jabón, documentado de forma similar en el Baix Vallès (Bonet et al., 2008). 
Para el típico juego de las comiditas se mencionaron un sinfín de plantas que imitaban a la comida real, entre ellas la amargaza (Rumex acetosa, R. cripus), el gamón (Asphodelus albus), el vino (Muscari racemosum) o la malva (Malva sylvestris). Un juego común entre las niñas era practicar la adivinación arrancando las flores liguladas de las margaritas (Anthemis arvensis, Bellis perennis, $B$. sylvestris, Leucanthemum vulgare) recitando las palabras "me quiere o no me quiere".

\section{Alucinógenas, narcóticas y fumatorias:}

Se han recogido 408 registros de uso, correspondientes a 42 taxones de 24 familias botánicas diferentes, 31 taxones de obtención silvestre y 11 cultivados, representando un 50,81\% del total de registros de uso para la categoría Uso social, simbólico y ritual.

TABLA 107: Relación de taxones empleados en la subcategoría Alucinógenas, narcóticas y fumatorias, ordenados alfabéticamente por familia, indicando número de registros de uso (RU), parte usada y empleo.

\begin{tabular}{|c|c|c|c|c|}
\hline Familia & $\begin{array}{l}\text { Nombre científico } \\
\text { Nombre vulgar }\end{array}$ & RU & Parte usada & Empleo \\
\hline Amaranthaceae & $\begin{array}{l}\text { Beta vulgaris var. altissima } \\
\text { Remolacha, remolacha forrajera }\end{array}$ & 1 & Hojas & Fumatoria \\
\hline Apiaceae & $\begin{array}{l}\text { Scandix australis } \\
\text { Anís, anís de lastra }\end{array}$ & 4 & Hojas & Fumatoria \\
\hline Araliaceae & $\begin{array}{l}\text { Hedera helix } \\
\text { Hiedra, yedra, enredadera }\end{array}$ & 1 & Tallo & Boquilla \\
\hline \multirow[t]{2}{*}{ Betulaceae } & $\begin{array}{l}\text { Betula pubescens } \\
\text { Abedul }\end{array}$ & 1 & Semilla & Fumatoria \\
\hline & $\begin{array}{l}\text { Corylus avellana } \\
\text { Avellano }\end{array}$ & 19 & Corteza & Fumatoria \\
\hline \multirow[t]{2}{*}{ Ericaceae } & $\begin{array}{l}\text { Calluna vulgaris } \\
\text { Brezo, graspo, brecina }\end{array}$ & 1 & Flores & Fumatoria \\
\hline & $\begin{array}{l}\text { Erica spp. } \\
\text { Brezo, urz, ayuz, graspo }\end{array}$ & 4 & Flores & Fumatoria \\
\hline \multirow[t]{2}{*}{ Fagaceae } & $\begin{array}{l}\text { Fagus sylvatica } \\
\text { Haya }\end{array}$ & 1 & Hojas & Fumatoria \\
\hline & $\begin{array}{l}\text { Quercus petraea } \\
\text { Q. pyrenaica } \\
\text { Q. robur } \\
\text { Roble, cajigo, matorro }\end{array}$ & 19 & Hojas & Fumatoria \\
\hline Juglandaceae & $\begin{array}{l}\text { Juglans regia } \\
\text { Nogal }\end{array}$ & 1 & Hojas & Fumatoria \\
\hline \multirow[t]{2}{*}{ Lamiaceae } & $\begin{array}{l}\text { Mentha longifolia } \\
\text { Poleo, menta poleo, menta }\end{array}$ & 1 & Hojas & Fumatoria \\
\hline & $\begin{array}{l}\text { Origanum vulgare } \\
\text { Orégano }\end{array}$ & 2 & Parte aérea & Fumatoria \\
\hline Malvaceae & $\begin{array}{l}\text { Althaea officinalis } \\
\text { Malvarisco, malvavisco }\end{array}$ & 1 & Tallo hueco & Fumatoria \\
\hline \multirow[t]{2}{*}{ Polygonaceae } & $\begin{array}{l}\text { Rumex conglomeratus } \\
\text { Chuma }\end{array}$ & 2 & Fruto & Fumatoria \\
\hline & $\begin{array}{l}\text { Rumex crispus } \\
\text { Amargaza, planta del tabaco }\end{array}$ & 8 & Fruto & Fumatoria \\
\hline Salicaceae & $\begin{array}{l}\text { Populus alba } \\
\text { P. nigra } \\
\text { Chopo }\end{array}$ & 3 & Hojas & Fumatoria \\
\hline Solanaceae & $\begin{array}{l}\text { Nicotiana tabacum } \\
\text { Tabaco }\end{array}$ & 12 & Hojas & Fumatoria \\
\hline
\end{tabular}




\begin{tabular}{llccc}
\hline TABLA 107: & $\begin{array}{l}\text { (Continuación) Relación de taxones empleados en la subcategoría Alucinógenas, narcóticas y fumatorias, } \\
\text { ordenados alfabéticamente por familia, indicando número de registros de uso (RU), parte usada y empleo. }\end{array}$ \\
\hline Familia & $\begin{array}{l}\text { Nombre científico } \\
\text { Nombre vulgar }\end{array}$ & RU & Parte usada & Empleo \\
\hline Solanaceae & $\begin{array}{l}\text { Solanum tuberosum } \\
\text { Patata }\end{array}$ & 17 & Hojas & Fumatoria \\
Ulmaceae & $\begin{array}{l}\text { Ulmus minor } \\
\text { Olmo } \\
\text { Fomes fomentarius } \\
\text { Yesca, yezca }\end{array}$ & 8 & Hojas & Fumatoria \\
\hline
\end{tabular}

Incluidas todas las especies con alguna utilidad en el proceso de fumar.

En cuanto a las plantas empleadas como sustitutivo del tabaco en épocas de necesidad o escasez, destacan la corteza de avellano (Corylus avellana) y la hoja del roble (Quercus petraea, $Q$. pyrenaica, $Q$. robur) obteniendo ambas 19 registros de uso. El uso de la corteza de avellano es común en otras zonas de la Península Ibérica como Piloña (San Miguel, 2004), Palacios del Sil (García Jiménez, 2007), Gallecs (Bonet et al., 2008) y L’Alt Emporda (Parada, 2008).

Todas las especies con utilidad fumatoria son silvestres, excepto la patata (Solanum tuberosum) y el tabaco (Nicotiana tabacum), del cual se hacían pequeños cultivos en las huertas para autoconsumo, sus hojas secas y desmenuzadas se fumaban. Otras especies con utilidad fumatoria significativa en la zona fueron las hojas de olmo (Ulmus minor), de anís (Scandix australis) y de chopo (Populus alba, P. nigra), así como las flores de brezo (Erica spp.). Uno de los nombres vulgares de Rumex crispus es planta del tabaco, indicando en él su provecho como planta fumatoria.

El proceso de elaboración del cigarro consta de secado, picado o desmenuzado y liado del material vegetal sobre un fino papel de fumar, en ocasiones se añade una boquilla hueca del tallo de la hiedra (Hedera helix).

\section{Fobias y filias:}

Se ha recogido 1 registro de uso, correspondiente a 1 taxón de obtención silvestre de la familia Compositae, representando un $0,13 \%$ del total de registros de uso para la categoría Uso social, simbólico y ritual.

TABLA 108: Relación de especies empleadas en la subcategoría Fobias y filias, indicando familia, número de registros de uso (RU), parte usada y empleo.

\begin{tabular}{llccc}
\hline Familia & $\begin{array}{l}\text { Nombre científico } \\
\text { Nombre vulgar }\end{array}$ & RU & Parte usada & Empleo \\
\hline Compositae & $\begin{array}{l}\text { Taraxacum campylodes } \\
\text { Achicoria, diente de león }\end{array}$ & 1 & Planta & Mear la cama \\
\hline
\end{tabular}

El único registro de uso obtenido en la presente subcategoría es atribuido a la achicoria (Taraxacum campylodes), ya que en la localidad de Guardo se aconsejaba a los niños no jugar con estas plantas porque podían mear la cama por la noche. Su uso como diurético está muy extendido en otras zonas, de ahí su nombre de meacama, también recogido en Cantabria (Pardo de Santayana, 2008) y en la Sierra Norte de Madrid (Aceituno Mata, 2010). 


\section{Árboles $\mathrm{o}$ arbustos singulares :}

Se han recogido 17 registros de uso, correspondientes a 5 taxones de 4 familias botánicas diferentes, 3 taxones de obtención silvestre y 2 cultivados, representando un 2,12\% del total de registros de uso para la categoría Uso social, simbólico y ritual.

TABLA 109: Relación de especies mencionadas en la subcategoría Árboles o arbustos singulares, ordenadas alfabéticamente por familia, indicando número de registros de uso (RU), localización y ejemplar.

\begin{tabular}{|c|c|c|c|c|}
\hline Familia & $\begin{array}{l}\text { Nombre científico } \\
\text { Nombre vulgar }\end{array}$ & RU & Localización & Ejemplar \\
\hline Fagaceae & $\begin{array}{l}\text { Quercus petraea } \\
\text { Roble, cajigo, matorro }\end{array}$ & 11 & $\begin{array}{c}\text { Estalaya } \\
\text { Resoba } \\
\text { Lebanza } \\
\text { Valberzoso } \\
\text { Pisón de Castrejón }\end{array}$ & $\begin{array}{l}\text { Roblón de Estalaya } \\
\text { Roble de la Tenada } \\
\text { Roble de Lebanza } \\
\text { Roble del Escurridero } \\
\text { Roble de Matarraposera }\end{array}$ \\
\hline \multirow[t]{2}{*}{ Pinaceae } & $\begin{array}{l}\text { Cedrus libani } \\
\text { Cedro de los Orioles }\end{array}$ & 1 & Vallejo Orbó & Cedro de los Orioles \\
\hline & $\begin{array}{l}\text { Pinus nigra } \\
\text { Pino }\end{array}$ & 1 & Vallejo Orbó & Pino de Don Luis \\
\hline Taxaceae & $\begin{array}{l}\text { Taxus baccata } \\
\text { Tejo }\end{array}$ & 3 & Tejeda Tosande & \\
\hline Ulmaceae & $\begin{array}{l}\text { Ulmus minor } \\
\text { Olmo }\end{array}$ & 1 & Camporredondo de Alba & Olma \\
\hline
\end{tabular}

Existen arboles longevos con un tamaño y porte excepcional, algunos de ellos convertidos en emblemáticos y que forman parte del rico patrimonio natural de la Montaña Palentina. Por citar algún ejemplo de robles (Quercus petraea): el Roblón de Estalaya, el Roble de Lebanza y el de La Tenada en Resoba. Otras especies significativas son el olmo (Ulmus minor) de la plaza de Camporredondo de Alba y el cedro (Cedrus libani) de los Orioles en Vallejo de Orbó.

Varios informantes de localidades próximas a la Tejeda de Tosande señalaron la popularidad y peculiaridad de varios ejemplares de tejo (Taxus baccata) de este bosque único.

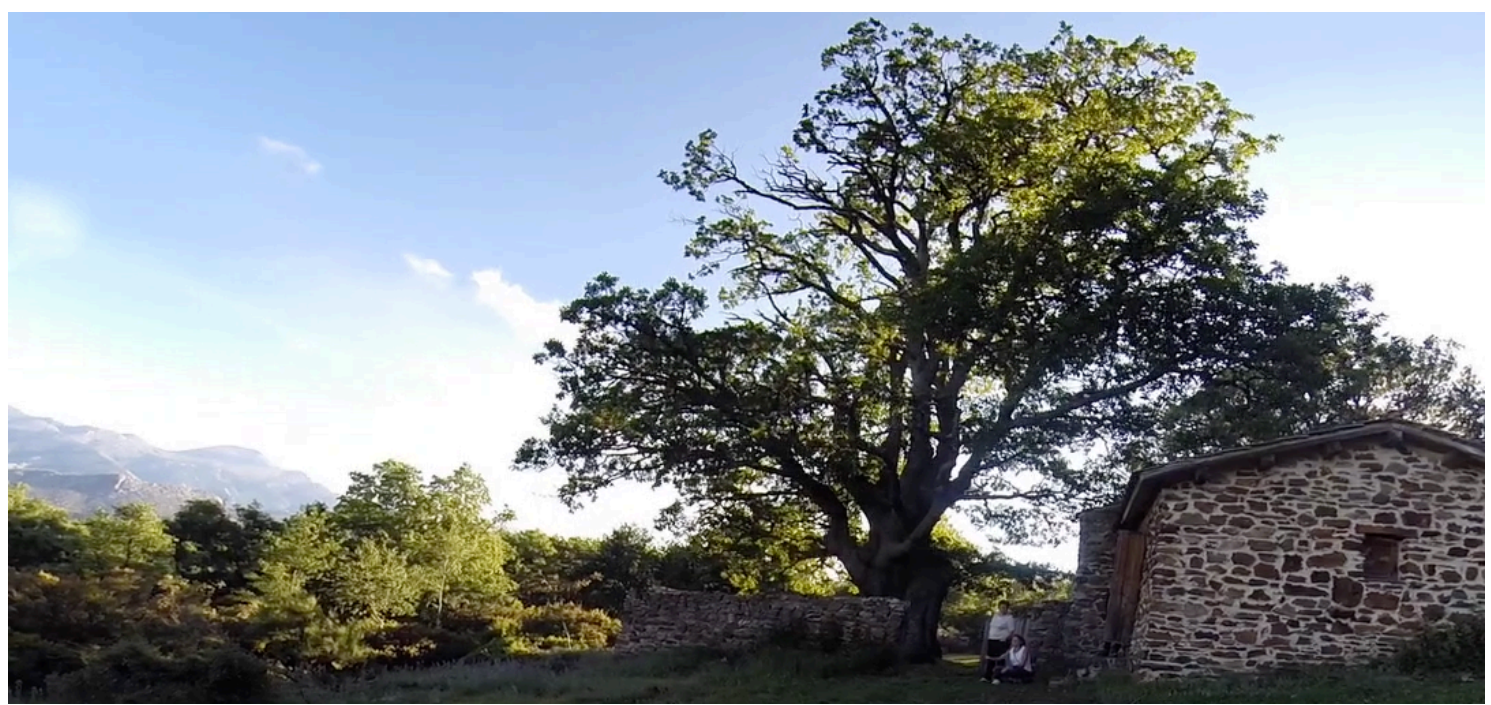

FIGURA 72: María de Resoba en el Roblón de la Tenada. 


\subsubsection{ANÁLISIS CUANTITATIVO DE LOS DATOS}

Una vez analizados los datos en función de la categoría de uso asignada, se examinan los resultados cuantitativos referidos exclusivamente a las especies de obtención silvestre citadas en el estudio.

Se han recogido usos de 327 taxones silvestres, siguiendo los criterios de Tardío y Pardo de Santayana (2008), se realiza una comparativa de las 20 especies con mayor valor.

\section{FRECUENCIA CitACIÓN (FC):}

La Frecuencia de Citación (FC) oscila entre 0 cuando una especie no es mencionada en ninguna entrevista, hasta 138 en el caso de nuestro estudio, resultando 139 el máximo posible.

TABLA 110: Relación de los 20 taxones silvestres con mayor Frecuencia de Citación (FC).

\begin{tabular}{|c|c|c|c|}
\hline Nombre científico & Nombre vulgar & Familia & $\begin{array}{c}\text { Frecuencia } \\
\text { de Citación (FC) }\end{array}$ \\
\hline Quercus spp. & Roble, cajigo, matorro & Fagaceae & 138 \\
\hline Cytisus scoparius & Escoba, ramo, escoba balera & Leguminosae & 126 \\
\hline Populus spp. & Chopo & Salicaceae & 122 \\
\hline Corylus avellana & Avellano & Betulaceae & 117 \\
\hline Chamaemelum nobile & Manzanilla, manzanilla campera & Compositae & 113 \\
\hline Prunus spinosa & Endrino, andino, espino & Rosaceae & 111 \\
\hline Salix spp. & Salguero, sota, salce, mimbrera & Salicaceae & 110 \\
\hline Ilex aquifolium & Acebo, aceba & Aquifoliaceae & 108 \\
\hline Rubus ulmifolius & Zarza, moral, espino & Rosaceae & 104 \\
\hline Fagus sylvatica & Haya & Fagaceae & 103 \\
\hline Sideritis hyssopifolia & Té, té de roca, té de lastra & Lamiaceae & 103 \\
\hline Origanum vulgare & Orégano & Lamiaceae & 102 \\
\hline Rumex acetosa & Tallos, acera, acedera, cornicabra & Polygonaceae & 102 \\
\hline Inula montana & Árnica & Compositae & 101 \\
\hline Crataegus monogyna & Espino, espino albar, majueto & Rosaceae & 99 \\
\hline Vaccinium myrtillus & Arráspano, ráspano, arándano & Ericaceae & 95 \\
\hline Erica spp. & Brezo, urz, ayuz, graspo & Ericaceae & 93 \\
\hline Sorbus aria & Mostajo, amostajo & Rosaceae & 93 \\
\hline Asphodelus albus & Gamón, gamonita & Xanthorrhoeaceae & 92 \\
\hline Malus sylvestris & Maíllo, amaíllo, maello, amaello & Rosaceae & 92 \\
\hline
\end{tabular}

El taxón silvestre con mayor frecuencia de citación es el roble (Quercus spp.) con 138 citas, un único informante no mencionó ninguna utilidad, le siguen a continuación la escoba (Cytisus scoparius) y el chopo (Populus spp.) con 126 y 122 citas, respectivamente.

Se comprueba que la frecuencia de citación otorga un mayor valor a aquellos taxones mencionados por mayor número de personas, sin otorgar relevancia al número de usos o a la importancia de los mismos. 


\section{NÚMERO DE USOS (NU):}

El número de usos (NU) oscila desde 1, en el caso de que una especie haya sido mencionada en una categoría de uso, hasta 9 en nuestro estudio, resultado 11 el máximo posible.

TABLA 111: Relación de los 20 taxones silvestres con mayor Número de Usos (NU).

\begin{tabular}{llll}
\hline Nombre científico & Nombre vulgar & Familia & Número de Usos (NU) \\
\hline Crataegus monogyna & Espino, espino albar, majueto & Rosaceae & 9 \\
\hline Sambucus nigra & Saúco, saúgo, sabúgo, taco & Adoxaceae & 8 \\
Erica spp. & Brezo, urz, ayuz, graspo & Ericaceae & 8 \\
Betula pubescens & Abedul & Betulaceae & 7 \\
Fagus sylvatica & Haya & Fagaceae & 7 \\
Quercus spp. & Roble, cajigo, matorro & Fagaceae & 7 \\
Cytisus scoparius & Escoba, ramo, escoba balera & Leguminosae & 7 \\
Sorbus aria & Mostajo, amostajo & Rosaceae & 7 \\
Sorbus aucuparia & Amargoso, serbal, drío, drido & Rosaceae & 7 \\
Pteridium aquilinum & Helecho, halecho & Dennstaedtiaceae & 6 \\
\hline Asphodelus albus & Gamón, gamonita & Xanthorrhoeaceae & 6 \\
Conium maculatum & Budaño, cañiguerra, canuto & Apiaceae & 6 \\
\hline Ilex aquifolium & Acebo, aceba & Aquifoliaceae & 6 \\
Corylus avellana & Avellano & Betulaceae & 6 \\
\hline Arctostaphylos uva-ursi & Gayuga, agayuga, gayuba & Ericaceae & 6 \\
Genista florida & Escoba, escoba albar, ramón & Leguminosae & 6 \\
Malva sylvestris & Malva, flor de malva & Malvaceae & 6 \\
\hline Fraxinus excelsior & Fresno & Oleaceae & 6 \\
Rumex crispus & Amargaza, acerón, ramagón & Polygonaceae & 6 \\
Prunus spinosa & Endrino, andrino, espino & Rosaceae & 6 \\
\hline
\end{tabular}

Destaca el espino (Crategus monogyna) como la especie silvestre con mayor número de usos, utilizada hasta en 9 categorías, las únicas categorías en las que no se mencionó ningún uso para esta especie fueron Veterinaria y Uso Tóxico y nocivo.

A continuación le sigue el saúco (Sambucus nigra) representado en 8 categorías de uso, utilizada en todas las categorías menos en Alimentación animal, Construcción y Uso Medioambiental, y el brezo (Erica spp.) empleado también en 8 categorías de uso, con citas en todas las categorías excepto en Alimentación humana, Veterinaria y Uso Tóxico y nocivo.

Observamos que las especies de porte arbóreo y arbustivo son las empleadas en mayor número de categorías. Encontramos ejemplos de especies herbáceas empleadas hasta en 6 categorías de uso como: Asphodelus albus, Conium maculatum, Malva sylvestris, Pteridium aquilinum o Rumex crispus.

\section{REGISTROS DE USO (RU):}

Se han recogido un total de 10438 registros de usos, por lo que el valor puede variar desde 0 cuando una especie no es mencionada por ningún informante en ninguna categoría, hasta 10438 en el caso de que todos los usos fueran mencionados en alguna de las categorías para la misma especie.

Los 3 taxones silvestres con mayor número de registros de uso son Quercus spp. (639), Populus spp. (335) y Fagus sylvatica (324). Comprobamos que los 12 taxones con mayor número de registros son especies arbóreas o arbustivas, Pardo de Santayana et al. (2006) afirman que las 
plantas más complejas tales como árboles y arbustos son más probables para ser plantas útiles (algunas veces con varios usos).

TABLA 112: Relación de los 20 taxones silvestres con mayor número de Registros de Uso (RU).

\begin{tabular}{|c|c|c|c|}
\hline Nombre científico & Nombre vulgar & Familia & Registros de Usos (RU) \\
\hline Quercus spp. & Roble, cajigo, matorro & Fagaceae & 639 \\
\hline Populus spp. & Chopo & Salicaceae & 335 \\
\hline Fagus sylvatica & Haya & Fagaceae & 324 \\
\hline Corylus avellana & Avellano & Betulaceae & 296 \\
\hline Cytisus scoparius & Escoba, ramo, escoba balera & Leguminosae & 243 \\
\hline Ilex aquifolium & Acebo, aceba & Aquifoliaceae & 233 \\
\hline Salix spp. & Salguero, sota, salce, mimbrera & Salicaceae & 205 \\
\hline Rosa spp. & Zarza, espino, rosal, calambrojo & Rosaceae & 181 \\
\hline Crataegus monogyna & Espino, espino albar, majueto & Rosaceae & 179 \\
\hline Prunus spinosa & Endrino, andrino, espino & Rosaceae & 177 \\
\hline Fraxinus excelsior & Fresno & Oleaceae & 166 \\
\hline Erica spp. & Brezo, urz, ayuz, graspo & Ericaceae & 162 \\
\hline Origanum vulgare & Orégano & Lamiaceae & 146 \\
\hline Ulmus minor & Olmo & Ulmaceae & 144 \\
\hline Chamaemelum nobile & Manzanilla, manzanilla campera & Compositae & 142 \\
\hline Rubus ulmifolius & Zarza, moral, espino & Rosaceae & 131 \\
\hline Sambucus nigra & Saúco, saúgo, sabúgo, taco & Adoxaceae & 120 \\
\hline Inula montana & Árnica & Compositae & 120 \\
\hline Sideritis hyssopifolia & Té, té de roca, té de lastra & Lamiaceae & 119 \\
\hline Asphodelus albus & Gamón, gamonita & Xanthorrhoeaceae & 110 \\
\hline
\end{tabular}

\section{frecuencia Relativa de Citación (FRC):}

La Frecuencia Relativa de Citación (FRC) en nuestro estudio oscila entre 0,01 y 0,99, muy cerca de su posible valor máximo 1.

TABLA 113: Relación de los 20 taxones silvestres con mayor Frecuencia Relativa de Citación (FRC).

\begin{tabular}{lllc}
\hline Nombre cientifico & Nombre vulgar & Familia & $\begin{array}{c}\text { Frecuencia Relativa } \\
\text { de Citación (FRC) }\end{array}$ \\
\hline $\begin{array}{l}\text { Quercus spp. } \\
\text { Cytisus scoparius }\end{array}$ & Roble, cajigo, matorro & Fagaceae & 0,99 \\
Populus spp. & Escoba, ramo, escoba balera & Leguminosae & 0,91 \\
Corylus avellana & Chopo & Salicaceae & 0,88 \\
Chamaemelum nobile & Manzanilla, manzanilla campera & Betulaceae & 0,84 \\
Prunus spinosa & Endrino, andino, espino & Rosaceae & 0,81 \\
Salix spp. & Salguero, sota, salce, mimbrera & Salicaceae & 0,80 \\
Ilex aquifolium & Acebo, aceba & Aquifoliaceae & 0,79 \\
Rubus ulmifolius & Zarza, moral, espino & Rosaceae & 0,78 \\
\hline Fagus sylvatica & Haya & Fagaceae & 0,75 \\
Sideritis hyssopifolia & Té, té de roca, té de lastra & Lamiaceae & 0,74 \\
\hline Origanum vulgare & Orégano & Lamiaceae & 0,74 \\
Rumex acetosa & Tallos, acera, acedera, cornicabra & Polygonaceae & 0,73 \\
\hline Inula montana & Árnica & Compositae & 0,73 \\
Crataegus monogyna & Espino, espino albar, majueto & Rosaceae & 0,73 \\
Vaccinium myrtillus & Arráspano, ráspano, arándano & Ericaceae & 0,71 \\
\hline Erica spp. & Brezo, urz, ayuz, graspo & Ericaceae & 0,68 \\
\hline Sorbus aria & Mostajo, amostajo & Rosaceae & 0,67 \\
\hline Asphodelus albus & Gamón, gamonita & Xanthorrhoeaceae & 0,67 \\
\hline Malus sylvestris & Maíllo, amaíllo, maello, amaello & Rosaceae & 0,66 \\
\hline
\end{tabular}


Se constata que el roble (Quercus spp.) obtuvo la frecuencia relativa de citación más alta, con un valor de 0,99, lo que significa que fue citado por un $99 \%$ de los informantes del estudio. Un alto índice de 0,91 obtuvo la escoba (Cytisus scoparius) y de 0,88 el chopo (Populus spp.).

Comparado con los estudios realizados en Campoo (Pardo de Santayana, 2003) y en La Pernía (Pascual, 2013) comprobamos que el roble (Quercus spp.) es la planta con una frecuencia relativa de citación más alto en todos ellos. También observamos como especies herbáceas como el té de roca (Sideritis hyssopifolia) y la manzanilla (Chamaemelum nobile) con un valor de 0,98 en el estudio de La Pernía obtienen valores más bajos en el presente estudio, debido a la ampliación del territorio y menor conocimiento de su uso en otras localidades, además en la zona de Campoo no aparecen entre las 20 especies con mayor frecuencia relativa de citación.

El haya (Fagus sylvatica) también disminuye su valor $(0,74)$ respecto a la zona de La Pernía $(0,88)$, motivado por la extensión de la comarca hacia áreas meridionales donde el haya no tiene presencia.

\section{ÍNDICE DE IMPORTANCIA CULTURAL (IC):}

El índice de Importancia Cultural (IC) oscila entre 0,01 y 4,60, lejos del máximo posible (11) debido a la dificultad de que una planta sea mencionada por todos los informantes en todas las categorías de uso.

TABLA 114: Relación de los 20 taxones silvestres con mayor Importancia Cultural (IC).

\begin{tabular}{|c|c|c|c|}
\hline Nombre científico & Nombre vulgar & Familia & $\begin{array}{c}\text { Importancia Cultural } \\
\text { (IC) }\end{array}$ \\
\hline Quercus spp. & Roble, cajigo, matorro & Fagaceae & 4,60 \\
\hline Populus spp. & Chopo & Salicaceae & 2,41 \\
\hline Fagus sylvatica & Haya & Fagaceae & 2,33 \\
\hline Corylus avellana & Avellano & Betulaceae & 2,13 \\
\hline Cytisus scoparius & Escoba, ramo, escoba balera & Leguminosae & 1,75 \\
\hline Ilex aquifolium & Acebo, aceba & Aquifoliaceae & 1,68 \\
\hline Salix spp. & Salguero, sota, salce, mimbrera & Salicaceae & 1,47 \\
\hline Rosa spp. & Zarza, espino, rosal, calambrojo & Rosaceae & 1,30 \\
\hline Crataegus monogyna & Espino, espino albar, majueto & Rosaceae & 1,29 \\
\hline Prunus spinosa & Endrino, andino, espino & Rosaceae & 1,27 \\
\hline Fraxinus excelsior & Fresno & Oleaceae & 1,19 \\
\hline Erica spp. & Brezo, urz, ayuz, graspo & Ericaceae & 1,17 \\
\hline Origanum vulgare & Orégano & Lamiaceae & 1,05 \\
\hline Ulmus minor & Olmo & Ulmaceae & 1,04 \\
\hline Chamaemelum nobile & Manzanilla, manzanilla campera & Compositae & 1,02 \\
\hline Rubus ulmifolius & Zarza, moral, espino & Rosaceae & 0,94 \\
\hline Inula montana & Árnica & Compositae & 0,86 \\
\hline Sambucus nigra & Saúco, saúgo, sabúgo, taco & Adoxaceae & 0,86 \\
\hline Sideritis hyssopifolia & Té, té de roca, té de lastra & Lamiaceae & 0,86 \\
\hline Rumex acetosa & Tallos, acera, acedera, cornicabra & Polygonaceae & 0,79 \\
\hline
\end{tabular}

En la relación de las 20 especies silvestres con mayor índice de Importancia Cultural expuestas en la tabla 114, destacan por su alto valor la presencia de especies arbóreas como el roble (Quercus spp.) que resulta ser la especie más versátil e importante de la zona de estudio con un valor de 4,60, el chopo (Populus spp.) o el haya (Fagus sylvatica), todas ellas de uso tradicional en la cultura popular de la Montaña Palentina, manejadas de forma frecuente 
como forraje para el ganado, como combustible, para la construcción de edificaciones y para la elaboración de diversas herramientas y utensilios por la versatilidad de la madera como materia prima.

Destacan también especies arbustivas como avellano (Corylus avellana), acebo (llex aquifolium), escoba (Cytisus scoparius), rosal (Rosa spp.), espino albar (Crataegus monogyna), endrino (Prunus spinosa) o brezo (Erica spp.). Muchas de estas especies incrementan su valor en este índice por la variedad de usos más que por las citas. En general, los árboles y arbustos poseen varios usos, más que las plantas herbáceas, encontrando resultados similares en otros estudios (San Miguel, 2004; Aceituno Mata, 2010).

Se observa como el sáuco (Sambucus nigra) y el árnica (Inula montana) obtienen valores idénticos en el índice de Importancia Cultural IC=0,86, sin embargo, distinta FC (frecuencia de citación: 80 frente a 101) y distinto NU (categorías de uso: 8 frente a 3).

La herbácea con mayor Índice de Importancia Cultural en el estudio resultó ser el orégano (Origanum vulgare) con un valor de 1,05, siendo utilizado frecuentemente como medicinal para el tratamiento de catarros y como condimento para para dar sabor a todo tipo de platos, guisos y en la tradicional matanza. Otro grupo relevante de herbáceas, lo forman las especies utilizadas en la medicina popular de la comarca, la manzanilla (Chamaemelum nobile), el árnica (Inula montana) y el té (Sideritis hyssopifolia), presentes aún en muchas casas de la zona y que sirven casi para sobreponerse a cualquier trastorno o enfermedad.

\section{IMPORTANCIA CULTURAL DE LAS CATEGORÍAS}

Otro modo interesante de analizar el índice de Importancia Cultural de un determinado taxón es valorando la relevancia que tiene este índice en cada categoría. En la figura 73 se muestran las 20 taxones silvestres con mayor índice de Importancia Cultural (IC) y la fracción que supone cada categoría de uso en el valor final del índice IC de cada una de ellas.

Observamos en dicha figura, la aportación a la categoría alimentación animal de taxones como: Quercus spp, Populus spp., Ilex aquifolium y Fraxinus excelsior, acreditado por el uso frecuente del ramón como forraje para el ganado. Además, los dos primeros taxones tienen altos valores en las categorías: combustible y construcción, llex aquifolium destaca en la categoría social, simbólica y ritual, y Fraxinus excelsior en industria y artesanía, categoría donde también destaca Salix spp. resultado de su utilización en cestería, herramientas y juguetes.

En cuanto a alimentación humana es el endrino (Prunus spinosa) la especie con mayor valor en el índice de Importancia Cultural en esta categoría, debido a la diversidad de usos alimentarios: empleada como fruta, como bebida alcohólica y como golosina aprovechando sus brotes tiernos.

Comprobamos que las categorías tóxica y nociva, medioambiental y ornamental tienen poca relevancia en el valor final del índice de Importancia Cultural en el listado de los 20 taxones silvestres con mayor índice de Importancia Cultural, se trata de categorías que congregan especies generalmente herbáceas y que tienen muy repartidos sus valores. 


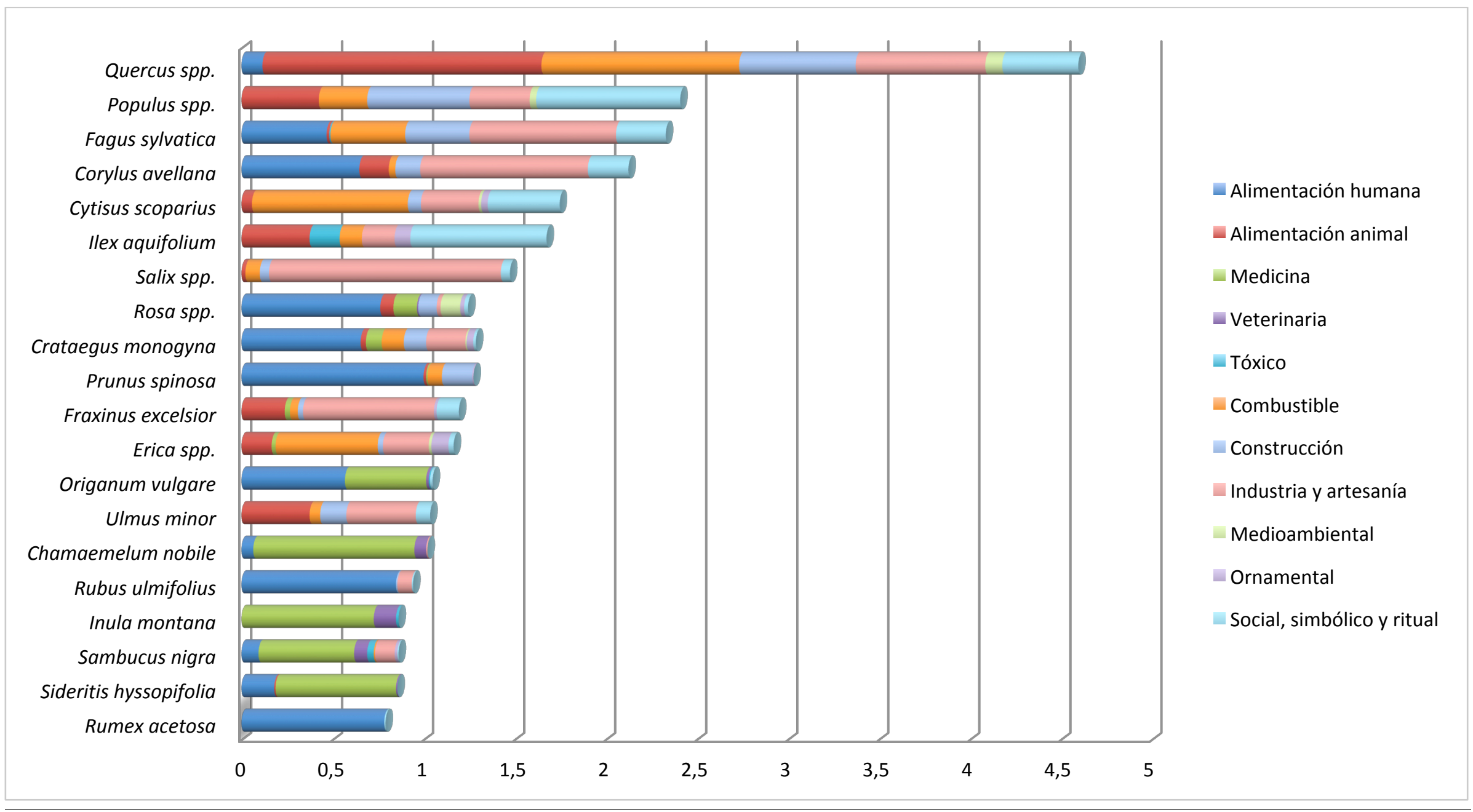

FIGURA 73: Listado de los 20 taxones silvestres con mayor valor en el índice de Importancia Cultural (IC), teniendo en cuenta los valores de cada una de las categorías de uso. 


\section{IMPORTANCIA CULTURAL DE LAS FAMILIAS}

Atendiendo al índice de Importancia Cultural (IC), la familia más destacada de las especies silvestres según la figura 74, es Rosaceae, que obtiene registros en todas las categorías de uso, aunque sin duda la categoría con mayor importancia en esta familia es la de alimentación humana, muchas especies pertenecientes a esta familia obtienen un alto valor en el índice de Importancia Cultural al ser sus frutos reconocidos y consumidos por gran cantidad de informantes, entre ellos: amíllomas (Amelanchier ovalis), majuetas (Crataegus monogyna), amiérganos (Fragaria vesca), maíllas (Malus sylvestris), endrinas (Prunus spinosa), calambrojos (Rosa spp.), antimoras (Rubus idaeus), moras (Rubus ulmifolius), mostajas (Sorbus aria). Además esta familia está representada hasta por 26 especies, lo que provoca el incremento en el índice de Importancia Cultural.

A continuación le sigue en importancia la familia Fagaceae representada por las grandes especies arbóreas que dominan el paisaje, roble (Quercus petraea, Q. pyrenaica, Q. robur) y haya (Fagus sylvatica) en la parte septentrional de la comarca y encina (Quercus rotundifolia) en pequeñas áreas de la parte meridional. Destaca la familia en las categorías alimentación animal, combustible e industria y artesanía, al igual que la familia Salicaceae.

Otras dos familias importantes son Compositae y Lamiaceae, que se distinguen en las categorías alimentación humana y medicina, observando que ambas pueden considerarse el botiquín de tratamientos de la comarca, además están representadas por 40 y 20 especies respectivamente. También Leguminosae tiene amplia representación con 21 especies, y registros en todas las categorías excepto la veterinaria.

Podemos concluir que las familias con mayor índice de Importancia Cultural en el estudio son: Rosaceae, Fagaceae, Compositae, Salicaceae, Leguminosae y Lamiaceae. En otros estudios etnobotánicos de la Península Ibérica consultados las familias más importantes fueron Leguminosae, Compositae, Rosaceae y Lamiaceae (Mesa, 1996; Bonet, 2001; Pardo de Santayana, 2003; Carvalho, 2005; Aceituno Mata, 2010), en algunos en diferente orden, resultados similares si exceptuamos la aparición de dos familias como Fagaceae y Salicaceae que obtienen gran número de registros en las categorías anteriormente mencionadas, resultando relevante la madera como materia prima en aplicaciones tecnológicas y artesanales, así como combustible para solventar la dureza de los rigores climatológicos de la zona, o como forraje.

Las especies de una misma familia botánica suelen tener propiedades y usos comunes, de tal modo que ciertas familias son especialmente adecuadas para determinados usos (Pardo de Santayana, 2008), este hecho se manifiesta en la familia Rosaceae que incluye cantidad de frutos comestibles, o en la familia Compositae con gran número de plantas medicinales u ornamentales. 


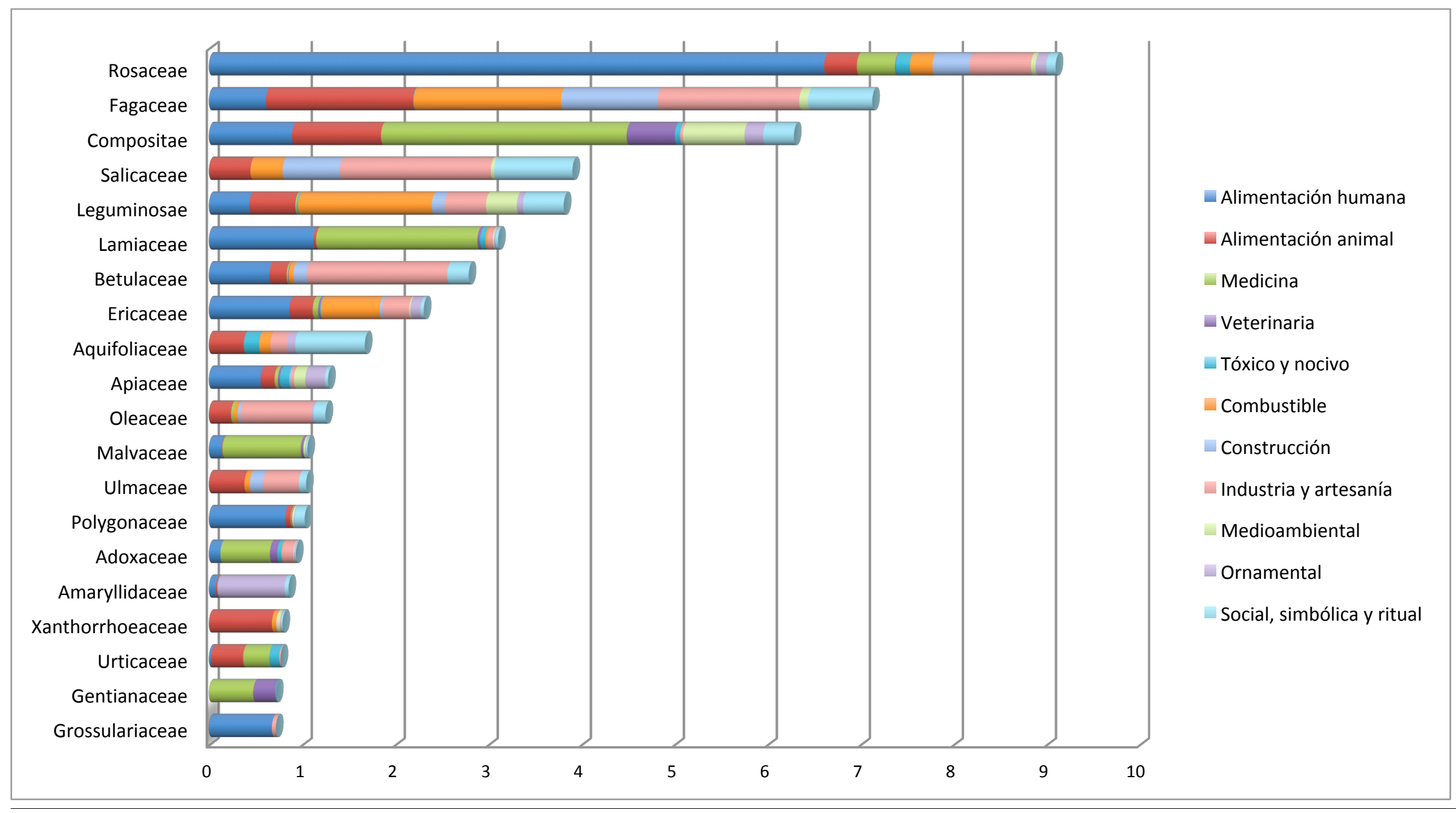

FIGURA 74: Listado de las 20 familias con mayor valor en el índice de Importancia Cultural (IC), teniendo en cuenta los valores de cada una de las categorías de uso. 


\section{COMPARATIVA DE ÍNDICES}

Considera Pardo de Santayana (2008) el Índice de Importancia Cultural (IC) como el índice más apropiado para evaluar la significación cultural de las especies en un estudio etnobotánico, así como para realizar comparaciones con el resto de índices.

Teniendo en cuenta esta consideración se realiza una comparación del índice de Importancia Cultural con el índice de Frecuencia Relativa de Citación según muestra la tabla 115, indicando el ranking basado en cada índice, así como los tres valores básicos del estudio, la Frecuencia de Citación (FC), número de registros de uso (RU) y número de categorías de uso (NU) para cada taxón.

TABLA 115: Comparativa de las plantas útiles en el área de estudio, usando dos índices cuantitativos. Listado de los primeros $\mathbf{2 0}$ taxones, ordenados según el índice Importancia cultural (IC) y orden de plantas basado en cada índice. Siendo: FC= Frecuencia de citación; RU = Registros de uso; NU = Número de categorías de uso; IC = Importancia cultural; FRC = Frecuencia relativa de citación.

\begin{tabular}{|c|c|c|c|c|c|c|c|c|}
\hline \multirow{2}{*}{ Nombre científico } & \multirow{2}{*}{ Nombre vulgar } & \multicolumn{3}{|c|}{ Valores } & \multicolumn{2}{|c|}{ Índices } & \multicolumn{2}{|c|}{ Orden } \\
\hline & & FC & RU & NU & IC & FRC & IC & FRC \\
\hline Quercus spp. & Roble, cajigo, matorro & 138 & 639 & 7 & 4,60 & 0,99 & 1 & 1 \\
\hline Populus spp. & Chopo & 122 & 335 & 6 & 2,41 & 0,88 & 2 & 3 \\
\hline Fagus sylvatica & Haya & 103 & 324 & 7 & 2,33 & 0,74 & 3 & 10 \\
\hline Corylus avellana & Avellano & 117 & 296 & 6 & 2,13 & 0,84 & 4 & 4 \\
\hline Cytisus scoparius & Escoba, ramo, escoba balera & 126 & 243 & 7 & 1,75 & 0,91 & 5 & 2 \\
\hline Ilex aquifolium & Acebo, aceba & 108 & 233 & 6 & 1,68 & 0,78 & 6 & 8 \\
\hline Salix spp. & Salguero, sota, salce, mimbrera & 110 & 205 & 5 & 1,47 & 0,79 & 7 & 7 \\
\hline Rosa spp. & Zarza, espino, rosal, calambrojo & 79 & 181 & 6 & 1,30 & 0,57 & 8 & 24 \\
\hline Crataegus monogyna & Espino, espino albar, majueto & 99 & 179 & 9 & 1,29 & 0,71 & 9 & 15 \\
\hline Prunus spinosa & Endrino, andino, espino & 111 & 177 & 6 & 1,27 & 0,80 & 10 & 6 \\
\hline Fraxinus excelsior & Fresno & 81 & 166 & 6 & 1,19 & 0,58 & 11 & 22 \\
\hline Erica spp. & Brezo, urz, ayuz, graspo & 93 & 151 & 3 & 1,09 & 0,68 & 12 & 17 \\
\hline Origanum vulgare & Orégano & 102 & 146 & 5 & 1,05 & 0,73 & 13 & 12 \\
\hline Ulmus minor & Olmo & 59 & 144 & 5 & 1,04 & 0,42 & 14 & 32 \\
\hline Chamaemelum nobile & Manzanilla, manzanilla campera & 113 & 142 & 4 & 1,02 & 0,81 & 15 & 5 \\
\hline Rubus ulmifolius & Zarza, moral, espino & 104 & 131 & 4 & 0,94 & 0,75 & 16 & 9 \\
\hline Inula montana & Árnica & 101 & 120 & 3 & 0,86 & 0,73 & 17 & 14 \\
\hline Sambucus nigra & Saúco, saúgo, sabúgo, taco & 80 & 120 & 8 & 0,86 & 0,58 & 18 & 23 \\
\hline Sideritis hyssopifolia & Té, té de roca, té de lastra & 103 & 119 & 4 & 0,86 & 0,74 & 19 & 11 \\
\hline Rumex acetosa & Tallos, acera, acedera, cornicabra & 102 & 110 & 2 & 0,79 & 0,73 & 20 & 13 \\
\hline
\end{tabular}

Quercus spp. es el taxón que se sitúa en primera posición en los dos índices analizados, resulta lógico al comprobar su alta frecuencia de citación $\mathrm{FC}=138$, y el valor más alto en registros de uso $\mathrm{RU}=639$. Su predominio en el paisaje y su versatilidad en usos confirman a este taxón como el más importante en ambos índices en la zona de estudio.

Resulta interesante el análisis de los índices referidos al haya (Fagus sylvatica), ocupa el tercer puesto en orden de Importancia Cultural y sin embargo, desciende hasta el décimo puesto en cuanto a Frecuencia Relativa de Citación, esto es debido a que a su Frecuencia de Citación FC = 103 es superada por hasta 9 taxones, lo que provoca una penalización en el orden de Frecuencia Relativa de Citación. La valoración de la versatilidad de usos de esta especie NU= 7 y la gran cantidad de registros de uso $\mathrm{RU}=324$, inducen el ascenso hasta el tercer puesto en el índice de Importancia Cultural. Los hayedos se situan en el área septentrional de la comarca, por lo que las citas se concentran en su mayoría en las localidades en las que aparece, siendo superado en Frecuencia de Citación por especies con una mayor distribución en la zona como el endrino (Prunus spinosa) o la manzanilla (Chamaemelum nobile). 
En caso contrario al haya, podemos indicar a la escoba (Cytisus scoparius) que ocupa el segundo puesto en orden de Frecuencia Relativa de Citación, con una alta distribución por toda la comarca y con gran número de citas, y sin embargo desciende hasta el quinto puesto en el índice de Importancia Cultural, al obtener menos registros de uso RU= 243 que otras especies.

Unicamente se mantienen en el mismo puesto de orden para los dos índices, el avellano (Corylus avellana) y el salguero (Salix spp.), cuarto y séptimo, respectivamente.

La especie con mayor número de usos NU=9, fue el espino (Crataegus monogyna), esta gran diversidad de usos elevan su posición en el índice de Importancia Cultural hasta el noveno puesto, frente a la Frecuencia Relativa de Citación que solo alcanza el decimoquinto lugar.

El menor valor en cuanto a número de usos $\mathrm{N}=2$ fue para la acera (Rumex acetosa), pero el gran número de citas $\mathrm{FC}=102$, logran aupar a esta especie hasta el puesto decimotercero en Frecuencia Relativa de Citación y el vigésimo en Importancia Cultural.

Otro ejemplo significativo observamos en el olmo (Ulmus minor), con poca frecuencia de citación $\mathrm{FC}=59$, a pesar de su amplia distribución por toda la comarca, pero con elevado número de registros de uso $\mathrm{RU}=144$, lo que ocasiona que ocupe el puesto decimocuarto en el índice de Importancia Cultural y caiga al trigesimosegundo en Frecuencia Relativa de Citación.

\section{COMPARATIVA DEL ÍNDICE DE IMPORTANCIA CULTURAL CON OTROS ESTUDIOS}

Según Heinrich et al. (1998) el término "Importancia Cultural" alude a plantas utilizadas por una gran cantidad de personas en una misma categoría de uso, asumiendo la idea de consenso cultural para valorar la importancia de las plantas para la gente. De acuerdo a Albuquerque et al. (2006) los términos "importancia cultural e importancia relativa" vienen a referir la importancia de ciertas plantas en una determinada cultura. Por todo ello Pardo de Santayana (2008) considera el término de "Importancia Cultural" el más apropiado para el índice propuesto.

Una de las ventajas más importantes de utilizar el Índice de Importancia Cultural (IC) es que es válido para comparar el conocimiento botánico de diferentes regiones estudiadas con un número variado de entrevistados (Pardo de Santayana et al., 2007). Esto es debido a que las variables de peso del índice IC son independientes del número de informadores, el denominador del índice.

En general, los índices de importancia cultural no miden el uso actual (usos activos) de las plantas, prefieren medir el conocimiento sobre su uso (conocimiento pasivo). El índice IC resulta muy útil para estudios cuyo objetivo principal es recopilar un registro de conocimientos pasivos. También es una herramienta eficaz para descubrir formas de acuerdos y desacuerdos en el conocimiento de plantas. El valor del índice IC de una planta para parte de la población no discrimina si una planta es importante para una categoría particular o para diversidad de categorías.

El acuerdo o desacuerdo en el uso de una planta también depende del espacio geográfico que se delimite en el estudio. Una planta con bajo consenso en el estudio puede ser importante para las personas de un determinado área. Este es el caso en nuestro estudio del tejo (Taxus baccata) el cual fue mencionado solamente en ciertas localidades donde destaca su presencia, 
sin embargo el índice IC puede comparar el conocimiento de plantas estudiando las diferencias intraculturales de demarcaciones geográficas establecidas.

Como se apuntaba anteriormente, una de las mayores ventajas del empleo del índice de Importancia Cultural es la comparación de datos entre diferentes regiones. Por ello procedemos a comparar estudios en los que se realiza un análisis de este índice para todas las especies en todas las categorías de uso propuestas. Los resultados se muestran en la tabla 116, en la cual aparece una comparación del índice de Importancia Cultural (IC) en cuatro áreas de estudio: "Comarca de Campoo" (Pardo de Santayana, 2003), "La Pernía, Polentinos y Valle de Castillería" (Pascual, 2013), "Comarca del Cerrato Palentino" (Pascual, 2016), y "Comarca Montaña Palentina", además se indica la Frecuencia de Citación (FC), Número de registros de uso (RU) y Número de categorías de uso (NU) para cada especie.

El estudio de Campoo (Pardo de Santayana, 2003) recopila conocimientos de plantas empleadas en el último siglo. La información se obtuvo a través de entrevistas realizadas a 107 personas de la comarca, distribuyendo la información en 10 categorías de uso, las mismas que para el estudio de La Pernía, Polentinos y Valle de Castillería (Pascual, 2013), que recoge información de 50 entrevistas. El estudio sobre la Montaña Palentina y el del Cerrato Palentino se distribuyen en 11 categorías de uso y recopilan información de 139 y 45 entrevistas, respectivamente.

Resultan valores más elevados del índice de Importancia Cultural en la Montaña Palentina y en La Pernía, Polentinos y Valle de Castillería, debido a una notable diferencia en la cantidad de número de registros de uso (RU) recogidos para cada especie, superior a los de la zona del Cerrato y de Campoo. También se puede acusar a un mayor consenso en el conocimiento existente entre las personas de estas zonas. La similitud de valores entre la zona de la Montaña Palentina y La Pernía, Polentinos y Valle de Castillería se justifica al estar el territorio de esta última englobada dentro de la primera, lo que confirma la homogeneidad de la zona en cuanto al conocimiento de la utilidad de las plantas, a pesar de la ampliación del área de estudio.

En primer lugar observamos que en el orden del índice de Importancia Cultural (IC) el roble (Quercus spp.) se sitúa en el primer puesto, y el haya (Fagus sy/vatica) en el tercero, en 2 de los estudios contrastados (Pardo de Santayana, 2003; Pascual, 2013), también mantienen esta posición en el presente trabajo. Una especie del mismo género (Quercus rotundifolia) es también la más destacada en este índice en la comarca del Cerrato, comprobando de este modo, que el tipo de bosque de un territorio determina la importancia cultural de las especies y por tanto su utilidad.

Aparecen especies arbóreas y arbustivas con valores elevados de IC en todos los estudios, a destacar el avellano (Corylus avellana), el acebo (Ilex aquifolium), el saúco (Sambucus nigra) y el espino albar (Crataegus monogyna) en los estudios de las zonas más septentrionales con clima de influencia océanica (Pardo de Santayana, 2003; Pascual, 2013), y romero (Rosmarinus officinalis) y lavanda (Lavandula latifolia) en el estudio de la zona más meridional con clima continental mediterráneo (Pascual, 2016), por tanto las especies de carácter arbustivo que se presentan en un territorio tienen valores elevados en el índice de importancia cultural, mostrando también gran versatilidad de usos, utilizadas todas ellas en más de 5 categorías de uso. 
TABLA 116: Comparativa de las plantas útiles en cuatro estudios etnobotánicos. Listado de los primeros 20 taxones en todos los estudios, siguiendo el orden del índice de Importancia Cultural (IC). Siendo FC = frecuencia de citación; RU = número de registros de uso; NU = número de categorías de uso; IC = índice de importancia cultural.

ESTUDIO ETNOBOTÁNICO COMARCA MONTAÑA PALENTINA (PALENCIA)

\section{ESTUDIO ETNOBOTÁNICO}

LA PERNÍA, POLENTINOS Y CASTILLERÍA

(PALENCIA)

Pascual (2013)

\begin{tabular}{lcc}
\hline Taxones & FC & RU \\
\hline Quercus spp. & 138 & 639 \\
\hline Populus spp. & 122 & 335 \\
\hline Fagus sylvatica & 103 & 324 \\
Corylus avellana & 117 & 296 \\
Cytisus scoparius & 126 & 243 \\
\hline Ilex aquifolium & 108 & 233 \\
Salix spp. & 110 & 205 \\
\hline Rosa spp. & 79 & 181 \\
\hline Crataegus monogyna & 99 & 179 \\
\hline Prunus spinosa & 111 & 177 \\
\hline Fraxinus excelsior & 81 & 166 \\
\hline Erica spp. & 93 & 151 \\
\hline Origanum vulgare & 102 & 146 \\
\hline Ulmus minor & 59 & 144 \\
\hline Chamaemelum nobile & 113 & 142 \\
\hline Rubus ulmifolius & 104 & 131 \\
\hline Inula montana & 101 & 120 \\
\hline Sambucus nigra & 80 & 120 \\
\hline Sideritis hyssopifolia & 103 & 119 \\
Rumex acetosa & 102 & 110 \\
\hline
\end{tabular}

\begin{tabular}{cc|lc} 
NU & IC & Taxones & FC \\
\hline 7 & 4,60 & Quercus spp. & 49 \\
6 & 2,41 & Corylus avellana & 48 \\
7 & 2,33 & Fagus sylvatica & 44 \\
6 & 2,13 & Populus nigra & 45 \\
7 & 1,75 & Ilex aquifolium & 43 \\
6 & 1,68 & Cytisus scoparius & 48 \\
5 & 1,47 & Origanum vulgare & 47 \\
6 & 1,30 & Sorbus aria & 4 \\
9 & 1,29 & Rosa spp. & 4 \\
6 & 1,27 & Crategus monogyna & 40 \\
6 & 1,19 & Sambucus nigra & 42 \\
3 & 1,09 & Sideritis hyssopyfolia & 49 \\
5 & 1,05 & Anthemis nobilis & 49 \\
5 & 1,04 & Vaccinium myrtillus & 48 \\
4 & 1,02 & Prunus spinosa & 47 \\
4 & 0,94 & Asphodelus albus & 43 \\
3 & 0,86 & Erica spp. & 33 \\
8 & 0,86 & Fraxinus excelsior & 31 \\
4 & 0,86 & Fragaria vesca & 45 \\
2 & 0,79 & Rubus ulmifolius & 43 \\
\hline
\end{tabular}

\begin{tabular}{lll}
\hline FC & RU \\
\hline 49 & 170 \\
48 & 112 \\
44 & 105 \\
45 & 90 \\
43 & 89 \\
48 & 87 \\
47 & 71 \\
44 & 60 \\
40 & & 59 \\
40 & & \\
42 & & \\
49 & & \\
49 & & \\
48 & & \\
47 & & \\
43 & 47 \\
33 & 46 \\
31 & 46 \\
45 & 45 \\
43 & 44 \\
\hline
\end{tabular}

\begin{tabular}{lcc|ll} 
& NU & IC & Taxones & FC \\
\hline 2 & 6 & 3,40 & Quercus spp. & 42 \\
2 & 6 & 2,24 & Crategus monogyna & 38 \\
5 & 5 & 2,10 & Fagus sy/vatica & 31 \\
0 & 4 & 1,80 & llex aquifolium & 36 \\
9 & 7 & 1,78 & Corylus avellana & 37 \\
8 & 6 & 1,74 & Sambucus nigra & 3 \\
1 & 3 & 1,42 & Ulmus minor & 30 \\
0 & 5 & 1,20 & Origanum vulgare & 36 \\
5 & 6 & 1,18 & Rubus ulmifolius & 33 \\
8 & 5 & 1,16 & Urtica dioica & 32 \\
4 & 4 & 1,08 & Rosa spp. & 2 \\
1 & 2 & 1,02 & Prunus spinosa & 32 \\
1 & 2 & 1,02 & Fraxinus excelsior & 32 \\
0 & 2 & 1,00 & Pteridium aquilinum & 23 \\
8 & 2 & 0,96 & Rumex acetosa & 36 \\
\hline 6 & 3 & 0,94 & Populus nigra & 28 \\
6 & 5 & 0,92 & Anthemis nobilis & 31 \\
6 & 5 & 0,92 & Salix spp. & 23 \\
45 & 1 & 0,90 & Asphodelus albus & 25 \\
44 & 2 & 0,88 & Ulex gallii & 22
\end{tabular}

ESTUDIO ETNOBOTÁNICO COMARCA DE CAMPOO

(CANTABRIA)

Pardo de Santayana (2003)
ESTUDIO ETNOBOTÁNICO COMARCA DEL CERRATO

(PALENCIA)

Pascual (2016)

\begin{tabular}{cccc|lcccc} 
FC & RU & NU & IC & Taxones & FC & RU & NU & IC \\
\hline 42 & 64 & 7 & 0,60 & Quercus rotundifolia & 42 & 102 & 6 & 2,27 \\
38 & 56 & 9 & 0,52 & Populus spp. & 40 & 95 & 7 & 2,11 \\
31 & 54 & 8 & 0,50 & Quercus faginea & 37 & 87 & 7 & 1,93 \\
36 & 50 & 7 & 0,47 & Rosmarinus officinalis & 41 & 86 & 7 & 1,91 \\
37 & 48 & 7 & 0,45 & Lavandula latifolia & 34 & 68 & 8 & 1,51 \\
36 & 48 & 4 & 0,45 & Papaver rhoeas & 37 & 66 & 5 & 1,47 \\
30 & 48 & 4 & 0,45 & Ulmus minor & 36 & 64 & 7 & 1,42 \\
36 & 45 & 2 & 0,42 & Thymus zygis & 37 & 61 & 7 & 1,36 \\
33 & 45 & 8 & 0,42 & Rosa spp. & 27 & 49 & 7 & 1,09 \\
32 & 44 & 6 & 0,41 & Malva sylvestris & 30 & 42 & 6 & 0,93 \\
29 & 43 & 4 & 0,40 & Helichrysum stoechas & 37 & 41 & 4 & 0,91 \\
32 & 42 & 6 & 0,39 & Prunus spinosa & 33 & 39 & 3 & 0,87 \\
32 & 42 & 5 & 0,39 & Crataegus monogyna & 25 & 38 & 8 & 0,84 \\
23 & 41 & 6 & 0,38 & Salvia officinalis & 23 & 37 & 7 & 0,82 \\
36 & 38 & 3 & 0,36 & Genista scorpius & 27 & 37 & 5 & 0,82 \\
28 & 38 & 5 & 0,36 & Rubus ulmifolius & 32 & 37 & 5 & 0,82 \\
31 & 34 & 4 & 0,32 & Medicago sativa & 28 & 36 & 3 & 0,80 \\
23 & 34 & 6 & 0,32 & Prunus dulcis & 30 & 35 & 3 & 0,78 \\
25 & 32 & 4 & 0,30 & Prunus cerasus & 27 & 33 & 4 & 0,73 \\
22 & 29 & 5 & 0,27 & Salix spp. & 27 & 30 & 5 & 0,67 \\
\hline
\end{tabular}


Una especie arbustiva de gran importancia en la Montaña Palentina y en La Pernía, Polentinos y Valle de Castillería como es la escoba (Cytisus scoparius) no aparece entre los 20 valores más altos de IC en la zona de Campoo, a pesar de comprobar que otras escobas (Cytisus cantabricus, Genista florida), tienen las mismas utilidades que en las zonas señaladas. La importancia de estas especies viene generalmente dada por su uso frecuente como combustible, en la comarca del Cerrato no se desarrolla esta especie, pero con uso combustible aparece la olaga (Genista scorpius) con un alto valor 0,82 en importancia cultural.

Otras similitudes de este estudio con otros trabajos previos (Pardo de Santayana, 2003; Pascual, 2013) aparecen al analizar las especie herbáceas, aparel orégano (Origanum vulgare) es la primera herbácea y la manzanilla (Chamaemelum nobile) también se encuentra entre las especies herbáceas más significativas en el orden IC. Sin embargo, en la comarca del Cerrato las primeras especie herbáceas son la amapola (Papaver rhoeas) y la malva (Malva sylvestris) con numerosos registros en la subcategoría de Malas hierbas. Estas diferencias están relacionadas a que en la comarca del Cerrato tiene mayor relevancia la explotación agrícola, mientras que en las otras tres lo es la ganadería.

En el orden de las veinte especies con mayor valor en el índice de Importancia Cultural encontramos 13 especies coincidentes con 2 estudios (Pardo de Santayana, 2003; Pascual, 2013), 15 especies coincidentes entre la zona de la Montaña Palentina y la de La Pernía, Polentinos y Valle de Castillería, y otras 15 entre la zona de la Montaña Palentina y la de Campoo. La cercanía de los territorios estudiados justifica la gran similitud existente en el listado de especies. Solamente 3 especies coinciden en todos los estudios comparados (Populus nigra, Crataegus monogyna y Rubus ulmifolius).

En resumen, se puede concluir que el Índice de Importancia Cultural nos sirve para medir el valor cultural de las plantas con utilidad en diferentes regiones, permitiendo probar diferentes hipótesis bajo el análisis de la estadística.

\section{ÍNDICE DE VIGENCIA (IV):}

Los valores del índice de Vigencia en nuestro estudio oscilan entre 0,01 y 0,69, lejos del máximo posible (11) debido a la dificultad de que una planta sea mencionada por todos los informantes en todas las categorías de uso y tenga vigentes todos sus usos. En el caso de que el índice de este valor resulte bajo, significa que nos encontramos ante la posible desaparición del uso de una especie.

En la relación de las 20 especies silvestres con mayor índice de Vigencia expuestas en la tabla 117 , observamos los mayores valores en especies herbáceas, destaca en el primer puesto el orégano (Origanum vulgare), debido a que se sigue recolectando como condimento para cocinar, además se utiliza de forma residual para elaboración de embutidos en la matanza del cerdo, puesto que la tradicional cría del cerdo se ha abandonado progresivamente. Según Pieroni et al. (2002) el saber relacionado con las plantas silvestres de uso alimentario tiene mayor probabilidad de conservarse, al estar ligado a la cocina tradicional y a los aspectos sociales que suponen su recolección y procesado. 
TABLA 117: Relación de los 20 taxones silvestres con mayor índice de Vigencia (IV).

\begin{tabular}{lllc}
\hline Nombre científico & Nombre vulgar & Familia & Índice de Vigencia (IV) \\
\hline Origanum vulgare & Orégano & Lamiaceae & 0,64 \\
Sideritis hyssopifolia & Té, té de roca, té de lastra & Lamiaceae & 0,59 \\
Chamaemelum nobile & Manzanilla, manzanilla campera & Compositae & 0,57 \\
Rubus ulmifolius & Zarza, moral, espino & Rosaceae & 0,57 \\
Quercus spp. & Roble, cajigo, matorro & Fagaceae & 0,46 \\
Cytisus scoparius & Escoba, ramo, escoba balera & Leguminosae & 0,42 \\
Prunus spinosa & Endrino, andino, espino & Rosaceae & 0,32 \\
Populus spp. & Chopo & Salicaceae & 0,27 \\
Corylus avellana & Avellano & Betulaceae & 0,26 \\
Erica spp. & Brezo, urz, ayuz, graspo & Ericaceae & 0,15 \\
Fagus sylvatica & Haya & Fagaceae & 0,14 \\
Genista florida & Escoba, escoba albar, ramón & Leguminosae & 0,13 \\
Malva sylvestris & Malva, flor de malva & Malvaceae & 0,13 \\
Malus sylvestris & Maíllo, amaíllo, maello & Rosaceae & 0,11 \\
Vaccinium myrtillus & Arráspano, ráspano, arándano & Ericaceae & 0,11 \\
Narcissus pseudonarcisus & Lirón, lirio, cancarico & Amaryllidaceae & 0,10 \\
\hline Helichrysum stoechas & Manzanilla, manzanilla de lastra & Compositae & 0,10 \\
Sambucus nigra & Saúco, saúgo, sabúgo, taco & Adoxaceae & 0,10 \\
Thymus zygis & Tomillo, cepico & Lamiaceae & 0,10 \\
Sempervivum vicentei & Siempreviva, suelda, sanalotodo & Crassulaceae & 0,09 \\
\hline
\end{tabular}

La población de la comarca sufre un claro decrecimiento desde los años 60 del siglo XX, la mayoría de la población es gente envejecida y que ha abandonado las actividades ganaderas tradicionales de la comarca, no apareciendo en el listado ninguna especie con uso vigente en alimentación animal o veterinaria. Sin embargo, si aparecen plantas de uso medicinal muy arraigadas en las costumbres locales y que en la actualidad continúan con plena vigencia, es el caso de especies como el té (Sideritis hyssopifolia), la manzanilla (Chamaemelum nobile, Helichrysum stoechas) y la malva (Malva sylvestris), utilizadas con gran frecuencia en infusiones o cataplasmas, en tratamientos de enfermedades poco importantes como dolores de barriga, catarros o golpes. Resultados similares encontramos en la provincia de León, donde aún se usan especies para tratar enfermedades banales, del resto de especies se ha perdido su uso (García Jiménez, 2007).

Respecto a las plantas de uso alimentario, sigue vigente el uso de algunos frutos silvestres recolectados de forma esporádica en paseos por el monte, bien para consumirlos en el momento, o bien para elaborar mermeladas o bebidas alcohólicas, preparaciones que se han ido incorporando en la cultura local, es el caso de las moras (Rubus ulmifolius), endrinas (Prunus spinosa), avellanas (Corylus avellana), maíllas (Malus sylvestris) o arráspanos (Vaccinium myrtillus). La recolección se sigue realizando no tanto por necesidad sino por recodar sabores y mantener costumbres que dan cohesión a las familias y a la comunidad (Aceituno Mata, 2010). Otras especies de uso alimentario se han asociado en la comarca a síntomas de pobreza, consumidas en épocas de gran escasez de recursos como fue la Posguerra, por lo que su uso no se ha conservado más que en la memoria de aquellos que sufrieron las penurias del momento. Algunos informantes denominaron estos alimentos silvestres con la palabra "garauja", término de carácter peyorativo que indica el desprecio que se tenía a la realización de estas actividades para combatir la hambruna del momento.

En la actualidad, la micología ha experimentado un aumento considerable en su valoración cultural e interés, la descofianza y el miedo que provocaba su consumo se ha superado y son consideradas como un recurso alimenticio a explotar. Continúa vigente el uso de las setas más apreciadas en la comarca, en concreto la senderilla (Marasmius oreades) y la seta blanca 
(Calocybe gambosa), otras especies se aprovechan en la actualidad pero sin embargo no eran ni siquiera reconocidas en el pasado.

Con altos valores aparecen especies arbóreas como el roble (Quercus spp.), el chopo (Populus spp.) y el haya (Fagus sylvatica), y arbustivas como las escobas (Cytisus scoparius, Genista florida) o el brezo (Erica spp.), cuyo manejo está ligado a actividades ganaderas, a la tecnología y la artesanía tradicional, y al uso combustible, es precisamente este último uso el único que permanece vigente en la comarca, pues sigue siendo la madera la principal fuente de energía empleada aún como combustible para calentar el hogar durante el invierno.

En el listado encontramos especies de uso fundamentalmente ornamental, el lirón (Narcissus pseudonarcissus) o la siempreviva (Sempervivum vicentei), aún se recolectan especies para la decoración del hogar y el jardín, el abandono de las labores del campo y la mayor disponibilidad de tiempo para los asuntos estéticos en el hogar mantienen la vigencia de uso de especies ornamentales, e incluso la incorporación de otras nuevas.

Por tanto, podemos comprobar cómo la vigencia o abandono de los usos está relacionado con las categorías, se mantienen algunos usos alimentarios derivados de la cocina tradicional de la comarca, o de aquellas actividades lúdicas por el campo que conllevan aprovechamientos esporádicos de determinados frutos o setas. Perduran también algunos usos combustibles y ornamentales, así como los medicinales que tratan problemas leves de salud, sin embargo, los usos veterinarios, ganaderos, medioambientales, tecnológicos y artesanales y los relacionados con la construcción se encuentran prácticamente abandonados. Los usos en el ámbito social, simbólico y ritual, también están en claro retroceso, pocas fiestas y tradiciones se mantienen vigentes, como el pinado del mayo en Velilla del Río Carrión que trata de restablecer el esplendor de esta celebración en el pasado.

En resumen, existe una pérdida importante de usos y conocimientos populares relacionados con las plantas, motivada por los cambios socioeconómicos que han alterado el tradicional modo de vida y consiguiente alteración de los usos de las plantas en la comarca.

\section{RELACIÓN ENTRE VIGENCIA E IMPORTANCIA CULTURAL}

Una vez analizados los índices de vigencia y de importancia cultural de las especies silvestres, podemos plantear como interrogante si las especies con mayor importancia cultural en la comarca continuan con vigencia en la actualidad, o si las que tienen menor importancia se abandonan. Para resolver esta cuestión se relaciona el índice de vigencia (IV) y el de importancia cultural (IC) de las 20 especies más relevantes en la zona.

En la figura 75 se muestran los 20 taxones con mayor valor en el índice de importancia cultural (IC), relacionado con su valor en el índice de vigencia (IV).

El diagrama de dispersión revela que las especies con mayor valor en el índice de importancia cultural tienen una vigencia menor, es el caso de Quercus spp, Populus spp. y Fagus sylvatica, mientras que especies con menor importancia cultural poseen valores de vigencia más altos como Origanum vulgare, Sideritis hyssopifolia o Chamaemelum nobile, que se sitúan en la parte alta de la tabla. Se confirma el abandono de usos asociados al manejo de especies arbóreas que en pasado tuvieron una gran importancia cultural, mientras que se mantienen con vigencia el empleo de especies herbáceas de menor importancia cultural pero que continuan manejándose de modo tradicional. 


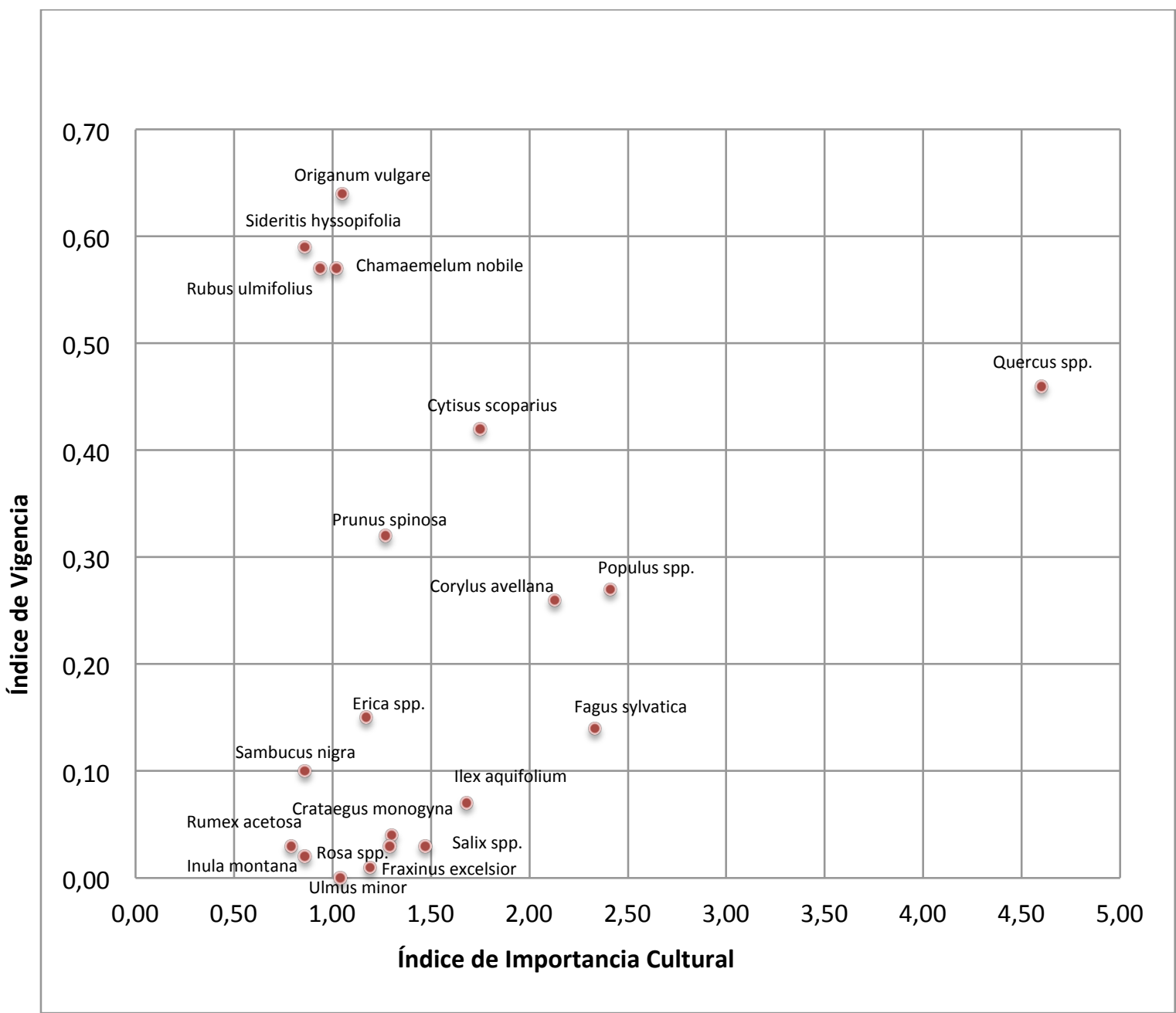

FIGURA 75: Diagrama de dispersión de los 20 taxones con mayor valor en el índice de Importancia Cultural (IC), teniendo en cuenta los valores de su índice de Vigencia (IV).

Por tanto, se demuestra que el abandono de usos no es mayor cuanto menor es su importancia cultural, sino que confirma la conjetura anteriormente señalada de que el abandono de los usos difiere según la categoría de uso implicada. Este resultado coincide con los datos consultados en la zona de la Sierra Norte de Madrid (Aceituno Mata, 2010).

\section{ÍNDICE DE ETNOBOTANICIDAD (IE):}

El número total de especies silvestres de la comarca es igual a 1968, dato obtenido del Listado de las plantas corresponientes al Parque Natural Fuentes Carriones y Fuente Cobre, en la Montaña Palentina, recogido en la página web Anthos, Sistema de información sobre plantas de España (www.anthos.es), donde el territorio tenido en cuenta practicamente coincide al cien por cien con el de nuestro estudio. En este trabajo etnobotánico se han recogido usos de 327 taxones silvestres.

El valor alcanzado en la comarca de la Montaña Palentina $(16,62 \%)$ es inferior al de otras zonas consultadas como El Caurel (Blanco, 1996), el Poniente Granadino (Benítez, 2009), Terra Chá 
(Anllo, 2011) o Campoo (Pardo de Santayana, 2008), donde en todas ellas el número total de especies presentes en el territorio es inferior al total de nuestro estudio. Por lo general, los trabajos centrados en territorios mayores muestran valores menores al ser la flora total superior.

TABla 118: Datos de diversos estudios etnobotánicos de la Península lbérica, señalando número total de especies de un territorio (NTS), número de especies útiles (NS) e índice de etnobotanicidad (IE).

\begin{tabular}{llrrr}
\hline Origen de los datos & Región & NTS & NS & IE \\
\hline Memoria tesis & Montaña Palentina & 1968 & 327 & 16,62 \\
Anllo, 2011 & Terra Chá & 617 & 136 & 22,04 \\
Benítez, 2009 & Poniente granadino & 1345 & 377 & 28,02 \\
\hline Blanco, 1996 & El Caurel & 800 & 150 & 18,75 \\
Galán, 1993 & Córdoba & 1641 & 145 & 8,80 \\
\hline Mulet, 1991 & Castellón & 2128 & 365 & 17,15 \\
Pardo de Santayana, 2008 & Campoo & 1230 & 283 & 23,00 \\
\hline Rigat et al. 2007 & Vall del Ter & 1938 & 220 & 11,30 \\
\hline
\end{tabular}

En la provincia de Castellón (Mulet, 1991) se consigue un índice similar, siendo junto con nuestra zona de estudio los territorios con mayor número total de especies, según se indica en la tabla 118. El índice obtenido en la comarca es indicativo de una gran riqueza etnobotánica en términos cualitativos y determina una elevada interrelación de las personas con el medio. 


\section{CONCLUSIONES}




\section{CONCLUSIONES}

- Se han realizado 139 entrevistas a 187 personas, en 76 localidades diferentes un 65,5\% del total de la comarca.

- Se ha obtenido información de 447 taxones pertenecientes a 101 familias botánicas, 429 taxones de plantas vasculares y 18 de hongos. De ellos, 327 son de obtención silvestre, representando el $73,15 \%$ del total, 113 cultivados, el $25,28 \%$ y 7 comprados, el $1,57 \%$.

- La familia con más representación en número de especies fue Compositae con 51, de ellas 40 silvestres y 11 cultivadas, destaca por su valor alimentario, medicinal, medioambiental y ornamental. Le siguen las familias Leguminosae con 21 especies silvestres y 14 cultivadas, y Rosaceae con 27 especies silvestres y 5 cultivadas, estas dos familias se distinguen por su importancia alimentaria, Leguminosae en alimentación animal y Rosaceae en alimentación humana.

- Para estos 447 taxones se han obtenido un total de 10438 informes de uso (RU) distribuidos en 11 categorías de uso diferentes: 2988 para la categoría Alimentación humana, un 28,63\% del total; 1608 para la categoría Alimentación animal, un 15,41\% del total; 1248 para la categoría Medicina, un 11,96\% del total; 210 para la categoría Veterinaria, un 2,01\% del total; 229 para la categoría de uso Tóxico y nocivo, un 2,19\% del total; 733 para la categoría Combustible, un 7,02\% del total; 473 para la categoría Construcción, un 4,53\% del total; 1183 para la categoría Industria y artesanía, un $11,33 \%$ del total; 416 para la categoría de uso Medioambiental, un 3,99\% del total; 547 para la categoría Ornamental, un 5,24\% del total; 803 para la categoría de uso Social, simbólico y ritual, un 7,69\% del total.

- Las categorías de uso más destacadas en cuanto a número de especies fueron: Alimentación humana con 149, Uso Ornamental con 141 especies y Alimentación animal con 115 especies.

- Las subcategorías de uso más destacas en cuanto a número de registros fueron: frutos y frutas dulces (1114) en la categoría Alimentación humana, forraje verde o seco (831) en la categoría Alimentación animal, y herramientas y utensilios (690) en la categoría Industria y artesanía.

- Los 3 taxones silvestres con mayor número de registros de uso son Quercus spp. (639), Populus spp. (335) y Fagus sylvatica (324). Comprobamos que los 12 taxones con mayor número de registros corresponden a especies arbóreas o arbustivas, que resultan con mayor probabilidad para ser útiles.

- Las plantas con mayor número de registros en la categoría Medicina fueron: manzanilla (Chamaemelum nobile), árnica (Inula montana), té de roca (Sideritis hyssopyfolia), y saúco (Sambucus nigra). Destacan las especies mencionadas para combatir trastornos digestivos, respiratorios y trastornos del aparato locomotor.

- En cuanto al índice de Frecuencia relativa de citación (FRC) los taxones silvestres con mayor valor en el estudio fueron: roble (Quercus spp.), escoba (Cytisus scoparius) y chopo (Populus spp.), en el caso del roble solamente un informante no mencionó ninguna utilidad. 
- El índice que mejor mide la importancia de las plantas es el índice de Importancia cultural (IC), por su mayor versatilidad y precisión en la expansión y diversidad de los usos. Destacan las especies arbóreas: roble (Quercus spp.), chopo (Populus spp.) y haya (Fagus sy/vatica), todas ellas de uso tradicional en la cultura popular de la Montaña Palentina, manejadas de forma frecuente como forraje para el ganado, como combustible, para la construcción de edificaciones y para la elaboración de diversas herramientas y utensilios por la versatilidad de la madera como materia prima.

- Comparando los 20 primeros taxones en el orden del índice de Importancia Cultural con 3 estudios previos, se encuentran coincidencias en especies: 15 con la comarca de Campoo (Pardo de Santayana, 2003), 15 con La Pernía, Polentinos y Valle de Castillería (Pascual, 2013) y 7 con la comarca del Cerrato (Pascual, 2016).

- Las categorías de uso más destacadas en Importancia Cultural fueron: Alimentación humana, Medicina y Alimentación animal.

- La familia con mayor valor en índice de Importancia Cultural es Rosaceae que obtiene registros en todas las categorías de uso, resultando la más destacada en alimentación humana, ya que muchas especies pertenecientes a esta familia se reconocen por sus frutos comestibles. Le sigue en importancia la familia Fagaceae representada por las grandes especies arbóreas que dominan el paisaje, roble (Quercus petraea, Q. pyrenaica, Q. robur) y haya (Fagus sylvatica).

- Se revela que la vigencia o abandono de los usos está relacionada con las categorías de uso, manteniéndose algunos usos en Alimentación humana derivados de aprovechamientos esporádicos de frutos y setas, también algunos usos combustibles y ornamentales, así como los medicinales que tratan problemas leves de salud.

- Los mayores valores en el índice de Vigencia se observan en especies herbáceas: orégano (Origanum vulgare), té (Sideritis hyssopifolia) y manzanilla (Chamaemelum nobile).

- Los taxones con mayor valor en el índice de Importancia Cultural tienen una vigencia menor, es el caso de Quercus spp., Populus spp. y Fagus sylvatica, mientras que especies con menor importancia cultural poseen valores de vigencia más alto, confirmándose el abandono de usos asociados al manejo de especies arbóreas que en el pasado tuvieron gran importancia cultural.

- A pesar de que muchos de estos conocimientos no son vigentes por los cambios en los modos de vida, este estudio etnobotánico puede ayudar al fomento del desarrollo de la comarca, al señalar recursos naturales locales que pudieran ser valorados como sostenibles, presentarse como reclamo turista ecológico, favorecer actividades saludables o difundirse para promover la educación ambiental que integre tradición e identidad local. 


\section{BIBLIOGRAFÍA}




\section{BIBLIOGRAFÍA}

ABELLA, I. (2009). La cultura del tejo. Esplendor y decadencia de un patrimonio esencial. Ediciones Cantabria Tradicional. Santander.

ACEITUNO MATA, L. (2010). Estudio etnobotánico y agroecológico de la Sierra Norte de Madrid. Tesis doctoral. Facultad de Ciencias. Universidad Autónoma de Madrid. Madrid.

AGELET, A. (1999). Estudis d'etnobotànica farmacéutica al Pallars. Tesis doctoral. Facultat de Farmàcia. Universitat de Barcelona. Barcelona.

AGELET, A. \& VALLÈS, J. (2001). Studies on pharmaceutical ethnobotany in the region of Pallars (Pyrenees, Catalonia, Iberian Peninsula). Part I. General results and new or very rare medicinal plants. Journal of Ethnopharmacology 77(1): 57-70.

AGELET, A. \& VALLÈS, J. (2003a). Studies on pharmaceutical ethnobotany in the region of Pallars (Pyrenees, Catalonia, Iberian Peninsula). Part III. Medicinal uses of non-vascular plants. Journal of Ethnopharmacology 84(2-3): 229-234.

AGELET, A. \& VALLÈS, J. (2003b). Studies on pharmaceutical ethnobotany in the region of Pallars (Pyrenees, Catalonia, Iberian Peninsula) Part II. New or very rare uses of previously known medicinal plants. Journal of Ethnopharmacology 84(2-3): 211-227.

AIZPURU, I., ASEGUINOLAZA, C., URIBE-ECHEBARRÍA, P. M. \& ZORRAKÍN, I. (1999). Claves ilustradas de la flora del País Vasco y Territorios limítrofes. Servicio Publicaciones del Gobierno Vasco. Vitoria.

ALARIO, M., CABALLERO, P., DELGADO, J. M., GARCÍA, J. L., GUERRA, J. C., MOLINERO, F., ORTEGA, J., ORTEGA, M. T. \& PASCUAL, H. (1999). La Montaña Palentina. Informe del Departamento de Geografía. Universidad de Valladolid. Valladolid

ALBUQUERQUE, U. P. \& LUCENA, R. F. P. (2005). Can apparency affect the use of plants by local people in Tropical forests?. Interciencia 30 (8): 506-511.

ALBUQUERQUE, U. P., LUCENA, R. F. P., MONTEIRO, J. M., FLORENTINO, A. T. N. \& ALMEIDA, C. F. C. B. R. (2006). Evaluating two quantitative ethnobotanical Techniques. Ethnobotany Research and Applications 4: 51-60.

AgUÑA AgUeRRI, M. A. (2003). El desarrollo turístico en la Montaña Palentina. Diputación Provincial de Palencia. Palencia.

AKERRETA, S. (2009). Etnobotánica farmacéutica en Navarra: del uso tradicional de las plantas medicinales a su evidencia científica. Tesis doctoral. Facultad de Ciencias. Universidad de Navarra. Pamplona.

AKERRETA, S., CALVO, M. I. \& CAVERO, R. Y. (2013). Sabiduría popular y plantas curativas (recopilación extraída de una estudio etnobotánico en Navarra). Ediciones i. Madrid.

ALCALDE CRESPO, G. (1981). La Montaña Palentina. Tomo III. La Pernía. Ediciones Merino. Palencia. 
ALCALDE CRESPO, G. (1982). La Montaña Palentina. Tomo IV. Fuentes Carrionas y la Peña. Ediciones Merino. Palencia.

AlCALDE CRESPO, G. (1991). La Montaña Palentina. Tomo II. La Braña. Ediciones Merino. Palencia.

AlCAlde CRESPO, G. (1992). La Montaña Palentina. Tomo I. La Lora. Ediciones Merino. Palencia.

ALEXIADES, M. N. (1996). Collecting ethnobotanical data: an introduction to basic concepts and techniques. In ALEXIADES, M. N. (ed.). Selected guidelines for ethnobotanical research: 53-94. The New York Botanical Garden. Bronx. New York.

ÁLVAREZ ESCOBAR, A. (2011). Contribución al estudio etnobotánico de la isla de Tenerife. Tesis doctoral. Departamento de Biología Vegetal (Botánica). Universidad de La Laguna. Tenerife.

ÁlVAREZ BAZ, G. (2004). Estudio etnobotánico de la Comarca de Aliste (Zamora). Trabajo fin de carrera. ETS de Ingenierías Agrarias de Palencia. Universidad de Valladolid. Palencia.

ANLLO NAVEIRAS, J. (2011). Estudio etnobotánico de la comarca de Terra Chá. Tesis doctoral. Facultad de Biología. Universidad de Santiago de Compostela. Santiago de Compostela.

ANÓNIMO. (1991). Libro de la montería de Alfonso XI. Ediciones Lex Nova. Madrid.

ANTÓN HERRERA, V. (2009). Etnobiología en el Cerrato Palentino (Palencia). Trabajo fin de carrera. ETS de Ingenierías Agrarias de Palencia. Universidad de Valladolid. Palencia.

APG IV. (2016). An update of the Angiosperm Phylogeny Gropus classification for the orders and families of flowering plants: APG IV. Botanical Journal of the Linnean Society 181: 1-20.

BARANDIARAN, J. M. \& MANTEROLA, A. (2004). Medicina popular en Vasconia. Atlas etnográfico de Vasconia. Vol. V. Etniker Euskalerria. Eusko Jaurlaritza-Gobierno de Navarra. Bilbao.

BARRIO Y MIER, M. (1908). Romance de la Despoblación de Carracedo. En ALCALDE CRESPO, G. (1981). La Montaña Palentina. Tomo III. La Pernía: 217-227. Ediciones Merino. Palencia.

BASTERRA, M. V. (2009). Las antiguas vías de comunicación de la Montaña Palentina. Publicaciones de la Institución Tello Téllez de Meneses 21: 109-149.

BENÍTEZ CRUZ, G. (2009). Etnobotánica y etnobiología del Poniente Granadino. Tesis doctoral. Facultad de Farmacia. Universidad de Granada. Granada.

BERLIN, B. (1992). Ethnobiological classification. Principles of categorization of plants and animals in traditional societes. Princeton Legacy Library. New Jersey.

BERNARD, H. R. (1994). Research methods in Antropology. Qualitative and quantitative approaches. Altamira Press. Walnut Creek.

BLANCO, E. (1996). El Caurel, las plantas y sus habitantes. Estudio etnobotánico de la Sierra del Caurel (Lugo): la importancia de las plantas para nuestros antepasados. Fundación Caixa Galicia. Santiago de Compostela. 
BLANCO, E. (1998). Diccionario de etnobotánica segoviana. Pervivencia del conocimiento sobre las plantas. Ayuntamiento de Segovia, Caja Segovia, Diputación de Segovia, Junta de Castilla y León. Segovia.

BLANCO, E. (2002). Etnobotánica en los Montes de Toledo. Asociación Cultural Montes de Toledo. Toledo.

BLANCO, E. (2015). Etnobotánica abulense. Las plantas de la cultura tradicional de Ávila. Colección Monografías de Botánica Ibérica № 16. Jolube. Jaca.

BLANCO, E. \& CUADRADO, C. (2000). Etnobotánica en Extremadura. Estudio de La Calabria y La Siberia extremeñas. Ed. Emilio Blanco Castro y CEP de Alcoba de los Montes. Madrid.

BLANCO, E. \& DíEZ, J. (2005). Guía de flora de Sanabria, Carballeda y Los Valles. Ediciones Adisac-La Voz. Puebla de Sanabria.

BLANCO, J. F. (1985). Medicina y veterinaria populares en la provincia de Salamanca. Diputación de Salamanca. Salamanca.

BLANCO ESTEBAN, B. (2007). Estudio etnobotánico de plantas medicinales en la Sierra de la Peña y la Sierra del Brezo (Palencia). Trabajo fin de carrera. ETS de Ingenierías Agrarias de Palencia. Universidad de Valladolid. Palencia.

BOCYL. (2007). Decreto 63/2007 de 14 de junio, por la que se crean el Catálogo de Flora Protegida de Castilla y León y la figura de protección denominada Microrreserva de Flora BOCyL 119: 13197-13204.

BONET, M. A. (1993). Etnobotánica de la Vall del Tenes (Vallès Oriental). Ayuntamiento de Bellpuig. Publicaciones de l'Abadia de Montserrat. Barcelona.

BONET, M. A. (2001). Estudi etnobotànic del Montseny. Tesis doctoral. Facultad de Farmacia. Universitat de Barcelona. Barcelona.

BONET, M. A. \& VALLÈS, J. (2002). Use of non-crop food vascular plants in Montseny biosphere reserve (Catalonia, Iberian Peninsula). International Journal of Food Sciences and Nutrition 53: 225-248.

BONET, M. A., ROLDÁN, M., CAMPRUBÍ, J. \& VALLÈS, J. (2008). Etnobotánica de Galecs. Plantes i cultura popular al Baix Vallès. Centre d’Estudis Molletans. Molet del Vallès.

BRUNO GÓMEZ, J. (1994). La flor del Páramo III. Diputación Provincial de León. León.

CARRIÓ, E. (2013). Contribució al coneixement etnobotànic de Mallorca. La biodiversitat vegetal i la seva gestió en una ila mediterrània. Tesis doctoral. Facultat de Farmàcia. Universitat de Barcelona. Barcelona.

CARVALHO, A. M. P. (2005). Etnobotánica del Parque Natural de Montesinho. Plantas, tradición y saber popular en un territorio del nordeste de Portugal. Tesis doctoral. Universidad Autónoma de Madrid. Madrid. 
CASANA, E. (1993). Patrimonio etnobotánico de la provincia de Córdoba: Subbética, Campiña y Vega del Guadalquivir. Tesis doctoral. E.T.S.I. Agrónomos y Montes. Universidad de Córdoba. Córdoba.

CASTROVIEJO, S. et al. (1986-2019). Flora Ibérica. Plantas vasculares de la Península Ibérica e Islas Baleares. Vol. 1-18, 20-21. CSIC. Madrid.

CEÑAL, M. A., GLARIA, G., BLANCO, A. \& BERMEJO M. A. (1988). Análisis del medio físico. Delimitación de unidades y estructura territorial de Palencia. Junta de Castilla y León. Valladolid.

CIRUJEDA, A., AIBAR, J., LEÓN, M. \& ZARAGOZA, C. (2010). La cara amable de las malas hierbas. Gobierno de Aragón. Departamento de Ciencia, Tecnología y Universidad. Zaragoza.

CHIEJ, R. (2003). Plantas medicinales. Ediciones Grijalbo. Barcelona.

COBO, M. P. \& TIJERA, R. E. (2008). Etnobotánica de Doñana. Mancomunidad de Desarrollo y Fomento de Aljarafe. Sevilla.

CONSUEGRA, V. (2009). La cultura de las plantas en La Mancha. Flora en el entorno de las Tablas de Daimiel. Diputación de Ciudad Real. Ciudad Real.

COROMINAS, J. (1972). Tópica Hespérica: Estudios sobre los antiguos dialectos, el sustrato y la toponimia romanas. Tomo II. Ediciones Gredos. Madrid.

COTTON, C. M. (2002). Ethnobotany. Principles and Applications. Wiley. London.

CRIADO, J., FERNÁNDEZ, M. J., LEOCADIO, G., NÚÑEZ, R. M. \& BLANCO, E. (2008). Uso tradicional de las plantas en Toledo. Diputación de Toledo. Toledo.

CUNNINGHAM, A. B. (2001). Etnobotánica aplicada, pueblos, uso de plantas silvestres y conservación. Ediciones Nordan-Comunidad. Montevideo.

DAPENA, E., MIÑARRO, M. \& BLÁZQUEZ, M. D. (2008). Recuperación y manejo de pumaradas tradicionales. SERIDA. Villaviciosa.

DE LA FUENTE SANZ, E. (1987). Flora silvestre ornamental de la provincia de Palencia. Departamento de Cultura del Excmo. Ayuntamiento de Palencia. Palencia.

DE LÓZAR, F. (2008). Cervera, Polentinos, Pernía y Castillería. Su historia, sus pueblos y sus gentes. Cultura \& Comunicación. Palencia.

DELAVEAU,P., LORRAIN, M., MORTIER, F., RIVOLIER, C., RIVOLIER, J. \& SCHWEITZER, P.R. (1981). Secretos y virtudes de las plantas medicinales. Selecciones del Reader's Digest. Madrid.

Delgado, C., GIL, C., HORTElANO, L. A., \& PLAZA, J. A. (2007). Dinámica territorial y transformación del paisaje en la montaña cantábrica. Plaza Universitaria Ediciones. Salamanca.

DÍAZ FERNÁNDEZ, P. M. \& DEL MONTE, M. (2012). Vegetales y hongos silvestres comestibles en la cara norte de la sierra de Ávila (Ávila). CONAMA. Congreso Nacional del Medio Ambiente. Madrid. 
DIPUTACIÓN DE PALENCIA. (2011a). Diagnóstico ambiental de la Provincia de Palencia. Vol. I Recursos naturales. Departamento de Medio Ambiente. Palencia.

DIPUTACIÓN DE PALENCIA. (2011b). Diagnóstico ambiental de la Provincia de Palencia. Vol. II Biodiversidad. Departamento de Medio Ambiente. Palencia.

DIPUTACIÓN DE PALENCIA. (2011c). Diagnóstico ambiental de la Provincia de Palencia. Vol. III Territorio y paisaje. Departamento de Medio Ambiente. Palencia.

DIPUTACIÓN DE PALENCIA. (2011d). Diagnóstico ambiental de la Provincia de Palencia. Vol. IV Situación ambiental. Departamento de Medio Ambiente. Palencia.

DIPUTACIÓN DE PALENCIA. (2011e). Diagnóstico ambiental de la Provincia de Palencia. Vol. V Aspectos socioeconómicos. Departamento de Medio Ambiente. Palencia.

DOPICO, E., SAN FABIAN, J. L. \& GARCÍA VAZQUEZ, E. (2008) Traditional medicine in twentyfirst Spain. Human Ecology 36(1): 125-129.

ESCOBAR GARCÍA, P. (2006). Estudio etnobotánico de los Montes Torozos (Valladolid y Palencia). Trabajo fin de carrera. ETS de Ingenierías Agrarias de Palencia. Universidad de Valladolid. Palencia.

ETKIN, N. L. (1996). Medicinal Cuisines: Diet an Ethnopharmacology. International Journal of Pharmacognosy 34: 313-326.

FAJARDO, J., VERDE, A., RIVERA, D. \& OBÓN, C. (2000). Las plantas en la cultura popular de la provincia de Albacete. Instituto de Estudios Albacetenses. Albacete.

FAJARDO, J., VERDE, A., RIVERA, D. \& OBÓN, C. (2007). Etnobotánica de la Serranía de Cuenca. Las plantas y el hombre. Diputación de Cuenca. Cuenca.

FERNÁNDEZ OCAÑA, A. M. (2000). Estudio etnobotánico en el Parque natural de las Sierras de Cazorla, Segura y las Vilas. Investigación química de un grupo de especies interesantes. Tesis doctoral. Facultad de Ciencias Experimentales. Universidad de Jaén. Jaén.

FERNÁNDEZ, M \& NIETO, A. (1982). Plantas medicinales. Consejo General de Colegios Oficiales de Farmacéuticos. Ediciones Universidad de Navarra. Pamplona.

FERRÁNDEZ, J. V. \& SANZ, J. M. (1993). Las plantas en la medicina popular de la comarca de Monzón. Instituto de Estudios Altoaragoneses. Diputación de Huesca. Huesca.

FONT QUER, P. (1962). Plantas medicinales. El Dioscórides renovado. Editorial Labor. Barcelona.

FORD, R. I. (1978). Ethnobotany. Historical diversity and synthesis. In FORD, R. I. (ed.). The nature and status of ethnobotany. Antropological papers: 33-49. University of Michigan. Ann Arbor.

GALÁN, R. (1993). Patrimonio etnobotánico de la provincia de Córdoba: Pedroches, Sierra Norte y Vega del Guadalquivir. Tesis doctoral. E.T.S.I. Agrónomos y Montes. Universidad de Córdoba. Córdoba. 
GALLEGO, E. (2009). Estudio etnobotánico del occidente alistano. Instituto de Estudios Zamoranos. CSIC. Diputación de Zamora. Zamora.

GALLEGO, E. \& GALLEGO, A. (2008). Usos, tradiciones y conocimiento de las plantas por las gentes de Sayago. Náyade Editorial. Medina del Campo.

GARCÍA GONZÁLEZ, M. E. (1990). Flora y vegetación de la Sierra del Brezo y de la comarca de la Peña (Palencia). Tesis doctoral. Universidad de León. León.

GARCÍA JIMÉNEZ, R. (2007). Etnobotánica leonesa. Municipio de Palacios del Sil. Tesis doctoral. Facultad de Biología. Universidad Complutense de Madrid. Madrid.

GARCÍA-LOMAS, A. (1966). El lenguaje popular de la Cantabria Montañesa. Diputación Provincial de Santander. Santander.

GARMENDIA, J. (2009). Hiztegi etnografikoa. Eusko Ikaskuntza. Donostia. San Sebastián.

GIL GONZÁlEZ, J., PEÑA HERNÁNDEZ, M., NIZ TORRES, R., RODRíGUEZ ROdRíGUEZ, E. \& PERERA BETANCORT, M. (2005). Los cultivos tradicionales de la isla de Lanzarote. Los granos: diversidad y ecología. Cabildo de Lanzarote. Arrecife.

GIL PINILLA, M. (1995). Estudio etnobotánico de la flora aromática y medicinal del termino municipal de Cantalojas (Guadalajara). Tesis doctoral. Facultad de Ciencias Biológicas. Universidad Complutense de Madrid. Madrid.

GISPERT, M. \& GONZÁLEZ, C. (1993). Plantas comestibles-plantas medicinales ¿matrimonio en concordia?. Antropológicas 7: 58-64.

GÓMEZ PELLÓN, E. (1999). Valor y significado del patrimonio etnográfico de Cantabria. Publicación Inst. Etnogr. Folklore "Hoyos Sainz" 14: 19-62.

GONZÁLEZ, J. A. (2009). Nombres vernáculos de la fauna y flora en Vilarino de los Aires (Parque Natural de Arribes del Duero, Salamanca). Un ejemplo del Patrimonio Cultural de nuestros pueblos en vías de desaparición. Salamanca. Revista de Estudios 57: 357-366.

GONZÁLEZ, J. A. , GARCÍA BARRIUSO, M. \& AMICH, F. (2011a). The consumption of Wild and Semi-Domesticated Edible Plants in the Arribes del Duero (Salamanca-Zamora, Spain): An Analysis of Traditional Knowledge. Genetic Resources and Crop Evolution 58: 991-1006.

GONZÁLEZ, J. A. , GARCÍA BARRIUSO, M. \& AMICH, F. (2011b). Ethnoveterinary Medecine in the Arribes del Duero (Salamanca-Zamora, Spain). Veterinary Research Communications 35: 283310.

GONZÁLEZ, J. A., GARCÍA BARRIUSO, M., RAMÍREZ RODRÍGUEZ, R., BERNARDOS, S. \& AMICH, F. (2013). Plantas usadas de manera tradicional en la fabricación de instrumentos musicales y juguetes en Los Arribes del Duero (Salamanca-Zamora). Revista de Folklore 371: 16-26.

GONZÁLEZ-TEJERO, M. R. (1989). Investigaciones etnobotánicas en la provincia de Granada. Tesis doctoral. Facultad de Farmacia. Universidad de Granada. Granada

GORDALIZA, R. (1991). Nuevo vocabulario palentino. Editorial Diario Palentino. Palencia. 
GORDALIZA APARICIO, F. \& CANAL SÁNCHEZ-PAGÍN, J. M. (1993). Toponimia palentina. Nuestros pueblos. Sus nombres y sus orígenes. Ediciones Caja España. Palencia

GRANZOW, I. (1993). Etnobotánica. El mundo vegetal en la tradición. Diputación de Salamanca. Salamanca.

GUARRERA, P. M. \& SAVO, V. (2016). Wild Food Plants Used in Traditional Vegetables Mixtures in Italy. Journal of Ethnopharmacology 185: 202-234.

GUZMÁN, M. A. (1997). Aproximación a la etnobotánica de la provincia de Jaén. Tesis doctoral. Universidad de Granada. Granada.

HADJICHAMBIS, A., PARASKEVA HADJICHAMBI, D., DELLA, A., GIUSTI, M. E., DE PASCUALE, C., LENZARINI, C., CENSORII, E., GONZÁLEZ-TEJERO, M. R., SÁNCHEZ ROJAS, C. P., RAMIRO GUTIÉRREZ, J. M., SKOULA, M., JOHNSON, C., SARPAKI, A., HMAMOUCHI, M., JORHI, S., ELDEMERDASH, M., EL-ZAYAT, M. \& PIERONI, A. (2008). Wild and semi-domesticated food plant consumption in seven circum-Mediterranean areas. International Journal of Food Sciences and Nutrition 59 (5): 383-414.

HARLAN, J. R. (1992). Crops an Man. American Society of Agronomy-Madyson. Wisconsin.

HARSHBERGER, J. W. (1996). The purpose of ethnobotany. Botanical Gazette 21 (3):146-154.

HEINRICH, M., ANKLY, A., FREI, B., WEIMANN, C. \& STICHER, O. (1998). Medicinal plantas in Mexico: Healers consensus and cultural importance. Social Science and Medecine 47: 18591871.

HERRERO, L. (1989). Flora y vegetación de la margen izquierda de la cuenca alta del río Pisuerga (Palencia). Tesis doctoral. Universidad de León. León.

HERRERO LABORDA, E. (1998). Estudio etnobotánico de la Montaña Palentina. Trabajo fin de carrera. ETS de Ingenierías Agrarias de Palencia. Universidad de Valladolid. Palencia.

HEYWOOD, V. (1999). Use and potential of wild plants in farm households. Rome: FAO Farm Systems Management Series 15.

HUNN, E. S. (1999). The value of subsistence for the future of the world. In: V.D. Ed. Nazarea, Ethnoecology. Situated knowledge. Located lives: 23-36. Tucson. Arizona.

INSTITUTO GEOGRÁFICO NACIONAL. Publicado en internet; http://www.ign.es/ (consultado 5 Marzo 2019).

INSTITUTO NACIONAL DE ESTADÍSTICA. Publicado en internet; http://www.ine.es/ (consultado 5 Febrero 2019).

JOHNS, T. (1990). With bitter herbs they shall eat it: chemical ecology and the origins of human diet and medicine. The University of Arizona Press. Tucson. Arizona.

JORRÍn, J. A. (1999). El patrimonio etnográfico mueble como exponenete del patrimonio cultural de Cantabria y expresión de sus formas de vida. Publi. Inst. Etnogr. Folklore "Hoyos Sainz" 14: 129-162. 
JUNTA DE CASTILLA Y LEÓN. (1989). Programa de ordenación y promoción de la zona de agricultura de montaña "Montaña Palentina" (Palencia). Equipo de la gerencia de Agricultura de Montaña "Montaña-Palentina". Delegación Territorial de Agricultura, Ganadería y Montes. Palencia.

JUNTA DE CASTILLA Y LEÓN. (2004). Árboles singulares de Castilla y León. Unoediciones. Godella.

KRAUSE, A., GONZÁLEZ GARZO, A., MARTíNEZ PRADA, A., CASADO, S., FERNÁNDEZ SAINZ, S., GOZALO GARCÍA, D., ALONSO, R., NAVAS, R., ORTEGA, C., HIDALGO, D. \& DÍAZ DIEGO J. (2006). Los guardianes de las semillas. Proyecto DESEMILLAS. Recuperación y puesta en valor del conocimiento tradicional y de la biodiversidad agrícola y forestal. ADISAC-La Voz, ASAM, CODINSE, CDR Tierra de Campos, CEDECO Tentudía. Zamora.

LASTRA MENÉNDEZ, J. J. (2003). Etnobotánica en el Parque Nacional de Picos de Europa. Organismo Autónomo Parques Nacionales. Oviedo.

LATORRE, J. A. (2008). Estudio etnobotánico de la provincia de La Coruña. Tesis doctoral. Facultad de Farmacia. Universidad de Valencia. Valencia.

LEDESMA, J. (2004). Estudio del uso tradicional de las plantas silvestres en la sierra de Montsant. Trabajo fin de carrera. Escuela de Ingeniería Forestal de Lleida. Lleida.

LÓPEZ GONZÁLEZ, G. (2007). Guía de los árboles y arbustos de la Península Ibérica y Baleares. Ed. Mundi-Prensa. Madrid.

LUCZAJ, L., FRESSEL, N. \& PERKOVIC. (2013). Wild food plants used in the villages of the Lake Vrana Nature Park (Northern Dalmatia, Croatia). Acta Societatis Botanicorum Poloniae 82 (4): 275-281.

LUCZAJ, L., STAWARCZYK, K., KOSIEK, T., PIETRAS, M. \& KUJAWA, A. (2015). Wild food plants and fungi used by ukranians in western part of the Maramures Region in Romania. Acta Societatis Botanicorum Poloniae 84 (3): 339-346.

LLISTOSELLA, J. \& SANCHEZ-CUXART, A. (2008). El herbario. Matas, hierbas y helechos. Publicaciones y Ediciones de la Universitat de Barcelona. Barcelona.

MACHO TOMÉ, A. (1893). Reseña de los productos naturales y más especialmente de las plantas medicinales espontáneas en el partido judicial de Saldaña. Edición facsímil año 2003. Ed. Beni-Gómez, Sociedad Civil. Palencia.

MARTIN, G. J. (1995). Ethnobotany: a methods manual. Champman \& Hall. London.

MARTín FRANCO, M. (2007). Estudio de la flora medicinal en el Páramo de Arlanzón (Burgos, Palencia). Trabajo fin de carrera. ETS de Ingenierías Agrarias de Palencia. Universidad de Valladolid. Palencia.

MARTíNEZ LIROLA, M. J., GONZÁLEZ TEJERO, M. R. \& MOLERO MESA, J. (1997). Investigaciones etnobotánicas en el Parque Natural de Cabo de Gata-Níjar (Almeria). Sociedad Almeriense de Historia Natural. Almería. 
MAYOR LÓPEZ, M. \& ÁLVAREZ RODRÍGUEZ, A. J. (1980). Plantas medicinales y venenosas de Asturias, Cantabria, Galicia, León y País Vasco. Ed. Ayalga. Oviedo.

MEAZA, G., AGUIRRE, M., AINZ, M. J., CADIÑANOS, A. GÓMEZ, L., GOGEASCOECHEA, A., GONZÁLEZ, M. J., IRIARTE, M. J., LÓPEZ, C., LOZANO, P., MUÑOZ, C., ORMAETXEA, O., RAMIL, P. \& ZAPATA, L. (2004). Biogeografía cultural de los espacios forestales de la reserva de la biosfera de Urdaibai. Proyecto de Investigación. Informe final. Vitoria.

MENENDEZ-BACETA, G., ACEITUNO MATA, L., TARDÍO, J., REYES GARCÍA, V. \& PARDO DE SANTAYANA, M. (2012). Wild edible plants traditionally gathered in Gorbeialdea (Biscay, Basque Country). Genetic Resources and Crop Evolution 59 (7): 1329-1347.

MESA, S. (1996). Estudio etnobotánico y agroecológico de la comarca de la Sierra de Mágina (Jaén). Tesis doctoral. Facultad de Ciencias Biológicas. Universidad Complutense de Madrid. Madrid.

MINISTERIO DE AGRICULTURA, PESCA Y ALIMENTACIÓN. (1985). Mapa de cultivos y aprovechamientos de la provincia de Palencia. Escala 1:200.000. Dirección General de la Producción Agraria. Madrid.

MOERMAN, D. E. (1994). North American food and drug plants. In ETKIN, N. L. (ed.). Eating on the wild side: 166-181. University of Arizona Press. Tucson.

MOLERO MESA, J., SOGUERO MUÑOZ, A. \& JIMÉNEZ, J. J. (2001). Estudio etnobotánico del macizo central de Sierra Morena (Sierra de San Andrés) y extremo suroriental del histórico Campo de Calatrava de la provincia de Ciudad Real. Facultad de Farmacia. Universidad de Granada. Granada.

MOLINA, M. (2001). Estudio de la flora de interés etnobotánico en el municipio de Carcabuey (Córdoba). Proyecto fin de carrera. E.T.S.I. Agrónomos y Montes. Universidad de Córdoba. Córdoba.

MOLINA, M., TARDÍO, J., ACEITUNO MATA, L., MORALES, R., REYES GARCÍA, V. \& PARDO DE SANTAYANA, M. (2014). Weed and food diversity: Natural yield assessment and future alternatives for traditionally consumed wild vegetables. Journal of Ethnobiology 34 (1): 44-67.

MORALES, R., TARDío, J., ACEITUNO, L., MOLINA, M. \& PARDO DE SANTAYANA, M. (2011). Biodiversidad y etnobotánica en España. Memorias Real Sociedad Española de Historia Natural 9: 157-207.

MULERO, A., FIGUEROA, M. \& CARRASCOSA, M. (2008). Guía sobre el manejo de la biodiversidad agrícola en la huerta mediterránea. Agrícola Pueblos Blancos y Red Andaluza de Semillas "Cultivando Biodiversidad". Cádiz.

MULET, L. (1991). Estudio etnobotánico de la provincia de Castellón. Diputación de Castellón. Castellón.

MUNTANÉ, J. (1991). Aportació al coneixement de l'etnobotánica de Cerdanya. Tesis doctoral. Facultad de Farmacia. Universidad de Barcelona. Barcelona.

MURIEL MARTíN, M. P. (2008). La medicina popular en la provincia de Palencia. Diputación Provincial de Palencia. Palencia. 
OBÓN, C. \& RIVERA, D. (1991). Las plantas medicinales de nuestra región. Consejería de Cultura y Educación. Editora Regional de Murcia. Murcia.

ORIA DE RUEDA, J. A. (1998). Los hayedos. Medio Ambiente Castilla y León 5: 2-9.

ORIA DE RUEDA, J. A. \& DÍEZ, J. (2003). Guía de árboles y arbustos de Castilla y León. Ed. Cálamo. Palencia.

ORIA DE RUEDA, J. A., DÍEZ, J. \& RODRÍGUEZ, M. (1996). Guía de las plantas silvestres de Palencia. Ed. Cálamo. Palencia.

ORTUÑO, I. (2003). Etnobotánica de Los Villares y Valdepeñas en Jaén (sur de la Península Ibérica). Tesis doctoral. Facultad de Ciencias Experimentales. Universidad de Jaén. Jaén.

PANERO, J. A. (2000). Sayago: costumbres, creencias y tradiciones. ADERISA. 2a edición. Bermillo de Sayago.

PALACIOS, M. \& URTASUN, R. (2011). Encuesta etnográfica de Izal (Navarra). Cuadernos de Etnología y Etnografía de Navarra 86: 205-224.

PARADA, M. (2008). Estudi etnobotànic de L'Alt Empordà. Tesis doctoral. Facultat de Farmàcia. Universidad de Barcelona. Barcelona.

PARADA, M., CARRIÓ, E. \& VALLÈS, J. (2011). Ethnobotany of food plants in the Alt Empordà Region (Catalonia, Iberian Peninsula). Journal of Applied Botany and Food Quality 84: 11-25.

PARDO DE SANTAYANA, M. (2003). Las plantas en la cultura tradicional de la antigua Merindad de Campoo. Tesis doctoral. Facultad de Ciencias. Universidad Autónoma de Madrid. Madrid.

PARDO DE SANTAYANA, M. (2004). Guía de las plantas medicinales de Cantabria. Salud y tradición popular. Stvdio. Santander.

PARDO DE SANTAYANA, M. (2008). Estudios etnobotánicos en Campoo. Conocimiento y uso tradicional de plantas. CSIC. Madrid.

PARDO DE SANTAYANA, M. \& GÓMEZ PELLÓN, E. (2003). Etnobotánica: Aprovechamiento tradicional de plantas y patrimonio cultural. Anales del Jardín Botánico de Madrid 60 (1): 171182.

PARDO DE SANTAYANA, M., MORALES, R., ACEITUNO, L. \& MOLINA, M. (2014). Inventario español de los conocimientos tradicionales relativos a la biodiversidad. Primera fase. Ministerio de Agricultura, Alimentación y Medio Ambiente. Madrid.

PARDO DE SANTAYANA, M., MORALES, R., TARDíO, J. \& MOLINA, M. (2018a). Inventario español de los conocimientos tradicionales relativos a la biodiversidad. Segunda fase (Tomo 1). Ministerio de Agricultura, Alimentación y Medio Ambiente. Madrid.

PARDO DE SANTAYANA, M., MORALES, R., TARDÍO, J., ACEITUNO, M. \& MOLINA, M. (2018b). Inventario español de los conocimientos tradicionales relativos a la biodiversidad. Segunda fase (Tomo 2). Ministerio de Agricultura, Alimentación y Medio Ambiente. Madrid. 
PARDO DE SANTAYANA, M., MORALES, R., TARDÍO, J., ACEITUNO, M. \& MOLINA, M. (2018c). Inventario español de los conocimientos tradicionales relativos a la biodiversidad. Segunda fase (Tomo 3). Ministerio de Agricultura, Alimentación y Medio Ambiente. Madrid.

PARDO DE SANTAYANA, M., TARDÍO, J., BLANCO, E., CARVALHO, A. M., LASTRA, J. J., SAN MIGUEL, E. \& MORALES, R. (2007). Traditional knowledge of wild edible plants used in the Northwest of the Iberian Peninsula (Spain and Portugal): A comparative study. Joournal of Ethnobiology and Ethnomedicine 3: 27-37.

PARDO DE SANTAYANA, M., SAN MIGUEL, E. \& MORALES, R. (2006). Digestive beverages as a medicinal food in cattle-farming community in northern Spain (Campoo, Cantabria). In PIERONI, A. \& PRICE, L. (ed.). Eating \& Healing. Traditional food as medecine: 131-151. Haworth Press. London.

PASCUAL GIL, J. C. (2013). Etnobotánica de La Pernía, Polentinos y Valle de Castillería (Palencia). Trabajo fin de carrera. ETS de Ingenierías Agrarias. Universidad de Valladolid. Palencia.

PASCUAL GIL, J. C. (2016). Estudio etnobotánico del Cerrato Palentino. Trabajo fin de master. Facultad de Ciencias. Universidad Autónoma de Madrid. Madrid.

PASCUAL, J. C. \& HERRERO, B. (2017). Wild food plants gathered in the upper Pisuerga river basin. Palencia. Spain. Botany Letters 164 (3): 163-172.

PASCUAL, J. C. \& HERRERO, B. (2017). Plantas de uso tradicional en la Montaña Palentina. Aruz Ediciones. Palencia.

PASCUAL, J. C., HeRRero, B., \& HeRrero, E. (2016). Plantas de uso tradicional en el Cerrato Palentino. Náyade Editorial. Valladolid.

PERERA LÓPEZ, J. (2006). Los nombres comunes de plantas, animales y hongos de El Hierro. Academia canaria de la lengua. 8 volúmenes. Edición Digital.

PÉREZ ALTAMIRA, D. (2007). La bellota como alimento de humanos. Avnia 17: 106-112.

PIERONI, A. (1999). Gathered wild food plants in the Upper Valley of the Serchio River (Garfagnana), Central Italy. Economic Botany 53(3): 327-341.

PIERONI, A., NEBEL, S., QUAVE, C., MÜNZ, H. \& HEINRICH, M. (2002). Ethnopharmacology of Liakra: Traditional weedy vegetables of the Abërëshe of the Vulture área in Southern Italy. Journal of Ethnopharmacology 82: 165-185.

PIERONI, A., NEDECHEVA, A. \& DOGAN, Y. (2015). Local knowledge of medicinal plants and wild food plants among Tatars and Romanians in Dobruja (South-East Romania). Genetic Resources and Crop Evolution 62 (4): 605-620.

PORTÈRES, R. (1970). Cours de ethno-botanique et ethno-zoologie (1969-1970). Volume I Ethnobotanique générale. Museum National d'Histoire Naturelle. Laboratoire d'ethnobotanique et d'ethno-zoologie. Paris

PRANCE, G.T., BALÉE, W., BOOM, B. M. \& CARNERINO, R. L. (1987). Quantitative ethnobotany and the for conservation in Amazonia. Conservation Biology 5 (1): 296-310. 
REYES GARCÍA, V., MENENDEZ BACETA, G., ACEITUNO MATA, L., ACOSTA NARANJO, R., CALVET MIR, L., DOMíNGUEZ, P., GARNATJE, et al. (2015). From famine foods to delicatesen: Interpreting trends in the use of wild edible plants through cultural ecosystem services. Ecological Economics 120: 303-311.

RIGAT, M. (2005). Estudi etnobotànic de la Vall de Camprodon (Alta Vall del Ter, Pirineus). Tesis de máster. Facultat de Farmàcia. Universitat de Barcelona. Barcelona.

RIGAT, M., GARNATJE, T. \& VALLÈS, J. (2009). Estudio etnobotánico del alto valle del río Ter (Pirineo catalán): resultados preliminares sobre la biodiversidad de los huertos familiares. En: Llamas f \& Acedo C (eds.). Botánica Pirenaico-Cantábrica en el siglo XXI: 339-408. Universidad de León. León.

RIVERA, D., ALCARAZ, F., VERDE, A., FAJARDO, J. \& OBÓN, C. (2008). Las plantas en la cultura popular. Enciclopedia divulgativa de la historia natural de Jumilla-Yecla 9. Caja de Ahorros del Mediterráneo. Sociedad Mediterránea de Historia Natural. Jumilla.

RIVERA, D. \& OBÓN, C. (1991). La guía de Incafo de las plantas útiles y venenosas de la Península Ibérica y Baleares (excluidas medicinales). Ediciones Incafo. Madrid.

RIVERA, D. \& OBÓN, C. (1998). Guía de teoría y prácticas de etnobotánica. Ed. DM Colección de textos docentes ICE-Universidad de Murcia. Murcia.

RIVERA, D., VERDE, A., FAJARDO, J., INOCENCIO, C., OBÓN, C. \& HEINRICH, M. (2006). Guía etnobotánica de los alimentos locales recolectados en la provincia de Albacete. Instituto de Estudios Albacetenses. Albacete.

ROBBINS, W. W.; HARRINGTON, J.P. \& FREIRE- MARRECO, B. (1916). Ethnobotany of the Tewa Indians. Smithsonian Institution Bureau of American Ethnology. Bulletin 55. Government Printing Office. Washington D.C.

SÁNCHEZ LÓPEZ, M. D. (1994). Plantas útiles de la comarca de La Manchuela (Albacete). Colectivo de Escuelas Rurales de La Manchuela. Centro de Desarrollo Rural Albacete. Albacete.

SÁNCHEZ RODRíguEZ, J. A. \& GARCÍA BLANCO, A. (2005). Atlas de los hongos de Castilla y León. Instituto de Restauración y Medio Ambiente. León.

SAN MIGUEL, E. (2004). Etnobotánica de Piloña (Asturias) Cultura y saber popular sobre las plantas en el concejo del centro-oriente asturiano. Tesis doctoral. Universidad Autónoma de Madrid. Madrid.

SEDANO PEREZ, J. (2011). Estudio Etnobotánico en Hoces de Alto Ebro y Rudrón (Burgos). Trabajo fin de carrera. ETS de Ingenierías Agrarias de Palencia. Universidad de Valladolid. Palencia.

SELGA, A. (1998). Estudis etnobotànics a les Guilleries. Tesis de licenciatura. Facultat de Farmàcia. Universitat de Barcelona. Barcelona.

SERRASOLSES, G., CALVET MIR, L., CARRIÓ, E., D’AMBROSIO, U., GARNATJE, T., PARADA, M., VALLÈS, J. \& REYES GARCÍA, V. (2016). A matter of taste: Local explanations for the consumption of wild food plants in the Catalan Pyrenees and the Balearic Island. Economic Botany $70(2):$ 176-189. 
SKIADAS, P. K. \& LASCARATOS, J. G. (2001). Dietetics in ancient greek philosophy: Plato's concepts of healthy diet. European Journal of Clinical Nutrition 55: 532-537.

TARDÍO, J. \& PARDO DE SANTAYANA, M. (2008). Cultural Importance Indices: A comparative analysis based on the useful wild plants of Southern Cantabria (Northern Spain). Economic Botany 62(1): 24-39.

TARDÍO, J., PARDO DE SANTAYANA, M., MORALES, R. (2006). Ethnobotanical review of wild edible plants in Spain. Botanical Journal of the Linnean Society 152: 27-71.

TARDío, J., PARDO DE SANTAYANA, M., MORALES, R., MOLINA, M. \& ACEITUNO, L. (2018). Inventario español de los conocimientos tradicionales relativos a la biodiversidad agrícola. Volumen 1. Ministerio de Agricultura, Alimentación y Medio Ambiente. Madrid.

TARDío, J., PASCUAL, H. \& MORALES, R. (2002). Alimentos silvestres de Madrid. Real Jardín Botánico, CSIC. Ed. La Librería. Madrid.

TARDÍO, J., PASCUAL, H. \& MORALES, R. (2005). Wild food plants traditionally used in the province of Madrid, Central Spain. Economic Botany 59 (2): 122-136.

TEJERINA, A. (2010). Usos y saberes sobre las plantas de Monfragüe. Etnobotánica de la Comarca Natural. Itomonfragüe. Cáceres.

THE PLANT LIST. (2013). Version 1.1. Published on the Internet; http://www.theplantlist.org./ (accessed 5th April 2019).

TOLEDO, V. M. (1982). La etnobotánica hoy: reversión del conocimiento, lucha indígena y proyecto nacional. Biótica 7(2): 141-150.

TYLOR, E. B. (1987). Antropología: introducción al estudio del hombre y de la civilización. Alta Fulla. Barcelona.

VELASCO SANTOS, J. M. (2009) Guía de las plantas útiles y perjudiciales en Castilla y León. Ed. Caja Duero. Salamanca.

VELASCO, J. M., CRIADO, J. \& BLANCO, E. (2010). Usos tradicionales de las plantas en la provincia de Salamanca. Diputación de Salamanca. Salamanca.

VERDE, A. (2002). Estudio etnofarmacológico de tres áreas de montaña de Castilla-La Mancha. Tesis doctoral. Universidad de Murcia. Murcia.

VERDE, A., RIVERA, D. \& OBÓN, C. (1998). Etnobotánica en las sierras de Segura y Alcaraz: las plantas y el hombre. Instituto de Estudios Albacetenses. Albacete.

VERDE, A., RIVERA, D., FAJARDO, J., OBÓN, C. \& CEBRIÁN, F. (2008). Guía de las plantas medicinales de Castilla-La Mancha (y otros recursos de uso tradicional). Altabán Ediciones. Albacete.

VIELBA INFANTE, E. (2012). Arquitectura pastoril en el norte de Palencia: chozos, tenadas, cabañas y corrales. Colección de Historia Montaña Palentina 6: 87-170. 
VILLAR, L., PALACíN, J. M., CALVO, C., GÓMEZ, D. \& MONTSERRAT, G. (1987) Plantas medicinales del Pirineo Aragonés y demás tierras oscenses. CSIC. Diputación de Huesca. Huesca.

ZAPATA, L. \& PEÑA, L. (2003). Uso y gestión del bosque en la Euskal Herria atlántica: aprovechamiento tradicional de los recursos forestales en Encartaciones y Gorbea. Eusko Ikaskuntza. Vitoria. 


\section{ÍNDICES}




\section{LISTADO DE NOMBRES CIENTÍFICOS Y VULGARES}

* Los números en negrita señalan la página del catálogo en la que aparece la ficha de ese taxón.

Abedul, 18, 19, 20, 23, 99, 100, 101, 249, 267, $272,285,286,303,312,320,322,323,324$, $328,329,360,364$

Abijano, 184, 235, 257

Abrojo, 156, 303, 314

Abubillo, 140, 141, 234, 235, 321, 322

Abubillo montesino, 140, 234, 321

Acacia, 161, 245, 321, 344, 346

Aceba, 96, 97, 249, 256, 298, 303, 308, 320, $328,341,345,352,355,356,358,363,364$, $365,366,371$

Acebo, 19, 20, 96, 97, 101, 152, 192, 249, 251, $256,257,298,299,303,304,308,320,322$, $328,329,341,343,345,348,352,354,355$, $356,357,358,363,364,365,366,367,371$, 373

Acedera, 177, 245, 363, 365, 366, 371

Acelga, 89, 179, 232, 233

Acer campestre, 18, 19, 201, 303, 304, 321, 344 Acera, 99, 177, 213, 233, 245, 359, 363, 365, $366,371,372$

Acerón, 177, 178, 233, 245, 251, 265, 336, 347, 359, 364

Achicoria, 29, 123, 125, 232, 233, 242, 249, 250, 252, 267, 271, 272, 273, 335, 361

Achillea ageratum, 111, 345

Achillea millefolium, 26, 112, 242, 262, 264, 266, 267, 268, 272, 273, 279, 280, 283, 285, 339, 345, 356, 357

Acidera, 177, 359

Acompango, 126

Aconito, 179, 278

Acónito, 179, 180, 278, 291, 299, 300, 347

Aconitum napellus, 179, 278, 291, 299, 300, 347

Aconitum vulparia, 179, 180, 278, 291, 299, 300,347

Acubillo, 140

Adelfilla, 21

Adenocarpus complicatus, 152, 318, 319, 321, 322

Aesculus hippocastanum, 201, 274, 299, 344

Agaricus arvensis, 209, 239
Agaricus campestris, 209, 239

Agayuba, 79, 129

Agayuga, 62, 129, 130, 234, 236, 256, 267, 285, 299, 328, 364

Agracejo, 17, 22, 23

Agrión, 140

Agrocybe aegerita, 210, 239

Agrostemma githago, 29, 108, 249, 335, 337

Agrostis capillaris, 24

Agrostis delicatula, 27, 76, 347, 349, 359

Aguileña, 180, 342, 347

Agüillo, 140, 141, 234, 235

Aguvillo, 140, 141

Aira caryophyllea, 77, 347

Ajenjo, 113, 114

Ajestrín, 69, 244, 256, 257, 298, 300, 344

Ajo, 68, 69, 243, 244, 246, 256, 268, 292, 298, $344,356,357,358$

Ajo pío, 68, 244

Ajuérjano, 93, 244, 246, 256, 258

Ajuga pyramidalis, 143, 346

Álamo, 18, 20, 28, 198, 304, 312, 332, 353

Albahaca, 146, 296, 297

Alcachofa, 116, 117, 232

Alcea rosea, 165, 342

Alegría, 98, 345, 349, 352, 354

Alentel, 175

Alfalfa, 28, 159, 250, 258

Algarroba, 163, 238, 250, 254, 255

Alholva, 162, 250, 254, 255

Aliso, 28

Allium ampeloprasum, 68, 232, 233, 357, 358

Allium cepa, 68, 234, 268, 273, 275, 283, 284

Allium oleraceum, 68, 244, 246

Allium sativum, 69, 243, 268, 292, 356, 357, 358

Allium sphaerocephalon, 69, 244, 246, 256, 257, 300, 344

Alnus glutinosa, 28

Althaea officinalis, 103, 165, 269, 270, 342, 343,360

Alubia, 160, 238

Amacuco, 140 
Amaello, 185, 235, 240, 242, 334, 363, 365

Amaíllo, 185, 334, 363, 365, 376

Amajueto, 183

Amamora, 193

Amapera, 117, 249, 252, 335

Amaperro, 173, 342, 346, 353

Amapola, 29, 173, 174, 214, 250, 252, 269, 276, $277,299,300,336,337,342,343,346,353$, $357,358,359,375$

Amapola real, 174

Amargacho, 113, 213, 249, 252, 271, 289, 290, 300, 358

Amargaza, 113, 178, 214, 251, 252, 265, 336, $347,359,360,364$

Amargoso, 19, 23, 195, 196, 251, 257, 299, 303, $321,322,328,334,344,353,364$

Amelanchier ovalis, 21, 182, 235, 236, 369

Amiérgano, 19, 184, 235, 236, 257, 369

Amijoma, 182

Amilloma, 182, 235, 236

Amoral, 193

Amostajo, 194, 235, 251, 257, 303, 306, 321, 328, 334, 344, 355, 363, 364, 365

Anacamptis morio, 76, 346

Anacyclus clavatus, 112, 345, 348, 352, 354

Ancera, 177

Ancerón, 177, 178

Ancina, 138, 236, 250, 254, 303, 306, 311, 323

Andriniego, 187, 235, 240

Andrino, 189, 235, 240, 245, 259, 262, 303, 314, 347, 364, 365

Andrino real, 187, 235, 236, 240

Anemone nemorosa, 18, 20, 21, 180, 216

Anemone pavoniana, 27

Angélica, 89, 90, 244, 262, 283, 292, 323

Angelica sylvestris, 89, 244, 246, 262, 283, 292, 323, 324

Aniétano, 182, 235

Anís, 91, 94, 95, 132, 191, 214, 241, 243, 244, $246,264,266,268,269,283,284,318,319$, 360,361

Anís de lastra, 95, 243, 244, 264, 269, 283, 318, 360

Anthemis arvensis, 112, 117, 124, 283, 284, $285,286,335,337,339,345,348,352,354$, 358,360

Anthriscus sylvestris, 90, 92
Anthyllis vulneraria, 25, 153, 245

Antimora, 193, 235, 257, 369

Antirrhinum majus, 175, 342

Antojil, 75, 289, 290, 342, 346

Aphyllanthes monspeliensis, 25

Apio, 90, 232, 278

Apium graveolens, 90, 232, 278

Apium nodiflorum, 90, 176, 298, 300

Aquilegia vulgaris, 180, 342, 343, 347

Arabis alpina, 27

Arándano, 18, 20, 21, 24, 27, 132, 183, 234, 240, 256, 267, 277, 363, 365, 376

Arctium minus, 90, 113, 249, 252, 271, 289, 290, 300, 358, 359

Arctostaphylos uva-ursi, 22, 25, 62, 79, 129, 234, 236, 256, 257, 267, 268, 285, 299, 328, 329,364

Argamón, 195

Argoma, 19, 22, 23, 25, 156, 258, 303, 307, 308, 321,322

Arguma, 162, 303, 304

Armeria pubinervis, 107, 176, 347, 359

Árnica, 86, 120, 121, 214, 262, 264, 269, 271, $272,273,274,288,289,298,363,365,366$, $367,371,381$

Arraspanera, 132

Arráspano, 132, 215, 234, 236, 240, 256, 258, 267, 268, 277, 363, 365, 376

Arrhenatherum elatius, 26, 77, 80, 336, 347

Arrica, 164, 250, 252, 254, 255

Arroz, 80, 178, 265, 266

Arroz de pajaritos, 127

Artemisia absinthium, 113, 216

Arum italicum, 23, 71, 289, 290, 298, 300

Arveja, 158, 161, 238, 250, 252, 254, 255, 257

Arvejana, 157, 163, 250, 252, 257, 336, 337, 346, 353

Arzolla, 116, 122, 264, 272, 273 274, 275, 288, 289, 290

Asphodelus albus, 84, 251, 252, 259, 308, 328, $329,336,337,338,348,359,360,363,364$, 365,374

Asplenium trichomanes, 62, 286

Astrantia major, 18

Avallico, 80, 251, 336

Avellano, 18, 20, 21, 23, 100, 101, 200, 214, $215,236,237,249,251,304,305,311,312$, 
$313,320,322,323,326,327,328,352,354$, $355,357,358,360,361,363,364,365,366$, $367,371,372,373,376$

Avena, 28, 77, 78, 247, 250, 252, 254, 255

Avena fatua, 29, 77, 336, 347

Avena loca, 29, 77, 336, 347

Avena sativa, 77, 247, 250, 252, 254, 255

Avena seca, 77

Avena sterilis, 29, 77, 336, 347

Ayuz, 130, 131, 256, 258, 267, 303, 305, 306, $307,308,312,320,322,332,346,349,360$, $363,364,365,366,371,376$

Azucena, 75, 289, 342, 346

Azulejo, 119, 249, 277, 335

Azulina, 29, 119, 249, 277, 335, 352

Ballota nigra, 143, 148, 245, 246

Balsamina, 112, 149, 242, 262, 267, 268, 272, 274, 277, 279, 280, 345, 356

Barbadillo, 19, 21, 87, 88, 234, 320

Barbaleña, 201, 302, 304, 321, 344

Barbarea intermedia, 103, 249, 335

Begonia spp., 98, 345, 349, 352, 354

Beleño, 203, 204, 265, 266, 272, 273, 285, 286, 292, 299

Bellardia trixago, 171, 336

Bellis perennis, 114, 328, 345, 348, 352, 358, 360

Bellis sylvestris, 114, 328, 345, 348, 352, 358, 360

Berberis vulgaris, 22, 23, 98, 234, 236, 244, 246, 256

Berenjena, 205, 233

Berezo, 130, 131

Bergaula, 141, 267, 272, 274, 276, 278, 285, 289, 291, 318

Berra, 90, 91, 176, 298, 300

Berraza, 176, 299, 300

Berro, 91, 105, 106, 176, 232, 233, 256, 300

Berza, 84, 88, 103, 104, 153, 177, 205, 213, 232, 233, 249, 252

Beta vulgaris var. altissima, 59, 88, 234, 249, 360

Beta vulgaris var. cicla, 59, 89, 232, 233

Betula pubescens, 18, 19, 20, 99, 249, 267, 272, $285,286,303,312,320,322,323,324,328$, 329, 360, 364

Bidens aurea, 114, 242
Birlenda, 112, 242, 262, 264, 267, 268, 272, 279, 280, 283, 285, 343, 356

Blechnum spicant, 20, 21

Boca de dragón, 175, 342

Bola de nieve, 108, 341

Boletus, 210, 239

Boletus edulis, 210, 239

Boletus pinophilus, 210, 239

Bolsa de pastor, 104, 264, 267, 268

Bonetero, 18, 23, 111, 320, 328, 341

Borago officinalis, 101, 232

Borracha, 211, 239

Borrachín, 98, 234, 244, 256

Borraja, 101, 102, 126, 232, 244, 249, 268

Botón, 181, 342, 3343, 347

Botrychium Iunaria, 64, 216

Brachypodium phoenicoides, 78, 293, 336

Brachypodium pinnatum, 20, 22, 25, 293

Brachypodium sylvaticum, 19

Bragas de cuco, 179, 245, 269, 276, 347

Bragas de cucubillo, 179

Brassica napus, 103, 234, 253, 257, 258

Brassica nigra, 29, 103, 335, 337

Brassica oleracea var. acephala, 59, 103, 232, 233, 249, 252

Brassica oleracea var. botrytis, 59, 104, 232

Brassica oleracea var. capitata, 59, 104, 232

Brassica oleracea var. gemmifera, 59, 104, 232

Brecina, 20, 21,25, 27, 130, 258, 267, 303, 306, 349,360

Brezo, 19, 20, 23, 24, 25, 60, 130, 131, 256, $258,259,267,268,303,304,304,306,307$, $308,312,313,320,322,332,346,349,360$, 361, 363, 364, 365, 366, 367, 371, 376, 377

Briza media, 19, 21, 78, 347, 349, 359

Bromus erectus, 25

Bryonia cretica, 19, 23, 71, 128, 289, 290, 299, 335

Budaño, 85, 92, 249, 252, 256, 257, 298, 300, 312, 313, 323, 324, 332, 335, 345, 364

Burrialón, 126

Cadillo, 91, 113, 174, 181, 196, 335, 336, 337, 357,358

Café, 196, 241, 242, 243

Cajiga, 18, 135

Cajigo, 135, 236, 240, 244, 250, 254, 256, 258, $303,305,306,311,312,315,319,321,323$, 
$326,328,329,332,337,352,355,357,359$, 360, 362, 363, 364, 365, 366, 371, 376

Calabacín, 129, 232, 233, 258

Calabaza, 129, 232, 233

Calambrojo, 190, 192, 235, 241, 245, 253, 257, $259,267,270,277,314,318,326,365,366$, 369,371

Calderón, 75, 245, 246, 346

Caléndula, 114, 115, 258, 272, 273, 285, 341

Calendula officinalis, 114, 258, 272, 273, 285, 286, 339, 341, 343

Calluna vulgaris, 20, 21, 24, 27, 130, 258, 259, $267,268,303,304,306,346,349,360$

Calocybe gambosa, 212, 239, 377

Camorro, 124, 244

Campanilla, 70, 75, 106, 175, 180, 245, 258, $299,341,342,343,344,345,346,347,352$, 358, 359

Campanilla de monte, 75

Campánula, 75

Campanula rapunculus, 18, 106, 345

Campsis radicans, 101, 341

Cancarico, 70, 258, 376

Canela, 152, 241,, 243

Cantarellus, 210, 239

Cantarellus cibarius, 210, 239

Cantarillo, 70, 344, 352, 358

Cantarujil, 70, 126, 244, 344

Canuto, 90, 91, 92, 249, 256, 298, 312, 323, 332, 335, 345, 364

Cañiguerra, 92, 249, 256, 298, 312, 323, 332, $335,345,364$

Capachera, 113

Capacho, 113, 249, 271, 289, 300, 358, 359

Capricho del cielo, 181, 342, 347

Capsella bursa-pastoris, 104, 264, 267, 268

Capsicum annuum, 203, 233, 243, 283, 284

Cardillo, 29

Cardincha, 106

Cardo, 93, 94, 106, 115, 118, 119, 205, 249, $252,256,257,258,259,287,323,335,337$, $338,345,356,358$

Cardo azul, 93, 256, 345, 349

Cardo borriquero, 94, 118, 124, 256, 335, 337

Cardo burrero, 119

Cardo burriquero, 93, 106, 119, 256, 258, 287, 335
Cardo cardador, 106, 258, 323, 324, 345, 349, 356, 358

Cardo de arzolla, 116, 264, 272, 273, 288, 289

Cardo de hisopo, 106

Cardo del ejido, 93

Cardo lecherín, 122, 124, 125, 249, 335, 337

Cardo lecherito, 125

Cardo lechero, 122, 125, 249

Cardo mariano, 29

Cardo morado, 93, 256, 345

Cardo negrero, 115, 118, 249, 258, 335

Cardo santo, 93, 106

Cardo triguero, 118

Cardón, 106, 323

Carduus carlinoides, 27

Carduus carpetanus, 115

Carduus pycnocephalus, 115

Carduus tenuiflorus, 115

Carduus crispus, 115, 118, 249, 335

Carex halleriana, 22

Carex sylvatica, 19, 20

Carlina vulgaris, 115, 345

Carquesa, 157, 250, 257

Carrigüela, 127

Carriyuela, 127

Carthamus mitissimus, 115, 116, 122, 273, 274, 275

Carum carvi, 91, 268

Castanea sativa, 133, 236

Castaña pilonga, 158, 201

Castaño, 133, 236

Castaño de indias, 201, 274, 299, 344

Caucalis platycarpos, 91, 335, 337, 357, 358

Cebada, 28, 79, 80, 176, 205, 237, 247, 251, 252, 253, 254, 255, 307, 312, 313, 332

Cebadilla de ratón, 29

Cebolla, 68, 120, 147, 185, 197, 234, 268, 273, $275,283,284$

Cebolleta, 69, 244, 256, 298, 344

Cedro, 65, 66, 362

Cedrus libani, 65, 362

Celedonia, 173

Celidonia, 173, 274, 289

Celingueña, 74

Cencellada, 171

Cencerra, 171

Cencerrada, 171, 172, 245, 246, 336, 337, 338, 
346

Cencerrón, 75, 245, 346

Cenizo, 89

Centaurea calcitrapa, 116, 122, 288, 289, 290

Centaurea lagascana, 116, 122, 264, 272, 273, 274, 288, 289, 290

Centaurea nigra, 117, 277

Centaurea ornata, 116, 275

Centaurea scabiosa, 117, 249, 252, 335

Centaurium erythraea, 138, 262, 263, 264

Centeno, 28, 63, 79, 80, 81, 82, 143, 188, 200, 205, 210, 211, 237, 247, 251, 252, 253, 254, $255,265,266,307,312,319,320,323,324$, $325,326,332,347,349$

Centidonia, 29, 173

Cepico, 151, 243, 267, 269, 280, 297, 307, 332, 376

Ceresuela, 188, 303, 327, 347, 349, 355

Cerezo, 186, 235, 236, 240, 245, 251, 259, 321, 323,353

Cerezo de Santa Lucía, 22

Cerigüeña, 173

Cerindeña, 74

Ceringueña, 174, 244, 256

Cervuno, 26

Chacleo, 110, 175

Chaerophyllum aureum, 90, 91, 249, 345

Chaerophyllum hirsutum, 92, 345

Chamaecyparis lawsoniana, 64, 341

Chamaemelum nobile, 113, 117, 150, 167, 240, $241,242,264,265,269,272,276,277,280$, $283,284,285,286,290,318,363,365,366$, $367,371,374,375,376,377,381,382$

Chamorro, 124, 244, 246

Champiñón, 209, 239

Champiñón campero, 209

Chelidonium majus, 173, 274, 275, 289, 290

Chenopodium album, 29, 89, 249, 335, 337

Chiflato, 89, 90, 244, 246, 262, 283, 292, 323, 324

Chocho, 159, 238, 254, 255, 278

Chopo, 28, 99, 101, 137, 192, 197, 198, 200, 201, 210, 211, 251, 304, 305, 311, 312, 313, $321,323,324,332,350,353,354,355,356$, $360,361,363,365,366,371,376,377,381$

Chuma, 178, 360

Chupa, 143, 147, 148, 162, 171, 179, 233, 245,
$246,250,257,258,259,269,276,277,299$, 347

Chupete, 171, 179, 245, 258

Chupete de grillo, 147, 245, 258

Chupón, 143, 162, 171, 233, 245, 258, 289

Chupona, 143, 245

Cicer arietinum, 153, 231, 238, 250, 312

Cichorium endivia, 118, 232

Cichorium intybus, 29

Cicuta, 90, 92

Cinnamomum verum, 152, 243

Cinta, 72, 345

Cirsium arvense, 118, 249, 252, 258, 259, 335, 337

Cirsium eriophorum, 119, 256, 257, 258, 287, 335

Cirsium vulgare, 118, 249, 252, 258, 259, 335, 337

Ciruelo, 187, 235, 236, 240, 251, 259, 334, 347

Citrus limon, 197, 265, 266, 270

Citrus sinensis, 197, 318

Clavel, 76, 108, 109, 114, 119, 173, 249, 258, $272,273,285,318,319,335,341,342,345$, $346,352,353$

Clavelina, 109, 318, 319, 345, 348, 352

Clavelina azul, 119

Clematis vitalba, 23

Coffea arabica, 196, 242, 243

Col, 103, 232, 249

Col de Bruselas, 204, 232

Cola de caballo, $64,110,118,150,167,256$, 262, 263, 267, 272, 273, 280, 336

Cola de perro, 78

Colchicum montanum, 72, 244, 246, 337, 378

Cóleo, 147, 346, 353, 354

Coliflor, 104, 232

Colleja, 110, 232, 233, 245, 258

Comida de pajaritos, 127

Comino, 94, 213, 244, 264

Comuña, 79, 80, 237, 251, 254, 255, 332

Conchita, 98, 345, 349, 352

Conium maculatum, 85, 90, 92, 249, 252, 256, $257,298,300,312,313,323,324,332,335$, 345,364

Conopodium majus, 92, 93, 244, 246, 256, 258 Conopodium pyrenaeum, 92, 93, 244, 246, 256, 258 
Consolida ajacis, 180, 342

Convolvulus arvensis, 127, 232, 233, 250, 252, 335, 337

Copo de nieve, 88, 341, 343, 352

Coprinus comatus, 211, 239

Corazoncitos, 78, 347, 359

Corazones, 78, 347, 349, 359

Cornejo, 18, 23

Cornicabra, 177, 178, 233, 259, 263, 265, 266, 271

Correyuela, 127, 232, 233, 250, 252, 335, 337

Corrigüela, 127, 232, 250, 335

Corveño, 65, 303, 307, 308, 320, 328, 336, 352, 358

Corydalis cava, 21

Corylus avellana, 18, 20, 21, 23, 100, 200, 236, $237,249,251,304,305,311,312,313,320$, $322,323,326,327,328,352,354,357,358$, $360,361,363,364,365,366,367,371,372$, 373, 374, 376

Crataegus monogyna, 18, 19, 20, 21, 22, 23, $24,183,189,233,235,236,240,241,245,251$, $257,259,262,263,269,303,306,314,321$, $322,326,334,347,349,353,359,363,364$, 365, 366, 367, 369, 371, 372, 373, 374, 375

Crepis pygmaea, 27

Cuajaleche, 196, 243, 270, 274, 347

Cucharilla, 124, 345

Cucubilla, 72, 74, 244, 246, 256, 258, 337

Cucubillo, 180

Cucumis sativus, 129, 232, 233

Cucurbita moschata, 129, 232, 233

Cucurbita pepo, 129, 232, 233, 258

Cuete, 84, 110, 175, 232, 299, 326, 345, 347, $348,358,359$

Culebrón, 126

Cuquillo, 179, 245, 246, 269, 276, 347

Currialón, 126

Cyanus segetum, 29, 119, 249, 277, 335, 352

Cynodon dactylon, 77, 78, 80, 336, 337

Cynosurus cristatus, 21, 26, 78, 347

Cystopteris fragilis, 62, 345

Cytisus cantabricus, 20, 24, 154, 375

Cytisus oromediterraneus, 24, 153, 154, 250, 251, 256, 257, 305, 307, 312, 313, 346, 349

Cytisus scoparius, 18, 19, 21, 24, 154, 256, 258, $303,304,305,307,312,313,321,322,336$,
$338,346,349,353,363,364,365,366,367$, $371,372,374,375,376,377,381$

Daboecia cantabrica, 24, 25

Dactylis glomerata, 21, 26, 27, 77, 79, 80, 285, 336, 337

Dahlia pinnata, 119, 339, 341

Dahlia x hortensis, 119

Dalia, 119, 339, 341

Daphne gnidium, 284

Daphne laureola, 20, 21, 205, 283, 284

Datura stramonium, 203, 299

Daucus carota, 93, 234, 253

Dedalera, 175, 299, 347, 348, 359

Deschampsia flexuosa, 20, 21, 27

Dianthus hyssopifolius, 109, 318, 319, 345, 348, 352

Diente de león, 125, 232, 242, 250, 267, 271, $272,273,275,335,361$

Digitalis parviflora, 175

Digitalis purpurea, 175, 299, 347, 348, 359

Dipsacus fullonum, 106, 119, 258, 259, 323, $324,345,349,356,358$

Dondiego, 169, 342, 343

Dracunculus vulgaris, 71, 72, 296, 297, 341

Drido, 195, 251, 257, 299, 303, 321, 328, 334, $344,353,364$

Drío, 195, 251, 257, 299, 303, 321, 328, 334, 344, 353, 364

Dryopteris affinis, 20, 63, 64, 312, 313, 341, 346

Dryopteris dilatata, 20

Dryopteris filix-mas, 20, 63, 64, 312

Echium vulgare, 29, 101, 264, 283, 284, 345

Elymus repens, 77, 79, 80, 336, 337, 347

Encantadera, 171, 245, 336, 337, 346

Encina, 21, 22, 25, 138, 236, 237, 250, 254, 255, 259, 303, 304, 306, 311, 322, 323, 324, 369

Endrino, 17, 19, 21, 24, 25, 189, 230, 235, 240, $245,259,262,303,304,314,347,363,364$, $365,366,367,371,376$

Enebro, 21, 22, 23, 25, 27, 65, 303, 307, 308, $320,328,352,358$

Enredadera, 97, 101, 128, 177, 245, 246, 273, 299, 333, 335, 341, 342, 349, 352, 355, 360

Ensayo, 214, 336, 357

Epipactis helleborine, 20

Equisetum arvense, 64, 256, 262, 263, 267, 
272, 280, 336, 337

Erica arborea, 20, 21, 24, 25, 27, 130, 131

Erica australis, 18, 24, 25, 130, 131

Erica cinerea, 18, 25, 130, 131

Erica spp., 19, 25, 60, 130, 256, 258, 259, 267, $268,303,304,305,306,307,308,312,313$, $320,322,332,346,349,360,361,363,364$, 365, 366, 367, 371, 374, 376, 377

Erica tetralix, 25, 28, 130, 131

Erica umbellata, 25

Erica vagans, 18, 19, 25, 130, 131

Eriophorum Iatifolium, 73, 345

Erodium ciconium, 29

Eryngium bourgatii, 93, 119, 256, 257, 345, 349

Eryngium campestre, 94, 119, 256, 257, 337, 338

Erythronium dens-canis, 21, 75, 342

Escándalo, 140, 141, 235, 321

Escarola, 118, 232

Eschscholzia californica, 173, 342

Escoba, 19, 20, 21, 153, 154, 155, 250, 251, $256,258,259,303,304,305,307,312,313$, $321,322,328,329,336,338,346,348,353$, $363,364,365,366,367,371,372,375,376$, 377,381

Escoba albar, 155, 156, 250, 258, 303, 305, 312, $321,328,346,353,364,376$

Escoba albera, 155

Escoba aujera, 29

Escoba balera, 154, 256, 258, 303, 305, 307, $312,321,336,338,346,353,363,364,365$, 366, 371, 376

Escoba barredera, 154

Escoba cabrera, 156, 250, 303, 304, 312

Escoba chiflona, 154

Escoba de la cuesta, 156

Escoba de rohíjo, 156

Escoba hornil, 153, 154, 250, 256, 257, 305, 307, 312, 346

Escoba serraniega, 154

Escobilla, 64, 256, 262, 267, 272, 280, 336

Esparceta, 160, 250

Espino, 183, 189, 190, 193, 233, 235, 240, 241, $245,251,253,257,259,262,267,269,270$, $283,303,306,314,318,321,326,327,328$, $334,347,353,359,363,364,365,366,371$, 372,376
Espino albar, 18, 20, 21, 22, 23, 24, 25, 183, $233,235,240,241,245,251,257,259,262$, $269,303,306,314,321,326,334,347,353$, 359, 363, 364, 365, 366, 367, 371, 373

Espino blanco, 183

Espino majolero, 183

Espirea, 21

Espuma, 140, 141, 321

Estramonio, 203, 299

Eucalito, 168, 269, 315, 323

Eucalipto, 66, 67, 147, 168, 169, 269, 270, 315, 323

Eucalyptus globulus, 168, 269, 315, 323

Euonymus europaeus, 18, 23, 111, 320, 323, 328, 329, 341

Euphorbia dulcis, 20

Euphorbia hyberna, 21, 132, 296

Euphorbia serrata, 132, 296

Fagus sylvatica, 18, 19, 20, 22, 133, 236, 237, $240,242,256,258,299,300,303,304,306$, $308,311,312,312,315,320,322,323,324$, $328,329,352,354,355,356,357,358,360$, $363,364,365,366,369,371,373,374,376$, 377, 381, 382

Fallopia balschuanica, 177, 245, 246, 342

Festuca burnatii, 27

Festuca eskia, 27

Festuca hystrix, 22

Festuca rubra, 21, 26

Ficus carica, 168, 235, 236

Filipendula ulmaria, 184, 267, 276

Filipendula vulgaris, 184, 276, 347

Flor de la corona, 107, 108, 358, 359

Flor de la droga, 174, 299, 300, 342, 346, 359

Flor de la plata, 105, 341, 345

Flor de lino, 164, 346

Flor de malva, 166, 245, 250, 265, 269, 277, 283, 287, 289, 336, 359, 364, 376

Flor de nuestra señora, 114

Flor de orina, 141

Flor de papel, 109, 262, 276, 280, 285

Flor de riachino, 180

Flor del tobar, 181

Foeniculum vulgare, 29, 94, 244, 246, 264, 266

Fomes fomentarius, 137, 211, 305, 338, 349, 364

Forraja, 126 
Fragaria vesca, 19, 184, 235, 236, 257, 369, 374

Fragaria $\mathrm{x}$ ananassa, 184, 235

Frambueso, 18, 193

Franco, 164, 250, 254

Frangula alnus, 182, 299

Fraxinus angustifolia, 170, 273

Fraxinus excelsior, 19, 23, 28, 169, 250, 251, $272,274,279,303,304,305,311,321,322$, $323,324,328,329,344,353,354,355,364$, $365,366,367,371,374$

Fréjol, 160, 231, 238

Fresa, 184, 185, 235, 257

Fresno, 19, 23, 28, 117, 169, 170, 195, 250, $251,272,273,274,279,303,304,305,311$, $321,322,323,324,328,329,344,353,354$, $355,364,365,366,371$

Fritillaria Iusitanica, 75, 245, 246, 346

Fritillaria pyrenaica, 75, 245, 246, 346

Fuchsia magellanica, 170, 346, 349, 354

Galium aparine, 91, 196, 336, 337, 357, 358

Galium verum, 196, 243, 244, 270, 271, 274, 347

Gamón, 84, 251, 259, 308, 328, 329, 336, 337, 338, 348, 359, 360, 363, 364, 365

Gamonita, 84, 251, 259, 308, 328, 336, 338, $348,359,363,364,365$

Garamujo, 190

Garbanzo, 104, 127, 153, 158, 177, 179, 213, $214,231,238,250,312$

Garbanzón, 177, 277

Gardincha, 101, 264, 283, 284, 345

Gatimora, 193, 236

Gatuña, 160, 250, 336, 337, 338

Gayuba, 22, 23, 25, 129, 234, 256, 267, 285, 299, 328, 364

Gayuga, 129, 130, 234, 256, 257, 267, 268, 285, 299, 328, 329, 364

Gébena, 29

Gébene, 103, 104, 106, 249, 335, 337

Genciana, 138, 139, 264, 266, 269, 270, 278, 279, 283, 284, 287, 291, 300

Genista anglica, 25

Genista florida, 18, 20, 24, 154, 155, 250, 251, $258,259,303,304,304,312,313,321,322$, 328, 329, 346, 353, 364, 375, 376, 377

Genista hispanica, 19, 19, 20, 21, 22, 25, 156,
258, 303, 304, 307, 308, 321, 322

Genista obtusiramea, 24, 154, 156, 250, 251, $303,304,312,313$

Genista scorpius, 21, 25, 156, 303, 304, 314, 374, 374, 375

Genista tridentata, 25, 157, 250, 257

Gentiana lutea, 138, 264, 266, 269, 270, 278, 279, 283, 284, 287, 291, 300

Geranio, 139, 140, 346, 349, 353, 354

Geum urbanum, 185, 265

Girasol, 120, 236

Gladiolo, 73, 342

Gladiolus communis, 73, 342

Glandora diffusa, 102, 244, 262, 263, 268

Golondrillo, 62, 286

Golondrino, 62, 286

Gordolobo, 96, 122, 202, 203, 262, 263, 270, 272, 283, 286, 287, 292, 293, 297, 348

Grama, 77, 78, 79, 80, 118, 150, 167, 285, 336, 337, 347

Graspo, 130, 131, 256, 258, 259, 267, 268, 303, $305,306,307,308,312,320,332,346,349$, $360,363,364,365,366,371,376$

Grosellero, 20, 21, 23, 140

Gualda, 182, 347

Guardalobo, 202, 262, 270, 272, 283, 286, 292, 297, 348

Guindal, 186, 187, 235, 236, 240, 265, 298, 303, $321,322,323$

Guisante, 161, 238, 250, 254, 359

Haba, 163, 238, 254

Halecho, 62, 307, 312, 320, 332, 336, 345, 357, 364

Halimium alyssoides, 25

Haya, 17, 18, 19, 20, 21, 22, 87, 99, 100, 101, $133,134,135,137,194,236,237,240,242$, 256, 258, 299, 300, 303, 304, 306, 308, 311, $312,313,315,320,322,323,324,328,329$, $352,354,355,356,357,358,360,363,364$, $365,366,369,371,372,373,376,377,381$, 382

Hedera helix, 18, 19, 23, 97, 273, 333, 335, 337, 341, 349, 352, 354, 355, 360, 361

Helecha, 63, 64, 312, 341, 346

Helecho, 19, 20, 28, 62, 63, 64, 74, 307, 312, $313,320,322,332,336,341,345,346,352$, $357,358,364$ 
Helianthus annuus, 120, 236

Helichrysum stoechas, 25, 117, 120, 242, 264, 265, 269, 277, 280, 283, 374, 376

Helleborus foetidus, 23, 71, 181, 245, 246, 299, 300

Helleborus viridis, 18, 20, 21, 24, 71, 181, 299, 300

Helictotrichon marginatum, 24

Heno, 77, 347

Heracleum sphondylium, 94, 249, 252

Hiedra, 18, 19, 23, 97, 98, 192, 273, 333, 335, $337,341,349,352,355,, 360,361$

Hierba alpericón, 141

Hierba bujanera, 121

Hierba de algodón, 73, 345

Hierba de la cólica, 151, 265, 266

Hierba de la colitis, 165, 265, 266

Hierba de la culebra, 71, 72, 289, 290, 296, 297, 298, 341

Hierba de la grama, 78, 336

Hierba de la leche, 132, 296

Hierba de la pulmonía, 196, 271

Hierba de las 7 sangrías, 102, 138, 262, 263, 264

Hierba de las culebras, 181, 245, 299, 300

Hierba de menta, 145

Hierba de San Benito, 185, 265

Hierba de San Juan, 141

Hierba de Santa Lucía, 149, 262, 274, 277

Hierba del cuajo, 196, 243, 244, 270, 271, 274, 347

Hierba del gusano, 121, 122, 335

Hierba del morro, 112

Hierba gusanera, 121, 122

Hierba la sabina, 265, 267

Hierba morena, 171, 257, 299

Hierba negreal, 171, 257, 299, 300

Hierba nube, 162, 250, 257, 277, 291, 299

Hierba piojera, 121, 179, 278, 291, 298, 299, 347

Hierba plumera, 82, 347, 349

Hierbabuena, 110, 144, 145, 242, 243, 264, 269, 342

Higuera, 168, 235, 236

Hinojo, 29, 94, 244, 246, 264, 266

Hipérico, 141, 142, 267, 268, 272, 273, 274, 276, 278, 285, 289, 290, 291, 292, 318
Hoja chupona, 128

Hoja de chupón, 127, 269, 271, 273

Hoja de la plata, 105, 341, 343, 345, 349

Hoja de la tiraina, 164

Hoja de la tiraña, 164, 283, 284, 286, 299

Hoja de lentén, 175, 262, 265, 269, 274, 277,

285, 289, 336

Hoja de llantel, 175

Hoja de patacaballo, 94, 249, 252

Hoja maldita, 98, 234, 244, 246, 256

Hoja mantequera, 176, 250

Hoja mora, 96, 202, 203, 292

Holcus lanatus, 26

Holcus mollis, 19, 79, 251, 347

Hongo, 209, 239

Hongo silvestre, 209

Hordeum murinum, 29

Hordeum vulgare, 79, 237, 247, 251, 252, 254, 255, 307, 312, 313, 332

Hortensia, 141, 342

Humarra, 117, 249, 335

Husera, 111, 320, 322, 328, 341

Hydrangea macrophylla, 141, 342

Hyoscyamus niger, 203, 265, 266, 272, 273, 285, 286, 288, 292, 299

Hypericum hirsutum, 142

Hypericum hyssopifolium, 142

Hypericum perforatum, 141, 142, 267, 272, $273,274,276,278,285,289,290,291,292$, 318

Hypericum undulatum, 142

Hypericumm pulchrum, 142

Ilex aquifolium, 18, 19, 20, 21, 23, 96, 251, $256,257,298,299,303,304,308,320,322$, $328,329,341,343,345,348,352,354,355$, $356,357,358,363,364,365,366,367,371$, 373,374

Impatiens balsamina, 98, 345, 349, 352, 354

Inula helenioides, 121

Inula helvetica, 120, 121, 262, 264, 273, 289

Inula montana, 86, 121, 269, 271, 272, 273, $274,288,298,363,365,366,367,371,374$, 381

Inula salicina, 121

Iris pseudacorus, 73, 346

Iris x germanica, 73, 342

Jabonera, 110, 345, 358, 359 
Jabonera de lastra, 110, 341

Jacobaea vulgaris, 121, 122, 272, 279, 291, 298, 335

Jamora, 202, 297

Judío, 96, 341

Juglans regia, 142, 236, 237, 240, 241, 264, $266,272,274,289,290,303,323,325,356$, 357,360

Junciana, 138, 139, 162, 264, 269, 278, 279, 283, 287, 291, 300

Junco, 23, 73, 74, 75, 96, 298, 312, 313

Juncus articulatus, 74, 312

Juncus effusus, 74, 312

Juncus inflexus, 74, 312

Juncus trifidus, 74, 312

Juniperus communis, $21,22,23,25,65,303$, $307,308,320,328,352,358$

Juniperus sabina, 22, 23, 25, 65, 303, 307, 308, 336, 352

Jurinea humilis, 116, 122, 273, 274, 289

Knautia arvensis, 107, 358

Koeleria vallesiana, 22

Lactarius deliciosus, 212, 239

Lactuca sativa, 122, 232, 233, 249

Lactuca serriola, 119, 122, 249, 252, 335

Lactuca viminea, 119

Lactuca virosa, 119, 123, 249

Ladilla, 79, 80, 237, 251, 254, 307, 312, 332

Lágrimas de Judas, 108, 341, 343

Lantel, 175

Lapa, 91, 113, 174, 196, 336, 337, 357, 358

Lathyrus cicera, 157, 238, 250, 254, 255

Lathyrus latifolius, 157, 346

Lathyrus sativus, 157, 231, 238, 247, 250, 252, 254, 255

Lathyrus tuberosus, 158, 245, 246

Laurel, 152, 243, 319, 320, 342, 353, 354

Laurus nobilis, 152, 243, 319, 320, 342, 353, 354

Layo, 89, 249

Lecherín, 122, 125, 126, 249, 335

Lecherina, 124, 125, 126, 244, 246

Lecherita, 126

Lechetrezna, 132, 296

Lechuga, 122, 125, 126, 232, 233, 244, 249

Lens culinaris, 158, 238

Lenteja, 158, 238
Lentel, 175, 262, 265, 269, 274, 277, 285, 289, 336

Lepista nuda, 212, 239

Lepista rickenii, 213, 239

Lepista sordida, 213, 239

Leucanthemum maximum, 123, 339, 341

Leucanthemum pallens, 123

Leucanthemum vulgare, 123, 328, 352, 354, 358,360

Ligustrum vulgare, 170, 318, 319, 321, 322, 346, 353

Lilar, 170, 342, 343, 353

Lilium candidum, 75, 342, 343

Lilium martagon, 18, 75, 289, 290, 342, 346

Linaria alpina, 28

Linaria triornithophora, 18, 19

Lino, 158, 164, 165, 240, 269, 283, 284, 328

Linum narbonense, 164, 346

Linum usitatissimum, 164, 240, 269, 283, 284

Lira, 70, 71, 341, 344, 348

Lirada, $112,113,123,124,335,337,345,352$, 358

Lirio, 70, 73, 74, 258, 342, 346, 376

Lirio amarillo, 73, 346

Lirio azul, 74, 346

Lirón, 70, 244, 258, 341, 344, 352, 376, 377

Lirón de Pineda, 70

Lirona, 70, 244, 344

Llantén, 175, 262, 265, 269, 274, 275, 277, 285, 289,336

Lolium multiflorum, 77, 80, 336, 337

Lolium perenne, 21, 80, 251, 336, 337

Lonceja, 158, 245, 246

Lonicera etrusca, 108

Lonicera japonica, 107, 341

Lonicera periclymenum, 18, 107, 244, 320, 322

Lonicera xylosteum, 18

Lotus corniculatus, 159, 257

Lunaria annua, 105, 341, 345, 349

Lupinus albus, 159, 238, 254, 255, 278

Luzula caespitosa, 27

Luzula lactea, 75, 346

Luzula sylvatica subs. henriquesii, 19, 20

Lycoperdon perlatum, 211, 274, 359

Lythrum salicaria, 165, 265, 266

Macrolepiota procera, 210, 239

Madreselva, 18, 107. 244. 320 
Maello, 185, 235, 240, 242, 334, 363, 365, 376 Maíllo, 18, 19, 24, 85, 235, 240, 241, 242, 334, 363, 365, 376

Maíz, 29, 83, 254, 285, 286, 325

Majueto, 183, 233, 235, 240, 245, 251, 257, $259,262,263,269,303,306,314,321,322$, $326,334,347,349,353,359,363,364,365$, 366,371

Malus domestica, 185, 235, 236, 253, 259, 269, 303,334

Malus sylvestris, 18, 19, 24, 185, 235, 236, 240, 241, 242, 334, 363, 365, 369, 376

Malva, 29, 103, 110, 147, 166, 167, 158, 176, $197,208,245,246,250,265,269,270,272$, $274,283,287,289,290,336,359,360,364$, $374,375,376$

Malva moschata, 166, 245, 246, 272

Malva sylvestris, 29, 103, 166, 245, 250, 265, $269,270,272,274,283,287,289,290,336$, 359, 360, 364, 374, 375, 376

Malvarisco, 103, 165, 269, 270, 342, 343, 360

Malvavisco, 165, 166, 269, 342, 360

Mantecón, 93, 181, 214, 244, 246, 256, 299

Manzanilla calar, 117, 120, 150, 167

Manzanilla campera, 117, 120, 167, 240, 242, $264,268,271,276,277,280,290,318,363$, $365,366,371,376$

Manzanilla de lastra, 120, 242, 376

Manzanilla de peña, 120, 242, 264, 269, 277, 280

Manzanilla de roca, 120

Manzanillón, 112, 113, 117, 123, 334, 345, 352

Manzano, 185, 195, 196, 235, 236, 253, 259, $269,303,334$

Marajojo, 200

Maraojo, 200, 262, 286, 289, 299, 336, 348, 356

Marasmius oreades, 212, 239, 376

Maravilla, 114, 258, 272, 273, 285, 286, 339, 341, 343

Margarita, 112, 113, 114, 123, 124, 125, 283, $285,286,328,335,339,341,345,348,352$, 358,360

Mariselva, 107, 244, 320, 322, 341

Marrubio, 144, 269, 274

Marrubium vulgare, 144, 269, 274

Matorro, 135, 236, 240, 244, 250, 254, 256,
$258,303,305,306,311,312,315,319,321$, $323,326,328,329,332,337,352,355,357$, 359, 360, 362, 363, 364, 365, 366, 371, 376

Meacamas, 125

Meaperro, 182, 299

Medicago sativa, 159, 250, 252, 258, 374

Mejorana, 150, 243, 265, 267, 269, 296, 297, 307

Melampyrum pratense, 19, 171, 257, 299, 300

Melica uniflora, 21

Meliloto, 159, 269

Melilotus officinalis, 159, 269

Melisa, 19, 112, 144, 242, 264, 276

Melittis melissophyllum, 19, 144, 242, 264, 276

Melocotón, 188, 189, 235, 236

Menta, 144, 145, 242, 243, 264, 269, 342, 360

Menta poleo, 145, 146, 242, 264, 269, 296, $318,356,360$

Mentha aquatica, 144, 243, 264, 269

Mentha longifolia, 145, 264, 265, 269, 296, 297, 318, 319, 321, 360

Mentha pulegium, 145, 242, 264, 269, 296, 356, 357

Mentha x piperita, 145, 242, 243, 342

Mercurialis perennis, 21

Mesino, 82, 237, 245, 251, 254, 262, 265, 283, $307,312,323,326,332,347,359$

Mielenrama, 112

Mielga, 159, 250, 252, 258

Miérgano, 184

Mijuelo, 187, 235, 240, 251, 259, 334, 347

Milenrama, 112, 118, 167, 242, 262, 264, 266, $267,272,273,279,280,283,285,339,345$, 356,357

Milgojo, 200

Mimbrera, 199, 259, 304, 311, 313, 321, 323, 325, 326, 327, 363, 365, 366, 371

Mingojo, 200, 262, 286, 289, 299, 336, 348, 356

Mirabilis jalapa, 169, 342, 343

Molino de color, 119

Mora de la reina, 193, 235, 257

Mora montesina, 193

Moral, 168, 192, 193, 230, 235, 241, 245, 314, $327,359,363,365,366,371,376$

Morera, 168, 235, 236

Morita, 161, 238, 250, 254, 259

Morito, 192, 193, 235 
Morus alba, 168, 235, 236

Morus nigra, 168, 235

Mostajo, 18, 19, 21, 22, 23, 24, 194, 195, 235, $251,257,303,304,305,306,321,328,329$, $334,344,355,363,364,365$

Mostaza, 106, 268, 271

Muela, 157, 238, 250, 254

Muérdago, 200, 201, 286, 289, 299, 336, 337, 348,356

Muscari racemosum, 72, 358, 360

Muzgaño, 92

Nabo, 103, 234, 253, 257, 258

Narcissus asturiensis, 70, 344, 348

Narcissus bulbocodium, 70, 244, 246, 344

Narcissus pseudonarcissus, 70, 258, 259, 341, 344, 348, 352, 358, 376, 377

Narcissus triandrus, 71, 344

Narthecium ossifragum, 28

Nardus stricta, 26

Nasturtium officinale, 105, 232, 233, 256

Naviza, 103, 249, 335

Neguilla, 29, 108, 249, 335, 337

Neguillón, 108, 249, 335

Nevada, 108

Nicotiana tabacum, 204, 291, 360, 361

Níscalo, 212, 239

Nogal, 142, 143, 236, 237, 240, 264, 272, 274, $289,290,303,323,325,356,357,360$

Nueza, 128, 289, 299, 335

Nuezgo, 85, 272, 288, 298, 335

Ocimum basilicum, 146, 296, 297

Olmo, 28, 87, 101, 195, 206, 251, 304, 305, $311,313,321,322,323,324,325,326,327$, $353,361,362,365,366,371,372$

Olmo monte, 205, 251

Onobrychis viciifolia, 160, 250

Ononis pusilla, 22, 25

Ononis spinosa, 160, 250, 336, 337, 338

Onopordum acanthium, 29, 119, 124, 254, 257, 335

Onopordum nervosum, 29

Orchis pallens, 76, 342

Orégano, 69, 110, 118, 145, 146, 147, 150, 166, $167,168,176,185,197,243,264,269,270$, $278,280,285,286,287,296,297,360,363$, $365,366,367,371,375,376,382$

Oreochloa blanka, 27
Oreochloa seslerioides, 28

Origanum vulgare, 146, 243, 264, 269, 270, $278,280,285,286,287,296,297,360,363$, $365,366,367,371,374,375,376,377,382$ Ortiga, 23, 64, 104, 205, 207, 208, 233, 251, $252,257,262,263,267,270,272,273,274$, $275,296,297,318$

Ortiga blanca, 143, 245, 289

Ortiga meña, 207, 251, 262, 296

Oryza sativa, 80, 265, 266

Ovillo, 140

Oxalis acetosella, 20, 24

Oxalis pes-caprae, 171, 336

Paeonia lactiflora, 172, 259, 328, 342, 343, 346 353, 354, 356, 357

Paeonia officinalis, 173, 342, 343, 346, 353, 354

Pamplina, 111, 249, 335

Pan de los pajaritos, 127, 256

Papaver rhoeas, 29, 173, 250, 252, 269, 276, $277,336,337,346,353,357,358,359,374$, 375

Papaver somniferum, 174, 299, 300, 342, 343, 346, 359

Parasol, 210, 239

Parnassia palustris, 28

Paronychia capitata, 110

Paronychia kapela, 109, 262, 263, 276, 280, 285

Parra, 209, 235, 245, 270, 286, 287, 304, 321, 333

Parra de culebra, 128

Pasiflora, 175, 342

Passiflora caeruela, 175, 342

Patata, 205, 234, 253, 326, 361

Paulina, 111, 249, 335, 337

Pedicularis comosa, 143, 148, 171, 245, 246, 258, 259

Pedicularis sylvatica, 143, 148, 171, 245, 246, 258, 259

Pedo de lobo, 211, 274, 359

Pegamanos, 196, 336, 357

Pegote, 113, 249, 271, 289, 300, 358

Pelargonium grandiflorum, 140

Pelargonium peltatum, 140

Pelargonium zonale, 139, 346, 349, 353, 354

Peluso, 82, 347 
Pendientes de la reina, $72,170,298,346,349$, 354

Pensamiento, 208, 209, 343

Peonía, 172, 173, 259, 328, 342, 343, 346, 353, $354,356,357$

Pepino, 129, 232, 233

Pera de la vega, 93

Peral, 189, 235, 236, 259

Peral de monte, 189, 235, 259

Peral silvestre, 189, 235, 259

Perejil, 92, 94, 243, 245

Pericol, 141

Pericón, 141, 207, 272, 274, 276, 278, 285, 289, 291, 318

Persicaria bistorta, 177, 233

Perujo, 189, 190, 235, 259

Petroselinum crispum, 94, 243

Petruco, 87, 88, 234, 236, 320

Petrujo, 87, 88

Phaseolus vulgaris, 160, 231, 238

Philadelphus coronarius, 141, 342, 343

Pilonga, 158, 245

Pimiento, 203, 233, 243, 283

Pinguicula grandiflora, 164, 283, 284, 286, 299, 300

Pinillo, 64, 256, 262, 267, 272, 280, 336, 337

Pino, 60, 66, 67, 305, 315, 332, 333, 353, 354, 362

Pino albar, 22

Pino negral, 22

Pinus nigra, 22, 60, 66, 305, 315, 332, 333, 353, 362

Pinus sylvestris, 22, 66, 305, 315, 332, 333, 353, 354, 362

Pipa, 71, 344

Pirigallo, 173, 174, 250, 269, 276, 277, 336, $346,353,357,359$

Pisum sativum, 151, 238, 250, 252, 254, 359

Planta de las culebras, 181

Planta del jabón, 110, 345, 358

Planta del tabaco, 178, 291, 360, 361

Planta del yodo, 173, 274, 275, 289, 290

Plantago coronopus, 29

Plantago lanceolata, 26, 175, 262, 265, 269, 272, 275, 277, 285, 289, 336

Plantago major, 21, 176, 250

Pleurotus eryngii, 94, 212, 239, 338
Plumillar, 141, 235, 321

Plumillo, 140, 234, 321

Poa pratensis, 26

Poleo, 145, 146, 242, 264, 265, 266, 269, 296, 297, 318, 319, 3231, 322, 356, 360

Polygonatum odoratum, 72, 298

Polygonatum verticillatum, 21

Polygonum aviculare, 29

Populus alba, 28, 197, 251, 304, 311, 312, 313, $321,323,324,325,332,351,353,355,360$, 361

Populus nigra, 197, 251, 304, 311, 312, 313, $321,323,324,325,332,351,353,355,360$, 361

Populus spp., 354, 355, 363, 364, 365, 366, 367, $371,374,376,377,381,382$

Populus tremula, 18, 20, 198, 304, 312, 332, 353

Populus x canadensis, 28

Potamogeton natans, 28

Potamogeton polygonifolius, 28

Primula elatior, 23, 179

Primula pedemontana, 28

Primula veris, 19, 24, 143, 148, 179, 245, 246, 269, 347

Prunella grandiflora, 19, 143, 147, 148, 245, 146, 258, 259

Prunella vulgaris, 19, 143, 147, 148, 245, 146, 258, 259

Pruno, 187, 235, 240, 251, 259, 334, 347

Prunus avium, 186, 235, 236, 240, 241, 265, 266, 298, 303, 321, 322, 323, 374

Prunus cerasus, 186, 235, 236, 240, 241, 265, 266, 298, 303, 321, 322, 323, 374

Prunus domestica, 187, 235, 236, 240, 251, 259, 334, 347

Prunus domestica subsp. insitia, 59, 187, 235, 236, 240

Prunus padus, 188, 303, 327, 347, 348, 355

Prunus persica, 188, 235, 236

Prunus spinosa, 19, 21, 24, 189, 230, 235, 236, $240,241,245,246,259,262,303,304,314$, $347,363,364,365,366,367,369,371,374$, 376

Pteridium aquilinum, 19, 62, 63, 307, 312, 313, $320,322,332,336,345,352,357,358,364$, 374 
Pudio, 17, 20, 21, 23, 182, 257, 321

Puerro, 68, 69, 232, 233, 357, 358

Pulmonaria, 19, 102, 268

Pulmonaria longifolia, 19, 102, 268

Puro, 84, 137, 326, 348, 349

Purrino, 75, 346

Pyrus communis, 189, 235, 236, 259

Pyrus cordata, 189, 235, 236, 259

Quercus spp., 60, 241, 363, 364, 365, 366, 367, $371,373,374,376,377,381,382$

Quercus faginea, 21, 22, 374

Quercus petraea, 18, 19, 20, 135, 236, 237, $240,244,250,251,254,255,256,258,259$, $303,304,305,311,312,313,315,319,320$, $321,322,323,324,325,326,328,329,332$, $337,338,352,354,355,356,357,359,360$, $361,362,369,382$

Quercus pyrenaica, 18, 19, 21, 135, 236, 237, $240,244,250,251,254,255,256,258,259$, $303,304,305,306,311,312,313,315,319$, $321,321,322,323,324,325,326,328,329$, $332,337,338,352,355,357,359,360,361$, 369,382

Quercus robur, 135, 236, 237, 240, 244, 250, $251,254,255,256,258,259,303,304,305$, $306,311,312,313,319,320,321,322,323$, $324,325,326,328,329,332,337,338,352$, $355,357,359,360,361,362,382$

Quercus rotundifolia, 21, 22, 138, 236, 237, $250,254,255,259,303,304,306,311,322$, $323,324,369,373,374$

Quitameriendas, 72, 244, 246, 337, 338

Raíz de la culebra, 71, 300

Ramagón, 89, 178, 179, 249, 251, 265, 283, 284, 335, 336, 347, 359, 364

Ramo, 154, 256, 258, 303, 305, 307, 312, 321, $322,336,338,346,353,363,364,365,366$, 371, 376

Ramo de azahar, 141, 242, 243

Ramón, 155, 250, 258, 321, 328, 346, 353, 364, 376

Ranunculus parnassifolius, 28

Raphanus raphanistrum, 29

Raspanera, 132, 183, 234, 240, 256, 267, 277, 363, 365, 376

Ráspano, 132, 183, 234, 240, 256, 267, 277, 363, 365, 376
Regaliz, 161, 245, 246

Reina de los prados, 184, 267, 276

Relojillo, 29

Remolacha, 88, 234, 249, 360

Remolacha forajera, 88, 360

Repollo, 104, 232

Reseda lutea, 182, 347

Rhamnus alpina, 21, 21, 23, 27, 182, 257, 258,

321

Rhaponticum coniferum, 124, 345

Rhinanthus minor, 26, 171, 245, 246, 336, 337, 338, 3467

Ribes alpinum, 21, 21, 23, 140, 234, 236, 321, 322

Ribes petraeum, 140, 234, 236, 321, 322

Ribes rubrum, 140, 235

Ribes uva-crispa, 141, 235, 236, 321, 322

Ricino, 133, 264, 266

Ricinus communis, 133, 264, 266

Risas y coscas, 76, 347, 348, 349, 359

Robinia pseudoacacia, 161, 245, 321, 344, 346

Roble, 19, 21, 60, 135, 236, 237, 240, 241, 244, $250,251,254,255,256,258,259,260,303$, $305,306,311,312,313,315,319,320,321$, $322,323,324,325,326,328,329,332,337$, $338,352,354,355,356,357,359,360,361$, $362,363,364,365,366,369,371,373,376$, $377,381,382$

Roble albar, 18, 19, 20, 135

Roble enciniego, 135

Roble matiego, 135

Romero, 148, 176, 243, 258, 259, 262, 269, 272, 273, 285, 342, 343, 354, 373

Romulea bulbocodium, 74, 244, 246, 256, 258

Rosa spinosissima, 18, 192, 235, 262, 263, 265, 270, 274, 275, 278, 357

Rosa spp., 19, 24, 60, 81, 189, 190, 191, 235, 236, 241, 245, 253, 257, 259, 267, 270, 277, $283,284,314,318,326,328,329,343,347$, $353,354,355,359,365,366,367,369,371$, 374

Rosal, 190, 191, 241, 245, 253, 257, 259, 262 $267,270,277,283,314,318,326,328,329$, 343, 347, 353, 355, 359, 365, 366, 367, 371

Rosal espinoso, 192, 235, 262, 265, 270,, 274, 278, 357

Rosmarinus officinalis, 148, 243, 258, 259, 262, 
269, 272, 273, 285, 342, 343, 354, 373, 374

Roso, 173, 342, 346, 353

Rubus caesius, 18, 192, 235

Rubus idaeus, 18, 193, 235, 236, 257, 369

Rubus ulmifolius, 18, 19, 23, 193, 230, 235, 236, 241, 245, 246, 314, 326, 327, 359, 363, $365,366,369,371,374,375,376$

Ruda, 197, 274, 275, 285, 286

Rumex acetosa, 177, 233, 245, 246, 359, 360, $363,365,366,371,372,374$

Rumex conglomeratus, 178, 360

Rumex crispus, 178, 252, 252, 265, 289, 336, 347, 359, 360, 361, 364

Rumex longifolius, 178, 233

Rumex pulcher, 179, 283, 284

Ruta montana, 197, 274, 275, 285, 286

Sabúgo, 85, 232, 234, 240, 264, 268, 272, 273, $276,277,287,289,296,298,303,319,320$, 323, 344, 352, 364, 365, 366, 371, 376

Salce, 199, 259, 304, 311, 313, 321, 323, 325, 326, 327, 353, 355, 363, 365, 366, 371

Salguera, 81, 199

Salguero, 199, 259, 304, 311, 313, 321, 322, $323,324,325,326,327,351,353,355,363$, $365,366,371,372$

Salix alba, 23, 28

Salix atrocinerea, 23, 199, 200, 321

Salix bicolor, 23, 200

Salix caprea, 200

Salix eleagnos, 23, 200

Salix neotricha, 200

Salix purpurea, 23, 200

Salix salviifolia, 200

Salix spp., 20, 81, 199, 259, 304, 311, 313, 321, $322,323,324,325,326,327,351,353,355$, $363,365,366,367,371,372,374$

Salix triandra, 23, 200

Salix viminalis, 200

Salix x fragilis, 23, 28, 200

Sallo, 89, 249, 252, 335

Salvia, 148, 149, 269, 274, 342

Salvia officinalis, 148, 269, 342, 374

Salvia pratensis, 149, 274

Salvia verbenaca, 149, 262, 274, 277

Sambucus ebulus, 85, 272, 288, 298, 335

Sambucus nigra, 85, 232, 234, 236, 240, 241, $264,266,268,270,272,273,275,276,277$,
$287,288,289,290,296,298,303,319,320$, $323,324,344,349,352,364,365,366,367$, $371,373,374,376,381$

Sanalotodo, 128, 273, 341, 376

Sanguinaria, 109, 110, 118, 150, 167, 214, 262, 276, 280, 285

Sanicula europaea, 21

Saponaria ocymoides, 110, 341

Saponaria officinalis, 110, 345, 358, 359

Saúco, 85, 86, 87, 121, 167, 195, 232, 234, 236, $240,241,264,266,268,270,272,273,275$, $276,277,287,288,289,290,296,298,303$, $319,320,323,324,344,349,352,364,365$, $366,371,373,376,381$

Saúgo, 85, 232, 234, 240, 364, 368, 372, 273, 276, 277, 287, 288, 289, 296, 298, 303, 319, 320, 323, 344, 352, 364, 365, 366, 371, 376

Savia, 112

Saxifraga canaliculata, 27

Saxifraga conifera, 27

Saxifraga pentadactylis, 28

Saxifraga tridactylites, 27

Scandix australis, 95, 243, 244, 246, 264, 266, 268, 283, 284, 318, 319, 360, 361

Scolymus hispanicus, 29

Scorzonera humilis, 124, 244, 246

Scorzonera laciniata, 124

Scrophularia canina, 96, 202, 203, 297

Secale cereale, $80,237,247,251,252,254$, $255,265,266,307,312,313,319,320,323$, $324,325,326,332,347,349$

Sedum album, 127, 256, 258

Sedum anglicum, 27

Sedum brevifolium, 27

Sedum hirsutum, 27

Sedum sediforme, 127, 256, 258

Sempervivum vicentei, 128, 273, 275, 289, 290, 341, 343, 376, 377

Senderilla, 212, 239, 376

Senderina, 212

Senderuela, 212

Serbal, 18, 20, 193, 196, 257, 299, 303, 321, $328,334,344,353,364$

Servendo, 80, 81, 237, 265, 307, 312, 319, 323, $325,326,332,347$

Seseli cantabricum, 25

Seta blanca, 212, 239, 376 
Seta de berezo, 213, 239

Seta de brezo, 213, 239

Seta de cardillo, 212, 239

Seta de cardo, 212, 239, 338

Seta de chopo, 210, 239

Seta de la buena, 212, 239

Seta de mango azul, 212

Seta de pezón azul, 212

Seta de pie azul, 212, 239

Seta de rabo azul, 212

Seta morada, 213, 239

Seta rojilla, 212, 239

Sideritis hirsuta, 150

Sideritis hyssopifolia, 149, 167, 242, 256, 264, $265,269,270,280,283,384,363,365,366$, $367,371,374,376,377,382$

Siempreviva, 128, 273, 275, 289, 290, 341, 343, 376

Silene ciliata, 27

Silene vulgaris, 110, 232, 233, 345, 358

Silybum marianum, 29

Sinapis alba, 106, 268, 271

Sinapis arvensis, 29, 106, 249, 335, 337

Sirvendo, 80, 81, 237, 265, 307, 312, 319, 323, $325,326,332,347$

Sisymbrium austriacum, 29

Solanum lycopersicon, 204, 233

Solanum melongena, 205, 233

Solanum tuberosum, 205, 234, 253, 361

Sombrerillo, 128, 274, 275, 289, 290

Sonchus asper, 119, 124, 249, 252, 335

Sonchus oleraceus, 119, 125, 249, 252, 335, 337

Sorbo, 182, 235

Sorbus aria, 18, 19, 21, 22, 23, 24, 194, 235, $236,251,257,303,304,306,321,328,329$, 334, 344, 355, 363, 364, 365, 369, 374

Sorbus aucuparia, 18, 19, 20, 195, 251, 257, 299, 303, 321, 322, 328, 334, 344, 364

Sota, 199, 259, 304, 311, 313, 321, 323, 325, 326, 327, 353, 355, 363, 365, 366, 371

Sparganium erectum, 28

Spergula viscosa, 28

Spiraea hypericifolia, 21

Stellaria holostea, 19, 20, 31

Stellaria media, 111, 249, 334, 337

Stipa iberica, 82, 347, 349
Suelda, 128, 273, 289, 341, 376

Symphoricarpos albus, 108, 341, 343

Syringa vulgaris, 170, 342, 343, 353

Tabaco, 204, 291, 360, 361

Taco, 85, 232, 234, 340, 264, 268, 272, 273, $276,277,287,288,289,296,298,303,319$, 320, 323, 344, 352, 364, 365, 366, 371, 376

Tagarnio, 95, 203, 296

Tagarno, 95, 96, 296, 297

Tallo de borrega, 126

Tallos, 177, 233, 245, 246, 359, 363, 365, 366, 371

Tanacetum corymbosum, 125, 339, 345, 348

Tanacetum parthenium, 125, 341

Tapaculo, 190

Taraxacum campylodes, 26, 125, 232, 233, 242, $250,252,267,271,272,273,275,335,361$

Taxus baccata, 19, 21, 22, 23, 67, 235, 299, $313,321,322,343,353,354,355,356,357$, 362,372

Té, $110,149,150,151,167,214,242,243,256$, $264,265,266,267,269,270,280,283,284$, $363,365,366,367,371,376,382$

Té de calar, 149

Té de huerta, 114, 242,

Té de lastra, 149, 242, 256, 264, 269, 280, 283, $363,365,366,371,376$

Té de menta, 145, 146, 242, 264, 269, 296, 318, 321, 356, 357

Té de peña, 149, 242

Té de roca, 149, 242, 256, 264, 269, 280, 283, 363, 365, 366, 371, 376, 381

Teja blanca, 182, 257, 321

Tejo, 19, 21, 22, 23, 67, 101, 152, 235, 299, 313, $321,322,343,353,354,355,356,357,362$, 372

Teucrium chamaedrys, 22

Teucrium scorodonia, 19, 21

Thapsia villosa, 95, 203, 296, 297

Thymus mastichina, 150, 243, 265, 266, 267, 268, 269, 270, 296, 297, 307, 308, 332, 333

Thymus praecox, 25, 151, 243, 258, 265, 267, 268

Thymus pulegioides, 151, 265, 266

Thymus zygis, 151, 243, 267, 269, 270, 271, 280, 297, 307, 308, 332, 333, 374, 376

Tilia platyphylos, 167, 265, 266, 269, 276, 280, 
342

Tilo, 167, 265, 266, 269, 276, 280, 342

Tiraña, 164, 283, 286, 299, 300

Titarro, 157, 158, 238, 250, 254, 255

Tito, 157, 158, 231, 238, 247, 250, 252, 254, 255

Tito esquinao, 157, 238, 250, 254

Tito redondo, 161

Toba, 124, 256, 335

Tomate, 204, 233

Tomillo, 69, 110, 118, 145, 147, 150, 151, 152, $167,243,258,265,266,267,268,269,270$, 271, 180, 296, 297, 307, 308, 332

Tragopogon castellanus, 126, 244

Tragopogon dubius, 126, 244, 246

Tragopogon pratensis, 126, 244, 246

Trébol, 162, 233, 245, 246, 250, 257, 277, 284, 299. 300

Tremesino, 82, 237, 245, 251, 254, 262, 265, 283, 307, 312, 323, 326, 332, 347, 359

Trifolium alpinum, 161, 245, 246

Trifolium pratense, 26, 143, 148, 162, 233, 245, 246, 250, 257, 277, 291, 299, 300

Trifolium repens, 162, 245, 246, 257

Trigo, 82, 83, 237, 245, 251, 252, 254, 255, 262, $265,266,283,307,312,313,323,324,326$, $332,337,347,349,359$

Trigonella foenum-graecum, 162, 250, 254, 255

Triticum aestivum, 82, 237, 245, 251, 252, 254, $255,262,265,266,283,307,312,313,323$, 324, 326, 332, 347, 349, 359

Trollius europaeus, 181, 342, 343, 347

Tulipa gesneriana, 76, 342

Tulipán, 76, 342

Tussilago farfara, 129, 269, 271, 273

Typha angustifolia, 84, 137, 326, 348, 349

Typha latifolia, 28

Ulaga, 152, 156, 258, 303, 304, 307, 314, 318, $319,321,322$

Ulaja, 152, 318, 321

Ulex gallii, 25, 374

Ulex europaeus, 25, 162, 303, 304

Ulmus glabra, 205, 251

Ulmus minor, 28, 206, 251, 304, 311, 313, 321, $322,323,324,325,326,327,353,361,362$, $365,366,371,372,374$
Umbilicus rupestris, 128, 274, 275, 289, 290

Urtica dioica, 23, 207, 233, 251, 252, 257, 262, $263,267,270,272,273,274,275,296,297$, 318,374

Urtica urens, 207, 251, 262, 263, 296

Urz, 130, 131, 256, 258, 267, 303, 305, 306, $307,308,312,320,332,346,349,360,363$, $364,365,366,371,376$

Uva de oso, 182, 257, 258, 321

Uva de perro, 128, 182, 289, 290, 299, 335

Vaccinium myrtillus, 18, 20, 21, 24, 25, 27, 132, $234,236,240,256,258,267,268,277,363$, $365,374,376$

Vaccinium uliginosum, 27

Vaina, 160, 238

Valeriana, 108, 276, 341

Valeriana montana, 108, 276

Valeriana pyrenaica, 108, 341

Vallico, 80, 251, 336, 337

Valluco, 80, 251, 336

Vara de San José, 75, 342, 343

Varillo, 170, 318, 319, 321, 322, 346, 353

Veneno de culebra, 71

Verbascum lychnitis, 202, 203, 262, 270, 272, 283, 286, 292, 297, 348

Verbascum pulverulentum, 202, 203, 262, 270, 272, 283, 286, 292, 297, 348

Verbascum thapsus, 202, 203, 262, 270, 272, $283,286,292,297,348$

Verbena, 176, 208, 262, 265, 270, 271, 357

Verbena officinalis, 208, 262, 265, 270, 271, 357

Veza,164, 250, 254

Viborera, 29

Viburnum lantana, 18, 19, 21, 87, 234, 236, 320

Viburnum opulus, 88, 341, 343, 352

Vicia articulata, 163, 238, 250, 254, 255

Vicia cracca, 163, 250, 252, 257, 336, 337, 353

Vicia ervilia, 163, 238, 247, 250, 252, 254, 255

Vicia faba, 163, 238, 254

Vicia pannonica, 163, 250, 252, 257, 336, 337, 353

Vicia sativa, 164, 247, 250, 252, 254, 255

Vinca major, 96, 341

Vino, 72, 358, 360

Viola alba, 208 
Viola bubanii, 208

Viola palustris, 208

Viola reichenbachiana, 208

Viola riviniana, 208

Viola spp., 60, 192, 270, 318, 343, 348

Violeta, 60, 192, 208, 270, 318, 343, 348

Viscum album, 200, 262, 286, 289, 299, 336,

337, 348, 356

Vitis vinifera, 202, 235, 245, 246, 270, 286, 287, 304, 321, 333

Yedra, 97, 273, 333, 335, 341, 349, 352, 354, 355, 360

Yerbancho, 79, 251, 347

Yero, 163, 238, 247, 250, 252, 254, 255

Yesca, 211, 305, 338, 349, 361

Yezca, 211, 305, 349, 361

Yezgo, 85, 271, 288, 298, 335

Zanahoria, 93, 234, 253

Zapatito del Niño Jesús, 159, 257

Zarza, 18, 19, 23, 81, 190, 193, 235, 241, 245, $253,257,259,262,267,270,277,283,284$, $314,18,326,327,328,357,359,363,365,366$, 371,376

Zarzamora, 18, 23, 193

Zarzaparrilla, 192, 235, 262, 263, 265, 270, 274, $275,278,357$

Zea mays, 83, 254, 285, 325 


\section{ÍNDICE DE FIGURAS}

Figura 1: $\quad$ Tipos de bienes que componen el patrimonio etnográfico...................................

Figura 2: $\quad$ Mapa provincial de Palencia. Instituto Geográfico Nacional (2014)....................... 11

Figura 3: $\quad$ Mapa geológico de la Montaña Palentina............................................................... 13

Figura 4: $\quad$ Mapa edafológico de la Montaña Palentina..................................................... 14

Figura 5: $\quad$ Resumen de temperaturas en la estación de Cervera de Pisuerga (1932-2018)...... 17

Figura 6: $\quad$ Evolución de la población de la Montaña Palentina desde el año 1900................... 31

Figura 7: $\quad$ Evolución de la población en los municipios de más de 2000 habitantes de la

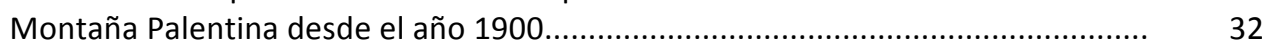

Figura 8: $\quad$ Pirámide de población de la Montaña Palentina año 2018................................... 32

FIgURA 9: $\quad$ Trabajadores por sector en la Montaña Palentina año 2018................................ 33

FıgURA 10 Mapa de cultivos y aprovechamientos de la Montaña Palentina........................... 34

Figura 11: Localidades de la Montaña Palentina donde se han realizado entrevistas.............. 38

FigURA 12: $\quad$ Porcentajes de rangos de edad de las personas entrevistadas............................... 43

FigURA 13: $\quad$ Porcentaje de personas entrevistadas según el sexo........................................... 43

Figura 14: Esquema metodológico del estudio etnobotánico realizado en la comarca de la Montaña Palentina.

FIGURA 15: Modelo tabla principal de recogida de datos..................................................... 52

FIGURA 16: Modelo tabla categorías de uso.................................................................. 52

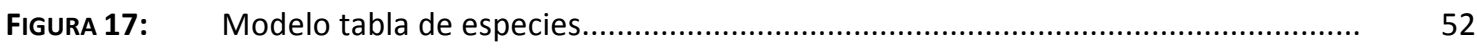

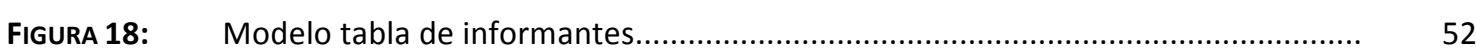

FigURA 19: Modelo tabla de comentarios o ficha de especies................................................. 53

Figura 20 Listado de familias con 5 o más especies, teniendo en cuenta el modo de obtención.............................................................................................. 217

Figura 21: Categorías y número total de registros de uso obtenidos en el estudio.................. 218

Figura 22: $\quad$ Taxones con mayor número de registros de uso en Alimentación humana............ 230

FiguRA 23: Familias con mayor representación de especies y número de registros de uso, en Alimentación humana................................................................................... 230

Figura 24: Registros de Uso de las subcategorías representadas en Alimentación humana..... 231

FIgURA 25: Victorina de San Salvador ofreciendo avellanas................................................... 237

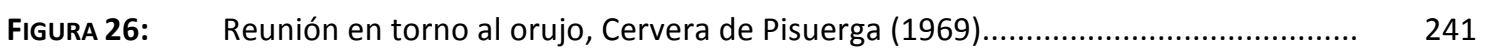

Figura 27: Máxima de Verdeña extrayendo ajuérjanos....................................................... 246

Figura 28: $\quad$ Taxones con mayor número de registros de uso en Alimentación animal............... 247

FiguRA 29: Familias con mayor representación de especies y número de registros de uso, en Alimentación animal...................................................................................... 247

Figura 30 Registros de Uso de las subcategorías representadas en Alimentación animal....... 248

FigURA 31: Majando el centeno, Valcobero (Años 60)............................................................ 252

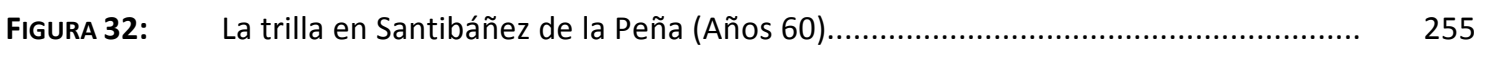

FIGURA 33: $\quad$ Especies con mayor número de registros de uso empleadas en Medicina............... 260

FIgURA 34: Familias de utilidad Medicinal con mayor representación de especies y número de registros de uso. 
Figura 35: Registros de Uso de las subcategorías representadas en Medicina....

Figura 36: Carlina de Villanueva de la Torre con hierba de las 7 sangrías.................................. 263

FIGURA 37: $\quad$ Oliva de La Lastra secando milenrama................................................................ 266

FIGURA 38: $\quad$ Edelmira de Celada de Roblecedo con atadillo de malvas..................................... 275

FIGURA 39: $\quad$ Especies con mayor número de registros de uso empleadas en Veterinaria............ 281

Figura 40 Familias de utilidad Veterinaria con mayor representación de especies y número de registros de uso

FIGURA 41: Registros de Uso de las subcategorías representadas en Veterinaria...................... 282

FIGURA 42: Pedro de Valsurbio con rizoma de genciana........................................................... 284

FIGURA 43: Paulino de Rebanal de las Llantas con atadillo de árnica.......................................... 288

Figura 44: $\quad$ Especies con mayor número de registros de uso de carácter Tóxico y Nocivo......... 294

FIGURA 45: Familias con mayor representación de especies y número de registros de uso de carácter Tóxico y nocivo

Figura 46: Registros de Uso de las subcategorías representadas en Uso Tóxico y Nocivo.........

FiguRA 47: Especies con mayor número de registros de uso empleadas como Combustible....

Figura 48: Familias con mayor representación de especies y número de registros de uso, de utilidad Combustible.

Figura 49: Registros de Uso de las subcategorías representadas en Uso Combustible.....

Figura 50 Especies con mayor número de registros de uso empleadas en Construcción.........

FIGURA 51: Familias con mayor representación de especies y número de registros de uso, en Construcción.

Figura 52: Registros de Uso de las subcategorías representadas en Construcción........

Figura 53: Carro de zarzo en Cervera de Pisuerga (1958)

Figura 54: $\quad$ Andrés de Monasterio mostrando ulagas.

FigURA 55: Taxones con mayor número de registros de uso empleadas en Industria y Artesanía......

FIGURA 56: Familias con mayor representación de especies y número de registros de uso, en Industria y artesanía.

Figura 57: $\quad$ Registros de Uso de las subcategorías representadas en Industria y Artesanía.......

Figura 58: Juego de los bolos en Ruesga (1961)

Figura 59: Pablo de Nava de Santullán explicando la técnica de elaboración de escriños con zarzas......

Figura 60 Elaboración tradicional de albarcas (Años 80)......

FIGURA 61: $\quad$ Especies con mayor número de registros de uso de carácter Medioambiental........

FIGURA 62: Familias de utilidad Medioambiental con mayor representación de especies y número de registros de uso.

FIGURA 63: Registros de Uso de las subcategorías representadas en Uso Medioambiental......

Figura 64: Taxones con mayor número de registros de uso empleados como Ornamental.....

FIGURA 65: Familias de utilidad ornamental con mayor representación de especies y número de registros de uso

FIGURA 66: $\quad$ Registros de Uso de las subcategorías representadas en Uso Ornamental.............. 340

FIGURA 67: Victorino de Valcobero con risas y coscas........................................................... 348

FiguRA 68: $\quad$ Taxones con mayor número de registros de uso Social, simbólico y ritual.............. 350 
Figura 69: Familias con mayor representación de especies y número de registros de uso, de uso Social, simbólico y ritual.......

Figura 70 Registros de Uso de las subcategorías representadas en Uso social, simbólico o ritual.

Figura 71: $\quad$ Arco decorativo en un cantamisa celebrado en Redondo (1956)........................... 354

Figura 72: María de Resoba en el Roblón de la Tenada.

Figura 73: $\quad$ Listado de los 20 taxones silvestres con mayor valor en el índice de Importancia Cultural, teniendo en cuenta los valores de cada una de las categorías de uso.......

Figura 74: Listado de las 20 familias con mayor valor en el índice de Importancia Cultural, teniendo en cuenta los valores de cada una de las categorías de uso.

Figura 75: Diagrama de dispersión de los 20 taxones con mayor valor en el índice de Importancia Cultural, teniendo en cuenta los valores de su índice de Vigencia...... 


\section{ÍNDICE DE TABLAS}

TABLA 1: Indicadores climáticos en la Montaña Palentina.

TABLA 2: $\quad$ Temperaturas de la estación de Cervera de Pisuerga para los años 1932-2018 .......... 16

TABLA 3: Población y densidad 2018 en la Montaña Palentina............................................... 30

TABLA 4: $\quad$ Evolución de la población en la Montaña Palentina.................................................. 31

TABLA 5: $\quad$ Distribución municipal de terrenos en la Montaña Palentina.................................... 34

TABLA 6: Listado de personas entrevistadas....................................................................... 39

TABLA 7: Listado de clasificación de categorías de uso en la primera fase de entrevistas......... 46

TABLA 8: Relación de categorías de uso consideradas......................................................... 48

TABLA 9: Estructura de la base de datos...................................................................... 51

TABLA 10: Listado de estudios etnobotánicos consultados................................................... 216

TABLA 11: Clasificación de categorías de uso.................................................................... 218

TABLA 12: Resumen de las categorías de uso........................................................................ 219

TABLA 13: Subcategorías con representación en la categoría Alimentación humana................ 231

TABLA 14: Relación de especies empleadas en la subcategoría Verduras y hortalizas................ 232

TABLA 15: Relación de especies empleadas en la subcategoría Raíces, bulbos, tubérculos y

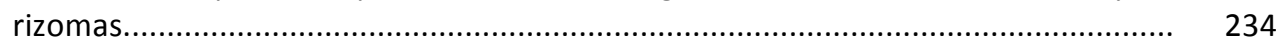

TABLA 16: Relación de taxones empleados en la subcategoría Frutas y frutos dulces............... 234

TABLA 17: Relación de especies empleadas en la subcategoría Frutos secos y oleaginosos....... 236

TABLA 18: Relación de especies empleadas en la subcategoría Cereales................................ 237

TABLA 19: Relación de especies empleadas en la subcategoría Legumbres.............................. 238

TABLA 20: Relación de especies empleadas en la subcategoría Setas y otros hongos................ 239

TABLA 21: Relación de especies empleadas en la subcategoría Grasas alimentarias.................. 240

TABLA 22: Relación de taxones empleados en la subcategoría Bebidas alcohólicas................... 240

TABLA 23: Relación de especies empleadas en la subcategoría Bebidas no alcohólicas............. 242

TABLA 24: Relación de especies empleadas en la subcategoría Condimentos y conservantes... 243

TABLA 25: Relación de especies empleadas en la subcategoría Golosinas y masticatorias......... 244

TABLA 26: Subcategorías con representación en la categoría Alimentación animal.................... 248

TABLA 27: Relación de especies empleadas en la subcategoría Forraje verde o seco................ 249

TABLA 28: Relación de especies empleadas en la subcategoría Raíces y tubérculos.................. 253

TABLA 29: Relación de especies empleadas en la subcategoría Frutas y frutos dulces............... 253

TABLA 30: Relación de especies empleadas en la subcategoría Pienso................................... 254

TABLA 31: Relación de taxones empleados en la subcategoría Pasto........................................ 256

TABLA 32: Relación de taxones empleados en la subcategoría Plantas melíferas...................... 258

TABLA 33: Subcategorías con representación en la categoría Medicina..................................... 261

TABLA 34: Relación de especies empleadas en la subcategoría Sistema circulatorio................ 262

TABLA 35: Relación de especies empleadas en la subcategoría Sistema digestivo.................... 264

TABLA 36: Relación de taxones empleados en la subcategoría Sistema genito-urinario............ 267 
TABLA 37: Relación de taxones empleados en la subcategoría Sistema respiratorio.....

TABLA 38: Relación de especies empleadas en la subcategoría Sistema endocrino-metabólico 271

TABLA 39: Relación de especies empleadas en la subcategoría Musculatura y esqueleto.......... 272

TABLA 40: Relación de especies empleadas en la subcategoría Piel y tejido celular.................. 273

TABLA 41: Relación de especies empleadas en la subcategoría Sistema nervioso y enfermedades mentales.

TABLA 42: Relación de taxones empleados en la subcategoría Órganos de los sentidos............

TABLA 43: Relación de especies empleadas en la subcategoría Enfermedades infecciosas y parasitarias.

TABLA 44: Relación de especies empleadas en la subcategoría Síntomas de origen indefinido.

TABLA 45: Relación de especies empleadas en la subcategoría Intoxicaciones y envenenamientos.

TABLA 46: Relación de especies empleadas en la subcategoría Otros usos medicinales......

TABLA 47: Subcategorías con representación en la categoría Veterinaria............................... 282

TABLA 48: Relación de taxones empleados en la subcategoría Sistema digestivo...................... 283

TABLA 49: Relación de especies empleadas en la subcategoría Sistema genito-urinario............ 285

TABLA 50: Relación de especies empleadas en la subcategoría Concepción, embarazo y parto 286

TABLA 51: Relación de especies empleadas en la subcategoría Sistema respiratorio................. 287

TABLA 52: Relación de especies empleadas en la subcategoría Musculatura y esqueleto......... 288

TABLA 53: Relación de especies empleadas en la subcategoría Piel y tejido celular................... 289

TABLA 54: Relación de especies empleadas en la subcategoría Órganos de los sentidos........... 290

TABLA 55: Relación de especies empleadas en la subcategoría Enfermedades infecciosas y parasitarias

TABLA 56: Relación de especies empleadas en la subcategoría Enfermedades "culturales"......

TABLA 57: Relación de especies empleadas en la subcategoría Intoxicaciones y envenenamientos.

TABLA 58: Relación de especies empleadas en la subcategoría Otros usos veterinarios............ 293

TABLA 59: Subcategorías con representación en la categoría Uso Tóxico y Nocivo.................... 295

TABLA 60: Relación de especies empleadas en la subcategoría Irritantes, urticantes y fotosensibilizantes.

TABLA 61: Relación de especies empleadas en la subcategoría Venenos, insecticidas y plaguicidas......

TABLA 62: Relación de especies empleadas en la subcategoría Trampas atrayentes.................

TABLA 63: Relación de especies empleadas en la subcategoría Tóxicas para personas y animales.

TABLA 64: Relación de especies empleadas en la subcategoría Elementos nocivos y repelentes..

TABLA 65: Subcategorías con representación en la categoría Uso Combustible....................... 302

TABLA 66: Relación de taxones empleados en la subcategoría Leña........................................... 303

TABLA 67: Relación de taxones empleados en la subcategoría Encendido o leña fina................ 305

TABLA 68: Relación de taxones empleados en la subcategoría Carbón...................................... 306

TABLA 69: Relación de taxones empleados en la subcategoría Para chamuscar........................ 307

TABLA 70: Relación de especies empleadas en la subcategoría Para ahumar.......................... 307

TABLA 71: Relación de taxones empleados en la subcategoría Luz.......................................... 308 
TABLA 72: Subcategorías con representación en la categoría Construcción............................. 310

TABLA 73: Relación de taxones empleados en la subcategoría Carros y otros vehículos............ 311

TABLA 74: Relación de taxones empleados en la subcategoría Casas, edificios e instalaciones agropecuarias

TABLA 75: Relación de taxones empleados en la subcategoría Cercas, tapias y vallas................ 314

TABLA 76: Relación de especies empleadas en la subcategoría Infraestructuras....................... 315

TABLA 77: Subcategorías con representación en la categoría Industria y artesanía.................. 317

TABLA 78: Relación de taxones empleados en la subcategoría Cosmética, perfumería y limpieza

TABLA 79: Relación de especies empleadas en la subcategoría Curtientes.

TABLA 80: Relación de especies empleadas en la subcategoría Sustancias tintóreas y pinturas

TABLA 81: Relación de taxones empleados en la subcategoría Herramientas y utensilios..........

TABLA 82: Relación de taxones empleados en la subcategoría Juguetes e instrumentos deportivos y musicales.

TABLA 83: Relación de taxones empleados en la subcategoría Mobiliario y enseres domésticos.

TABLA 84: Relación de taxones empleados en la subcategoría Cestos, recipientes y envoltorios.

TABLA 85: Relación de taxones empleados en la subcategoría Cuerdas y ataduras

TABLA 86: Relación de taxones empleados en la subcategoría Vestimenta y adornos personales...

TABLA 87: Relación de especies empleadas en la subcategoría Otros usos industriales.

TABLA 88: Subcategorías con representación en la categoría Uso Medioambiental.................. 331

TABLA 89: Relación de taxones empleados en la subcategoría Mejora del suelo....................... 332

TABLA 90: Relación de especies empleadas en la subcategoría Setos y cortavientos................ 333

TABLA 91: Relación de especies empleadas en la subcategoría Sombra y protección................. 333

TABLA 92: Relación de especies empleadas en la subcategoría Injerto...................................... 334

TABLA 93: Relación de especies empleadas en la subcategoría Malas hierbas............................ 335

TABLA 94: Relación de especies empleadas en la subcategoría Bioindicadores......................... 337

TABLA 95: Relación de especies empleadas en la subcategoría Predicción del tiempo.............. 338

TABLA 96: Subcategorías con representación en la categoría Uso Ornamental......................... 340

TABLA 97: Relación de taxones empleados en la subcategoría Patios, huertos y jardines.......... 341

TABLA 98: Relación de especies empleadas en la subcategoría Calles y caminos....................... 344

TABLA 99: Relación de taxones empleados en la subcategoría Adornos florales y plantas de interior......

TABLA 100: Relación de taxones empleados en la subcategoría Otros adornos.......................... 349

TABLA 101: Subcategorías con representación en la categoría Uso social, simbólico y ritual....... 351

TABLA 102: Relación de taxones empleados en la subcategoría Ritual de ciclo anual.................. 352

TABLA 103: Relación de taxones empleados en la subcategoría Ritual de ciclo de vida............... 355

TABLA 104: Relación de especies empleadas en la subcategoría Ritual de incertidumbre, protección y aflicción

TABLA 105: Relación de especies mencionadas en la subcategoría Literatura oral popular......... 357

TABLA 106: Relación de taxones empleados en la subcategoría Uso recreativo............................ 358 
TABLA 107: Relación de taxones empleados en la subcategoría Alucinógenas, narcóticas y fumatorias.

TABLA 108: Relación de especies empleadas en la subcategoría Fobias y filias.

TABLA 109: Relación de especies mencionadas en la subcategoría Árboles o arbustos singulares.

TABLA 110: Relación de los 20 taxones silvestres con mayor Frecuencia de Citación 363

TABLA 111: Relación de los 20 taxones silvestres con mayor Número de Usos......... 364

TABLA 112: Relación de los 20 taxones silvestres con mayor número de Registros de Uso. 365

TABLA 113: Relación de los 20 taxones silvestres con mayor Frecuencia Relativa de Citación..... 365

TABLA 114: Relación de los 20 taxones silvestres con mayor Importancia Cultural. 366

TABLA 115: Comparativa de las plantas útiles en el área de estudio, usando dos índices cuantitativos. Listado de los primeros 20 taxones.

TABLA 116: Comparativa de las plantas útiles en cuatro estudios etnobotánicos. Listado de los primeros 20 taxones..

TABLA 117: Relación de los 20 taxones silvestres con mayor índice de Vigencia.......

TABLA 118: Datos de diversos estudios etnobotánicos de la Península lbérica. 